\title{
Fouilles à Marseille
}

objets quotidiens médiévaux et modernes

\section{Véronique Abel, Marc Bouiron et Florence Parent (dir.)}

DOI : 10.4000/books.pccj.3443

Éditeur : Publications du Centre Camille Jullian, Éditions Errance Année d'édition : 2014

Date de mise en ligne : 6 avril 2020

Collection : Bibliothèque d'archéologie méditerranéenne et africaine

ISBN électronique : 9782491788056

\section{opanatition}

http://books.openedition.org

\section{Édition imprimée}

ISBN : 9782877725569

Nombre de pages : 409

\section{Référence électronique}

ABEL, Véronique (dir.) ; BOUIRON, Marc (dir.) ; et PARENT, Florence (dir.). Fouilles à Marseille : Objets quotidiens médiévaux et modernes. Nouvelle édition [en ligne]. Publications du Centre Camille Jullian, 2014 (généré le 10 décembre 2020). Disponible sur Internet : <http://books.openedition.org/pccj/ 3443>. ISBN : 9782491788056 . DOI : https://doi.org/10.4000/books.pccj.3443. 


\section{Bibliothèque d'Archéologie Méditerranéenne et Africaine 16}


Dans la lignée des anciens Travaux du Centre Camille Jullian, la Bibliothèque d'Archéologie Méditerranéenne et Africaine (BiAMA) regroupe des travaux (monographies, actes de colloques, ouvrages collectifs) en relation avec les programmes scientifiques du Centre Camille Jullian, sur l'histoire et l'archéologie de la Gaule méridionale, de l'Afrique du Nord et du bassin méditerranéen. La BiAMA peut comprendre des sous-séries, comme la collection Études massaliètes (EtMassa).

\section{Responsable légal :}

Marie-Brigitte Carre, Directrice du CCJ

Directeurs de la publication :

Sophie Bouffier et Henri Tréziny

Comité de pilotage :

S. Bouffier, M.-Br. Carre, X. Delestre, H. Tréziny

Conception graphique et mise en page :

Véronique Gémonet

Direction scientifique de la série Etudes massaliètes :

M. Bats et H. Tréziny

\section{Comité de lecture :}

S. Bouffier (CCJ, Aix-Marseille Université), J.-P. Brun (Collège de France), M-Br. Carre (CCJ, CNRS), X. Delestre (CCJ, DRAC PACA), D. Garcia (CCJ, AMU, Inst. Univ. de France), M. Griesheimer (CCJ, AMU), A. Hermary (CCJ, AMU), Ph. Jockey (CCJ, AMU), M. Lombardo (Professeur à l'Université de Lecce), T. S. Loseby (Professeur à l'Université de Sheffield), J.-M. Mignon (Service archéologique départemental du Vaucluse), P. Pomey (CCJ,CNRS), L. Rivet (CCJ, CNRS), J. Sanmarti (Professeur à l'Université de Barcelone), J.-Chr. Sourisseau (CCJ, AMU), H. Tréziny (CCJ, CNRS), C. Virlouvet (École française de Rome), E. Voutiras (Professeur à l'Université de Thessalonique).

(C) 2014 pour tous pays,

Édition Errance, éditeur du groupe Actes Sud,

BP 9003813633 Arles Cédex

Tel. 04-88-65-92-05 / 06-99-30-70-87

Fax : 0143293488

Courriel : contact@editions-errance.fr

http://www.libairie-epona.fr

Centre Camille Jullian

Maison Méditerranéenne des Sciences de l'Homme

5 rue du Château de l'Horloge. BP 647, 13094 Aix-en-Provence Cedex 2

ISBN : 978-2-87772-556-9

ISSN BiAMA : 2101-2849

ISSN EtMassa : 0986-3974

Illustration de couverture :

Assiette de Montelupo. Fort Saint-Jean (V. Abel/Inrap).

Illustration $4^{\text {ème }}$ de couverture :

Plaque de bénitier moulée de l'arrière-pays marseillais (fin du XVI ${ }^{\mathrm{e}} \mathrm{s}$.), ancienne collection Arthur-Jean Held, musée de Genève

(d'après Les Cahiers de Céramique).

\section{Publications du Centre Camille Jullian}

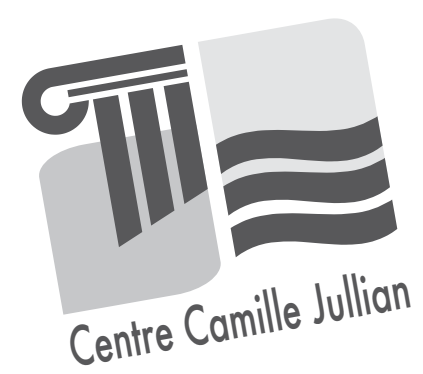

Ouvrage financé par

le Ministère de la Culture (CPDRA)

et l'Institut national pour la recherche archéologique préventive

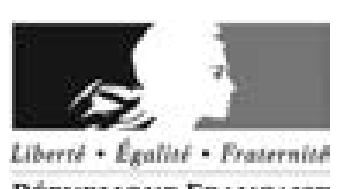

RÉPUBUQUE FrançaISE
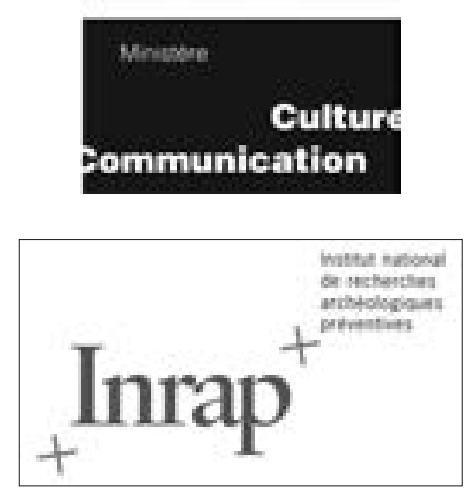

Envoyer les manuscrits à :

Bibliothèque d'Archéologie Méditerranéenne et Africaine Centre Camille Jullian

Maison Méditerranéenne des Sciences de l'Homme

5 rue du Château de l'Horloge. BP 647,

13094 Aix-en-Provence Cedex 2 


\section{FOUILLES À MARSEILLE. \\ OBJETS QUOTIDIENS MÉDIÉVAUX ET MODERNES}

sous la direction de Véronique Abel, Marc Bouiron, Florence Parent
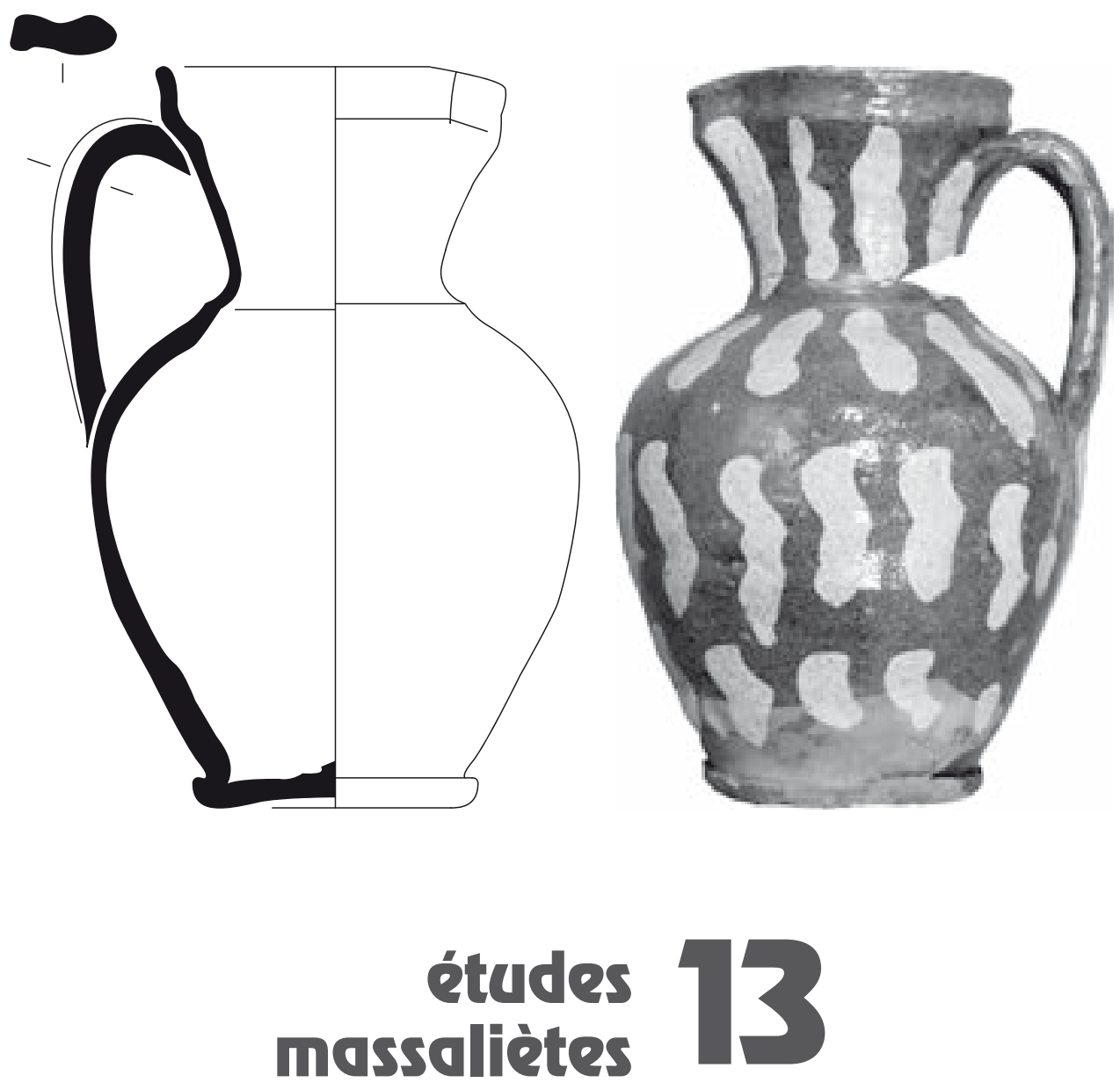


\section{Sommaire}

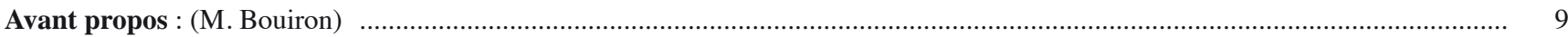

Introduction générale : (V. Abel, Fl. Parent avec la coll. de M. Bouiron)

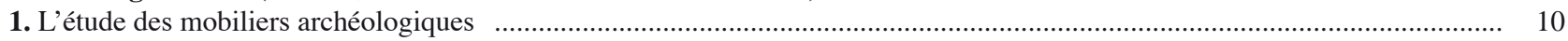

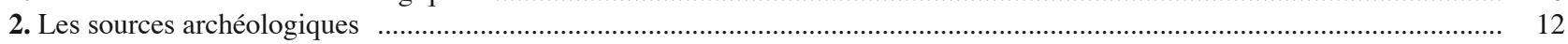

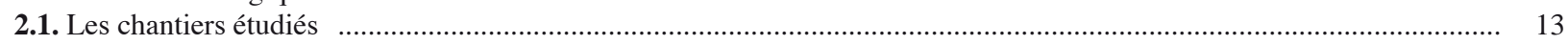

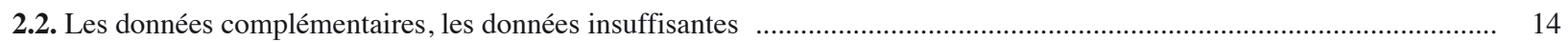

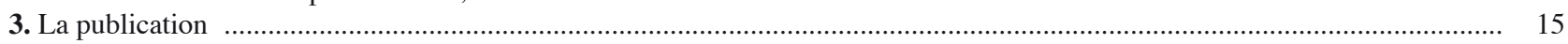

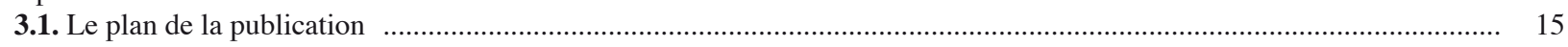

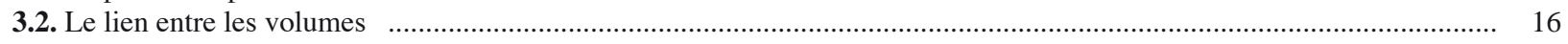

\section{PREMIÈRE PARTIE : LES CÉRAMIQUES}

Introduction à l'étude des céramiques médiévales et modernes de Marseille (V. Abel, Fl. Parent) ................................................19

Chapitre 1 : Le premier Moyen Âge : l'Antiquité tardive en héritage (Fl. Parent, C. Richarté) ..............................................23

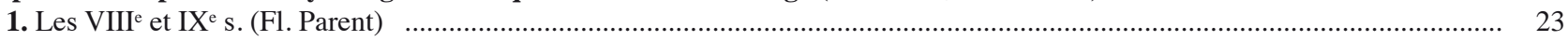

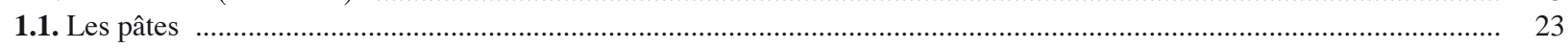

1.2. Les formes

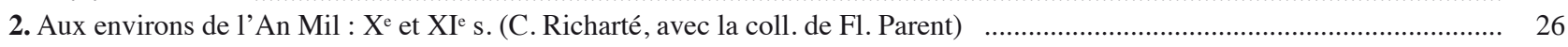

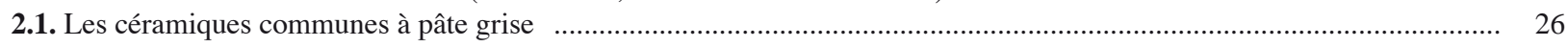

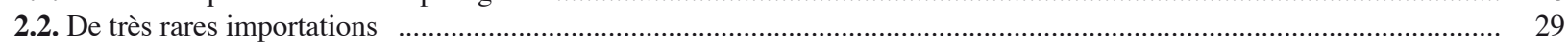

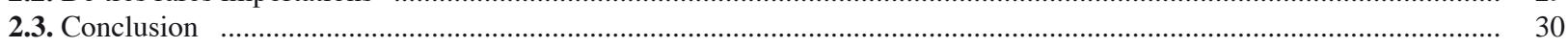

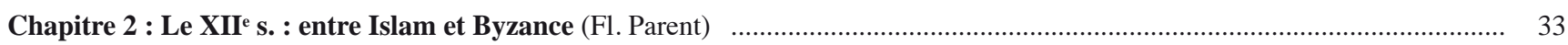

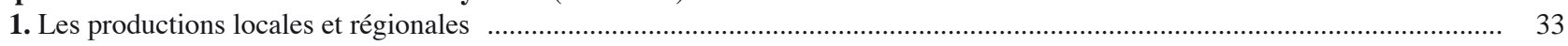

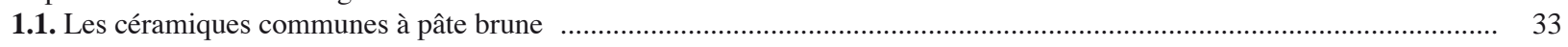

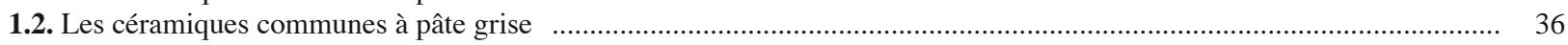

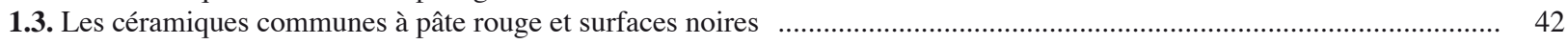

1.4. Les productions de l'ouest du Rhône : céramiques à pâte rouge et surface polie ...................................................... 43

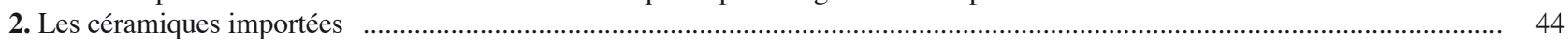

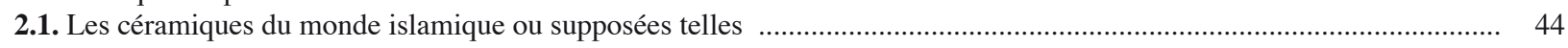

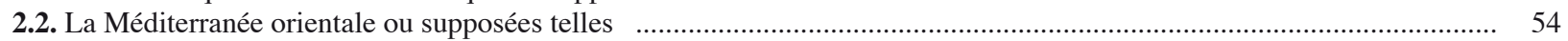

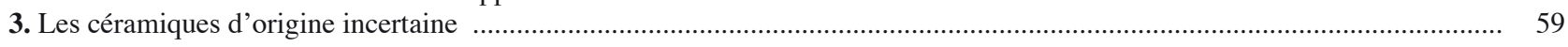

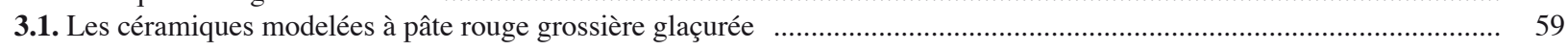

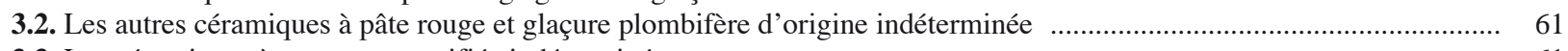

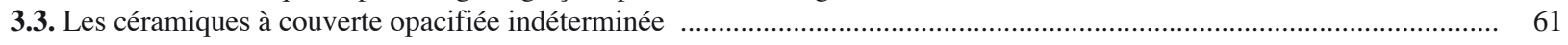

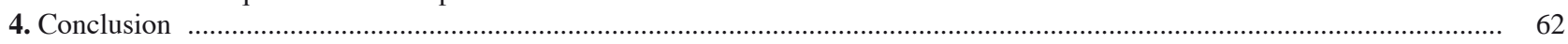

Chapitre 3 : La fin du XII ${ }^{\mathrm{e}}$ s. et le XIII' ${ }^{\mathrm{e}}$ s. : les potiers s'installent aux portes de la cité (Fl. Parent et C. Richarté) …............... 63

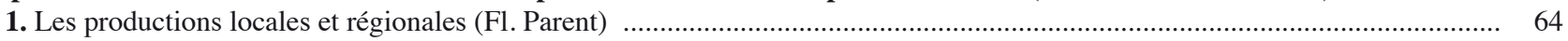

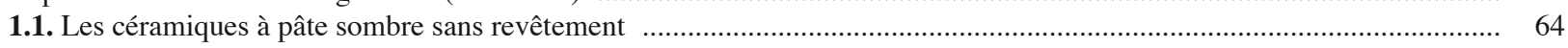

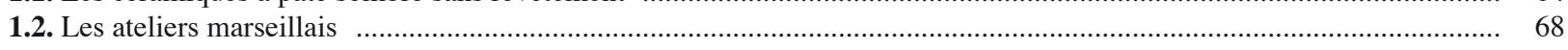

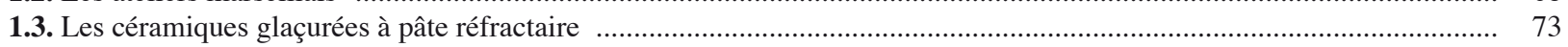

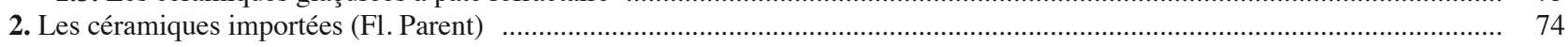

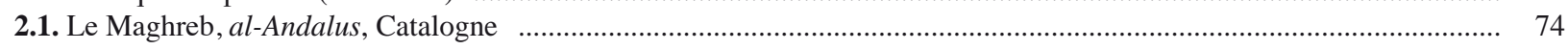

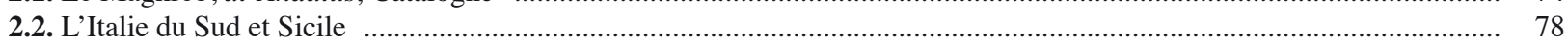

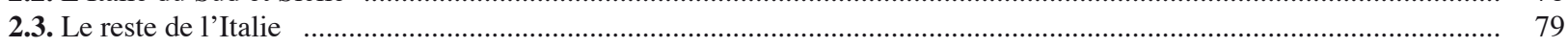

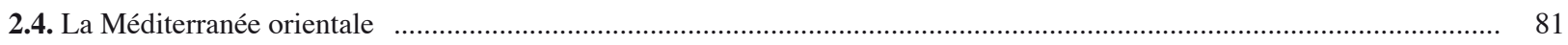

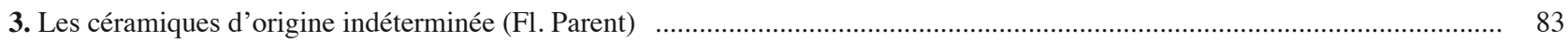


3.1. Les céramiques modelées à pâte rouge glaçurée

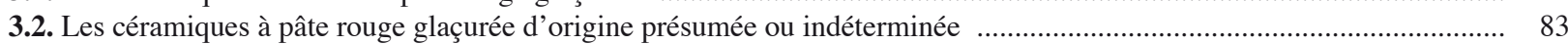

4. L'opulent quartier canonial de la Major? Un exemple de l'approvisionnement en céramiques aux XII et XIII' s. (C. Richarté) 83

4.1. L'omniprésence des récipients régionaux

4.2. La vaisselle et les vases importés d'al-Andalus à l'Orient

4.3. Les productions de l'aire byzantine

4.4. Dans l'influence de la chrétienté occidentale

4.5. Le quartier canonial, miroir du commerce méditerranéen

5. Conclusion (Fl. Parent)

Chapitre 4 : Les derniers siècles du Moyen Âge : de la lumière à l'ombre (Fl. Parent, V. Abel)

1. La fin du XIII' et le XIV e s. : vers l'hégémonie de quelques grands centres ? (Fl. Parent)

1.1. La rue Trinquet

1.2. Le collège Vieux-Port

1.3. La rue de la république (Surverse Vieux-Port)

1.4. L'Alcazar

1.5. La place Villeneuve-Bargemon

1.6. Regard sur un $X I V^{\mathrm{e}} \mathrm{s}$. riche en mobilier céramique

2. La céramique du XV e s. (Fl. Parent, V. Abel)

2.1. La nuit marseillaise du $X V^{\mathrm{e}} \mathrm{s}$.

2.2. Une vaisselle en théorie

Chapitre 5 : Le flou du XVI ${ }^{e}$ s. marseillais : de la fin du XV ${ }^{\mathrm{e}}$ s. au début du XVII ${ }^{\mathrm{e}}$ s. (V. Abel)

1.1. Les faïences

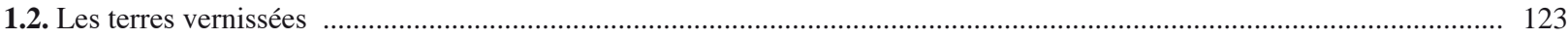

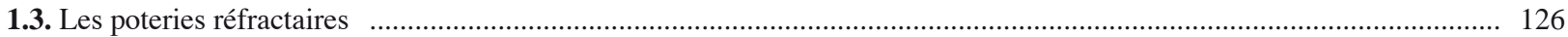

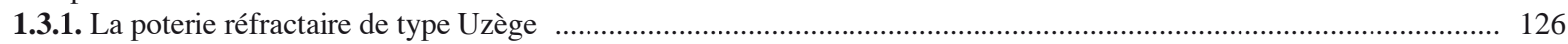

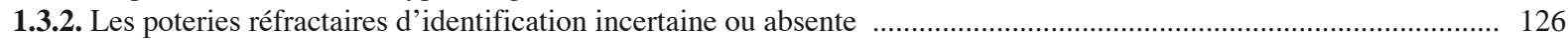

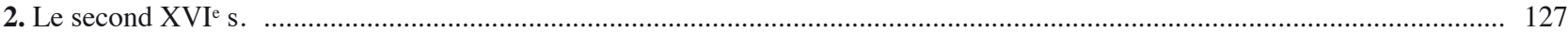

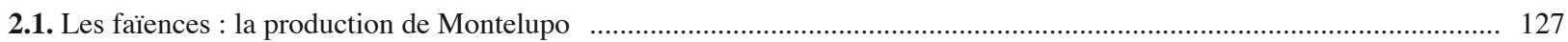

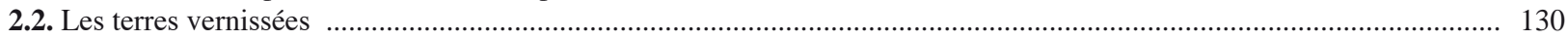

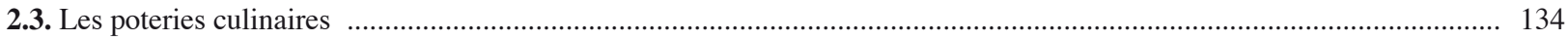

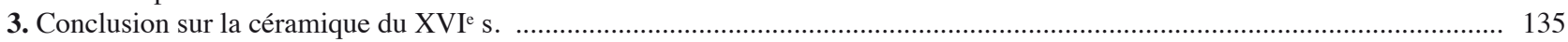

Chapitre 6 : Les productions naissantes des ateliers de la vallée de l'Huveaune face aux importations, milieu du XVII ${ }^{\mathrm{s}}$. (V. Abel)

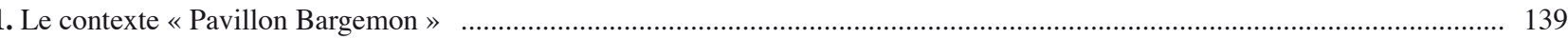

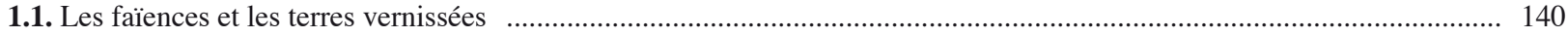

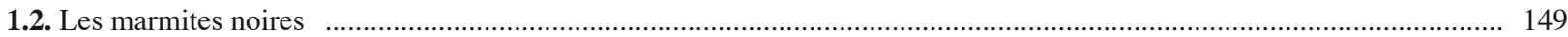

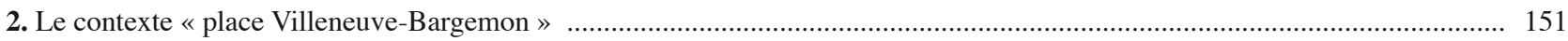

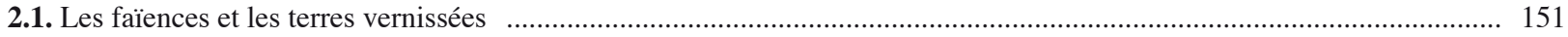

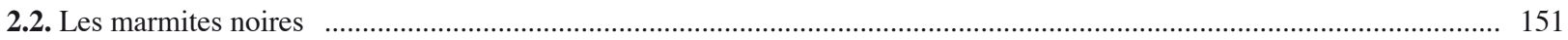

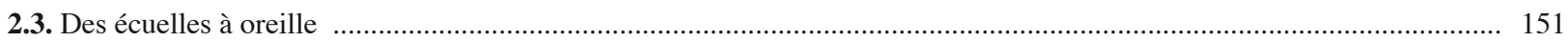

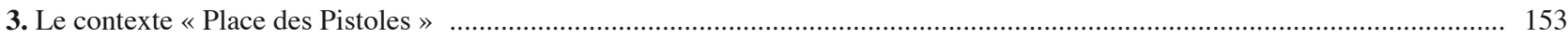

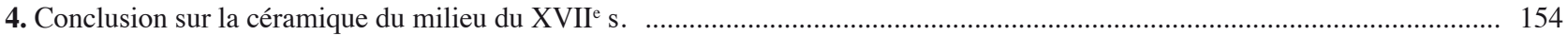

Chapitre 7 : La céramique d'usage quotidien à Marseille de 1660 à 1710 : la créativité exceptionnelle des ateliers de l'arrière-pays marseillais

1. Les importations au long cours : Orient et Europe du Nord

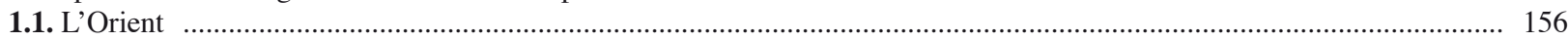

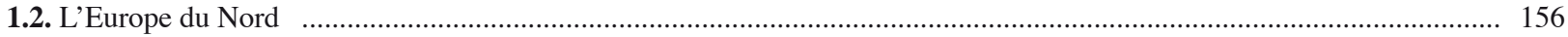

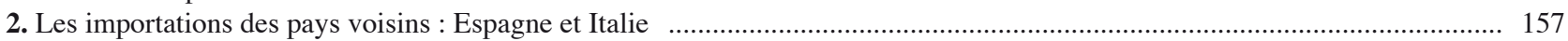

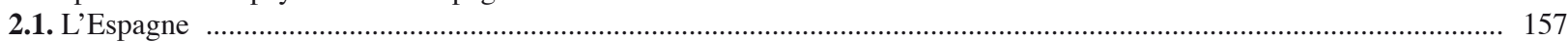

2.2. La question de la Ligurie et de l'ancien type « génois » .................................................................................. 158

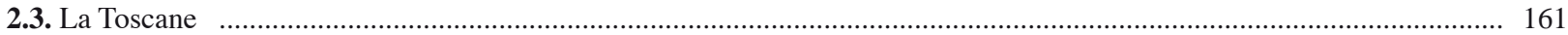

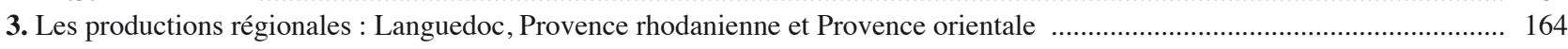

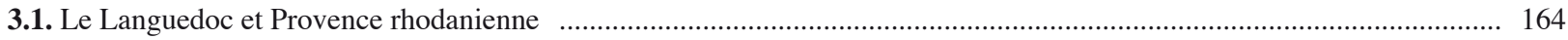

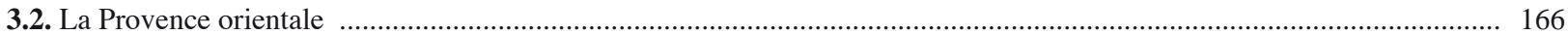

4. Production locale et assimilée : la terre vernissée de l'arrière-pays marseillais et la faïence régionale …................................ 166

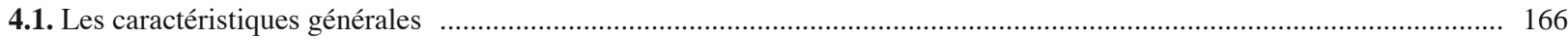

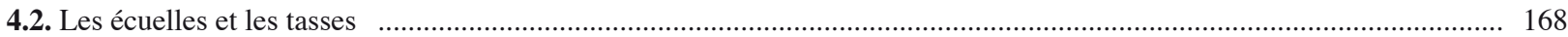


4.3. Les assiettes et les plats

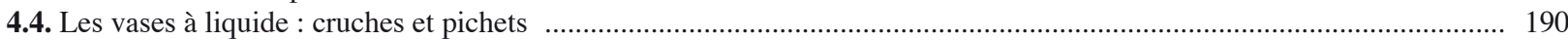

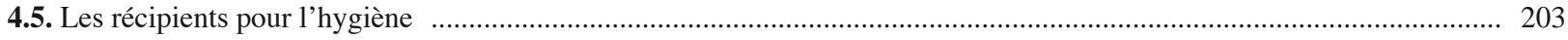

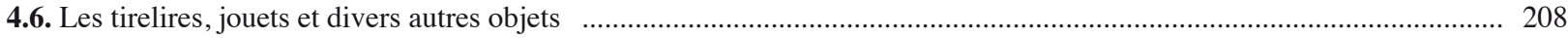

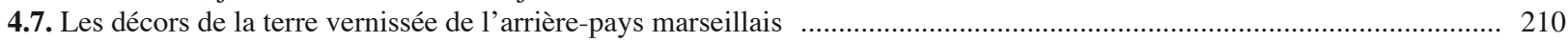

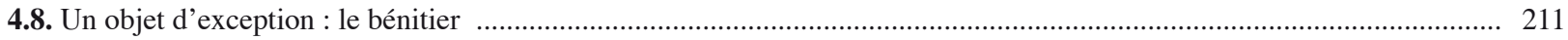

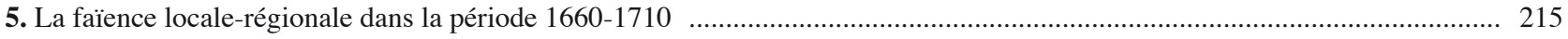

5.1. Le chantier près du hameau de Saint-Jean-du-Désert (rocade L2) .......................................................................... 215

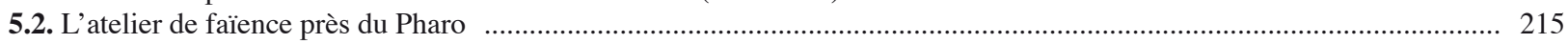

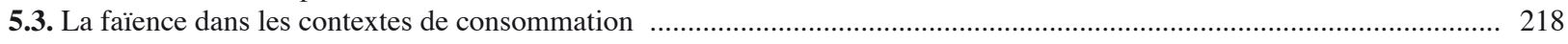

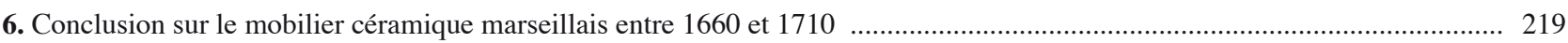

Chapitre 8 : Du début au milieu du XVIII' ${ }^{\mathrm{e}}$ s. : le règne des productions de la vallée de l'Huveaune (V. Abel) …................... 221

1. L'installation de la faïence régionale dans la première moitié du XVIII ${ }^{\mathrm{e}}$ s. ................................................................. 221

1.1. Les faïences

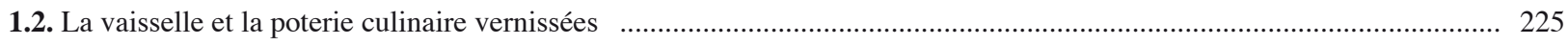

1.3. Les céramiques à pâte calcaire de la basse Vallée du Rhône dites de «type Meynes » ................................................. 2227

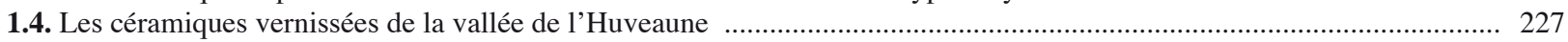

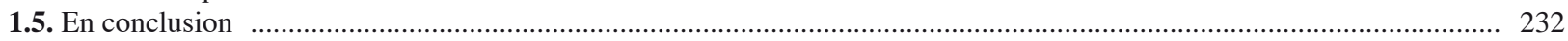

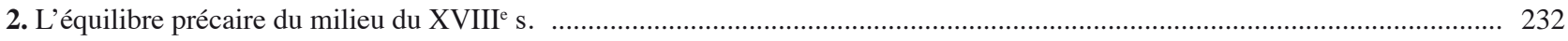

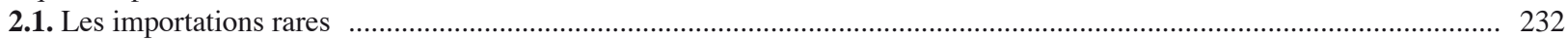

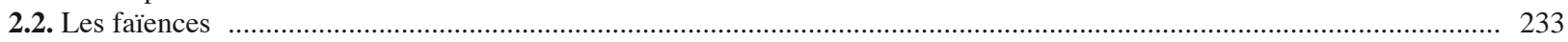

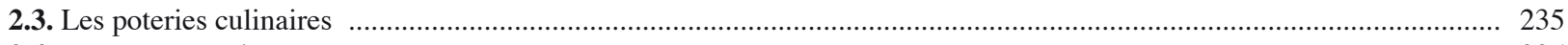

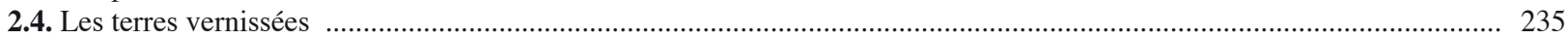

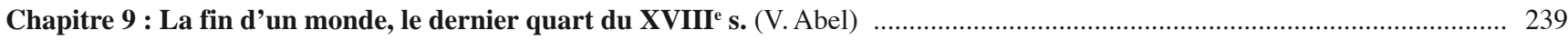

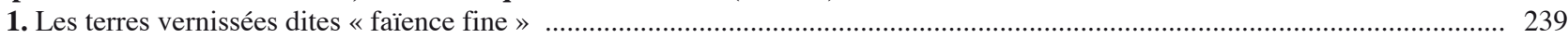

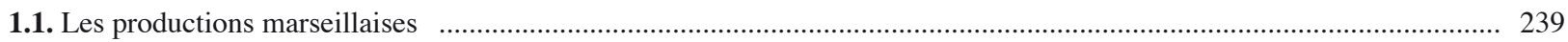

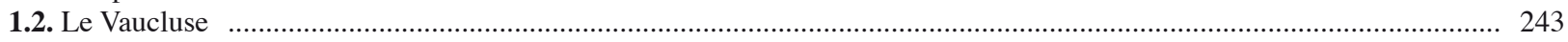

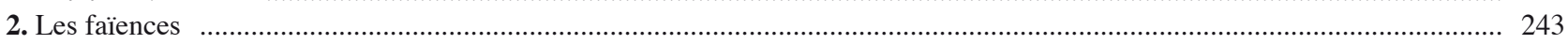

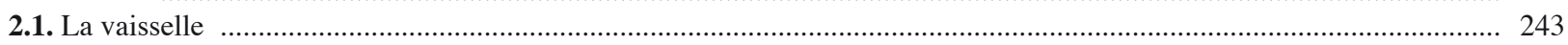

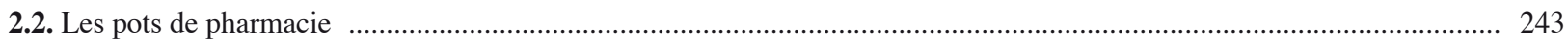

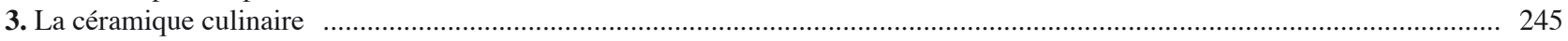

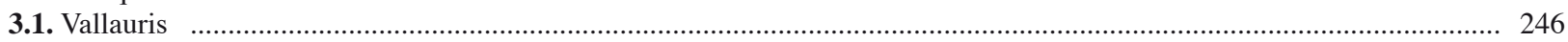

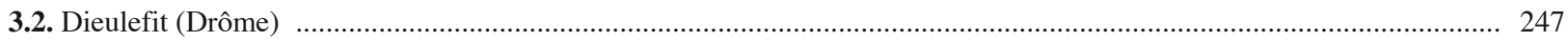

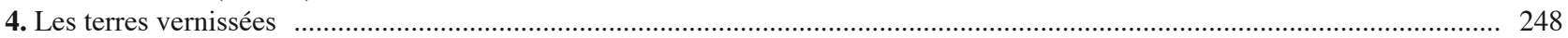

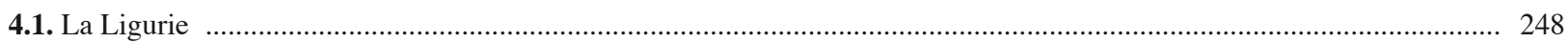

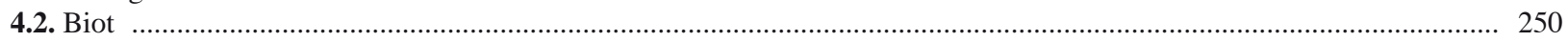

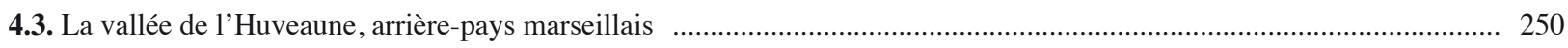

\section{DEUXIÈME PARTIE : LES AUTRES MOBILIERS}

Chapitre 1 : Les verres médiévaux des fouilles de Marseille (D. Foy, D. Michel) ................................................................ 259

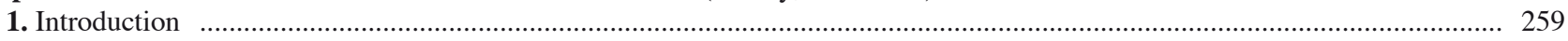

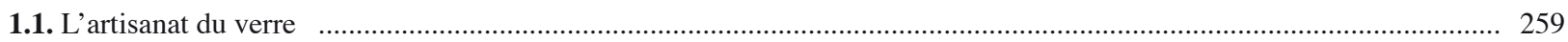

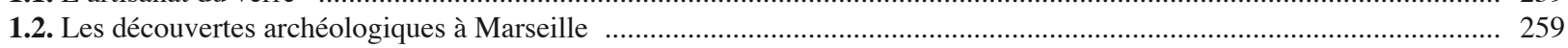

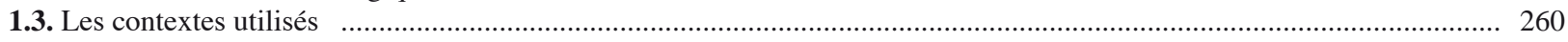

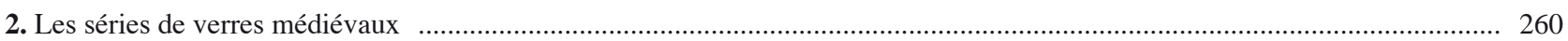

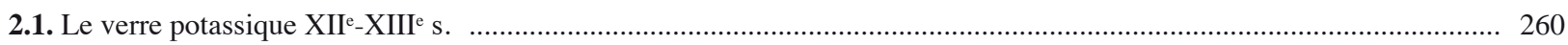

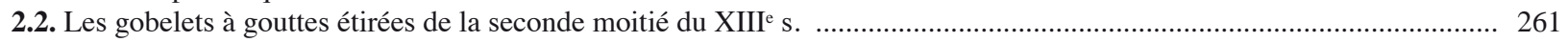

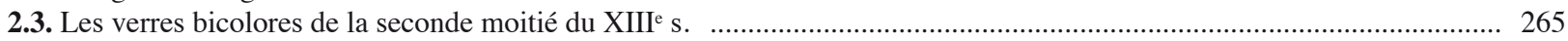

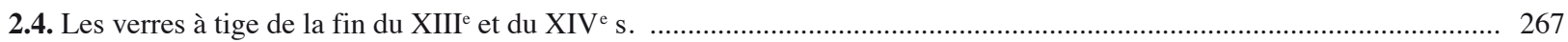

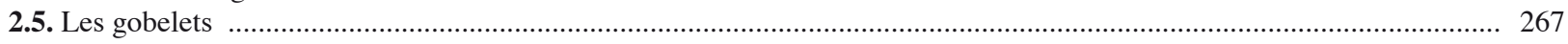

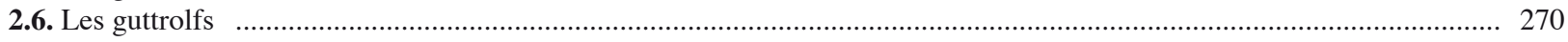

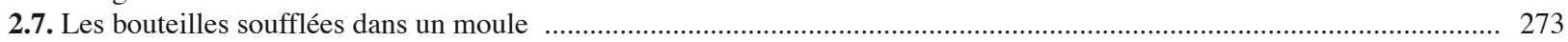

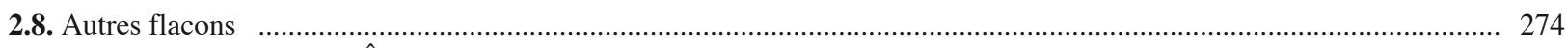

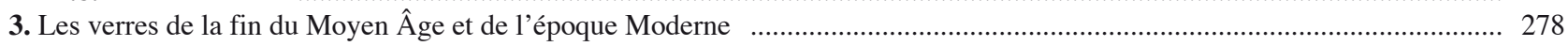

Chapitre 2 : Les monnaies médiévales et modernes (Alcazar et Tunnel de la Major) (J. Bouvry) ........................................... 279

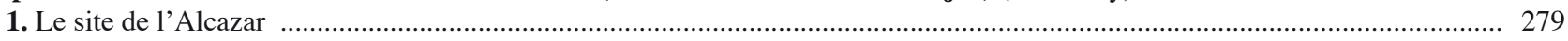

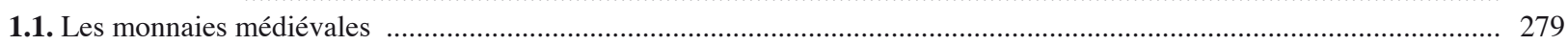




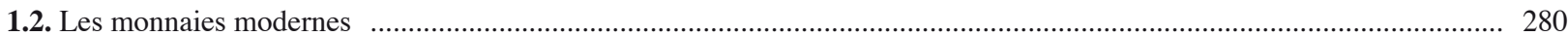

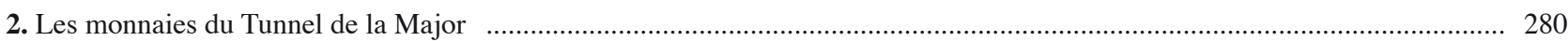

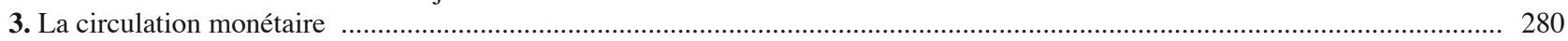

Chapitre 3 : Quelques pipes en terre issues des fouilles de Marseille (P. J. Davey) …............................................................ 283

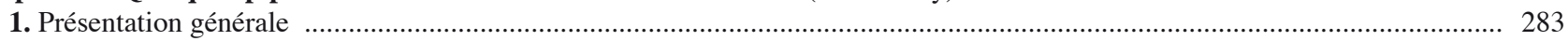

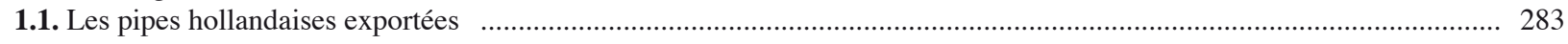

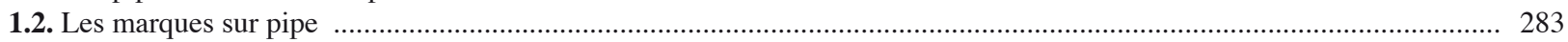

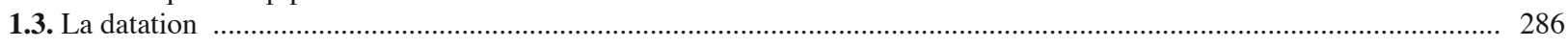

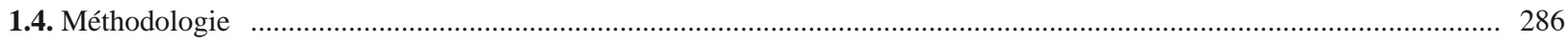

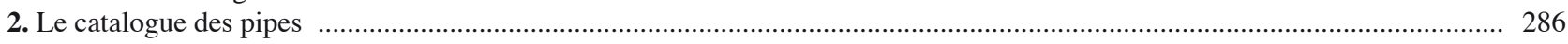

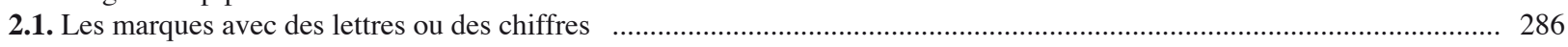

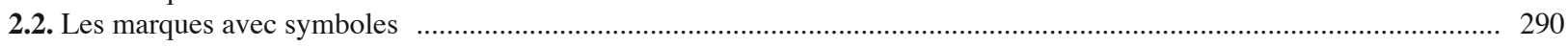

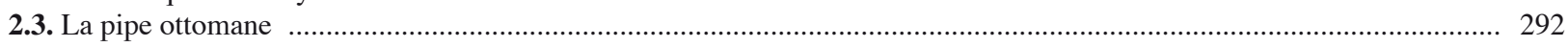

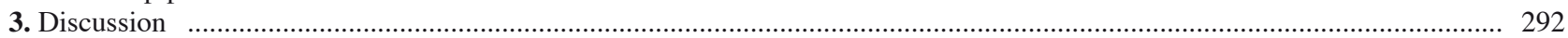

Chapitre 4 : Étude du mobilier manufacturé non céramique (O. Thuaudet, M.-A. Chazottes) ................................................... 295

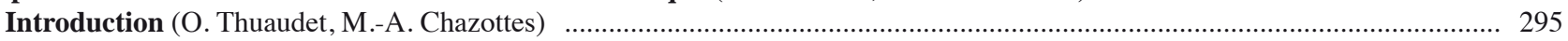

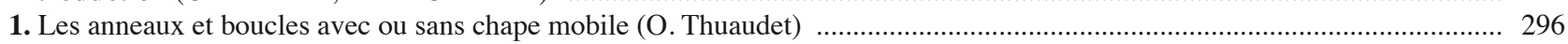

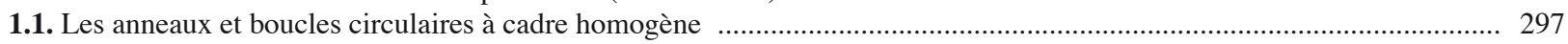

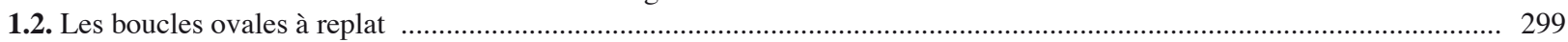

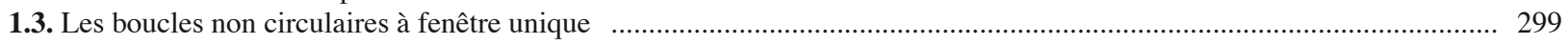

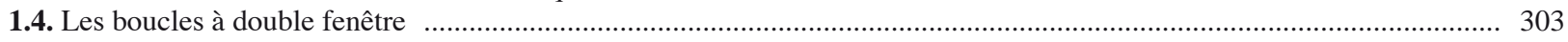

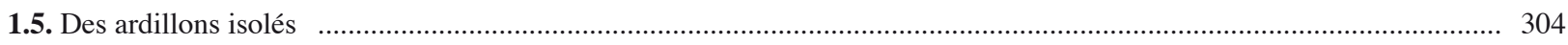

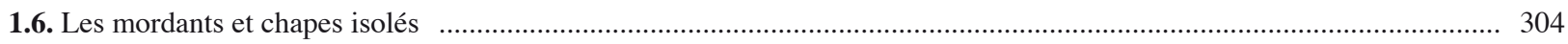

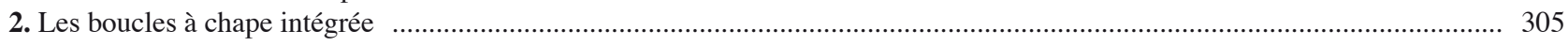

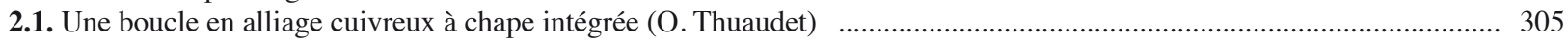

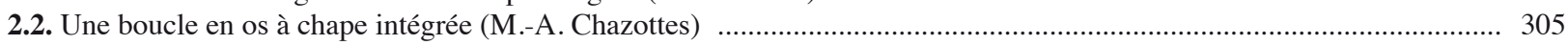

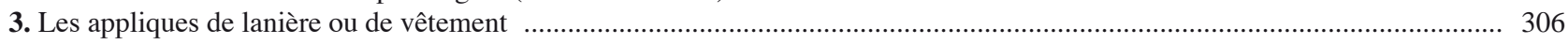

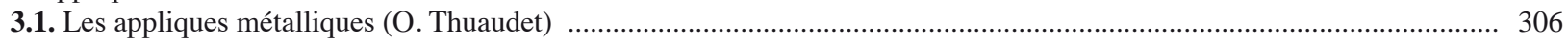

3.2. Les appliques en nacre (M.-A. Chazottes, O. Thuaudet) .................................................................................. 309

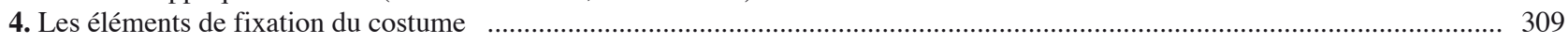

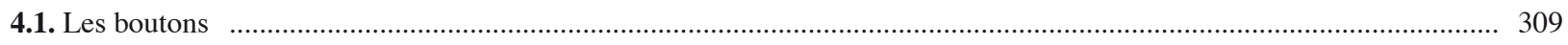

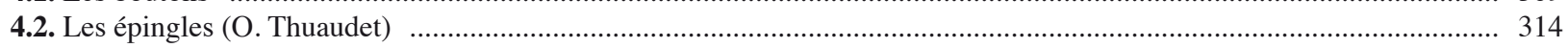

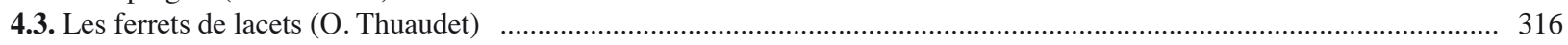

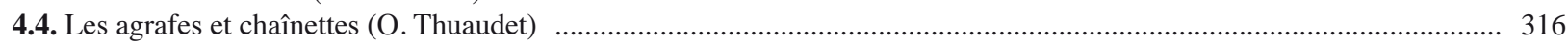

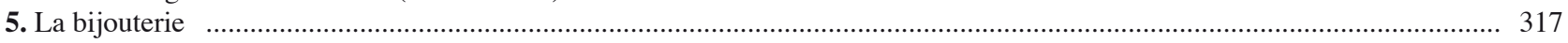

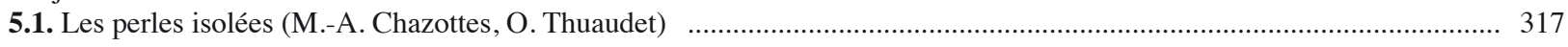

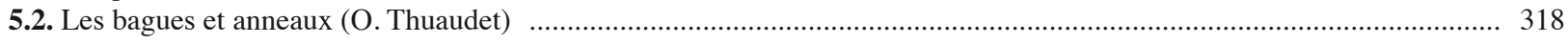

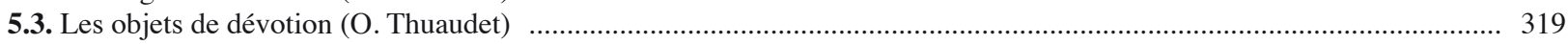

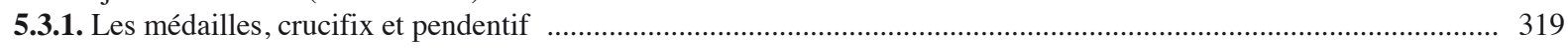

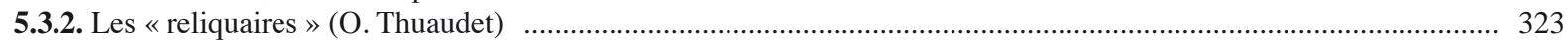

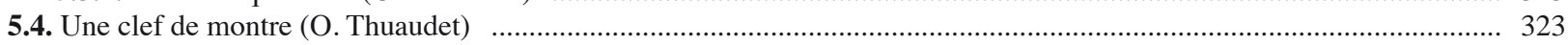

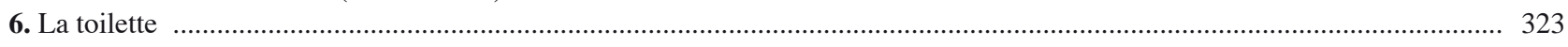

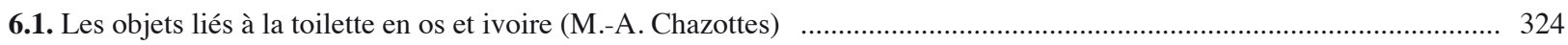

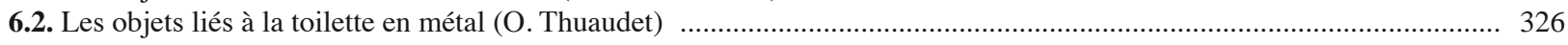

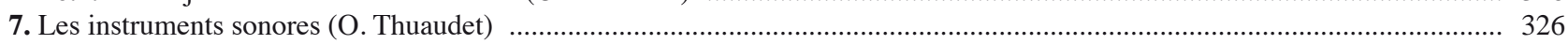

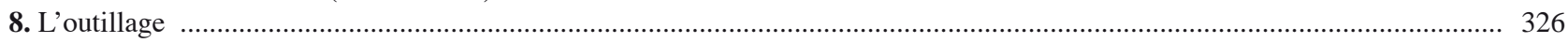

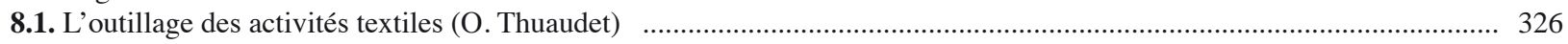

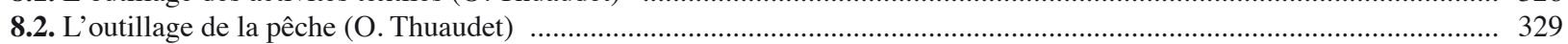

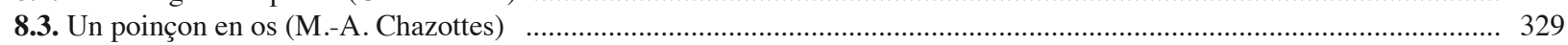

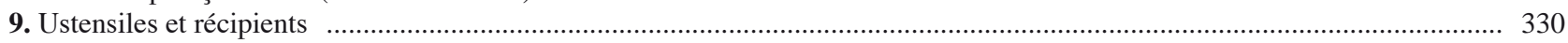

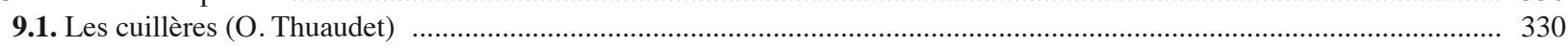

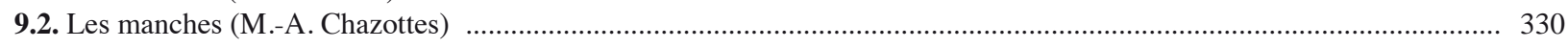

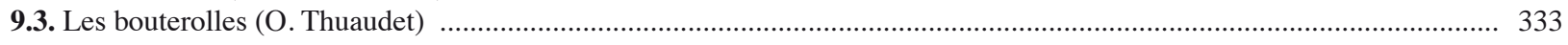

9.4. Un récipient indéterminé $(\mathrm{O}$. Thuaudet)

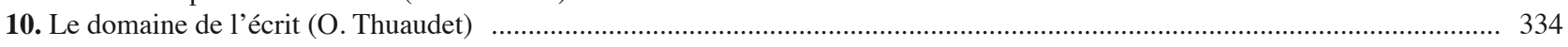

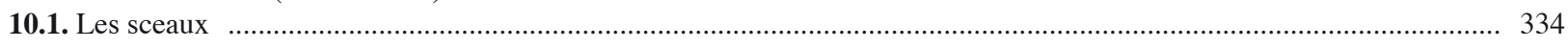

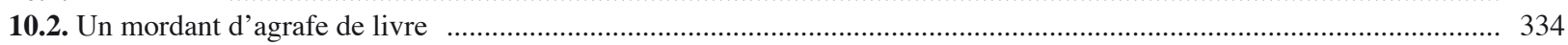

11. Le jeu

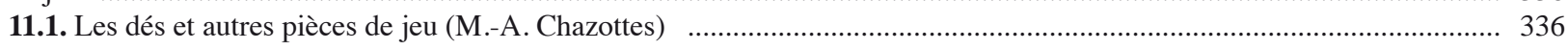

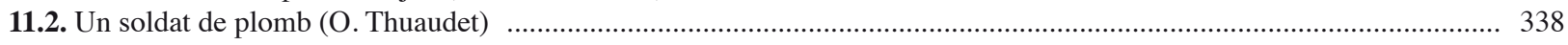




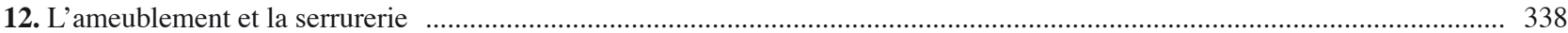

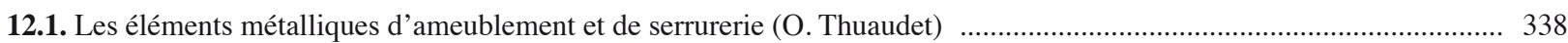

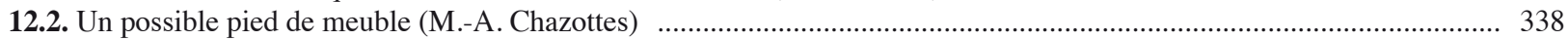

13. Les clous et rivets $(\mathrm{O}$. Thuaudet)

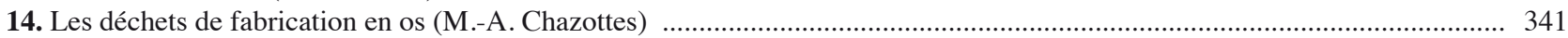

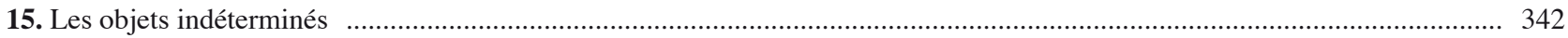

15.1. Les objets indéterminés en os ou en nacre (M.-A. Chazottes) ….................................................................. 342

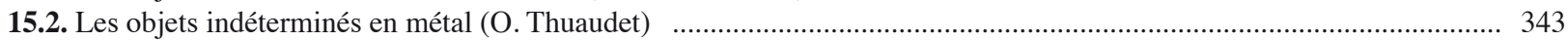

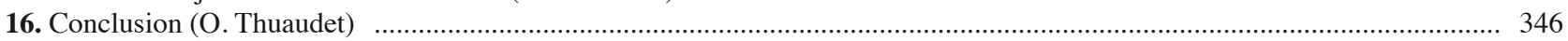

Conclusion générale L'exception marseillaise : absences surprenantes et luxe étonnant (V. Abel, Fl. Parent) .......................... 351

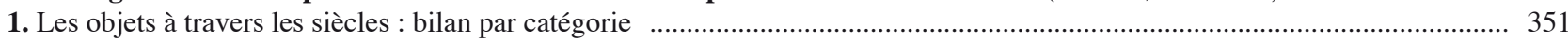

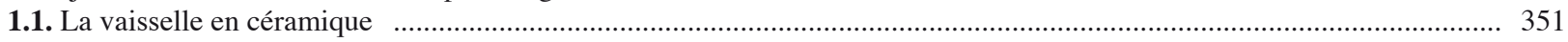

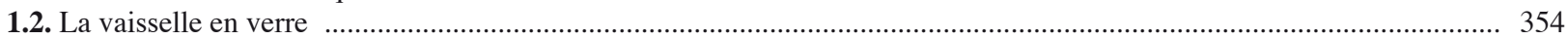

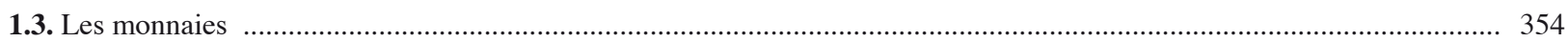

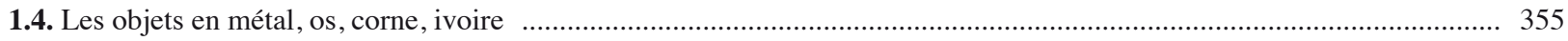

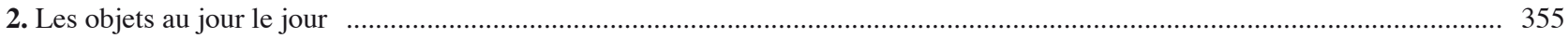

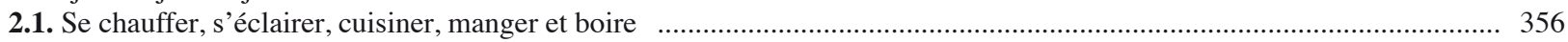

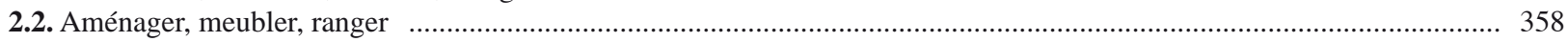

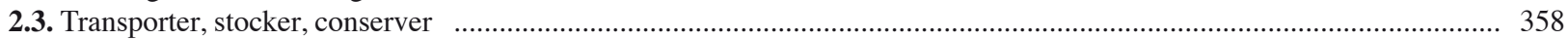

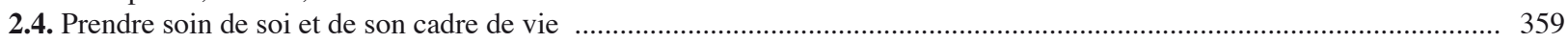

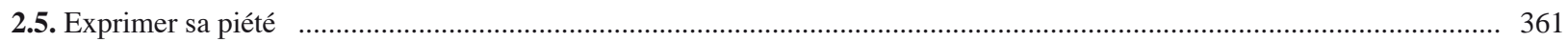

2.6. Ecrire

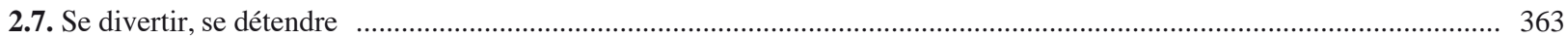

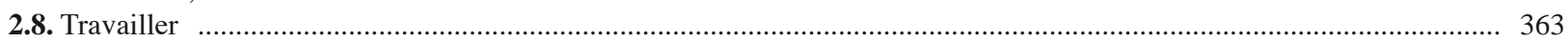

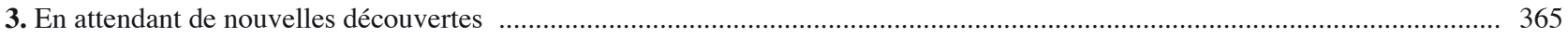

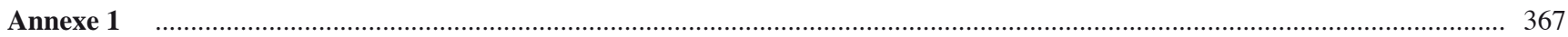

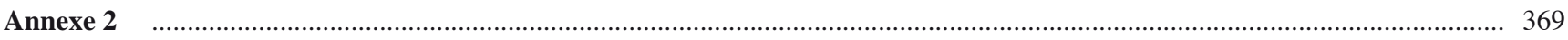

Annexe $3 \quad$ (n)

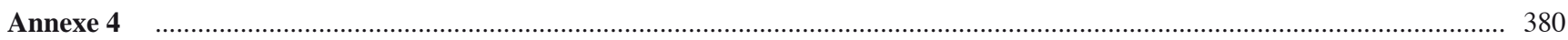

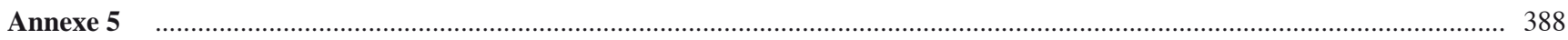

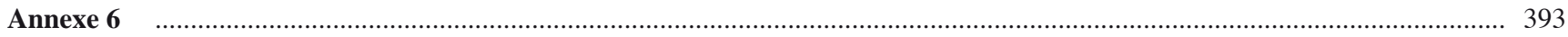

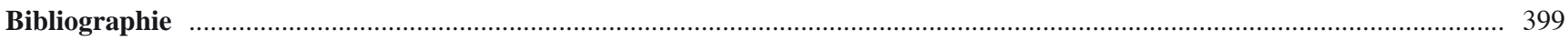




\section{Avant propos}

\section{Marc Bouiron - Directeur du Service Archéologie de la Ville de Nice Chercheur associé au CEPAM (UMR 7264)}

Avec cet ouvrage prend corps, lentement mais sûrement, la publication d'ensemble des fouilles marseillaises récentes que nous annoncions dans le premier volume, $\mathrm{n}^{\circ} 7$ de cette même collection. Les objets du quotidien, devenus mobilier archéologique du fait de leur enfouissement dans les couches sédimentaires ou de leur insertion dans des maçonneries, font partie intégrante des données que les archéologues utilisent pour la compréhension d'un site archéologique.

Ainsi, après avoir donné dans le premier volume le détail de la stratigraphie médiévale et moderne de quelques grands sites fouillés à Marseille, l'évolution de leurs constructions et les avoir replacés dans le contexte plus général de la cité, fallait-il exposer la nature des objets retrouvés. Là encore, il n'était pas possible de décrire précisément le mobilier par unité stratigraphique, ou même de l'indiquer par site archéologique. C'est pourquoi nous avons pris le parti de globaliser ces mobiliers, par grande catégorie en fonction du matériau de fabrication, découpage pratique pour les différents spécialistes qui interviennent dans ce domaine.

L'ouvrage a été conduit en collaboration étroite avec Véronique Abel et Florence Parent, deux céramologues expertes de l'Inrap, avec lesquelles nous avons eu l'occasion de travailler tout au long de ces années passées à fouiller et à étudier les contextes marseillais. Elles ont toutes deux une vision large de ce mobilier et ont été à même d'appréhender pleinement la totalité du champ d'étude de ces objets de la vie quotidienne. Notre travail a consisté, à leurs côtés, à coordonner et mettre en forme finale ce travail collectif, travail parfois ingrat mais ô combien nécessaire pour que paraisse le présent ouvrage.

Les spécialistes contactés, chevronnés pour certains (comme Danièle Foy, Peter J. Davey, Catherine Richarté ou Joëlle Pournot), un peu moins pour d'autres (Denis Michel) voire beaucoup plus jeunes pour le «petit mobilier » (Olivier Thuaudet et Marie-Astrid Chazottes), ont tous relevé le challenge que représentait la réalisation de ce volume, qui aura nécessité quatre années d'un travail régulier pour voir le jour. Leurs contributions sont précieuses pour élargir un ouvrage qui aurait autrement concerné uniquement le mobilier céramique.

Nous voudrions remercier ici les institutions qui continuent à nous faire confiance. Tout d'abord le Ministère de la Culture et de la Communication, puisque ces volumes sont conçus dans le cadre d'un Projet collectif de recherches (PCR), labellisé par ce ministère ; l'appui du Service régional de l'Archéologie (DRAC-PACA), et de Stefan Tzorzis en particulier, sous le direction de Xavier Delestre, est ainsi primordial. Ce volume a aussi bénéficié d'un financement direct de la direction générale des patrimoines (sous-direction de l'archéologie). C'est ensuite, l'Inrap qui, année après année, permet à ses agents, par le biais des moyens annuels scientifiques, de disposer du temps nécessaire à l'écriture des différentes contributions. Que Jean-Paul Jacob, son président, François Souq, son directeur interrégional Méditerranée et Hervé Guy, l'adjoint scientifique et technique soient ici remerciés, de même que Pascal Depaepe et Mark Guillon, de la la direction scientifique et technique parisienne de cet organisme. Troisième partenaire indispensable, le Centre Camille Jullian dont les directeurs successifs, Dominique Garcia puis Marie-Brigitte Carre et les directeurs de la publication, Michel Bats puis Henri Tréziny, ont accepté de publier dans la Bibliothèque d'Archéologie Méditerranéenne et Africaine, tous les volumes de notre série « Fouilles à Marseille »; volumes mis en page grâce au travail précieux de Véronique Gémonet, responsable de la cellule éditoriale.

Enfin, il nous est agréable de dédier ce volume à Gabrielle Démians d'Archimbaud, fondatrice du Laboratoire d'Archéologie Médiévale, actuellement placé sous la direction de Henri Amouric avec l'intitulé de Laboratoire d'Archéologie médiévale et moderne en Méditerranée (LA3M). Elle a très largement contribué à susciter, chez Véronique Abel, Florence Parent ou moi-même, le goût de cette archéologie des périodes médiévale et moderne qui a émergé au cours de la seconde moitié du $\mathrm{XX}^{\mathrm{e}} \mathrm{s}$. Nous lui devons beaucoup.

À Gabrielle Démians d'Archimbaud 


\title{
Introduction générale
}

\section{L'objet quotidien devient mobilier archéologique}

\author{
Véronique Abel ${ }^{1}$, Florence Parent ${ }^{2}$ avec la coll. de Marc Bouiron ${ }^{3}$
}

Nous accordons rarement beaucoup d'attention aux objets qui nous accompagnent au quotidien. Un faux mouvement et l'assiette se brise au sol, la pièce de monnaie roule sous un meuble, nous arrachant tout au plus un soupir d'exaspération à l'idée de se courber pour aller récupérer celle-ci ou les morceaux de celle-là. Nous utilisons, usons et jetons nombre d'ustensiles sans même leur accorder une pensée.

Si en revanche au détour d'un étal de brocante tintent des pièces de vingt centimes de francs ou revient entre nos mains un mazagran identique à celui dans lequel notre grand-mère servait le café, une bouffée de nostalgie nous envahit, renaissent intactes les joies ou les craintes de jadis. Ces objets, leur bruit ou leur toucher, sans parler bien sûr de leur image, nous replongent en un instant dans le passé tant ils nous ont aidés et suivis, tous les jours et tant de temps.

Si les objets ordinaires savent faire renaître en un clin d'œil les souvenirs de la mémoire de chacun, peuvent-ils témoigner, à leur mesure, de notre passé collectif ? Sont-ils suffisamment solides, explicites et fiables ? Un artiste s'était posé ces questions en 1983, et il prépara une réponse pour les chercheurs à venir, désormais archéologues d'aujourd'hui. Ainsi fut fouillé par l'Inrap en 2010 le Déjeuner sous l'herbe de Daniel Spoerri démontrant un apport qui est loin d'être anecdotique sur les durées de conservation des matériaux et en comparaison avec d'autres disciplines ${ }^{4}$.

Avant lui, mais étranger à cette démarche artistique, Jerome K. Jerome, prophète à sa manière et moqueur comme à son habitude, se demandait en 1889 dans son célèbre Trois hommes et un bateau si les tasses ordinaires cassées à son époque seraient « recollées avec soin puis amoureusement exposées sur des étagères par des maîtresses de maison qui, seules, auront le droit de les épousseter »... Le romancier anglais était visionnaire, et en effet « les gobelets en faïence des auberges de campagne » du XIX ${ }^{\mathrm{e}}$ s. sont bel et bien « la proie des collectionneurs ». Il n'avait cependant pas imaginé l'intérêt que les archéologues porteraient aux vieilles tasses cassées ou à leur équivalent médiéval ou baroque.

En effet, une fois lui-même ou ses quelques restes abandonnés, jetés ou perdus, l'objet quotidien se retrouve orphelin de propriétaire et entre dans une nouvelle dimension. Lentement (ou promptement) enfoui dans la terre, son statut change radicalement. N'étant plus le bien de personne, il devient le patrimoine de tous si l'injure du temps l'épargne un tant soit peu. Il s'est métamorphosé en mobilier archéologique.

Ajoutés les uns aux autres et au fil des siècles, ces objets de la vie quotidienne forment des masses parfois imposantes à récolter pendant le chantier, à gérer et à traiter pour les conserver dignement et à étudier alors que l'acte de fouille archéologique est définitivement terminé et tout empilement stratigraphique disparu. Ils créent un lien indéfectible de responsabilité entre leurs inventeurs et eux, parfois transférés pour un temps à ceux qui les étudient.

\section{L'étude des mobiliers archéologiques}

L'étude du ou des mobiliers archéologiques est en premier lieu tributaire des conditions de conservation, puis de découverte et soumis au bon vouloir des « inventeurs ». Ainsi, les périodes médiévale et moderne ont longtemps été considérées comme trop récentes pour faire l'objet d'investigations archéologiques, d'autant qu'on les pensait

1 Inrap, chargée d'opération et de recherche.

2 Inrap, chargée d'opération et de recherche, chercheur associée au LA3M, UMR 7298.

3 Directeur du Service Archéologie de la Ville de Nice, chercheur associé au CEPAM, UMR 7264.

4 Voir l'article que Jean-Paul Demoule consacre à cette fouille (http://jeanpauldemoule.wordpress.com/2011/06/13/, consulté le 3 septembre 2013). 
suffisamment documentées par les archives pour alimenter la recherche historique. Elles ont donc été largement délaissées par les archéologues français et européens déjà fort préoccupés par les périodes antiques et pré ou protohistorique. En France, il a fallu attendre la sortie de la Seconde guerre mondiale pour que naisse enfin une nouvelle forme d'archéologie médiévale, qui ne soit plus une histoire de l'art mais un outil essentiel pour mieux comprendre l'histoire de l'homme et de son habitat. Le fondateur de cette discipline, Michel de Boüard, en Normandie, avec ses importants travaux au château de Caen à partir de 1949, fut rapidement suivi par Gabrielle Démians d'Archimbaud et ses recherches sur l'habitat perché de Rougiers dans le Var, entreprises dans les années 1960, auxquelles succédèrent celles dans l'abbaye Saint-Victor de Marseille. La région provençale peut donc s'enorgueillir d'être le second berceau de l'archéologie médiévale en France.

La publication des résultats de la fouille de Rougiers par $\mathrm{M}^{\text {lle }}$ Démians d'Archimbaud en 1981 fait date. En donnant une large place aux mobiliers archéologiques, elle est pionnière dans l'étude de la culture matérielle du Moyen Âge en Provence. Trois décennies plus tard, et toujours sous son impulsion intellectuelle, les recherches n'ont cessé de progresser dans le sud-est de la France et les publications de se multiplier. Le développement assez récent des «fouilles de sauvetage » (aujourd'hui appelées fouilles préventives), spécialement en milieu urbain, a permis d'augmenter considérablement la documentation en la matière. Axé dans un premier temps essentiellement sur la période médiévale, le champ de la recherche a rapidement englobé celle des Temps modernes. Les découvertes de Fréjus font entrer la céramique moderne dans la recherche provençale dès 1982.

Initiée à la fin des années 1960, l'archéologie préventive a presque toujours été la grande, voire la seule pourvoyeuse de mobilier médiéval et moderne à Marseille, mobilier au sein duquel les céramiques ont toujours pris la part dominante. Néanmoins, les résultats sont très irréguliers suivant les chantiers car, pendant longtemps, priorité a été donnée aux niveaux antiques ${ }^{5}$, dont l'étendue chronologique et stratigraphique est sans pareille dans les autres villes de France. Les niveaux supérieurs sont souvent partis en vrac à la décharge, soit par crainte de ne pas venir à bout de cet empilement archéologique, soit par ignorance des problématiques, soit par simple désintérêt. Quelques lots de mobilier de périodes plus récentes ont cependant échappé à ce funeste destin grâce à l'indulgence, à «l'ouverture d'esprit» ou à la pugnacité d'une poignée d'archéologues. Ce fut le cas notamment d'un lot de céramiques modernes qui sera présenté plus loin, recueilli entre 1967 et 1984 sur le site de la Bourse. Ce fut encore le cas, plus récemment, de la fouille de la place Jules-Verne (dans les années 1990) où seules réchappèrent les céramiques médiévales et modernes presque intactes conservées au fond des puits se trouvant au même niveau que les vestiges antiques. Non loin de là, et quasiment au même moment, deux gros chantiers entreprenaient la fouille exhaustive des niveaux médiévaux et modernes, avec récolte du mobilier en stratigraphie : la fouille des ateliers de potiers du quartier Sainte-Barbe et celle du bourg Sainte-Catherine sous la place Général-de-Gaulle, ces deux sites ayant donné lieu à des monographies intégrant l'étude des mobiliers (Marchesi et al. 1997 ; Bouiron 2001). Dès lors, l'archéologie préventive marseillaise a plus volontiers intégré ces périodes qu'elle avait longtemps malmenées.

Dans l'esprit de beaucoup d'archéologues cependant, l'étude du mobilier archéologique se résume à celle de la céramique, probablement parce que ces témoins sont toujours beaucoup plus abondants et les « séries » plus rapidement constituées. En outre, l'observation peut se faire dans un délai assez court après leur découverte, un simple nettoyage à l'eau se révélant généralement suffisant pour entamer les analyses. La recherche en ce domaine est aussi beaucoup plus avancée que pour d'autres matériaux. L'archéologue « de terrain » (dit aussi «fouilleur ») travaillant dans l'urgence est préoccupé par la datation des vestiges et privilégie l'étude de la céramique pour y parvenir, négligeant ou sacrifiant non seulement l'apport d'autres types d'objets mais aussi les autres apports de la céramique. L'étude des autres catégories ne doit pas être oubliée, même s'ils sont d'un abord infiniment plus ingrat et leur connaissance bien moins avancée.

La céramique est effectivement le premier argument, en liaison avec la stratigraphie, qui permet la datation des contextes de toute fouille archéologique. Les monnaies apportent aussi des informations, mais leur rareté et leur durée de circulation, parfois très longues, relativisent leur contribution. Les études sur les mobiliers autres que céramiques, moins fréquentes et sur des corpus fatalement moins importants, peuvent toutefois procurer d'autres indices chronologiques comme l'illustre l'exemple d'une boucle en métal du Tunnel de la Major (cf. $2^{\mathrm{e}}$ partie, ch. 4 § 2.3). L'étude des mobiliers ne s'arrête pas à une simple datation, elle ne s'attache pas non plus à des considérations esthétiques et artistiques. L'objet en tant que tel, et ceci est particulièrement vrai pour la céramique, n'est en fait qu'un ambassadeur. En étudiant un objet, après toutes les étapes techniques inhérentes à son étude, il nous revient de passer

5 Concernant l'histoire de l'archéologie préventive du Moyen Âge aux Temps modernes à Marseille, nous invitons le lecteur à se reporter au premier volume de cette série (Bouiron et al. 2011, p. 23-25). 
outre cet objet et d'essayer de décrypter le message qu'il véhicule. Ce questionnement permanent qui nous habite lors de toute étude de mobilier, c'est à $\mathbf{M}^{\text {Ile }}$ Démians d'Archimbaud que nous le devons. Conscientes de cette dette, nous voudrions aujourd'hui lui dédier ce volume.

\section{Les sources archéologiques}

Cette publication s'inscrit dans une collection de plusieurs volumes destinée à enrichir la connaissance historique de Marseille à travers l'archéologie récente (fig. 1). Elle suit et complète un premier volume consacré à la ville médiévale et moderne (Bouiron et al. 2011). Nous donnons ci-dessous le contexte archéologique des fouilles ayant

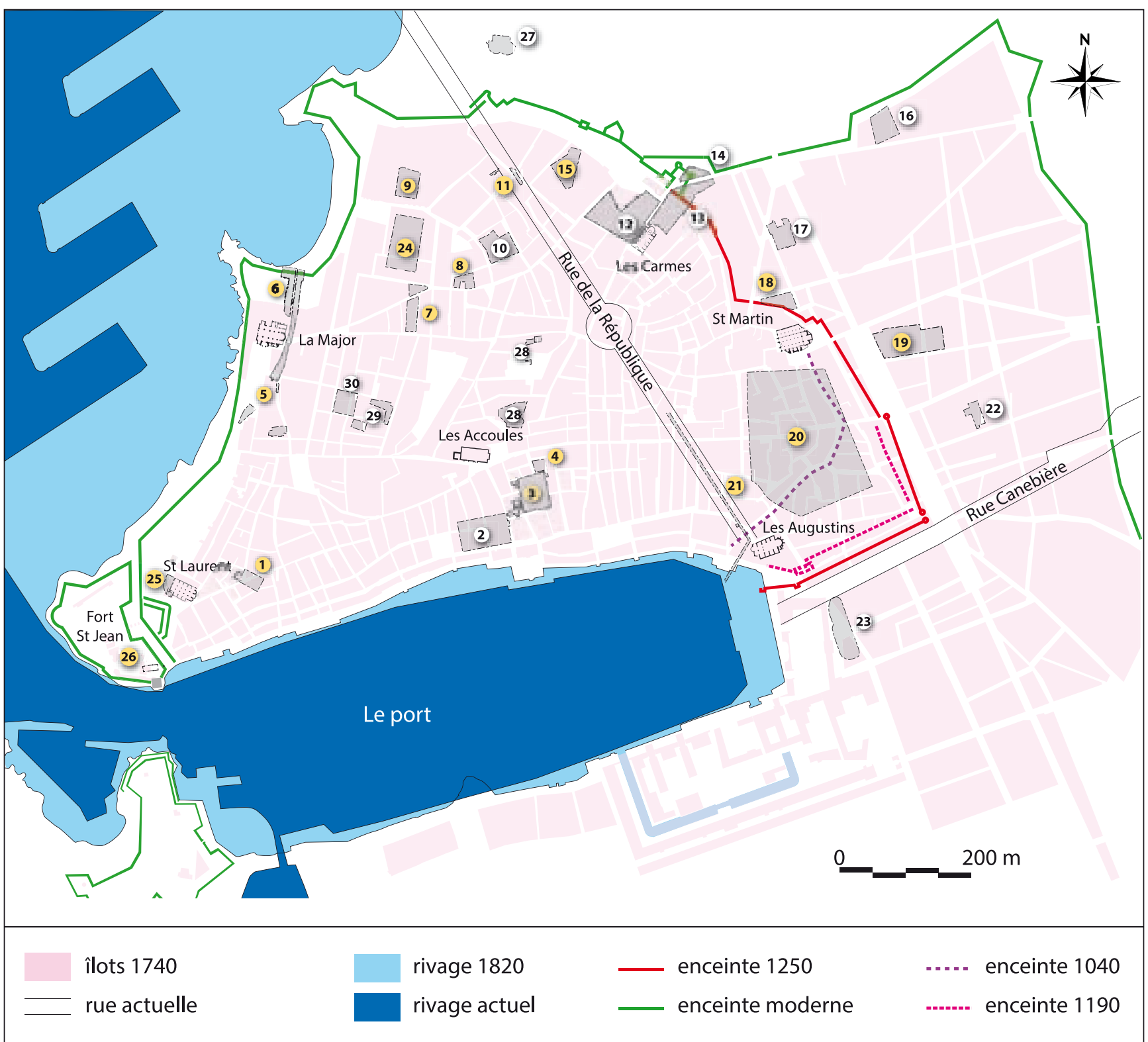

Fig. 1. Plan de situation des différents chantiers archéologiques mentionnés dans l'ouvrage : en jaune, les chantiers étudiés dans ce volume. 1 : collège Vieux Port, $\mathbf{2}$ : parking Jules Verne, $\mathbf{3}$ : place Bargemon, $\mathbf{4}$ : espace Bargemon, $\mathbf{5}:$ tunnel de la Major, $\mathbf{6}:$ esplanade de la Major, $\mathbf{7}:$ place des

Pistoles, 8 : RHI Bon Jésus, 9 : rue Leca, 10 : parking des Phocéens, 11 : parking République, 12 : les Carmelins, 13 : les Carmes, 14 : îlot N, 15 : rue Trinquet, 16 : Bernard Dubois, 17 : Sainte Barbe, 18 : Puget III, 19 : BMVR (Alcazar), 20 : la Bourse, 21 : République, surverse Vieux Port, 22 : 25 rue Thubaneau, jeu de paume, 23 : place Général de Gaulle, 24 : Vieille Charité, 25 : église Saint-Laurent, 26 : Fort Saint-Jean, 27 : rue Malaval, 28 : Hôtel-Dieu, 29 : place de la Madeleine, 30 : place du Refuge (DAO B. Sillano/Inrap, M. Bouiron/SAVN). 
livré du mobilier présenté dans ce volume, sans entrer dans le niveau de précision que l'on trouve dans l'ouvrage que nous venons de mentionner.

\subsection{Les chantiers étudiés}

Ambitieux au départ, le projet prévoyait de synthétiser toutes les données des opérations d'archéologie préventive marseillaises. La réduction de temps de recherche octroyé nous a conduits finalement à délaisser tous les sites qui nécessitaient une étude complète des mobiliers archéologiques et une relecture de la stratigraphie, pour nous concentrer sur ceux dont l'étude était déjà bien entamée, voire presque aboutie. Pour l'essentiel, les mobiliers présentés dans ce volume proviennent de gros chantiers urbains, un seul ensemble d'un chantier suburbain. Ils sont complétés par des lots issus d'autres opérations de moindre envergure dont la plus récente a eu lieu en 2009. Ont donc été laissés de côté les chantiers antérieurs à 1995, quand ils n'avaient pas donné lieu à des études préalables des mobiliers médiévaux et modernes.

\subsubsection{Les abords du Port}

Ce quartier a fait l'objet de plusieurs campagnes de fouilles préventives entre 1992 et 2002. Sur la première, occasionnée par la construction d'un parking souterrain place Jules-Verne, les vestiges médiévaux et modernes n'ont quasiment pas été observés. Seuls ont été prélevés les éléments de mobilier les mieux conservés, c'est-à-dire ceux enfouis au fond des puits. Une grande partie de cette collection, principalement des vases à liquide, a rapidement été confiée au Musée d'Histoire de Marseille, étant donnée son exceptionnelle qualité de conservation : bien souvent les récipients ne s'étaient même pas brisés au fond des puits. Quelques objets ont été ponctuellement publiés, figurant en guise de comparaisons avec d'autres vaisseliers. Un seul comblement de puits, daté de la fin du XIII au début du $\mathrm{XIV}^{\mathrm{e}}$ s., a fait l'objet d'une publication dans son ensemble (Démians d'Archimbaud, Vallauri 1998).

La place Villeneuve-Bargemon a été le lieu de multiples opérations consécutives à des projets municipaux plusieurs fois modifiés. Les niveaux médiévaux et modernes sous la place ont été examinés sur $1700 \mathrm{~m}^{2}$ par une première équipe : il s'agit de l'opération «César 1 » réalisée en 1995. L'opération « César 2 » concernait les niveaux antiques et a été conduite par une autre équipe en 1996 sur $2500 \mathrm{~m}^{2}$. À cette occasion, une partie des vestiges médiévaux et modernes, qui n'avait pu être observée durant la première opération pour diverses raisons, a été étudiée et intégrée au rapport de la première opération. Il n'en a pas été de même des mobiliers. Alors que l'étude du mobilier céramique avait été permise pendant la première phase de travaux, aucun délai n'a été accordé pour effectuer celle de la seconde phase, qui ne figure donc que ponctuellement dans ce volume. L'excavation destinée à la construction d'un musée souterrain s'est ensuite vu changer d'affectation (annexes de la Mairie et salles d'exposition), nécessitant des explorations archéologiques additionnelles. En 2002, a donc eu lieu un complément de fouilles intitulé Espace Bargemon. Les lots étudiés à l'occasion des campagnes César 1 et Espace Bargemon forment un ensemble cohérent et sont désignés dans ce volume sous l'appellation générique de "place Villeneuve-Bargemon ».

La conservation des vestiges médiévaux et modernes sous cette place est très inégale (Bouiron et al. 2011, p. 241-336). Outre le creusement systématique de caves à l'époque Moderne, le dynamitage méthodique du secteur en 1943 et le déblaiement des décombres ont pour partie perturbé le sous-sol. Les différentes fouilles ont mis cependant en évidence que ce secteur stratégique de la ville, puisqu'à proximité immédiate du port, est occupé depuis la fin du $\mathrm{VI}^{\mathrm{e}} \mathrm{s}$. avant notre ère. Aux chantiers navals de la période hellénistique, au complexe thermal et aux entrepôts de stockage de l'époque romaine, aux nouvelles créations de l'Antiquité tardive, succède une campagne de démolition et de récupération de matériaux qui s'étend du VIII ${ }^{\mathrm{e}}$ jusqu'au XII ${ }^{\mathrm{e}} \mathrm{s}$. Au cours du XII ${ }^{\mathrm{e}}$ s., les espaces vacants sont investis par un artisanat de métallurgie suivi rapidement par la création d'un quartier d'habitations et de ses rues. L'essentiel du mobilier médiéval recueilli provient des sols et rechapages de ces rues : la rue de la Guirlande, la rue du Petit-Mazeau conservée sur près de $2 \mathrm{~m}$ de haut équivalant à près d'un siècle d'occupation, la rue de la Taulisse à la stratigraphie moins dense. Les sols postérieurs au XIII ${ }^{\mathrm{e}} \mathrm{s}$. ont tous disparu. Au nord-est du site, un espace ouvert accueille une noria. L'intérieur des maisons d'habitation n'a pu être observé qu'au travers des constructions et de quelques sols épargnés par le creusement de caves plus tardives. En effet, à partir de l'extrême fin du XVI ${ }^{\mathrm{e}}$ s., les caves se généralisent et occupent tout l'espace bâti intérieur, effaçant donc toute trace d'occupation, et empiétant même parfois sous les rues. La conséquence en est l'absence quasi totale de mobilier archéologique à ces endroits . 


\subsubsection{Les abords de la Cathédrale}

Les alentours de la Cathédrale ont vu se succéder plusieurs interventions archéologiques de 1995 à 2008.

La plus importante (celle du Tunnel de la Major) a eu lieu dans les années 2000-2001, dans le quartier du groupe épiscopal, à l'ouest de la ville médiévale, à proximité de la mer et des remparts. Occasionnés par le percement d'un tunnel reliant le Vieux-Port à la Joliette, ces travaux concernaient une bande étroite de terrain de $350 \mathrm{~m}$ de long pour seulement $10 \mathrm{~m}$ de large. Les vestiges médiévaux et modernes ont été fortement arasés, notamment par la création du boulevard Robert Schuman à la fin du $\mathrm{XIX}^{\mathrm{e}} \mathrm{s}$. Toutefois, cette fouille a permis de cerner l'évolution du quartier autour du groupe épiscopal de Marseille. Elle a montré que, si les abords immédiats de la Cathédrale sont occupés jusqu'à l'époque Moderne par un cimetière, ailleurs l'habitat ne cesse de se densifier et d'évoluer. Les apports de cette fouille ont été récemment complétés par une intervention réalisée à proximité immédiate, en vue du réaménagement de l'esplanade autour de la Cathédrale (opération Esplanade de la Major). Bien que l'étude de ces vestiges n'apparaisse pas dans le premier volume de cette collection, puisqu'en cours de réalisation au moment de son écriture, les premiers résultats de l'étude céramologique sont intégrés dans le présent volume, en raison de leur intérêt majeur.

\subsubsection{Les abords de la ville}

Certains faubourgs de la ville ont déjà été en partie explorés, le bourg des Olliers par les fouilles de Sainte-Barbe et le bourg Sainte-Catherine par la fouille de la place Général-de-Gaulle. La construction de la Bibliothèque Municipale à Vocation Régionale (BMVR) à l'emplacement de l'ancien théâtre de l'Alcazar a ajouté le bourg de Morier à ce panel. La fouille, entreprise entre 1999 et 2000, se situe en bordure de la ville, immédiatement à l'est du rempart médiéval. Il s'agit ici du seul site de notre étude situé extra muros. Cette fouille d'une superficie de $4400 \mathrm{~m}^{2}$ a permis de réunir de nombreuses informations, notamment sur les époques médiévale et moderne. À une occupation réduite au cours du $\mathrm{XII}^{\mathrm{e}}$ s., succède l'établissement d'un complexe artisanal identifié comme une tannerie. Au cours de la seconde moitié du XIII s. s., cette activité artisanale périclite. Se mettent alors en place, progressivement, un quartier d'habitation et ses rues. Ce faubourg est abandonné vers le milieu du XIVees., méthodiquement et entièrement détruit, sans doute en prévision des attaques des Routiers. Certaines maisons sont même incendiées. Il faut attendre le courant du XVII ${ }^{\mathrm{s}}$. pour que l'urbanisation regagne ces terrains. À la fin du XVII ${ }^{\mathrm{e}}$ s., la construction d'une nouvelle ligne de remparts ceignant les anciens faubourgs et les intégrant intra muros, donne lieu à une importante opération d'urbanisme, la création d'une Ville Nouvelle, dont profite l'ancien bourg de Morier.

\subsubsection{Au quartier de Cavaillon (la Vieille Charité) et de la Blanquerie (la Bourse)}

Dans les années 1970, la ville de Marseille décide de réhabiliter l'Hospice de la Charité, construit aux XVII et XVIII ${ }^{e}$ s. pour l'hébergement des sans-abris. Plusieurs sondages, nécessités par le chantier de restauration, révèlent que la vaste cour intérieure conservait, dans ses niveaux supérieurs, des vestiges témoignant de l'activité de l'EEuvre de la Charité aux Temps modernes, qui ont été le point de départ de la recherche sur les céramiques modernes dans notre ville.

Le quartier de la Bourse a été le point de mire de l'archéologie de sauvetage dans les années 1960-1970. Les vestiges les plus spectaculaires sont ceux de la Corne du Port, les remparts, le bassin d'eau douce, le monument aux triglyphes... Sans oublier la fouille des niveaux de l'Antiquité tardive. Dans les coulisses, les fouilleurs vidaient aussi précautionneusement de nombreux puits modernes, qui ont livré une grande partie des céramiques modernes présentées dans ce volume.

\subsection{Les données complémentaires, les données insuffisantes}

Les quantités de mobilier accumulées au fil de ces gros chantiers, certes de qualité inégale et concernant des périodes différentes, ont permis peu à peu la constitution de petites séries. Ces modestes collections sont ponctuellement améliorées par des découvertes d'opérations plus récentes et de moindre envergure. Nous les citons dans l'ordre de leur réalisation : une intervention à chaque extrémité de la rue de la République (Parking République au nord et Surverse Vieux-Port au sud), ZAC de la Bourse, rue Trinquet, collège Vieux-Port et, la dernière en date, Hôtel-Dieu.

Le projet homérique d'origine s'est donc finalement accompli plus modestement. Certains chantiers devant être intégrés au départ ont rapidement été écartés faute de données suffisantes. D'une manière générale, il s'agit de toutes 
les fouilles antérieures à 1995, donc à César 1, qui n'avaient pas donné lieu à des études préalables de mobilier pour les périodes médiévales et modernes. Mais il s'agit aussi de la deuxième partie de cette opération (César 2) dont le mobilier médiéval et moderne n'a jamais dépassé le stade de la mise en boites pour stockage.

Certains lots de mobilier, surtout céramique, ont déjà été sujets de publication : nous avons évoqué plus haut celui d'un puits de la place Jules-Verne (Démians d'Archimbaud, Vallauri 1998), celui du bourg des Olliers (Marchesi et al. 1997) ou celui de Sainte-Catherine (Richarté 2001, Abel 2001). Ajoutons à ceux-là, le mobilier issu d'un puits du quartier du Panier (îlot 55 de la rue de la Cathédrale : Moliner 1990). Ces articles ou monographies ont parfois servi ici de référence, sans toutefois faire l'objet d'une étude détaillée.

Aucun des chantiers abordés dans ce volume, quelle que soit sa taille, n'avait donné lieu à une étude de mobilier autre que celle de la céramique avant la rédaction de ce manuscrit. Les dernières études en date concernant les objets non-céramiques remontaient à la publication des fouilles du faubourg Sainte-Catherine, soit à 2001. Saluons les deux jeunes chercheurs dont les contributions figurent en deuxième partie de cette publication, aux côtés des éminents spécialistes du verre ou des monnaies.

\section{La publication}

Une grande part de ce volume sur les mobiliers est consacrée à la céramique du Moyen Âge et des Temps modernes. Il ne s'agit pas tant d'une volonté délibérée que du témoignage d'une situation établie depuis longtemps dans le domaine de la recherche archéologique. À l'issue d'une fouille, la céramique constitue généralement le matériel le plus abondant en masse et est considérée comme le premier critère de datation après la stratigraphie relative. Voilà maintenant une trentaine d'années que nous opérons dans la cité et dans ce domaine : l'analyse et la réflexion l'accompagnant sont donc plus abouties que celles des autres catégories de mobilier encore trop délaissées.

\subsection{Le plan de la publication}

Dans la première partie de cet ouvrage, concernant le mobilier céramique, la présentation chronologique (et non stratigraphique) s'est imposée comme une évidence, comme le nécessaire passage à une vision plus synthétique. Elle rend compte d'un stade de réflexion avancée. Mais cette réflexion s'est d'abord basée sur les connaissances régionales et locales existantes dans le domaine. Elle s'est placée au plus près de la stratigraphie de chaque chantier; chacun des rapports rédigés en fin de fouilles en rend compte. Cette étape indispensable, effectuée depuis une vingtaine d'années pour chacun des chantiers, permet aujourd'hui de présenter ces ensembles dans un cadre plus général que celui de la stratigraphie d'un site : celui de son contexte d'utilisation.

Le passage à un nouveau chapitre s'opère lors de l'arrivée de nouvelles productions en même temps que de nouveaux procédés de cuisson et de décoration des officines provençales. Il ne s'agit en aucun cas d'une rupture brutale dans les procédés de fabrication, ni dans la distribution ou la consommation de produits locaux et importés, mais d'un changement progressif.

Hasard des découvertes et qualité de conservation des vestiges font que chaque période est focalisée sur un gros chantier de fouilles dans une zone particulière de la ville : le premier Moyen Âge par les fouilles aux abords de la Cathédrale (Tunnel et Esplanade de la Major), le XII ${ }^{\mathrm{e}}$ s. par les différentes opérations en rive nord du Vieux-Port (place Villeneuve-Bargemon). Le chantier de l'Alcazar documente mieux les XIII et XIV ${ }^{\mathrm{e}}$ s., périodes par ailleurs déjà largement illustrées par d'autres sites publiés (place du Général-de-Gaulle, quartier Sainte-Barbe et rue de la Cathédrale). C'est pourquoi les périodes s'étendant du VIII à la fin du XII ${ }^{\mathrm{e}} \mathrm{s}$. seront plus développées dans cet ouvrage que les XIII ${ }^{e}$ et $\mathrm{XIV}^{\mathrm{e}} \mathrm{s}$., maintenant bien connus pas les publications déjà citées. L'apport de ces derniers n'est cependant pas négligeable, dans le sens où ils confortent en grande partie les constations déjà effectuées sur de nombreux sites en Provence et à Marseille. La période Moderne a pu bénéficier d'une attention particulière des archéologues sur ces différentes opérations. Malgré des contextes parfois tronqués chronologiquement par des destructions récentes, et des méthodes de fouille, mécaniques, souvent rapides et n'autorisant pas de ramassages exhaustifs du mobilier, les apports de l'archéologie urbaine marseillaise sont nombreux pour cette période. Chacun des gros chantiers urbains évoqués permet par la quantité de matériel exhumé d'appréhender certains aspects de la vie quotidienne à une époque donnée. La réunion de tout ce matériel apporte également un éclairage sur les évolutions technologiques. Elle est aussi le reflet des relations commerciales du port de Marseille au cours des siècles. 
La seconde partie de notre ouvrage évoque un pan souvent occulté de la vie quotidienne des habitants de la cité phocéenne : les vestiges de leur fragile vaisselle en verre, les rares monnaies égarées et une catégorie qu'on a trop souvent tendance à désigner sous le terme de «petits » objets, ce qualificatif montrant bien l'importance accordée par certains chercheurs à ces objets. Ils sont ici présentés au sein de leur catégorie technologique. La présentation diachronique s'attache à faire ressortir l'usage spécifique de chacun : vêtement, ameublement, jeu... L'étude détaillée des rares éléments de vaisselle en verre montre également tout l'intérêt, y compris en termes de datation, que présente la connaissance de ce mobilier. Enfin, nous regretterons que les découvertes de monnaies soient si rares dans les fouilles ; un lot plus important aurait certainement pu conduire à une analyse économique intéressante.

Si ce n'est leurs différences de présentation, une même question réunit toutes les contributions : le mobilier archéologique peut-il aider à comprendre l'histoire et la vie quotidienne des habitants de Marseille aux époques médiévale et moderne?

\subsection{Le lien entre les volumes}

On l'a dit, cette étude sur les mobiliers médiévaux et modernes à Marseille s'inscrit dans le cadre plus large d'un Projet collectif de recherches (PCR) qui a débuté en 2005. Il s'agit de publier plusieurs fouilles alors récentes (Alcazar, fouilles autour de la mairie, Tunnel de la Major). Un premier volume a mis en place une réflexion d'ensemble de la ville médiévale et moderne. Nous avons pris alors le parti, afin de permettre une meilleure compréhension par les historiens, de ne pas faire apparaître la numérotation des unités stratigraphiques propres aux archéologues. Pour que l'on puisse néanmoins revenir à cette information, nous avons indiqué en annexe dans le présent volume les correspondances entre les numéros d'inventaire des objets (par figure) et les indications stratigraphiques. Le spécialiste pourra dès lors se référer aux différents rapports de fouille qui conservent l'ensemble des informations techniques ; ceux-ci restent disponibles à la consultation au Service régional de l'archéologie ou, pour celui de l'Alcazar, sur l'Intranet de l'Inrap.

Ce principe sera respecté pour la suite des ouvrages sur les fouilles récentes à Marseille, actuellement en cours : le volume sur les mobiliers antiques et antiques tardifs comprendra également ces annexes, tandis que celui sur la ville antique et antique tardive restera sur le même modèle que celui de Marseille médiévale et moderne. À l'issue de ces travaux, le projet global de publication prendra alors tout son sens. 


$$
\text { Première Partie }
$$

\section{LES CÉRAMIQUES}

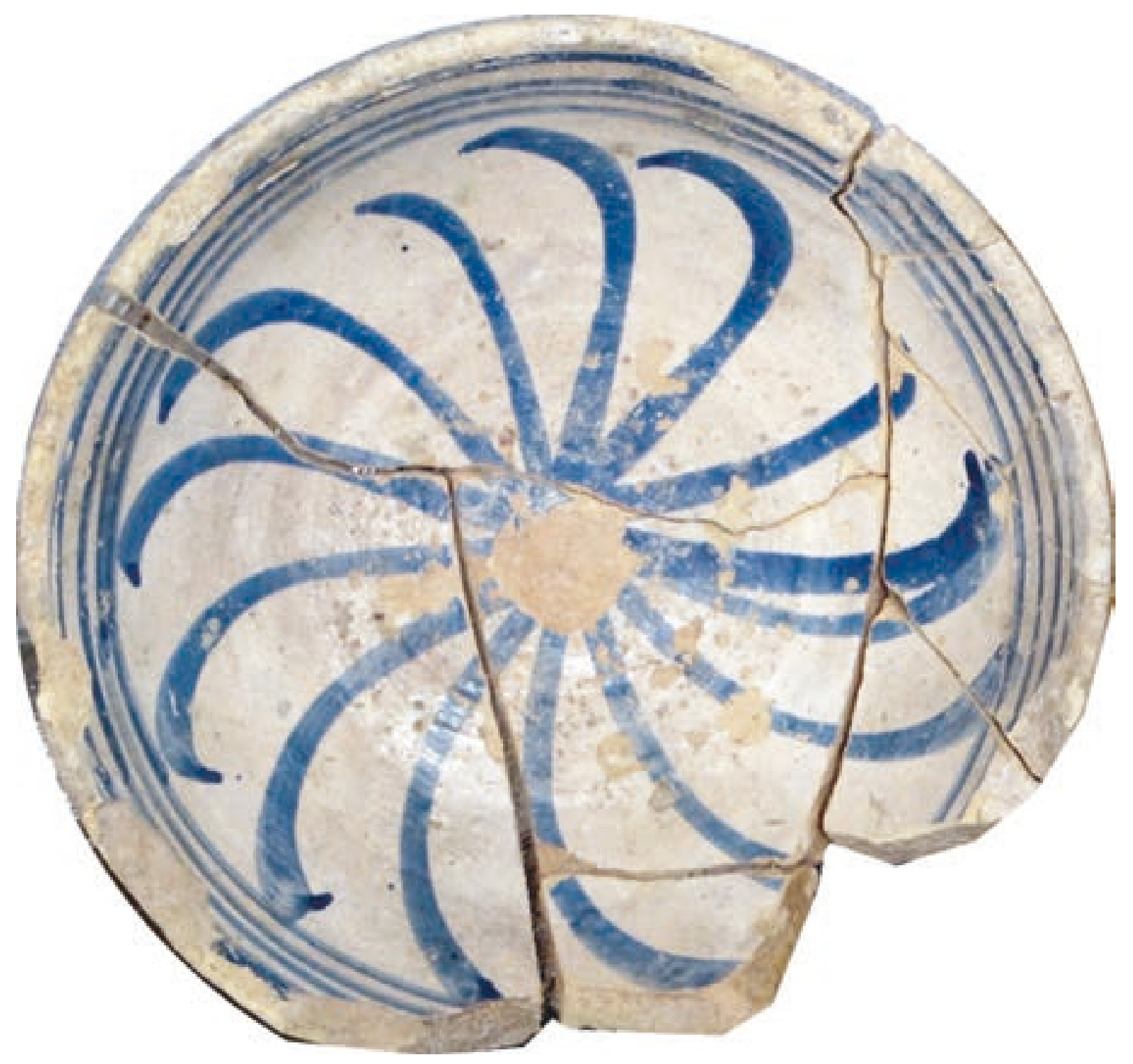





\section{Introduction à l'étude des céramiques médiévales et modernes de Marseille}

(Véronique Abel, Florence Parent)

A vant d'entrer dans le vif du sujet, il convient de signaler plusieurs difficultés majeures rencontrées dans l'étude de ces lots de céramiques, certaines d'ordre méthodologique, d'autres d'ordre plus général.

La céramique n'est qu'un mobilier archéologique parmi d'autres, que sont le verre, le métal ou les matières organiques. Ce qui la distingue de ces derniers dès la fouille, et qui parfois la rend malaisée à gérer, c'est sa masse. Les objets en terre cuite, sous une apparente fragilité, sont presque indestructibles rendus à l'état de tessons. Ils sont par conséquent bien plus nombreux que n'importe quel autre mobilier archéologique à nous parvenir pour le Moyen Âge et les Temps modernes. L'étude de ces tessons, autrement dits céramiques archéologiques, ne va pas sans l'acquisition et la conscience de notions primordiales sur les technologies utilisées pour les mettre en œuvre à l'état d'objets.

L'argile est une roche détritique composée de très fines particules minérales (des silicates d'aluminium) arrachées à d'autres roches par l'érosion et déposées dans des zones lacustres de l'ère tertiaire. Ces minéraux se présentent sous forme de feuillets microscopiques qui, par une architecture et des empilements variés notamment, constituent des types d'argiles différents ; l'eau qui peut se glisser entre eux donne sa plasticité à la roche. L'illite est l'argile la plus courante, la kaolinite est plus recherchée. Les potiers de jadis n'en avaient qu'une connaissance empirique : les propriétés de l'argile n'étaient reconnues qu'après avoir vu comment se comportaient les objets lors de leur cuisson et de leur utilisation.

L'argile est souvent mélangée naturellement avec d'autres minéraux (sable, oxyde de fer, calcaire, etc.) ou d'autres matériaux (débris végétaux, fragments de coquillages). Hydratée, elle devient malléable. Le potier améliore son aspect ou sa tenue par malaxage, tamisage, lavage ou rajout d'autres matériaux dits « dégraissants » qu'il est parfois difficile de distinguer des éléments non plastiques inclus naturellement.
Les poteries, nées du besoin de cuire et de conserver des aliments dans le cadre d'un mode de vie qui se sédentarisait au Néolithique, sont devenues une infinité dont la vision très large ne sera sans doute jamais exhaustive. Les vases en terre cuite de la période historique sont, dans leur grande majorité, obtenues au tour par un véritable potier formé à cette activité pendant des années d'apprentissage. Cette technique n'est cependant pas la seule : modelage strict ou complété par un tour lent ou une tournette, moulage d'objets ou appendices complexes, et plus tard coulage en grandes séries sont d'autres modes de mise en œuvre qu'il importe de discerner dans le cadre d'une histoire des techniques.

Une fois l'objet façonné et avant la cuisson, plusieurs possibilités s'offrent à l'artisan, selon la fonction que remplira la céramique ou les moyens disponibles. Certains vases vont ainsi être laissés sans revêtement, comme les premières marmites médiévales et quelquesunes de la période moderne. Les revêtements vont devenir de plus en plus fréquents et couvrants tout au long de la période que nous présentons ici, jusqu'à devenir une règle, qui bien sûr connaît quelques exceptions, comme par exemple les tirelires.

Dans l'Antiquité, ce sont les revêtements argileux qui furent privilégiés, depuis les vernis noirs attiques jusqu'aux engobes des Dérivées des Sigillées Paléochrétiennes car bien filtrés et passés en couche mince, les engobes grèsent et se vitrifient en une surface brillante ou métallescente. Après quelques essais sans lendemain, les revêtements non argileux sont adoptés progressivement.

Dans nos régions, ils ne sont que sable (silice) pulvérisé qui doit fondre lors de la cuisson de l'objet. Ils réussissent à bien imperméabiliser les vases et à leur procurer un bel aspect brillant, mais ils sont plus onéreux et plus difficiles à réussir. Le fondant qui doit être ajouté à la silice est de la galène (sulfure de plomb) dont les mines principales se trouvent en Espagne et dans le sud du Massif Central pour la France méditerranéenne.

Nous les nommons ici de deux manières, recouvrant la même réalité, glaçure (pour les céramiques médiévales) ou vernis (pour les céramiques modernes), ces 
noms communs ne valant en principe que s'ils sont suivis du bel adjectif qualificatif plombifère, que nous éludons cependant bien souvent contrairement à ce que préconisait Maurice Picon dans un ouvrage essentiel sur les technologies de la céramique destiné aux archéologues (Picon 1973).

Entre la surface de la pâte et les revêtements vitrifiés transparents s'intercale souvent, et de plus en plus tout au long des deux périodes, une couche fine de revêtement argileux, l'engobe. Préparé à base d'argile, il en garde les couleurs, blanc, rose, rouge, orangé, mais dans une version unifiée car filtrée par le potier. Contrairement au vernis, il est mat et opaque. Il nappe l'objet qui peut recevoir un décor mis en valeur par un fond homogène.

Les inconvénients des revêtements vitrifiés sont, nous l'avons dit, un coût élevé, mais aussi le risque que les objets ne se soudent entre eux pendant le processus de fusion de la silice. Le potier doit donc en tenir compte et charger son four très soigneusement, parfois en utilisant des sortes de cales, les pernettes.

Les revêtements vitrifiés, s'ils sont toujours plombifères, ont parfois également d'autres composants : transparents même s'ils sont colorés, on les dit plombifères, mais s'ils sont opaques, de couleur blanc laiteux, bleue, verte ou autre, ils contiennent souvent une part d'étain. Cet apport fait de la céramique une majolique (période médiévale) ou une faïence (période moderne), ces deux termes signifiant que le revêtement est stannifère.

Les céramiques archéologiques conservent en elles des indices concernant la cuisson et la solidification de leur âme d'argile. Si l'on croit qu'une céramique noire a cuit dans un four plein de fumée et une céramique claire parmi de gaies flammes rouges et jaunes, la réalité est toute autre et un chapitre entier ne suffirait pas à expliquer ce qui peut se passer lors d'une cuisson au bois. Pour résumer, disons que celle-ci dure des heures voire des jours, temps pendant lequel le potier et ses aides ne cessent d'alimenter le feu, qu'elle doit atteindre $900^{\circ} \mathrm{C}$ mais ne pas aller trop haut sinon la céramique se déforme puis coule comme de la lave et que son refroidissement est très lent. Celui-ci a été appelé postcuisson par M. Picon : les céramiques sont, à ce stade, encore très réceptives à divers échanges gazeux car non encore solidifiées. Ainsi, les grises médiévales ou noires modernes prennent leurs tons charbonneux définitifs en post-cuisson, sur décision du potier, qui enfume son four et en bouche les ouvertures, et non parce que l'artisan l'a laissé s'enfumer imprudemment.

Deux à dix siècles plus tard, les fouilleurs trouvent, ramassent, étiquettent les tessons et le travail des céramologues commence. Le lavage fait partie de celui-ci, et désormais les fouilles urbaines ont conduit à adopter d'autres outils que la brosse à dents en mécanisant cette étape.

Le tri est une des étapes primordiales de l'étude puisqu'elle revient à scinder des ensembles de céramiques en plusieurs groupes distincts sur la base de critères technologiques, de critères de provenance, etc., en essayant d'écarter le mobilier considéré comme résiduel, c'est-à-dire notoirement plus ancien que le reste des céramiques du contexte parmi lequel il a été recueilli. L'identification du mobilier résiduel repose sur la connaissance préalable des céramiques, dans le cas de mobilier peu connu ces proportions sont toujours sujettes à caution. Les fragments antiques sont, après décompte, systématiquement extraits des ensembles. Après un examen rapide et une première analyse chronologique basée sur notre connaissance des céramiques archéologiques de la période, l'homogénéité d'un lot est posée comme hypothèse de travail lorsque rien ne s'y oppose manifestement. La proportion de céramiques dites résiduelles dans les contextes archéologiques marseillais est impressionnante, elle frôle souvent les $80 \%$ pour les périodes concernées ici. Ce phénomène est bien sûr lié aux nombreux remaniements et réaménagements effectués au cours des siècles, chaque campagne de travaux bouleversant et brassant amplement les terrains et les constructions plus anciennes et/ ou les remblayant avec des apports de terre provenant d'autres lieux.

Une fois triés, les tessons toujours en vrac sont scrutés par les céramologues lors des séances extrêmement chronophages de recollage. Certes l'œil et le cerveau exercés peuvent devenir assez performants à la reconstitution de ces milliers de petits puzzles formant un puzzle gigantesque, l'opération n'en demeure pas moins très longue à chaque fois. Sans celle-ci pourtant, que présenterions-nous aux collègues, aux lecteurs, aux visiteurs d'expositions...? Des «cruches » de $3 \mathrm{~cm}^{2}$, des «assiettes» pas plus volumineuses. Le céramologue arrive à discerner l'objet dans le tesson, mais il est bien le seul quand les formes ne sont pas reconstituées.

Les pièces plus complètes permettent des identifications plus aisées mais aussi plus sûres, nul besoin de l'expliquer davantage.

Passée cette étape, vient le problème de la quantification au sein de chaque catégorie et de chaque contexte, quand la plupart des lots ne constituent pas encore de véritables séries et sont dans des états de conservation très divers, de l'infime fragment à la pièce complète. Le problème du comptage est, et sera encore longtemps, sujet de réflexions et de débats pour tous ceux qui ont eu, ont, ou auront à étudier un lot 
de mobilier archéologique : certains penchent pour le pesage, d'autres dissertent sur les différentes méthodes d'étalonnage pour parvenir à un nombre minimum d'individus... Le problème est ici flagrant, car nous ne disposons pas d'ensembles clos et homogènes, les fragments d'un même objet peuvent se répartir sur une hauteur stratigraphique qu'il est impossible d'évaluer ou de visualiser et donc impossible de prendre en compte. Point n'est besoin ici d'entrer dans le débat général, bien qu'à notre avis chacune de ces méthodes conduise à une distorsion de la réalité. Aussi, nous avons pris le parti, dès le début de nos études sur ce type de mobilier, de comptabiliser le nombre de fragments présents dans chacune des unités stratigraphiques, en les répartissant à chaque fois à l'intérieur de catégories. Dans le cas d'ensembles clos (situation extrêmement rare à Marseille), un comptage par nombre d'individu a pu être effectué parallèlement au comptage par fragment. Sont alors pris en compte, dans l'ordre, les critères typologiques, morphologiques et décoratifs.

Mais en fin de compte, pourquoi passe-t-on tant de temps sur cette matière réputée ingrate?

En premier lieu certainement parce que la céramique est l'un des éléments les plus fiables pour dater les niveaux archéologiques. Rappelons cependant que si ces céramiques sont datées, et qu'elles permettent la datation des vestiges, c'est précisément parce que des études céramologiques précédentes ont permis, par comparaisons, croisements des données et des sources, etc. de déterminer leur âge avec une précision maximale. Il importe donc de ne point adopter une logique de prédateur et de rendre à la connaissance de la céramique ce qu'elle apporte à l'étude d'un site. On ne peut se contenter de prendre des renseignements sans en apporter à son tour. On analyse donc du mieux possible et avec les moyens dont on dispose les masses fournies par un chantier archéologique. Naissent des typologies périodisées, les typo-chronologies. Des rapprochements sont tentés avec des lots antérieurs, avec ceux d'autres sites, avec des publications plus lointaines. Des hypothèses sont émises, sur des provenances, des pratiques, des transferts de technologies. Vient le temps des interprétations, puis de la communication, dans des rapports de fouille, des colloques, des revues de chercheurs ou d'amateurs. Un jour vint le temps de cet ouvrage.

Que nous dit la céramique récoltée à Marseille sur cette cité marseillaise ? Par sa masse permet-elle d'accéder à des données économiques comme l'approvisionnement d'un grand nombre d'habitants sur une très longue durée, à une plus grande échelle que d'autres mobiliers, mais aussi, grâce à des pièces plus rares à des aspects peut-être anecdotiques ou plus inédits ? 



\section{Chapitre 1}

\section{Le premier Moyen Âge : l’Antiquité tardive en héritage}

\section{(Florence Parent, Catherine Richarté)}

$\mathrm{I}$ 1 ne semble pas qu'il y ait une rupture à proprement parler avec les formes en usage à l'extrême fin de l'Antiquité, mais plutôt un glissement progressif conduisant à une «médiévalisation » des formes. Cette période est également marquée par l'abandon à la fois des formes ouvertes et de la post-cuisson oxydante. On assiste donc à un «appauvrissement », ou plutôt à une restriction technologique du répertoire potier peutêtre lié à de nouveaux modes de vie. Parallèlement, le volume des céramiques importées décroît réellement, indiquant un net fléchissement du commerce (Cathma 1993, p. 115). Ces approches ponctuelles ne prétendent cependant pas appréhender la totalité de la culture matérielle, que l'on saisit très mal à Marseille pour cette période.

\section{Les VIII ${ }^{\mathrm{e}}$ et $\mathrm{IX}^{\mathrm{e}}$ s. (Fl. Parent)}

Dans le projet initial, ces siècles auraient dû n'être évoqués que succinctement en introduction, étant donné l'absence d'information archéologique et céramologique les concernant à Marseille. De très récentes découvertes nous ont conduits à insérer in extremis les résultats du dernier chantier réalisé aux abords de la cathédrale, le chantier dit de l'Esplanade de la Major exécuté fin 2008 et dont le rapport de fouille vient d'être achevé à l'heure où nous écrivons. Le mobilier qui va être exposé ici est exceptionnel à plus d'un titre. Il illustre la fin de l'occupation et l'abandon de ce qui est interprété comme le premier palais épiscopal de Marseille, construit au début $\mathrm{du} \mathrm{V}^{\mathrm{e}} \mathrm{s}$. de notre ère. De surcroît, les données concernant cette période sont encore rares et succinctes en Provence, hormis peut-être le cas d'Eyguières dans les Bouches-du-Rhône (Pelletier et al. 2000), et elles sont uniques pour la ville de Marseille. En dernier lieu, ce site a livré plusieurs récipients presque archéologiquement complets qui permettent d'avoir une meilleure appréciation de leur forme, de leur qualité et surtout, qui complètent le corpus entrepris sur le site d'Eyguières.
Tous les éléments morphologiques que nous allons évoquer indiquent une datation confirmée par leur position stratigraphique : dans des contextes postérieurs au $\mathrm{VII}^{\mathrm{e}}$ s., voire au $3^{\mathrm{e}}$ quart du $\mathrm{VII}^{\mathrm{e}} \mathrm{s}$. pour certains. Si la plupart des types reconnus apparaissent dès le $\mathrm{VI}^{\mathrm{e}} \mathrm{s}$. en Provence, certaines formes sont flanquées ici de fonds de transition préfigurant la forme nettement plus large qu'ils adopteront aux environs de l'An Mil. Les éléments comparables les plus proches se situent à Eyguières dans des niveaux des $\mathrm{VIII}^{\mathrm{e}}-\mathrm{IX}^{\mathrm{e}} \mathrm{s}$. (Pelletier et al. 2000). Toutefois, apparaissent dans les contextes marseillais des formes à la fois innovantes et encore proches de l'héritage de l'Antiquité tardive, et dont la présence pourrait peut-être restreindre la datation aux environs du VIII' $\mathrm{s}$.; mais seules d'autres découvertes permettront de l'affirmer (ou de l'infirmer).

Cette présentation ne se prétend pas exhaustive, loin de là. Comme nous l'avons dit, ce mobilier semble se situer à une période charnière entre Antiquité tardive et premier Moyen Âge, période encore mal connue d'un point de vue archéologique et céramologique en Provence. Une partie des productions traditionnelles de l'Antiquité tardive a vraisemblablement continué à circuler, telles des amphores importées d'Afrique ou d'Orient ou de la vaisselle fine comme les sigillées claires $D$, mais l'état actuel des connaissances ne permet pas de les identifier. Dans ces conditions, nous avons pris le parti de ne considérer ici que les éléments significatifs, révélateurs d'une évolution, que sont les céramiques communes à pâte grise de production locale et régionale. Elles sont, pour l'instant, les premiers jalons de notre connaissance du vaisselier marseillais au seuil du Moyen Âge.

\subsection{Les pâtes}

Le lot examiné se compose exclusivement de céramiques cuites en atmosphère réductrice. Si les pâtes offrent une relative diversité dans leur composition et leur apparence, sans doute due à de multiples sources d'approvisionnement, elles peuvent cependant se scinder globalement en 3 groupes liés à leurs caractéristiques premières. 
Pâte 1 : pâte réfractaire, le plus souvent de texture fine et dense mais au contact rugueux, abondamment micacée et contenant de nombreux points de chaux. Les vases adoptent différentes tonalités de gris, allant du presque blanc au gris noirâtre, toutes les nuances se retrouvant souvent sur un même objet.

Pâte 2: pâte réfractaire également mais de texture extrêmement grossière, présentant des inclusions noirâtres parfois de taille importante. Certaines ont pu fondre à la cuisson comme le suggèrent les nombreuses et importantes vacuoles visibles en surface. Comme dans le groupe précédent, les vases présentent toute une palette de nuances de gris, du plus clair au plus foncé, en passant par le brun. Certains fragments semblent modelés.

Pâte 3: pâte calcaire, tendre, contenant de nombreuses paillettes de mica. En surface, les vases adoptent des nuances brunes pouvant passer par l'orangé à cœur, ou noires à cœur rouge. Toutefois certains exemplaires sont nettement gris foncé, conséquence d'une intense utilisation sur le feu. Ses caractéristiques apparentent la pâte 3 à la fois aux Dérivées de Sigillées Paléochrétiennes (DS.P.) et aux céramiques communes à pâte grise en pâte calcaire.

\subsection{Les formes}

Les formes énumérées ci-après sont classées, quand cela est possible, selon la nomenclature élaborée par le groupe Cathma (Cathma 1993).

Les derniers niveaux d'occupation du complexe épiscopal recèlent peu de mobilier caractéristique. Cependant, trois fonds de pots légèrement bombés (à angle légèrement marqué pour celui en pâte 2 et bien marqué pour ceux en pâte 1 et 3 ) nous introduisent déjà à l'extrême fin de l'Antiquité tardive voire au début du haut Moyen Âge. En effet, alors que les fonds plats, étroits et plutôt épais caractérisent les $\mathrm{V}^{\mathrm{e}}$ et $\mathrm{VI}^{\mathrm{e}} \mathrm{s}$., au cours des $\mathrm{VII}^{\mathrm{e}}$, VIII ${ }^{\mathrm{e}}$ et $\mathrm{IX}^{\mathrm{e}}$ s. ces fonds deviennent plus larges, concaves puis bombés et s'amincissent considérablement (Pelletier 1997, p. 115. Pelletier et al. 2000, p. 322). Plusieurs fragments appartiennent probablement à un même vase à panse carénée, en pâte 2 , dérivé des formes L/E (couvercle/bol). Les parois de ce vase, tronconiques, se redressent presque à la verticale dans la partie supérieure et se terminent par un bord droit coupé. Un autre bord porte une lèvre simple en bourrelet, légèrement déversée jusqu'à former une gorge sur la face interne. Ce bord est à rapprocher d'un exemplaire retrouvé à Eyguières dans les Bouches-du-Rhône, exemplaire attribué au haut Moyen Âge sans être postérieur à l'An Mil (Pelletier et al. 2000, fig. 46-5).
L'abandon du palais recèle la quantité de mobilier la plus importante et les éléments les plus caractéristiques. Le matériel y semble homogène, chronologiquement parlant. Les fonds bombés à angle plus ou moins marqué y sont toujours un indice révélateur. Outre quelques vases quasi complets, ces contextes renferment différents éléments de formes fortement inspirées de celles de l'Antiquité tardive tout en intégrant les nouveautés du haut Moyen Âge.

\subsubsection{La forme $M A 2$}

Un objet quasi complet illustre parfaitement le propos (fig. 2). Le bord de ce pot à 2 anses étroites et verticales correspond au type 2 très fréquent au $\mathrm{VI}^{\mathrm{e}} \mathrm{s}$. ap. J.-C. Cependant, le fond qui peut lui être associé est très large et bombé, contrairement à ceux des formes MA2 encore en usage au $\mathrm{VII}^{\mathrm{e}} \mathrm{s}$. Le phénomène a également été observé à Saint-Pierre d'Eyguières (Bouches-duRhône) où les bords MA2 sont parfois combinés à un fond large nettement concave (Pelletier et al. 2000, p. 312, fig. 42-1). Ces formes illustrent la transition entre l'Antiquité tardive et le haut Moyen Âge. À SaintPierre d'Eyguières, elles s'intègrent dans des contextes antérieurs à l'An Mil. Le pot de l'Esplanade de la Major est fabriqué en pâte 1, des cannelures plus ou moins prononcées scandent la partie supérieure de la panse. Sa contenance peut être estimée à 6,5 litres.

Un deuxième bord de ce type est élaboré quant à lui en pâte 3 de couleur gris clair très proche des DS.P.

\subsubsection{La forme A2 ou MA2}

Six bords appartiennent à ce type sans qu'on puisse savoir s'ils sont dotés d'anses ou non. Ils pourraient appartenir à des pots de forme intermédiaire comme les deux précédents mais aucun fond ne peut y être associé pour le confirmer.

\subsubsection{La dérivée de la forme AB36}

Les formes pourvues d'un bec tubulaire font partie du répertoire «classique » des DS.P. (forme 36). Les quatre exemplaires découverts ici (fig. 3), dont un quasi complet, sont façonnés dans une argile très proche de ces productions (pâte 3). Ces vases à liquide comportent un rebord simple (de type A) ou en léger bourrelet externe, toujours déversé et formant une gorge sur sa face supérieure. Un bec tubulaire est inséré directement sous le rebord. Sa morphologie rappelle celle d'une cruche : il est formé par un tube court à l'extrémité duquel un rebord à lèvre simple déversée est pincé pour former un bec verseur. Ces formes, à panse globulaire plus large 


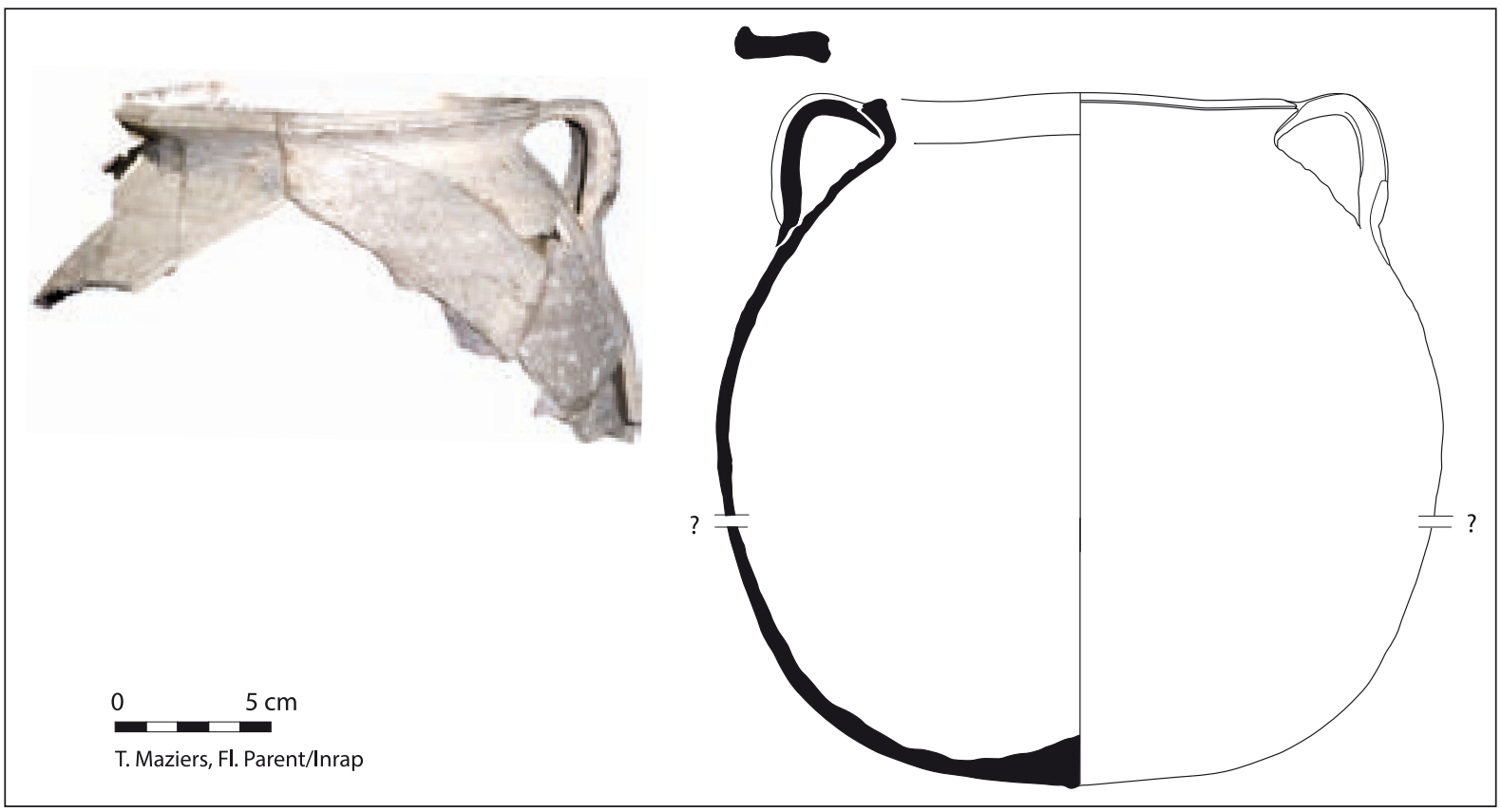

Fig. 2. Céramique commune grise locale (VIII $\mathrm{s}$. ?) : pot de forme MA2. Esplanade de la Major.

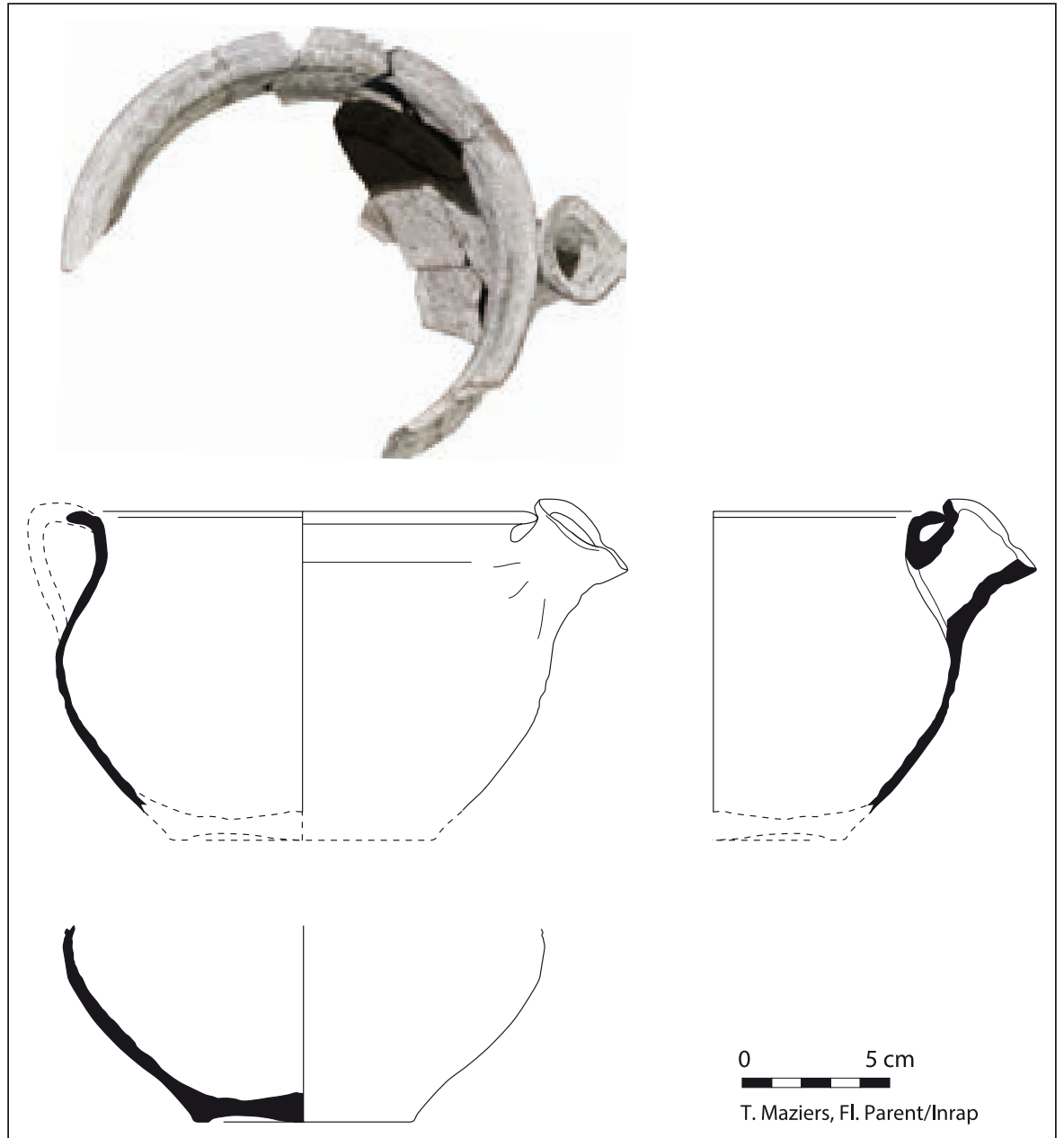

Fig. 3. Céramique commune grise locale (VIII $\mathrm{S}$. ?) : vase dérivé de la forme AB36. Esplanade de la Major. 
que haute, devaient être portées par un fond plat surcreusé de manière à former un anneau et ombiliqué tel celui représenté sur la fig. $\mathbf{3}, \mathbf{n}^{\circ} \mathbf{1}$. De même, on peut supposer qu'une anse se trouvait à l'opposé du bec. Tous les exemplaires découverts ici présentent des parois d'une finesse exceptionnelle attestant du savoir-faire du potier. Les formes AB36, comme les formes MA2, apparaissent dès le $\mathrm{VI}^{\mathrm{e}}$ s. (Pelletier et al. 2000, p. 312-313) : leur présence systématique dans chacun des contextes correspondant à l'abandon du bâtiment, leur association avec la forme MA2 à fond de transition, leur morphologie et leur extrême finesse incitent à leur attribuer une datation plus tardive.

\subsubsection{La dérivée des formes $K$}

Une cruche en pâte 1 (fig. 4) peut être assimilée aux exemplaires distribués dès le $\mathrm{VI}^{\mathrm{e}} \mathrm{s}$. en Provence. Elle est caractérisée par une panse globulaire, un col court resserré portant une lèvre en léger bandeau déversée, un bec pincé et une anse cannelée à l'opposé, ainsi qu'un fond irrégulier très légèrement bombé. L'anse est fixée sur la lèvre et retombe sur le diamètre maximal de la panse.

Ce coup de projecteur ponctuel sur une période encore obscure demande évidemment à être conforté par de nouvelles découvertes. En l'état actuel des maigres connaissances sur cette période, une datation précise ne peut être envisagée, même si tous les indices, stratigraphiques et typologiques, suggèrent une datation assez précoce pour cet ensemble.

\section{Aux environs de l'An Mil : $\mathrm{X}^{\mathrm{e}}$ et $\mathrm{XI}^{\mathrm{e}} \mathrm{s}$. (C. Richarté, avec la coll. de Fl. Parent)}

Les découvertes réalisées ces vingt dernières années ont peu à peu favorisé la perception de cette période du premier Moyen Âge à Marseille. Les contextes des $\mathrm{X}^{\mathrm{e}}$ et $\mathrm{XI}^{\mathrm{e}}$ s. ont été observés sur les chantiers autour de la Major, ZAC de la Bourse, rue Trinquet, rue de la République (Vieux-Port) et collège Vieux-Port. Tous présentent une certaine indigence. Le mobilier y est, en effet, à la fois rare et en assez mauvais état de conservation. Cela semble consécutif aux multiples aménagements urbains qu'ont subis ces secteurs. Cet état de fait ne donne pas, certes, la meilleure vision de la culture matérielle des sites, mais renseigne, malgré tout et dans la mesure de nos connaissances, sur les faciès en usage et sur la répartition de l'approvisionnement pour ces périodes encore assez mal cernées du haut Moyen Âge provençal.

L'approche est ici basée sur des comparaisons de site à site. En effet, ce sont les fouilles préventives et surtout les travaux réalisés sur les sites ruraux de Provence, principalement à Saint-Pierre d'Eyguières dans les Bouches-du-Rhône qui renseignent le mieux (Pelletier et al. 2000 ; Pelletier, Poguet 2008; Amouric et al. 2009, p. 32-33). Les études de J.-P. Pelletier sur la céramique commune, seule production tournée qui subsiste en Provence occidentale durant cette période, permettent de disposer d'un outil de datation fiable pour établir une chronologie des contextes du haut Moyen Âge. Le Languedoc et le Roussillon, notamment avec les travaux de la CATHMA, ont également contribué à faire avancer la recherche pour cette période avec de nombreuses données de terrain. La confrontation des mobiliers découverts et la réflexion issue de ces enquêtes a ainsi permis l'ébauche d'un cadre de référence et la distinction des productions en usage aux abords de l'An Mil, qui ne devrait que s'enrichir progressivement.

La céramique culinaire - permettant la cuisson des denrées - est prédominante en contexte d'habitat. Elle correspond à des pots dans la tradition des ollae romaines et tardo-antiques. Celles-ci possèdent généralement un profil globulaire, sont munies parfois de bec verseur et de préhension et dotées d'une capacité moyenne de 1 à 3 litres (ce qui doit correspondre à peu près à la valeur d'un repas). L'olla ou l'oule porte un fond lenticulaire permettant de la poser sur un trépied ou de la caler sur les braises, la chaleur se transmettant naturellement à travers la pâte réfractaire par conduction. Ces vases permettent donc de réaliser des cuissons bouillies ou mijotées.

Les récipients, de différents modules, présentent de nombreuses variantes typologiques. À ces vases, il faut vraisemblablement associer des couvercles. Parmi ces productions essentiellement en pâte grise ou parfois gris brun se détachent quelques importations limitées à de très rares produits glaçurés, d'un type technique plus élaboré.

\subsection{Les céramiques communes à pâte grise}

On remarquera à Marseille, comme c'est assez souvent le cas ailleurs en Provence pour cette période, la faiblesse du volume étudié et l'omniprésence, « classique » dirons-nous, du mobilier en pâte grise kaolinitique. Ces vases sont obtenus en atmosphère réductrice, procédé technique quasi exclusif des ateliers régionaux jusqu'à la fin du XII ${ }^{\mathrm{e}} \mathrm{s}$. et parfois au-delà dans certaines officines, comme à Ollières dans le Var où des récipients en commune grise sont fabriqués jusqu'à la fin du XIII ${ }^{\mathrm{e}} \mathrm{s}$. au moins (Démians d'Archimbaud, Picon 1980).

Les vases possèdent des parois relativement minces et sont généralement tournés. Ils portent fréquemment 


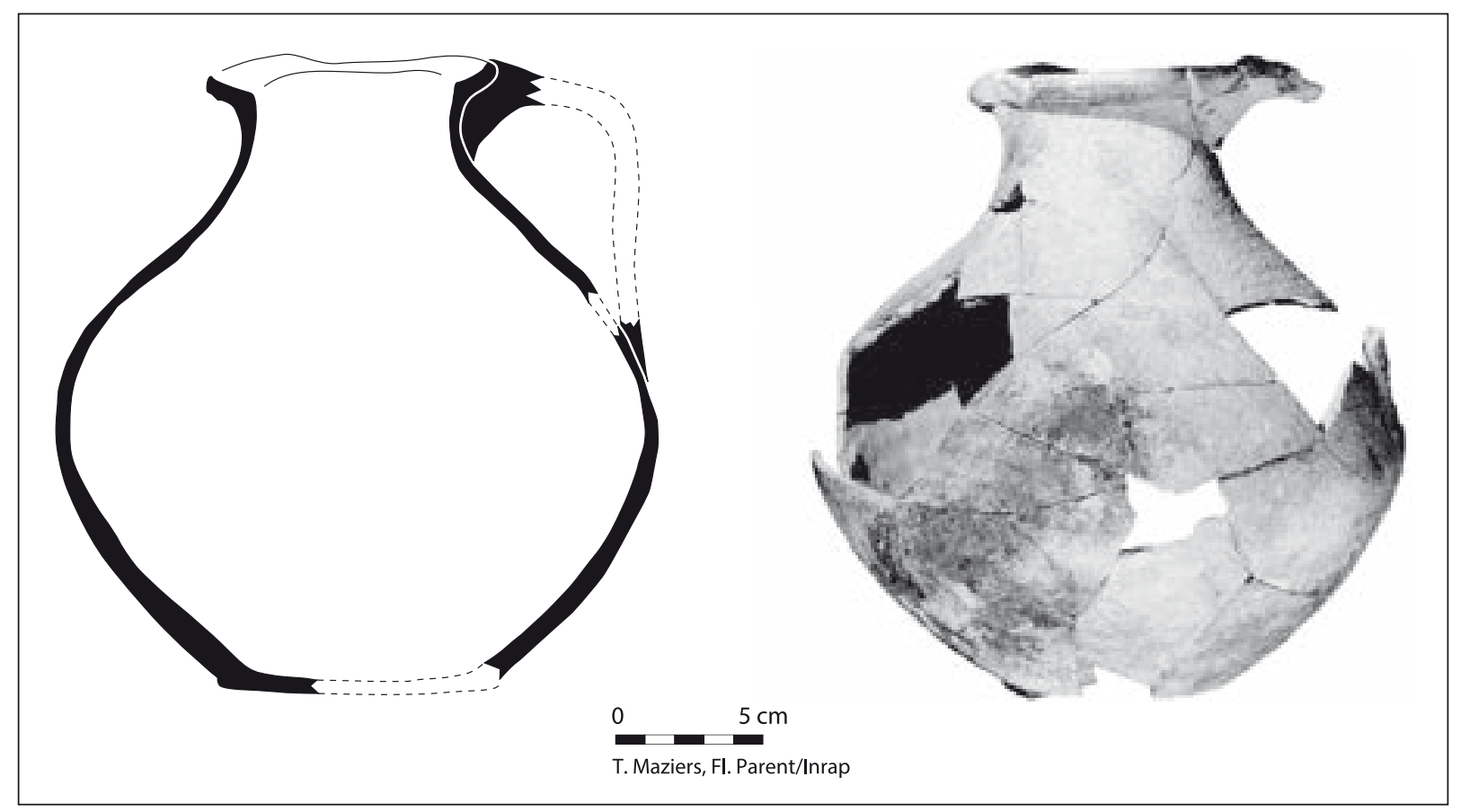

Fig. 4. Céramique commune grise locale (VIII $\mathrm{s}$. ?) ; cruche dérivée de la forme K. Esplanade de la Major.

des traces de déformation : les parois, par exemple, sont souvent retrouvées enfoncées.

Le grand groupe des céramiques communes à pâte grise est occasionnellement associé à des vases culinaires à pâte micacée gris-brunâtre à rouge (obtenus, eux aussi, par cuisson en atmosphère principalement réductrice). Pour cette catégorie, l'origine précise de l'approvisionnement demeure hypothétique, mais reste en tout état de cause régionale, voire interrégionale.

\subsubsection{Les pâtes}

Dans l'état actuel des connaissances, et pour clarifier cette situation complexe, nous proposons de distinguer quatre groupes principaux de pâte, au sein desquels plusieurs sous-groupes coexistent. Ce classement basé sur l'aspect et la texture de la pâte - bien qu'insatisfaisant - permet néanmoins une sériation en l'absence d'analyses physico-chimiques. Les différents types de pâtes identifiables proviennent vraisemblablement de divers ateliers.

Pâte 4 : pâte grise kaolinitique réfractaire grossière, à grosses inclusions minérales (calcite, nodules ferrugineux, etc.). Les argiles utilisées sont - à l'œil nu - assez proches de celles observées dans le bassin d'Ollières (Var).

Pâte 5 : pâte grise kaolinitique, de couleur gris clair, fine avec particules noires et nombreuses écailles de mica. La provenance demeure indéterminée, peut-être la région de Marseille. Cette pâte semble identique à la pâte 1 de la période précédente (cf. supra $§ 1.1$.).

Pâte 6: pâte grise kaolinitique de texture fine, de couleur gris bleuté, à gros points de chaux dont la provenance, peut-être rhodanienne, est, pour l'heure, d'attribution incertaine.

Pâte 7 : pâte brune à rougeâtre dans les cassures, alors que les surfaces sont plus foncées grises à noires, technique et aspect déjà repérés dans la région d'Apt (Pelletier et al. 2000, p. 312 ; Démians d'Archimbaud, Pelletier 1995) mais les nombreuses paillettes de mica pourraient suggérer une provenance locale.

Le répertoire typologique est composé d'ollae, formes fermées globulaires sans anse (de type A), exclusivement de couleur grise, dérivant de celles en usage en Provence du $\mathrm{IV}^{\mathrm{e}}$ au VI ${ }^{\mathrm{e}} \mathrm{s}$. (CATHMA 1986, p. 45-47). Ces pots d'abord à lèvre triangulaire (type A4) évoluent graduellement, jusqu'à aboutir à des bords en bandeau décrivant un crochet interne (type A6) puis, aux environs de l'An Mil, à des rebords en poulie (Pelletier et al. 2000, p. 312) comme celui de deux exemplaires marseillais (fig. 5, $n^{\circ}$ 7-8).

\subsubsection{La caractérisation du faciès d'après les profils}

Les formes découvertes sur les sites marseillais s'intègrent généralement à la typologie établie au fil des recherches par le groupe Cathma et sont donc présentées ici selon ses références (Cathma 1993 : 134 - fig. 11). 


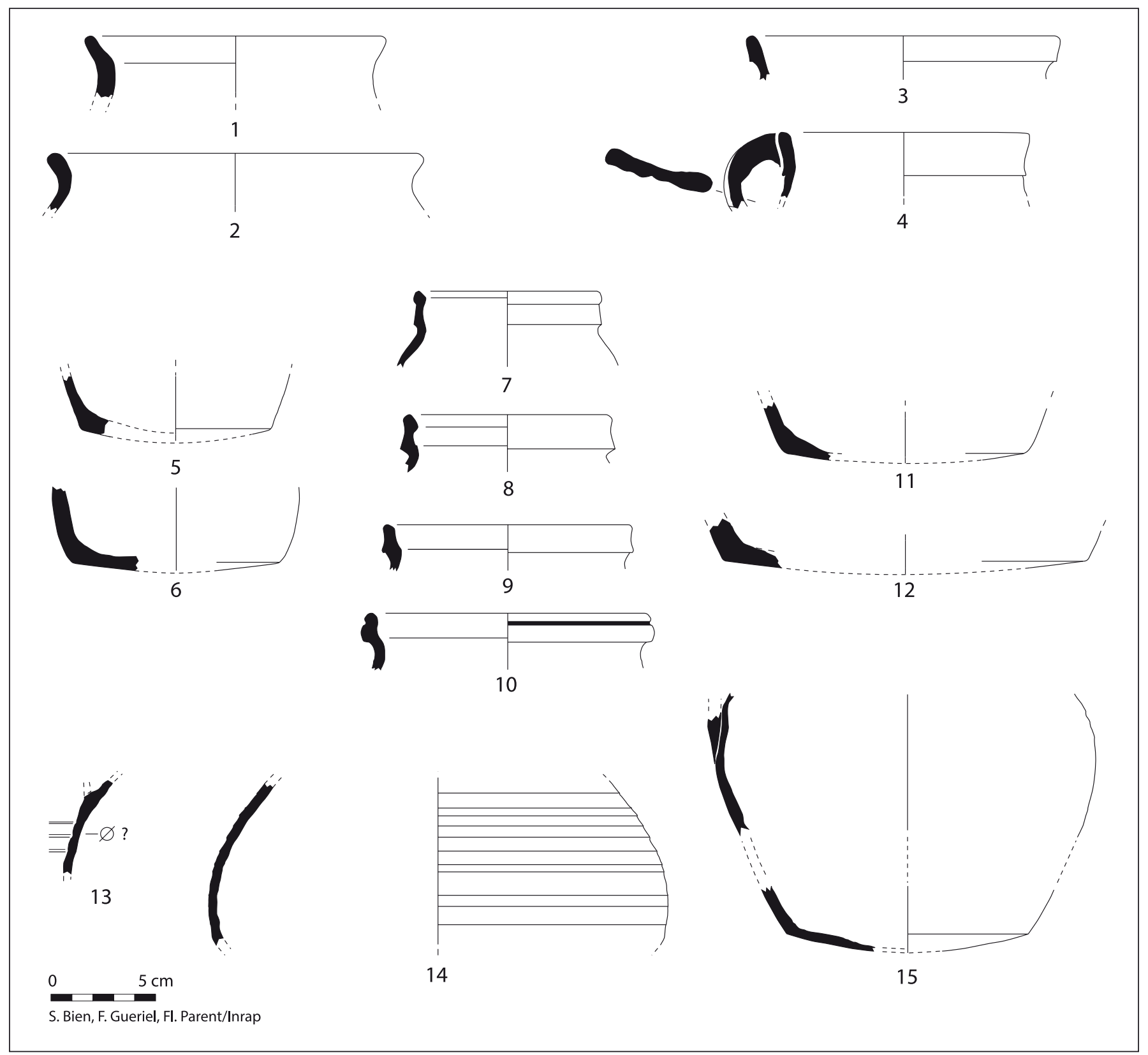

Fig. 5. Céramiques communes grises locales du Haut Moyen Âge. 1, 2, 4-8, 11-14 : Tunnel de la Major ; 3, 9, 15 : rue Trinquet ; 10 : rue de la République (Surverse Vieux-Port).

\section{Profil Cathma 2}

Ce groupe rassemble des pots globulaires (fig. 5, $\mathbf{n}^{\circ}$ 2) d'environ $18 \mathrm{~cm}$ de diamètre, généralement en pâte grise à points de chaux (pâte 6). Quelques exemplaires sont cependant fabriqués dans la pâte 4 . Ces récipients possèdent un rebord simple déversé, à lèvre en bourrelet (Pelletier 1996, p. 33, fig. 7 n 3 et 4). Ces grands pots, parfois mono-ansés (Pelletier 1996, p. 38, fig. 7 n¹-5), ont été prélevés dans les séquences stratigraphiques les plus basses de la phase médiévale du chantier du Tunnel de la Major. Sur le site de la rue Trinquet, des récipients au même profil sont, eux, fabriqués dans des argiles correspondant à la pâte 5 .

\section{Profil Cathma7b}

Dans le contexte le plus ancien, pour le Moyen Âge, de la fouille de la rue de la République, a été retrouvé un rebord de pot (fig. 5, $\mathbf{n}^{\circ} \mathbf{1 0}$ ) dont la morphologie lèvre repliée et légèrement déversée soulignée d'une gorge dans sa partie supérieure, diamètre d'ouverture d'environ $15 \mathrm{~cm}$ - évoque celle de récipients contemporains découverts à Eyguières (Pelletier et al. 2000 : 315, 
fig. $45 \mathrm{n}^{\circ}$ 2). L'exemplaire repéré à Marseille est en pâte grise kaolinitique fine contenant des particules noires et de nombreuses écailles de mica (pâte 5). C'est une forme courante en Languedoc (Cathma 1993).

\section{Profil Cathma 8}

Les bords de pots en bandeau en pâte 5, au profil étiré et moins anguleux, ont été trouvés rue Trinquet: l'un de $15 \mathrm{~cm}$ de diamètre dans le comblement d'une tranchée (fig. 5, $\mathbf{n}^{\circ} \mathbf{3}$ ), l'autre, d'un module légèrement inférieur (12 cm de diamètre) dans une fosse (fig. 5, $\mathbf{n}^{\circ}$ 9). Tous deux s'apparentent par leur typologie à des exemplaires découverts dans la tranchée de fondation de l'enceinte de Cadrix dans le Var (Fixot 1982 ; Pelletier 1997a, fig. 8-1), contenant également un denier d'Othon III frappé entre 983 et 1002. Ils se rapprochent également de spécimens découverts à Apt dans le Vaucluse (Pelletier 1996, fig. 3-71) et datés de la fin du $\mathrm{X}^{\mathrm{e}}$ ou du $\mathrm{XI}^{\mathrm{e}} \mathrm{s}$. Un fragment de fond bombé à angle bien marqué, également issu du site de la rue Trinquet, et élaboré dans la même argile que les rebords évoqués, s'intègre parfaitement à cette chronologie et pourrait appartenir à l'un de ces vases.

Sur le chantier du Tunnel de la Major, le même type de profil, mais cette fois équipé d'une anse rubanée (fig. 5, $\mathbf{n}^{\circ} \mathbf{4}$ ), est également reconnu dans des niveaux précoces. La pâte est cependant plus grossière avec de nombreuses inclusions minérales (pâte 4).

Cet ensemble se rapproche, par sa morphologie, des exemplaires retrouvés à Saint-Pierre d'Eyguières dans les Bouches-du-Rhône (Pelletier, Poguet 2000, fig. 43), à Bédoin dans le Vaucluse (Pelletier et al. 2006, fig. 3, 96), à Ganagobie dans les Alpes-de-Haute-Provence (Pelletier, Fixot 1995, p.45, fig. 34-13). Tous ont été datés aux environs de l'An Mil.

\section{Profil Cathma 9}

Il s'agit de pots à rebord simple, déversé en bourrelet légèrement étiré (fig. $\left.\mathbf{5}, \mathbf{n}^{\circ} \mathbf{1}\right)$ et portant un ressaut interne à peine marqué (Pelletier et al. 2000, p. 316, fig. 46 $\left.\mathrm{n}^{\circ} 2\right)$. Le diamètre d'ouverture est de $15 \mathrm{~cm}$. Ils sont fabriqués dans les argiles du deuxième groupe, c'est-àdire une pâte grise kaolinitique à fines particules noires et écailles de mica, pouvant trouver son origine dans le bassin de Marseille.

\subsubsection{Les autres éléments de caractérisation (fonds, anses, décors...)}

L'apparition des fonds bombés marque, d'un point de vue typologique, le début de ce premier Moyen Âge. L'état de conservation du mobilier marseillais ne permet malheureusement pas de rapprocher avec assurance un profil d'un fond. Les éléments de fond conservés sont de trois modules :

- ceux compris entre 9 et $12 \mathrm{~cm}\left(\mathbf{f i g} .5, \mathbf{n}^{\circ} \mathbf{5 - 6}, \mathbf{1 1}\right)$ semblent les plus fréquents ;

- ceux dont le diamètre varie entre 14 et $16 \mathrm{~cm}$ (fig. 5, $\mathbf{n}^{\circ}$ 15). Celui prélevé sur le site du Tunnel de la Major est en pâte brune à rougeâtre avec des surfaces grises à noires, correspondant au groupe 4 ;

- ceux plus larges, autour de $18 \mathrm{~cm}$ de diamètre comme celui du chantier du Tunnel de la Major (fig. 5, $\mathbf{n}^{\circ} 12$ ).

Tous ces fonds sont lenticulaires ce qui les intègre parfaitement dans la typologie des productions de l'An Mil (Pelletier 1997a, p. 115-120, fig. 8). Leur paroi est plus fine que celle du bas de la panse avec laquelle elle forme un angle nettement marqué. Cela correspond généralement aux bases de gros pots, à cuire, à stocker ou à verser qui sont habituels et significatifs des productions du premier Moyen Âge (Démians d'Archimbaud, Pelletier 1995, p. 43 ; Pelletier 1997a, p. 115 ; Pelletier et al. 2006, p. 96).

Les pots de cette période ne possèdent que rarement une anse, et lorsqu'elle existe, elle est rubanée (fig. 5, $\mathbf{n}^{\circ} \mathbf{4}, \mathbf{1 5}$ ). Elle est, le plus souvent, verticale et directement attachée à un rebord simple (Démians d'Archimbaud, Pelletier 1995, p. 43 ; Pelletier 1997a, p. 115 ; Pelletier et al. 2006, p. 96).

Parfois, les hauts de panse, voire les trois quarts de la pièce, sont scandés par des stries sur leur face externe, mais rien n'assure qu'il s'agisse d'un décor (fig. 5, $\mathbf{n}^{\circ}$ 13-14). Les cannelures formant de vraies aspérités permettent, en l'absence d'autre système de préhension, une prise efficace. On notera que les cannelures sont assez souvent associées aux rebords en bandeau.

Sur certains fragments observés, les parois sont particulièrement fines. Elles portent des traces de déformations intervenues lors de leur cuisson. C'est le cas de fragments découverts dans un sondage de la ZAC de la Bourse qui sont, par ailleurs, fortement noircis aussi bien à l'intérieur qu'à l'extérieur.

\subsection{De très rares importations}

Comme sur certains sites provençaux, on observe à Marseille l'apparition occasionnelle de fragments de vaisselle, glaçurée ou non, en provenance des rivages méditerranéens.

\subsubsection{Les céramiques à glaçure}

De rares pièces, appartenant au répertoire des vases à verser, portent une couverte plombifère épaisse. 


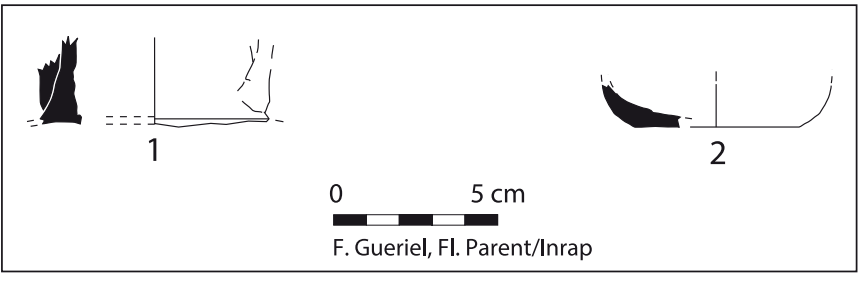

Fig. 6. Céramiques importées du Haut Moyen Âge. 1 : cruche africaine (Collège Vieux-Port) ; 2 : Forum Ware? (Alcazar).

Ce mobilier est suffisamment singulier pour être remarquable. Ces produits retrouvés dans les contextes de l'An Mil, voire légèrement postérieurs, sont le témoignage des échanges de la cité de Marseille au sein du bassin méditerranéen. Les lieux de provenance pourraient être le Maghreb (Ifriqiya, royaume Ziride, Idrisside, dynastie Rusténide), l'Italie et vraisemblablement aussi l'aire byzantine (Amouric et al. 1999, p. 8-9).

$\mathrm{Si}$, sur le site de la rue Trinquet, il n'existe pas de céramique glaçurée, le cas de la fouille au sud de la rue de la République, paraît plus délicat. En effet, une production glaçurée en pâte fine réfractaire de couleur beige à grise a été découverte dans un niveau de l'An Mil. Il s'agit d'un fragment de fond de forme fermée à parois très fines portant une glaçure interne jaune orangé. Bien qu'une production utilisant la même technologie soit connue dans le Gard pour des périodes plus récentes (céramiques réfractaires glaçurées dites de l'Uzège), une identification à la région gardoise de ce fragment est improbable. Il s'agit plutôt d'une importation en provenance de rivages méditerranéens. Les rainures bien marquées scandant le bas de la pièce pourraient évoquer des techniques de Méditerranée orientale (Amouric, Vallauri 2005) ou du monde siculo-maghrébin (Pelletier 1996, p. 34, fig. $12 \mathrm{n}^{\circ} 11$ ).

Un autre fragment, issu cette fois des fouilles de l'Alcazar mais présent de manière résiduelle dans un contexte du XIV ${ }^{\mathrm{e}} \mathrm{s}$., montre la base d'une forme fermée à fond plat d'environ $5 \mathrm{~cm}$ de diamètre (fig. $6, \mathbf{n}^{\circ} \mathbf{2}$ ), recouverte à l'extérieur d'une épaisse glaçure au plomb vert olive. La pâte de cette pièce est grise et très cuite.

La fouille du secteur sud-ouest du port de la Bourse à Marseille a également permis de mettre en évidence une occupation au cours des $\mathrm{X}^{\mathrm{e}}-\mathrm{XI}^{\mathrm{e}} \mathrm{s}$. livrant une association analogue de céramiques communes grises et de vases glaçurés importés d'Italie (Bonifay 1983).

Souvent repérées dans des contextes de l'An Mil, ces céramiques à glaçure épaisse brun-vert ont été également découvertes récemment à Montmajour et dans Arles intra muros sur les sites de la commanderie de Sainte-Luce, rue du Sauvage et place Suarez (Treglia et al. 2012, p. 205). Elles se rattachent vraisemblablement aux productions d'Italie du Nord ou du Latium, fréquemment définies sous le terme générique de vetrina pesante ou de Forum ware (Peduto 2000, p. 81, fig. 1). Il s'agit pour l'essentiel de formes fermées, cruches et pots, parfois décorés de cordons rapportés godronnés ou d'écailles ou bien encore de chafing dishes (chauffe-plat). Ce groupe d'objets est attesté sur des sites côtiers comme Fréjus (Cathma 1986, p. 50), également sur quelques sites aristocratiques plus à l'intérieur des terres comme le castrum de Fos (Piton 1993), la motte castrale de Niozelles (Mouton 1995, p. 50, fig. 77-78), sur les fortifications de Cucuron (Pelletier 1996, p. 34) et Cadrix (Amouric et al. 1999, p. 8-9) ainsi qu'à Digne à la cathédrale Notre-Dame du Bourg (Démians d'Archimbaud, Pelletier 1995, fig. 7). En Italie, des exemplaires ont été exhumés en bordure de la côte amalfitaine sur le site de la villa Rufolo di Ravello, dans un contexte daté des $\mathrm{IX}^{\mathrm{e}}$ et $\mathrm{X}^{\mathrm{e}} \mathrm{s}$. (Peduto 2000) ainsi qu'en Sardaigne (Milanese et al. 2006). Ces tessons demeurent exceptionnels et il s'agit toujours de céramiques d'importation. En l'occurrence, même si le fragment de l'Alcazar est hors contexte, il témoigne tout de même des échanges commerciaux de la ville à cette période.

\subsubsection{La céramique africaine à surface blanchie}

Un fragment de vase à liquide en pâte beige rosé, à nombreuses inclusions jaunes, a été retrouvé, également en contexte résiduel, sur la fouille du collège Vieux-Port. Ce fragment ne porte aucun revêtement, seule sa surface externe est blanchie. Le col est droit, le raccord de l'anse verticale s'effectue juste au-dessus de sa jonction avec la panse qui apparaît quasi ovoïde. La présence d'un filtre à l'intérieur du col est signalée par une incision au couteau d'un centimètre de long environ réalisée avant cuisson (fig. 6, $\mathbf{n}^{\circ} \mathbf{1}$ ). Compte-tenu de ses caractéristiques de pâte et de sa morphologie, il pourrait s'agir d'une importation de Tunisie. Une production de ce type a été reconnue lors des fouilles de Șabra al-Manșūriya en Tunisie, ville occupée du milieu du $\mathrm{X}^{\mathrm{e}} \mathrm{s}$. au milieu du $\mathrm{XI}^{\mathrm{e}} \mathrm{s}$. (Gragueb Chatti 2006).

L'introduction de produits méditerranéens demeure remarquable en Provence et dans le sud de la France durant le $\mathrm{X}^{\mathrm{e}} \mathrm{s}$. et ils sont à peine plus fréquents à partir du siècle suivant (Démians d'Archimbaud, Vallauri 1998, p. 82-83).

\subsection{Conclusion}

Cette nouvelle enquête sur la caractérisation du mobilier des niveaux alto-médiévaux à Marseille a nécessité de revisiter - rapidement - une partie du mobilier quelques 
années après les premières études. Cette révision s'est dans le même temps partiellement accompagnée de l'examen des données stratigraphiques et des inventaires réalisés. Pour cette période chronologique, la mise en perspective des sites marseillais, des fouilles les plus anciennes aux plus récentes, mettent systématiquement en évidence un "cortège » de céramiques communes grises assorti d'exceptionnels produits d'importation, vases glaçurés d'Italie, de l'aire byzantine ou encore relevant de la tradition orientale.

Le raisonnement est ici basé sur des phénomènes de présence/absence : omniprésence de formes fermées, absence de becs pontés ou pincés (indices manifestes d'ancienneté), rareté des anses et des décors (à la roulette) plus fréquents après le $\mathrm{XI}^{\mathrm{e}} \mathrm{s}$., absence de pégaus qui apparaissent plutôt vers la

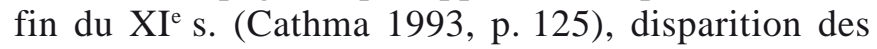

formes ouvertes vraisemblablement remplacées par des ustensiles en bois.

Par ailleurs, l'existence d'une multitude de textures et d'aspects de pâtes - résultant de la diversité des argiles utilisées, d'une plus ou moins grande maîtrise de la cuisson, mais aussi de l'existence de nombreux ateliers de proximité fournissant les communautés - rend la situation extrêmement complexe. D'autant qu'il y a peu de découvertes d'ateliers de cette période : il est donc délicat d'attribuer de manière fiable un récipient à une production. De surcroît, ce mobilier est souvent accompagné d'éléments résiduels de la fin de l'Antiquité, ce qui a pu être équivoque pour la sériation séquentielle.

En dépit de toutes ces difficultés, une datation comprise entre le $\mathrm{X}^{\mathrm{e}}$ et le $\mathrm{XI}^{\mathrm{e}} \mathrm{s}$. peut être avancée pour l'ensemble de ces mobiliers. 


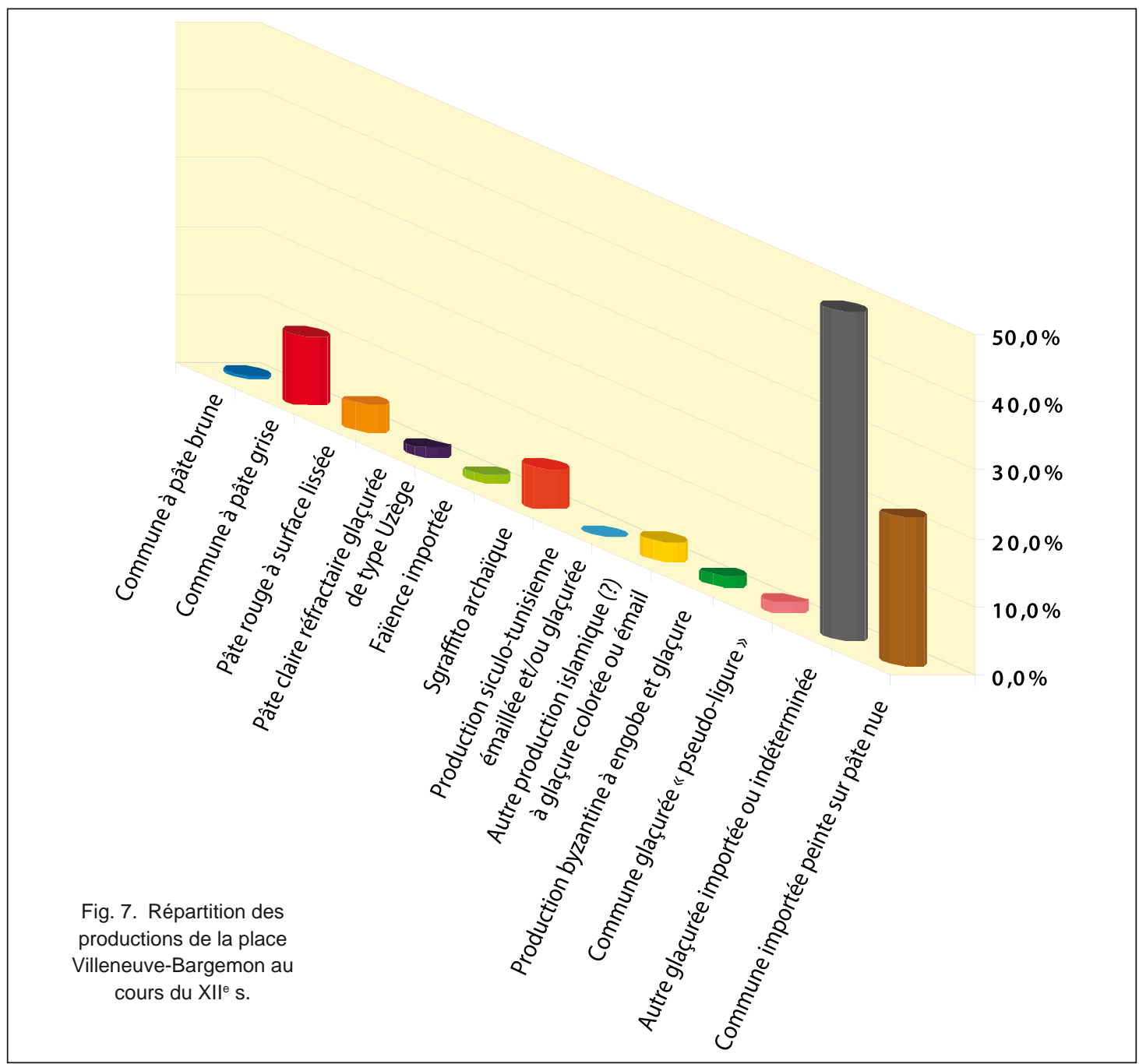

\begin{tabular}{|c|c|c|c|c|}
\hline \multicolumn{2}{|r|}{ Catégories } & habitats & rues & Total fragments \\
\hline \multirow{5}{*}{$\begin{array}{l}\text { productions locales } \\
\text { et régionales }\end{array}$} & Commune à pâte brune & 38 & 646 & 684 \\
\hline & Commune à pâte grise & 164 & 1356 & 1520 \\
\hline & Pâte rouge à surface lissée & 4 & 48 & 52 \\
\hline & Pâte claire réfractaire glaçurée de type Uzège & 14 & 37 & 51 \\
\hline & Total & 220 & 2087 & 2307 \\
\hline \multirow{10}{*}{ importations } & Faïence importée & 12 & 83 & 95 \\
\hline & Sgaffito archaïque & 0 & 2 & 2 \\
\hline & Production siculo-tunisienne émaillée et/ou glaçurée & 34 & 153 & 187 \\
\hline & Autre production islamique (?) à glaçure colorée ou émail & 6 & 32 & 38 \\
\hline & Production byzantine à engobe et glaçure & 6 & 39 & 45 \\
\hline & Commune glaçurée « pseudo-ligure » & 8 & 113 & 121 \\
\hline & Autre glaçurée importée ou indéterminée & 35 & 284 & 319 \\
\hline & Commune importée peinte sur pâte nue & 0 & 14 & 14 \\
\hline & Total & 101 & 720 & 821 \\
\hline & Total fragments & 321 & 2807 & 3128 \\
\hline
\end{tabular}

Tableau I : répartition des productions dans les contextes du XII $\mathrm{s}$. sur la place Villeneuve-Bargemon. 


\section{Chapitre 2}

\section{Le XII ${ }^{\mathrm{e}}$ s. : entre Islam et Byzance}

\section{(Florence Parent)}

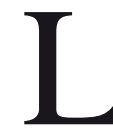

es découvertes concernant le $\mathrm{XII}^{\mathrm{e}} \mathrm{s}$. se sont multipliées depuis une vingtaine d'années. Initiée avec les explorations autour de l'Hôtel de Ville, la connaissance du vaisselier marseillais au $\mathrm{XII}^{\mathrm{e}} \mathrm{s}$. ne cesse de s'enrichir. La documentation provient essentiellement de ces premiers chantiers de la place Villeneuve-Bargemon (environ 3000 fragments), que viennent compléter d'autres trouvailles plus ponctuelles. La plus grande part concerne l'habitat urbain et la voirie desservant ces bâtiments (Villeneuve-Bargemon, Tunnel de la Major et Bourse). De petits lots ont toutefois été exhumés dans des contextes d'habitats plus isolés à la frange de la ville (habitat et chemin de Alcazar et silos de la rue Trinquet). La nature même de ces contextes, sols piétinés de rues et d'habitats et remblaiement de silos à leur abandon, n'a pas favorisé la conservation du mobilier. Aussi est-ce d'un matériel extrêmement fragmenté et incomplet dont il est question dans ce chapitre (tableau I et fig. 7).

L'état actuel des découvertes et des recherches régionales ne permet guère d'affiner la chronologie et donc la typologie au sein de cette période. L'extrême rareté des monnaies dans ces contextes marseillais ainsi que leur mauvais état de conservation ne remédient pas à cette imprécision.

À cette époque, les produits régionaux sont toujours largement prépondérants. Leur cuisson en atmosphère réductrice et leur fonction en sont toujours les dénominateurs communs bien que quelques exceptions apparaissent : qu'il s'agisse de céramiques à pâte brune, à pâte grise ou exceptionnellement rouge ou claire, elles ne portent aucun revêtement et sont toutes à usage culinaire ou de stockage. Mais les qualités de pâte et les formes, détaillées plus loin, permettent de distinguer plusieurs provenances locales et régionales, sans qu'il soit possible de les attribuer à un atelier en particulier.

À leur différence, les produits importés sont tous cuits en atmosphère oxydante. Les formes en sont plus variées. La plupart sont glaçurées et semblent avoir un double usage : cuisine et table. La vaisselle émaillée ou engobée est rare et peut être considérée comme un produit luxueux donc précieux. Bien que présentes en faible proportion, ces importations offrent un échantillonnage de diverses productions issues de tout le bassin méditerranéen, où règnent culture byzantine et culture islamique.

\section{Les productions locales et régionales}

Qu'elles soient de provenance locale ou régionale, les céramiques cuites en atmosphère réductrice sont toujours prépondérantes : dans toutes les découvertes, elles rassemblent plus ou moins $80 \%$ des produits destinés aux cuisines marseillaises. Elles sont omniprésentes en Provence à cette époque et donc relativement bien connues d'un point de vue typologique, même si très peu d'ateliers sont reconnus pour l'instant. À cette période, on assiste à l'apparition et à la généralisation des fonds plats sur certaines formes, sans doute à mettre en relation avec un changement dans les pratiques des habitants : certains vases n'auraient plus uniquement une fonction de stockage et/ou de cuisson mais aussi celle de service. Ces changements de pratiques se manifestent également par l'introduction des pégaus vers la fin du $\mathrm{XI}^{\mathrm{e}} \mathrm{s}$. : ces pots à une anse, de contenance réduite et ne comportant ni col ni bec verseur, sont systématiquement équipés d'un fond plat permettant leur utilisation aussi bien sur les braises que sur la table. Pots et pégaus sont les équipements incontournables des cuisines provençales au $\mathrm{XII}^{\mathrm{e}} \mathrm{s}$. mais celles de Marseille sont également parfois pourvues d'ustensiles inédits pour la région.

Le procédé de cuisson en atmosphère oxydante (qui confère à la pâte des tons beige à rouge) ne semble pas pour autant abandonné mais demeure nettement minoritaire, voire marginal.

\subsection{Les céramiques communes à pâte brune}

Cette catégorie de céramique commune est caractéristique non seulement par sa pâte aux tons de brun variés mais aussi par la présence d'une multitude de 


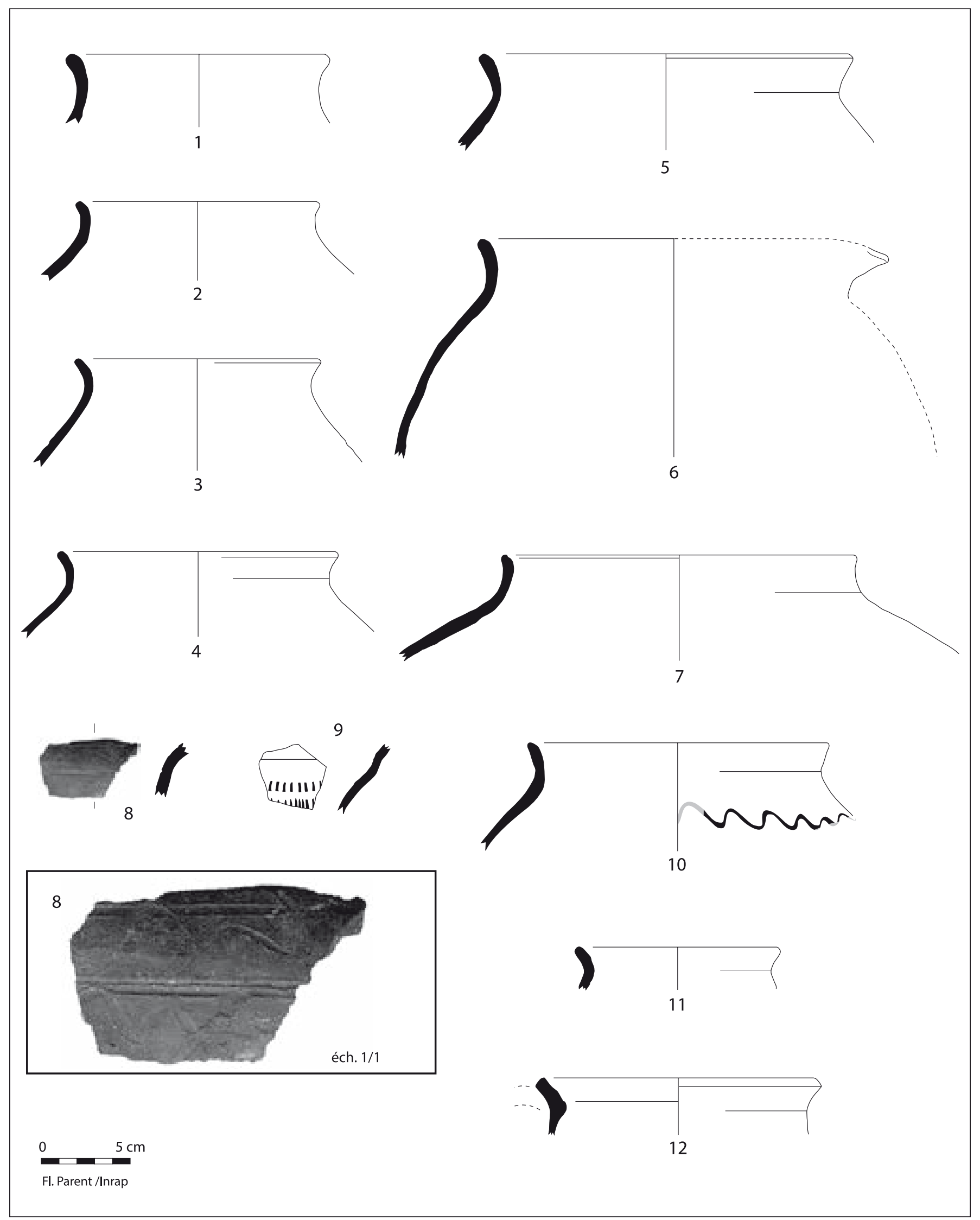

Fig. 8. Céramiques communes à pâte brune du XII s. : formes fermées. 1-10, 12 : place Villeneuve-Bargemon ; 11 : rue Trinquet. 


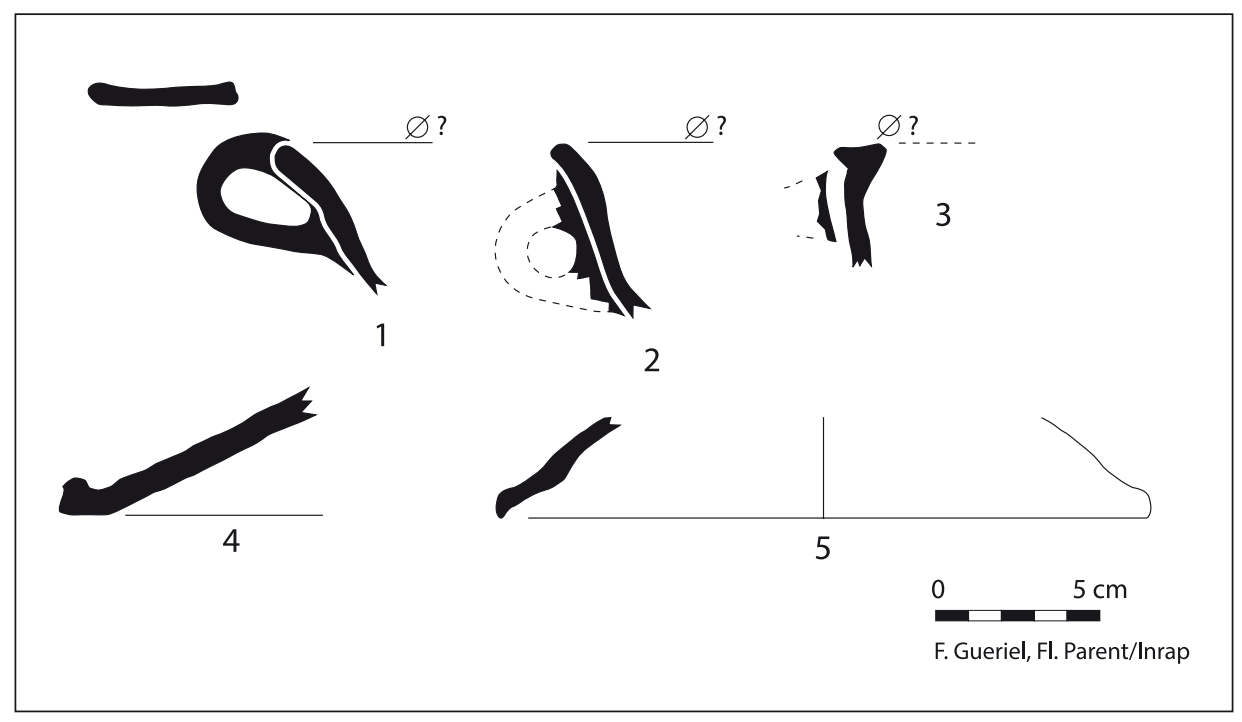

Fig. 9. Céramiques communes à pâte brune du XII $\mathrm{s}$. : formes rares. 1-4 : place Villeneuve-Bargemon ; 5 : rue Trinquet.

paillettes de mica. Outre ces paillettes, des particules blanches ou grises anguleuses (dont certaines pourraient être du quartz) sont nombreuses et nettement visibles dans l'épaisseur, aussi bien qu'en surface. Sont présents également, en moindre quantité, des nodules plus sombres probablement ferrugineux.

Le problème de l'origine de ces céramiques n'est pas encore résolu, même si de nombreuses hypothèses la situent dans le Var, où une production de ce type est connue depuis l'Antiquité et plus exactement dans la vallée de l'Argens ou le Massif des Maures (Pelletier 1997b, p. 68 ; Amouric et al. 2009, p. 34-35).

L'essentiel du répertoire réside dans des pots, le plus fréquemment de grandes dimensions $(20 \mathrm{~cm}$ et plus à l'ouverture). De manière anecdotique apparaissent ça et là, quelques pots de taille moyenne (diamètre oscillant entre 12 et $16,5 \mathrm{~cm}$ à l'ouverture) (fig. 8, $\mathbf{n}^{\circ} \mathbf{1 - 2}, \mathbf{1 0}$ ). Quelle que soit leur dimension, leur forme est simple et rudimentaire à l'image de leur façonnage : les lèvres simplement déversées (fig. 8, $\mathbf{n}^{\circ}$ 5-7) sont parfois légèrement effilées (fig. $8, n^{\circ} 3-4$ ), et vont habituellement de pair avec un bec pincé, les parois globulaires et les fonds nettement bombés (fig. 8, $\mathbf{n}^{\circ} \mathbf{5 - 6}, \mathbf{7}$ ). Ces pots ne comportent généralement pas d'anse; quand cellesci existent, elles sont rubanées et posées verticalement à l'opposé du bec. Bien que son diamètre d'ouverture l'intègre aux pots de moyenne dimension $(16 \mathrm{~cm})$, un fragment retrouvé à Villeneuve-Bargemon peut être rapproché par sa morphologie du type «pot de petite dimension » identifié à Sainte-Barbe (Pelletier 1997b, p. 68, fig. $43 \mathrm{n}^{\circ} 12$ ) dans des contextes sensiblement contemporains: la lèvre rectangulaire est étirée vers l'extérieur tandis qu'à l'intérieur elle est soulignée d'une gorge et d'un ressaut (fig. $8, \mathbf{n}^{\circ} \mathbf{1 2}$ ). La forme ne semble pas très pansue vu l'orientation des parois. Un deuxième vase de petites dimensions $(11,5 \mathrm{~cm}$ de diamètre à l'ouverture) adopte quant à lui le profil classique des séries de dimensions supérieures (fig. 8, $\mathbf{n}^{\circ} \mathbf{1 1}$ ).

Les éléments décoratifs restent exceptionnels. Il peut s'agir d'un décor ondé organisé en registres verticaux délimités par une gorge (fig. $8, \mathbf{n}^{\circ} \mathbf{8}, \mathbf{1 0}$ ) ou d'une simple molette de bâtonnets étagés sur plusieurs registres comme sur le fragment fig. $8, \mathbf{n}^{\circ} \mathbf{9}$, à rapprocher de celui découvert sur la place Général-de-Gaulle (Richarté 2001, p. 140).

Les formes ouvertes sont tout aussi rares : deux exemples de jattes découverts place VilleneuveBargemon (fig. 9, $\mathbf{n}^{\circ} \mathbf{1 - 2}$ ) présentent une lèvre simple légèrement déversée à l'extérieur sur laquelle vient s'attacher une anse courte verticale. Un fragment provenant du même site (fig. $9, \mathbf{n}^{\circ} \mathbf{3}$ ) pourrait correspondre à une nouvelle forme de jatte à moins qu'il ne s'agisse du premier exemple de marmite reconnu pour cette période : le bord rentrant est replié en bourrelet vers l'extérieur de manière à former une lèvre triangulaire saillante des deux côtés, l'attache de l'anse horizontale s'effectue sur le bord externe.

Les seuls couvercles qui peuvent être associés à ces produits sont tronconiques avec une lèvre rectangulaire repliée vers l'extérieur et soulignée d'une gorge tandis que la face interne de la lèvre forme un replat afin de s'adapter à son support (fig. 9, $\mathbf{n}^{\circ} \mathbf{4}$ ). Un exemplaire d'un type légèrement différent a été découvert place Général-de-Gaulle (Richarté 2001, fig. 177-1) et un dernier d'un type encore différent sur le site de la rue Trinquet (fig. 9, $\mathbf{n}^{\circ} \mathbf{5}$ ). 


\subsection{Les céramiques communes à pâte grise}

De consommation courante durant le XII e et encore au début du $\mathrm{XIII}^{\mathrm{e}} \mathrm{s}$., les productions en pâte grise totalisent plus de la moitié des produits en usage, suivant en cela un schéma désormais classique dans toute la Provence. Trois groupes peuvent être nettement individualisés, essentiellement à partir de leurs caractéristiques de pâte, mais aussi par leur procédé de fabrication. Cependant rien n'exclut qu'un même atelier ait produit et fourni des vases à partir de différents bancs d'argile et/ou de différentes techniques de fabrication, le cas des officines de Sainte-Barbe au siècle suivant en est un exemple patent (Marchesi et al. 1997). Seules des analyses géochimiques et/ou pétrographiques permettraient d'individualiser les différentes origines de production.

\subsubsection{Les céramiques communes à pâte grise grossière}

Cette première catégorie de céramiques communes à pâte grise apparaît de manière sporadique mais régulière dans les contextes marseillais du XII ${ }^{\mathrm{e}} \mathrm{s}$., notamment dans les niveaux de voirie de la place Villeneuve-Bargemon et dans quelques silos de la rue Trinquet.
Ces pots présentent de fortes affinités avec les produits du bassin de Saint-Maximin (Var) dont certaines productions sont connues de l'Antiquité tardive jusqu'au $\mathrm{XI}^{\mathrm{e}} \mathrm{s}$. puis de nouveau à partir de la fin du XII $\mathrm{s}$. (Démians d'Archimbaud 1980 ; Pelletier 1997a ; Pelletier 1997b ; Pelletier-Bérard 1997 ; Argueyrolles 2000). Même si la chronologie de nos exemplaires ne correspond pas à cette chronologie, il est vraisemblable que ces éléments aient été fabriqués sur le même territoire car rien ne permet de certifier ni de justifier que les officines du territoire varois aient interrompu leur activité durant près d'un siècle (le XII ${ }^{\mathrm{e}}$ ) pour la reprendre ensuite.

Quelques fragments présentent une pâte gris foncé où les nodules ferrugineux sont quasiment absents mais qui est criblée de particules blanchâtres de toutes tailles dont certaines peuvent atteindre $3 \mathrm{~mm}$ et apparaître en surface. Elle est très rugueuse au toucher. Contrairement aux autres céramiques à pâte grise, celles-ci ne semblent pas tournées mais plutôt modelées. Un fragment de pot porte un décor à la molette aux motifs élaborés organisé en plusieurs registres superposés (fig. 10, $\mathbf{n}^{\circ} \mathbf{4}$ ). Ce genre de décor reste exceptionnel pour l'époque et la région : il n'est reconnu pour l'instant que sur un inhabituel pégau à trois becs pincés attribué au XII ${ }^{\mathrm{e}} \mathrm{s}$. (Zérubia 1995, p. 71,

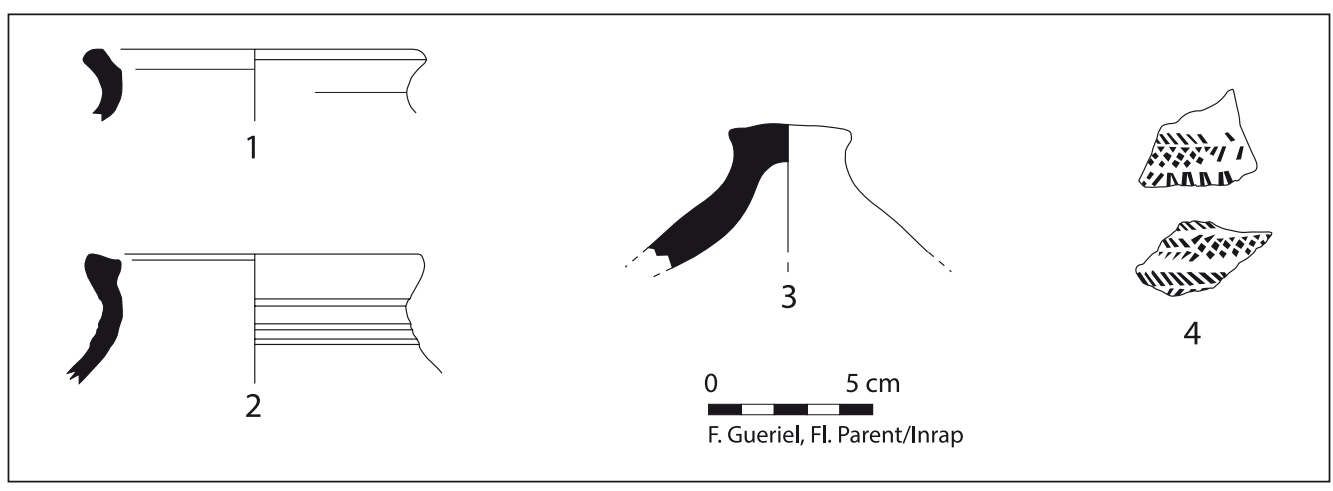

Fig. 10. Céramiques communes à pâte grise grossière du XII ${ }^{\mathrm{s}}$ s. 1-4 : place Villeneuve-Bargemon.

La plupart des éléments semblent façonnés dans une argile très nettement réfractaire. De couleur gris clair à cœur, elle forme souvent une pellicule très foncée en surface. Les inclusions y sont très nombreuses et les nodules ferrugineux sont prééminents. Contrairement à toutes les céramiques grises évoquées à la suite, le mica en est totalement absent. Les rares éléments de forme conservés correspondent essentiellement à des pots à lèvre simple (fig. $\mathbf{1 0}, \mathbf{n}^{\circ} \mathbf{1}$ ) d'une dizaine de centimètres de diamètre à l'ouverture. L'un d'entre eux se distingue par sa lèvre triangulaire, (fig. 10, $\mathbf{n}^{\circ} \mathbf{2}$ ). L'extérieur de sa panse est strié. La gorge, plus ou moins prononcée, aménagée sur la lèvre, semble destinée à supporter un couvercle tel l'exemplaire (fig. 10, $\mathbf{n}^{\circ} \mathbf{3}$ ). fig. 85-87) et sur des marmites ou des couvercles légèrement plus tardifs, datés de la fin du XII ${ }^{\mathrm{e}} \mathrm{s}$. au moins (Démians d'Archimbaud 1980, p. 313 ; Pelletier 1997a, p. 119 ; Pelletier 1997b, p. 68-70, fig. 44-45).

\subsubsection{Les céramiques communes à pâte grise micacée}

Ce groupe est largement majoritaire au sein des céramiques à pâte grise. En général, la pâte contient une multitude de paillettes de mica. L'omniprésence d'inclusions blanches à grisâtres de toutes tailles en est un autre trait caractéristique, même si leur quantité est très variable d'un fragment à l'autre, tout comme les nodules plus sombres (ferrugineux ?). La qualité 
CHAPITRE 2 - LE XII ${ }^{e}$ S. : ENTRE ISLAM ET BYZANCE

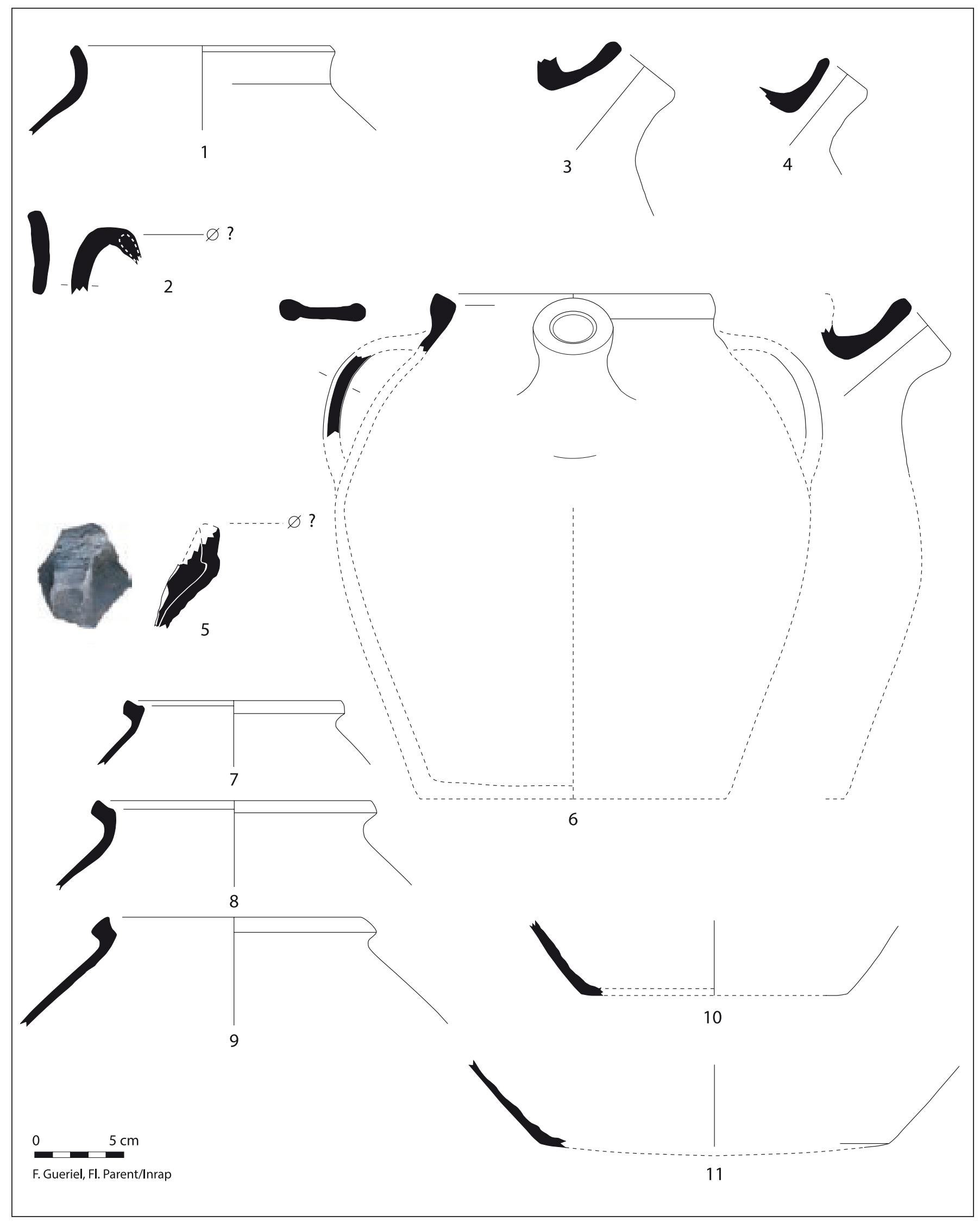

Fig. 11. Pots en céramique commune à pâte grise micacée du XII ${ }^{\mathrm{e}}$ s. 1, 3, 4, 6-9, 11 : place Villeneuve-Bargemon ; 2, 5, 10 : rue Trinquet.

37 


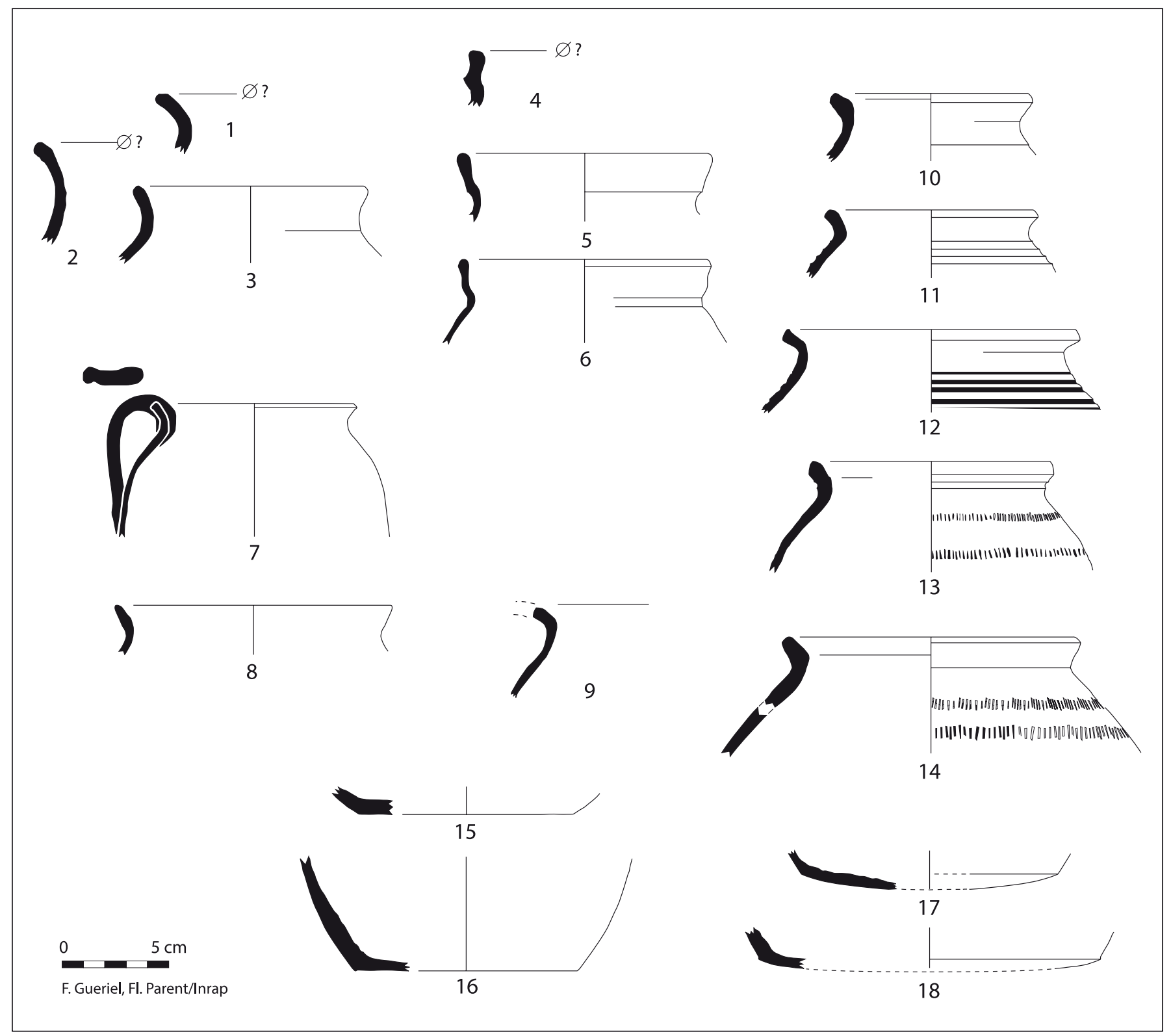

Fig. 12. Pégaus en céramique commune à pâte grise micacée du XII $\mathrm{e}$ s. 1-7, 9-13, 16,18 : place Villeneuve-Bargemon ;

8, 15, 17 : rue Trinquet ; 14 : Alcazar.

des pâtes et la température de cuisson semblent ellesmêmes irrégulières: certains fragments présentent une texture plus fine ou plus tendre, une couleur grise plus ou moins claire ou une pâte extrêmement cuite et donc très dure, à l'aspect presque grésé. La relative diversité des pâtes n'exclut pas pour autant qu'il s'agisse d'une même aire de production et grandes sont les affinités avec les productions situées aux alentours du massif de l'Étoile (Pelletier, Vallauri 1992) mais les analyses pratiquées sur certains exemplaires indiquent également une autre origine (Vallauri 1997a, p. 73). Par ailleurs, leur prédominance dans les vaisseliers marseillais du $\mathrm{XII}^{\mathrm{e}} \mathrm{s}$. conforte l'hypothèse d'une provenance locale.
À l'instar de leurs cousins provençaux, les récipients marseillais se composent essentiellement de pots et pégaus, formes privilégiées jusqu'à l'apparition des marmites à la fin du XII e s. (Pelletier 1997a, p. 119). Ils servent aussi bien à la conservation qu'à la cuisson des aliments.

\section{Les pots et pégaus}

Certains pots sont globulaires, à lèvre simple (fig. 11, $\left.\mathbf{n}^{\circ} \mathbf{1}\right)$. Rares sont les anses retrouvées, pourtant certains exemplaires devaient en comporter comme en témoigne celui retrouvé dans un silo de la rue Trinquet (fig. 11, $\mathbf{n}^{\circ} \mathbf{2}$ ). Sur cet exemple, l'anse large et rubanée englobe 


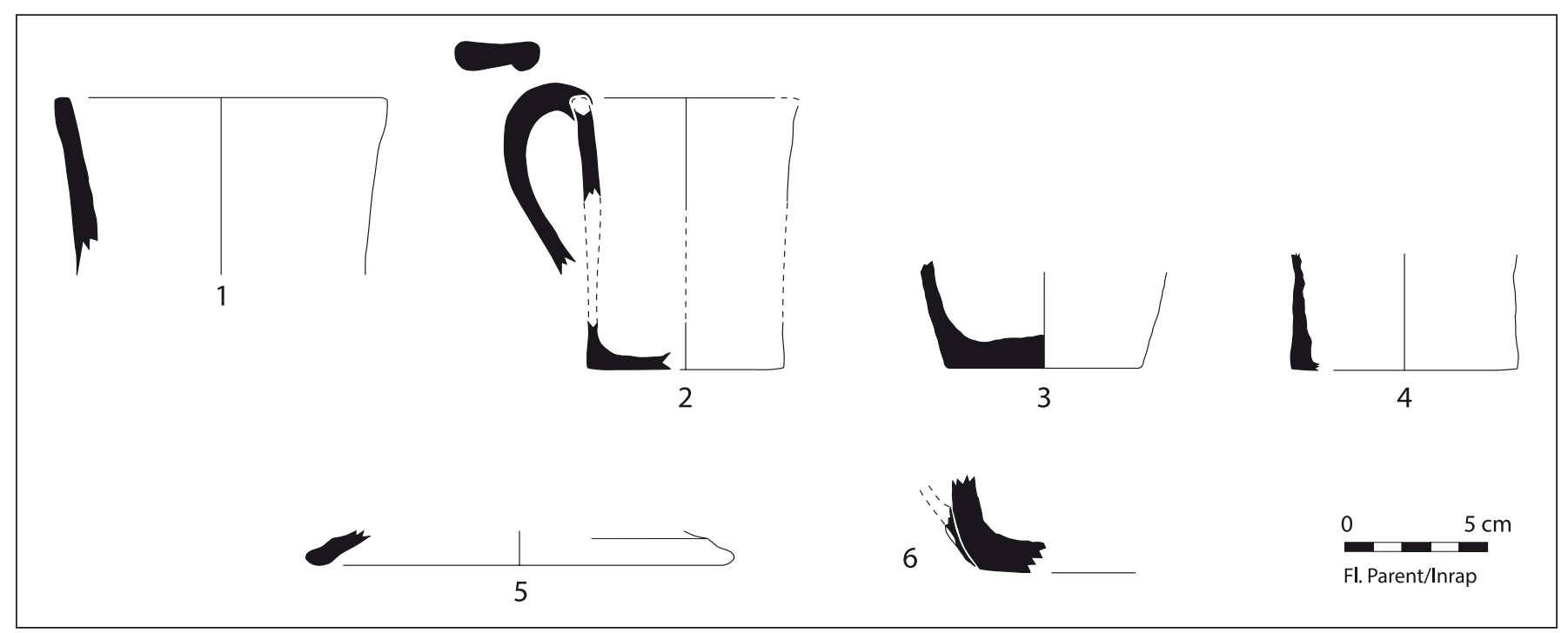

Fig. 13. Formes rares en céramique commune à pâte grise micacée du XIIe s. 1, 2, 4, 6 : place Villeneuve-Bargemon ; 3 : Alcazar ; 5 : rue Trinquet.

totalement la lèvre. D'autres pots comportent un bord rectangulaire plus ou moins incurvé (fig. 11, $\mathbf{n}^{\circ}$ 7-9) sous lequel vient s'attacher l'anse, toujours large et rubanée (fig. 11, n⿳6). Ceux-là sont en général pourvus d'un bec tubulaire (Pelletier, Vallauri 1992, p. 234, fig. 6) (fig. 11, $\mathbf{n}^{\circ}$ 3-4, 6). Enfin, un dernier exemplaire montre un rebord en poulie, sur lequel est appliqué un renfort de pâte posé à la verticale et digité (fig. 11, $\left.\mathbf{n}^{\circ} \mathbf{5}\right)$, identique au spécimen avec préhension en anse de panier au décor digité retrouvé dans les dépotoirs de Mimet (Pelletier, Vallauri 1992, fig. 8, n¹). Les fonds bombés semblent exister de manière anecdotique (fig. 11, $\mathbf{n}^{\circ} \mathbf{1 1}$ ), car la plupart sont plats (fig. 11, $\mathbf{n}^{\circ} \mathbf{1 0}$ ). D'ailleurs, l'aplanissement des fonds des céramiques régionales est un phénomène observé sur tous les sites provençaux dès le début du XII ${ }^{\mathrm{e}}$ s. (Pelletier 1997a, p. 119).

Les pégaus se distinguent par leur petite taille, leur diamètre d'ouverture varie de 9 à 14 centimètres. Les bords sont simples ou en poulie (fig. 12, $\mathbf{n}^{\circ} \mathbf{1 - 9}$ ) mais peuvent parfois être plus structurés (fig. 12, $\mathbf{n}^{\circ} \mathbf{1 0}-\mathbf{1 1}$, 13-14), les anses conservées englobent totalement la lèvre; ils rejoignent par ces traits morphologiques les productions supposées du massif de l'Étoile (Pelletier, Vallauri 1992, p. 231-234, fig. 5). Quelques panses sont animées de raies de tournage ou de cannelures (fig. 12, $\mathbf{n}^{\circ}$ 11-12), plus fréquemment de molette simple (fig. 12, $\mathbf{n}^{\circ} \mathbf{1 3 - 1 4}$ ). Leur typologie renvoie très nettement à celle d'autres découvertes provençales du XII ${ }^{\mathrm{e}} \mathrm{s}$. (Fixot, Pelletier 1995, p. 47-48, fig. 36 ; Démians d'Archimbaud, Pelletier 1995, p. 60-61, fig. 51-53; Pelletier 1997a ; Blaison et al. 1995). Les fonds qui peuvent être associés à ces formes sont généralement plats (fig. 12, $\mathbf{n}^{\circ}$ 15-16), parfois légèrement bombés (fig. 12, $\mathbf{n}^{\circ}$ 17-18) et les quelques fragments d'anses découverts sont larges et rubanés.

\section{Les autres formes}

Place Villeneuve-Bargemon, ces pots et pégaus sont accompagnés de formes sans équivalent pour la période et pour la région que sont les chopes ou gobelets à une anse (fig. 13, $\mathbf{n}^{\circ} \mathbf{1 - 4}$ ). La panse tronconique, donc presque verticale, repose sur un fond plat dont le diamètre est légèrement inférieur à celui du bord (diamètre d'ouverture entre 7,5 et $11 \mathrm{~cm}$ ). La lèvre simple est retouchée pour offrir un rebord plat et supporte le départ de l'anse rubanée qui retombe vraisemblablement sur la moitié inférieure de la paroi. Ces exemplaires sont pour l'instant trop peu nombreux pour évaluer leur calibrage mais il est possible qu'ils aient servi également de mesures à liquides.

Un fond plat pourrait appartenir à une forme équivalente. Les parois et le fond sont nettement plus épais que sur les chopes précédemment évoquées mais les parois semblent également peu évasées (fig. 13, $\mathbf{n}^{\circ} \mathbf{6}$ ). Le départ de l'anse verticale s'effectue juste au-dessus du fond et une empreinte digitée à la base, engendrée par son application, est bien nette. Il pourrait s'agir d'une jatte ou d'une tasse comparable à des éléments plus anciens retrouvés dans les Alpes-de-Haute-Provence (Démians d'Archimbaud, Pelletier 1995, p. 57, fig. 48). Le fragment est trop petit pour pouvoir déterminer le diamètre qui permettrait de trancher entre ces deux formes.

Les fragments de couvercle sont très rares. Le couvercle tronconique à lèvre presque en amande, d'une quinzaine de centimètres de diamètre, s'adapte sans doute sur la gorge d'un pot à lèvre rectangulaire (fig. 13, $\mathbf{n}^{\circ} \mathbf{5}$ ). 


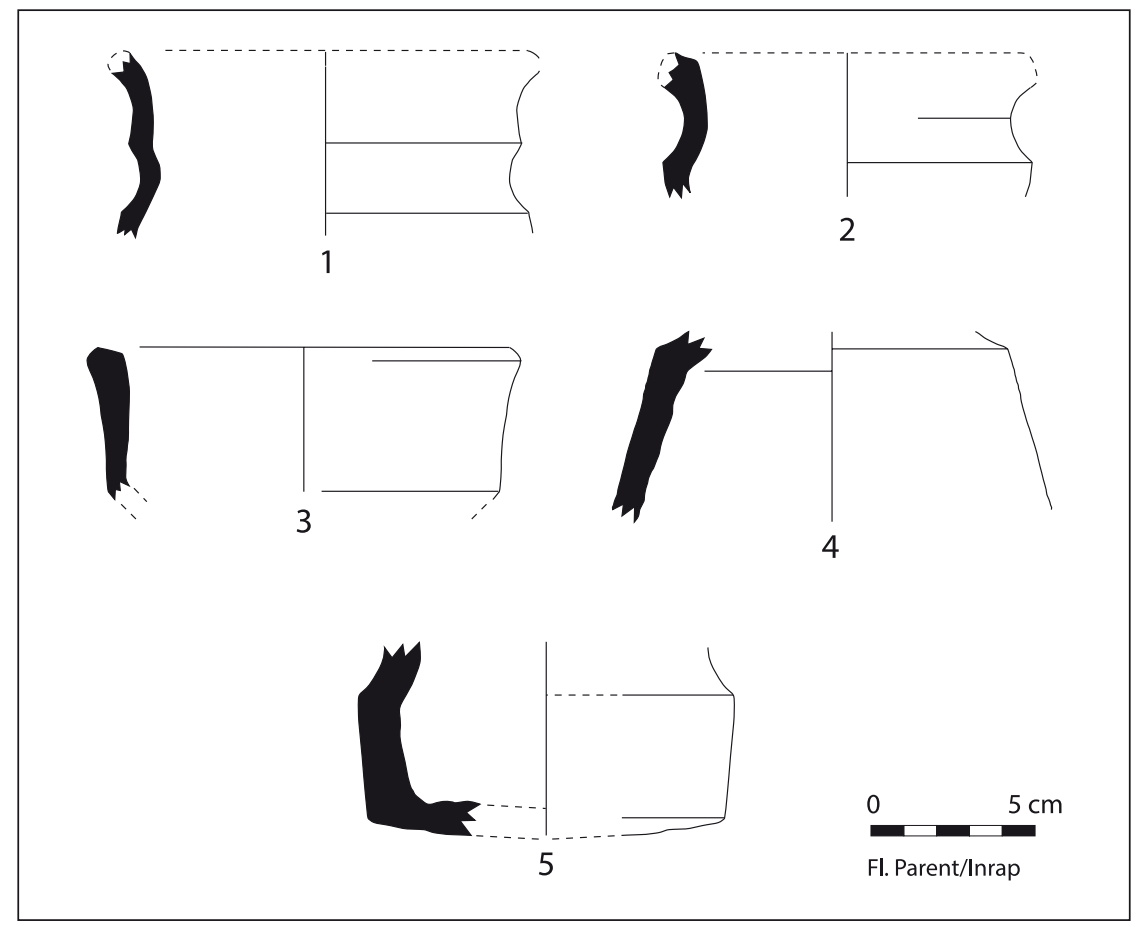

Fig. 14. Godets de noria en céramique commune à pâte grise micacée du XII $\mathrm{S}$. 1-4 : place Villeneuve-Bargemon ; 5 : Hôtel Dieu.

\section{Les godets et tuyaux}

Certains sites ont livré des éléments bien particuliers, tous relatifs à des ouvrages hydrauliques.

La noria de la place Villeneuve-Bargemon recelait encore quelques fragments des godets ayant servi à y puiser l'eau (au moins trois bords et quatre fragments de panse), tous bien reconnaissables à la ou les gorges qui servaient à passer la corde (fig. 14, $\mathbf{n}^{\circ} \mathbf{1 - 4}$ ). Trois fragments de fonds très épais trouvés dans un contexte à proximité appartiennent vraisemblablement à ces godets (fig. 14, $\mathbf{n}^{\circ}$ 5). La pâte de ces objets les rend tout à fait comparables aux godets de type 2 retrouvés au palais Monclar à Aix, eux-mêmes datés du XII ${ }^{\mathrm{e}} \mathrm{s}$. (Nin et al. 1996, vol. 3, p. 15). Par sa morphologie, l'exemplaire fig. 14, $n^{\circ} 2$ renvoie également aux découvertes aixoise (Nin et al. 1996, vol. 5, pl. LXXXVIII-LXXXIX). Les deux autres bords (fig. 14, ${ }^{\circ} 1,3$ ) ne trouvent pas de correspondance parmi leurs homologues ni à Aix ni ailleurs en Provence où les découvertes de ce type sont très rares : on connaît seulement quelques exemplaires plus récents (XIII ${ }^{\mathrm{e}} \mathrm{s}$.) dans les ateliers de Saint-Gilles-duGard (Leenhardt, Thiriot 1989, p. 98-100, fig. $18 \mathrm{n}^{\circ} 1-2$, 14-15) et dans les officines de Sainte-Barbe à Marseille (Vallauri, Leenhardt 1997, p. 305-306).

Dans un sondage récent autour du Centre Bourse, c'est toute une canalisation (fig. 15) servant à écouler les eaux de pluie de la toiture qui a été découverte au pied d'une maison (Scherrer 2011, p. 51). Elle était composée de plusieurs tubes emboîtés les uns dans les autres. Les tubulures mesurent environ $11 \mathrm{~cm}$ à l'ouverture côté collerette et $14 \mathrm{~cm}$ à l'opposé, pour une hauteur oscillant entre 33 et $34,5 \mathrm{~cm}$. Au premier examen, la conduite semble associer à la fois des éléments en pâte claire et d'autres en pâte grise mais les deux teintes se retrouvent aussi bien sur un même tuyau, adoptant même parfois des nuances brunes. Ces éléments montrent l'extrême prudence qu'il faut adopter dans la classification des éléments au sein d'une catégorie quand ne sont conservés que des fragments : cette canalisation, si elle n'avait pas été entière, aurait pu être classée aussi bien au sein des pâtes claires non-glaçurées, que des pâtes brunes ou des pâtes grises suivant les fragments retrouvés. Pourtant, ils sont tous façonnés dans la même argile. Si l'on excepte leur couleur, l'examen visuel des pâtes montre une grande similitude entre les tubulures, et également avec la pâte des pots et pégaus évoqués juste au-dessus, c'est pourquoi ils sont classés ici dans les communes grises.

Étant donné le caractère unique de cette découverte, il est impossible de savoir si ces variations de couleur d'un tube à l'autre sont dues à un accident en cours de cuisson ou si elles sont le témoignage d'une production locale antérieure au XIII ${ }^{\mathrm{e}} \mathrm{s}$. utilisant deux modes de cuisson (réducteur et oxydant). Vue la destination éminemment utilitaire de ces tuyaux, leur fonctionnalité doit l'emporter sur leur apparence, d'autant qu'une partie au moins est enterrée : un accident de cuisson n'entraînerait 

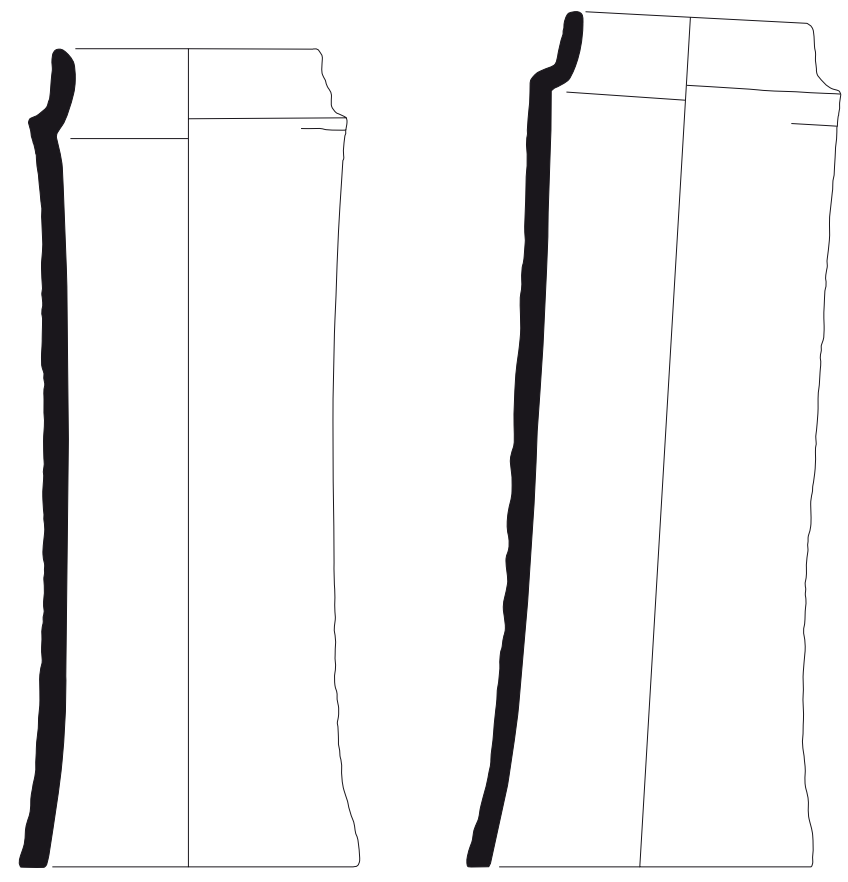

$0 \quad 5 \mathrm{~cm} \quad$ F. Gueriel, Fl. Parent/Inrap échelle $1 / 4$

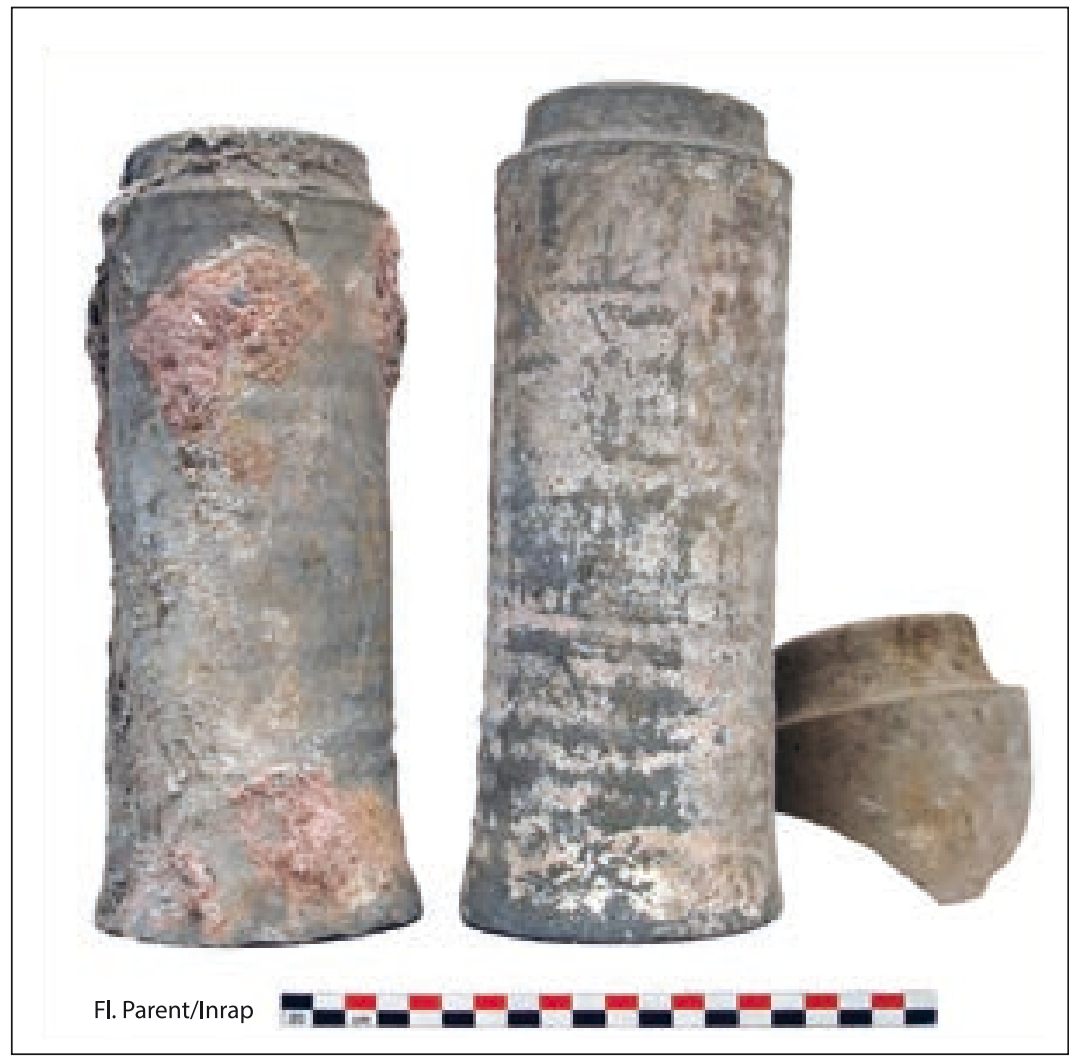

Fig. 15. Tuyaux de canalisation en céramique commune à pâte grise micacée du XII s. Zac de la Bourse. 


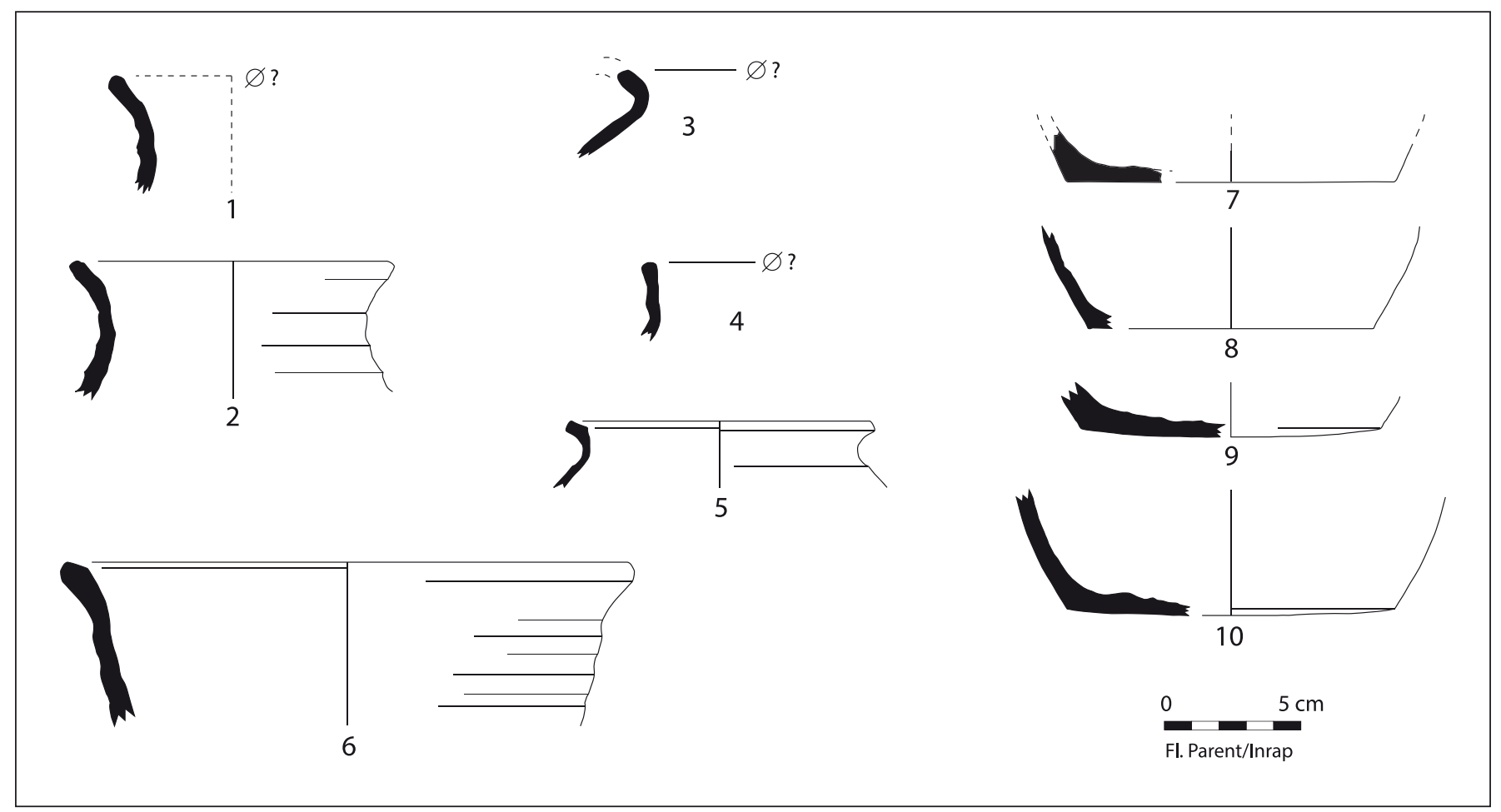

Fig. 16. Céramiques communes à pâte rouge et surface noire du XIIe s. 1-6, 8-10 : place Villeneuve-Bargemon ; 7 : Alcazar.

donc pas leur mise au rebut du moment que leur performance n'est pas remise en cause. D'un autre côté, il était admis jusqu'à peu que l'utilisation de la cuisson en mode oxydant disparaissait en Provence vers la fin de l'Antiquité et était réintroduite au tout début du XIII' $\mathrm{s}$. (Démians d'Archimbaud, Pelletier 1995). Cependant, les découvertes de ces dernières années montrent qu'elle persiste de manière marginale à travers ces siècles. La catégorie qui suit en est la démonstration.

\subsection{Les céramiques communes à pâte rouge et surfaces noires}

Ce groupe minoritaire ne se retrouve qu'en deux endroits de la ville : place Villeneuve-Bargemon et rue Trinquet. Il se distingue principalement par son mode de cuisson mixte car ses caractéristiques de pâte - inclusions et texture - sont quasiment identiques au groupe précédent.

Les vases sont d'abord cuits en atmosphère oxydante, conférant ainsi à la pâte une couleur rouge pouvant tirer sur le violet. La fin de la cuisson se déroulant en atmosphère réductrice, se forme une pellicule gris foncé ou noire en surface des pots, d'où leur intégration à la catégorie des céramiques communes à pâte grise puisque l'effet recherché est un vase d'aspect extérieur sombre. Les découvertes se généralisant, il est maintenant admis que la couleur de ces pots n'est pas due à un accident de cuisson mais bien à un mode de production particulier.

Les paillettes de mica sont très nombreuses et bien visibles en surface, au contraire des autres inclusions : nodules ferrugineux de différentes tailles et particules blanches souvent de forme allongée et de taille parfois importante. Sur plusieurs exemplaires, des inclusions semblent avoir fondu dans la pâte occasionnant des taches gris foncé à l'intérieur.

Ces caractéristiques de pâte semblent indiquer une même aire de production locale que la catégorie précédente même si le procédé de cuisson diffère, ce qui peut tout aussi bien désigner des ateliers multiples s'approvisionnant dans les mêmes gisements que des techniques mixtes s'exerçant au sein d'une même officine. Un atelier utilisant une technique de cuisson analogue est soupçonné dans la région d'Apt (Pelletier 1996, p. 26-29) dès le haut Moyen Âge, mais rien n'interdit de penser qu'une production similaire ait existé dans la région marseillaise comme semble l'indiquer l'examen visuel des pâtes. Cet examen ainsi que la technique de cuisson particulière permettent par ailleurs de les rapprocher des récipients confectionnés en pâte 7 aux environs de l'An Mil (cf. supra ch. $1 \S 2.1 .1$ )

Peu de formes peuvent être attachées à ce groupe mais, pour autant, elles se distinguent par un répertoire singulier. À l'extérieur, les stries de tournage très 
nettement visibles dans la partie supérieure confèrent aux vases un aspect quelque peu mouluré. Cinq éléments au moins appartiennent à des formes fermées. Les lèvres sont simples et déversées, la déformation des embouchures laisse deviner la présence d'un bec pincé et rend difficile la détermination du diamètre qui semble cependant osciller aux alentours de $10 \mathrm{~cm}$. Dans deux cas, la lèvre et la panse sont séparées par un léger col (fig. 16, $\mathbf{n}^{\circ} \mathbf{1}, 2$ ), ce qui tend à les assimiler plutôt à des cruches ou des pichets qu'à des pégaus, tandis que les derniers fragments appartiennent plus sûrement à des pégaus. À lèvre simple déversée (fig. 16, $\mathbf{n}^{\circ}$ 3), rectangulaire (fig. 16, $\mathbf{n}^{\circ} \mathbf{4}$ ) ou en poulie (fig. 16, $\mathbf{n}^{\circ} \mathbf{5}$ ), ils correspondent aux types a1 et a2 définis à Rougiers sur des pégaus en pâte grise (Démians d'Archimbaud 1981, p. 293 fig. 236237). Des pégaus identiques par leur type et par leur mode de cuisson ont été mis en évidence à Aix, dans les fouilles du Palais de l'Archevêché, dans des niveaux du XII' s. (Raffaelli 2002, p. 19-20), mais leur pâte semble différer de celle des exemplaires marseillais. Les fragments de cruches, quant à eux, ne trouvent pas de rapprochement dans l'état actuel des découvertes, de même que le bord de plus grand diamètre appartenant probablement à une jatte (fig. 16, $\mathbf{n}^{\circ} \mathbf{6}$ ). À ces formes viennent s'associer des fonds plats légèrement bombés dont le diamètre avoisine les $10 \mathrm{~cm}$ (fig. 16, $\mathbf{n}^{\circ}$ 7-10).

À Aix, ces productions sont attestées jusque dans le courant du $\mathrm{XIV}^{\mathrm{e}} \mathrm{s}$. ; à partir du XIII ${ }^{\mathrm{e}} \mathrm{s}$., la forme des pégaus évolue et ils sont accompagnés de marmites (Raffaelli 2002, p. 20-27); ces dernières sont par contre complètement inconnues dans le répertoire marseillais évoqué ici, ce qui tendrait à confirmer une datation antérieure à la fin du $\mathrm{XII}^{\mathrm{e}} \mathrm{s}$.

\subsection{Les productions de l'ouest du Rhône : céramiques à pâte rouge et surface polie}

Cette production est attestée de manière extrêmement restreinte sur tous les sites marseillais de cette époque : place Général-de-Gaulle (Richarté 2001, p. 140, fig. 178179), fouilles de l'Alcazar (Parent 2001, p. 400), place Villeneuve-Bargemon (Parent 1997, p. 6 ; Parent 2005, p. 855) et Tunnel de la Major (Richarté 2004, p. 179). En revanche, elle n'est mentionnée à l'heure actuelle sur aucun autre site provençal de même chronologie.

L'examen visuel des pâtes et des formes rapproche les exemplaires découverts à Marseille de produits recensés en Languedoc, plus précisément dans l'Hérault : sur plusieurs sites consommateurs dans la vallée de l'Hérault et sur le littoral, à Montpellier (Leenhardt 1995a ; Leenhardt 1995b ; Leenhardt 1999) et son arrière-pays où un atelier est attesté à Argelliers aux $\mathrm{XI}^{\mathrm{e}}$-XIII ${ }^{\mathrm{e}} \mathrm{s}$.
(Leenhardt et al. 1995 ; Breichner 2000 ; Breichner et al. 2002).

Ces vases présentent une pâte rouge orangé à tendance siliceuse avec de nombreuses inclusions blanches et quelques nodules ferrugineux. La surface externe des céramiques est polie (lissée) sur la presque totalité des formes et offre parfois à ces endroits un aspect grésé. Un tel traitement de surface, destiné à imperméabiliser les pièces, n'était connu jusqu'alors en Provence que sur des produits en pâte grise. Révélant les mêmes caractéristiques de pâte, un fragment se détache de cette catégorie par son traitement de surface particulier : un décor de lignes horizontales peintes en brun (fig. 17, $\left.\mathbf{n}^{\circ} \mathbf{6}\right)$.

Bien que l'existence de formes ouvertes et de couvercles soit avérée en Languedoc, les sites marseillais offrent exclusivement des vases de stockage des liquides, à paroi bombée et à bec tubulaire (fig. 17, $\mathbf{n}^{\circ} \mathbf{1 - 2}$ ) ou à bec pincé de type cruche (fig. $\mathbf{1 7}, \mathbf{n}^{\circ} \mathbf{4}$ ), dont les panses s'ornent parfois, outre le lissage ou les bandes peintes déjà évoqués, d'appliques de cordons digités (fig. 17, $\mathbf{n}^{\circ} \mathbf{3}$ ). Leur fonction est corroborée par l'important dépôt de calcite qui recouvre l'intérieur des vases.

Les bords à bec tubulaire retrouvés correspondent aux pots de type A1 définis dans les ateliers d'Argelliers (Breichner et al. 2002, fig. 17). Ces pots ont une lèvre résolument rentrante; sur l'exemplaire $n^{\circ} 2$, sa surface plane est surcreusée pour former une gorge, offrant ainsi la possibilité d'y adapter un couvercle. À l'extérieur, la liaison panse/bord est marquée par un bourrelet. La position du départ de l'anse largement décentrée, et non en vis-à-vis par rapport au bec, suggère que ces récipients possédaient au moins deux anses, ce qui devait faciliter le versement des liquides contenus.

Le fragment de cruche (fig. 17, $\mathbf{n}^{\circ} \mathbf{4}$ ), de type A4a ne possède quasiment pas de col. La lèvre en bourrelet est soulignée d'un ressaut sous lequel vient immédiatement s'attacher l'anse rubanée verticale.

Tous ces vases à liquide peuvent être portés par des fonds aussi bien légèrement bombés (fig. 17, $\mathbf{n}^{\circ} \mathbf{3}$ ) que plats. Les anses sont soit rubanées (ce qui semble le plus fréquent), soit rondes ou légèrement cannelées.

Les analyses de pâte effectuées sur quelques fragments ${ }^{6}$ confirment la filiation des exemplaires marseillais avec les découvertes de la région de Montpellier dont la diffusion semble débuter au milieu du XII ${ }^{\mathrm{e}} \mathrm{s}$. (Leenhardt 1995 ; Leenhardt et al. 1995 ; Breichner 2000 ; Breichner et al. 2002). Pourtant, à ce jour, aucun élément de ce qui fait l'originalité de ces ateliers, soit la fixation des anses par « tenons et mortaises », n'a été mis en évidence dans les découvertes marseillaises (Breichner 2002, p. 69),

6 Échantillons provenant des sites de la place VilleneuveBargemon et du Tunnel de la Major. 


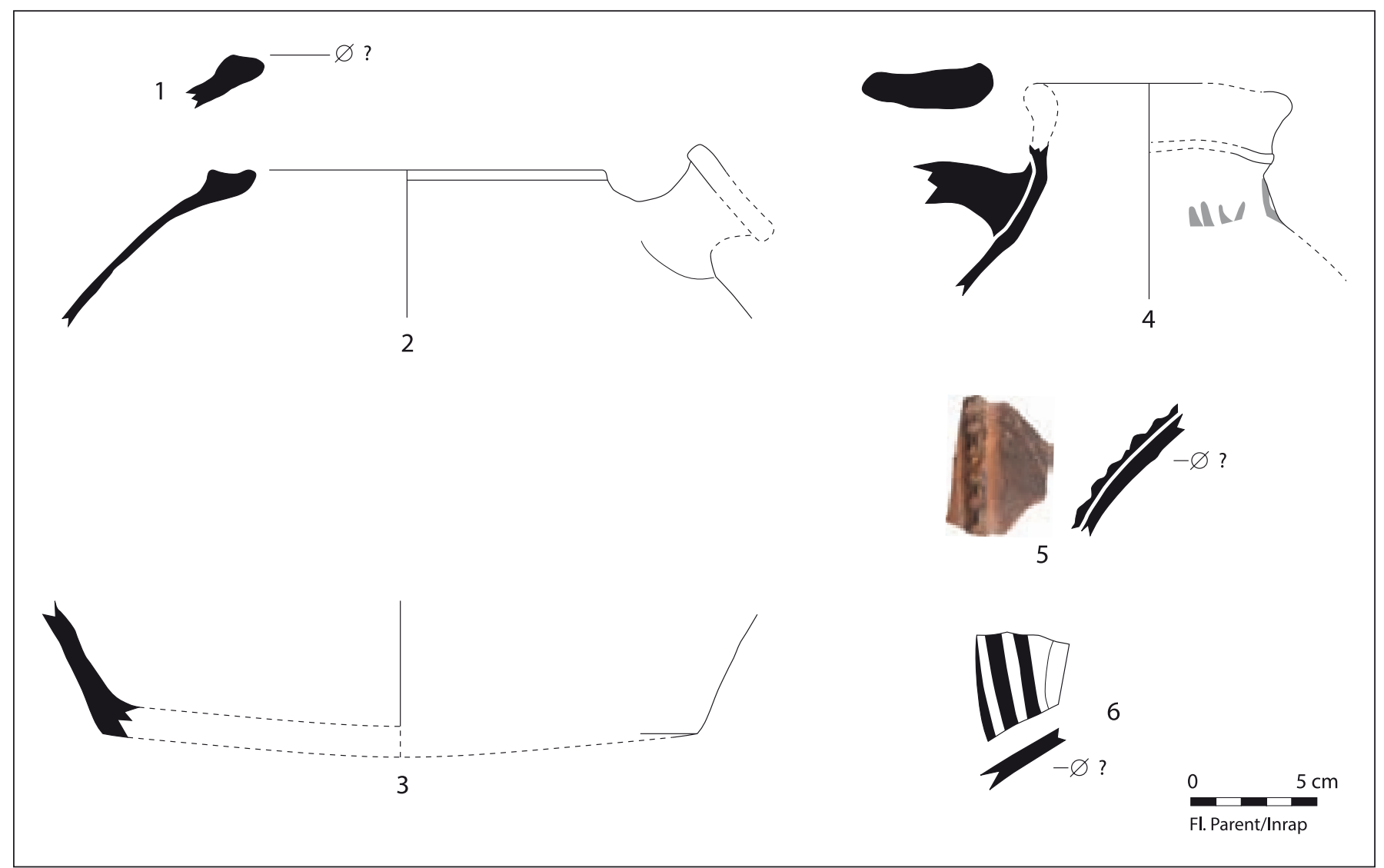

Fig. 17. Céramiques à pâte rouge et surface polie du XII $\mathrm{s}$. Place Villeneuve-Bargemon.

mais ceci peut n'être que conjoncturel et simplement lié à l'état de conservation des objets.

Il est par ailleurs intéressant de constater que la diffusion de ces produits héraultais se cantonne au port de Marseille et ne concerne aucun autre site de l'actuelle Provence.

\section{Les céramiques importées}

Au cours du XII ${ }^{\mathrm{e}}$ s., la quasi totalité des importations provient du monde islamique et du monde byzantin. Certaines sont clairement attribuables à l'une ou l'autre de ces cultures, surtout lorsque l'attribution a pu être confirmée ou indiquée par des analyses de pâtes, minéralogiques ou pétrographiques. Quand ce n'est pas le cas, l'attribution peut s'avérer plus délicate, sachant que parfois les productions de ces deux mondes peuvent être sensiblement similaires. C'est pourquoi le classement des céramiques réalisé dans ce chapitre privilégie des critères techniques : leur appartenance à un centre producteur particulier est difficile à établir, parfois en raison de l'absence de découvertes d'ateliers, d'autres fois devant la multiplicité des ateliers utilisant les mêmes techniques. Face à ces incertitudes, il n'est pas possible de quantifier la part de marché de chacune de ces civilisations, d'autant que les bouleversements politiques ne modifient pas du jour au lendemain les habitudes quotidiennes.

La grande diversité des « rubriques » qui suivent et leur longue énumération ne doivent pas tromper: au $\mathrm{XII}^{\mathrm{e}}$ s., les importations ne représentent guère que 10 à $20 \%$ du vaisselier marseillais.

\subsection{Les céramiques du monde islamique ou supposées telles}

Une bonne part des céramiques regroupées sous cette appellation générique est en provenance du monde islamique ou de régions sous son influence culturelle. Il est souvent impossible de faire la distinction entre les produits importés d'Afrique du Nord (Égypte, Tunisie, Algérie, Maroc), d'Espagne du Sud ou même de Sicile. $\mathrm{Au} \mathrm{XII{ } ^ { e }}$ s., les artisans arabo-musulmans continuent à exercer leur activité même dans les régions passées sous une autre domination comme la Sicile. Ils y produisent des formes et des décors quasi identiques partout (D’Angelo 2004, p. 130-131) et les analyses de pâte permettent rarement de distinguer les différentes origines 


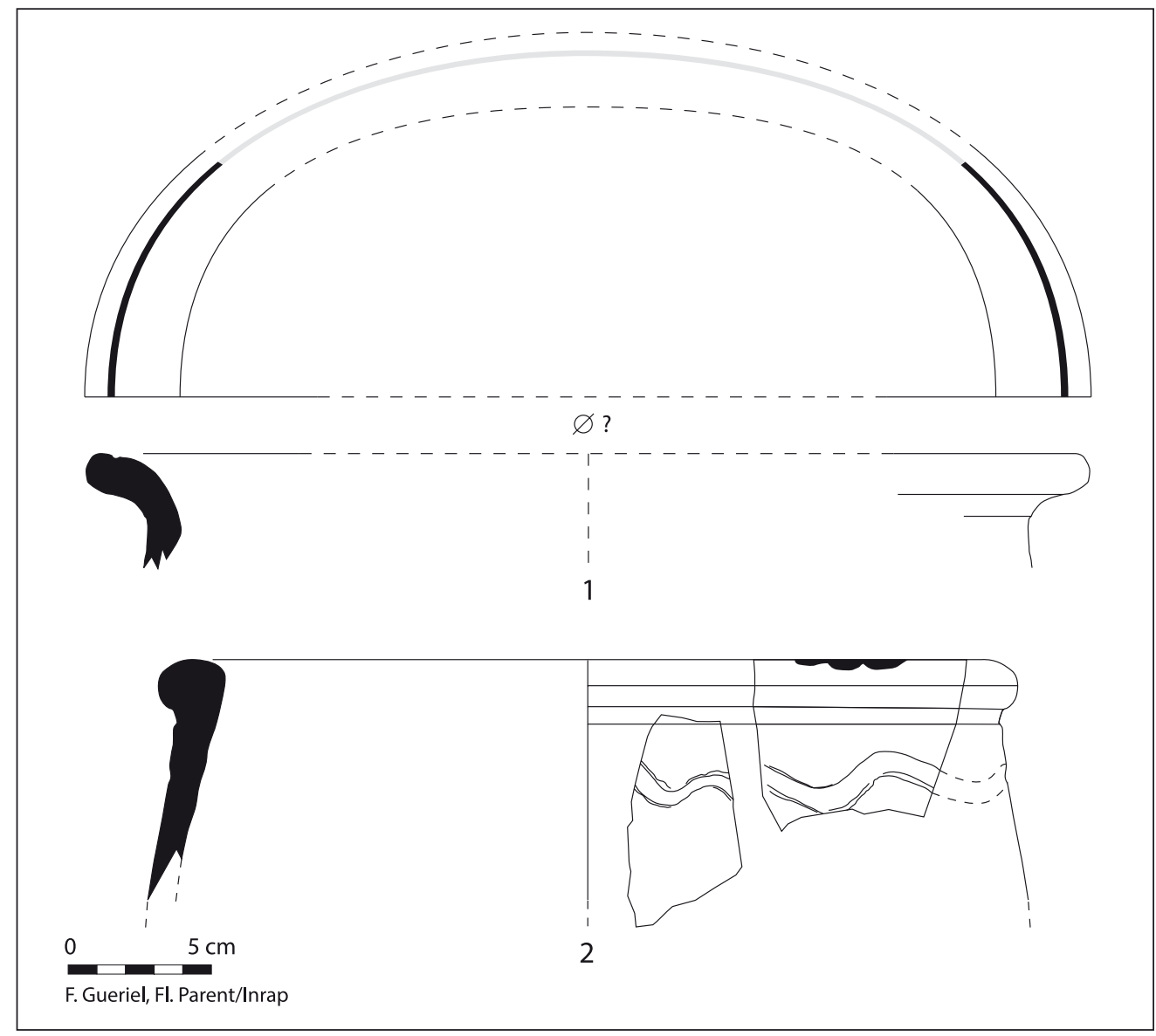

Fig. 18. Céramiques communes sans revêtement, importées d'Afrique du Nord au XII s. Place Villeneuve-Bargemon. des argiles. L'hypothèse a même été émise que les potiers arabes, installés en Sicile, ont vraisemblablement privilégié des argiles locales possédant les mêmes caractéristiques que celles de leur région d'origine, l'Afrique du Nord (Paterson 1995, p. 218). Ces artisans maîtrisent des techniques variées : pâte laissée nue, peinte ou incisée, glaçurée voire émaillée, parfois à décor polychrome, constituent l'éventail des productions prisées dans les cuisines et sur les tables marseillaises du XII" s.

\subsection{1. À pâte nue et surface blanchie}

La technique qui consiste à éclaircir les surfaces externes des vases à travers une succession de gestes, dont l'adjonction de sel dans la pâte, est attestée en Afrique du Nord dès l'Antiquité (Ardizzone et al. 2004) et perdure plusieurs siècles encore comme l'attestent les exemplaires importés en nombre dans tout le bassin méditerranéen, et donc à Marseille, jusqu'au VII ${ }^{\mathrm{e}} \mathrm{s}$. Au $\mathrm{XII}^{\mathrm{e}} \mathrm{s}$, , bien qu'encore en usage, ces produits semblent moins recherchés, en tout cas à Marseille, puisque seuls deux bords de bassin ont été repérés, sur le site de la place Villeneuve-Bargemon (fig. 18). Leurs caractéristiques les apparentent aux productions tunisiennes importées à Marseille à la fin de l'Antiquité. La pâte rose et bien cuite contient du quartz éolien tout aussi significatif que la surface blanchie par le sel. Cette pâte est analogue à celle des amphores africaines si répandues à Marseille durant l'Antiquité tardive.

La forme du premier bassin (fig. 18, $\mathbf{n}^{\circ} \mathbf{1}$ ) est dans la lignée de celle des grands bassins de la fin $\mathrm{III}^{\mathrm{e}}$ et du $\mathrm{IV}^{\mathrm{e}} \mathrm{s}$. (forme Uzita 3 var. B : Bonifay 2004, p. 260 et fig. 144) reprise avec variantes au siècle suivant (Bonifay 2004, p. 267 ; Fulford-Peacock jar 2 : Fulford, Peacock 1984, fig. 73). Ces bassins parfois ovales possèdent un bord à lèvre simple arrondie presque verticale, très convexe, fréquemment marquée sur sa partie supérieure d'une cannelure. Un renflement et une arête plus ou moins prononcée amorcent la jonction avec la panse. Toutes ces caractéristiques morphologiques se retrouvent sur l'exemplaire du XII ${ }^{\mathrm{e}}$ s. de la place Villeneuve-Bargemon. Ces vases utilitaires semblent donc être produits pendant plusieurs siècles sans grande variation.

\subsection{2 À pâte nue et décor peint ou incisé}

En provenance de l'Espagne du Sud, les jarres à décor de bandes brunes servaient au stockage de l'eau 


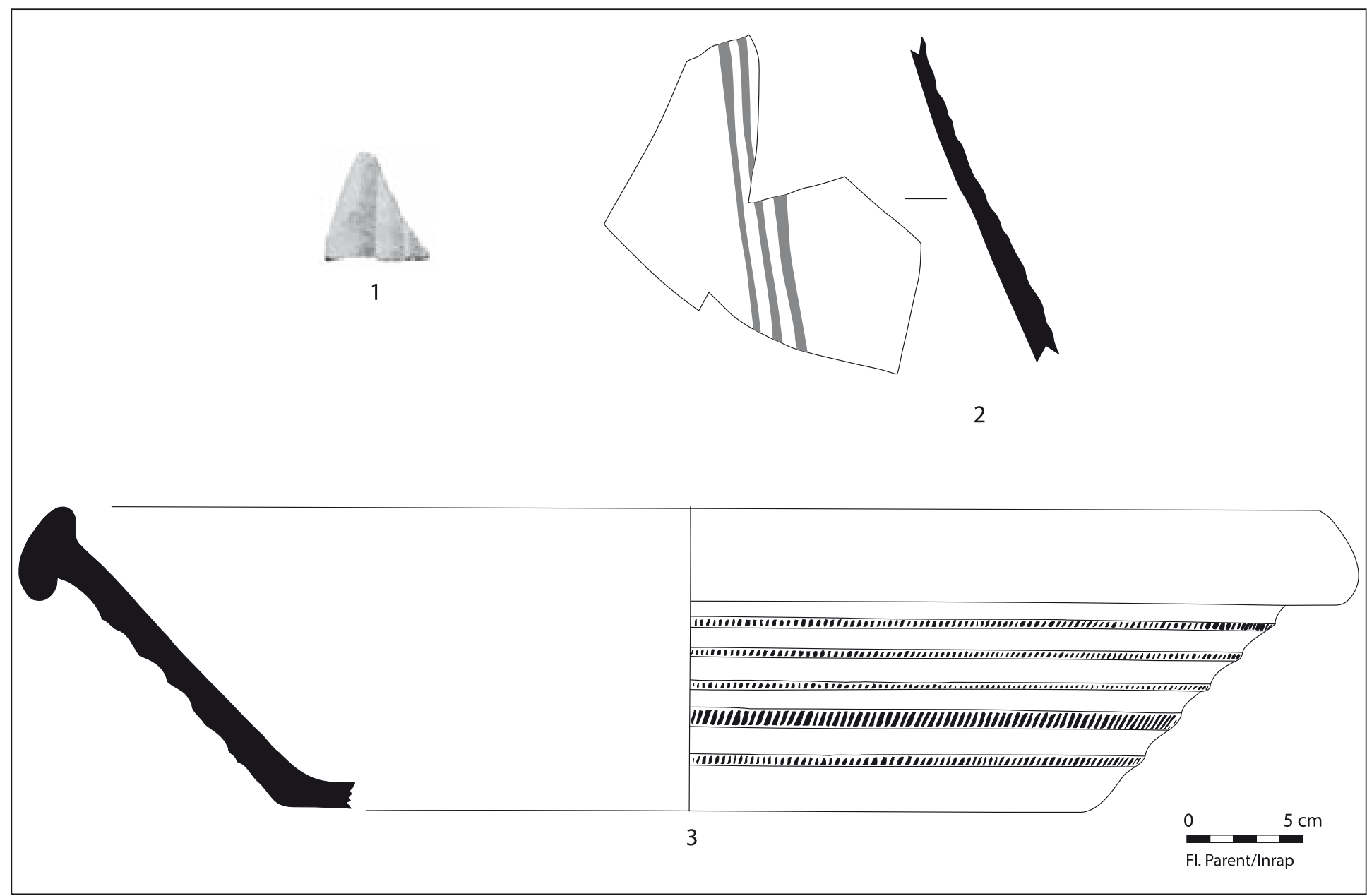

Fig. 19. Céramiques communes sans revêtement importées d'Espagne du Sud au XII ${ }^{\mathrm{s}}$. Place Villeneuve-Bargemon.

(Rossello Bordoy 1978). Leur présence est exceptionnelle mais assurée aussi bien en Italie (fouilles du Palazzo Ducale à Gênes) qu'à Marseille, sur les fouilles de la place Villeneuve-Bargemon (fig. 19, $\mathbf{n}^{\circ} \mathbf{1 - 2}$ ) et du quartier Sainte-Barbe, tout au long du XII ${ }^{\mathrm{e}} \mathrm{s}$. (Cabona et al. 1986, p. 460-461; Parent 1997, p. 7, fig. 12 ; Parent 2001, p. 401 ; Vallauri 1997a, p. 83). Ces jarres à fond plat, panse plutôt piriforme et col tronconique, sont de contenances diverses et décorées de bandes verticales tracées au manganèse à l'aide d'un pinceau. Elles sont produites en Espagne, notamment dans les ateliers valenciens au moins jusqu'au $\mathrm{XV}^{\mathrm{e}} \mathrm{s}$. (Amigues, Mesquida Garcia 1993). De même provenance, plusieurs fragments de bassins (ou tians) ont été découverts place Villeneuve-Bargemon (fig. 19, $\mathbf{n}^{\circ} \mathbf{3}$ ). Il s'agit de bassins à pâte beige grossière, à lèvre en massue et fond plat portant un décor de bandes rapportées et moletées à l'extérieur. Une datation et une origine identiques à celles des jarres peintes en brun ont été proposées pour des exemplaires découverts au Palazzo Ducale de Gênes (Cabona et al. 1986, tav. V-2). Les bassins guillochés

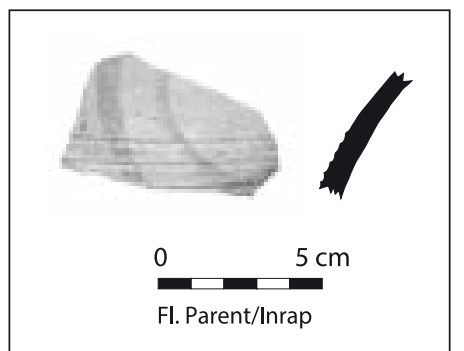

Fig. 20. Céramique commune sans revêtement, d'origine indéterminée, importée au XII ${ }^{\mathrm{e}} \mathrm{s}$. Place Villeneuve-Bargemon.

sont des produits fréquents en al-Andalus, notamment à Algésiras, jusqu'au XIV ${ }^{\mathrm{e}} \mathrm{s}$. au moins (Bernal Casasola et al. 2003, p. 57).

Enfin, plusieurs fragments de panse portent un décor peigné, ondulé ou rectiligne, et un dernier, de forme fermée, présente quant à lui un décor (fig. 20) de cercles concentriques, peint en rouge sur une pâte fine et bien cuite, de couleur beige, légèrement micacée. De tels décors, qu'ils soient peints ou peignés, sont connus en Espagne du Sud et au Portugal (Gomez Martinez 1997, p. 314, fig. 2.12) au XII ${ }^{\mathrm{e}} \mathrm{s}$. mais aussi dans la région byzantine (Oikonomou, Laniado 1997, fig. 2-3). Seules 
des comparaisons de pâte permettraient de trancher en faveur de l'une ou l'autre de ces provenances.

\subsubsection{Les céramiques à glaçure miel (melado) et décor brun (negro)}

Cette petite série, repérée dans le quartier de la Mairie et dans une moindre mesure rue Trinquet, se distingue par sa pâte rouge orangé très fine, contenant de fines particules blanches et grisâtres ainsi que de rares petits nodules ferrugineux. Les pièces très bien tournées sont recouvertes d'une glaçure aux tons miel de bonne qualité et appliquée de manière homogène sur l'une ou sur les deux faces suivant qu'il s'agit de formes fermées ou de formes ouvertes. Certains fragments portent des traces de décors informels (gouttes, traits) ou géométriques (arcs segmentés, motifs circulaires), tracés généralement en brun, plus rarement en vert.

Bien qu'aucune analyse n'ait été effectuée pour confirmer leur origine, l'ensemble du répertoire typologique évoque résolument le registre islamique, tels redomas/botelles et ataifores. La technique décorative semble elle aussi directement issue du monde islamique et les analogies sont nombreuses avec des découvertes en al-Andalus où plusieurs centres de productions sont attestés.

Malgré les nombreuses études et typologies dévolues aux céramiques islamiques en Espagne du Sud et au Portugal, aucune ne s'est attachée particulièrement à ces séries de "glaçurées bichromes », pourtant abondantes dans ces contrées entre le $\mathrm{X}^{\mathrm{e}}$ et le XIII ${ }^{\mathrm{e}} \mathrm{s}$. (Bazzana 1983, p. 63, fig. 15 ; Bazzana 1990 ; Gomez Martinez 2006 ; Jimenez Castillo et al. 1997 ; Rosselo Bordoy 1978 ; Gomez et al. à paraître, Salinas Pleguezuelo à paraître). Les plus fréquentes y sont les «melado y negro » mais parfois le noir est remplacé par du vert ou le fond miel par un fond blanc (Gomez Martinez 2006, p. 236).

Les éléments identifiés sur les sites marseillais sont très fragmentaires et fragmentés. Sont néanmoins reconnaissables 4 formes différentes, appartenant exclusivement au service de table :

- Les redomas, selon le vocable utilisé dans les typologies d'al-Andalus (Bazzana 1979, p. 157, fig. $6 \mathrm{n}^{\circ} 6-7$ ) correspondent à des formes fermées à panse globulaire ou piriforme (fig. 21, $\mathbf{n}^{\circ}$ 14-17), col cylindrique étroit et haut, souvent orné d'une moulure comme sur l'exemplaire ${ }^{\circ} 5$, et terminé par une lèvre simple ou arrondie (fig. 21, $\mathbf{n}^{\circ}$ 7, 13). Ces vases, qu'on dit servir de vinaigrier ou d'huilier (Bazzana 1979, p. 157), sont pourvus d'une anse en boudin (fig. 21, $\mathbf{n}^{\circ}$ 13-14).

- Les bords $\mathrm{n}^{\circ} 10$ à 12 pourraient appartenir à de petites jarres ou jarritas : vases à liquide à panse globulaire portant un large col vertical ou légèrement rentrant.
Ils sont généralement dotés d'une à deux anses et ne possèdent aucun bec pour faciliter le versement du liquide.

- Les ataifores ou coupes possèdent des parois hémisphériques, parfois légèrement redressées (fig. 21, $\mathbf{n}^{\circ} \mathbf{2}$ ), terminées ici par une lèvre triangulaire déversée vers l'extérieur (fig. 21, $\mathbf{n}^{\circ} \mathbf{1 - 2}$ ). L'ataifor, comme la redoma, est une forme typique de la table islamique médiévale. L'ataifor semble connaître une diffusion particulièrement massive au XII ${ }^{\mathrm{e}}$ s. (Fuertes Santos 2002, p. 71). Redomas, jarritas et ataifores sont portées par des pieds annulaires ombiliqués et parfois surcreusés sur leur face antérieure (fig. 21, $\mathbf{n}^{\circ}$ 3-4). Enfin, le luminaire (candiles) est ici composé de lampes sur pied (fig. 21, $\mathbf{n}^{\circ} \mathbf{6}, \mathbf{8}$ ) et probablement de lampes en coupelle (fig. $21, \mathbf{n}^{\circ} \mathbf{9}$ ).

Si les lampes (candiles) portent uniquement une glaçure miel sans autre forme de décor, une ornementation au manganèse d'une grande sobriété vient compléter le vernis de la majorité des pièces marseillaises. Sur trois des exemplaires de la série retrouvée dans la ville, s’y adjoint une troisième couleur : un engobe ou émail blanc à jaunâtre recouvrant uniformément la surface (fig. 21, $\mathbf{n}^{\circ}$ 2) ou des taches d'oxydes de couleur jaune (fig. 21, $\mathbf{n}^{\circ} \mathbf{1 1}$ ).

\subsubsection{Les céramiques à pâte claire émaillées en turquoise monochrome}

Cette catégorie représente une part très infime du matériel marseillais à cette période. Il s'agit d'une production à pâte calcaire presque blanche, assez granuleuse, revêtue d'un vernis opaque de couleur turquoise qui pourrait être de l'émail. Ces produits présentent une qualité de cuisson variable entraînant une plus ou moins grande granulosité de la pâte et de temps à autre la formation de bulles dans la couverte glaçurée. Il est parfois assez difficile de discerner cette production de celle à pâte siliceuse du Proche-Orient (type Raqqa), étant donné la granulosité occasionnelle de la pâte et la petitesse des fragments. Ces quelques produits ont été découverts uniquement en bordure du port, place Villeneuve-Bargemon. Il s'agit de lampes en coupelle avec bec pincé et une anse à l'opposé dont l'attache supérieure se situe à l'intérieur de la coupelle (fig. $22, \mathbf{n}^{\circ} \mathbf{2}$ ), de coupes et coupelles à fond plat dont une à marli (fig. 22, $\mathbf{n}^{\circ} \mathbf{1}, \mathbf{4}$ ), d'un bord de pot miniature à lèvre simple déversée (fig. $\left.\mathbf{2 2}, \mathbf{n}^{\circ} \mathbf{5}\right)$ et d'un morceau de panse de forme fermée avec départ d'anse en boudin, à la courbure de panse peu prononcée (fig. 22, $\left.\mathbf{n}^{\circ} \mathbf{6}\right)$. Signalons également la découverte de 2 éléments (d'environ $3 \mathrm{~cm}$ de hauteur), découpés ou moulés, composés de plusieurs branches et recouverts totalement de glaçure. Ces éléments de décoration n'ont pu être rattachés à une forme précise (fig. $\mathbf{2 2}, \mathbf{n}^{\circ} \mathbf{3}$ ). Des productions similaires sont connues à Samarcande au XII ${ }^{\mathrm{e}} \mathrm{s}$. (Shishkina, Pavchinskaya 1992, p. 70-71, 107, 114) ou 

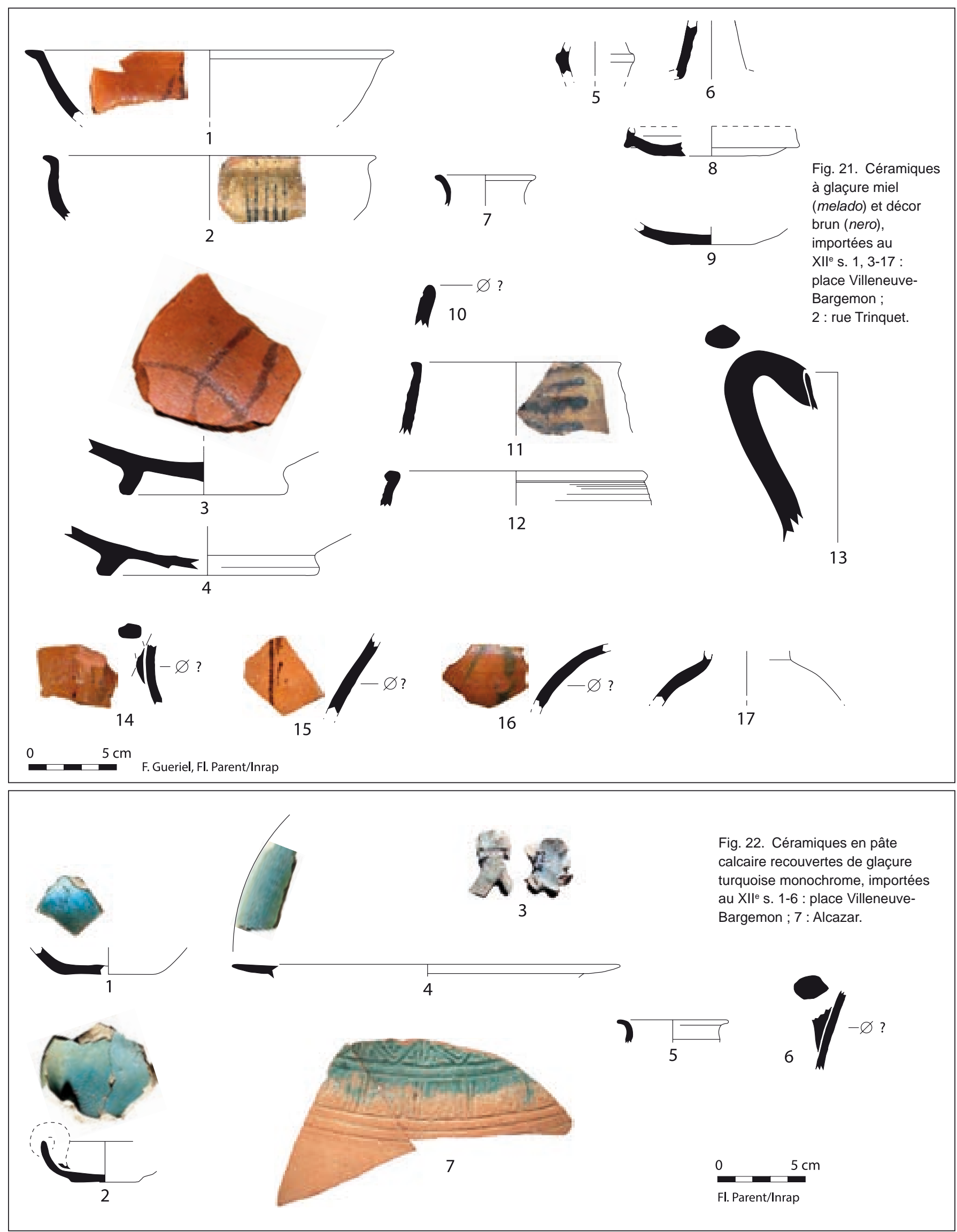


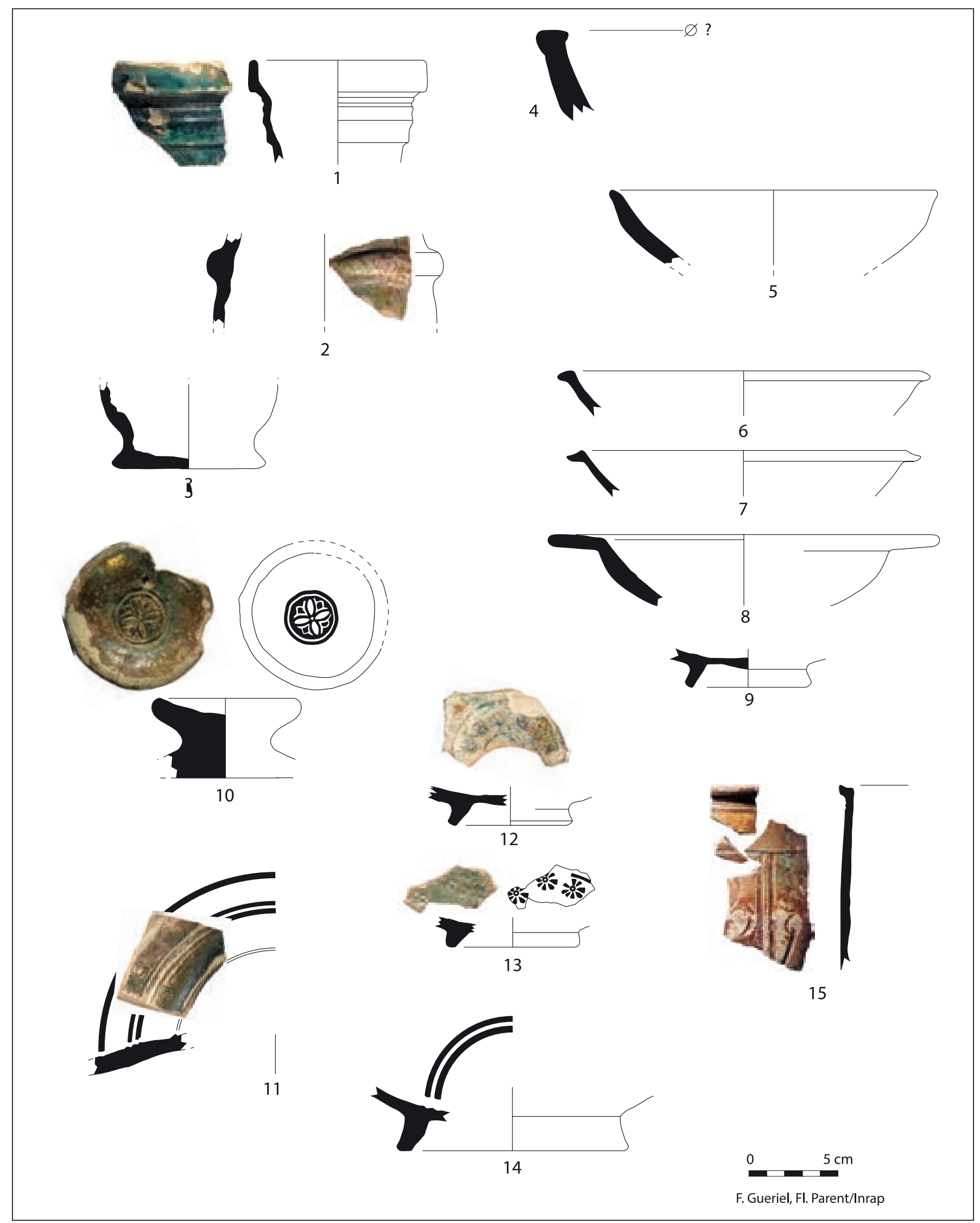

Fig. 23. Céramiques islamiques glaçurées ou émaillées en vert monochrome, importées au XIle s. Place Villeneuve-Bargemon. 
en Égypte dès la fin du X $\mathrm{X}^{\mathrm{e}}$ jusqu'au XVII ${ }^{\mathrm{e}} \mathrm{s}$. (Gayraud 1997, p. 268) et ont pu également exister dans le reste du monde islamique. À ces mêmes productions, on peut sans doute rattacher 3 fragments d'une même jarre à glaçure turquoise opaque (fig. 22, $\mathbf{n}^{\circ}$ 7), découverts sur le site de l'Alcazar dans un contexte du XII ${ }^{\mathrm{s}} \mathrm{s}$.

\subsubsection{Les céramiques islamiques glaçurées ou émaillées en vert monochrome}

Sous cette appellation sont regroupées des céramiques aux diverses caractéristiques de pâte, provenant donc d'officines multiples, mettant en œuvre des techniques similaires. Ces céramiques sont systématiquement en pâte claire, dont la couleur varie du beige au rosâtre, et couvertes d'une glaçure transparente ou opaque (émail) monochrome verte.

Un premier groupe possède des caractéristiques visuelles de pâte identiques à celles des céramiques à glaçure turquoise évoquées au-dessus. Il n'est pas exclu qu'il provienne des mêmes officines. Il s'agit d'un bord mouluré et d'un fond plat de cruche en pâte calcaire, portant tous les deux un émail vert foncé (fig. $\mathbf{2 3}, \mathbf{n}^{\circ} \mathbf{1}$, 3) et d'une panse en pâte calcaire émaillée vert clair et à décor de bande rapportée (fig. 23, $\mathbf{n}^{\circ} \mathbf{2}$ ). En effet, la couleur de l'émail n'est pas un critère discriminant puisque l'oxyde de cuivre, responsable de l'émail turquoise, peut facilement virer jusqu'au vert foncé suivant le degré de cuisson.

La série de fonds annulaires ornés d'un décor de rosettes estampé, organisé en registres concentriques (fig. 23, $\mathbf{n}^{\circ} \mathbf{1 2}$-14), appartient sans doute à celle des plats carénés fabriqués en Afrique du Nord et en Espagne du Sud au XII ${ }^{\mathrm{e}}$ s., tels l'exemplaire unique découvert en Sardaigne (Biccone 2006), ceux en Toscane - notamment sur les églises pisanes (Berti, Tongiorgi 1981, p. 219-220) -, ou encore en Ligurie comme à Gênes (Cabona et al. 1986, p. 464, tav. VII.54) ou dans la région de Tolède (Martinez Lillo, Matesanz Vera 1991, fig. $2 \mathrm{f}$ et $\mathrm{h}$ ). Ces fonds sont semblables à celui d'un plat archéologiquement complet découvert dans les fouilles de Saint-Victor à Marseille (Capelli et al. 2006, tav. 2-7). Les analyses archéométriques effectuées sur les exemplaires marseillais penchent en faveur d'une production d'Espagne méridionale (Capelli et al. 2006, p. 193).

Le fragment de jarre à paroi fine (fig. 23, $\mathbf{n}^{\circ} 11$ ) évoque par sa technique décorative les grandes jarres (tinaja) à décor épigraphique moulé si fréquentes dans la civilisation islamique médiévale, que ce soit en Afrique du Nord, en Espagne ou au Portugal. Si le décor ici ne laisse aucun doute quant à sa filiation, les parois du vase semblent bien fines par rapport aux jarres habituelles : il s'agit sans doute d'un exemplaire de moindre contenance. Sa pâte semble très proche de celle des fonds estampés précédents et une provenance d'Espagne du Sud est très probable.

Enfin, provenant toujours du quartier de l'Hôtel de Ville, un bord à parois minces qui pourrait appartenir à un col de jarrita haut et droit porte un décor d'arabesques en creux, dont il n'est guère possible de préciser s'il est moulé ou incisé. L'ensemble de la pièce, intérieur comme extérieur, est recouvert d'une glaçure verte transparente (fig. $23, \mathbf{n}^{\circ} \mathbf{1 5}$ ).

L'appartenance des fragments suivants à des centres de production sous influence islamique reste à préciser. Il s'agit pour l'essentiel de formes ouvertes (plats ou coupelles) à pâte claire rosée, assez rêche, contenant des inclusions en forme de bâtonnets noirs. Leur lèvre est étirée presque à l'horizontale jusqu'à former parfois un marli (fig. 23, $\mathbf{n}^{\circ} \mathbf{6 - 8}$ ) et leur pied est annulaire (fig. 23, $\mathbf{n}^{\circ} \mathbf{9}$ ). Signalons aussi la présence dans ce groupe d'un couvercle dont n'est conservé que le bouton de préhension, avec un départ de la calotte plate aux parois très épaisses. La surface externe est couverte d'une glaçure verte épaisse et le haut du bouton porte en médaillon un motif floral estampé (fig. 23, $\mathbf{n}^{\circ} \mathbf{1 0}$ ). Ses dimensions indiquent que ce couvercle servait à protéger le contenu d'une grande jarre, estampée elle aussi, tels les nombreux couvercles de jarres produits en al-Andalus, que ce soit au Portugal (Varella Gomes 2011, fig. 1.45, fig. 2 $\left.\mathrm{n}^{\circ} 19\right)$ comme dans le sud de l'Espagne (Torremocha Silva, Oliva-Cozar 2002, p. 187).

Enfin, un bord de bassin caréné évoque par sa morphologie les grandes séries de bacini islamiques ornant fréquemment aux $\mathrm{XII}^{\mathrm{e}}-\mathrm{XIII}{ }^{\mathrm{e}} \mathrm{s}$. les églises pisanes et, dans une moindre mesure, provençales (Berti, Tongiorgi 1981, p. 166 ; Vallauri 1995). Ce bassin rejoint par ses caractéristiques techniques une autre coupelle (fig. 23, $\mathbf{n}^{\circ}$ 4-5) : ils sont tous deux façonnés dans la même pâte claire rosée, dure et grossière et recouverts, sur leur face interne ainsi que sur l'extérieur de la lèvre, d'une glaçure opacifiée verte à tendance jaunâtre, le tout leur conférant un aspect plutôt « rustique ».

\subsubsection{Les céramiques islamiques émaillées et/ou glaçurées polychromes}

Un grand bassin (fig. 24, $\mathbf{n}^{\circ} \mathbf{1}$ ) découvert dans le quartier de l'Hôtel de Ville n'est pas sans rappeler certains bacini importés d'Ifriqiya (vraisemblablement de Tunisie) au XII ${ }^{\mathrm{e}}$ s. et insérés sur les façades des églises de Pise en Italie (Berti, Tongiorgi 1981, p. 167, fig. 109, tav. CXXI ; Berti, Gelichi 1995, p. 132, 152, n¹1, $153 \mathrm{n}^{\circ} 111$ ). L'intérieur de sa panse carénée est décoré $\mathrm{du}$ motif épigraphique stylisé «al-yumm» (le bonheur), peint en brun sous une glaçure turquoise opaque. 
Ce décor est organisé en registre horizontal délimité par 2 larges filets bruns. Un bassin en tous points semblables - portant le même motif épigraphique peint en brun sous glaçure turquoise - a été découvert à proximité immédiate, dans le comblement d'un puits de la place Jules-Verne (Amouric et al. 1999, p. 11, fig. 21). Ce motif épigraphique est également identifié sur plusieurs bassins découverts à Carthage (Tunisie) datables des $\mathrm{XI}^{\mathrm{e}}-\mathrm{XII}^{\mathrm{e}}$ s. (Daoulatli 1995, p. 75, 86-87 n 49-50 ; Berti Giorgio 2011).

Ce bassin était accompagné d'un vase à goulot étroit mouluré et deux anses, décoré en brun sous une glaçure opaque verte, provenant vraisemblablement de la même ambiance culturelle (fig. 24, $\mathbf{n}^{\circ} \mathbf{2}$ ).

\subsubsection{Les céramiques supposées siculo-maghrébines}

La présence plus ou moins dense d'inclusions jaunâtres ou blanchâtres dans une pâte rouge, dure et fine relie plusieurs fragments dans un même ensemble. La plupart des exemplaires portent sur leur face visible un vernis vert allant du vert clair au vert bouteille, opacifié ou non. Mais des glaçures bicolores (jaunes et vertes) existent aussi, ainsi que dans de rares cas de l'émail blanc. Cet émail ou cette glaçure peut recouvrir aussi l'autre face pour les formes ouvertes ou être remplacé par une glaçure transparente, en excluant le pied. Les formes fermées sont recouvertes à l'intérieur du même vernis qu'à l'extérieur, uniquement sur le rebord, le reste de la surface interne pouvant soit porter une glaçure transparente soit rester nue. Les formes sont fines, leur façonnage et leur couverte de qualité.

L'essentiel du répertoire des formes ouvertes consiste en coupes et coupelles hémisphériques portées par un pied annulaire et dont la lèvre peut être étirée jusqu'à former un marli (fig. 25, $\mathbf{n}^{\circ} \mathbf{1}$-7). Un cas unique de lèvre simple redressée est recensé place Villeneuve-Bargemon (fig. 25, $\mathbf{n}^{\circ}$ 13) ainsi qu'un couvercle reconnaissable au listel permettant de le maintenir sur son réceptacle et qui, lui, est entièrement recouvert d'émail turquoise (fig. 25, $\mathbf{n}^{\circ} 12$ ).

Les pots sont globulaires à col court et cannelé sous une lèvre effilée (fig. 25, $\mathbf{n}^{\circ} \mathbf{8 - 1 1}$ ). Ils ne semblent pas comporter d'anse, au contraire des petites jarres à col haut et mouluré (fig. 26, n'1-6). Ces dernières, souvent bicolores, possèdent une panse piriforme, un col droit ou évasé et 2 anses, comme l'atteste le seul exemplaire complet découvert à Marseille dans un puits de la place Jules-Verne (Amouric et al. 1999, fig. 30). Ces anses sont attachées en général sur les moulures soulignant la jonction col/panse et retombent au-dessus du diamètre maximal de la panse. Ces éléments de préhension sont de morphologie variée: de section ovale parfois aplatie (fig. 26, $\mathbf{n}^{\circ} \mathbf{1 2 - 1 4}$ ), bifide avec ergot et/ou poucier (fig. 26, $\mathbf{n}^{\circ} \mathbf{6}, \mathbf{1 5}$ ). Peuvent vraisemblablement être associés à ces jarres des bords à col haut et lèvre simple, parfois soulignés de cannelures (fig. 26, $\mathbf{n}^{\circ} \mathbf{7 - 8}$ ); à moins qu'ils n'appartiennent à des cruches telle celle découverte complète à Gémenos (Démians d'Archimbaud, Vallauri 1998, fig. 25). Jarres, cruches, et sans doute pots globulaires, reposent sur des pieds annulaires (fig. 26, $\mathbf{n}^{\circ}$ 9-11).

Ces produits sont attestés de manière récurrente dans les contextes provençaux des $\mathrm{XII}^{\mathrm{e}}$ et $\mathrm{XIII}^{\mathrm{e}} \mathrm{s}$. (Amouric et al. 1999, p. 14-15, fig. 28, 30-31), mais également en Italie à Gênes (Cabona et al. 1986, p. 454-482, fig. 42-53 tav. VII) et en Espagne à Barcelone (Beltran, à paraître). Il n'est pas rare de les découvrir dans certains chargements accompagnés de jarres islamiques estampées, comme sur l'épave de l'îlot aux Moines en Corse (Amouric et al. 1999), ou encore à Rougiers et à Marseille (Démians d'Archimbaud 1980; Vallauri 1997a). Les analyses effectuées sur des échantillons génois comme marseillais confirment l'hypothèse d'une production sicilienne ou maghrébine (Capelli et al. 2006, p. 194 ; Capelli et al. 2010).

\subsubsection{Les céramique à décor de cuerda seca partielle}

Alors que la cuerda seca totale, souvent comparée à la technique de l'émail cloisonné, privilégie l'emploi de trois couleurs - vert, brun et jaune - posées sur émail blanc, la cuerda seca partielle n'emploie que deux couleurs - le vert et le brun - posé sur la pâte qui reste nue en grande partie. Ces deux techniques issues de l'Andalousie (al-Andalus) y cohabitent de la fin du $\mathrm{X}^{\mathrm{e}}$ jusqu' au début XII ${ }^{\mathrm{e}}$ s. (Rossello Bordoy 1995, p. 108) et la cuerda seca partielle demeure en vigueur durant tout le $\mathrm{XII}^{\mathrm{e}} \mathrm{s}$. (Déléry 20003 ; Déléry 2004). La fabrication de céramiques à décor de cuerda seca partielle est attestée à Almeria, Malaga et dans la région valencienne (Démians d'Archimbaud et al. 1986, p. 45). Les découvertes de ce genre sont très rares en Provence (Vallauri 1995; Démians d'Archimbaud, Vallauri 1998). Le fragment de panse retrouvé place Villeneuve-Bargemon appartient à une petite jarre (jarrita) (fig. 27). Ces formes portées par un pied annulaire possèdent un corps globulaire surmonté d'un col cylindrique et deux anses qui s'attachent au niveau du bord et s'ornent d'un décor organisé en registres horizontaux (Jimenez Catillo, et al. 1997). Il s'agit le plus souvent de décor à motifs géométriques ; ici, le registre inférieur consiste en une ligne de glaçure verte cernée de brun, le registre immédiatement supérieur représente une série de triangles alternés où l'épaisse glaçure verte est emprisonnée à l'intérieur de traits bruns. 

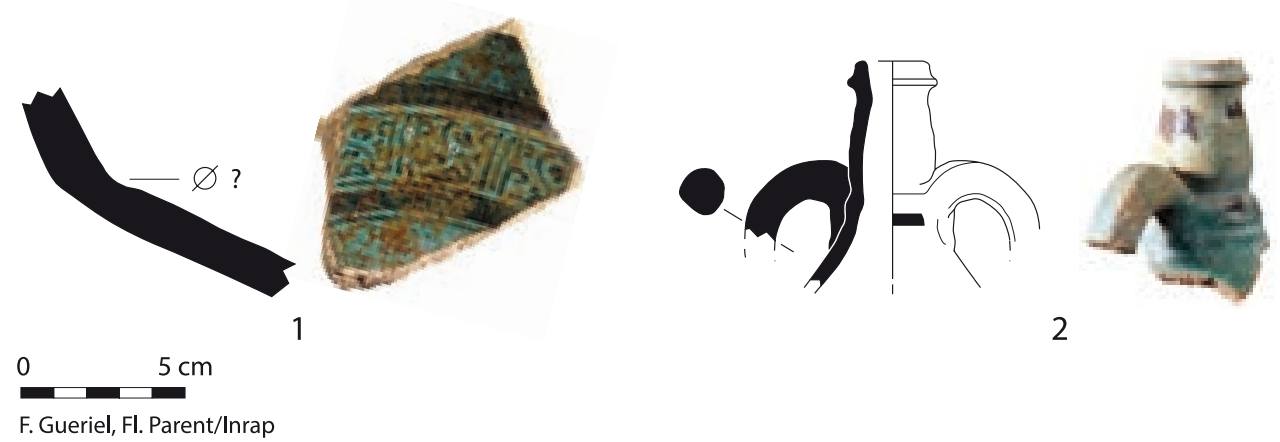

F. Gueriel, Fl. Parent/Inrap

Fig. 24. Céramiques islamiques émaillées et/ou glaçurées polychromes, importées au XII s. Place Villeneuve-Bargemon.

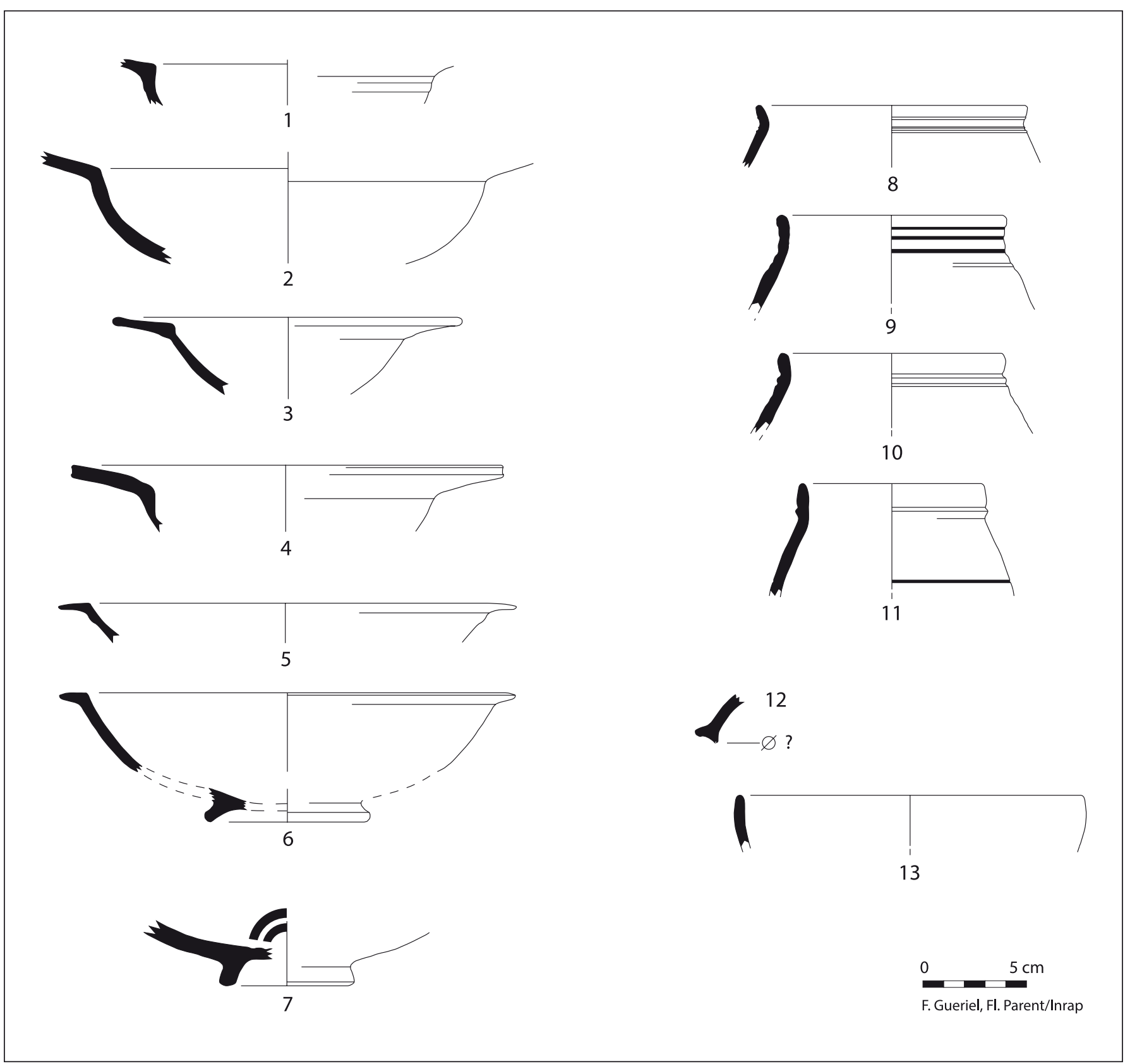

Fig. 25. Céramiques supposées d'origine siculo-maghrébine, importées au XII s. Place Villeneuve-Bargemon. 


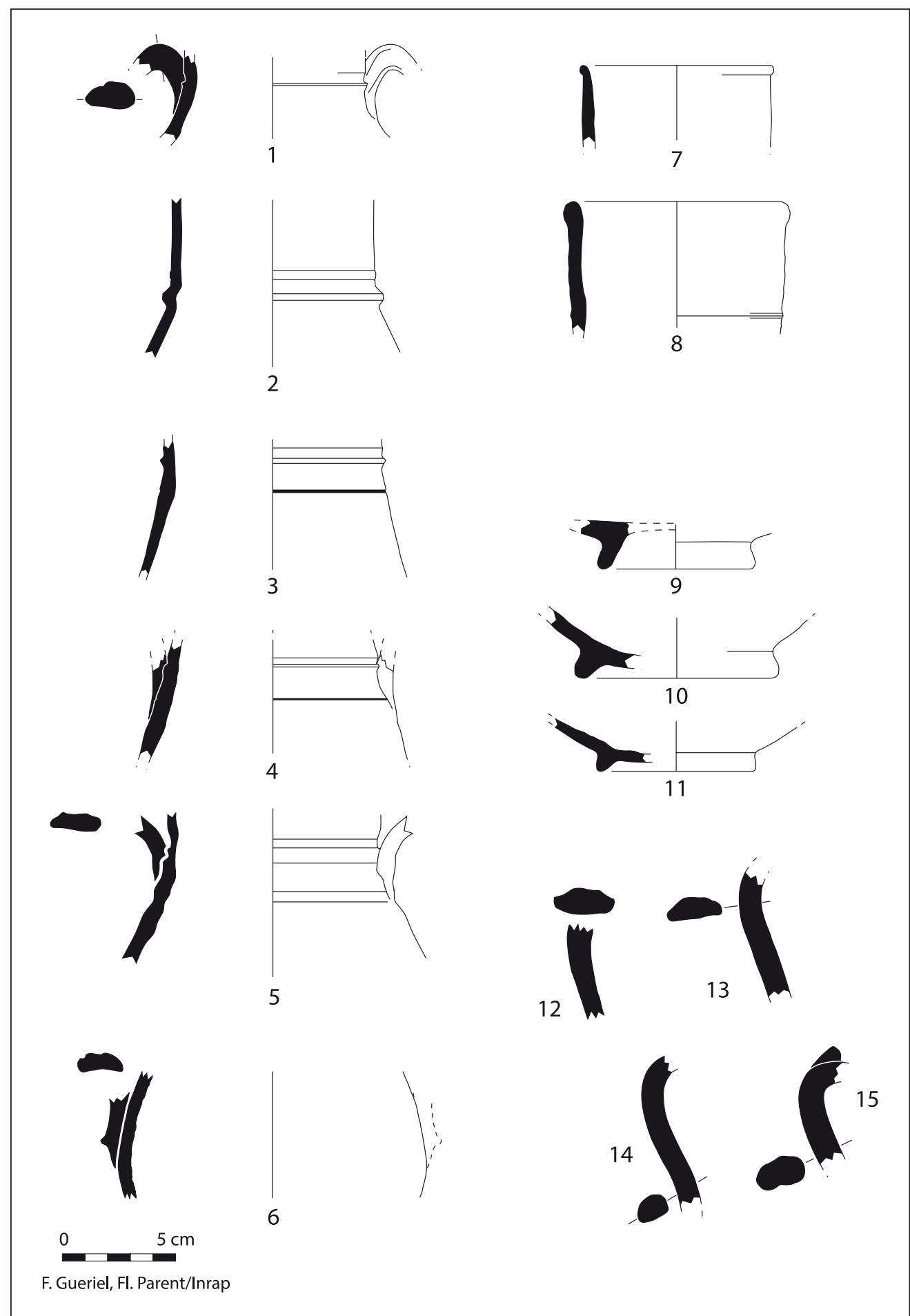

Fig. 26. Céramiques supposées d'origine siculo-maghrébine, importées au XII $\mathrm{s}$.

Place Villeneuve-Bargemon.

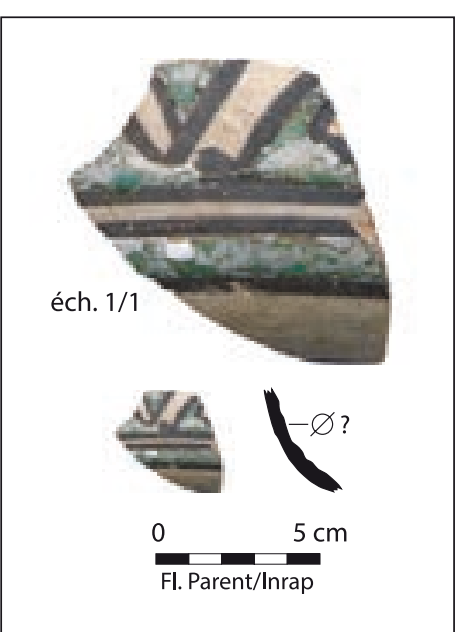




\subsubsection{Les céramiques à pâte siliceuse et décor polychrome}

Un pied annulaire de forme ouverte en pâte blanche siliceuse, très haut et fin, formant piédouche, est à signaler pour sa qualité exceptionnelle (fig. 28). L'intérieur porte un décor polychrome d'une extrême finesse accompagné d'une glaçure alcaline transparente: les motifs sont cernés de filets noirs très fins, les motifs floraux remplis de rouge (boutons de fleurs ?) sont séparés par un aplat jaune ou vert. Le revers porte la même glaçure transparente sauf le pied qui semble nu.

De tels objets ont rarement été découverts dans notre région: six fragments à décor polychrome ont été recensés (Thiriot 1991, p. 296, fig. 4 ; Thiriot 1995, p. 26), un seul d'entre eux portant une ornementation utilisant le rouge : un fragment d'albarello découvert à Avignon (Thiriot 1991, p. 296, fig. 4.4 ; Thiriot 1995, p. $\left.26,39 \mathrm{n}^{\circ} 10\right)$. La provenance exacte de cette céramique luxueuse est difficile à déterminer, d'autant que de multiples auteurs se sont penchés sur la question sans jamais la résoudre. L'emploi d'une argile siliceuse avec glaçure alcaline et décor est généralement attribué au Proche et au Moyen-Orient (Thiriot 1991, p. 296-297: origine «mamelouk syro-égyptienne ») et les affinités de décor avec les productions iraniennes et syriennes souvent évoquées. L'usage du rouge dans les motifs, floraux notamment, ainsi que la délicatesse des dessins sont signalés dans les poteries dites « de mina $\bar{a} i$ », une production iranienne des XII - XIII ${ }^{\mathrm{e}}$ s. (Allan 1971, p. 30 ; Grube 1976, p. 195) ainsi que dans des productions supposées syriennes ou égyptiennes du XIII ${ }^{\mathrm{e}} \mathrm{s}$. et souvent désignées sous le terme générique de Rusafa (Grube 1976, p. 268 ; Soustiel 1985, p. 118-121 et fig. 255). Toutes ces productions seraient les précurseurs des célèbres productions ottomanes. Seule la découverte d'un ou plusieurs ateliers permettrait de trancher les diverses opinions.

\subsection{La Méditerranée orientale ou supposées telles}

Une poignée de produits témoigne des échanges de la cité phocéenne avec Byzance et le monde grec. Ce commerce avec le Levant chrétien fut probablement relayé pour l'essentiel par les cités italiennes.

\subsubsection{Les céramiques à pâte claire, engobées et glaçurées, en provenance de Méditerranée orientale}

Un premier groupe, apparemment homogène, peut facilement être rapproché de découvertes effectuées au Palazzo Ducale à Gênes (Cabona et al. 1986, p. 471472) et plus récemment à Naples (Carsana 2002, p. 501).
Les pièces présentent une pâte de couleur beige clair ou beige foncé, contenant une grande quantité de mica doré ainsi que des inclusions ferrugineuses ou blanches et des particules anguleuses translucides pouvant atteindre $2 \mathrm{~mm}$ environ (visibles en surface des pièces). Elles sont recouvertes à l'intérieur d'un engobe blanc et d'une glaçure qui est transparente pour la plupart, parfois colorée en jaune monochrome (fig. 29, $\mathbf{n}^{\circ} \mathbf{1}$ ) ou vert monochrome (fig. 29, $\mathbf{n}^{\circ}$ 3). Engobe et glaçure débordent largement sur l'extérieur de la lèvre.

Il s'agit essentiellement de formes ouvertes : coupelles hémisphériques à lèvre simple (fig. $\left.29, \mathbf{n}^{\circ} \mathbf{1 - 2}\right)$ ou à marli (fig. 29, $\mathbf{n}^{\circ} \mathbf{3}, \mathbf{5 - 6}$ ), auxquelles ne sont associables que des fonds annulaires (fig. $\mathbf{2 9}, \mathbf{n}^{\circ} \mathbf{4}, \mathbf{7}, \mathbf{8}, \mathbf{1 0}$ ). La plupart des fragments portent encore la trace d'un décor tracé en vert sous la glaçure transparente, décor informel mêlant traits, points et taches (fig. 29, $\mathbf{n}^{\circ} \mathbf{4}-\mathbf{7}, \mathbf{9}-10$ ).

Les formes fermées semblent beaucoup plus rares : un fragment retrouvé rue Trinquet porte une glaçure vert bouteille recouvrant l'engobe blanc et, dans le quartier de l'Hôtel de Ville, deux fragments d'un même vase à liquide à panse cannelée et au fond plat sont enduits partiellement sur la surface externe d'un engobe blanc et recouverts entièrement d'une glaçure transparente (fig. 29, $\mathrm{n}^{\circ}$ 11-12).

Les analyses effectuées sur certains exemplaires de Gênes situent cette production dans l'Attique. Les vases marseillais comme génois peuvent aussi être confrontés à un groupe de bacini de Pise datable de la première moitié $\mathrm{du} \mathrm{XII}^{\mathrm{e}}$ s., que les analyses chimiques renvoient à une possible production de la Grèce nord-orientale, de l'Anatolie ou d'une quelconque île égéenne (Carsana 2002, p. 502503). À Gênes, ils sont issus de contextes de la seconde moitié du XII et du début du XIII' ${ }^{\mathrm{e}}$ s. (Cabona et al. 1986, p. 472), à Naples de contextes du début du XII jusqu'au début du XIII ${ }^{\mathrm{e}}$ s. (Carsana 2002, p. 503), datations confirmées par d'autres découvertes du sud de l'Italie et de Sicile (Di Gangi, Lebole 1997 ; Molinari 1997).

\subsubsection{Les céramiques à pâte rouge, engobées et glaçurées, en provenance de Méditerranée orientale}

Un deuxième ensemble (fig. 30, $\mathbf{n}^{\circ} \mathbf{1}, \mathbf{3 - 5}$ ) offre une pâte rouge brique, dure, fine et vacuolaire, contenant quelques inclusions jaunâtres. L'extérieur montre des stries de tournage bien marquées. Les pièces, toutes des formes ouvertes, portent un engobe épais sur leur face interne tandis qu'une glaçure de couleur vive recouvre l'intégralité des vases. Les formes, bien qu'épaisses, sont tournées et retouchées avec soin. Il s'agit d'un plat à marli très développé, de couleur jaune paille et de plusieurs fonds annulaires dont l'un, à glaçure verte, est orné d'un décor brun (fig. $30, \mathbf{n}^{\circ} \mathbf{3}$ ). 
Toujours dans la série des décors peints, un fond annulaire surcreusé présente au revers un engobe rouge de type barbotine tandis qu'un décor brun linéaire semble tracé au recto, sous la glaçure jaune qui recouvre l'engobe blanc (fig. 30, $\mathbf{n}^{\circ} \mathbf{6}$ ).

Enfin, un dernier bord possède une pâte rose à grise, très dure, surtout en comparaison des précédentes, et toujours quelques paillettes de mica $\left(\mathbf{f i g} .30, \mathbf{n}^{\circ} 2\right)$. La forme de la pièce est élaborée et élancée, avec une petite lèvre étirée surmontant la panse hémisphérique. Au revers, les stries de tournage et de tournassage sont bien visibles. Le décor est lui aussi plus élaboré. Bien que toujours informel, il allie le jaune et le vert, tous les points et aplats verts étant cernés d'un mince filet jaune. Le revers ne porte toujours pas de glaçure ni aucun revêtement à part l'engobe débordant sur la lèvre.

\subsubsection{Le sgraffito byzantin}

La technique de décoration incisée est caractéristique de la production byzantine médiévale la plus célèbre et la plus couramment illustrée. Elle consiste à inciser les décors dans l'engobe, le plus souvent de couleur claire, préalablement déposé sur le vase. Ces incisions plus ou moins larges ou profondes laissent apparaître la couleur de la pâte et produisent ainsi un décor en réserve. Celui-ci peut, ou non, être rehaussé de couleur et le vase est ensuite recouvert uniformément de glaçure transparente ou colorée. De nombreux ateliers byzantins ont pratiqué cette technique au Moyen Âge, mais peu sont connus de nos jours. Les quelques exemplaires retrouvés à Marseille témoignent de cette diversité.

Le fragment fig. 31, $\mathbf{n}^{\circ} \mathbf{1}$, recouvert de glaçure verte, pourrait appartenir aux productions de la mer Égée, connues par une cargaison coulée au large de Rhodes à la fin $\mathrm{du} \mathrm{XII}{ }^{\mathrm{e}} \mathrm{s}$. (épave de Castellorizo), notamment celles dont les décors de lignes incurvées évoquent des tentacules de poulpe (Papanikola-Bakirtzi 1999, p. 143151. Vallauri et al. 2003 , p. 144 , fig. $7.6-7$, fig. 8 ; Amouric et al. 1999, p. 21, fig. 49-50). À défaut de présenter une lèvre redressée comme ses consœurs de l'épave, la coupe marseillaise présente de fortes affinités avec celles-ci par ses caractéristiques de décor et de pâte (argile rouge contenant des nodules rouges et blancs).

Le plat à marli fig. $\mathbf{3 1}, \mathbf{n}^{\circ} \mathbf{3}$ offre un décor foisonnant malgré la taille réduite du fragment conservé : le treillis d'incisions ornant l'intérieur est rehaussé de glaçure jaune et coulures vertes, tandis que l'extérieur non décoré est recouvert d'une glaçure plombifère épaisse laissant apparaître la couleur rouge de la pâte.

Le groupe des Zeuxippus Ware et de leurs imitations (fig. 31, $\mathbf{n}^{\circ} \mathbf{2}, 4$ ) fait partie des productions de céramiques médiévales byzantines les plus reconnues mais encore mal identifiées. Il s'agit toujours de fines coupes à la pâte brun rouge, engobées et revêtues d'une glaçure plombifère de belle qualité, au décor alliant fines incisions et champlevé. Ce type de céramiques est maintenant assez bien connu dans notre région : il est distribué dès le milieu du $\mathrm{XII}^{\mathrm{e}} \mathrm{s}$. et perdure au siècle suivant (Vallauri et al. 2003). Sa diffusion est assez large en Méditerranée, du Levant au sud de la France en passant par l'Italie, la Mer Noire et l'Égypte. Les analyses pétrochimiques suggèrent des centres de productions multiples (François 1997 ; Waksman, François 2004-2005 ; Waksman et al. 2008). À Marseille et sur le littoral provençal, une dizaine de fragments ont été reconnus qui apparaissent systématiquement dans les niveaux du début du XIII" s. (Vallauri et al. 2003, p. 147) mais les exemplaires de la seconde moitié du XII ${ }^{\mathrm{e}}$ sont beaucoup plus rares; deux seulement ont été recensés à Marseille. Un bord de coupelle, simple et relevé, à pâte rouge fine, dure et bien cuite, provient des environs de l'Hôtel de Ville. L'intérieur de cette pièce d'environ vingt centimètres de diamètre porte un décor en champlevé associé à des incisions plus fines rehaussées de brun, sur un engobe blanc jaunâtre et sous une glaçure transparente, ce décor figure une patte d'animal (fig. 31, $\mathbf{n}^{\circ} \mathbf{4}$ ). Une coupe de plus grande dimension présente une pâte très cuite, presque grésée. Elle est décorée d'incisions fines dans l'engobe blanc, rehaussées de brun, le tout recouvert d'une glaçure épaisse transparente orangé (fig. 31, $\mathbf{n}^{\circ}$ 2). Il est probable que la pièce s'ornait d'un motif central aujourd'hui disparu, à l'image de certaines productions supposées chypriotes (Stern, Waksman 2003, p. 172).

\subsubsection{Les céramiques à pâte rouge glaçurées attribuables à la Méditerranée orientale}

Les productions de céramiques utilitaires des régions byzantines sont encore mal connues. Les nombreuses études portant sur les productions de ces contrées traitent principalement des productions à ornementation plus ou moins élaborée et les céramiques considérées comme communes ont largement été laissées pour compte. Longtemps ignoré, ce groupe a été mis en lumière par de récentes fouilles et travaux. Deux articles de synthèse (Vallauri et al. 2003 ; Capelli et al. 2006), faisant suite à une série d'analyses, dressent l'inventaire des découvertes dans notre région et l'état actuel de nos connaissances en ce domaine, complétés par une étude typologique et chronologique du matériel médiéval découvert au Liban, dans la ville de Beyrouth (HomsyGottwalles 2009).

Tous les éléments présentés ici proviennent du quartier de l'Hôtel de Ville. 


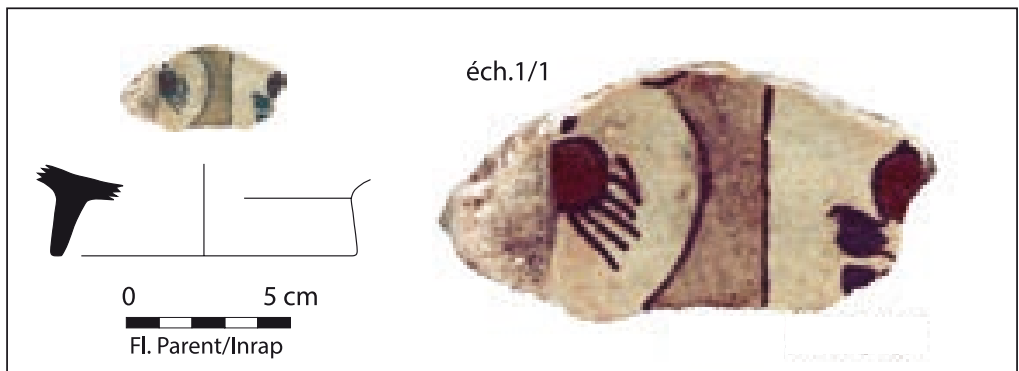

Fig. 28. Céramiques à pâte siliceuse et décor polychrome, importées au XII' $\mathrm{S}$.

Place Villeneuve-Bargemon.

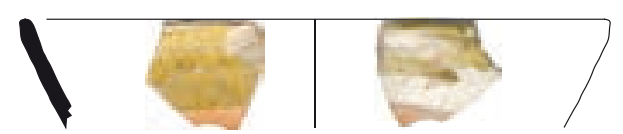

1

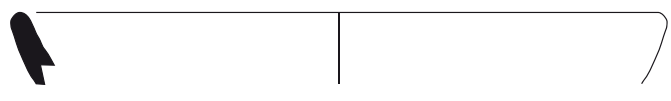

2
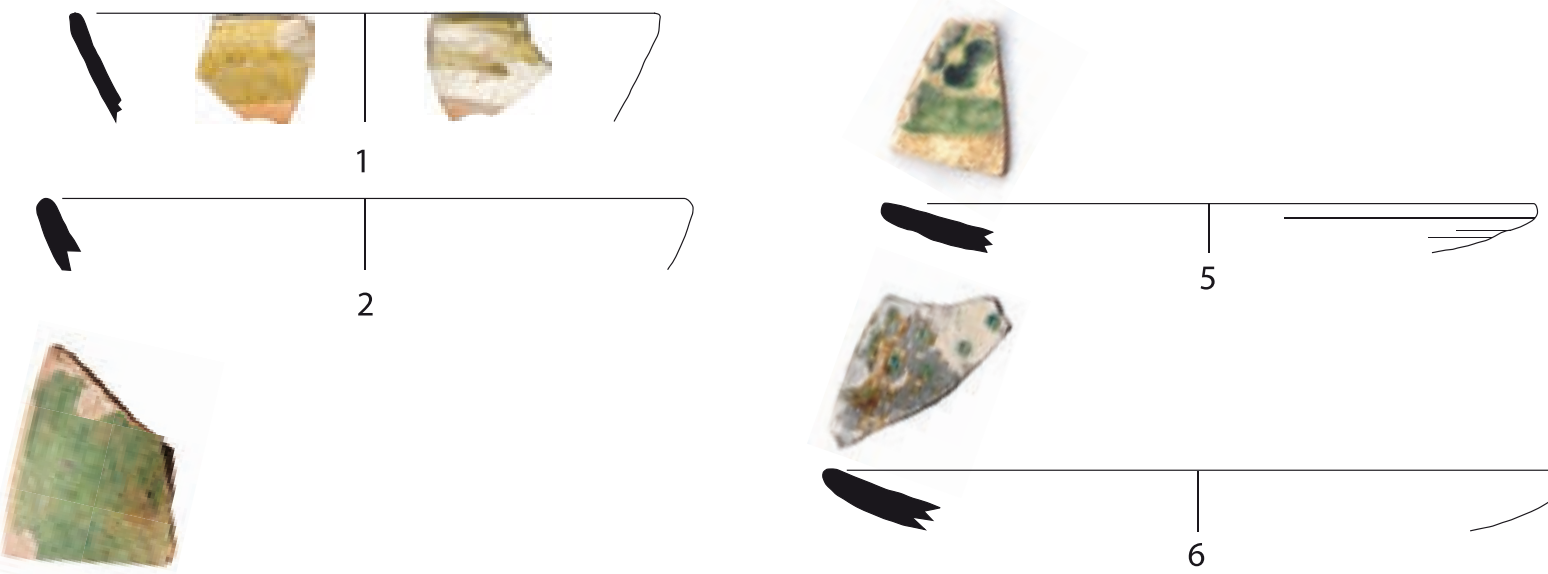

5

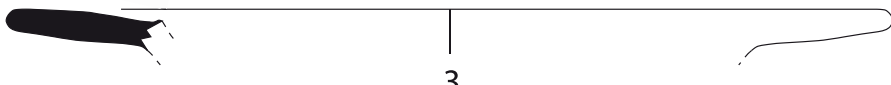

3
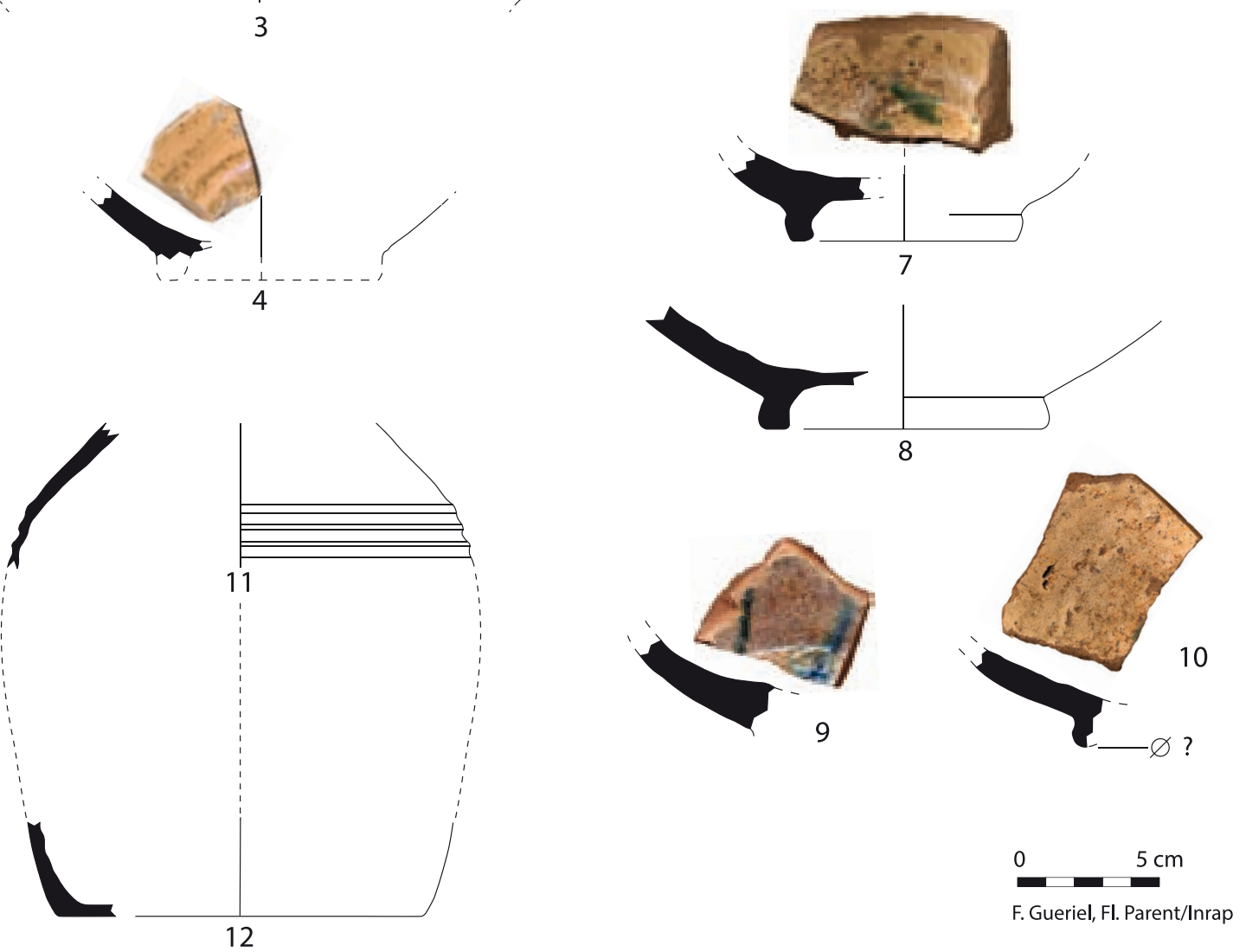

Fig. 29. Céramiques à pâte claire micacée, engobées et glaçurées en provenance de Méditerranée orientale au XII s. 1 : rue Trinquet ; 2-12 : place Villeneuve-Bargemon. 


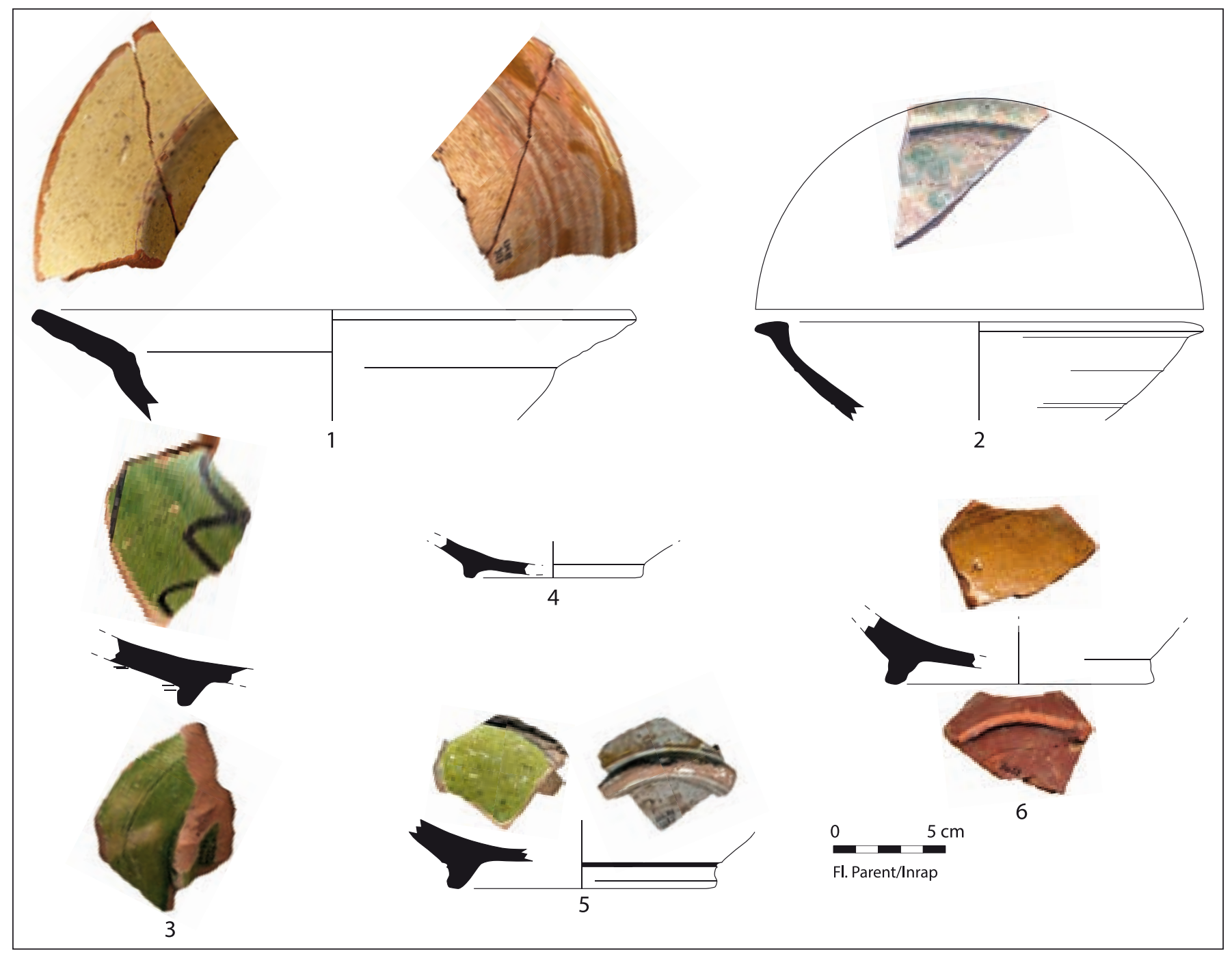

Fig. 30. Céramiques à pâte rouge, engobées et glaçurées en provenance de Méditerranée orientale importées au XII s. Place Villeneuve-Bargemon.

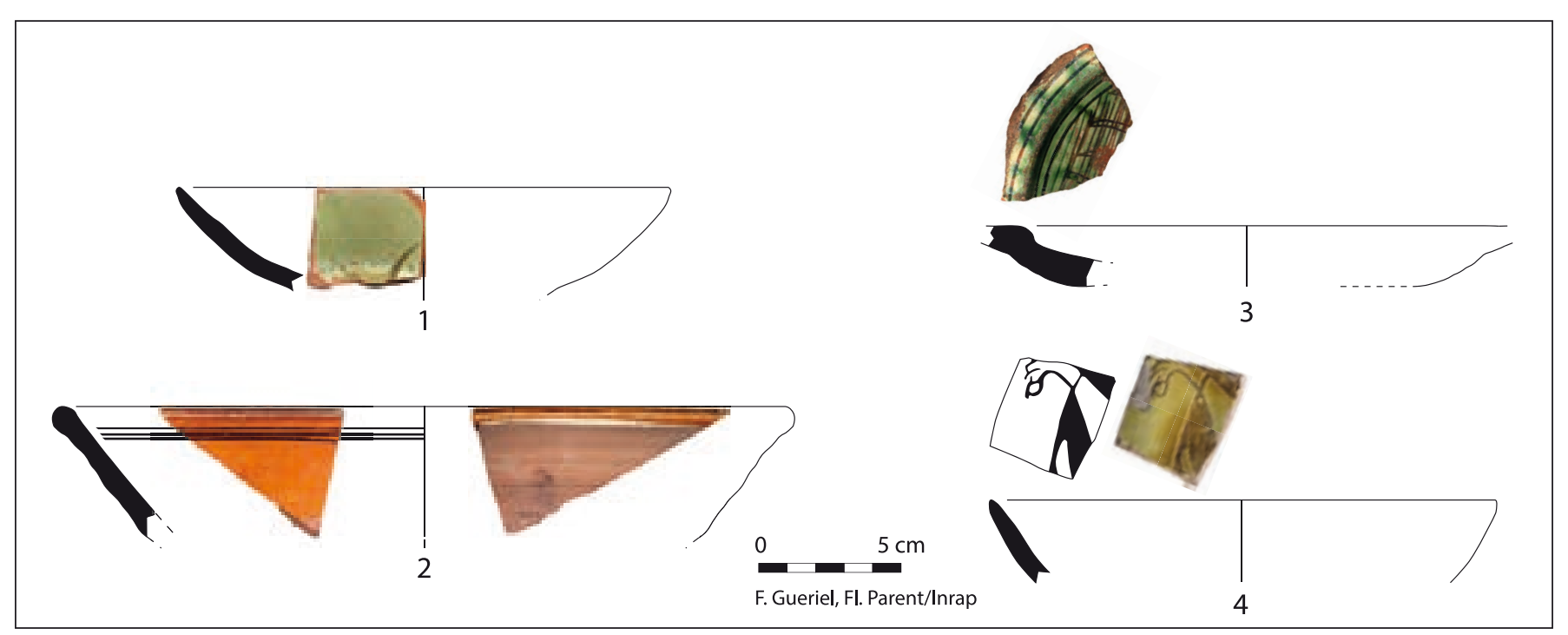

Fig. 31. Sgraffito byzantin importé au XII ${ }^{\mathrm{s}}$. Place Villeneuve-Bargemon. 


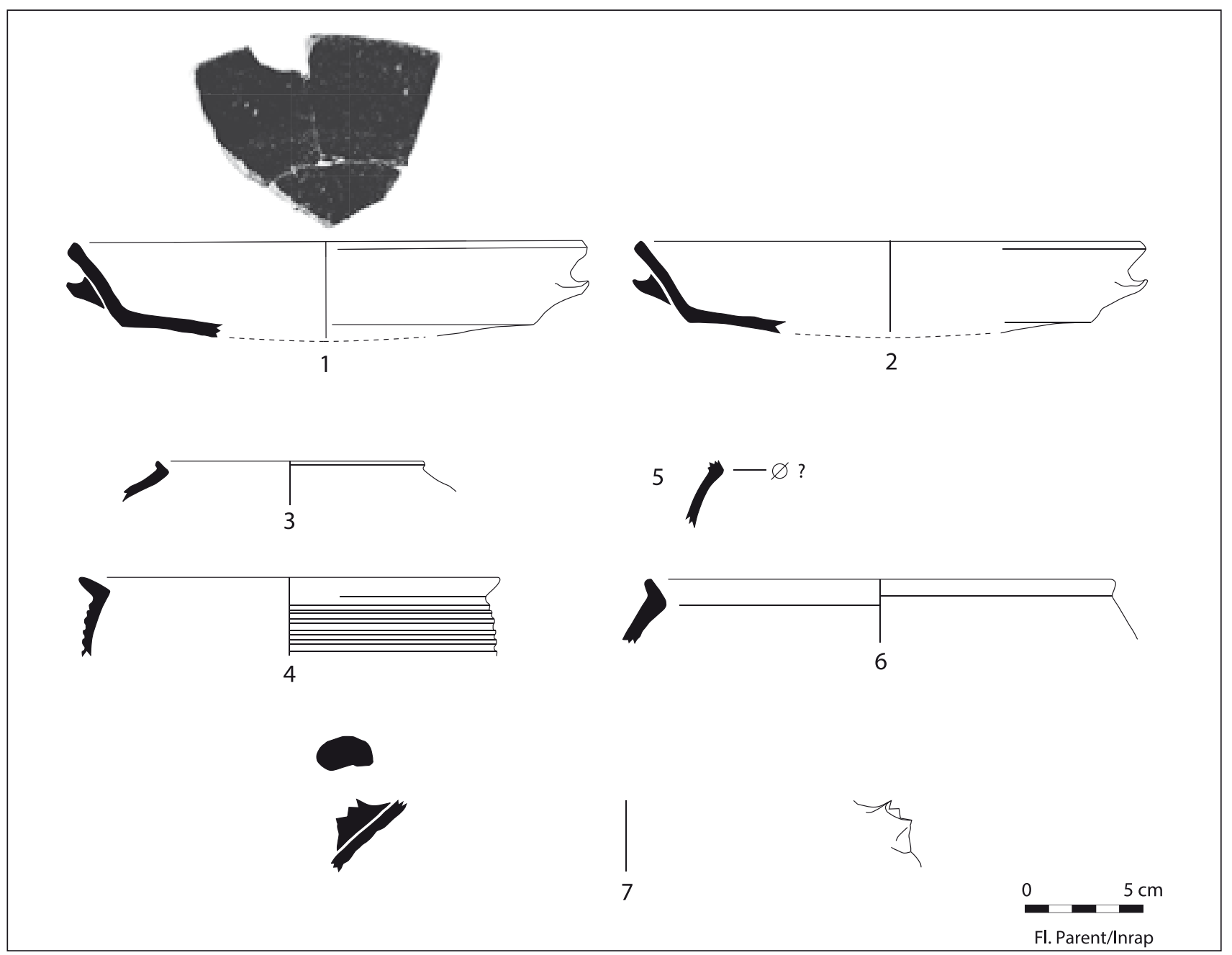

Fig. 32. Céramiques à pâte rouge et glaçure plombifère transparente, importées de Beyrouth au XIIe s. (ou supposées telles). Place Villeneuve-Bargemon.

D'usage proprement culinaire, des fragments de poêles et de pots/marmites présentent une pâte fine et dure, rouge, et des parois fines. La surface interne de ces formes porte une glaçure transparente marron foncé tandis que la surface externe est laissée nue. Ces formes sont de petite taille. Les poêles sont à lèvre simple, à paroi légèrement déversée, fond bombé, et sont munies de tenons fins et plats en forme d'ailette (fig. 32, $\mathbf{n}^{\circ} \mathbf{1 - 2}$ ). Les pots globulaires (fig. 32, $\mathbf{n}^{\circ} \mathbf{3 - 4}$ ), sans col, ont des lèvres étirées perpendiculairement à la panse qui peut être cannelée à l'extérieur. Ces pots devaient également posséder des préhensions à ailettes. Les résultats des analyses géochimiques et archéométriques s'entendent pour les attribuer à la région de Beyrouth (Capelli et al. 2006, p. 190 ; François et al. 2003, p. 333). Tous ces récipients culinaires rappellent, par leur forme et leur pâte, et à l'exception de la glaçure, les productions de l'Antiquité tardive issues des mêmes contrées. Plusieurs autres fragments de pots globulaires à lèvre étirée (fig. 32, $\mathbf{n}^{\circ}$ 5-6) ainsi qu'une marmite à deux anses (fig. 32, $\mathbf{n}^{\circ}$ 7) sont assimilables aux mêmes productions, par leur typologie et par leur caractéristique de pâte, bien qu'aucune analyse n'ait été effectuée sur ceux-ci.

Auparavant intégrée au même groupe levantin sur une base typologique, une petite série de pots ou marmites globulaires (fig. 33, $\mathbf{n}^{\circ} \mathbf{1 - 3}$ ) en a définitivement été écartée par les analyses archéométriques. Ces ustensiles de cuisson, destinés à recevoir un couvercle comme l'indique le listel de leur lèvre, proviendraient plutôt de la zone égéenne ou d'Anatolie occidentale (Capelli et al. 2006, p. 190-191).

D'autres exemplaires sont à rapprocher de séries découvertes en Italie au Palazzo Ducale de Gênes (Cabona et al. 1986) dans des contextes également datés du XII ${ }^{\mathrm{e}} \mathrm{s}$. et du début du XIII' s. Pour l'essentiel, il s'agit de coupelles hémisphériques à lèvre fine et déversée (fig. 34, $\mathbf{n}^{\circ} \mathbf{1}$ ), desquelles peut être rapproché un fond annulaire haut et fin formant piédouche (fig. 34, $\mathbf{n}^{\circ} \mathbf{2}$ ). L'intérieur 


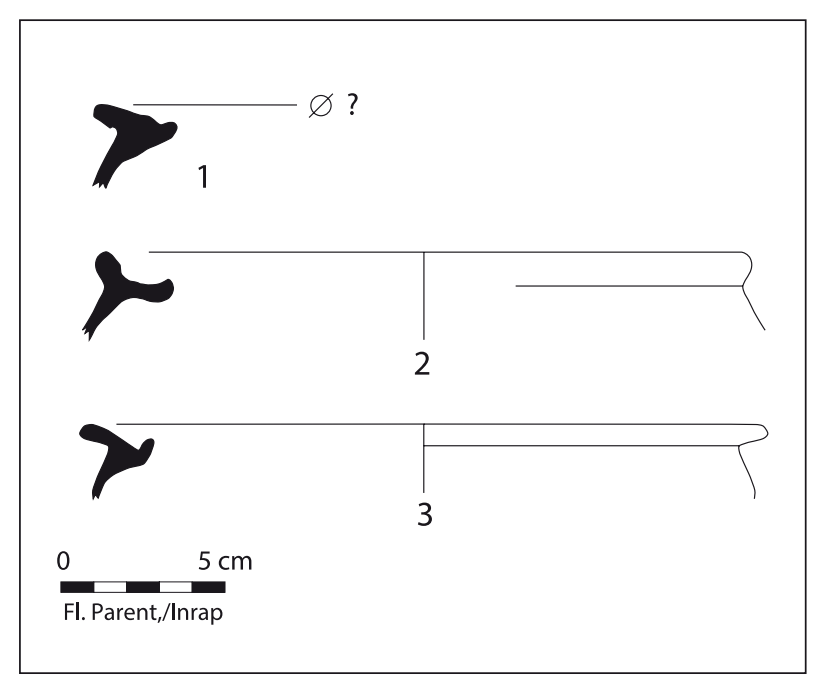

Fig. 33. Céramiques à pâte rouge et glaçure plombifère transparente, en provenance des régions égéo-anatoliennes au XII s. Place Villeneuve-Bargemon.

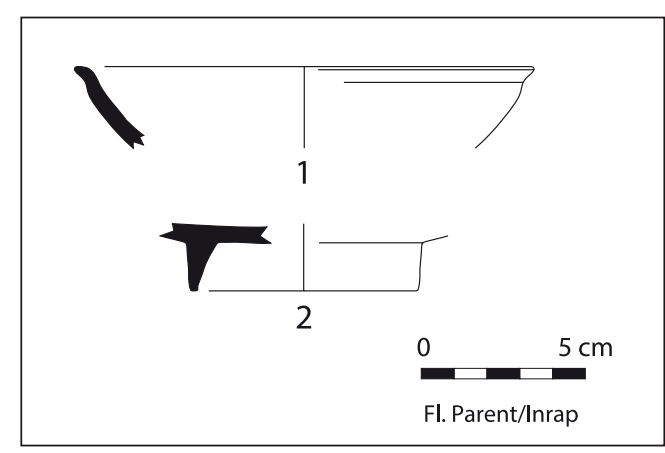

Fig. 34. Céramiques à pâte rouge et glaçure teintée au manganèse, importées de Méditerranée orientale au $\mathrm{XII}$ s. Place Villeneuve-Bargemon.

est recouvert par une glaçure épaisse, lisse et brillante, colorée au manganèse, qui confère à la surface une teinte et un aspect de «peau d'aubergine ». L'extérieur est parfois revêtu d'une glaçure transparente. Ces produits de très bonne qualité étaient, sans doute aucun, destinés au service. La série est pour l'instant attribuée à l'aire byzantine (Grèce) par les analyses minéralogiques effectuées sur certains exemplaires du Palazzo Ducale (Cabona et al. 1986, p. 465), tandis que les résultats d'analyses géochimiques de l'échantillonnage marseillais excluent les productions similaires de Beyrouth et de Chypre (Vallauri et al. 2003 ; François et al. 2003).

\section{Les céramiques d'origine incertaine}

Bon nombre de produits en céramique demeure encore de provenance inconnue : soit qu'ils ne trouvent aucun parallèle dans la littérature, soit que les analyses

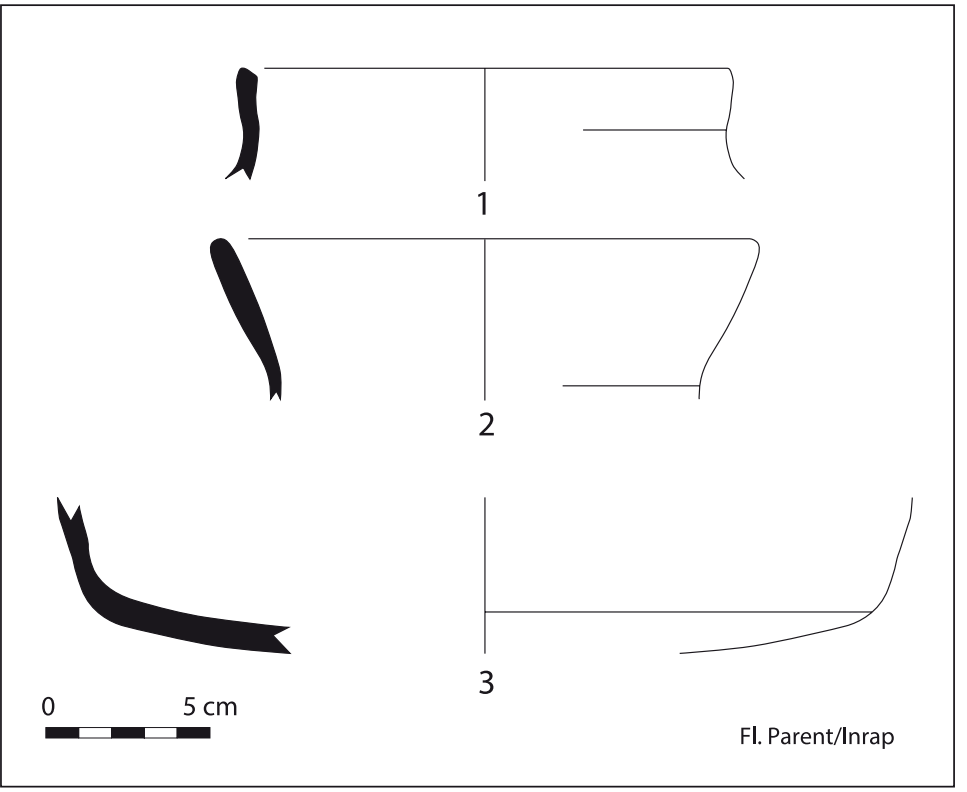

Fig. 35. Céramiques modelées à pâte rouge et glaçure plombifère, d'origine indéterminée, importées au XII s. Place Villeneuve-Bargemon.

dont certains ont pu bénéficier ont donné des résultats trop « génériques », c'est à dire communs à de multiples secteurs autour de la Méditerranée.

\subsection{Les céramiques modelées à pâte rouge grossière glaçurée}

Les céramiques modelées à pâte rouge grossière glaçurées, importées, arrivent dans notre région dès le $\mathrm{XII}^{\mathrm{e}} \mathrm{s}$. Elles sont, de toutes les céramiques importées sur le sol marseillais à cette époque, parmi les mieux représentées avec les siculo-maghrébines. L'essentiel du répertoire consiste alors en marmites de forme globulaire, à fond bombé, col et lèvre simple, et sont souvent munies de tenons de préhension (fig. 35). Les fragments de plats, le plus souvent à tenons également, sont plus rares. Ces vases sont façonnés dans une argile rouge, grossière et granuleuse, qui contient de gros nodules ferrugineux ; leurs parois sont massives et l'intérieur est généralement recouvert de glaçure transparente épaisse. L'extérieur du fond porte souvent des traces de lissage. Leur origine était autrefois attribuée à la Ligurie, car retrouvés en grand nombre dans cette région (Mannoni 1975, p. 57-60 ; Cabona et al. 1986, p. 479, tav. V, 2-3). Mais cette origine est aujourd'hui remise en cause par de récentes analyses minéralogiques et pétrographiques, les résultats ajoutant maintenant à la première hypothèse celle d'une production en Provence (Capelli et al. 2006, p. 189 ; Capelli et al. 2010, p. 937). 


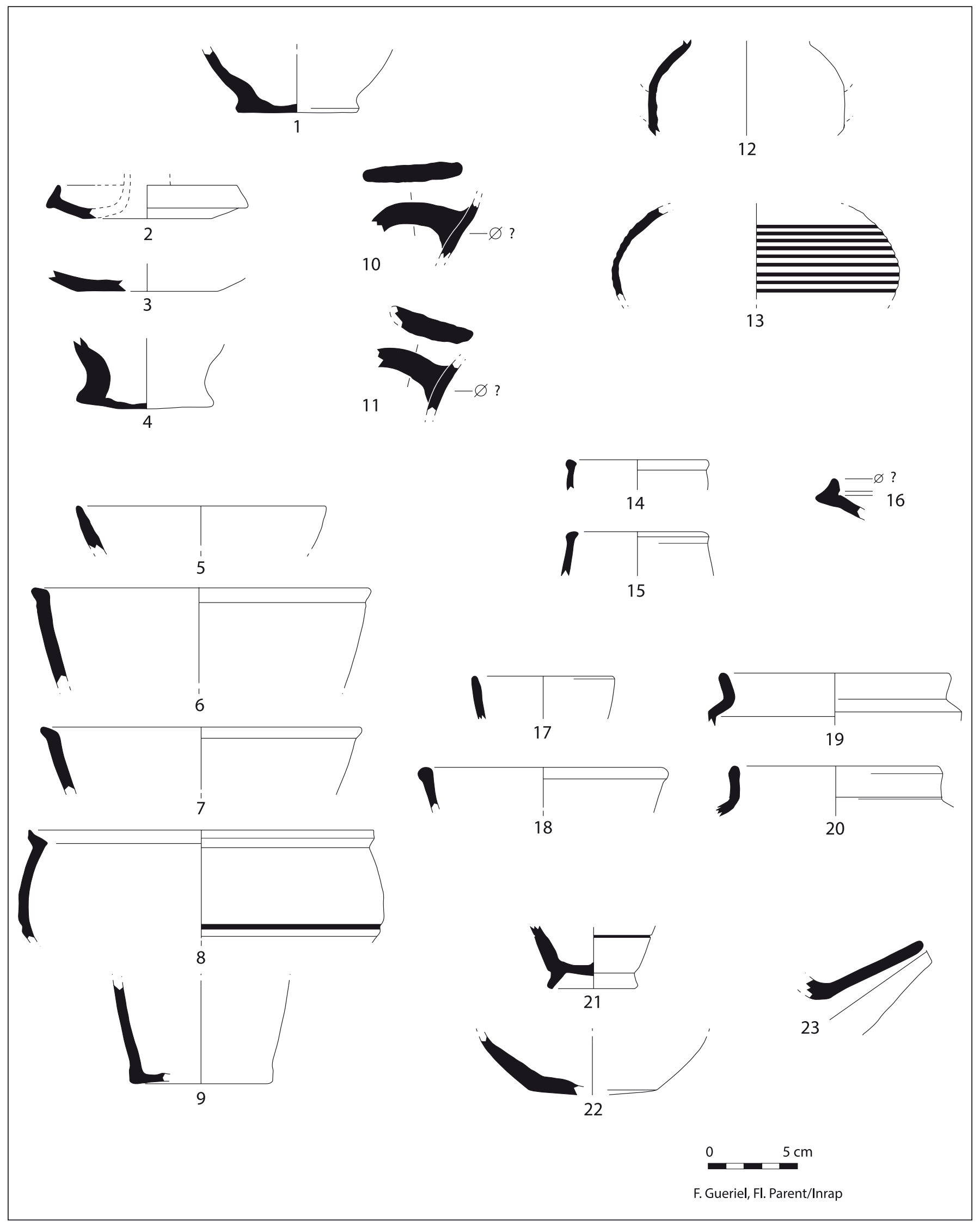

Fig. 36. Céramiques à pâte rouge et glaçure plombifère transparente, d'origine indéterminée, importées au XIIe s. Place Villeneuve-Bargemon. 


\subsection{Les autres céramiques à pâte rouge et glaçure plombifère d'origine indéterminée}

Les derniers éléments n'ont pu s'intégrer à aucun des groupes précédemment évoqués. Même si certains ont bénéficié d'analyses pétrographiques (Capelli et al. 2006 et 2010), leur origine demeure toujours indéterminée sans qu'aucune hypothèse ne puisse être valablement exprimée pour l'instant. Ils sont donc tous rassemblés ici. Même s'ils offrent des différences flagrantes dans leur pâte, leur typologie et leur revêtement, ils sont réunis, en dehors de l'indétermination de leur origine, par leur mode de cuisson en atmosphère oxydante (ce qui confère aux vases leur couleur rouge) et par leur couverte plombifère transparente (qui peut dans de rares cas être colorée : fig. $\mathbf{3 6}, \mathbf{n}^{\circ} \mathbf{1 - 3}$ ).

À l'intérieur de cet ensemble disparate, quelques sous-groupes peuvent être individualisés sur des critères essentiellement d'apparences de pâtes ou de revêtements.

Un premier groupe (fig. 36, $\mathbf{n}^{\circ} \mathbf{1}$ ) rassemble des fragments appartenant tous à des pichets. Ces vases à panses piriformes cannelées et à fond plat dégagé sont recouverts d'une glaçure vert bouteille. Par leurs caractéristiques, ils pourraient éventuellement être rapprochés des pichets cannelés à glaçure verte connus au siècle suivant dont l'origine se situerait en Catalogne (Capelli et al. 2010).

Trois autres objets peuvent être réunis dans un autre groupe : deux coupelles de lampes et un pichet (fig. 36, $\mathbf{n}^{\circ}$ 2-4). Ils ont subi une partie de leur cuisson en atmosphère réductrice conduisant à une teinte grisâtre de la pâte et une coloration olivâtre de la glaçure miel sur une partie des pièces. En outre, ces objets présentent de légers défauts, déformations ou bulles d'air emprisonnées dans les parois.

Un troisième regroupement associe des objets en pâte rouge rosâtre à surface externe beige. La pâte contient de nombreuses inclusions blanches et ferrugineuses de petite taille, ainsi que quelques paillettes de mica. Seul l'intérieur est recouvert d'une glaçure transparente, débordant à l'extérieur sur le haut de certains objets. Les formes ouvertes s'apparentent à des bols et des jattes (fig. 36, $\mathbf{n}^{\circ}$ 5-7) à lèvre simple effilée ou arrondie et déversée vers l'extérieur. Le pot/marmite $\mathbf{n}^{\circ} \boldsymbol{8}$ adopte une forme globulaire soulignée d'une ou plusieurs cannelures à mi-hauteur, son extrémité est directement repliée vers l'extérieur pour former une lèvre rectangulaire. Le fond $\mathbf{n}^{\circ} \mathbf{9}$ appartient à une forme fermée indéterminée : il est légèrement concave et l'extérieur est retouché pour former un léger talon anguleux.

Quelques fonds bombés de grande dimension et des anses en boudin présentent une pâte rouge, grossière et granuleuse, qui contient de grosses inclusions blanches, translucides et rouges. La glaçure qui recouvre partiellement l'intérieur de ces pots-marmites est épaisse, «piquetée », transparente, de couleur jaune à verte. La surface externe des fonds est noircie, témoignant, s'il le faut, de leur usage culinaire.

Le reste des récipients n'offre pas de similitudes entre eux. Une description de chaque objet serait fastidieuse et peu enrichissante puisque leur origine est totalement inconnue. Ils contribuent cependant à illustrer la diversité des apports à l'intérieur de la cité marseillaise et la diversité des ustensiles utilisés (fig. 36, $\mathbf{n}^{\circ} \mathbf{1 0 - 2 3}$ ) : marmites à anses rubanées, pots ou pichets à panse plus ou moins globulaire, pots à parois verticales, vase à liquide à bec tubulaire ; lampe et bol complètent cet assemblage hétéroclite.

\subsection{Les céramiques à couverte opacifiée indéterminée}

Les quelques formes ouvertes présentées dans ce paragraphe réunissent des céramiques dont le dénominateur commun est une couverte blanche opacifiée. L'altération et la corrosion de ces coupes et coupelles sont telles qu'il est difficile de se prononcer sur un émail ou sur un engobe blanc recouvert de glaçure : seules des analyses permettraient de lancer une affirmation.

La forme élégante et fine de la coupelle à lèvre effilée et paroi hémisphérique et du fond annulaire surcreusé (fig. 37, $\mathbf{n}^{\circ} \mathbf{1}-\mathbf{2}$ ) n'est pas sans rappeler celle des

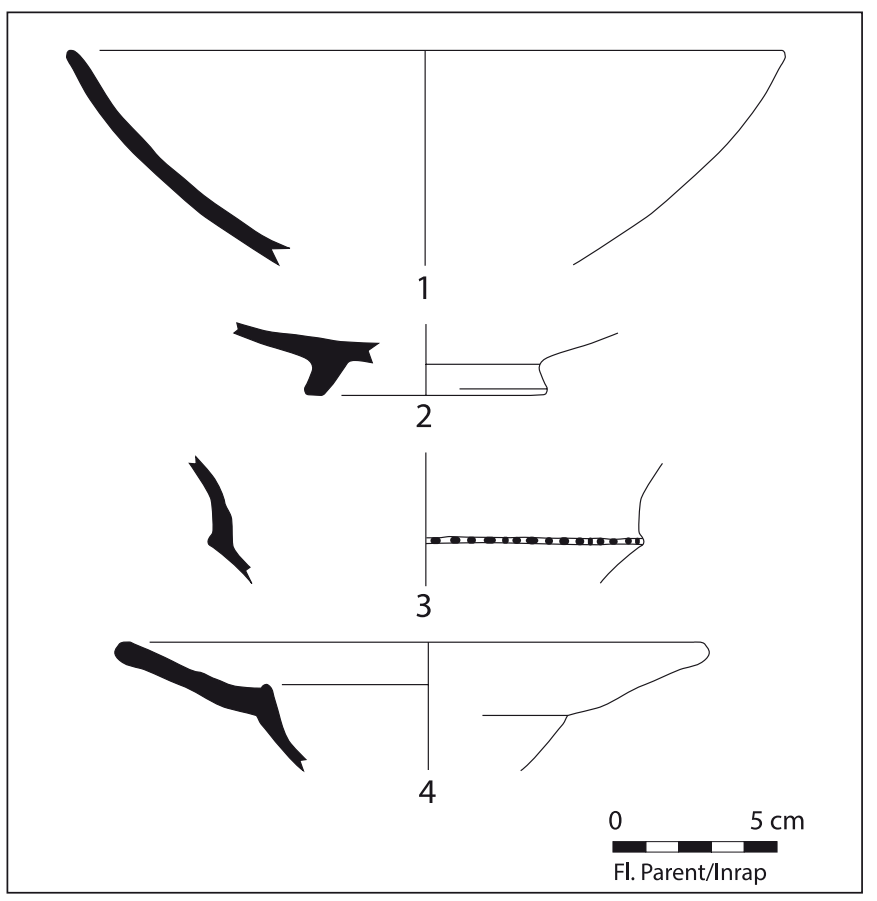

Fig. 37. Céramiques à couverte opacifiée indéterminée, importées au XII ${ }^{\mathrm{s}}$ s. Place Villeneuve-Bargemon. 
productions émaillées islamiques du sud de l'Espagne, et notamment celles de Malaga. Il en est de même pour trois fragments de coupe carénée et décor de godrons imprimé sur cette carène (fig. $\mathbf{3 7}, \mathbf{n}^{\circ} \mathbf{3}$ ).

Enfin, une coupe à marli très développé (fig. $37, \mathbf{n}^{\circ} \mathbf{4}$ ) et panse en calotte profonde porte une couverte interne épaisse mais très concrétionnée, débordant à peine sur l'extérieur du marli. Sa pâte beige, calcaire et tendre, les très nombreuses et fines paillettes de mica doré, ainsi que le tournassage soigneux de l'extérieur de la forme la rapprocheraient des productions engobées et glaçurées à pâte claire micacée évoquées légèrement plus haut (cf. supra $\S 2.2 .1$.), mais la forme est ici plus fine et plus élégante.

\section{Conclusion}

Les découvertes de cette époque sont encore rares dans nos régions. Qu'elles aient lieu à Marseille, et qu'elles y soient aussi nombreuses n'est pas le fruit du hasard mais bien lié à l'activité économique de cette cité entièrement tournée vers son port et par là-même vers la Méditerranée. Que les confrontations les plus proches se trouvent en Italie dans les cités portuaires d'égale importance que sont Gênes et Naples, ou en Sicile (Cabona et al. 1986 ; Molinari 1997 ; Carsana 2002), n'est pas une coïncidence non plus.

Toutes les importations évoquées dans ce chapitre mettent en exergue que les relations inter-méditerranéennes ne se limitent pas aux conflits des croisades. $\mathrm{Au}$ contraire, les relations commerciales avec le Maghreb, l'Orient et le Proche-Orient sont nettement privilégiées. Cependant, rares sont ces importations qui pénètrent à l'intérieur des terres. Les productions locales et régionales, logiquement et abondamment utilisées dans toute la Provence, semblent bien moroses et monotones face à la diversité des produits étrangers : absence de revêtement, répertoire cantonné presque exclusivement aux pots et aux pégaus, donc aux récipients utilitaires. Ces « carences » sont comblées par l'adoption, certes en quantité limitée, de produits importés ; produits dont les officines provençales vont rapidement s'inspirer. 


\section{Chapitre 3}

\section{La fin du XII ${ }^{\mathrm{e}}$ s. et le XIII ${ }^{\mathrm{e}}$ s. : les potiers s'installent aux portes de la cité}

\section{(Florence Parent et Catherine Richarté)}

L a fin du XII ${ }^{\mathrm{e}}$ s. est marquée par l'adoption de nouveaux procédés (cuisson et décoration) dans les officines provençales. Il ne s'agit en aucun cas d'une rupture brutale dans les procédés de fabrication, ni dans la distribution ou la consommation de produits locaux et importés, mais d'un changement progressif. Les premières marmites de fabrication régionale apparaissent à la fin du XII ${ }^{\mathrm{e}}$ s., façonnées dans les ateliers varois de la région de Saint-Maximin (Ollières). $\mathrm{Au}$ tout début du XIII ${ }^{\mathrm{e}}$ s., à Marseille même, dans le quartier Sainte-Barbe au nord des remparts, s'installent les premiers ateliers de potiers médiévaux connus à ce jour dans la ville. Ceux-ci vont notamment produire de la vaisselle glaçurée ainsi que des majoliques (faïences) décorées, jusqu'alors absentes des répertoires régionaux. Leur vocabulaire typologique et stylistique est très nettement inspiré du monde islamique. Parallèlement, les officines plus anciennes de la région varoise adoptent elles aussi progressivement la cuisson oxydante et vont employer des revêtements glaçurés sur leurs articles.

Durant toute cette période, le dynamisme économique de la cité portuaire ne cesse de s'observer. Les échanges avec l'Orient et le monde islamique se poursuivent tandis que de nouvelles sources d'approvisionnement émergent, notamment l'Italie. La variété des céramiques importées témoigne à elle seule du dynamisme de Marseille et de la diversité de ses réseaux économiques.

L'ensemble du mobilier présenté ici livre sensiblement les mêmes assemblages de vaisselles que ceux observés dans les fouilles à peine plus anciennes de la rue de la Cathédrale (Moliner 1990), du bourg SainteCatherine (Richarté 2001) et de Sainte-Barbe (Marchesi et al. 1997).

Le site de la place Villeneuve-Bargemon comptabilise environ 600 fragments pour cette période. On aperçoit, dans les sols de rue les plus récents, les premières marmites en pâte grise de type Ollières ainsi que des articles en pâte calcaire, glaçurés ou non, qui peuvent être attribués aux toutes premières productions des officines marseillaises du quartier Sainte-Barbe.
Associés à quelques fragments de céramique à pâte réfractaire de type Uzège, à des bassins glaçurés catalans et à des sgraffito archaïques ligures, ces produits nous introduisent au moins dans les toutes dernières décennies du XII ${ }^{\mathrm{e}} \mathrm{s}$. ; ce que semble confirmer la présence de deux monnaies, une obole et un denier de Guillaume IV de Forcalquier (1150-1209).

Sur le site de l'Alcazar (bourg de Morier), la fin du $\mathrm{XII}^{\mathrm{e}} \mathrm{s}$. correspond à l'établissement et à l'occupation d'un complexe artisanal (une tannerie) en usage jusqu' au milieu du XIII ${ }^{\mathrm{e}} \mathrm{s}$. qui sera ensuite détruit au profit d'un quartier d'habitations. Les niveaux en sont très détériorés ; cependant ils ont livré près d'un millier de fragments pour cette période. Les productions locales et régionales sont prépondérantes, notamment en ce qui concerne les céramiques utilitaires. Les céramiques communes à pâte grise dominent le marché avec près de $25 \%$. S'y côtoient les mêmes produits locaux que précédemment (ateliers de la chaîne de l'Étoile) et les premières productions d'Ollières, essentiellement des marmites de type a décorées à la molette. La moitié du mobilier restant se partage de manière quasi équivalente entre quatre pôles de fabrication : les ateliers voisins de Sainte-Barbe qui commencent timidement à émerger et approvisionnent le site à raison d'environ $10 \%$, majoritairement des céramiques en pâte rouge glaçurée et pâte calcaire non glaçurée ; les manufactures de l'Uzège (Languedoc) qui, au cours des périodes suivantes, vont submerger le site de leur produits culinaires ${ }^{7}$; les productions communes à pâte brune représentent ici près de $12 \%$ des produits consommés mais leur déclin sera très rapide par la suite, suivant en cela l'évolution des céramiques modelées à pâte rouge grossière glaçurées, qui pour cette période sont présentes à raison de $14 \%$ environ. Toutes les catégories mentionnées ci-dessus totalisent à elles seules les trois-quarts du mobilier issu du complexe artisanal et de la création du faubourg, le reste consistant en d'autres importations. Les produits plus luxueux, comme les faïences, sont rares. Il est possible qu'une partie du mobilier ait, outre un usage domestique, une destination

7 Ainsi de $14,7 \%$ ici elles atteindront près de la moitié des productions dans le dernier état médiéval. 


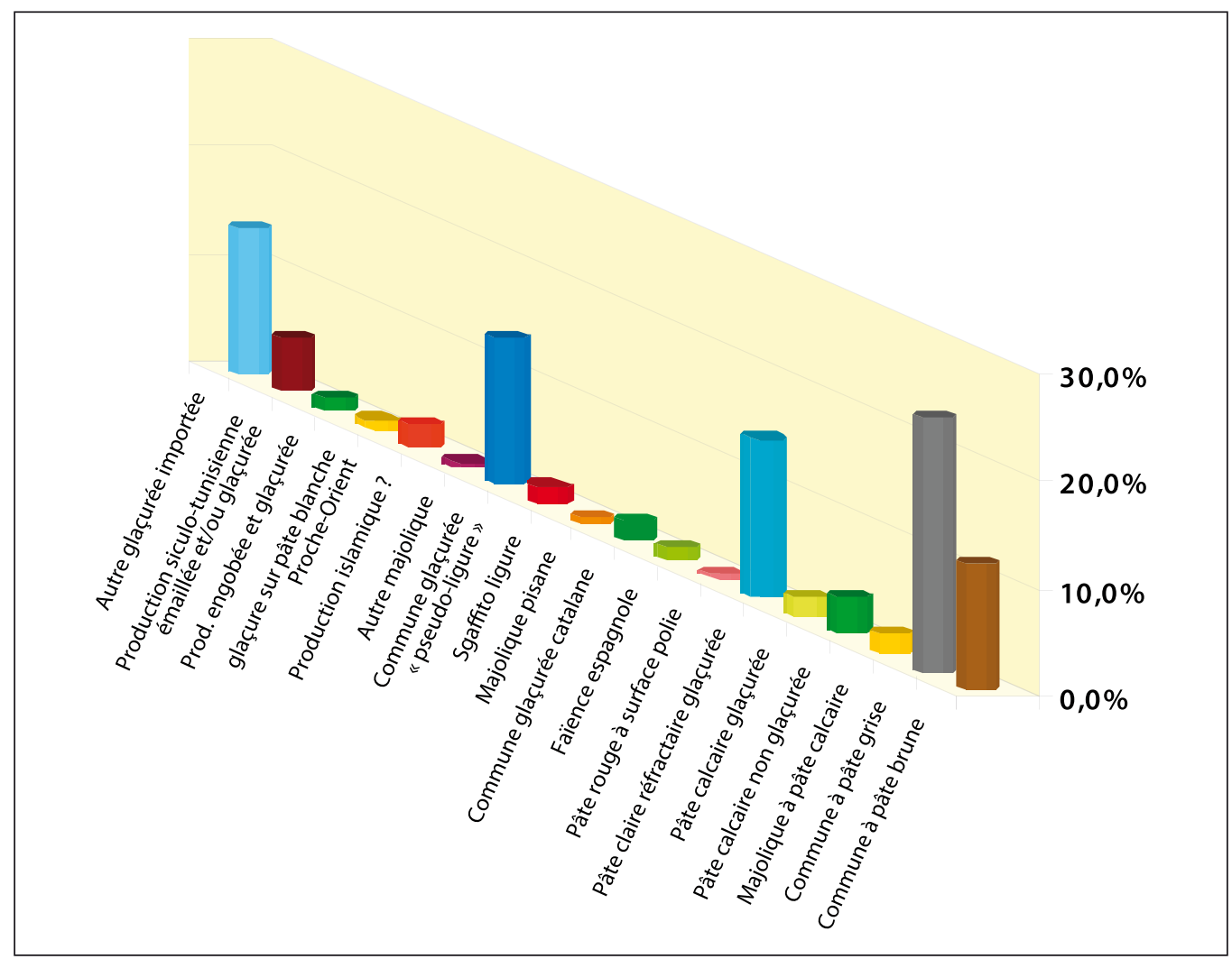

Fig. 38. Répartition des productions de l'Alcazar de la fin du XIle et du XIII' $\mathrm{s}$.

plus spécifique en liaison avec l'activité artisanale qui se déroule ici dans la majeure partie de la période considérée. La faible représentativité des produits des ateliers voisins peut sembler surprenante, étant donné la proximité de leur lieu de fabrication, mais le répertoire réduit des vaisselles consommées ici montre que nous nous situons vraisemblablement aux premiers temps de fonctionnement de ces ateliers. En effet, avec l'installation du faubourg vers le milieu du XIII ${ }^{\mathrm{e}}$ s., ces productions passent à un peu plus de $15 \%$. Les produits sans revêtement sont les plus consommés sur le site à cette époque alors que les céramiques glaçurées ou émaillées sont nettement moins représentées, peut-être moins appréciées ou plus chères (fig. 38).

Les céramiques consommées au cours des $\mathrm{XII}^{\mathrm{e}}$ et $\mathrm{XIII}^{\mathrm{e}} \mathrm{s}$. dans le quartier de la cathédrale ne se démarquent pas de ce cadre comme le montre leur exposé en fin de chapitre (cf. infra § 3.4.).

\section{Les productions locales et régionales (Fl. Parent)}

Faut-il y voir l'influence des divers produits méditerranéens circulant ou transitant à Marseille au cours du $\mathrm{XII}^{\mathrm{e}}$ s., les productions locales et régionales diversifient leur production dès la fin de ce même siècle : anciens et nouveaux ateliers façonnent des formes nouvelles pour eux, telles les marmites, et emploient peu à peu de nouveaux procédés de fabrication aboutissant à la généralisation progressive de la cuisson en atmosphère oxydante et de la glaçure.

\subsection{Les céramiques à pâte sombre sans revêtement}

À cette époque, ces produits composent une part toujours importante du vaisselier. Les sources d'approvisionnement ne semblent pas modifiées. Cependant, certains ateliers sont identifiés plus clairement, notamment grâce à des analyses chimiques.

\subsubsection{Les céramiques communes à pâte grise grossière}

La diffusion des pégaus varois, apparus au XII ${ }^{\mathrm{e}} \mathrm{s}$, chute considérablement dès la fin du même siècle. C'est le moment où ces ateliers, notamment ceux d'Ollières dans le Var, approvisionnent la ville presque exclusivement de marmites, le plus souvent décorées à la molette, parfois de cordons rapportés. Ces produits se caractérisent par une pâte grossière, de couleur grise, souvent 
plus foncée vers l'extérieur, contenant des nodules blancs et bruns (ferrugineux) en abondance. Bien qu'aucun vestige d'ateliers n'ait été découvert, leur existence est avérée depuis les années 1980 par les analyses géochimiques effectuées sur l'abondant mobilier du site de Rougiers, habitat de hauteur à proximité d'Ollières (Démians d'Archimbaud, Picon 1986. Démians d'Archimbaud, Picon 1987 ; Pelletier 1997). Depuis, les recherches n'ont cessé de mettre en évidence leur diffusion dans toute la Provence.

L'un des rares pégaus retrouvé, décoré de guillochis (fig. 39), est identique à un exemplaire de type a2 découvert à Rougiers (Démians d'Archimbaud 1980, fig. 238-9), et illustre un type déclinant dès la fin du XII ${ }^{\mathrm{e}}$ s. (Pelletier 1997a, p. 73).

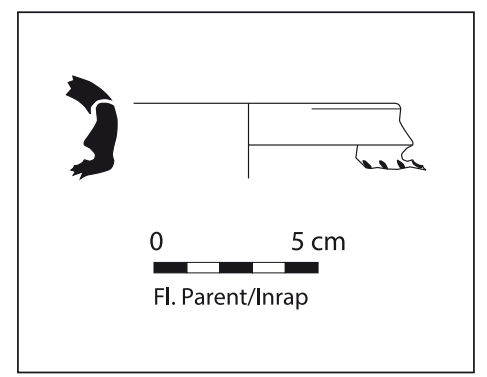

Fig. 39. Pégau en céramique à pâte sombre sans revêtement, fabriquée dans la région d'Ollières dès la fin du XIIe $\mathrm{s}$. Place Villeneuve-Bargemon.
Les premières marmites (fig. $\left.\mathbf{4 0}, \mathbf{n}^{\circ} \mathbf{1}-\mathbf{3}, \mathbf{5}\right)$ diffusées à Marseille correspondent au type a de Rougiers (Démians d'Archimbaud 1980, p. 297-300), type largement distribué en Provence et à Marseille à la fin du XII ${ }^{e}$ s. et au début du siècle suivant. On les retrouve en divers points de la ville à la même époque : quartier Sainte-Barbe (Pelletier 1997, p. 68-71), place Général-de-Gaulle (Richarté 2001), place Villeneuve-Bargemon, Alcazar... Ces marmites à panse globulaire portent un col bombé curviligne surmonté d'une lèvre repliée vers l'extérieur souvent soulignée d'une gorge. Deux anses horizontales, posées sur la partie supérieure de la panse, permettent de manier l'ustensile. Ces récipients sont très fréquemment décorés de motifs géométriques plus ou moins complexes réalisés à la molette (fig. $\mathbf{4 0}, \mathbf{n}^{\circ} \mathbf{1 - 3}, \mathbf{6 - 8}$ ), exceptionnellement accompagnés de stries (fig. 40, $\mathbf{n}^{\circ} \mathbf{5}$ ). L'ornementation couvre le col ainsi qu'une bonne partie de la panse et est organisé en registres horizontaux. De rares fragments présentent des motifs plus élaborés de végétaux stylisés comme sur l'un des fragments (fig. 40, $\mathbf{n}^{\circ} \mathbf{9}$ ), ce dernier étant identique à un exemplaire trouvé dans le quartier de Sainte-Barbe (Pelletier 1997, p. 70, fig. $44 \mathrm{n}^{\circ} 27$ ), indiquant par là une même provenance.

À partir du milieu du siècle, on retrouve plutôt des marmites de type b (fig. 40, $\mathbf{n}^{\circ} \mathbf{4}$ ), dont le profil du col
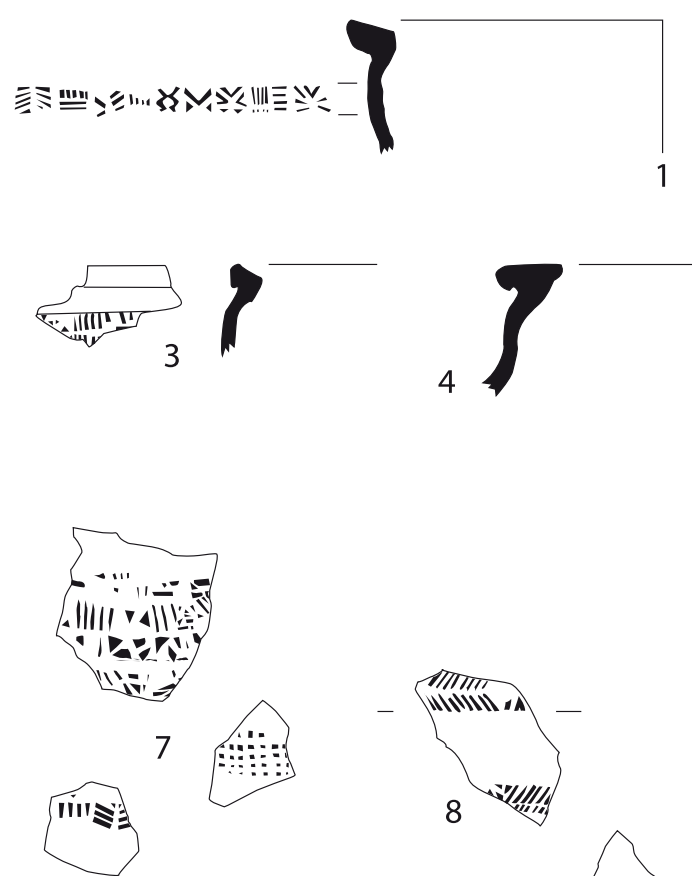

0

J. Isnard, Fl. Parent/Inrap
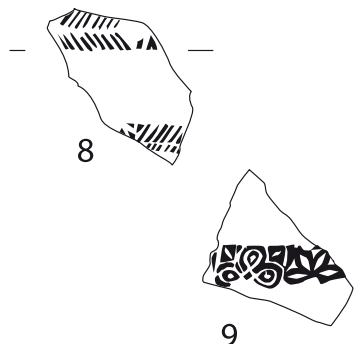

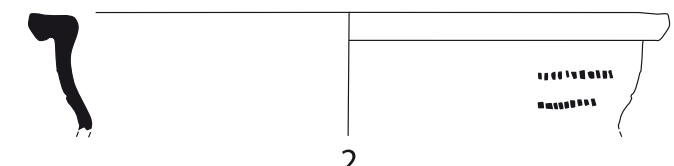

1

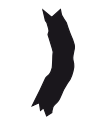

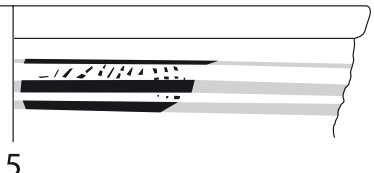

5
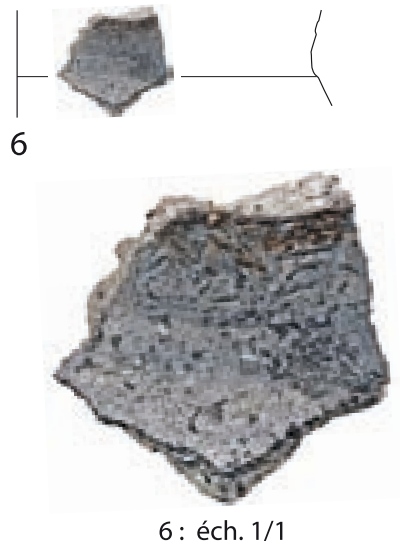

Fig. 40. Marmites en céramique à pâte grise sans revêtement, fabriquées dans la région d'Ollières dès la fin du XIIe $\mathrm{s}$. 1, 3-5, 7-9 : Alcazar ; 2 : Place de la Providence ; 6 : rue de la République. 
devient plus rigide que sur les précédentes (Démians d'Archimbaud 1981, p. 299-300). Le rebord, presque horizontal et proéminent à l'intérieur, est nettement séparé du col par une gorge. Les anses sont généralement cannelées. Les décors ont tendance à se raréfier. La forme fig. 40, $\mathbf{n}^{\circ} 5$ ne correspond à aucun type connu, son décor alliant stries et molette non plus, mais se rapproche tout de même des marmites de type a. Il est possible qu'elle provienne d'une autre zone de production, varoise également à en juger par ses caractéristiques de pâte. Toutes ces marmites possèdent un fond lenticulaire permettant de les caler dans le foyer.

Les couvercles sont rares. Leur présence coïncide généralement avec celle des premières marmites et ne dépasse pas le milieu du XIII ${ }^{e}$ s. (Démians d'Archimbaud 1981, p. 306). Encore plus rare, le fragment de trompe d'appel (fig. 41) est comparable à ceux signalés à Rougiers dans des contextes du XIII ${ }^{\mathrm{e}} \mathrm{s}$. (Démians d'Archimbaud 1981, p. 308-310), sa présence dans un niveau de destruction du bourg de Morier (vers 1360) serait donc résiduelle.

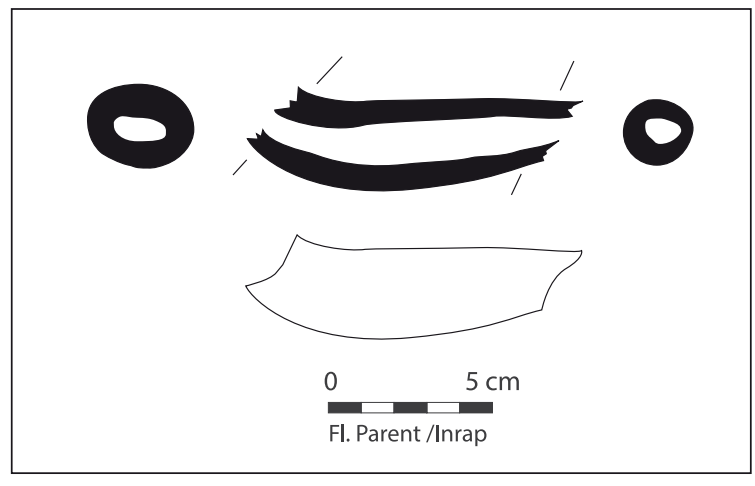

Fig. 41. Trompe d'appel en céramique à pâte grise sans revêtement, fabriquée dans la région d'Ollières dès la fin du XII $\mathrm{e}$. Alcazar.

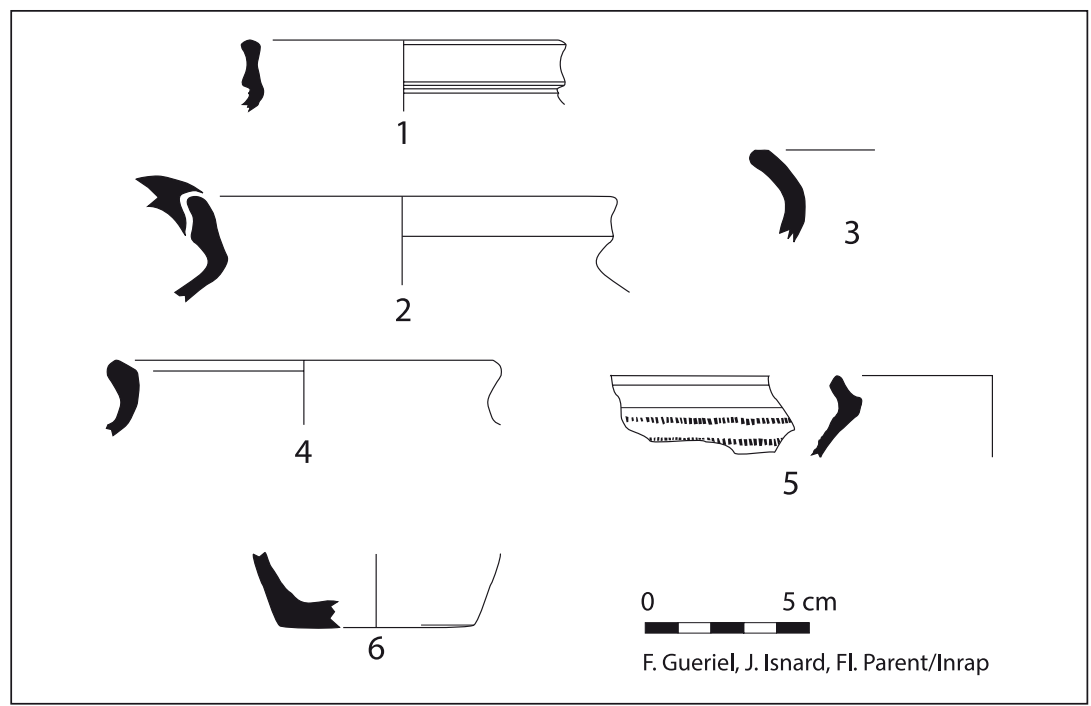

\subsubsection{Les céramiques communes à pâte grise micacée}

Comme celle de leurs cousins varois, la diffusion des produits de l'arrière pays marseillais à pâte grise micacée (cf. supra ch. $2 \S 1.2 .2$.) s'amenuise dès la fin du $\mathrm{XII}^{\mathrm{e}} \mathrm{s}$. ou au début du siècle suivant. Leurs formes ont également tendance à être moins diversifiées.

Les pégaus sont de plusieurs types : ceux à rebord en poulie (fig. $42, n^{\circ} \mathbf{1 - 2}$ ), qui correspondrait au type a2 défini à Rougiers, et ceux à rebord court et lèvre déversée vers l'extérieur qui coïnciderait avec le type c (fig. 42, $\mathbf{n}^{\circ} \mathbf{3}$ ). La panse de certains peut s'orner de motifs guillochés, exécutés à la molette (fig. $\mathbf{4 2}, \mathbf{n}^{\circ} \mathbf{5}$ ). Des fonds plats (fig. 42, n⿳6) s'adaptent sans doute à ces formes. Leur consommation dans la cité suit la même évolution que celles de leurs sosies varois (Démians d'Archimbaud 1980, p. 295 ; Pelletier 1997a, p. 72-73).

Les gros pots sont toujours présents à cette période. Ces vases de grande dimension possèdent des rebords carrés, reposant directement sur la panse (fig. $43, \mathbf{n}^{\circ} \mathbf{1}, \mathbf{3}$ ). Celle-ci peut parfois être décorée de petits guillochis et l'ensemble de la pièce consolidée par des cordons rapportés et digités, comme sur les exemplaires fig. $\mathbf{4 3}, \mathbf{n}^{\circ} \mathbf{2}, \mathbf{4}$. Ces récipients se rencontrent régulièrement durant la première moitié du XIII ${ }^{\mathrm{e}} \mathrm{s}$. à Marseille (Pelletier 1997, p. 73-74). La découverte d'un exemplaire identique et complet, dans le comblement d'un silo du palais archiépiscopal d'Aix, témoigne de leur survivance durant la seconde moitié du siècle (Fixot et al. 1989, fig. 31 ; Pelletier, Vallauri 1992, p. 234, fig. 6 n5).

Le fragment de tuyau rejeté dans le comblement d'une cuve de la tannerie sur le site de l'Alcazar (fig. 44, $\mathbf{n}^{\circ}$ 2) présente une pâte micacée, légèrement sableuse, contenant des nodules de couleur blanche de taille parfois importante. À ce titre, il pourrait être
Fig. 42. Pégaus en céramique commune à pâte grise micacée de la fin du XII et du XIII s. 1, 4-6 : Alcazar ;

2 : place de la Providence

3 : place Villeneuve-Bargemon. 


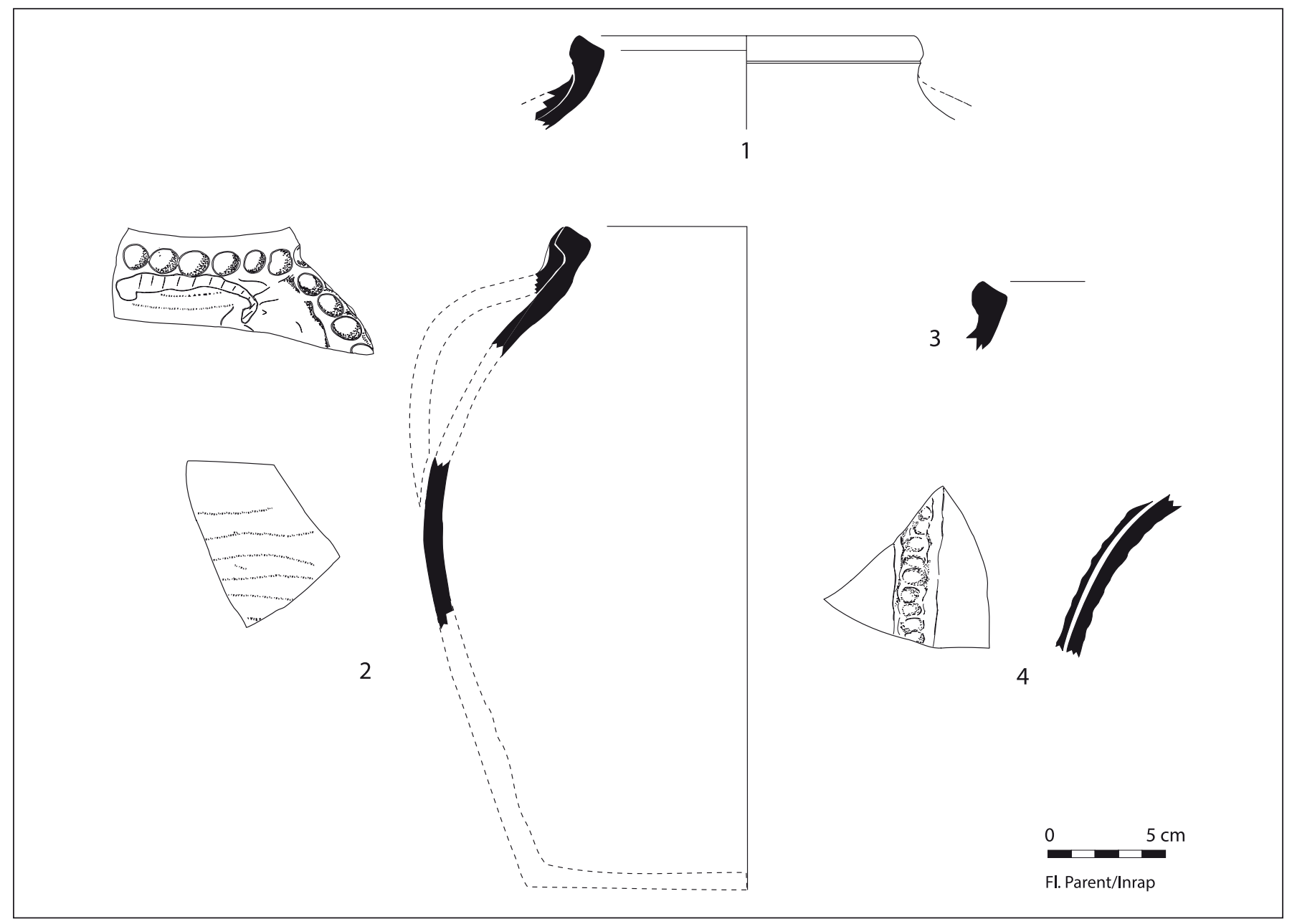

Fig. 43. Pots en céramique commune à pâte grise micacée de la fin du XII et du XIII' s. 1, 3 : place Villeneuve-Bargemon ; 2, 4 : Alcazar.

originaire des mêmes officines que les gros pots. Les seuls ateliers reconnus ayant fabriqués ce genre de pots dans cette période sont les ateliers de Mimet à quelques kilomètres de Marseille (Pelletier, Vallauri 1992), mais les quelques analyses géochimiques effectuées sur les échantillons de Sainte-Barbe ont révélé des différences notables entre eux qui n'excluent donc pas l'existence d'autres centres à proximité du Massif de l'Etoile (Pelletier 1997, p. 73).

\subsubsection{Les céramiques communes à pâte brune}

Des productions à pâte brune micacées évoquées au chapitre précédent (cf. supra ch. $2 \S 1$ 1.1.), seuls les pots semblent avoir encore cours durant le XIII ${ }^{\mathrm{e}} \mathrm{s}$. Les formes ouvertes, déjà rares au siècle passé, sont ici complètement absentes. Aucune variation morphologique n'apparaît sur les pots par rapport à la période précédente : les formes sont toujours rudimentaires, les lèvres simples déversées vers l'extérieur sont souvent pincées de manière à former un bec verseur, ce qui rend parfois

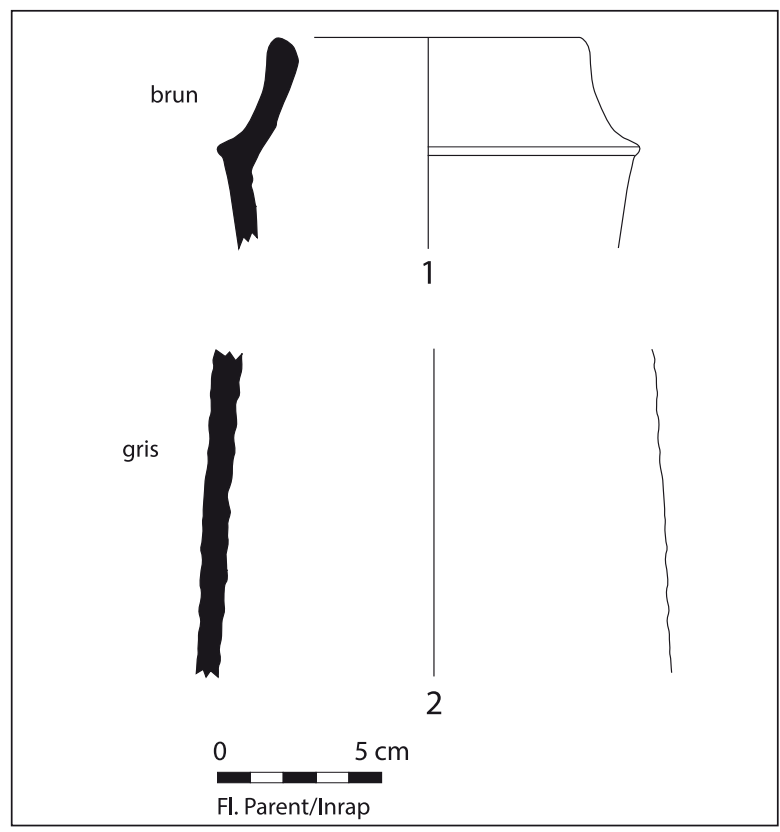

Fig. 44. Fragments de tuyau en céramique commune à pâte grise micacée de la fin du XII et du XIII' $\mathrm{s}$. Alcazar. 
difficile la mesure du diamètre d'ouverture de ces récipients. La panse est parfois soulignée d'un ressaut sur la partie supérieure. À quelques exceptions près, il s'agit toujours d'objets de taille moyenne à grande. On retrouve ces produits en pâte brune micacée de manière systématique sur l'ensemble des sites marseillais à cette époque, du bourg de Morier (Alcazar) jusqu'au quartier épiscopal (quartier de la Major). Ils sont encore présents dans la seconde moitié du XIII ${ }^{\mathrm{e}} \mathrm{s}$. et disparaissent à la fin du siècle (Gantès et al. 1990, p. 55-56 ; Pelletier 1997a, p. 66 ; Richarté 2001, p. 141). Issus vraisemblablement de Provence orientale, ils sont très largement diffusés en Provence, notamment sur la zone littorale jusqu'à Arles (Pelletier 1997a, p. 66).

Un fragment de canalisation (fig. $\mathbf{4 4}, \mathbf{n}^{\circ} \mathbf{1}$ ) rejeté dans une cuve de la tannerie du bourg de Morier (Alcazar), pourrait appartenir à ces productions. Cependant, il convient de rester prudent après les observations effectuées sur les tubulures de la Bourse évoquées au chapitre précédent (cf. supra ch. $2 \S 1$ 1.2.2.) : le rebord brun pourrait appartenir au même objet que le fragment en pâte grise évoqué plus haut (fig. 44, $\mathbf{n}^{\circ} \mathbf{2}$ ). Sur ce rebord, la collerette est plus accentuée, plus saillante que sur ceux plus anciens retrouvés à la Bourse, le diamètre (autour de $11 \mathrm{~cm}$ ) étant sensiblement identique.

\subsection{Les ateliers marseillais}

À Marseille, les seuls ateliers de potiers médiévaux fouillés et étudiés à ce jour s'installent dans les toutes premières années du $\mathrm{XIII}^{\mathrm{e}} \mathrm{s}$. à la périphérie immédiate de la ville, à l'est, dans le bourg des Olliers (Marchesi et al. 1997). L'abondant mobilier recueilli lors de leur dégagement a permis d'établir que plusieurs productions cohabitaient au sein de ces officines, toutes tournées et cuites en atmosphère oxydante :

- des céramiques à pâte calcaire soit laissée nue, soit glaçurée ou encore émaillée à décor vert et brun. Les argiles calcaires sont utilisées dans les productions marseillaises depuis l'Antiquité grecque jusqu'à l'Époque contemporaine, le territoire marseillais recelant de nombreux gisements adéquats encore à l'heure actuelle.

- des céramiques glaçurées à pâte rouge siliceuse dont les gisements n'ont pu être localisés. Sans doute ont-ils disparu à l'heure actuelle.

L'étude des rebuts de fabrication de ces ateliers a donné lieu à la publication d'une typologie dont nous reprendrons ici la terminologie, sachant que comme le signalaient les auteurs «les formes révélées sur un atelier sont plus nombreuses que celles reconnues sur un site de consommation qui ne rend compte que des principaux types » (Vallauri, Leenhardt 1997, p. 166).
De la même façon, le mobilier d'un seul atelier ne rend pas compte de l'ensemble des produits fabriqués à la même époque et il est possible que plusieurs ateliers aient coexisté à ou autour de Marseille, se fournissant dans les mêmes carrières d'argile, et que les habitants de Marseille se soient donc équipés auprès de plusieurs fabricants locaux et non uniquement auprès des officines fouillées à Sainte-Barbe. Quoi qu'il en soit, les mobiliers recueillis sur les différents chantiers qui nous intéressent offrent de grandes similarités typologiques avec celui découvert dans les dépotoirs du faubourg des potiers de Sainte-Barbe.

\subsubsection{Les céramiques glaçurées à pâte rouge}

Ces produits présentent une pâte siliceuse assez grossière de couleur rouge, micacée, contenant des nodules ferrugineux et de gros nodules blancs moins nombreux. L'intérieur est revêtu d'une glaçure jaunâtre ou verdâtre à l'aspect souvent marbré et piqueté. Leur fabrication est bien attestée durant les phases 1 et $2 \mathrm{~A}$ de ces officines, c'est-à-dire dès les premières décennies du XIII $\mathrm{s}$. jusque dans la deuxième moitié du siècle puis elle disparaît (Marchesi et al. 1997, p. 321 ; Amouric et al. 1995, p. 191-192).

Tous les produits élaborés de cette manière et diffusés ici sont à usage culinaire. Pourtant, ces ateliers fabriquent de la vaisselle de table dans la même catégorie, bien qu'en moindre quantité. Il existe différents volumes pour une même forme, s'adaptant à autant de portions et proportions différentes.

Le répertoire des formes utilisées dans les maisons marseillaises est étonnamment peu varié. Les plus fréquentes sont les plats à tétons (fig. 45, $\mathbf{n}^{\circ} \mathbf{1 - 3}$ ) qui ne sont pas sans rappeler ceux des productions modelées et glaçurées autrefois attribuées à la Ligurie, jusqu'aux tenons de préhension souvent doubles (cf. supra ch. 2 $\S 2.3$. et infra $\S 3.1$.). Il s'agit de plats plus larges que hauts, aux parois verticales ou légèrement évasées terminées par une lèvre simple généralement biseautée. Le fond habituellement bombé peut parfois être plat, comme sur l'exemplaire fig. $45, \mathbf{n}^{\circ} \mathbf{3}$. Appliqués à l'extérieur de la lèvre et diamétralement opposés, deux doubles tétons horizontaux servent à la préhension de l'objet (fig. 45, $\mathbf{n}^{\circ} \mathbf{1}$ ).

L'exemplaire $\mathbf{n}^{\circ} \mathbf{4}$ (fig. 45) n'a pas d'équivalent dans les dépotoirs d'ateliers du bourg des Olliers, il pourrait s'agir d'un plat à tétons d'un type légèrement différent des précédents, ou d'une jatte.

La jatte découverte sur le site de l'Alcazar (fig. 45, $\mathbf{n}^{\circ} \mathbf{5}$ ), devait comporter deux anses verticales à l'instar de ses homologues du faubourg Sainte-Barbe. Avec son bord en bandeau peu rentrant, elle doit appartenir aux 


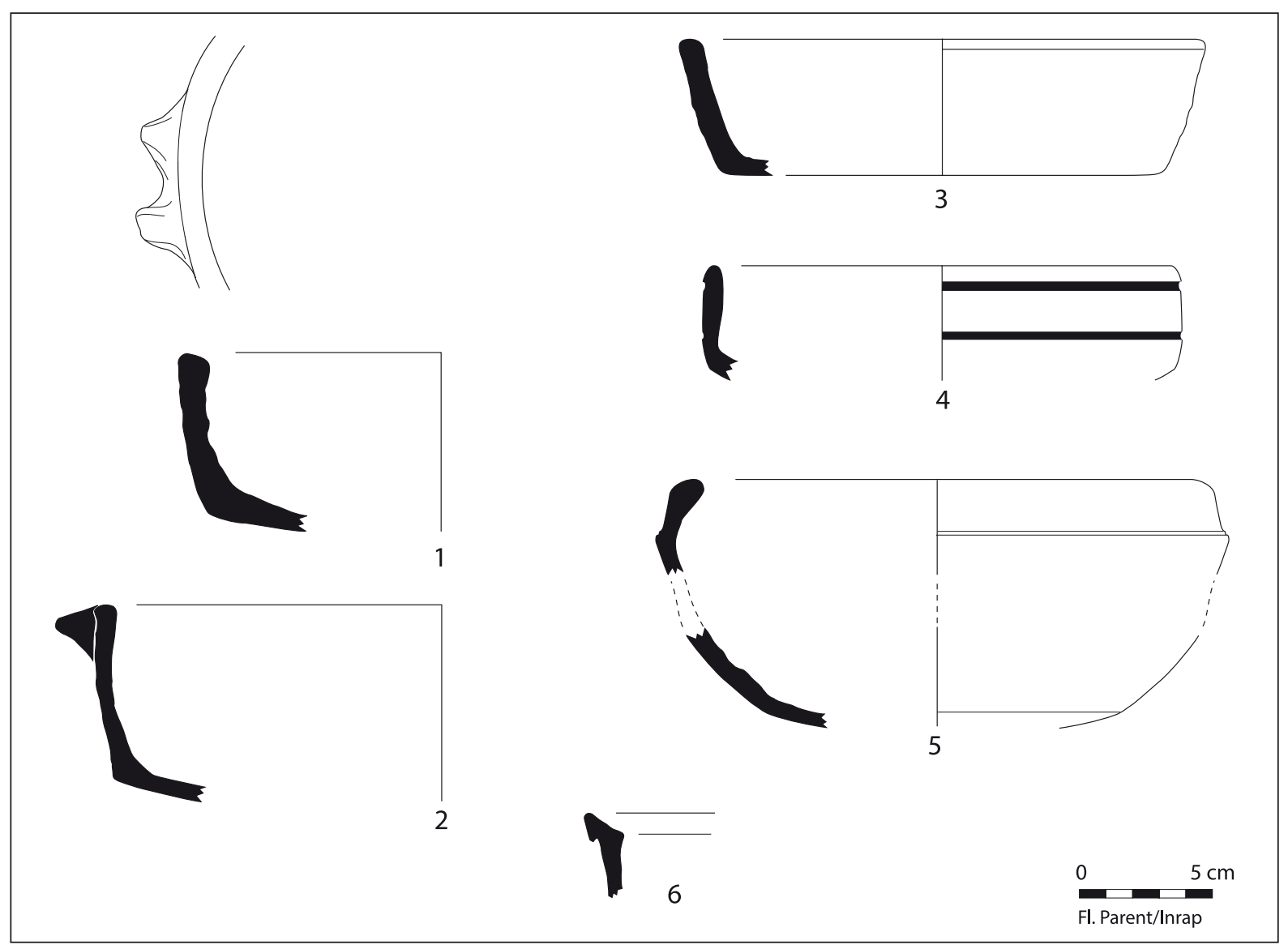

Fig. 45. Céramiques glaçurées à pâte rouge fabriquées à Marseille au cours du XIII $\mathrm{s}$. Alcazar.

dernières productions de cette catégorie : les premières "générations » de jattes en pâte rouge glaçurée de ces ateliers présentent une forme générale moins lourde et un bord en bandeau rentrant très nettement (Vallauri, Leenhardt 1997, p. 210, fig. 181-183).

Quelques rebords semblent assimilables à des marmites. D'après les rebuts de l'atelier, des anses en boudin et des fonds lenticulaires sont toujours associés à ces formes globulaires : les marmites 3 (Vallauri, Leenhardt 1997, p. 200, fig. 174) se distinguent par un rebord rectangulaire (fig. $45, \mathbf{n}^{\circ} \mathbf{6}$ ).

\subsubsection{Les céramiques à pâte calcaire sans revêtement (biscuit)}

Caractérisées par une pâte calcaire de couleur beige à rose de texture fine mais contenant quelques particules blanches et nodules ferrugineux ainsi que des paillettes de mica, ces céramiques ne portent aucun revêtement. Elles sont destinées aussi bien à un usage de table qu'à un usage utilitaire, mais certainement pas culinaire car ces argiles n'offrent pas les qualités appropriées. Le registre des formes est nettement plus varié que celui de la vaisselle de la catégorie précédente et s'inspire très largement du répertoire arabo-andalou (Rosselo-Bordoy 1978, p. 44). Ces céramiques en pâte calcaire sans revêtement sont fabriquées jusqu'à l'abandon des ateliers dans le premier tiers du XIV ${ }^{\mathrm{e}} \mathrm{s}$. (Marchesi et al. 1997).

Dès les premiers temps de leur production, les ateliers marseillais diffusent amplement cette catégorie sur leur territoire. En toute logique, c'est dans leur voisinage immédiat, au bourg de Morier (Alcazar), que les découvertes y sont les plus nombreuses. Le répertoire des formes utilisées en ce lieu est évidemment amplement déterminé par l'activité qui s'y déroule et la forme la plus courante reste celle des grands bassins ou lebrillo, aux usages multiples, qui ont pu aussi bien avoir un usage professionnel que domestique dans le complexe artisanal (fig. 46, $\mathbf{n}^{\circ} \mathbf{5 - 8}$ ). La même remarque peut s'appliquer aux chopes/mesures, aux écuelles basses (fig. 46, $\mathbf{n}^{\circ} \mathbf{2}$ ) et aux jarres. Mais on y retrouve également des tirelires (fig. 46, $\mathbf{n}^{\circ} \mathbf{1 3}$ ), des pots à découpes (pot à bulbe ?), des vases à anse de panier, des écuelles, toutes formes présentes dans les autres lieux de vie marseillais (place Villeneuve-Bargemon, Tunnel de la Major et rue Trinquet). 


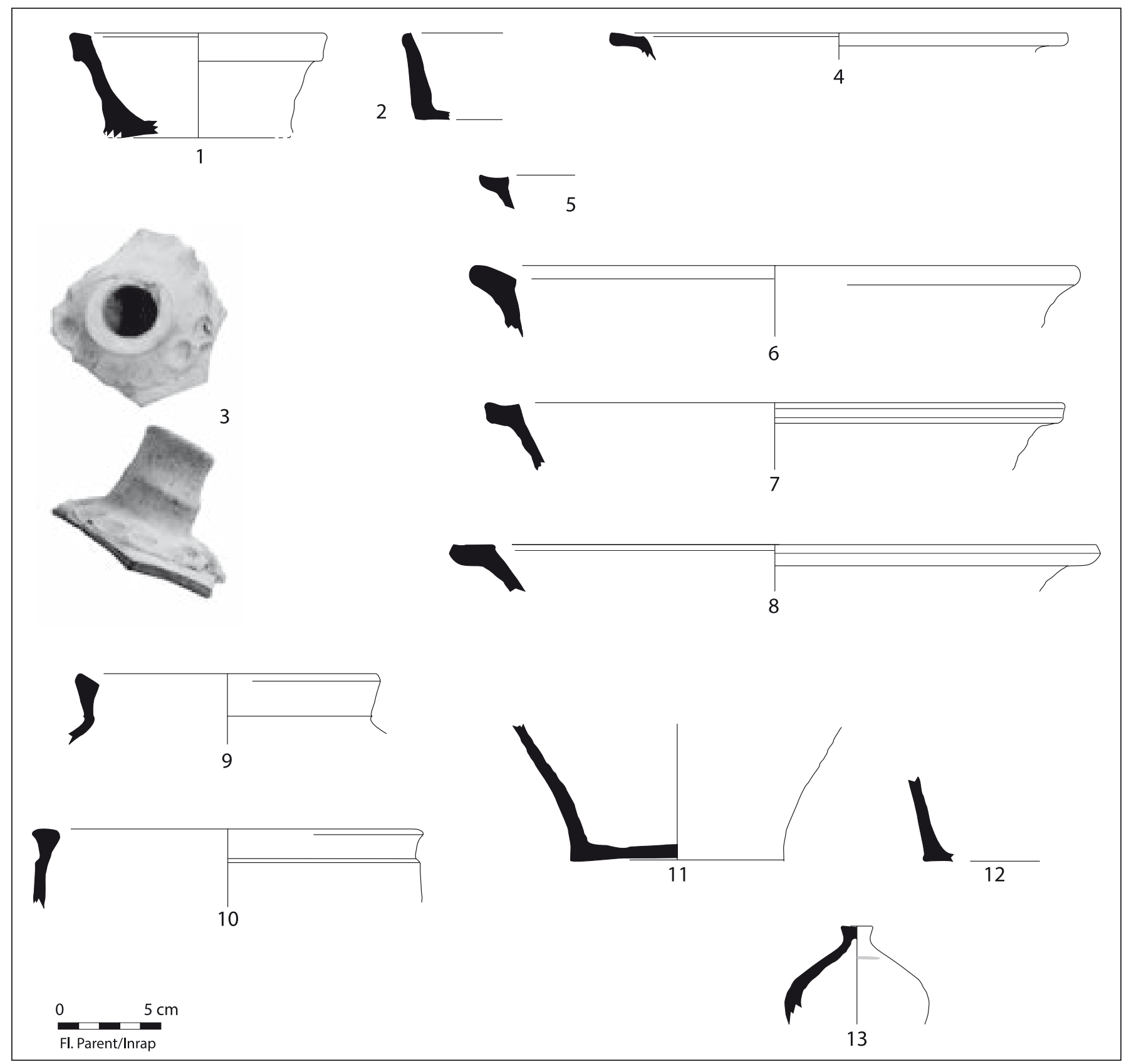

Fig. 46. Céramiques en pâte calcaire sans revêtement (biscuit) fabriquées à Marseille au cours du XIII $\mathrm{s}$. 2-3, 5-9, 11-12 : Alcazar ; 1, 4, 10, 13 : place Villeneuve-Bargemon.

Les pots « à découpes » nous sont parvenus dans un état d'extrême fragmentation (pour cette raison, ils n'ont pu être représentés ici). Ils sont toutefois nettement reconnaissables à leur panse qui présente de nettes découpes volontaires, pratiquées avant cuisson, de forme semblet-il triangulaire. De tels pots ont été retrouvés en nombre dans les dépotoirs des ateliers (Vallauri, Leenhardt 1997, p. 272). Même si aucun des éléments retrouvés sur nos chantiers ne permet de déterminer précisément leur morphologie, ces pots présentent en général un fond percé, une carène située dans la partie supérieure ou à mi-hauteur de la panse, au-dessus de laquelle sont pratiquées des ouvertures, soient triangulaires, soient circulaires, soient les deux en alternance (Vallauri, Leenhardt 1997, p. 272, 277, fig. 242).

Les tirelires fabriquées dans les ateliers de Marseille ne portent jamais de glaçure. On en retrouve des débris sur la plupart des sites de la ville, qu'elles aient été cassées volontairement ou non. Ces petits objets sphériques et creux sont portés sur un fond plat. Ils se terminent 
par un bouton sommital qui peut être bombé ou aplati comme sur l'exemplaire ${ }^{\circ} 13$. Une fente pratiquée sous le bouton et qui est toujours placée à l'horizontale permet d'y glisser ses pièces (Vallauri, Leenhardt 1997, p. 283, 286, fig. 250-251).

La petite écuelle presque complète (fig. $46, \mathbf{n}^{\circ} \mathbf{1}$ ) provient du quartier de la Mairie. Elle mesure $12,5 \mathrm{~cm}$ de diamètre d'ouverture pour une hauteur de $5 \mathrm{~cm}$ et un fond de $9 \mathrm{~cm}$ de diamètre. Ses parois rectilignes sont légèrement évasées, son fond est convexe et présente un talon à l'extérieur, et le bord replié est rectangulaire. Ses caractéristiques de pâte permettent de l'attribuer aux ateliers marseillais bien qu' aucune forme de ce type n'ait été recensée dans leurs dépotoirs. En revanche, les coupelles hémisphérique à marli court et incliné tel l'exemplaire $\mathrm{n}^{\circ} \mathbf{4}$ de la fig. $\mathbf{4 6}$ sont identiques aux coupelles de type 1 de ces officines, coupelles qu'elles fabriquent tout au long de leur activité (Vallauri, Leenhardt 1997, p. 224, 228, fig. 196-197).

Les bassins ou tians (fig. 46, $\mathbf{n}^{\circ} \mathbf{5 - 8}$ ), nombreux sur tous les sites marseillais, adoptent des morphologies aussi variées que peuvent l'être leurs usages: préparation culinaire, lessive, vaisselle, alimentation des animaux... Leurs parois sont tronconiques ou presque verticales, et plus ou moins profondes. Leur fond est toujours plat (fig. 46, $\mathbf{n}^{\circ} \mathbf{1 1 - 1 2}$ ), garantissant ainsi leur stabilité. Quel que soit le type de lèvre, ronde ou plutôt rectangulaire (fig. 46, $\mathbf{n}^{\circ} \mathbf{5 - 8}$ ), elle est toujours inclinée presque à l'horizontale vers l'extérieur, de manière à faciliter la manutention de ces objets ne comportant généralement pas d'anse.

Les formes fermées semblent parmi les plus fragiles. Est-ce leur panse bombée qui les rend particulièrement vulnérables aux chocs ? La plupart du temps, seuls sont identifiables ces fragments de panse et il est rarement possible de déterminer s'ils appartiennent plutôt à une forme qu'à une autre. Il est tout aussi difficile de quantifier le nombre d'objets découverts. Pour exemple, les bouteilles-bonbonnes et les jarres à bec (Vallauri, Leenhardt 1997, p. 253, 259, fig. 219-222) paraissent être des objets assez prisés par les Marseillais à l'époque. Cependant, leur corpulence, la finesse de leur paroi, ainsi que le poids de ces objets contenant jusqu'à 16 litres d'eau et qui sont manipulés quotidiennement, en font des vases se cassant facilement. Si bien que dans les lots de mobilier qui nous concernent, ils sont tellement éclatés que seuls sont reconnaissables les éléments verseurs comme le bec tubulaire dans le cas des jarres (fig. 46, $\mathrm{n}^{\circ} 3$ ).

Il en est de même pour les petits pots tel le $\mathbf{n}^{\circ} \mathbf{9}$ (fig. 46), appartenant à la catégorie des pots à anse de type 4 (Vallauri Leenhardt 1997, p. 196, fig. 171). Bien qu'aucun élément morphologique autre que le rebord à lèvre triangulaire n'ait été identifié, ce type de pot comporte généralement une anse large et rubanée dont l'attache inclue le bord, un fond plat et l'épaulement est généralement souligné de cannelures.

Le dernier objet (fig. 46, $\left.\mathbf{n}^{\circ} \mathbf{1 0}\right)$ peut être rapproché des marmites de type 5 des ateliers marseillais (Vallauri, Leenhardt 1997, p. 203, fig. 176), qui sont des marmites en pâte calcaire à col court et à anses rubanées horizontales posées sur l'épaulement. Il paraît improbable que ces objets aient été destinés à la cuisson : fabriqués en pâte calcaire non thermorésistante, ils devaient plutôt être réservés au service à table.

Enfin, il convient d'aborder la série des céramiques architecturales que sont les tuyaux de canalisation, produits par les officines marseillaises en grande quantité pendant toute leur période d' activité (Vallauri, Leenhardt 1997, p. 305, fig. $270 \mathrm{n}^{\circ} 1-3$ ). Il est étonnant d'en retrouver si peu dans les différents quartiers marseillais de l'époque. Les seuls fragments ont été découverts dans un dépotoir de la tannerie du bourg de Morier, tannerie qu'ils avaient sans doute servi à alimenter, avant d'être rejetés (fig. 47). Ces tuyaux ne portent pas de glaçure. Le bord, rentrant et souligné d'une collerette, a un diamètre n'excédant pas $10 \mathrm{~cm}$ à l'ouverture. Sur l'exemplaire le mieux conservé, le diamètre maximal de la tubulure atteint 13,5 cm (fig. 47, $\mathbf{n}^{\circ}$ ).

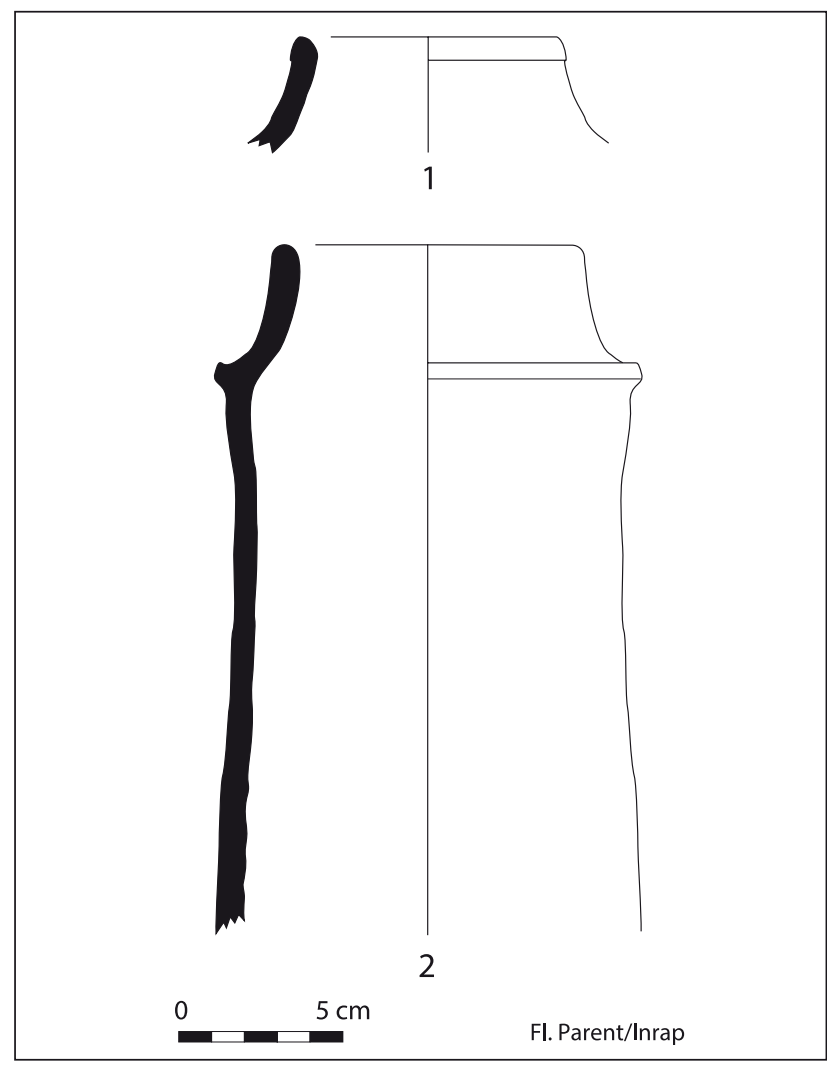

Fig. 47. Tuyau en céramique à pâte calcaire sans revêtement (biscuit) fabriquée à Marseille au cours du XIII $\mathrm{e}$. Alcazar. 


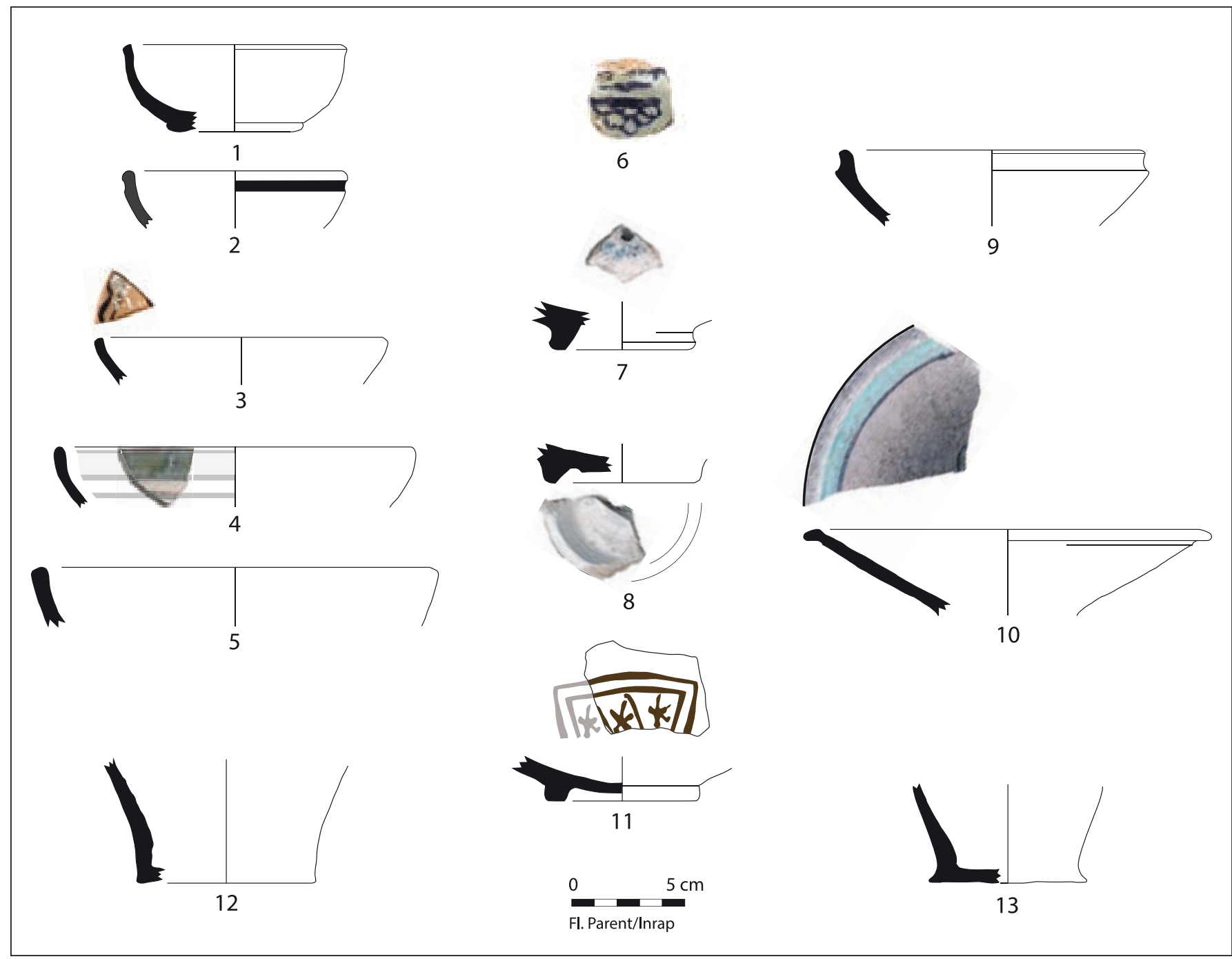

Fig. 48. Céramiques en pâte calcaire glaçurées monochromes ou émaillées à décor polychrome, fabriquées à Marseille au cours du XIII $\mathrm{s}$. 1, 6, 9 : Alcazar ; 2 : rue de la République (rue Moisson) ; 3 : Collège Vieux-Port ; 4, 5, 8 : rue de la République (Surverse - Vieux-Port) ; 7,10 : place Villeneuve-Bargemon ; 11-13 : parvis de l'église Saint-Laurent.

\subsubsection{Les céramiques à pâte calcaire glaçurées monochromes ou émaillées à décor polychrome}

L'atelier marseillais produit également des pièces en pâte claire vernissée qui paraissent quantitativement beaucoup moins bien représentées. Cette catégorie ne se distingue de la précédente que par la pose, à la surface des vases, d'une glaçure monochrome généralement jaune ou verte. Cette pose n'est pas uniforme d'où la difficulté de distinguer objets revêtus et objets non revêtus quand très peu d'éléments morphologiques nous sont parvenus. Ils sont volontairement rassemblés avec les céramiques émaillées (majoliques) dans ce paragraphe, car la plupart du temps les mêmes formes ont été fabriquées indifféremment avec l'une ou l'autre couverte.
Comme dans le cas des récipients en pâte calcaire sans revêtement, les formes fermées glaçurées ou émaillées semblent particulièrement sensibles à la casse et à la fragmentation. La présence de cruches n'est jamais discernable que par des fragments de fonds (fig. 48, $\mathbf{n}^{\circ} \mathbf{1 2 - 1 3}$ ). Panse, bec pincé ou anse sont si informes ou si petits qu'il n'a pas été envisageable de les représenter graphiquement ici, si ce n'est par une photo d'un petit fragment de cruche émaillée (fig. 48, $\mathbf{n}^{\circ} \mathbf{6}$ ). Bien qu'il soit impossible de chiffrer leur masse (peut-être éventuellement en poids), elles sont omniprésentes sur les sites marseillais au XIII ${ }^{\mathrm{e}} \mathrm{s}$. Leur morphologie générale ne nous est connue qu'au travers des rebuts de fabrication des ateliers (Vallauri, Leenhardt 1997, p. 239-252). Ces formes semblent 
porter indifféremment un revêtement interne ou externe, voire les deux.

Par contre, les éléments de formes ouvertes sont toujours revêtus uniquement sur leur face interne. C'est le cas d'une coupe émaillée (fig. 48, $\mathbf{n}^{\circ} \mathbf{1 0}$ ), dont la forme tronconique s'apparente aux coupes de type 8 des dernières productions de l'atelier Sainte-Barbe (Vallauri-Leenhardt 1997, p. 233, fig. 200) mais sa facture très fine et son allure élancée l'intègrent plutôt aux premières productions de ces ateliers. Le pied annulaire d'une seconde coupe est beaucoup plus épais. L'émail qui revêt l'intérieur est très poreux et a absorbé le décor en brun de manganèse (fig. $\mathbf{4 8}, \mathbf{n}^{\circ} \mathbf{7}$ ). L'un des fonds de coupelle (fig. $48, n^{\circ} 8$ ) est caractéristique des premières productions émaillées des ateliers de Sainte-Barbe : sa morphologie - annulaire, surcreusée et bien dégagée - l'identifie aux coupes de type 2 pour lesquelles l'influence sicilienne est indéniable et qui sont fabriquées durant toute la première moitié du XIII ${ }^{\mathrm{e}} \mathrm{s}$. (Marchesi et al. 1997, p. 220, fig. 190). C'est également à ce type que renvoie la série de coupes hémisphériques repérées en différents points de la ville (fig. 48, $\mathbf{n}^{\circ} \mathbf{3 - 5}$ ). Leurs décors fins ont souvent disparu, seul le brun a parfois persisté (fig. 48, $n^{\circ} 3$ ). Les motifs de liserés bruns soulignant le haut du vase sont fréquents sur les premières productions de faïences marseillaises. Les formes, fines et élégantes au début de la production, ont tendance à s'épaissir vers la fin et l'exemplaire $\mathbf{n}^{\circ} \mathbf{5}$ pourrait appartenir aux exemplaires tardifs des coupe de type 2. Les coupelles légèrement carénées de type 10 (fig. 48, $\mathbf{n}^{\circ} \mathbf{9}$ ) font partie des dernières productions des artisans de Sainte-Barbe, soit celles de la seconde moitié du $\mathrm{XIII}{ }^{\mathrm{e}} \mathrm{s}$. et des premières années du siècle suivant. Les mini-coupelles (fig. 48, $\mathbf{n}^{\circ} \mathbf{1 - 2}$ ) sont la réplique à échelle réduite des coupes 2 , mais avec un diamètre avoisinant les $10 \mathrm{~cm}$. Hémisphériques, à fonds larges et plats, parfois dégagés comme dans le cas de celle de l'Alcazar (fig. 48, $\mathbf{n}^{\circ}$ ). Ces miniatures de type 2 portent toujours une glaçure jaune à verte et sont fabriquées durant tout le XIII $^{\mathrm{e}}$ s. (Vallauri, Leenhardt 1997, p. 238-239).

\subsection{Les céramiques glaçurées à pâte réfractaire}

Plusieurs centres potiers ayant abondamment utilisé la cuisson en mode réducteur dans les périodes précédentes (céramiques à pâte sombre), l'abandonnent peu à peu au profit de celle en mode oxydant au cours du $\mathrm{XIII}^{\mathrm{e}} \mathrm{s}$. Il s'agit la plupart du temps d'ateliers employant des argiles réfractaires de type kaolinitique. La qualité de ces argiles, résistant à de hautes températures, en font une matière première de choix pour la fabrication des céramiques destinées à la cuisson des aliments. Deux zones principales de production ont été identifiées: l'une à l'est de Marseille au cœur de l'actuel département du Var, l'autre à l'ouest de la cité dans la basse vallée du Rhône.

\subsubsection{Du Centre Var}

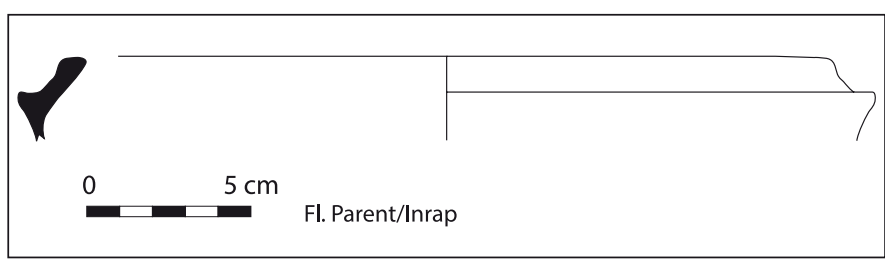

Fig. 49. Céramique fabriquée dans le Centre Var au cours du XIII $\mathrm{s}$., à pâte réfractaire et glaçurée. Alcazar.

Facilement identifiables à leur pâte kaolinitique criblée de nodules ferrugineux, les productions médiévales varoises ont été mises en évidence pour la première fois sur le site consommateur de Rougiers dans le Var (Démians d'Archimbaud 1980). Une partie de ces objets est attribuée aux ateliers d'Ollières (Var) par ailleurs mentionnés dans les textes depuis la fin du XII ${ }^{\mathrm{e}} \mathrm{s}$. (Argueyrolles 2000, p. 121). Ces ateliers ont produit sur une longue durée des récipients culinaires ou utilitaires : à partir du XIII ${ }^{\mathrm{e}}$ s., ils utilisent en concomitance la cuisson en mode réducteur pour une partie de leurs produits (ceux-ci sont présentés supra $§ 1.1 .1$.) et celle en mode oxydant pour d'autres. Dans ce cas, les produits portent toujours une glaçure (Amouric et al. 1995, p. 191). D'autres ateliers aux productions similaires sont connus dans la région varoise, une cinquantaine de kilomètres plus à l'est, à Cabasse.

Par ailleurs, on sait que les argiles du bassin de Saint-Maximin ont été essayées ponctuellement dans les ateliers marseillais, notamment pour le façonnage d'alambics ou de creusets en pâte réfractaire glaçurée (Marchesi et al. 1997, p. 190, 278), peut-être même pour quelques ustensiles de cuisine comme les marmites (mais cela est moins sûr : Vallauri 1997a, p. 79). Il devient alors difficile de savoir si les rares objets retrouvés sur les sites de consommation marseillais ont été fabriqués à Marseille ou dans le Var. La question reste donc ouverte pour les quelques fragments de marmites (dont une anse cannelée horizontale) et de jattes, à bord en poulie rentrant souligné d'un ressaut très proéminent (fig. 49), retrouvés dans l'abandon des tanneries du site de l'Alcazar, abandon remontant au milieu du XIII' $\mathrm{s}$.

De très rares objets, de belle qualité, reconnaissables à leur pâte kaolinitique très claire, presque blanche, recouverte d'une glaçure jaune ou verte à l'aspect souvent moucheté, apparaissent dans les contextes des 
premières décennies du siècle. Il s'agit le plus souvent de vases à liquide élégants, aux parois fines, et dont la panse s'orne de fines bandes d'argile apposées en diagonale, guillochées et soulignées de manganèse (Leenhardt 1997, p. 76). Le seul exemplaire quasi complet a été découvert dans le comblement d'un puits place JulesVerne. Plusieurs hypothèses circulent sur l'origine de cette production. L'une propose que ces objets puissent être fabriqués dans les officines de Sainte-Barbe à titre expérimental, soit par des potiers extérieurs (varois ?) ayant emprunté de l'oxyde de manganèse aux potiers marseillais, ou inversement par des potiers marseillais ayant emprunté de l'argile kaolinitique à des potiers varois (Vallauri 1997a, p. 77-78).

\subsubsection{De l'ouest du Rhône}

À partir de la fin du XII ${ }^{\mathrm{e}}$ s., les ateliers de l'Uzège dans le Gard commencent également à commercialiser de la vaisselle utilitaire en pâte kaolinitique glaçurée. Si ces ateliers sont connus par les textes, ils n'ont encore jamais été localisés. D'autres centres de productions ont existé dans la moyenne et basse vallée du Rhône (Leenhardt et al. 1996, p. 108), dont un fouillé récemment à Beaucaire (Carme, Demangeot 2012). En l'état des découvertes, l'appellation «de l'Uzège » ou « de type Uzège » reste la dénomination usuelle pour désigner leurs produits. Ces centres potiers sont les principaux concurrents des officines varoises et vont progressivement supplanter leurs rivaux sur tous les marchés provençaux, jusqu'à connaître leur âge d'or au $\mathrm{XIV}^{\mathrm{e}}$ s. Mais dans le Marseille du XIII ${ }^{\mathrm{e}}$ s., les produits glaçurés de l'ouest rhodanien, comme leurs homologues varois, ne font pas encore le poids face aux céramiques grises varoises et marseillaises (cf. supra $§ 1.1$.).

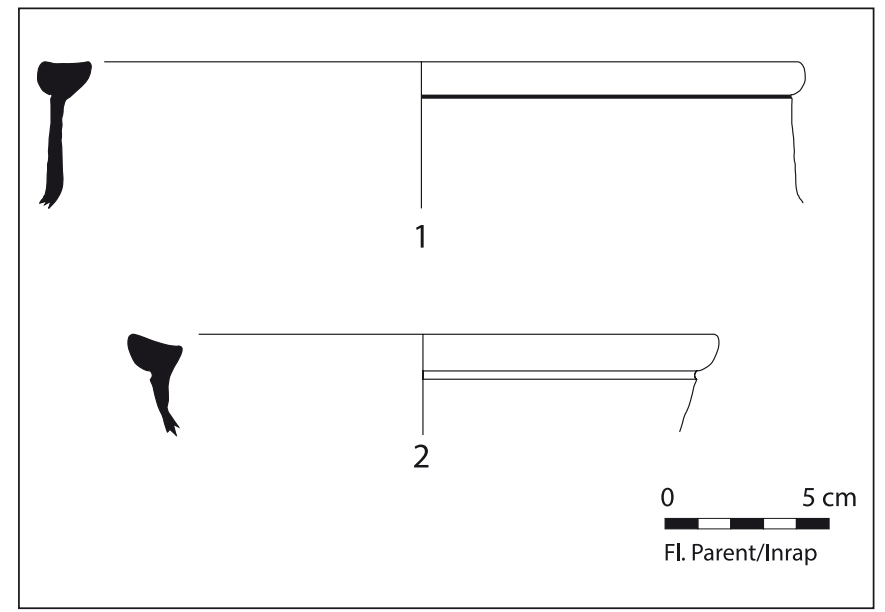

Fig. 50. Céramiques fabriquées à l'ouest du Rhône au cours du XIII ${ }^{\mathrm{e}} \mathrm{S}$., à pâte réfractaire et glaçurées. 1 : parvis de l'église Saint-Laurent ; 2 : rue de la République.
Pour cette période, le répertoire des céramiques à pâte claire kaolinitique glaçurée commercialisées à Marseille par les ateliers de l'ouest rhodanien se réduit principalement à des marmites (fig. 50). La qualité particulière des argiles et l'habileté des potiers de cette région sont révélées par la finesse des parois de ces ustensiles de cuisine. Cette finesse les rend sujets à une extrême fragmentation lorsqu'ils se brisent. La plupart du temps, ces récipients - caractérisés par une large ouverture, un col court, un corps et un fond globulaire ou piriforme et deux anses - ne sont identifiables que par des fragments de panse ou de fonds, parfois plus opportunément par des fragments d'anses cannelées ou de bords. Il en est de même pour les rares gargoulettes retrouvées, qui sont discernées uniquement grâce à leur fin bec verseur tubulaire. Tous ces récipients portent une glaçure au plomb, de tonalité verdâtre ou jaunâtre, destinée à améliorer leur étanchéité. Si l'usage des marmites de l'Uzège est assuré dès les premières décennies du XIII ${ }^{\mathrm{e}} \mathrm{s}$., il semblerait que les gargoulettes ne soient employées sur le site qu'à partir du milieu ou dans la deuxième moitié de ce siècle.

Plusieurs fragments de céramiques à pâte rouge et surfaces polies de la région de Montpellier ont été retrouvés dans le bourg de Morier (chantier de l'Alcazar). Présente déjà au siècle précédent (cf. supra ch. 2 $\S 1.4$.), cette production existe encore au moins jusqu'à la fin $\mathrm{du} \mathrm{XIII}^{\mathrm{e}} \mathrm{s}$. sans variations morphologiques tangibles, comme l'indique l'étude du mobilier d'un puits de la rue Barallerie à Montpellier (Leenhardt 1995).

\section{Les céramiques importées (Fl. Parent)}

La vaisselle en provenance des autres rivages méditerranéens semble prendre une place bien plus importante qu'auparavant dans les maisons et officines marseillaises. Sur le site de l'Alcazar, par exemple, elle représente près de $40 \%$ du mobilier céramique recueilli pour cette période. Même si elles sont encore relativement variées, les principales sources d'approvisionnement extérieures se rapprochent au fil du XIII ${ }^{\mathrm{e}} \mathrm{s}$.

\subsection{Le Maghreb, al-Andalus, la Catalogne}

L'essentiel des échanges commerciaux, du moins ceux perçus au travers des céramiques importées, semble d'avantage se resserrer autour des «proches » rivages de Méditerranée occidentale. Les productions du littoral nord africain et de la péninsule ibérique sont toujours appréciées mais sont moins nombreuses qu'au siècle précédent. 


\subsubsection{Al-Andalus}

Les régions d'al-Andalus encore sous influence islamique (Espagne, Portugal) continuent à figurer de façon minoritaire dans les importations : le port de Marseille servant vraisemblablement d'escale entre les cités portuaires italiennes et espagnoles de l'époque.

Les jarres estampées (fig. 51), également appelées tinajas, sont aujourd'hui reconnues sur la plupart des sites provençaux jusqu'à Sisteron et sur les côtes languedociennes (Vallauri 1999, fig. 1). Leur origine est encore incertaine mais la diversité des pâtes plaide en faveur de plusieurs centres de production qui se situeraient au Maghreb et/ou en Espagne du Sud, voire au Portugal. Ces produits ne sont pas rares en Provence, même s'ils sont toujours peu nombreux, et apparaissent à partir du XII ${ }^{\mathrm{e}} \mathrm{s}$. Ils sont encore utilisés au $\mathrm{XIV}^{\mathrm{e}} \mathrm{s}$. (Amouric, Richez, Vallauri 1999, p. 11-14 ; Carru 1995, p. 49 ; Vallauri 1999), alors qu'en Espagne, ces gros récipients sont attestés dès les $\mathrm{X}^{\mathrm{e}}-\mathrm{XI}^{\mathrm{e}} \mathrm{s}$. (Thiriot 1991 , p. 290). Ils sont généralement destinés au stockage de l'eau (Navarro-Palazon 1991, p. 39). Leur riche décor estampé, assez complexe, se développe soit sur la partie supérieure de la panse soit sur la totalité de la pièce. Ce décor est organisé en registres horizontaux dans lequel se mêlent arabesques et inscriptions coufiques. Dans la plupart des cas, ces vases sont recouverts sur la majorité de la pièce d'une glaçure ou d'un émail de couleur variant du vert bouteille au turquoise. Sur le col de jarre sans couverte issu d'un niveau du début du XIII ${ }^{\mathrm{e}} \mathrm{s}$. de la place Villeneuve-Bargemon (fig. 51, $\mathbf{n}^{\circ} \mathbf{3}$ ), le ressaut interne à la liaison col/panse (très abîmé) suggère la pose d'un filtre comme c'est l'usage parfois.

Enfin, un magnifique fragment de faïence décorée au lustre seul provient d'un niveau du début du XIV ${ }^{\mathrm{e}} \mathrm{s}$. de la place Villeneuve-Bargemon (fig. 52, $\mathbf{n}^{\circ} \mathbf{2}$ ). Cependant cette pièce archéologiquement complète pourrait être plus ancienne. Sa forme, sa facture et son ornementation ne sont pas sans évoquer les céramiques décorées au lustre seul fabriquées dans la seconde moitié du XIII ${ }^{\mathrm{e}} \mathrm{s}$. en Espagne du Sud, notamment à Malaga (Lerma et al. 1991, p. 194-196, fig. 13) ou dans certains ateliers de la région de Valence (Amouric et al. 1999, p. 32 ; Démians d'Archimbaud et al. 1986). Ici le décor de la pièce s'organise en trois registres superposés au moins et est très empreint de l'influence islamique. Même si le décor interne n'est pas toujours clairement lisible, on peut distinguer sur la lèvre et la partie supérieure de la panse une succession de motifs pseudo-épigraphiques séparés du médaillon central par un registre de fines arabesques. Le médaillon central est très endommagé mais on croit discerner une combinaison de motifs pseudo-épigraphiques et d'arabesques. Le revers de la pièce est entièrement émaillé et pourrait porter des traces de lustre même s'il est difficile d'être catégorique à ce sujet. Un fragment de jarrita émaillée, retrouvé dans le bourg de Morier, semble appartenir aux mêmes productions (fig. 52, $\mathbf{n}^{\circ} \mathbf{1}$ ), bien qu'il ne conserve plus aucune trace de son ornementation au lustre.

\subsubsection{La Catalogne}

Les céramiques glaçurées en provenance de Catalogne sont constituées principalement de grands bassins (alcadafe) principalement à lèvre en crochet, tombante à l'image de leurs homologues d'Afrique du Nord, parfois à lèvre moins proéminente comme sur l'exemplaire découvert à l'église Saint-Laurent (fig. 53, $\left.\mathbf{n}^{\circ} \mathbf{1}\right)$. Il arrive parfois de retrouver des pièces de service, tasse à deux anses comme celles découvertes sur le site de la place Général-de-Gaulle (Richarté 2001, p. 151, fig. 188 n¹ et 3). Tous ces vases, caractérisés par une pâte rouge à inclusions ferrugineuses, sont glaçurés en jaune ou en vert sur leur face interne pour les bassins et tasses, et en vert uniquement pour les pichets. Ces derniers possèdent une panse globulaire incisée de profondes cannelures. Cette catégorie, émergente au début du XIII ${ }^{\mathrm{e}}$ s., va surtout être massivement diffusée à la fin du XIII et au début du $\mathrm{XIV}^{\mathrm{e}} \mathrm{s}$. Elle tient une assez faible part dans la consommation marseillaise de vaisselles culinaires importées (Vallauri 1997a, p. 88, fig. 59 ; Richarté 2001, p. 149).

\subsubsection{Le Maghreb}

De grands bassins carénés à décor bleu et brun sur émail blanc accompagnent fréquemment les jarres estampées évoquées à l'instant (fig. 54). En provenance du Maghreb, plus précisément de Tunisie, ils sont diffusés au XIII ${ }^{\mathrm{e}}$ s. en quantité limitée dans toute la Provence, et de manière plus large en Italie (Berti, Tongiorgi 1981 ; Démians d'Archimbaud, Vallauri 1995, p. 70 ; Démians d'Archimbaud, Vallauri 1998, p. 85). Caractérisés par une pâte granuleuse de couleur jaune clair, ces bassins au profil anguleux, à carène prononcée et aux parois épaisses, sont pourvus soit d'une lèvre simplement repliée pour former un bourrelet (fig. 54, $\mathbf{n}^{\circ} \mathbf{1}$ ), soit d'une lèvre étirée vers l'extérieur presque à l'horizontale jusqu'à former un marli. Ils sont en général entièrement émaillés. Un décor d'arabesques au cobalt est organisé en registres horizontaux délimités par des filets tracés au brun de manganèse autour d'un motif central (fig. 54, $\mathbf{n}^{\circ} \mathbf{2}$ ), le plus souvent zoomorphe (fig. 54, $\mathbf{n}^{\circ} \mathbf{3}$ ). Les exemplaires de l'Alcazar et de la place Villeneuve-Bargemon viennent compléter la série de ceux découverts dans un puits du Panier (Moliner 1990) ou dans le quartier Sainte-Barbe (Vallauri 1997a, p. 86). 


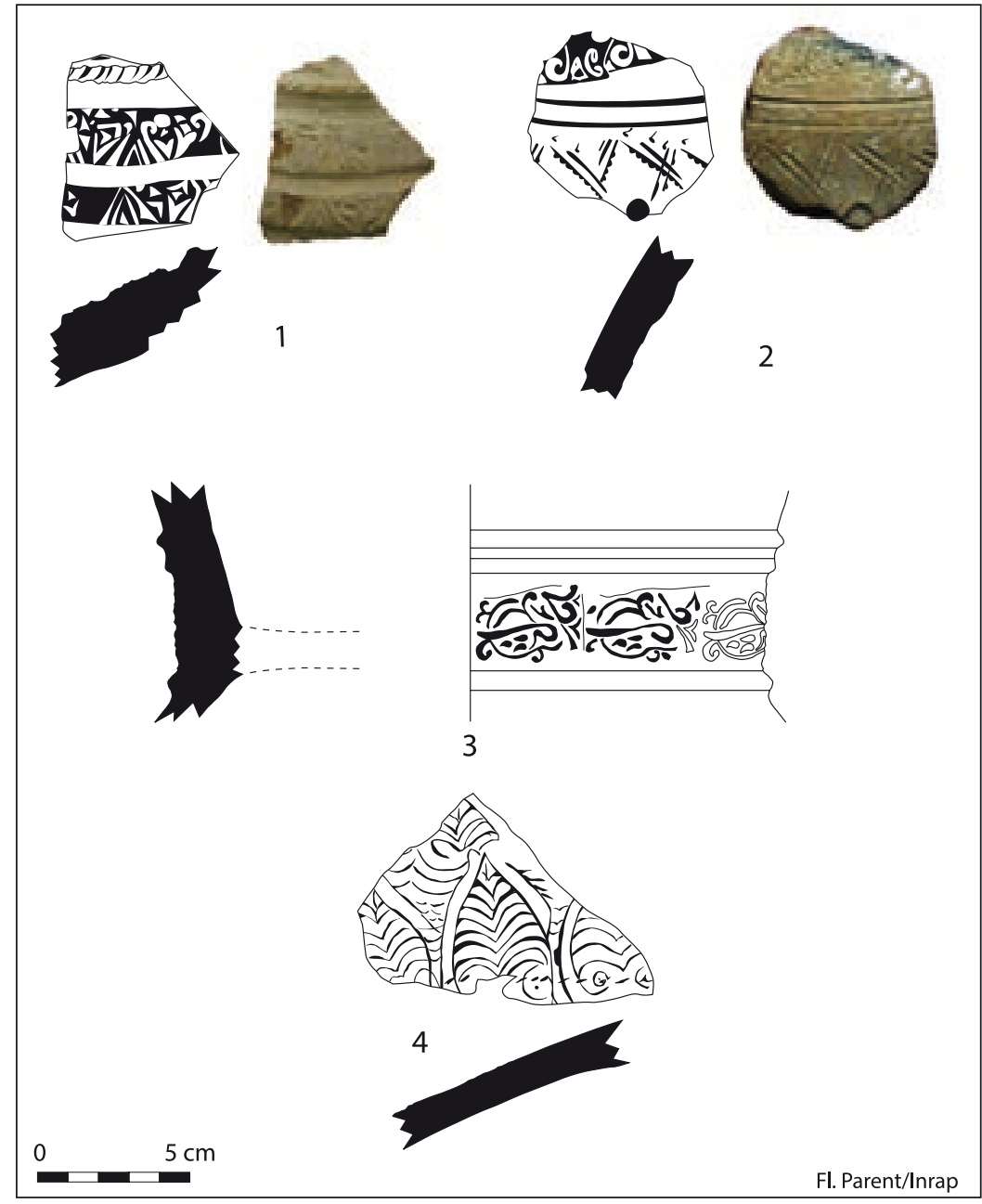

Fig. 51. Jarres estampées à glaçure verte importées d'Espagne du Sud au cours du XIII s. 1-2 : Alcazar ; 3 : Bargemon ; 4 : parvis de l'église Saint-Laurent.

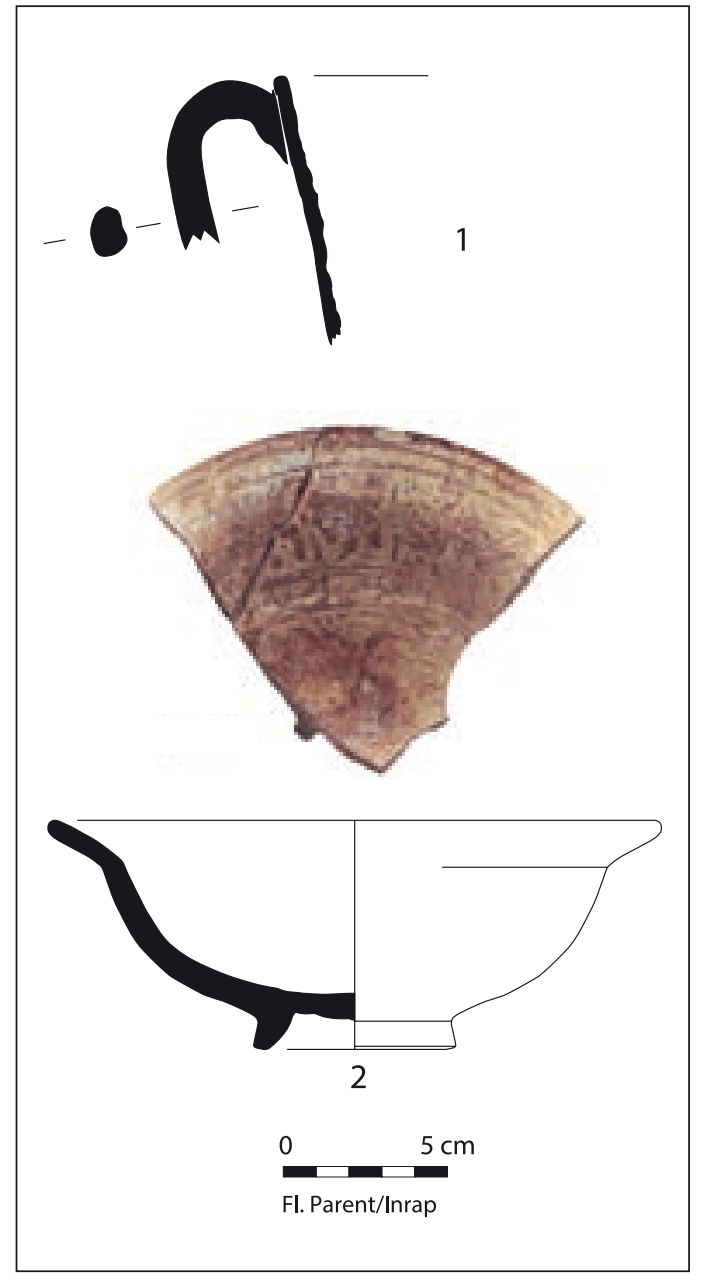

Fig. 52. Céramiques émaillées à décor de lustre importées d'Espagne du Sud au cours du XIII $\mathrm{s}$.

1 : Alcazar ; 2 : place Villeneuve-Bargemon.

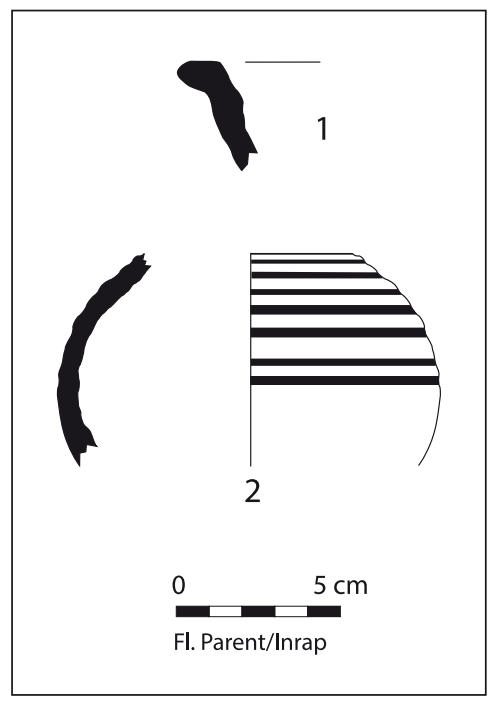

Fig. 53. Céramiques communes en provenance d'Espagne au cours du XIII ${ }^{\mathrm{e}} \mathrm{s}$. : 1 : place de la Providence ; 2 : Alcazar.

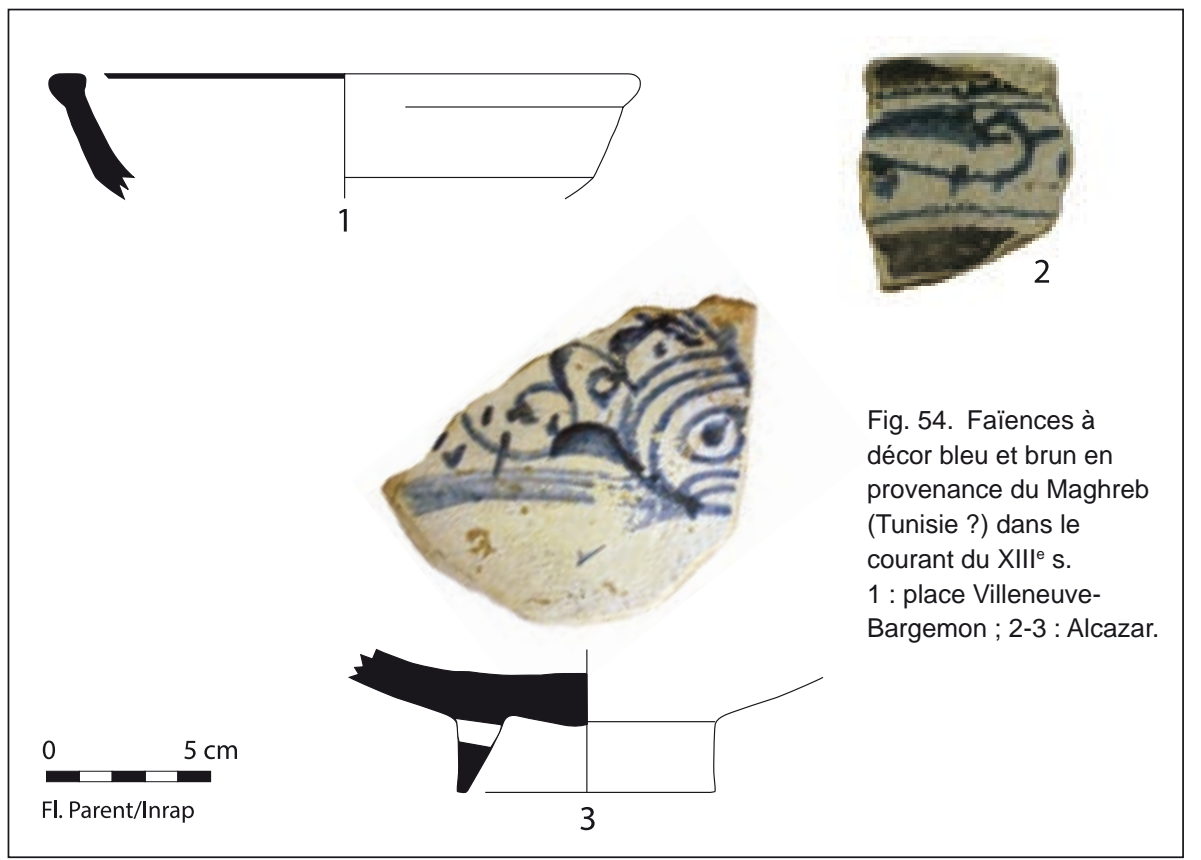




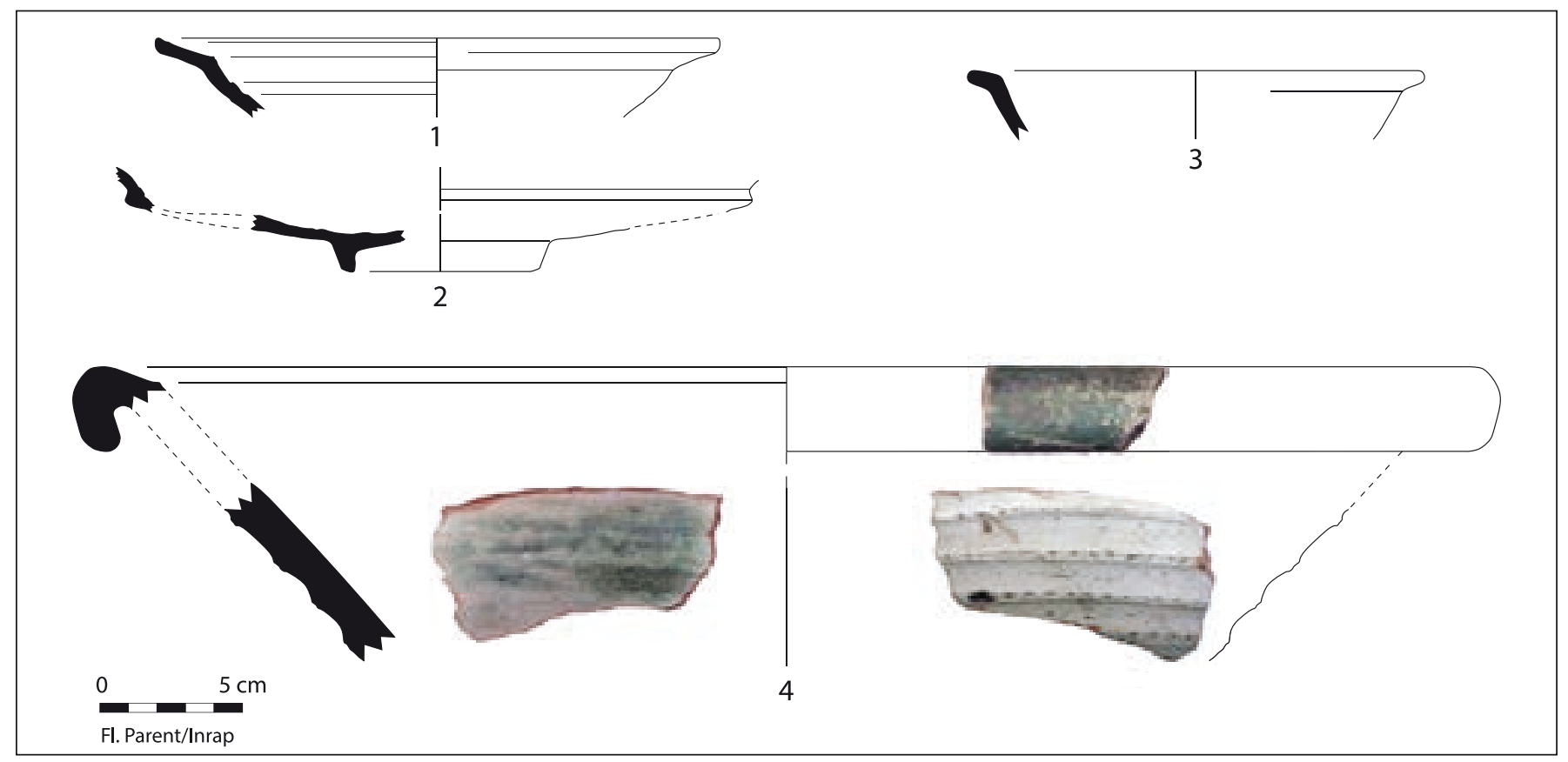

Fig. 55. Céramiques à glaçure verte supposées maghrébines importées au cours du XIIIe S. 1-2, 4 : Alcazar ; 3: rue de la République (Surverse - Vieux-Port)

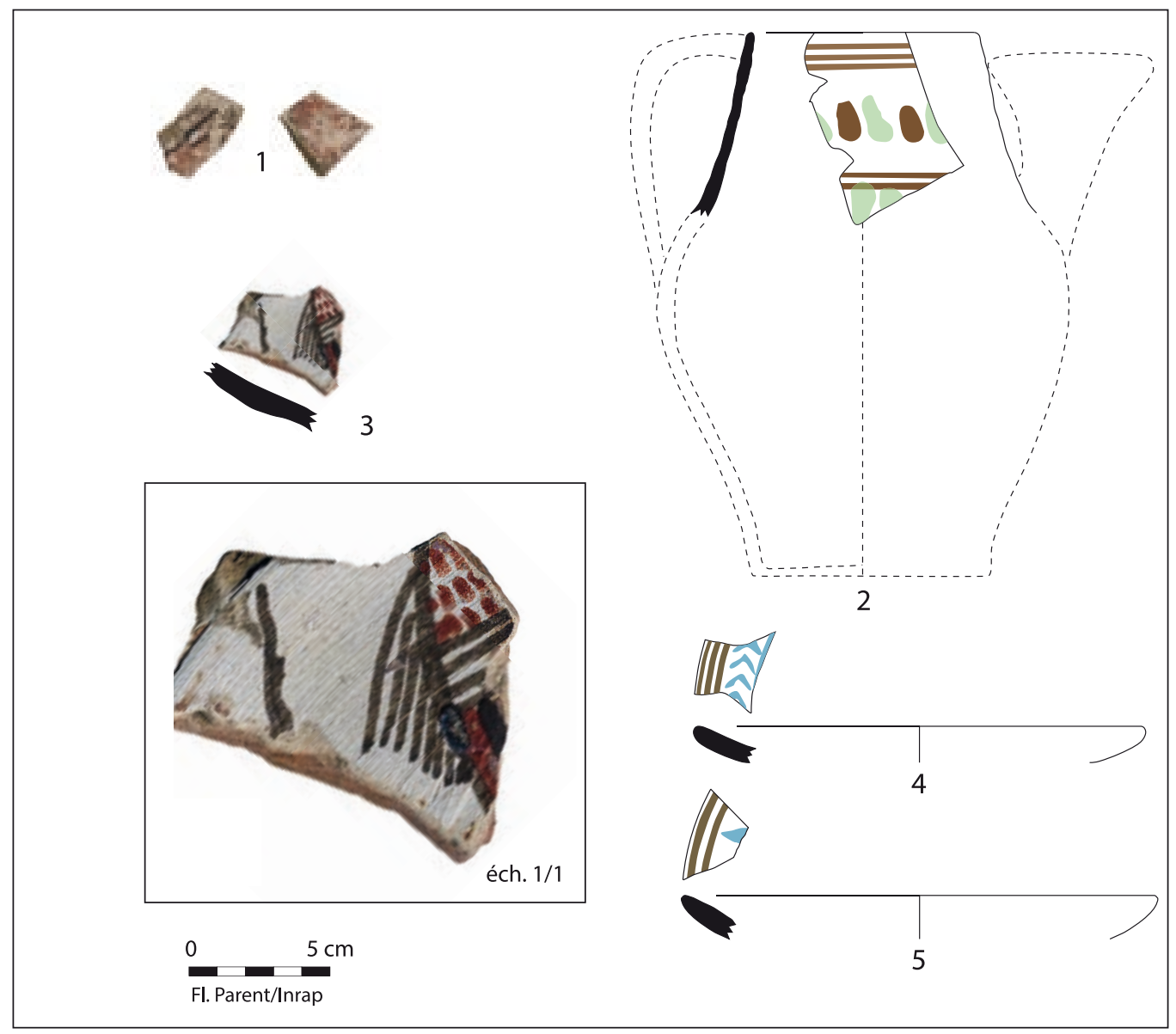

Fig. 56. Proto-majoliques originaires d'Italie du Sud ( $n^{\circ} 1$ et 3-5) et du Latium ( $\left.{ }^{\circ} 2\right)$, importées au cours du XIII ${ }^{S}$. 1 : rue de la République (Surverse - Vieux-Port)/ 2, 4, 5 : parvis de l'église Saint-Laurent ; 3 : place de la Providence. 


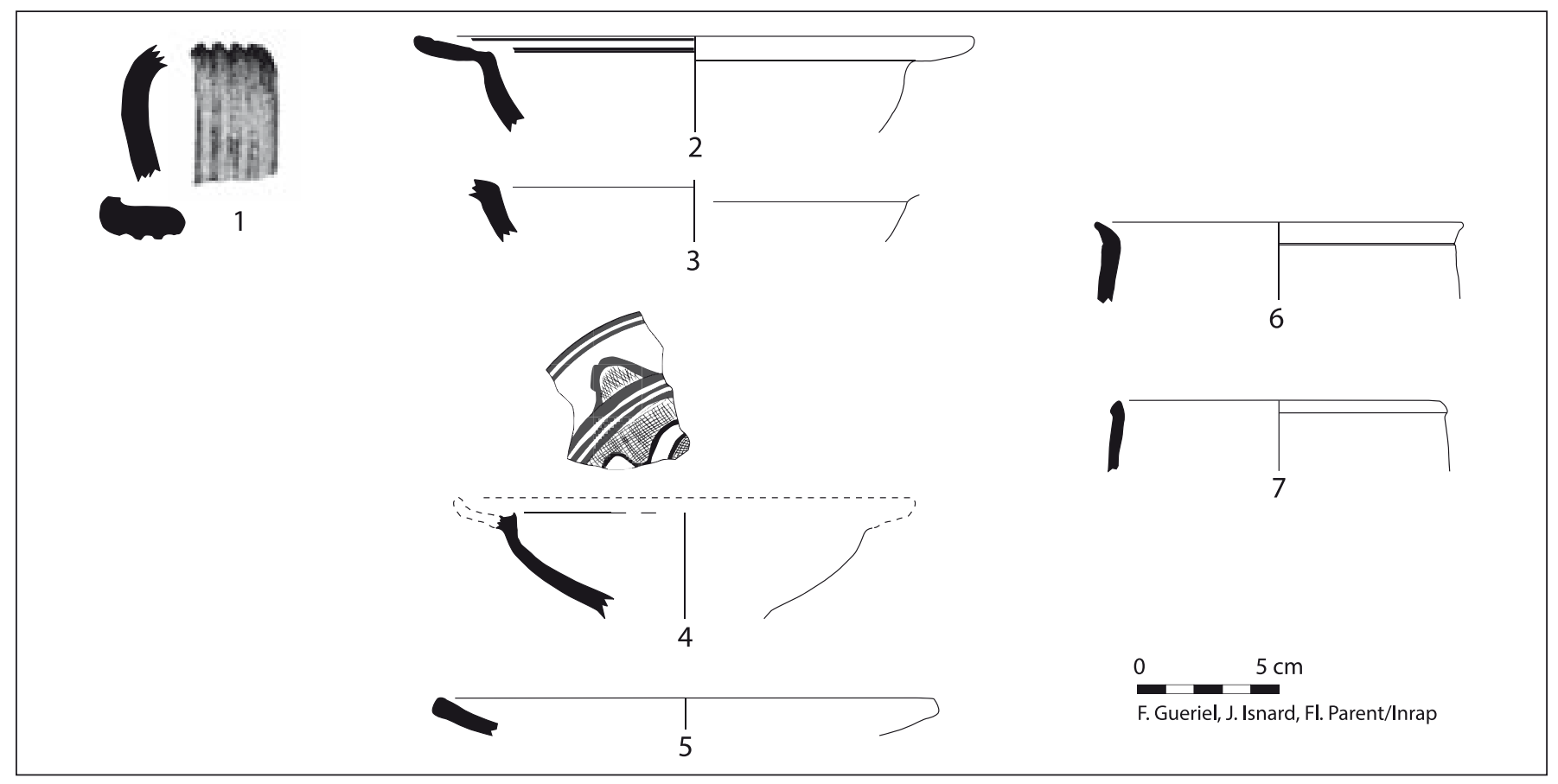

Fig. 57. Céramiques supposées d'origine siculo-maghrébine, importées au XIII s. 1, 3 : place Villeneuve-Bargemon ; 2, $6:$ Alcazar ; 4 : parvis de l'église Saint-Laurent ; 5,7 : place de la Providence.

D'autres éléments peuvent être rapprochés de ces productions mais cette attribution est plus aléatoire, fondée uniquement sur l'aspect de leur pâte : même pâte sableuse de couleur claire, vacuolaire et contenant un fin dégraissant noir, très proche visuellement de celle composant les faïences à décor bleu et brun tout juste présentées. Par contre, leur forme n'appartient absolument pas au même registre. Ce sont des coupes et coupelles aux parois fines, à marli, aux stries de tournage très prononcées (fig. 55, $\mathbf{n}^{\circ} \mathbf{1}$ ). Une autre se rapprocherait plutôt d'un plat à carène soulignée d'un ressaut ou bien d'un couvercle mouluré (fig. 55, $\mathbf{n}^{\circ} \mathbf{2}$ ). Le profil de la dernière est plus lourd et semble moins travaillé (fig. 55, $\mathbf{n}^{\circ} \mathbf{3}$ ). Elles sont toutes recouvertes de glaçure verte opaque et épaisse, peut-être un émail, parfois accompagnée d'une glaçure transparente comme sur les $n^{\circ} 1$ et 2 . Â l'Alcazar et à la rue de la République, elles se retrouvent toujours dans des contextes du XIII ${ }^{\mathrm{e}}$ s., et plus précisément de la première moitié pour la $\mathbf{n}^{\circ} \mathbf{3}$.

Un bassin aux dimensions imposantes (environ $50 \mathrm{~cm}$ de diamètre, fig. 55, $\mathbf{n}^{\circ} \mathbf{4}$ ), n'est pas sans évoquer ceux qui proviennent du monde islamique au siècle précédent (cf. supra ch. 2 § 2.1.6.) avec ses parois tronconiques décorées de bandes guillochées terminées par une lèvre en crochet tombante. Contrairement à ces « précurseurs », celui-ci est enduit d'une glaçure interne vert bouteille qui recouvre également toute la lèvre en crochet. Ses caractéristiques de pâte et sa surface externe blanchie incitent à localiser sa fabrication dans le nord de l'Afrique.

\subsection{L'Italie du Sud et Sicile}

Les céramiques émaillées et décorées en provenance du sud de l'Italie et de Sicile au XIII ${ }^{\mathrm{e}}$ s., autrement appelées proto-majoliques, sont extrêmement rares. Elles sont cependant repérées sur plusieurs sites provençaux et plus particulièrement à Marseille où quelques spécimens ont été dégagés au fond d'un puits du quartier du Panier (Moliner 1990), dans le quartier de potiers de Sainte-Barbe (Vallauri 1997a) ou encore dans le bourg Sainte-Catherine (Richarté 2001), en bien meilleur état de conservation que ceux des chantiers étudiés dans cet ouvrage. En effet, si plusieurs exemplaires ont pu être identifiés, rares sont ceux qui ont pu être figurés ici car aucun élément de forme assez important ne nous est parvenu ; mais il n'en demeure pas moins important de les signaler. Les coupelles provenant de la région de Gela en Sicile se distinguent par leur décor associant trois couleurs différentes - le jaune, le vert et le brun -, avec des motifs de tresses pointées sur le marli encadrant un dessin zoomorphe au centre de la calotte de la panse. Ces coupelles circulent de la fin du XII jusqu'au début du $\mathrm{XIV}^{\mathrm{e}}$ s., et semblent être assez appréciées puisqu'elles ont été imitées dans la première moitié du XIII ${ }^{\mathrm{e}} \mathrm{s}$. par les potiers marseillais de Sainte-Barbe d'une part (Vallauri, Leenhardt 1997, p. 83), et par les potiers de Ligurie d'autres part (Milanese 1982 a, p. 90-91 ; Milanese 1982b, p. 94, 98). 
Encore plus rares sont les faïences importées à décor dit RMR alliant le brun, le vert et le rouge. Deux fragments de ce type retrouvés à proximité du Vieux-Port permettent d'identifier un vase fermé, probablement un pichet (fig. 56, $\mathbf{n}^{\circ} \mathbf{1}$ ). En Italie, de tels produits apparaissent surtout dans des contextes du XIII ${ }^{\mathrm{e}}$ s., comme à Naples, en Campanie ou dans les Pouilles (Peduto 2000, p. 85 ; Ebanista, Fusaro 2000, p. 126). Ils sont également diffusés jusqu'à 'Atlit (Riavez 2000) et Acre (Avissar, Stern 2005 , p. 69) à la fin du XIII ${ }^{\mathrm{s}}$ s. La plupart sont attribués à la région de Brindisi. Le fragment de coupelle décoré d'un poisson tracé en brun, aux écailles rouges, trouvé à proximité de l'Alcazar (fig. 56, $\mathbf{n}^{\circ} \mathbf{3}$ ) pourrait être rapproché de ces productions du sud de l'Italie.

Deux bords de coupes (fig. 56, $\mathbf{n}^{\circ}$ 4-5) peuvent également être attribués à des productions de la région de Brindisi dans les Pouilles (Pattitucci Uggeri 1997). À pâte siliceuse grisâtre ou beige rosé, leur face externe est nue et leur face interne est couverte d'un émail blanc très fin légèrement transparent (sans doute pauvre en étain). Leur lèvre effilée porte un autre décor typique de ces productions : des filets bruns encadrant un registre de chevrons bleus. Ces productions sont attestées de manière diffuse au XIII ${ }^{\mathrm{e}} \mathrm{s}$. sur tout le littoral provençal. À Marseille, elles se retrouvent également dans un puits du quartier de la Cathédrale et dans le bourg des Olliers (Moliner 1990 ; Marchesi et al. 1997, p. 83, fig. 56-1).

La série des céramiques supposées siculo-maghrébines, à pâte rouge et glaçure, importée dès le XII ${ }^{\mathrm{e}} \mathrm{s}$. à Marseille et sur le littoral provençal (cf. supra § 2.1.7.) continue d'être diffusée au cours du XIII ${ }^{\mathrm{e}} \mathrm{s}$. mais tend à disparaître à la fin de ce siècle ou au début du suivant. Le répertoire ne semble pas évoluer par rapport au siècle précédent comme l'illustrent les quelques exemplaires de la fig. 57.

\subsection{Le reste de l'Italie}

La fin du XII ${ }^{e}$ s. et le siècle suivant voit l'introduction de nouvelles aires d'approvisionnement, avec des régions jusqu'alors quasi-absentes, du moins dans l'état actuel de nos connaissances, comme le Latium et la puissante Ligurie.

\subsubsection{La Ligurie}

Les céramiques engobées, incisées puis glaçurées, en provenance de la côte ligure, sont généralement désignées dans la littérature sous les termes de sgraffito archaïque ou graffita arcaica tirrenica. Comme partout où elles sont diffusées, seules sont présentes à Marseille des formes ouvertes, que ce soient des coupes tronconiques (fig. 58, $\mathbf{n}^{\circ} \mathbf{3}$ ) ou, plus fréquemment, des écuelles à marli (fig. 58, $\left.\mathbf{n}^{\circ} \mathbf{1}, \mathbf{4}\right)$. Présentes dans toute la région provençale, ces céramiques ligures sont utilisées durant tout le $\mathrm{XIII}^{\mathrm{e}} \mathrm{s}$. et encore au tout début du $\mathrm{XIV}^{\mathrm{e}} \mathrm{s}$. avant d'être ensuite supplantées sur le marché par les majoliques pisanes (Démians d'Archimbaud, Vallauri 1998, p. 86-87). Les motifs décoratifs, incisés et rehaussés de vert et brun sous la glaçure, sont essentiellement géométriques (entrelacs, chevrons, quadrillages...) et combinés de manière plus ou moins dense suivant les exemplaires (fig. 58, $\mathbf{n}^{\circ} \mathbf{2 - 5}$ ). La coupe au décor très soigné de poissons, motif rare même en Italie (Varaldo 1997, p. 443), échappe à cette nomenclature (fig. 58, $\mathbf{n}^{\circ} \mathbf{1}$ ). Elle appartient sans doute aux importations les plus anciennes de ce type, de la fin du $\mathrm{XII}^{\mathrm{e}} \mathrm{s}$. ou de la première moitié du XIII ${ }^{\mathrm{e}} \mathrm{s}$., même si elle a été découverte dans la destruction du bourg de Morier (vers 1360). Quelques fragments ne portent aucun décor. L'engobe blanc interne est uniquement recouvert d'une glaçure soit incolore soit monochrome vert foncé ou jaune.

\subsubsection{Le Latium}

Les proto-majoliques du Latium se caractérisent par une pâte calcaire de couleur beige à jaunâtre, sur laquelle est déposé un émail blanc fin rehaussé d'un décor aux oxydes de cuivre (vert), manganèse (brun) et antimoine (jaune). Les exemplaires, rares en Provence, ne réunissent que des fragments de cruches. À Marseille, très peu de spécimens sont recensés jusqu'à maintenant : un sur le site de la place Jules-Verne (Vallauri 1995, p. 71, fig. 6-1), une cruche presque complète et quelques fragments d'une deuxième dans un puits de la rue de la Cathédrale (Moliner 1990, p. 204-205, fig. 4-6), encore un fragment issu de la fouilles des ateliers de SainteBarbe (Marchesi et al. 1997, p. 83, fig. 56-4), un autre aux abords de l'église Saint-Laurent (fig. 56, $\mathbf{n}^{\circ} \mathbf{2}$ ). À ceux-ci, il convient désormais d'en rajouter un septième dans le bourg de Morier. Ces cruches sont de dimension variable et adoptent un profil quelque peu «standardisé » : un bord légèrement rentrant, à col peu marqué dans l'alignement de la panse, une anse large rubanée, un fond plat. Mais l'élément caractéristique reste le bec dit « en mandorle», directement héritée des formes plus anciennes dites «a vetrina pesante » et originaires des mêmes contrées. Ces formes peuvent être ornées de motif géométrique ou végétal stylisé, voire les deux, ou exceptionnellement de motif héraldique (Molinari 1990, p. 408-417). À Rome, ces cruches ont été retrouvées en grande quantité dans des niveaux de la première moitié du XIII ${ }^{\mathrm{e}}$ s., en majorité sur leurs sites de production (Molinari 1990, p. 398-400). 


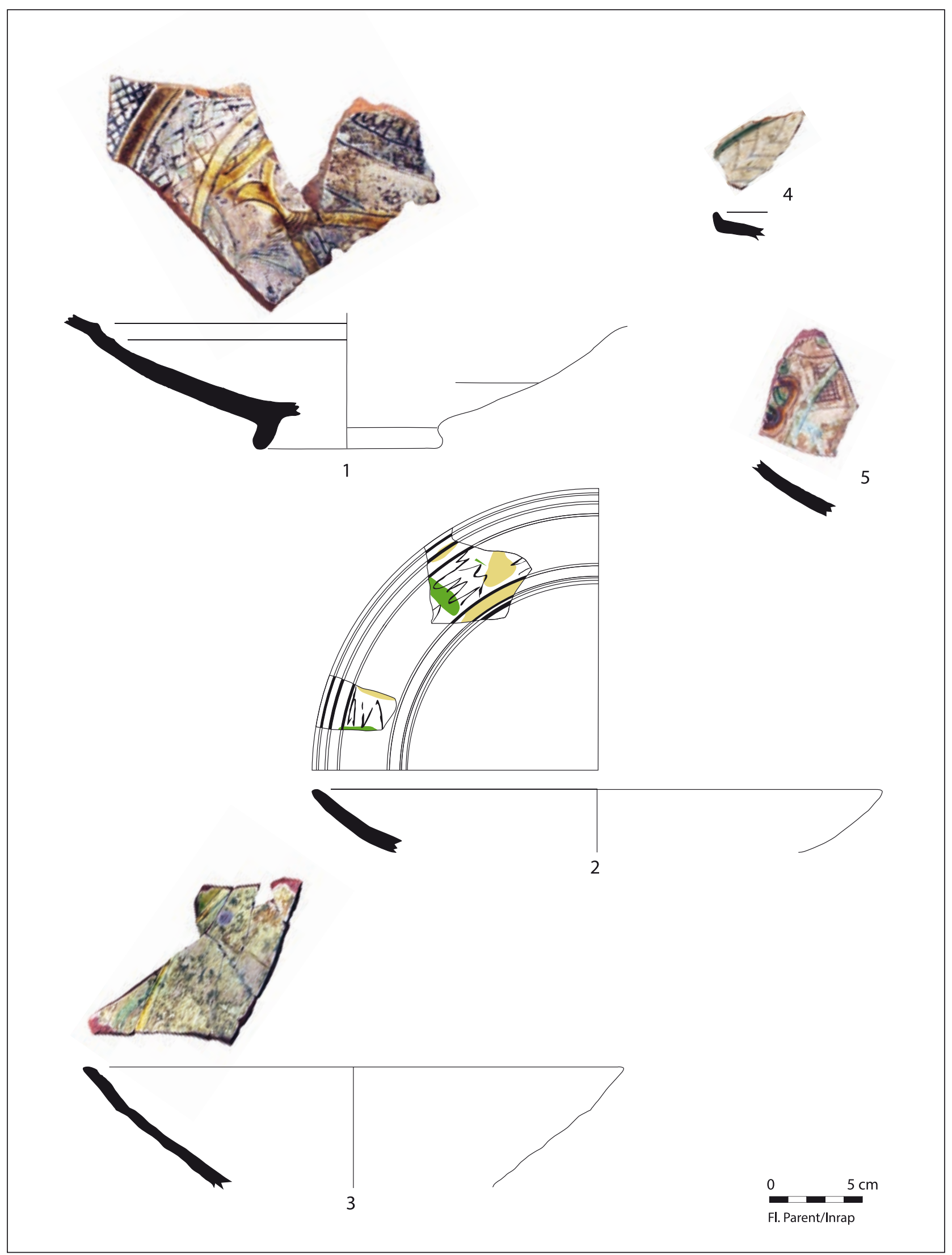

Fig. 58. Céramiques engobées et glaçurées à décor incisé (graffita archaica tirrenica) importées de Ligurie au cours du XIII' s. 1 : Alcazar ; 2 : parvis de l'église Saint-Laurent ; 3,5 : Collège Vieux-Port ; 4 : rue de la République (Surverse Vieux-Port). 


\subsection{La Méditerranée orientale}

La découverte de rares produits en provenance de ces contrées éloignées ne sauraient impliquer, du seul fait de leur présence, un véritable commerce de la céramique avec la Méditerranée orientale. Peut-être ont-ils été débarqués sur les quais marseillais à l'occasion du déchargement d'une autre cargaison ou dans les bagages d'un négociant.

\subsubsection{Les céramiques à pâte siliceuse et décor brun sous glaçure alcaline}

Il y a une vingtaine d'années maintenant qu'a été entamé, dans le sud de la France, l'inventaire de ces céramiques aussi rares que précieuses, provenant de l'Orient qu'on dit «fabuleux » (Thiriot 1991; Thiriot 1995). Ces céramiques sont réalisées à partir d'une argile de synthèse permettant la confection de formes particulièrement fines et élégantes, soit par tournage, soit par moulage. La glaçure alcaline épaisse qui les recouvre est très souvent teintée en bleu, bleu turquoise ou bleu foncé, et les motifs (d'une grande finesse également) sont traités en brun-noir. Ce recensement démontre que les vases de ce type sont très peu diffusés et se retrouvent dans le sud de la France sur une période assez longue s'étendant du $\mathrm{XII}^{\mathrm{e}}$ s. jusqu'aux $\mathrm{XV}^{\mathrm{e}}-\mathrm{XVI}^{\mathrm{e}} \mathrm{s}$. au moins. Leurs lieux de production ne sont pas connus et peuvent être multiples. Ils semblent se situer autour de l'Égypte ou de la Syrie.

Même si les quelques fragments (fig. 59) qui viennent compléter ici cet inventaire ont été découverts dans des contextes du XIII' s., il convient de garder à l'esprit qu'ils peuvent être plus anciens. Leur raffinement exotique et leur fragilité ayant sans doute conduit leur propriétaire à en prendre le plus grand soin pendant de longues années. Aujourd'hui, ils nous sont parvenus en très petits fragments, ce qui rend difficile l'identification de leur forme et encore plus leur représentation. Une douzaine de fragments de ce type a été découvert sur le site de l'Alcazar. Il s'agit pour l'essentiel de fragments de coupelles pour moitié à glaçure verte uniforme, et de formes fermées à décor brun sous une glaçure turquoise ou bleu foncé (fig. 59, $\mathbf{n}^{\circ} \mathbf{3}$ ). Un fragment de forme ouverte à glaçure turquoise a également été découvert sur le site du collège Vieux-Port (fig. 59, $\left.\mathbf{n}^{\circ} \mathbf{1}\right)$.

\subsubsection{Les céramiques engobées et glaçurées en provenance de Méditerranée orientale}

Les contacts avec la Méditerranée orientale, minimes mais évidents au XII ${ }^{\mathrm{e}}$ s. (cf. supra ch. 2 \$ 2.2.), semblent se poursuivre. Au début du XIII' s., on aperçoit toujours, dans les contextes marseillais, quelques importations

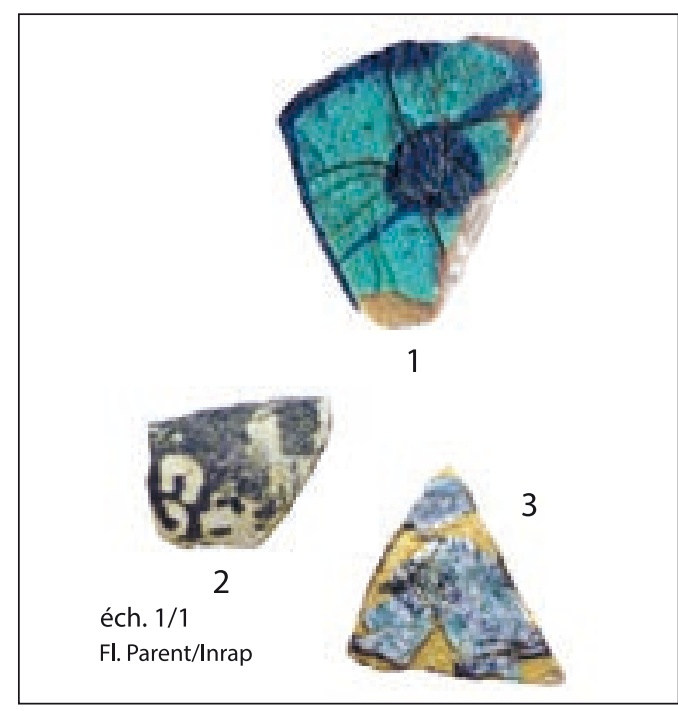

Fig. 59. Céramiques à pâte siliceuse et décor sous glaçure alcaline, en provenance du Proche-Orient. 1 : Collège Vieux-Port ; 2-3 : Alcazar.

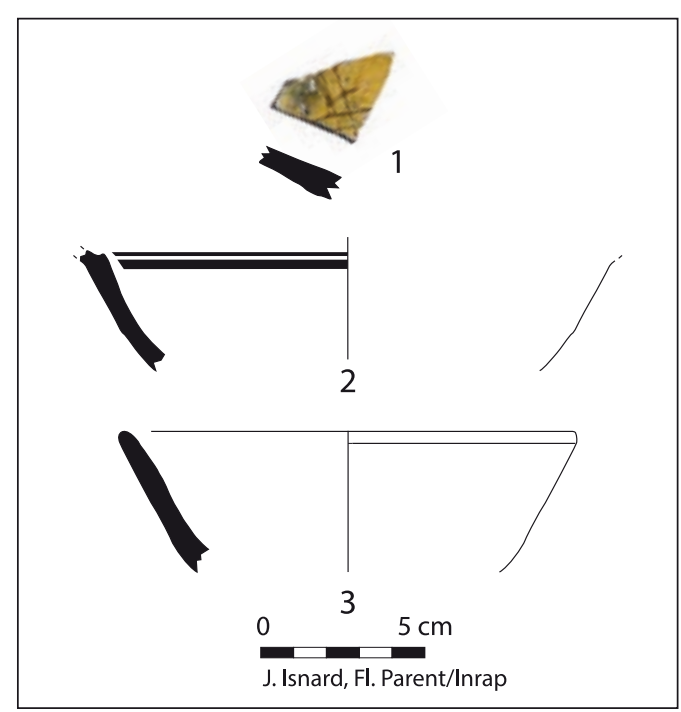

Fig. 60. Céramiques engobées et glaçurées en provenance de Méditerranée orientale au cours du XIII' $\mathrm{S}$. 1 : collège VieuX-Port ; 2 : place de la Providence ; 3 : Alcazar.

supposées égéennes (Démians d'Archimbaud et al. 2003), à pâte claire micacée, engobées et vernissées monochromes et/ou à décor de coulures, dont la morphologie ne semble pas évoluer : coupes à large marli et calotte hémisphérique, portées par un fond annulaire surcreusé ou coupes à parois redressées (fig. 60, $\mathbf{n}^{\circ} \mathbf{3}$ ). Elles sont également accompagnées de leurs homologues en pâte rouge brique dure aux formes plus épaisses. Cependant leur consommation ne semble pas excéder les premières décennies du siècle.

Le petit fragment de coupelle à marli, au décor de fines incisions sous couverte jaune moutarde, illustre à 


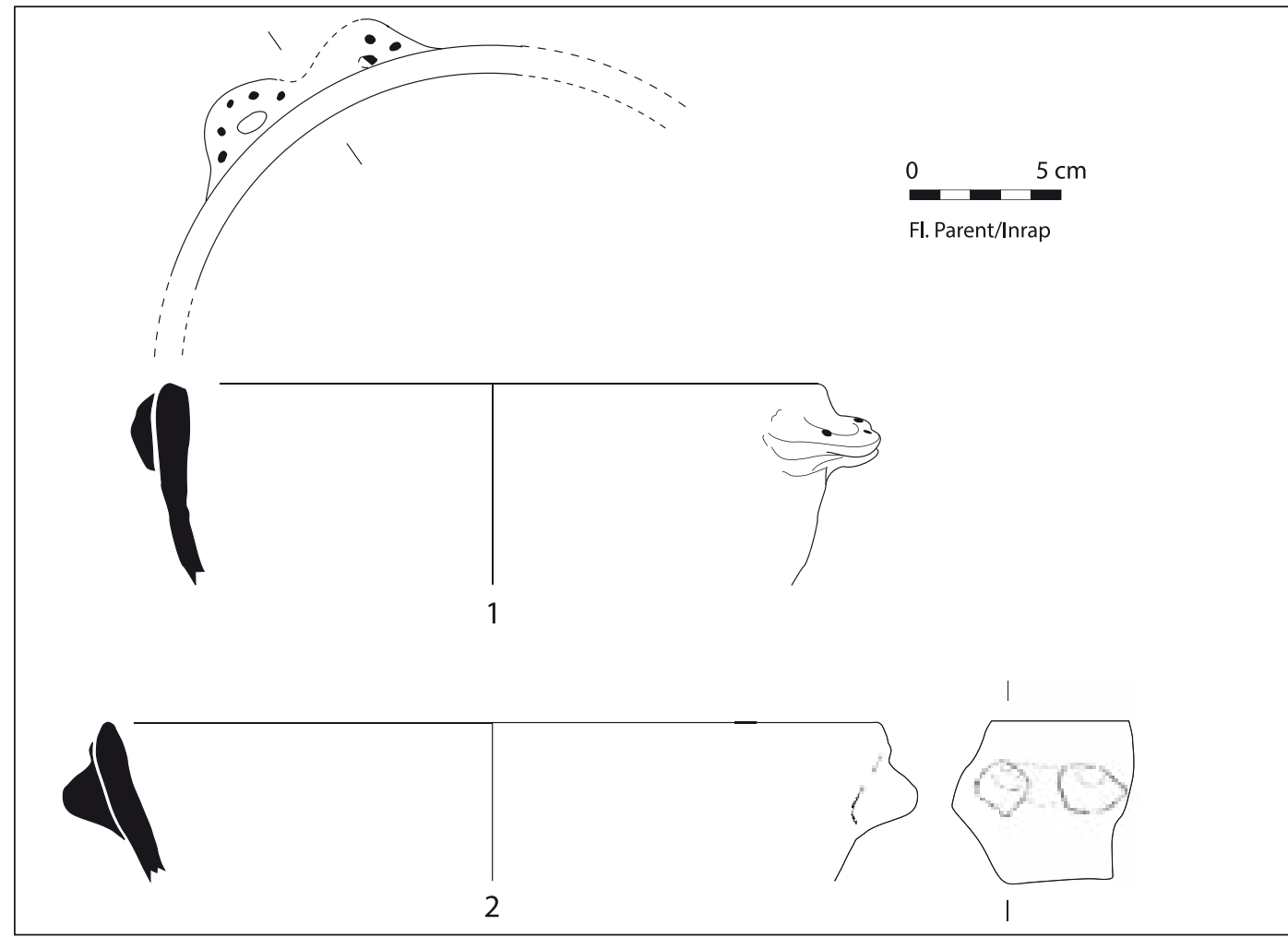

Fig. 61. Céramiques à pâte rouge modelées et glaçurées du XIII $\mathrm{e}$., d'origine indéterminée. 1 : Alcazar ;

2 : parvis de l'église Saint-Laurent.
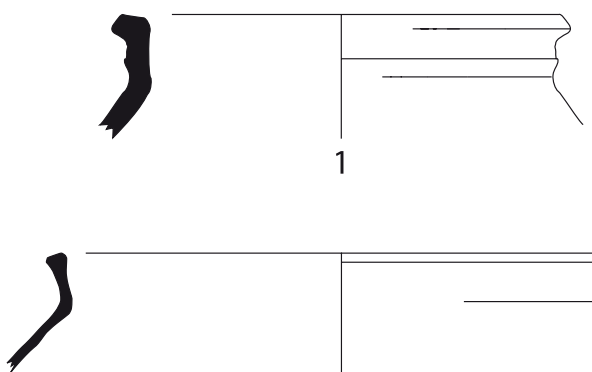

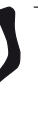
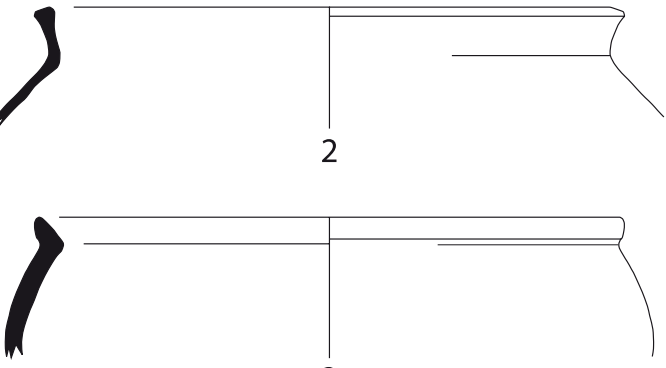

3
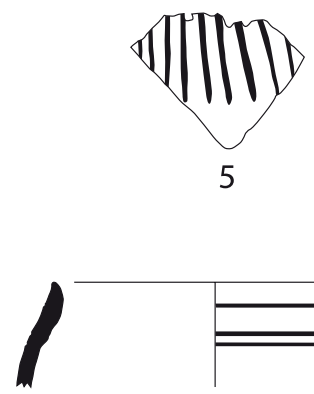

5
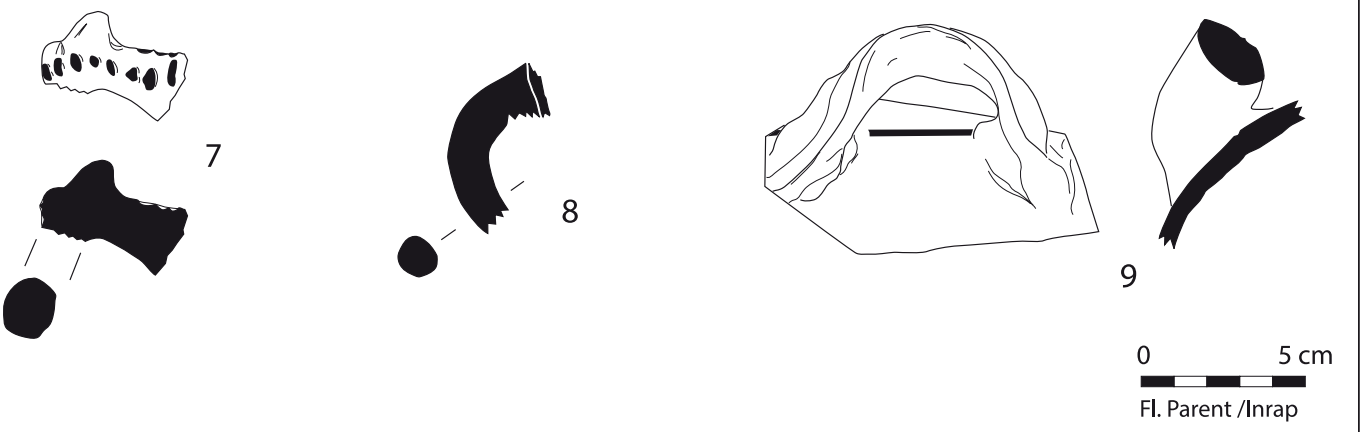

Fig. 62. Céramiques à pâte rouge glaçurée d'origine supposée ou indéterminée, importées à Marseille à la fin du XIIe s. et au cours du XIII s. 1, 6-9 : Alcazar : 2 : collège Vieux-Port ; 3-5: place

Villeneuve-Bargemon. 
nouveau les riches et variées productions à décor incisé de cette partie du bassin méditerranéen (fig. 60, n⿳1 1 ), tout comme le fragment découvert à proximité du bourg de Morier (fig. 60, $\mathbf{n}^{\circ} \mathbf{2}$ ). Cette coupelle à marli au décor incisé appartient à la grande famille des Zeuxippus Ware et dérivés (cf. supra ch. 2 § 2.2.3.). Il n'est pas impossible que le fond de ces deux coupelles, aujourd'hui disparu, ait été orné d'un médaillon central incisé.

\section{Les céramiques d'origine indéterminée (Fl. Parent)}

Comme chaque période évoquée dans ce volume, celle-ci contient son lot de céramiques dont l'origine n'a pu être décelée avec certitude ou dont la provenance demeure encore totalement inconnue. Il s'agit ici essentiellement de céramiques en pâte rouge glaçurée.

\subsection{Les céramiques modelées à pâte rouge glaçurée}

Comme nous l'avons déjà évoqué (cf. supra ch. 2 § 2.3.1.), les céramiques modelées à pâte rouge glaçurées importées (fig. 61) arrivent dans notre région au cours du XII ${ }^{\mathrm{e}}$ s. mais c'est au XIII ${ }^{\mathrm{e}}$ qu'elles deviennent plus nombreuses, comme l'ont démontré les fouilles de ces dernières années à Marseille et alentour (Richarté 2001 ; Vallauri 1995; Vallauri 1997a ; Parent 1997, Parent 2001 ; Leenhardt et al. 1996 ; Démians d'Archimbaud, Vallauri 1998). Leur déclin semble lentement s'amorcer dès la seconde moitié du XIII ${ }^{\mathrm{e}} \mathrm{s}$. et elles tendent à se raréfier à partir du premier quart du $\mathrm{XIV}^{\mathrm{e}} \mathrm{s}$. Longtemps dites « ligures », elles sont identifiables à leur pâte rouge vif, à gros dégraissants anguleux de feldspath et de quartz (Capelli et al. 2009, p. 937-946). Nous l'avons vu précédemment, de récentes analyses (Capelli et al. 2006, p. 937, Capelli et al. 2009, p. 937-938) ont exclu la côte ligure des aires de production, et propose maintenant le Midi de la France, l'Espagne nord-orientale ou encore le secteur égéo-anatolien occidental, bien que cette dernière proposition paraisse peu probable.

\subsection{Les céramiques à pâte rouge glaçurée d'origine présumée ou indéterminée}

Les récipients regroupés ici proviennent certainement d'horizons divers. C'est du moins ce que suggère la diversité de leurs pâtes toujours rouges et de leur formes, bien qu'ils soient tous revêtus d'une glaçure plombifère mais chacun à des degrés divers, passant de la simple goutte jusqu'au recouvrement uniforme des deux faces.
Certains marquent le prolongement, dans le XIII ${ }^{\mathrm{e}} \mathrm{s}$, d'importations déjà présentes au siècle précédent, à l'image du fragment de forme fermée recouvert d'une glaçure teintée au manganèse qui lui confère un aspect de peau d'aubergine (fig. $\mathbf{6 2}, \mathbf{n}^{\circ} \mathbf{5}$ ). Celui-ci rejoint une précédente série attribuée à l'aire byzantine (cf. supra ch. 2 $\S 2.2 .4$.). Avec le bord de pot à panse globulaire rainurée et lèvre étirée (fig. 62, $\mathrm{n}^{\circ} \mathbf{3}$ ) et le fragment de "marmite » à anse horizontale (fig. $\mathbf{6 2}, \mathbf{n}^{\circ} \mathbf{9}$ ), il témoigne de la continuité des rapports commerciaux entre Marseille et cette région au début du XIII ${ }^{\mathrm{e}} \mathrm{s}$. et, par là-même, que les relations avec le Levant ne s'arrêtent pas brutalement à la fin du XII ${ }^{\mathrm{e}} \mathrm{s}$.

Un fragment de petit pot et une anse de pichet (fig. 62, $\mathbf{n}^{\circ} \mathbf{6}, \mathbf{8}$ ), tous deux à couverte miel (melado), attestent également du suivi des rapports avec l'Espagne du Sud en ce début de siècle (cf. supra ch. 2 § 2.1.3.).

Le fragment de pichet découvert place VilleneuveBargemon (fig. 62, $\mathbf{n}^{\circ} \mathbf{4}$ ) pourrait trouver un rapprochement avec deux coupelles de lampes et un fond de pichet (fig. 34, ${ }^{\circ}$ 4-6) trouvés au même endroit dans des contextes du XII $\mathrm{s}$.

L'origine d'un certain nombre d'objets demeure cependant énigmatique : un bord de marmite ou de pot en pâte rouge grossière (fig. $\mathbf{6 2}, \mathrm{n}^{\circ} \mathbf{1}$ ), un autre bord de pot à pâte rouge kaolinitique qui pourrait éventuellement être de production régionale (fig. $\mathbf{6 2}, \mathbf{n}^{\circ} \mathbf{2}$ ) et une anse à ergot, en boudin et parsemée de perforations circulaires (fig. $62, \mathbf{n}^{\circ}$ 7) en pâte rouge siliceuse.

\section{L'opulent quartier canonial de la Major ? Un exemple de l'approvisionnement en céramiques aux $\mathrm{XII}^{\mathrm{e}}$ et XIII ${ }^{\mathrm{e}}$ s. (C. Richarté)}

La mise en perspective des données céramiques recueillies lors des fouilles du Tunnel de la Major a permis d'ébaucher une image de la consommation et de proposer une répartition des entrées et des «parts de marché » dans l'approvisionnement de ce quartier de Marseille aux XII ${ }^{\mathrm{e}}$ et XIII' ${ }^{\mathrm{e}}$ s. (Richarté 2004, p. 175-186). L'étude de ce matériel, qui s'avère très diversifié, permet non seulement de préciser des origines de productions, mais également de définir de larges aires d'influence. Nous proposerons ici une vision centrée sur ce seul espace urbain, au sein du quartier canonial.

Les assemblages céramiques caractéristiques des séquences stratigraphiques du XII ${ }^{\mathrm{e}} \mathrm{s}$. et a fortiori au $\mathrm{XIII}^{\mathrm{e}}$ s., sont radicalement marqués par un phénomène de diversification. On observe en effet un changement de la composition du vaisselier remarquable à la fois par un début de panachage, avec l'introduction graduelle de terres vernissées (14\%) qui tranchent avec le mobilier 


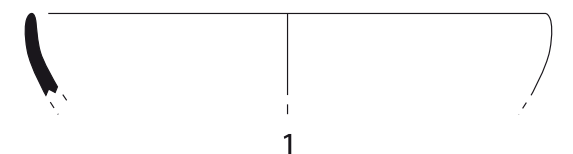

1

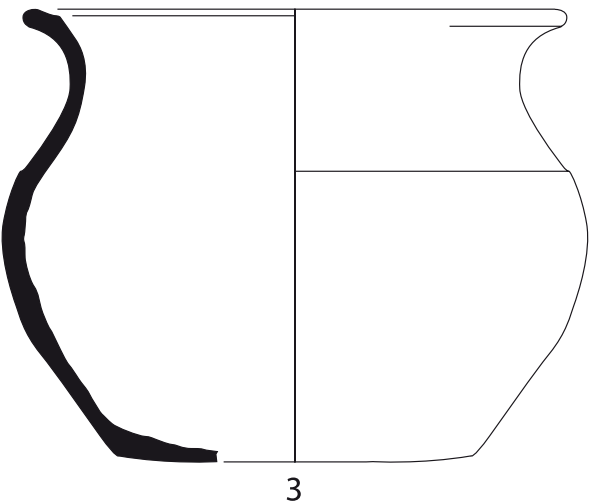

3

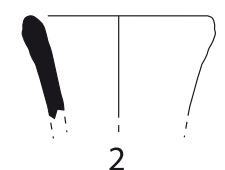

2

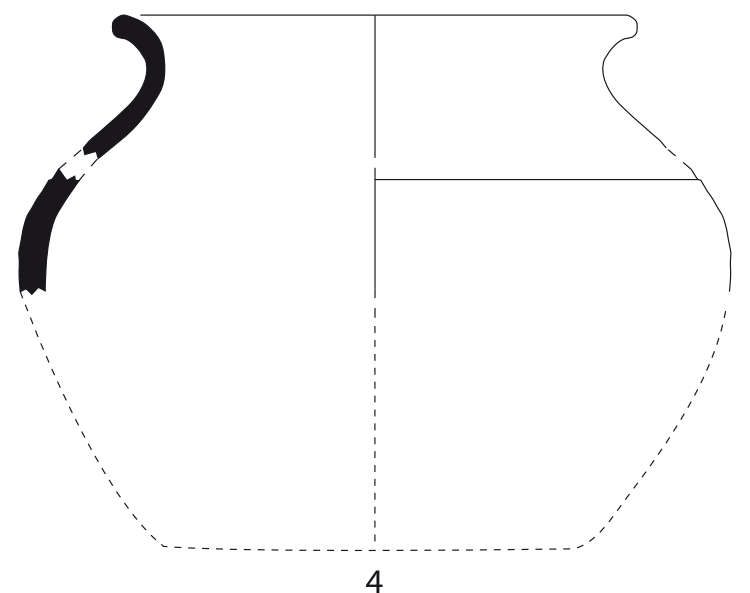

4
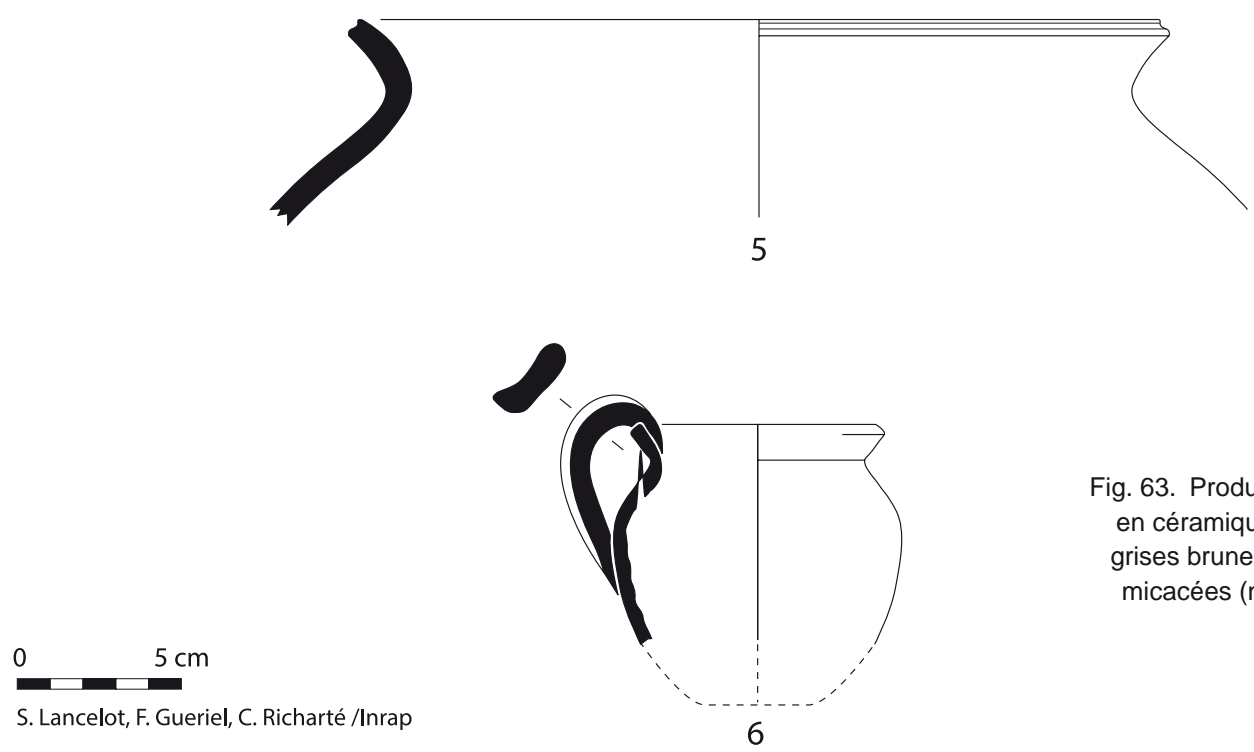

Fig. 63. Productions régionales des $\mathrm{XIII}$ es. en céramique grise/brune. Communes grises brunes $\left(n^{\circ} 1-2\right)$, culinaires brunes micacées ( $\left.n^{\circ} 3-6\right)$. Tunnel de la Major.

gris ordinairement en usage (86\%), et par une diversification du corpus avec l'arrivée de nouvelles pièces, notamment ouvertes, puis ornées. La vaisselle vernissée, plus spécialement apparentée au service à verser, en pâte rouge ou claire et à vernis brun, vert ou même transparent devient en effet très présente. Par la suite, des majoliques à couvertes opacifiées (engobe et émail) et décors d'oxydes peints s'insèrent progressivement dans ce vaisselier médiéval et enrichissent considérablement un répertoire typologique jusque-là presque essentiellement composé de récipients à usage culinaires.

\subsection{L'omniprésence des récipients régionaux}

On retrouve au cours des $\mathrm{XII}^{\mathrm{e}}$ et $\mathrm{XIII}{ }^{\mathrm{e}} \mathrm{s}$. sur le site la prégnance de la tradition régionale parmi les productions «consommées », avec une forte proportion ${ }^{8}$ de

8 Pour le XII ${ }^{\mathrm{e}}$ s., le groupe des céramiques communes en pâte grise représente environ $50 \%$ de la masse des pots à feu et les vases en pâte brune $20 \%$. Au XIII ${ }^{\mathrm{e}}$ s., la tendance s'inverse, les récipients gris se réduisent à $15 \%$ tandis que les pièces à pâte brune explosent avec $50 \%$ du total des culinaires. 


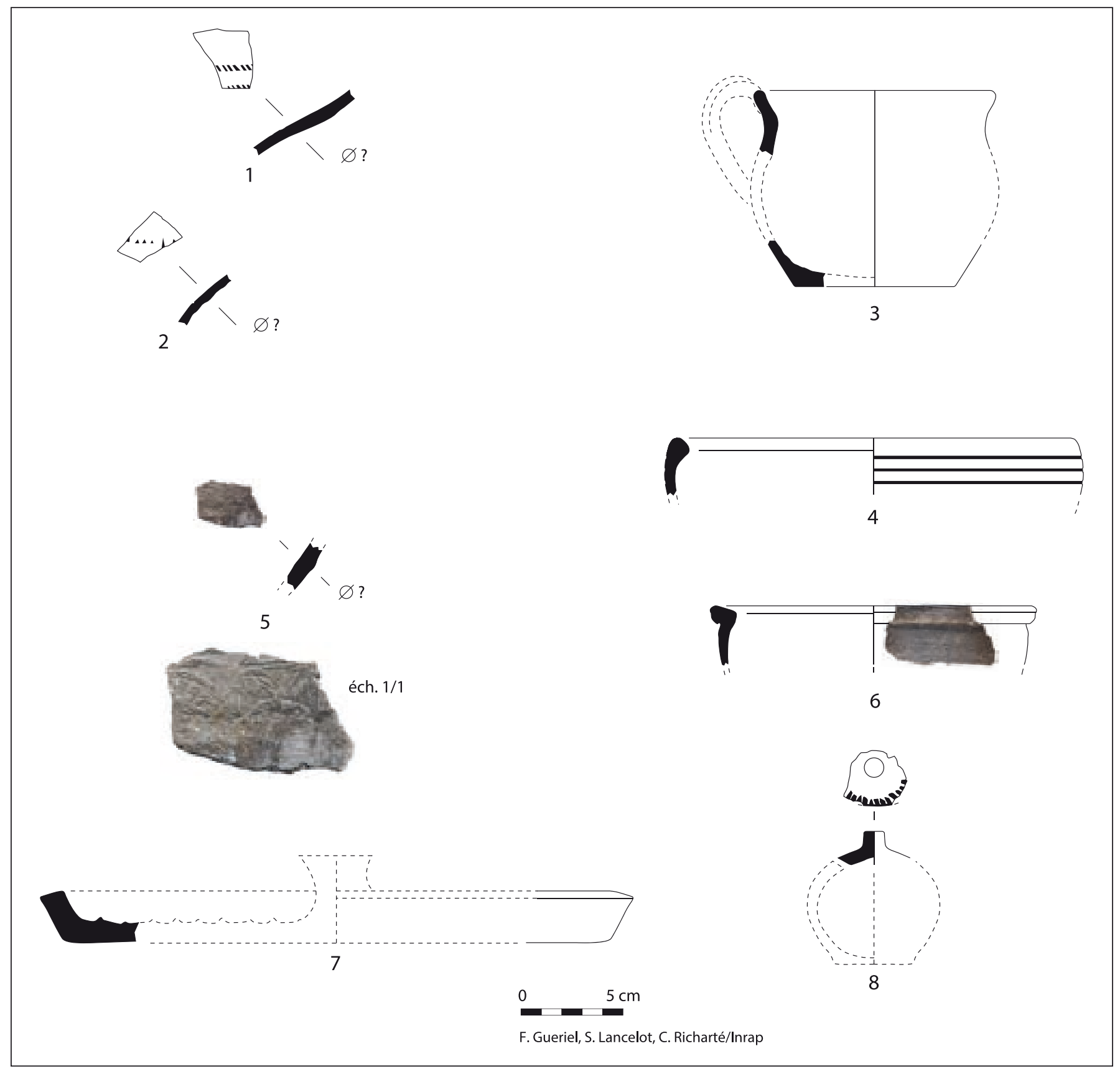

Fig. 64. Céramiques communes grises régionales du XIIIle $\mathrm{S}$., micacées ( $\left.n^{\circ} 1-4\right)$ et varoises (atelier d'Ollières) ( $\left.n^{\circ} 5-8\right)$. Tunnel de la Major.

récipients culinaires en pâte réfractaire (fig. 63), obtenus en atmosphère réductrice et venant d'officines locales et régionales (56\% de l'ensemble). Ces céramiques grises, comme pour les phases précédentes, sont issues de plusieurs ateliers que des analyses géochimiques permettent nettement de distinguer. Deux centres potiers ont, à ce jour, des productions bien individualisées. Ce sont d'une part, des officines varoises localisées dans le bassin d'Ollières fabriquant des récipients kaolinitiques (fig. 64), et d'autre part, celles situées dans le massif de l'Etoile, autour du castrum de Mimet (Pelletier, Vallauri
1992) qui réalisent des pots à cuire et couvercles dans des argiles micacées (fig. $\mathbf{6 5}, \mathbf{n}^{\circ} \mathbf{4 - 6}$ ). Ces catégories possèdent un répertoire constitué de formes fermées, pots à stocker, mesures et des ustensiles allant au feu : ollae, pégaus, marmites ainsi que quelques formes plus rares (fig. 63, n'3-4). Ce large groupe technique est complété par des productions, obtenues en post-cuisson oxydante, rassemblant de grands vaisseaux brun-rougeâtres. Certains d'entre eux, totalement rouges et originaires du Languedoc (Leenhardt et al. 1995, p. 34-35), restent définis par un répertoire fermé et un traitement de surface 


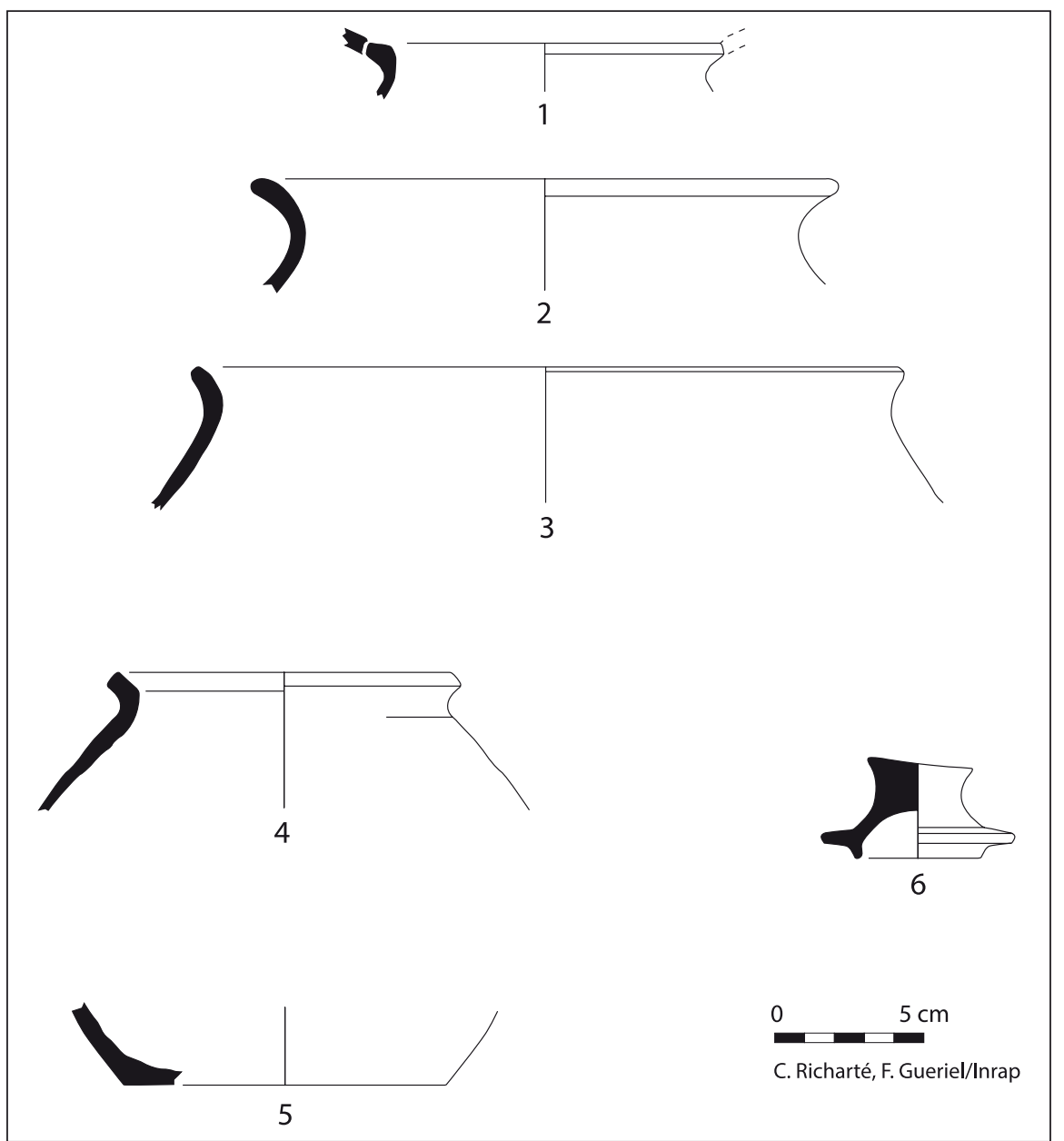

Fig. 65. Productions régionales du XII $\mathrm{s}$. Pots en pâte brune micacée ( $\left.\mathrm{n}^{\circ} 1-3\right)$, vases et couvercle en pâte grise micacée ( $\left.n^{\circ} 4-6\right)$. Tunnel de la Major.

polie, espátulata (fig. 17, $\left.\mathbf{n}^{\circ} \mathbf{1}\right)$. À cette catégorie s'ajoute une série de pots, sans revêtement et micacés, qui font leur apparition dans le courant du XII ${ }^{\mathrm{e}} \mathrm{s}$. (fig. 65, $\mathbf{n}^{\circ} \mathbf{1 -}$ 3), et perdurent jusqu'à la fin du XIII' ${ }^{\mathrm{e}}$ s. (fig. 63, n⿳亠口冋-6) voire le début du siècle suivant (Richarté 2001, p. 140142 fig. 178 et 179; Gantès, Moliner 1990, p. 55-56). Ils possèdent une pâte grossière à inclusions minérales. Leur couleur n'est pas homogène (brun-gris à orangé) et leur façonnage est mixte : tournés et retouchés au tour lent. Observés dans les niveaux à partir du XII ${ }^{\mathrm{e}}$ s., ces objets sont de taille moyenne à grande, principalement fermés : vases à verser, parfois à bec pincé et pots à cuire occasionnellement munis d'une anse (fig. $\mathbf{6 3}, \mathbf{n}^{\circ} \mathbf{5}$ 6). L'origine de la production n'est pas formellement définie, Provence orientale, région varoise, vallée de l'Argens ou encore massif des Maures (Pelletier 1997, p. 68) peuvent être pressentis. Également bien diffusés en Languedoc, ces pots se retrouvent dans la cité d'Arles (Leenhardt et al. 1996, p. 107), de même qu'à Aix-enProvence (Richarté 2009, p. 109-134).

\subsubsection{L'apparition d'ustensiles culinaires glaçurés régionaux}

À la fin du XII ${ }^{\mathrm{e}}$ et le début du XIII ${ }^{\mathrm{e}}$ s., on observe l'entrée dans les foyers d'un petit nombre de récipients en pâte claire kaolinitique revêtue d'une glaçure maigre au plomb. Ils proviendraient en grande partie de la région d'Uzès, mais peut-être pas exclusivement, car les ateliers du sud Ventoux dont ceux de Bédoin ont fourni des produits similaires (Richarté et al. 2010). Le groupe est alors caractérisé par une certaine finesse des parois et l'aspect moucheté des glaçures habituellement vertes. Le répertoire se limite à des formes de marmites (fig. 66, n' ${ }^{\circ}$ 1-2). Ce n'est qu' au tournant du XIII ${ }^{\mathrm{e}}$ s. que la production explose et se diversifie avec la déclinaison de modules de marmites, de jattes et de gargoulettes. Cet assemblage, d'un usage extrêmement courant, se retrouve sur la plupart des tables provençales à partir du milieu du XIII ${ }^{\mathrm{e}}$ s. : à Marseille, aux bourgs des Olliers et Sainte-Catherine (Richarté 2001, p. 144-145) ainsi 


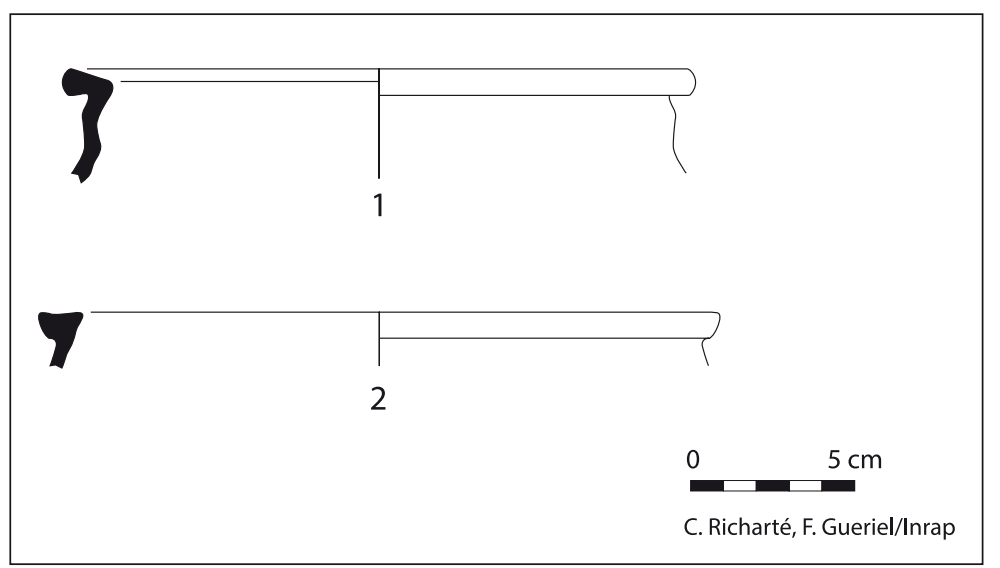

Fig. 66. Productions régionales en pâte claire glaçurées (Uzège ?) du XIII $\mathrm{s}$. Tunnel de la Major. qu'à Aix-en-Provence, rue des Magnans et au couvent des Dominicaines de Notre-Dame de Nazareth (Richarté 2009, p. 113-117). La diffusion continue de s'amplifier durant tout le siècle. Cette mutation dans les apports confirme une ouverture sur des marchés commerciaux plus élargis, et traduit non seulement une transformation dans les régimes et les normes diététiques, mais induit d'autres pratiques dans le domaine des arts de la table et jusque dans les modes de cuisson et de conservation des denrées (Alexandre-Bidon 2005, p. 147).

\subsubsection{Les officines diversifient et spécialisent leurs productions}

De nombreux contextes, fouillés aux abords de la Major et plus largement dans la cité, ont livré de la céramique de production locale. L'innovation apportée par l'atelier marseillais du bourg des Olliers, actif dès 1186, concerne à la fois technique de fabrication et renouvellement du répertoire proposé (Marchesi, Vallauri 1997, p. 107). Les vaisselles calcaires non glaçurées sont réintroduites : elles avaient disparu à la fin de l'Antiquité. Désormais plutôt dévolues au stockage, elles réapparaissent dans une ambiance générale très largement influencée par le sud de l'Espagne. Pots, coupes (ataifores), coupelles (cuencos), couvercles coniques et creux (Vallauri 1997, p. 252, fig. 218-1), vases à liquide (aquamaniles), cuviers et bassins (lebrillos et alcadafes) de différents types (fig. 67, n'1-2) sont prisés et produits avec/ou sans glaçure durant les premiers temps de l'officine. Il en va de même pour la bouteille piriforme à goulot bagué (fig. $67 \mathrm{n}^{\circ}$ 3); ce conteneur, sorti de cet atelier (Vallauri 1997, p. 254, fig. 219-6) évoque redomas et limetas présentes dans les cuisines ou sur les tables orientales, notamment illustrées sur le site califal ibérique de Madinat al-Zahra (Vallejo-Triano, Escudero-Aranda 1998, p. 149, fig. 2). Ces objets sont donc très largement inspirés du répertoire arabo-andalou (Rosselo-Bordoy 1978, p. 44).
Quant aux vaisselles glaçurées, comme les coupes à marli redressé et les écuelles, elles ne font leur pleine apparition dans la cité qu'à la fin du XIII ${ }^{\mathrm{e}} \mathrm{s}$., période où l'on note une montée en puissance de la production et où l'on perçoit un engouement particulier pour les pièces portant un décor vert et brun (fig. $68, \mathbf{n}^{\circ} \mathbf{1}$ ).

Les potiers de Marseille ont également produit des récipients en terre vernissée destinés au feu qui semblent moins bien représentés dans les niveaux de la Major. Ces ustensiles en pâtes rouges, parcimonieusement vernis, regroupent principalement des vases culinaires, marmites, pots et jattes (Leenhardt 1997, p. 198-201, fig. 172-173). Les premières sont à col haut et portent une rainure sur l'épaulement et une glaçure interne au plomb (fig. 68, $\mathbf{n}^{\circ} \mathbf{2}, \mathbf{4}$ ). Les jattes, au profil caréné et bord anguleux (fig. 68, $\mathbf{n}^{\circ} \mathbf{5}$ ), semblent réalisées à l'imitation de pièces importées et désignées comme pseudo ligures (fig. 69).

À partir du XIII ${ }^{e}$ s., des objets indéniablement inscrits dans la tradition islamique sont fabriqués sur place. Ces réalisations « typées » que l'on trouve dans de nombreux sites de consommation, non seulement intra muros, mais également à l'intérieur des terres, témoignent d'une destination au plus grand nombre, et pas simplement de commandes spécialisées réservées à un groupe de population. Les modèles fournis par les potiers andalusí, montre un goût pour les vaisselles et pièces décoratives d'apparat, et jusque dans les objets plus usuels, plats, coupes, écuelles, aiguières et gobelets ainsi que dans les carreaux de céramique architecturale (zelliges) utilisés dans le décor des maisons marseillaises (Richarté 2001, p. 148 fig. 186-4 ; le Vert et le Brun 1995, p. 212). Là encore, on en devine l'empreinte culturelle et esthétique. Les pièces et vaisselles de ce nouveau corpus sont remarquables par l'utilisation de la couleur et le recours à un répertoire décoratif original, adapté à toutes les formes et à tous les supports, où dominent motifs géométriques, végétaux, et plus rarement figuratifs. 
PREMIÈRE PARTIE : LES CÉRAMIQUES

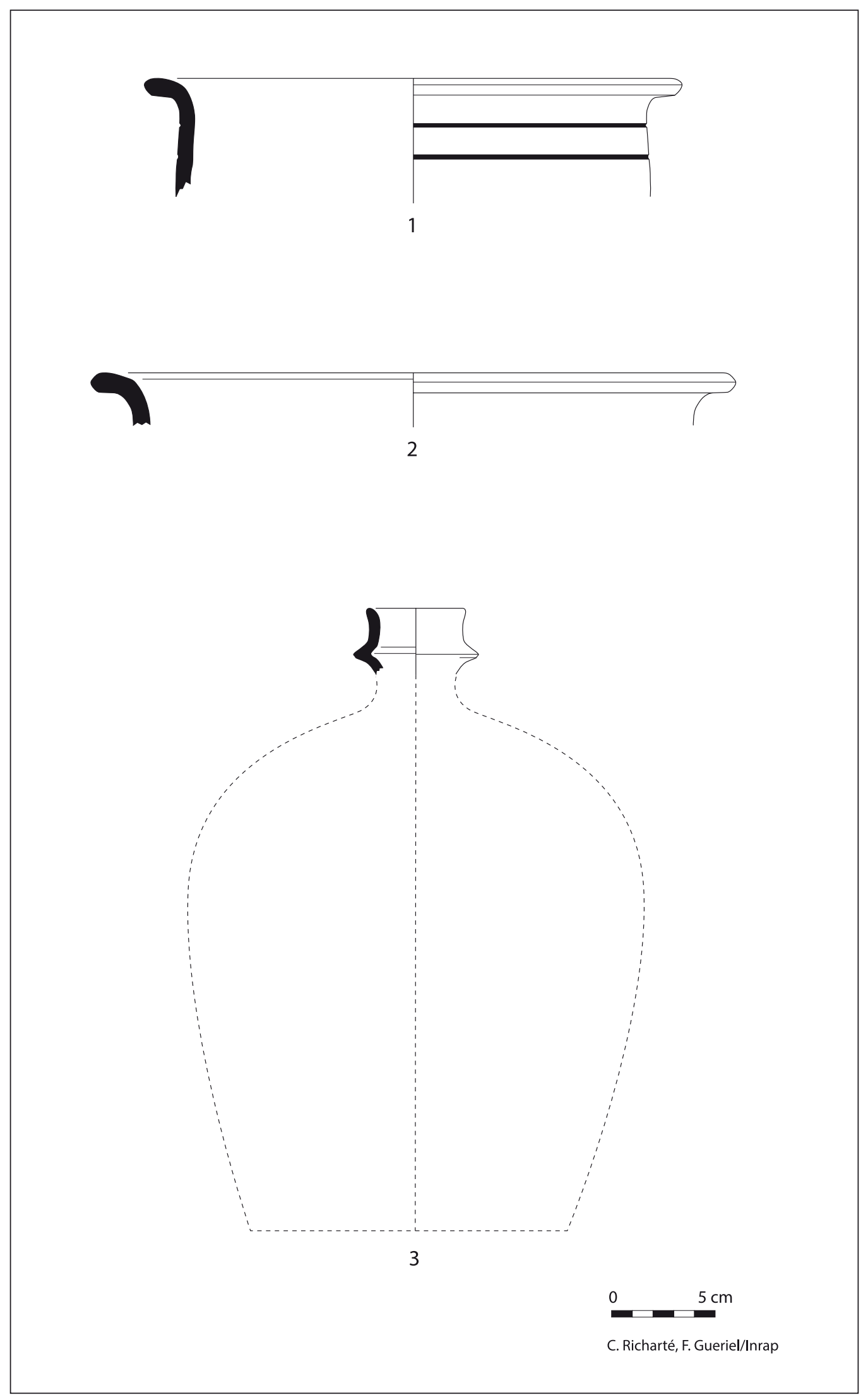

Fig. 67. Production régionale en pâte calcaire sans revêtement (atelier de Marseille) dans le courant du XII $\mathrm{s}$. et le XIII $\mathrm{s}$. Tunnel de la Major.

88 


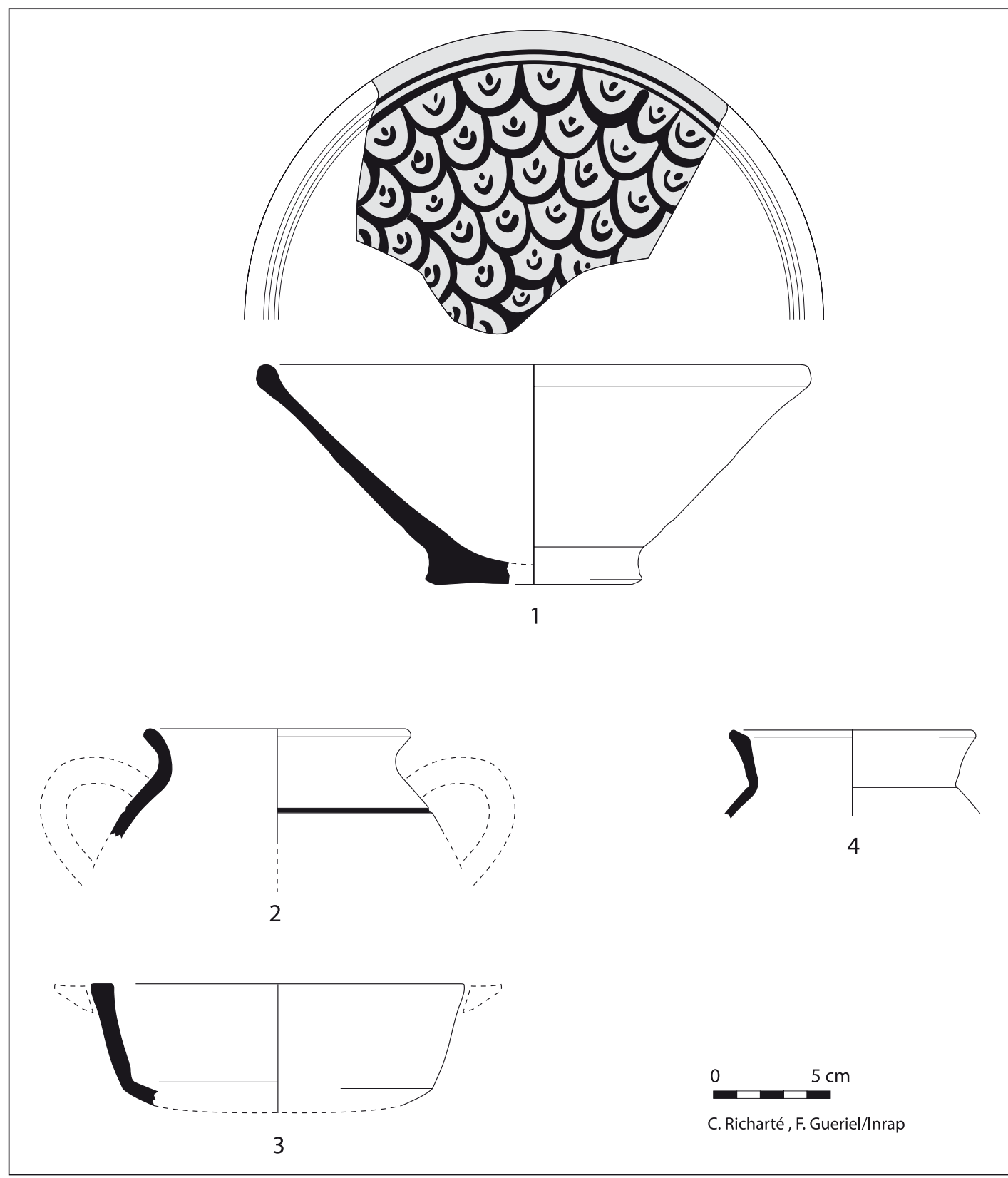

Fig. 68. Productions régionales des ateliers de Marseille au XIIIe $s$. Coupe à décor manganèse sur émail stannifère $\left(n^{\circ} 1\right)$, céramiques à pâte rouge glaçurée $\left(n^{\circ} 2-4\right)$. Tunnel de la Major.

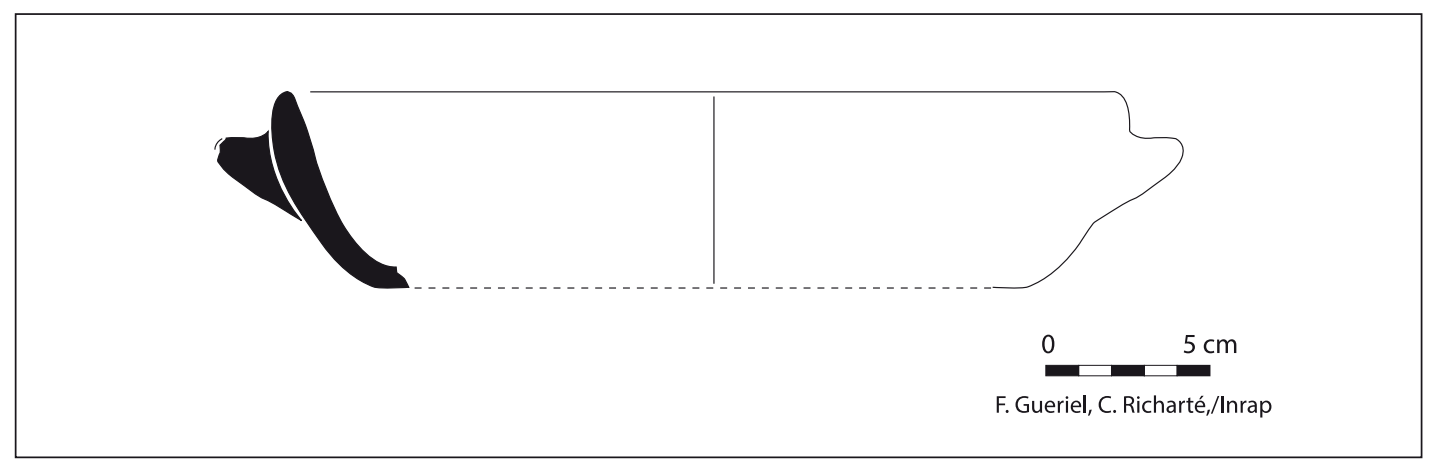

Fig. 69. Marmite modelée à pâte rouge et glaçure transparente (pseudo-ligure) des XIIe et XIII s. Tunnel de la Major. 


\subsection{La vaisselle et les vases importés d'al-Andalus à l'Orient}

Au côté des productions locales et régionales ci-dessus évoquées, un certains nombre de récipients provient des rivages méditerranéens plus ou moins proches où domine la culture islamique.

\subsubsection{Al-Andalus}

L'innovation de ce tournant de siècle est l'essor de nouvelles techniques de fabrication (technique de cuisson élaborée - four à barres - et généralisation des glaçures opacifiées à l'étain), lié à des procédés décoratifs et à des fonctions assurées par des produits «exotiques», plus prestigieux du simple fait qu'ils sont des articles importés. Ces objets étaient acheminés depuis l'Espagne qui devient pour la période, un important centre de fabrication et de diffusion de céramiques et surtout de faïences.

Ces apports restent continus dans la ville de Marseille quelles que soient les phases abordées ; cela sans doute en raison du jeu des alliances politico-commerciales. La cité est incontestablement liée aux puissances italiennes (Gênes et Pise) - elles-mêmes en lien avec les comptoirs du sud de l'Espagne. De plus, elle occupe géographiquement une place centrale entre l'Italie et l'Espagne, et de ce fait, est irriguée en flux réduits, mais néanmoins constants, de produits ibériques.

L'Espagne commercialise des objets émaillés polychromes, présents sur le site, dont les techniques de fabrication sont ingénieuses et variées : produits à décor peint, estampé, incisé et montrant une certaine unité stylistique notamment dans l'intérêt porté au foisonnement décoratif et aux éléments orientalisants.

Le vaisselier de l'habitat comprend quelques fragments de grande coupe à carène haute, de type d'ataifores, sur pied annulaire, revêtues d'un épais vernis cuivreux interne (fig. 71, $\mathbf{n}^{\circ} \mathbf{1}$ ). Elles sont pourvues d'un décor d'estampilles de rosettes, palmettes ou motifs cordiformes posées sous glaçure, en général au centre de la pièce, en registre concentrique comme sur les fragments retrouvés au Fort Saint-Jean (fig. 71, $\mathbf{n}^{\circ} \mathbf{2}$ 3). Au revers, ces coupes portent une glaçure verdâtre particulièrement maigre. Actuellement bien repérées à Marseille (Richarté 2001, p. 151, fig. 188-2 ; Fixot, Pelletier 2004, p. 116 ; Parent 2005, p. 862, fig. $17 \mathrm{n}^{\circ} 1-$ 2 ), elles sont fréquentes dans les séquences du $\mathrm{XII}^{\mathrm{e}}$ et du XIII ${ }^{e}$ s. (Capelli et al. 2009, p. 942), de même que des pichets cannelés à glaçure verte (Capelli et al. 2009, p. 941, fig. 5). Cet ensemble habituel des contextes tardifs d'al-Andalus (Zozaya 1981, p. 266-267; Aguado 1986, p. 130 ; Martinez, Mantesanz 1991, p. 282), trouve, bien entendu, son origine en Espagne méridionale (Capelli et al. 2009, p. 942, fig. 6 et p. 943-944).

Les vases à liquide à décor de cuerda seca partielle, utilisant une technique d'émail cloisonné, ont été faiblement introduits à la Major et, plus encore généralement en Provence. Ces objets viennent également aussi des ateliers hispaniques et du Portugal (Delery 2006). La juxtaposition de plusieurs glaçures colorées séparées par un trait noir de manganèse, comme on le voit sur le fragment d'un vase à liquide (fig. 71, $\mathbf{n}^{\circ} \mathbf{6}$ ), obéit à un savoir-faire apparu au IX ${ }^{\mathrm{e}}$ s. en Iran, puis diffusé en Espagne (Delery, Gomez-Martinez 2006). Plusieurs glaçures colorées sont ainsi employées sans se mêler dans le décor. En effet, on isole les émaux par un trait au préalablement gravé, et cernés à l'aide d'un corps gras. Ce procédé est utilisé très tôt, au X $\mathrm{X}^{\mathrm{e}}$ s., dans l'Espagne musulmane.

Les jarritas esgrafiadas ou petites jarres à décor peint et incisé aux parois très fines, proviennent pareillement du sud de la péninsule se rattachent aux périodes almoravide et almohade. Cette catégorie, avait été mise en évidence à Marseille sur les sites de la place Général-de-Gaulle (fig. 70, $\mathbf{n}^{\circ} \mathbf{3}-4$ ) et du bourg des Olliers dans des niveaux d'occupations datés des XIII ${ }^{e}$ et $\mathrm{XIV}^{\mathrm{e}}$ s. (Richarté 2001, p. 162-163, fig. 206 ; Vallauri, Leenhardt 1997, p. 85), et figurent parmi les vaisselles d'importation consommées dans le quartier canonial.

C'est également une technique islamique ancienne, largement empruntée au traitement du métal, qui a inspiré cette ornementation. La profusion du décor évoque, en fait, le procédé de la niellure. Répartis en registres superposés, les motifs sont obtenus par jeux d'incisions sur un fond brun peint à l'oxyde de manganèse (fig. 70, $\mathbf{n}^{\circ}$ 1-2). Durant le XII ${ }^{\mathrm{e}}$ et le XIII ${ }^{\mathrm{e}}$ s., la ville de Murcia fut l'un des principaux centres producteurs de céramique esgrafiada sur manganèse (Navarro-Palazon 1993, p. 124).

Autres éléments importés et couramment retrouvés dans les niveaux marseillais et dans les habitations groupées autour de la Major sont les tinajas (Richarté 2001, p. 153, fig. 192, 194). Ces grandes jarres estampées toujours influencées par le modèle arabo-hispanique, proviennent d'Ifriqiya ou d'Espagne du Sud (fig. 70, n 5-7). Elles sont destinées à la conservation des liquides (huile, vin) et au stockage de l'eau, et sont exposées dans les cours des maisons andalouses (Navarro-Palazon 1991, p. 39). Elles portent un riche décor d'impressions, assez complexe, qui se développe soit sur la partie supérieure de la panse soit sur la totalité de la pièce. Ce décor structuré en registres horizontaux se compose de motifs épigraphiques cursifs prophylactiques (eulogies) et d'atauriques juxtaposés. Dans la plupart des cas, ces vases sont recouverts d'une glaçure monochrome, bleu turquoise mêlant plomb et cuivre, En Espagne, ces pièces 

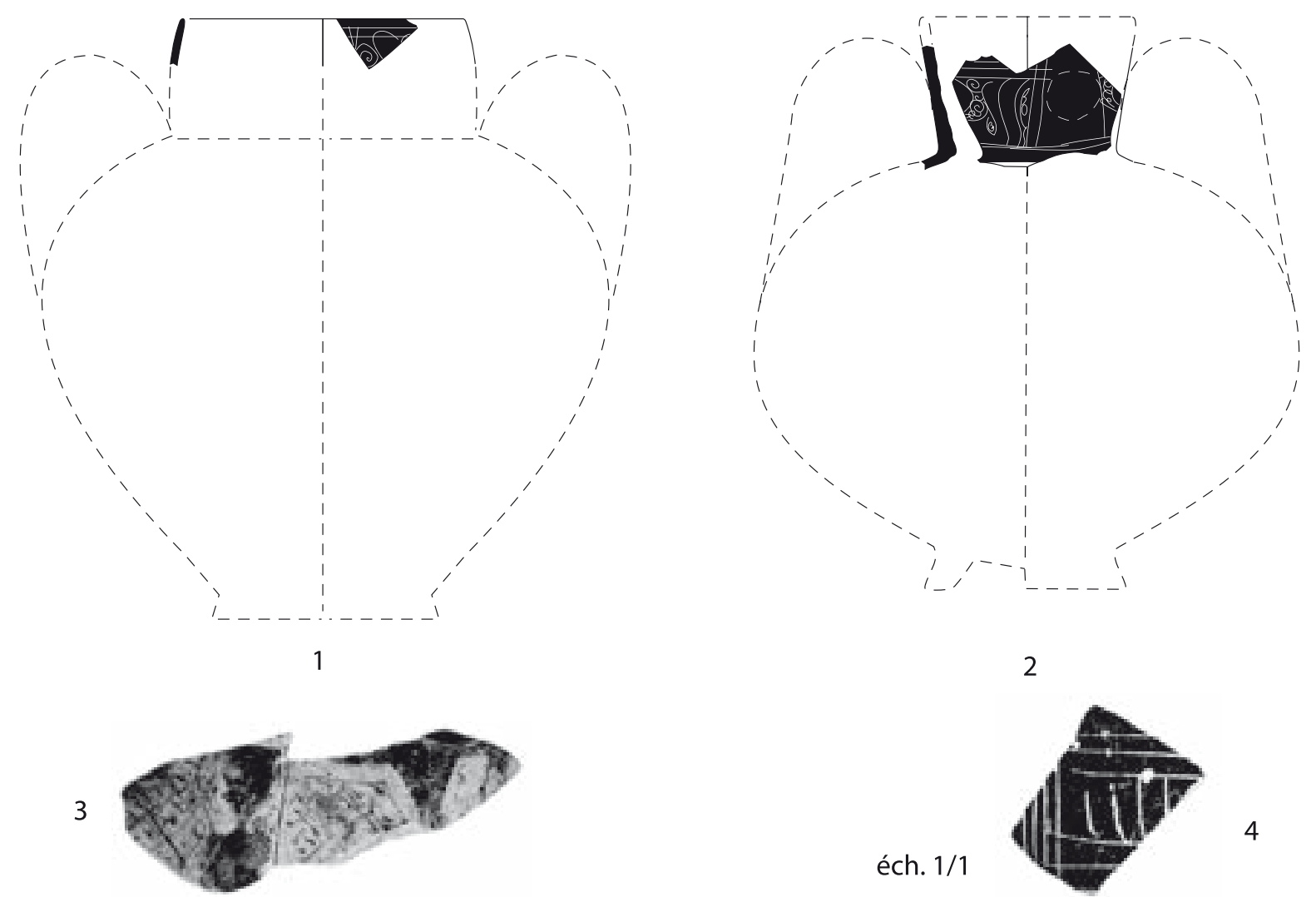

éch. 1/1

éch. $1 / 1$

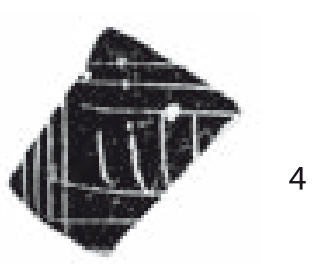

6
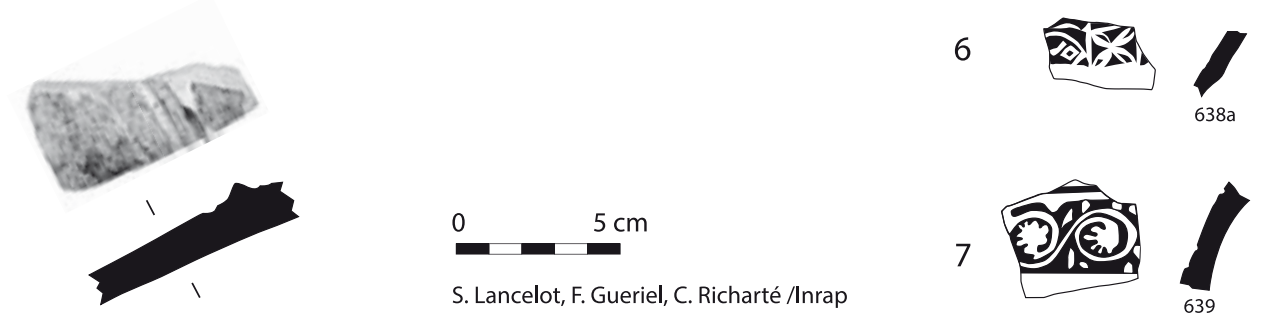

Fig. 70. Productions d'al-Andalus au XIII ${ }^{\circ} \mathrm{s}$. Jarritas esgrafiadas ( $\left.{ }^{\circ} 1-2\right)$, jarrita peinte aux oxydes de fer $\left(n^{\circ} 3\right)$, jarrita esgrafiada $\left(n^{\circ} 4\right)$, jarre estampée sous glaçure verte opacifiée $\left(n^{\circ} 5\right)$, jarres estampées sur pâte crue $\left(n^{\circ} 6-7\right)$. 1-2, 5-7 : Tunnel de la Major ; 3-4 : place Général-de-Gaulle (Bouiron 2001, fig. 206).

sont attestées dès le $\mathrm{X}^{\mathrm{e}} \mathrm{s}$. (Thiriot 1991, p. 290). Dans les contextes provençaux, souvent rattachées aux ensembles de la fin du XII ${ }^{\mathrm{e}}$ s., elles sont présentes jusqu'à la fin $\mathrm{XIV}^{\text {e }}$ s. (Richarté 1994, p. 318, vol. 2, fig. 131 ; Vallauri 1997, p. 83).

Participant toujours à cette ambiance délibérément arabo-andalouse, quelques pièces utilitaires plus modestes, jarra, jarón et lebrillo (fig. 73, n' ${ }^{\circ}$-7), portent souvent des bandes peintes à l'oxyde de fer ou un décor d'impressions sommaires appliqués sur pâte crue (fig. 73, n' ${ }^{\circ}$-7).

Enfin, les vaisselles à décor bleu et/ou reflet métallique regroupent de rares fragments de coupes aux parois effilées portant d'exubérants décors peints au cobalt avec parfois des motifs de remplissage tracés au lustre métallique, mais qui ne sont que rarement conservés. La création de la couleur métallique est encore, à l'origine, une technique irakienne diffusée dans le bassin méditerranéen avec l'expansion islamique et jusqu'en Espagne (Miroudot 2008, p. 15). Ces productions lustrées seraient peut-être apparues avant le $\mathrm{XII}^{\mathrm{e}} \mathrm{s}$. en Andalousie, notamment dans les centres d'Almeria, Murcia et de Málaga (Delery 2008, p. 74), puis la technique se serait transmise aux officines de la région de Valence à partir du XIII ${ }^{\mathrm{e}}$ s., et jusqu' au XVII's. 

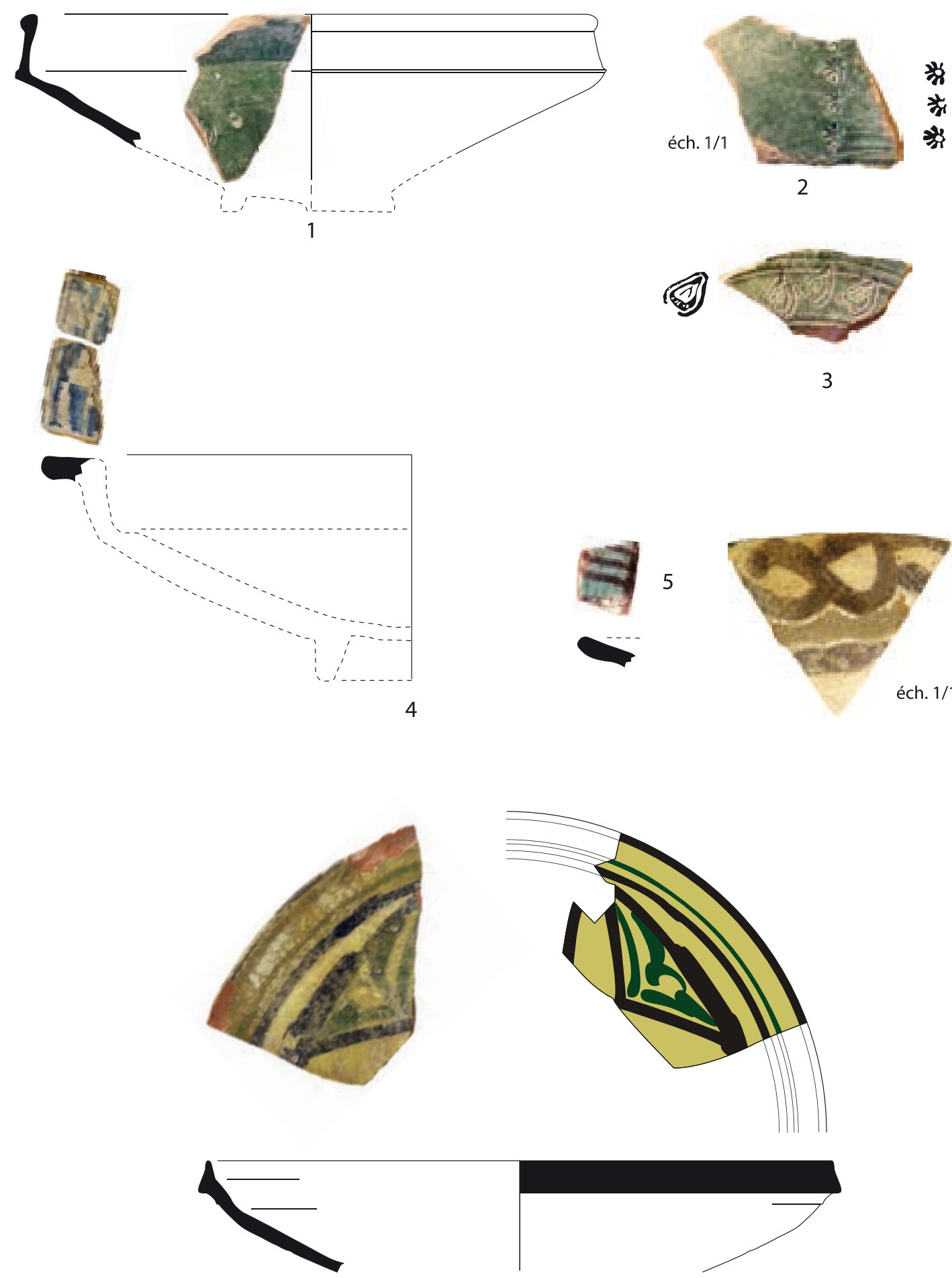

7

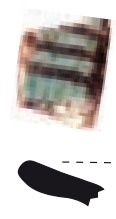

5

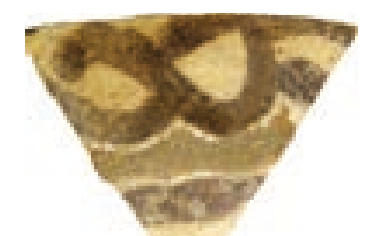

éch. 1/1

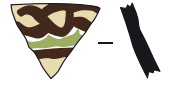

6

\section{尚 \\ \%}

:




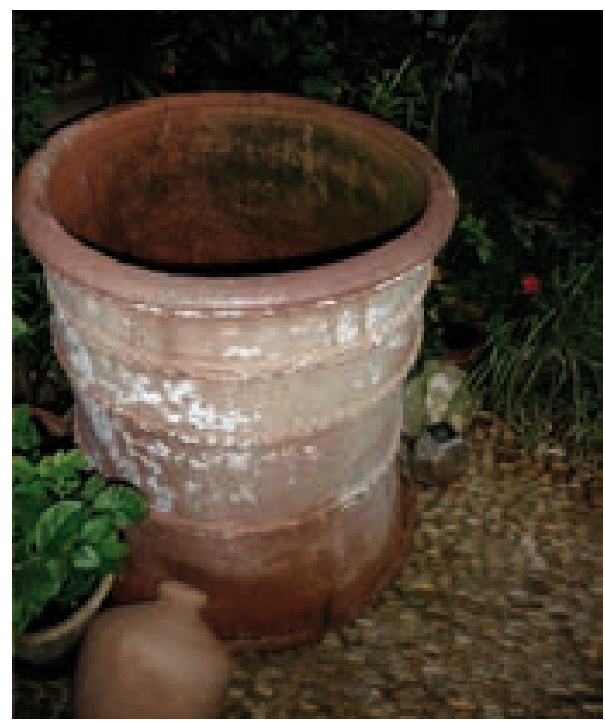

1
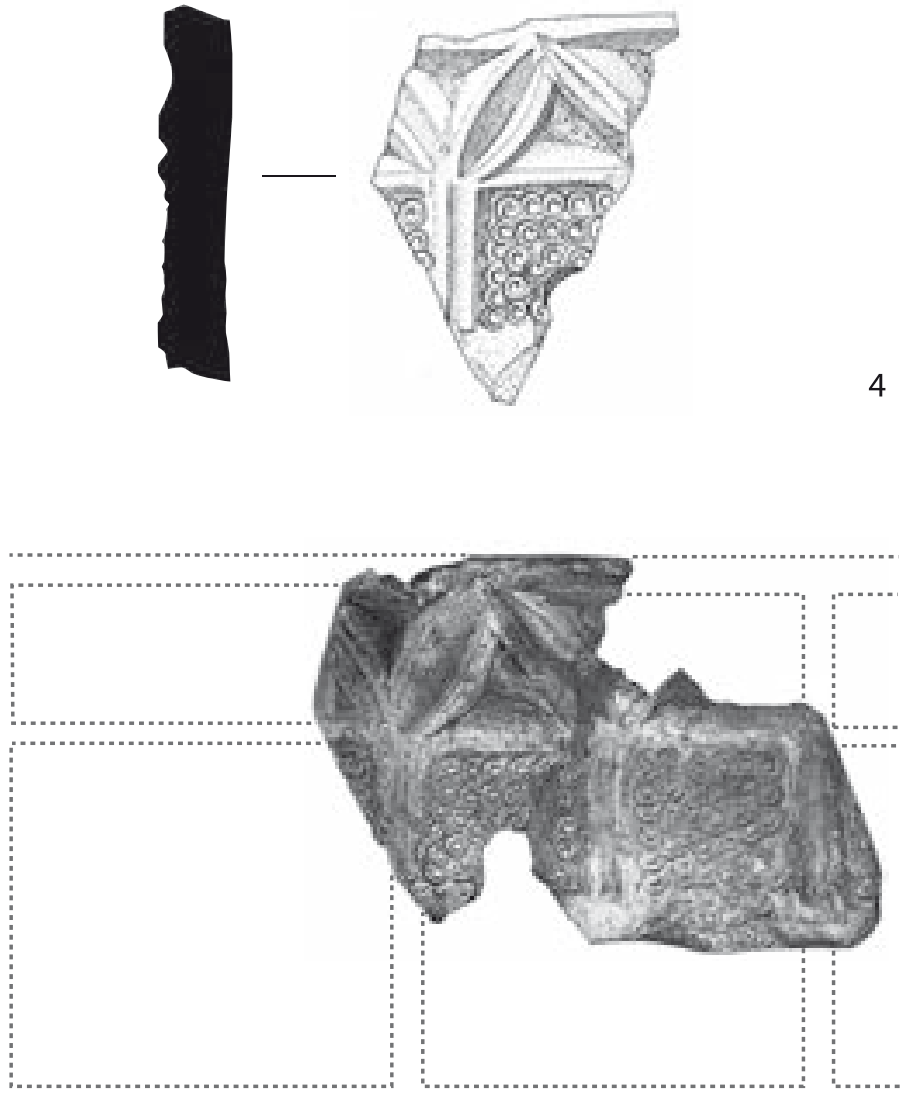

2
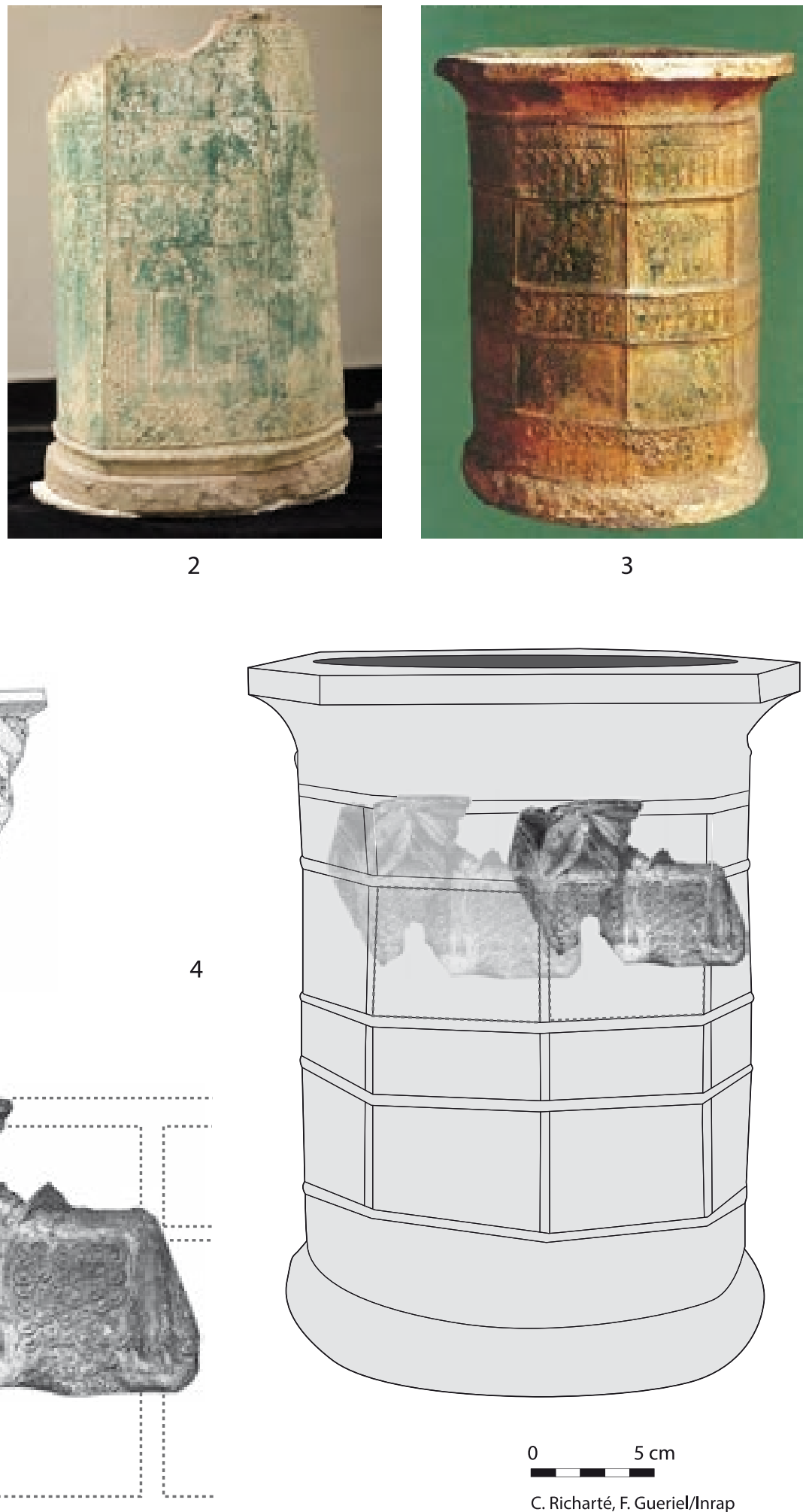

Fig. 72. Margelles de puits en terre cuite du XII ${ }^{\mathrm{e}} \mathrm{s}$. Maison cordouane $\left(\mathrm{n}^{\circ} 1, \mathrm{cl}\right.$. Ph. Vesco) ; musée de Tlemcen, Algérie $\left(\mathrm{n}^{\circ} 2\right.$, cl. Medcherif Abada/ Qantara) ; musée ethnographique Tétouan, Maroc ( $n^{\circ} 3, \mathrm{cl}$. Ph. Maillard/Qantara) ; proposition de restitution de l'exemplaire marseillais $\left(n^{\circ} 4\right.$, Tunnel de la Major). 

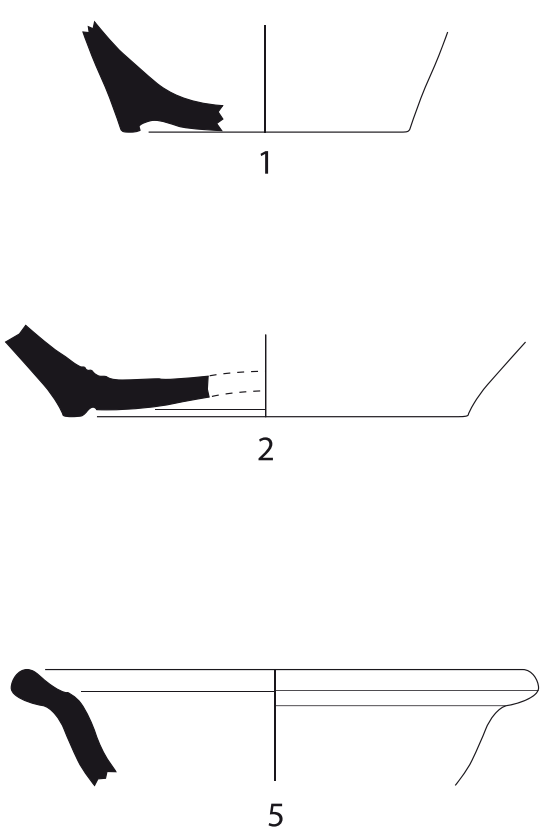

5

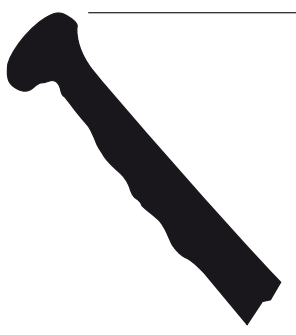

F. Gueriel, S. Lancelot, Fl. Parent, C. Richarté/Inrap

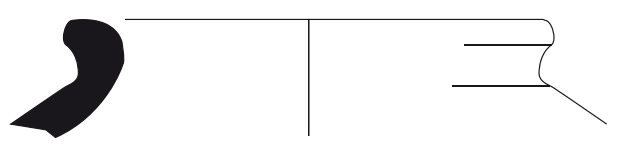

3

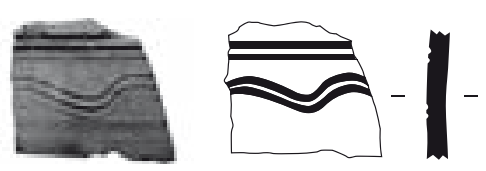

4

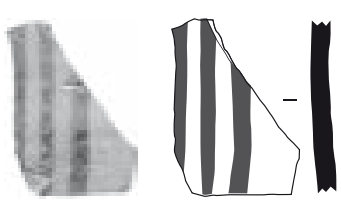

6

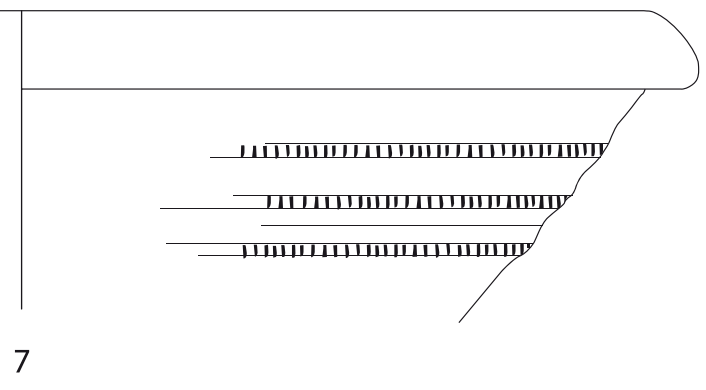

Fig. 73. Productions de tradition arabo-andalouse du XII $\mathrm{s}$. Jarres à stocker en pâte claire sans revêtement $\left(n^{\circ} 1-4\right)$, céramique blanchie au sel d'Afrique du nord $\left(n^{\circ} 5\right)$, jarre à décor peint aux oxydes de fer $\left(n^{\circ} 6\right)$, lebrillo non glaçuré $\left(n^{\circ} 7\right)$. Tunnel de la Major.

\subsubsection{Un exemple de terre cuite architecturale}

Une pièce découverte sur le site figure également parmi les formes remarquables répertoriées en Provence. Il s'agit d'un épais fragment en terre cuite sans revêtement portant un décor grossièrement estampé d'arcs brisés et de remplissage d'ocelles (fig. 72). Le tracé régulateur, retouché à la pointe sèche, semble s'organiser en plusieurs panneaux. Sa morphologie, à pans coupés avec sans doute un corps cylindrique d'un diamètre d'environ $60 \mathrm{~cm}$, le rattache aux margelles de puits en terre cuite. De tels éléments, parfois recouverts de glaçure ou d'un décor de cuerda seca, se trouvaient également dans les patios des maisons d'al-Andalus ainsi que dans les jardins et cloîtres de fondations religieuses. Les margelles facilitaient le puisage de l'eau et leur usage a été transmis du monde arabe à la Provence via l'Espagne chrétienne. C'est dans les cours des abbayes et notamment dans le couvent aixois de Notre-Dame de Nazareth (Richarté 2009), qu'ont été également découverts des fragments similaires, estampés et glaçurés. Cependant, les pièces les plus complètes sont exposées en Andalousie, au musée archéologique de Córdoba et en Algérie, au musée de Tlemcen (fig. $\mathbf{7 2}, \mathbf{n}^{\circ} \mathbf{1 - 3}$ ). 


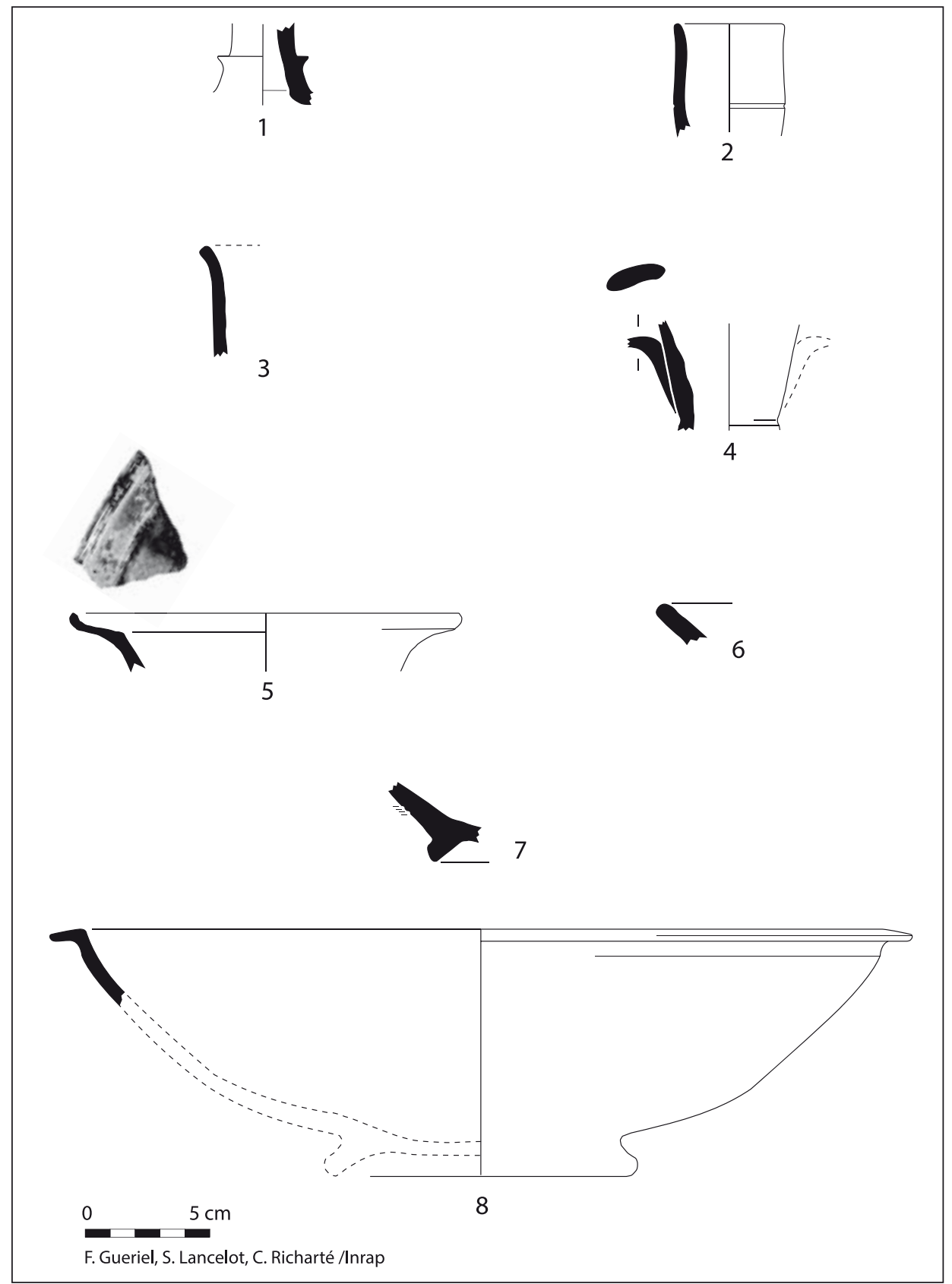

Fig. 74. Céramiques glaçurées siculomaghrébines des $\mathrm{XII}^{\mathrm{e}}\left(\mathrm{n}^{\circ} 1-4\right)$ et $\mathrm{XIII}{ }^{\mathrm{e}} \mathrm{s}$. $\left(n^{\circ} 6-8\right)$. Vases à liquide $\left(n^{\circ} 1-4\right)$, coupes et coupelles $\left(n^{\circ} 5-8\right)$. Tunnel de la Major.

\subsubsection{Les céramiques siculo-maghrébines et proto-majoliques d'Italie du Sud}

Les céramiques à pâte claire opacifiée à l'étain et/ ou au cuivre, fréquentes en Provence, sont particulièrement bien représentées à Marseille. Elles regroupent des plats à marli (fig. $\mathbf{7 4}, \mathbf{n}^{\circ} \mathbf{5 - 8}$ et fig. $\mathbf{2 5}, \mathbf{n}^{\circ} \mathbf{4}$ ) et des vases à liquide de style nettement oriental (fig. 74, ${ }^{\circ}$ 1-4). La couverte est épaisse, d'un vert émeraude très soutenu, et rappelle les céramiques du sud de l'Espagne. Le vernis couvre les deux faces de la pièce (fig. $\left.\mathbf{7 4}, \mathbf{n}^{\circ} \mathbf{5}\right)$. Les coupes, assez fines, portent en général un pied annulaire. Certains de ces produits ont été analysés et les résultats les font apparaître dans le groupe des céramiques provenant de l'aire siculo-tunisienne (Capelli et al. 2009, p. 944 , fig. 88 ).

La catégorie des proto majoliques regroupe des vases dont les techniques d'élaboration sont communes à l'Italie centrale, méridionale, à la Sicile et au Maghreb. Le procédé de fabrication est spécifique, la pâte est calcaire, jaunâtre à revêtement polychrome : bleu/brun, c'est-àdire cobalt/manganèse (fig. 71, $\mathbf{n}^{\circ} \mathbf{4 - 5}$ ) ou bien vert/ brun/jaune, cuivre/manganèse/fer (fig. 71, $\mathbf{n}^{\circ}$ 7). Ce sont essentiellement des fragments de coupes à marli et de cruches qui sont présents dans nos niveaux du XIII ${ }^{\mathrm{e}} \mathrm{s}$. (fig. 75, $\mathbf{n}^{\circ} \mathbf{1}$ ). 


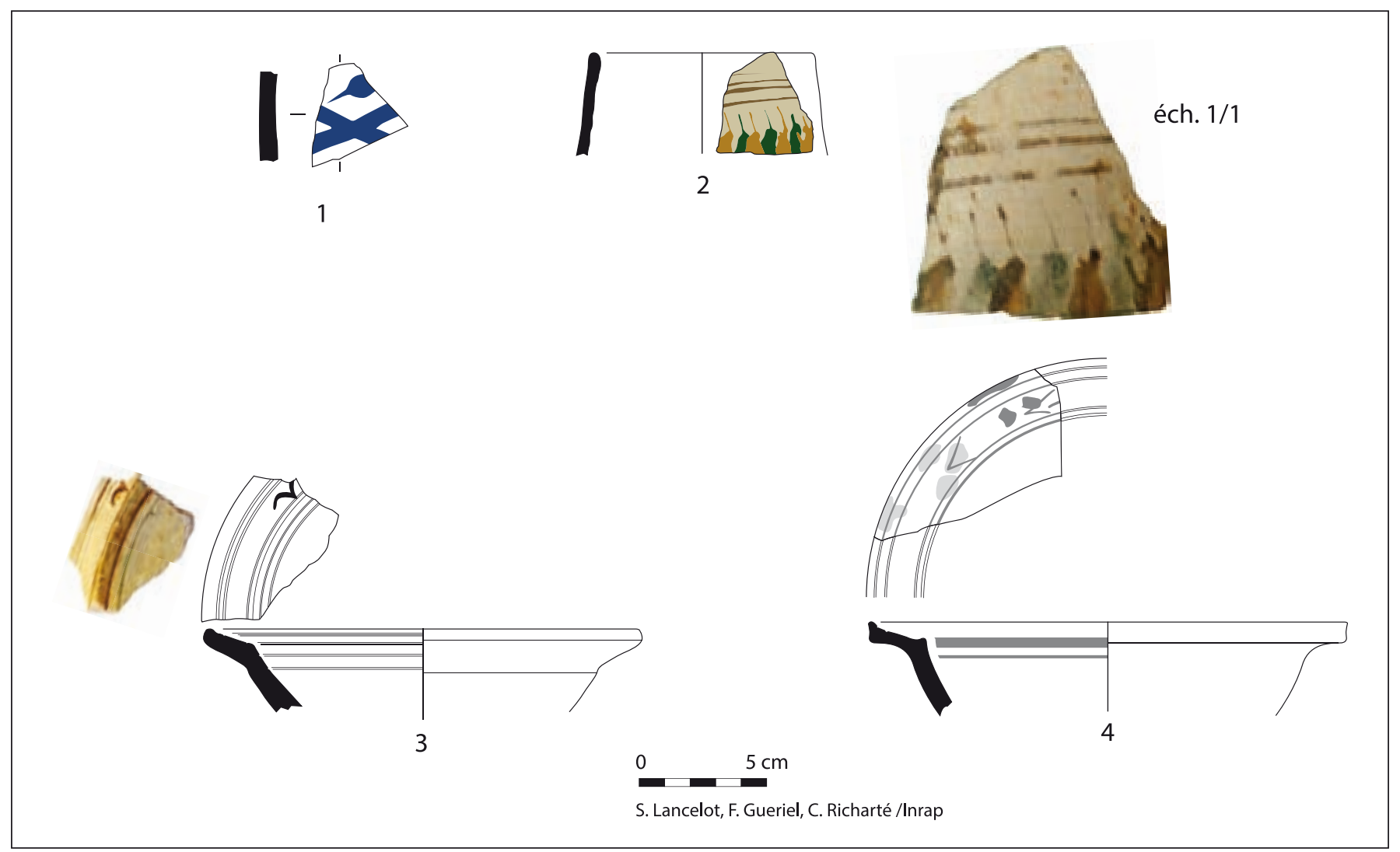

Fig. 75. Productions italiques des $\mathrm{XII}^{\mathrm{e}}$ et $\mathrm{XIII}{ }^{\mathrm{e}} \mathrm{s}$. Majolique italique à décor bleu et brun $\left(\mathrm{n}^{\circ} 1\right)$, majolique du Latium $\left(\mathrm{n}^{\circ} 2\right)$, sgraffito tyrrhénien ( $\left.n^{\circ} 3-4\right)$. Tunnel de la Major.

Quelques majoliques venant du Latium (fig. 75, $\mathbf{n}^{\circ} \mathbf{2}$ ) sont représentées par des fragments de vases fermés à décor vert, jaune et brun sur émail stannifère (Moliner 1990, p. 200-217 ; Richarté 2001, p. 153, fig. 196-2 ; Ricci 2010, p. 47-49). Les vaisselles décorées cobalto e manganese opacifiées à l'étain constituent avec des fragments siciliens, de la région de Gela, et ornés d'un décor bleu, vert, jaune et brun sur émail stannifère, l'essentiel des importations du sud de l'Italie (Ragona 1995, p. 32-33, fig. 36-39).

\subsubsection{Les vases précieux du Proche-Orient}

Quelques pièces particulièrement luxueuses importées du Moyen-Orient faisaient partie des éléments retrouvés parcimonieusement sur les sites marseillais, parmi lesquels figure un exemplaire sur celui du Tunnel de la Major. Il s'agit d'un fragment d'albarello en pâte siliceuse blanche, mêlant sable et quartz, portant un décor peint au noir de manganèse sous glaçure alcaline bleue (fig. 76). Ce petit vase syrien, rare et précieux, provient de la région de Raqqa (cf. Thiriot 1991). C'est l'exemple d'une technique d'élaboration originale utilisée dans l'empire musulman du IX ${ }^{\mathrm{e}}$ au XVIII's.

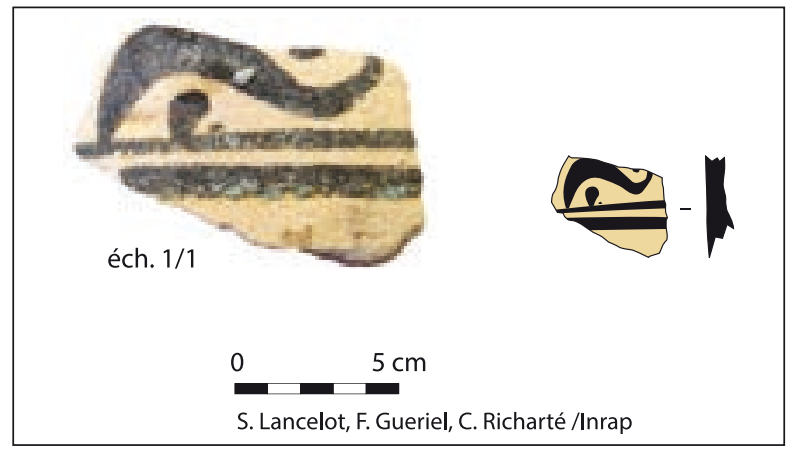

Fig. 76. Production proche orientales à glaçure alcaline du XIII $\mathrm{s}$. Tunnel de la Major.

\subsection{Les productions de l'aire byzantine}

Une autre aire culturelle pèse d'un poids certain sur le commerce et sur le choix des consommateurs de céramiques, c'est le monde byzantin. En effet, bon nombre de céramiques sont issues des rives orientales de la Méditerranée. Les productions possèdent des pâtes claires ou rouges, souvent bien cuites et dures, à grains de quartz, points de chaux, chamotte et écailles de mica doré. Certaines sont caractérisées par l'emploi d'un 


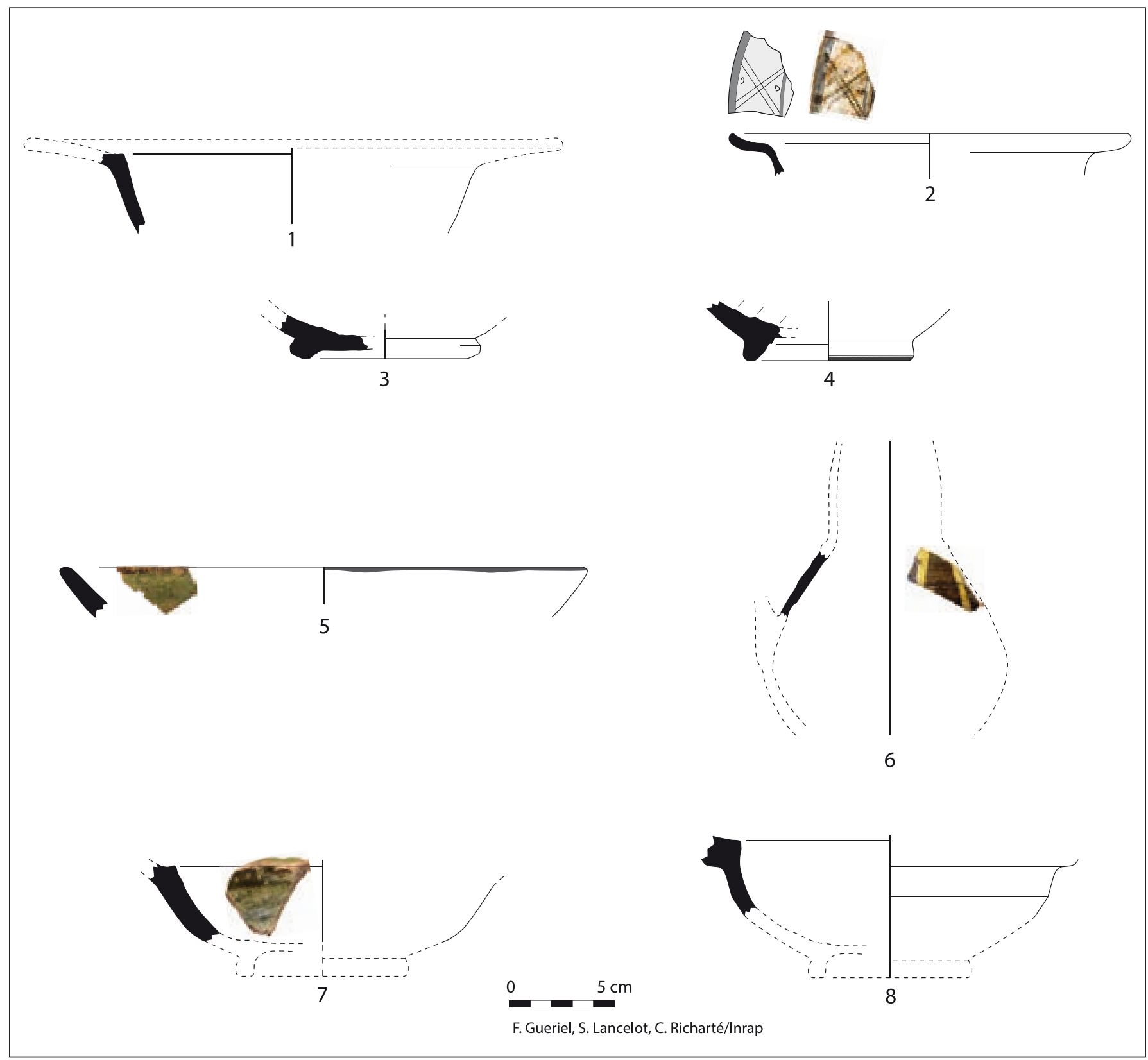

Fig. 77. Productions de l'ère byzantine des $X I^{e}\left(n^{\circ} 1-4\right)$ et XIII $s$. ( $\left.n^{\circ} 5-8\right)$. Pâte claire engobée sous glaçure (Aegean Ware) ( $\left.n^{\circ} 1\right)$, céramique incisée de Méditerranée orientale $\left(n^{\circ} 2\right)$, pâte rouge engobée sous glaçure $\left(n^{\circ} 3-4\right)$, pâtes claires engobées sous glaçure (Aegean Ware) ( $\left.n^{\circ} 5-6\right)$, production de Paphos $\left(n^{\circ} 7\right)$, pâte rouge, engobe sous glaçure verte $\left(n^{\circ} 8\right)$. Tunnel de la Major.

engobe sous couverte brillante et rassemble des vaisselles monochromes blanchâtres ou vertes ou portant un décor de coulures de taches brunes à l'extérieur des pièces (type Aegean Ware, Splashed Ware ou Splashed Blobs of brown Colour; Démians d'Archimbaud et al. 2003, p. 147-48 ; Capelli et al. 2004, p. 191). Le corpus se compose surtout de coupes avec ou sans marli incurvé, à rehauts bruns soulignant sur les bords internes et externes des pièces (fig. $\mathbf{7 7}, \mathbf{n}^{\circ} \mathbf{1}, \mathbf{5 - 6}, \mathbf{8}, \mathbf{f i g} . \mathbf{2 9}, \mathbf{n}^{\circ} \mathbf{3}$ et fig. 31, $\left.\mathbf{n}^{\circ} \mathbf{1}\right)$. À ce type de pièce, il faut rattacher un pied de forme annulaire (fig. 77, $\mathbf{n}^{\circ}$ 3-4). Des parallèles sont à établir avec la cargaison de l'épave d'un navire échoué non loin de l'île de Kastellorizo (Bakirtzi 1999, p. 144).

Autre groupe appartenant à cette zone d'influence, celui de Lemba-Paphos, a été rarement mis en évidence en Provence (Démians d'Archimbaud et al. 2003, p. 149 , fig. $10 \mathrm{n}^{\circ}$ 2). Il correspond à des formes fermées spécifiques à décor engobé clair sur fond brun (fig. 77, $\left.\mathbf{n}^{\circ} \mathbf{6}\right)$. Ce sont des pichets globulaires à col étroit qui renvoient aux officines situées sur la côte occidentale de l'île de Chypre. Cette production est illustrée sur le site par un vase, en tous points identique à celui 


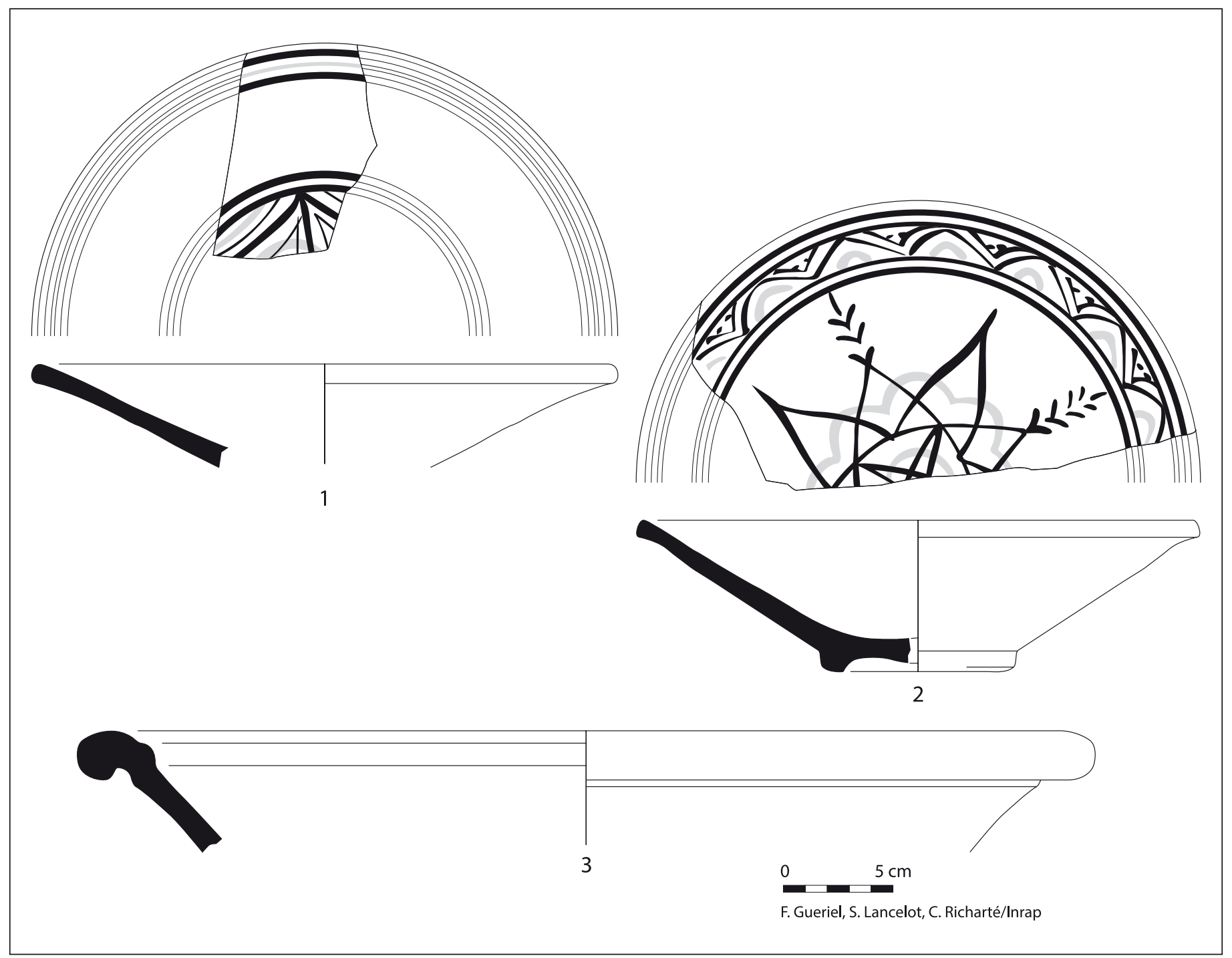

Fig. 78. Productions ibériques du XIII ${ }^{e} \mathrm{~s}$. Faïences vertes et brunes catalanes ( $\left.n^{\circ} 1-2\right)$, lebrillo ou bassin glaçuré catalan ( $\left.n^{\circ} 3\right)$. Tunnel de la Major.

retrouvé sur la fouille de la place Général-de-Gaulle (Papanikola-Bakirtzi 1999, p. 62 ; Richarté 2001, p. 162, fig. 209).

Enfin, pour compléter le panorama des céramiques de Méditerranée orientale, il faut mentionner la présence remarquable de vaisselles engobées, à décor incisé sous glaçure. Ces sgraffitos byzantins correspondent principalement aux types Zeuxippus Ware (Popovic 1989, p. 122 ; Cabona 1986, p. 472-73, Papanikola-Bakirtzi 1999, p. 143-157) et Saint Symeon Ware (Capelli et al. 2004, p. 82 ; Richarté 2001, p. 162-63, fig. 208), ici représenté par des plats à marli, de diamètre d'une vingtaine de centimètres environ, revêtu d'une glaçure au plomb de très belle qualité. Le type Zeuxippus Ware porte un décor incisé de quadrillage pointé sur engobe (fig. $77, \mathbf{n}^{\circ} \mathbf{2}$ ). Ces objets font leur apparition à partir du $\mathrm{XII}^{\mathrm{e}} \mathrm{s}$, notamment sur les sites portuaires.

\subsection{Dans l'influence de la chrétienté occidentale}

Dans le courant du XIII ${ }^{\mathrm{e}}$ s., il semble que l'on change d'aire d'influence; le flux d'importations islamiques s'interrompt peu à peu pour laisser la place à d'autres types de produits importés. Apparaissent alors des céramiques émaillées à décor vert et brun ou encore bleu et/ou lustre venant d'Espagne, mais cette fois d'ateliers valenciens ou catalans. Concomitamment, les apports italiens sont aussi constitués de faïences polychromes provenant plus massivement des régions septentrionales de la péninsule italique, comme Savone et Pise.

\subsubsection{Les faïences aragonaises et catalanes}

C'est à partir de la deuxième moitié du XIII ${ }^{\mathrm{e}}$ s., sans doute à la faveur d'un transfert de population et 
de savoir-faire (Dectot 2008, p. 86), que les officines de Manisès-Paterna, supplantent les productions d'alAndalus et amorcent la diffusion en nombre de faïences blanches à décor de pigment vert, brun et bleu à reflets métalliques. L'essentiel du premier répertoire andalou est reproduit, écuelles, plats, pichets, mais les créations moins élégantes, car moins fines que celles des ateliers méridionaux. Elles portent une ornementation plus stéréotypée, à la différence des productions d'AlmériaMálaga, qui se développe aussi au revers des pièces, notamment sur les pièces ornées de bleu et de lustre. Les potiers aragonais ont parallèlement fabriqué des objets à décor vert et brun toutefois moins répandus sur les sites que les précédentes.

Simultanément, un autre flux de céramiques importées de Catalogne inonde la Provence. Marseille n'échappera pas à ce phénomène. Ce sont des centaines de séries d'écuelles et de gran des coupes tronconiques, émaillées à décor vert et brun (fig. $\mathbf{7 8}, \mathbf{n}^{\circ} \mathbf{1 - 2}$ ) qui sont «consommées » sans doute au détriment des produits levantins. Les céramiques utilitaires catalanes sont elles aussi présentes avec de larges bassins glaçurés (fig. 78, $\mathbf{n}^{\circ}$ 3) dont la production est complétée par des éléments de service à boire, tasse à deux anses et pichet comme les exemplaires mis au jour place Général-de-Gaulle (Richarté 2001 , p. 151 , fig. $188, n^{\circ} 1$ et 3 ). Mais la catégorie ne compte qu'une assez faible part de culinaires importées (Vallauri 1997, p. 88, fig. 59 ; Richarté 2001, p. 149). Les récipients en pâte rouge à inclusions ferrugineuses, systématiquement tournassées, sont glaçurés au plomb sur leur face interne. Ces productions émergentes vont être surtout diffusées en masse à la fin du XIII ${ }^{\mathrm{e}}$ s. et dans la toute première moitié du siècle suivant.

\subsubsection{Les majoliques liguro-toscanes}

Pour les importations italiennes, les sgraffito tyrrhéniens correspondent à des pièces polychromes engobées, incisées et vernissées originaires des centres ligures d'Albisola et de Savone, mais également, et dans une moindre part, de Toscane. Le répertoire se compose de coupes et d'écuelles hémisphériques à marli oblique et à pied annulaire (fig. $\mathbf{7 5}, \mathbf{n}^{\circ} \mathbf{4 - 5}$ ). Les coupes portent des décors incisés géométriques et rehaussés de taches colorées, vertes, jaunes ou brunes. Ces singulières petites écuelles sont toujours présentes dans les contextes datés de la deuxième moitié du XII ${ }^{\mathrm{e}} \mathrm{s}$. (Mannoni 1975, p. 72-75 ; Lavagna-Varaldo 1989, p. 119-130) et jusque dans le courant du XIV ${ }^{\mathrm{e}} \mathrm{s}$.

L'autre apport important de l'Italie centrale pour la fin de ce XIII ${ }^{\mathrm{e}}$ s., sont les faïences pisano-ligures. Elles possèdent une pâte très épurée, issue des alluvions de l'Arno (Berti-Tongorgi 1977, p. 13), ainsi qu'une couleur rouge brique caractéristique. Ces vaisselles portent un décor vert et brun stylisé sur émail stannifère. Malgré la prédominance des formes ouvertes (coupes et écuelles hémisphériques), se trouve abondamment des pichets. Les premiers exemplaires portent une ornementation également empruntée au vocabulaire oriental. Très en vogue, et vraisemblablement assez peu coûteuses, ces faïences au décor schématisé sont produites en série, dès la fin du XIII ${ }^{\mathrm{e}}$ s., puis se raréfie pour réapparaître en nombre à la fin du $\mathrm{XV}^{\mathrm{e}} \mathrm{s}$. À Marseille, la production est alors remplacée par des vaisselles dites $a$ stecca au tournant du $\mathrm{XV}^{\mathrm{e}}$ s., dont le centre de diffusion est apparemment la région de Pise (Démians d'Archimbaud 1981, p. 42).

\subsection{Le quartier canonial, miroir du commerce méditerranéen}

L'ensemble de ce mobilier céramique s'inscrit pleinement dans le processus de circulation et d'échanges des produits, à l'arrivée comme au départ, du port de Marseille. Il livre une assez juste idée de l'ampleur de cet horizon maritime, et des spécificités de son commerce dans la Méditerranée des XII ${ }^{\mathrm{e}}$ et XIII ${ }^{\mathrm{e}}$ s. Marseille est un port actif dans le grand commerce méditerranéen qui s'appuie sur le relais des places italiennes, de Pise et de Gênes notamment, ainsi que de Majorque, véritables pôles de redistribution des marchandises pour un trafic vers ou depuis l'Orient et les côtes méditerranéennes. Les expéditions commerciales sont ainsi principalement organisées, d'une part vers certains ports de la Méditerranée occidentale, notamment vers le littoral provençal et languedocien, dans l'espace maritime catalan, et vers l'Ifriqiya, et d'autre part, vers Chypre, Tyr et les ports côtiers de la péninsule italique comme Gênes, Savone ou la Sardaigne (Coulon et al. 2007, p. 16-17). Marseille joue alors un rôle d'envergure, à cette période où les déplacements de pèlerins et de croisés se multiplient. Le brassage induit par ces échanges se perçoit bien à travers le mobilier varié mis au jour dans les fouilles marseillaises.

Les flux exportés donnent un reflet de cette ouverture particulièrement orientée sur le bassin méditerranéen qui, par-delà les mers, s'avère spécialement perméable aux mondes byzantin et islamique et à leurs codes esthétiques. En effet, pour autant que nous puissions en juger aucun objet ne paraît provenir des contrées septentrionales, aucune production rhône-alpine, de la Saintonge ou du Beauvaisis identifiées; mais des produits d'Espagne, d'Italie, du Maghreb, de l'aire byzantine, du Proche-Orient qui complètent des apports régionaux, et traduisent un attrait pour des objets plus 
rares ou «à la mode » évoquant une certaine idée du raffinement médiéval.

\section{Conclusion (Fl. Parent)}

L'évocation du vaisselier marseillais de la fin du XII ${ }^{e}$ et du XIII ${ }^{e}$ s. ne paraît pas se démarquer des connaissances recueillies sur le vaisselier provençal de même époque; tout au plus ressent-on une menue discordance, sensible au travers des importations. En effet, le registre des productions provençales et limitrophes ne dénote en rien de celui observé sur d'autres sites régionaux. Malgré l'apparition de la cuisson oxydante et de la glaçure dans certains centres régionaux, malgré l'installation d'officines utilisant ces procédés à Marseille même, les préférences des consommateurs marseillais vont aux «traditionnelles » vaisselles à pâte grise et, quand il s'agit de nouveaux procédés, ils se dotent de préférence de produits fabriqués outre Rhône (glaçurés de l'Uzège) pourtant plus éloignés.

Concernant les produits importés, la position littorale stratégique de Marseille semble insuffler à ses habitants des usages, non pas hors du commun, mais plus diversifiés que dans la Provence intérieure. À Marseille, la possession de ces importations ne semble pas l'apanage d'une catégorie de population particulière et leur proportion se retrouvent sensiblement à l'identique dans tous les points de la ville étudiés, que ce soit dans le quartier marchand de la Ville basse (place VilleneuveBargemon), dans le quartier épiscopal (Tunnel de la Major, rue de la Cathédrale), dans les quartiers artisanaux (tanneurs de l'Alcazar, potiers de Sainte-Barbe) ou dans les nouveaux faubourgs (bourg de Morier/Alcazar, bourg Sainte-Catherine/place Général-de-Gaulle)... 


\section{Chapitre 4}

\section{Les derniers siècles du Moyen Âge : de la lumière à l'ombre}

\section{(Florence Parent, Véronique Abel)}

$\mathrm{L}$ e contraste est saisissant entre d'une part la fin du XIII et le $\mathrm{XIV}^{\mathrm{e}} \mathrm{s}$., qui constitue certainement la période la mieux documentée archéologiquement et le $\mathrm{XV}^{\mathrm{e}}$ s. qui apparaît comme totalement absent des grandes fouilles marseillaises.

\section{La fin du XIII ${ }^{\mathrm{e}}$ et le $\mathrm{XIV}^{\mathrm{e}} \mathrm{s}$. : vers} l'hégémonie de quelques grands centres? (Fl. Parent)

Cette période ne sera pas abordée suivant le schéma adopté dans les précédents, une description détaillée d'un mobilier déjà maintes fois documenté pour cette période serait superflue. En effet, le faciès observé sur les quelques chantiers évoqués dans ce recueil obéit à un schéma désormais classique en Provence. Cette période est donc déjà très bien renseignée, ne serait-ce que par certaines des publications concernant des fouilles plus anciennes en Provence mais également dans la cité phocéenne, publications auxquelles nous renvoyons (notamment: Marchesi et al. 1997 ; Démians d'Archimbaud, Vallauri 1995 ; Vallauri 1998 ; Parent 2001 ; Bouiron 2001). L'exposé, au travers d'un bref aperçu des assemblages de chaque site (certes de qualités inégales), nous a semblé plus judicieux pour illustrer la manière dont ce mobilier s'intègre ou parfois se singularise du vaisselier provençal « ordinaire » de cette période qui s'étend de la fin du XIII ${ }^{\mathrm{e}} \mathrm{s}$. à la fin du XIV ${ }^{\mathrm{e}} \mathrm{s}$. Quelques fragments éloquents, provenant des fouilles du parvis de l'église Saint-Laurent, viennent compléter le panel de ceux des sites évoqués tout au long de ce volume.

\subsection{La rue Trinquet}

Un puits, construit au cours du haut Moyen Âge, a vraisemblablement été «reconverti » en dépotoir dans sa dernière phase d'utilisation, au début du $\mathrm{XIV}^{\mathrm{e}} \mathrm{s}$. Son comblement a livré près de 200 fragments, 198 pour être précis, équivalant au minimum à 71 vases différents ${ }^{9}$. Ces récipients étaient accompagnés de plusieurs objets en bois, dont l'étude n'a pu être intégrée dans ce volume, la fouille étant encore trop récente par rapport à l'écriture du manuscrit. Il s'agit d'un des rares ensembles clos de la période médiévale à Marseille, avec ceux de la place Jules-Verne à proximité de la Mairie. Près du tiers de ces vases provient d'importations ; en toute logique, les productions locales et régionales sont donc largement majoritaires.

\subsubsection{Les céramiques locales et régionales}

Les rares fragments recensés de céramiques communes à pâte brune correspondent vraisemblablement à un seul pot ou pégau. Il provient de centres de production identiques à ceux évoqués dans les chapitres précédents (cf. supra ch. $2 \S 1.1$. et ch. $3 \S 1.1 .3$.), sans doute le bassin de l'Argens. Les céramiques communes à pâte grise locales comptabilisent 2 individus : un gros pot et une marmite à bord rectangulaire porté par un col sinueux. Ils s'accompagnent d'une marmite varoise (Ollières) en pâte grise également, dont le bord triangulaire évoque une datation plus tardive que les marmites du chapitre précédent (cf. supra ch. 3 § 1.1.1.) (Démians d'Archimbaud 1980). Le puits contient également quatre pièces en pâte rouge diffusées par les ateliers varois : les fragments de deux marmites à glaçure transparente (dont une avec anses verticales), un fond annulaire à glaçure verte interne pouvant appartenir à une forme ouverte ou à un gros vase à liquide, enfin un téton de préhension perforé pourrait provenir d'une lampe. Elles ne sont en général présentes que de manière ponctuelle sur les sites marseillais où la concurrence de produits languedociens analogues les dessert (Pelletier 1997b, p. 79).

D'ailleurs ces céramiques communes à pâte claire glaçurée dites de l'Uzège sont de loin la catégorie de céramiques communes la mieux représentée dans ce puits, et suivent en cela un schéma familier à Marseille et plus largement en Provence au XIV ${ }^{\mathrm{e}}$ s. Seize individus

9 Ce comblement a été dégagé à l'aide de la pelle mécanique. Autant dire qu'il devait en contenir plus, mais toute fouille comporte son lot d'oubliés. 
ont ainsi pu être recensés, parmi lesquelles au moins onze marmites. Ces récipients globulaires offrent une relative variété dans la forme de leur lèvre : triangulaire, plus ou moins carrée ou encore en amande, parfois soulignée d'une gorge, autant d'éléments typologiques qui, associés à la présence d'anses verticales, évoquent les productions de la première moitié du $\mathrm{XIV}^{\mathrm{e}} \mathrm{s}$. (Leenhardt et al. 1996, p. 113). Aux côtés de ces vases, apparaissent un fond de cruche, un fragment de petit pégau, un autre de couvercle et deux bords de jattes.

Un bord de plat en pâte rouge grossière glaçurée était vraisemblablement pourvu de tétons de préhension. Cette forme est attestée dans les ateliers et le faubourg de Sainte-Barbe tout au long du XIII ${ }^{\mathrm{e}} \mathrm{s}$. (Vallauri et al., p. 209). Cinq vases en pâte calcaire non glaçurées sont issus des mêmes ateliers marseillais: deux bords et un fond proviennent de coupelles de type 1, qui sont fabriquées au cours du XIII ${ }^{\mathrm{e}} \mathrm{s}$. (Vallauri et al. 1997, p. 225-228). En revanche, les exemplaires similaires mais de plus grand diamètre (coupe de type 1), dont un exemple figure dans ce puits, perdurent jusque dans le premier quart du XIV e s. (Vallauri et al. 1997, p. 217 220). Enfin, un bord droit à lèvre simplement arrondie pourrait s'apparenter à une marmite, de type 4 marginal, produite dans les premières années du XIV ${ }^{\mathrm{e}} \mathrm{s}$. (Vallauri et al. 1997, p. 203 et fig. 175-12).

Ces mêmes ateliers marseillais ont fourni une dizaine de pièces glaçurées sur pâte calcaire: plusieurs fonds plats et divers fragments émanent d'au moins six cruches ou pichets. Les mini-coupelles 3, auxquelles appartient un bord à glaçure très fine, font partie des dernières productions des ateliers marseillais, celles du premier quart du $\mathrm{XIV}^{\mathrm{e}} \mathrm{s}$. La même chronologie s'applique pour la mini-coupelle de type 2 dont deux bords nous sont parvenus (Vallauri et al. 1997, p. 238-239, fig. 205). Quelques faïences viennent compléter cet éventail des produits marseillais. Pour l'essentiel, il s'agit de coupes tronconiques à lèvre repliée formant un bourrelet interne. Ces coupes de type 8 portent un décor vert et brun géométrique dont la caractéristique principale est l'organisation quadrilobée ou en registre horizontaux. Elles appartiennent aux dernières productions des officines de Sainte-Barbe (Vallauri et al. 1997, p. 233), comme la cruche de type 3 à l'anse rubanée caractéristique (Vallauri et al. 1997, p. 247-249).

\subsubsection{Les céramiques importées}

Un tiers des céramiques abandonnées dans ce puits provient d'horizons méditerranéens divers où l'Espagne tient une place de choix. Effectivement, la moitié des exemplaires étrangers est importé de Catalogne, phénomène surprenant dans la cité phocéenne et plus généralement en Provence, dans une période où les produits italiens obtiennent la faveur. L'absence de produits ligures, notamment de sgraffito archaïques, une des importations italiennes les plus précoces dans notre région puisque introduite dès le début du XIII ${ }^{\mathrm{e}}$ s., confirme la chronologie évoquée par les produits régionaux du contexte.

Les majoliques pisanes à décor vert et brun sont introduites dès le début du $\mathrm{XIV}^{\mathrm{e}} \mathrm{s}$. en Provence (Démians d'Archimbaud, Vallauri 1998, p. 86). Vu leur qualité et leur finesse, les six exemplaires décomptés ici appartiennent à ces premières importations. Les formes sont façonnées avec soin, leurs parois sont fines, et les décors sont réalisés avec précision, que ce soit pour la coupe à rebord étiré et paroi carénée que pour les trois bols à décor dit «à la croix ». Les deux fonds de cruche ne présentent pas trace de décor.

Comme nous l'avons signalé, l'Espagne tient une place importante dans la vaisselle de ce comblement, notamment la Catalogne qui totalise au moins douze vases. Deux fonds plat et un bord en « crochet » appartiennent à de grands bassins glaçurés (ou lebrillo en catalan) que l'on retrouve sur la majorité des sites provençaux. Apparaissant dès la fin du XII ${ }^{e}$ s., ces produits deviennent plus fréquents au cours du XIII ${ }^{\mathrm{e}} \mathrm{s}$. et perdurent encore quand leurs compatriotes émaillés et souvent décorés sont introduits dans les vaisseliers à la fin $\mathrm{du} \mathrm{XIII}^{\mathrm{e}} \mathrm{s}$. Une dizaine d'objets appartiennent ici à cette dernière catégorie, tous issus de formes ouvertes : coupes, coupelles et bols. Les coupes portent un décor polychrome vert et brun géométrique ou végétal stylisé (fig. 79, $\mathbf{n}^{\circ} \mathbf{1 - 2}$ ). Les éléments de petite taille, bol à lèvre simple et coupelle à marli, sont revêtus uniquement d'un émail monochrome blanc, parfois rehaussé au centre d'un simple motif brun (ici une étoile). Ces importations de la région de Barcelone tombent en désuétude dès le milieu du XIV ${ }^{\text {e }}$ s. au profit des majoliques pisanes.

Toujours en provenance de l'Espagne, trois fragments d'un même bol recouvert d'émail sur les deux faces et d'un décor bleu à l'intérieur évoquent les productions de l'aire valencienne. Le décor bleu s'accompagne le plus souvent de motifs au lustre métallique qui a pu disparaître sur cet exemplaire comme sur ceux découverts à l'église Saint-Laurent (fig. 80). Ces produits sont très fréquents en Provence dans la seconde moitié du $\mathrm{XIV}^{\mathrm{e}} \mathrm{s}$., mais apparaissent déjà dans la première moitié de ce siècle (Démians d'Archimbaud, Vallauri 1998, p. 88).

Un autre fragment de coupe à marli aux parois très fines, auquel peut probablement être associé un fond annulaire à décor radial bleu, pourrait se rattacher aux productions andalouses diffusées en Provence à l'extrême fin $\mathrm{du} \mathrm{XIII}^{\mathrm{e}} \mathrm{s}$. et au début du siècle suivant (Démians d'Archimbaud, Vallauri 1998, p. 88) et un bord de bassin de profil carré et à décor très érodé (sans doute vert 


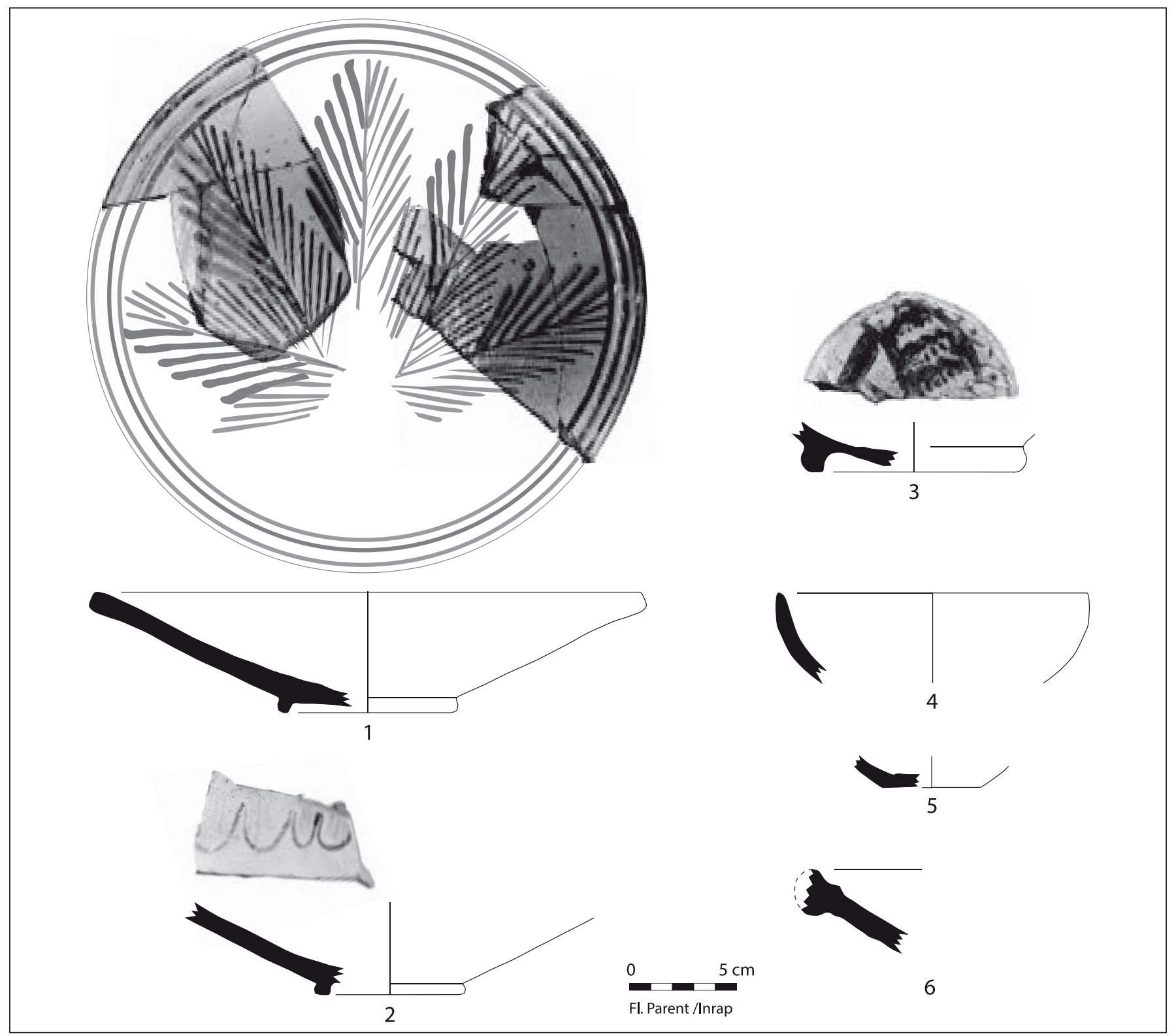

Fig. 79. Faïences à décor vert et brun en provenance de Catalogne, importées à Marseille de la fin du XIIIe $\mathrm{s}$. au milieu du XIVe 1 1-2 : rue Trinquet ; 3 : rue de la République (Surverse Vieux-Port, diagnostic) ; 4-6 : parvis de l'église Saint Laurent.

et brun) trouve probablement son origine en Afrique du Nord. Un bord de panse de pichet, très globulaire, a sans doute été fabriqué dans la même aire d'influence. Sa pâte rouge, dure et sonore, recouverte d'une belle glaçure verte à l'extérieur est caractéristique des productions attribuées aux régions siculo-maghrébines. Nous avons déjà vu que ces productions se retrouvaient en Provence, et à Marseille, dès le XII ${ }^{\mathrm{e}} \mathrm{s}$. (cf. supra ch. 3 § 2.2.). On les rencontre encore de manière exceptionnelle en ce début de siècle, comme l'atteste le récipient quasi complet dégagé d'un puits de la place Jules-Verne (Démians d'Archimbaud, Vallauri 1998, fig. 47-7; Capelli et al. 2006 ; Capelli et al. 2010).

\subsection{Le collège Vieux-Port}

Ici encore, le seul mobilier archéologique illustrant cette période provient d'un puits. Malheureusement celui-ci n'a pu être fouillé entièrement - la fouille ayant été interrompue avant sa fin pour permettre la conservation des vestiges : le comblement de ce puits a pu être dégagé sur $1 \mathrm{~m}$ de profondeur tout au plus. C'est dire que les céramiques qui en sont sorties ne sont qu'un pâle reflet de celles qu'il peut encore receler : les plus belles pièces presque intactes se trouvent généralement dans le fond, qu'elles y soient tombées par accident ou qu'elles y aient été mises volontairement au rebus. 


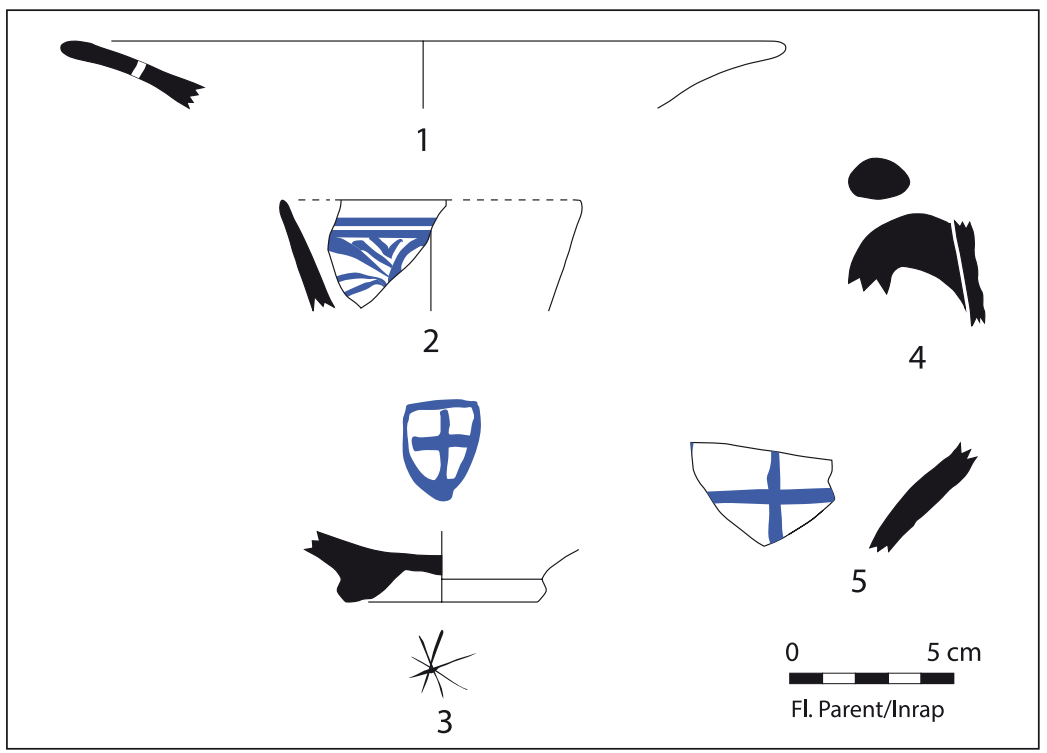

Fig. 80. Faïences à décor de cobalt et/ ou lustre en provenance de la région de Valence (Espagne) au XIVe $s$.

Parvis de l'église Saint-Laurent.
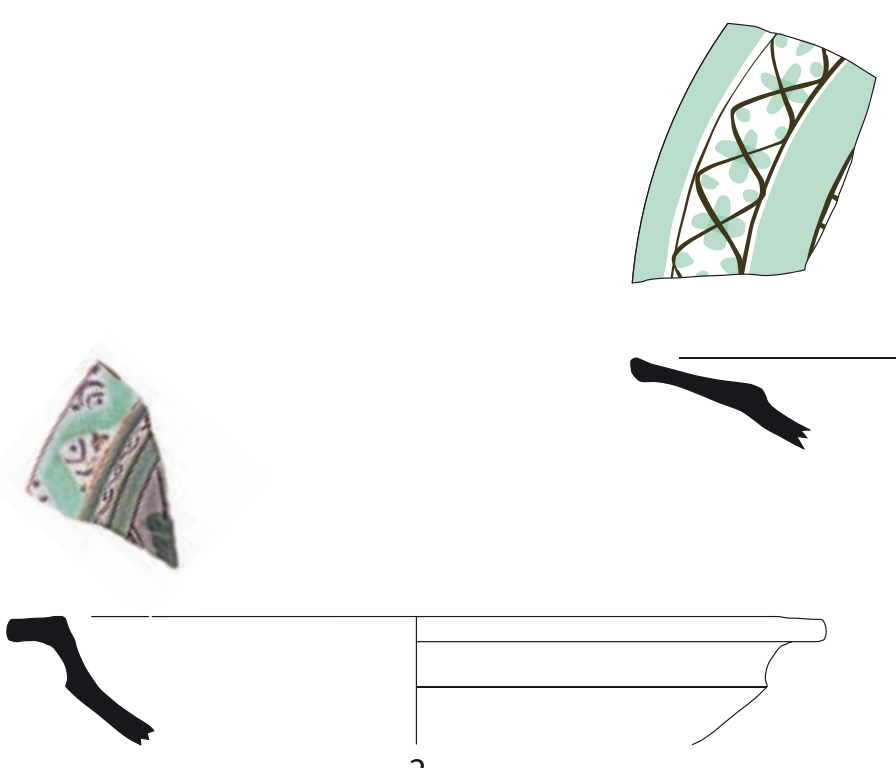

2

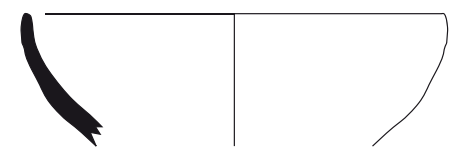

4
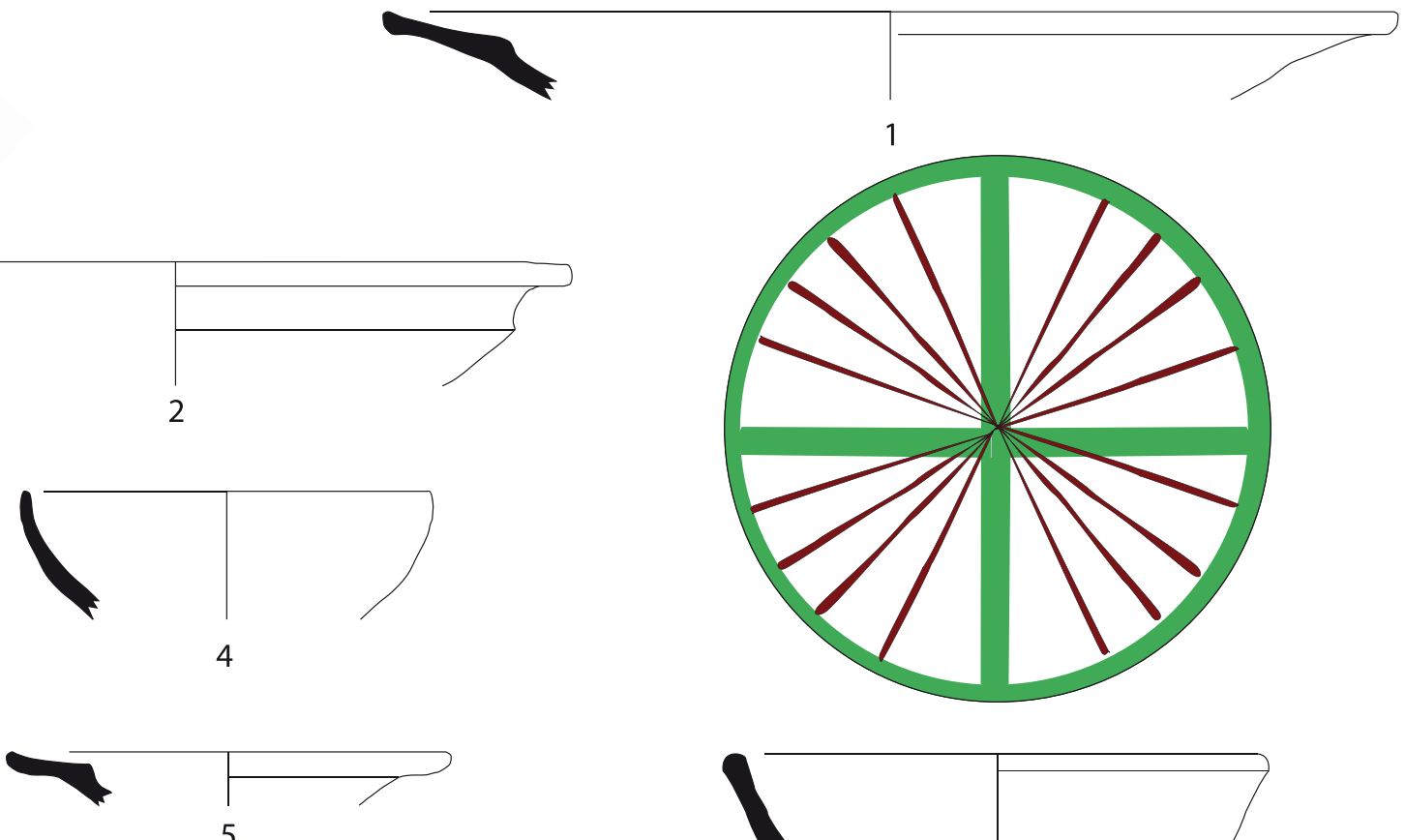

5

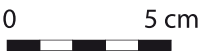

Fl. Parent/Inrap

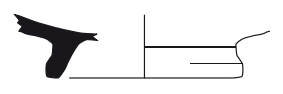

6

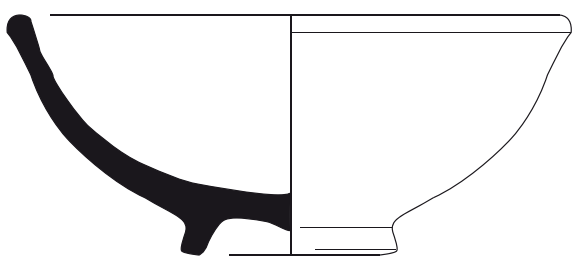

3

Fig. 81. Faïences monochromes ou à décor vert et brun produites dans la région de Pise au XIVe s. 1, 4, 6 : parvis de l'église Saint-Laurent ; 2 : collège Vieux-Port ; 3 : Alcazar ; 5 : rue de la République (Surverse Vieux-Port). 


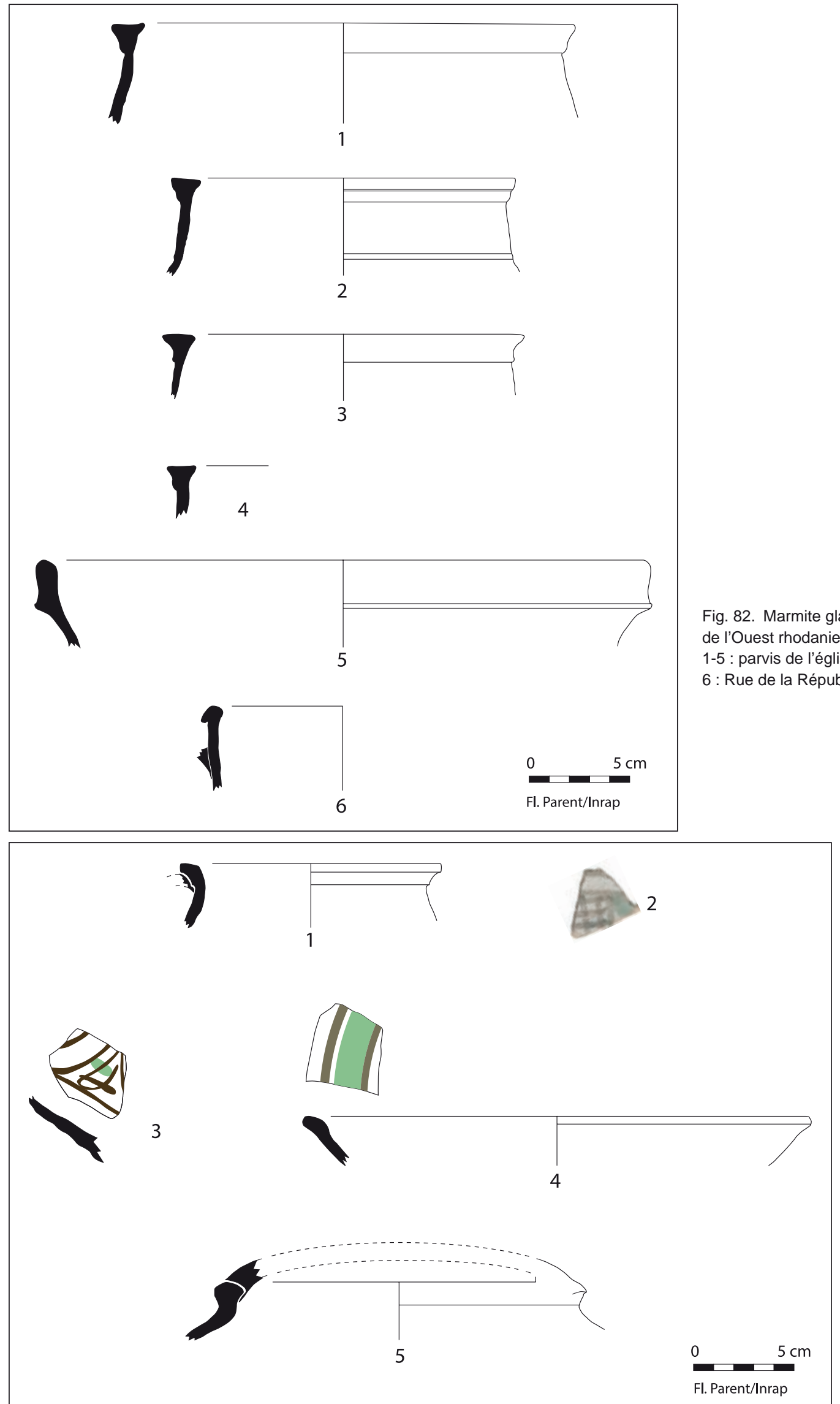

Fig. 83. Céramiques produites à Marseille dans les ateliers de Sainte-Barbe.

1-2: Rue de la République (Surverse Vieux-Port) ; 3-5: parvis de l'église Saint-Laurent. 
Le comblement matérialisant son abandon contient essentiellement des céramiques communes : quelques fragments de cruches vernissées jaune en provenance de l'Uzège, d'autres à glaçure verte sur pâte calcaire attribuables aux ateliers marseillais, tandis que les fragments de plats et les fragments de tians, tous glaçurés, proviennent respectivement d'Italie (Ligurie) et d'Espagne (Catalogne). Ajoutons à ces produits, quelques fragments de coupes ou de plats décorés en vert et brun pour les faïences de production marseillaise ou pisane (fig. 81, $\mathbf{n}^{\circ}$ 2), par des incisions rehaussées de vert et jaune pour la graffita arcaica tirrenica. Ce maigre assemblage paraît donc se constituer à l'extrême fin du XIII ${ }^{\mathrm{e}}$ ou au tout début du XIV ${ }^{\mathrm{e}} \mathrm{s}$.

\subsection{La rue de la République (Surverse Vieux-Port)}

Comme précédemment, les niveaux de cette époque ont livré un mobilier bien chiche: ce ne sont que 25 fragments qui révèlent ce faciès. Les céramiques communes à pâte claire glaçurée de l'Uzège y sont prépondérantes, une douzaine de fragments : une marmite à bord triangulaire (fig. 82) et un bord de poêlon sont caractéristiques des productions de la première moitié du XIV ${ }^{\mathrm{e}}$ s. (Leenhardt 1995, p. 113, 115). De rares fragments de céramique commune grise (une panse de pégau à décor à la roulette) et de céramique commune brune (deux panses de pot) y sont associés.

Les productions proprement locales des ateliers de Sainte-Barbe sont également représentées au travers d'un bord de pégau en pâte rouge glaçurée. Son grand diamètre à l'ouverture $(13 \mathrm{~cm})$ tendrait à le rapprocher du type 3 des pots à une anse (Marchesi et al., p. 193, fig. 169), produits déjà rares dans la deuxième moitié du XIII' ${ }^{\mathrm{e}}$ s. (fig. 83, $\mathbf{n}^{\circ} \mathbf{1}$ ). Les faïences issues des mêmes ateliers adoptent sensiblement la même chronologie. Un fragment de bord de coupelle de type 2 (Marchesi et al. 1997 , p. 228, fig. 198) porte un décor sinusoïdal caractéristique de ces productions dans la première moitié du $\mathrm{XIII}{ }^{\mathrm{e}} \mathrm{s}$. Mais il est accompagné d'un fragment de coupe à décor de quadrillage serré brun organisé en registre concentrique agrémenté d'une ébauche de décor vert (fig. 83, $\mathbf{n}^{\circ}$ 2). Cette organisation du décor et ce répertoire sont typiques du style régional assez répétitif de la première moitié du XIV ${ }^{\mathrm{e}} \mathrm{s}$. (Marchesi et al. 1997, p. 223).

Les importations ne figurent ici qu'à la marge, bien que celles en provenance de la région pisane, faïences à décor vert et brun ou tout simplement monochromes (fig. 81, $\mathbf{n}^{\circ} \mathbf{5}$ ), soient de consommation courante dans toute la Provence de la seconde moitié du XIII ${ }^{\mathrm{e}} \mathrm{s}$. jusqu'au milieu du XIV ${ }^{\mathrm{e}} \mathrm{s}$. (Leenhardt 1995, p. 128 ; Leenhardt et al. 1996).

\subsection{L'Alcazar}

Le site de l'Alcazar (fig. 84) est de loin le chantier qui a livré le plus de mobilier pour cette période. Ici, les dernières décennies du XIII ${ }^{\mathrm{e}} \mathrm{s}$. et les premières du siècle suivant sont marquées par l'occupation du bourg de Morier, juste avant la destruction volontaire des maisons. Cette période réunit la part la plus importante de mobilier médiéval pour le site, un peu plus de 2500 tessons. On assiste alors à l'implantation plus marquée de certains centres. Les ateliers de Marseille (Sainte-Barbe) occupent une part du marché de plus en plus importante, ils dépassent les $15 \%$, cependant que les ateliers de l'Uzège commencent à se tailler la part belle en assurant plus du tiers de l'approvisionnement du faubourg. Cet essor se fait inévitablement au détriment de certains centres auparavant plus importants : la consommation de céramiques communes à pâte brune et à pâte grise régresse nettement (d'un peu plus de $5 \%$ chacune) alors que les communes modelées et glaçurées à pâte rouge grossière ont tendance à se raréfier (elles chutent à $3,9 \%$ ). La proportion de céramiques plus luxueuses, dont l'essentiel est importé, reste quasiment analogue (aux environs de $15 \%$ ), mais les apports se renouvellent: alors que dans les siècles précédents, les deux tiers provenaient des mondes byzantin et islamique, l'essentiel provient maintenant de pays limitrophes, Espagne et Italie, tandis qu'une part toujours aussi infime est attribuée aux majoliques locales (4\% du total). Ces constatations pourraient témoigner du niveau de vie peu élevé des résidents de ce faubourg, ou du fait que les habitants ont eu le temps d'emporter leurs biens, au moins les plus précieux, avant l'incendie des îlots, les deux hypothèses n'étant pas incompatibles et d'autres pouvant exister.

À la destruction du faubourg et la récupération des vestiges à partir des premières décennies du $\mathrm{XIV}^{\mathrm{e}} \mathrm{s}$., succèdent l'établissement et l'entretien de jardins dans la deuxième moitié du siècle (et peut-être encore au cours du $\mathrm{XV}^{\mathrm{e}} \mathrm{s}$.). Ces épisodes totalisent une masse de fragments médiévaux nettement moins considérable que la phase précédente (environ 1500 fragments). Ici s'illustre le problème de la datation par la céramique de l'incendie du faubourg, car le faciès céramique situerait cet événement dans les premières décennies du XIV ${ }^{\mathrm{e}} \mathrm{s}$. alors que les textes d'archives qui le mentionnent le place juste après le milieu du siècle, vers 1357-1358. Le déclin de certaines productions auparavant majoritaires, déclin déjà nettement perceptible à la fin $\mathrm{du}_{\mathrm{XIII}}{ }^{\mathrm{e}} \mathrm{s}$. et au début du XIV ${ }^{\mathrm{e}} \mathrm{s}$., s' accentue encore et elles disparaissent presque totalement avant le milieu du $\mathrm{XIV}^{\mathrm{e}} \mathrm{s}$. : c'est le cas des céramiques communes à pâte brune et de celles modelées à pâte rouge glaçurées, qui atteignent à peine 
$1 \%$, et, dans une moindre mesure, des céramiques communes à pâte grise dont la proportion chute de moitié. Parallèlement, les produits en provenance de l'Uzège ne cessent d'augmenter puisqu'ils totalisent presque $50 \%$ du vaisselier. Dans les niveaux d'incendie du faubourg, apparaissent les toutes dernières productions des ateliers de Sainte-Barbe, en biscuits majoritairement, accompagnées de rares majoliques de la Vallée du Rhône. Les importations de céramiques de table conservent les mêmes proportions qu'auparavant, soit près de $15 \%$. Mais, tandis que les importations italiennes et espagnoles se répartissaient presque équitablement (aux environs de $5 \%$ ) dans la phase précédente, ici les produits italiens prennent davantage d'importance, au détriment des productions espagnoles.

\subsubsection{Les céramiques communes}

Parmi la catégorie des céramiques communes, les ateliers de l'ouest rhodanien se taillent donc la part du lion : marmites, jattes, gargoulettes occupent une très grande place. Signalons également la présence d'une trompe d'appel peinte à l'ocre (fig. 85) dont les caractéristiques de pâte rappellent les productions à pâte claire glaçurées des ateliers varois. De tels objets, aux usages bien spécifiques puisque destinés à émettre un signal sonore puissant, sont connus depuis le haut Moyen Âge (Démians d'Archimbaud 1981, p. 308-310) jusqu'au $\mathrm{XIII}^{\mathrm{e}} \mathrm{s}$., époque où les ateliers marseillais de SainteBarbe en ont également fabriqué (Vallauri, Leenhardt 1997, p. 289). Les ateliers de l'Uzège en confectionnent aussi au XIV ${ }^{\mathrm{e}}$ s., glaçurés ou uniquement peints à l'ocre comme ici (Leenhardt 1995, fig. 75).

Les céramiques communes en provenance d'Espagne sont en nette minorité au sein des importations. Comme à la période précédente, il s'agit majoritairement de grands bassins aux fonctions domestiques multiples. L'intérieur de ces pièces est couvert d'une glaçure plombifère épaisse, le plus souvent de couleur miel ; l'extérieur est laissé nu et porte toujours des traces de tournassage. Leur fond est plat et l'élément le plus caractéristique est leur lèvre en massue, très proéminente vers l'extérieur, ce qui devait assurer une meilleure préhension de l'objet.

\subsubsection{Les faïences espagnoles}

Les 4/5 des faïences espagnoles sont issus de Catalogne. Ce sont en majorité des coupes en faïence blanche portant un décor vert et brun. Ce décor est géométrique ou végétal, les deux tendances pouvant se combiner comme le montrent certains vases mieux conservés. Ces faïences polychromes sont importées dès la fin du XIII ${ }^{\mathrm{e}} \mathrm{s}$. en Provence et encore au siècle suivant mais, dès la première moitié du $\mathrm{XIV}^{\mathrm{e}} \mathrm{s}$., le décor devient de moins en moins élaboré se réduisant souvent à un simple motif central (géométrique ou héraldique) tracé au manganèse, quand il ne disparaît pas totalement. Curieusement, cette restriction dans le décor semble s'accompagner d'une légère diversification dans les formes importées, plats et coupes, bols et écuelles, plus ou moins évasés, à marli ou non, alors que les éléments à décor polychrome appartiennent tous ici à des coupes tronconiques à lèvre simple. Cette évolution a déjà été signalée place Général-de-Gaulle (Richarté 2001). Dès la seconde moitié du $\mathrm{XIV}^{\mathrm{e}} \mathrm{s}$., les importations de Barcelone disparaissent presque totalement. À cette époque et au siècle suivant, les préférences semblent se tourner vers les faïences à décor de bleu et lustre de la région de Valence que les ateliers catalans ont tenté d'imiter comme en témoigne un fragment de coupelle, à décor bleu mais avec une pâte de toute évidence catalane.

Les premiers produits valenciens à décor de lustre apparaissent avec l'installation du faubourg, mais ils sont peu nombreux (au total à peine plus d'une trentaine de fragments) aussi bien pendant l'occupation de ce faubourg que dans les couches qui matérialisent ou qui scellent sa destruction. De plus, comme le reste du matériel, ils sont extrêmement fragmentés et de petite taille, ce qui ne donne qu'une vue extrêmement réduite de leur décor. Il est ainsi impossible de savoir dans la plupart des cas si les fragments qui ne présentent qu'un décor monochrome, soit au cobalt seul soit au lustre seul, sont significatifs de l'ensemble de la pièce ou si le reste du vase qui a disparu associait les deux couleurs. Les éléments retrouvés appartiennent tous à des formes ouvertes de coupes ou de bols. Un seul tesson fait exception : il s'agit d'un fragment de pied de chandelier dont la partie conservée porte un décor lustré. Les ateliers de Paterna, dans la région de Valence (Espagne), ont simultanément fabriqué des faïences à décor de cobalt (bleu) et de lustre et des faïences à décor vert et brun et ce, dès la seconde moitié du XIII ${ }^{\mathrm{e}} \mathrm{s}$. Les pièces à décor vert et brun sont très peu diffusées en Provence : les 4 fragments retrouvés à l'Alcazar sont donc exceptionnels (fig. 86) et pourraient provenir du même chargement que la cruche découverte à proximité du port place JulesVerne (Démians d'Archimbaud, Vallauri 1997, fig. 35). Deux sont en position résiduelle dans un contexte d'Époque moderne, les deux autres ont été découverts dans des contextes datés du premier tiers du $\mathrm{XIV}^{\mathrm{e}} \mathrm{s}$. Les formes sont fines et élégantes, de même que les décors. Ces coupelles ont une lèvre simplement effilée (fig. 86, $\mathbf{n}^{\circ} \mathbf{3}$ ) ou biseautée (fig. 86, $\mathbf{n}^{\circ} \mathbf{1}$ ), les fonds annulaires sont légèrement surcreusés (fig. 86, $\mathbf{n}^{\circ} \mathbf{2}, \mathbf{4}$ ). D'une manière générale, ce groupe est toujours très minoritaire par rapport aux autres importations hispaniques, aussi bien en 


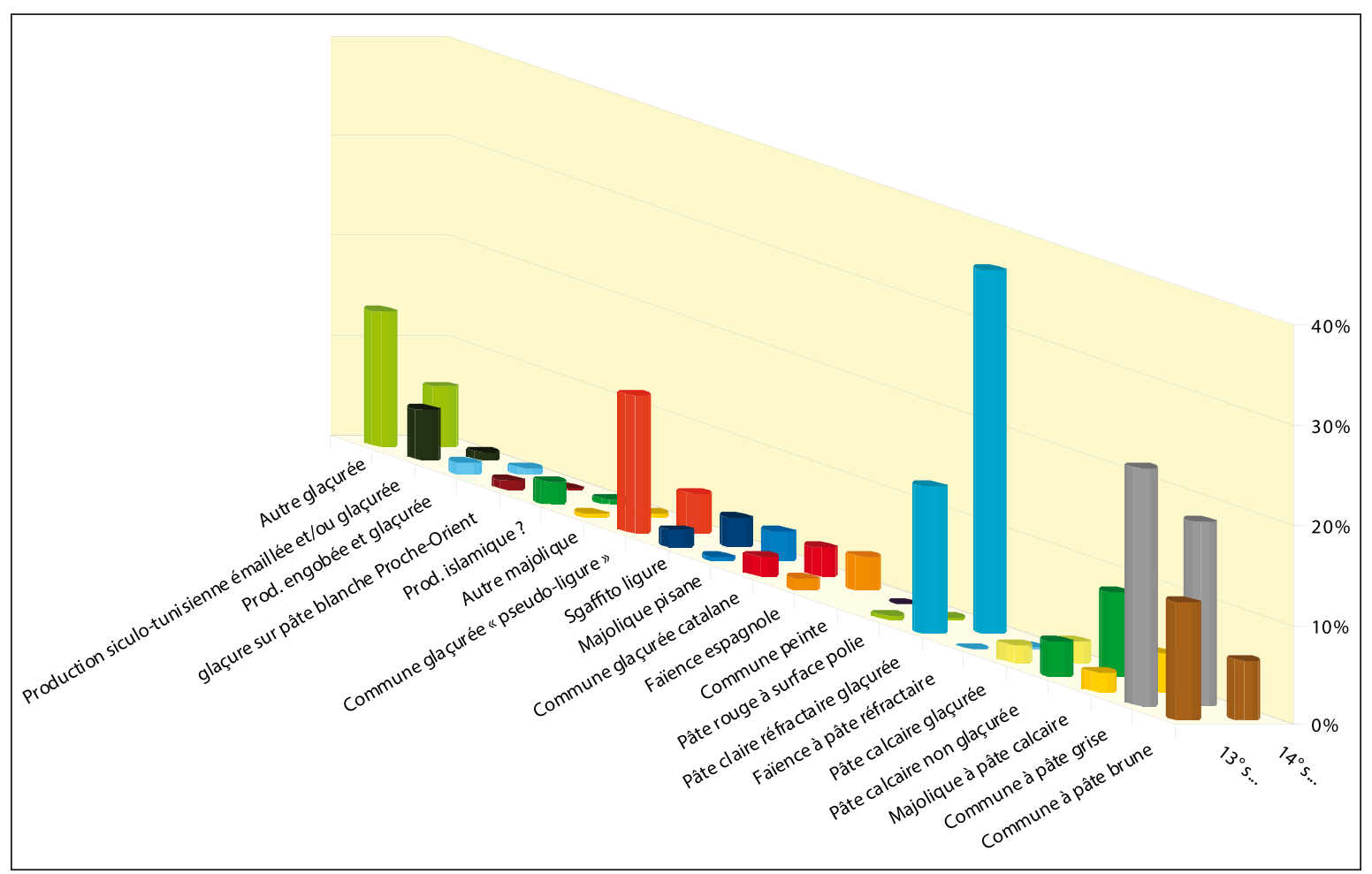

Fig. 84. Répartition des productions de l'Alcazar entre le XIII et la première moitié du XIVe $\mathrm{s}$.

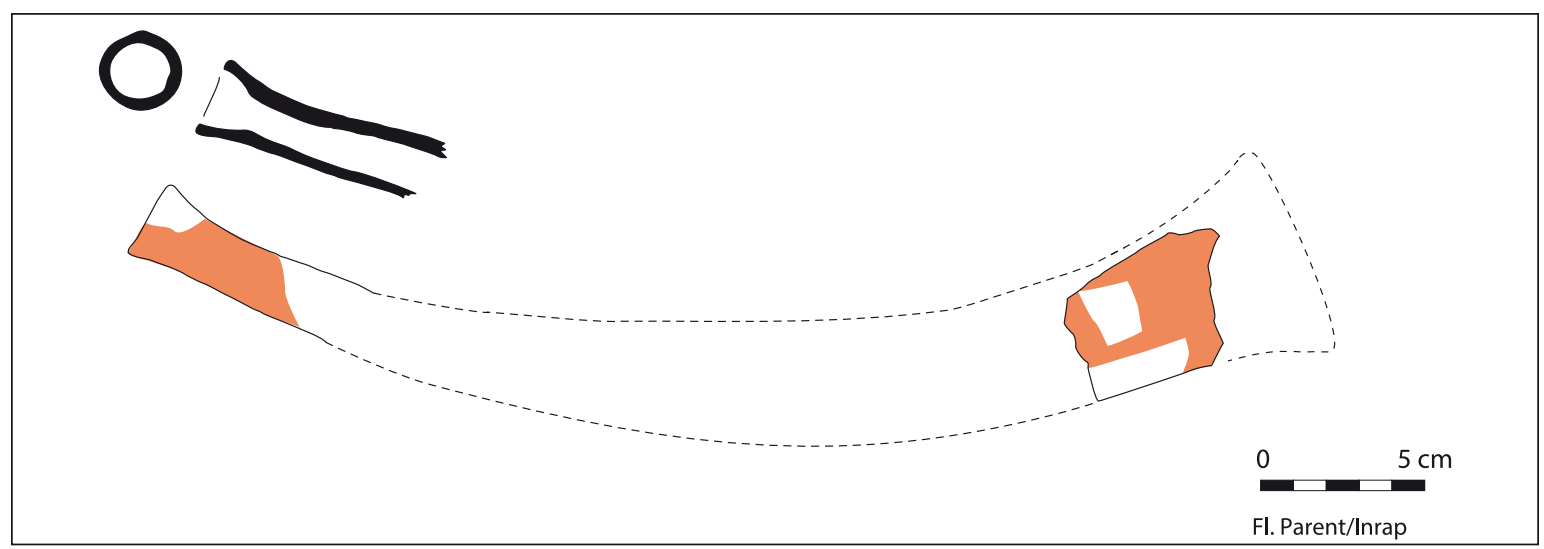

Fig. 85. Trompe d'appel peinte à l'ocre, en pâte réfractaire d'origine régionale. Alcazar.

Languedoc qu'en Provence (Amouric, Richez, Vallauri 1999, p. 50 ; Richarté et al. 2005).

\subsubsection{Les majoliques pisanes}

Les premières majoliques pisanes apparaissent pendant l'occupation du faubourg et sont encore plus abondantes pendant et après sa destruction. Elles consistent essentiellement en fragments de bols et de cruches, à décor d'émail monochrome blanc ou rehaussé de vert et de brun. Quelques fragments de coupes apparaissent parfois dans les niveaux d'occupation du faubourg, tel un bord de coupe carénée à décor d'écailles identique à celui retrouvé à Olbia (Parent 1991, fig. $23 \mathrm{n}^{\circ} 1$ ) et à ceux des bacini du début du $\mathrm{XIV}^{\mathrm{e}} \mathrm{s}$. ornant certaines églises pisanes (Berti, Tongorgi 1981, tav. CLXIII-CLXXXI). Cependant, la majorité des éléments de formes ouvertes porte un décor classique dit « à la croix », décor fréquemment rencontré sur les majoliques de ce type au cours du $\mathrm{XIV}^{\mathrm{e}} \mathrm{s}$. et que les ateliers ligures copient amplement à cette période et au début du siècle suivant comme l'illustre le bol $n^{\circ} 3$ de la fig. 81, découvert sur le sol d'une maison du faubourg (Berti 1997).

Les dernières et rares productions engobées et glaçurées de Méditerranée orientale se rencontrent encore 


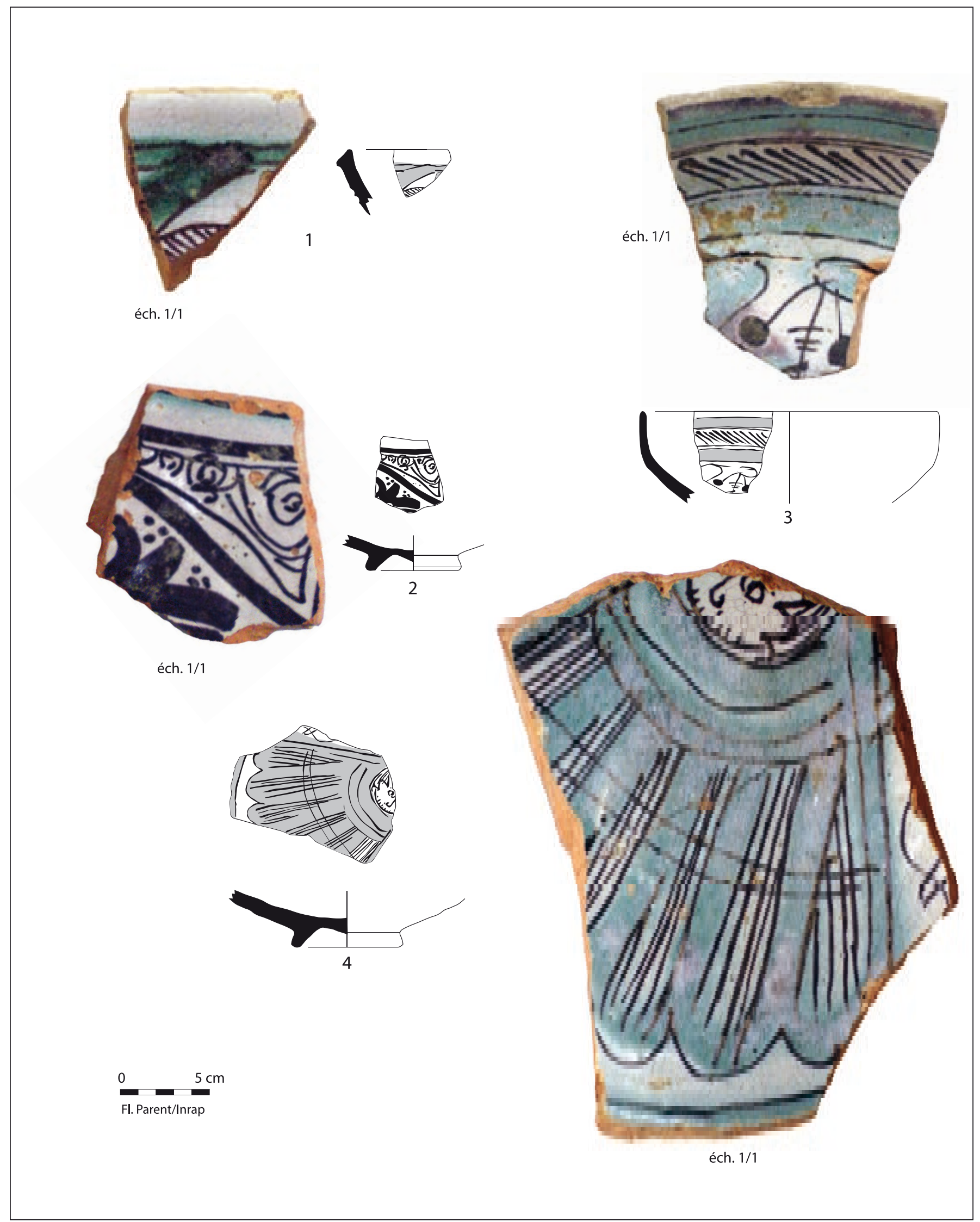

Fig. 86. Faïences à décor vert et brun en provenance de Paterna (Espagne). Alcazar. 


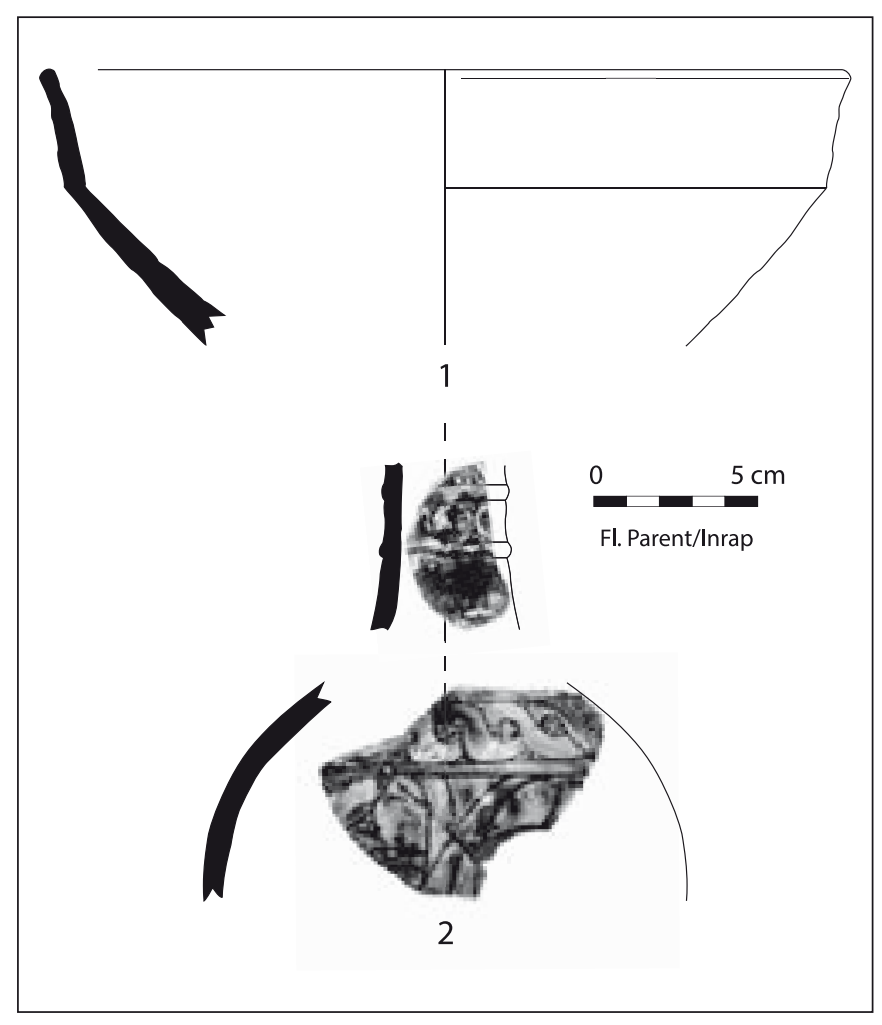

Fig. 87. Céramiques engobées et glaçurées, en provenance de Méditerranée orientale au début du XIVe s. Alcazar.

dans l'ultime occupation du faubourg, telle une coupe à bord redressé et glaçure verte (fig. 87, $\mathbf{n}^{\circ} \mathbf{1}$ ) ou une exceptionnelle cruche au décor incisé rehaussé de vert et de brun (fig. 87, ${ }^{\circ} \mathbf{2}$ ), qui semblerait provenir de Chypre. Plus aucune n'apparaît dans les niveaux succédant à la destruction du faubourg.

\subsection{La place Villeneuve-Bargemon}

Les fouilles de la place Villeneuve-Bargemon n'ont livré qu'une très faible quantité de matériel pour cette époque. Dans les quelques contextes préservés de l'ultime occupation médiévale du site, les productions de céramiques communes grises et brunes tendent à disparaître - elles peuvent même être considérées comme résiduelles - au profit de céramiques en pâte claire réfractaire glaçurées en provenance de l'Uzège ou de ses environs et d'autres en pâte calcaire des ateliers marseillais. Les formes à usage culinaire sont diversifiées : marmites, jattes, bassins, cruches... En ce qui concerne les importations, les grands centres d'approvisionnement se sont rapprochés - Catalogne, Ligurie, Toscane - mais quelques échanges avec le monde islamique perdurent. Ces importations concernent maintenant essentiellement des céramiques de table émaillées.
La fouille des niveaux antiques sous cette place a révélé quelques fragments intéressants mais pour lesquels nous ne possédons pas les contextes. Il s'agit notamment d'une marmite glaçurée complète fabriquée dans les ateliers de l'Uzège. Sa typologie renvoie à des exemplaires de la seconde moitié du $\mathrm{XIV}^{\mathrm{e}} \mathrm{s}$. : larges anses verticales et cannelées et rebord triangulaire (fig. 88, $\mathbf{n}^{\circ} \mathbf{3}$ ). Le dégagement du fond d'un puits a permis de mettre au jour un assemblage remarquable d'objets et de récipients. Remarquable dans le sens où les récipients, essentiellement des vases à liquide, sont encore entiers et accompagnés d'un attirail d'objet de toutes sortes : dés en os, gobelets et bouteilles de verre, accessoires en métal. Tous ceux-ci seront détaillés en seconde partie, dans les chapitres alloués à leur catégorie.

Revenons-en à la quinzaine de poteries rejetées ou perdues dans ce puits. Une majorité écrasante appartient à la vaisselle dite de service (11 objets sur 16$)$. Deux cruches produites dans la Basse Vallée du Rhône portent pour tout décor leur émail blanc (fig. 89, $\mathbf{n}^{\circ} \mathbf{1}$ et 2). De formes trapues, elles sont analogues aux séries de l'extrême fin du XIV ${ }^{\mathrm{e}}$ ou du début du $\mathrm{XV}^{\mathrm{e}} \mathrm{s}$. découvertes dans la fouille des jardins de l'Hôtel de Brion à Avignon (Démians d'Archimbaud et al. 1980b, fig. 19). Vraisemblablement de même provenance, une mini-coupelle (fig. 89, $\mathbf{n}^{\circ} \mathbf{3}$ ) est elle aussi émaillée sans décor et deux fonds de jarre ou de pot de grande contenance dont l'un porte des taches accidentelles d'émail blanc sur leur pâte nue (fig. 89, $\mathbf{n}^{\circ} \mathbf{4}$ ) et l'autre une glaçure interne. Ils ont pu servir au stockage de l'eau. Autres céramiques utilitaires, deux bords de marmites glaçurées sur leur pâte réfractaire émanent de la même région (fig. 88, $\mathbf{n}^{\circ} \mathbf{1}-\mathbf{2}$ ).

Deux coupelles à marli en provenance d'Espagne (région de Valence) présentent un décor couvrant et élaboré, tracé au lustre métallique. La première (fig. 90, $\left.\mathbf{n}^{\circ} \mathbf{1}\right)$ mêle de fines spirales entrelacées à des feuilles de chêne et de lierre, le tout organisé en plusieurs registres délimités par des filets et des aplats. La seconde, beaucoup moins bien conservée (fig. 90, $\mathbf{n}^{\circ} \mathbf{2}$ ), conjugue décor métallisé et aplat au cobalt sur le marli. Le même motif de traits verticaux ponctués de spirales se retrouve sur les deux coupelles. Il s'agit d'un motif récurrent dans les productions de Paterna (Espagne) dans la seconde moitié du $\mathrm{XIV}^{\mathrm{e}} \mathrm{s}$. et encore courant au début du $\mathrm{XV}^{\mathrm{e}} \mathrm{s}$. (Mesquida Garcia 2006, p. 15, fig. 12). Toujours issus d'Espagne mais cette fois de Catalogne, ont été découverts un grand bassin à glaçure vert olive (fig. 91, $\left.\mathbf{n}^{\circ} \mathbf{1}\right)$ et un fond de coupelle émaillée portant pour seul décor, au centre, une étoile brune tracée hâtivement. Nous avons vu supra, en évoquant les céramiques du bourg de Morier (Alcazar), que les décors de ces productions deviennent de moins en moins élaborés au cours du $\mathrm{XIV}^{\mathrm{e}} \mathrm{s}$. ; nous en avons encore un exemple ici. 


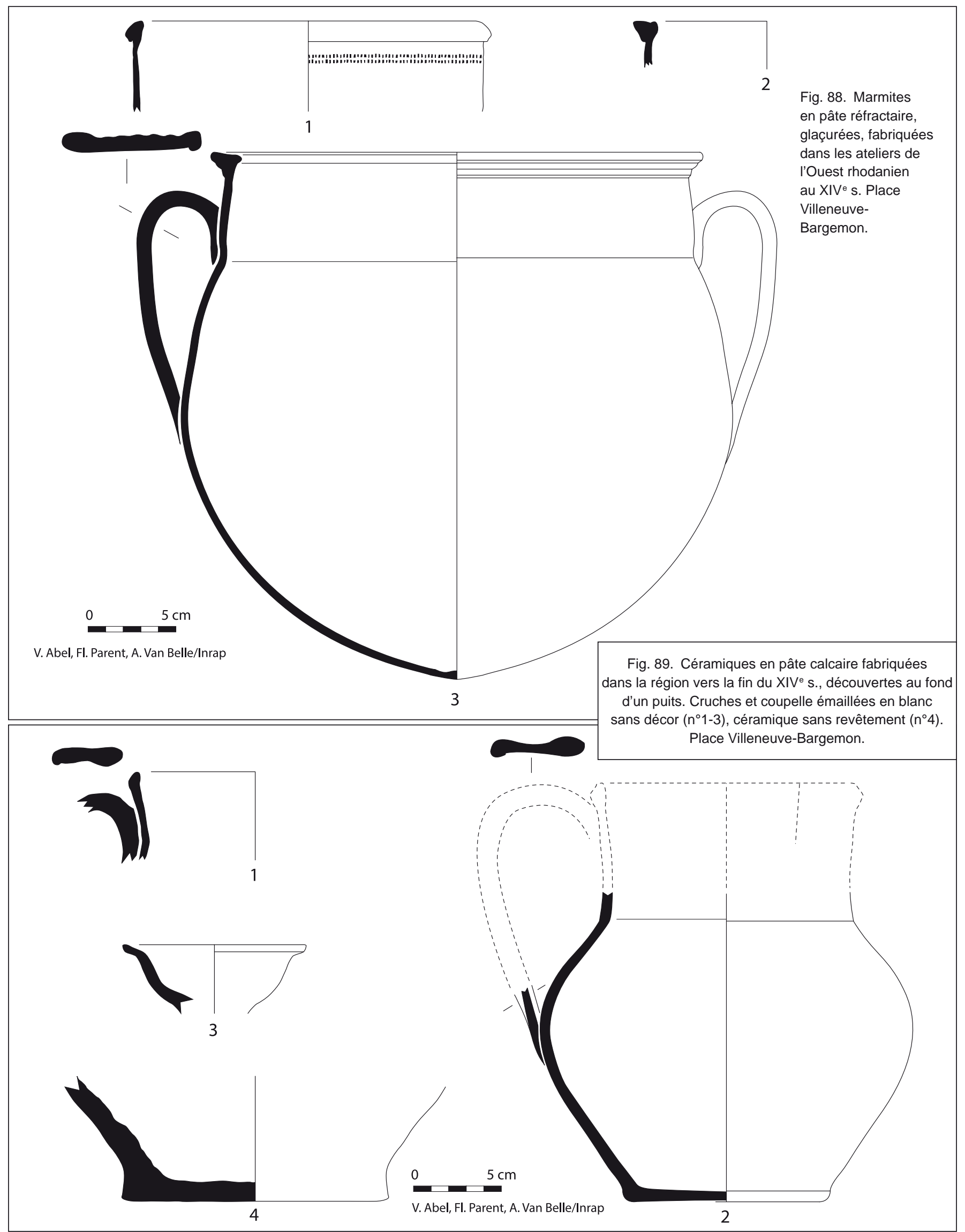




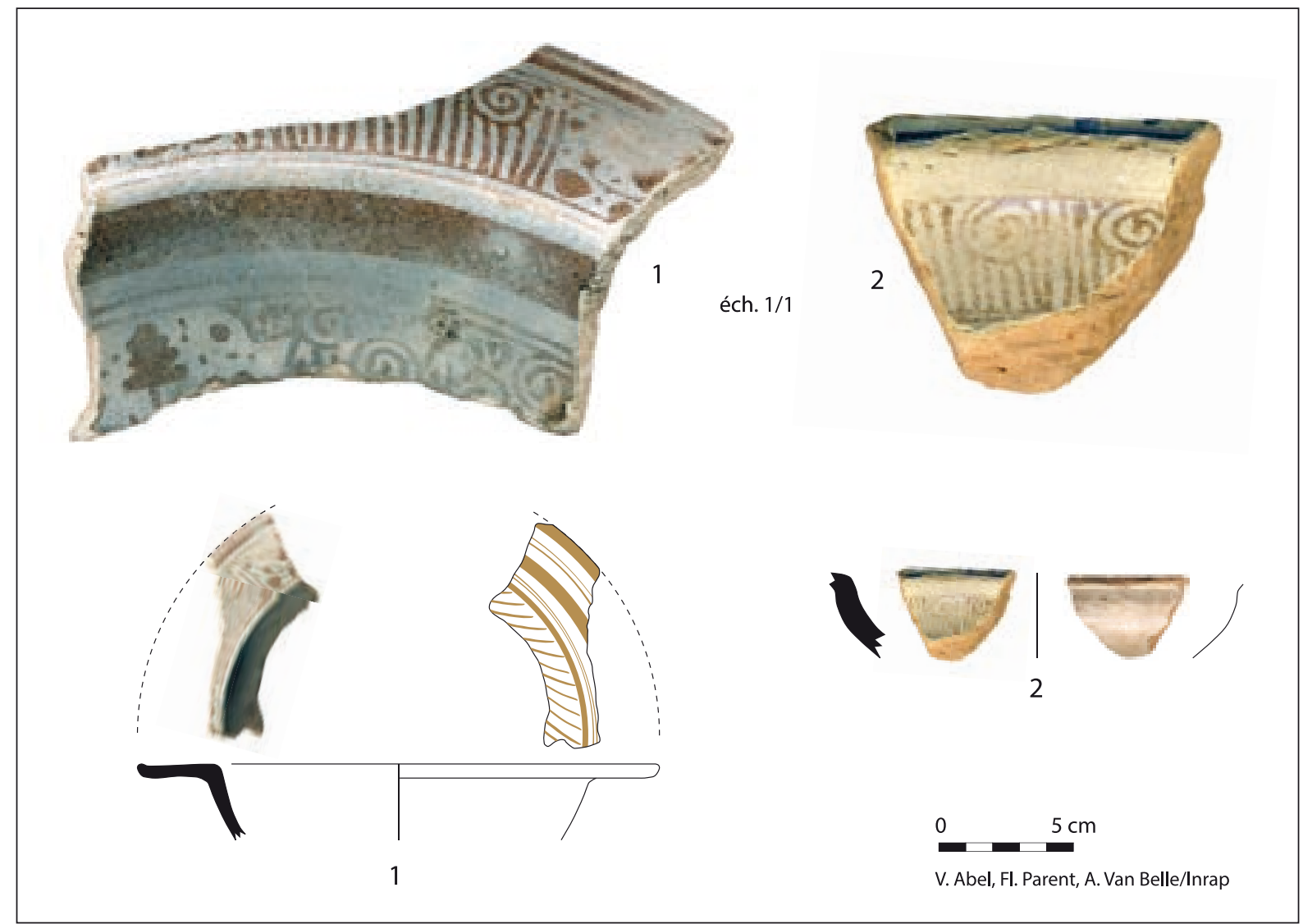

Fig. 90. Faïences à décor de cobalt et/ou lustre en provenance de la région de Valence (Espagne) à la fin du XIVe s. et retrouvées au fond d'un puits. Place Villeneuve-Bargemon.

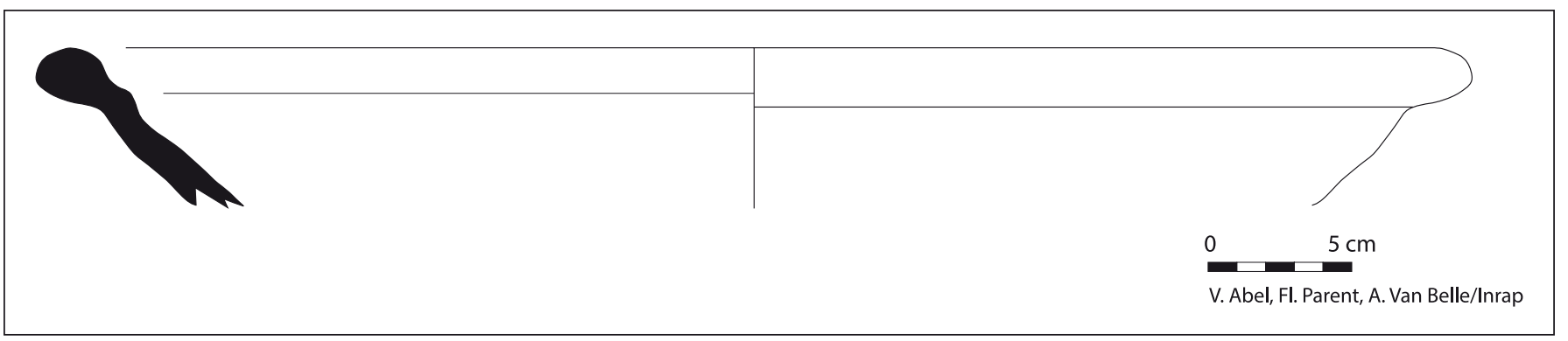

Fig. 91. Céramiques commune en provenance de Catalogne vers la fin du XIVe $\mathrm{s}$., découvertes au fond d'un puits. Place Villeneuve-Bargemon.

Fig. 92. Quelques unes des céramiques découvertes au fond d'un puits. Les décors de certaines cruches ne sont plus visibles qu'en négatif après leur séjour dans l'eau saumâtre et dans les déchets organiques. Place VilleneuveBargemon. Cl. T. Maziers/Inrap.

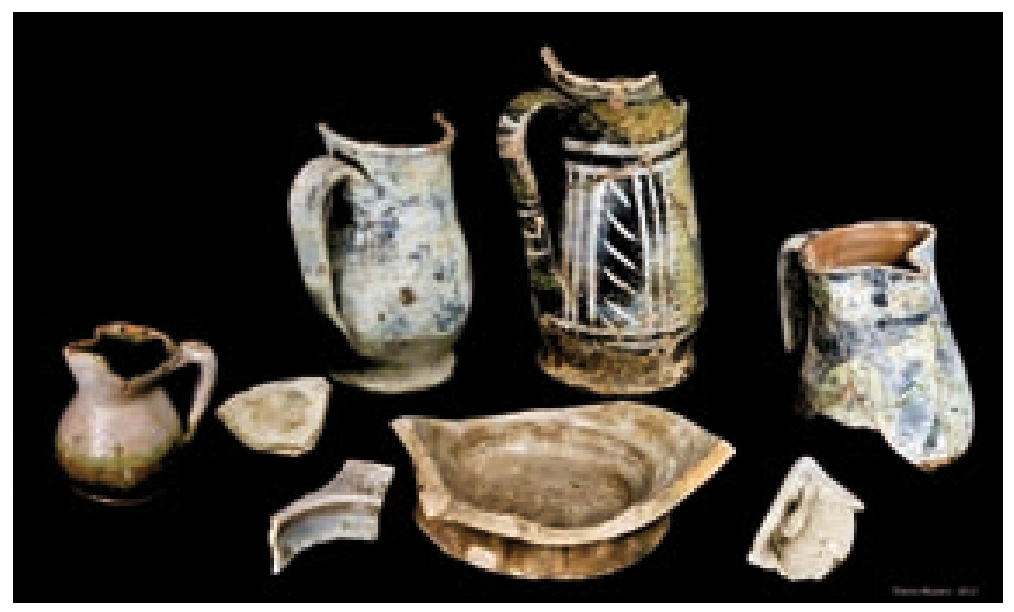




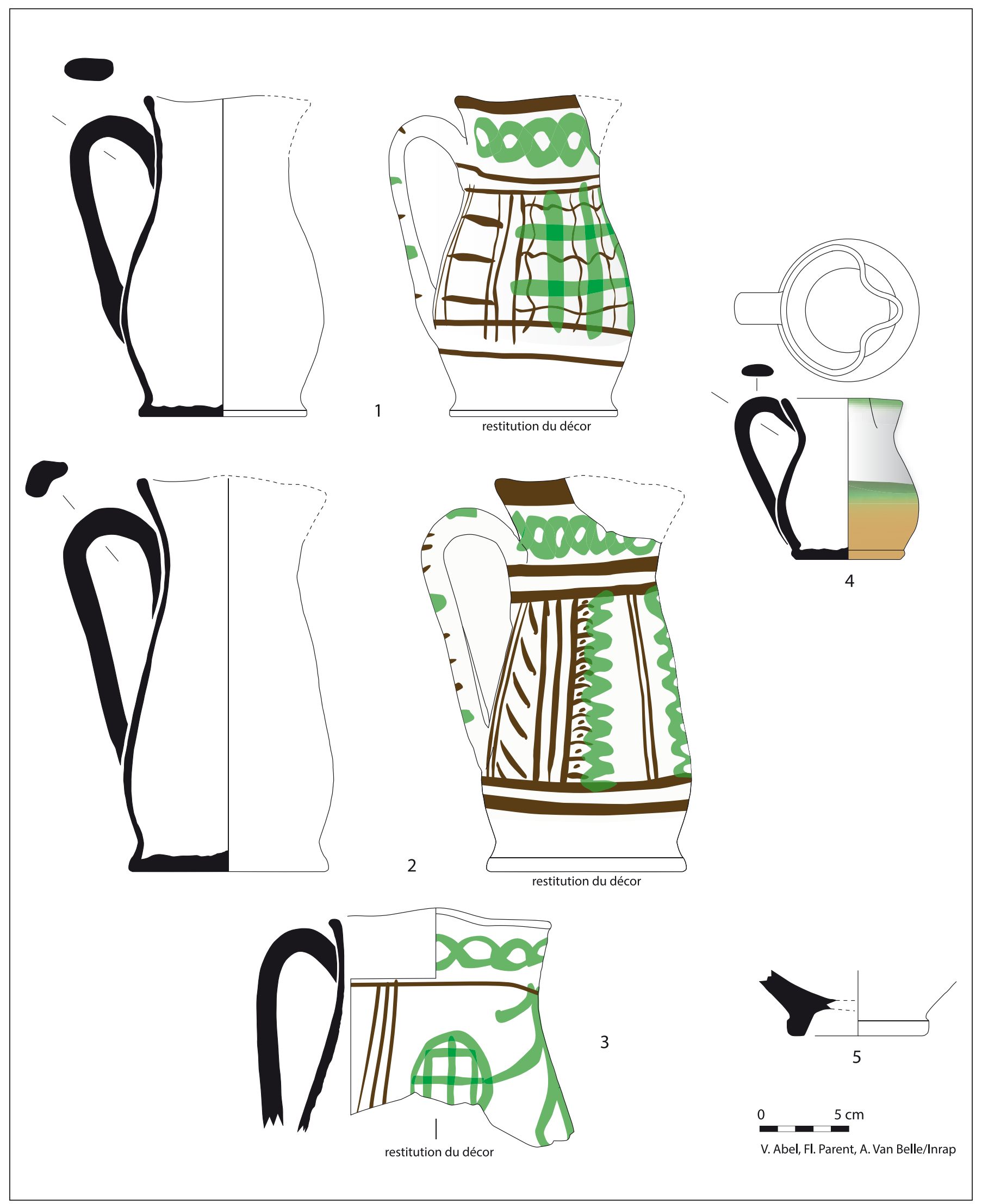

Fig. 93. Faïences monochromes ou à décor vert et brun produites dans la région de Pise vers la fin du XIVe S., découvertes au fond d'un puits. Place Villeneuve-Bargemon. 
Les derniers vases proviennent de Toscane et constituent à eux seuls le tiers de ce petit lot. Leur séjour au fond du puits, entourés d'éléments organiques en décomposition dans de l'eau saumâtre, a fortement altéré les décors des cruches polychromes émaillées. Il se devine cependant en négatif, l'émail blanc est devenu noir, le brun de manganèse est devenu blanchâtre, le vert de cuivre s'est affadi et n'est pas toujours perceptible (fig. 92). Les cruches ou pichets offrent les formes et les décors caractéristiques du XIV ${ }^{\mathrm{e}} \mathrm{s}$. Le fond peu dégagé, la forme un peu trapue d'un exemplaire pourraient évoquer la seconde partie du siècle (fig. 93, $\mathbf{n}^{\circ} \mathbf{1}$ à 3). Apparaît aussi un exemplaire miniature, émaillé mais non décoré. Il possède la particularité d'être entièrement glaçuré, la glaçure plombifère recouvrant même l'émail, d'où les nuances vertes à certains points de contact. D'après certaines recherches, ces répliques de cruches en miniature ne seraient produites qu'à partir de l'extrême fin du XIV ${ }^{\mathrm{e}}$ ou le début du XV e s. (Giorgio 2010, p. 221).

\subsection{Regard sur un $\mathrm{XIV}^{\mathrm{e}} \mathrm{s}$. riche en mobilier céramique}

Le vaisselier marseillais au seuil et dans le courant $\mathrm{du} \mathrm{XIV}^{\mathrm{e}} \mathrm{s}$. se conforme dans les grandes lignes au vaisselier provençal. Ceci est surtout vrai pour les approvisionnements locaux et régionaux. Sur la table, comme à la cuisine, les vaisselles sont alors toujours glaçurées. La diffusion de récipients varois est très restreinte à Marseille, presque anecdotique, et sans commune mesure avec la commercialisation par ces mêmes ateliers, dans les siècles précédents, de céramiques cuites en atmosphère réductrice. Sont largement préférés les produits de même catégorie du Languedoc, qui sont distribués dans toute la Provence et le Languedoc, et constituent l'essentiel des ustensiles. À cet égard, on peut considérer que les ateliers de l'Uzège, à partir de la fin du XIII ${ }^{e}$ s., exercent une espèce d'hégémonie sur le marché de la vaisselle en terre. Leur renommée dépasse même les frontières, leurs produits étant transportés jusqu'à Saint-Jean d'Acre (Stern 2009, p. 230).

Le bilan des importations est plus nuancé. Leur proportion et leur répartition varient d'un site à l'autre et semblent fonction du contexte de leur découverte. Les observations effectuées sur les ensembles clos que sont les puits de la rue Trinquet et du collège Vieux-Port ne concordent pas avec celles de l'ensemble stratifié du faubourg de l'Alcazar. Dans les premiers cas, les importations espagnoles sont majoritaires et se démarquent de la vision d'ensemble où les importations espagnoles sont généralement deux fois moins nombreuses que les importations italiennes. En revanche, la répartition
Italie-Espagne est conforme sur le site de l'Alcazar et identique à celle des récipients abandonnés au fond d'un puits de la place Jules-Verne au début du XIV e $\mathrm{s}$. (Démians d'Archimbaud, Vallauri 1998, p. 95-99). Cette répartition obéit à une réalité géographique : plus on se rapproche des frontières italiennes et plus les produits ligures et toscans sont présents, plus on se dirige vers l'Espagne et plus la tendance s'inverse au profit des produits de Catalogne et d'Aragon. Les sources d'approvisionnement extérieures sont donc plus proches mais, à côté de ces importations pouvant être considérées comme massives, apparaissent toujours des produits plus rares, plus lointains, plus exotiques qui indiquent que le port de Marseille continue d'être une plaque tournante du commerce maritime en Méditerranée.

\section{La céramique du XV e ${ }^{\text {e }}$ (Fl. Parent, V. Abel)}

De nombreuses incertitudes demeurent dans la connaissance des céramiques de Méditerranée nord occidentale à l'extrême fin du Moyen Âge et au début de l'Époque moderne. Les productions sont plus ou moins bien connues, plus ou moins bien localisées, leur typologie rarement bien établie, malgré une attention désormais attirée sur cette période.

\subsection{La nuit marseillaise du $X V^{e} s$.}

À Marseille, la période s'étendant de l'extrême fin du $X I V^{\mathrm{e}}$ à la fin du $\mathrm{XV}^{\mathrm{e}} \mathrm{s}$. constitue encore une grande nébuleuse. Si a pu tenir un temps l'hypothèse d'une méconnaissance où les modernistes auraient jugé cette céramique trop ancienne et les médiévistes trop récente pour lui accorder leur attention, force est de constater que leur rareté demeure malgré des recherches particulièrement assidues à travers les sacs de tessons livrés par les fouilles de notre cité. Une exception de taille cependant relativise cette affirmation: la réalité de l'archéologie marseillaise fait qu'aucune étude de la céramique moderne n'a été réalisée pour la place Jules-Verne et pour le chantier César 2. À travers une masse excessivement importante (informe et négligée) de mobilier générée par la fouille de ces deux sites très proches l'un de l'autre, retrouver les hypothétiques niveaux des $\mathrm{XV}^{\mathrm{e}}$ et $\mathrm{XVI}^{\mathrm{e}} \mathrm{s}$. aurait été irréaliste pour ce volume.

\subsection{Une vaisselle en théorie}

À défaut de données tangibles et ne pouvant nous résoudre à cette carence, force a été de réunir les 
données acquises pour les époques et les villes voisines afin d'ébaucher ce que nous pourrions nommer la « vaisselle théorique du $X V^{\mathrm{e}} \mathrm{s}$. ». Ainsi peuvent s'échafauder les premières hypothèses sur cette période, prémices de la réflexion et de la recherche.

Ces hypothèses reposent essentiellement sur le principe de la «présence/absence ». Une partie des céramiques repérées à la fin du siècle précédent, subsisteraient donc quelques temps au cours du $\mathrm{XV}^{\mathrm{e}} \mathrm{s}$., voire pendant tout le $X V^{\mathrm{e}} \mathrm{s}$. pour celles encore présentes au $\mathrm{XVI}^{\mathrm{e}} \mathrm{s}$. C'est le cas notamment des faïences/majoliques des pays frontaliers : celles à décor de bleu et/ou lustre, dites hispano-mauresques, fabriquées en Espagne dans la région de Valence et celles à décor vert et brun en provenance de Toscane qui continuent à être fabriquées à Pise jusqu'au tout début du XVI ${ }^{\mathrm{e}} \mathrm{s}$. et qui sont concurrencées à la fin de leur production par les productions engobées et incisées et par les premières majoliques en provenance de Montelupo (Giorgio 2009, Giorgio 2010).

Il n'est guère risqué non plus de s'avancer au sujet des faïences de la Basse Vallée du Rhône : bien présentes encore dans les contextes marseillais de la fin du $\mathrm{XIV}^{\mathrm{e}} \mathrm{s}$. et totalement inexistantes au $\mathrm{XVI}^{\mathrm{e}}$ s., il est légitime d'en conclure que ces productions s'éteignent (doucement ou brutalement ?) au cours du $\mathrm{XV}^{\mathrm{e}} \mathrm{s}$.

Dans la même logique, certains produits inconnus au $\mathrm{XIV}^{\mathrm{e}}$ et présents au XVI $\mathrm{XI}^{\mathrm{e}}$ s., apparaissent vraisemblablement au cours du $X^{\mathrm{e}} \mathrm{s}$. En effet, les sources principales d'approvisionnement en vaisselle utilitaire ont complètement changé au siècle suivant. La consommation des poteries réfractaires glaçurées de la Basse Vallée du Rhône (type Uzège) doit largement décliner au cours $\mathrm{du} X \mathrm{XV}^{\mathrm{e}} \mathrm{s}$., car elles ne sont présentes que de manière anecdotique au siècle suivant. Où se fournissaient les Marseillais à cette époque, rien ne le laisse supposer : dans des ateliers locaux, auprès de ceux de Provence orientale?

Ces quelques bases théoriques servent de point de départ à la réflexion mais nul doute que la découverte de lots de cette époque modulera fortement nos propos actuels. 



\section{Chapitre 5}

\section{Le flou du XVI $I^{\mathrm{s}}$. marseillais : de la fin du $X^{\mathrm{e}} \mathrm{s}$. au début du XVII's.}

\section{(Véronique Abel)}

L es fouilles de Marseille ont fourni quelques lots de céramiques, diverses mais récurrentes, d'une période allant approximativement de la fin du XV ${ }^{\mathrm{e}} \mathrm{s}$. au premier quart du XVII ${ }^{\mathrm{e}} \mathrm{s}$. Ces ensembles parfois très réduits, étaient en grande partie datés au moment de la fouille par les importations qu'ils comptaient. S'y retrouvent des faïences dont le revêtement stannifère est total ou partiel, de la vaisselle vernissée dont la surface vitrifiée contient du plomb, et des vases culinaires dont la terre est réfractaire.

La connaissance des céramiques de l'arc méditerranéen au début de l'Époque moderne progresse mais pas aussi rapidement qu'on aurait pu le souhaiter. Rien n'est venu contredire au fil du temps les hypothèses formulées vers le milieu des années 1980 selon lesquelles la céramique et sa consommation à Marseille demeureraient en ce $\mathrm{XVI}^{\mathrm{e}} \mathrm{s}$. dans la tradition médiévale, tout en accueillant quelques nouveautés significatives et en faisant renaître d'apparents archaïsmes.

Jusqu'il y a peu, les données étaient si minces que, tout comme aux premières lueurs de l'aube les détails des choses les plus familières restent encore imperceptibles, la céramique du $\mathrm{XVI}^{\mathrm{e}} \mathrm{s}$. restait à Marseille nimbée d'un flou handicapant qui interpellait les fouilleurs et pourrait étonner l'historien.

Que la fin du Moyen Âge soit placée à la conquête de Constantinople par les Ottomans ou à la découverte de l'île d'Hispaniola par Christophe Colomb, elle n'est évidemment qu'un découpage décidé par commodité de langage et ceci est tout aussi vrai pour la céramique. Loin d'un réel tournant, le début des Temps modernes est dans ce domaine plutôt une période de continuité que de bouleversements. Dès les années 1980 nous avions remarqué grâce au chantier de la Bourse (Abel 1988) que les technologies de la céramique et les objets du quotidien des populations du $\mathrm{XVI}^{\mathrm{e}} \mathrm{s}$. demeuraient dans la tradition médiévale. À l'échelle du continent européen, ou plus modestement de la partie nord occidentale du bassin méditerranéen, bon nombre de transformations technologiques et morphologiques ont déjà été effectuées progressivement durant le Moyen Âge : revêtements vitrifiés, marginalisation des post-cuissons réductrices, division fonctionnelle des vases, etc. D'autres mutations restent à venir, qui interviendront bien plus tard.

Des pointillés supplémentaires ont été tracés par le mobilier du Musée César en 1995, celui du Fort Saint-Jean en 1994 et en 2005, mais pas de contextes homogènes et suffisamment bien fournis, malgré une étude assez systématique des mobiliers modernes de Marseille. Les découvertes importantes et bien datées ayant eu lieu sur d'autres chantiers de France méditerranéenne et dont l'étude nous échut permettent d'évacuer assurément l'hypothèse d'une chronologie trop «tassée » vers le XVII $\mathrm{e}$.

Une hypothèse pourtant, avancée pour expliquer le peu de données céramologiques et l'obscurité régnant aujourd'hui encore sur le $\mathrm{XV}^{\mathrm{e}} \mathrm{s}$., verrait une contraction de la ville autour du port et en particulier sur sa rive nord, hélas peu prise en compte pour cette époque. Cette période de presque 150 ans a été caractérisée par des travaux sur des mobiliers archéologiques exhumés à la fin des années 1960 et en 1984 du site de la Bourse. L'étude de la céramique en usage au XVI ${ }^{\mathrm{e}} \mathrm{s}$. à Marseille, qui faisait suite à celle du XVII ${ }^{\mathrm{e}} \mathrm{s}$. dans le cadre de nos travaux universitaires sous la direction de $\mathrm{M}^{\text {lle }}$ Démians d'Archimbaud, a été entreprise en 1988 et rapidement publiée (Abel 1988) afin de mettre à la disposition d'autres chercheurs des premières données et susciter des investigations sur une période jusque là ignorée par l'archéologie en France méditerranéenne.

Il faut souligner que les productions sont peu connues, rarement localisées, leur typologie à construire. Parfois l'origine de groupes d'objets aux caractères bien cernés n'est pas établie, ceux-ci sont alors identifiés par leur pâte ou autre critère significatif, faute de mieux ; l'écueil principal de l'accès à cette connaissance étant l'absence presque totale d'ateliers reconnus archéologiquement.

Il n'était pas imaginable en 1988 que, deux décennies plus tard, la plupart des observations formulées sur la céramique de Marseille ne seraient pas vraiment complétées honorablement par quelques contextes de 
référence, milieux clos, formes complètes, identifications d'origine, et il aurait d'ailleurs été décourageant de le penser. Seuls quelques nouveaux points d'accroche se sont fait jour à travers les fouilles engagées depuis, ils en sont d'autant plus précieux.

D'autant que l'analyse de la céramique moderne de la récente fouille de l'Hôtel-Dieu a généré de séduisantes hypothèses qui semblent se vérifier rétroactivement pour les niveaux étudiés après 1988. La céramique du secteur de l'atelier de bronzier repéré en 2008 a été placée dès le départ dans le large créneau du XVI ${ }^{\mathrm{e}} \mathrm{s}$. comprenant la fin du XV et le début du XVII ${ }^{\mathrm{e}}$ s. La fouille, outre les intéressants résultats sur le travail du métal (Thomas 2011), a permis d'établir à propos de la céramique de nouveaux constats basés sur les données stratigraphiques, d'en affiner la perception et d'ainsi cliver hypothétiquement la période allant de la fin du $X V^{\mathrm{e}} \mathrm{s}$. au premier quart du $\mathrm{XVII}{ }^{\mathrm{e}} \mathrm{s}$. en deux parties dont la frontière se situerait très approximativement vers 1570 .

Cette période céramologique, dont les informations sont ténues et pourtant récurrentes, manque cruellement des précisions typo-chronologiques les plus élémentaires, ceci malgré l'image de dynamisme que conserve le $\mathrm{XVI}^{\mathrm{e}} \mathrm{s}$. pour les historiens. Il reste surprenant que le fonds archéologique pour cette longue période ne dépasse pas quelques centaines de fragments à Marseille et ne réussisse pas vraiment à s'étoffer. Il est difficile d'estimer le nombre de fragments et d'objets du XVI ${ }^{\mathrm{e}} \mathrm{s}$. recueillis à travers les sites marseillais car les données sont excessivement fugaces, les stratigraphies presque toujours aphasiques, les contextes de référence absents (notre motivation intacte cependant !).

\section{Le premier $X V I^{e} s$.}

Si les séries de la fouille de l'Hôtel-Dieu sont hélas trop courtes pour bien préciser et fixer cette chronologie des céramiques du $\mathrm{XVI}^{\mathrm{e}} \mathrm{s}$., elles confirment cependant que le comblement du puits de la Bourse était bel et bien un contexte de référence, désormais plus nettement fixé vers le dernier quart du $\mathrm{XVI}^{\mathrm{e}} \mathrm{s}$. Les deux autres lots de la Bourse sont alors pour l'un d'une date équivalente, tandis que l'autre trouve correspondance dans la céramique antérieure et contemporaine du four. Ces niveaux, dits désormais du "premier $\mathrm{XVI}^{\mathrm{e}}$ s. », affichent suffisamment de points communs pour offrir une continuité à rebrousse-temps aux séries plus tardives et permettre des précisions chronologiques pour d'autres ensembles du large $X I^{e}{ }^{\mathrm{s}}$. C'est le cas, particulièrement intéressant, du mobilier du fort Saint-Jean (église de la Commanderie, 1994, Philippe Mellinand ; chapelle 2005, Françoise Paone).

\subsection{Les faïences}

La faïence, à revêtement essentiellement blanc, plus rarement coloré - stannifère -, brillant et opaque, est une vaisselle de luxe, volontiers décorée. Au-delà de sa fonction utilitaire presque secondaire, son rôle ne s'arrête pas au plaisir de son utilisateur : elle constitue aussi un marqueur social à connotation ostentatoire.

Cette catégorie demeure aujourd'hui un indice chronologique intéressant mais relatif. Un décalage est souvent observé entre ces importations de luxe et les céramiques communes. La faïence compense une masse généralement très faible (quelques \% à peine) par une grande lisibilité à travers les mobiliers archéologiques. Celle d'Italie et celle d'Espagne se côtoyaient dans les maisons.

\subsubsection{La faïence «de Pise » et de la basse vallée de l'Arno de tradition médiévale}

La faïence dite «de Pise» est diffusée dans notre région dès la seconde partie $\mathrm{XIV}^{\mathrm{e}} \mathrm{s}$. (cf. supra $\mathrm{ch} .4$ $\S$ 1.4.3.). La plupart des études semblent privilégier la production plus nettement médiévale (Berti et al. 1986); les références pour les périodes plus récentes ne sont pas très nombreuses. Comme précédemment, à la fin du Moyen Âge et pendant la période intermédiaire du $X V^{\mathrm{e}}$ s., l'utilisation conjointe de revêtements stannifère et plombifère sur les mêmes récipients est la signature de cette production à émail monochrome ou décoré en vert et brun. Face interne des vases ouverts et flancs de pichets, zones les plus offertes au regard, bénéficient de revêtements émaillés, tandis que les extérieurs de vases ouverts et intérieurs et bases des vases fermés sont recouverts de vernis dans un second temps et parfois assez largement.

La pâte est généralement rouge, brique ou orangé, sans éléments non plastiques visibles. Certaines de ces céramiques ont sans doute été produites hors de Toscane, en Ligurie par exemple, mais leur distinction n'est pas actuellement possible à travers le mobilier marseillais où cette catégorie est alors en net déclin.

Dans l'une des recharges du four de bronzier de l'Hôtel-Dieu se trouve un fond d'écuelle très fragmentaire (fig. 94, $\mathbf{n}^{\circ} \mathbf{1}$ ), mais dont l'extérieur est vernissé et l'intérieur émaillé en blanc grisé sans décor est d'un type connu dans le $\mathrm{XV}^{\mathrm{e}}$ s. et au début du $\mathrm{XVI}^{\mathrm{e}}$ s. environ. On trouve des pièces semblables dans les niveaux de la place Général-de-Gaulle, où un ensemble stratigraphique avait été interprété comme une sédimentation dans une rue après le changement d'axe en 1524 (Abel 2001, p. 174). Dans la chapelle du fort Saint-Jean en 2005 (F. Paone), une écuelle laissait voir un vestige non interprétable de décor de manganèse (fig. 94, $\mathbf{n}^{\circ}$ 2). 


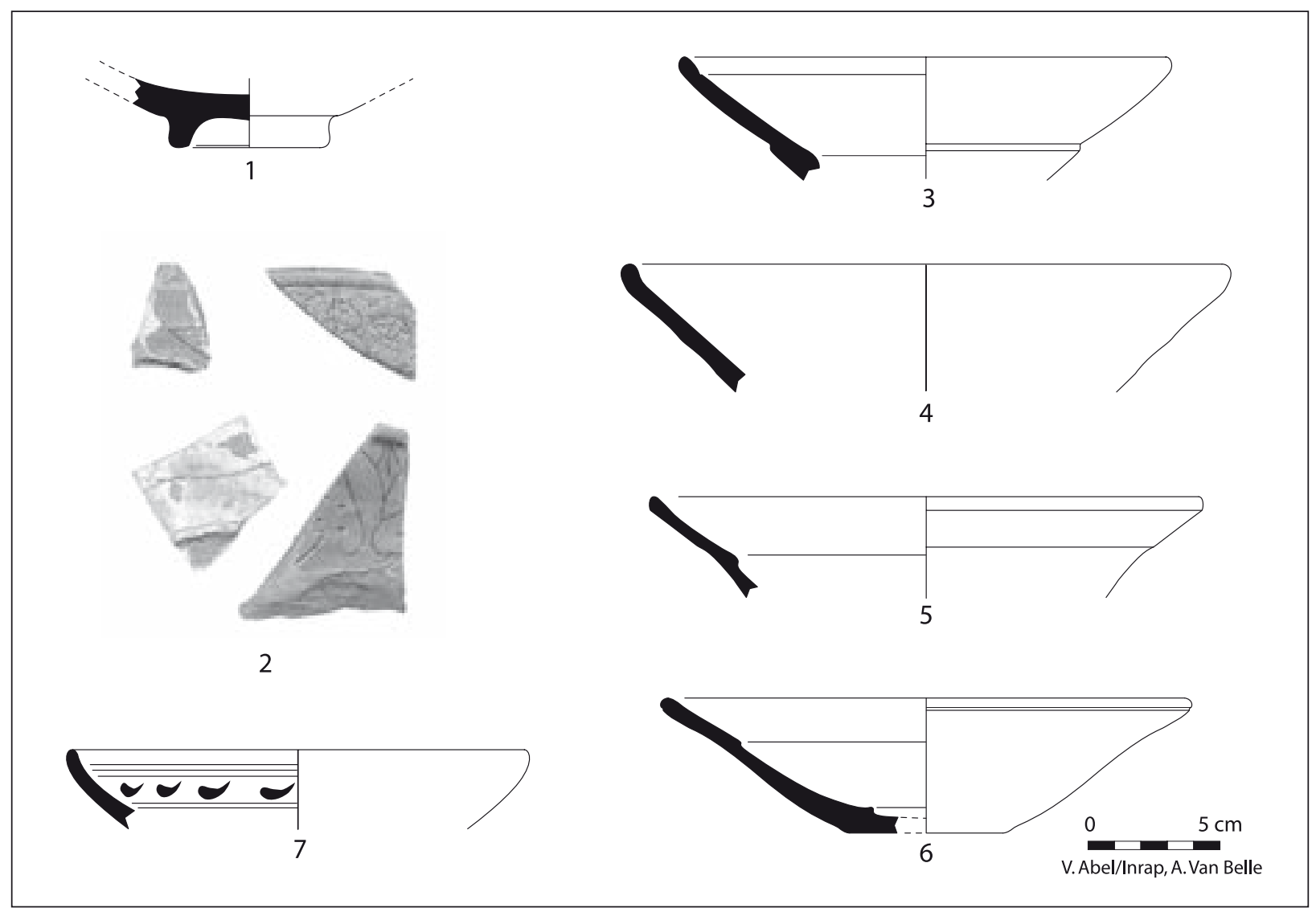

Fig. 94. Productions ligures (premier $X V l^{e}$ s.). 1 : Hôtel-Dieu ; 2-6 : Fort Saint-Jean ; 7 : la Bourse.

Les autres pièces (plats à aile, ou à carène et lèvre aplatie, fig. 94, $n^{\circ}$ 3-7) sont plus fragmentaires encore et n'offrent qu'un fragment de décor, rayonnant le plus souvent, sur un émail pauvre en étain, pulvérulent ou presque transparent. Cette qualité moindre est souvent interprétée comme le signe de la fin de cette production précise. Des pichets accompagnaient les vases ouverts, il ne nous en parvient que des tessons très limités. La chronologie de ces objets en est d'autant plus difficile à percevoir, que ce soit de manière relative sur la fouille ou grâce aux références bibliographiques. Cependant, une présence persistante parmi les mobiliers du premier XVI ${ }^{\mathrm{e}} \mathrm{s}$. qui n'incluent pas d'autres céramiques plus anciennes en dépôt secondaire, permet de déduire qu'il s'agit véritablement d'une catégorie sinon toujours produite tout au moins encore en usage, peut-être conservée longtemps grâce à sa solidité évidente, et ceci pour bien peu de temps.

Ce sont en fin de compte deux pièces recueillies au sein du même contexte en 1994 (mais étudié récemment) dans l'église de la Commanderie du fort Saint-Jean qui vont peut-être expliquer la « disparition » de cette catégorie. La première écuelle (fig. $95, \mathbf{n}^{\circ} \mathbf{2}$ ) est d'une mise en œuvre classique (pâte rouge brique foncé, très dure ; hémisphérique sur pied annulaire), sa face interne émaillée et sa face externe vernissée comme de coutume. À l'intérieur se voit un arrachement de pernette «très italien ». L'émail une fois cuit n'a pas réussi à masquer parfaitement la tonalité rouge foncé de la pâte, et il en devient rosé.

Est associée à cette écuelle une seconde (fig. 95, $\left.\mathbf{n}^{\circ} \mathbf{1}\right)$, quasiment identique, à peine plus grande, plus large et plus blanche, témoignant du même arrachement de pernette. Là où cette seconde écuelle se distingue nettement de la première, c'est en sa face externe : l'émail ne s'interrompt pas sur la lèvre, mais revêt au contraire les deux tiers supérieurs du vase, tandis que la partie inférieure est laissée sans aucun revêtement. Cette absence de vernis permet de voir une finition extrêmement soignée, où le tournassage du pied annulaire et de la base du vase ne laisse aucune aspérité, tout comme les céramiques vernissées à décor a stecca de même provenance.

Un autre fragment d'écuelle (église de la Commanderie, inv. 8507), manifestement retaillé pour un usage secondaire, associe un revêtement interne stannifère peu opaque, un vernis plombifère externe recouvrant une coulure d'émail et une zone non revêtue en partie basse. Ce tesson, d'apparence anodine, 


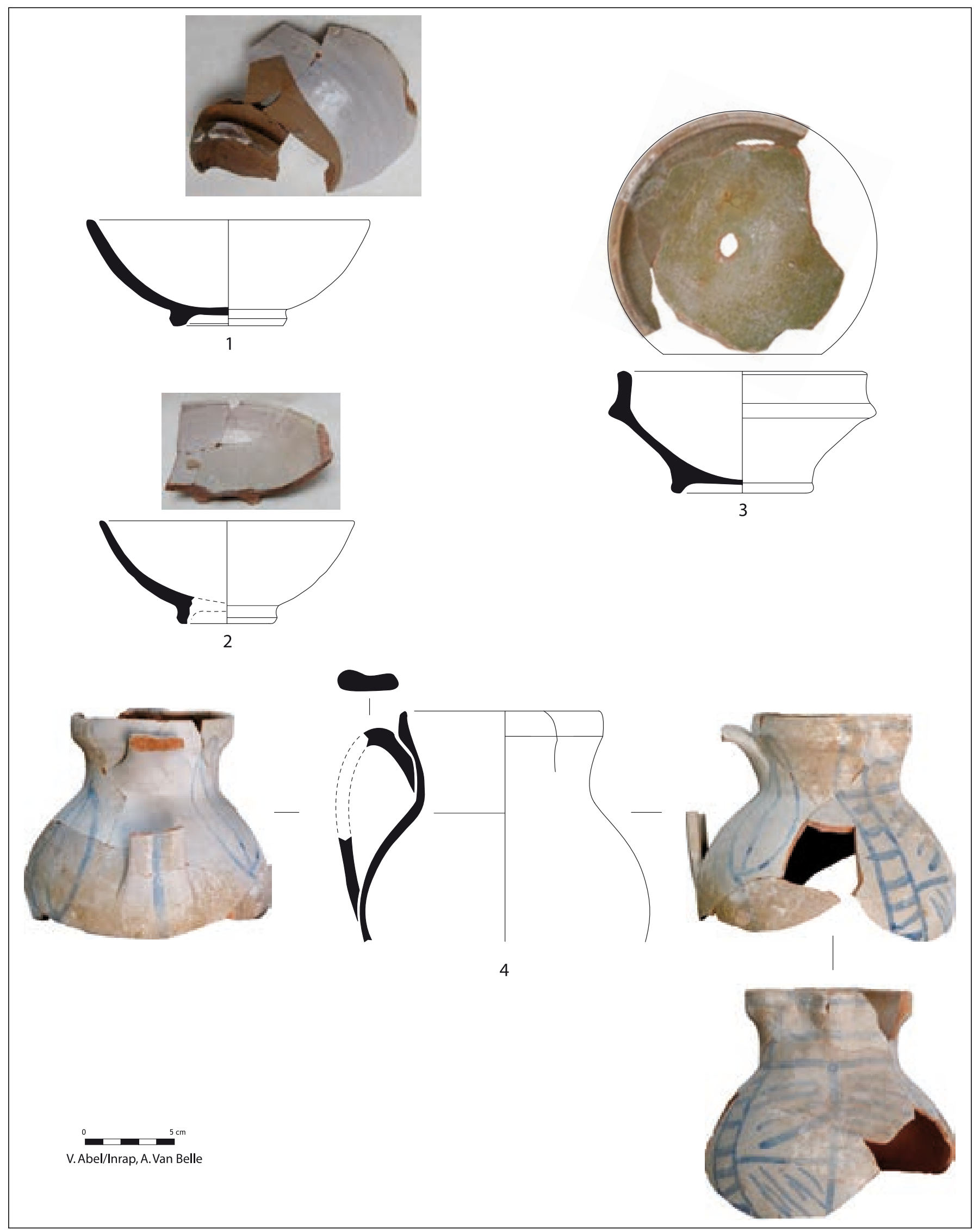

Fig. 95. Écuelles pisanes (n`1-2), écuelles et pichets d'origine incertaine ( $\left.n^{\circ} 3-4\right)$ (premier XVle $\left.s.\right)$. Fort Saint-Jean. 


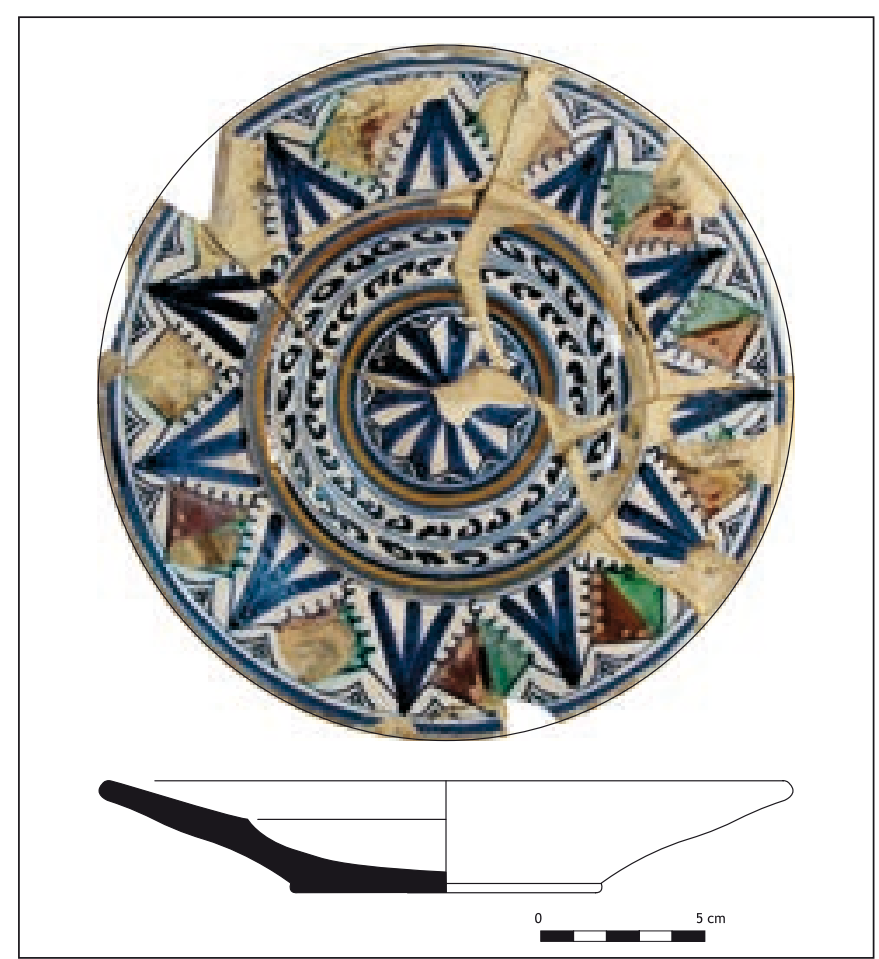

Fig. 96. Assiette de Montelupo. Fort Saint-Jean (V. Abel/Inrap).

annonce les choix que feront peu après les céramistes de Pise dont les argiles se révèlent après cuisson rouge vif et dures («fermées »). La faïence de la même région de la vallée d'Arno, mais utilisant des bancs d'argile cuisant clair, Montelupo, prenant un essor remarquable depuis quelques décennies, celle qui était faite à partir d'argile cuisant rouge est abandonnée au profit d'une technologie plus adaptée à cette matière première, à savoir l'association d'engobe blanc et de vernis, coloré ou non.

\subsubsection{La faïence de Montelupo}

Cette faïence toscane à pâte claire et souvent crayeuse est quant à elle connue depuis la fin du Moyen Âge et étudiée avec une certaine constance en Italie où elle est bien sûr très fréquente. Elle compense dans le mobilier archéologique marseillais son petit nombre de tessons par un aspect voyant, voire bariolé, accentuant sa lisibilité. Sa chronologie est plus accessible car elle peut se baser sur les décors, identifiables même sur des fragments de taille limitée. D'un attrait certain par ses décors chatoyants, cette céramique privilégie les formes qui laissent le plus de surface disponible, assiettes et plats, pichets dans une moindre mesure.

L'église de la Commanderie du fort Saint-Jean (fouille de P. Mellinand) a livré en 1994 un ensemble de vaisselle de la période comprenant quelques pièces de faïence. Une assiette polychrome, dans un état de conservation exceptionnel parmi les mobiliers marseillais (fig. 96), illustre cet accent mis sur le décor. D'un diamètre plutôt moyen $(22 \mathrm{~cm})$, la forme est des plus simples : ample bassin peu creusé, aile très plate bien développée, large fond plat. Un décor a fascie geometriche, généralement daté de l'extrême fin du XV ${ }^{\mathrm{e}} \mathrm{s}$. (Berti 1998, genere 18) s'y développe largement. Séparés par des chevrons bleus, onze losanges bicolores verts et rouges se répartissent sur l'aile. Si la couleur verte est habituelle dans la palette de Montelupo, le rouge y est rare. Il ne semble pas s'agir d'un remplissage orange (la couleur attendue pour les losanges des fascie geometriche) qui aurait mal tourné. Le pigment rouge n'a pas pénétré dans la couche d'émail, à l'inverse des autres couleurs. Il pourrait s'agir d'un rouge posé sur émail cuit, qui expliquerait sa détérioration plus importante que les autres couleurs de la même assiette.

D'autres assiettes de même provenance accompagnaient la première : à motivi vegetali della «famiglia bleu » (inv. 45.93.8509; Berti 1998, genere 40); à ovali e rombi (inv. 45.93.8510; Berti 1998, genere 26) ; à bleu graffito (inv. 45.93.8515 ; Berti 1998, genere 34).

\subsubsection{La faïence de Ligurie}

Seul un fragment de faïence (inv. 134.05.1384) provient d'Italie dans le contexte du $\mathrm{XVI}^{\mathrm{e}} \mathrm{s}$. fouillé au fort Saint-Jean en 2005. Il appartient à une assiette ligure à décor calligrafico a volute ou a fiori sparsi. Très fragmentaire il ne permet pas une identification claire du décor.

Une telle rareté, malgré la relative proximité de ce lieu de production de vases bien identifiables, reste sans explication. Nous rencontrerons plus tardivement des terres vernissées de même provenance géographique, ce qui ne fait qu'accroître les questions.

\subsubsection{La faïence de Valence}

La faïence de Valence est produite depuis le Moyen Âge, variablement diffusée et utilisée selon les périodes et le niveau de vie des habitants. Elle est plutôt discrète à Marseille au XVI ${ }^{\mathrm{e}}$ s., mais assidue. Les formes ouvertes sont toujours les plus courantes à l'exportation, les vases fermés rares.

Comme souvent dans la faïence, les décors sont plus propices aux datations, avec un écueil pour celle-ci, la fragilité du décor de lustre métallique, souvent disparu au cours de son utilisation. À cette technique s'apparente le «petit feu » des faïenciers du XVIII ${ }^{\mathrm{e}} \mathrm{s}$. : dans les deux cas le décor est posé sur un émail déjà vitrifié par une cuisson puis recuit à température plus modérée. Pour les lozas doradas, les pigments sont fixés par une cuisson 
conduite jusqu'à son refroidissement (post-cuisson) en atmosphère réductrice qui conserve leur aspect métallique. Comme ils ne pénètrent pas dans le revêtement, ils sont particulièrement fragiles.

Issue de l'un des niveaux les plus anciens du secteur du four de l'Hôtel-Dieu, une écuelle de faïence de la région valencienne (fig. $\mathbf{9 7}, \mathbf{n}^{\circ} \mathbf{2}$ ) a été décorée selon le procédé du «pinzell-pinta de tres puntes ». Des faisceaux de trois tracés parallèles rectilignes ou sinueux sont réalisés d'un seul mouvement à l'aide d'un pinceau à trois brins, deux traits fins encadrant un trait central plus épais (Llorens 1989, p. 177-183; Cerdà i Mellado p. 252 , fig. 15 , p. 165 et 209 , taula XIX).

Dans de nombreux cas, les tessons sont de taille trop réduite pour permettre une interprétation du décor. Dans le contexte de l'Hôtel-Dieu et de même provenance hispanique se trouvait un plat, très mal conservé, décoré d'un large cercle bleu sur l'émail blanc qui a pu recevoir des reflets dorés aujourd'hui disparus (fig. 97, $\mathbf{n}^{\circ} \mathbf{1}$ ). L'émail peu opaque d'un fond de plat, à décor bleu très limité, permet de penser qu'il a été produit dans le $\mathrm{XVI}^{\mathrm{e}} \mathrm{s}$. ou plus tard, de même que le revêtement « maigre » d'un fond d'écuelle).

Du site du fort Saint-Jean, qui a livré en 2005 un ensemble de céramiques caractéristiques du XVI ${ }^{\mathrm{e}} \mathrm{s}$. comparable aux niveaux antérieurs et contemporains du four de bronzier de l'Hôtel-Dieu, provient une écuelle de faïence à décor de reflets métalliques dans un état remarquable par rapport aux autres restes de provenance espagnole à cette époque. La forme en est complète à l'exception de l'oreille (fig. 97, $\mathbf{n}^{\circ}$ 5). Cette écuelle hémisphérique apode mesure $5,5 \mathrm{~cm}$ et environ $13 \mathrm{~cm}$ de diamètre externe. À l'extérieur, le fond est concave et étroit (4,5 $\mathrm{cm}$ de diamètre) et légèrement bombé en face interne. Après un angle marqué se développe la paroi qui s'épaissit à mi-hauteur et s'amincit à nouveau vers la lèvre sans carène nettement marquée. L'oreille, disparue, devait être assez large par rapport au reste de l'objet et pouvait mesurer environ $7 \mathrm{~cm}$ de large. La partie restante laisse voir un bord polylobé en relief.

L'émail blanc est «crémeux » et non pas transparent comme cela se remarque souvent dans les productions du $\mathrm{XVI}^{\mathrm{e}} \mathrm{s}$. Le décor, en grande partie effacé, est entièrement réalisé par lustre métallique brun doré sur les deux faces. L'extérieur de l'écuelle est simplement animé de deux registres horizontaux de boucles ovales non fermées, accolées à une seconde boucle, bien plus petite, ronde et fermée, une dernière boucle étant placée sous le fond. À l'intérieur, le décor est constitué d'au moins trois bandes linéaires traversant le bassin parallèlement à l'axe des oreilles lorsque l'objet est appréhendé en vue zénithale.

Chaque bande ou registre est traité indépendamment pour un effet de patchwork. Le registre supérieur, aujourd'hui le plus lisible et qui forme en réalité une demi-lune sur la paroi, est rempli de plusieurs motifs hétéroclites. Une guirlande de "perles enfilées» part de la lèvre et descend vers le centre du vase. À droite (et peut-être à gauche) est placée une palmette horizontale qui rappelle les feuilles de certains végétaux de ces répertoires décoratifs relativement stéréotypés. De part et d'autre de la guirlande de perles, l'espace sous la lèvre est occupé par de fines hachures horizontales et de courts et plus larges traits verticaux. Le deuxième registre accueille des motifs ondoyants, sortes de volutes tracées à l'aide d'un pinceau épais à partir des deux larges lignes de bordure du registre complétées de lignes très fines. Le troisième registre occupe approximativement la moitié inférieure du vase, partie la moins lisible. Un quatrième registre, entièrement effacé n'est pas à exclure. On reconnaît tout de même à nouveau le motif des perles enfilées descendant de la lèvre et des motifs sinueux sur la paroi, alors qu'au fond du bassin est placée une fleur stylisée, rosette ou œillet. Le reste du décor a disparu.

Cette mise en scène par bandes linéaires brise visuellement la courbe de l'écuelle. Cette répartition est différente du schéma décoratif de la période «haute» (du XIV e au début du XVI ${ }^{\mathrm{e}} \mathrm{s}$.) des lustres métalliques du nord-est de l'Espagne dont les décors sont volontiers rayonnants à partir du centre ou développés en registres concentriques, basés par conséquent sur le cadre circulaire imposé par le vase. Une organisation dissidente paraît déjà inspirer à la fin du $\mathrm{XV}^{\mathrm{e}} \mathrm{s}$. les décors en « fers à cheval imbriqués » recueillis notamment à Avignon (Carru 1989, Carru 1995).

Cette écuelle présente des similitudes de décors avec des objets de la collection du musée des Beaux-arts de Lyon publiés à l'occasion d'une exposition en 2002. Ainsi, se remarque une guirlande de perles enfilées sur un plat attribué aux ateliers de Muel en Aragon, au nordouest de Valence (le Calife 2002, p. 248). Sa forme n'est en revanche pas directement documentée par une pièce précise à travers cette exposition. Elle s'apparente à d'autres trouvées à Avignon pour le deuxième quart du $\mathrm{XVI}^{\mathrm{e}}$ s. (Carru 1995, p. 73), mais sans comparaison très nette, en particulier car sa paroi est épaisse et presque rectiligne à l'intérieur du vase.

Le reste du contexte de la chapelle du fort Saint-Jean comprend d'autres fragments provenant d'Espagne : une écuelle de Valence (forme complète, inv. 134.05.1410) est animée d'un décor rayonnant et filets sous la lèvre en bleu seul. Un fragment d'écuelle à petite oreille triangulaire laisse voir sous la lèvre une tache bleue ayant peut-être été enrichie de lustre (inv. 134.05.1390).

Une écuelle à décor de bleu seul est issue de la fouille du fort en 1994. Elle est animée d'un décor rayonnant de 14 arcs qui se rejoignaient au centre du bassin 
(fig. 97, $\mathbf{n}^{\circ} 3$ ). Une pièce semblable est issue de la fouille du même site en 2005 (fig. 97, $\mathbf{n}^{\circ} \mathbf{4}$ ). Dans la même période, était retrouvée une pièce identique à Avignon (Carru 1995, p. 71).

Ces céramiques de la région de Valence sont plutôt rares dans les courtes séries du $\mathrm{XVI}^{\mathrm{e}} \mathrm{s}$. marseillais vu dans son ensemble, et essentiellement constituées d'écuelles. Elles sont davantage présentes dans le contexte de la chapelle du fort Saint-Jean au détriment des faïences italiennes, ce rapport inversé pouvant tenir à la chronologie, ceci sans certitude possible.

\subsubsection{Les faïences de provenance indéterminée : une éventuelle production du terroir marseillais?}

Un pichet lacunaire à décor bleu trouvé sur le fort Saint-Jean en 1994 (fig. 95, $\mathbf{n}^{\circ} \mathbf{4}$ ) est un objet unique pour l'instant dans le corpus marseillais. Pouvant passer de prime abord pour un produit espagnol, cette attribution ne résiste pas à un second coup d'œil plus acéré porté sur sa pâte et sa mise en œuvre. Sa terre est très rouge, d'un ton plus attendu pour des terres vernissées que pour des faïences. Bien que le fond en soit absent, on peut estimer qu'il s'agit de l'œuvre d'un tourneur expérimenté et non d'un essai ou d'une production marginale. La partie de panse restante est approximativement globulaire, le col est plutôt large et de hauteur moyenne, une légère arrête souligne la lèvre, simple. Le bec est pincé pour être fonctionnel et sans exagération. Une anse obtenue par tournage et soigneusement façonnée est attachée sous l'arête du bord et se termine au niveau du diamètre maximal de la panse.

L'impression de maîtrise de la matière que donne la forme ne se retrouve nullement dans le décor. Sorte d'hybridation entre le bleu de cobalt valencien et les schémas décoratifs des pichets de Montelupo, on peine à voir dans ces quelques motifs équivoques la main d'un vrai peintre en faïence. L'essentiel du décor se place autour et sous le bec dans une large zone, divisée en quartiers rapidement remplis de quelques hachures réparties au hasard du pinceau. La partie absente semble avoir vu s'incurver les deux traits démarrant de la lèvre et réunis par d'autres traits, courts et irréguliers. Deux feuilles lancéolées d'une extrême simplicité encadrent l'œuvre et la séparent de l'anse dont la discrète cannelure a été soulignée en bleu. Les traits sont tous épais et hésitants, les remplissages aléatoires, le message du manieur de pinceau reste indéchiffrable, de même que reste mystérieuse l'origine géographique de ce vase contradictoire.

Aucun tesson de faïence issu des fouilles de Marseille dans leur ensemble ne peut jusqu'aujourd'hui être attribué à l'atelier que le marquis de Forbin aurait installé en 1526 sur son domaine des bords de l'Huveaune (Arnaud
d'Agnel 1912) aujourd'hui quartier de Saint-Marcel. Cette pièce est pour l'instant la seule dont la provenance reste mystérieuse. Sa pâte rouge ressemble à celle des productions locales. Peut-on dès lors émettre l'hypothèse d'une production locale ? Ce serait prématuré en l'état actuel des connaissances, mais non déraisonnable.

\subsection{Les terres vernissées}

Selon les choix que nous avons faits et pour une meilleure distinction des catégories entre elles, le terme de « terres vernissées » se rapporte aux céramiques à revêtement plombifère mais ne comprend pas (de manière un peu artificielle) les vases destinés à la cuisson ou façonnés en argile notoirement réfractaire.

\subsubsection{La terre vernissée de Pise et Valdarno}

Les terres vernissées enregistrées sous la dénomination de «Pise », et cela vaudra pour toute la période moderne, proviennent vraisemblablement d'une zone plus large que la ville de Pise elle-même et correspondant à la basse vallée de l'Arno, dite Valdarno en Italie.

Elles sont peu fréquentes dans les rares niveaux datés du premier $\mathrm{XVI}^{\mathrm{e}} \mathrm{s}$., pour une raison inexpliquée et qui peut tenir au simple hasard de l'échantillonnage. Une écuelle vernissée blanche très fragmentaire, issue du contexte du fort Saint-Jean, semble devoir être attribuée à ces ateliers; elle n'est pas décorée (inv. 134.05.1386). Un bord d'écuelle à vernis vert incisé a stecca provient du comblement du puits DI14 de la Bourse qui resterait dans ce premier $\mathrm{XVI}^{\mathrm{e}}$ s. (fig. 94, $\mathbf{n}^{\circ}$ 7). De la fouille de l'église de la Commanderie en 1994, proviennent deux pièces.

Les deux «provenances» suivantes sont assez proches géographiquement et les terres vernissées qui en sont issues au $\mathrm{XVI}^{\mathrm{e}}$ s. se ressemblent parfois beaucoup sur des tessons de taille très réduite. La répartition entre les deux zones de production s'effectue souvent par défaut. Fréjus est connu pour des productions plus sommaires, les vases plus soignés sont plus volontiers attribués à la Ligurie, l'incertitude demeurant pour des vases de facture intermédiaire ou des tessons de taille trop réduite.

\subsubsection{La terre vernissée de Ligurie}

Les céramiques vernissées de Ligurie sont peu utilisées à Marseille au XVI $\mathrm{XI}^{\mathrm{e}}$ s. dans son acception large. Des couches archéologiques de l'Hôtel-Dieu provient, attribué à la Ligurie, un fragment de panse de plat dont l'extérieur est tournassé, l'intérieur revêtu d'engobe 


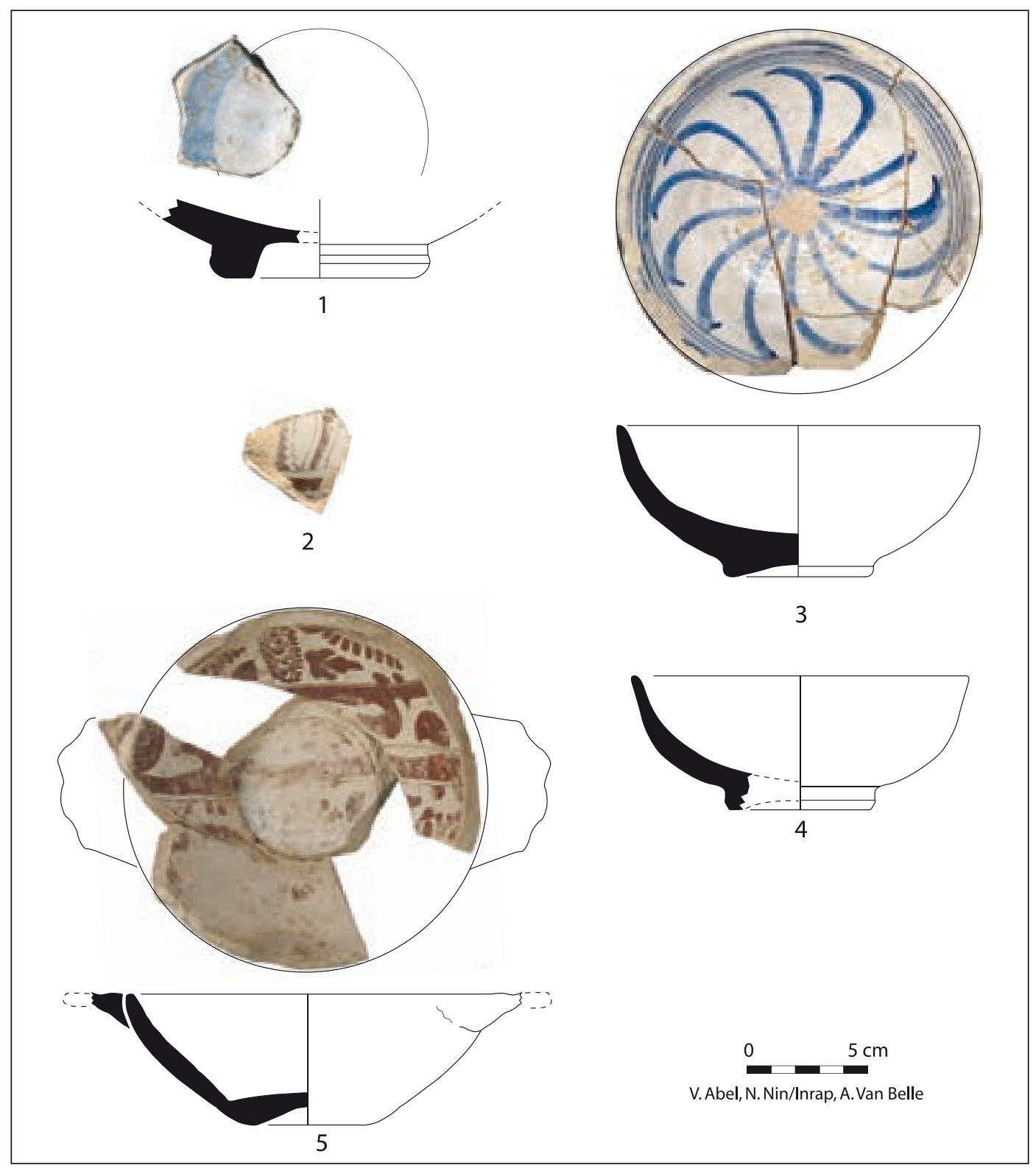

Fig. 97. Productions de Valence (premier XVle s.). 1-2 : Hôtel-Dieu ; 3-5 : Fort Saint-Jean.

blanc et de vernis incolore (inv. 155.09.2840). La panse nettement carénée d'un autre plat à engobe blanc laisse voir une sommaire tache verte (inv. 155.09.2834). Le puits DI14 de la Bourse avait recueilli un bord de plat jaune à aile de $3 \mathrm{~cm}$ (inv. 86.67.1057).

Une dizaine de plats et assiettes différents sont issus des niveaux explorés dans l'église de la Commanderie du fort Saint-Jean en 1994 (fig. 94, n' 2-6). Cinq plats et assiettes différents sont répertoriés dans les niveaux fouillés en 2005 dans la chapelle du fort Saint-Jean. Tous sont animés d'incisions variées sur engobe blanc recouvert de vernis jaune (inv. 134.05.1373 et 1393 à 1395). Une rare écuelle à oreille figurerait parmi ce mobilier (inv. 134.05.1407).

\subsubsection{La terre vernissée de Fréjus}

Les céramiques vernissées de Fréjus (fig. 98), présentes à Marseille dès le début des Temps modernes, sont d'aspect assez proche des productions ligures, mais leurs décors sont rares et les incisions exceptionnelles. Elles constituent en principe une part importante des objets usuels à Marseille pendant le $\mathrm{XVI}^{\mathrm{e}} \mathrm{s}$. et pour plus d'un demi-siècle encore. Malgré la place de choix que ceux-ci occupent, il est parfois difficile de les appréhender clairement en typologie et chronologie tant les séries sont courtes.

Le modèle de l'écuelle de Fréjus est simplement et approximativement hémisphérique, tourné à partir 


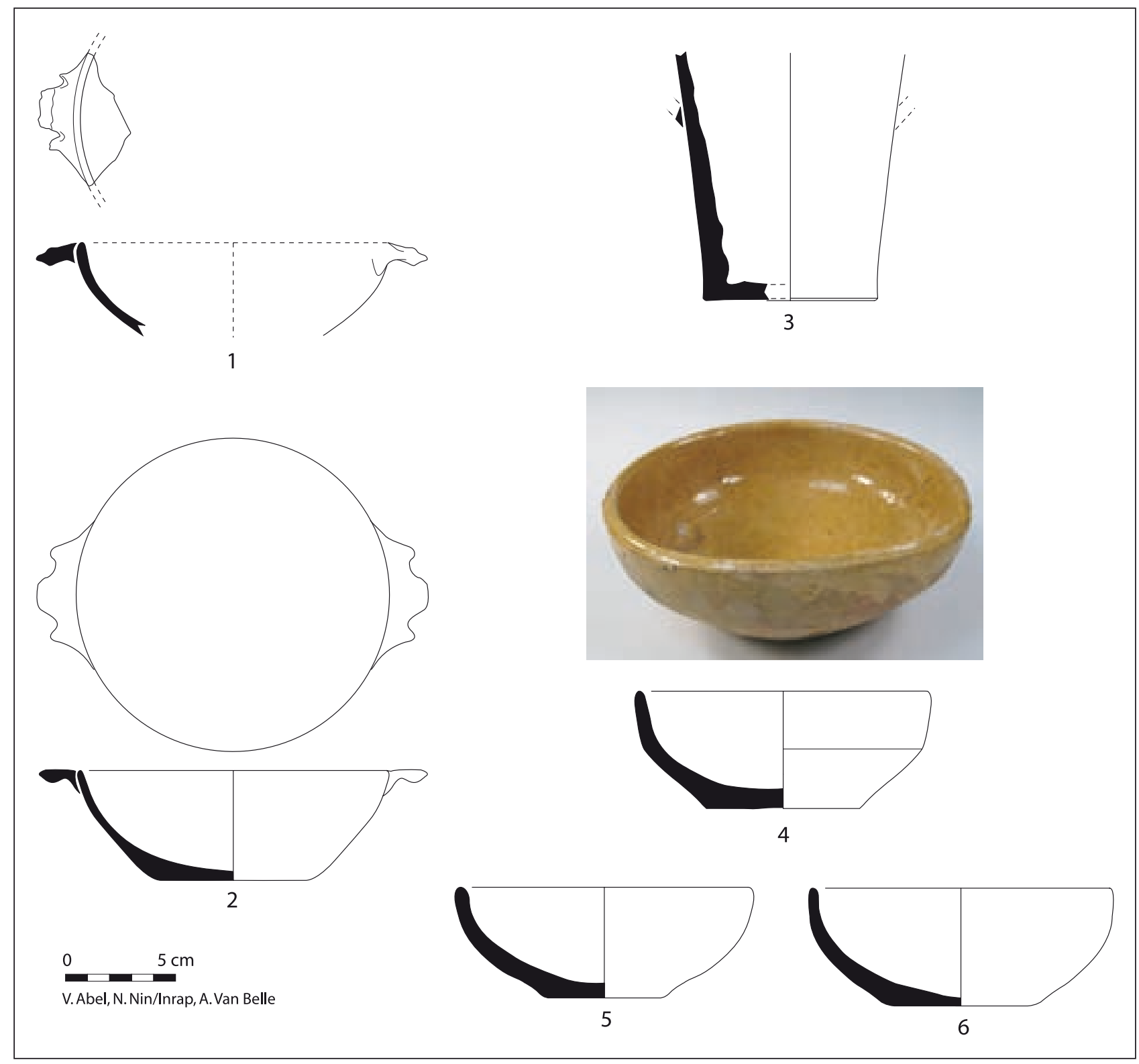

Fig. 98. Terres vernissées de Fréjus (premier XVIe s.). 1-2, 4, 6 : Fort Saint-Jean ; 3 : Hôtel-Dieu ; 5 : la Bourse.

d'un fond plat. Elle ne semble être conçue que comme un instrument servant à se nourrir, dénuée de fioriture et de décor, «basique» comme on pourrait le dire aujourd'hui. Le vernis de certaines d'entre elles est incolore sur engobe blanc, en particulier dans cette période. Il est de tonalité miel pour d'autres, ou vert pour des exemplaires encore moins nombreux.

Issus de la phase d'utilisation du four de l'HôtelDieu, deux écuelles (inv. 155.09.2838 et 2841) et un pichet (inv. 155.09.2827) sont connus mais leur état ne permet ni représentation graphique ni commentaire. Le comblement du puits DI14 de la Bourse qui resterait dans ce premier $\mathrm{XVI}^{\mathrm{e}}$ s. a livré deux écuelles (fig. 98, $\mathbf{n}^{\circ}$ 5) ${ }^{10}$. Deux écuelles morphologiquement intéressantes figurent dans le mobilier des deux unités stratigraphiques du fort Saint-Jean, dont l'une (fig. 98, $\mathbf{n}^{\circ} \mathbf{2}$ ) est intacte et rappelle l'absence d'oreille sur une partie de la production alors que la seconde (fig. 98, $\mathbf{n}^{\circ} \mathbf{1}$ ) est munie d'une oreille très courte, faite d'un rectangle de terre terminé en biseau et découpé de deux encoches.

Les plats sont de deux sortes : ceux à aile, courte en cette période (inv. 86.67.1054 et 1055), ou en bandeau externe (inv. 86.67.1058).

10 La seconde porte le $\mathrm{n}^{\circ}$ d'inventaire 86.67.1053. 


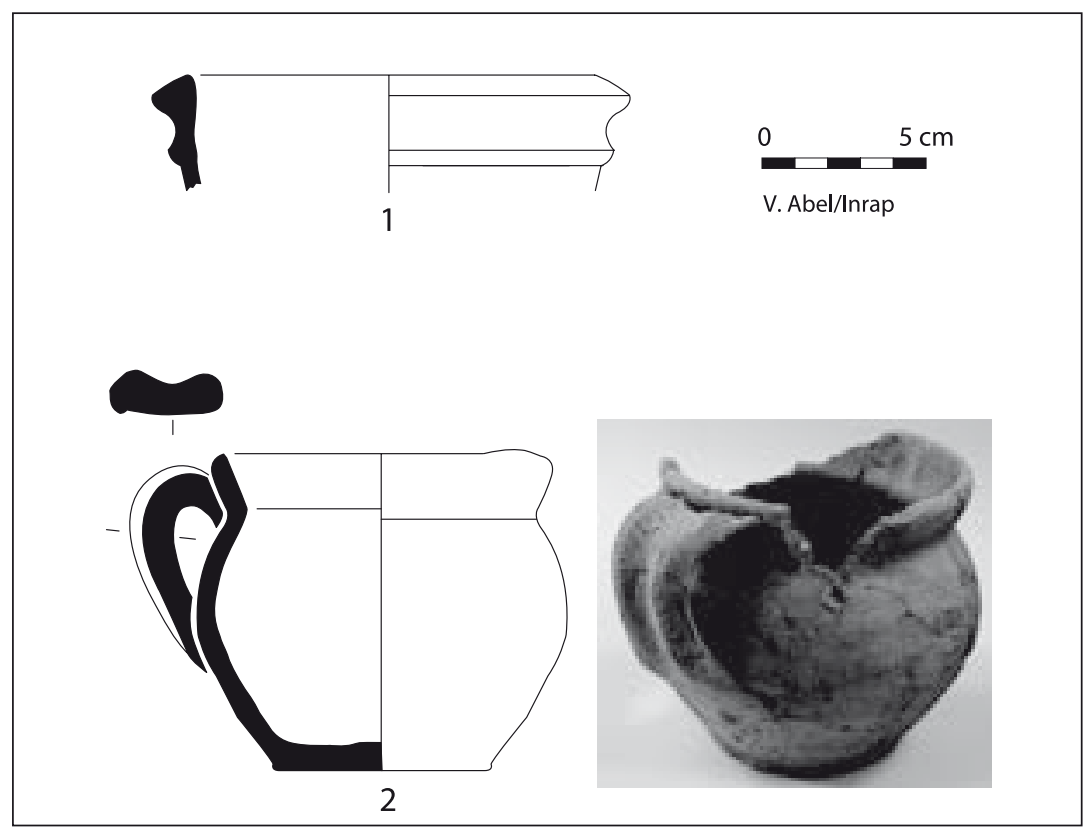

Fig. 99. Productions réfractaires : marmite de type « Uzège » $\left(n^{\circ} 1\right)$, toupin d'origine inconnue $\left(n^{\circ} 2\right)$ (premier XVI $\mathrm{s}$.). La Bourse.

Le fond d'un pot de chambre de l'Hôtel-Dieu est suffisamment conservé pour laisser voir son diamètre réduit $(7,7 \mathrm{~cm})$ et l'attache basse d'une anse dont on ne peut savoir si elle était unique (fig. $\mathbf{9 8}, \mathbf{n}^{\circ} \mathbf{3}$ ). Cet objet serait, en l'état actuel de nos connaissances, le plus ancien vase de ce type livré par les fouilles de Marseille, avec le bord à aile étroite $(2 \mathrm{~cm})$ du fort Saint-Jean (inv. 134.05.1376) où se trouvent les mêmes associations (sur lesquelles on ne peut cependant pas s'appesantir tant elles perdurent).

\subsubsection{Les terres vernissées d'identification incertaine ou absente}

Une production de terre vernissée à pâte claire, finement mais densément micacée, se remarque parmi les céramiques du large $\mathrm{XVI}^{\mathrm{e}} \mathrm{s}$., sans qu'il puisse être pour l'instant répondu à la plupart des interrogations nées des premières études céramologiques des années 1980. Leur origine géographique n'est pas même l'objet d'une hypothèse. Les vases, aux parois très amincies, sont généralement tournés avec beaucoup de grâce et de soin. Elles semblent appartenir davantage au second $\mathrm{XVI}^{\mathrm{e}} \mathrm{s}$. au vu des résultats de la fouille de l'Hôtel-Dieu, hypothèse qui se confirmerait rétrospectivement avec le contexte du fort Saint-Jean ; mais le comblement DI14 de la Bourse recelait un exemplaire, limité donc incertain, de vase fermé engobé en rouge.

\subsection{Les poteries réfractaires}

Pendant cette période de premier $\mathrm{XVI}^{\mathrm{e}} \mathrm{s}$, , bien des incertitudes demeurent et la poterie de cuisine, loin de faire exception à cette règle vient plutôt la renforcer. Une variété certaine règne, dont les différentes composantes sont difficiles à cerner clairement dans un contexte de mobilier rare et dispersé. Quelques tessons de vases culinaires appartiennent à des groupes ou des ateliers relativement bien définis, d'autres ont vu récemment leur origine géographique rectifiée.

\subsubsection{La poterie réfractaire de type Uzège}

Connus et très fréquents en Languedoc et Provence occidentale dès le Moyen Âge, les vases culinaires de l'Uzège sont si rares à Marseille qu'ils en sont presque anecdotiques.

À travers les niveaux antérieurs et contemporains du four de bronzier de l'Hôtel-Dieu, quelques tessons de panses à peine témoignent de cette production et des ateliers apparentés, accompagnés par une large anse (inv. 155.09.2842) dont la couleur de pâte pourrait orienter vers le début du $\mathrm{XVI}^{\mathrm{e}} \mathrm{s}$., une même indigence s'observant au fort Saint-Jean. Un bord triangulaire caractéristique du XVI ${ }^{e}$ s. a été recueilli dans le comblement du puits DI14 de la Bourse (fig. 99, $\mathbf{n}^{\circ} \mathbf{1}$ ).

\subsubsection{Les poteries réfractaires d'identification incertaine ou absente}

Parmi les céramiques culinaires du contexte du fort Saint-Jean, figure un bord triangulaire à bandeau (inv. 134.05.1408), classique de la période pour les ateliers en activité depuis le Moyen Âge comme l'Uzège et Ollières. Quelques fragments sont de type Uzège, d'autres à pâte blanche ou rose et grossière restent 
indéterminés. Deux marmites semblent pouvoir être attribuées à la Ligurie dont elles ont l'argile orangée fine caractéristique. Leur col ouvert est aménagé sur la panse sans recherche formelle (inv. 134.05.1400 et 1401). Un fragment de petite taille est animé d'un cordon de pâte non digité mais scarifié.

Le comblement DI14 de la Bourse a livré un «toupin » (pot à cuire à une anse) à pâte claire, non micacée, et à vernis limité à la partie centrale interne. Il possède une anse plate façonnée au tour, attachée sous le bord et non pas sur la lèvre, et un bec pincé (fig. 99, $\mathbf{n}^{\circ} \mathbf{2}$ ). Ces éléments en font un vase caractéristique de cette période, d'une forme se retrouvant très fréquemment sur d'autres sites à travers Provence et Languedoc.

\section{Le second $\mathrm{XVI}^{\mathrm{e}} \mathrm{s}$.}

C'est le comblement de l'un des puits du site de la Bourse (fouille Michel Bonifay, secteur de Sylvie Grange, 1983) qui a amorcé véritablement le travail sur la céramique du « large XVI ${ }^{\mathrm{e}} \mathrm{s}$. » à Marseille. Les 240 fragments de céramique proviennent d'une quarantaine d'objets variés, comprenant de la vaisselle de table et des poteries culinaires en plus des quelques vases à liquide attendus dans ce type de contexte. Ils étaient restés jusqu'il y a peu flottant dans une période de près de 150 ans, trop longue pour que les datations en soient bien crédibles et utiles. On peut désormais les confronter aux récentes données de l'Hôtel-Dieu en 2009. «L'apparition » (ainsi qu'on se plaît à le dire...), dans ce comblement 5026 de la Bourse, de marmites obtenues en post-cuisson réductrice semble alors un indice de choix. En effet, ces vases culinaires inattendus se rencontrent, en nombre raisonnable et constant, dans les lots du $\mathrm{XVI}^{\mathrm{e}} \mathrm{s}$. et se maintiennent clairement jusqu' au milieu du XVII ${ }^{\mathrm{e}} \mathrm{s}$. Il n'est donc pas question de voir en elles des vases anecdotiques, mais plutôt des céramiques d'usage, et par conséquent des marqueurs chronologiques à prendre en compte.

Malgré les réserves qui doivent être faites eu égard à la faible masse de céramiques disponibles à travers la séquence stratigraphique du four de bronzier de l'HôtelDieu, les résultats tendent à prouver que le comblement du puits de la Bourse était bien un contexte de référence, désormais plus nettement fixé vers le dernier quart du $\mathrm{XVI}^{\mathrm{e}} \mathrm{s}$. Les céramiques les plus marquantes de ce puits trouvent pour la plupart des correspondances dans le mobilier de l'abandon du four de bronzier, notamment les fameuses marmites noires.

Un mobilier homogène recueilli sur le site de la place Villeneuve-Bargemon (Musée César, us 11082) contient des associations identiques parmi lesquelles à nouveau ces marmites noires. Il se placerait dans la même chronologie tout en complétant notre connaissance des objets d'usage courant à cette époque.

Des objets isolés sont à l'occasion mentionnés ou illustrés afin de compléter la vision parfois étriquée donnée de certaines productions.

\subsection{Les faïences : la production de Montelupo}

Bien que toujours très minoritaires en nombre, les faïences, dont le revêtement comprend une partie de sels d'étain et devient opaque à la cuisson, restent un mobilier attachant, par sa fragilité et dans de nombreux cas, des décors voyants mais évocateurs. Les provenances assez peu nombreuses permettent souvent des identifications claires et des datations semblant aisées, mais celles-ci doivent être relativisées par la durée de vie plus longue d'objets plus précieux et les imitations entre producteurs. L'Italie semble désormais privilégiée.

Le comblement 5026 du puits de la Bourse a livré un grand plat peu profond à large fond plat, lèvre légèrement épaissie arrivant à l'horizontale par une ample courbe continue de grande élégance (fig. 100, $\mathbf{n}^{\circ}$ 2). Cette forme, courante dans la production, ménage une large surface à décorer: des volutes orangées alternent avec des traits courbes de même couleur, entre lesquels de fins traits en bleu remplissent l'espace. La fouille de la Crypta Balbi à Rome a daté un plat semblable dans sa forme et son décor des deux derniers tiers du XVI ${ }^{\mathrm{e}} \mathrm{s}$. (Ricci 1985).

Un décor identique (les traits courbes décroissants y sont bleus) est posé sur un plat creux (fig. 100, $\mathbf{n}^{\circ} \mathbf{3}$ ) trouvé isolé sur le même site. Un bord redressé de vase ouvert tronconique (fig. 100, $\mathbf{n}^{\circ} \mathbf{1}$ ), mal conservé mais décoré d'une frise d'arabesque en bleu, fournit la même date (Ricci 1985).

Les vases fermés sont bien moins nombreux, situation habituelle pour des importations. L'exemplaire le plus marquant de céramique de Montelupo parmi ce mobilier est sans doute le spectaculaire et attachant pichet orné d'un profil de personnage féminin placé dans un médaillon polychrome. Cette pièce fort séduisante bien que très fragmentée et lacunaire, recueillie sur le site de l'Hôtel-Dieu, est sans rapport avec le four de bronzier (fig. 101). Les seize fragments, tous connexes mais d'une grande fragilité et n'offrant pas suffisamment de matière pour le collage, laissent apparaître un boccale (pichet) de Montelupo orné d'un profil féminin traité en polychromie, d'à peine $17,5 \mathrm{~cm}$ de haut et dont la morphologie piriforme met en valeur la zone décorée de la panse sous le bec pincé. Dans un médaillon déterminé par deux cercles orangés concentriques rattachés par de 
larges hachures est placée une figure féminine d'exécution rapide mais sûre. Un seul trait de manganèse dessine un visage au front haut et dégagé ainsi que l'exigeait la mode de la Renaissance. La coiffe, aujourd'hui incomplète, dépassait du cadre du médaillon.

Le « ritratto » (portrait) est un thème décoratif apprécié dans la céramique italienne de la période. Attesté dès les années 1420-1440, il s'affirme durant le $\mathrm{XV}^{\mathrm{e}}$ s. dans la production toscane et correspond au développement du portrait proprement dit dans la peinture, magnifié par La Joconde : les peintres traitent des personnages sans destinée remarquable, suffisamment nantis cependant pour commander des tableaux à leur effigie. La céramique haut de gamme est souvent un reflet de la peinture de chevalet, mais paradoxalement dans ce cas, son caractère spécifique de production de masse gomme les particularismes propres au portrait dont elle se fait l'écho. Traitées aussi bien dans la faïence que dans la terre vernissée, de grandes séries d'objets (Ravanelli Guidotti 2000) montrent que le visage de face ou de trois quarts, qui demande davantage de maîtrise, est moins courant que le profil, tourné indifféremment vers la droite ou la gauche, tandis que nos sociétés contemporaines privilégient le regard vers la droite, censé représenter l'avenir.

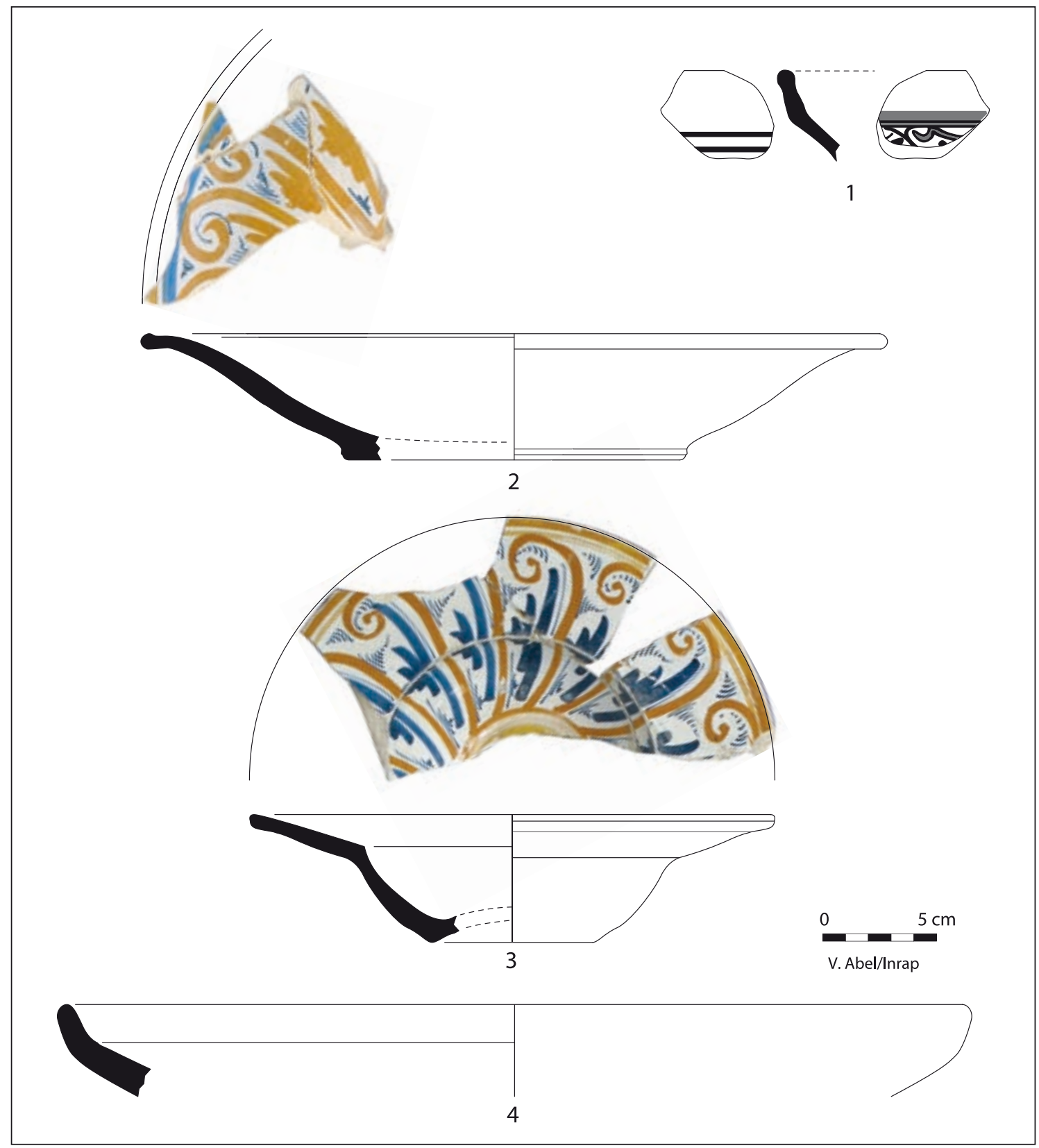

Fig. 100. Faïences italiennes : Montelupo ( $\left.n^{\circ} 1-3\right)$, Pise ? ( $\left.n^{\circ} 4\right)$ (second $\left.X V l^{\circ} s.\right)$.

1-3 : La Bourse ; 4 : place Villeneuve-Bargemon. 


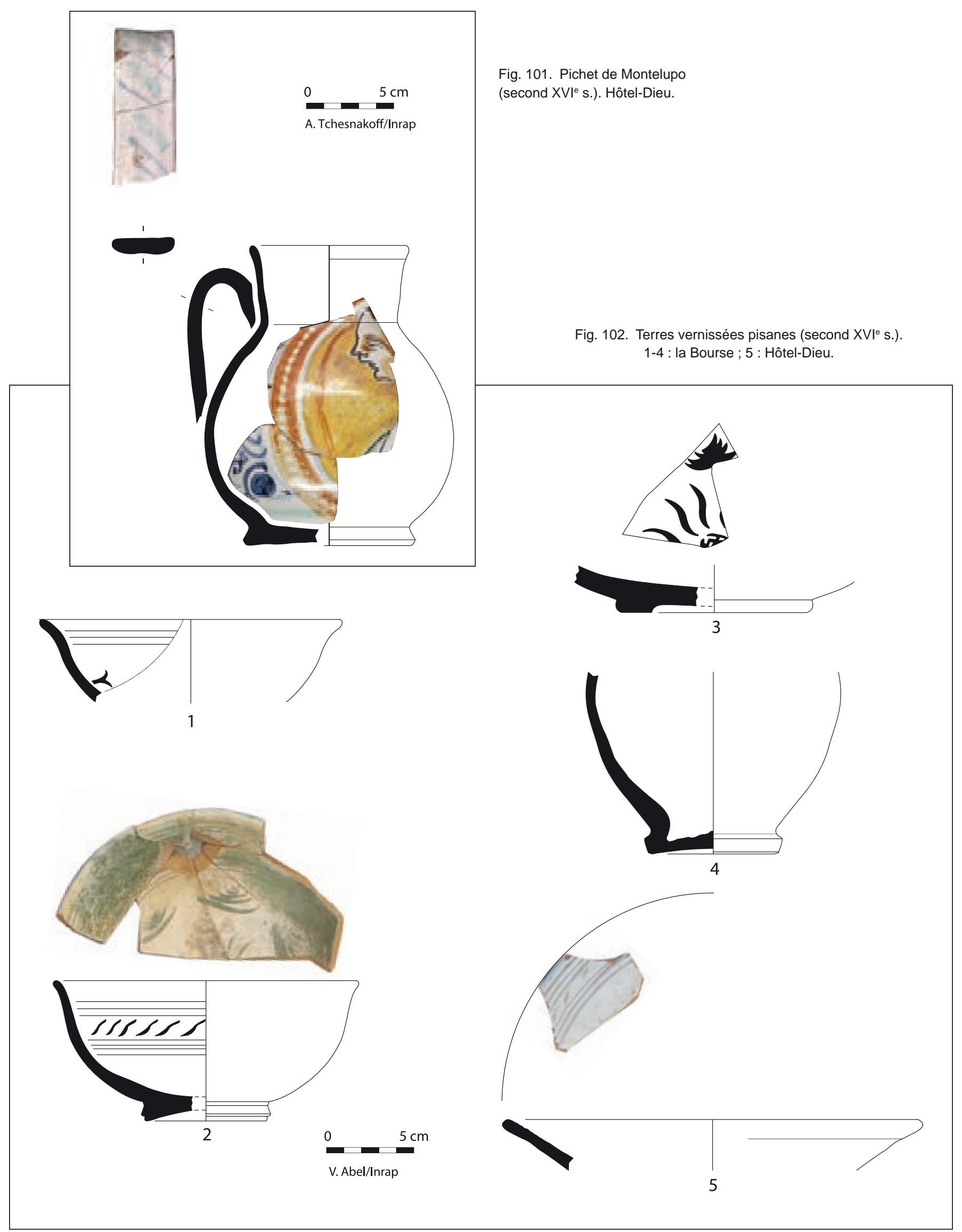


Sur la plupart des vases de faïence du Valdarno, le profil est mis en valeur par un fond sombre en bleu de cobalt, masquant judicieusement les reprises du trait, laissant le visage en réserve. En revanche, le fond du médaillon du pichet de l'Hôtel-Dieu est jaune, couleur plus volontiers attribuée à la seconde moitié du $\mathrm{XVI}^{\mathrm{e}} \mathrm{s}$., de même que l'orangé. Seuls deux traits de l'épaule droite du personnage subsistent, le reste du buste, le cou et l'arrière du crâne sont perdus, limitant d'autant les interprétations mais non l'imagination. Le XVII ${ }^{\mathrm{e}}$ s. préfèrera sur la faïence des personnages en pied et en pleine action, soldats, cavaliers ou comédiens. Faut-il y voir un signe des temps? Il reste ici indéchiffrable.

Une tentative de réparation, dont on ne sait si elle réussit, fut pratiquée en perçant la paroi, un seul trou subsiste sur l'un des tessons du bord proche de l'anse. Ce type de réparation ne semble pas signifier davantage que ce qui peut être déduit de la provenance et de la richesse du décor.

\subsection{Les terres vernissées}

On retrouve pour ce second $\mathrm{XVI}^{\mathrm{e}} \mathrm{s}$. les mêmes catégories que précédemment, avec une nette prédominance pour les productions de Fréjus.

\subsubsection{La terre vernissée de Pise et Valdarno}

Après les derniers avatars des céramiques «vertes et brunes » médiévales dont le vaste mais très fragmentaire plat du site du Musée César serait une ultime illustration (fig. 100, $\mathbf{n}^{\circ} \mathbf{4}$ ), les terres vernissées pisanes du XVI et début du XVII ${ }^{\mathrm{e}} \mathrm{s}$. parvenant à Marseille sont presque exclusivement des formes ouvertes décorées de larges incisions a stecca (Berti, Tongiorgi 1982). Le plus souvent ces objets sont recouverts de vernis vert, comme plusieurs issus du comblement de puits 5026 de la Bourse (fig. 102, $\mathbf{n}^{\circ}$ 1-3).

Les autres couleurs et tonalités de vernis, du marron presque noir au vernis incolore, semblent signe de postériorité dans les niveaux archéologiques de Marseille. Une panse de plat à vernis marron (inv. 155.09.2816) orienterait vers la fin du $\mathrm{XVI}^{\mathrm{e}}$ s., date confirmée par un bord de plat plus légèrement incisé sous un vernis incolore qui met en valeur la blancheur de l'engobe ${ }^{11}$ semblant annoncer les graffitta tarda du XVII $\mathrm{e}$ s.

Fait extrêmement rare, une cruche du puits de la Bourse est attribuable à Pise (fig. 102, $\mathbf{n}^{\circ}$ 4), ainsi qu'un

11 Phase d'abandon rapide du four de l'Hôtel-Dieu, inv. 155.09.2755. pied de vase sur tige courte peu interprétable, tous les deux recouvertes en vert.

\subsubsection{La terre vernissée de Ligurie}

Un fragment très limité de la place VilleneuveBargemon (Musée César) (fig. 103, $\mathbf{n}^{\circ} \mathbf{3}$ ) est décoré en vert et brun rappelant la mode du bas Moyen Âge, mais il s'agit dans ce cas d'un décor posé sur engobe blanc recouvert de vernis incolore. Le motif, récurrent, des incisions doubles en croix se retrouve sur un plat creux du même contexte, qui a aussi livré un bord de plat caréné, sans doute comparable (fig. 103, $\mathbf{n}^{\circ} \mathbf{1 - 2}$ ).

\subsubsection{La terre vernissée de Fréjus}

La terre vernissée de Fréjus reste la vaisselle d'usage commun mais nous parvient très dégradée, peut-être suite à un usage intensif. Il est donc difficile de percevoir nettement une évolution, qui n'a pas dû manquer de voir le jour en trois quarts de siècle, dans les productions de ces ateliers.

L'écuelle, comme l'exemple à engobe blanc sous vernis incolore (fig. 104, $\mathbf{n}^{\circ} \mathbf{1}$ ), reste l'objet le plus fréquent. Elle est accompagnée des mêmes plats que quelques décennies plus tôt, comme celui à bandeau externe (fig. 104, $\mathbf{n}^{\circ} \mathbf{2}$ ). Un possible «plat creux» postérieur au four de bronzier de l'Hôtel-Dieu est revêtu d'engobe rose sous vernis jaune, le tesson restant est trop limité pour bien en comprendre la forme (fig. 104, $\left.\mathbf{n}^{\circ} \mathbf{4}\right)$. L'éventuelle évolution, que nous n'avions pas décelée en 1988, reste pour l'instant imperceptible à travers le mobilier des fouilles de Marseille. À peine pourrait-on dire que le bord des plats à aile semble se redresser et s'épaissir (fig. 104, $\mathbf{n}^{\circ} \mathbf{3}$ ). Un bord de très grand plat a été terminé par une lèvre bifide pincée en onde régulière (fig. 104, $\mathbf{n}^{\circ}$ 5), un type apparemment absent précédemment.

Un autre plat se distingue par la taille de son fond annulaire massif et des parois particulièrement épaisses qui évoquent un vase très puissant (fig. 104, $\mathbf{n}^{\circ} \mathbf{6}$ ).

Un pot de chambre est issu d'un comblement d'un puits de la Bourse ; un fragment de panse et d'épaule témoigne d'une production de cruches parvenue jusqu'à Marseille, tandis que seul subsiste le fond d'un grand vase fermé d'aspect rustique et puissant (fig. 105, $\mathbf{n}^{\circ} \mathbf{4}$ ). Le comblement du puits 5026 de la Bourse a permis de reconstituer, au moins graphiquement, un pichet de Fréjus, à décor vert en fleur de lys sur engobe blanc (fig. 105, $\mathbf{n}^{\circ} 3$ ), ainsi que de voir une certaine variété des objets avec un petit vase sur tige (salière ? fig. 105, $\mathbf{n}^{\circ} \mathbf{1}$ ) et un vase fermé à bord enroulé (fig. 105, $\mathbf{n}^{\circ} \mathbf{2}$ ). 

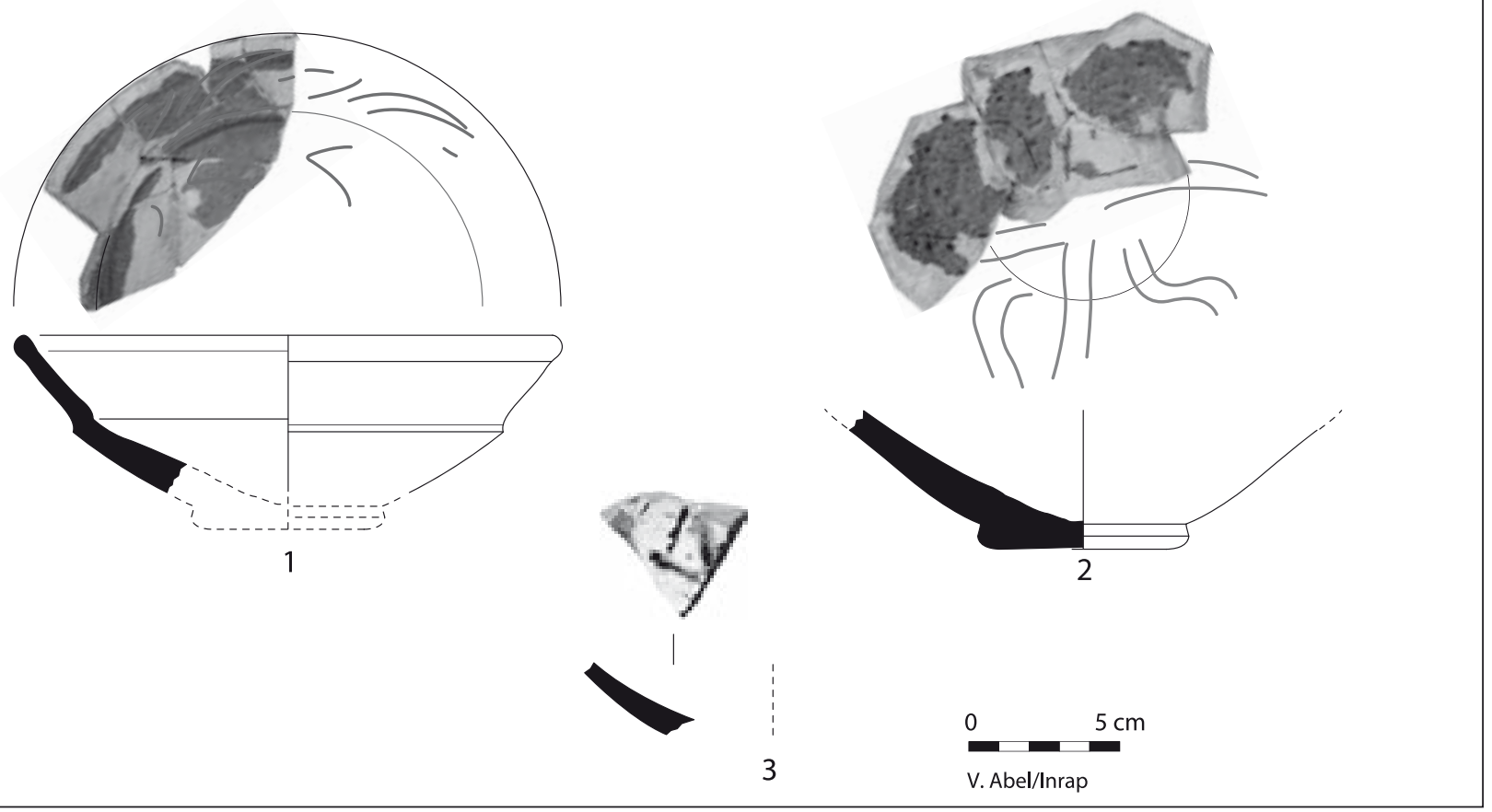

Fig. 103. Terres vernissées de Ligurie et apparentées (second $\mathrm{XVle}$ s.).

Place Villeneuve-Bargemon.

Fig. 104. Terres vernissées de Fréjus, formes ouvertes (second $\mathrm{XVle}$ s.).

1-3 : place Villeneuve-

Bargemon ; 4, 6 : Hôtel-Dieu ;
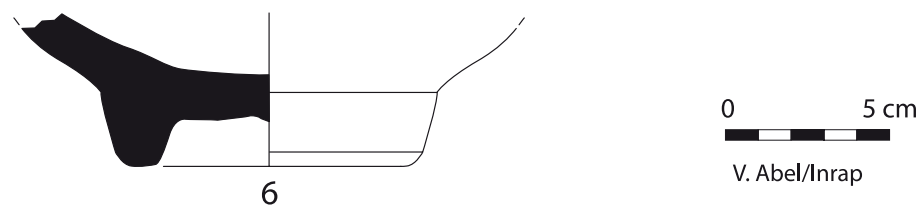

5 : la Bourse. 


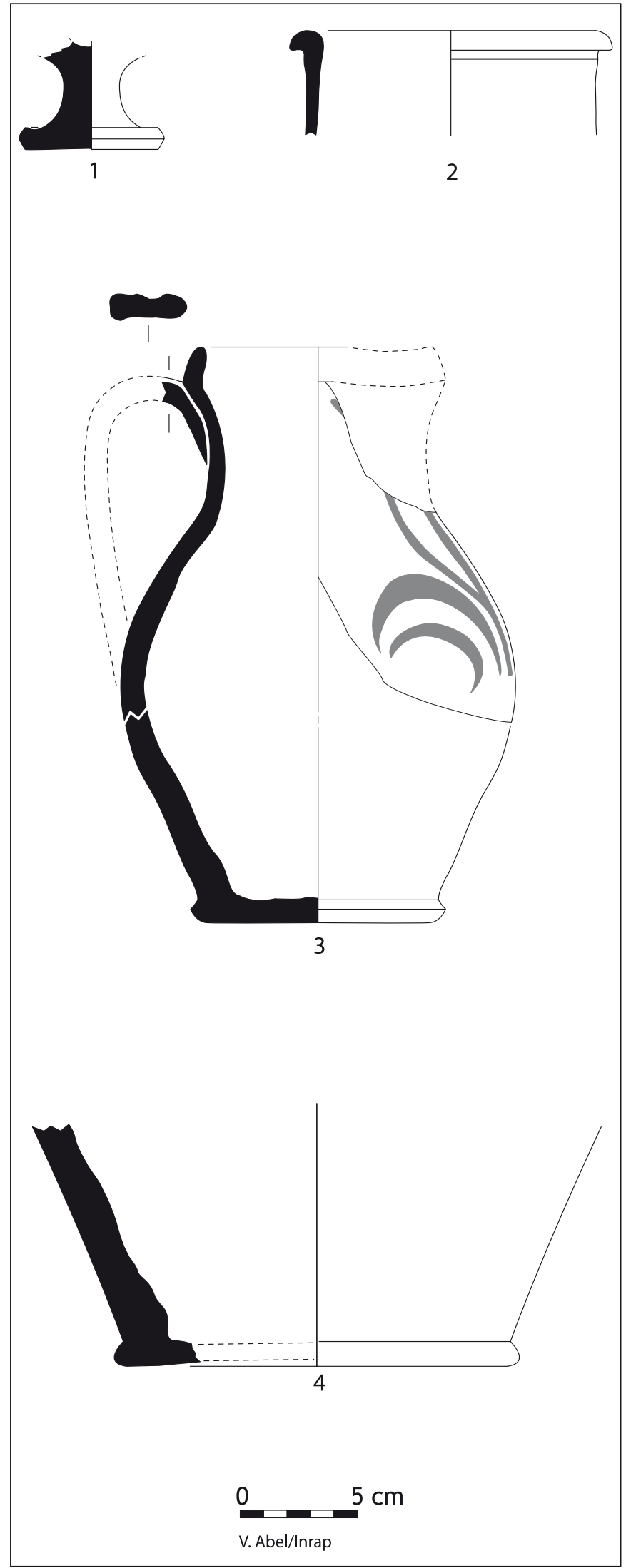

Fig. 105. Terres vernissées de Fréjus, formes fermées (second XVle s.). 1-3 : la Bourse ; 4 : Hôtel-Dieu.

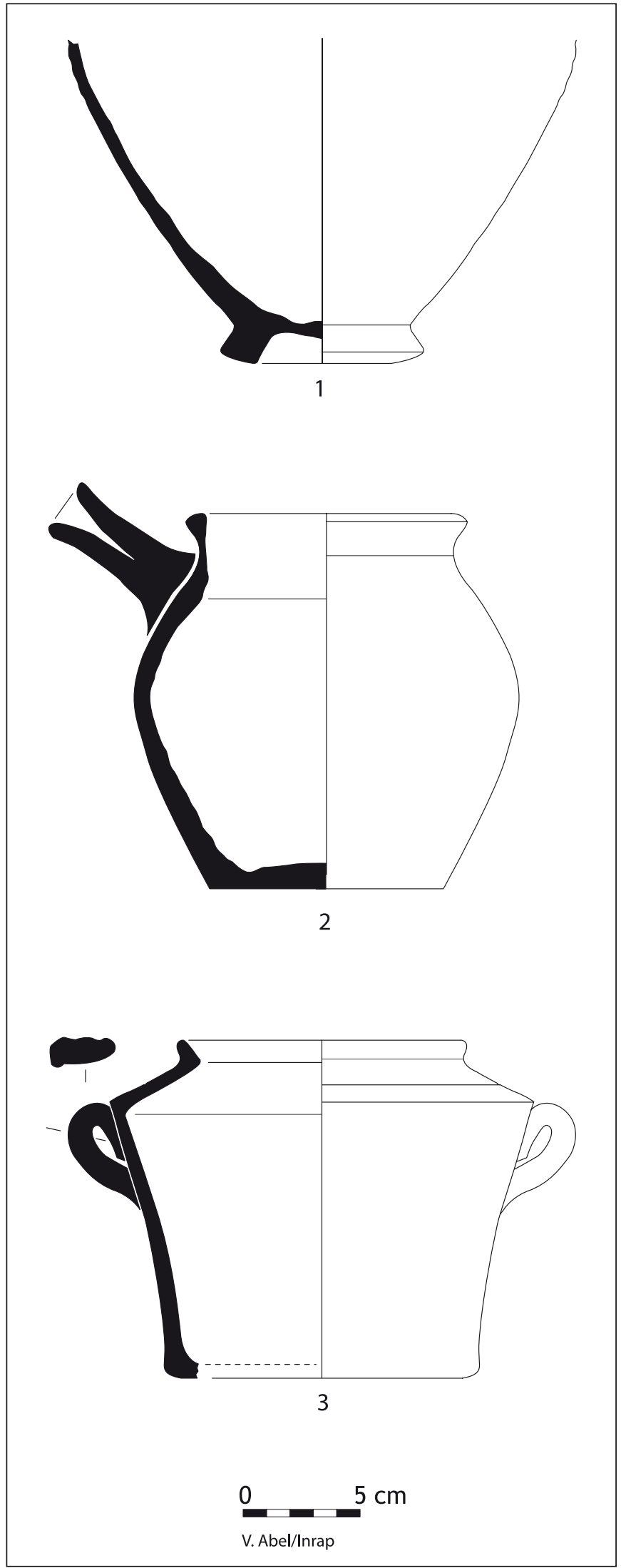

Fig. 106. Productions indéterminées $\left(n^{\circ} 1\right)$ (second $\mathrm{XVl}{ }^{\mathrm{e}} \mathrm{s}$.). La Bourse. 


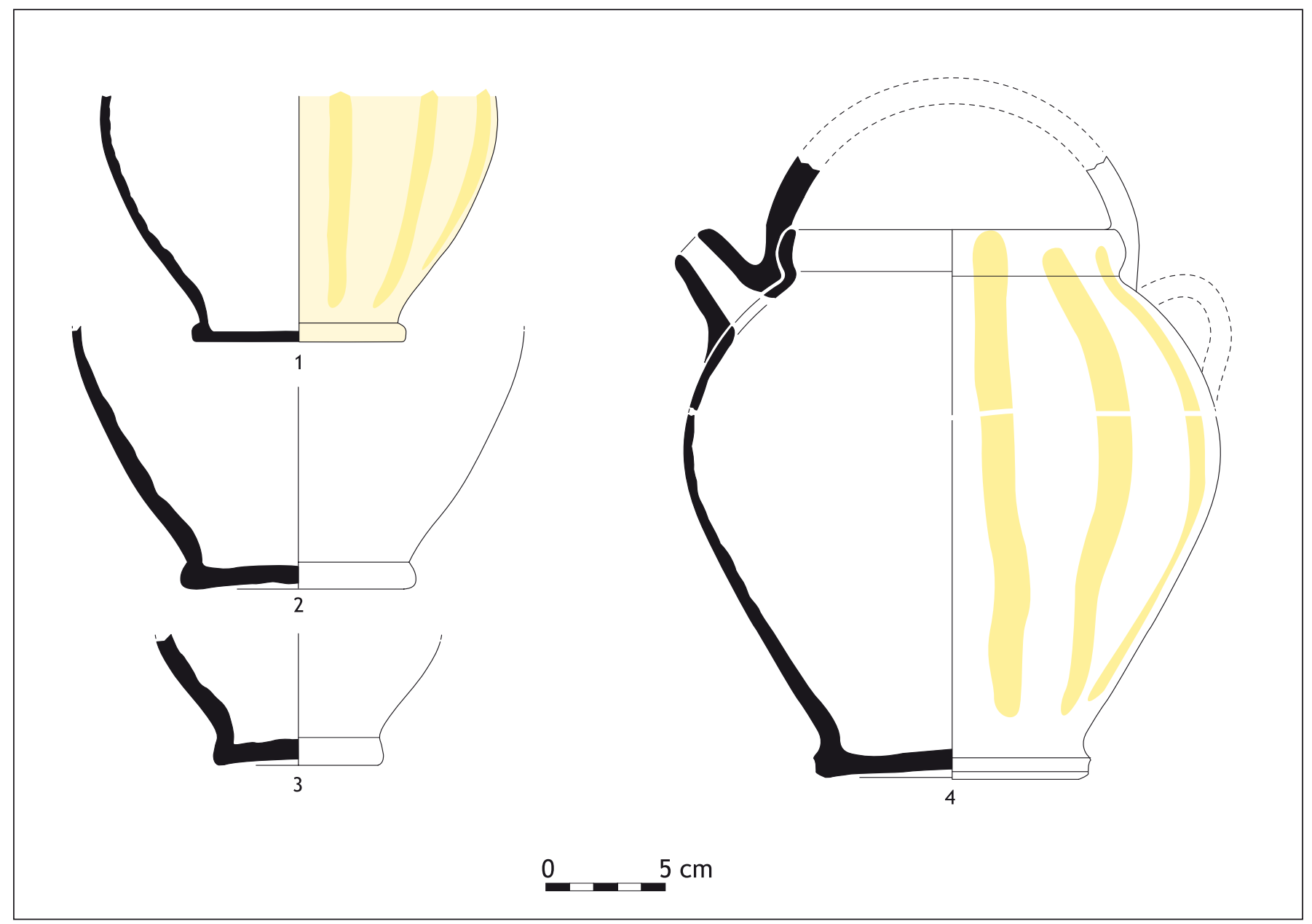

Fig. 107. Vases à liquide en pâte claire micacée (second XVIe s.). La Bourse.

\subsubsection{Les terres vernissées d'identification incertaine ou absente}

Bien que sans revêtement décelable, un fond de vase est placé parmi les terres vernissées (fig. 106, $\mathbf{n}^{\circ} \mathbf{1}$ ). Sa pâte est rouge brique à brun rouge et inclut de gros éléments non plastiques mis en évidence par un tournassage du fond pratiqué jusqu'à $7 \mathrm{~cm}$ de haut, dégageant un pied annulaire peu fréquent dans les vases fermés. Il était et demeure jusqu'à aujourd'hui le seul exemplaire de sa catégorie.

Une écuelle provenant de l'église de la Commanderie $\mathrm{du}$ fort Saint-Jean (fig. 95, $\mathbf{n}^{\circ} \mathbf{3}$ ) pose quelques problèmes d'attribution. Sa terre est rouge orangé soutenu, sableuse, à éléments non plastiques fins et noirs. Sur un fond creusé par le fil de découpe du potier, se développe une paroi assez mince dont le galbe est interrompu par une puissante carène externe peu sensible à l'intérieur. Aucun engobe ne semble lui avoir été appliqué avant le vernis auquel la cuisson a donné une tonalité verdâtre peu séduisante qui n'était peut-être pas le but recherché.
Ce vernis conserve la trace des trois pieds de la pernette qui indique un mode d'enfournement des céramiques relativement élaboré.

Une production de terre vernissée à pâte claire, finement mais densément micacée, se distingue très nettement parmi le mobilier tout au long du $\mathrm{XVI}^{\mathrm{e}} \mathrm{s}$., sans qu'il puisse être pour l'instant répondu à la plupart des interrogations nées des premières études céramologiques des années 1980. Les vases, aux parois très amincies, sont généralement tournés avec beaucoup de grâce et de soin. Elles semblent appartenir davantage au second XVI $\mathrm{s}$. au vu des résultats de l'Hôtel-Dieu, hypothèse qui se confirmerait rétrospectivement avec le comblement DI14 de la Bourse et les contextes du fort Saint-Jean.

Leur typologie se dessine en pointillés, leur origine géographique est inconnue. Les comblements 5026 et 1984 de la Bourse ont fourni l'essentiel de l'information les concernant, complété par le contexte de la place Villeneuve-Bargemon (Musée César). Dans le premier comblement se trouvaient cinq fonds de vases à liquide (fig. 107) et quatre becs tubulaires ; le second 


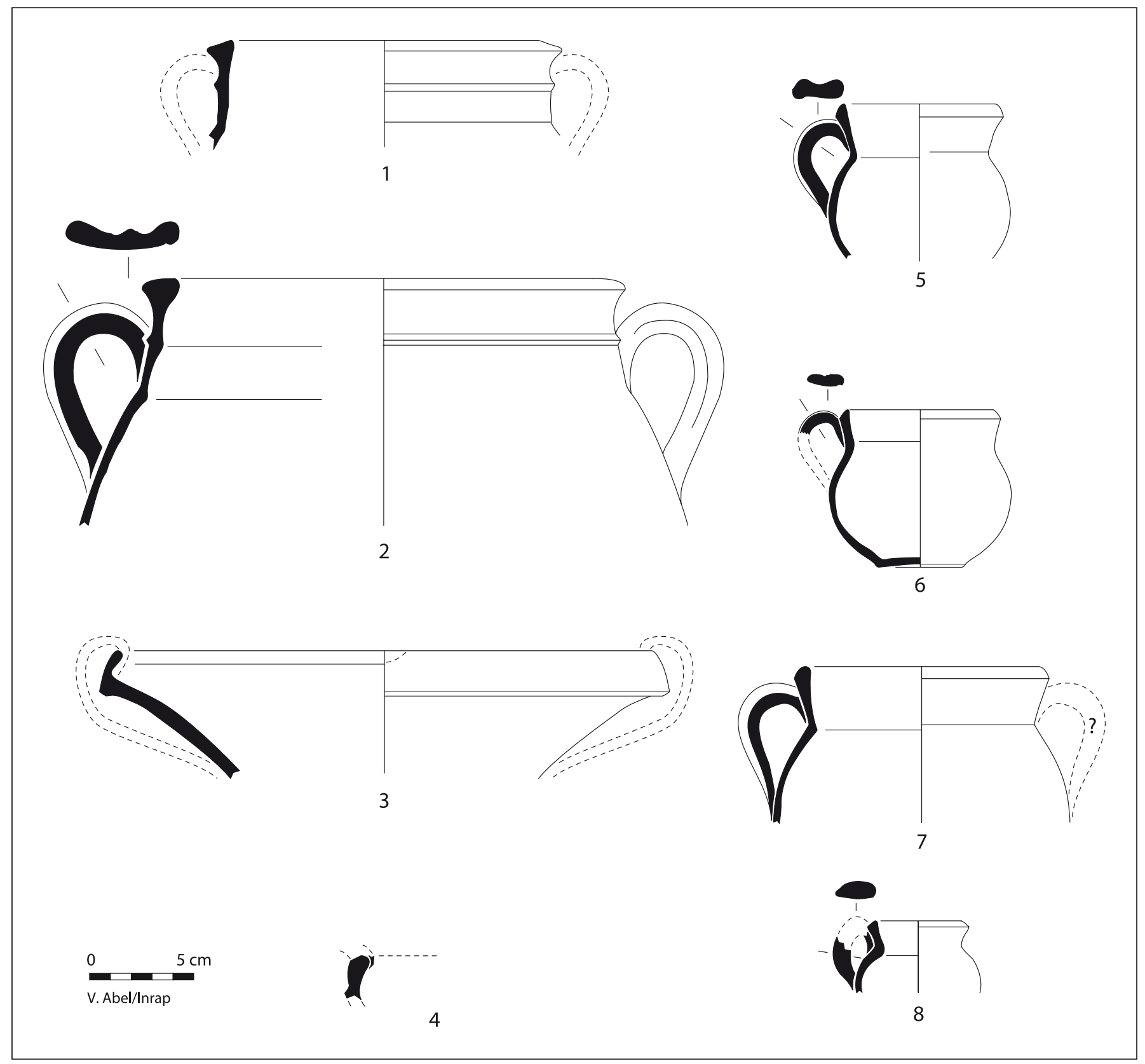

Fig. 108. Production à pâte claire micacée (second XV|e s.). 1, 4, 8 : la Bourse ; 2-3, 5-7 : place Villeneuve-Bargemon.

comblement témoignait d'un reste de tirelire et d'un plat à engobe rose sous vernis incolore. Une très belle cruche, aux parois minces malgré sa grande taille, a pu être reconstituée graphiquement. Une jatte est extraite du contexte du Musée César (fig. 108, $\mathbf{n}^{\circ}$ 3), tendant à prouver qu'il nous reste une grande partie du répertoire de cette «pâte claire micacée » à retrouver, d'autant que celle-ci sert aussi à façonner des vases culinaires qu'elle nous permet d'aborder.

Depuis les grandes marmites à col haut restant encore dans le schéma médiéval, mais adoptant de nouveaux bords comme le bord triangulaire à ressaut (Musée César fig. 108, $\mathbf{n}^{\circ} \mathbf{2}$, puits 1984 de la Bourse, fig. 108, $\mathbf{n}^{\circ} \mathbf{1}$ ), jusqu'au plus petit des toupins (fig. 108, $\mathbf{n}^{\circ} \mathbf{5 - 7}$ ) et même « taraïettes » les imitant (jouet en terre, fig. 108, $\mathbf{n}^{\circ} \mathbf{8}$ ), l'éventail est large. Cette production semble utiliser une matière première de qualité permettant à des artisans soigneux et virtuoses de d'exprimer leur savoir-faire.

\subsection{Les poteries culinaires}

Les poteries culinaires sont pour l'essentiel revêtues de vernis plombifères, vernissées elles aussi mais par 
commodité elles sont ici distinguées des terres vernissées, d'autant qu'une partie de ces vases culinaires sont dépourvus de revêtement et obtenus en post-cuisson réductrice.

\subsubsection{La poterie réfractaire de type Uzège}

La production réfractaire de la région de l'Uzège et ateliers apparentés est peu rencontrée à Marseille sur toute la période moderne (fig. $108, \mathbf{n}^{\circ} \mathbf{4}$ ). Seuls quelques tessons de panses la rappellent sur le site de l'Hôtel-Dieu.

Deux vases, ayant servi au feu et graphiquement complets, issus des comblements 5026 et 1984 de la Bourse n'ont pas vu leur groupe s'étoffer. L'un (fig. 106, $\mathbf{n}^{\circ} \mathbf{3}$ ) est un vase aux parois très légèrement évasées qui se referment à angle droit avant de se terminer par une lèvre redressée. Sous la rupture de courbe est fixée une épaisse et courte anse en point d'interrogation. Sa pâte rouge et fine, vernissée, semble la rattacher aux ateliers de réfractaires ligures. L'autre (fig. $106, \mathbf{n}^{\circ} \mathbf{2}$ ) est un vase massif à queue tubulaire. Sa pâte rose et fine n'a reçu aucun revêtement. La paroi, épaisse pour tout le corps $\mathrm{du}$ vase, s'amincit radicalement pour former un bord redressé. Aucune hypothèse d'origine géographique ne peut être émise.

\subsubsection{Les marmites noires, la post-cuisson réductrice}

La poterie réfractaire à post-cuisson réductrice est relativement plus parlante. La problématique des «marmites noires » et de leur apport à la connaissance de la chronologie, non seulement à Marseille mais sur un horizon plus large, demeure à l'ordre du jour. Sous ce terme de «marmites noires » (nom générique qui traduit l'aspect des vases et se démarque de la " céramique grise » plus particulièrement médiévale) se trouvent des vases culinaires sans revêtement dont la post-cuisson a été menée en atmosphère réductrice (Abel 2011). Elles ont été remarquées pour la première fois sur le site de la Bourse (Abel 1988, fig. 109, $\mathbf{n}^{\circ} \mathbf{4}$ ), contemporaines de productions du $\mathrm{XVI}^{\mathrm{e}} \mathrm{s}$.

Les niveaux directement postérieurs à l'utilisation du four de bronzier de l'Hôtel-Dieu en contenaient trois alors que les niveaux antérieurs n'en ont pas livré un seul fragment. La pâte d'une première marmite noire (fig. 109, $\mathbf{n}^{\circ} \mathbf{1}$ ) comporte de nombreux éléments non plastiques pris dans une matrice lisse, fine, de tonalité gris mat, donnant une grande rugosité à la surface de l'objet, tant en face interne qu'en face externe puisque aucun traitement de surface n'est appliqué. L'anse est épaisse mais apparemment tournée pour ce vase aussi ; elle est légèrement dissymétrique. Un objet identique a été recueilli sur le site de la place Villeneuve-Bargemon
(Musée César) sans contexte (fig. 109, $\mathbf{n}^{\circ} \mathbf{3}$ ) et un autre à pâte identique mais au profil différent sur le site de la Bourse (fig. 109, $\mathbf{n}^{\circ} \mathbf{6}$ ).

La deuxième marmite noire, recueillie dans les premiers niveaux d'abandon du four, est plus complète que la précédente, presque archéologiquement complète même (fig. 109, $\mathbf{n}^{\circ}$ 7). Sa pâte est assez semblable à celle de l'objet $\mathrm{n}^{\circ} 1$, mais contient un peu plus d'éléments non plastiques. La forme est globulaire, le fond bombé, la paroi légèrement carénée en partie basse. La paroi se resserre puis se rouvre presque à angle droit pour ménager une ouverture terminée par une lèvre aplatie. L'anse, tournée, est posée en point d'interrogation sur l'épaule sans atteindre la lèvre.

La marmite recueillie lors du diagnostic du site de l'Hôtel-Dieu en 2008 (fig. 109, $\mathbf{n}^{\circ} \mathbf{8}$ ), est la plus récente par sa position stratigraphique dans les niveaux au four. Elle se démarque des marmites noires précédentes par sa pâte, tendant vers le gris foncé et contenant peu d'éléments non plastiques qui ne paraît pas (d'après un simple examen à l'œil) façonnée dans une argile semblable. Les flancs de la partie conservée offrent un aspect soigné, d'autant que les stries de tournage, nettes à l'intérieur, sont imperceptibles à l'extérieur.

Par référence aux objets semblables connus, on imagine un fond bombé à ce récipient. Sans col vertical individualisé, le bord incliné vers l'extérieur se développe sur 3,5 cm de long directement à angle droit après une rupture de la courbe de la panse qui était jusque là régulière.

Quatre « cordons » d'argile en demi-cercles ouverts vers le bas sont apposés dans la zone entre les anses et à peu près au même niveau que celles-ci. Ces demi-cercles presque parfaits sont agrémentés de quadrillages imprimés mécaniquement ne suivant pas le cercle de pâte et sans reprise visible.

\section{Conclusion sur la céramique du $\mathrm{XVI}^{\mathrm{e}} \mathrm{S}$.}

À l'issue de cette évocation des céramiques utilisées à Marseille au XVI ${ }^{\mathrm{e}}$ s., dont l'inventaire est sinon exhaustif du moins le plus complet possible dans le cadre de cet ouvrage, on est en droit de rester sur sa faim. Point de pourcentages ni de proportions, il ne s'agit que d'un millier de tessons à peine qui témoignent à travers les fouilles récentes et plus anciennes, de près d'un siècle et demi de vie quotidienne. Il ne peut, d'un corpus aussi limité, être tiré de véritable conclusion, mais plutôt un bilan d'étape.

Se confirme la continuité des principales importations déjà connues à la fin du Moyen Âge et encore pour la plupart présentes jusqu'à l'orée du XVII ${ }^{\mathrm{e}}$ s., avec des 


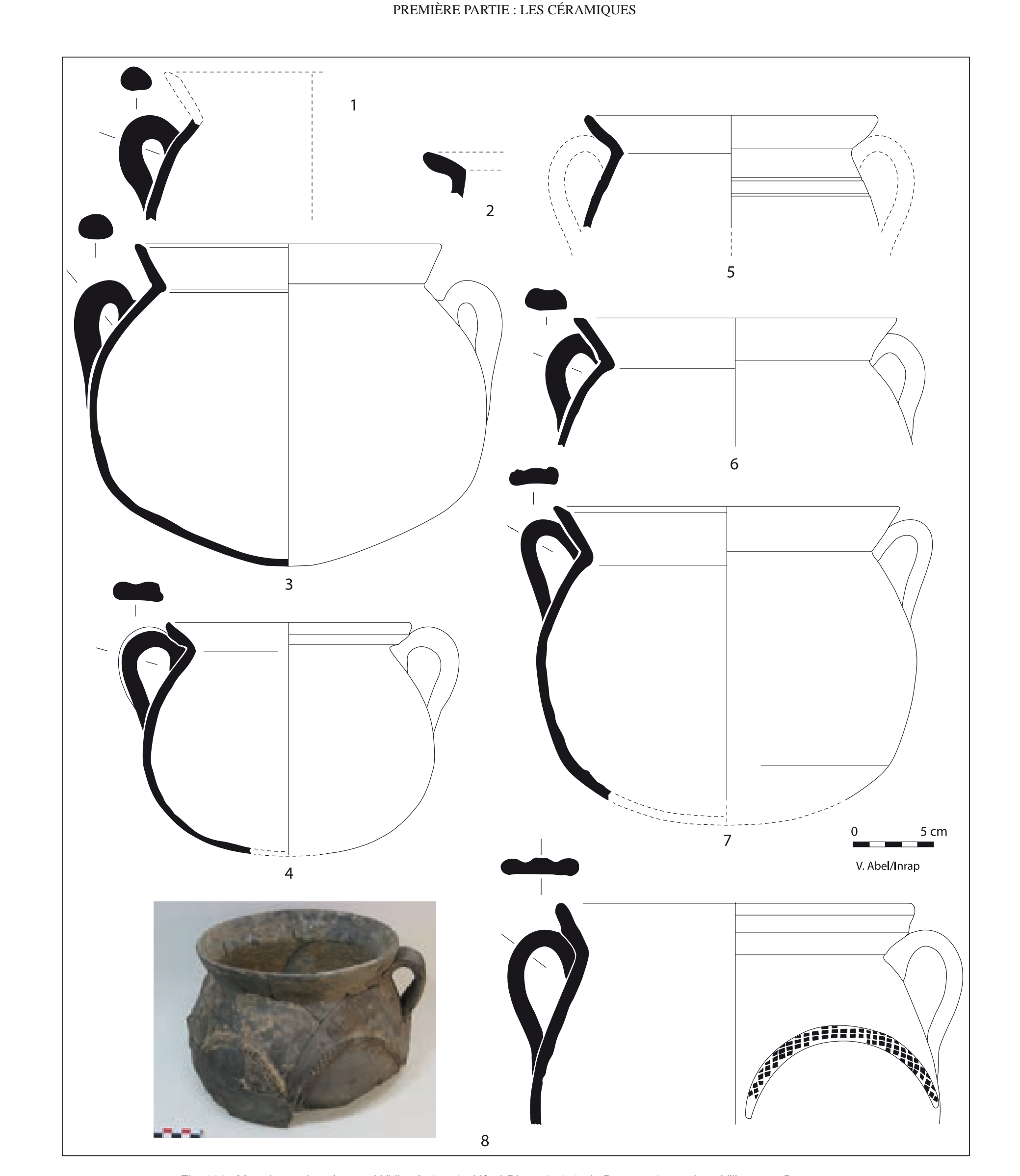


fortunes diverses : faïence de Valence et de Toscane, d'où viennent aussi des terres vernissées complétées par celles de Ligurie. Que doit-on penser de la préférence affichée sur les tables des mieux lotis pour les écuelles espagnoles d'une part et les assiettes et pichets d'Italie d'autre part? La question reste en suspens.

Des nouveautés se sont fait jour, en bas de l'échelle ou dans les arrière-cuisines, comme la vaisselle vernissée de Fréjus, sans doute particulièrement adaptée au marché marseillais ou comblant efficacement la niche des céramiques d'entrée de gamme, les deux choses n'étant pas d'ailleurs contradictoires. L'intérêt de cette production de masse est alors de révéler par petits indices la véritable vie quotidienne, faite de nourriture mangée dans les écuelles et de pots de chambre enfin réinventés...

Les vases culinaires sont assez hétérogènes et évoquent mieux les techniques des potiers que les comportements ou niveaux de vie des acheteurs de céramiques. Tous les ateliers ne sont pas identifiés, ils sont certainement multiples. Les productions à pâte claire micacée et celles à post-cuisson réductrice indiquent, chacune à leur manière, la vigueur d'un artisanat qui semble limité dans ses moyens (mise en œuvre des vernis par exemple) mais pas dans ses intentions : les objets en sont bien conçus, bien réalisés, bien finis.

D'autres vases et de nombreux tessons restent en revanche sans identification. Altérés, fragmentaires et dispersés, leur inventaire a été dressé lors des comptages et de la collecte des données mais ne peuvent trouver leur place ici. La céramologie est, en tout premier lieu, attentive aux séries, celle qu'elle sait interpréter et qui renseignent sur des contextes, des ensembles, des tendances. À l'intérieur de ceux-ci, peuvent s'insérer des particularismes, des exceptions et des pépites. Que sont ces objets sans l'environnement humain qui fait leur sens et que sait restituer l'archéologie ? Des objets hétéroclites sans message. Formons par conséquent le vœu que ces tessons puissent retrouver une signification par la fouille de sédiments plus riches en données matérielles sur cette période dans l'avenir. 



\section{Chapitre 6}

\section{Les productions naissantes des ateliers de la vallée de l'Huveaune face aux importations, milieu du XVII ${ }^{\mathrm{e}} \mathrm{s}$.}

\section{(Véronique Abel)}

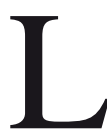
'étape suivante se situe directement autour du milieu du XVII ${ }^{\mathrm{e}}$ s., la continuité avec la précédente étant pour l'instant encore impossible : aucune donnée céramologique n'a été livrée par l'archéologie marseillaise pour l'intervalle entre les années 1610 et 1640 environ. On peut d'autant plus le regretter, qu'à l'abord du milieu du XVII ${ }^{\mathrm{e}}$ s., le contraste est saisissant avec la période précédente.

Un bouleversement de taille affecte les approvisionnements en céramique peu avant le milieu du XVII ${ }^{\mathrm{e}} \mathrm{s}$. Si les courants d'importations observés pour le $\mathrm{XVI}^{\mathrm{e}} \mathrm{s}$. sont pour la plupart maintenus, l'événement majeur consiste en l'apparition de la production de proximité de la vallée de l'Huveaune dans un contexte général d'exploitation plus systématique des argiles non réfractaires. Les importations traditionnelles italiennes, de vernissées
(Pise essentiellement) et faïences (Ligurie et Toscane), se maintiennent encore bien à Marseille, de même que les vernissées de Fréjus. Le domaine de la cuisine voit l'apparition des productions de Vallauris dont l'importance est grande sur toute la période.

Trois ensembles retrouvés en fouille, l'un de l'Hôtel Bargemon, le deuxième de la place VilleneuveBargemon et le troisième de la place des Pistoles sont de chronologie globalement semblable mais diffèrent par certains points. C'est la raison pour laquelle nous les étudierons de manière distincte car ils peuvent servir de contextes de référence pour le milieu du XVII $\mathrm{e}$ s.

\section{Le contexte « Pavillon Bargemon»}

Au printemps 1994, Frédéric Raynaud (Inrap, alors Afan) a recueilli au fond d'une profonde excavation sous le Pavillon Bargemon attenant à l'Hôtel de ville, alors

\begin{tabular}{|l|c|c|c|c|}
\hline \multicolumn{1}{|c|}{ Catégories } & Fragments & $\%$ & NMI & $\%$ \\
\hline Faïence de Ligurie & 8 & 3 & 1 & 2 \\
\hline Faïence de Montelupo & 1 & 0,3 & 1 & 2 \\
\hline Faïence de Valence & 0 & $/$ & $/$ & $/$ \\
\hline Terre vernissée de Pise & 44 & 15 & 6 & 13 \\
\hline Terre vernissée de Manosque & 0 & $/$ & $/$ & $/$ \\
\hline Terre vernissée de Type Fréjus & 43 & 14 & 7 & 16 \\
\hline Terre vernissée de Biot & 5 & 2 & 1 & 2 \\
\hline Terre vernissée de l'arrière-pays marseillais & 70 & 23 & 16 & 36 \\
\hline Terre vernissée indéterminée & 1 & 0,3 & 1 & 2 \\
\hline Culinaire de Ligurie & 19 & 6 & 1 & 2 \\
\hline Culinaire de Vallauris & 36 & 12 & 5 & 11 \\
\hline Culinaire noire (post-cuisson réd.) & 60 & 20 & 4 & 9 \\
\hline Culinaire rouge & 11 & 4 & 2 & 4 \\
\hline Réfractaire de type Uzège & 0 & $/$ & $/$ & $/$ \\
\hline Total & $\mathbf{2 9 8}$ & & 45 & \\
\hline Fragments en dépôt secondaire & 4 & 1 & & \\
\hline
\end{tabular}

Tableau II : le contexte de la fouille « Pavillon Bargemon » (unité stratigraphique 147). 


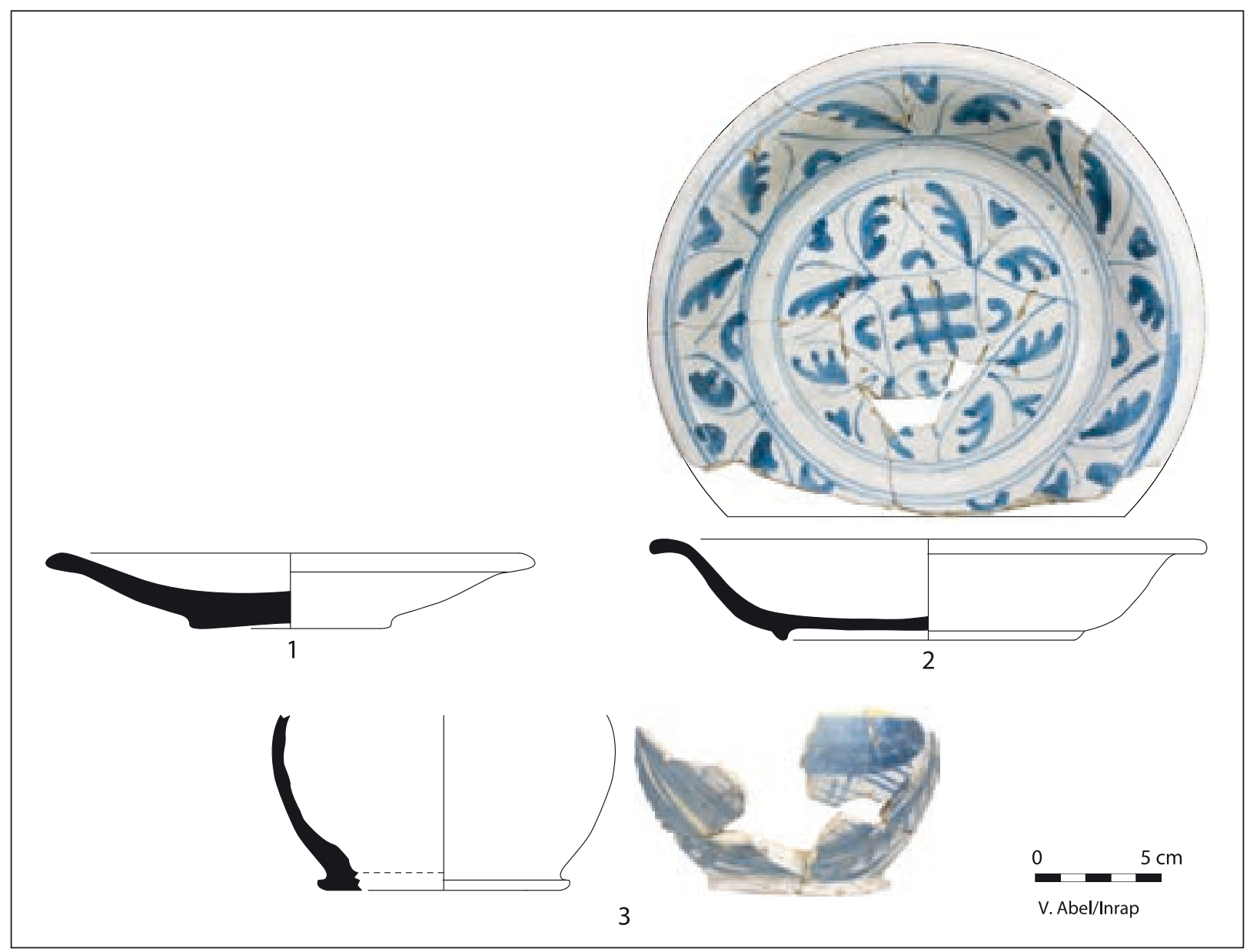

Fig. 110. Faïences italiennes (milieu du XVII s.). 1-2 : Pavillon Bargemon. 3 : place des Pistoles.

en phase de confortement, un ensemble de céramiques dont un rapide examen révélait dès l'abord un ensemble à la fois homogène et varié (tableau II). Les vases ont pu être reconstitués rapidement et avec un certain succès, pour une présentation au grand public. Cet avantage s'est actuellement mué en inconvénient puisque le mobilier est scindé en deux lots, l'un à notre disposition au dépôt municipal de Marseille, l'autre au Musée d'histoire dont l'accès est difficile (en travaux au moment de la rédaction du manuscrit). Plusieurs vases sont en outre demeurés introuvables à l'automne 2010 (une assiette et deux vases fermés en faïence italienne).

\subsection{Les faïences et les terres vernissées}

La faïence décorée est représentée par le plus bel exemplaire retrouvé à Marseille d'assiette ligure à décor de palmettes (fig. 110, $\mathbf{n}^{\circ} \mathbf{2}$ ). Un pot de pharmacie assorti est à retrouver, ainsi qu'un vase à médaillon et qu'une assiette toscane à décor de feuilles de chêne dont le profil avait heureusement été relevé (fig. 110, $\left.\mathbf{n}^{\circ} \mathbf{1}\right)$.
La vaisselle vernissée pisane (fig. 111, $\mathrm{n}^{\circ} \mathbf{2}-\mathbf{4}$ et fig. 112, $\mathbf{n}^{\circ}$ ) associe ici le dernier avatar des céramiques a stecca, le modèle dit a girandola et le début des incisées polychromes tardives ( raffita tarda). Elle date donc approximativement le lot du deuxième quart du XVII ${ }^{e} s$.

Les céramiques de Fréjus sont encore bien représentées : assiette à marli court, grand tian, pichets, et pot de chambre (fig. 113, $\mathbf{n}^{\circ} \mathbf{1}$ et fig. $114 \mathbf{n}^{\circ} \mathbf{1}$ ). Cette vaisselle vernissée, très utilisée à Marseille au XVI $\mathrm{s}$. rentre déjà en concurrence avec les premières productions des ateliers de l'arrière-pays marseillais (vallée de l'Huveaune), ici débutantes, mais laissant déjà percer des idées originales (fig. 115 à fig. 119). On remarque des décors recherchés, tels les mélanges d'engobes, et formes nouvelles, telles ces assiettes (fig. 117, $\mathbf{n}^{\circ}$ 3-4) qui semblent à l' origine de deux formes postérieures dans le répertoire (fig. 117, $\mathbf{n}^{\circ}$ 5-6) et une écuelle (fig. 115, $\mathbf{n}^{\circ} \mathbf{1}$ ), nettement hémisphérique et à bord épaissi à l'intérieur, qui se distingue ainsi de celles de Fréjus.

Un vase à liquide original, une cruche refermée (fig. 118, $\mathbf{n}^{\circ} \mathbf{3}$ ), révèle la grande habileté de l'artisan qui l'a confectionné. 

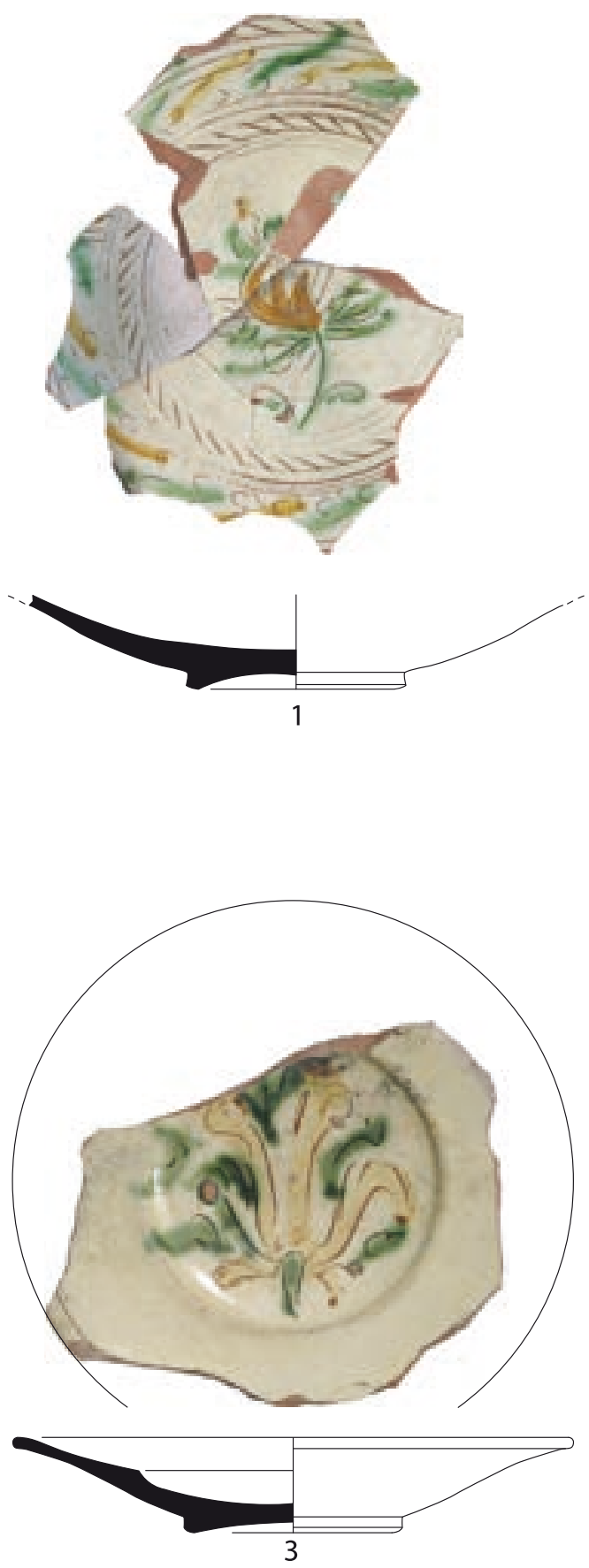

$\quad 5 \mathrm{~cm}$

V. Abel/Inrap
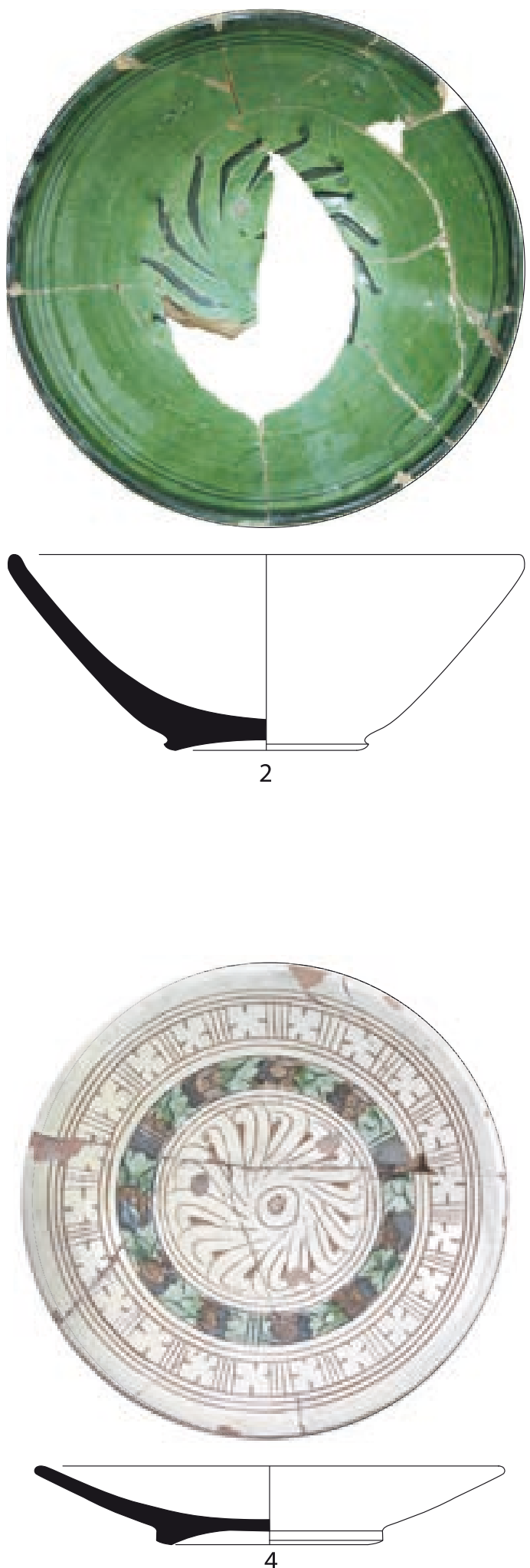

Fig. 111. Terres vernissées de Pise (Val d’Arno) (milieu du XVIIe s.). 1 : place des Pistoles ; 2-4 : Pavillon Bargemon. 

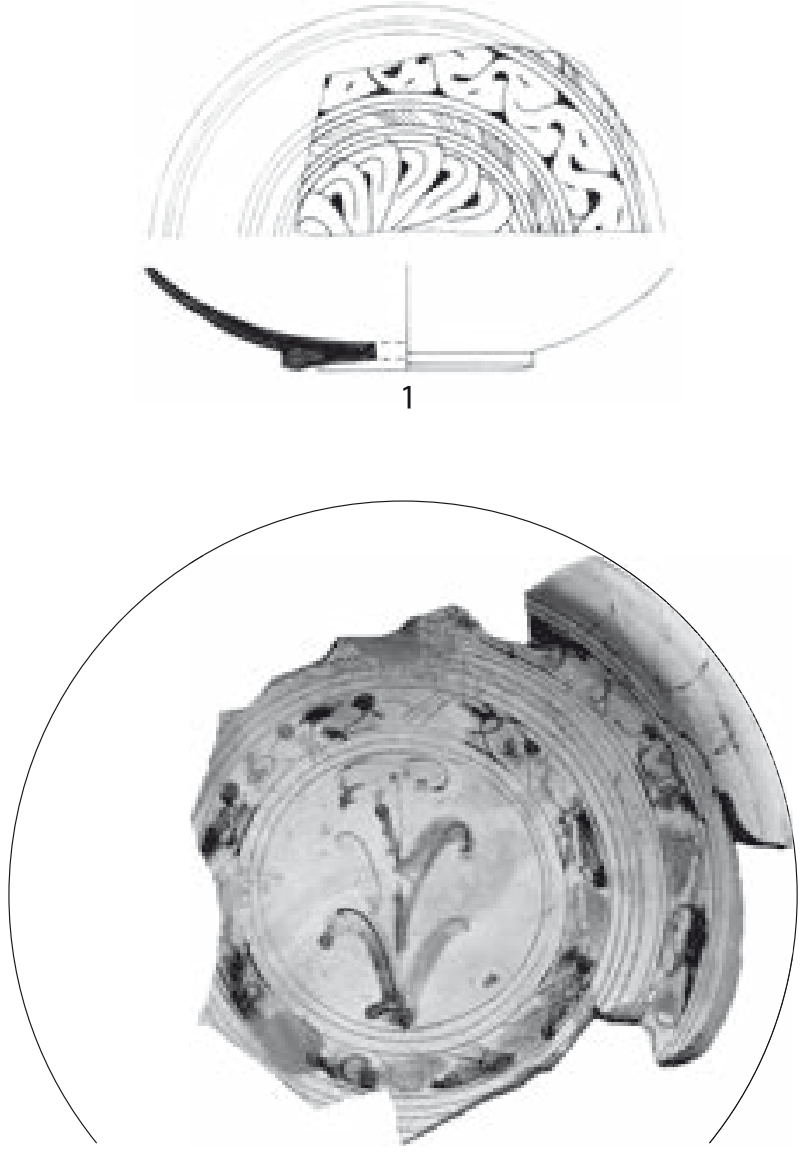

2

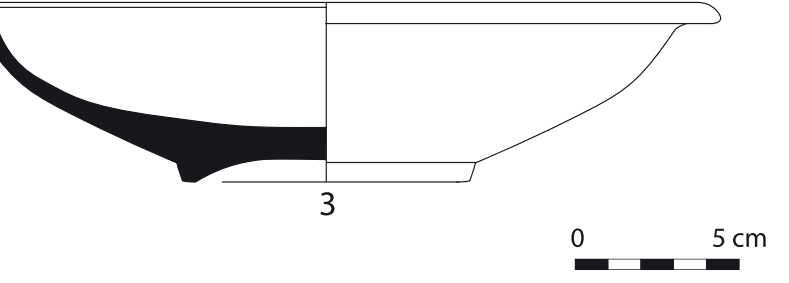

V. Abel/Inrap
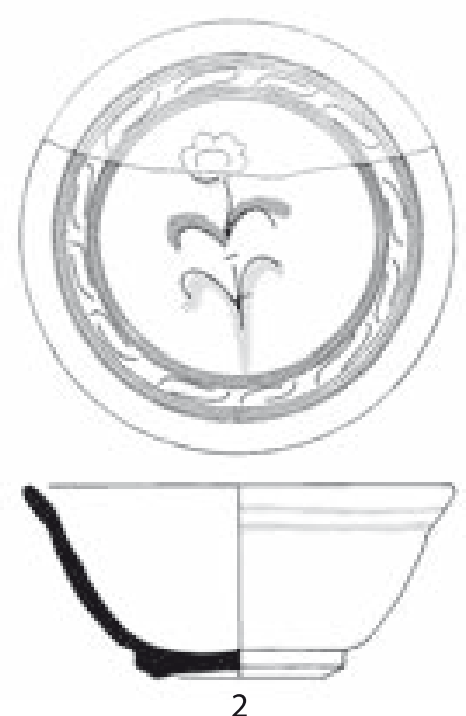

2

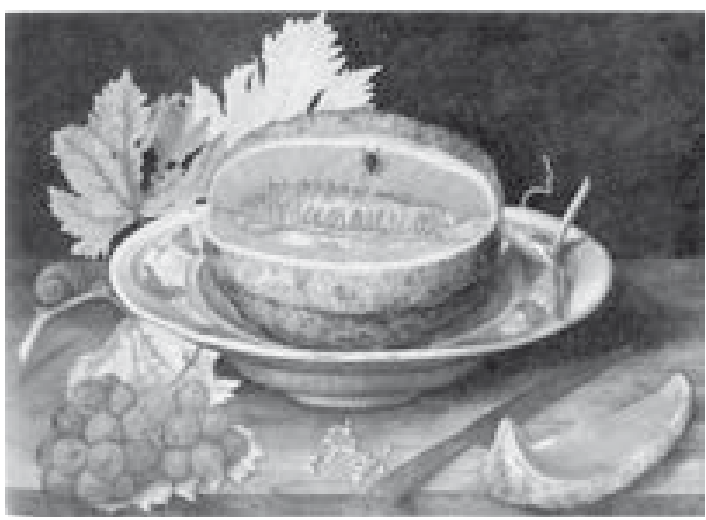

Fig. 112. Terres vernissées de Pise (Val d'Arno) (milieu du XVIIe s.). 1-2 : la Bourse ; 3 : Pavillon Bargemon. « Assiette au melon et tranche de pastèque », tableau de Giovanna Garzoni (1650), Palais Pitti, galerie Palatine, Florence $\odot$ akg-images/Orsi Battaglini : rare exemple de terre vernissée représentée en peinture. 

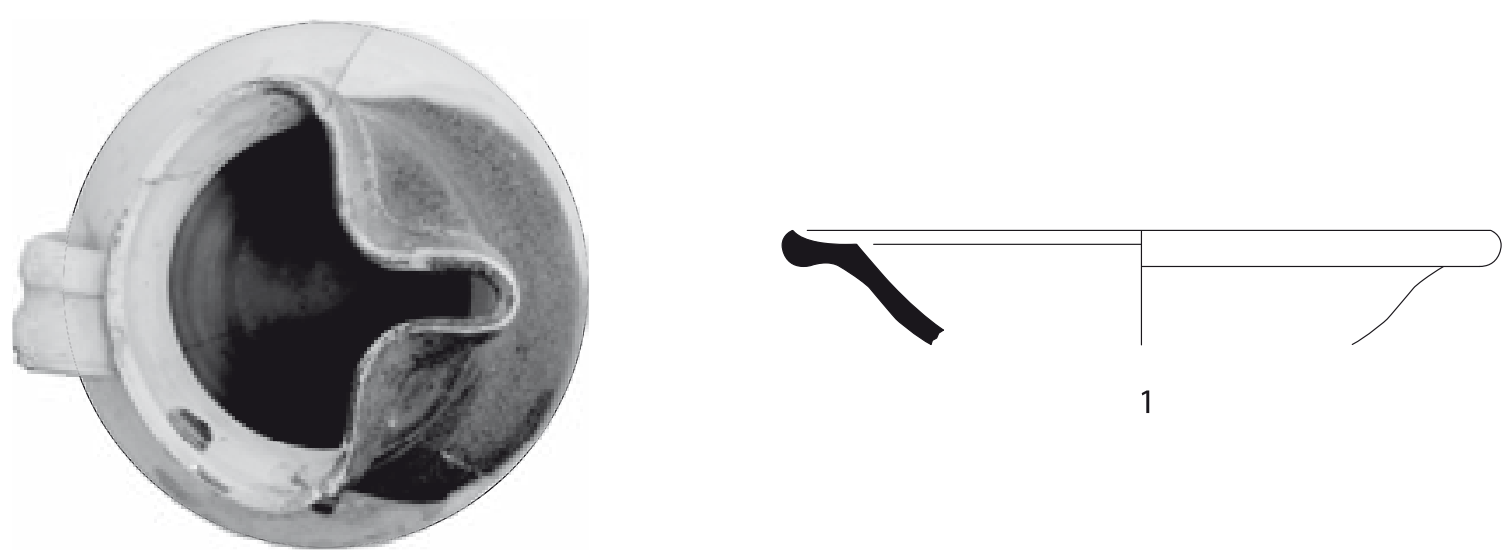

1
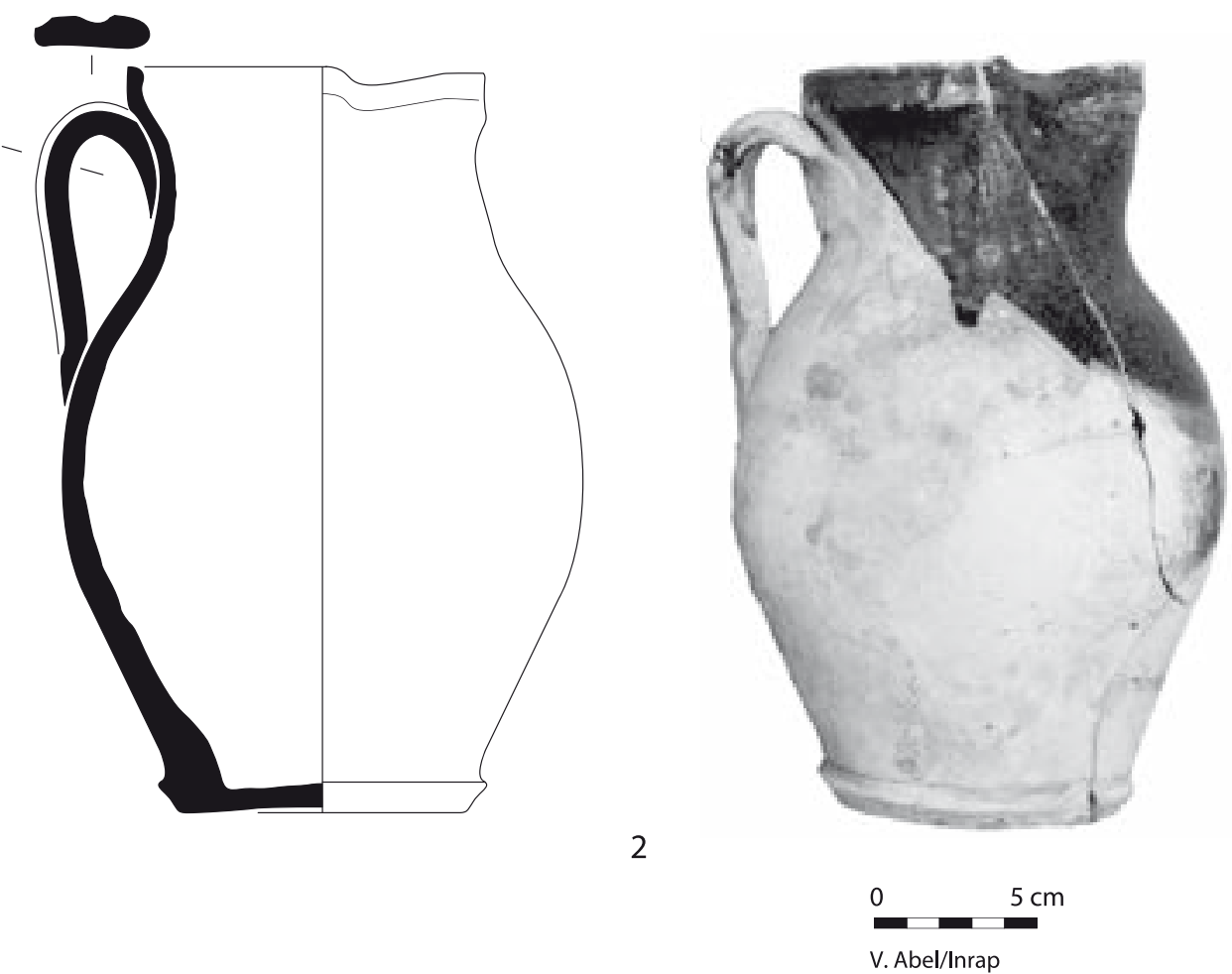

Fig. 113. Terres vernissées de type Fréjus (milieu du XVII ${ }^{e}$ s.). Pavillon Bargemon. 


$$
2
$$



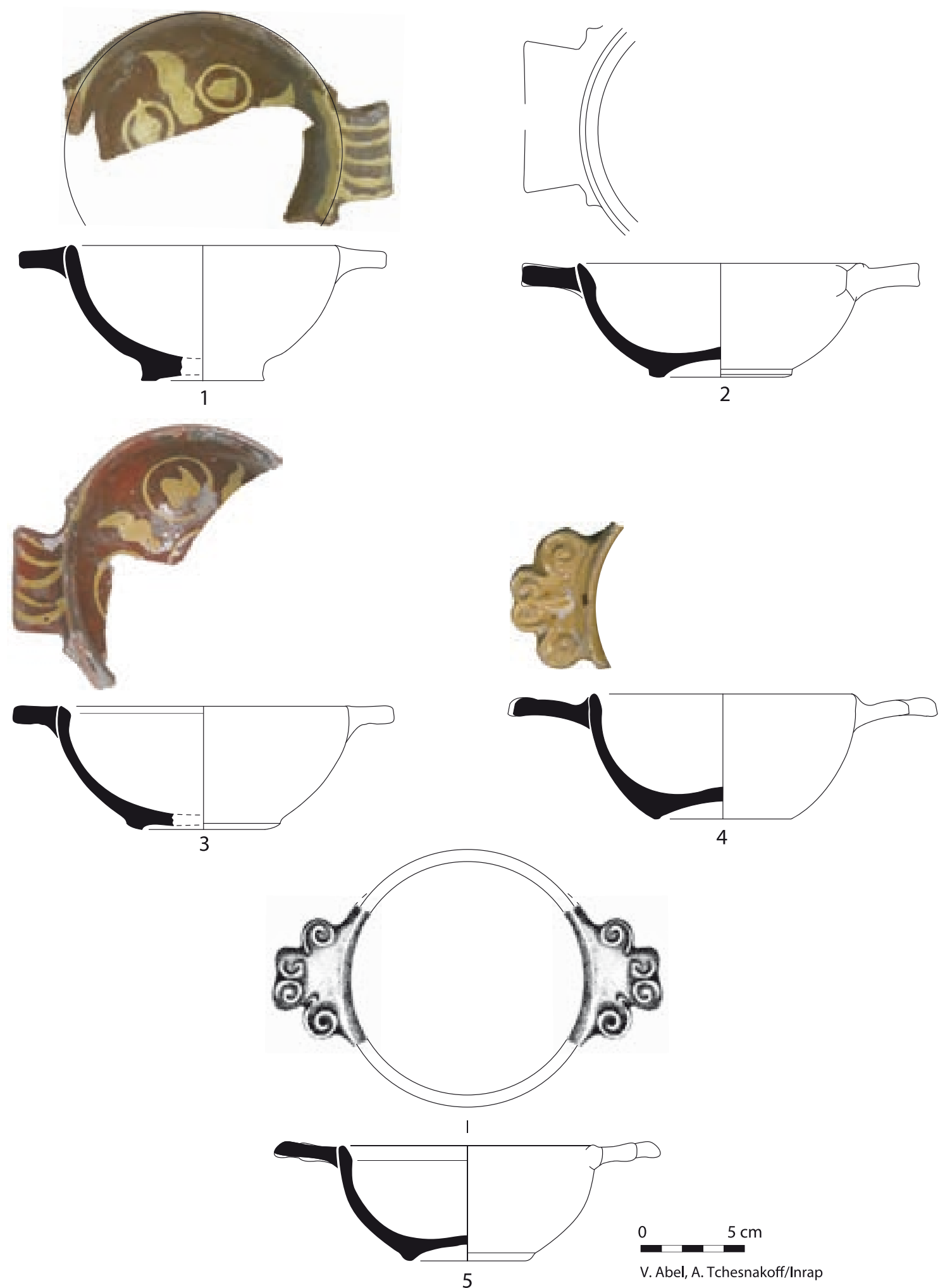

Fig. 115. Terres vernissées de l'arrière-pays marseillais (vallée de l'Huveaune) - écuelles (milieu du XVII s.). 1 : Pavillon Bargemon ; 2-4 : place des Pistoles ; 5 : la Bourse. 

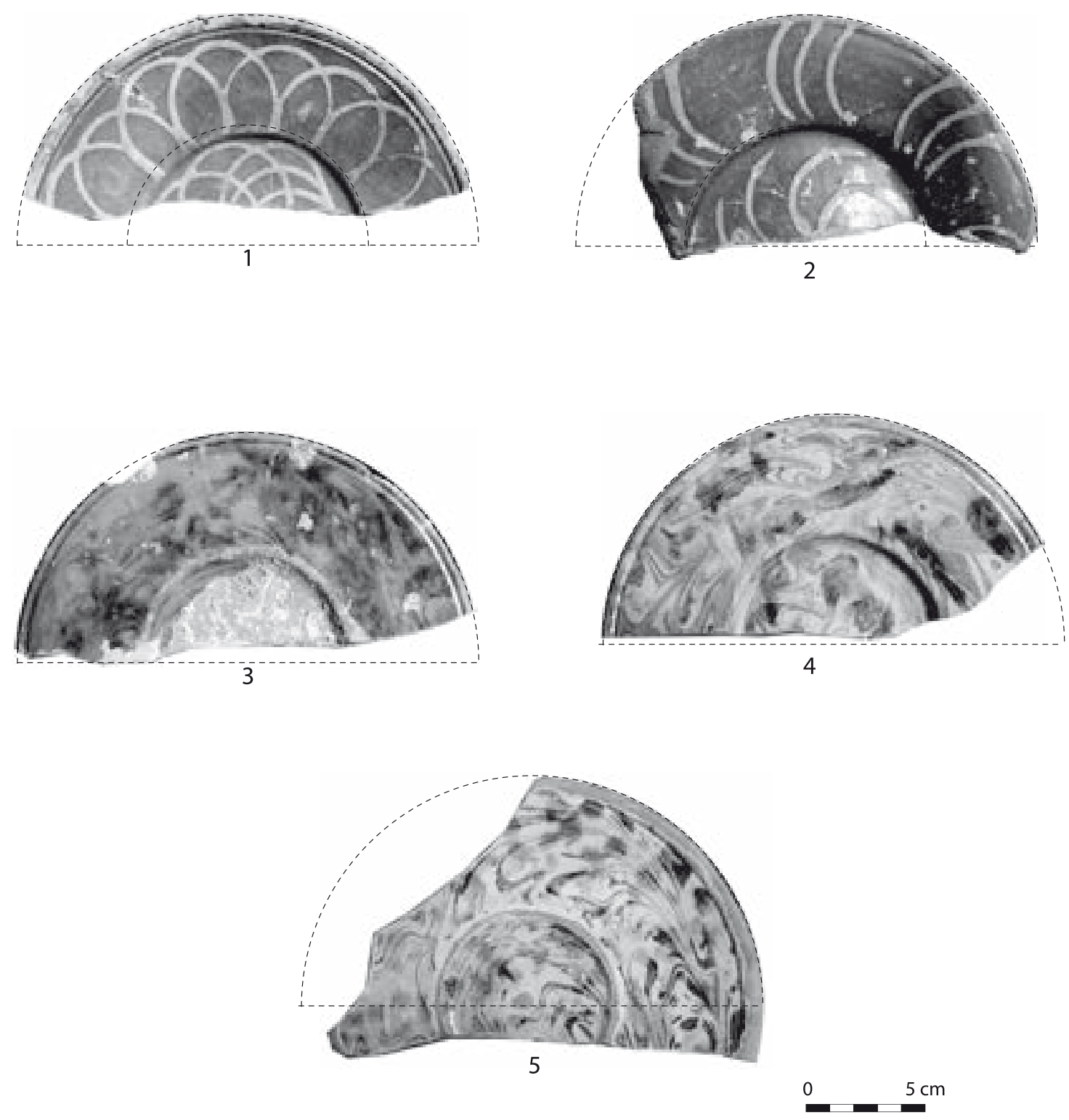

V. Abel/Inrap

Fig. 116. Terres vernissées de l'arrière-pays marseillais (vallée de l'Huveaune) - assiettes (milieu du XVIIe s.). Les Catalans (fouille sous-marine Luc Long, 2005). 

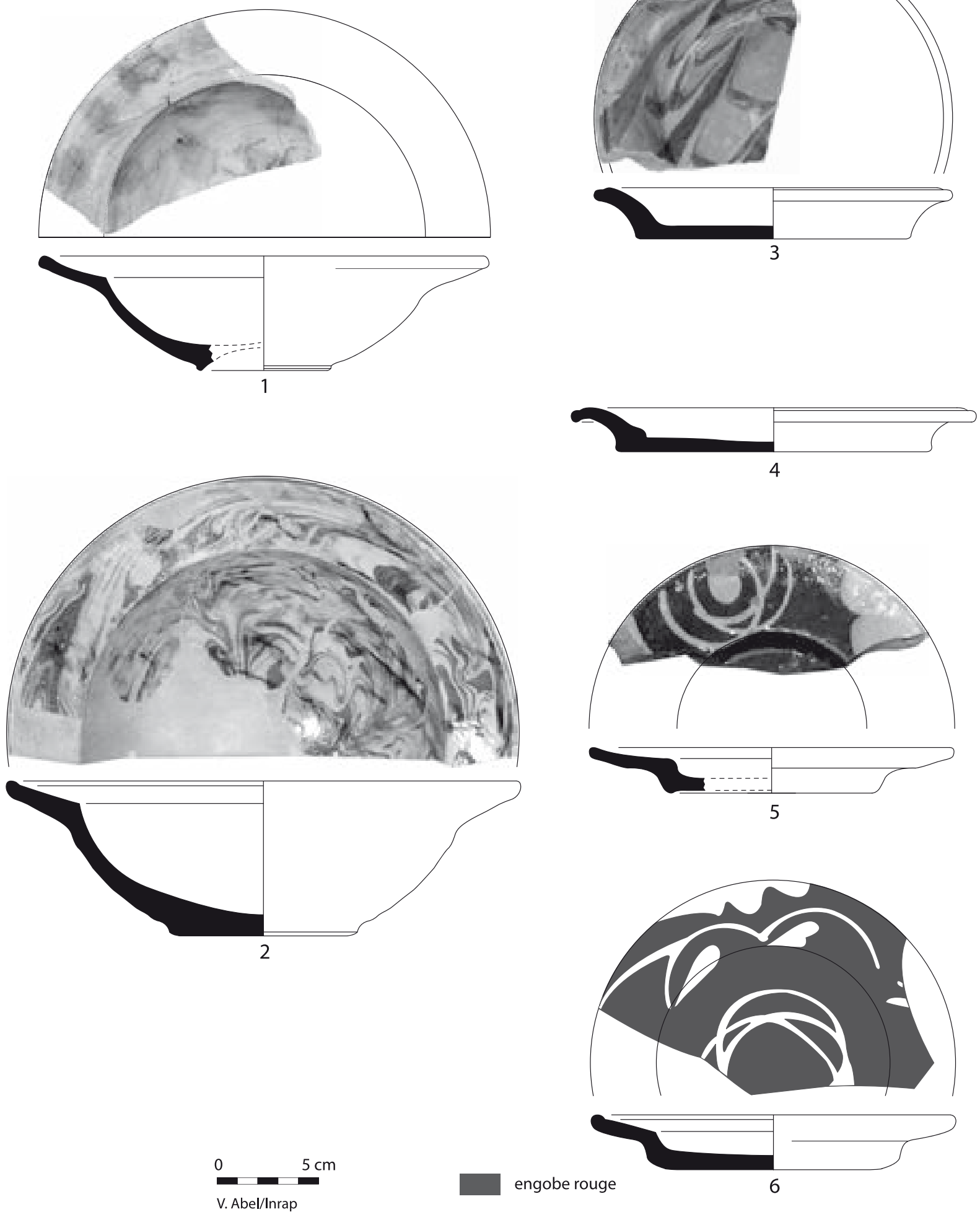
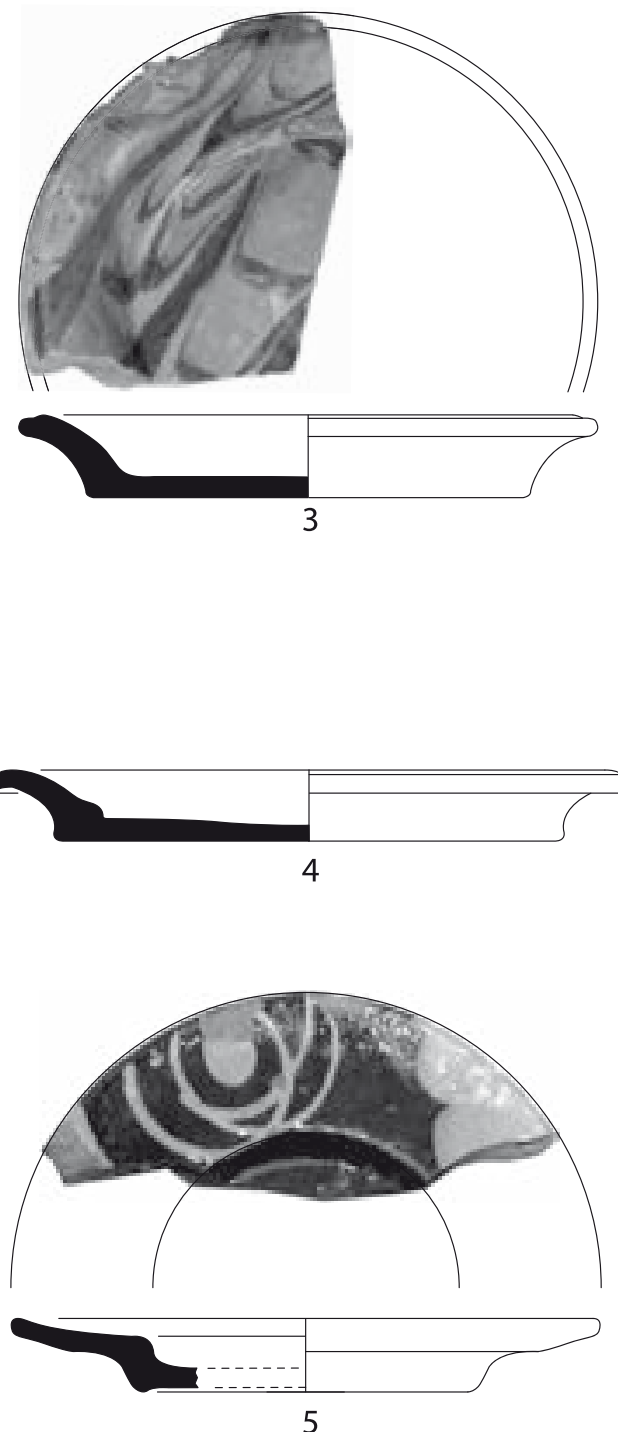

5
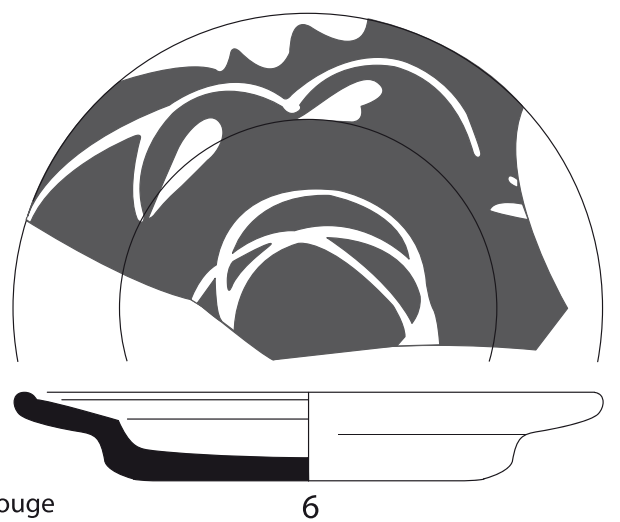

Fig. 117. Terres vernissées de l'arrière-pays marseillais (vallée de l'Huveaune) - assiettes et plats (milieu du XVII $s$.$) .$ 1-2, 5-6 : place des Pistoles ; 3-4 : Pavillon Bargemon. 


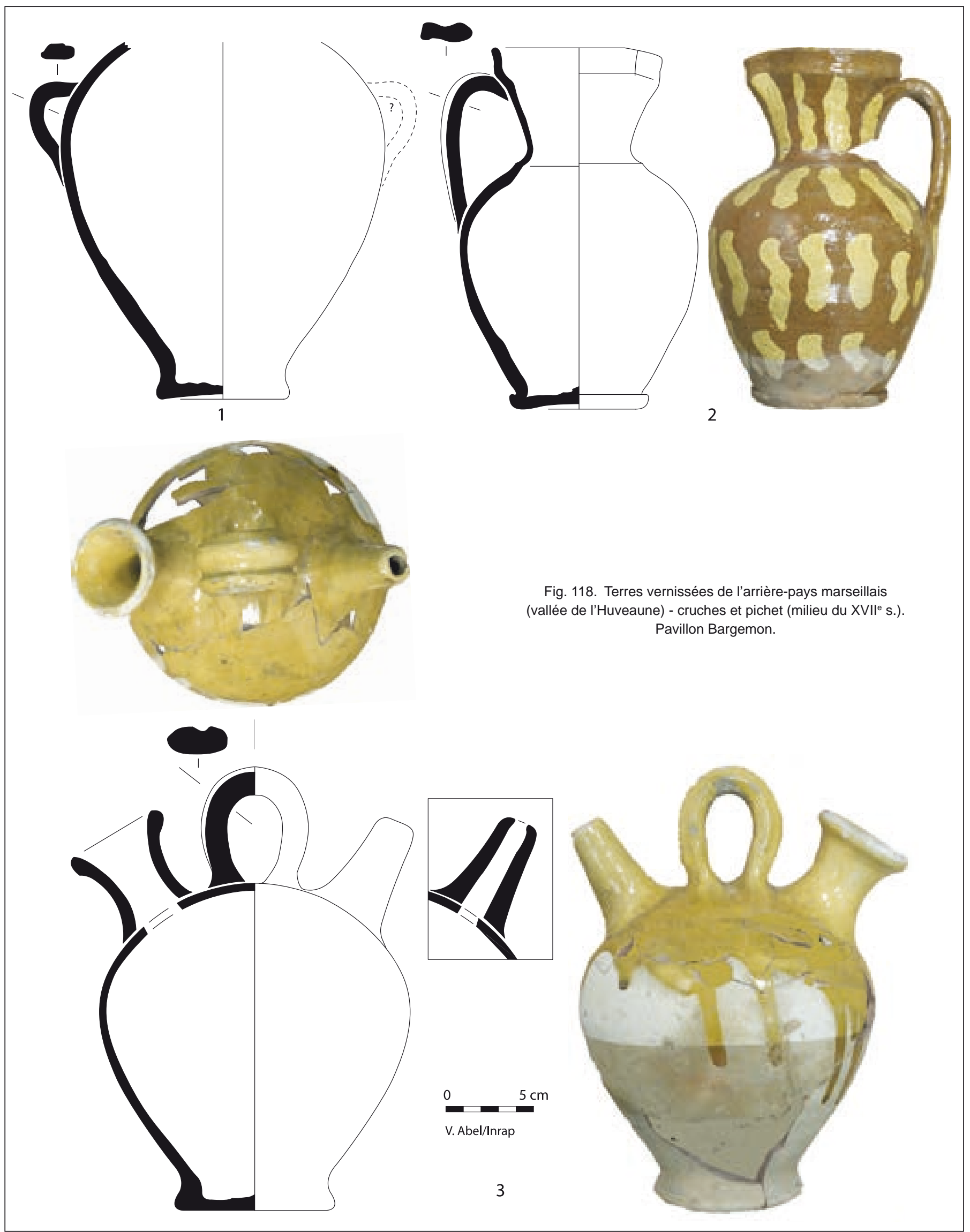




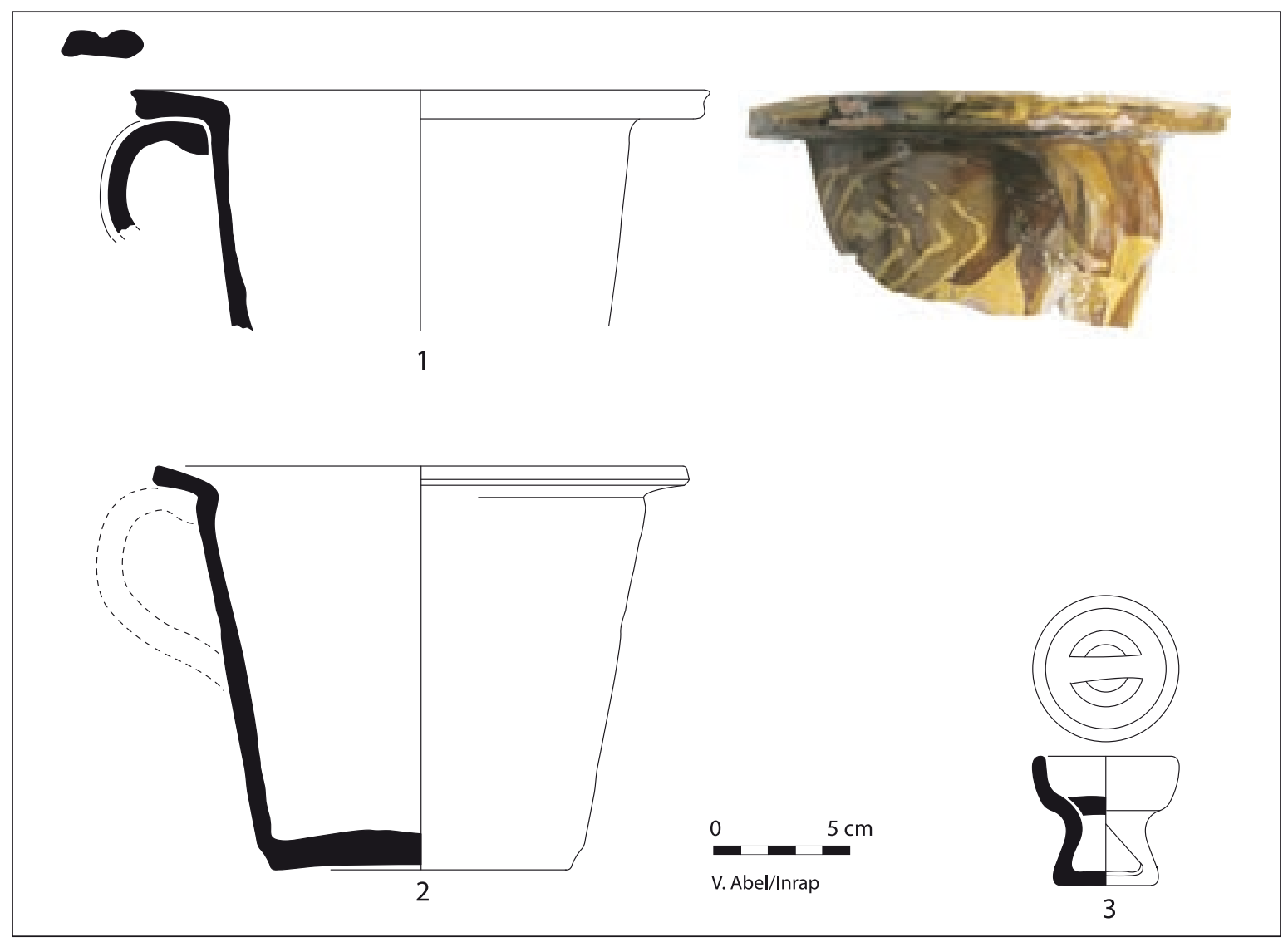

Fig. 119. Terres vernissées de l'arrière-pays marseillais (vallée de l'Huveaune) - pots de chambre et taraïette (milieu du XVIIe $\mathrm{s}$.). Place des Pistoles.

\subsection{Les marmites noires}

Il faut souligner pour ce milieu de XVII ${ }^{\mathrm{e}}$ s. les éléments particulièrement intéressants que constituent les marmites uniformément noires, de différentes tailles (fig. 120, $\mathbf{n}^{\circ}$ 1-3), dont la production n'est toutefois pas encore localisée. Ces objets, déjà mentionnés pour le second $\mathrm{XVI}^{\mathrm{e}} \mathrm{s}$., sont ici encore présents, récurrents et bien dans leur contexte d'utilisation, et ils attestent un maintien ou une résurgence inattendue d'une technique de cuisson des céramiques que l'on pensait abandonnée dès le $\mathrm{XIV}^{\mathrm{e}} \mathrm{s}$. : la post-cuisson réductrice. L'utilisation d'un four à flamme nue autorise, à la fin de la cuisson, l'enfumage des vases qui prennent une couleur noirâtre caractéristique en s'imprégnant de carbone, élément qui leur donne une couleur noire contrastant avec la vaisselle de table de la même période, et les imperméabiliserait à la place d'un vernis (Picon 1973), cette opération économisant matériaux, temps et combustible. Cette technique est « archaïsante » dans le sens où les potiers ont réutilisé d'anciens procédés, mais elle pourrait dénoter une certaine recherche d'artisans qui, à une époque où la cuisson oxydante est la seule utilisée, maîtrisent la post-cuisson réductrice et produisent des poteries aux formes nouvelles (marmites nettement globulaires, de taille moyenne et sans col vertical). Ceux-ci ne semblent pas négligés par la clientèle puisqu' on les rencontre, en nombre limité mais de manière constante dans le $\mathrm{XVII}^{\mathrm{e}} \mathrm{s}$. et sur une large aire géographique. Leur forme moderne n'est pas sans rappeler les poteries culinaires de Vallauris dont les marmites font une entrée remarquée dans les foyers marseillais, alors que les poteries réfractaires de Saint-Quentin (Gard) sont tout simplement absentes ici et à ce moment.

Ce contexte de référence combine originalité, variété et homogénéité. Originalité, car il est le premier à se placer dans le deuxième quart du XVII ${ }^{\mathrm{e}} \mathrm{s}$. Variété, car tous les types de céramiques y sont représentés, des luxueuses faïences aux simples pots à cuire, en passant par la vaisselle intermédiaire vernissée, elle même déclinée en plusieurs catégories. Homogénéité chronologique, qui ne peut être décelée qu'en perspective avec les situations précédente et suivante. On constate ainsi que ce lot est plus récent que les très rares ensembles marseillais du $\mathrm{XVI}^{\mathrm{e}}$ s. et un peu plus ancien que ceux de Saint-Victor 


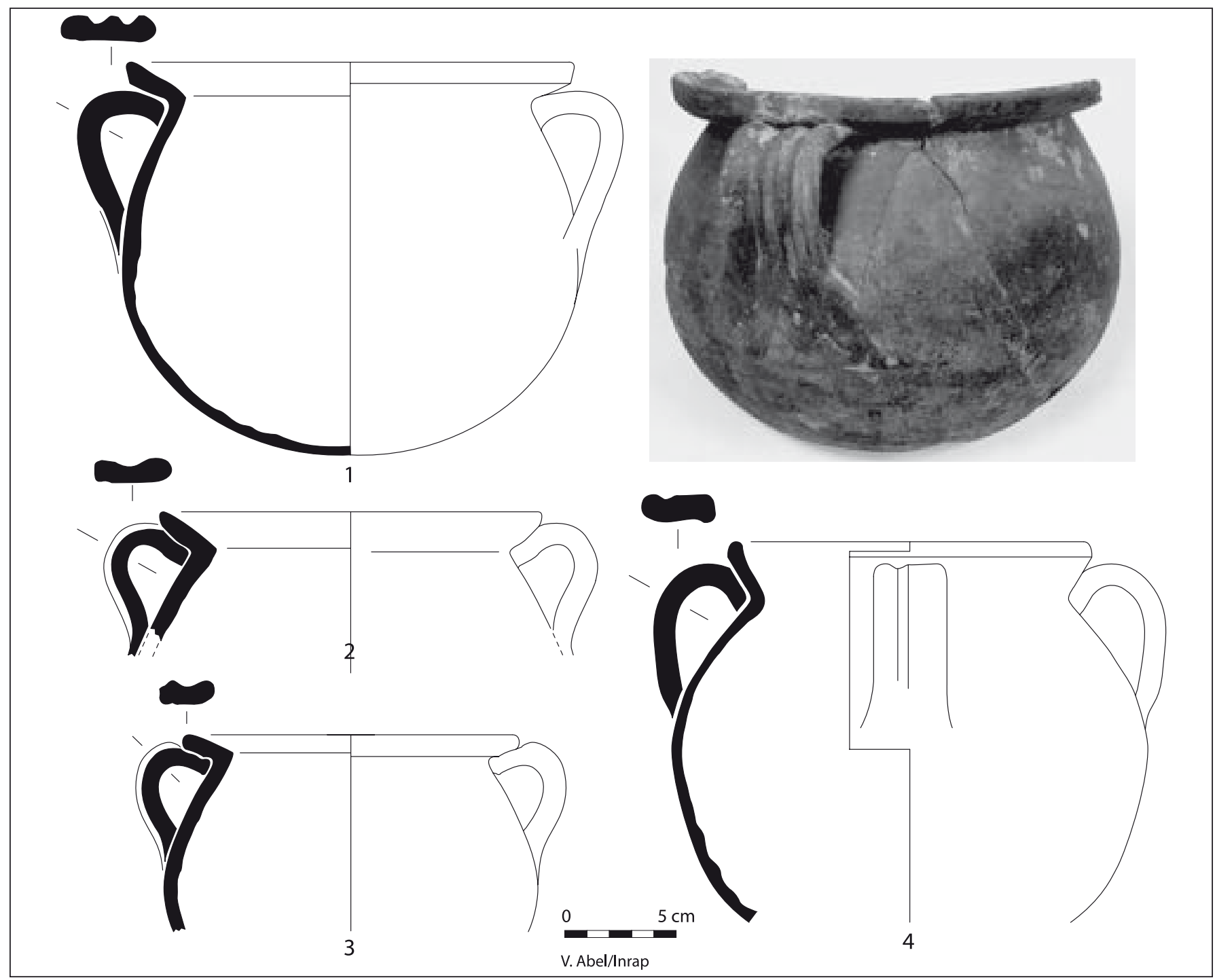

\begin{tabular}{|l|c|c|c|c|}
\hline \multicolumn{1}{|c|}{ Catégories } & Fragments & $\%$ & NMI & $\%$ \\
\hline Faïence de Ligurie & 4 & 4,5 & 1 & 5,6 \\
\hline Faïence de Montelupo & 1 & 1,4 & 1 & 5,6 \\
\hline Faïence de Valence & 0 & $/$ & $/$ & $/$ \\
\hline Terre vernissée de Pise & 2 & 2,7 & 2 & 11 \\
\hline Terre vernissée de Manosque & 2 & 2,7 & 1 & 5,6 \\
\hline Terre vernissée de Type Fréjus & 25 & 34 & 5 & 28 \\
\hline Terre vernissée de Biot & 0 & $/$ & $/$ & $/$ \\
\hline Terre vernissée de l'arrière-pays marseillais & 12 & 16 & 2 & 11 \\
\hline Culinaire de Ligurie & 1 & 1,4 & 1 & 5,6 \\
\hline Culinaire de Vallauris & 11 & 15 & 1 & 5,6 \\
\hline Culinaire noire (post-cuisson réd.) & 10 & 14 & 3 & 16 \\
\hline Culinaire rouge & 5 & 7 & 1 & 5,6 \\
\hline Réfractaire de type Uzège & 0 & $/$ & $/$ & $/$ \\
\hline Total & 73 & & 18 & \\
\hline Fragments en dépôt secondaire & 25 & 25 & & \\
\hline
\end{tabular}

Fig. 120. Marmites noires ( $\left.n^{\circ} 1-3\right)$ et marmite vernissée $\left(n^{\circ} 4\right)$ (milieu du XVII $\mathrm{S}$.). Pavillon Bargemon.
Tableau III : le contexte de la fouille « Espace Bargemon » (unité stratigraphique 5319). 
ou de la rue des Pistoles que nous entamerons ci-dessous et où la place des poteries de la vallée de l'Huveaune sera nettement plus affirmée.

\section{Le contexte « place Villeneuve-Bargemon »}

Dans le comblement d'une fosse (unité stratigraphique 5319) de la place Villeneuve-Bargemon, les trois quarts de la petite centaine de fragments sont en contexte (tableau III). Malgré cette masse limitée, ce mobilier est caractéristique des années 1640-1650. Cette couche recelait d'une part du mobilier pouvant être rattaché à la première partie du XVII ${ }^{\mathrm{e}} \mathrm{s}$. et d'autre part deux objets de la vallée de l'Huveaune dont la production démarre peu avant le milieu du siècle. La très forte fragmentation du mobilier de ce comblement a certainement occulté une bonne partie des informations qu'un lot de cette date pourrait apporter. On peut cependant remarquer d'originales associations de formes et de provenance, ainsi que des objets non identifiés parmi les céramiques culinaires ou des groupes identifiés sans origine déterminée.

\subsection{Les faïences et les terres vernissées}

L'un des deux objets de la vallée de l'Huveaune est une cruche du milieu du XVII ${ }^{\mathrm{e}} \mathrm{s}$. dont il ne reste que le bec et un départ de décor caractéristique d'engobe blanc sur fond d'engobe rouge (inv. 52.02.10687). Le second est une écuelle à engobe blanc représentée par son oreille (inv. 52.02.10688).

Les céramiques classiques de Fréjus restent présentes avec deux écuelles (inv. 52.02.10680 et 10682), un plat (inv. 52.02.10681), un pot de chambre (inv. 52.02.10679) et un vase à liquide (inv. 52.02.10683). L'aile du pot de chambre est plus longue que dans les exemplaires antérieurs : elle mesure $4 \mathrm{~cm}$, du marli au bord.

Les terres vernissées de Pise restent elles aussi dans l'ambiance de la période précédente. Deux fonds vernissés de Pise à paroi très épaisse pour les fragments conservés, correspondent sans doute à de grandes pièces, l'une décorée $a$ stecca classique sous vernis jaune-miel (inv. 52.02.10667), l'autre à incision de type «a girandola» sous vernis vert (inv. 52.02.10666). En l'état des connaissances, ces objets ne fournissent pas de datation très précise, les décors dits a girandola étant généralement datés du début du XVII ${ }^{\mathrm{e}} \mathrm{s}$.

Le seul fragment de faïence de Montelupo (inv. 52.02.10665) est décoré sur les deux faces, l'extérieur étant animé d'un remplissage de filets, hachures, volutes en bleu, jaune, orange, noir, l'intérieur figurant des feuilles bicolores bleues et blanches, jaune et orange.
Ce tesson rappelle le décor 59 «foglia con frutta policroma» de F. Berti (Berti 1998) daté du premier tiers du XVII ${ }^{\mathrm{e}} \mathrm{s}$.

L'unique fragment de faïence de Ligurie de ce comblement est mal conservé (inv. 52.02.10664), son émail a presque totalement disparu. Il se rapproche du type à palmettes dans une variante à croisillons. Aucune terre vernissée ne provient de cette région de la Ligurie, la seule céramique culinaire n'est pas vraiment identifiable, alors qu'un bord sans canal de marmite de Vallauris signe l'apparition de cette catégorie céramique réfractaire, appelée à se développer rapidement.

\subsection{Les marmites noires}

Trois bords différents de marmites noires démontrent l'importance de cette catégorie particulière de céramiques de cuisine dans la première moitié du XVII $\mathrm{s}$. (inv. 52.02.10674 à 10676). L'aspect de ces céramiques, dénuées de tout revêtement et remarquablement noires, peut étonner dans un contexte du XVII ${ }^{\mathrm{e}} \mathrm{s}$. Il est dû à la technique de post-cuisson réductrice que nous avons évoquée ci-dessus : vers la fin de la cuisson, le potier a volontairement enfumé l'atmosphère du four. La tranche de tessons laisse voir, outre de très nombreux éléments non plastiques de gravier roulé, régulièrement répartis mais de toutes tailles allant jusqu'à $5 \mathrm{~mm}$ de côté, une pâte brun-rouge. Une zone de couleur rougeâtre au cœur de la tranche dénote donc une atmosphère de cuisson oxydante pouvant indiquer une bonne maîtrise de l'opération, qui se termine par une obstruction des ouvertures du four, un enfumage volontaire à l'aide de combustibles spécifiques étant envisageable.

Les fragments présents laissent percevoir toujours une forme unique : sur une panse globulaire, absente ici, est aménagé un col étranglé et un bord en amande sous lequel sont attachées des anses tournées à simple ou double canal. Cette forme est très nettement une forme de marmite moderne, dépourvue du haut col des marmites de tradition médiévale. L'origine géographique de ces marmites pourtant si caractéristiques n'est pour l'instant pas déterminée avec certitude alors que nous avons pu les mettre en évidence dès 1988 sur le site de la Bourse dans un contexte de «large $\mathrm{XVI}^{\mathrm{e}}$ s. ». Une carte de répartition des sites consommateurs indiquerait certainement une origine régionale côtière.

\subsection{Des écuelles à oreille}

Dans un cas comparable à celui des marmites noires (très bien identifiables, présentes sur une durée 

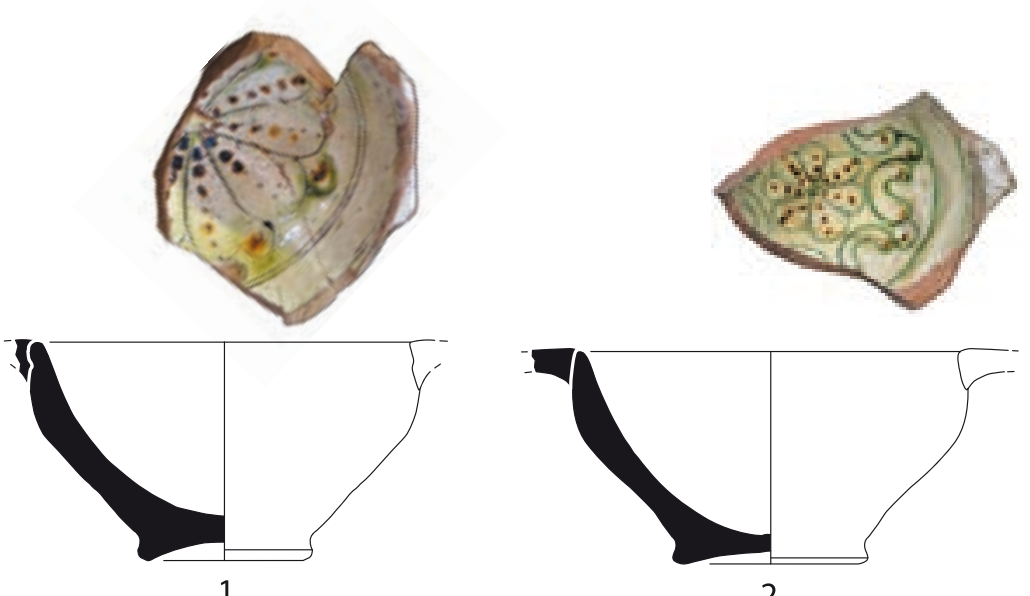

2
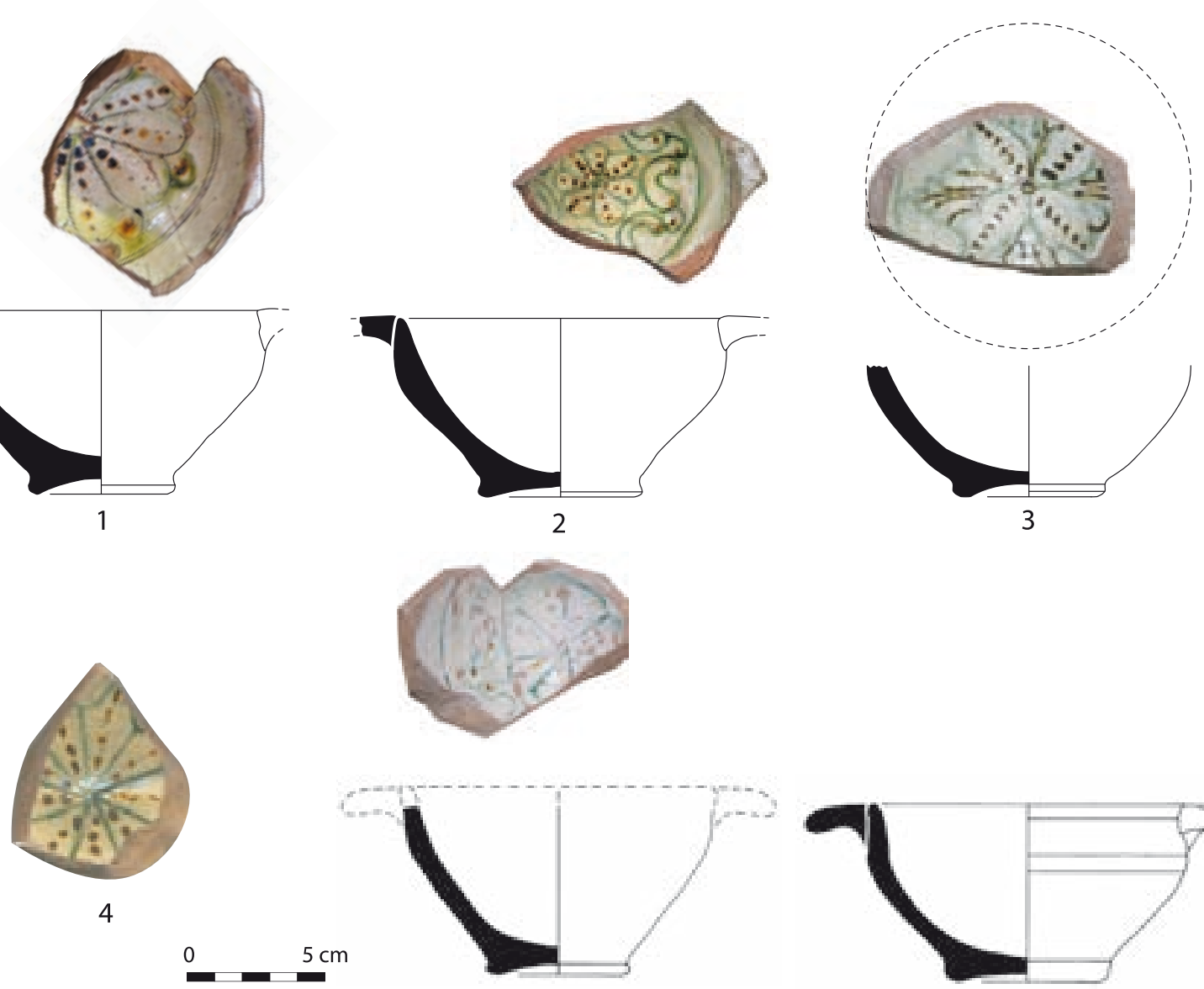

V. Abel, J. Isnard/Inrap

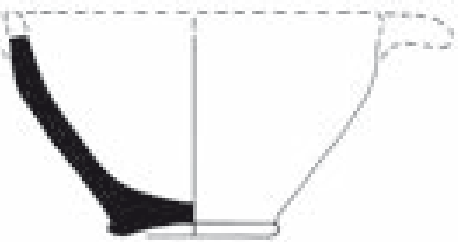

5

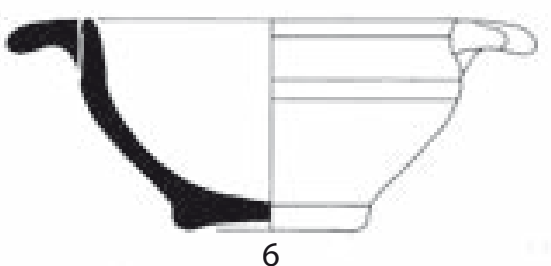

Fig. 121. Terres vernissées attribuées à la Haute-Provence (milieu du XVII es.). 1-2, 4 : place Bargemon ; 3 : place des Pistoles ; 5 : la Charité ; 6 : Saint-Victor.

\begin{tabular}{|l|c|c|c|}
\hline \multicolumn{1}{|c|}{ Catégories } & Fragments & $\%$ & \\
\hline Faïence de Ligurie & 11 & 1 & Pas de NMI \\
\hline Faïence de Montelupo & 15 & 1,2 & \\
\hline Faïence de Valence & 6 & 0,5 & \\
\hline Terre vernissée de Pise & 88 & 7 & \\
\hline Terre vernissée de Manosque & 8 & 0,7 & \\
\hline Terre vernissée de Type Fréjus & 224 & 18 & \\
\hline Terre vernissée de Biot & 3 & 0,25 & \\
\hline Terre vernissée de l'arrière-pays marseillais & 346 & 28 & \\
\hline Culinaire de Ligurie & 40 & 3 & \\
\hline Culinaire de Vallauris & 388 & 32 & \\
\hline Culinaire noire (post-cuisson réd.) & 21 & 2 & \\
\hline Culinaire rouge & 70 & 6 & \\
\hline Réfractaire de type Uzège & 0 & $/$ & \\
\hline Pipes & $0 ?$ & & \\
\hline Total & $\mathbf{1 2 2 0}$ & & \\
\hline
\end{tabular}

Tableau IV : le contexte de la place des Pistoles (unité stratigraphique 294). 
relativement courte et cependant d'origine toujours hypothétique) se trouve un groupe de terres vernissées incisées polychromes dont un exemplaire figure dans le mobilier de l'unité stratigraphique 5319 (fig. 121, ${ }^{\circ} \mathbf{4}$ ). D'autres exemplaires du même groupe céramique sont issus de la place Villeneuve-Bargemon (fig. 121, $\mathbf{n}^{\circ} \mathbf{1 - 2}$ ). Une seule forme, l'écuelle à oreilles, est recensée dans le mobilier actuellement connu à Marseille. La pâte de ces objets est rose clair, dure et bien qu'homogène, elle contient de nombreux éléments non plastiques visibles à l'œil. L'origine géographique de ces écuelles demeure incertaine, bien que quelques hypothèses soient nées de recensements rapides et de récentes découvertes dans les Alpes-de-Haute-Provence ${ }^{12}$. Sur un pied dégagé plutôt étroit, et très légèrement concave, se développe une paroi dont la courbe interne est continue alors qu'à l'extérieur une carène se forme dans le tiers supérieur. La lèvre est soulignée à l'extérieur par un sillon horizontal pratiqué à quelques millimètres du bord lors du tournage. Une oreille est conservée dans une autre unité stratigraphique, elle n'est pas moulée mais découpée pour former trois pointes.

Très soigneusement et entièrement revêtues d'engobe blanc, ces écuelles sont décorées d'incisions en face interne, dans la zone centrale et en bandeau dans le tiers supérieur. Les oreilles et la face externe ne sont pas décorées sur les exemplaires actuellement connus. Les incisions, peu profondes et très régulières, privilégient les lignes courbes et sinueuses organisées en motifs rayonnants et ne sont pas figuratives. Les deux formes complètes de Bargemon (fig. 121, $\mathbf{n}^{\circ} \mathbf{1 - 2}$ ) laissent voir deux décors différents mais sur ce même principe, avec un bandeau non décoré au tiers supérieur. En revanche le bord encore pourvu d'une oreille montre un bandeau à remplissage d'incisions en forme de $\mathrm{S}$ (inv. 52.02.10525). Des rehauts aux oxydes colorants, fer et cuivre en l'occurrence, sont ensuite posés en traits et petites taches régulièrement réparties. Ces écuelles ne se rencontrent que vers le milieu et le troisième quart du XVII ${ }^{\mathrm{e}} \mathrm{s}$. dans l'état actuel de nos minces connaissances à leur sujet. Des réserves doivent être émises car le mobilier du premier quart du XVII ${ }^{\mathrm{e}}$ s. est presque inexistant à Marseille.

\section{Le contexte « Place des Pistoles »}

L'ensemble de céramiques a été recueilli par L.-F. Gantès et Manuel Moliner de l'Équipe archéologique municipale en 1987 sur le chantier de la place des

12 Opération archéologique de Manosque-Observantins, par Catherine Barra/Inrap.
Pistoles, situé devant la Charité dans le quartier du Panier. Il est constitué de plus d'un millier de fragments issus de plusieurs dizaines d'objets dont le décompte n'a pas pu être opéré précisément pour l'instant, une partie du mobilier étant en dépôt au Musée d'histoire de Marseille (tableau IV).

Cet ensemble a été identifié comme lot de référence depuis son exhumation en 1987, daté du milieu du $\mathrm{XVII}^{\mathrm{e}}$ s. à la fois par la céramique et par cinq doublestournois frappés entre 1620 et 1639. Il a été montré au public lors de l'exposition «Itinéraire d'une mémoire » (Abel 1990). Le travail de céramologie ayant précédé notre intervention de 2010, réalisé à la fin des années 1980 par l'Équipe archéologique municipale, avait consisté en la reconstitution de quelques objets dans l'objectif de les exposer. Depuis lors, une partie des objets se trouve en dépôt au Musée d'histoire de Marseille, certains d'entre eux exposés au public. La part la plus importante du lot est conservée au dépôt archéologique municipal. Cette scission a généré quelques difficultés, conjuguées au récent projet de rénovation du Musée d'histoire de Marseille pour 2013, impliquant un vaste programme muséographique (en cours au moment de la rédaction de cet ouvrage).

Des incisées polychromes pisanes, sont déjà présentes (fig. 111, $\mathbf{n}^{\circ} \mathbf{1}$ ), mais on remarque encore la fin des céramiques a stecca, qui semblent être conservées longtemps, précieuses et/ou à fond solide et souvent retaillés.

Des terres vernissées de type Manosque, sont en contexte et acquièrent donc un nouveau point d'ancrage chronologique (fig. 121, $\mathbf{n}^{\circ}$ 3) ${ }^{13}$.

Parmi les fabrications locales, celles de l'arrière-pays marseillais, aucun décor incisé rehaussé de polychromie n'est recensé. Cette technique décorative devient extrêmement populaire dans les années 1670 ; cette absence est donc considérée comme un indice chronologique. Sont en revanche au goût du jour les décors d'engobe clair sur fond d'engobe rouge (fig. 115, $n^{\circ} 2-4$ et fig. 117, n 5-6). Ces décors sont posés en série à l'aide d'outils adaptés tels que des cylindres formant des cercles, ou des cylindres déformés réalisant des navettes. Ces décors d'engobe, presque exclusivement en blanc sur rouge, devenant jaune sur marron, existent en deux autres versions : un fond de cruche en négatif, et un fragment de panse de cruche revêtue de vernis vert, très détériorée. Autres vases, les pots de chambre (fig. 119, $\left.\mathbf{n}^{\circ} \mathbf{1 - 2}\right)$ et les cruches qui reçoivent des décors semblables.

Un seul pichet a été recensé (engobes jaspés). Quelques petits tians (fig. 114, $\mathbf{n}^{\circ}$ 2), plat creux à bord replié (fig. 117, $\mathbf{n}^{\circ} \mathbf{1 - 2}$ ), sont utilisés (à décor d’engobe,

13 En dépôt dans les réserves du Musée d'histoire. 
à engobe blanc et taches de vernis vert, ou engobes jaspés), de même que des assiettes plates à aile, ou des plats à aile même si ceux-ci sont plus rares. Se rencontrent encore dans ce contexte les écuelles à oreilles carrées découpées mais déjà des oreilles moulées à volutes en relief, la plupart des exemplaires restant monochromes. Une seule marmite noire est recensée et peut-être un couvercle peut-il lui être associé. Les vases culinaires de Vallauris sont bien plus présents que dans le contexte du Pavillon Bargemon. Le travail de céramologie devra être poursuivi sur ce contexte de référence homogène et fourni qui se placerait postérieurement mais peu après le contexte du Pavillon Bargemon.

\section{Conclusion sur la céramique du milieu du XVII ${ }^{\mathrm{e}} \mathrm{s}$.}

Ces trois contextes de référence, répartis chacun sur une chronologie située autour de 1650 fournissent des informations largement convergentes. Les catégories de céramiques alors en usage à Marseille ne sont pas encore fixées de manière si tranchée qu'à la fin du siècle. On utilise encore des vernissées communes de plusieurs origines (Fréjus, Haute-Provence supposée, arrièrepays marseillais). Les marmites noires conservent leurs adeptes. Les vernissées de milieu de gamme comportent encore des monochromes (stecca). Les faïences ne sont qu'abondamment décorées et l'émail blanc ignoré.

Les formes semblent annoncer la période suivante. Les écuelles et les assiettes sont bien caractérisées (massives pour les premières, petites pour les secondes. Cruches, pichets, pots de chambre ont quasiment trouvé leur forme type pour une longue période.

La présence de céramiques attribuables de manière hypothétique à la Haute-Provence dans les contextes marseillais de cette date précise, absentes auparavant, complètement disparues par la suite, procure à celles-ci un ancrage chronologique plus que crédible. 


\section{Chapitre 7}

\section{La céramique d'usage quotidien à Marseille de 1660 à 1710 : la créativité exceptionnelle des ateliers de l'arrière-pays marseillais}

$\mathrm{I}$ I faut, d'emblée et nécessairement, identifier ces années 1660 à 1710 . Le critère retenu pour circonscrire cette période est la présence de vaisselle vernissée à décor incisé et polychrome provenant de la vallée de l'Huveaune dans l'arrière-pays marseillais. Une description rapide de ce marqueur chronologique peut être faite : sur un vase dont l'argile est rouge orangé, les potiers passent une couche d'engobe blanc qu'ils incisent de traits fins faisant réapparaître la couleur de la pâte et qu'ils rehaussent de taches rouges et vertes issues respectivement d'engobe rouge chargé en fer et d'une préparation à base d'oxyde de cuivre.

Si les débuts de cette production de la vallée de l'Huveaune sont encore mal connus car les mobiliers archéologiques marseillais de la première moitié du $\mathrm{XVII}^{\mathrm{e}} \mathrm{s}$. sont rares et le milieu du XVII ${ }^{\mathrm{e}}$ s. reste encore un peu flou, la période autour des années 1670 est plus riche d'enseignements céramologiques. L'ensemble de la Charité notamment a fourni vers 1983 (L.-F. Gantès) des informations pionnières ayant permis la détermination (par nos soins dans un cadre universitaire, sous la direction de $\mathbf{M}^{\text {lle }}$ Démians d'Archimbaud) de cette production. Il faut le souligner ici car nous n'y reviendrons plus, aucune structure de fabrication antérieure au $\mathrm{XIX}^{\mathrm{e}} \mathrm{s}$. n'a été trouvée dans la vallée de l'Huveaune. Ce n'est donc que par le mobilier des sites de consommation, et en premier lieu celui de Marseille, que ces produits sont connus. Les premiers ensembles ont été complétés avantageusement par les lots de la Bourse issus des fouilles de 1967 à 1984 et ils ont permis l'établissement d'une typologie et d'une « cartographie » des approvisionnements extérieurs utilisées pour les chantiers postérieurs : ce n'est souvent, dans le cas de courtes séries notamment, que grâce à ces études antérieures que le mobilier de cette période peut être daté, compris et analysé.

L'apport du chantier de l'Alcazar (M. Bouiron) à la connaissance des ateliers de l'arrière-pays marseillais est resté limité. Quelques pièces et certaines associations sont intéressantes, leur apport est davantage perçu grâce aux travaux précédents que par leur valeur propre. Pour la période étudiée ici, les niveaux de l'Espace Bargemon (P. Mellinand) ne sont pas très nombreux, mais 176 objets dont 28 formes archéologiquement complètes en ont été extraits (avec toutefois $45 \%$ de tessons résiduels sur 1182 fragments, ce qui en limite clairement l'intérêt).

Quant au Tunnel de la Major (O. Maufras) aucun mobilier n'est utilisable pour la période traitée (8 unités stratigraphiques totalisant à peine 18 fragments).

L'absence, sur ces deux grands chantiers marseillais, de périodes relativement bien représentées par ailleurs, prouve s'il en était besoin que le hasard des découvertes préside à nos modestes recherches, influe sur notre perception et crée des hiatus qu'il faut se garder de combler artificiellement en tirant les datations. Sur la place Villeneuve-Bargemon, le chantier César 1 n'a pas fourni de mobilier utilisable pour cette période. Le mobilier du chantier César 2 n'a pas été étudié lors des temps de post-fouille, aucun moyen n'ayant été consacré à cette céramique, de même que celui de la place Jules-Verne. Compte tenu du volume total de ces deux collections, il n'était pas envisageable de l'explorer pour cette synthèse.

Les chantiers plus récents (collège Vieux-Port, opérations de la rue de la République, opérations du fort Saint-Jean, ZAC de la Bourse, etc.) n'offrent pas de nouvelles données pour la céramologie de la seconde moitié du XVII ${ }^{e} s$. Des objets particulièrement significatifs, caractéristiques ou insolites, pourront cependant être cités ponctuellement.

Les vases fabriqués dans cet arrière-pays, entre 10 et $30 \mathrm{~km}$ à l'est de la ville de Marseille, sont considérés pour la cité marseillaise comme des productions locales, d'usage commun, façonnés et utilisés sans délai. Certaines formes et quelques types de revêtements et de décors ont démontré qu'ils étaient des indices particulièrement pertinents, dont la fiabilité est encore renforcée en croisant les deux informations de forme et de décor. Le décor incisé et polychrome, dans ses aspects les plus soignés en particulier, est intensément diffusé pendant cette période se situant entre les années 1660 et les années 1710 environ. Les céramiques ainsi décorées sont extrêmement répandues dans une période relativement courte, de quelques dizaines d'années vraisemblablement, correspondant sans doute à quelques générations d'artisans tout au plus. 
Cette vaisselle vernissée constitue au minimum la moitié des objets et des fragments significatifs de la seconde moitié du XVII ${ }^{\mathrm{e}} \mathrm{s}$. issus des chantiers marseillais, parfois davantage allant jusqu'aux deux tiers ou aux trois quarts du mobilier. Elle ne sait assurer tous les besoins : elle est façonnée en terre non réfractaire, on ne peut l'utiliser au feu ; sa présence sur les tables modestes signe son statut de vaisselle commune. Il reste quelque place sur le marché des céramiques pour les faïences tant que les provençaux ne les produisent pas (après les années 1680), pour les vases à cuire et les pipes, devant être tournés dans des argiles réfractaires, et pour quelques terres vernissées proches de celles de l'arrière-pays marseillais qui parviennent à s'infiltrer ça et là.

\section{Les importations au long cours : Orient et Europe du Nord}

Les pièces les plus rares se retrouvant dans les intérieurs marseillais pendant les périodes qui nous préoccupent ici sont évidemment celles ayant voyagé au long cours. Les provenances lointaines sont finalement peu nombreuses sur toute la période moderne. Elles sont diverses, et sauf une exception, relativement anecdotiques dans le sens où elles ne sont pas de véritables approvisionnements en marchandises à l'échelle de la cité mais plutôt des choix personnels de quelques habitants fortunés ou aventureux.

\subsection{L'Orient}

Les céramiques de provenance la plus lointaine seraient, dit-on, celles qui proviennent de Chine, mais aucun tesson de ce type n'est recensé dans la période en question à l'exception d'un bord de bol à décor de lustre métallique interne et revêtement bleu extérieur ${ }^{14}$.

Un fragment isolé de l'Alcazar (fig. 122, $\mathbf{n}^{\circ} \mathbf{1}$ ) est issu d'un vase ayant été fabriqué en Turquie. Il s'agit d'une anse de section ronde appartenant à un vase fermé, animée de filets noirs longitudinaux encadrant des traits transversaux. Il est d'une taille regrettablement réduite. Son état de conservation est, comme souvent dans le cas de ces céramiques à pâte siliceuse synthétique, assez mauvais. Malgré ces réserves d'interprétation, nous avancerons l'hypothèse d'un fragment de pichet ou d'aiguière produit à Iznik dans le $\mathrm{XVI}^{\mathrm{e}} \mathrm{s}$. Ces types de vases sont en effet très richement et très diversement

14 La Bourse D IV 13, inv. 30830, fig. 1498. décorés sur leurs panses (nuages, style aux quatre fleurs, etc.) mais sont affublés d'anses extrêmement stéréotypées dont le système décoratif du fragment de l'Alcazar se rapproche étroitement (Atasoy, Raby 1990, p. 271, 296...).

\subsection{L'Europe du Nord}

Les contrées d'Europe du Nord sont aussi très peu représentées sur la période strictement Moderne : nulle vaisselle n'en parvient. La Hollande fournit deux produits très différents et très contrastés, les carreaux de Delft et les pipes blanches hollandaises. Les carreaux de Delft sont très prisés aux XVII et $\mathrm{XVIII}^{\mathrm{e}} \mathrm{s}$. en Europe, mais ils resteront inconnus ici jusqu' au XVIII ${ }^{\mathrm{e}} \mathrm{s}$. pour ce qu'en laisse voir le mobilier archéologique marseillais.

À l'opposé de cette production de revêtements muraux, on trouve celle des pipes, qui se classe bien évidemment parmi les céramiques. Les pipes en terre blanche d'Europe du Nord sont assez emblématiques d'une période allant approximativement à Marseille de la deuxième moitié du XVII ${ }^{\mathrm{e}} \mathrm{s}$. à la fin du XVIII ${ }^{\mathrm{e}} \mathrm{s}$. Leur production débute en Angleterre à la fin du $\mathrm{XVI}^{\mathrm{e}} \mathrm{s}$. et se poursuit de manière importante en Hollande (Raphaël 1991). Les fragments de pipes sont au nombre de 89 sur l'ensemble du chantier de l'Alcazar, soit environ 1,7\% de l'ensemble des fragments en contexte. Parmi ceuxci, figure un seul talon marqué d'un oiseau. Un seul fourneau est décoré, alors qu'une autre pipe porte un monogramme fragmentaire dans un médaillon en relief face au fumeur. Un fourneau d'une pipe de Bargemon (inv. 52.02.11616) est marqué sur son talon du monogramme «EB» assez répandu dans les productions hollandaises ${ }^{15}$.

L'inventaire des céramiques de provenance septentrionale est relativement rapide à faire sur la période concernée. Cette faible présence interroge. La voie terrestre était moins évidente que la voie maritime qui est certainement celle qui a été empruntée pour l'importation de pipes. Si la quantité de celles-ci, bien que faible, n'est pas négligeable, elle est sans doute due à l'absence de production proche qui oblige à des importations lointaines. La voie que les pipes ouvraient n'a pas facilité par exemple l'importation des carreaux hollandais. La qualité et certainement le coût de ceux-ci ne ciblait évidemment pas le même public. Les vaisselles d'autres zones européennes sont totalement absentes de Marseille pour l'image qu'en donne l'archéologie.

15 Nous ne détaillons pas plus cette production particulière et renvoyons, dans cet ouvrage, à la participation de Peter Davey. 


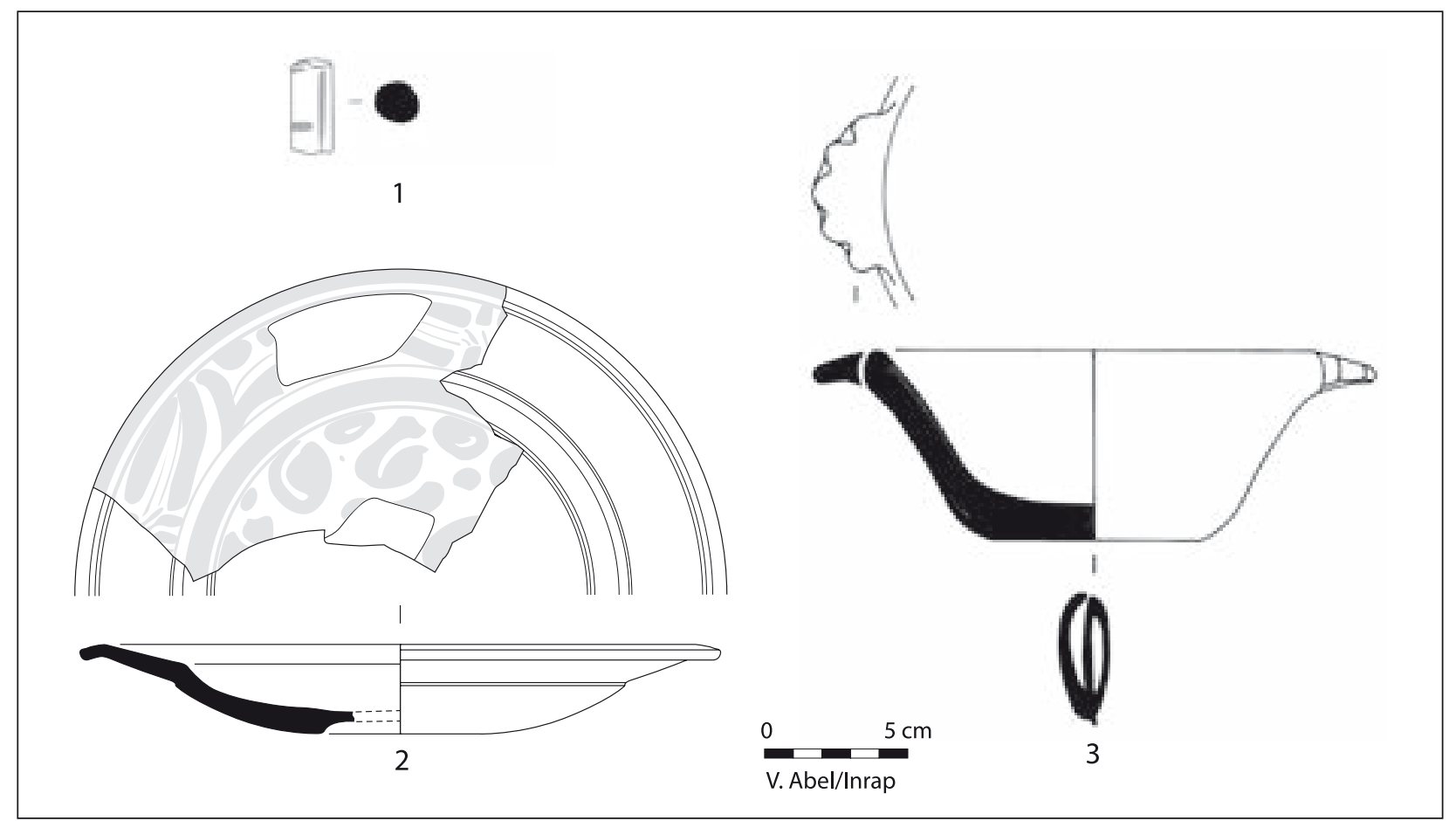

Fig. 122. Céramique d’Iznik ( ${ }^{\circ} 1$ ) et céramiques d'Espagne (n`2-3) (fin du XVII s.). 1-2 : Alcazar ; 3 : la Bourse.

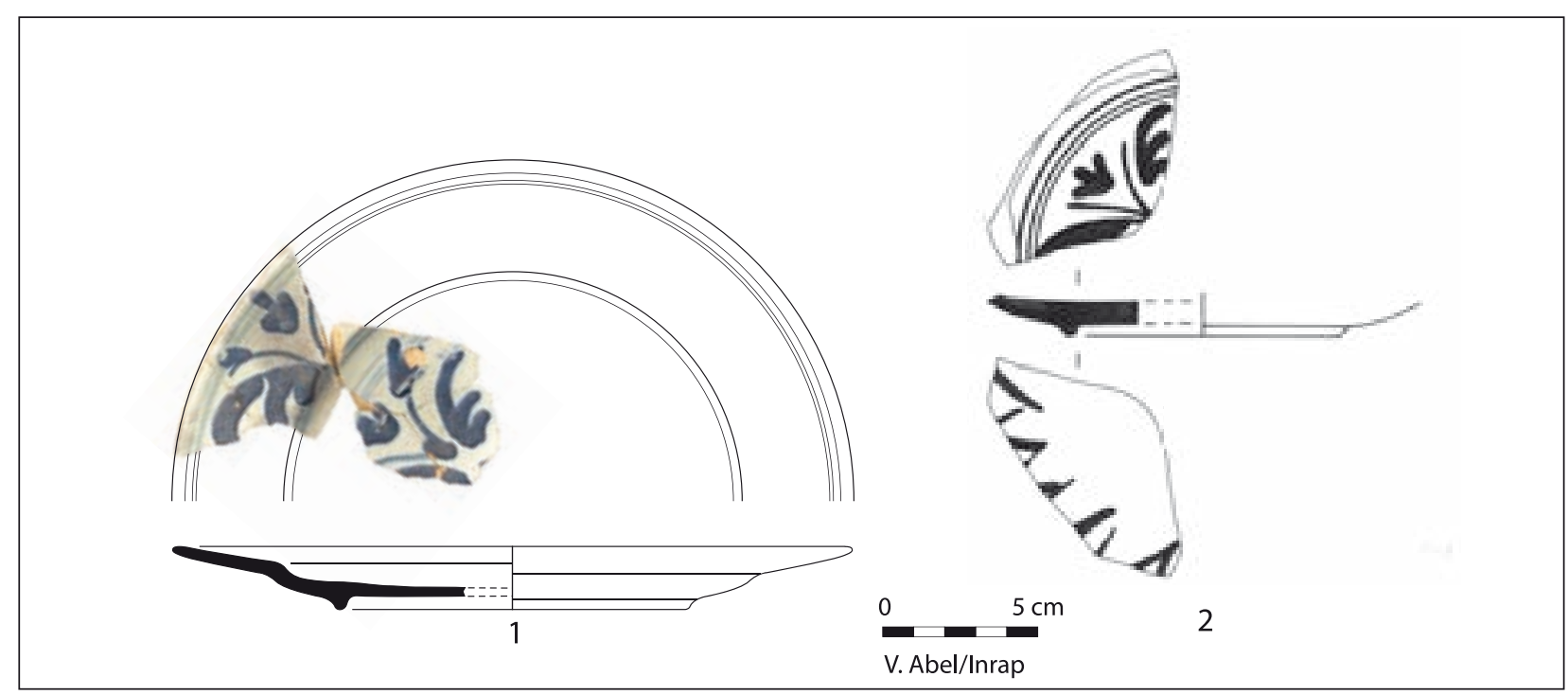

Fig. 123. Faïence de Ligurie (fin du XVII $\mathrm{s}$.). 1 : Alcazar ; 2 : la Bourse.

\section{Les importations des pays voisins : Espagne et Italie}

L'hétérogénéité des importations marseillaises se remarque pour des origines moins lointaines. Même du sud de l'Europe, certaines provenances sont préférées au détriment d'autres. Ainsi l'Espagne est toujours assez négligée.

\subsection{L'Espagne}

Une assiette de faïence à décor de lustre seul (fig. 122, $\mathbf{n}^{\circ} 2$ ) a été recueillie dans un contexte du troisième quart du XVII ${ }^{\mathrm{e}}$ s. Cette assiette se trouvait en compagnie d'une seconde assiette, de plus petite taille, de profil différent, dont le décor était entièrement effacé (inv. 24.99.1710). Cette forme à aile est caractéristique de la production moderne. Le décor est constitué de volutes dans le 
bassin et de traits larges et épais sur l'aile. L'état de conservation de l'objet ne permet pas d'interpréter avec certitude ce décor (figuratif ou purement ornemental ?). Cette assiette pourrait dater du début du XVII ${ }^{e}$ s. et avoir été utilisée, davantage en tant qu'élément de décor et de prestige que comme vaisselle jusque dans la période qui est traitée ici.

L'Italie en revanche, guère plus proche que l'Espagne, est représentée, sans commune mesure. Se sont en réalité plusieurs provinces italiennes qui sont ainsi totalisées, les plus généreuses (ou celles avec lesquelles les Marseillais se sont montrés les plus généreux) étant la Ligurie et la Toscane. Les produits en sont variés puisqu'ils vont de la faïence à la poterie culinaire pour la première, de la faïence à la terre vernissée pour la seconde.

\subsection{La question de la Ligurie et de l'ancien type « génois »}

Les faïences ligures étaient jusqu'il y a peu considérées depuis la Provence comme diverses, étonnamment diverses : certaines pouvaient être richement décorées (fig. 123, $\mathbf{n}^{\circ}$ 1-2) d'autres au contraire se rapprocher par leur facture de la céramique commune. Les faïences ligures du $\mathrm{XVI}^{\mathrm{e}} \mathrm{s}$. étaient rares à Marseille. Elles semblaient simplement s'affirmer davantage sur le marché marseillais pendant le XVII ${ }^{\mathrm{e}} \mathrm{s}$.

Longtemps ces faïences sans décor, aux parois plutôt épaisses et aux formes simplissimes reçurent dans nos travaux, à l'imitation de certains de nos formateurs, une identification «ligure ». Il était parfois des cas, comme dans le mobilier d'une séquence stratigraphique du début du XVIII ${ }^{e}$ s. du chantier de la Source du Pré à La Ciotat (P. Mellinand) où la discrimination de tessons à revêtement blanc sans décor entre les origines « ligure » et toscane relevait du casse-tête et finissait en migraine.

Ce n'est que récemment, et grâce au travail de synthèse requis pour cet ouvrage que l'historiographie précise de cette attribution a été reprise. Plusieurs indices troublants sont alors relevés. Les publications italiennes relativement récentes ne mentionnent pas cette production, bien reconnaissable, dans les études de faïences de Ligurie. L'absence n'apportant cependant pas de preuve dans un sens quelconque, remontons le fil de l'histoire pour voir comment s'est forgée cette « certitude ». C'est dans une publication, datant des balbutiements de la céramologie «post medievale » et résumant les premiers travaux de notre éminent collègue Marco Milanese, qu'apparaît un plat à paroi épaisse légendé «maiolica italiana» (Milanese 1976, p. 280-281, 300, tav. III, fig. 39). Ce terme vague fut certainement choisi avec soin par l'auteur et contraste avec la précision d'autres attributions, qui se sont par la suite avérées, à la Ligurie de céramiques de la même étude.

Dix ans plus tard, des chercheurs provençaux utilisent cette référence pourtant explicite dans son imprécision afin d'identifier comme ligure une série d'assiettes blanches retrouvées sur un site artisanal varois du XVIII ${ }^{\mathrm{e}} \mathrm{s}$. (Foy et al. 1986, p. 143, 145 fig. 10-1 à 4). Prenons un indulgent raccourci, ouvrons l'ouvrage de Fausto Berti qui présente des vases ouverts de Montelupo non décorés : ce sont, à s'y méprendre, des «assiettes de Gênes » provençales (Berti 1998, p. 405406). La perplexité est le minimum que l'on puisse alors ressentir.

Que faire désormais, après cette remise en question? Tout d'abord garder à l'esprit qu'il ne s'agit que d'une question, parvenue tardivement à la conscience embrumée d'une céramologue iconoclaste, trop tardivement hélas pour user d'archéométrie. Ensuite constater que la faïence ne dépasse jamais quelques unités pour cent d'un mobilier céramique urbain domestique. Les batailles entre provenances, si passionnantes qu'elles soient à l'intérieur d'une catégorie céramique, deviennent presque dérisoires à l'échelle d'un quotidien des Temps modernes, celui que nous tentons de comprendre.

Voici qu'un tas de récipients au rebut, que s'arrachaient des affamés à l'intérieur d'une véritable prison, permet aujourd'hui de dire que dès le dernier quart du $\mathrm{XVII}^{\mathrm{e}} \mathrm{s}$. les faïences que nous disions jadis génoises et sans doute plutôt toscanes font leur première apparition, sous la forme de quelques vases d'un blanc immaculé, contrastant parmi de nombreux autres aux couleurs voyantes qui les datent et les font comprendre. Les deux objets de La Charité sont remarquables de clarté si l'on choisit notre interprétation «toscane»: si tant est que l'on puisse interpréter des typologies, il suffit de comparer celle des vases ouverts de Pise et celle des assiettes blanches. Les tailles sont les mêmes, les formes identiques, les pieds et bases tournassés. Seules les parois sont plus fortes, la terre claire de la vallée de l'Arno restant crayeuse après cuisson, tout à l'inverse de la terre rouge dure et sonore utilisée pour les céramiques vernissées qui leur sont contemporaines (cf. infra § 2.3.).

Ces faïences italiennes sont presque les seules céramiques de luxe présentes sur la fouille de l'Espace Bargemon, et parmi celles-ci, la Ligurie a une place de choix (7 à $8 \%$ du mobilier). Elles sont, avant l'apparition de la faïence régionale dans le courant de cette période, à peu de chose près les seules faïences connues. Le dépotoir de la place Villeneuve-Bargemon offre ce type luxueux et un autre fort différent: trois autres assiettes et plats représentent le type ligure décoré. Les deux plats ont un bord déversé et un fond dégagé en 


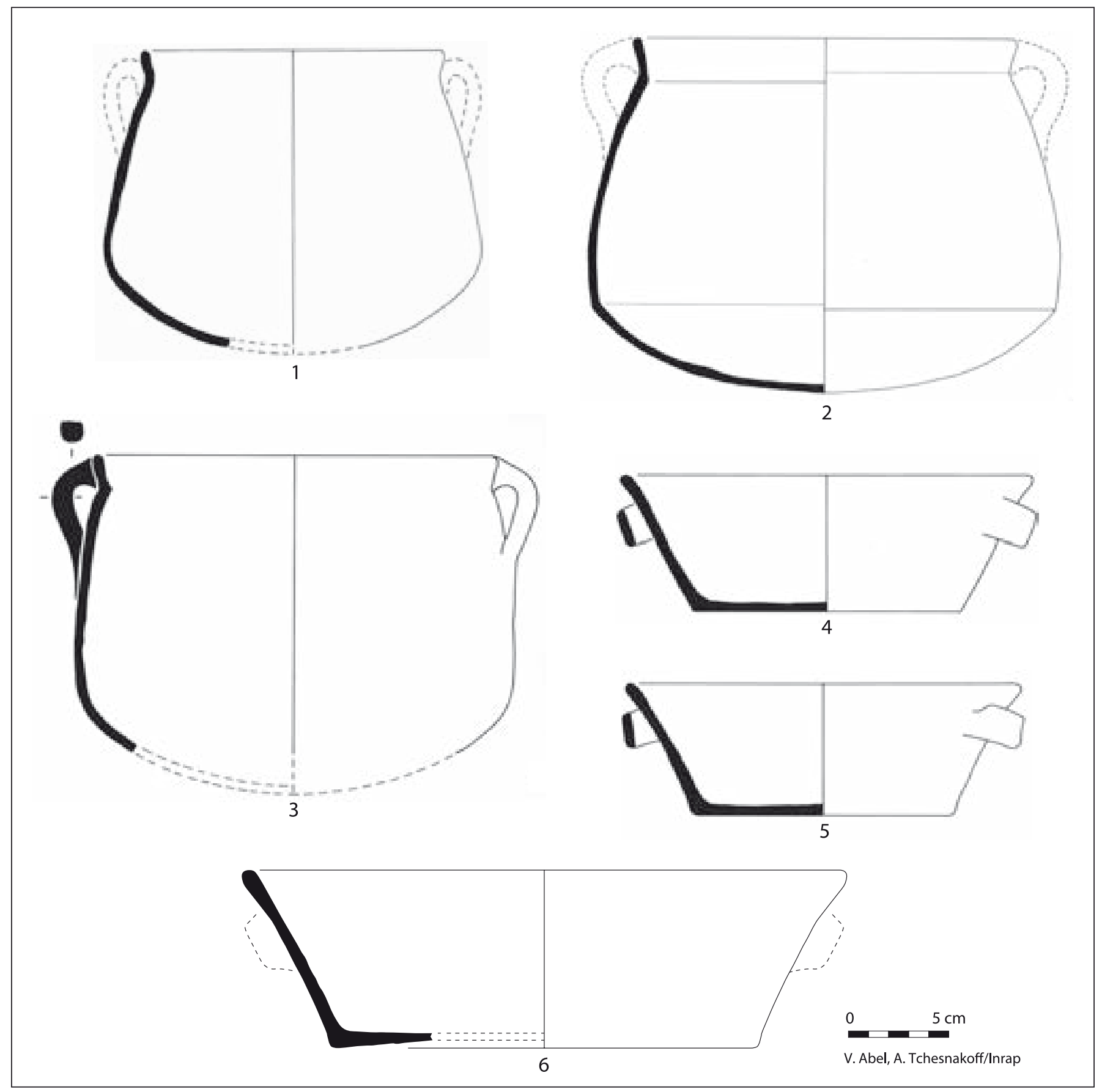

Fig. 124. Céramiques culinaires de Ligurie. 1, 3-5 : la Bourse ; 2 : fort Saint-Jean ; 6 : la Charité.

anneau (inv. 52.02.11506, paroi absente, et 11507); il faut y adjoindre une aile d'assiette (inv. 52.02.11508). Les décors sont différents d'un vase à l'autre, mais restent dans le même esprit: palmettes, croisillons et grandes ferronneries.

La vaisselle vernissée de cette région de Ligurie parvenait à Marseille au $\mathrm{XVI}^{\mathrm{e}} \mathrm{s}$. ; elle est déjà absente du mobilier marseillais de la seconde moitié du XVII ${ }^{\mathrm{s}} \mathrm{s}$. pour ce qui peut en être identifié.
Une autre catégorie intéressante par sa masse en provenance de Ligurie est constituée par les poteries réfractaires qui, si elles sont restées d'une remarquable discrétion sur le site de l'Alcazar tout comme à l'Espace Bargemon, sont bien présentes dans la cour de la Charité, à la Bourse (fig. 124, $\mathbf{n}^{\circ} \mathbf{1 - 3}$ ). Parmi les vases culinaires de Bargemon, dont la relative rareté $(13 \%)$ demeure inexpliquée à travers ce dépotoir, nous trouvons trois marmites de Ligurie de forme courante, très 


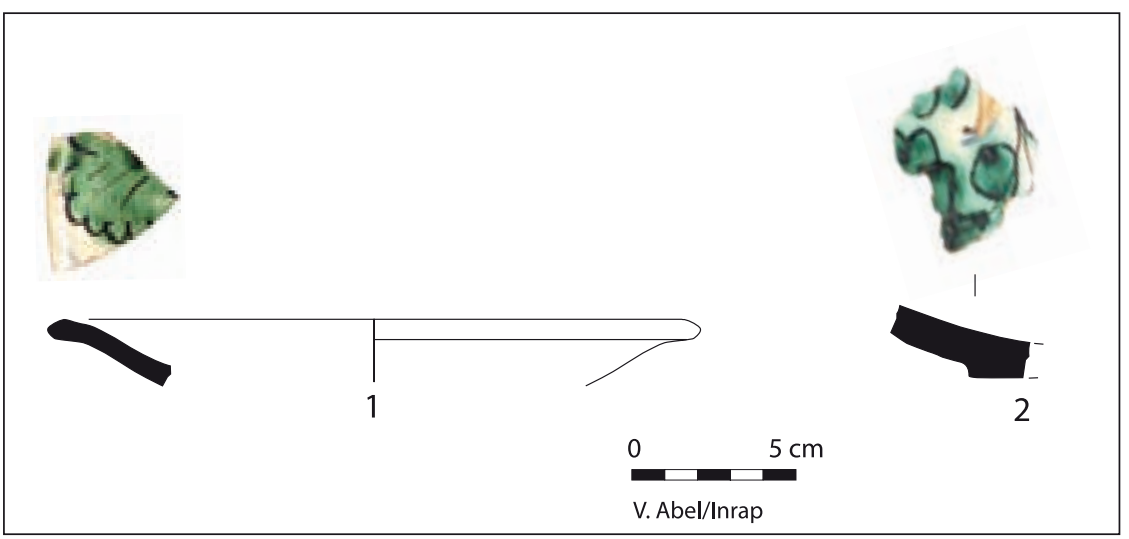

Fig. 125. Assiettes de Montelupo : faïence à décor de feuilles de chêne - assiettes (fin du XVII $\mathrm{s}$.). Alcazar.

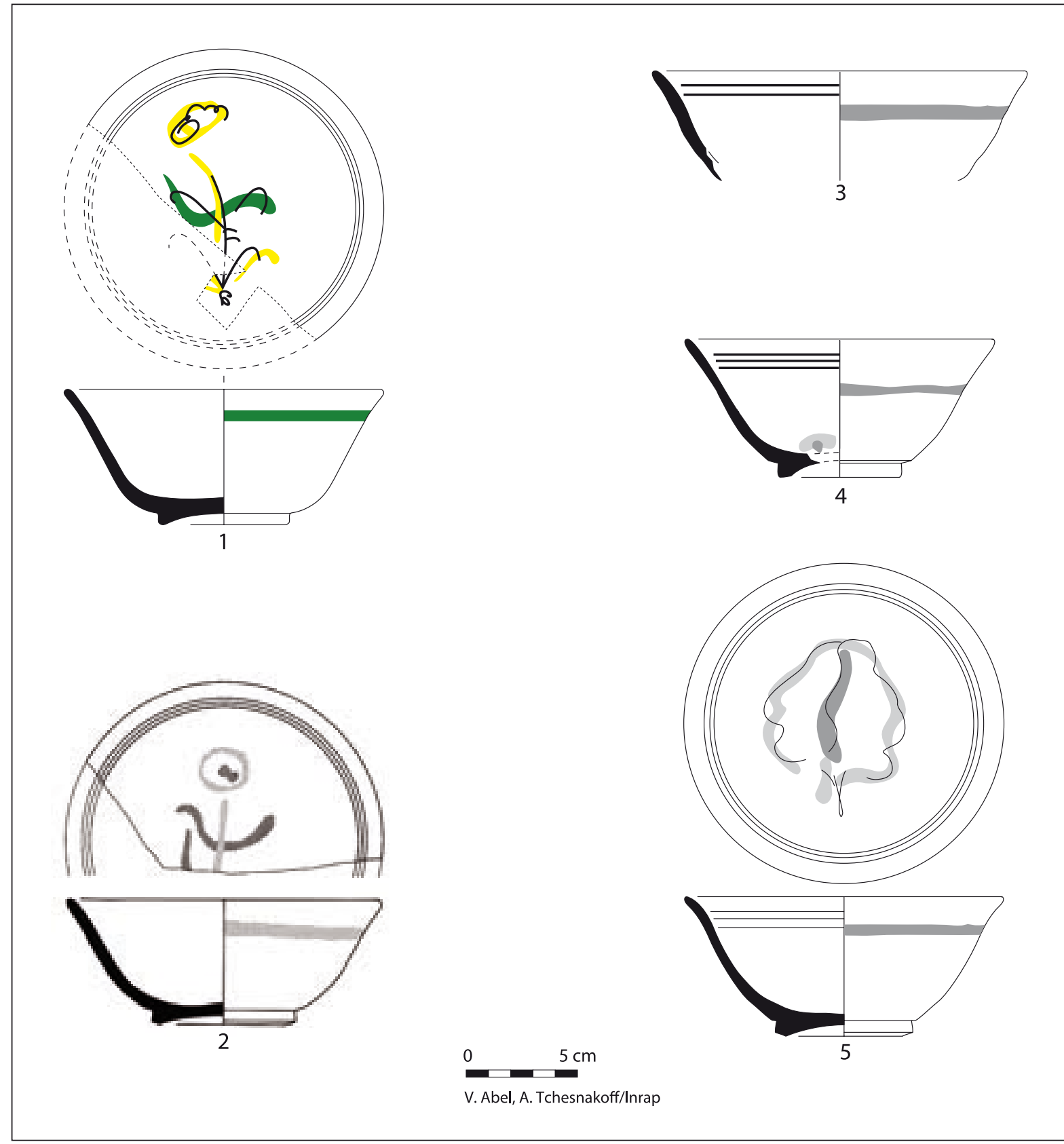

Fig. 126. Terres vernissées de Pise - écuelles (fin du XVII s.). 1-2, 5 : la Bourse ; 3-4 : la Charité. 
appréciées à Marseille mais pendant un temps assez bref (inv. 52.02.11520 à 11522) et côtoyant des objets moins connus comme une petite forme à bord en canal de Vallauris (inv. 52.02.11527).

Ces vases culinaires de Ligurie sont caractéristiques et relativement bien datés. La faible présence des vases à cuire ligures dans l'ensemble de ce mobilier ne s'explique pas sur le chantier de l'Espace Bargemon (5\% des fragments significatifs et $3,5 \%$ des formes). Cela vient-il d'une rareté des niveaux stratigraphiques des périodes relativement courtes où ils sont les plus utilisés, ou d'une moindre habitude de consommation de ces articles sur toute la période ? Les marmites de Ligurie ont un bord obtenu par simple changement de l'orientation de la paroi, elles ont de petites anses de section circulaire caractéristiques (Cameirana, Varaldo 1976). Elles sont fréquemment accompagnées de jattes (fig. 124, $\mathbf{n}^{\circ}$ 4-6).

\subsection{La Toscane}

La Toscane bénéficie d'une certaine primauté sur le marché marseillais; ses faïences, à décor vert et brun par exemple, étaient appréciées à Marseille depuis le Moyen Âge classique et pendant une longue période : les faïences décorées de Montelupo restent présentes du $\mathrm{XV}^{\mathrm{e}} \mathrm{s}$. jusqu' au milieu du $\mathrm{XVIII}^{\mathrm{e}} \mathrm{s}$. environ. Elles sont souvent peu nombreuses en nombre de fragments mais de plus de poids dans le dénombrement par objets ce qui semble indiquer une bonne (ou trop grande) lisibilité de cette catégorie.

Dans le XVII ${ }^{\mathrm{e}}$ s., la faïence de Montelupo est fréquemment représentée à Marseille par la série à décor de «feuilles de chêne » (foglia verde; Berti 1998, p. 397) que l'on retrouve sur plusieurs fragments de l'Alcazar dont un bord d'assiette et un fond (fig. 125, $\mathbf{n}^{\circ} \mathbf{1 - 2}$ ).

Trois assiettes du dépotoir de la place VilleneuveBargemon appartiennent au fameux type anciennement dit «génois », caractérisé par des objets assez lourds, dont l'émail est peu soigné et reste sans décor. Ce groupe apparaît donc vers la fin du XVII ${ }^{\mathrm{e}}$ s. et se maintient fortement pendant le XVIII ${ }^{\mathrm{e}} \mathrm{s}$. En effet, parallèlement à des faïences historiées, la faïence commune fait son chemin. On retrouve ces assiettes blanches à l'Alcazar (inv. 24.99.1492 et 1503) et en grand nombre sur le site de la Bourse.

Parallèlement à cette production à revêtement stannifère se développent en Toscane de fortes séries de céramiques vernissées mettant particulièrement à l'honneur le travail sur les engobes (incisions, rehauts, mélanges). Parmi les premières remarquées à Marseille sur la période Moderne figurent les vernissées de Pise dites $a$ stecca et les graffitta tarda, qui présentent une surface d'engobe décorée de fines incisions. Les écuelles (fig. 126, $\mathbf{n}^{\circ} \mathbf{1 - 5}$ ), les assiettes (fig. 127, $\mathbf{n}^{\circ} \mathbf{1}, \mathbf{4 - 5}$ ), les plats à bord déversé à sillon (fig. $127, \mathbf{n}^{\circ} \mathbf{2}$ et $\mathbf{6}$ ) et les plats à aile (fig. 127, $\mathbf{n}^{\circ} \mathbf{7}$ et $\mathbf{1 2 8}, \mathbf{n}^{\circ} \mathbf{6}-\mathbf{7}$ ) sont bien illustrés par plusieurs chantiers de la cité marseillaise.

Comme il est ordinaire dans cette série, les œillets placés au centre du vase animent le plat, le reste étant occupé par des incisions concentriques, des remplissages et quelques rehauts de couleur (Berti 1994, fig. 17 et 18). Une seconde série de même origine et utilisant les mêmes techniques laisse toutefois davantage d'espace libre dans le vase. Sur ces pièces, on rencontre occasionnellement des oiseaux et d'autres décors figurés, ainsi que des décors héraldiques. Le blason central, qui a perdu alors toute signification politique pour n'être plus qu'un thème ornemental, est animé d'une série de points ou de simples traits transversaux (Berti 1994, fig. 19).

Cette céramique vernissée est l'une des rares à pouvoir être formellement reconnue dans une œuvre picturale. Giovanna Garzoni (1600-1670) vécut en Toscane et s'est consacrée à la représentation de natures mortes agrémentées de petits animaux. Le «plat au melon et tranche de pastèque » conservé à la galerie des Offices de Florence est un plat de Pise parfait de forme et de décor (fig. 128).

Une exceptionnelle série de petites assiettes à décor d'engobes jaspés a été recueillie sur le chantier de l'Alcazar (fig. 128, $\mathbf{n}^{\circ}$ 1-3). Ces objets n'étaient pas réellement inconnus à Marseille. Leur forme et leur revêtement sont courants sur leur lieu de production (Berti 1994, fig. 33). Leur bord déversé à sillon fait déjà partie des trois types de bords répertoriés à Marseille pour les assiettes et plats pisans tardifs. C'est plutôt leur taille réduite qui fait leur originalité, ainsi que leur nombre qui tend à évoquer un système de service, rarement perceptible dans du mobilier archéologique, en particulier celui de Marseille.

Les céramiques vernissées de Pise, bien que toujours peu nombreuses (sauf dans les contextes particuliers comme celui de l'abbaye Saint-Victor et pour une date légèrement plus haute), sont en général assez courantes dans cette période. Dans le mobilier de la fosse de l'Espace Bargemon, un unique tesson témoigne de cette catégorie (inv. 52.02.11515). Il s'agit d'un bord d'assiette sans doute décorée d'incisions et polychromie, mais le bord est trop fragmentaire pour laisser voir le moindre décor.

Un autre objet, exceptionnel pour notre cité, consistait en un pichet pisan à décor incisé et polychrome (fig. 127, $\left.n^{\circ} 3\right)$. Un fragment est suffisamment caractéristique par sa pâte, son aspect extérieur et son décor pour se signaler clairement. Les vases fermés d'origine pisane ne sont jamais exportés vers Marseille, alors que les vases ouverts le sont couramment. Le fragment de l'Alcazar est un vestige de panse dépourvu de toute ébauche de bord, 


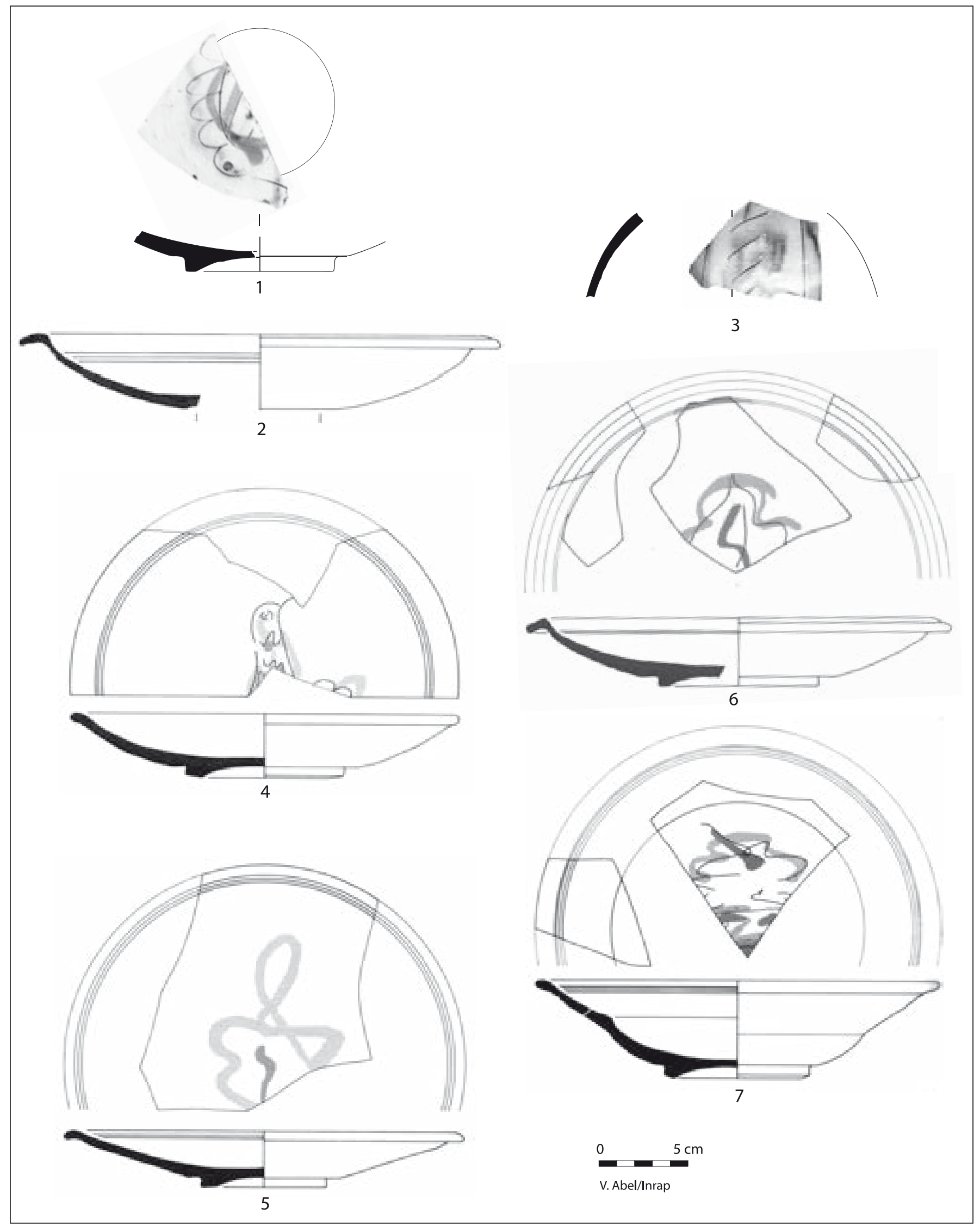

Fig. 127. Terres vernissées de Pise - assiettes ( $\left.n^{\circ} 1-2,4-7\right)$ et pichet ( $\left.{ }^{\circ} 3\right)$ (fin du XVII ${ }^{\text {s. }}$ ). 1,3 : Alcazar ; 2, 4-5 : la Bourse ; 6-7 : la Charité. 


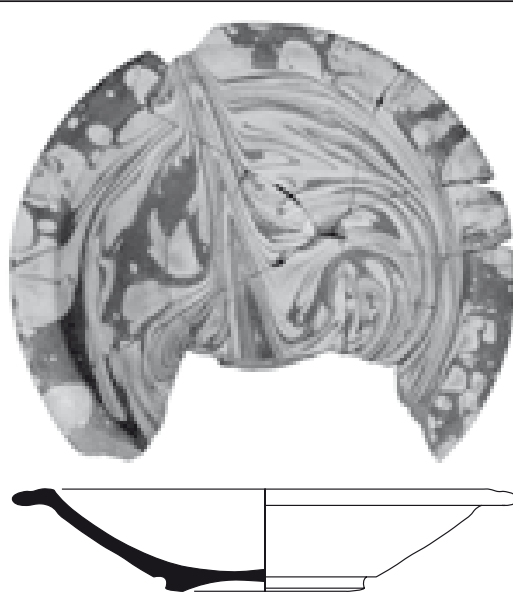

1
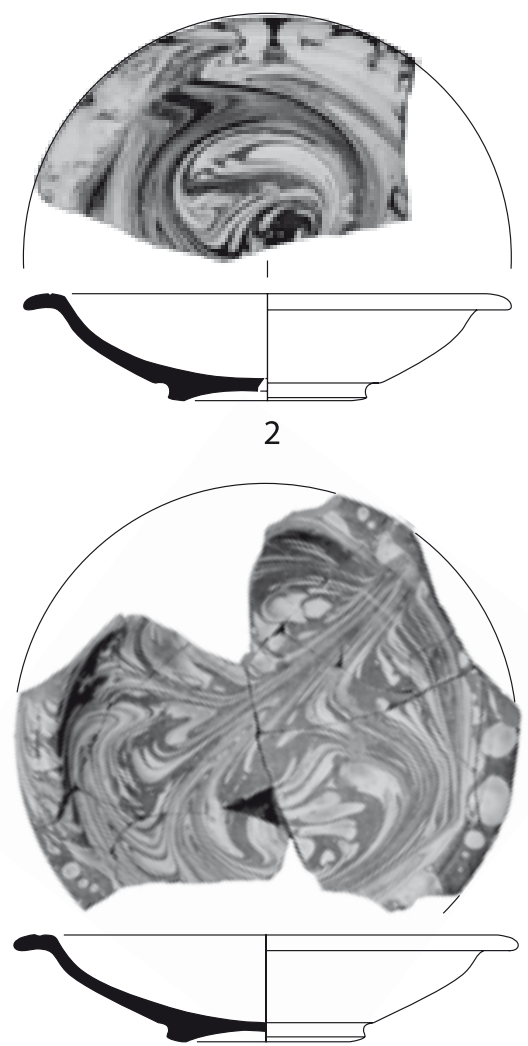

3

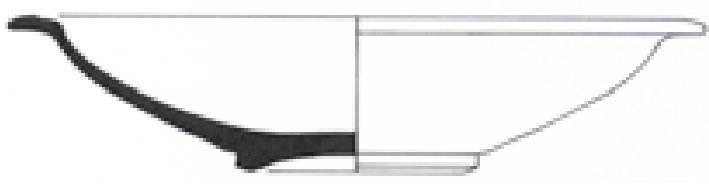

4

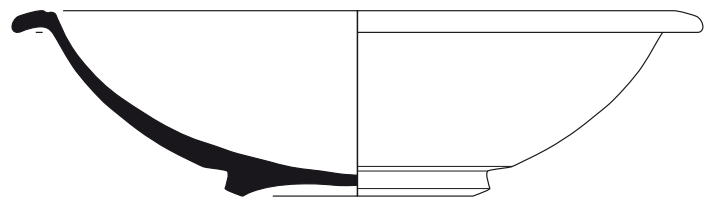

5
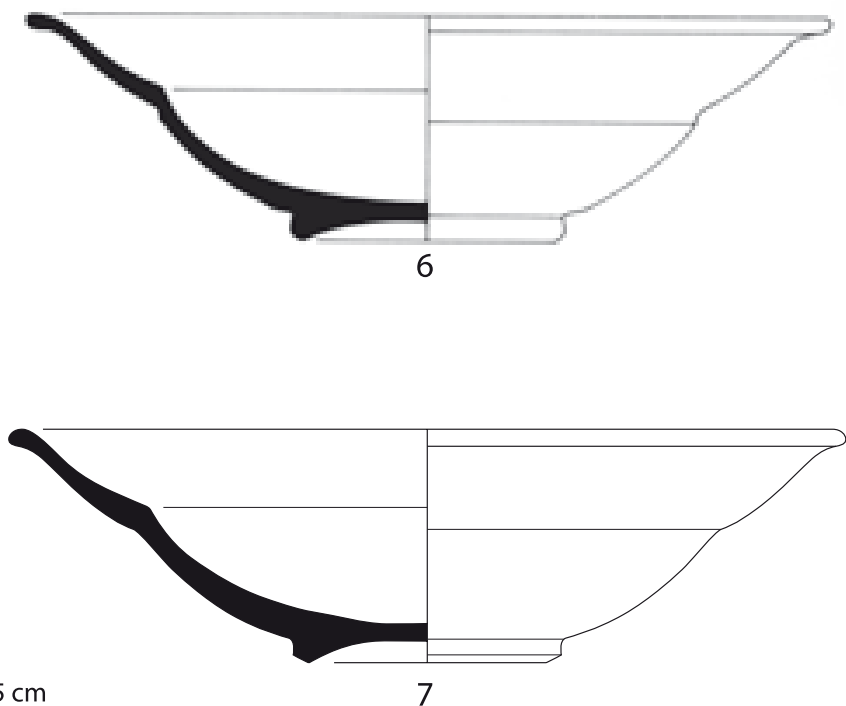

V. Abel, A. Tchesnakoff/Inrap

Fig. 128. Terres vernissées de Pise - assiettes et plats (fin du XVII s.). 1-3 : Alcazar ; 4, 6 : la Bourse ; 5, 7 : la Charité. de fond ou d'appendice, toutes choses auxquelles il a pu être rattaché. L'intérieur de l'objet n'est que sommairement revêtu d'un vernis maigre. L'extérieur a reçu une couche d'engobe blanc qui a été incisée rapidement de traits verticaux et d'une onde large de même orientation. Des taches de couleurs, verte pour l'essentiel et jaune par endroits, sont posées de manière approximative. Le vernis de bonne qualité a conservé toutes ses qualités de brillance et de transparence. Ce seul témoignage à travers les mobiliers archéologiques d'un second vase fermé pisan parvenu à Marseille pendant la période moderne est en fait doublement exceptionnel (le premier vase à liquide pisan, une simple cruche non décorée revêtue de vert, a été recueilli dans l'un des puits de la Bourse, accompagnée de céramiques du XVI s. ; Abel 1988). Les «boccali graffiti tipo pisano (tipo 63) », attribués au XVI ${ }^{\mathrm{e}} \mathrm{s}$. ont été déterminées par Tiziano Mannoni dès 1968 (Mannoni 1975, p. 82), mais leur rareté ne les fait apparaître que très rarement en bibliographie. L'objet de l'Alcazar conserverait le décalage chronologique généralement observé entre les importations luxueuses et les productions locales. 


\section{Les productions régionales : Languedoc, Provence rhodanienne et Provence orientale}

Nous avons vu que les importations au long cours privilégient les origines «orientales », préférant les produits des états italiens aux céramiques espagnoles. Nous retrouvons, en réduction, un schéma globalement semblable pour les importations moins lointaines, celles de Provence occidentale et Languedoc étant moins répandues dans les mobiliers archéologiques marseillais que celles de Provence orientale.

\subsection{Le Languedoc et la Provence rhodanienne}

Les poteries vernissées dites «du Bas-Rhône » sont encore aujourd'hui en attente d'identification exacte et formelle. Ce terme vague avait été choisi au début de cette recherche car la pâte de ces objets présentait des
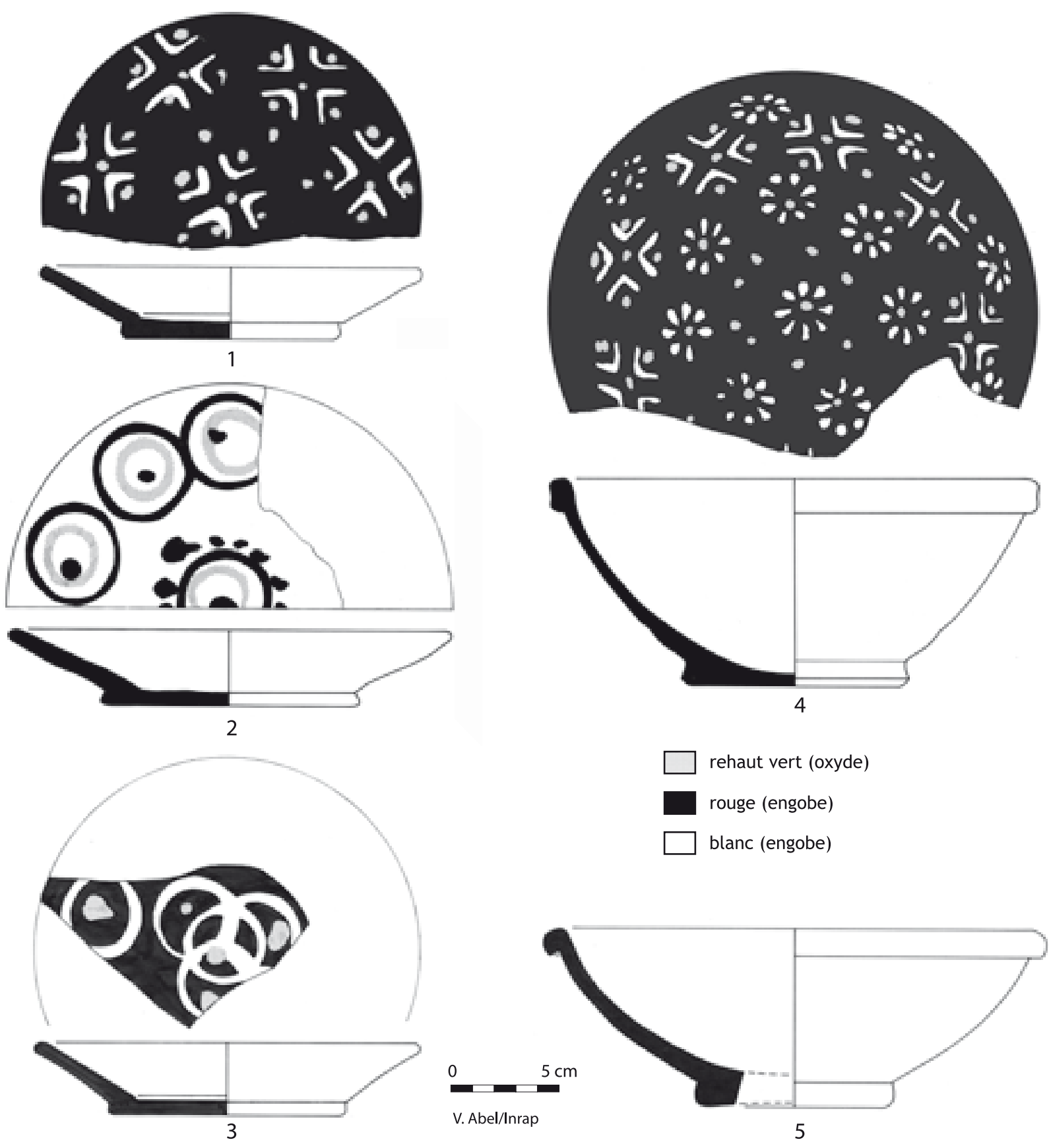

Fig. 129. Céramiques de Provence rhodanienne - vases ouverts (fin du XVII s.). 1-2, 4-5 : la Bourse ; 3 : les Carmes. 


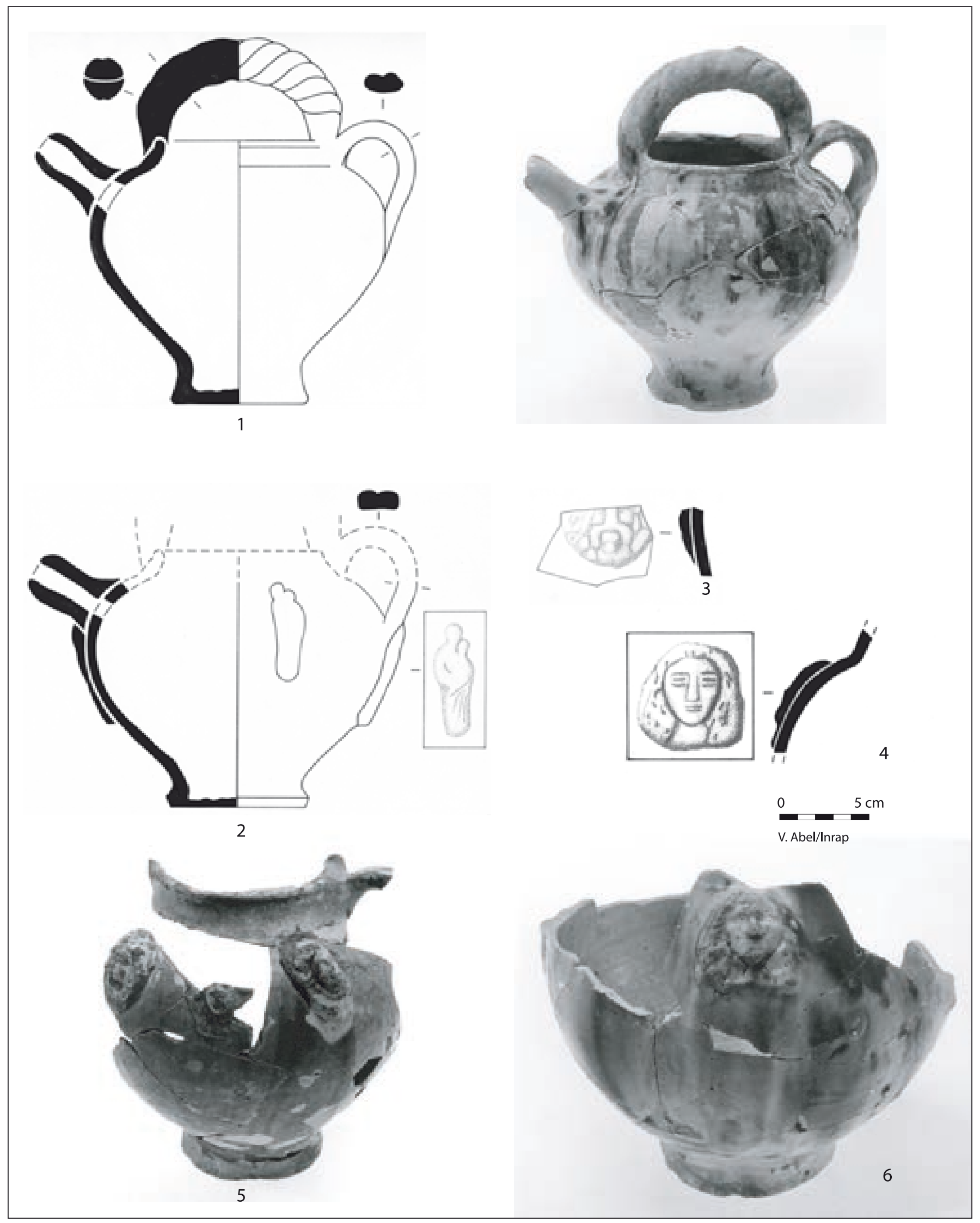

Fig. 130. Céramiques de Provence rhodanienne - vases à liquide (fin du XVIIe s.). La Bourse. 
analogies visuelles avec celle des productions de faïences médiévales avignonnaises. Cette hypothèse ne s'est pas vue contredite. Plus nombreuses dans le Gard, elles semblent devoir être rattachées à la ville de Meynes. Un pichet de l'Alcazar, à large col, pâte jaune et vernis jaune décoré d'une lourde traînée de manganèse sur l'épaule, a été placé à l'actif de cette "production ». C'est aussi le cas d'un vaste pot de fleurs à bord caractéristique qui se trouvait décoré d'appliques en relief semblant imiter un étrange tressage.

Deux fragments de l'Espace Bargemon, fond et bord replié appartiennent à un même plat creux à engobes jaspés sur fond blanc formant un large pétale (inv. 52.02.11516). Le vernis est agrémenté de taches vertes.

L'essentiel de la typologie est fournie par les puits de la Bourse où plusieurs assiettes (fig. 129, $\mathbf{n}^{\circ} \mathbf{1 - 3}$ ) et plats à bord replié (fig. 129, $\mathbf{n}^{\circ} \mathbf{4 - 5}$ ), entiers, viennent offrir des compléments de choix à des vases à liquide en nombre relativement important (fig. 130), parmi lesquels des cruches à décors d'applique en relief sont très originales (fig. 130, $\mathbf{n}^{\circ} \mathbf{2 - 5}$ ).

Tout à l'inverse des incertitudes pesant sur la catégorie précédente, les poteries réfractaires de type Uzège sont bien connues (exemple Thiriot 1985). Elles sont présentes à Marseille de manière à peu près continue, mais presque insignifiantes avec $3 \%$ de l'ensemble des fragments. Aucun objet de «type Uzège » n'est représenté dans le mobilier de l'Alcazar de la fin du XVII ${ }^{\mathrm{e}} \mathrm{s}$. et ils sont anecdotiques place Villeneuve-Bargemon, alors qu'on rencontre ailleurs des toupins, couvercles et des pièces de vaisselle comme des plats à aile. La cour de la Charité avait livré quelques éléments de formes et deux fragments issus d'un puits de la Bourse ont été rassemblés graphiquement.

\subsection{La Provence orientale}

Les céramiques de Provence orientale sont bien présentes dans les intérieurs marseillais sur toute la période considérée. Dès le $\mathrm{XVI}^{\mathrm{e}} \mathrm{s}$., les ateliers de Fréjus fournissent Marseille en vaisselle commune, écuelles, plats, et pot de chambre pour l'essentiel.

À partir du milieu du XVII ${ }^{\mathrm{e}} \mathrm{s}$. de manière très nette, les poteries culinaires de Vallauris (fig. 131) s'imposent aux consommateurs marseillais. Les pièces de vaisselle de table (fig. 131, $\mathbf{n}^{\circ}$ 5-7), aussi produites à Vallauris, sont peu utilisées à Marseille, où la marmite (fig. 131, n' 1 -4) reste la pièce culinaire essentielle sur toute la période moderne. Dans la seconde moitié du XVII ${ }^{\mathrm{e}}$ s. arrivent les formes à col court, à canal interne marqué pour certaines. Quelques objets un peu plus rares sont aussi recueillis sur l'ensemble de la ville, comme les jattes à lèvres triangulaires les « toupins » à bords sinueux.

Les poteries vernissées de Fréjus de la place Villeneuve-Bargemon sont plus nombreuses que celles de Pise, bien qu'assez discrètes, avec un bord d'écuelle (inv. 52.02.11535), deux ailes courtes de plats (inv. 52.02.11536 et 11537) et deux bords de pots de chambre (inv. 52.02.11533 et 11534). Un troisième pot de chambre est archéologiquement complet (inv. 52.02.11532). Les parois sont épaisses, à peu près verticales jusqu'à une aile aménagée sans rupture de courbe. Les anses, en paire, sont de forte section, tournées et à plusieurs canaux, posées en forme de point d'interrogation, évolution marquante depuis les anses en parenthèses des modèles antérieurs.

Près de Vallauris se trouve le centre de Biot, que la géologie n'a pas doté d'argiles réfractaires mais simplement calcaires. Dans cette ville sont produites, depuis le $\mathrm{XVI}^{\mathrm{e}} \mathrm{s}$. dit-on, les célèbres jarres du même nom. D'autres villages de potiers de la même région ont produit des jarres mais les origines ne sont pas discernables. Sur le site de l'Alcazar, une petite dizaine de fragments seulement se répartissent en trois jarres et cinq pots.

Malgré cette dernière note discordante, on constate plutôt une forte présence des céramiques de Provence orientale, qui constituent environ un cinquième de l'ensemble du mobilier, là où les zones occidentales de France méditerranéenne ne représentent qu'une part presque négligeable et remplaçable dans tous les cas.

\section{La production locale et assimilée : la terre vernissée de l'arrière-pays marseillais et la faïence régionale}

Comme cela a été dit en introduction, il s'agit de céramiques fabriquées entre 10 et $30 \mathrm{~km}$ à l'est de la ville, dans la zone de la vallée de l'Huveaune. Elles sont considérées pour la cité marseillaise comme des productions locales.

\subsection{Les caractéristiques générales}

L'Huveaune prend sa source dans la région de SaintZacharie, village de l'ouest du département actuel du Var, et coule vers l'ouest en direction de Marseille, tout en traversant une région appelée par les géologues «bassin de Marseille et de la Haute-Huveaune », une zone riche en argile exploitée par des potiers jusque dans les années 1930 et encore aujourd'hui par des tuileries. Quelques sondages dans les archives de SaintZacharie en dépôt à Draguignan (Var) ont permis de 


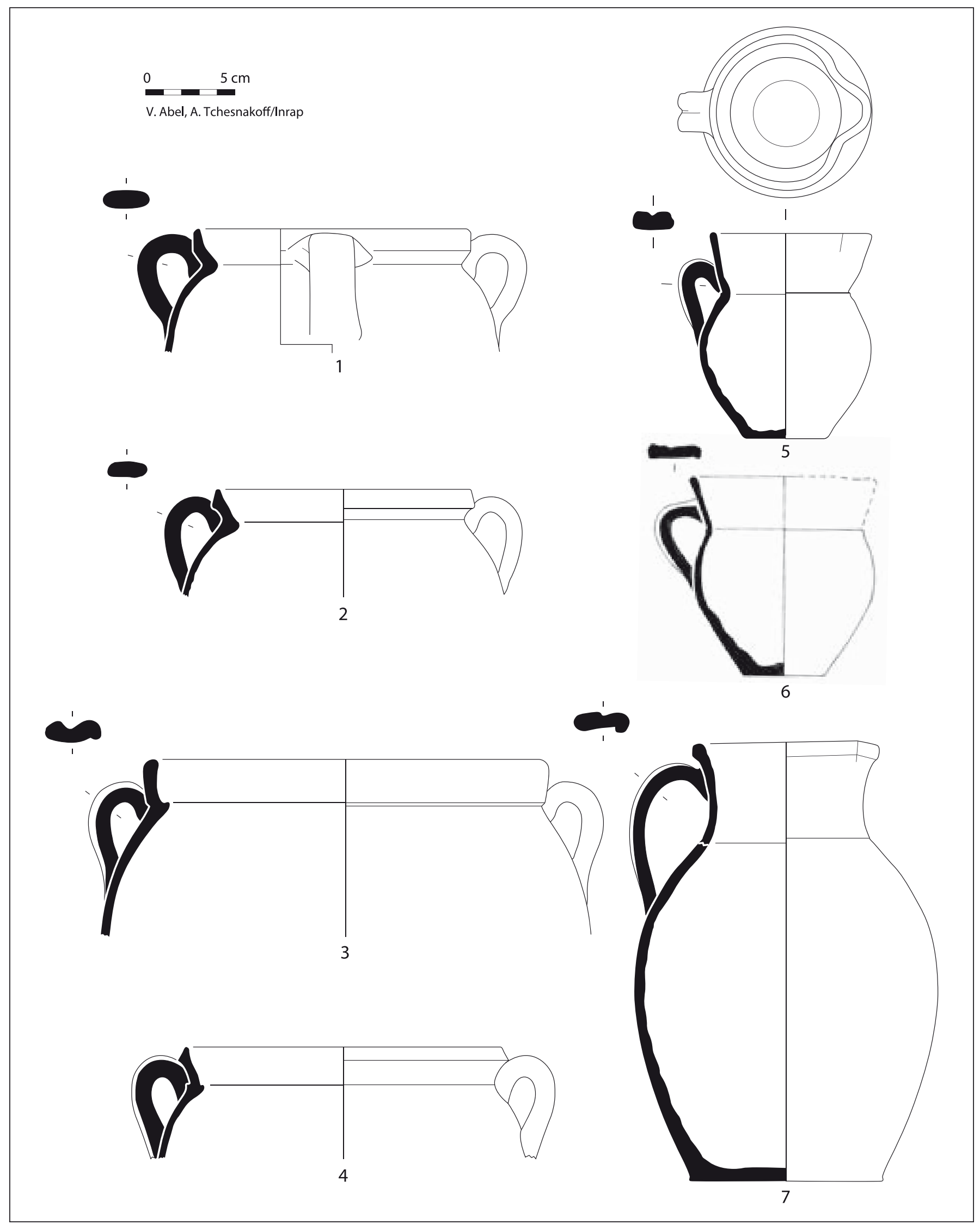

Fig. 131. Céramiques réfractaires de Vallauris (fin du XVII ${ }^{\mathrm{e}} \mathrm{s}$ ). La Bourse. 
situer approximativement les débuts de cette production vers 1630 (Abel, Amouric, 1991) et selon le mobilier archéologique, les terres vernissées de l'arrière-pays apparaissent sur les tables marseillaises vers le milieu du XVII ${ }^{e}$ s. Des analyses pratiquées en 1990 par Maurice Picon ont confirmé les « très fortes analogies » physicochimiques des argiles géologiques du secteur avec les groupes de céramiques constitués lors des études des mobiliers de la Charité et de la Bourse.

La vaisselle de cet arrière-pays marseillais se signale clairement par une pâte rouge orangée, dure et contenant peu ou pas d'éléments non plastiques. Dans certains cas, la pâte peut prendre des tonalités plus claires, moins ferriques en tranche ou en surface, sous l'action d'une cuisson ou post-cuisson moins oxydante. Cette production est déclinée en de très nombreuses formes, dont certaines fort courantes comme les écuelles ou les assiettes. D'autres sont rares, et bien d'autres sans doute nous restent encore à découvrir. Les caractéristiques communes à tous ces objets sont des épaisseurs de parois bien adaptées à la taille de la forme, des centres de gravité bien placés rendant les manipulations aisées, un engobe systématique sous le vernis, une certaine attention à la mode, particulièrement perceptible au travers des décors, conjuguée à la volonté de couvrir au maximum les besoins des consommateurs.

\subsection{Les écuelles et les tasses}

Au premier plan des formes produites dans la vallée de l'Huveaune se trouve l'écuelle (fig. 132 à 136). Les plus anciennes de ces formes avaient des oreilles découpées de forme rectangulaire, des parois galbées et un fond creux. Dans le troisième quart du XVII ${ }^{\mathrm{e}} \mathrm{s}$. est mis au point un moule d'oreille décorative comportant quatre volutes et un pendentif central. Ce modèle est longtemps utilisé, en original ou copie au relief émoussé. Le schéma de l'oreille polylobée est très en vogue pendant toute la deuxième moitié du XVII et au tout début du XVIII ${ }^{\mathrm{e}} \mathrm{s}$. L'écuelle de l'Huveaune, à l'exception d'un modèle particulier peu usité et d'un modèle à fond dégagé, est toujours munie de deux oreilles de bonne largeur et d'épaisseur à peu près équivalente à celle de la panse. Celle-ci, verticale ou courbe, prolonge un fond généralement plat, parfois creux, jamais annulaire. La lèvre est terminée en amande dans la plupart des cas. La forme n'est pas rigoureusement fixée. Toutes les écuelles ont approximativement le même aspect, mais rares sont celles qui sont absolument identiques entre elles. La pose des oreilles déformait systématiquement le travail, certainement déjà très rapide, des tourneurs répartis dans différents ateliers.
De manière attendue et nettement accentuée sur la place Villeneuve-Bargemon, on retrouve la nette prééminence de l'écuelle avec 18 exemplaires sur 47 objets. L'instantané qu'offre ce mobilier gomme la variété des formes des productions de l'Huveaune remarquée à travers le mobilier archéologique marseillais.

Les formes novatrices du XVII ${ }^{\mathrm{e}} \mathrm{s}$. sont assez peu représentées sur le chantier de l'Alcazar: les tasses identifiées sont par exemple au nombre de cinq seulement dont aucune n'est dessinable. Vers la fin du $\mathrm{XVII}^{\mathrm{e}} \mathrm{s}$., on rencontre à l'Alcazar les écuelles à fond creux dont le bord est légèrement épaissi en face interne à l'approche de la lèvre, et les écuelles à fond plat dont la lèvre est simplement arrondie. Une taraïette (jouet en terre cuite) reprend exactement la forme de la pièce de vaisselle de table.

Seul un bord de tasse signale place VilleneuveBargemon la présence des formes «alternatives", adaptations aux goûts et usages du temps, remarquable pour la date à laquelle elle est créée et pour le monde de la terre vernissée (inv. 52.02.11570). Les chantiers plus anciens de la Bourse et de la Charité ont en revanche permis de mettre en lumière ces formes particulières.

On a pu constater jusqu'ici dans cet ouvrage que l'écuelle s'est imposée comme contenant en terre cuite pour la part de nourriture individuelle. À peu près hémisphérique et plus ou moins creux, c'est l'élément de vaisselle typique des Temps modernes sans doute car il est certes adapté aux préparations liquides, mais éventuellement à d'autres plus solides. De plus aucune céramique à boire à usage individuel ne se rencontre dans le mobilier archéologique de Marseille. On se sert à l'occasion d'écuelles vernissées pisanes, de forme plus élancée mais de même capacité. Les potiers de l'arrière-pays marseillais imitent franchement et pour un temps, dans le dernier quart du XVII ${ }^{\mathrm{e}}$ s., cette écuelle de la basse vallée de l'Arno : à partir d'un pied creux dégagé, les parois sont légèrement évasées et ne portent aucun appendice de préhension (fig. 137), les décors privilégiant incisions et polychromie particulièrement évocateurs. Cette écuelle de type italien constitue une exception dans le répertoire de l'Huveaune dont les inspirations sont si mystérieuses qu'elles semblent n'être que créations pures.

Fig. 132. Écuelles à fond plat de l'arrière-pays marseillais (fin du XVII ${ }^{e}$ s.). 1-2 : place VilleneuveBargemon ; 3, 5, 6-8 : la Bourse ; 4 : la Charité 


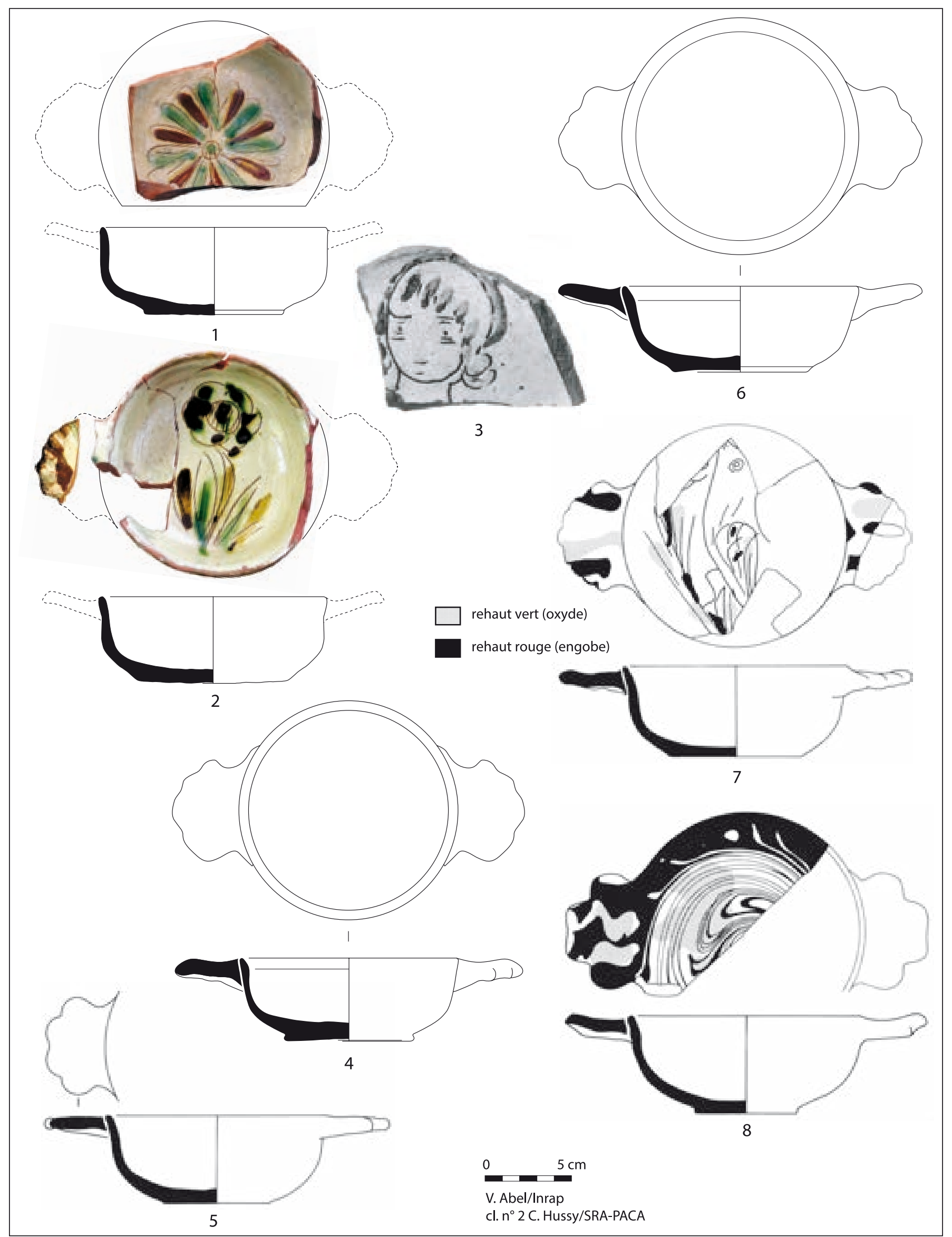




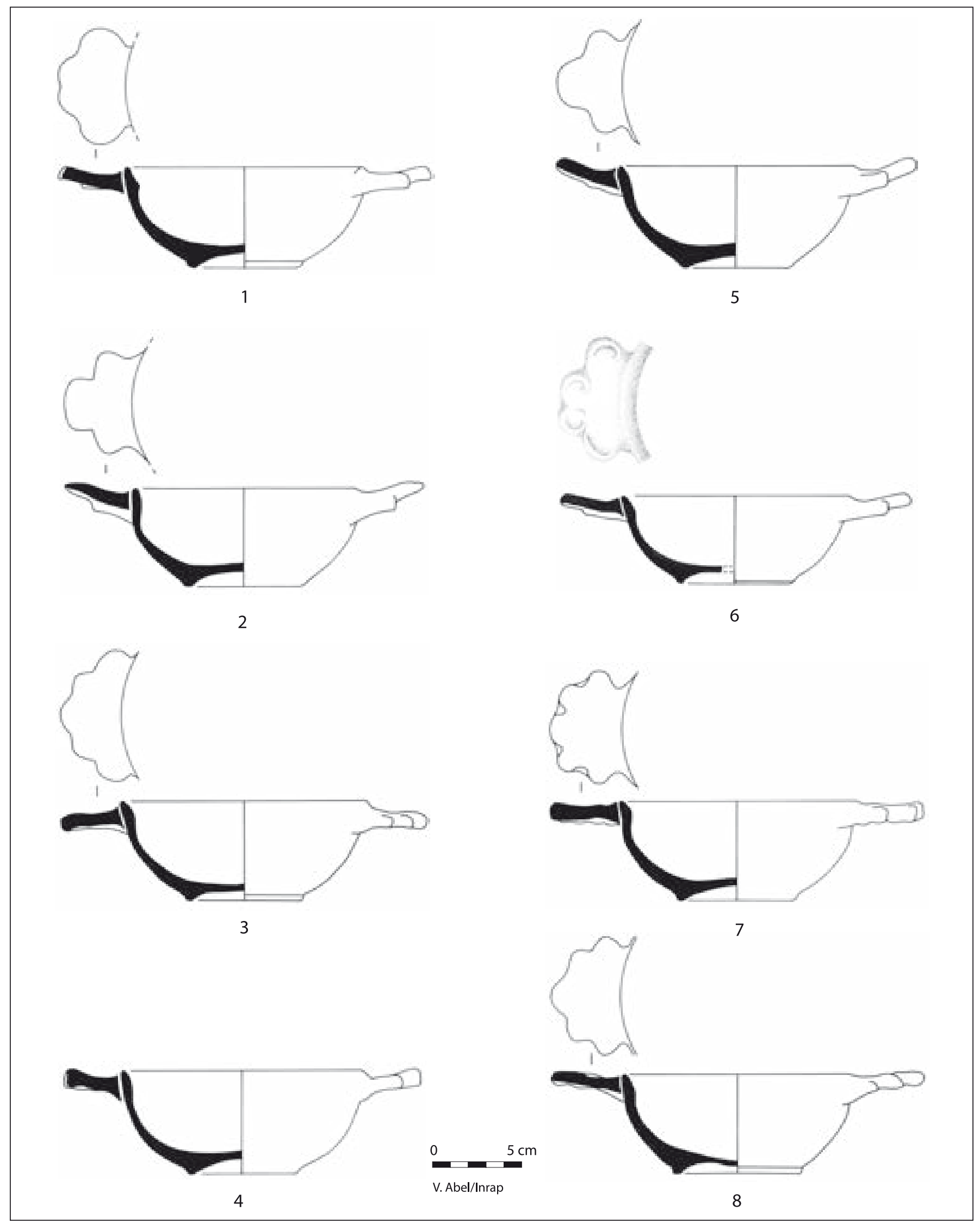

Fig. 133. Écuelles de l'arrière-pays marseillais (fin du XVII ${ }^{\mathrm{S}}$.). La Bourse. 
CHAPITRE 7 - LA CÉRAMIQUE D’USAGE QUOTIDIEN À MARSEILLE DE 1660 À 1710

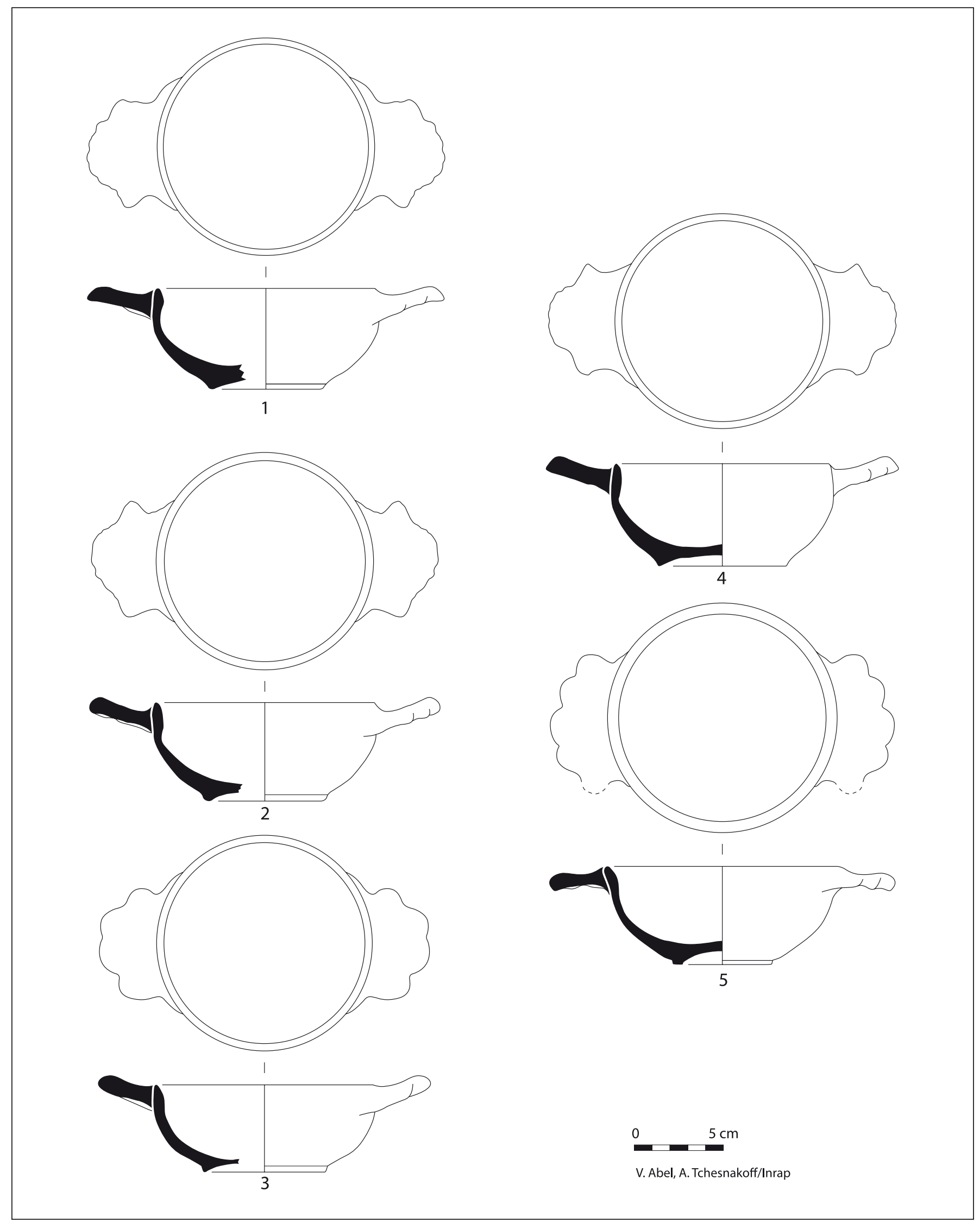

Fig. 134. Écuelles de l'arrière-pays marseillais (fin du XVII'e s.). La Charité.

171 


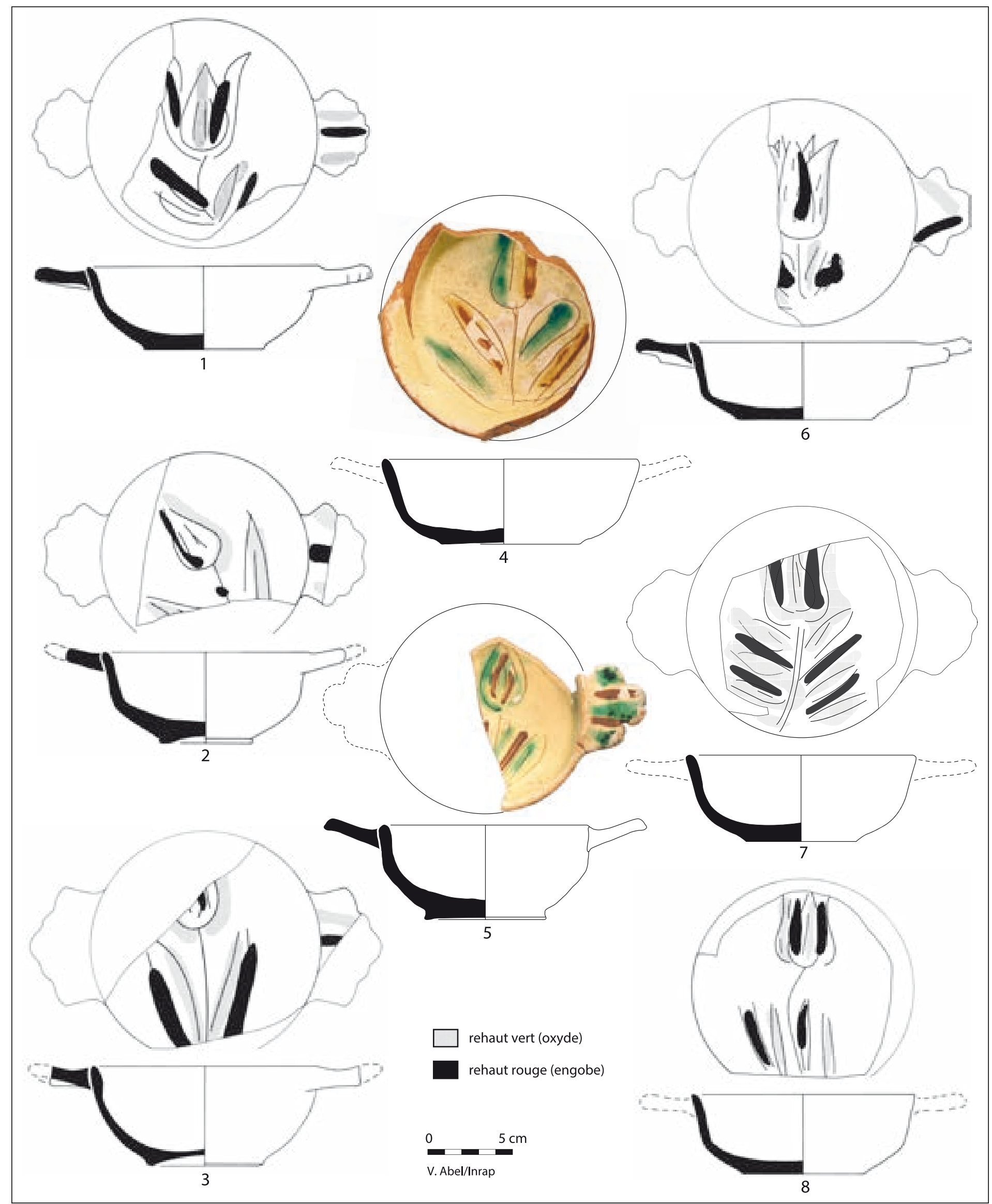




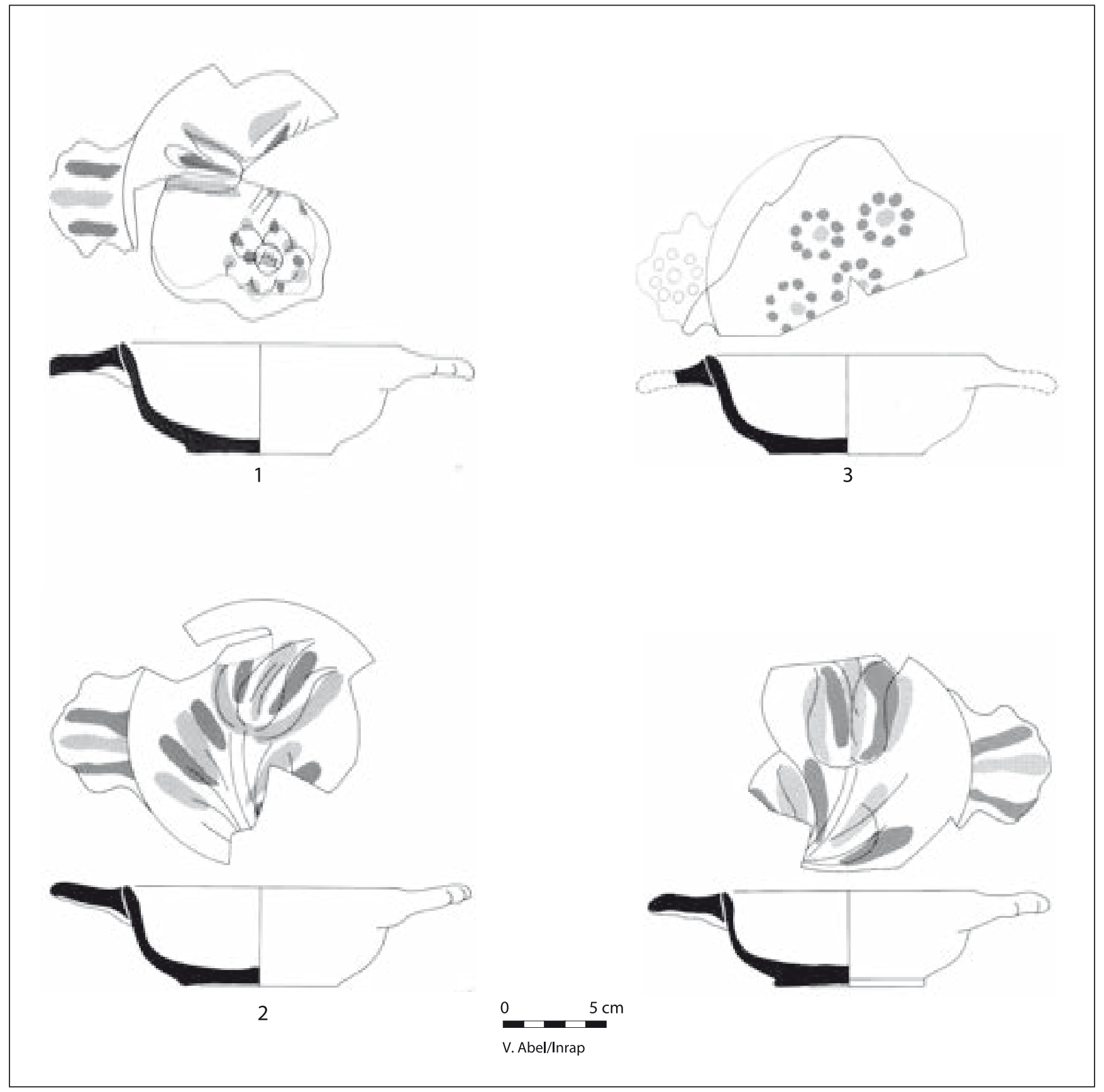

Fig. 136. Écuelles de l'arrière-pays marseillais (fin du XVII s.). La Charité.

Fig. 135. Écuelles «champ de tulipes»

de l'arrière-pays marseillais (fin du XVII $\mathrm{s}$.).

1-3, 6, 8 : la Bourse ; 4-5 : place Villeneuve-Bargemon ;

7 : fort Saint-Jean. 


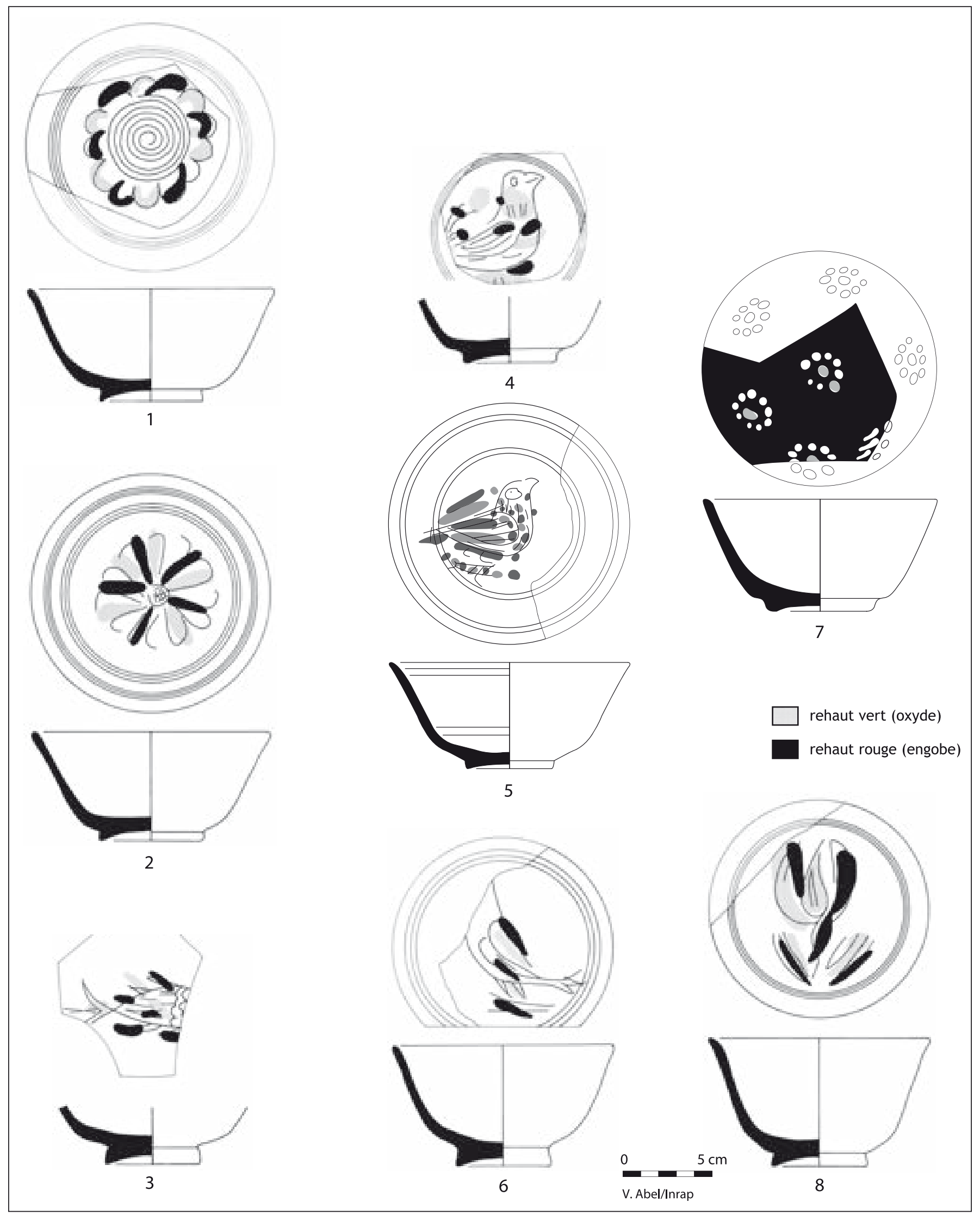

Fig. 137. Écuelles à fond dégagé type « Pise » de l'arrière-pays marseillais (fin du XVIIe s.). 1-6, 8 : la Bourse ; 7 : la Charité. 
Une autre pièce du répertoire des terres vernissées de l'aire marseillaise, contemporaine de la précédente, est en revanche plus inattendue et illustre précisément ce processus de création. Il s'agit de la tasse "véritable», proche de la nôtre (fig. 138). Ses parois sont plus verticales et plus courtes, elle est agrémentée de deux petites anses opposées en forme de point d'interrogation et sa contenance est plus faible. On ne lui connaît aucun précédent ou précurseur dans les productions de céramiques locales. Même si ce récipient n'est pas le plus courant dans cette production vernissée locale de Marseille, les exemplaires en sont suffisamment nombreux pour constituer une référence typologique.

L'originalité de sa forme laisse penser que la tasse répond à l'envie d'utiliser un récipient se démarquant de la solide écuelle à bouillie. Les décors ne sont cependant pas vraiment différenciés du reste de la production : bien que plus rares, les incisés et polychromes figuratifs ou géométriques alternent avec les engobes monochromes ou jaspés et des vernis tachetés. Cette tasse atteste sans doute de la diffusion dans la société marseillaise de la consommation du café et du chocolat auquel le sucre est associé par nécessité gustative.

La tasse en terre vernissée n'a pas eu une vie très longue, elle disparaît dans le deuxième quart du XVIII ${ }^{\mathrm{e}}$ s., sans doute reléguée par la faïence. Elle acquiert donc un statut de marqueur chronologique. Bien qu'éphémère, cette céramique archéologique rend possible la perception à Marseille et dans sa proche région de l'arrivée et de l'usage dans la vie quotidienne des produits exotiques (café, sucre, chocolat).
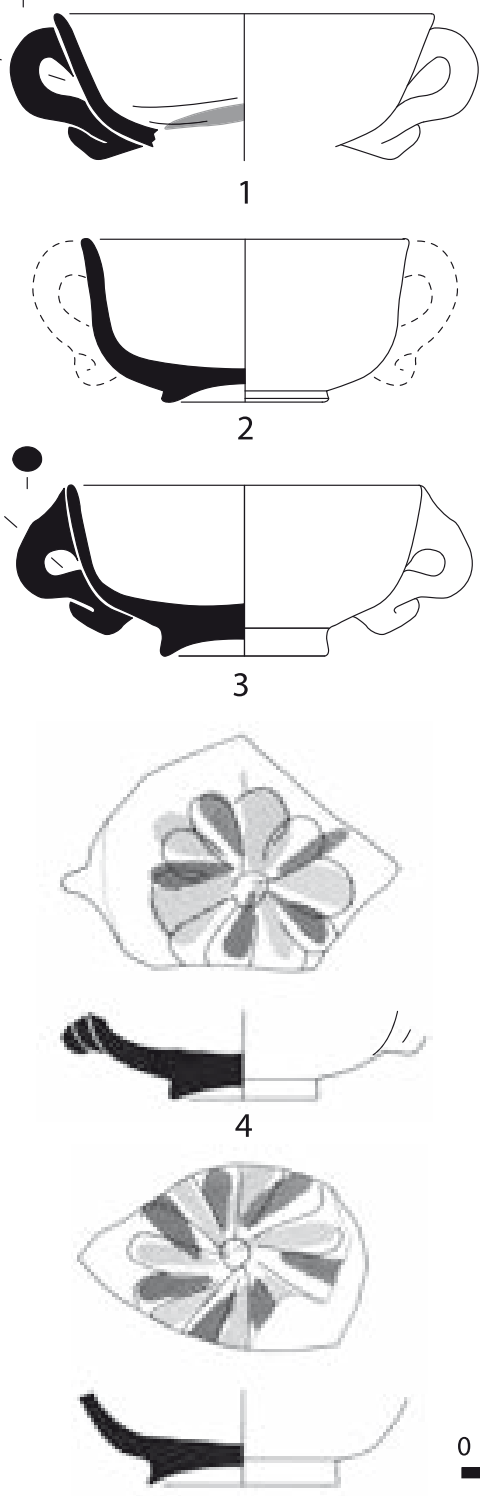

5

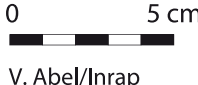

V. Abel/Inrap
Fig. 138. Tasses de l'arrière-pays marseillais : $\left(n^{\circ} 1-7\right)$; tasses en faïence supposées marseillaises : (n॰8-9) (fin du XVII $\mathrm{s}$.) 1, 3-5 : la Charité ; 2, 6-7 : la Bourse ; 8-9 : Alcazar.
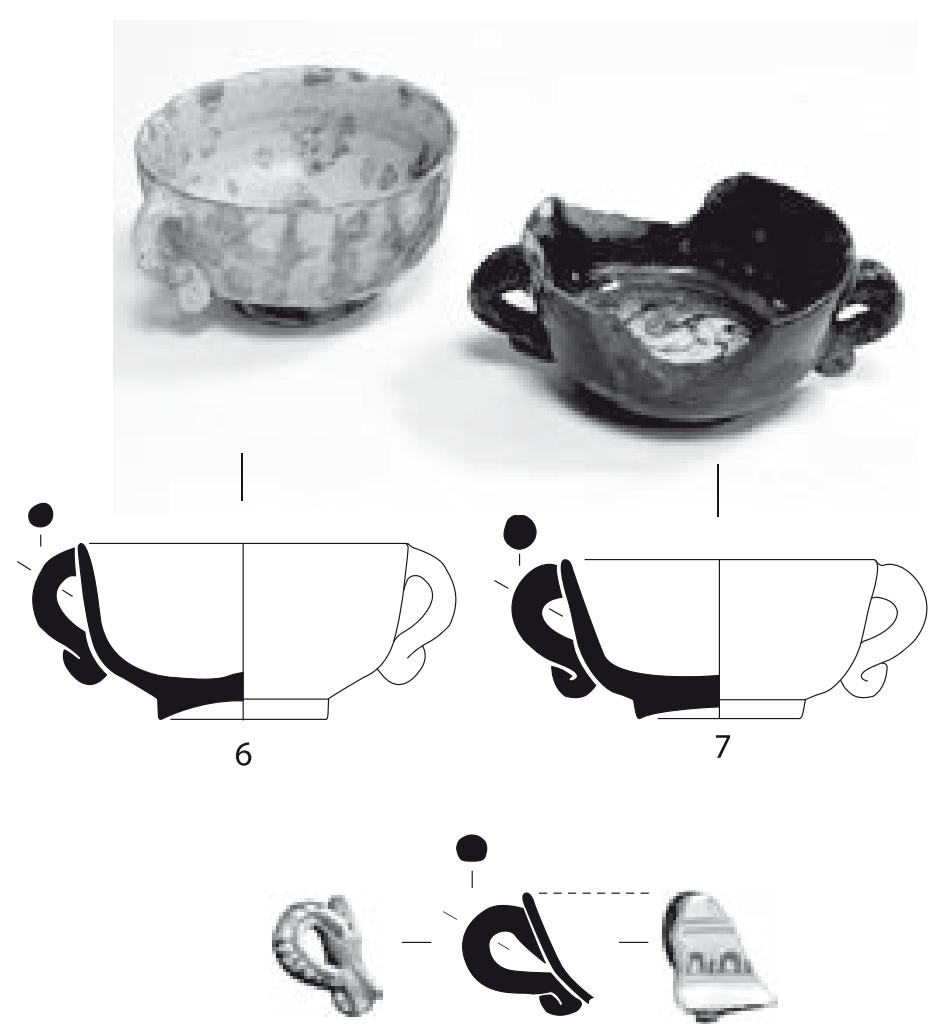

8

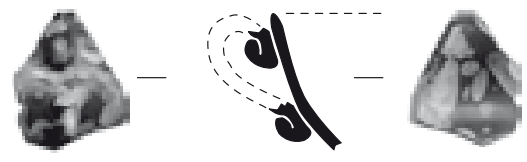

9 


\subsection{Les assiettes et les plats}

L'une des assiettes de l'Huveaune développe rapidement une aile rectiligne s'accrochant directement sur le fond plat et large formant une cuvette interne (inv. 24.99.1456). La forme est produite dans toute la seconde moitié du XVII ${ }^{e}$ s. (fig. 139). L'aile était de longueur moyenne au début de la production, elle s'allonge ensuite, et s'incurve légèrement. Ce modèle disparaît vers le début du XVIII' $\mathrm{s}$.

D'autres assiettes ont vu le jour (fig. 140 à 143). Les principales sont les formes à pied plein dégagé de la panse dont la paroi à courbe interne régulière est terminée par un bord déversé soigné. Très courantes, elles sont abondamment illustrées par la Charité et la Bourse mais très peu par le chantier de l'Alcazar. Les deux formes coexistent dans la seconde moitié du XVII ${ }^{\mathrm{e}} \mathrm{s}$. Avec 17 exemplaires sur 47 objets, les assiettes sont quasiment aussi nombreuses que les écuelles parmi les productions de l'Huveaune issues du dépotoir de l'Espace Bargemon. Si les constantes de la forme sont un pied plein et dégagé, l'approximation dans le tournage, remarquée pour les écuelles, règne aussi parmi les assiettes. Le diamètre du pied, qui est plus ou moins bien dégagé, varie, le bord est plus ou moins déversé, etc. La première forme est relativement mieux fixée. Les assiettes ne sont en principe pas tournassées. En revanche, les plats qui les accompagnent, dont certains déclinent la forme de la première assiette (à aile) de manière plus vaste et plus creuse, voient leur pied dégagé par tournassage.

Les formes des plats «de service» suivent pour la plupart de près l'évolution de l'assiette. Le plat le plus courant dans la seconde moitié du XVII ${ }^{\mathrm{e}} \mathrm{s}$. a une vasque ni très profonde ni très large, alors que son aile se développe amplement (fig. 144 à 149). Cette forme recherchée et virtuose, malgré le peu de soin qui est, là encore, accordée aux détails, fait partie du cortège d'objets novateurs produits dans un laps de temps relativement bref. Elle est abandonnée au début du XVIII ${ }^{\mathrm{e}}$ s., au profit des plats à bord déversé qui sont bien présents dans la période dont il est ici question (fig. 150). Le petit «tian» (jatte profonde à parois évasées et bord replié) est aussi proposé aux consommateurs (fig. 151 et 152).

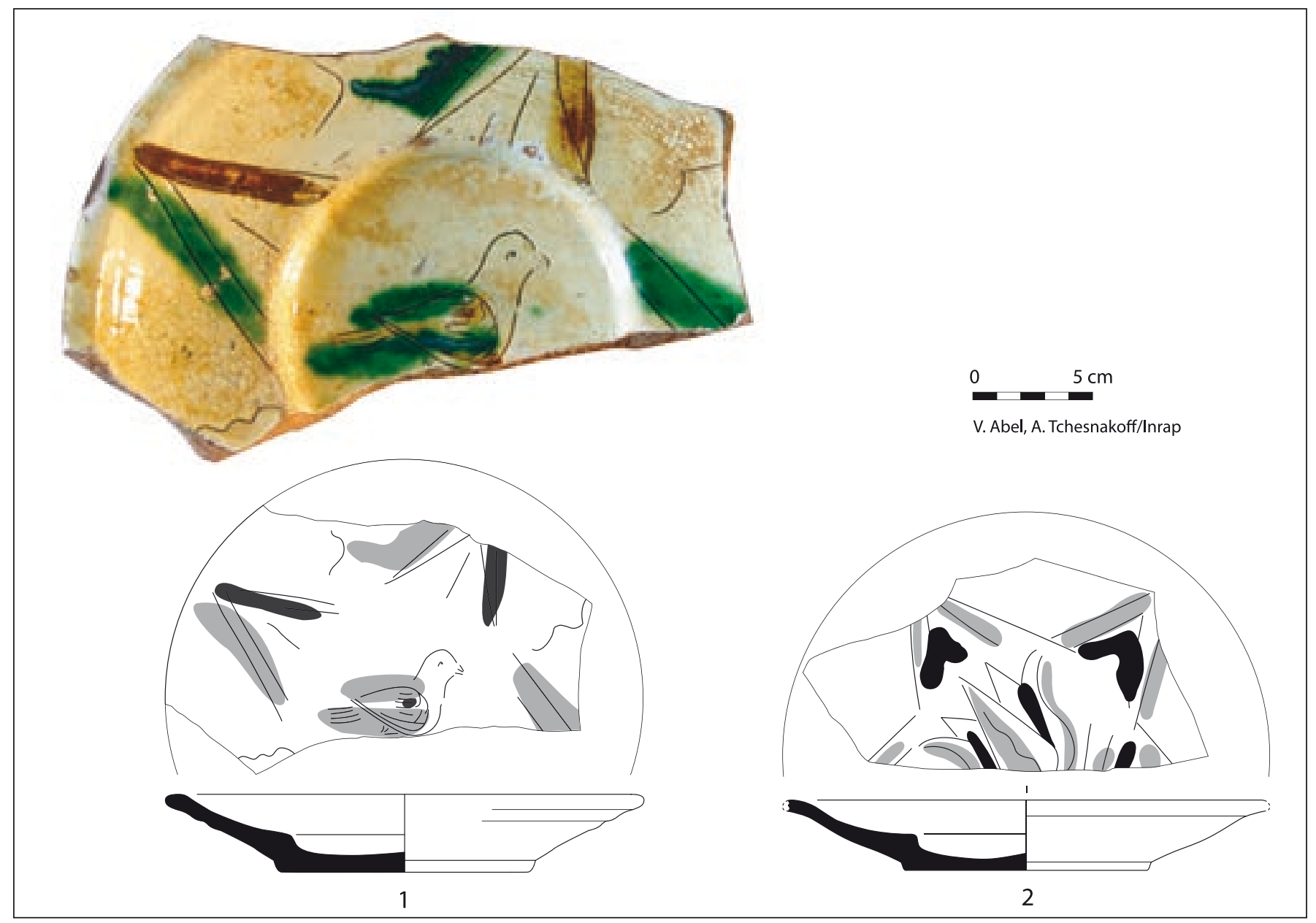

Fig. 139. Assiettes à aile de l'arrière-pays marseillais (fin du XVII ${ }^{\mathrm{e}} \mathrm{s}$.). La Bourse. 


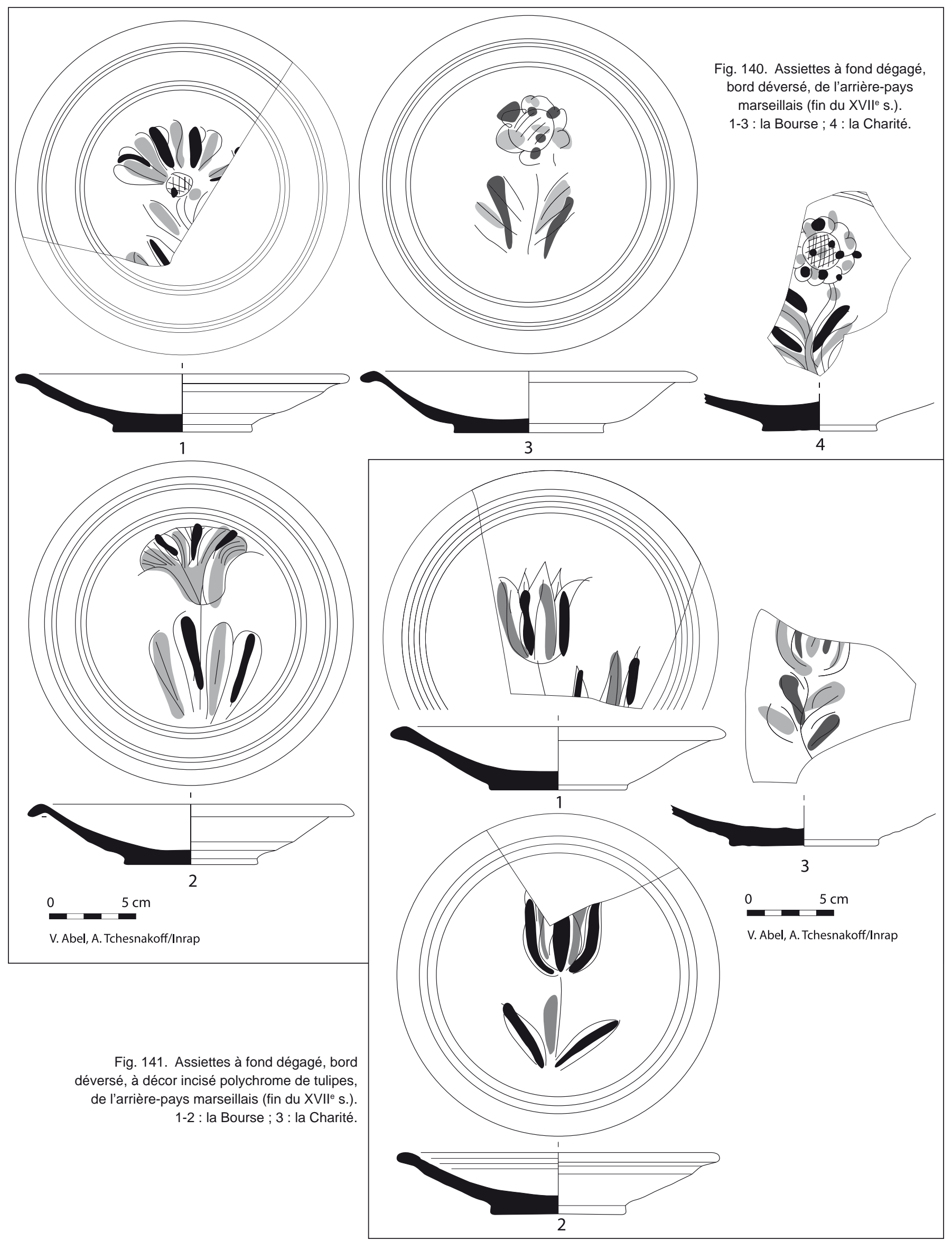




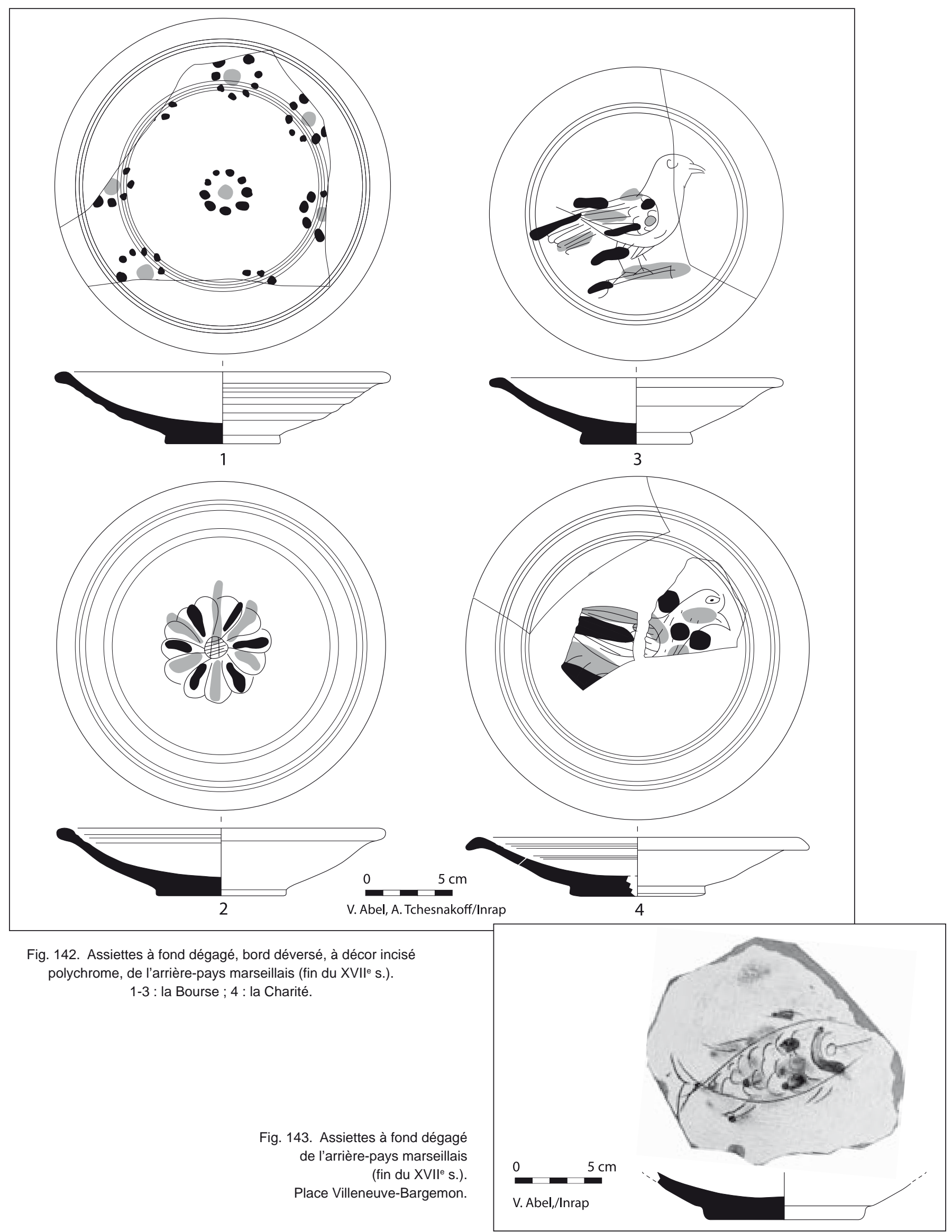




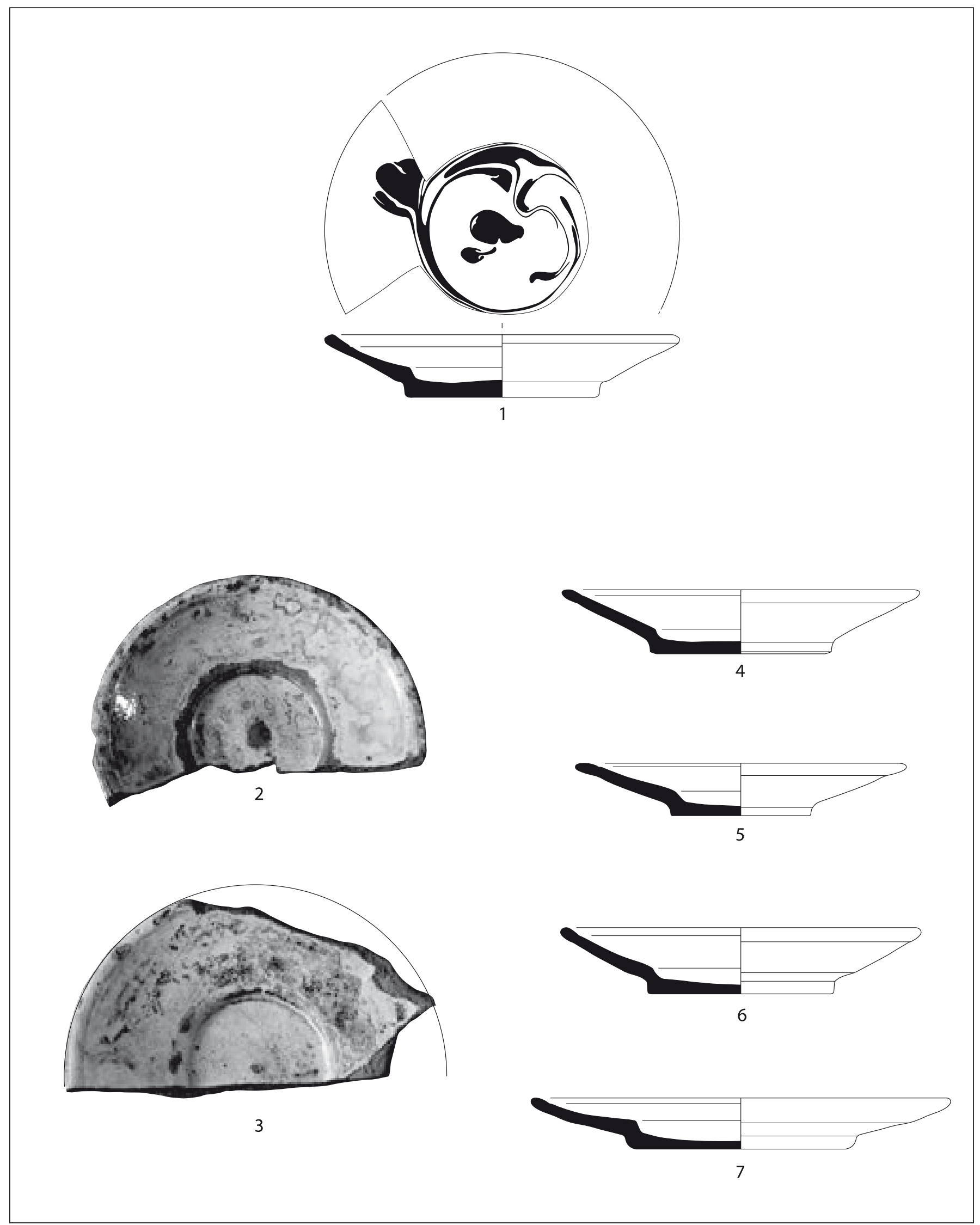

Fig. 144. Assiettes à ailes de l'arrière-pays marseillais (fin du XVII ${ }^{\mathrm{s}}$ s.). La Bourse. 


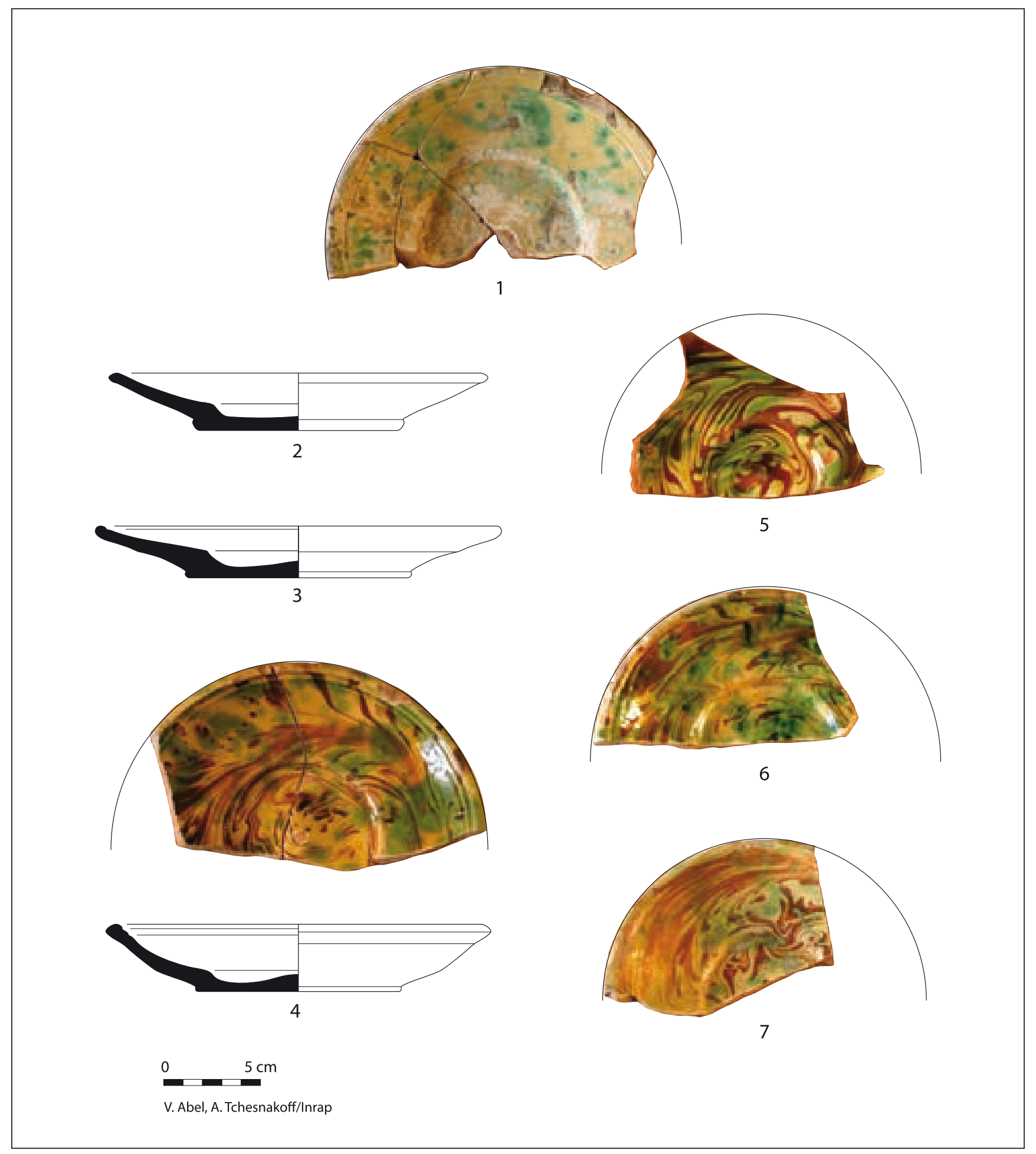

Fig. 145. Assiettes à ailes à fond plat, aile pour seule paroi, décorées de l'arrière-pays marseillais (fin du XVIIe s.). La Bourse. 


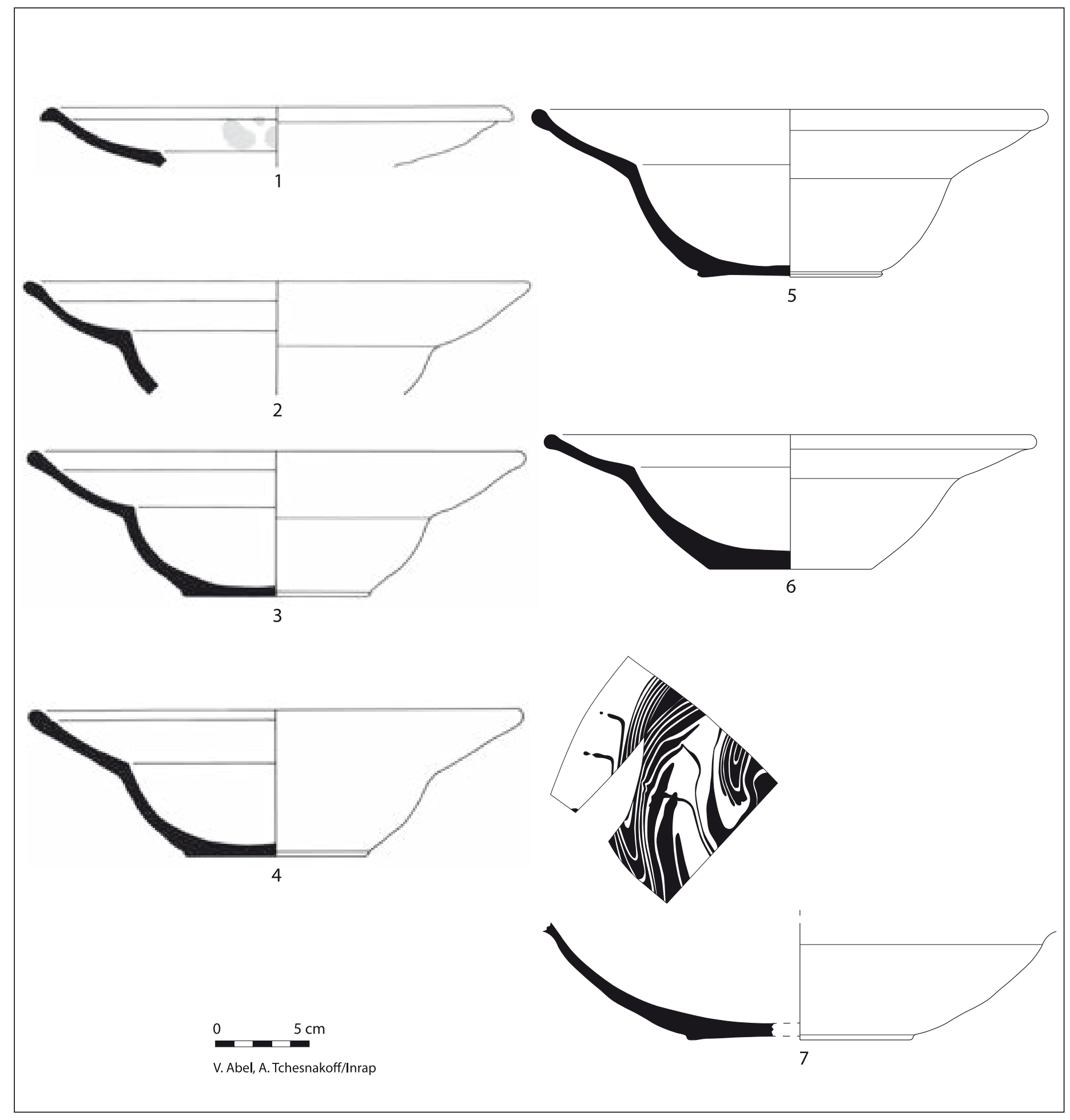

Fig. 146. Plats à aile de l'arrière-pays marseillais : vert sur jaspé (n²-3, 5), jaspé (n6) (fin du XVIIe s.). 1-4 : la Bourse ; 5-7 : la Charité. 


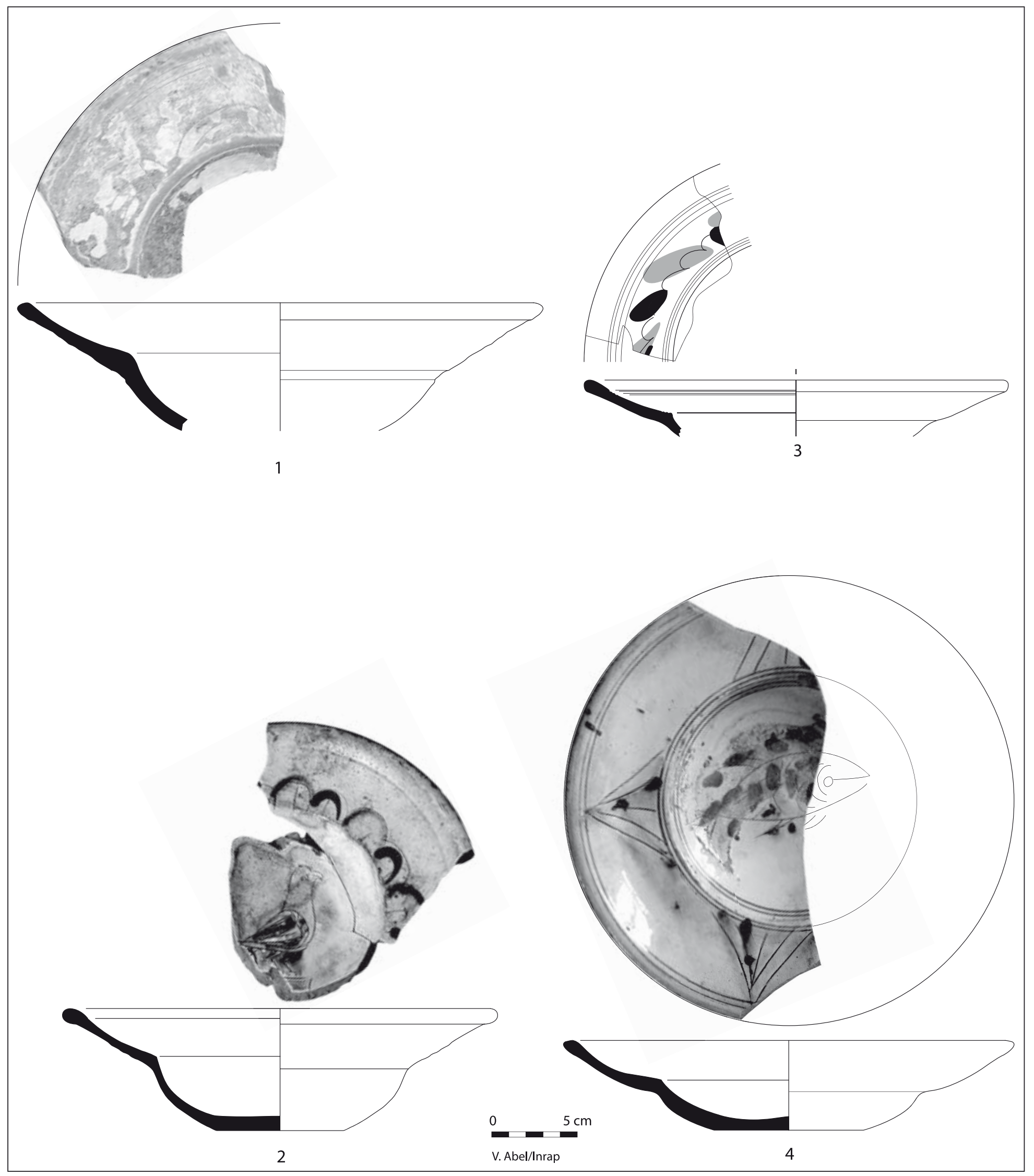

Fig. 147. Plats à aile de l'arrière-pays marseillais (fin du XVII s.). 1 : Hôtel-Dieu ; 2, 4 : la Bourse ; 3 : la Charité. 


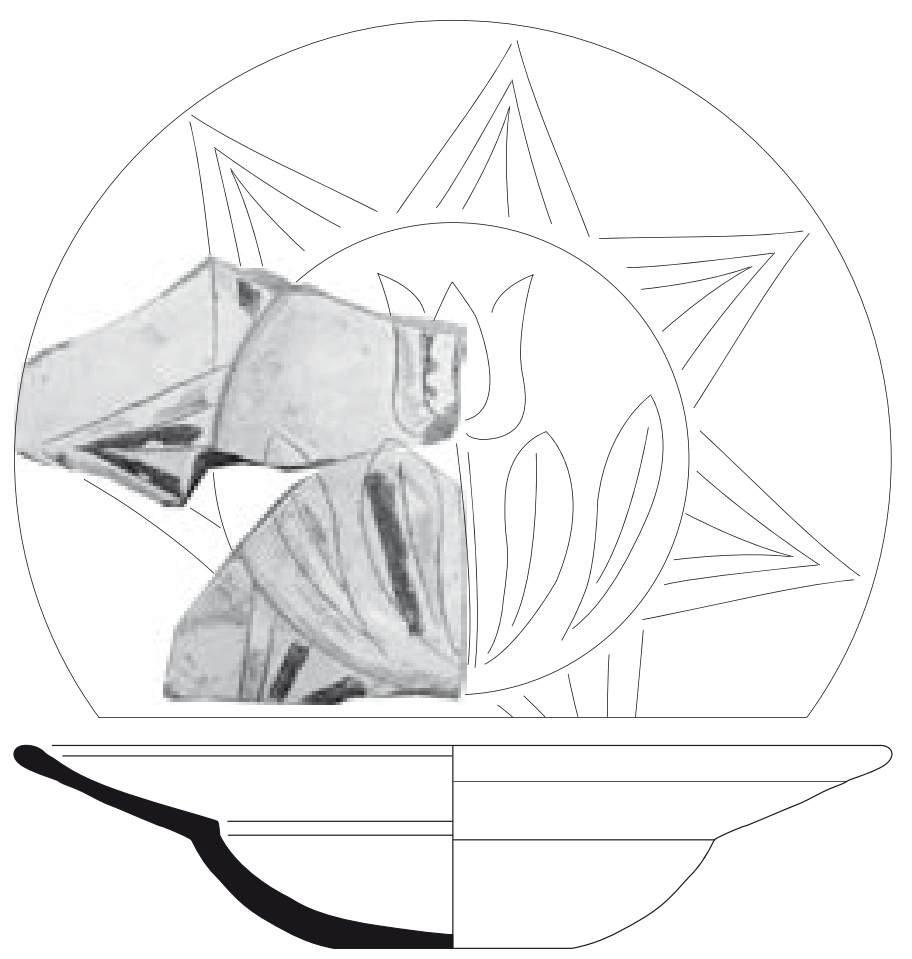

1
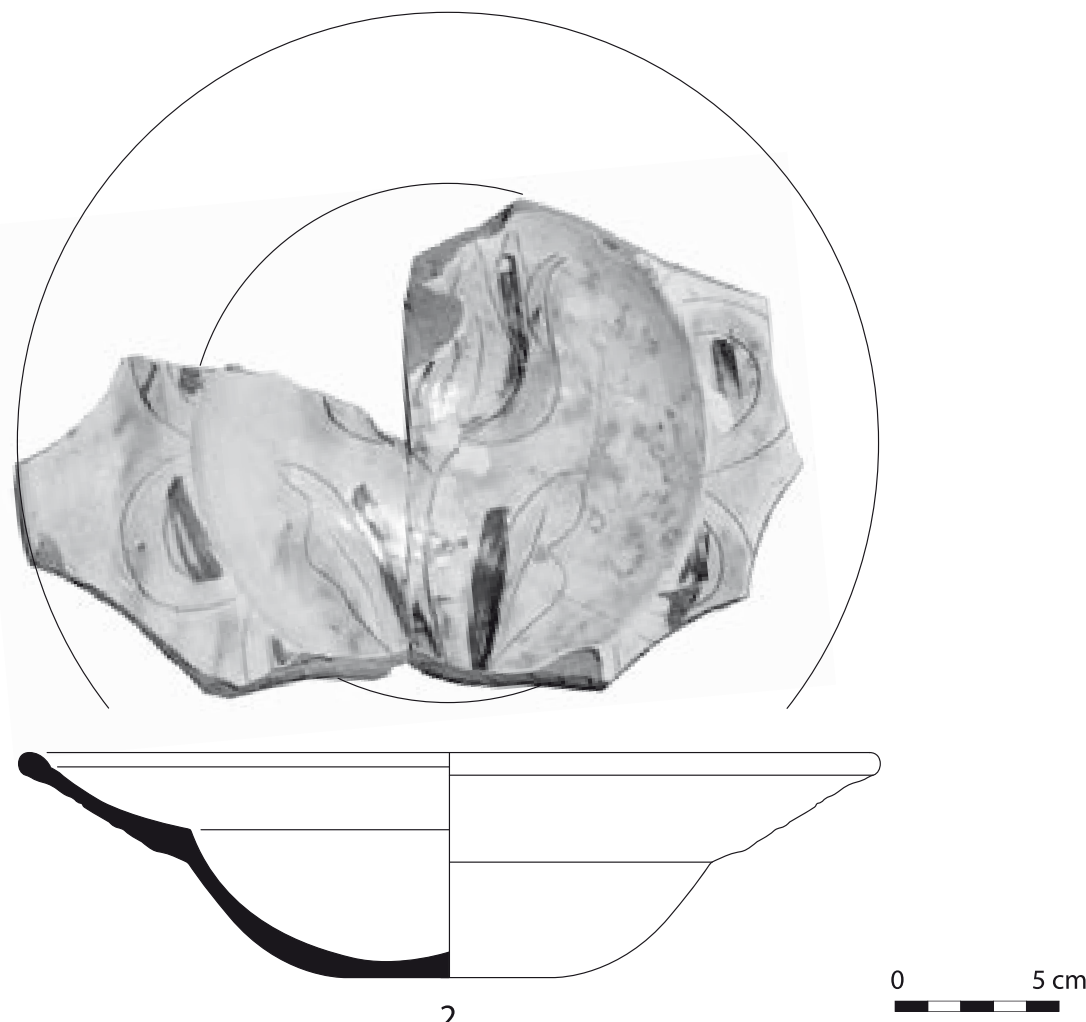

V. Abel/Inrap

Fig. 148. Plats à aile, bassin creux et aile ample, à décors incisés et polychromes, de l'arrière-pays marseillais (fin du XVII es.). 1 : Alcazar ; 2 : la Bourse. 


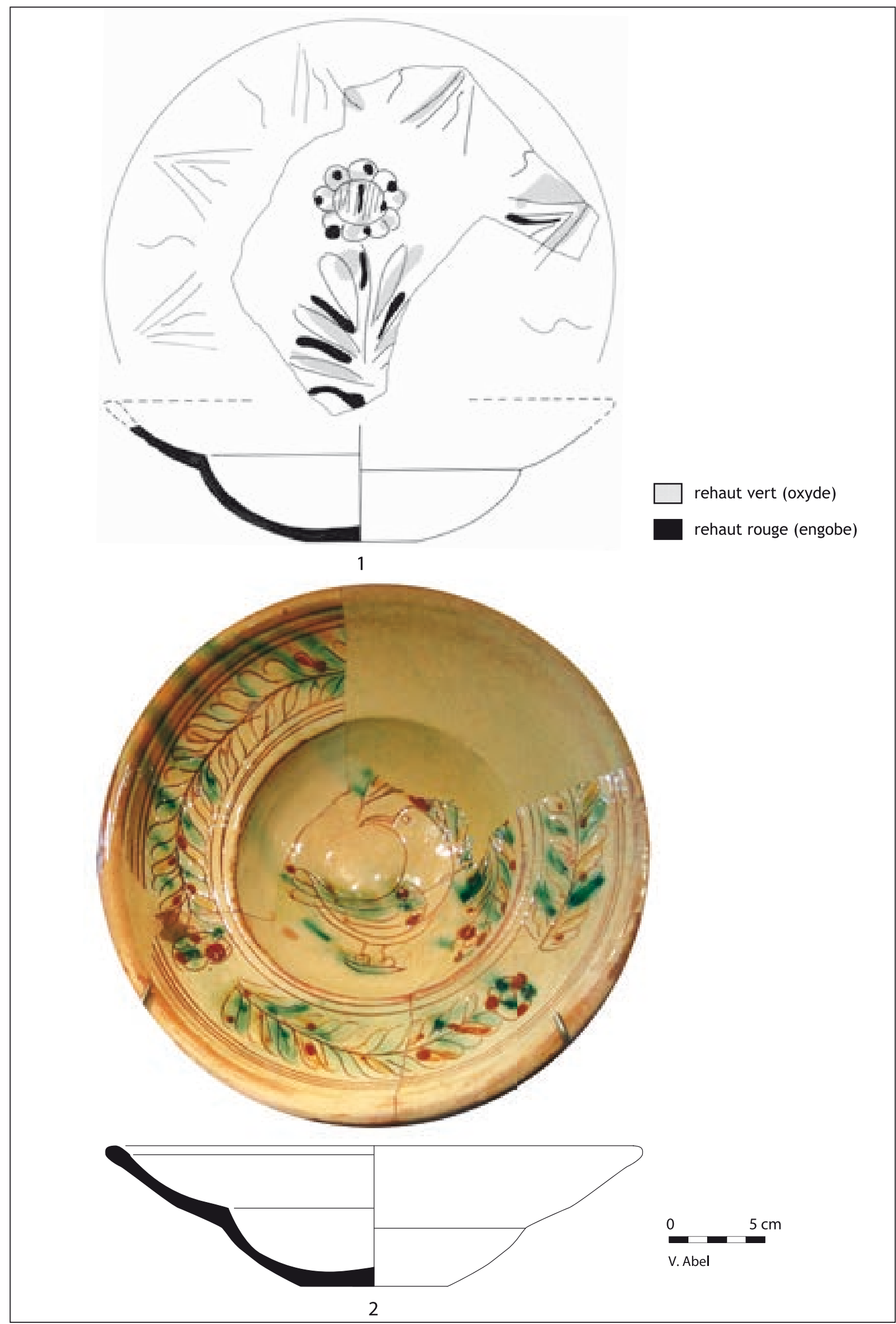

Fig. 149. Plats à décor incisé polychrome complexe, de l'arrière-pays marseillais (fin du XVII S.). La Bourse. 


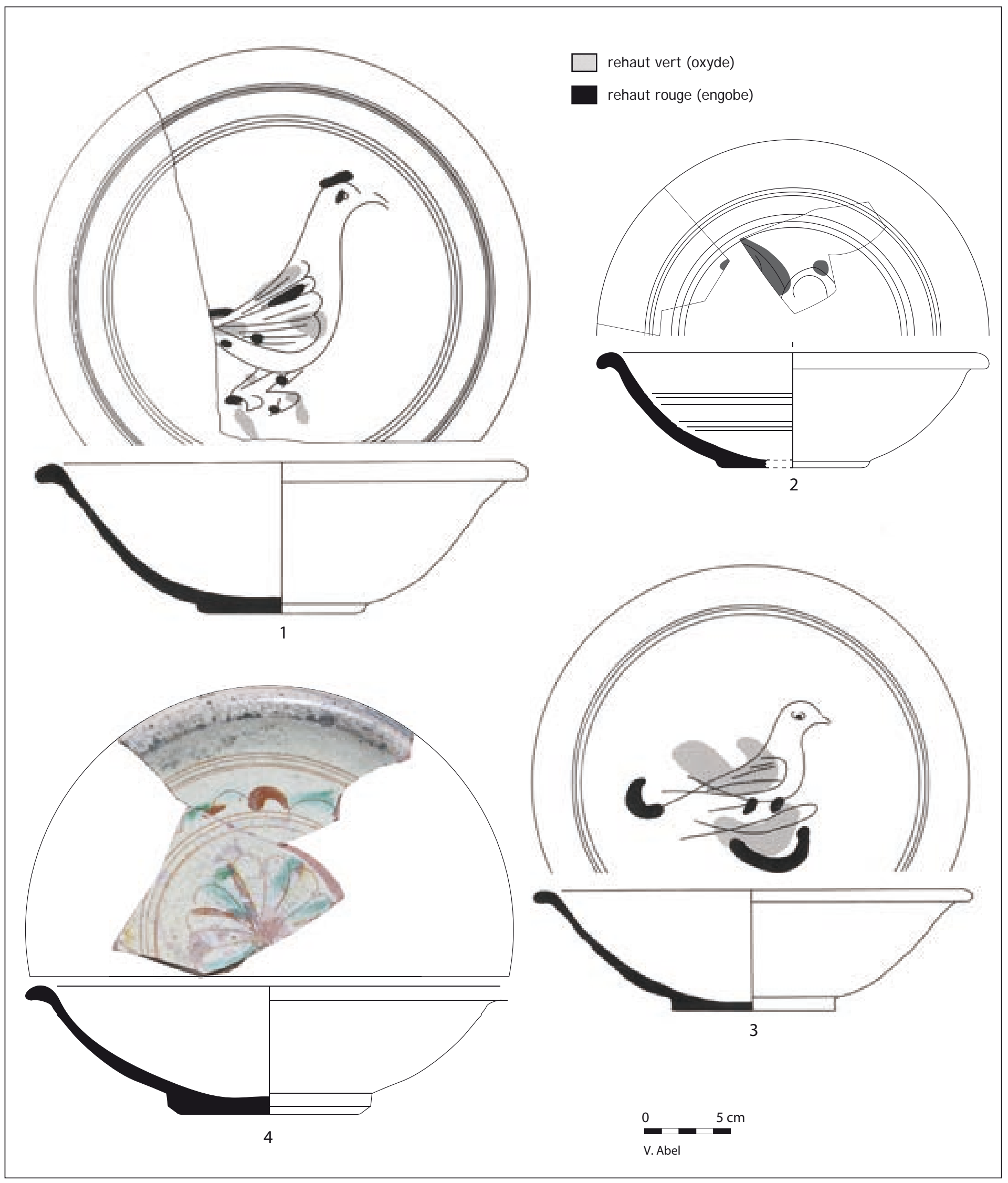

Fig. 150. Plats creux de l'arrière-pays marseillais (fin du XVII' s.). 1, 3 : la Bourse ; 2 : la Charité ; 4 : Hôtel-Dieu. 


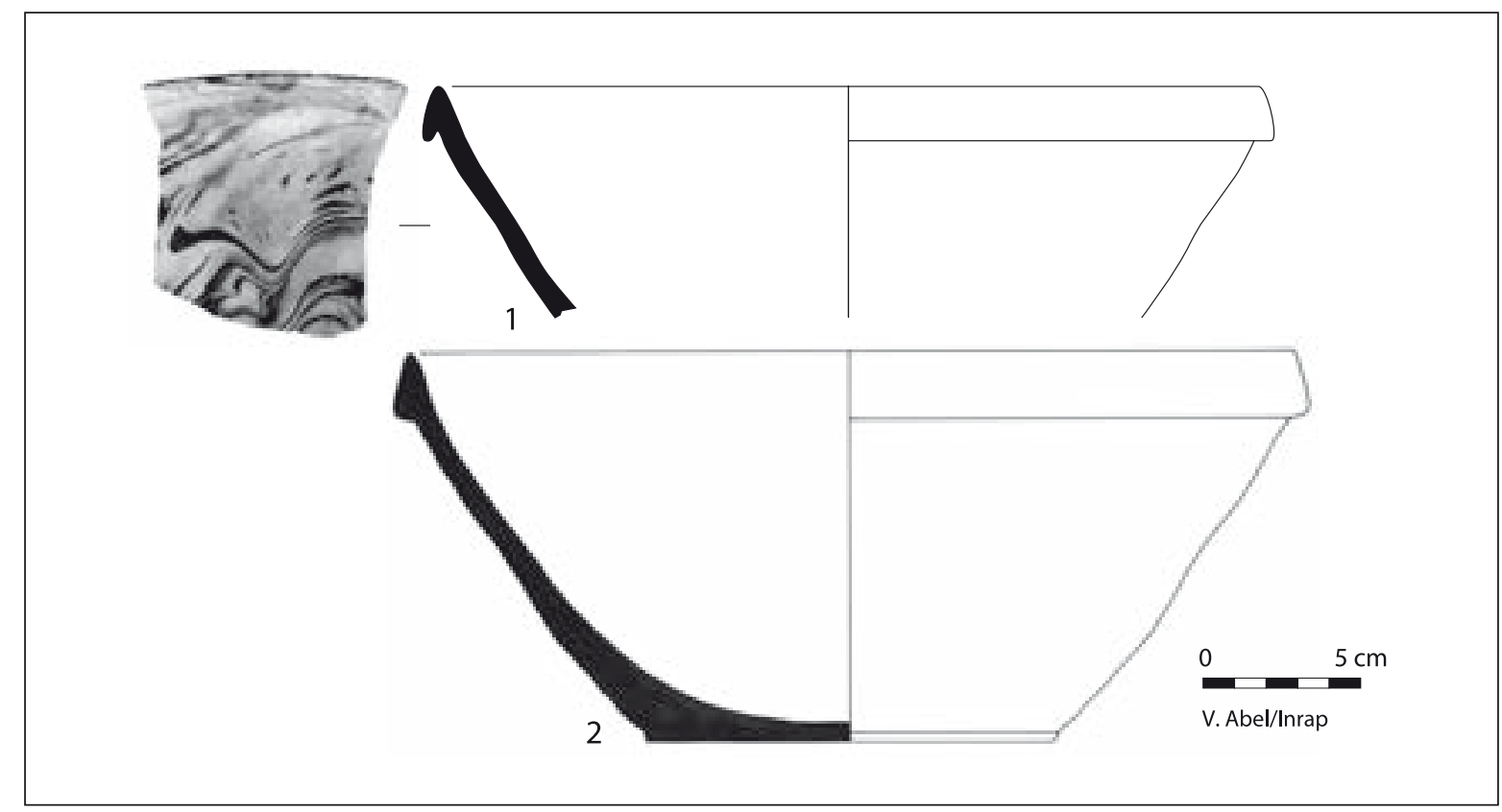

Fig. 151. Petits «tians » de l'arrière-pays marseillais (fin du XVII s.). 1 : Alcazar ; 2 : la Bourse.

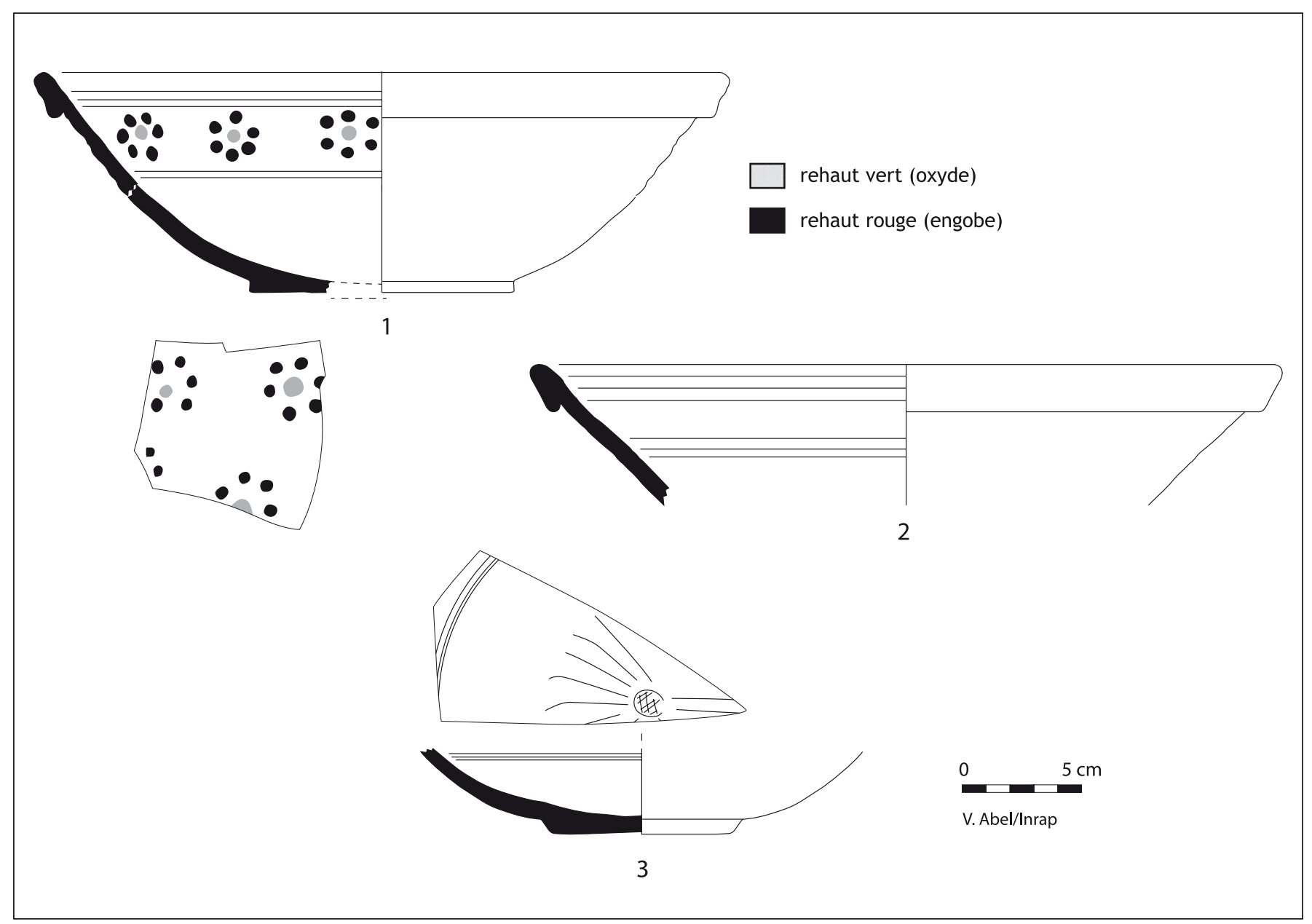

Fig. 152. Petits « tians » à décors incisés et polychromes, de l'arrière-pays marseillais (fin du XVII s.). La Charité. 
Sur des modèles courants d'assiettes ou de plats, parfois exceptionnellement amincis par tournassage, sont posés des décors plus recherchés. Une gamme de plats plus luxueux est donc proposée, vraisemblablement pour des occasions particulières (fig. 153 à 157).

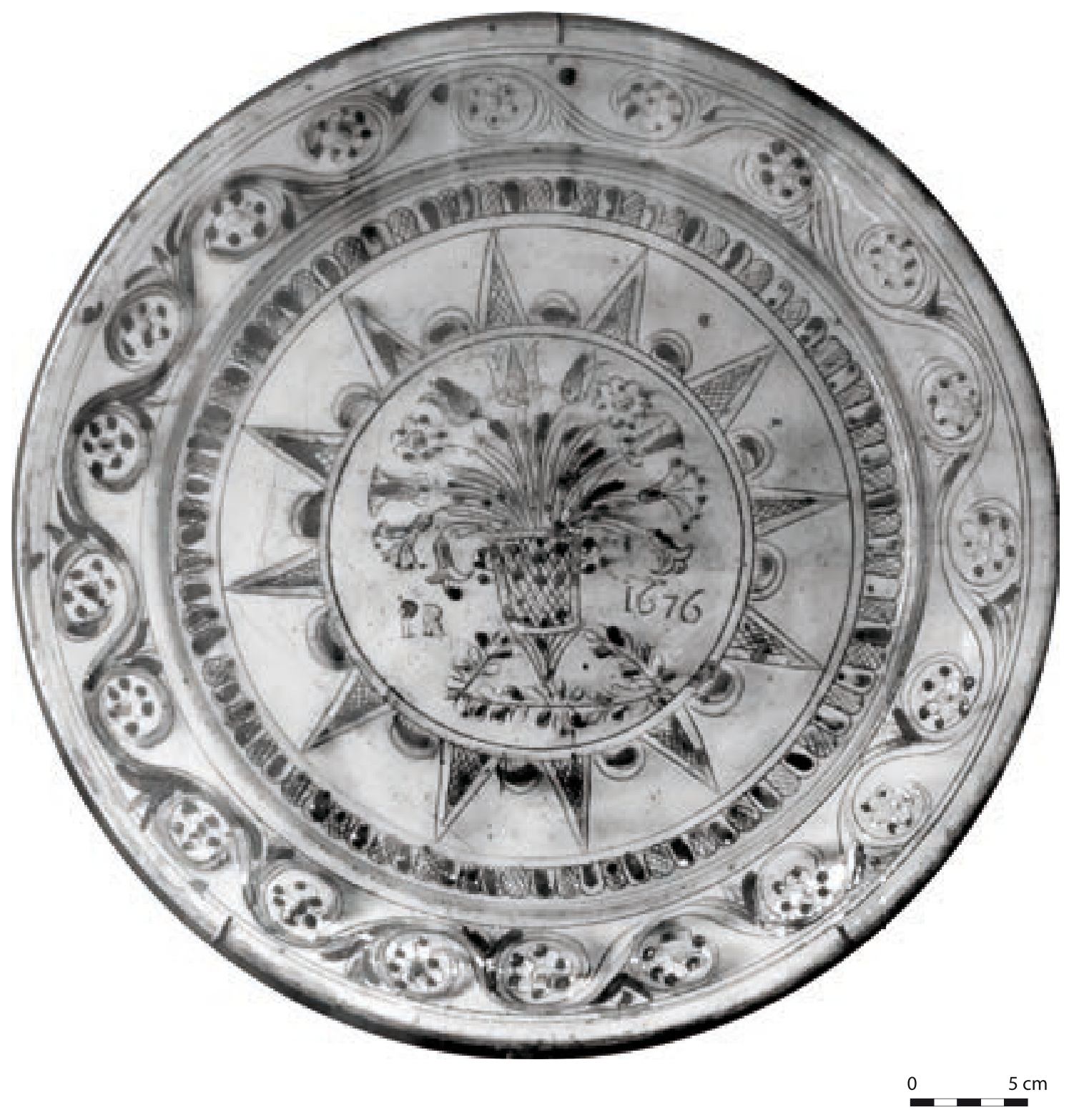

Fig. 153. Plat exposé au Musée de la faïence jusqu'en 2012 « aujourd'hui au Musée d'histoire ». Mention « I R ... 1676 » de part et d'autre du bouquet central (cl. Musées de Marseille). 

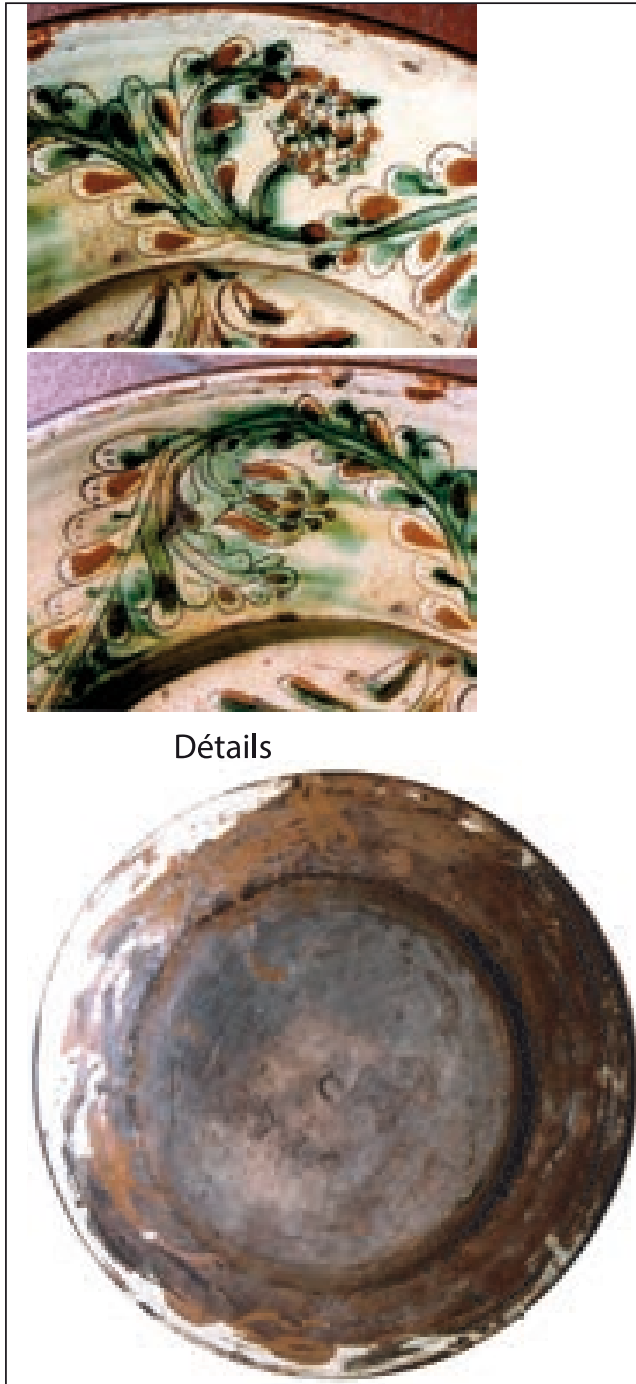

Revers

$0 \quad 5 \mathrm{~cm}$

Fig. 154. Plats à décor incisé polychrome complexe, de l'arrière-pays marseillais (fin du XVIIle S.). Plat appartenant à une famille aubagnaise, exposé en 1993 à Aubagne (Argilla) et en 1994 à Savone, forteresse du Priamar (coll. part.), (cl. V. Abel/Inrap).

Fig. 155. Plat exposé au Musée de la faïence jusqu'en 2012 (anc. Musée Cantini). Mention « Joseph Roubaud » sous la terrasse, pouvant être le nom du potier et/ou du décorateur (cl. V. Abel/Inrap).

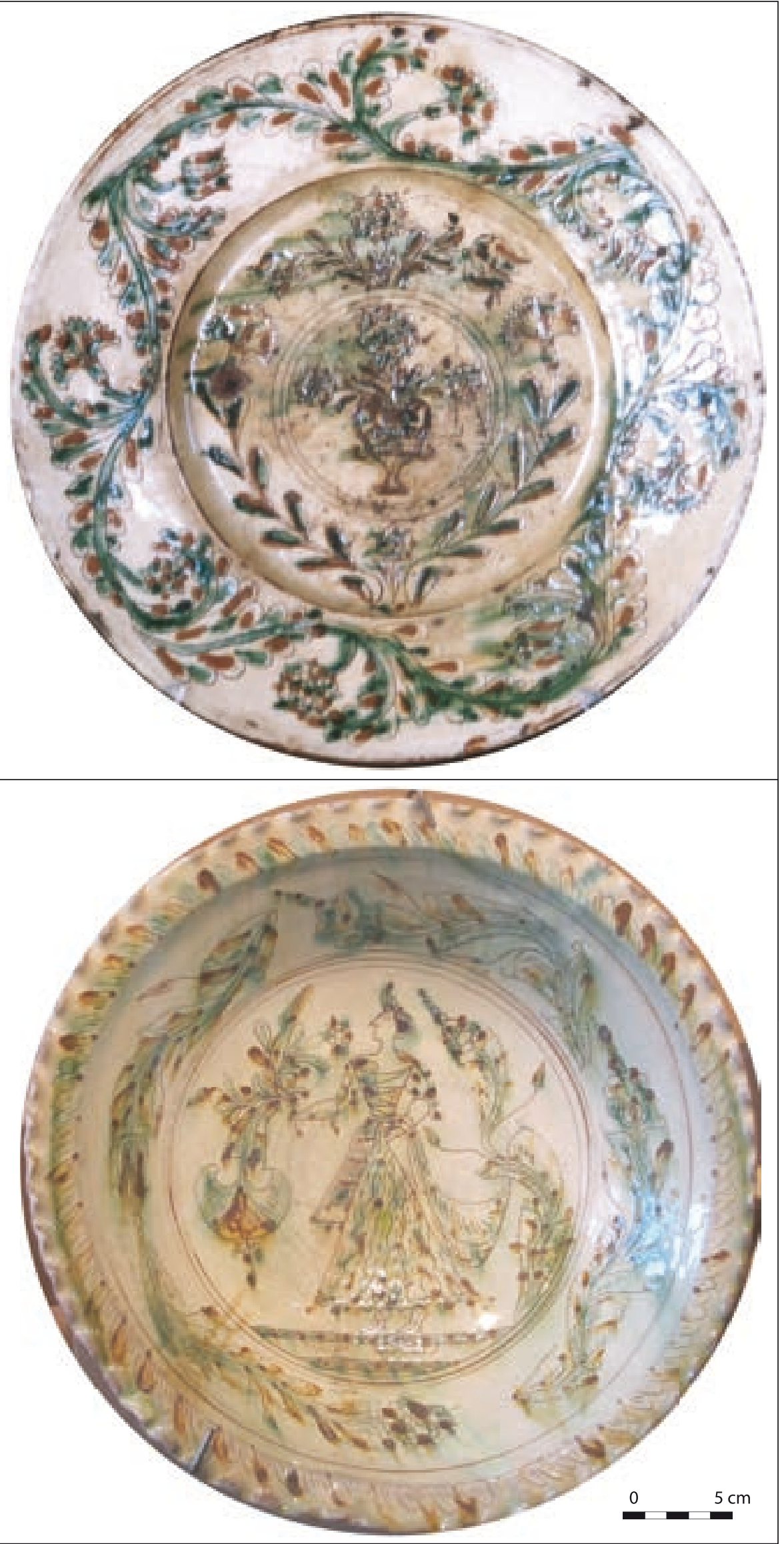




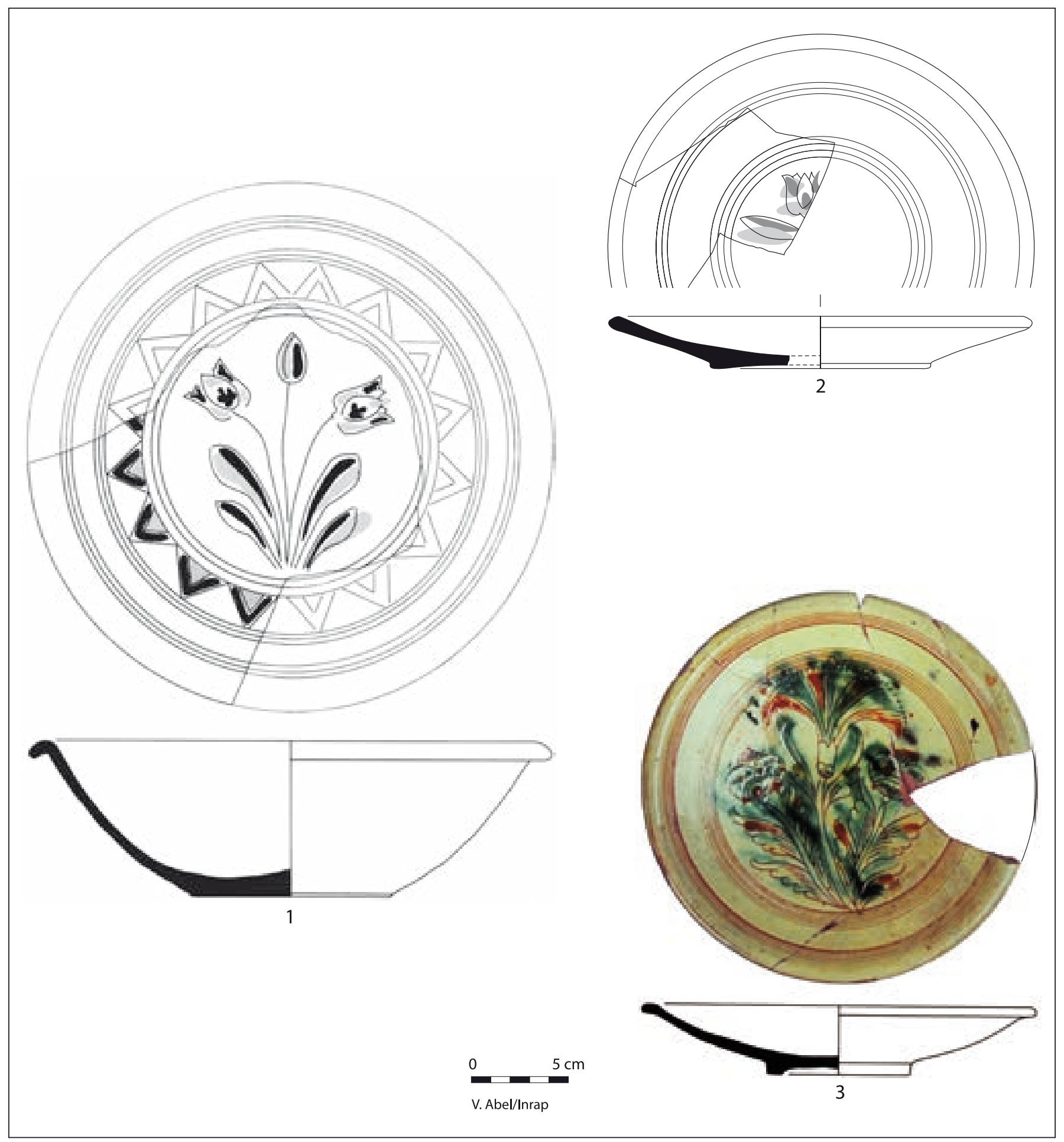

Fig. 156. Plats et assiettes à décor incisé polychrome complexe, de l'arrière-pays marseillais (fin du XVII $\mathrm{S}$.). 1,3 : la Bourse ; 2 : Alcazar. 


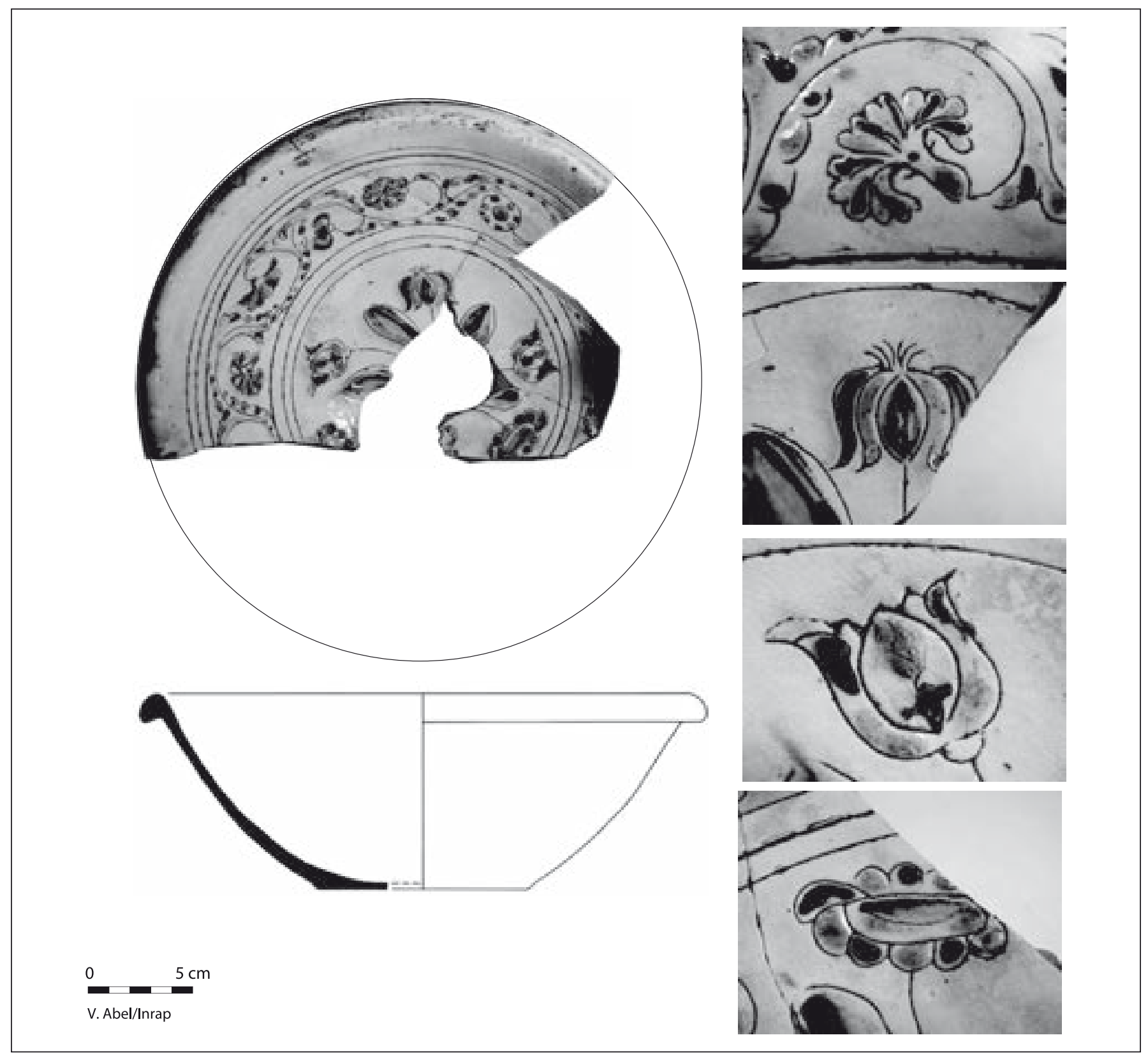

Fig. 157. Plats à décor incisé polychrome complexe, de l'arrière-pays marseillais (fin du XVIIe s.). La Bourse.

\subsection{Les vases à liquides : cruches et pichets}

Le site de la Bourse a livré le mobilier nécessaire (fig. 158 à 173) pour établir une typologie des vases à liquides, alors qu'ils sont difficilement perceptibles dans des niveaux d'habitat hors puits et autres structures du même type. Ce site a largement contribué à la connaissance des vernissées locales et, plus largement des céramiques d'usage quotidien par un unique type de structure, les puits, qui restent encore aujourd'hui presque les seuls de Marseille pour cette période. Vingtquatre puits modernes ont été vidés de leur comblement pendant les chantiers de la Bourse et leur mobilier plus ou moins récupéré. L'ensemble le plus complet est issu d'un puits du carré virtuel F-I 9 et dépasse 3000 fragments, soit le quart du total des tessons de modernes étudiés pour ce site.

La question que posent ces céramiques est celle de leur homogénéité chronologique. Un puits contient en majeure partie des poteries directement en rapport avec sa fonction : des cruches et pichets pour puiser et transporter l'eau brisés dans la manœuvre. Il peut rester en service très longtemps, mais comme il est régulièrement 
Fig. 158. Vases à liquides de l'arrière-pays marseillais : pichets à vernis vert et pichet à décor incisé polychrome (fin du XVII s.). La Bourse.

$$
\text { V. Abel, A. Tchesnakoff/Inrap }
$$

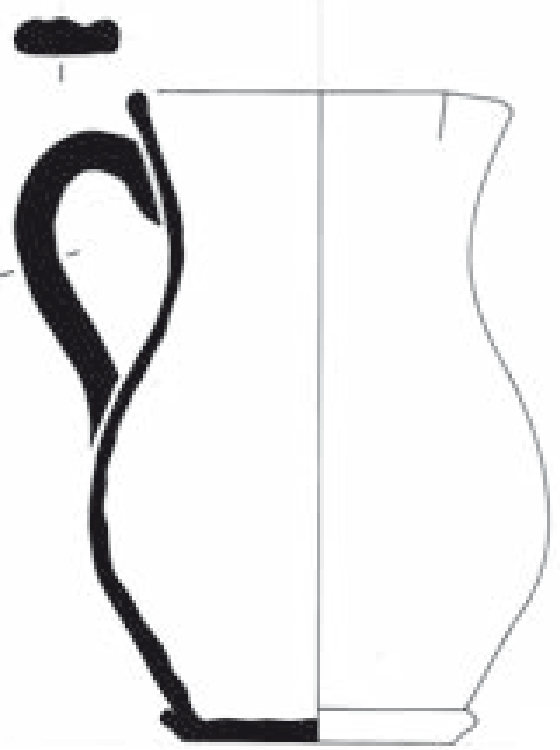

2

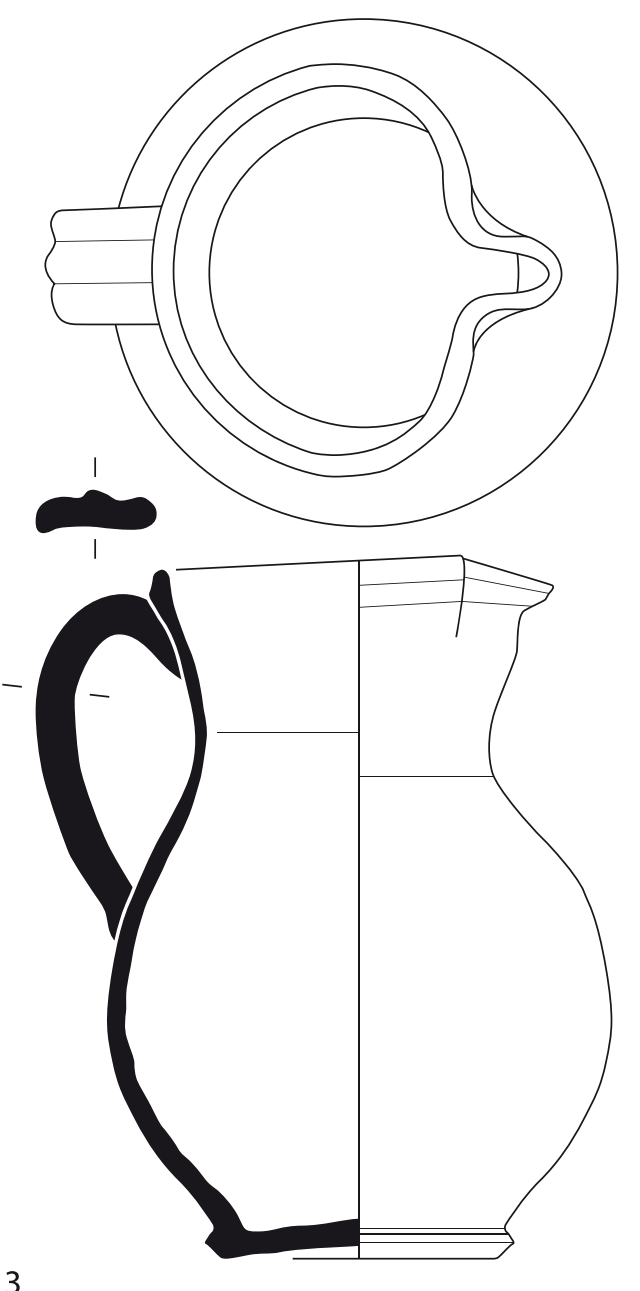

3 


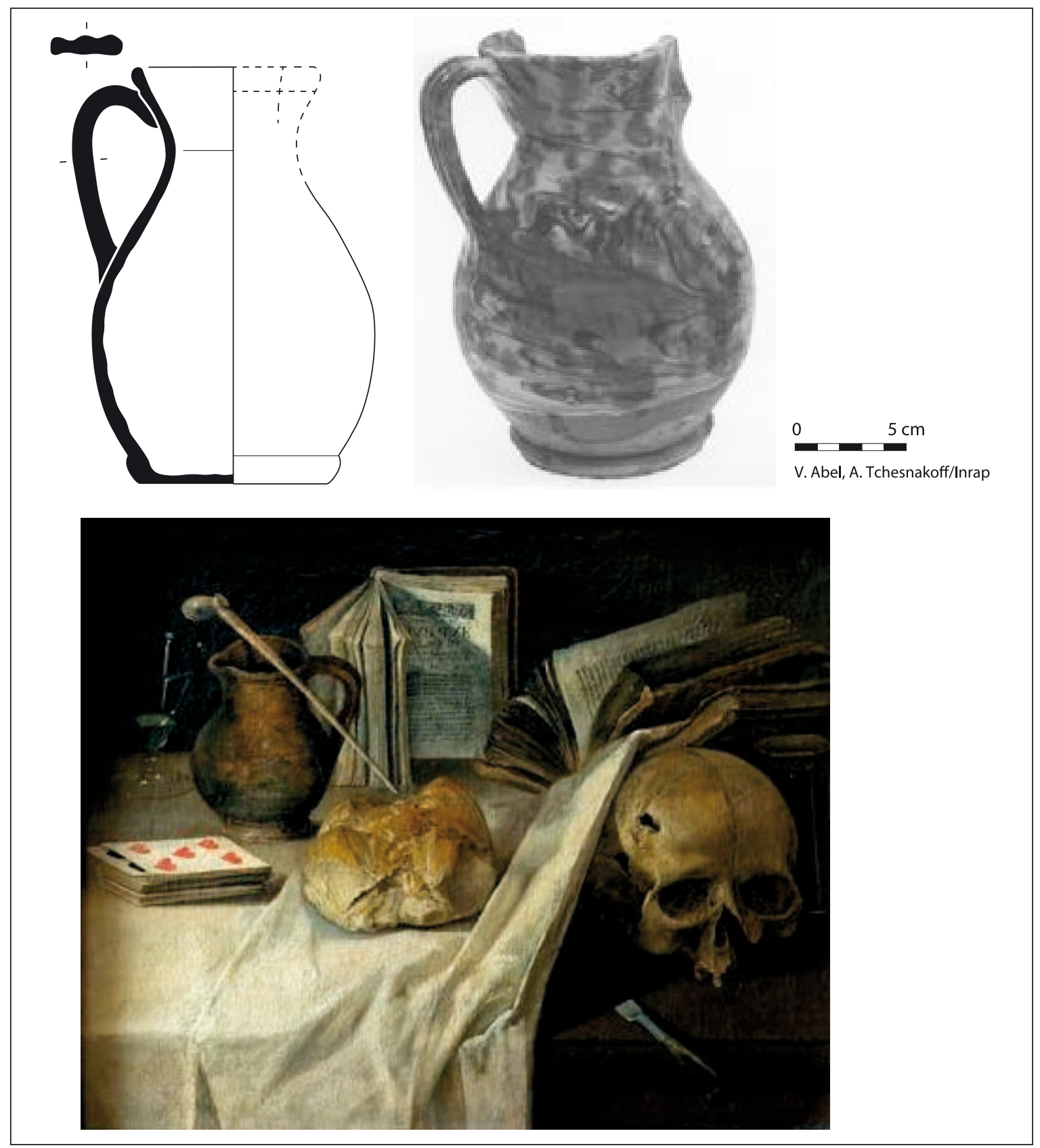

Fig. 159. Pichets à vernis jaspé (fin du XVII $\mathrm{S}$.). La Bourse. Maître de l'almanach,

Damien Lhomme (attribué à), École Française, «Vanité », vers 1640. Peinture. Huile sur toile. 50,5 x 60,5 cm. (Musée d'art moderne de Saint-Étienne, DR).

nettoyé, notamment en période de sécheresse où le niveau de la nappe phréatique baisse, les vases qui y sont retrouvés témoignent de la dernière période d'utilisation. Le puits est abandonné à la suite d'un tarissement, d'une pollution ou d'une modification du bâti. Il sert alors de dépotoir et concentre les déchets domestiques de tous ordres en plus des vases à liquide, puis parfois des décombres. Son comblement témoigne donc d'une période d'utilisation assez courte en tant que puits et en tant que dépotoir. Sur le site de la Bourse, les différentes terres vernissées italiennes, pisanes graffita a stecca, puis graffita tarda ensuite et enfin vaisselle à taches noires d'Albisola, n'étaient pas associées dans les même puits, confirmant l'homogénéité des comblements.

Au premier rang des vases les plus utilisés pour le transport et le service des liquides se distinguent toujours la cruche et le pichet. La première est cordiforme plus que piriforme, elle a une forte anse supérieure rappelant celle des paniers, aux attaches de laquelle sont placés une petite anse latérale et un bec tubulaire opposé. 


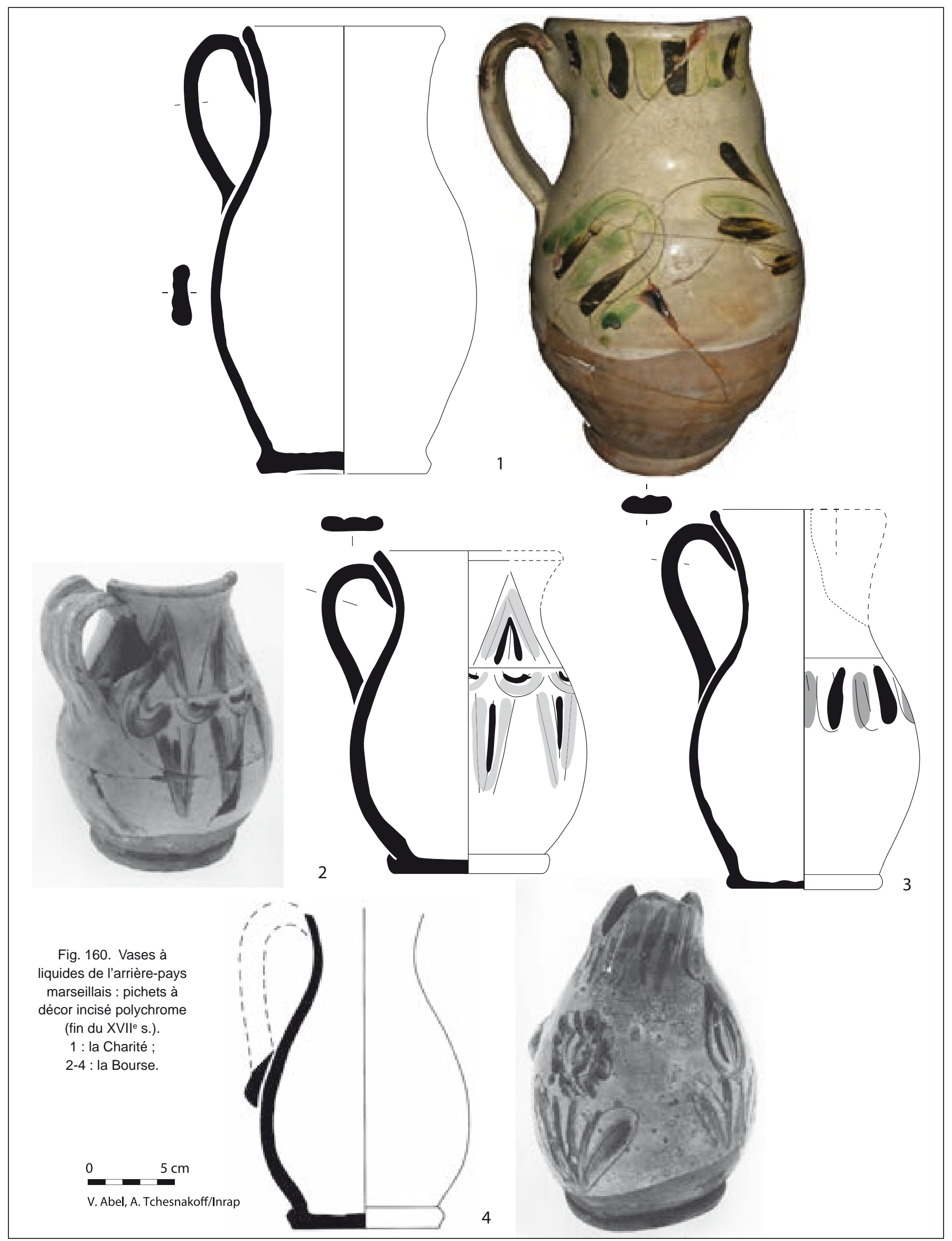




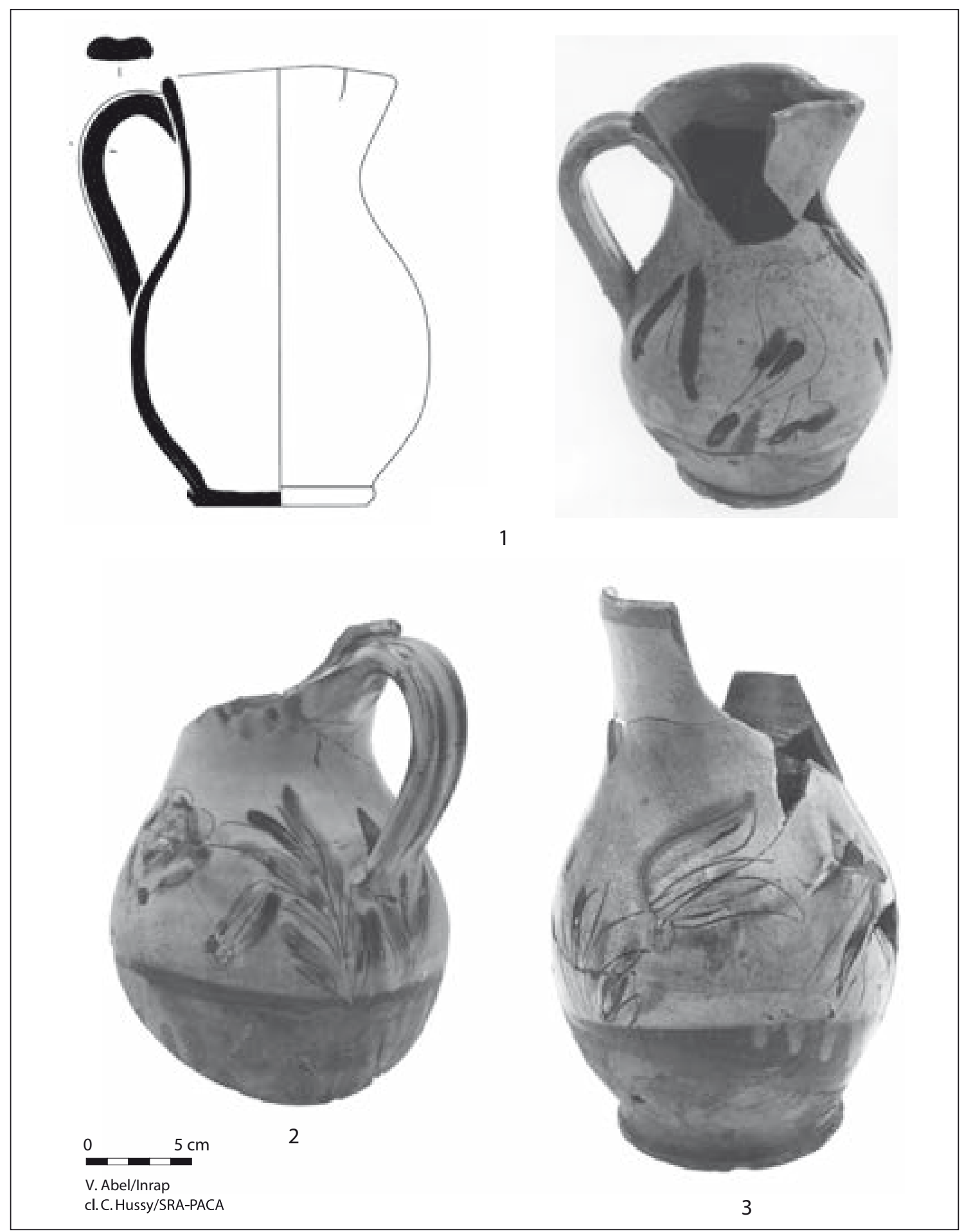

Fig. 161. Vases à liquides de l'arrière-pays marseillais : pichets à décor incisé polychrome (fin du XVIIe s.). La Bourse. 

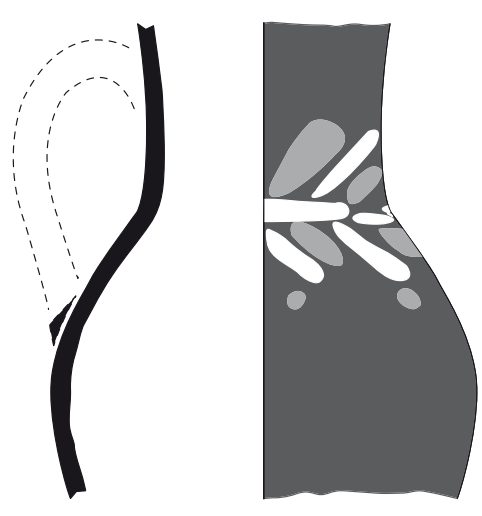

1

engobe rouge engobe blanc

engobe blanc et oxyde de cuivre

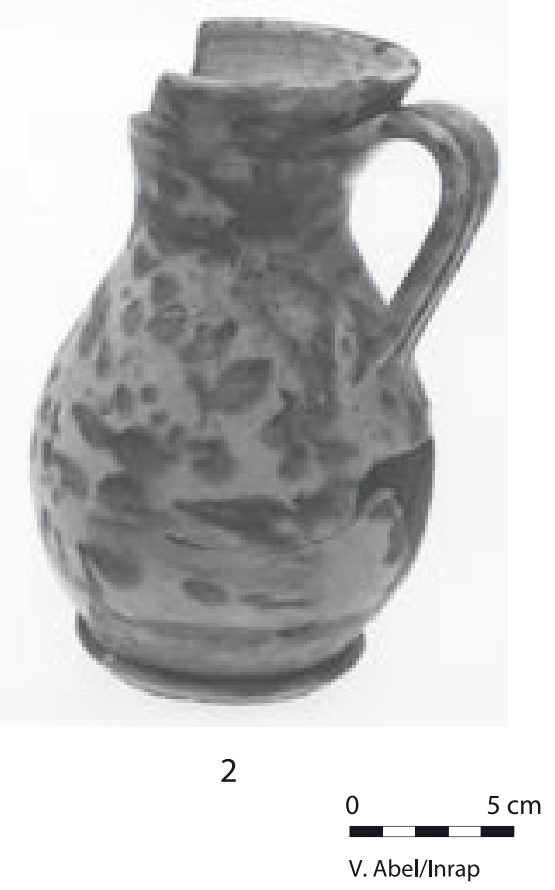

Fig. 162. Vases à liquides de l'arrière-pays marseillais : pichets à décor polychrome (fin du XVII' s.). La Bourse.

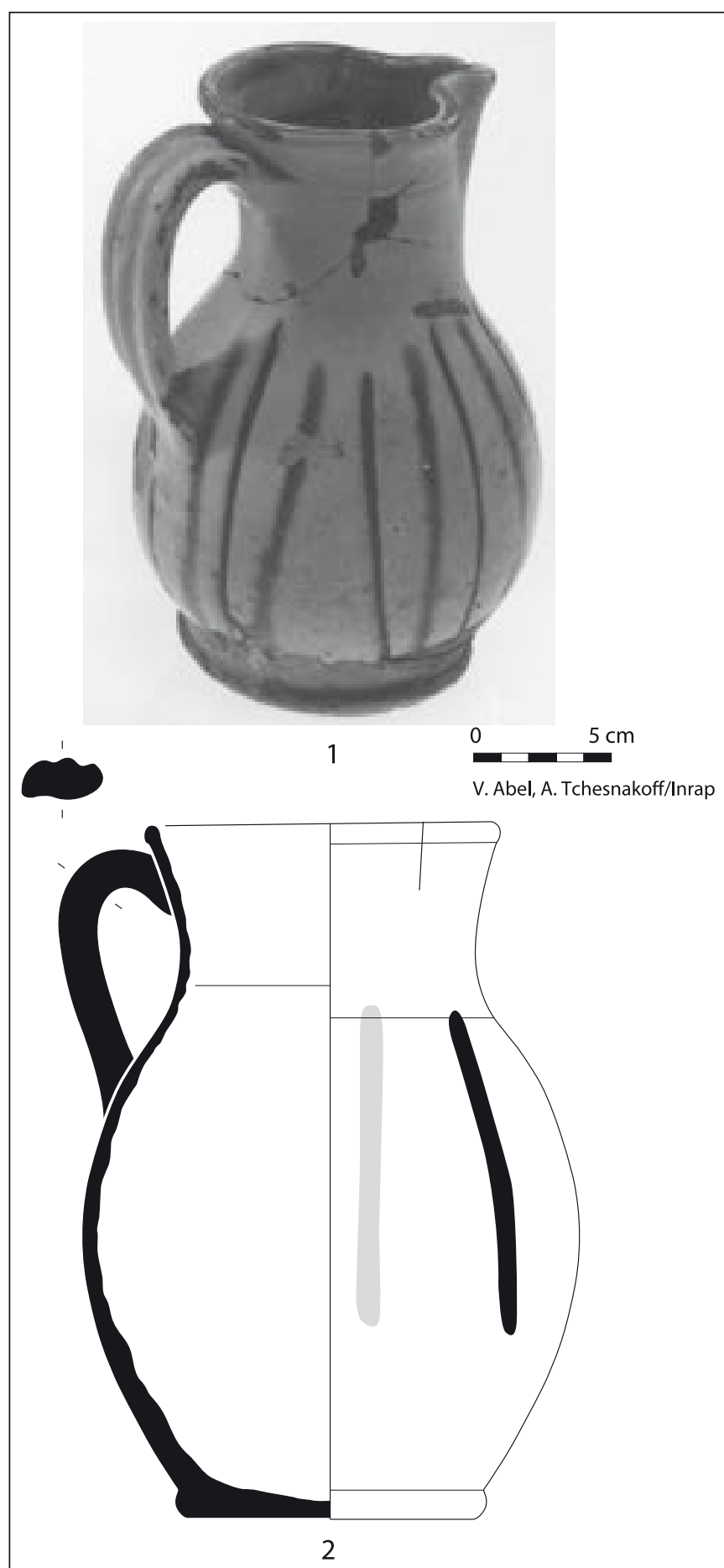

Fig. 163. Vases à liquides de l'arrière-pays marseillais : pichets à décor polychrome (fin du XVII $\mathrm{s}$.). La Bourse. 

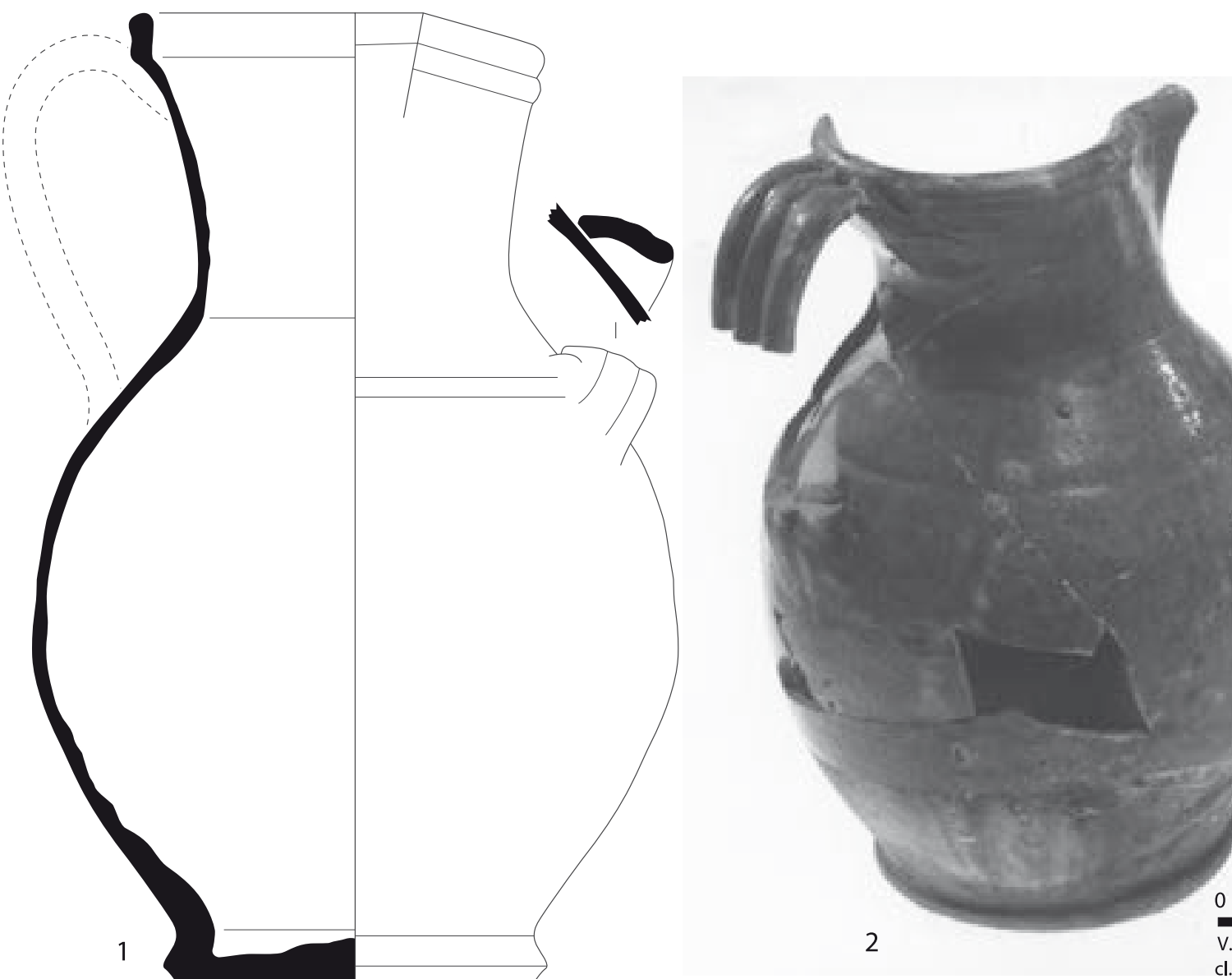

Fig. 164. Vases à

liquides de l'arrière-

pays marseillais : pichet (fin du XVII $\mathrm{e}$.). La Bourse.
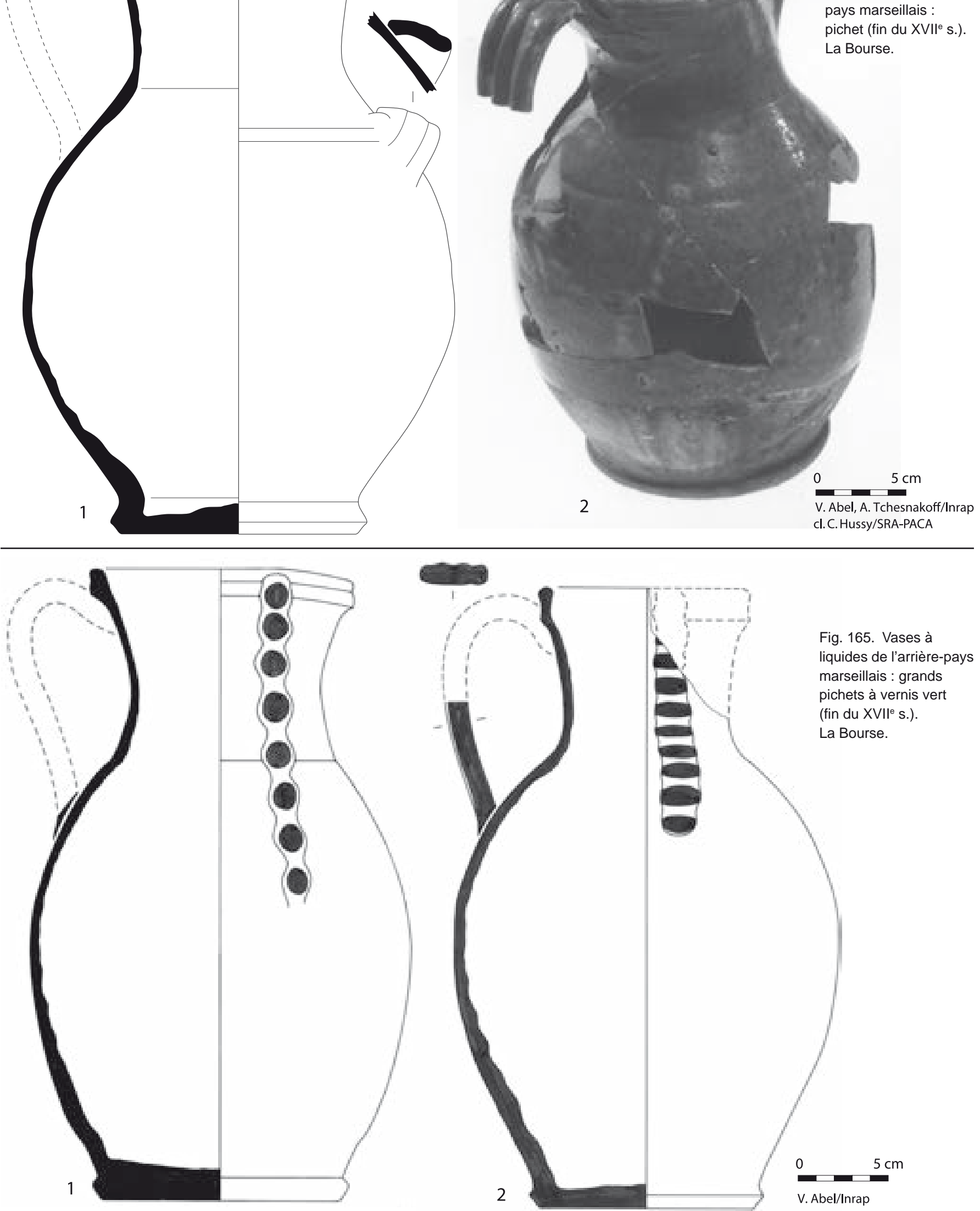


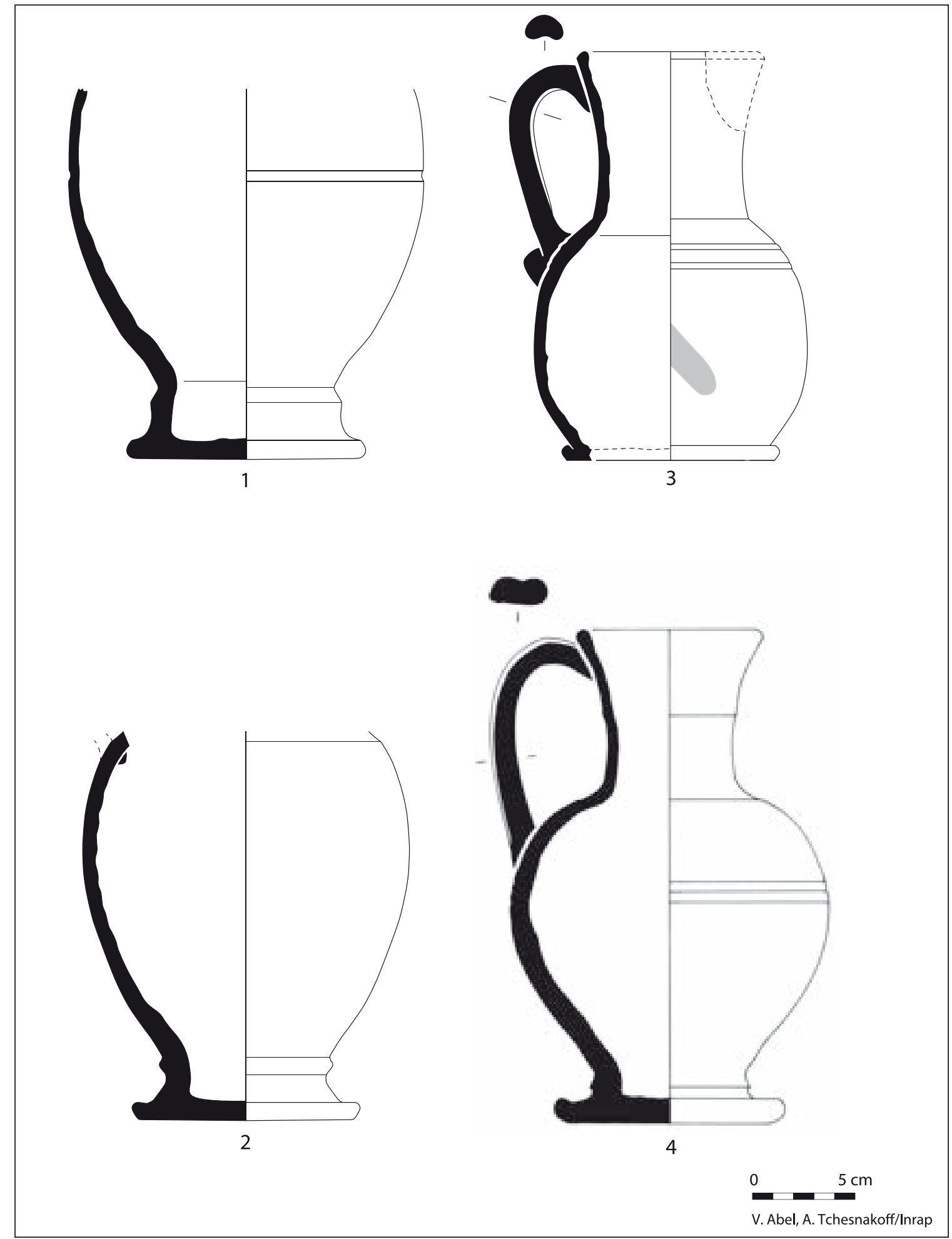

Fig. 166. Vases à liquides de l'arrière-pays marseillais : aiguières (fin du XVII $\mathrm{s}$.). La Bourse. 


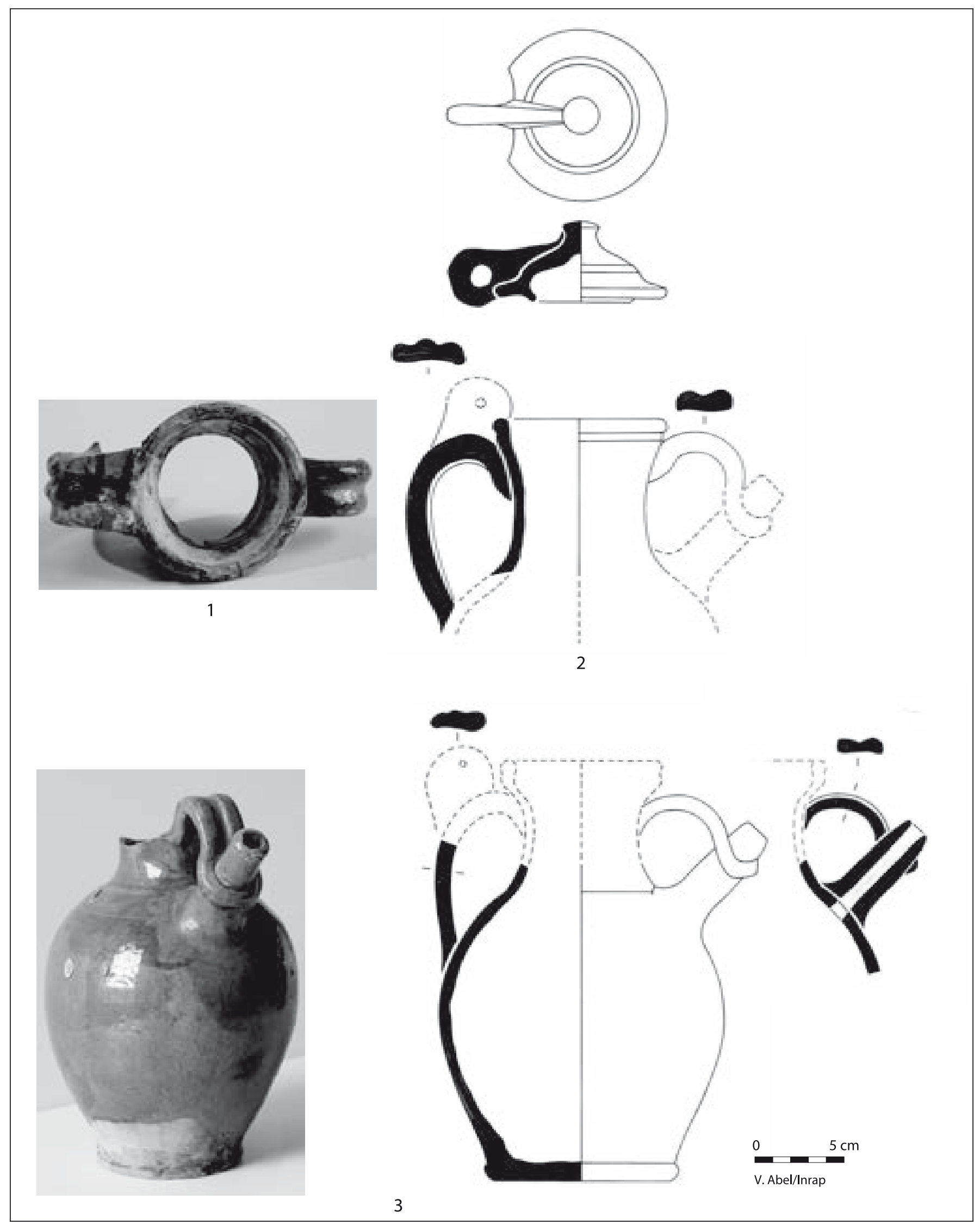

Fig. 167. Vases à liquides de l'arrière-pays marseillais : pichets à système de charnière et couvercle s'y adaptant (fin du XVIIe s.). La Bourse. 
CHAPITRE 7 - LA CÉRAMIQUE D’USAGE QUOTIDIEN À MARSEILLE DE 1660 À 1710

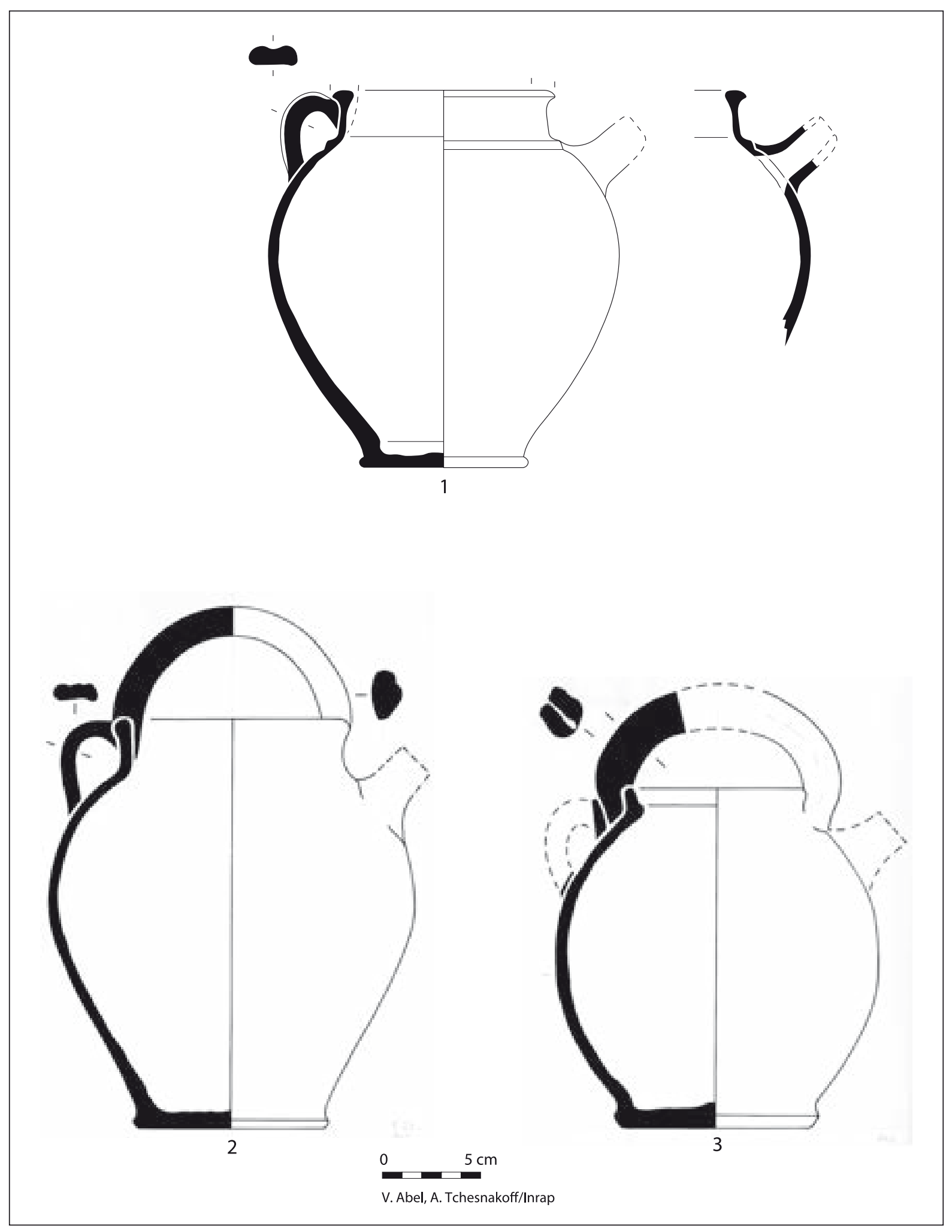

Fig. 168. Vases à liquides de l'arrière-pays marseillais : cruches (fin du XVII' s.). La Bourse.

199 


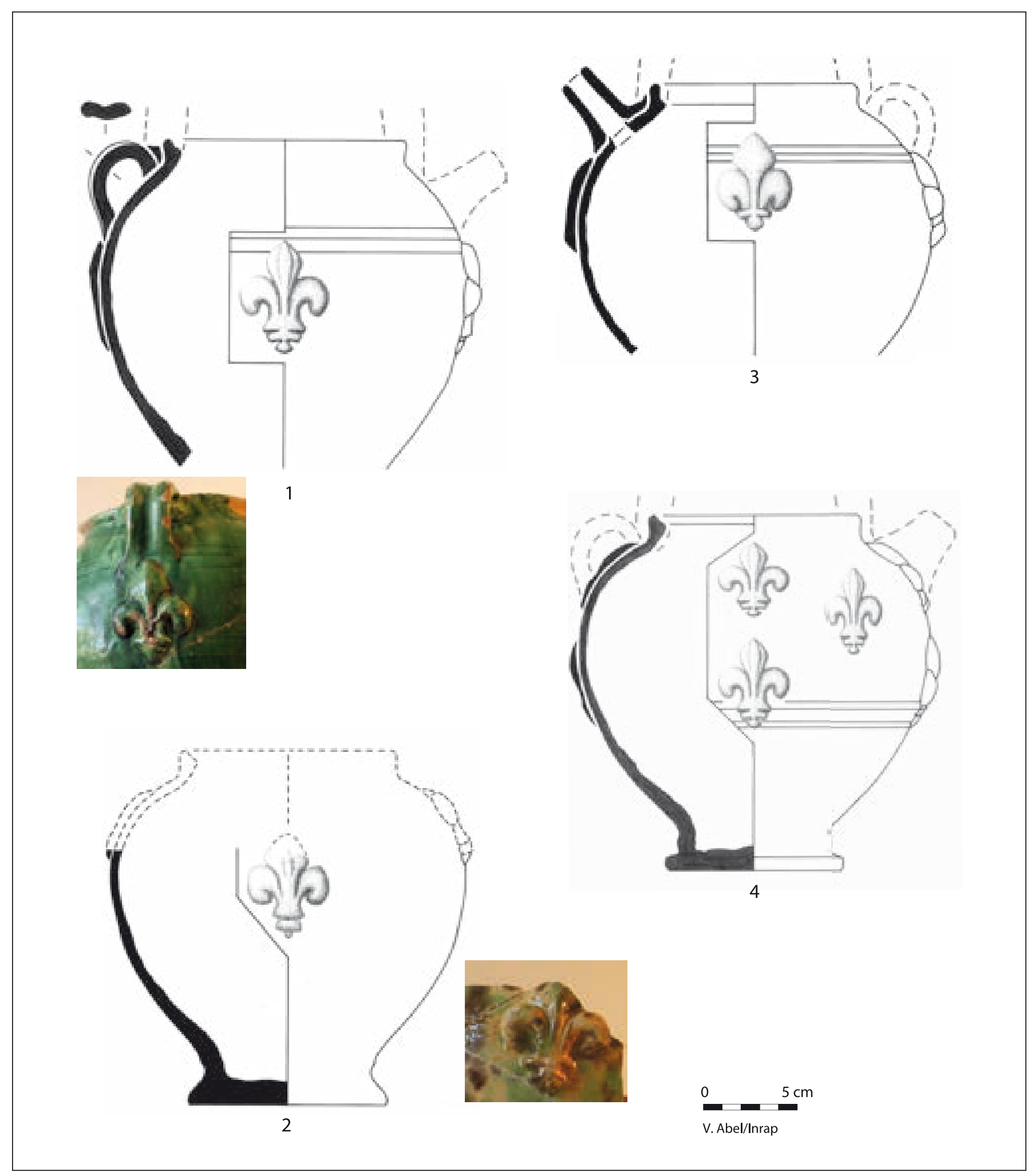

Fig. 169. Vases à liquides de l'arrière-pays marseillais : cruches à décor d'applique avec fleur de lys (fin du XVIIe S.). La Bourse. 


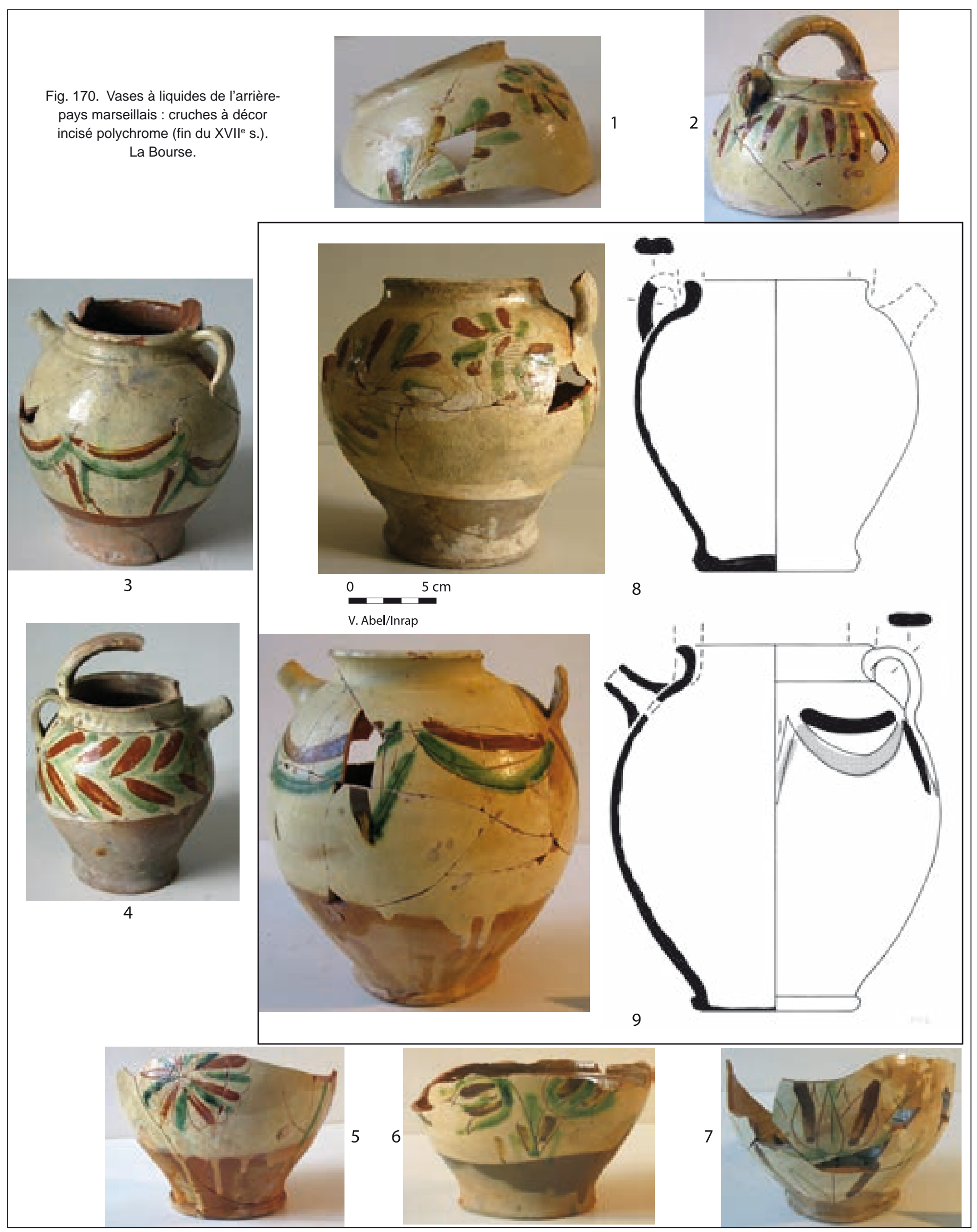




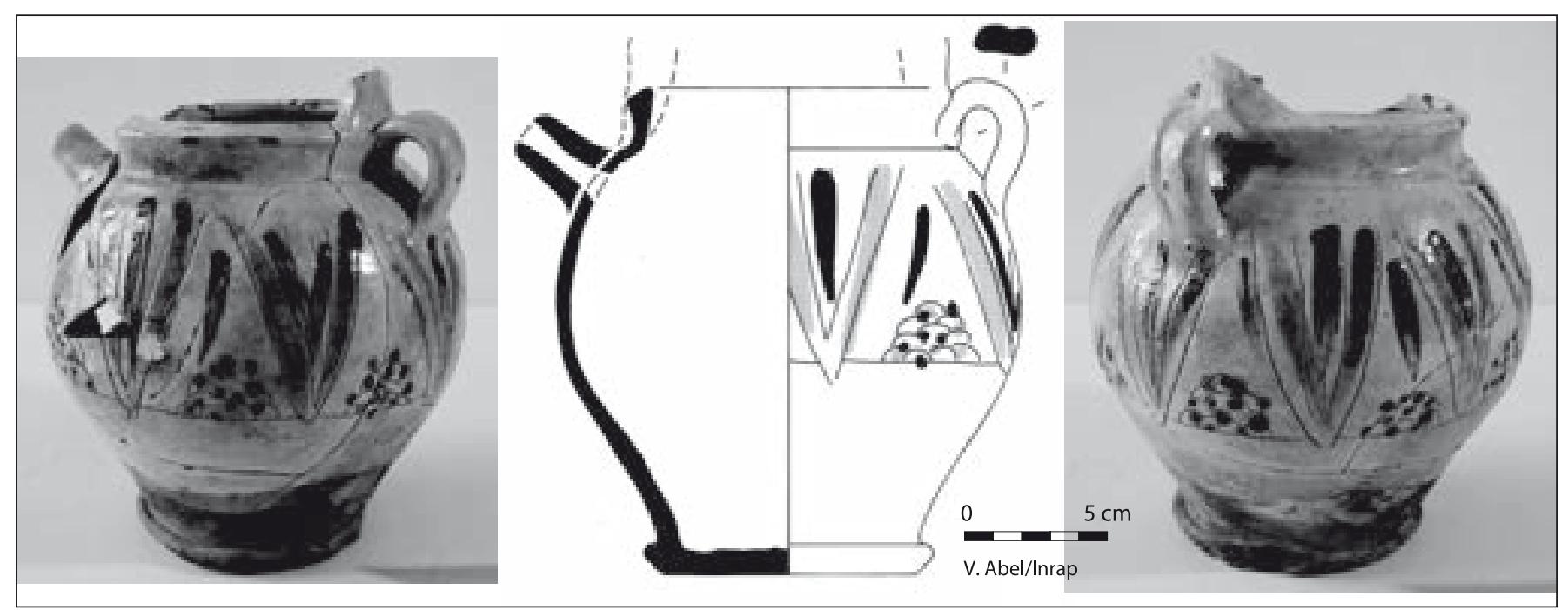

Fig. 171. Vases à liquides de l'arrière-pays marseillais : cruches à décor incisé polychrome (fin du XVII s.). La Bourse.

Fig. 172. Vases à liquides de l'arrière-pays marseillais : cruches à décor polychrome (fin du XVII' S.). La Bourse.
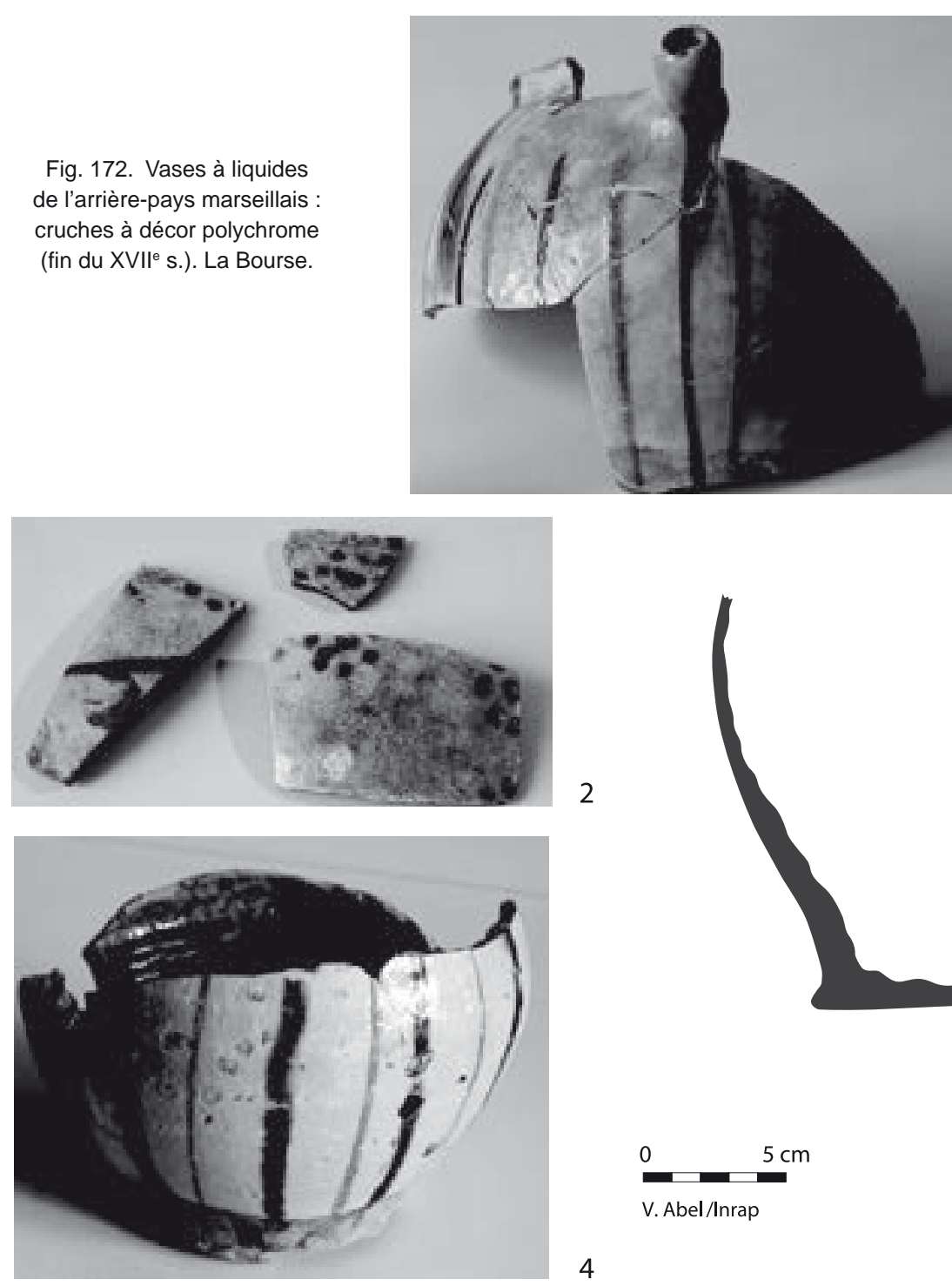

2
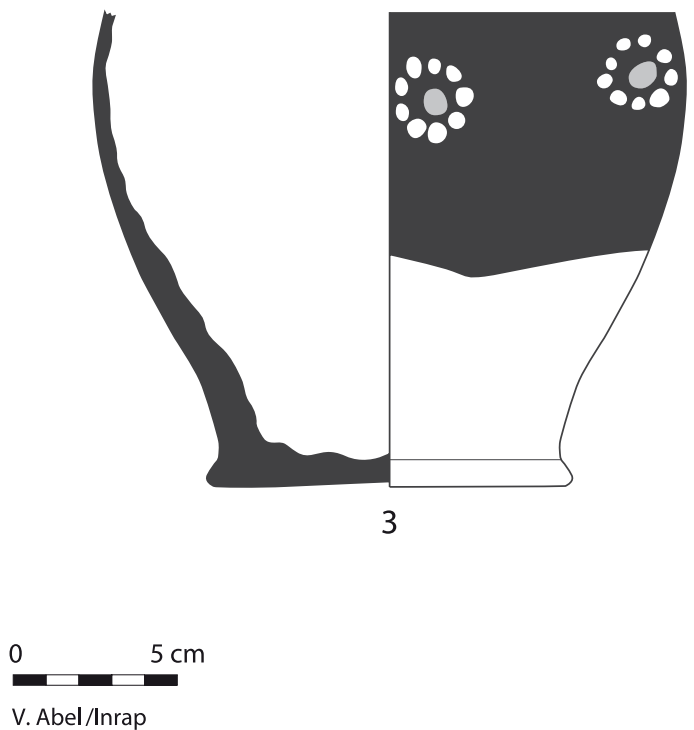


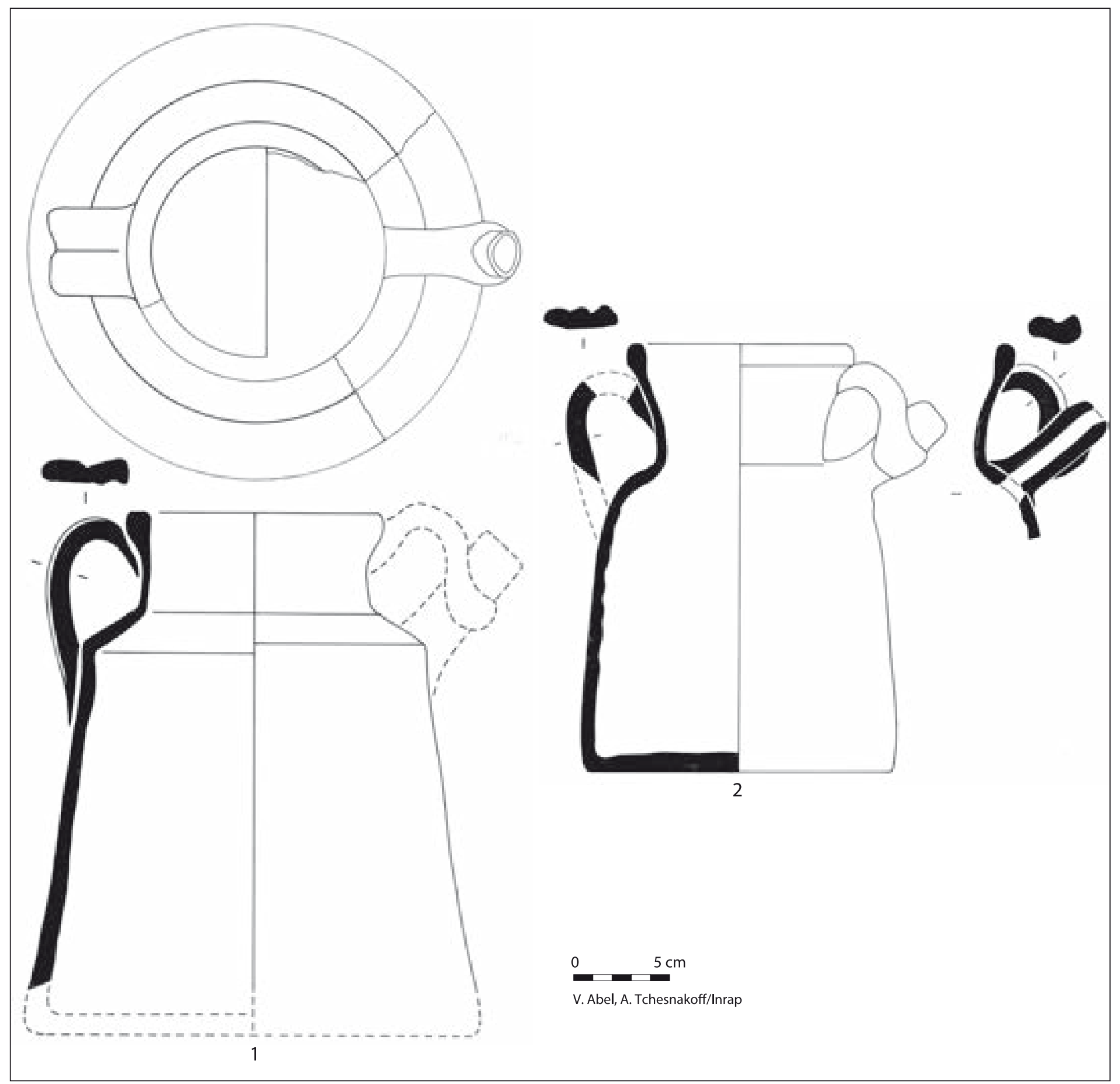

Fig. 173. Vases à liquides de l'arrière-pays marseillais : cruches de barque à vernis vert (fin du XVIIe s.). La Bourse.

\subsection{Les récipients pour l'hygiène}

D'autres vases peuvent être rapidement passés en revue : le grand tian aux multiples fonctions de bassine à vaisselle, toilette ou lessive (fig. 174).

Sans doute à la faveur de la grande densité urbaine de la cité, les potiers proches ont fait du pot de chambre un de leurs articles à succès. Ils se plient aux contraintes de la fonction tout en adaptant la forme à leurs «principes » : parois sans épaisseur inutile, dimensions revues pour une meilleure ergonomie (fig. 175 à 178). C'est ainsi que dès le milieu du XVII ${ }^{\mathrm{e}}$ s., le pot de chambre de l'Huveaune s'allège par rapport au schéma des premiers exemplaires reconnus à Marseille venant de Fréjus, se raccourcit, perd une anse et développe celle qui reste, et surtout se pare volontiers de décors identiques 
PREMIÈRE PARTIE : LES CÉRAMIQUES

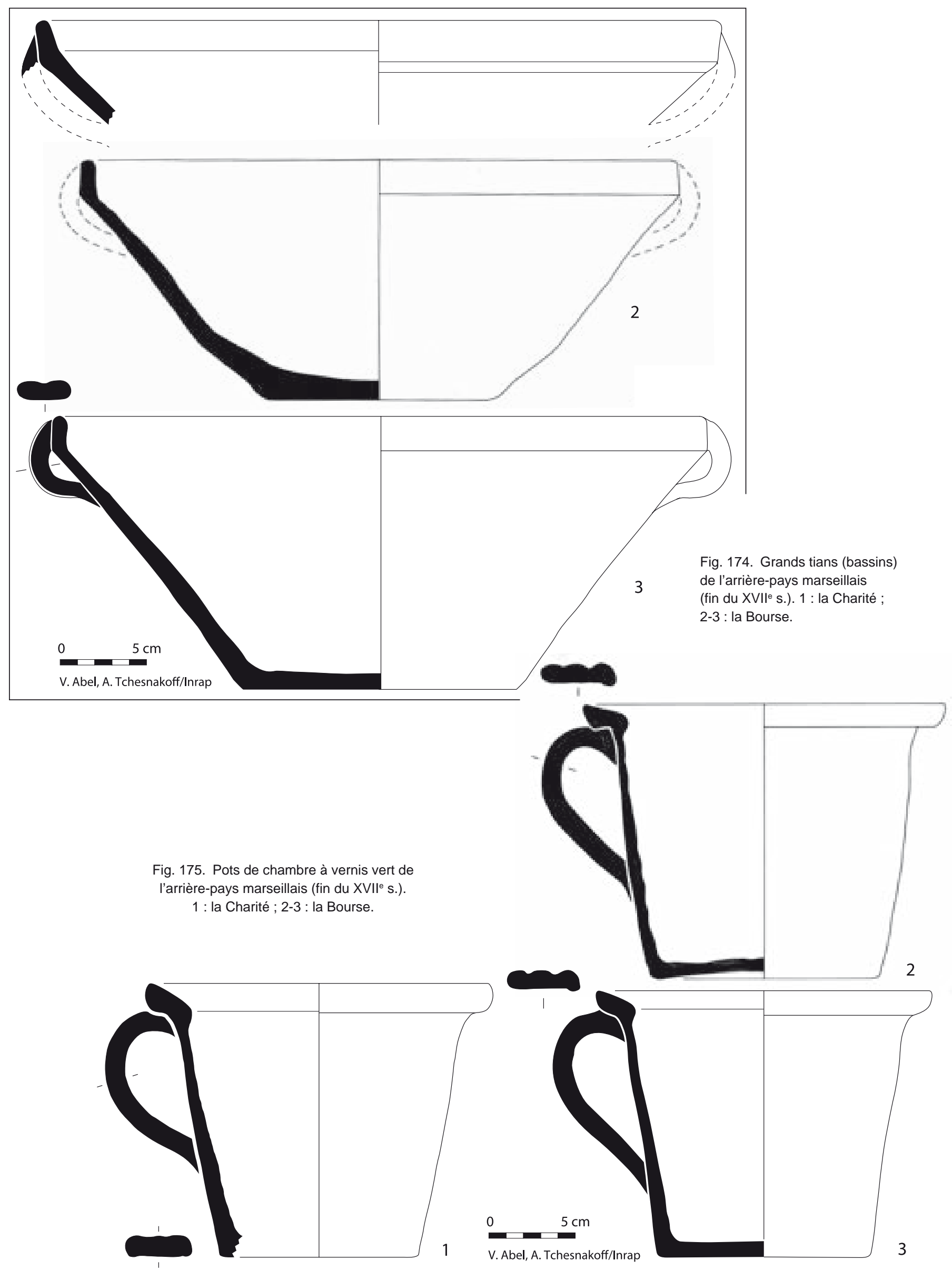

204 


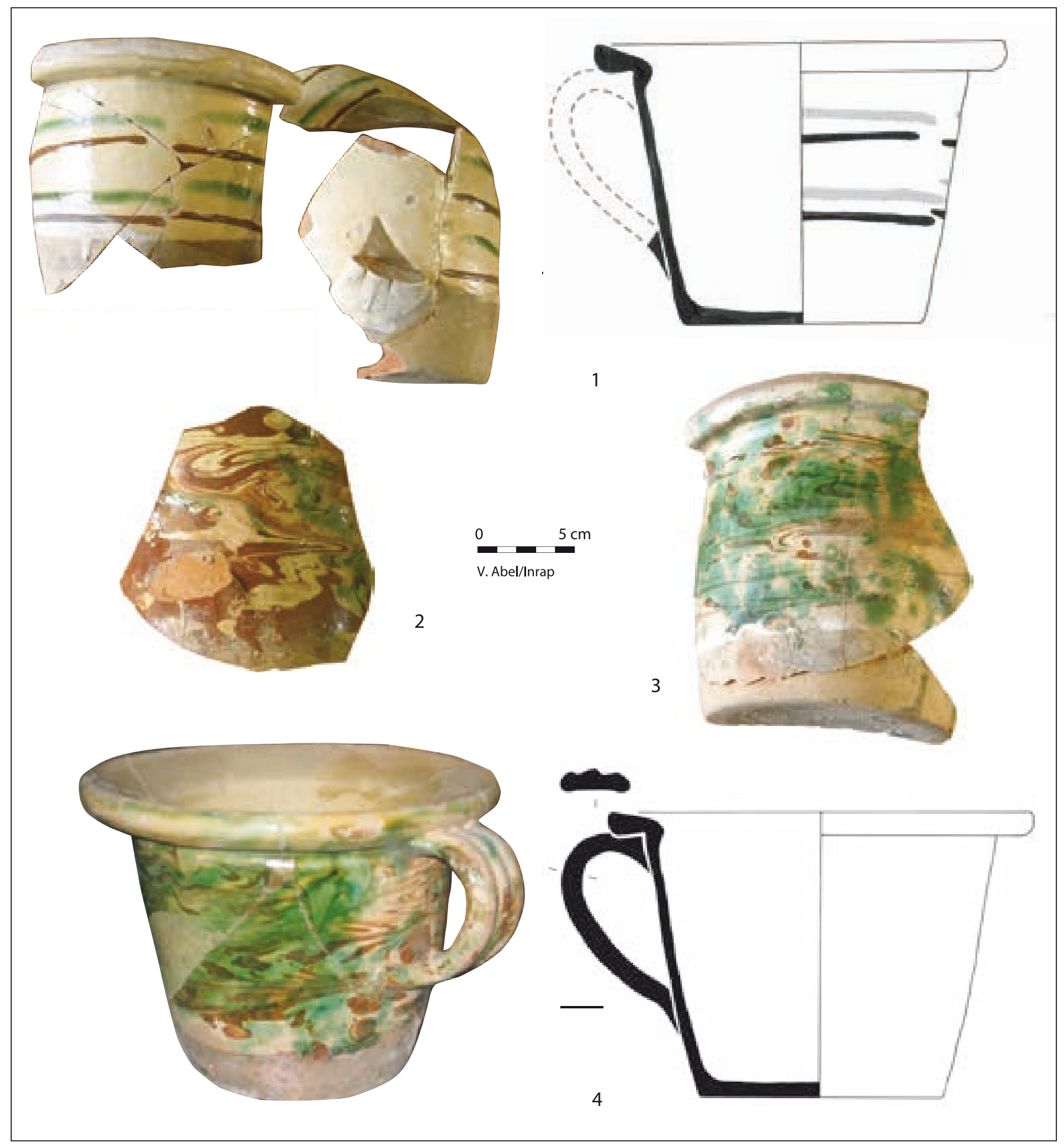

Fig. 176. Pots de chambre de l'arrière-pays marseillais : décor polychrome, filets sans incisions, engobes jaspés et taches vertes (fin du XVII s.). 1-3 : la Bourse ; 4 : la Charité.

à la vaisselle de table... Ces choix correspondent-ils à une évolution des mœurs, à une mode ou au hasard d'une conjoncture ? Peut-être faudrait-il trancher cette question en la replaçant dans son contexte historique.

La fin du XVII ${ }^{\mathrm{e}}$ s. reste dans l'impulsion décoratrice précédente. Rares sont les exemplaires sans décor, ils sont de plus grande taille, non revêtus à l'extérieur et un cordon d'argile digité en renforce l'aile (fig. 178). Ils se rencontrent surtout à la Charité, et peut-être faut-il y voir des récipients communs à plusieurs utilisateurs. 


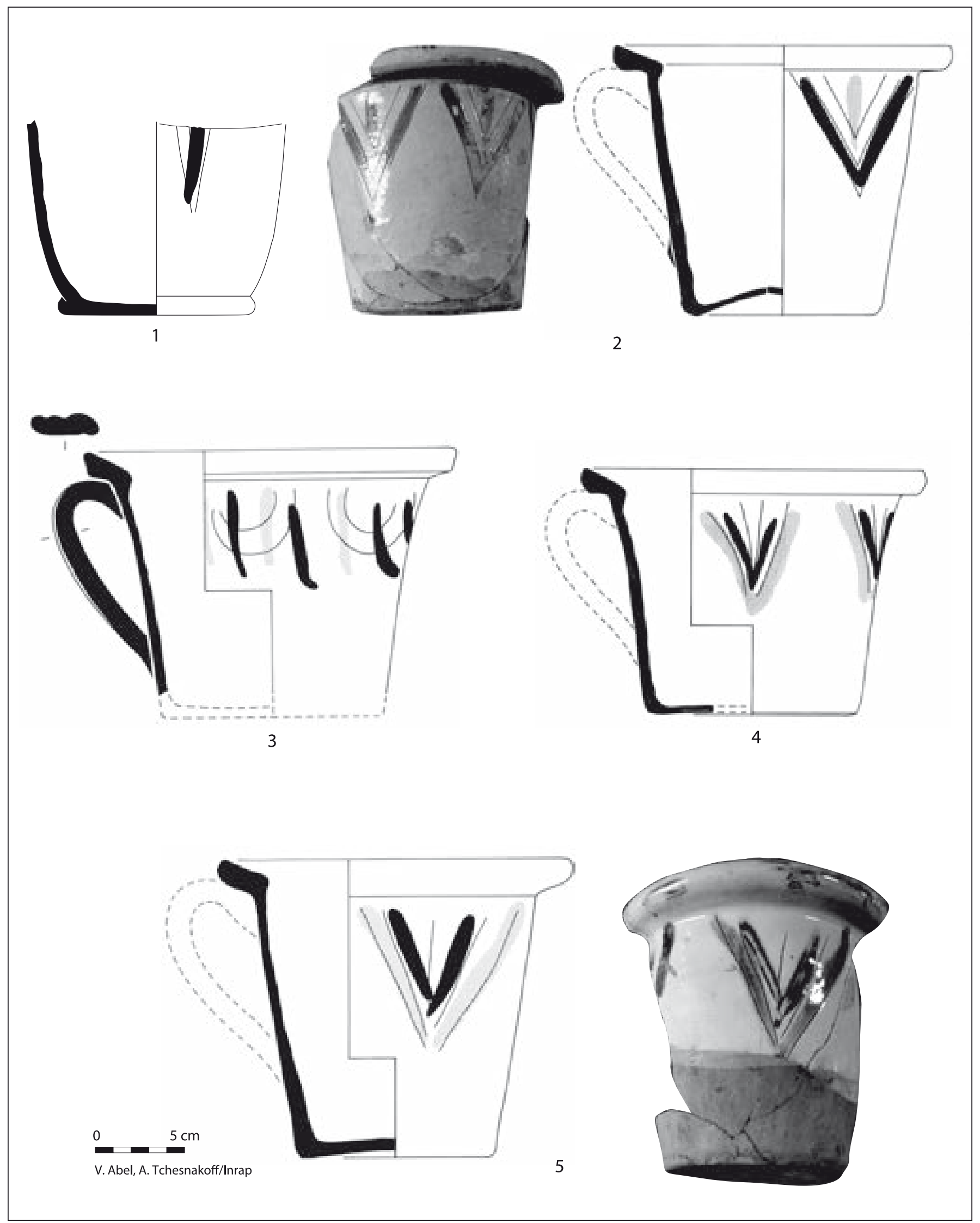

Fig. 177. Pots de chambre de l'arrière-pays marseillais (fin du XVII ${ }^{e}$ s.). La Bourse. 

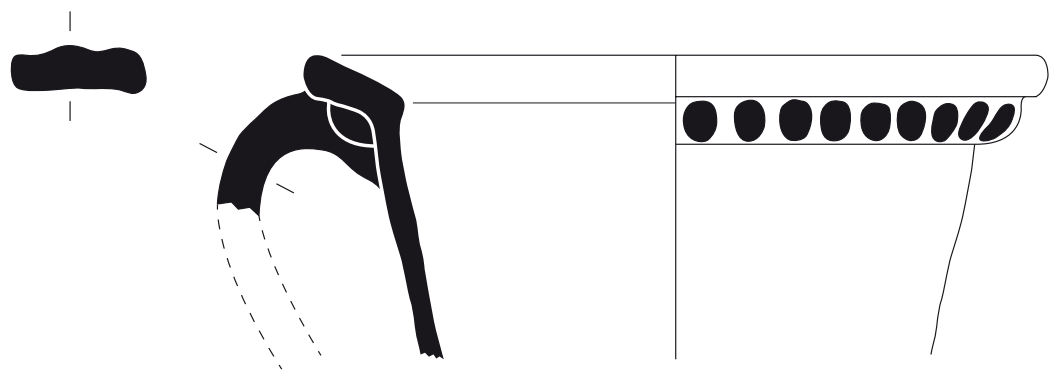

1
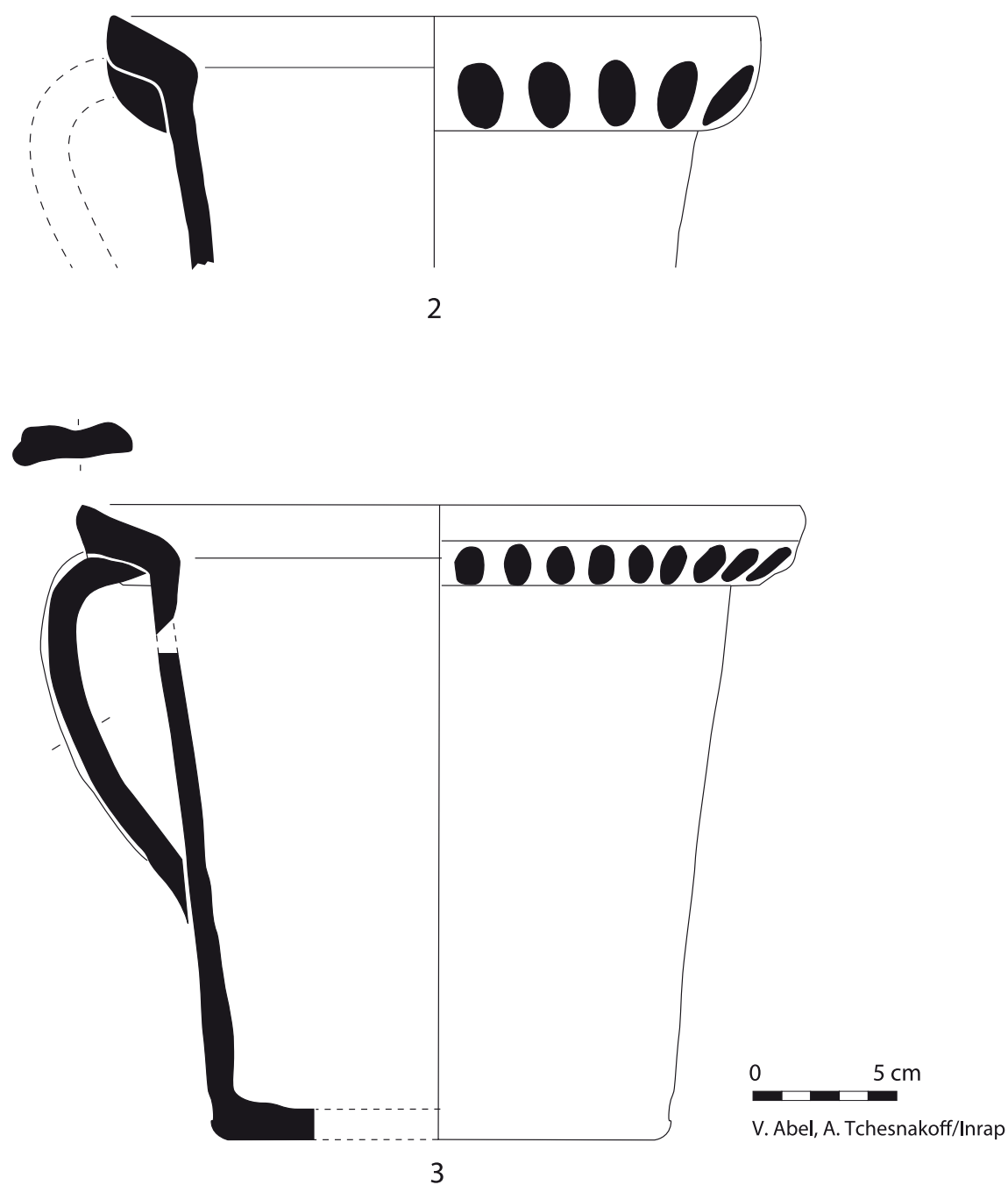

Fig. 178. Pots de chambre à cordon digité renforçant le bord, extérieur non revêtu (fin du XVII s.). La Charité. 

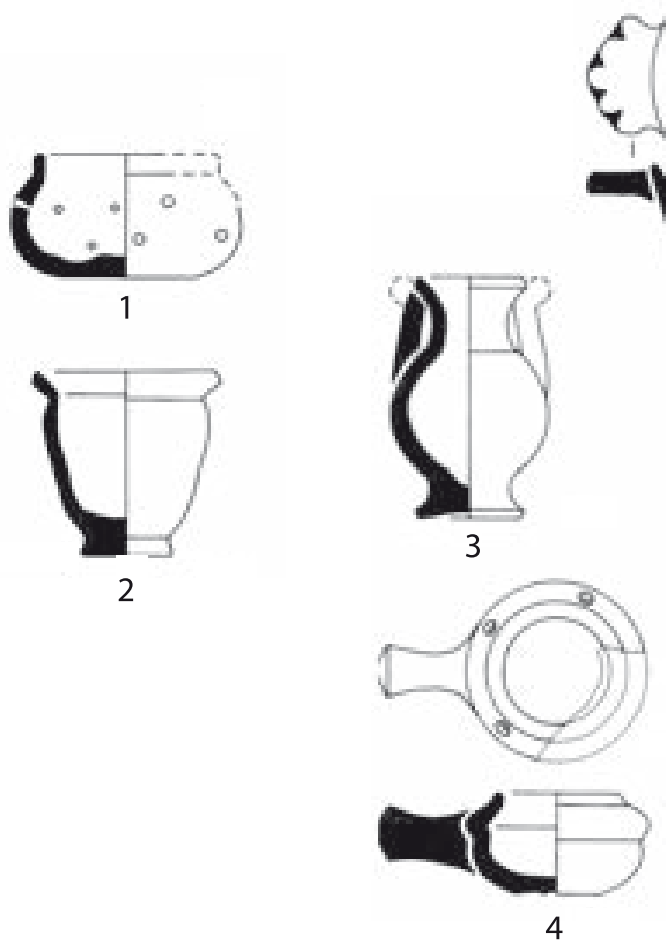
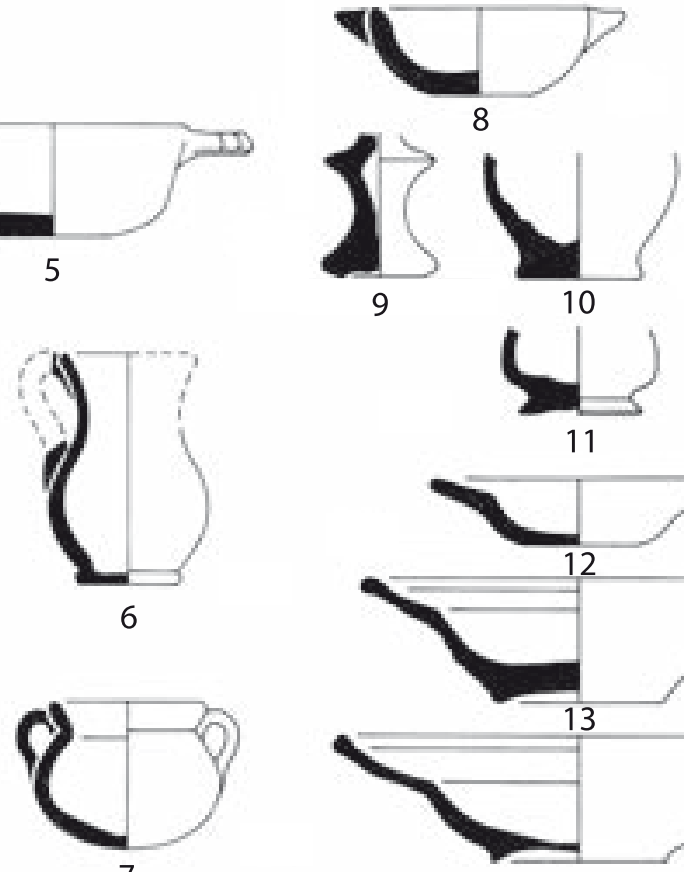

7
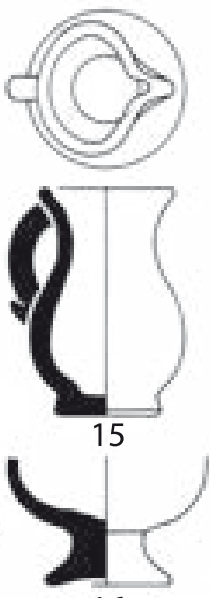

16

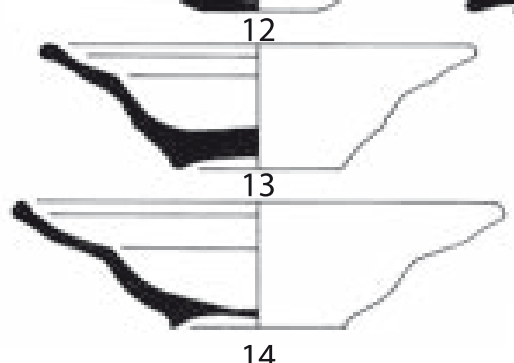

14

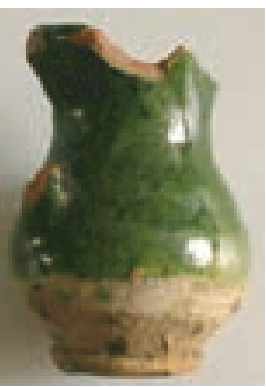

17

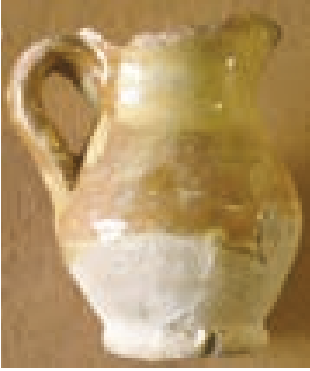

18

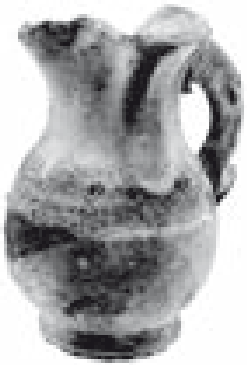

19

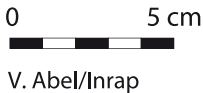

Fig. 179. Taraïettes (dinettes) de l'arrière-pays marseillais (fin du XVII' s.). La Bourse.

\subsection{Les tirelires, jouets, et divers autres objets}

Le pot de fleurs est exceptionnel en milieu urbain. Celui de l'Huveaune est orné d'appliques en fleurs de lys et revêtu de vernis vert. Un exemplaire décoré d'incisons et polychromie est en situation de dépôt secondaire dans la fosse des pestiférés de la rue Leca.

Les jouets, dînettes ( «taraïettes ») ou sifflets sont les seuls objets directement en rapport avec l'enfance dans ce mobilier. Les formes des vaisselles miniatures sont les mêmes que les productions d'usage (fig. 179). En revanche aucun décor d'incisions et polychromie n'est connu sur ces supports. Quelques cruches peuvent avoir connu une fonction ludique, mais quoique de taille réduite, elles peuvent remplir une fonction de vase à liquide utilisé avec parcimonie (fig. 180). Les tirelires sont parfois considérées comme des jouets. Rien n'est moins sûr. La tirelire de l'Huveaune, assez pansue et terminée par un bouton qui la referme, reste obstinément sans revêtement (fig. 181). 


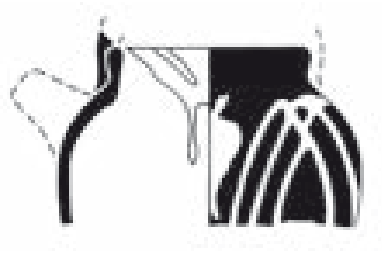

1
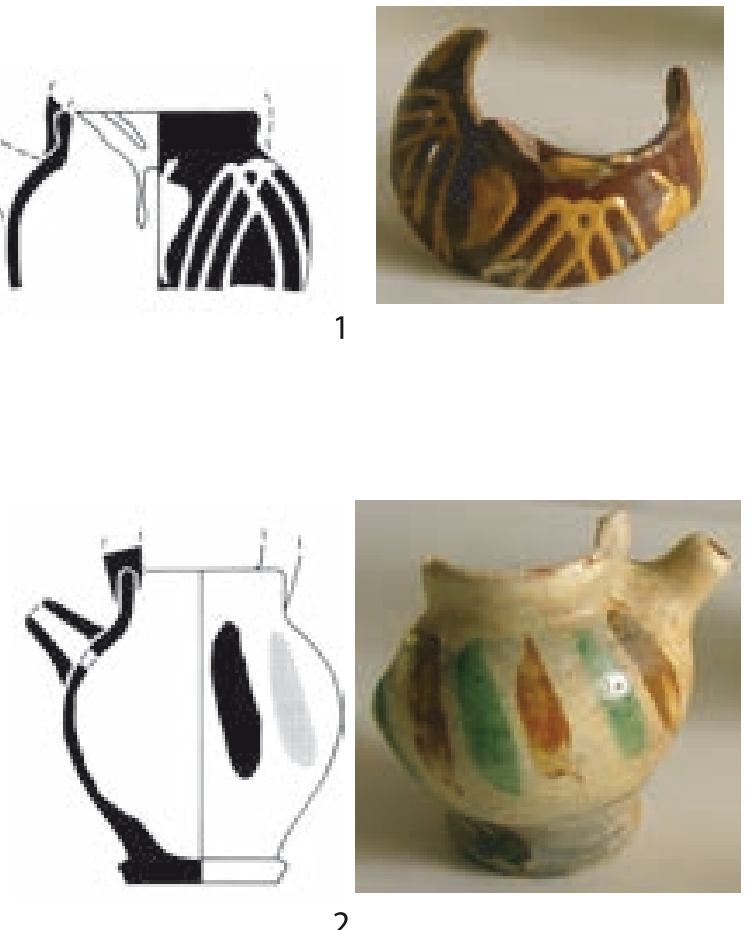

2

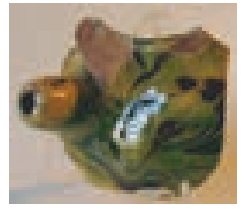

3
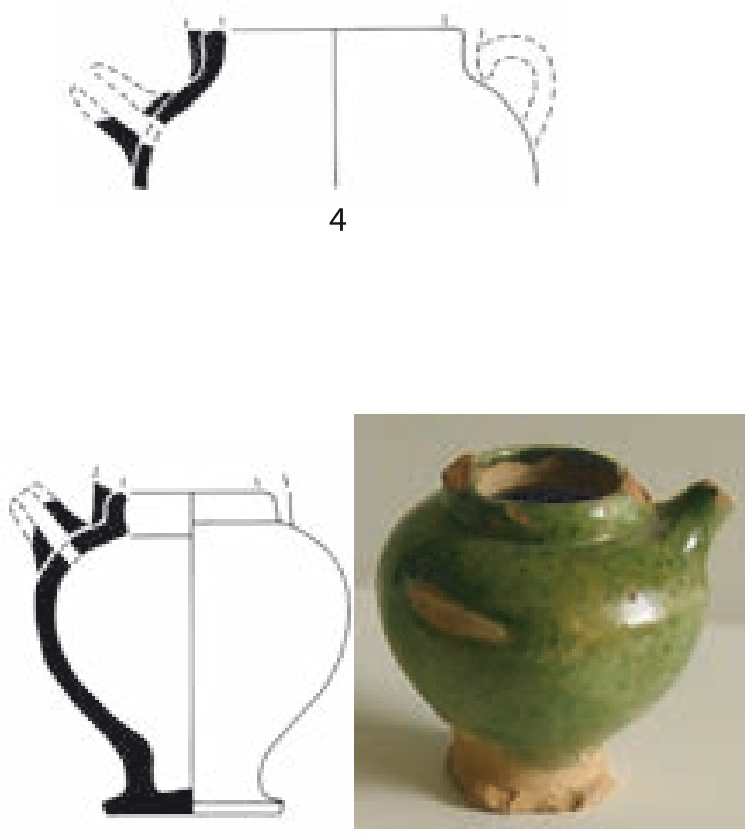

5
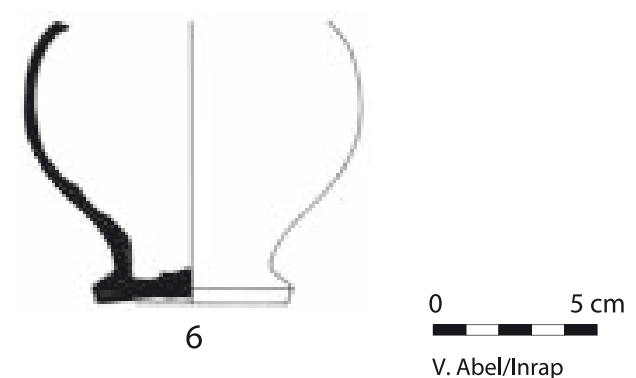

Fig. 180. Cruches miniatures (taraïettes) de l'arrière-pays marseillais (fin du XVII $\mathrm{S}$.). La Bourse.

Le sucre laisse à Marseille des indices de sa consommation, mais pour l'instant aucune trace de sa fabrication et ce jusque dans le courant du XVIII's. Malgré les masses de mobilier étudiées, seuls trois fragments de formes à sucre ont été récoltées en tout et pour tout. Ils se placent dans cette période (1670 à 1710 environ). Ces objets ne conservent quasiment que leur pointe et leur petit orifice caractéristique. Ils ont été prélevés par Fernand Benoît en 1950 dans le secteur de l'Hôtel-Dieu, donc relativement près du port, et non dans le quartier de l'Observance où se trouverait alors une raffinerie
(Raveux 2010). Leur pâte les rattacherait aux ateliers de l'arrière-pays marseillais. Les céramiques associées indiquent un équipement domestique de l'extrême fin du $X V I I^{e} s$. : quelques vases à cuire importés et de la vaisselle de table en terre vernissée et en faïence d'origine locale et d'Italie. Les formes à sucre ont pu avoir une fonction secondaire (entonnoir par exemple) avant de se retrouver dans un dépotoir de quartier. Seul le chantier de la Major pour les XVIII ${ }^{\mathrm{e}}$ et $\mathrm{XIX}^{\mathrm{e}} \mathrm{s}$. a livré quelques vases assez nombreux pour indiquer une activité de raffinage de sucre. 


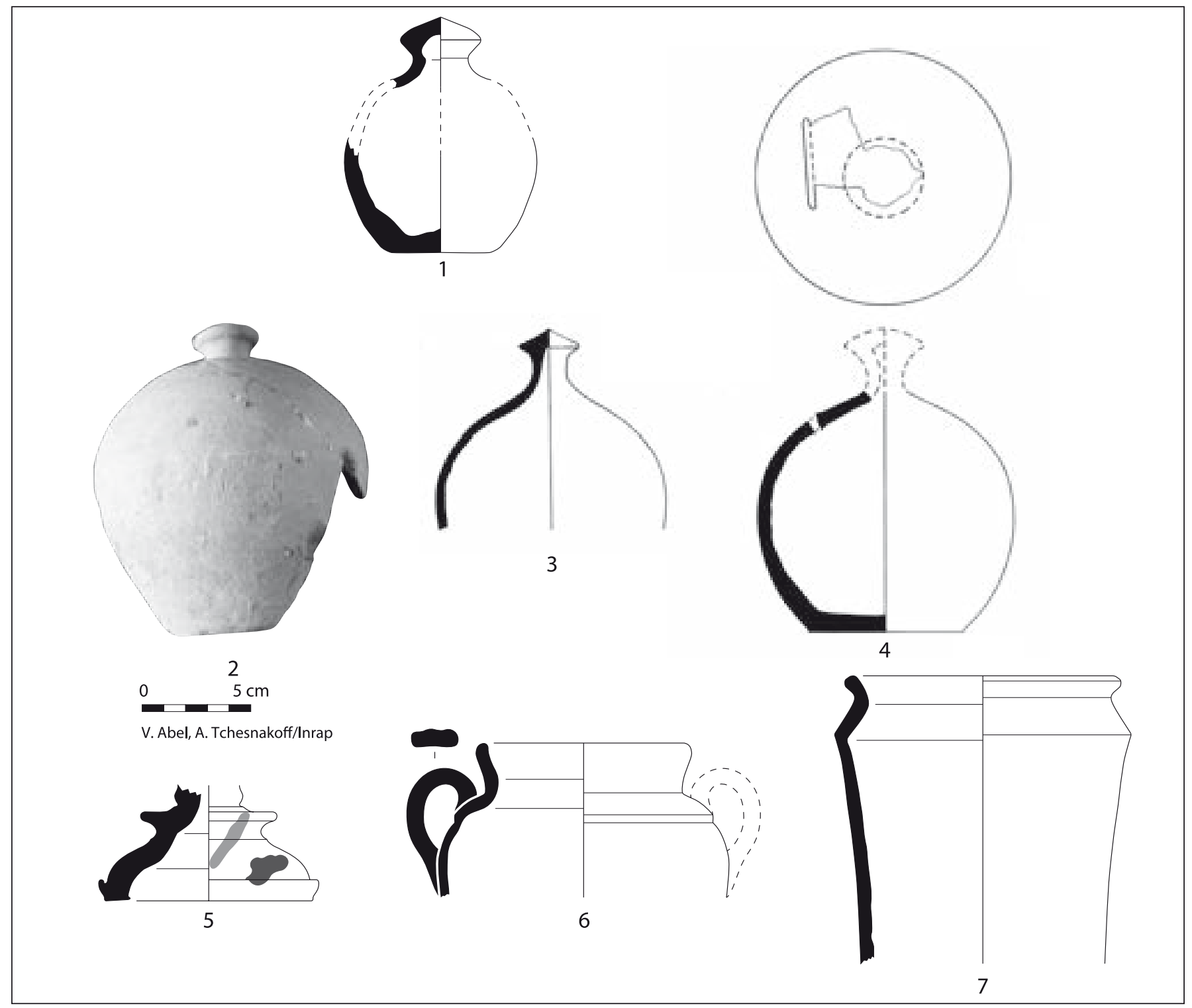

Fig. 181. Tirelires ( $\left.n^{\circ} 1-4\right)$ et diverses pièces ( $\left.n^{\circ} 5-7\right)$ de l'arrière-pays marseillais (fin du XVII ${ }^{\mathrm{e}}$ s.). 1 : La Charité ; 2-7 : la Bourse.

\subsection{Les décors de la terre vernissée de l'arrière-pays marseillais}

Cette vaisselle, fréquemment décorée depuis son apparition jusque vers le milieu du XVIII ${ }^{\mathrm{e}}$ s., l'est particulièrement et avec recherche dans cette période, et c'est l'une des caractéristiques de cette production à ce moment de son histoire. Engobes posés, engobes jaspés et incisions rehaussées de couleurs sont les trois types d'animation de la surface des vases adoptés par les potiers de l'Huveaune et il est possible d'établir pour son analyse une typologie des décors parallèle à celle des formes. Ces techniques sont déclinées au fil du temps, parfois couvrantes, parfois discrètes, parfois figuratives ou strictement géométriques.
Nés vers le milieu du XVII ${ }^{\mathrm{e}}$ s., les décors d'engobes mêlés, aussi appelés jaspés, donnent un effet jaspé, volontiers rehaussé de taches vertes à l'oxyde de cuivre. Une évolution dans leur exécution est perceptible depuis les plus anciennes versions (peignées) aux versions de la fin du XVII ${ }^{e}$ s. souvent en rouge sur fond blanc. Les décors d'engobes mêlés sont appliqués plus volontiers sur les écuelles à fond creux, les tasses, les assiettes plates, les plats à aile, les petits tians, les pichets et les pots de chambre.

Bien que les marbrures qui leur sont contemporaines soient souvent d'une grande virtuosité, les réalisations les plus réussies des ateliers de la vallée de l'Huveaune 
restent les décors incisés et polychromes. Le chantier de l'Alcazar illustre mal la variété et la créativité qui s'expriment alors, le chantier Bargemon un peu mieux ; les premières découvertes de la Bourse et de la Charité ont été primordiales pour en comprendre la richesse. Les décors floraux, naturalistes ou stylisés sont les plus fréquents, et parmi ceux-ci la tulipe (fig. 135 et 136, $\mathbf{n}^{\circ}$ 2-4), fleur emblématique du XVII ${ }^{\mathrm{e}}$ s., a une place de choix. L'une des assiettes de l'Alcazar était une pièce de qualité (fig. $156, \mathbf{n}^{\circ} \mathbf{2}$ ), reconnue grâce à un plat de même facture trouvé dans un puits du site de la Bourse en 1969 (fig. 156, $\mathbf{n}^{\circ} \mathbf{1}$ ). Le temps devra être pris pour analyser le message de cette fleur sur une production de terres vernissées, mais il est clair que ce sujet passionnant est significatif des implications que peut avoir une étude de céramiques archéologiques modernes. La tulipe est particulièrement prisée puisqu'elle est identifiée sur le tiers des décors incisés polychromes de l'Espace Bargemon. Elle repose toujours sur une tige encadrée de feuilles. Elle est interprétée de manières variées selon les décorateurs, fleur plus ou moins fermée, tige souple ou raide, faite d'un seul trait ou de deux traits parallèles, extrémité des feuilles pointue ou arrondie... Après les incisions, de larges traits d'engobe rouge et de vernis vert sont appliqués, parfois assez grossièrement sur un dessin simple mais très évocateur.

Une demi-douzaine de vases ouverts de la place Villeneuve-Bargemon dont les décors sont identifiables porte une fleur stylisée à cœur hachuré appelée «marguerite » (fig. $\mathbf{1 3 2}, \mathbf{n}^{\circ} \mathbf{2}$ ), dont la forme se rapprocherait cependant plutôt d'une anémone. Ce type de fleur a volontiers un cœur quadrillé. D'autres stylisations de fleurs se retrouvent en nombre plus limité dans l'Espace Bargemon. Une fleur en vue zénithale à petit cœur peut occuper tout le centre d'une écuelle (fig. 132, $\mathbf{n}^{\circ} \mathbf{1}$ ), schéma reproduit sur une écuelle à petit fond dégagé de la Bourse, (fig. 137, $\mathbf{n}^{\circ} \mathbf{2}$ ). Une fleur, dite «dahlia », est constituée de pétales placés au-dessus seulement du cœur, celui-ci étant directement attaché à une tige sinueuse (fig. 140, $n^{\circ} 4$ ).

Rares sont les décors animaux. Les oiseaux sont les plus courants. Le mobilier de l'Espace Bargemon en donne deux exemplaires très fragmentaires, alors que le site de la Bourse en offre un grand nombre (fig. 137, $\mathbf{n}^{\circ}$ 4-5, fig. 139, $n^{\circ} 1$ et fig. 142, $\left.n^{\circ} 3-4\right)$. Un exceptionnel poisson figure au centre d'une assiette et d'une écuelle à fond dégagé de la Bourse (fig. 137, $\mathbf{n}^{\circ} 3$ et fig. 144).

Les décors incisés et polychromes sont placés préférentiellement sur les écuelles à fond plat, celles à fond dégagé, les assiettes plates et à bord déversé, les plats à aile et à bord déversé, les pichets et les cruches, les pots de chambre.

\subsection{Un objet d'exception : le bénitier}

Ce chapitre sur les terres vernissées de l'arrière-pays marseillais peut se clore avec une pièce exceptionnelle issue du chantier César 2, auquel quelques fragments du même ordre sont associés. L'extrême rareté des bénitiers dits « de chevet» à travers les mobiliers archéologiques tient certainement à leur fonction, ne les soumettant à aucun choc, et leur évitant d'être cassés et jetés. Moins de dix fragments en terre vernissée étaient connus à travers le mobilier des fouilles de Marseille avant cette découverte, et plus récemment par des exemplaires réalisés par un faïencier marseillais (cf. infra $§ 5.2$.).

\subsubsection{Le contexte archéologique de découverte du bénitier}

La plaque de terre cuite vernissée (fig. 182, $\left.\mathbf{n}^{\circ} \mathbf{1}\right)$ a été remontée en 1996-1997 d'un puits profond de la place Villeneuve-Bargemon (fouille A. Hesnard) dans lequel elle avait été jetée en compagnie d'un petit cortège de céramiques de l'extrême fin du XVII ${ }^{\mathrm{e}} \mathrm{s}$. Parmi cellesci, les mieux datées sont un fragment d'assiette de Pise (inv. 52.96.8076) et des vernissées locales, dont un grand pichet vert (inv. 52.96.8088) et un autre à décor incisé et polychromie (inv. 52.96.8087), une écuelle à décor de tulipe (inv. 52.96.8089) et une tasse (inv. 52.96.8090). Une assiette en faïence régionale est décorée d'une frise de courtes guirlandes et d'un motif central simple en fines volutes (inv. 52.96.8093). Moins habituelle est une tasse islamique à décor de lustre métallique dont l'extérieur est revêtu en bleu, et hors du mobilier que nous étudions malgré son nom, un fragment de "porcelaine » (coquillage de genre cypraea).

\subsubsection{La plaque de bénitier}

La plaque subsistant du bénitier mesure $24,8 \mathrm{~cm}$ de haut, 13,2 cm en son point de plus large, et de 1 à $1,4 \mathrm{~cm}$ d'épaisseur. Elle est façonnée dans une terre rouge correspondant en tout point à celle de la vaisselle vernissée de la vallée de l'Huveaune. Cette argile a été appliquée dans un moule d'une grande qualité de composition et de détails représentant le baptême du Christ. Le revers révèle déjà la « main » rapide des potiers de l'Huveaune, peu soigneux des détails : la matière a été rapidement raclée puis découpée sur les côtés de la plaque. La vasque dont il ne reste qu'une trace conservée sur $5,5 \mathrm{~cm}$ de haut, était façonnée au tour et fixée avant cuisson dans la partie inférieure de la plaque.

L'ensemble de la face de l'objet et sans doute aussi l'extérieur de la vasque disparue ont été recouverts d'engobe blanc, tacheté de rouge et de vert, et d'un 


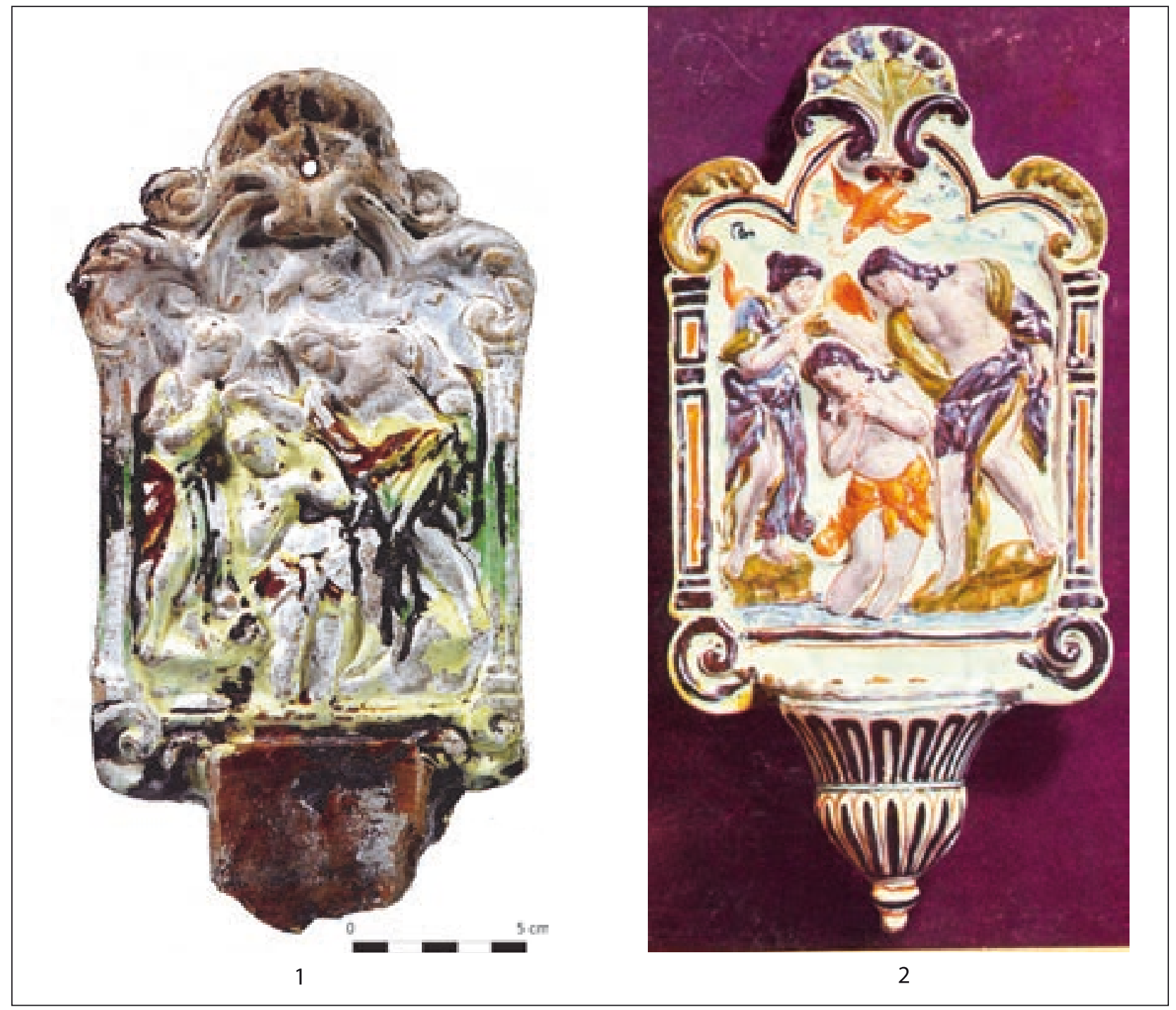

Fig. 182. Plaques de bénitier moulées de l'arrière-pays marseillais : terre vernissée et faïence issues de la même matrice (fin du XVII $\mathrm{s}$.).

1 : place Villeneuve-Bargemon (cl. Giancatarina/MHM) ; 2 : ancienne collection d'Arthur-Jean Held, Musée de Genève (Suisse) (d'après Les Cahiers de la Céramique).

vernis plombifère. Ce revêtement, aujourd'hui partiellement disparu, empâtait largement les détails du décor en relief, les rehauts de couleurs quelque peu hasardeux signant de nouveau le travail des potiers de l'Huveaune.

La scène en bas-relief, étonnante de précision et de qualités artistiques, ne peut en revanche être l'œuvre de ces mêmes potiers qui n'ont guère utilisé la technique du moulage que pour les oreilles d'écuelles et des appliques en fleurs de lys ornant parfois les panses de cruches (fig. 169) qui ne parviennent pas au degré de maîtrise nécessaire pour confectionner un moule de la qualité de celui du bénitier. Cette scène prend place dans un cadre évoquant une architecture, baroque par les volutes et la coquille mousseuse qui la surmonte, mais dont la partie supérieure en arc trilobé semble une réminiscence d'un style antérieur. Au premier plan se tient le Christ, un pagne noué autour des reins, mains l'une sur l'autre et non jointes dans une attitude de prière ; il penche la tête et le buste vers sa gauche dans une position d'humilité déterminée par Jean-Baptiste. Jambes décalées, pieds pointés et drapé du manteau suggérant le mouvement ; le saint est placé plus haut que Jésus, sur la tête duquel il vient de verser l'eau du Jourdain. En arrière-plan et équilibrant l'ensemble, l'ange, dont les deux ailes se distinguent nettement, est vêtu et coiffé comme une figure féminine. Il est le témoin de la scène, pour laquelle le Saint-Esprit apparaît sous la forme d'une colombe, bec pointé vers Jésus, dont les pieds, non représentés, sont censés tremper dans la vasque d'eau bénite que le croyant partage ainsi avec lui. 


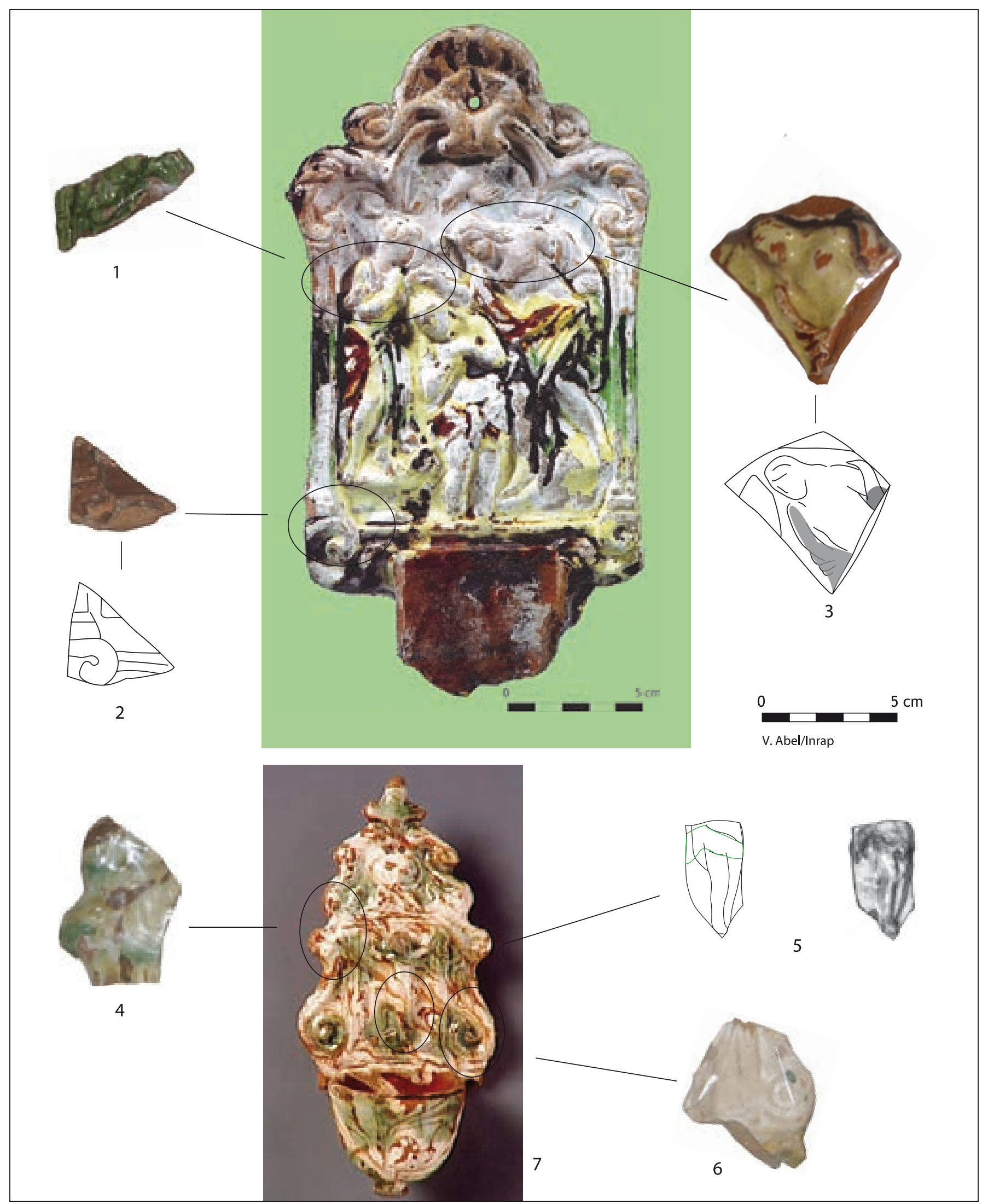

Fig. 183. Plaques de bénitier moulées de l'arrière-pays marseillais : positionnement des autres fragments trouvés dans les fouilles marseillaises par rapport au bénitier de la place Villeneuve-Bargemon (en haut) ou de l'ancienne collection de David David-Weil, ATP,

(C) RMN-Grand Palais (MuCEM) / Droits réservés (nº 7, en bas). 1, 4, 6 : Hôtel-Dieu ; 2-3, 5 : la Charité (DAO V. Abel/Inrap). 
Les modelés anatomiques, les drapés des vêtements, la composition dissymétrique révèlent un artiste maîtrisant parfaitement son sujet. Plusieurs hypothèses sont envisageables pour expliquer cette production. Une première verrait la création d'un moule obtenu sur une pièce originale, une plaque d'orfèvrerie en bas-relief par exemple. La seconde admettrait l'utilisation par les potiers d'un moule créé par d'autres artisans, tels que les faïenciers.

Trois autres objets issus du même moule ont été recueillis par les archéologues marseillais. Un premier fragment, où figure le bas du visage, l'aile gauche, et le bras droit de l'ange ainsi qu'une partie de la main de Jean-Baptiste, a été trouvée par Fernand Benoît dans la grotte de l'Hôtel-Dieu il y a plus de cinquante ans (fig. 183, $\mathbf{n}^{\circ} \mathbf{1}$ ); il est recouvert d'engobe blanc et de vernis vert. Deux fragments proviennent de la fouille de L.-Fr. Gantès dans la cour de la Charité en 1983. L'un ne présente que la volute inférieure gauche du cadre, traitée à l'engobe rouge et au vernis incolore (fig. 183, $\mathbf{n}^{\circ} \mathbf{2}$ ). L' autre conserve le buste de celui qui est désormais identifié comme Jean-Baptiste, associé à l'aile de l'ange. Il est recouvert d'engobe blanc tacheté de violet de manganèse (fig. 183, $\mathbf{n}^{\circ} \mathbf{3}$; Abel 1987, fig. 15).

Ce bénitier de chevet orné du baptême du Christ est remarquable à plus d'un titre. Ses qualités artistiques et son excellent état de conservation en font une pièce exceptionnelle. Ses caractéristiques techniques signent le travail des artisans de l'arrière-pays marseillais, dont elles dénotent la volonté de diversifier les produits au-delà de la simple poterie. Cette intention se double d'une conscience de leurs propres limites créatives qui conduisit ces derniers, décidés à ne pas se borner à une expérience sans lendemain, à se procurer un outil particulièrement efficace pour mener à bien leur entreprise.

\subsubsection{D'autres bénitiers de chevet en terre vernissée ou en faïence}

De cette même fouille est issu un fragment représentant les jambes d'un christ en croix (fig. 183, $\mathbf{n}^{\circ} \mathbf{5}$; Abel 1987, fig. 15) indiquant qu'au moins un autre modèle de bénitier est sorti des fours des potiers de l'Huveaune. Le bénitier du MuCEM (fig. 183, no7) semble en effet permettre de rassembler les deux fragments.

Un autre bénitier doit être signalé même s'il sort du cadre spécifiquement archéologique. Revêtu d'émail et de rehauts polychromes, il semble tiré du même moule que celui du puits de la place Villeneuve-Bargemon. Il n'est pas facilement accessible pour les céramologues marseillais car il se trouve dans un musée suisse auquel l'érudit Dr Chompret fit don de sa collection de

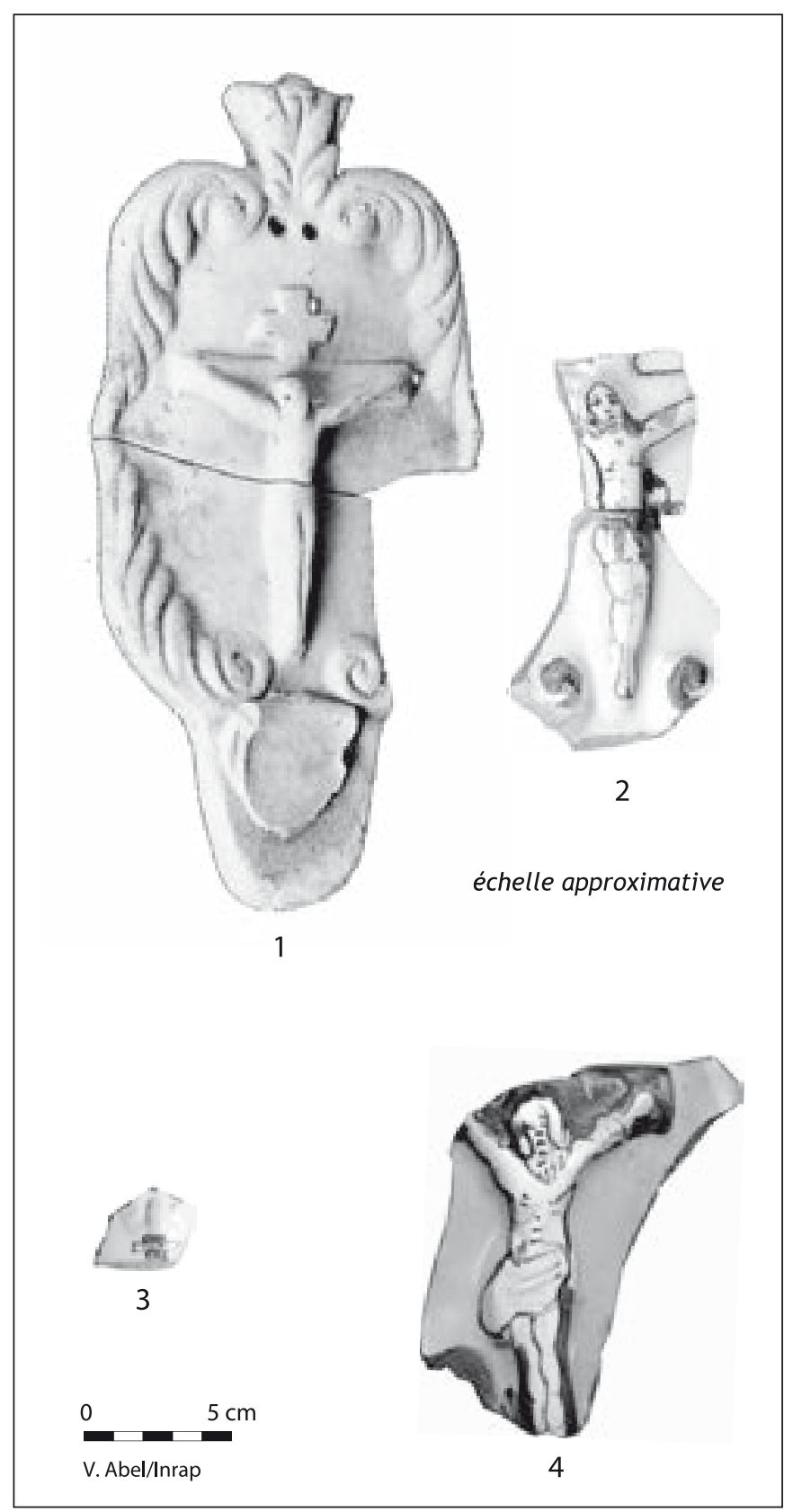

Fig. 184. Plaques de bénitier en faïence du dépotoir du Pharo ( $\left.n^{\circ} 1-2\right)$ ou des zones d'habitat ( $\left.n^{\circ} 3-4\right)$. 1-2 : le Pharo ; 3 : la Bourse ; 4 : Alcazar.

faïences provençales (fig. $\left.182, \mathbf{n}^{\circ} \mathbf{2}\right)^{\mathbf{1 6}}$. Toutefois, son analyse stylistique laisse penser que sa date de fabrication est postérieure au bénitier vernissé de la place Villeneuve-Bargemon.

D'autres fragments ont été retrouvés en contexte archéologique (fig. 184).

16 Cahiers de la céramique et du verre et des arts du feu, 18, 1, 1960. 


\section{La faïence locale-régionale dans la période 1660-1710}

Selon les historiens de l'art, la Provence verrait naître en 1679 très précisément une production de faïence extrêmement virtuose dès ses premiers jours, dont Marseille et Moustiers se disputent l'aînesse. Ateliers, influences, terres et artisans se croiseraient ou se marieraient, selon les conjonctures... pendant que le mobilier archéologique reste particulièrement avare. La faïence régionale cumule les difficultés pour qui en recherche les traces archéologiques. Elle est absente des mobiliers avant la fin du siècle ; elle ne l'est que sous l'apparence d'objets simples et peu décorés inconnus des répertoires habituels ; il n'est pas possible de distinguer selon des critères de céramologue les produits de Moustiers, de Marseille, de Varages, ou ceux d'autres ateliers encore.

Jusqu'aux années 1990, aucune des très nombreuses manufactures marseillaises n'avait laissé de trace à travers les chantiers archéologiques, il est vrai plutôt pratiqués dans le centre ancien alors que les faïenceries sont censées prendre place dans les faubourgs (Abel 1993).

\subsection{Le chantier près du hameau de Saint-Jean-du- Désert (rocade L2)}

La fouille de l'emplacement supposé de la faïencerie de Saint-Jean-du-Désert sur les travaux de la rocade L2 n'a révélé aucun indice de production, déconvenue certaine. Des résultats inattendus furent cependant obtenus : pour des raisons encore inconnues parmi lesquelles sûrement le manque de main-d'œuvre qualifiée ou de moyens de la rémunérer, certains faïenciers ont adopté des systèmes de report en série pour les décors relativement complexes (Abel 1994c, Abel 1997). L'illusion d'un décor peint à la main était conservée par hasard ou par calcul grâce à des touches de pinceau bien visibles. Aucun exemplaire n'a encore été retrouvé à Marseille intra muros, où ce sont presque toujours des carreaux décorés hispaniques, et en nombre assez restreint, qui ont été exhumés des chantiers archéologiques (la Bourse, les Carmes, fort Saint-Jean, rue Leca, Hôtel-Dieu, la plupart en édifices religieux).

Les 6000 fragments issus de la fouille de Saint-Jeandu-Désert ont permis de percevoir toute la dimension novatrice d'une partie de la production, dont l'argile a été rattachée au bassin de Marseille et de la HauteHuveaune par Maurice Picon en 1994. Les archives en revanche n' avaient gardé aucune trace de cette technique reconnue désormais pour des pièces de collections privées ou publiques. L'une des explications de ce prodige serait un transfert de technologie entre les artisans de la faïence et d'autres de métiers différents, tels que les indienneurs ou les cartiers.

\subsection{L'atelier de faïence près du Pharo}

Les biscuits et faïences archéologiques retrouvés sur le site du Pharo en 1994 (M. Moliner) figurent donc parmi les premières traces archéologiques de la production moderne de faïence à Marseille. Quatre cents fragments de céramique épargnés par la savonnerie postérieure étaient mêlés à des cendres et des charbons dans un dépotoir pris entre des niveaux du $\mathrm{XIX}^{\mathrm{e}} \mathrm{s}$. et le terrain géologique. Y figurent $70 \%$ de biscuits de faïence, $20 \%$ de fragments de vases émaillés, et $6 \%$ de matériel d'enfournement de céramiste. Les $4 \%$ restant sont des poteries vernissées qui se situent à la fin du XVII ${ }^{\mathrm{e}} \mathrm{s}$. ou au tout début du $\mathrm{XVIII}^{\mathrm{e}} \mathrm{s}$. : un plat à bord déversé à double engobe (rose puis blanc) et quatre fragments connexes de petit pichet vert. La céramique de la Bourse permet de confirmer cette datation puisqu'une série de sept écuelles monochromes identiques à celles du Pharo (fig. 185) a été recueillie dans l'un des puits ${ }^{17}$ en 1975 accompagnée de pièces vernissées de la vallée de l'Huveaune et d'Italie de cette date.

Dès la première étape du façonnage de l'objet, la faïence des $\mathrm{XVII}^{\mathrm{e}}$ et $\mathrm{XVIII}^{\mathrm{e}} \mathrm{s}$. se distingue de la terre vernissée. L'âme de terre nue subit une première fois l'épreuve du feu, ce qui lui permet d'affronter sans peine celle du bain d'émail. À ce stade, les faïenciers mettent à cuire des objets sans revêtement qui ne risquent pas de se coller à la cuisson. Ils utilisent toutefois pour les séparer des colombins d'argile en guise de cales d'enfournement, dont neuf fragments se trouvent dans le dépotoir du Pharo.

Plus des deux tiers (264 fragments) du mobilier extrait du dépotoir du Pharo sont des tessons de biscuits rejetés après la cuisson de « dégourdi ». Les parois des vases affinées au maximum et les formes très complexes imposent une première cuisson avant l'émaillage. Les assiettes (fig. 186, $\mathbf{n}^{\circ} \mathbf{1}$ ) sont d'un type simple, courant de la fin du XVII ${ }^{\mathrm{e}} \mathrm{s}$. à la fin du XVIII ${ }^{\mathrm{e}}$ s. en France méridionale : apodes, circulaires à bord droit, et terminées par une aile légèrement incurvée. Parmi les autres objets moins représentés, se trouvent au moins six écuelles semblables à celles de la Bourse (fig. 187), des pichets (une anse en biscuit et une autre émaillée à décor bleu de petits traits horizontaux, bougeoirs, soucoupes, vase fermé sur tige, cruche miniature, jardinière sur petits pieds, couvercles, nombreuses anses de type «panier »

17 Guy Bertucchi (SRA-PACA), carré D IV 13 inv. 1289 à 1296. 


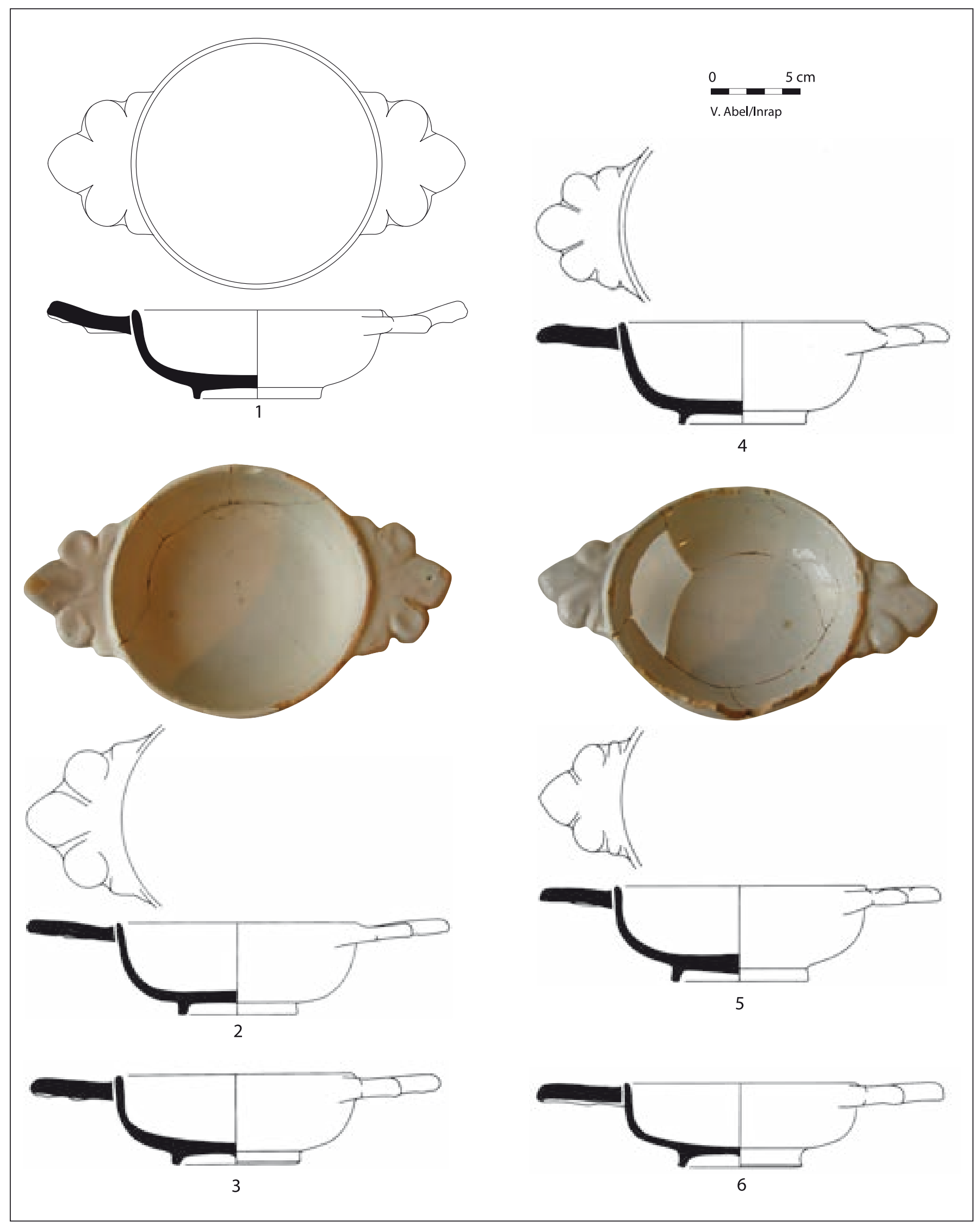

Fig. 185. Écuelles en faïence des zones d'habitat (fin du XVII s.). La Bourse. 


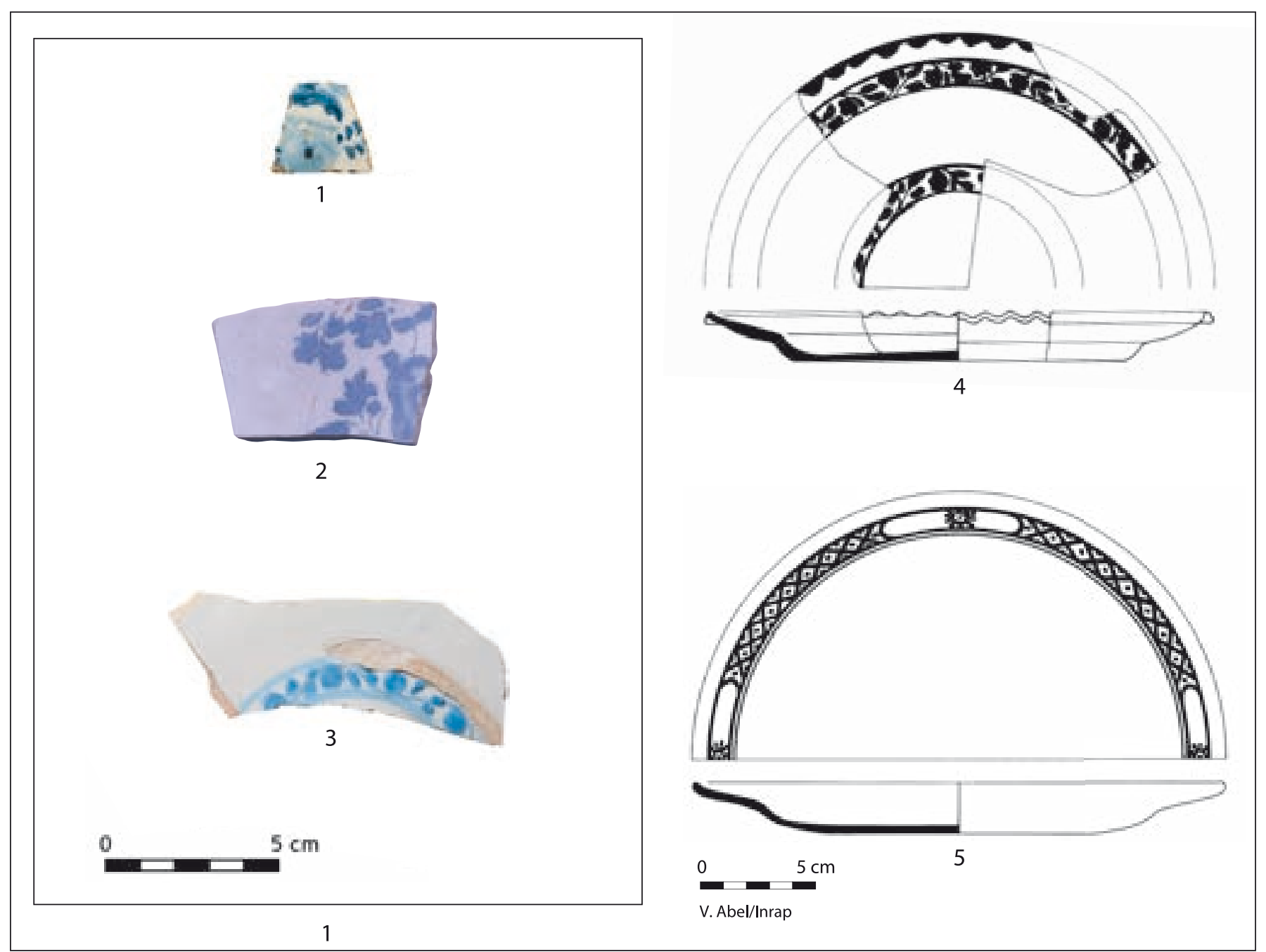

Fig. 186. Faïences, dépotoir du Pharo (n॰1) et rejets domestiques (n॰2-3) (fin du XVII s.). 1-3 : le Pharo ; 4 : la Bourse ; 5 : fort Saint-Jean.
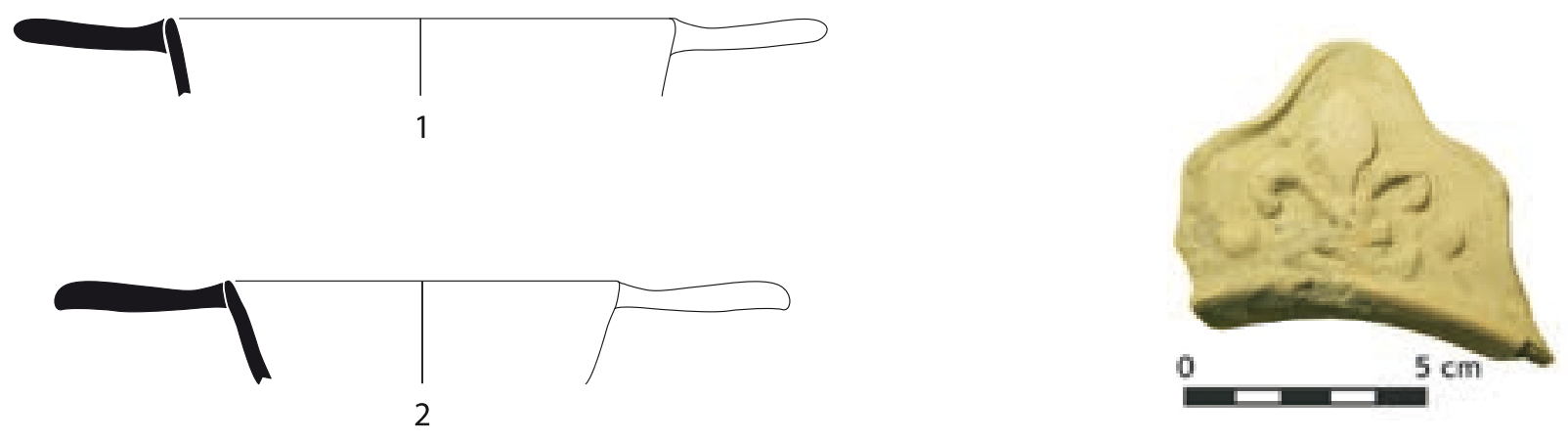

3

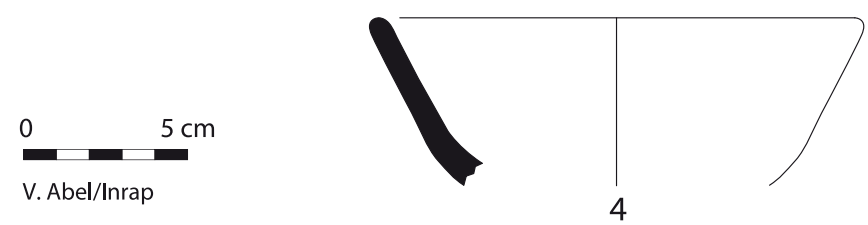

Fig. 187. Écuelles en faïence, dépotoir du Pharo (fin du XVII s.). Le Pharo. 
de différentes tailles, torsadées à trois brins, et des bénitiers de chevet portant un Christ en croix (trois biscuit et un exemplaire identique émaillé et décoré en bleu et noir, fig. 184, $\left.\mathbf{n}^{\circ} 1-2\right)$. Un bec d'aiguière est orné d'un masque d'indien moulé d'une grande précision, un bord de pot de fleurs d'une préhension torsadée.

Entre les mains du faïencier, le revêtement d'émail cru se présente sous la forme d'un liquide épais contenant des matériaux en suspension. La silice, la galène et l'étain sont réduits en poudre, mélangés et mis au four où ils fondent et s'amalgament en un matériau dur, la fritte dont un petit bloc de $8 \times 2,5 \times 1 \mathrm{~cm}$ collé à deux tessons figure dans le mobilier du Pharo.

Une fois refroidi, ce matériau vitreux est à son tour réduit en poudre pour le bain d'émail. Plusieurs vases, parmi lesquels un plat à fond dégagé, une assiette à aile et un petit vase fermé, ont été trempés dans la solution d'émail, mais n'ont pas été passés au four et conservent encore cette poudre blanchâtre caractéristique.

La cazette, cylindre de terre cuite à l'intérieur duquel l'artisan dépose les vases et qu'il place ensuite dans le four permet d'éviter que les objets ne se collent entre eux pendant la fusion du revêtement, de rentabiliser l'opération par l'empilement des objets au plus serré tout en les protégeant des cendres et du carbone qui peuvent se diffuser dans le four. Les parois de ces grandes «marmites » à large trou à la base sont percées de petits trous triangulaires où s'engagent les pernettes (cales). Les neuf fragments de cazettes sont les indices les plus évidents d'une production stannifère, dont l'un présente une couche d'émail. Complémentaires des cazettes, cinq pernettes sont aussi tachées d'émail.

Un bord d'écuelle revêtue d'émail blanc seul est d'une forme connue pour la terre vernissée mais inédite pour la faïence. Les écuelles identiques à celles de la Bourse conservent aussi leur émail sans ornement. Des assiettes sont sommairement décorées d'une frise bleue sur l'aile, des plats sont animés de simples rinceaux évoquant un décor floral grâce à de petites touches de cobalt parfois guidées de manganèse. Une tasse s'orne d'une série d'oves qui rappelant les vases attribués à Saint-Jean-duDésert sur des critères stylistiques. Les traits du Christ du bénitier sont renforcés de manganèse et de cobalt.

Un fragment d'assiette, enfin, est décoré selon la technique mise en évidence grâce à l'étude des carreaux du chantier de la rocade L2 à Saint-Jean-du-Désert en 1994 : l'impression des cernes de manganèse et de rehauts de cobalt. Il s'agit du seul tesson recueilli en contexte archéologique en dehors du site originel et sur un autre support qu'un carreau de revêtement. Il est bien sûr tentant de voir dans le site faïencier du Pharo le lieu de production des objets à décor imprimé ; rien ne permet cependant de l'affirmer au vu du mobilier présenté ici.
Les objets tels que les cazettes, les cales ou les biscuits, fournissent les preuves d'une production les plus fiables possibles après les découvertes de structures bâties en bon état de conservation : le trafic de cazettes usagées, de biscuits ratés ou de cales d'enfournement brisées n'est envisageable que sur de courtes distances mais n'est cependant pas exclu. La question se pose de la localisation précise d'une faïencerie vers la fin du $\mathrm{XVII}^{\mathrm{e}} \mathrm{s}$. dans la parcelle du dépotoir ou dans le quartier. Après les découvertes du Pharo, une recherche d'archives, effectuée par Annick Riani (Atelier du Patrimoine de la Ville de Marseille), a permis de retrouver le nom du propriétaire des lieux à cette date : Joseph Fabre. Ce personnage est un banquier qui n'est autre que le possesseur du terrain où est censé s'installer Joseph Clérissy à Saint-Jean-du-Désert en 1679 (Desnuelle 1984, p. 68-69), et où précisément la fouille de 1993-1994 a été pratiquée. Il n'est cependant pas possible d'affirmer que c'est Joseph Fabre qui avait installé une manufacture de faïence près la savonnerie sur son terrain du Pharo. Quoi qu'il en soit, la faïencerie était déjà en ruine en 1739 (Riani 1996, p. 7).

Les sources archéologiques semblent se compléter parfaitement l'une l'autre. Un contexte où les céramiques étaient consommées (la Bourse) offre une chronologie à un contexte de production (le Pharo), vingt ans après sa fouille. Une fouille du terroir marseillais (Saint-Jeandu-Désert) permet de comprendre ce qui pourrait passer pour un insignifiant petit tesson d'assiette et qui est en réalité de première importance, rattachant des preuves de la présence d'une faïencerie (au Pharo) à des objets en grand nombre (retrouvés à Saint-Jean-du-Désert). Les deux mobiliers prouvent de concert que les artisans marseillais, pour des raisons qui n'étaient peut-être pas avouables et qui leur ont fait garder leur secret, n'hésitaient pas à sortir des sentiers battus. Il semblait, voici quelques années, tout à fait improbable de trouver de la faïence à décor imprimé.

Le petit ensemble du Pharo donne à voir de manière directe, par des biscuits et des ratés, une partie de la production stannifère marseillaise vers la fin du XVII ${ }^{\mathrm{e}} \mathrm{s}$. ou le début du XVIII ${ }^{\mathrm{e}} \mathrm{s}$. : des assiettes, des écuelles, des vases quotidiens et quelques formes plus recherchées, auxquels sont joint de petits bénitiers de chevet. Ces objets sont modestement revêtus d'émail restant parfois blanc, mais le plus souvent orné de décors très simples au cobalt seul ou associé au manganèse.

\subsection{La faïence dans les contextes de consommation}

Ces céramiques sont donc classées ici en production locale marseillaise, à la manière de la vallée de 
l'Huveaune, érigée par nos soins depuis 1985 à la qualité de production locale de Marseille. On retrouve ces objets nouveaux dans certains contextes archéologiques associés à des terres vernissées de la vallée de l'Huveaune alors qu'elle est absente d'autres. L'hypothèse qui est développée ici est que son "apparition », de quelque centre producteur qu'elle sorte, s'est effectuée à l'époque de floraison des décors incisés rehaussés de polychromie dans l'arrière-pays marseillais.

Les assiettes «classiques », de forme simple, à bord droit et frise de bâtonnets sur l'aile sont les plus nombreuses, la frise étant en règle générale monochrome bleue. On les retrouve par exemple dans le puits dont a été extrait le bénitier exceptionnel.

Les tasses sont moins nombreuses que les assiettes, mais le site de l'Alcazar nous en fournit de très intéressants exemples. Le premier fragment est hors contexte. Sa forme (au minimum ce qui nous en est parvenu) est identique aux tasses réalisées en terre vernissée dans la vallée de l'Huveaune dans le troisième quart du XVII ${ }^{\mathrm{e}} \mathrm{s}$. Cette forme munie de deux petites anses en point d'interrogation est inhabituelle dans la terre vernissée en général, elle semble spécifique de ces ateliers (Abel 1987, fig. 7-10 et 13). Trois pièces de l'Alcazar parmi quelques autres possèdent incontestablement ces anses caractéristiques.

Parmi les premières, le fragment à anse complète est décoré d'ornements bleus sur fond blanc. Le bord (inv. 24.99.1464) reste dans ce schéma classique. Deux autres pièces sont en revanche revêtues d'émail coloré, ce qui n'est pas en soi extraordinaire, bien que rare. $\mathrm{Ce}$ qui confère un caractère inédit à ces deux fragments de tasse, c'est le décor qui est appliqué sur ce fond coloré : un effet de marbrures en blanc fixe (le décor en blanc est ainsi nommé dans le domaine de la faïence). Dans les deux cas, des gouttes de pigment blanc ont été jetées de manière informelle sur le fond coloré. On ne peut s'empêcher de se référer à la production locale de terres vernissées qui utilise, comme d'ailleurs les ateliers pisans, les techniques des engobes mêlés et des vernis tachetés. Aucun lien ne peut être actuellement attesté entre ces deux artisanats, mais rappelons qu'ils sont, de manière évidente, géographiquement proches, qu'ils exploitent les mêmes terres et que les amateurs de faïence utilisent obligatoirement des produits vernissés dans leur vie quotidienne.

Un fragment de bénitier a été peint de manière assez maladroite en bleu et brun sur un relief représentant un christ en croix dont on perçoit l'essentiel. Il vient nous rappeler que toute la production des ateliers locaux de faïence n'était pas à l'image des splendides réalisations des faïenciers prestigieux.

Le mobilier de faïence local/régional de l'Alcazar, malgré sa dispersion à travers le site et sa faible masse, permet de fait naître d'intéressantes hypothèses, parmi lesquelles se trouvent la possible mise en œuvre d'émaux colorés et la question des rapports que cette production entretient avec l'artisanat local de terres vernissées, toutes choses moins perceptibles à travers le mobilier d'autres sites.

\section{Conclusion sur le mobilier céramique marseillais entre 1660 et 1710}

Les décors incisés et polychromes de la production locale de Marseille et les formes associées servent de référence chronologique extrêmement efficace et fiable pour les années 1660 à 1710 environ. Une grande créativité règne alors. Formes et décors se multiplient, se croisent et parviennent à occuper la plupart du marché marseillais, relativement considérable. Cette vaisselle, qui reste quotidienne bien que parée de décors très travaillés, se retrouve en masse dans le mobilier archéologique et permet par conséquent de mieux dater les périodes d'utilisation de céramiques importées parfois mal connues.

Les importations, oscillant entre un quart et un tiers du mobilier, font apparaître une ville évidemment très tournée vers la mer, approvisionnée essentiellement par l'est, depuis Vallauris jusqu'à la Toscane. Les vents et courants du golfe du Lion et du golfe de Gênes ont certainement contribué à cette préférence, reléguant les importations terrestres (Gard, Uzège) et celles d'Europe du Nord à la portion congrue. Les céramiques dont la place est encore honorable sont des « compléments » à celles de l'arrière-pays marseillais : terres réfractaires et tradition de vases plus luxueux.

Les ateliers de potiers de cet arrière-pays alimentent prioritairement la cité marseillaise, en laquelle ils trouvent des débouchés évidents, facilités par une voie de communication naturelle le long d'une vallée, par une population importante et par des perspectives intéressantes d'exportation à plus long cours offertes par le port. Une part sans doute non négligeable de la production alimente la région proche, puisqu'elle se retrouve aujourd'hui sur les sites d'Aix ou sur la frange côtière de la basse Provence, comme en a témoigné la fouille de la Source du Pré à La Ciotat (P. Mellinand). Elle est pour l'archéologie régionale et méditerranéenne un marqueur chronologique essentiel.

À l'analyse des productions sorties de ces ateliers entre les années 1660 et les années 1710, il est difficile ne pas envisager un grand dynamisme fermement organisé pour conquérir des marchés. Qu'en était-il réellement, il est évidemment impossible de le savoir. Cette théorisation contemporaine d'un artisanat céramique 
essentiellement empirique dans ses choix techniques et économiques ne correspond sans doute que peu aux intentions des potiers de l'Huveaune. Il est vraisemblable que ceux-ci aient été davantage attachés à leur survie à court terme qu'animés de grands desseins capitalistes. Quelques artisans, dont les «mains » se retrouvent sur les décors, semblent avoir été particulièrement doués et ont pu servir d'exemple à des collègues moins créatifs, mais il ne s'agit là que de conjectures. L'angle de vue de l'archéologue sur ces objets de vies quotidiennes de producteurs ou de consommateurs fait apparaître en un instantané des laps de temps dont la durée réelle fut variable, de quelques mois de rejets dans une excavation de taille moyenne transformée en dépotoir, à plusieurs années ou quelques dizaines d'années peut-être dans certains cas. 


\section{Chapitre 8}

\section{Du début au milieu du XVIII ${ }^{\mathrm{e}}$ s. : le règne des productions de la vallée de l'Huveaune}

\section{(Véronique Abel)}

\section{L'installation de la faïence régionale dans la première moitié du XVIII ${ }^{\mathrm{e}} \mathrm{s}$.}

À partir des années 1720 , la créativité des ateliers de l'Huveaune décline nettement alors que son rôle de céramique d'usage quotidien n'est que peu contesté. Un virage va s'amorcer dans la consommation de céramiques avec une plus grande utilisation de la faïence et un rééquilibrage des terres vernissées entre les produits locaux et les importations.

L'émergence de la faïence régionale est la préoccupation majeure des historiens des arts décoratifs dans la région. S'il est difficile d'appréhender précisément la date de naissance de cette production par le mobilier de fouille, l'apport de l'archéologie est pourtant exceptionnel car il montre la diffusion progressive dans la vie quotidienne des faïences non prestigieuses qui formaient sans doute la plupart des produits. Les conséquences de la production et diffusion de la faïence régionale sur la terre vernissée ne sont pas négligeables, qu'il s'agisse de la vernissée locale ou extra locale (restriction des formes et limitation des décors notamment). L'apparition de la terre d'Albisola serait un événement d'importance mais le rôle exact sur les tables marseillaises et sur la production locale de cette catégorie sera réévalué par l'analyse précise des comptages dont nous disposons et non par approximations partiales. Les céramiques venant de l'ouest du Rhône sont davantage présentes (type « Uzège », Gard) que dans la période précédente.

Pour cette période, nous étudierons de manière spécifique un contexte issu de chacun des deux chantiers suivants : la rue Leca et l'Esplanade Major (fig. 188 à fig. 195).

Rue Leca, plus de 1200 fragments sur 1920 ont été recueillis en contexte, les fragments en dépôt secondaire constituant un tiers du lot (tableau V). Le mobilier

\begin{tabular}{|c|c|c|c|c|}
\hline Catégories & Fragments & $\%$ & NMI & $\%$ \\
\hline Faïence de Ligurie & 36 & 3 & 8 & 10 \\
\hline Faïence de Montelupo & 10 & 1 & 1 & 1 \\
\hline Faïence de Provence & 64 & 5 & 5 & 6 \\
\hline Terre vernissée de Pise & 55 & 4 & 1 & 1 \\
\hline Terre vernissée de Type Fréjus & 79 & 5 & 1 & 1 \\
\hline Terre vernissée de Biot & 10 & 1 & 1 & 1 \\
\hline Terre vernissée de type Meynes & 206 & 16 & 28 & 35 \\
\hline Terre vernissée de l'arrière-pays marseillais & 458 & 35 & 17 & 21 \\
\hline Culinaire de Ligurie & 25 & 2 & 1 & 1 \\
\hline Culinaire de Vallauris & 80 & 6 & 5 & 6 \\
\hline Culinaire rouge & 67 & 5 & 1 & 1 \\
\hline Réfractaire de type Uzège & 110 & 9 & 12 & 15 \\
\hline Céramique ottomane & 2 & 0,15 & 2 & 2 \\
\hline Pipes & 86 & 7 & 2 & 2 \\
\hline Total & 1288 & & 85 & \\
\hline Fragments en dépôt secondaire & 630 & 33 & & \\
\hline
\end{tabular}

Tableau V : le contexte de la rue Leca du début du XVIII $\mathrm{S}$. (unité stratigraphique 1151). 


\begin{tabular}{|l|c|c|c|c|}
\hline \multicolumn{1}{|c|}{ Catégories } & Fragments & $\%$ & NMI & $\%$ \\
\hline Faïence de Ligurie & 20 & 7 & 8 & 7 \\
\hline Faïence de Montelupo & 6 & 2 & 3 & 3 \\
\hline Faïence de Provence & 12 & 4 & 6 & 5 \\
\hline Terre vernissée de Pise & 3 & 1 & 1 & 1 \\
\hline Terre vernissée de Type Fréjus & 0 & $/$ & $/$ & $/$ \\
\hline Terre vernissée de Biot & 0 & $/$ & $/$ & $/$ \\
\hline Terre vernissée de type Meynes & 27 & 9 & 13 & 12 \\
\hline Terre vernissée de l'arrière-pays marseillais & 138 & 46 & 55 & 50 \\
\hline Culinaire de Ligurie & 4 & 1 & 1 & 1 \\
\hline Culinaire de Vallauris & 71 & 24 & 13 & 12 \\
\hline Réfractaire de type Uzège & 17 & 6 & 8 & 7 \\
\hline Porcelaine asiatique & 1 & 0,3 & 1 & 1 \\
\hline Pipes & 2 & 0,6 & 1 & 1 \\
\hline
\end{tabular}

Tableau VI : le contexte de l'Esplanade de la Major du début du XVIII' S. (unité stratigraphique 2007).

provient dans l'ensemble du comblement d'une vaste fosse où avaient été inhumés des pestiférés. Ce creusement a été réalisé dans les jardins du couvent de l'Observance, où une sédimentation datant de l'Époque moderne s'était vraisemblablement opérée. Seule une partie de la fosse a été utilisée : il a donc été estimé que ce creusement datait de la fin de l'épidémie, en 1722.

La céramique avait permis, en 1994, de confirmer que cet ensevelissement, prévu comme massif, de victimes d'une épidémie s'était bien produit au début du $\mathrm{XVIII}^{\mathrm{e}} \mathrm{s}$. et non précédemment car Marseille a connu plusieurs épisodes de peste dans le XVII ${ }^{\mathrm{e}} \mathrm{s}$., notamment en 1633.

Les céramiques résiduelles sont très nombreuses, environ le tiers des fragments, peut-être même davantage. En effet, s'il est relativement aisé de discriminer des tessons de l'Antiquité ou même du $\mathrm{XVI}^{\mathrm{e}} \mathrm{s}$. de ce lot, distinguer des céramiques de la fin du XVII ${ }^{\mathrm{e}} \mathrm{s}$. en dépôt secondaire d'objets encore produits ou utilisés une génération plus tard est moins évident. Les terres vernissées de Fréjus sont présentes dans ce lot, alors qu'elles sont absentes de celui de l'Esplanade de la Major. De nombreux fragments présentent des traces de recuisson (noircis, vernis recuit). C'est en particulier le cas des assiettes du bas Rhône, certains tessons de couleur différente, vernis tressaillant).

Peu volumineux car non totalement fouillé par respect des contraintes du site, le contexte du début du $\mathrm{XVIII}^{\mathrm{e}} \mathrm{s}$. de l'Esplanade de la Major est cependant très caractéristique. Le mobilier (tableau VI) y était associé à des sépultures en nombre, là encore probablement en lien avec l'épidémie de peste. Les trois cents fragments proviennent de 110 objets, les fragments en dépôt secondaire sont en quantité très limitée (moins de $1 \%$ ). Les faïences sont peu présentes, mais la production locale ou régionale, Marseille, Moustiers, Varages ou autres sont présentes dans la vie quotidienne, de manière discrète. Faïences ligures et toscanes sont mieux représentées. Les terres vernissées de Fréjus sont absentes de ce lot et les pipes en terre sont rares.

Le contexte de la Rue Leca est étudié ci-dessous de manière plus approfondie, l'ensemble de l'Esplanade de la Major, aux séries plus courtes mais plus homogènes permet de relire le contexte de la Rue Leca sous un nouveau jour, confirmant la plupart des hypothèses émises lors de son étude. Pour ces deux sites, des illustrations restent à faire afin que la typo-chronologie de cette période-clef de l'histoire marseillaise soit la plus complète possible et serve réellement de référence à l'archéologie des Temps modernes.

La céramique turque ne comporte que deux fragments à glaçure alcaline caractéristique : un fond de petite tasse décorée et un fragment de vase à émail turquoise. Enfin, une quarantaine de fragments de pipes dont deux fourneaux à talon marqué de deux monogrammes $\mathrm{E} \mathrm{B}$.

\subsection{Les faïences}

Les faïences italiennes (fig. 188, $\mathbf{n}^{\circ}$ 4-7) regroupent ici dans les comptages de fragments les productions toscanes et ligures, ainsi que les objets monochromes ou 


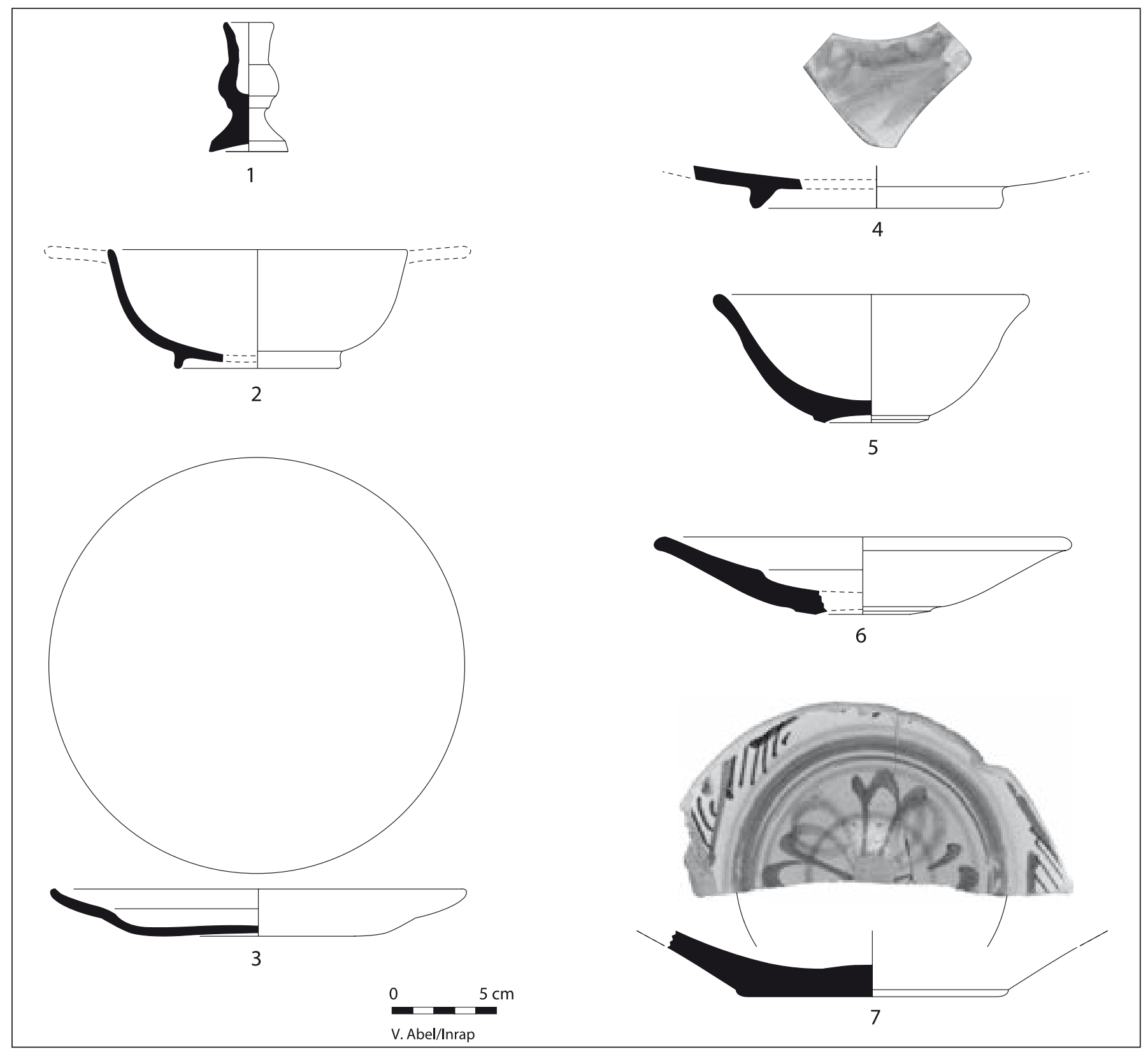

Fig. 188. Faïences (début du XVIII' s.). Bougeoir à émail turquoise $\left(n^{\circ} 1\right)$, écuelle et assiette de Provence $\left(n^{\circ} 2-3\right)$, plat de Ligurie $\left(n^{\circ} 4\right)$, écuelle et assiette anciennement dites de Gênes ( $\left.n^{\circ} 5-6\right)$, plat de Montelupo ( $\left.n^{\circ} 7\right)$. 1, 5, 7 : Esplanade de la Major ; 2-4, 6 : rue Leca.

décorés. Les faïences toscanes sont encore bien représentées ici. Leur datation habituelle ne correspond pourtant pas avec les fragments les plus récents du contexte. Le décalage observé est important: plus d'un demi-siècle. Il est identique pour des faïences ligures à décor a foglie, mais un peu moins important pour des faïences toscanes à décor de feuilles de chêne.

À côté de ces catégories « anciennes », des faïences ligures à décor bleu datées du début du XVIII ${ }^{\mathrm{e}} \mathrm{s}$. s'intègrent en revanche très bien à l'ensemble des céramiques les plus récentes.
Les lourdes faïences monochromes aujourd'hui atribuées à la Toscane demeurent encore très discrètes, alors que dans le courant du XVIII ${ }^{\mathrm{e}}$ s., elles occupent une part importante du marché marseillais de vaisselle commune.

Pour les faïences provençales (fig. 188, $\mathbf{n}^{\circ} \mathbf{2 - 3}$ ), on ne peut distinguer, dans l'état actuel de nos connaissances sur les faïences archéologiques, les différentes productions régionales. Les individus-objets sont nombreux, mais le recollage ne fut pas exceptionnel pour une fragmentation aussi importante. 


$$
\frac{2}{9}
$$




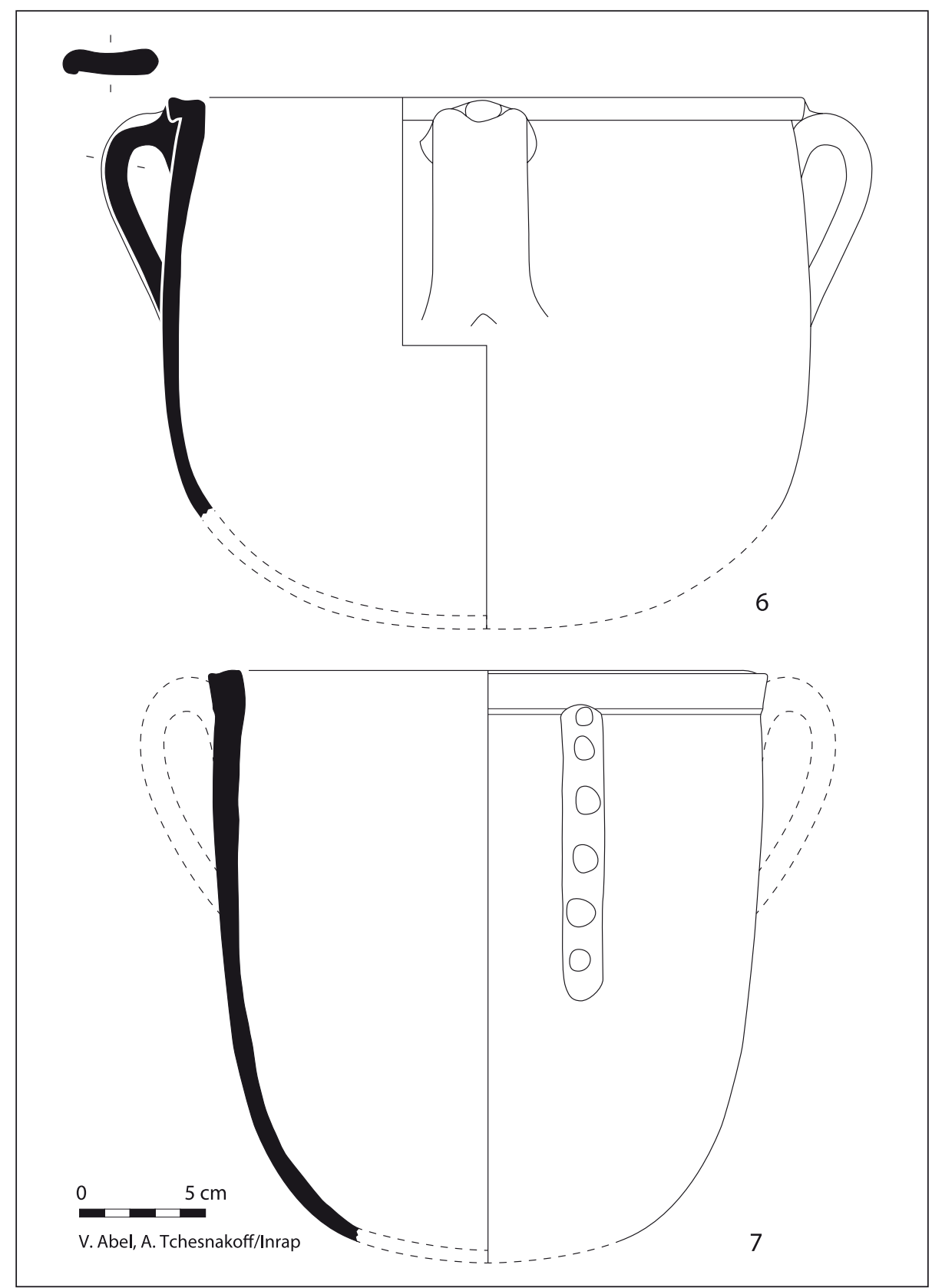

\subsection{La vaisselle et la poterie culinaire vernissées}

Les poteries vernissées pisanes font partie des catégories que nous pourrions qualifier $\mathrm{d}^{\prime}$ " anachroniques ». Il est cependant important de signaler que la catégorie de céramiques vernissées italiennes, la poterie brune à taches noires d'Albisola, qui lui succède au XVIII ${ }^{\mathrm{e}}$ s. est ici absolument absente. Cette information est sans doute l'une des plus intéressantes fournies par cette fouille.

Les céramiques culinaires de Ligurie (exemple fig. 189) (marmites et jattes) sont encore régulièrement exportées vers Marseille à la fin du XVII ${ }^{\mathrm{e}} \mathrm{s}$., mais elles ne se sont jamais rencontrées au delà du tournant du siècle.
Cette catégorie est ici relativement marginale, représentée par 25 fragments à peine. La durée de vie de ces vases culinaires de Ligurie, aux parois minces et soumis à la contrainte de cuissons quotidiennes, ne peut raisonnablement excéder quelques mois, voire quelques années. Il y aurait ici un écart de plusieurs dizaines d'années entre ces vases culinaires et les céramiques les plus récentes du lot.

Les bords des vases de céramiques culinaires de Vallauris (fig. 190) sont généralement de bons indices chronologiques bien que manquant de précision. Les marmites se répartissent ici en deux types : le premier à bord allongé ou en canal, le second à bord carré. Le premier se rencontre, notamment à la Charité (fig. 190, $\left.\mathbf{n}^{\circ} \mathbf{3}\right)$, 


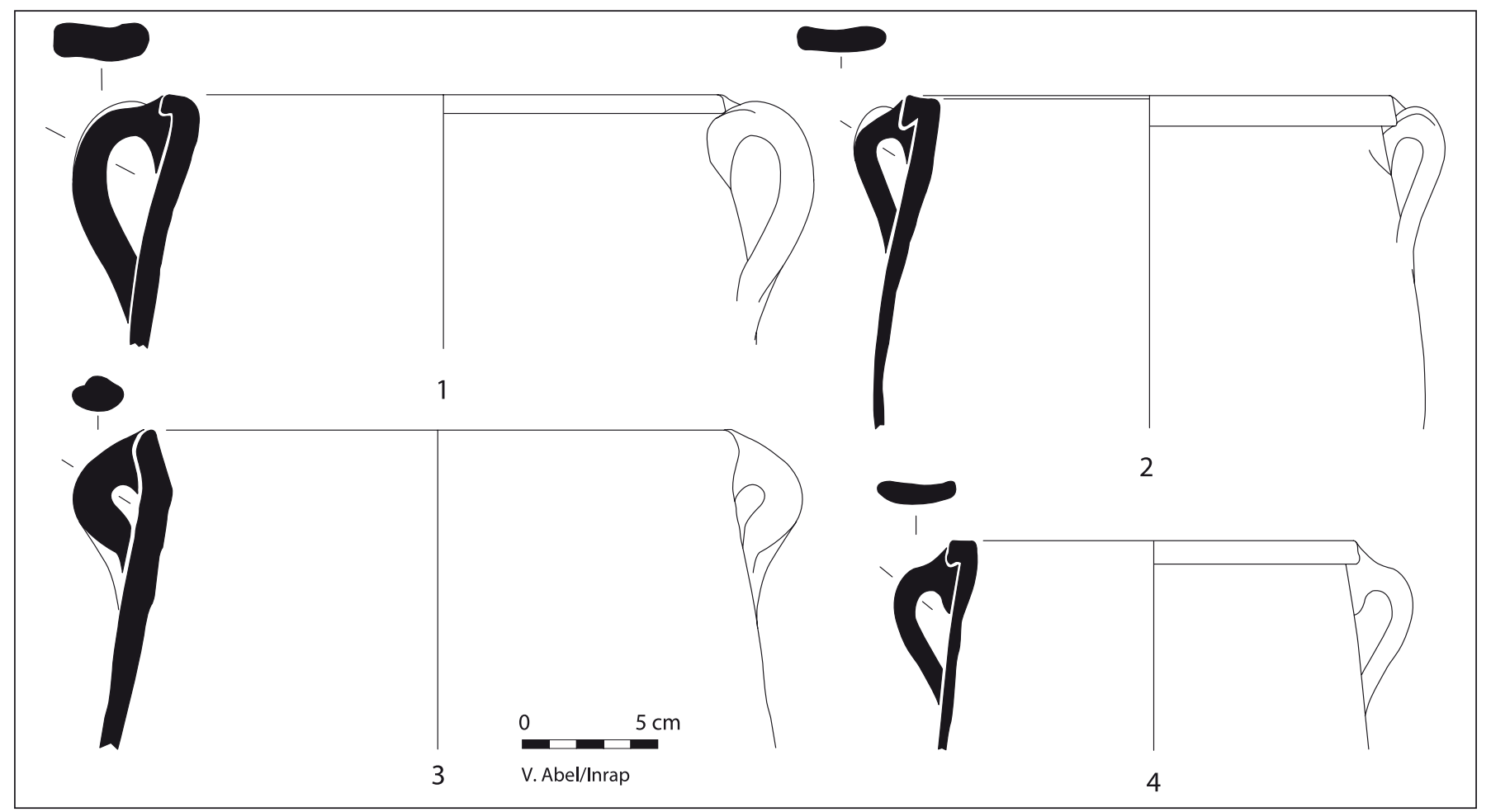

Fig. 190. Marmites en poterie réfractaire (début du XVIII ${ }^{e}$ S.). 1-3 : Esplanade de la Major ; 4 : rue Leca.

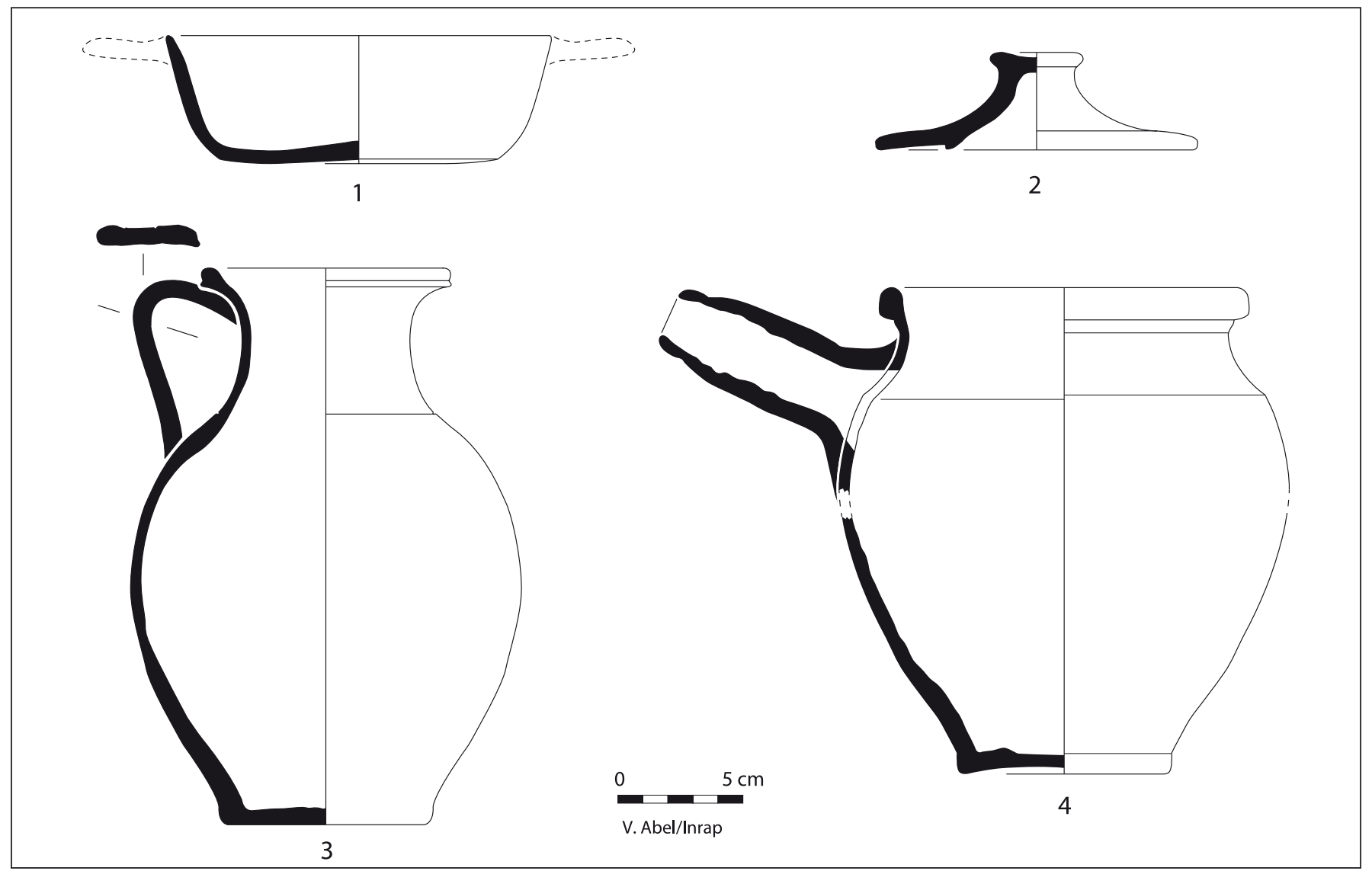

Fig. 191. Céramiques réfractaires de Languedoc (type Uzège) (début du XVIII' $s$.). Écuelle $\left(n^{\circ} 1\right)$, couvercle $\left(n^{\circ} 2\right)$, pichet $\left(n^{\circ} 3\right)$ et toupin $\left(n^{\circ} 4\right)$. 1, 3 : rue Leca ; 2 : Esplanade de la Major ; 4 : la Bourse. 
dans des contextes de la deuxième moitié du XVII ${ }^{\mathrm{e}} \mathrm{s}$. ; quant au second, il est caractéristique du XVIII ${ }^{e}$, sans toutefois que sa typo-chronologie ne soit vraiment précise (fig. 190, $\left.\mathbf{n}^{\circ} 1,2-4\right)$. Pour cette catégorie aussi, se pose la question de la cohabitation de deux types habituellement considérés comme successifs dans la production. Si, pour les catégories de luxe, les objets peuvent avoir eu une durée de vie plutôt longue, cela paraît peu vraisemblable pour des vases soumis aux règles d'usage des culinaires. La présence des bords les plus récents dits rapidement «carrés » par commodité est particulièrement intéressante : leur date d'apparition se voit ici située avant 1720. Un contexte de la butte des Carmes fouillé en 1982 (M. Willaume) offrait une large déclinaison de ce modèle de marmite et contenait des terres vernissées leur apportant un tribut chronologique (fig. 189).

Les céramiques culinaires de Saint-Quentin-laPoterie (fig. 191) constituent une catégorie généralement assez marginale dans les contextes modernes marseillais. Elle est ici plutôt bien représentée, mais en fait plus par des vases de table que par les traditionnels pots à cuire. Un pichet et des vases ouverts, écuelles, assiettes, sont toutefois complétés par des toupins (pots à une anse).

La production de céramiques vernissées de Fréjus disparaît quasiment, dans les contextes marseillais étudiés jusqu'ici, vers le milieu du XVII ${ }^{\mathrm{e}}$ s., alors que Fréjus fournissait la plus grande partie de la vaisselle de table marseillaise au XVI ${ }^{e}$ s. Vers la fin du XVII ${ }^{e}$ s. sont pourtant utilisés de grands vases, tians (bassines) et petites jarres à bec et anses, qui se rapprochent de la production de Fréjus. Ce ne sont pas ces derniers types qui pourraient être attribués aux productions fréjussiennes de la fin du XVII s., qui sont présents ici, mais au contraire ceux rencontrés vers le milieu du siècle. Une fois encore, si l'on peut admettre que des céramiques de luxe survivent assez longtemps, puisque le cas a été rencontré précédemment, cela paraît plus difficilement envisageable pour des céramiques communes.

Les jarres de Biot sont les vases de stockage de denrées les plus utilisées à Marseille, où elles sont présentes dès la deuxième moitié du XVII ${ }^{\mathrm{e}} \mathrm{s}$., et jusqu'à l'Époque contemporaine. Leur chronologie, en contexte archéologique, n'est pas encore déterminée car leur «immobilité » en réduit la casse, donc le nombre de restes archéologiques et les éléments servant à établir les typologies périodisées.

\subsection{Les céramiques à pâte calcaire de la basse Vallée du Rhône dites « de type Meynes »}

Une catégorie qui est ici particulièrement bien fournie est la poterie vernissée attribuée à la basse vallée du Rhône, dite «de type Meynes ». Cette attribution est faite en fonction de trouvailles importantes de poteries de type identique dans le secteur du nord-ouest des Bouches-du Rhône et de l'ouest du Vaucluse, et plus particulièrement dans la région de Meynes, encore totalement inexplorée en matière de céramologie.

Cette production est pour le moment absente des contextes de la deuxième moitié du XVII ${ }^{\mathrm{e}} \mathrm{s}$. à Marseille. Elle se rencontrait déjà dans ceux du début du XVIII ${ }^{\mathrm{e}} \mathrm{s}$., en particulier ceux de la Bourse où quelques puits avaient fourni les premiers spécimens marseillais, malheureusement sans datation très précise, et, sur les vases ouverts, un décor d'engobe géométrique organisé. Le mobilier de la fosse de la rue Leca comprend :

- Neuf assiettes, dont une seule à décor d'engobe organisé (cercles clairs et des points verts sur fond rouge), les autres décorées d'engobe jaspé (fig. 192).

- Six plats creux : trois à décor organisé de cercles rouges sur fond clair et pites vertes, deux à décor jaspé de trois couleurs, le dernier à revêtement monochrome clair.

- Un seul fragment indique la présence d'une écuelle.

- Un grand plat, de forme tronconique, très fragmentaire, à fond plat, parois rectilignes, bord à marli et lèvre bifide ; il est revêtu d'engobe blanc supportant un décor d'engobe et d'oxydes rapportés.

- Deux cruches signalées par quelques tessons seulement, à vernis vert et l'autre à vernis jaune ; une applique de fleur de lys appartient à un vase de ce type à vernis vert.

- Une cruche de barque dont il ne reste que le fond, a pu être reconnue par comparaison avec d'autres ensembles marseillais.

- Un pot de chambre est caractéristique de cette production : les parois sont verticales et forment quasiment un angle droit avec le bord, qui n'est que peu épaissi. Sur un engobe monochrome blanc, le vernis est irrégulièrement tacheté d'oxydes de cuivre et de manganèse

La chronologie marseillaise de cette catégorie n'est pas encore très bien connue. Le caractère relativement complet de certains vases, les vases ouverts en particulier, va dans le sens d'une homogénéité chronologique de ces objets, assez rare dans ce contexte pour être signalé.

\subsection{Les céramiques vernissées de la vallée de l'Huveaune}

Cette catégorie est considérée à partir du milieu du XVII ${ }^{\mathrm{e}}$ s., comme la céramique locale marseillaise (fig. 193 à 195). C'est en effet le centre le plus proche de Marseille et fonctionnant en grande partie pour le marché marseillais. Nous observons encore, sur cette catégorie mieux connue, du matériel sur une longue période. Cette observation est particulièrement sensible pour les vases ouverts. 


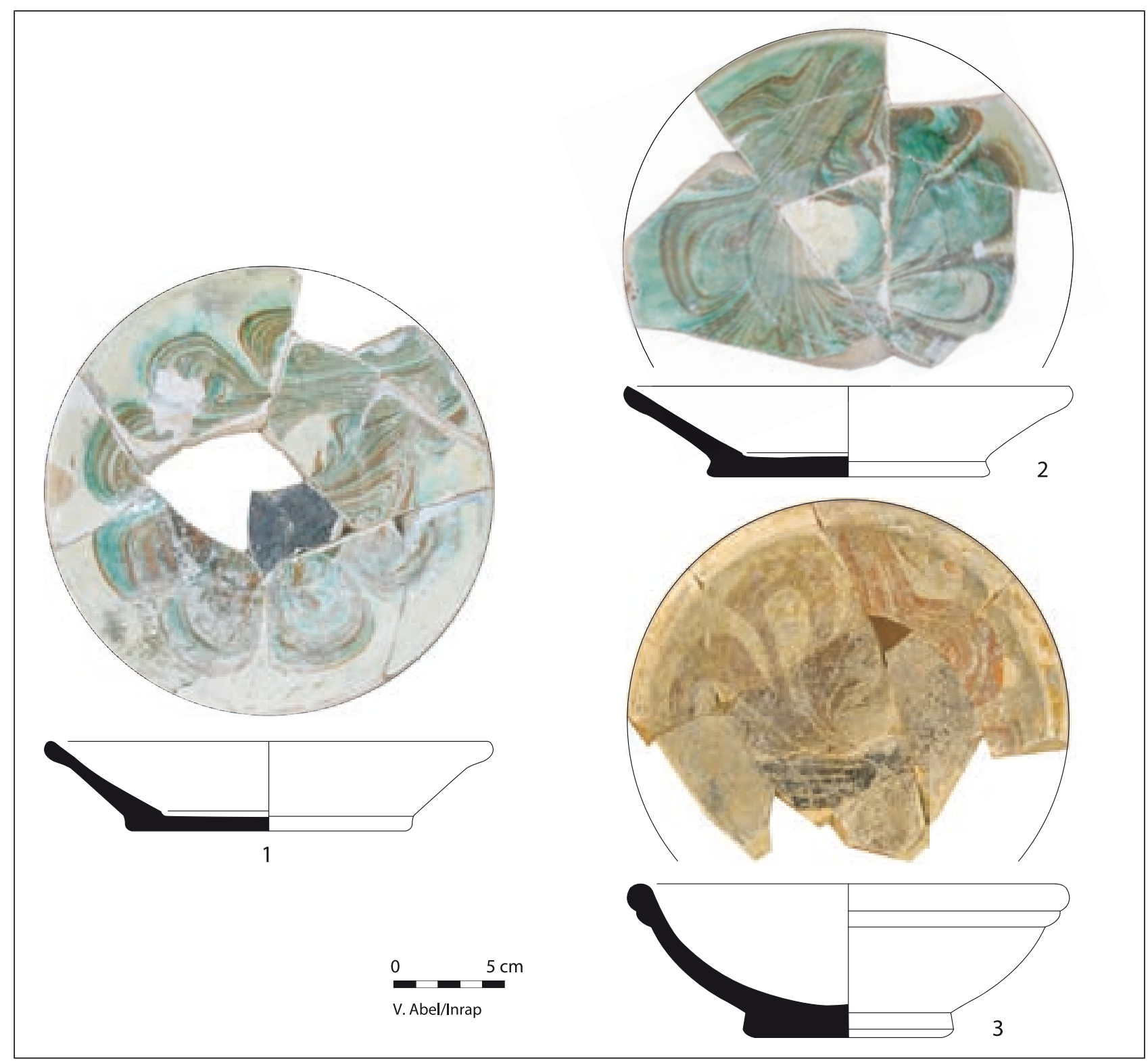

Fig. 192. Assiettes en terre vernissée de Languedoc (type Meynes) (début du XVIII s.). Rue Leca.

Pour les écuelles de modèle sans pied et avec oreilles (fig. 193, $\mathbf{n}^{\circ} \mathbf{1 - 5}, \mathbf{7 - 8}$ ), ces derniers appendices sont assez caractéristiques, alors que les bords sont trop irréguliers. Six oreilles appartiennent à des écuelles jaspées ou incisées polychromes, donc « anciennes » (deuxième moitié du XVII ${ }^{\mathrm{e}} \mathrm{s}$.), mais on trouve aussi deux oreilles d'écuelles à décor d'engobe clair, typique du milieu du XVII ${ }^{\mathrm{e}}$ s. Quant aux plus récentes écuelles, au nombre de huit, elles datent du début du XVIII ${ }^{\mathrm{e}}$ s. : elles sont monochromes à fond très plat.

L'écuelle de modèle à pied dégagé et sans oreille (fig. 193, $\mathbf{n}^{\circ}$ 6), que nous disons « à l'italienne » par référence à l'écuelle pisane de la seconde moitié du XVII ${ }^{\mathrm{e}}$ s., était associée à une sépulture et se trouve absolument intacte. Signalons qu'elle est, à travers ce mobilier, la seule représentante de ce type, si idéalement abâtardi, de l'écuelle à fond dégagé et décor polychrome, apparue dans la deuxième moitié du XVII $\mathrm{s}$.

Cette écuelle est assez proche de celle de la fin du XVII ${ }^{\mathrm{e}}$ s., mais elle s'est déjà « avachie ». Une première écuelle identique, issue d'une fouille marseillaise, semblait prouver déjà que la forme n'évoluait que peu, alors que le décor se simplifie radicalement: de la représentation florale élaborée de la fin du XVII ${ }^{\mathrm{e}} \mathrm{s}$., il ne reste plus que les taches de couleur qui rehaussaient les incisions. Elle est ainsi caractéristique de l'abâtardissement du décor incisé polychrome. 

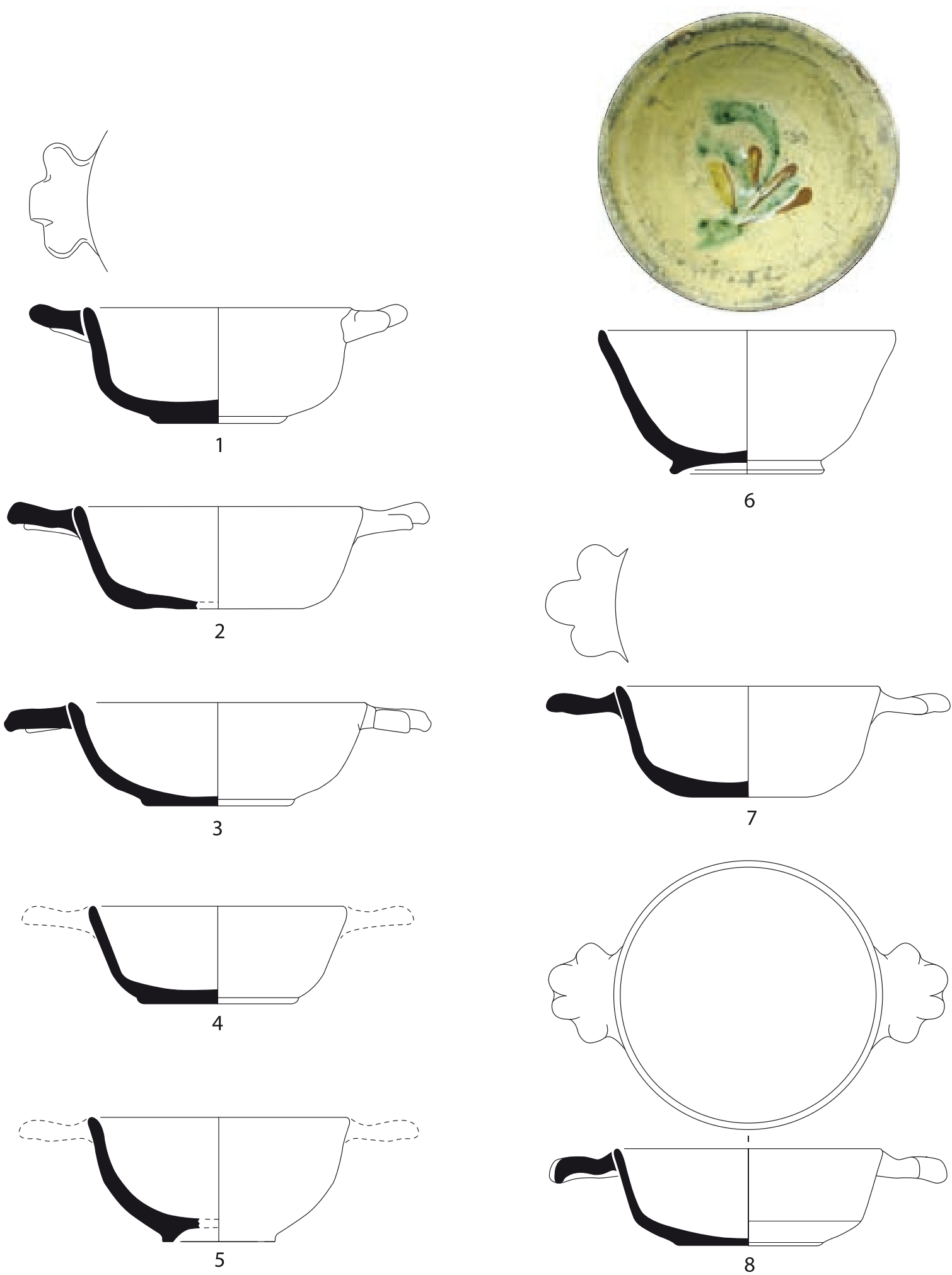

$\begin{array}{ll}0 & 5 \mathrm{~cm} \\ \text { V. Abel/Inrap }\end{array}$

Fig. 193. Terres vernissées de la vallée de l'Huveaune, arrière-pays marseillais (début du XVIIIe $\mathrm{S}$.).

Écuelles ( $\left.n^{\circ} 1-5\right)$, écuelle à l'italienne ( $\left.n^{\circ} 6\right)$, écuelle blanche ( $\left.n^{\circ} 7-8\right)$. 1-4 : Esplanade de la Major ; 5-7 : rue Leca ; 8 : la Bourse 


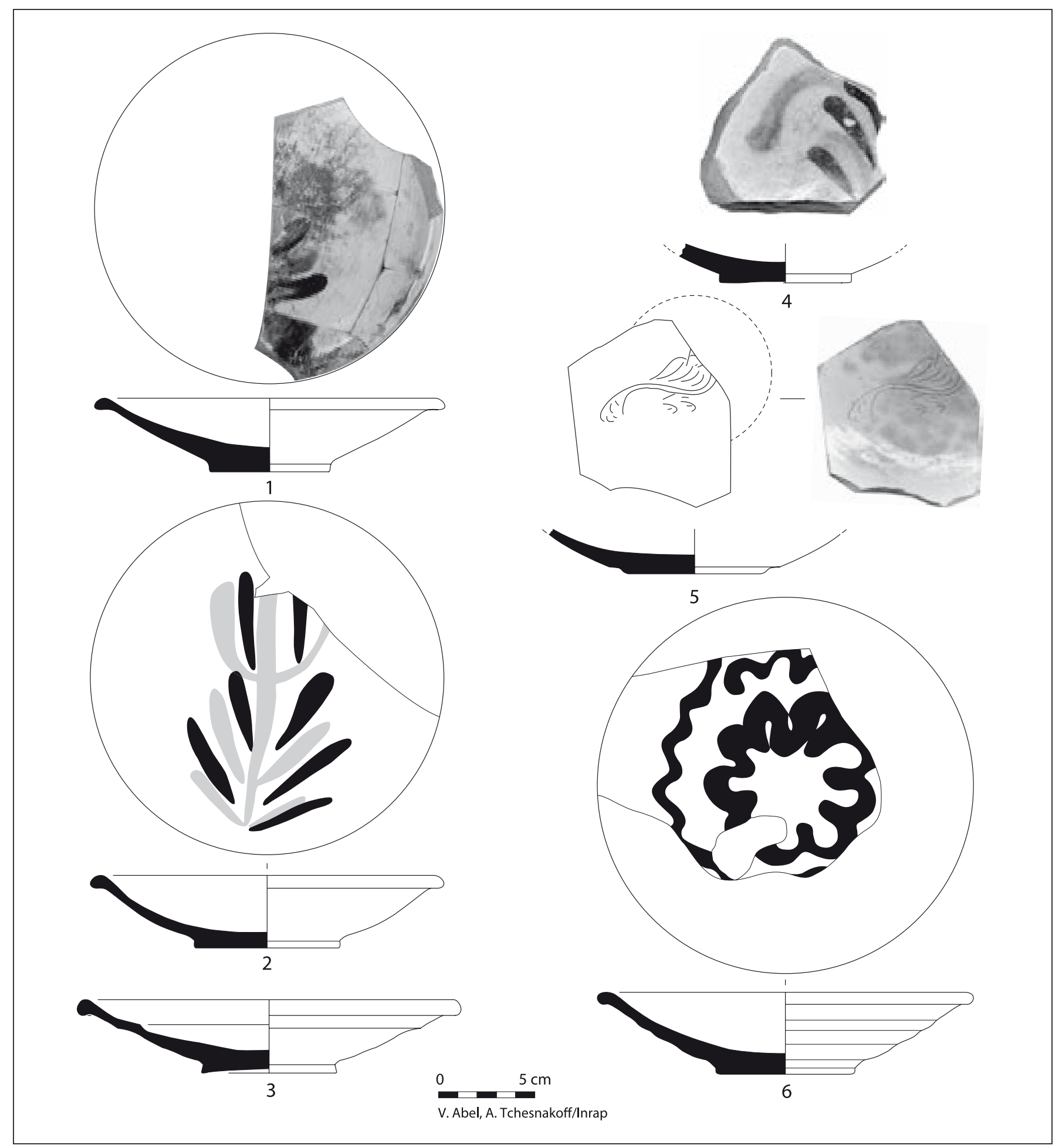

Fig. 194. Assiettes à fond dégagé de l'arrière-pays marseillais (début du XVIII' s.). 1 : rue Leca ; 2, 6 : la Bourse ; 3-5 : Esplanade de la Major.

Dans les autres vases ouverts (fig. 194), assiettes et plats, les types incisés polychromes à cercles incisés sur les bords (dernier tiers du XVII ${ }^{\mathrm{e}} \mathrm{s}$.) côtoient les types sans cercles et les types à taches organisées sans incisions, deux séries systématiquement rencontrées dans des contextes du début du XVIII ${ }^{\mathrm{e}} \mathrm{s}$. Peu de fragments de vases à liquide sont recensés, cette catégorie étant fragmentée à l'extrême.

Pour les pots de chambre (fig. 195, $\mathbf{n}^{\circ} \mathbf{2}$ ), la situation est semblable à celle des autres formes. Les types 


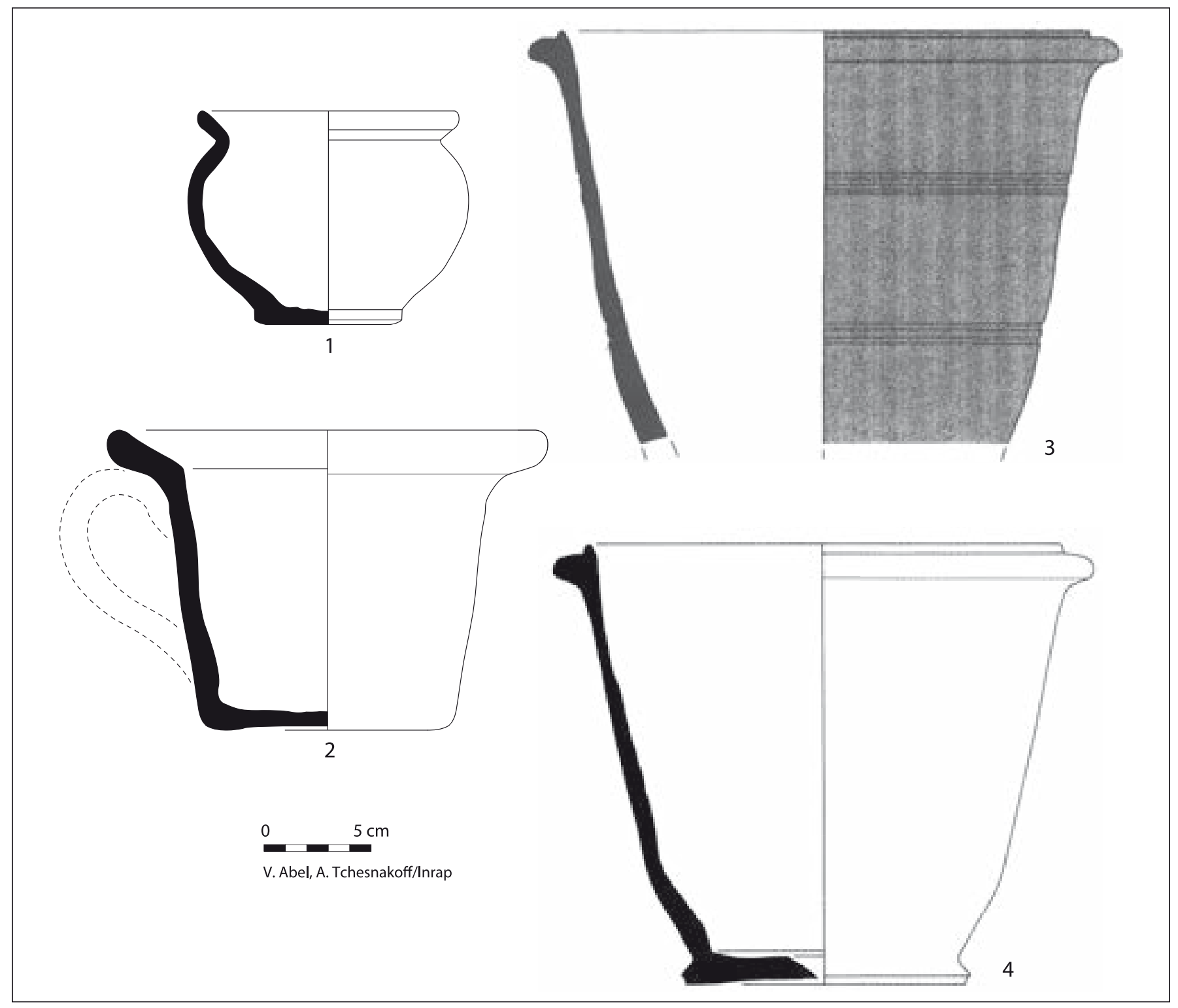

Fig. 195. Pots de l'arrière-pays marseillais (début du XVIII' s.). Pot à conserves $\left(n^{\circ} 1\right)$, pot de chambre $\left(n^{\circ} 2\right)$, pot de fleurs $\left(n^{\circ} 3-4\right)$. 1 : rue Leca ; 2 : Esplanade de la Major ; 3 : rue Leca ; 4 : les Carmes.

anciens, décorés avec autant de soin que n'importe quel autre vase, côtoient les types nouveaux, dont un spécimen, bien que sa forme ne soit pas archéologiquement complète, est caractéristique de la production du $\mathrm{XVIII}^{\mathrm{e}} \mathrm{s}$. Les parois très droites présentent à l'extérieur des stries de tournage qui ne se voient jamais sur ces mêmes objets au XVII ${ }^{\mathrm{e}} \mathrm{s}$. ; le bord est épais, en particulier dans l'angle avec la paroi. L'engobe blanc et le vernis incolore recouvrent bien l'intérieur, alors que l'extérieur est vert et moins soigné.

Plusieurs pots de fleurs (fig. 195, $\mathbf{n}^{\circ} \mathbf{3 - 4}$ ) ont été répertoriés. Ils possèdent un bord triangulaire caractéristique, et l'intérieur des vases n'est jamais revêtu. Ces objets sont relativement rares dans le mobilier céramique des Temps modernes, et présents dans cette zone de jardins ayant juste précédé les inhumations. On peut penser que le type apparaît ou réapparaît à cette époque, car il est absent des contextes marseillais antérieurs étudiés jusqu'ici, et présent, quoique rare dans ceux qui sont approximativement contemporains ou postérieurs. Il est vrai que la plupart des contextes céramiques modernes retrouvés jusque là était en zone purement urbaine dont les jardins sont exclus.

L'un de ces pots de fleurs est vernissé en vert à l'extérieur, l'intérieur étant laissé brut. Un autre est sans revêtement, il possède une préhension, posée horizontalement sous le bord, identique à celles des grands tians monochromes. Une applique en forme de fleurs de lys en relief appartient à un vase de ce type. 
Une base de pot de fleur sur pied, ne peut être rattachée aux ateliers de l'Huveaune, ayant une pâte rouge à nombreux éléments non-plastiques blancs. Ce vase est revêtu de vernis taché de cuivre et de manganèse.

Un fond de vase émaillé à décor vert et brun est inédit, sa provenance n'a pas encore été déterminée avec certitude ; il pourrait s'agir d'un vase d'Anduze (Gard).

\subsection{En conclusion}

Le fait marquant observé dans cet ensemble de mobilier moderne est la concomitance de plusieurs types à datation différente dans les séries dont nous connaissons le mieux la chronologie. Il s'agit notamment des productions de luxe d'Italie, des céramiques culinaires en général et des céramiques vernissées locales. Si pour la première catégorie, on peut admettre que les vases ont eu une durée de vie assez longue, il n'en va pas de même pour les céramiques culinaires : elles sont particulièrement sollicitées, et il n'est pas concevable qu'une dizaine de marmites en terre ait pu servir pendant plusieurs dizaines d'années.

Il faut donc plutôt considérer certaines céramiques, modernes mais antérieures au XVIII ${ }^{\mathrm{e}}$ s., comme du matériel en dépôt secondaire dû au creusement des jardins. Celui-ci constitue environ un tiers du total du mobilier. Il n'est toutefois pas possible d'effectuer un inventaire très précis, isolant les céramiques de la fin du XVII ${ }^{\mathrm{e}}$ de celles du XVIII ${ }^{e} \mathrm{~s}$. : les types en étant évidemment très proches, il est difficile de les distinguer avec une absolue certitude. La chronologie des objets, en particulier des objets non décorés, dans la plupart des catégories est à préciser.

C'est précisément le cas des productions de la vallée de l'Huveaune, qui sont les céramiques «locales » de Marseille, sa vaisselle quotidienne. La présence systématique et simultanée de types rencontrés habituellement dans la deuxième moitié du XVII ${ }^{\mathrm{e}} \mathrm{s}$. et d'autres au début du XVIII $\mathrm{s}$. ne peut, à notre avis, être considérée comme une survivance de vases anciens dans un milieu très conservateur: les objets en question ne sont représentés, pour la plupart, que par un fragment à chaque fois, rien ne réussissant recoller.

Les céramiques à pâte calcaire attribuées, sous toutes réserves, à Meynes (Gard) dans la basse vallée du Rhône ont pu en revanche être relativement bien reconstituées, ce qui tendrait à prouver qu'il s'agirait bien là de la vaisselle contemporaine de l'enfouissement. Leur chronologie à Marseille n'est pas encore déterminée avec précision, mais il semble certain qu'elles ne sont pas utilisées avant l'extrême fin du XVII ${ }^{\mathrm{e}} \mathrm{s}$., ou de manière très exceptionnelle. Un des apports les plus intéressants de ce contexte est la mise en lumière de leur utilisation certaine dans le premier quart du XVIII ${ }^{\mathrm{e}} \mathrm{s}$. Contrairement à toute attente, elles semblent même plus utilisées que les céramiques de la vallée de l'Huveaune, cette nouvelle donnée pouvant n'être valable que pour une courte période où les ateliers de l'Huveaune auraient été en difficulté, peut-être, mais l'évocation est prudente, à cause de la maladie qui ravage les alentours de Marseille de 1720 à 1722.

Les ateliers de l'arrière-pays marseillais (vallée de l'Huveaune) sont ici représentés par des spécimens intéressants, qui confirment les indications d'autres sites: utilisation dans le premier quart du XVIII ${ }^{\mathrm{e}} \mathrm{s}$. du répertoire typologique de la deuxième moitié du $\mathrm{XVII}{ }^{\mathrm{e}} \mathrm{s}$., avec cependant une limitation de la variété et un alourdissement des formes ; simplification des décors polychromes, cantonnés sur les vases ouverts, avec limitation du recours à l'incision.

L'une des contributions essentielles de ce site à la connaissance de la céramique utilisée à Marseille aux Temps modernes est la révélation de l'absence des céramiques d'Albisola dans le premier quart du XVIII' $\mathrm{s}$. : ces céramiques brunes à taches noires sont très nombreuses dans les contextes marseillais du XVIII' $\mathrm{s}$. On sait que la production s'en poursuit jusqu'à la fin du siècle au moins, mais leur date d'apparition sur les marchés marseillais restait assez vague. Bien qu'un argument $a$ silentio ne soit pas totalement satisfaisant, il nous semble cependant intéressant d'y recourir, vu la masse de fragments en présence. La date d'apparition de ces céramiques se situerait donc après 1720 .

\section{L'équilibre précaire du milieu du XVIII' ${ }^{\mathrm{e}} \mathrm{s}$.}

Un virage s'amorce dans la consommation de céramiques dès le deuxième quart du XVIII ${ }^{\mathrm{e}} \mathrm{s}$. à Marseille. D'après les diverses fouilles marseillaises, cette période inaugure notamment une plus grande utilisation de la faïence et un rééquilibrage des terres vernissées entre les produits locaux et les importations.

\subsection{Les importations rares}

Certaines importations demeurent, comme précédemment, des raretés. Ainsi quelques fragments de céramiques ottomanes sont reconnus dans le mobilier de la place Villeneuve-Bargemon. L'un d'entre eux a été recueilli dans un contexte céramique du $\mathrm{XIX}^{\mathrm{e}} \mathrm{s}$. comprenant un lot homogène de céramiques du siècle précédent. Ce fragment appartient à une tasse de Kutahya (fig. 196) datée du XVIII ${ }^{\mathrm{e}} \mathrm{s}$., dont la forme est presque complète. La finesse des parois conduirait à la dater de la première 


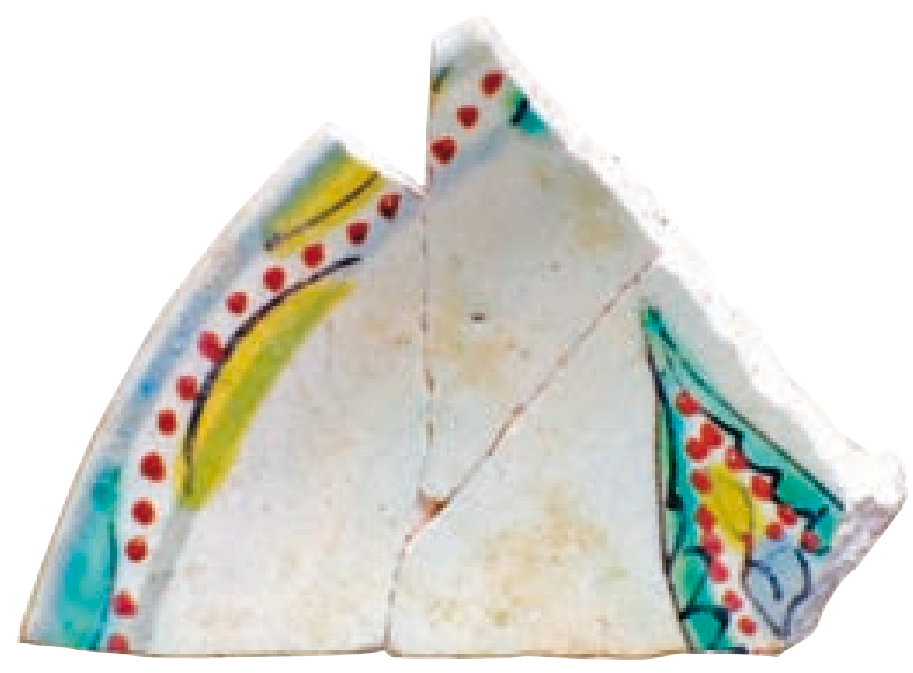

Fig. 196. Faïence de Kutahya (milieu du XVIII' s.). Place Villeneuve-Bargemon.

moitié du siècle. À cette époque, les ateliers de ce centre de l'Anatolie utilisent des techniques identiques à celles d'Iznik, mais, dirigés par des Arméniens, ils ont varié leur répertoire iconographique et morphologique. Il n'est pas aisé d'interpréter le décor central de la pièce, qu'il s'agisse d'une extrémité pointue de feuille ou autre, encadré d'une frise courant sous la lèvre. Remarquons cependant, aux côtés des couleurs traditionnelles, des rehauts d'un jaune particulièrement vif ou citron, adopté dans les années 1720 (Soustiel 1985, p. 346).

\subsection{Les faïences}

La faïence était jusqu'à la fin du $\mathrm{XVII}^{\mathrm{e}} \mathrm{s}$. de provenance extrarégionale uniquement. Les faïences décorées de Montelupo n'ont pas complètement déserté le marché marseillais par la suite et résistent encore avec des décors en spirales (Berti 1998, genere 72, « spirali verdi $»$ ) et en bouquet central (Berti 1998, genere 75, « mazzetto fiorito verde ») constituant en moyenne $1 \%$ des objets en usage.

La Ligurie procure à la marge quelques objets recherchés décorant des maisons du quartier de la place Villeneuve-Bargemon au XVIII ${ }^{\mathrm{e}} \mathrm{s}$.

L'ensemble des faïences italiennes constitue moins de $5 \%$ des objets en usage dont l'essentiel est constitué d'assettes toscanes lourdes et sans décor que nous avons vues apparaître à la période précédente.

Dans les années 1670, selon l'histoire de l'art, et à l'extrême fin du XVII ${ }^{\mathrm{e}}$ pour l'archéologie en site consommateurs, la faïence commence à être fournie par des ateliers régionaux. La faïence provençale (fig. 197) et la faïence italienne du milieu du XVIII ${ }^{\mathrm{e}} \mathrm{s}$. sont très différentes l'une de l'autre, alors que les productions des différents centres provençaux (Marseille, Moustiers, Varages, etc.) sont au contraire très semblables entre elles. Sur le chantier de la place Villeneuve-Bargemon, ces dernières représentent entre 10 et $15 \%$ du mobilier, neuf dixièmes des objets stannifères étant provençaux. Il s'agit essentiellement d'assiettes et de plats, les écuelles étant plus rares, de même que les couvercles.

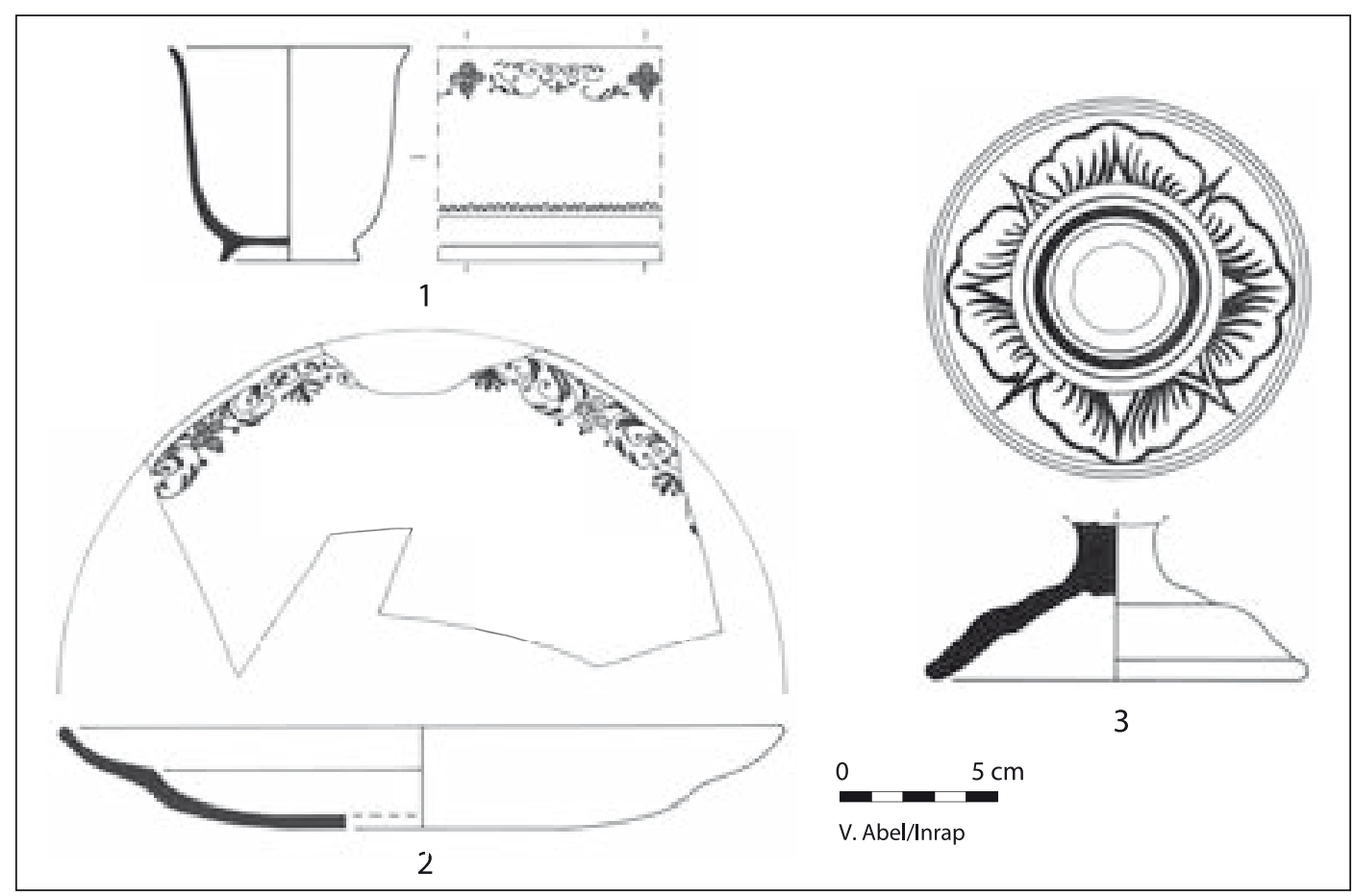

Fig. 197. Faïences régionales (milieu du XVIII $\mathrm{S}$.). La Bourse. 


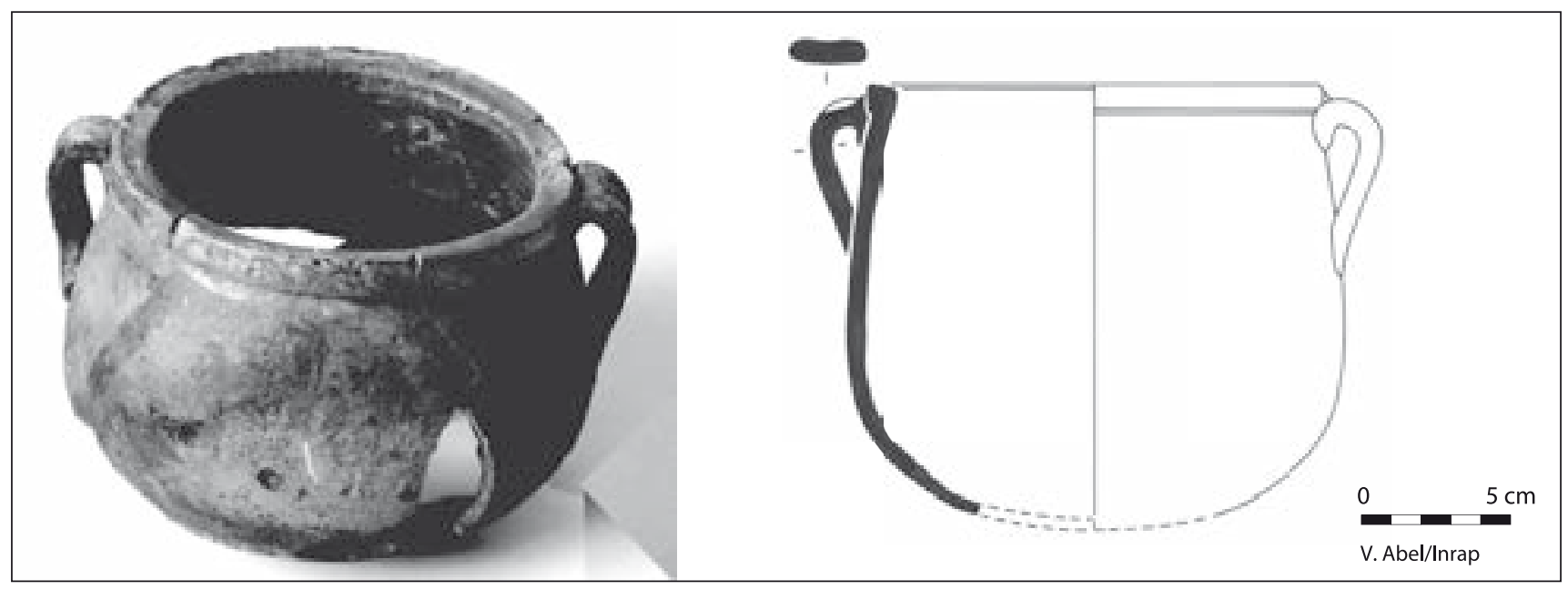

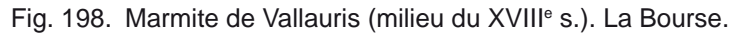

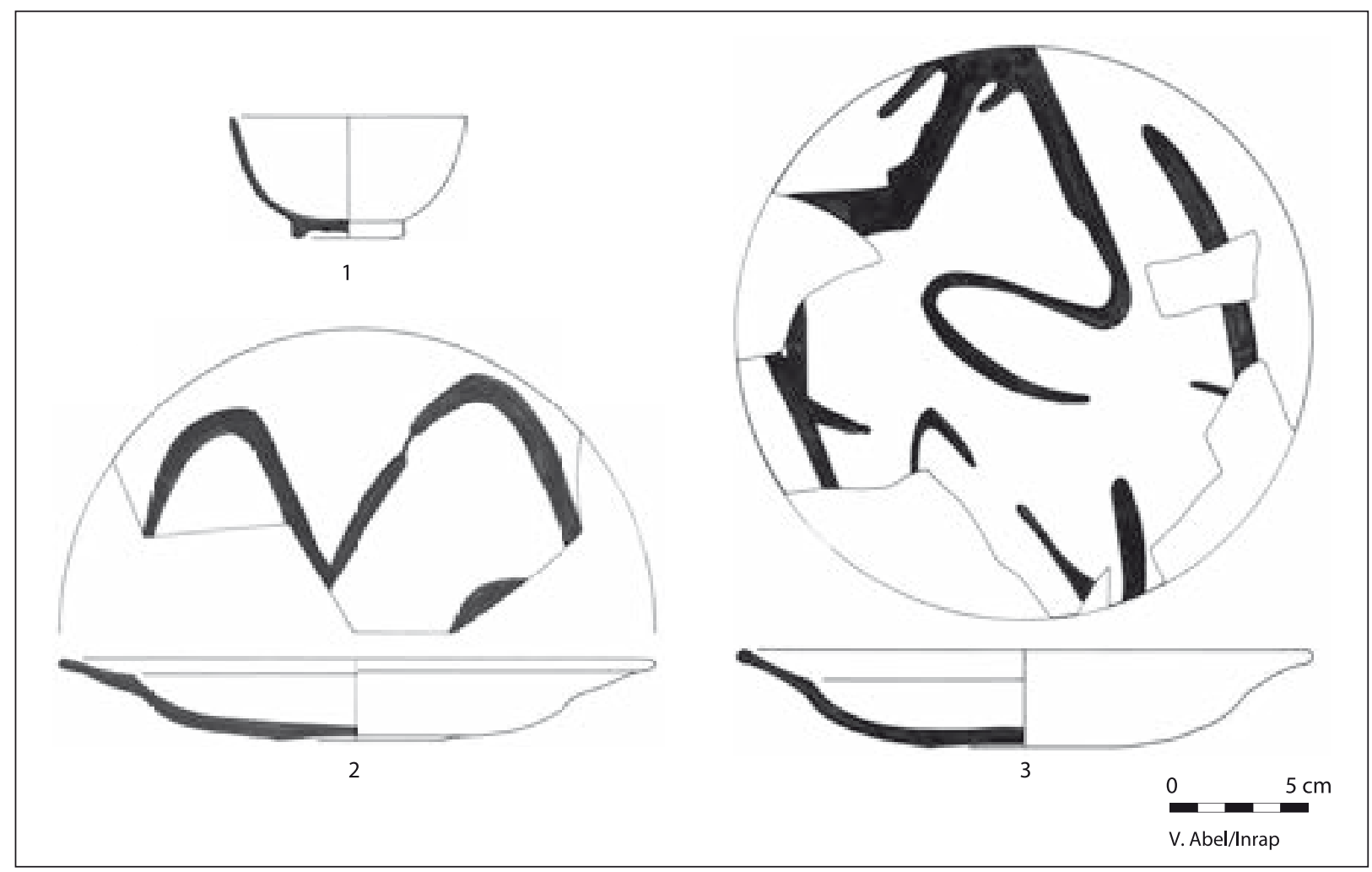

Fig. 199. Céramiques d'Albisola (milieu du XVIII ${ }^{e}$ s.). La Bourse.

Sur les 18 objets reconnus, sept ne présentaient pas de décor sur les fragments recueillis, l'émail d'une écuelle était resté uni (inv. 52.02.10312), et dix objets portaient encore des traces de décors. Il s'agit pour la plupart (huit d'entre eux) de décors au bleu de cobalt, comme ces frises de bâtonnets ou de broderies, très prisées (inv. 52.02.10315, 10163 et 10568). Un décor en vert et manganèse a été décelé sur un petit fragment d'écuelle à émail blanc (inv. 52.02.10266), pendant qu'un décor aux couleurs semblables était posé sur un objet non identifié à émail jaune (inv. 52.02.10313).

La masse de cette faïence provençale est relativement faible, mais ses enseignements ne sont pas négligeables pour la céramologie : les produits à revêtement émaillé ont trouvé dans la vie quotidienne une place limitée mais assez constante et sans doute une fonction précise de vaisselle intermédiaire, plus élégante que la terre vernissée et moins onéreuse que les objets très recherchés. Cet 
aspect, peu documenté dans les études stylistiques, est davantage à la portée de l'archéologie.

\subsection{Les poteries culinaires}

Les luttes entre approvisionnements, quels que soient leurs moteurs, ont lieu dans tous les domaines de la céramique. Les vases culinaires de Vallauris (fig. 198) prennent alors le pas sur tous les autres dans la cité marseillaise, avec le quart des fragments significatifs pour le XVIII ${ }^{\mathrm{e}}$ s., et $9 / 10^{\mathrm{e}}$ des fragments réfractaires, constituant les trois quarts des vases culinaires.

Ils fournissent des indices chronologiques relativement fiables, mais encore trop peu précis. On peut dire de manière générale que le XVIII ${ }^{\mathrm{e}} \mathrm{s}$. a vu l'avènement des marmites à «bord carré » et des poêlons à lèvre épaissie légèrement déversée et queue en guise de préhension. Ces objets ne sont pas sans poser des problèmes de chronologie tant leur évolution est peu perceptible. C'est plutôt dans les techniques qu'il faut trouver des indices : l'engobe est d'abord absent, il apparaît vers le milieu du XVIII ${ }^{\mathrm{e}}$ s., puis se généralise peu à peu, sans jamais devenir une règle.

Les céramiques réfractaires de type «Uzège » sont peu utilisées à Marseille pendant toute l'Époque moderne. Dans le courant du XVIII ${ }^{\mathrm{e}}$ s., ce sont les formes de vaisselle (écuelles et grands plats à aile) et les poêlons qui ont les faveurs de quelques rares acheteurs.

Le phénomène de spécialisation dans les approvisionnements, qui s'est produit dans la seconde moitié du $\mathrm{XVII}{ }^{\mathrm{e}} \mathrm{s}$. pour les terres vernissées au profit des ateliers de la vallée de l'Huveaune, se répète au début du XVIII' $s$. en faveur des ateliers de Vallauris dans le domaine des vases de cuisine.

\subsection{Les terres vernissées}

L'apparition des céramiques vernissées «à taches noires » d'Albisola (fig. 199) constitue le marqueur du plein XVIII s. à Marseille. Il s'agit certes d'un indice chronologique intéressant et facilement identifiable. $\mathrm{Si}$ les formes sont assez bien répertoriées, leur typo-chronologie reste cependant à affiner. Elles n'apparaissent pas à Marseille avant le deuxième quart du XVIII ${ }^{\mathrm{e}} \mathrm{s}$. et semblent se maintenir jusqu'à la fin du XVIII ${ }^{\mathrm{e}} \mathrm{s}$. Ces trois quarts de siècle restent pour l'instant indistincts, sans aucune typologie précise et périodisée (Cameirana 1970 ; Milanese et al. 1994).

Malgré une image de catégorie très vigoureuse et très envahissante véhiculée par quelque littérature archéologique, elles ne constituent pourtant, à travers le mobilier de l'ensemble des chantiers marseillais sur cette période guère plus d'un vingtième des fragments et des individus. Assiettes et plats très simples sont les plus courants, suivis par les écuelles et les tasses ; couvercles et grands plats parfois non circulaires, soupières et divers articles de vaisselle circulent aussi.

Les productions de Biot les mieux connues sont les jarres (Mari 1996) et celles-ci demeurent l'essentiel parmi les objets attribués à ce centre, parfois difficiles à appréhender tant sont rares les fragments de ce «mobilier» si peu mobile. Une bugadière (grand récipient à lessive), bien connue de ce centre mais plus rarement importée, vient varier les inventaires.

Que devient la terre vernissée de la vallée de l'Huveaune (fig. 200) au delà des années 1720 environ dans les maisons marseillaises? Il existe deux manières de répondre à cette question : la première prend acte de la masse de tessons et d'objets qui nous parviennent à travers le filtre de l'archéologie, la seconde est un peu plus subjective bien qu'elle soit issue de constats et de l'analyse des objets eux-mêmes.

On peut donc en premier lieu affirmer que la part de ces ateliers dans la consommation marseillaise reste considérable, avec par exemple pour la place VilleneuveBargemon le tiers des fragments significatifs et la même proportion des objets.

On ne peut cependant s'empêcher de remarquer en second lieu, grâce au mobilier de l'ensemble des sites marseillais, que le foisonnement des formes et la virtuosité des décors du dernier quart du XVII ${ }^{\mathrm{e}} \mathrm{s}$. ne sont plus atteints dès le début du siècle suivant. Les engobes unis (excepté l'engobe blanc sous vernis vert) étaient exception, ils deviennent la règle, avec les trois quarts des objets reconnus. L'engobe rose, qui n'était utilisé qu'en sous-couche dans la période florissante de l'Huveaune, trouve sa place en revêtant le cinquième des objets et se combine au vernis jaune pour donner des vases à tonalité orangée. Il est parfois posé avant un vernis vert, conférant à ce revêtement une couleur peu flatteuse. Les décors figurés, de fleurs ou d'oiseaux, ont disparu, et avec eux la technique de l'incision et polychromie. Les décors jaspés, plus virtuoses qu'ils ne paraissent, ont considérablement décliné. À la fin du siècle précédent, certains artisans les maîtrisaient à un point tel qu'ils pouvaient couvrir entièrement la surface de vases fermés comme des pichets ou des pots de chambre. Ce savoir-faire se perd dès le premier quart du $\mathrm{XVIII}^{\mathrm{e}} \mathrm{s}$. et est peu à peu abandonné. Ces décors jaspés ne savent plus animer que le centre de quelques assiettes et plats, où ils sont faciles à poser, avant de disparaître. 


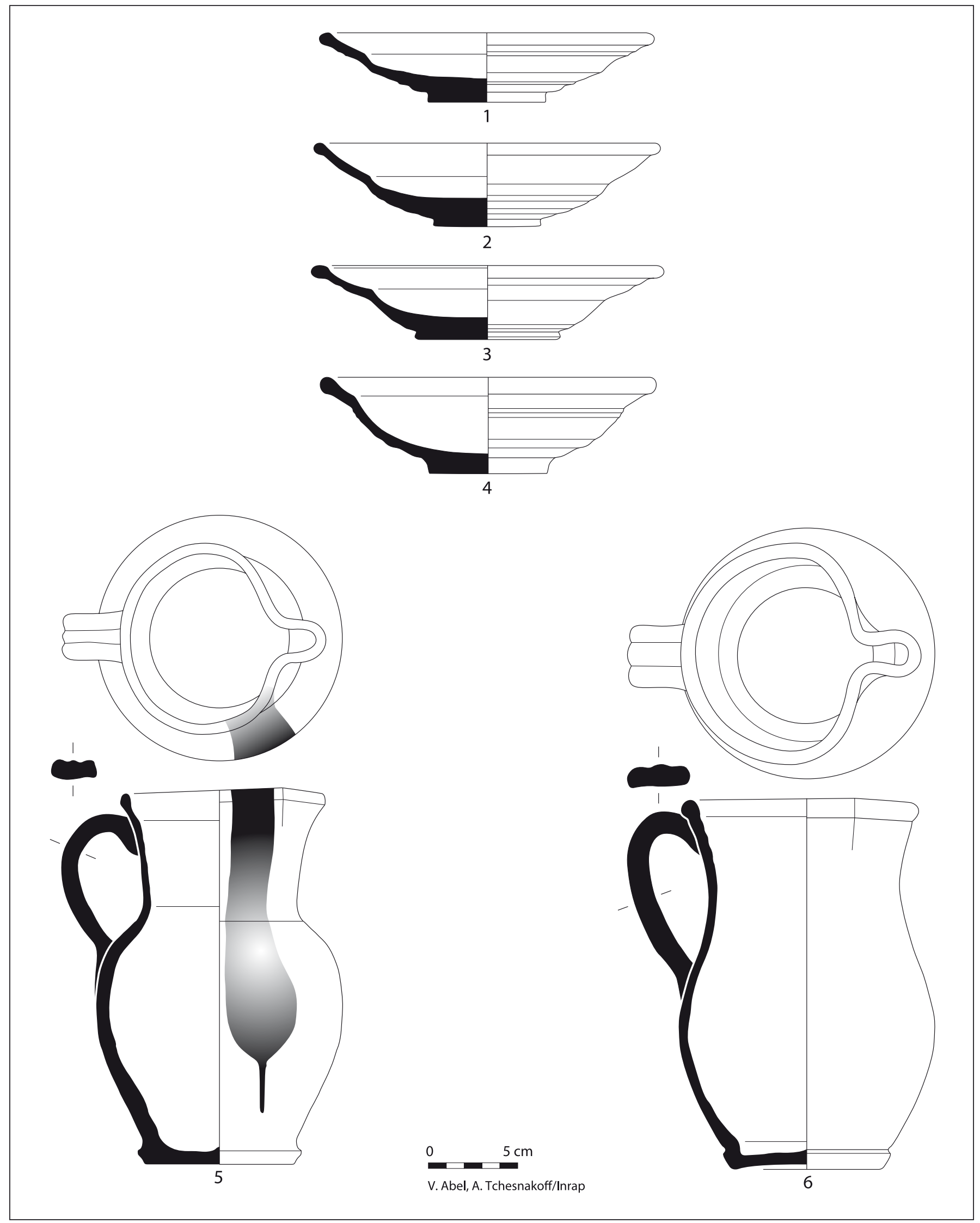

Fig. 200. Terres vernissées de la vallée de l'Huveaune (milieu du XVIII ${ }^{\mathrm{S}}$ s.). Assiettes ( $\left.n^{\circ} 1-4\right)$ et pichets $\left(n^{\circ} 5-6\right)$. La Bourse. 
Les décors d'engobes posés « en rubans » réussissent à survivre, certainement grâce à leur facilité d'exécution qui permet d'animer le vase à peu de frais. Les formes imaginées au siècle précédent sont dans un premier temps partiellement reconduites. Puis vers le milieu du siècle ou peu après, certainement sous l'influence de facteurs multiples, la platerie est simplifiée par l'adoption d'une forme, à base large et aile courte, déclinée en tailles, profondeurs et couleurs variées.

Les rapports entre la faïence et la vernissée locales ne sont pas à proprement parler perceptibles à travers le mobilier archéologique. Sont-ils faits d'ignorance réciproque ou de liens étroits? $\mathrm{Si}$ aucun vestige ou reste archéologique ne vient encore nous éclairer, gardons-nous cependant d'en déduire une absence totale de rapports. Il serait difficile d'envisager que deux arts de la terre cuite sur une même zone géographique évoluent sans rapports humains ou économiques entre eux. Il n'est cependant pas possible de les imaginer, l'archéologie ne nous menant pour l'instant qu'à des raisonnements par l'absence. Qu'il y ait eu ou pas des transferts, de techniques, de matières premières, de savoir-faire ou de main d'œuvre, ou de marchés, nous n'en avons pas de trace. Pour l'archéologie, cela ressemblerait plutôt à une absence de concertation et une concurrence certaine, résultant ou conduisant à un grignotage de la catégorie de vaisselle intermédiaire par la faïence. 



\section{Chapitre 9}

\section{La fin d'un monde, le dernier quart du XVIII ${ }^{\mathrm{e}}$ s.}

\section{(Véronique Abel)}

$\mathrm{L}$ a céramique utilisée à Marseille vers la fin $\mathrm{du} \quad \mathrm{XVIII}^{\mathrm{e}} \mathrm{s}$. était très mal connue jusqu'à la fouille de la place Villeneuve-Bargemon qui a livré deux lots de mobilier provenant de deux unités stratigraphiques, proches mais non connexes, d'un peu moins de cinq cents fragments qu'un intéressant élément de datation a permis de placer dans les dernières années de ce siècle (tableau VII).

\section{Les terres vernissées dites «faïence fine »}

Durant cette période apparaît une nouvelle catégorie de terre vernissée plus fine qui se rapproche de la faïence et que l'on appelle ainsi «faïence fine ». On la retrouve aussi bien dans les productions locales que plus éloignées, dont témoigne l'archéologie marseillaise.

\subsection{Les productions marseillaises}

L'étude du mobilier des deux contextes de la place Villeneuve-Bargemon avait révélé une nouvelle catégorie dans le mobilier moderne de Marseille. Quelques années plus tard, la fouille de l'Hôtel-Dieu est venue confirmer l'homogénéité de ce mobilier par un dépotoir relativement riche, avec la présence d'une terre vernissée dite « faïence fine de Marseille » pour laquelle deux rappels sont nécessaires : l'un sur la nature exacte de cette catégorie et l'autre sur sa «nouveauté ». Cette céramique, dont la pâte est claire à cassure granuleuse après cuisson donc fort différente de celle de la terre vernissée et de la faïence locales, est façonnée selon des techniques qui semblent issues ou inspirées pour l'essentiel des techniques faïencières, comme le moulage et le calibrage, alors que son revêtement est un vernis transparent en tonalités de jaune couvrant tout l'objet. Longtemps en Provence, terre vernissée et faïence semblent vivre dans des mondes séparés, ne partageant que peu en techniques ou matières premières, tout au moins en apparence.

La rareté et l'originalité des objets, leur absence avant l'extrême fin du XVIII ${ }^{\mathrm{e}} \mathrm{s}$. dont les niveaux archéologiques sont assez peu exploités, expliquent qu'elle soit passée inaperçue ou mal identifiée jusqu'à la découverte de la « boîte à épices » de la place Villeneuve-Bargemon (fig. 201, $\mathbf{n}^{\circ} \mathbf{1}$ ). Échappant de justesse à un obscur destin de cendrier contemporain, cet objet était identique à deux autres conservés dans les collections du Musée de la faïence (Maternati-Baldouy 1997, p. 289), dont l'une

\begin{tabular}{|l|c|c|c|}
\hline \multicolumn{1}{|c|}{ Catégories } & Fragments & NMI & N \\
\hline Faïence de Ligurie & 1 & 0,21 & 1,18 \\
\hline Faïence de Montelupo & 2 & 0,43 & 1,18 \\
\hline Faïence de Provence & 51 & 10,85 & 12 \\
\hline Pipe d'Europe du Nord & 1 & 14,11 \\
\hline Poterie réfractaire de la Drôme/Nord-Vaucluse & 1 & 1,18 \\
\hline Poterie réfractaire de Vallauris & 14 & 0,21 & 1,18 \\
\hline Terre vernissée d'Albisola & 16 & 2,98 & 4,71 \\
\hline Terre vernissée de Biot & 3 & 3,4 & 4 \\
\hline Terre vernissée de l'arrière-pays marseillais & 372 & 0,64 & 2 \\
\hline Terre vernissée de Ligurie & 3 & 79,15 & 51 \\
\hline Terre vernissée dite « faïence fine » de Marseille & 6 & 0,64 & 2,35 \\
\hline Total & $\mathbf{4 7 0}$ & 1,28 & 6 \\
\hline
\end{tabular}

Tableau VII : le contexte de l'Hôtel-Dieu du début du XVIII $\mathrm{s}$. (unité stratigraphique 2153). 


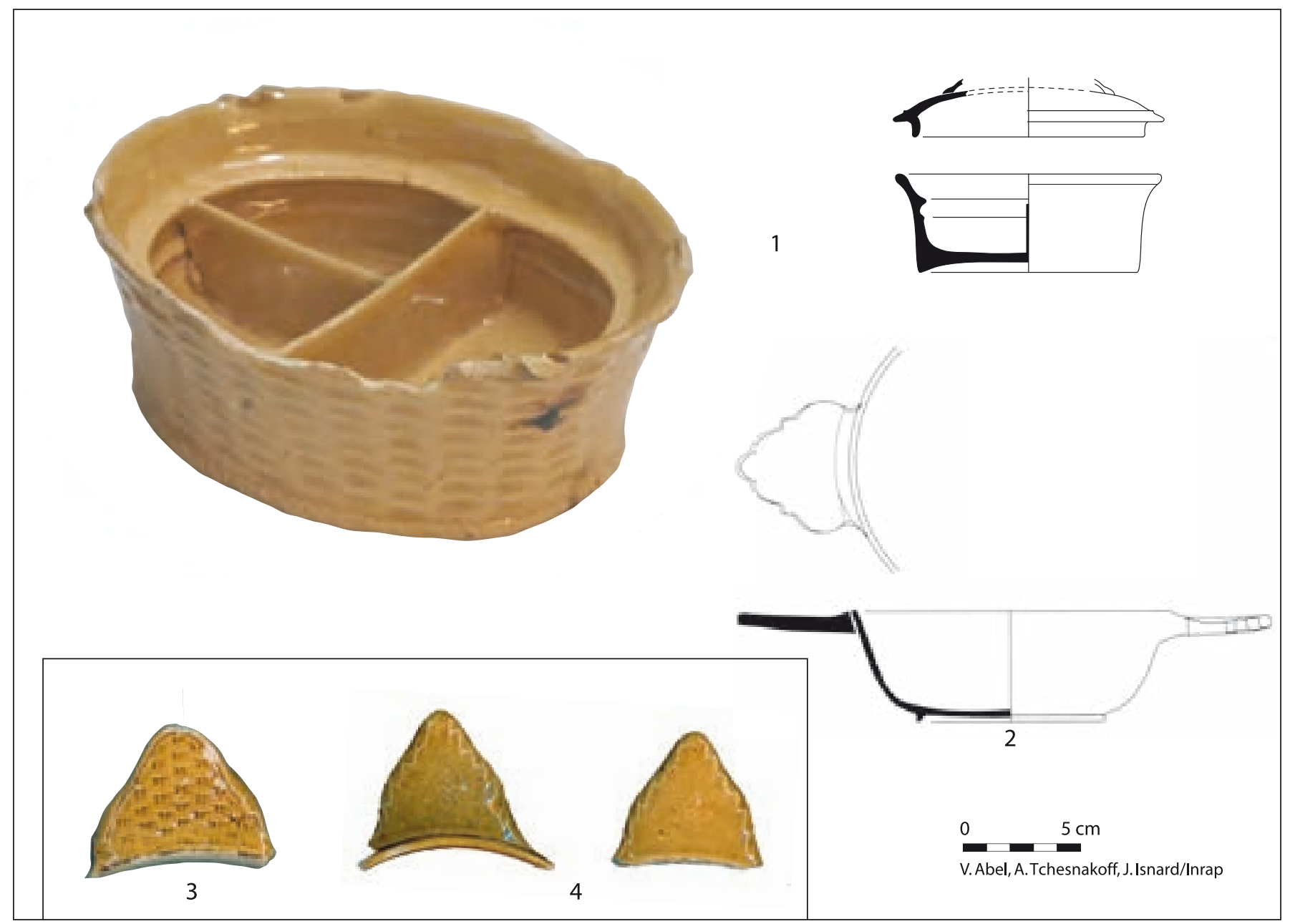

Fig. 201. Terre vernissée « faïence fine » de Marseille. Boîte à épices ( $\left.n^{\circ} 1\right)$, écuelles ( $\left.n^{\circ} 2-3\right)$ (fin du XVIII $\left.s.\right)$.

1 : place Villeneuve-Bargemon ; 2 : place Général-de-Gaulle ; 3 : la Fourragère ; 4 : la Parette.

était signée par Martin, faïencier « hors la Porte d'Aix, 1791 ». Joseph-Henri Martin était mentionné par l'abbé G. Arnaud d'Agnel dès 1910 (Arnaud d'Agnel 1910, p. $163,456,461$ ) qui ne pouvait alors lui attribuer de pièce, mais qui le faisait dans un ouvrage postérieur.

Cette «boîte à épices » de forme ovale et imitant un panier d'osier, en terre vernissée dite «faïence fine » a été fabriquée à Marseille à la fin du XVIII ${ }^{\mathrm{e}} \mathrm{s}$. Celle-ci mesure $4 \mathrm{~cm}$ de haut sur $11 \mathrm{~cm}$ d'ouverture dans sa plus grande largeur. L'extérieur est décoré d'une imitation de vannerie en léger relief. Trois compartiments déterminés par deux parois divisent l'intérieur de l'objet, le premier compartiment équivalant aux deux autres réunis. Le bord droit à canal intérieur était sans doute destiné à supporter un couvercle. Quatre traces d'attaches sur la lèvre témoignent de l'existence de deux anses latérales, recouvertes de vernis plus foncé, de tonalité brun-verdâtre. Un éclat situé près du pied permet de comprendre la mise en œuvre de cet objet exceptionnel : la paroi extérieure, en deux plaques préalablement moulées en relief, a été posée autour du fond et des parois des compartiments déjà en place, les extrémités des parois se trouvant réunies sur les petits côtés.

Alors que la terre de cet objet est très claire, presque blanche, le pied porte une trace d'arrachement d'un objet en pâte rouge dont le vernis s'est collé à celui de la boîte à épices pendant la cuisson. Il pourrait s'agir d'une pernette, ou de l'appendice d'un autre objet en cas de cuisson en échappade, ce type de disposition des pièces dans le four étant plutôt le fait des potiers. Une signature a été gravée sous le fond. Hélas, elle demeure en grande partie illisible, car elle s'est empâtée dans l'argile fraîche et a été recouverte de vernis jaune. On pense pouvoir y distinguer : «L ... /...ort ».

Deux objets identiques à celui de la fouille de la place Villeneuve-Bargemon, conservés jusqu'à récemment au musée de la Faïence de Marseille à la Campagne Pastré, sont à l'origine de l'identification de la pièce du chantier. Ces pièces remarquables sont signées et permettent d'attribuer la pièce archéologique à un atelier marseillais 
de la fin du XVIII e s., celui de Joseph-Henri Martin situé près de la porte d'Aix (Maternati-Baldouy 1997, 289). L'un des objets exposés au musée de la Faïence a des reliefs moulés à effets de vannerie en panneaux verticaux et l'autre des reliefs fleuris, très prononcés, évoquant les tissus imprimés. Leurs dimensions sont communes et identiques à l'exemplaire de la fouille de Bargemon. Leurs bords sont en lobes festonnés. Selon le catalogue, le premier, à panneaux, porte au revers l'inscription «fabrique de ...in » et le second «fabrique de Martin hors la porte d'Aix, $1791 »$. Selon les cartels des vitrines du musée, cette marque plus explicite se trouve sous l'exemplaire à vannerie en panneaux verticaux, l'exemplaire à reliefs fleuris portant «fabrique de Martin». La tonalité du vernis des deux pièces n'est pas semblable. L'exemplaire à vannerie est plus foncé et plus rouge, des taches d'oxyde de fer étant visibles à l'intérieur. Les restaurations, à l'identique, subies par les objets ne sont pas mentionnées. On peut cependant les déceler : la base de la boîte à décor fleuri est en grande partie reconstituée et les traces d'arrachement des préhensions des deux boîtes ont été dissimulées par une reprise à l'identique du bord ondé. On remarque aussi une couleur plus foncée dans cette partie des vases. Les anses semblent avoir été façonnées dans une terre plus foncée, ou recouvertes d'engobe rouge. Aucun autre objet, couvercle ou pièce de vaisselle ne se trouve exposé ou publié. JosephHenri Martin est signalé dès 1810 par Arnaud d'Agnel (Arnaud d'Agnel 1910, p. 165 notamment) qui ne peut cependant lui attribuer de pièce. Il signale sa présence à des assemblées de corporation pendant la Révolution et les mentions de ses ateliers jusqu'au milieu du $\mathrm{XIX}^{\mathrm{e}} \mathrm{s}$.

La boîte à épice de la place Villeneuve-Bargemon identifiée, une série «d'objets » (en réalité des tessons de très petite taille), provenant de ce chantier ou de fouilles antérieures et dont l'origine restait mystérieuse, a pu lui être rattachée. Il en va de même pour quelques restes d'objets archéologiques similaires en pâte, façonnage et revêtement, représentant peu de volume dans le mobilier de la fin du XVIII ${ }^{\mathrm{e}}$ s. de la place VilleneuveBargemon (2,3\% des fragments des deux contextes de la même date, $11 \%$ des objets recensés).

Un fragment de couvercle a été associé hypothétiquement à la boîte à épices (fig. 201, n⿳101). Il n'est pas possible de déterminer si ce couvercle, très fragmentaire, était rond ou ovale. Il est surmonté d'un frétel, très partiellement conservé, semblant figurer des végétaux. Une oreille de forme triangulaire a une surface granuleuse, signe par exemple d'un vernis mal tamisé ou d'un accident de cuisson (inv. 52.02.10740). Une seconde oreille, particulièrement fragmentaire, a bénéficié d'un décor en relief, imprimé ou moulé, en forme de croix (inv. 52.02.10741).
Bien que discrète sur le site de l'Hôtel-Dieu aussi (1,3\% des fragments, $7 \%$ des objets), cette production est désormais très significative et permet de dater avec davantage de certitude les mobiliers de la fin du XVIII ${ }^{\mathrm{e}}$ s. Les écuelles sont un peu plus présentes (fig. 202). Le profil de l'une d'entre elles est complet, bien que manquent centre et oreille (fig. 202, $\mathbf{n}^{\circ} \mathbf{1}$ ); le large fond est légèrement dégagé et creux, les parois peu épaisses et à courbe continue, le travail manifestement très soigné. Deux appendices issus d'autres écuelles disparues permettent d'appréhender plus complètement ces objets si courants pendant la période moderne dans leur version en terre vernissée fine de Marseille (fig. 202, $\mathbf{n}^{\circ} 2-3$ ) : l'oreille de forme globalement triangulaire est large et plate et légèrement festonnée.

Encore dénommé «écuelle», par défaut et par parenté avec ce récipient, un petit vase d'environ $5 \mathrm{~cm}$ de haut et $9,5 \mathrm{~cm}$ de diamètre à pied dégagé, est agrémenté d'une queue tubulaire, incomplète ici, et d'un bec pincé sur la gauche (fig. 202, $\left.\mathbf{n}^{\circ} \mathbf{4}\right)$. L'objet est très soigné aussi. Deux autres pièces très lacunaires, à bord mouluré identique, potentielles écuelles verseuses, sont recensées (inv. 155.09.2671 et 2726). La fonction de ce petit récipient n'est pas des plus claires. Bec pincé et queue évoquent une utilisation plus pratique que décorative et si la finesse des appendices démontrent que l'élégance était recherchée, on peine à trouver une explication satisfaisante tenant compte de ces deux observations.

Le fond d'une tasse à paroi verticale, de forme dite « litron» est malheureusement très morcelé (fig. 202, $\mathbf{n}^{\circ} \mathbf{5}$ ) mais une pièce de comparaison est connue dans les niveaux supérieurs du chantier de Saint-Jean-du-Désert de 1994 (par l'auteur) (inv. 53.94.201) et une autre tasse litron est issue de la place Villeneuve-Bargemon (inv. 52.02.10739). Cette tasse a pu être utilisée avec une soucoupe de ce même mobilier, de forme droite elle aussi (inv. 52.02.10738). Ces types de tasse et de soucoupe sont connues dans les répertoires de faïence de la seconde moitié du XVIII ${ }^{\mathrm{e}}$ s. (Maternati-Baldouy 1997, p. 171-172, 276-277).

On peut adjoindre à cette liste un vase sur pied mouluré dont l'intérieur a été recreusé au tournage et par tournassage, puis recouvert de vernis jaune (fig. 202, $\left.\mathbf{n}^{\circ} \mathbf{6}\right)$. Aucun autre fragment récolté ne peut faire entrevoir le reste de la forme, qu'il s'agisse d'un chandelier ou toute pièce à tige.

Ces productions marseillaises semblent au total assez modestes par rapport à ce qui commence à se faire dans le reste de l'Europe : les seuls objets identifiés dans les collections publiques ne sont pas très recherchés et les témoignages archéologiques sont minces. L'argile est très claire, de couleur blanche à sable clair. Or l'argile locale, chargée en oxyde de fer, cuit rouge, et la terre 


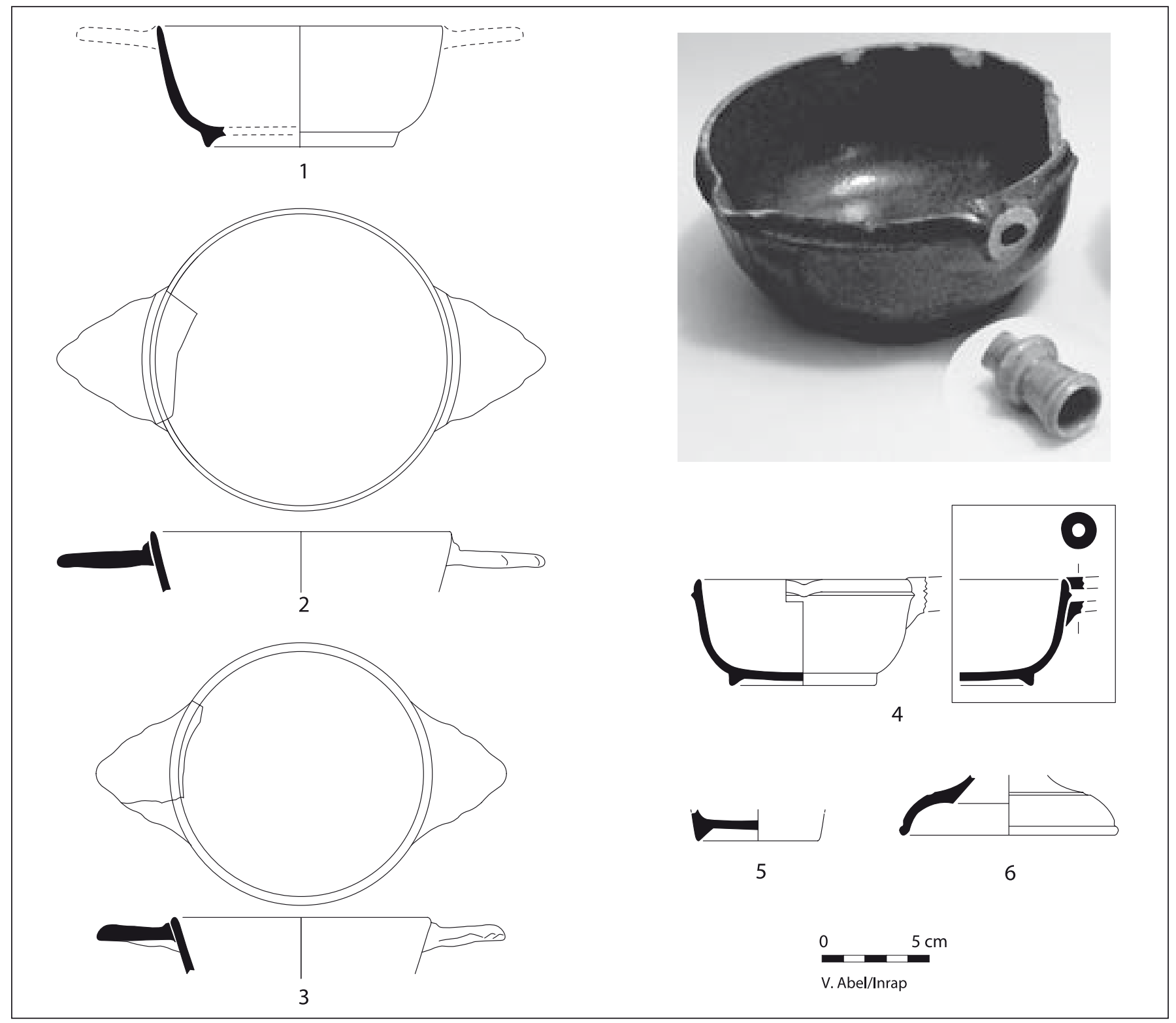

Fig. 202. Terre vernissée «faïence fine » de Marseille. Écuelles ( $\left.n^{\circ} 1-3\right)$, écuelle verseuse $\left(n^{\circ} 4\right)$, fond de tasse-litron $\left(n^{\circ} 5\right)$, pied de vase de forme $\left(n^{\circ} 6\right)$ (fin du XVIII' $\mathrm{s}$.). Hôtel-Dieu.

des faïences stannifères marseillaises n'est pas blanche. Comment un atelier marseillais a-t-il pu produire des objets à pâte cuisant blanc ? Plusieurs explications sont à envisager: l'importation de terre, l'adjonction d'un additif qui rendrait la terre claire à la cuisson, une improbable cuisson spécifique sans oxydation du biscuit.

Aucun objet, de collection publique ou privée, exposé ou publié, ne permet pour l'instant de compléter virtuellement l'ébauche de typologie de la terre vernissée fine de Marseille fournie par l'archéologie et entamée précisément grâce à un catalogue de musée. Bien des points restent à élucider au-delà de la typo-chronologie sur laquelle nous fondons de raisonnables espoirs, comme l'approvisionnement en terre blanche qui vient d'être évoqué ou encore l'emplacement de l'atelier dans le quartier marseillais de la porte d'Aix, en pleine restructuration urbaine à l'heure actuelle.

L'examen de cet embryon de série conduit aussi au constat d'une parenté technologique manifeste avec la faïence stannifère. La faïence de France méridionale s'est principalement développée au XVIII ${ }^{\mathrm{e}}$ s., chronologie particulière qui l'a sans doute conduite à privilégier des techniques de façonnage proto-industrielles par moules et calibres notamment. Ce sont ces choix de façonnage qui se retrouvent dans les terres vernissées dites «faïence fine de Marseille». 


\subsection{Le Vaucluse}

Un autre type de «faïence fine » (de terre vernissée fine) serait produit depuis les années 1730 à Castellet dans le Vaucluse, puis à Apt selon les historiens de l'art. Ces productions sont connues dans le monde de l'histoire de l'art car elles sont caractéristiques et très recherchées (terres mêlées, vases à reliefs rappelant l'argenterie) et auraient duré assez longtemps. Elles sont cependant très peu documentées par l'archéologie. Un bord d'assiette très simple figure dans le mobilier de la place Villeneuve-Bargemon (inv. 52.02.10357).

\section{Les faïences}

La faïence stannifère traditionnelle est encore relativement présente à cette époque. Avec un peu plus du dixième du mobilier environ, elle se maintient à peu près au niveau qu'elle avait tout au long du XVIII ${ }^{\mathrm{e}} \mathrm{s}$. dans le mobilier archéologique. La production « régionale » (les origines marseillaise et provençale indistinctes car non distinguables selon nos critères) est préférée à l'italienne qui n'est mentionnée que grâce à un bord de plat non décoré pour la Ligurie (inv. 155.09.2632) et un fond de vase fermé, potentiellement résiduel, pour celle de Montelupo (inv. 155.09.2631).

La faïence stannifère de tradition provençale (11\% des fragments, $14 \%$ des objets), bien que tout autant morcelée, est toutefois un peu plus perceptible que la «terre vernissée fine de Marseille » car elle est étudiée et répertoriée depuis la fin du $\mathrm{XIX}^{\mathrm{e}} \mathrm{s}$. par les amateurs d'art (fig. 203). Ce sont toutefois plus souvent les décors qui ont suscité les passions et rares sont les pièces de l'Hôtel-Dieu qui ont reçu autre chose qu'un émail immaculé ; les rapprochements sont donc difficiles.

\subsection{La vaisselle}

Deux écuelles sont connues toutes deux par une seule de leurs oreilles auxquelles était encore raccroché un vestige de bord. Ces appendices sont moulés, très plats et à bord légèrement sinueux (fig. 203, $\mathbf{n}^{\circ} \mathbf{1 - 2}$ ). Le bord du bassin est des plus simples.

Simples aussi sont les assiettes blanches sans décor, que ce soit les formes complètes (fig. 203, $\mathbf{n}^{\circ} \mathbf{4}$ et inv. 52.02.10353) ou le bord à émail très légèrement gris bleuté (inv. 155.09.2675), de même que le très grand plat blanc non décoré dont ne subsiste qu'un fond, de $8 \mathrm{~mm}$ d'épaisseur, une très forte assise pour une faïence (inv. 155.09.2707). D'autres assiettes n'ont pas de décor peint, mais sont animées de reliefs sur l'aile, un bord ondulé ou chantourné (inv. 52.02.10425 et 10355).

Un bord d'assiette est orné d'une classique frise de bâtonnets bleus (inv. 52.02.10350). Cette frise connaît un succès certain depuis son apparition à la fin du XVII ${ }^{\mathrm{e}} \mathrm{s}$. On la retrouve sur un plat dont le fond dégagé de $11 \mathrm{~cm}$ de diamètre est classique, mais dont les parois à courbe continue sont terminées par une aile très courte d'un centimètre et demi de large à bord en accolades qui en fait l'originalité. Sur un émail d'une blancheur laissant à désirer s'organisait un décor floral jaune, aujourd'hui des plus fragmentaires, auquel la frise de bâtonnets fait écho le long de la lèvre sinueuse (inv. 52.02.10347).

Un plat a été décoré d'une frise de broderies polychromes dont le cerne n'est pas tracé au traditionnel manganèse, mais chatironné en jaune (52.02.10349).

On remarque enfin un fragment de couvercle à décor polychrome dans le goût de ce qui a fait la réputation de Marseille dans le domaine de la faïence, un décor floral rappelant ceux qui sont attribués au faïencier Fauchier (inv. 52.02.10348).

Rappelant la tasse en «terre vernissée fine de Marseille » (fig. 203, $\left.{ }^{\circ} \mathbf{5}\right)$, une tasse-litron blanche n'est pas mieux conservée (inv. 155.09.2667). Cette forme droite est bien identifiée dans les répertoires de faïence stannifère de la seconde moitié du XVIII ${ }^{\mathrm{e}} \mathrm{s}$. (MaternatiBaldouy 1997, p. 171-172, 276-277).

Grâce à la présence du départ d'un opercule partiel sur la lèvre d'une écuelle, celle-ci a pu être identifiée comme un biberon de malade (fig. 203, $\mathbf{n}^{\circ} \mathbf{3}$ ), une forme inconnue jusque là dans la céramique issue des fouilles de Marseille.

\subsection{Les pots de pharmacie}

Nouveaux aussi parmi le mobilier archéologique marseillais se trouvent deux pots de pharmacie à spécialité mentionnée sur le vase.

Le premier fragment est un tesson de panse globulaire à décor bleu sur émail blanc (fig. 203, $\mathbf{n}^{\circ} 8$ ). L'orientation hypothétique envisagée en l'absence de tout bord ou fond le ferait classer parmi les pots de monstre (du verbe monstrare) ou les chevrettes (une variété de cruche), ceci sous toutes réserves, car on remarque un départ d'appendice dans la zone supérieure du tesson. Un décor très couvrant au bleu de cobalt s'étend de part et d'autre d'une zone réservée où n'est placée que la mention de la spécialité que le pot était destiné à conserver.

Un blason figure sous ce bandeau. Il ne correspond pas à celui de l'Hôtel-Dieu de Marseille qui regroupe la colombe du Saint-Esprit et les coquilles de saint Jacques de Galice, symboles des deux ordres religieux qui y 
PREMIÈRE PARTIE : LES CÉRAMIQUES

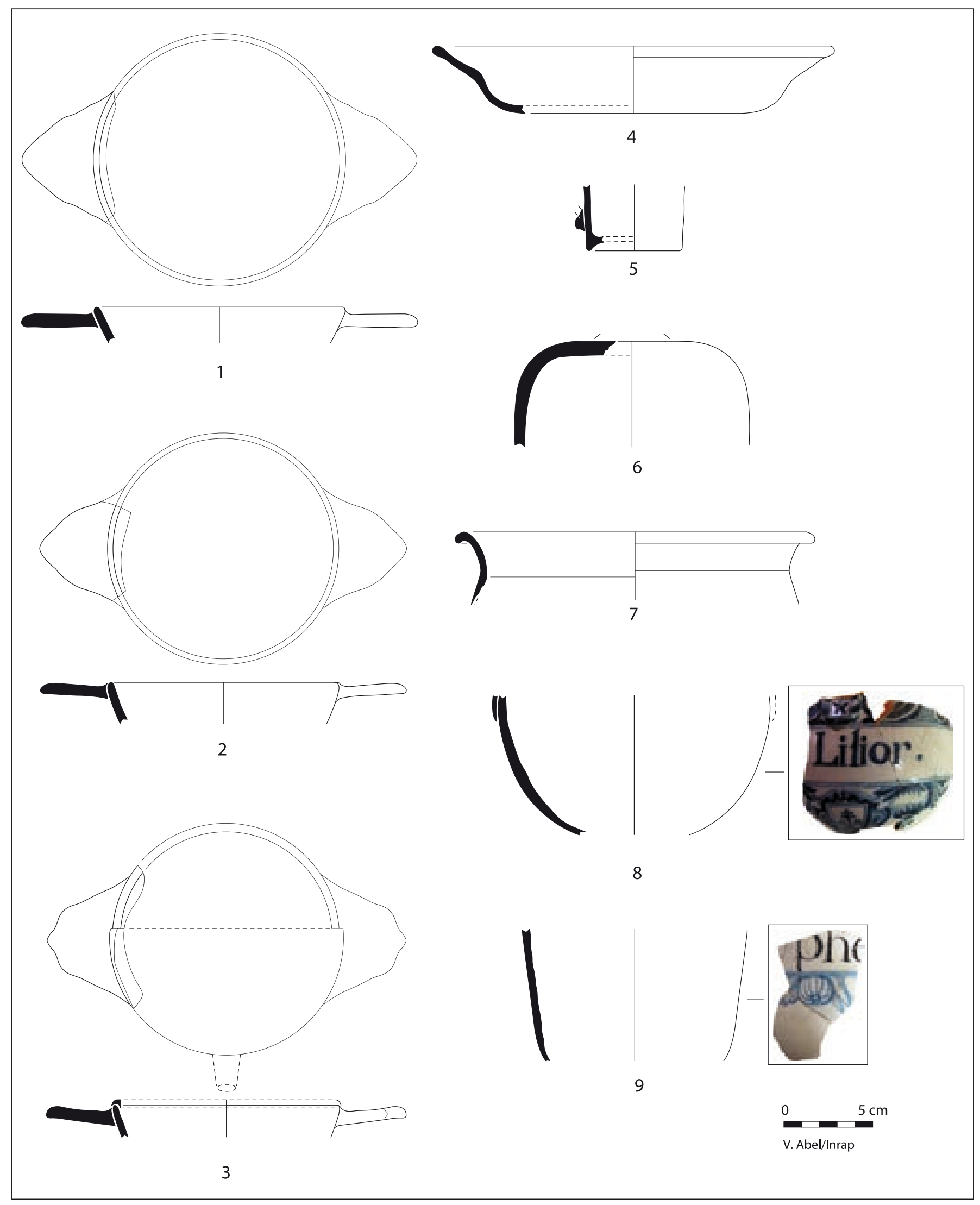

Fig. 203. Faïences provençales. Écuelles ( $\left.n^{\circ} 1-3\right)$, assiette ( $\left.n^{\circ} 4\right)$, fond de tasse-litron ( $\left.n^{\circ} 5\right)$, pots $\left(n^{\circ} 6-7\right)$, pots à pharmacie $\left(n^{\circ} 8-9\right)($ fin du XVIII' $s$.). Hôtel-Dieu.

244 
sont rassemblés, à moins que les deux objets figurant de part et d'autre de la croix à double traverse (ou croix archiépiscopale) ne soient des coquilles Saint-Jacques librement interprétées.

Les pots de pharmacie ont su très tôt intéresser les amateurs d'art qui les ont plus volontiers considérés sous l'angle des arts décoratifs que pour leur fonction, pourtant accessible grâce à l'indication de leur contenu porté par le fabricant sur le vase dès le milieu $\mathrm{du} \mathrm{XV}^{\mathrm{e}}$ s. environ, en Espagne et en Italie (Drey 1984, p. 11). Les vases sans inscription restent toutefois les plus courants, car ils autorisent l'apothicaire à changer le contenu à sa guise.

La partie la plus significative de la spécialité du premier pot de l'Hôtel-Dieu de Marseille posée par le faïencier avant cuisson du vase a été par chance conservée. «...Lilior.» indique vraisemblablement l'Oleum liliorum alborum, macérât huileux de fleurs de lys (dont un exemple sur pot de faïence est donné par Drey 1984, p. 120). Le lilium candidum offre vers la fin du mois de mai en Provence ses pétales qui, mis à tremper dans de l'huile (parfois aussi dans de l'alcool), sont réputés guérir de nombreuses affections de la peau.

Un second vase (fig. 203, $\mathbf{n}^{\circ} \mathbf{9}$ ), interprété comme un pot de pharmacie, tronconique à paroi rectiligne dans la partie conservée, est orné d'une frise végétale horizontale en bleu de cobalt, placée sous une inscription fragmentaire «phe » au manganèse.

Deux chevrettes pharmaceutiques, attribuées à Montpellier (Drey 1984, p. 71, 73) arborent des feuilles identiques à celles du fragment de l'Hôtel-Dieu. Le fruit charnu placé sous le bandeau semble assez couramment utilisé pour orner les bandeaux d'indications de substances.

Les lettres «phe » sont moins explicites que la mention «Lilior» portée sur le pot précédent. Il s'agit de l'attaque d'un mot car la lettre $\mathrm{P}$ est précédée d'une zone laissée blanche sur $7 \mathrm{~mm}$, les deux espaces séparant les trois lettres présentes n'étant que de 1,6 et 2,3 mm. Cette première syllabe potentiellement fragmentaire est assez peu répandue tant en français qu'en latin, les deux langues également utilisées pour désigner les simples ou les préparations pharmaceutiques, parfois complétées par noms vernaculaires. Les plantes médicinales constituent l'essentiel de l'arsenal thérapeutique du XVIII ${ }^{\mathrm{e}}$ s., mais d'autres substances, minérales ou animales sont utilisées dans la pharmacopée.

La syllabe «phe» pourrait appartenir à plusieurs mentions de substances. La datte, utilisée dans la pharmacopée moderne provient du Phoenix dactylifera dont on tire aussi le « vin de Palmier » (Fournier 2010-1947, p. 337). Il existe aussi une plante nommée «phénope »
(Fournier 2010-1947, p. 545), la laitue des murailles. Si l'eau de laitue figure bien par exemple dans l'inventaire de l'Hôtel-Dieu Saint-Nicolas de Tarascon, elle est orthographiée « eau de leteu » (Desnuelle 1995, p. 57). L'hypothèse d'un pot de faïence dédié à la phénope paraît moins convaincante, et bien sûr moins séduisante, que celle qui verrait enfin le pot abriter de la phellandre, Enanthe phellandrium (Fournier 2010-1947, p. 690692). Cette plante, hautement toxique aussi appelée " ciguë aquatique » intéressa la thérapeutique à partir du $\mathrm{XVIII}^{\mathrm{e}} \mathrm{s}$. où elle est d'abord préconisée contre la fièvre et la tuberculose, puis volontiers prescrite contre la phtisie (tuberculose pulmonaire) et de nombreuses autres affections.

La fouille de ces niveaux archéologiques de la fin $\mathrm{du} \mathrm{XVIII}^{\mathrm{e}} \mathrm{s}$. offre-t-elle une illustration inattendue des pratiques médicales de l'établissement de santé de l'Hôtel-Dieu de Marseille, parfaitement en accord avec ce qui se pratiquait à cette époque ? On peut l'envisager.

Un fragment de panse et de base ou d'épaule de vase ne présente en revanche aucun décor sur son émail blanc et pourrait être un autre pot de pharmacie ou, selon la représentation que nous avons privilégiée, le couvercle d'un de ceux-ci (fig. 203, $\mathbf{n}^{\circ} \mathbf{6}$ ). Un vase fermé à col, sans décor sur son émail blanc (fig. $203, \mathbf{n}^{\circ}$ 7), pourrait être un autre pot de pharmacie ou encore un urinoir.

Le mobilier archéologique exhumé récemment pour la fin du XVIII ${ }^{\mathrm{e}}$ s. ne donne pas d'exemple de décor au petit feu tel qu'avait pu le faire la place du Général-deGaulle. Cette technique est-elle déjà en cours d'abandon ou trop recherchée pour se trouver dans les deux mobiliers analysés ici ? La question reste en suspens.

La petite collection de faïence stannifère de l'HôtelDieu, modeste et morcelée, apporte des informations nouvelles. La confection de vases à fonction pharmaceutique par les faïenciers régionaux était connue, mais n'avait encore jamais été documentée par l'archéologie à Marseille. Elle l'est dans le milieu particulier de son utilisation première et se trouve accompagnée de vases destinés à l'assistance aux malades, un aspect de la production en revanche parfaitement ignoré jusque là et que l'archéologie seule, proche du quotidien des populations de jadis, sait documenter.

\section{La céramique culinaire}

$\mathrm{Si}$ les céramiques culinaires formaient $46 \%$ des fragments et - seulement $-18 \%$ des individus de l'ensemble de la place Villeneuve-Bargemon, elle frappe paradoxalement par sa discrétion sur le site de l'HôtelDieu, présente en proportion infime (3\% des fragments, $6 \%$ des objets). 


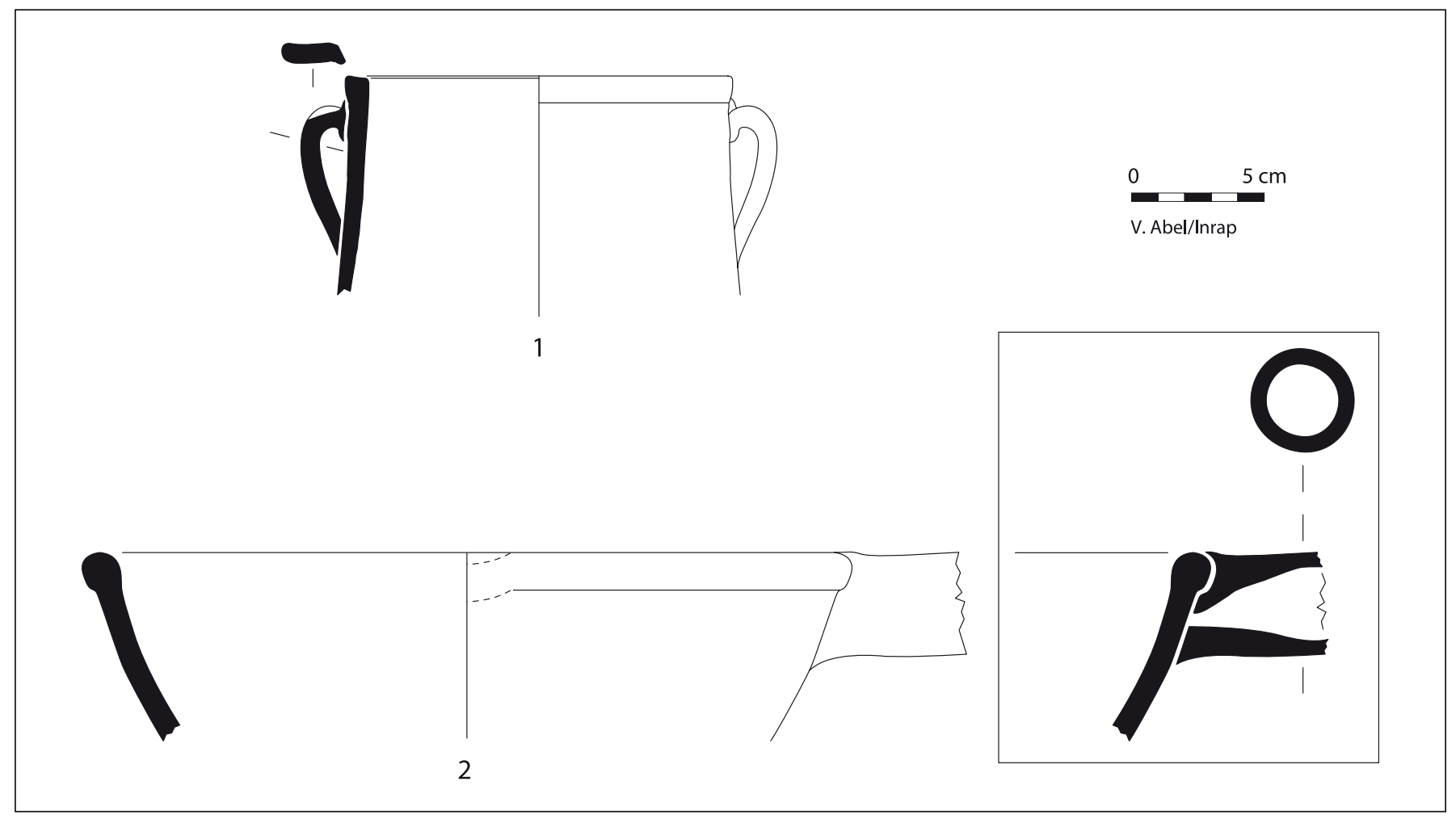

Fig. 204. Céramiques culinaires de Vallauris. Marmite ( $\left.{ }^{\circ} 1\right)$, poêlon (n²) (fin du XVIII' s.).1 : place Villeneuve-Bargemon ; 2 : Hôtel-Dieu.

\subsection{Vallauris}

La marmite est une des formes de Vallauris (36\% des fragments, $15 \%$ des individus) les plus répandues dans ce mobilier. Pour l'une d'entre elles, la hauteur totale est d'environ $23 \mathrm{~cm}$ (inv. 52.02.10332). Le fond, bombé, a suivi un autre chemin et reste absent. La paroi, très droite et verticale, finit en «carré » : un léger relief est obtenu à l'extérieur par un bandeau d'un centimètre de haut, la lèvre est légèrement déprimée et horizontale. Cet exemplaire est engobé, comme souvent à partir du milieu du XVIII ${ }^{\mathrm{e}}$ s. ; l'engobe interne est rosé avec quelques discrètes taches de fer. Le diamètre d'ouverture est d'environ $22 \mathrm{~cm}$; l'anse, sans canal, est en point d'interrogation, attachée sur le bandeau extérieur, avec une nette marque de doigt bien formée.

Une deuxième marmite de Vallauris (inv. 52.02.10327) est à peu près identique, mais se distingue par sa forte taille (diamètre d'environ $29 \mathrm{~cm}$ ) et l'absence d'engobe. L'anse est large et un cordon digité d'un centimètre de large, interrompu par la cassure du fragment, descend le long de la paroi. Sa fonction était sans doute davantage d'assurer la préhension que de renforcer la solidité du vase.

Une marmite semblable se retrouve à l'Hôtel-Dieu (fig. 204, $\mathbf{n}^{\circ} \mathbf{1}$ ). La partie inférieure du vase (carène et fond bombé) est là aussi perdue, la paroi est très droite et légèrement rentrante et finit abruptement à l'extérieur par un petit bandeau à lèvre déprimée. Cet exemplaire n'est pas engobé. Le diamètre d'ouverture est d'environ $13 \mathrm{~cm}$, l'anse plutôt plate et sans canal, est en forme de point d'interrogation, attachée sous le bandeau extérieur, avec une empreinte de doigt bien marquée à la jonction avec le bord.

Une nouvelle forme apparaît, annonçant déjà le $\mathrm{XIX}^{\mathrm{e}} \mathrm{s}$. : la marmite droite. La courbe de la panse de cette forme reste continue depuis la base de la paroi jusqu'à la lèvre, simplement arrondie sans épaississement.

Le poêlon est aussi un des vases classiques de Vallauris sur le marché marseillais dans le XVIII ${ }^{\mathrm{e}}$ s. Les poêlons de l'Hôtel-Dieu sont très mal conservés, le plus complet n'a plus qu'un appendice tronqué (fig. 204, $\mathbf{n}^{\circ} \mathbf{2}$ ) placé juste au niveau du bord qui est arrondi et légèrement plus épais que la paroi galbée et ouverte.

Un exemplaire de la place Villeneuve-Bargemon (inv. 52.02.10333) est de forme semblable, à paroi régulière et bord en léger épaississement. Sa queue a disparu, de même que son fond plat, non dégagé à l'extérieur et sans rupture de la courbe de la paroi. La couleur blanche de l'engobe, peu fréquente, donne un jaune soutenu sous le vernis. Quatre autres exemplaires trouvés au même endroit ne sont pas engobés, alors qu'un cinquième est engobé en rose, couleur plus commune. Nous aurions pu aussi rencontrer un engobe rouge. 


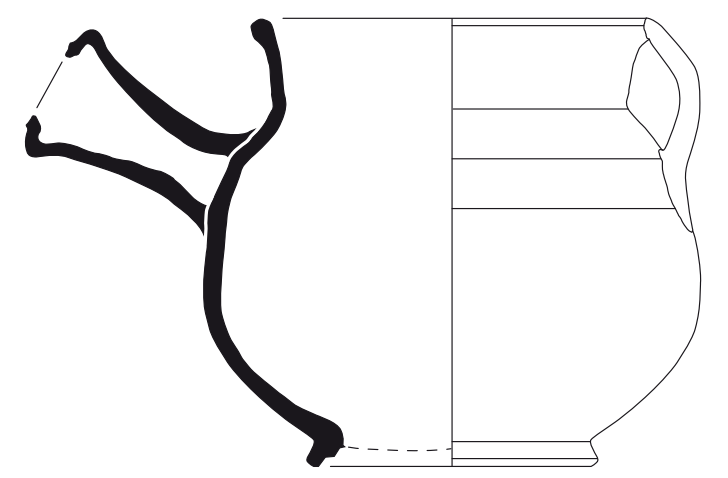

1
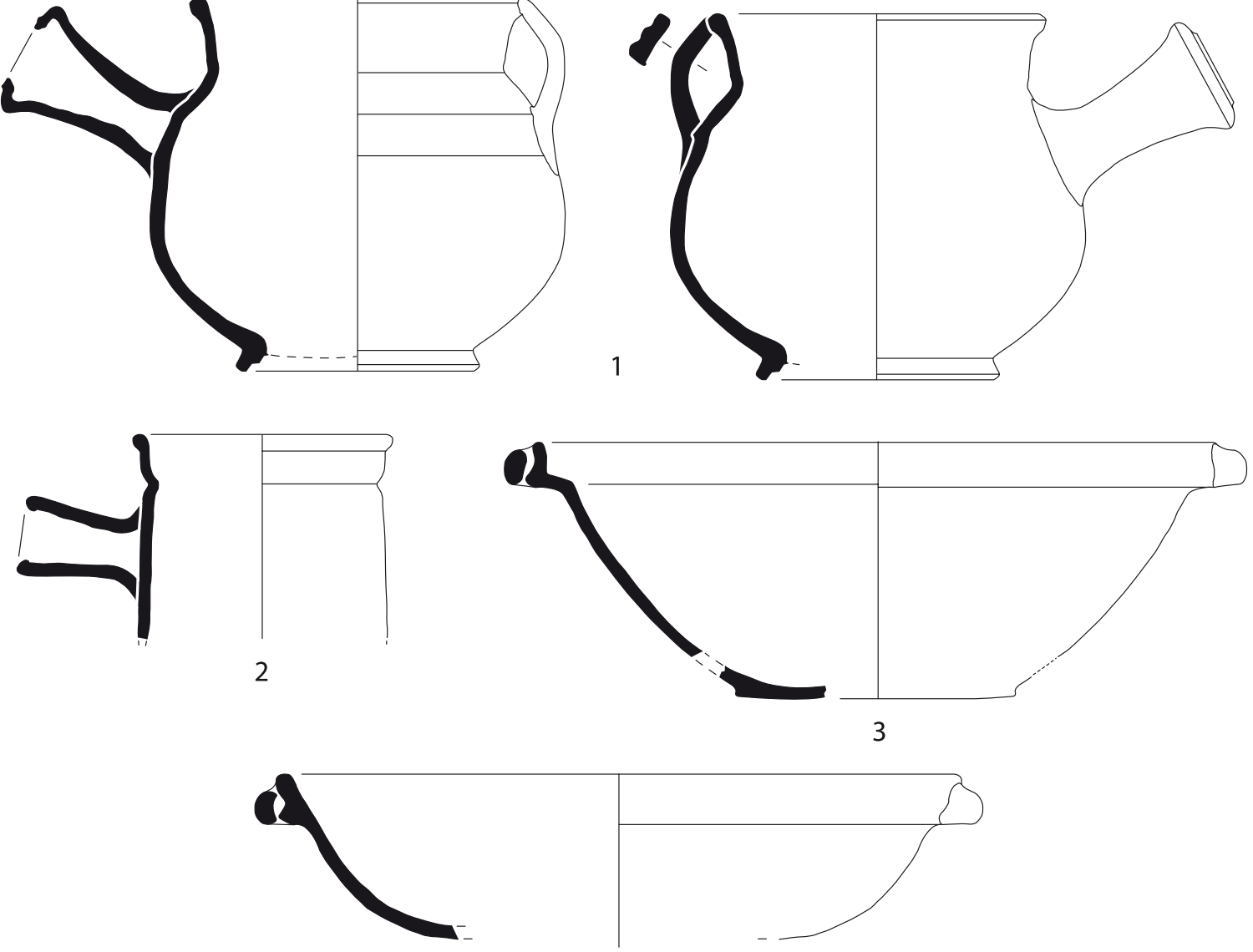

4

Fig. 205. Production de Dieulefit (fin du XVIII' s.). Place Villeneuve-Bargemon.
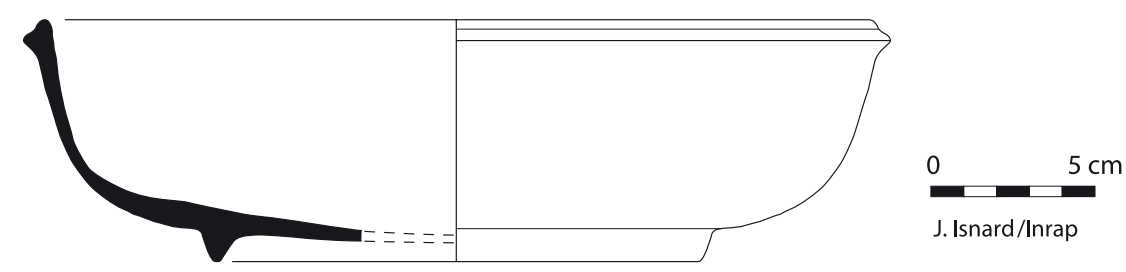

\subsection{Dieulefit (Drôme)}

La céramique réfractaire de Dieulefit et du nord du Vaucluse (fig. 205) est particulièrement discrète $(0,2 \%$ des fragments, $1,2 \%$ des objets) dans le contexte de l'Hôtel-Dieu. Un seul « toupin », à engobe rose sous vernis jaune a été recensé, et encore ne se remarque-t-il que par un fragment de panse auquel reste attaché un départ de queue (inv. 155.09.2666). Les céramiques culinaires de la Drôme font leur apparition sur le marché marseillais quelque part dans la seconde moitié du XVIII ${ }^{\mathrm{e}} \mathrm{s}$. Certainement façonnées de manière mécanique (par calibrage notamment), elles ont des parois minces rendant les objets légers. Ces céramiques sont toutes engobées, en rose, en rouge, en blanc ou en nuances intermédiaires, sur une terre très claire presque blanche, comportant de petites taches rose foncé. Elles ont un profil anguleux dont la mise en œuvre doit sûrement à des techniques préindustrielles, pour des aménagements fonctionnels, même pour les formes simples. Une jatte a par exemple un listel extérieur prononcé devant certainement favoriser la prise en main (fig. 205, $\mathbf{n}^{\circ} \mathbf{4}$ ). La paroi galbée d'une autre jatte finit en forme d'angle droit, la paroi rabaissée à l'horizontale puis redressée à la verticale sur $1 \mathrm{~cm}$ (fig. 205, $\mathbf{n}^{\circ} \mathbf{3}$ ). Cet aménagement peut laisser supposer un couvercle, mais on n'en dispose pas dans le fonds du mobilier de la place Villeneuve-Bargemon.

Un toupin présente les mêmes caractéristiques techniques d'engobe, de paroi mince, et de bord recherché. Un étranglement est pratiqué à $2 \mathrm{~cm}$ de la lèvre (fig. 205, $\mathbf{n}^{\circ} \mathbf{2}$ ). 
La queue, tournée, a des parois minces. De large section, elle serait pratique, mais on ne peut la serrer avec plus de deux doigts car elle est très courte.

Dans des milieux domestiques marseillais, à peu près contemporains ou plus anciens que le contexte de l'Hôtel-Dieu, la poterie culinaire constitue environ un tiers de l'équipement en céramique et à peu près autant des tessons qui nous en sont parvenus. Pour cette catégorie se pose de manière pressante la question de l'utilisation d'autres matériaux; on s'interroge aussi sur un contexte qui serait plutôt lié aux soins apportés aux malades (thérapeutique et assistance), où la pratique de la cuisine serait exceptionnelle voire exclue, et où même les vases culinaires pourraient par conséquent avoir été détournés de la fonction à laquelle on les destinait originellement.

\section{Les terres vernissées}

La vaisselle vernissée de conception traditionnelle (par opposition à la terre vernissée fine évoquée plus haut et en excluant les vases polyvalent confectionnés en terre réfractaire) atteint classiquement des proportions très importantes $(84 \%$ des fragments, $68 \%$ des objets du dépotoir de l'Hôtel-Dieu ; la moitié du nombre d'objets et $40 \%$ des fragments pour la place VilleneuveBargemon). Parmi cette catégorie, les provenances sont cependant très déséquilibrées, la part belle étant faite comme on s'y attend aux productions locales et proches.

\subsection{La Ligurie}

Parmi les importations, déjà connues dans le courant du siècle, se trouvent les céramiques brunes « à taches noires » d'Albisola (fig. 206) utilisées à Marseille depuis le deuxième quart du siècle et comptant pour $3 \%$ des fragments et moins de $5 \%$ des objets recensés dans le contexte de l'Hôtel-Dieu et $6 \%$ des fragments et moins de $10 \%$ des objets de la place Villeneuve-Bargemon, soit au total très peu sur l'un et l'autre site.

Les assiettes simples à bord droit sont les plus nombreuses. L'une d'entre elle est d'un diamètre très réduit (fig. 206, $\mathbf{n}^{\circ} \mathbf{1}$ ). Une assiette est revêtue d'un vernis assez clair où le décor noir contraste (fig. 206, $\left.\mathbf{n}^{\circ} \mathbf{2}\right)$ alors que deux autres ont un revêtement plus foncé (fig. 206, $\mathbf{n}^{\circ} \mathbf{3}$ et 155.09.2615). Inversement, une assiette de la place Villeneuve-Bargemon est revêtue d'un vernis assez clair, rouge-jaune, ce qui accentue le contraste avec le décor noir (inv. 52.02.10339). Plusieurs objets issus du même contexte présentent les mêmes tonalités de vernis.
Un plat, plus large et plus profond, a un marli assez anguleux, le bord est droit mais travaillé en ondes régulières (inv. 52.02.10340). Le vernis extérieur, peu épais, a pris un aspect grésé. Il est passé en couche plus importante depuis le dessous de la lèvre jusqu'à l'intérieur du vase, où il est de tonalité foncée. Un petit fragment témoigne de l'utilisation d'un plat non-circulaire (inv. 52.02.10424).

Les écuelles et les tasses sont moins fréquentes et très fragmentaires dans ces mobiliers. L'une d'entre elles a un bord épaissi (inv. 52.02.10344) ; une seule autre écuelle, sous la forme d'un petit fragment de bord, se remarque à l'Hôtel-Dieu (inv. 155.09.2614). Un petit vase ouvert, dont le vernis est opacifié au manganèse, a été rattaché hypothétiquement à la production d'Albisola pour des critères de pâte et de façonnage (inv. 52.02.10745).

Une vaisselle vernissée assez discrète $(0,6 \%$ des fragments, $2 \%$ des objets), à pâte rouge, engobe blanc interne et vernis jaune entièrement couvrant, est attribuée à la même région ligure par analogie apparente de pâte avec la terre vernissée d'Albisola. Une assiette à aile animée de reliefs (inv. 155.09.2668) et un plat d'assez bonne taille (inv. 155.09.2669) à l'Hôtel-Dieu sont trop fragmentaires pour bénéficier d'une représentation graphique, tandis qu'un exemplaire de la place Villeneuve-Bargemon a un profil presque complet: fond plat non dégagé et large et se poursuivant en courbe continue jusqu'à un marli amorçant une aile légèrement incurvée et terminée par un bord découpé en accolades et souligné d'un filet en creux (inv. 52.02.10366). Cette assiette, d'un diamètre semblable aux assiettes de faïence stannifère et calibrée selon les mêmes techniques, est d'une finition extérieure très nette. Un engobe blanc recouvre parfaitement l'intérieur et laisse cependant quelques taches à l'extérieur. Toute la pièce est soigneusement revêtue d'un vernis jaune. L'ensemble donne un objet séduisant, mais lourd à manier. Les parois sont épaisses, laissant penser que la terre utilisée n'était pas vraiment adaptée à ces techniques de façonnage.

Cette assiette est accompagnée dans le même contexte d'une série de bords de facture semblable: un plat et quatre assiettes dont il ne reste plus que des fragments très limités. Seule l'aile de ces objets apporte quelque variété. Ainsi deux assiettes ont une aile découpée en bord ondulé à relief en cupules (inv. 52.02.10368 et 10369) et deux autres un bord travaillé à fine gorge (inv. 52.02.10434) dont un bord chantourné (inv. 52.02.10367). Dans le même groupe, un grand plat a une paroi verticale épaisse et côtelée, terminée par une aile très courte, et un bord découpé en accolades (inv. 52.02.10252).

D'autres formes furent sans doute produites, comme le laisse penser ce bougeoir à engobe blanc uni sous 


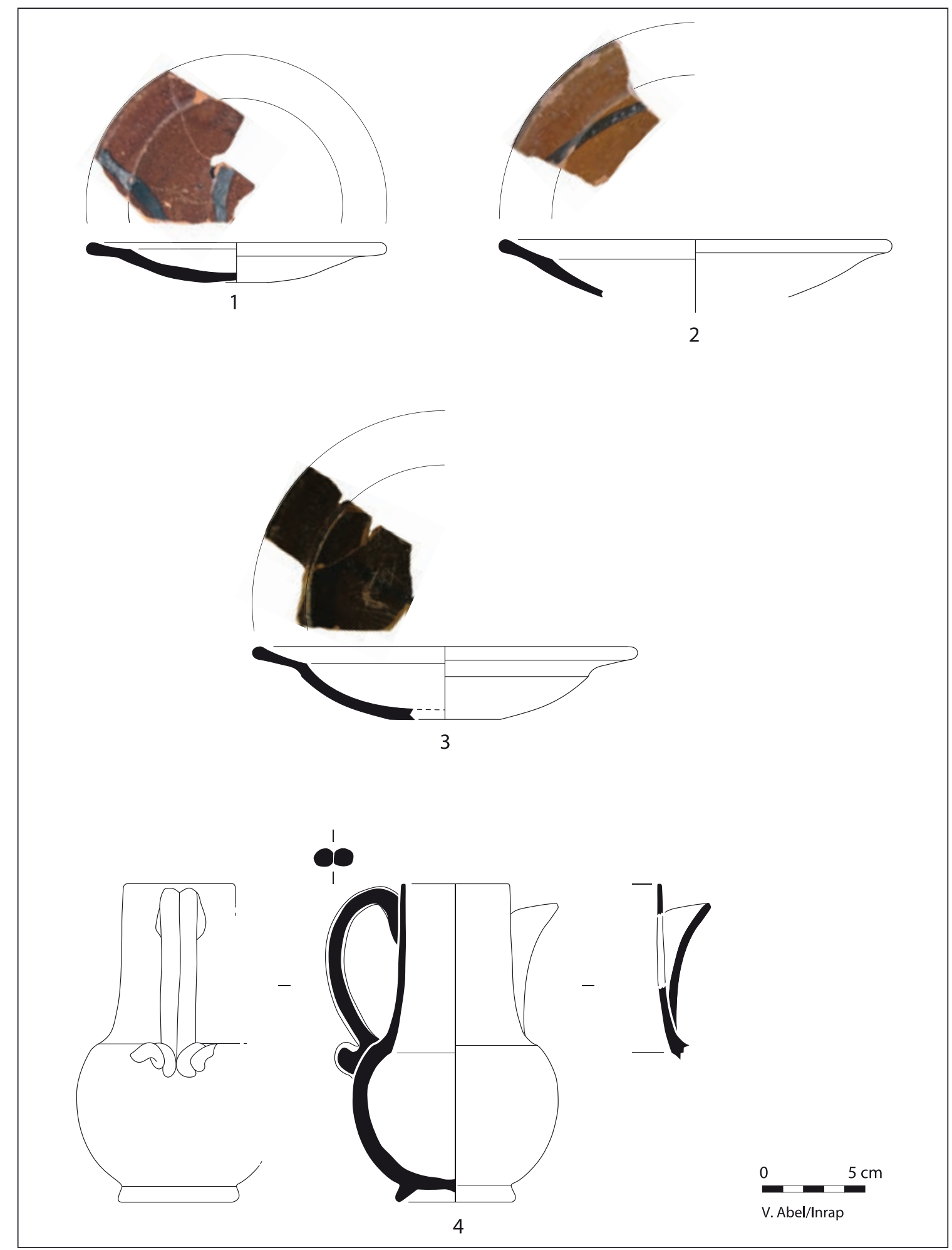

Fig. 206. Terres vernissées d'Albisola. Assiettes ( $\left.n^{\circ} 1-3\right)$, cafetière (n4) (fin du XVIII ${ }^{\mathrm{e}}$ s.). 1-3 : Hôtel-Dieu ; 4 : la Bourse.

vernis jaune (inv. 52.02.10245). En effet, d'autres céramiques, issues de quelques us de ce chantier et d'autres sites marseillais, sont façonnées de manière comparable, leurs formes sont identiques. Une constante est la pâte de couleur rouge, qui révèle une matière première de terre vernissée commune. De manière plus modeste, on retrouve ici les constats formulés pour la boîte à épice qui signalait un façonnage influencé par la faïence. 


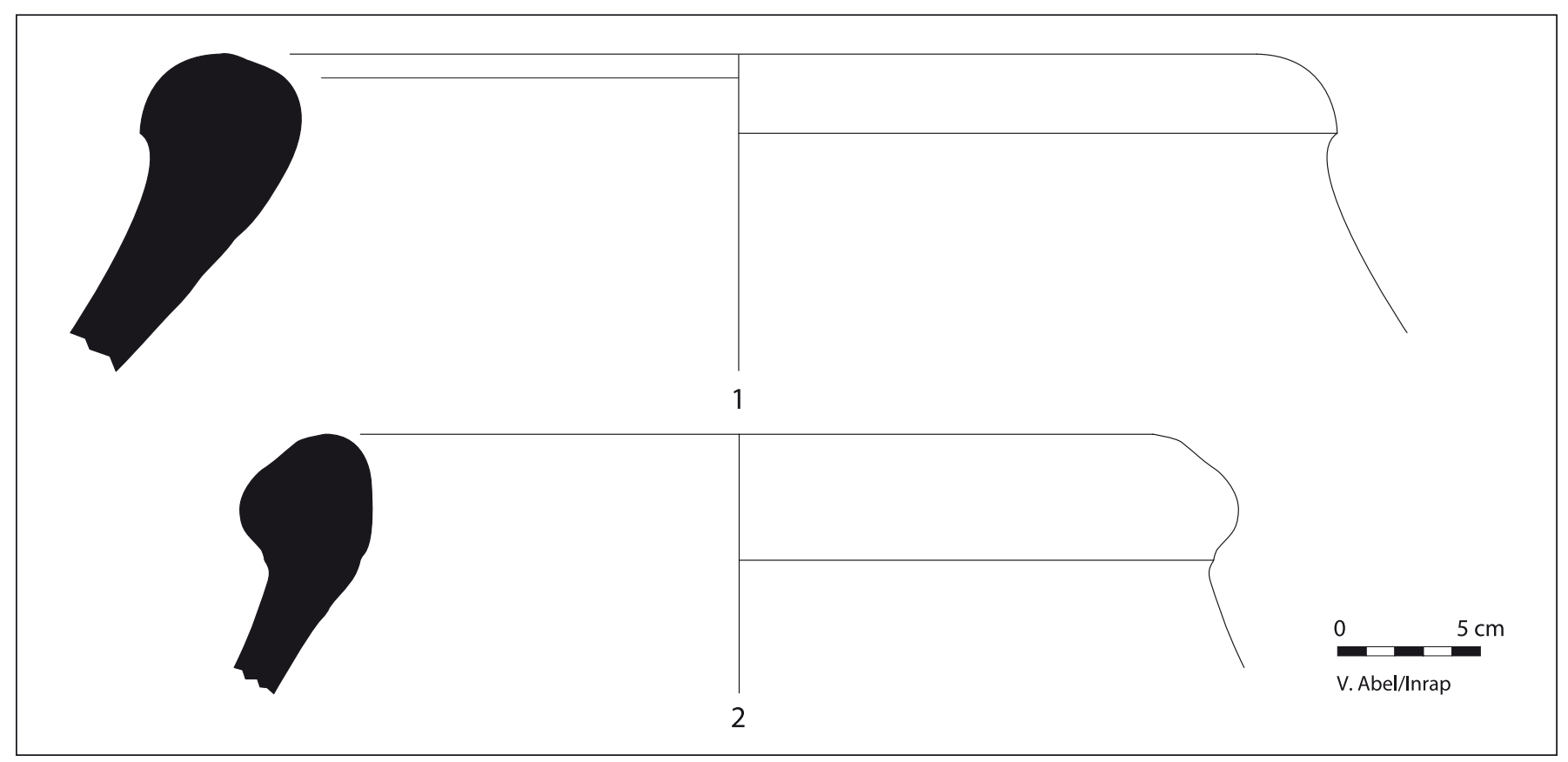

Fig. 207. Jarres de Biot (fin du XVIII S.). Hôtel-Dieu.

\subsection{Biot}

Les grands vases de stockage de Biot sont eux aussi des terres vernissées, exceptionnelles par leur taille. Les deux bords issus de l'Hôtel-Dieu (fig. 207, $\mathbf{n}^{\circ} \mathbf{1 - 2}$ ) ne présentent pas de col, mais leur état de conservation (un unique fragment de panse les accompagne) ne permet de tirer aucune conclusion. Quelques fragments, dont un bord, indiquent la présence d'une jarre de Biot dans le contexte de la place Villeneuve-Bargemon (inv. 52.02.10370).

\subsection{La vallée de l'Huveaune, arrière-pays marseillais}

Les terres vernissées, provenant de la région proche de la vallée de l'Huveaune et considérées comme locales (fig. 208 à 212), restent privilégiées ici en cette fin de $\mathrm{XVIII}^{\mathrm{e}} \mathrm{s}$. Elles constituent le quart des fragments significatifs, soit un peu plus du tiers des objets de la place Villeneuve-Bargemon et quatre cinquièmes des fragments, presque deux tiers des objets de l'Hôtel-Dieu. Leur typologie précise pour cette fin du XVIII ${ }^{\mathrm{e}}$ s. n'a été vraiment amorcée que sur la place Villeneuve-Bargemon dans les années 2000. Auparavant les informations étaient trop dispersées pour prendre corps et nombre d'interrogations subsistaient après cette étude qui avait ébauché la typologie des céramiques vernissées de la vallée de l'Huveaune à la fin du XVIII' s.
De manière intéressante car elle n'est plus en principe la pièce de vaisselle maîtresse à cette époque, l'écuelle est pour la céramique de l'arrière-pays marseillais comme pour la terre vernissée fine de Marseille et la faïence stannifère, une forme bien représentée dans le dépotoir du site de l'Hôtel-Dieu. Elle ne l'était pas place Villeneuve-Bargemon où deux exemplaires étaient extrêmement lacunaires.

L'écuelle a fait en grande partie le succès de ces ateliers un siècle plus tôt, mais vers la fin du XVIII ${ }^{\mathrm{e}}$ s., elle n'est plus la pièce de vaisselle maîtresse (fig. 208). Des deux exemplaires de la place Villeneuve-Bargemon, la première dont il ne reste qu'un fragment de bord, a des parois plutôt minces et régulières dont le galbe laisse imaginer une forme assez creuse (inv. 52.02.10257). Elle possède une couleur orange résultant d'un engobe rose foncé posé sous un vernis jaune. Le seul indice de la seconde écuelle est l'une de ses deux oreilles (inv. 52.02.10437).

Sur le site de l'Hôtel-Dieu en revanche, le profil de plusieurs de ces récipients est conservé, dont un toujours pourvu d'une oreille. Deux modèles se côtoient, de manière très déséquilibrée.

Une écuelle nettement hémisphérique, à parois galbées et assez épaisses (fig. 208, $\mathbf{n}^{\circ} \mathbf{1}$ ), dont l'oreille en éventail conserve un certain relief sous l'engobe rose et le vernis jaune donnant un résultat orangé.

Sous des revêtements identiques mais pour des résultats variés (clair, rosé, moucheté de fer ou taché de cuivre), neuf écuelles recensées, parmi lesquelles 


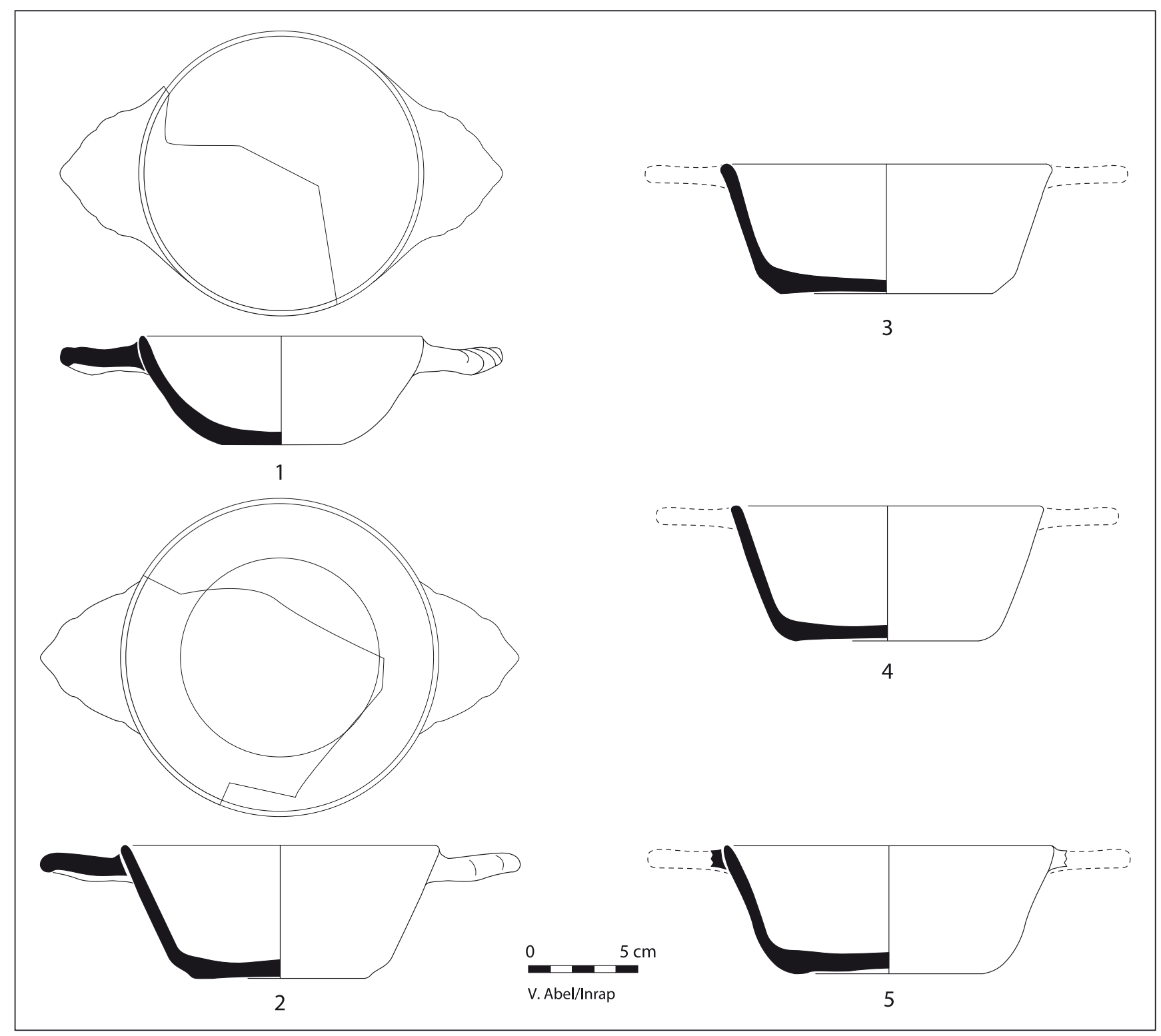

Fig. 208. Terre vernissée de l'arrière-pays marseillais. Écuelles (fin du XVIII' s.). Hôtel-Dieu.

quatre sont archéologiquement complètes, présentent des profils identiques se démarquant de la précédente. Elles sont en effet plus tronconiques qu'hémisphériques, leur large fond plat supportant des parois rectilignes plus minces, simplement terminées par une lèvre arrondie (fig. 208, $\mathbf{n}^{\circ}$ 3-6). La dernière forme complète est encore pourvue d'une oreille, différente elle aussi de l'écuelle en calotte (fig. 208, $\mathbf{n}^{\circ} \mathbf{1}$ ). L'appendice est moins épais et moins en relief, ses bords ne sont que légèrement sinueux (fig. 208, $\mathbf{n}^{\circ}$ 2). Cinq autres écuelles de ce type sont recensées (inv. 155.09.2731 à 2735).

Si les écuelles sont moins nombreuses parmi les terres vernissées locales, c'est sans doute parce que les assiettes sont devenues plus creuses que celles qui accompagnaient les écuelles pendant leur âge d'or de la seconde moitié du XVII ${ }^{\mathrm{e}}$ s. (fig. 209). La forme d'assiette à aile apparue dans le courant du XVIII ${ }^{\mathrm{e}} \mathrm{s}$. a été remarquée sur d'autres sites marseillais. Déclinée en tailles et profondeurs variées, elle est venue se substituer (à partir de quand précisément et selon quel rythme, cela reste à évaluer) à toutes les autres formes de platerie de la vallée de l'Huveaune jusqu'aux plats de service. Le fond est plat, sans pied dégagé et large, la paroi s'y attache directement et se termine par une aile courte.

Un exemple est donné dans le mobilier de la place Villeneuve-Bargemon par une assiette, vaste pour une terre vernissée commune (inv. 52.02.10388). Son diamètre est de $24 \mathrm{~cm}$, ce qui est le diamètre des assiettes de faïence. Le fond plat est ample, la paroi est quasiment 


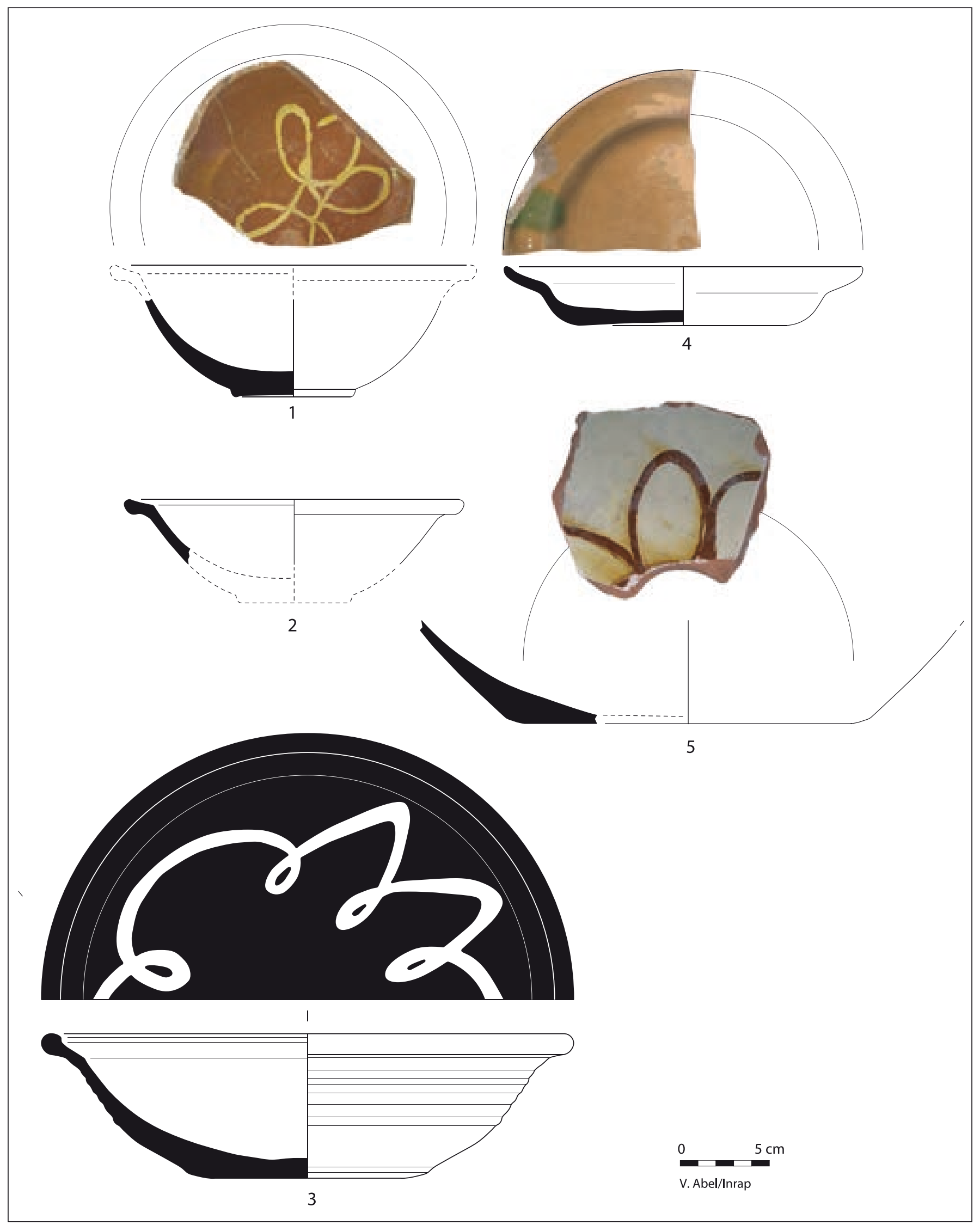

Fig. 209. Terre vernissée de l'arrière-pays marseillais. Assiettes et plats (fin du XVIII' s.). 1-2, 4-5 : Hôtel-Dieu ; 3 : la Bourse. 
inexistante. Après la pose d'un engobe rouge, un ruban ondoyant est dessiné sur l'aile à l'engobe clair. Divers revêtements peuvent être appliqués sur cette même forme d'assiette à aile. Deux tessons ont des engobes unis sans qu'il soit possible de savoir si le vase était orné par ailleurs : un bord à engobe rouge uni sous vernis incolore (inv. 52.02.10385) et un fond à engobe rose uni sous vernis miel (inv. 52.02.10438); une petite assiette plus fine et creuse a un engobe rose uni sous vernis jaune (inv. 52.02.10255). Un fragment de fond est décoré d'un ruban rouge sur engobe rose (inv. 52.02.10394) ; une aile, associée à un fond, porte sur engobe rouge des chevrons blancs descendant vers le bassin (inv. 52.02.10389); un petit fragment de bord est orné de manière comparable (inv. 52.02.10390).

On retrouve l'assiette à l'Hôtel-Dieu sous la forme d'une pièce à engobe rose et vernis donnant une tonalité orangé clair agrémenté d'une tache verte pouvant être aussi bien accidentelle qu'intentionnelle (fig. 209, $\mathbf{n}^{\circ} \mathbf{4}$ ), accompagnée d'une assiette de base identique et fragmentaire (inv. 155.09.2728).

Deux pièces à profil incomplet, un bord et un fond, diffèrent de cette forme par une paroi plus développée et incurvée les élevant au statut d'assiette creuse. Le bord de l'un des deux objets est une aile courte et épaisse recouverte d'engobe rose s'ouvrant à $18 \mathrm{~cm}$ de diamètre (fig. 209, $\mathbf{n}^{\circ}$ 2), le fond de l' autre est plat et supporte une paroi galbée, le bassin décoré d'un ruban jeté d'engobe blanc sur fond rouge (fig. 209, $\mathbf{n}^{\circ} \mathbf{1}$ ).
Le plat creux développe cependant une paroi plus haute et galbée dont la courbe régulière se casse au niveau d'un marli qui détermine une aile incurvée d'à peine $2,5 \mathrm{~cm}$ de large pour un diamètre d'ouverture d'environ $30 \mathrm{~cm}$. Sur un engobe rose est appliqué un décor sommaire de rubans d'engobe rouge formant des sortes de pétales limités au centre du vase (inv. 52.02.10391). Semblable au premier, un autre plat a cependant un pied un peu plus étroit. Les engobes de revêtement et de décor sont identiques au précédent, mais pour celuici, un ruban court sur l'aile et de gros «pétales » se développent jusqu'au marli depuis un cercle central (inv. 52.02.10392).

Ce type de décor se retrouve sur un grand plat de l'Hôtel-Dieu recouvert d'engobe blanc agrémenté rubans à l'engobe rouge (fig. 209, ${ }^{\circ} 4$ ) entourant vraisemblablement un cercle placé dans la zone centrale disparue. Trois fragments non connexes pourraient provenir du même vase, dont un bord à aile courte et épaisse. Un bord de grand plat à engobe blanc et décor rouge révèle une lèvre presque bifide et rappelant celle des pots de chambre (inv. 52.02.10254), tandis qu'un autre, à engobe rose uni a une lèvre ondulée (inv. 52.02.10393).

Les vases à liquide sont relativement bien représentés dans le lot de l'Hôtel-Dieu, complétant opportunément les données presque inexistantes sur ce type de vase de la place Villeneuve-Bargemon (fig. 210). Un dépotoir domestique ne les concentre généralement pas, ils sont plutôt recueillis dans les puits. Les principaux récipients

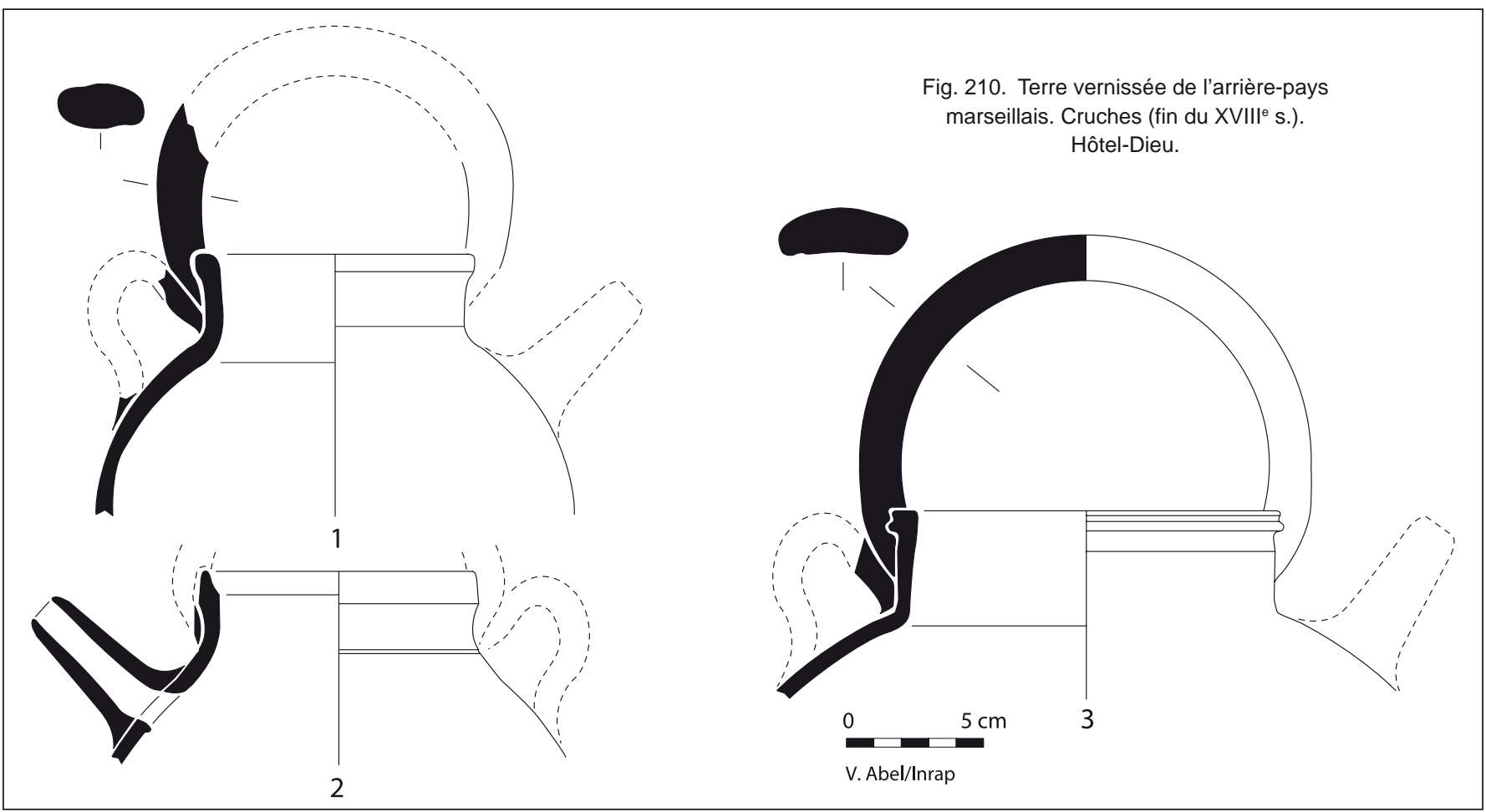




$$
\begin{array}{ll} 
& 0 \\
1 & 1 \\
7 & 1 \\
1 & -
\end{array}
$$


(et presque les seuls) remplissant cette fonction dans la production de l'arrière-pays marseillais sont le pichet et la cruche, dont les morphologies sont bien distinctes dès le $\mathrm{XVII}^{\mathrm{e}} \mathrm{s}$. Depuis lors, l'un ne prend jamais le pas sur l'autre. Ici en revanche, les pichets sont nettement en minorité. Tous trois, identifiés grâce à leur bec pincé, sont revêtus de vernis vert après engobage en rose (inv. 155.09.2717 à 2719) et sont très mal conservés.

Quelques vases, bien que très lacunaires, ont été dessinés. Cette étape a permis de remarquer que l'appendice supérieur en anse de panier de l'une des cruches à engobe rose sous vernis jaune dont le bec manque est parfaitement circulaire et qu'il a donc été sûrement calibré sur une forme après que le cordon d'argile a été tourné (fig. 210, $\left.\mathbf{n}^{\circ} \mathbf{3}\right)$. Selon toute vraisemblance, le calibre a dû rester en place sur l'ouverture de la cruche le temps que l'anse ait acquis une certaine résistance, alors que pour faire corps avec le vase l'appendice doit être encore souple lors de la fixation. Le bord du vase est mouluré, il coiffe un col bien marqué et assez haut (bien que la proportion de celui-ci par rapport au reste du vase soit indéterminable comme la taille totale et le diamètre maximal de l'objet) terminant une panse hypothétiquement globulaire. Rappelons que ces récipients relativement récents ne sont pas les mieux connus de la typo-chronologie des céramiques de la vallée de l'Huveaune.

Revêtue de même manière que la précédente, une cruche ne conserve qu'une anse supérieure fragmentaire, greffée sur un bord simplement épaissi (fig. 210, $\left.\mathbf{n}^{\circ} \mathbf{1}\right)$. Sa morphologie demeure à peu près semblable à la précédente. Le bord d'une troisième cruche à engobe rose sous vernis jaune est encore différent: un léger canal est aménagé dans l'embouchure, amincissant la lèvre. Aucune anse ne subsiste, un bec tubulaire est en revanche présent dans la partie conservée (fig. 210, $\mathbf{n}^{\circ}$ 2). Quatre becs tubulaires de cruche qui ne peuvent être associés aux objets précédents sont revêtus d'engobe rose sous vernis vert (inv. 155.09.2713 à 2716). Six autres becs tubulaires de cruche sont revêtus du même engobe rose et vernis jaune (inv. 155.09.2610 et 2721 à 2724) et confirment la représentativité de la troisième cruche signalée ci-dessus.

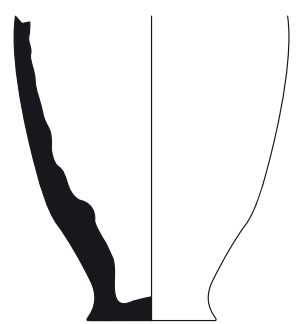

1

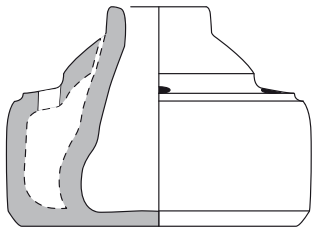

3

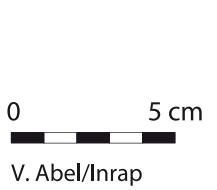

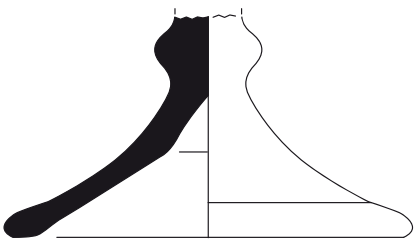

5

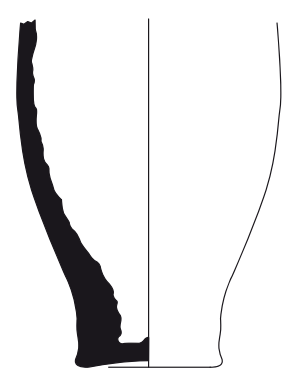

2
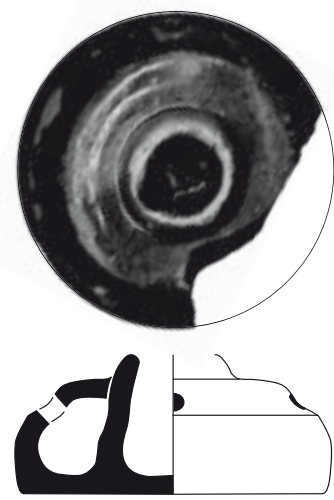

4

Fig. 212. Terre vernissée de l'arrière-pays marseillais. Pots à fraise ( $\left.n^{\circ} 1-2\right)$ et encrier ( $\left.n^{\circ} 3-4\right)$ (fin du XVIIII $\left.s.\right)$. 1-2, 4-5 : Hôtel-Dieu ; 3 : Espace Bargemon. 
Le pot de chambre est l'une des formes les plus pérennes des ateliers de l'arrière-pays marseillais, à la disposition des utilisateurs dès le deuxième quart du $\mathrm{XVII}{ }^{\mathrm{e}} \mathrm{s}$. et sur plus d'un siècle et demi (fig. 211). Cet ensemble en recelait plus d'une vingtaine, malheureusement très morcelés. Un seul d'entre eux conserve son profil complet, sur ses $19 \mathrm{~cm}$ de haut malgré des lacunes (fig. 211, $\mathbf{n}^{\circ}$ 6). L'anse, toujours unique pour cette forme, est fragmentaire, laissant toutefois la possibilité d'en relever la section, obtenue au tour et agrémentée de deux cannelures peu profondes. L'intérieur des pots de chambre reste immuablement recouvert d'engobe blanc et de vernis incolore. L'extérieur est ici recouvert d'engobe rose au tiers de la hauteur, qui donne un effet brun-vert sombre sous le vernis à l'oxyde de cuivre. Le second pot de chambre à vernis vert représenté graphiquement (fig. 211, $\mathbf{n}^{\circ} \mathbf{5}$ ) est semblable à l'objet complet, de même que tous ceux recensés dans ce mobilier (inv. 155.09.2692, 2697 à 2698 et 2700 à 2705).

La plupart des pots de chambre à vernis jaune extérieur posé sur engobe rose (revêtement à aspect orangé déjà rencontré sur la vaisselle) reste identique au « modèle vert » (inv. 155.09.2687 à 2691 et 2693 à 2694). Un de ces vases, fragmentaire, a en revanche, sur une paroi semblable aux précédents, une aile moins épaisse et un marli plus anguleux (inv. 155.09.2696).

L'un des rares pots de chambre de la place VilleneuveBargemon, au profil complet, est étonnant par sa petite taille, son diamètre d'ouverture est de $18 \mathrm{~cm}$ au total, incluant une aile de $2,5 \mathrm{~cm}$ de large proportionnée à sa taille (inv. 52.02.10374). Il ne possède qu'une seule anse, de manière habituelle. L'extérieur est recouvert d'engobe rose au tiers de sa hauteur, qui donne un effet orangé sous le vernis, l'intérieur étant recouvert d'engobe blanc.

Ce mobilier a offert une forme sanitaire inédite. Bien que le fond de l'objet soit perdu, la partie inférieure du tesson restant commence à s'incurver, indiquant l'amorce de la base du récipient à $8 \mathrm{~cm}$ seulement au-dessous du plan d'ouverture du bord caractéristique des pots de chambre (fig. 211, $\mathbf{n}^{\circ} \mathbf{4}$ ). Le récipient ne possède pas d'anse latérale mais un départ de queue tubulaire, dont un second exemplaire est recensé ici (inv. 155.09.2686). Il s'agit vraisemblablement d'un bassin réservé aux malades alités, aménagé spécialement pour être utilisé plus facilement auprès d'eux. L'extérieur du vase n'est pas revêtu.

Dans cette catégorie de poteries sanitaires sont rangées les bassines dites « tians ». Ces objets ne sont jamais décorés. L'engobe blanc leur est rarement attribué, sans doute par souci économique. Sur la place VilleneuveBargemon, ce revêtement est rouge dans cinq cas sur sept, rose dans les deux autres cas.

Deux couvercles ont été recensés, dont l'un, rouge, présente l'originalité d'une préhension en anse plate et non en bouton (inv. 52.02.10253).

Trois tirelires dites «cachemaille » se signalent par leur très caractéristique bouton de préhension. Ces objets destinés à être cassé à plus ou moins long terme, ne reçoivent jamais aucun revêtement, ni engobe ni vernis.

Quelques formes enfin sont présentes en moins grand nombre. Leur fonction est parfois très précise et connue, sans que puisse être exclu le recyclage en utilisation secondaire dans ce milieu particulier de l'Hôtel-Dieu. Deux cruches-jouets (taraïettes) en terre vernissée en vert sont par exemple reconnaissables (inv. 155.09.2729 et 2730), jouets, d'évidence, mais à la base petits vases, de très faible contenance, imperméabilisés avec autant de soin que de grands récipients domestiques. De même ces pots à fraises (inv. 155.09.2681 à 2684) petits récipients fermés, précurseurs des «emballages perdus » (fig. 212, n' 1-2). Apparus dans le courant du XVIII ${ }^{\circ}$ s., ils sont les premiers produits de la vallée de l'Huveaune après les tirelires dès le milieu du XVII ${ }^{\mathrm{e}} \mathrm{s}$., à ne recevoir aucun revêtement, ni engobe ni vernis. On peut évoquer dans leur cas la consommation de fraises par agrément, mais aussi par médication, ou la récupération des vases pour des usages secondaires.

L'encrier pique-plume est en revanche sans doute resté dans la fonction première qui lui était destinée (fig. 212, $\mathbf{n}^{\circ}$ 2). Un objet semblable avait été recueilli lors du chantier de la place Villeneuve-Bargemon (fig. 212, $\mathbf{n}^{\circ} \mathbf{3}$ ) sans qu'on puisse avoir la certitude de sa représentativité. On peut aujourd'hui confirmer celleci grâce à l'objet de l'Hôtel-Dieu et mieux comprendre son façonnage : une petite vasque centrale se refermant sur un goulot étroit est entourée, dans la même masse d'argile par le potier, d'une cavité circulaire en bouée refermée et percée dans sa partie supérieure de quatre petits trous, les pique-plume. Si les encriers sont connus depuis longtemps, aucun n'était pour l'instant répertorié dans la production vernissée de l'arrière-pays marseillais avant ces deux pièces de la fin du XVIII $\mathrm{e}$ s.

Un dernier objet restera au contraire mystérieux car très lacunaire. Sa base est en forme de cône renversé, recreusé à l'estèque et surmonté d'une tige à renflement, brisée à $7 \mathrm{~cm}$ de haut (fig. 212, $\mathbf{n}^{\circ} \mathbf{5}$ ). Son revêtement est fait de vernis incolore sur un engobe rouge très couvrant. 
Deuxième Partie

\section{Les Autres MobILIERS}

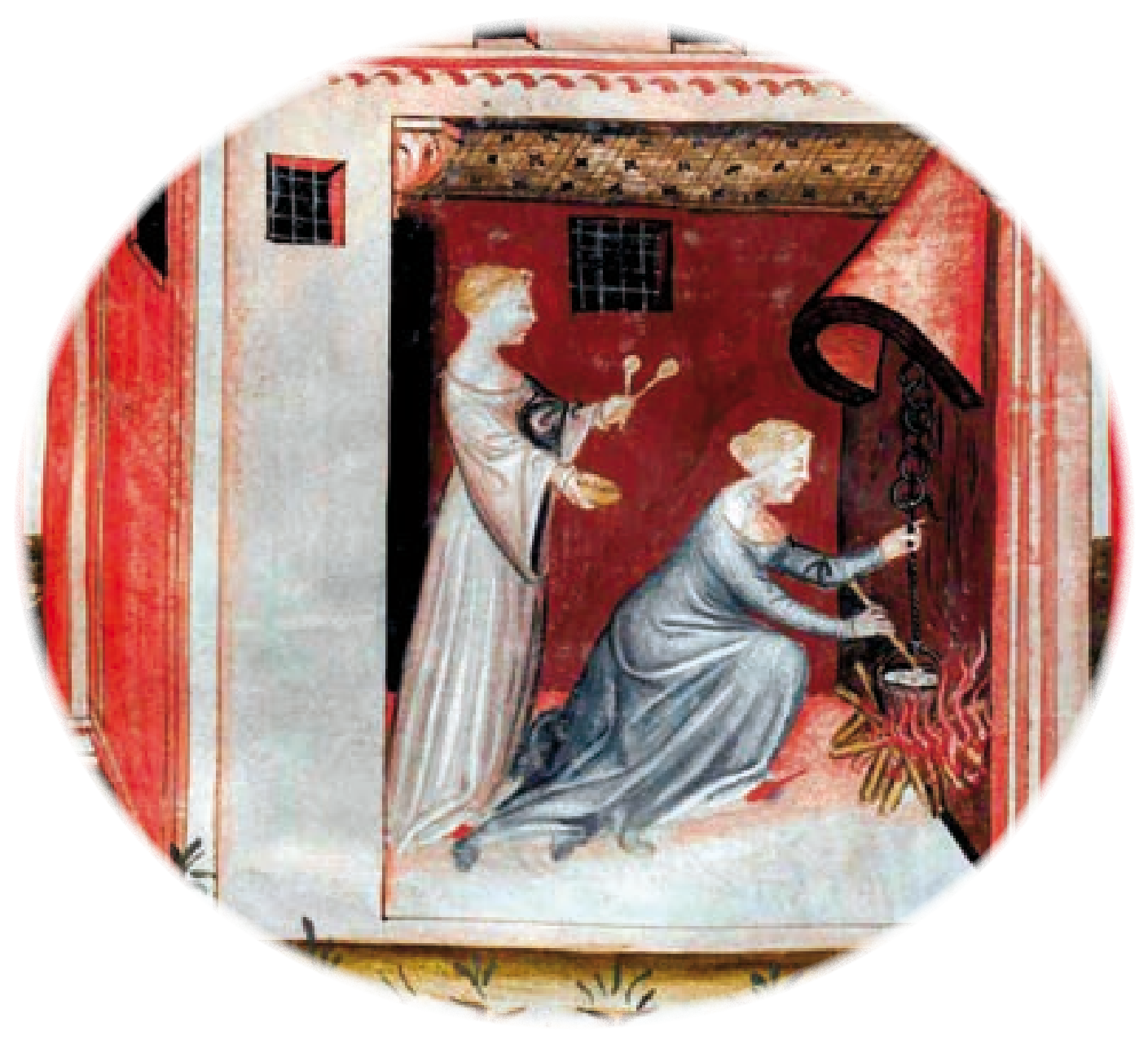





\section{Chapitre 1}

\section{Les verres médiévaux des fouilles de Marseille}

\section{(Danièle Foy ${ }^{18}$ et Denis Michel ${ }^{19}$ )}

\section{Introduction}

\subsection{L'artisanat du verre}

À l'époque médiévale, l'artisanat du verre est principalement une activité forestière, le premier déterminant de l'implantation des ateliers étant le combustible. Il existait pourtant, dans les villes d'importance, des officines urbaines ou périurbaines dont les textes ont gardé le souvenir. À Marseille, dès le tout début du XIV ${ }^{\mathrm{e}}$ s., plusieurs artisans sont mentionnés et le métier est, en partie au moins, contrôlé et protégé par la cité qui réglemente la vente du verre cassé destiné au recyclage ${ }^{20}$.

La production locale était cependant insuffisante pour répondre aux besoins des consommateurs. Une partie des verres (probablement la plus grande) utilisés dans les maisons provenait des ateliers fixés dans les collines boisées au nord du bassin de Saint-Maximin et dans le massif de la Sainte-Baume, le plus étendu de tous les chaînons provençaux, situé à une vingtaine de kilomètres de la Méditerranée.

Les officines installées dans cette zone forestière sont documentées par l'archéologie et les sources écrites. Celles-ci rendent compte des liens qui unissaient la métropole marseillaise et cette aire artisanale. Des marchands spécialisés investissaient dans l'artisanat verrier en apportant les capitaux initiaux et les matières premières entrantes dans la composition du verre. En échange ils recevaient des cargaisons de produits finis que les muletiers ramenaient dans la cité après avoir déchargé les saumées de soude et de verre brisé. Ces mêmes verriers recevaient de Marseille des commandes publiques concernant la fabrication $d^{\prime}$ '«amphore» à

18 Centre Camille Jullian, UMR 7299.

19 Chargé d'études, Inrap.

20 Délibérations de la commune de Marseille en 1331 interdisant la sortie du verre brisé et fixant son prix avec obligation de le vendre à la ville ou au four du verrier : Foy 1988, 39 et annexes 4 à 6 . mesurer le vin, telle celle qui fut passée en 1338 pour 3 ans (Baratier, Reynaud 1951, p. 830 ; Foy 1988, p. 379) ${ }^{21}$. À la fin du Moyen Âge, le savoir faire et probablement la compétitivité des artisans marseillais était reconnue : c'est ce que reflète la transaction passée, en 1480, entre l'un d'eux et un marchand vénitien pour la fabrication (contrefaçon ?) de mille aiguières qui devaient être les copies des deux modèles fournis par le marchand (Baratier, Reynaud 1951, p. 830 ; Foy 1988, p. 379). À Marseille, transitaient donc d'énormes quantités de verre destinées à une consommation locale, mais aussi vouées à l'exportation. De ces milliers d'objets que Marseille retirait de ses fabriques urbaines et surtout de son hinterland provençal, il ne reste que de maigres témoignages matériels.

\subsection{Les découvertes archéologiques à Marseille}

Les seuls verres médiévaux de Marseille publiés proviennent des fouilles de Saint-Victor et du quartier artisanal de Sainte-Barbe. Le premier site a livré des vitraux décorés et une lampe, datés des $\mathrm{XII}^{\mathrm{e}}-\mathrm{XIII}{ }^{\mathrm{e}} \mathrm{s}$. Le mobilier en verre très fragmenté du quartier Sainte Barbe appartient aux différentes phases d'occupation datées entre le $\mathrm{XII}^{\mathrm{e}}$ et la fin du $\mathrm{XIV}^{\mathrm{e}} \mathrm{s}$. Les formes reconnues sont celles que l'on retrouve dans les neuf sites marseillais étudiés ici : l'Alcazar, rue Jean-François Leca, rue Jean Trinquet, Tunnel de la Major, place Général-deGaulle, place Villeneuve-Bargemon, place Jules-Verne, îlot Puget III et îlot 24 N.

Ce mobilier bien qu'en quantité réduite est répétitif et ne comprend aucune pièce d'époque carolingienne ou du $\mathrm{XI}^{\mathrm{e}} \mathrm{s}$. ; presque tous les fragments appartiennent au XIII ${ }^{\mathrm{e}}$ ou au XIV ${ }^{\mathrm{e}} \mathrm{s}$. Les formes ne sont pas inédites, mais certaines pièces offrent des variantes dans les gabarits et les motifs décoratifs. Deux pièces de la fin du Moyen Âge

21 Baratier, Reynaud 1951, p. 264, note 5 ; Foy 1988, p. 249-250. Ces amphores sont probablement des carafes de divers gabarits et dont la capacité est certifiée. Elles étaient utilisées chez les taverniers, mais sans doute aussi pour acheter au détail divers liquides : huile, sauces, vins... 
ont été prises en compte ainsi que cinq verres décorés d'Époque moderne. Le corpus comprend 87 objets.

\subsection{Les contextes utilisés}

- Les fragments de verre médiévaux des fouilles Puget III semblent antérieurs au milieu du $\mathrm{XIII}^{\mathrm{e}}$ s. et viennent de trois contextes différents.

- Les deux fragments issus des fouilles de la rue Leca proviennent d'un niveau de surface (2001) dans lequel était un mobilier de datation hétérogène.

- Les deux verres du chantier du Tunnel de la Major sont issus de niveaux bien datés par la céramique du $\mathrm{XIII}^{\mathrm{e}}$ et du début du XIV ${ }^{\mathrm{e}} \mathrm{s}$.

- Les verres des fouilles de l'Alcazar, un peu plus nombreux mais tout aussi fragmentés, ont été collectés dans 12 contextes souvent datés par la céramique. Très peu sont en position résiduelle et quelques-uns forment de très petits assemblages homogènes (US 4348 et 4276).

- De la fouille de la place Général-de-Gaulle, provient une vingtaine de pièces qui sortent d'autant de contextes datés du milieu du XIII ${ }^{\mathrm{e}}$ s. au XV ${ }^{\mathrm{e}}$ s. (Bouiron 2001). La plupart de ces fragments sont datés de la fin du XIII ${ }^{\mathrm{e}} \mathrm{s}$.

- Le puits PT2017 des fouilles de la rue Trinquet a fourni un petit lot de quatre objets datables du courant $\mathrm{du} \mathrm{XIV}^{\mathrm{e}}$ s., probablement de la première moitié de ce siècle.

- Les trois chantiers de fouilles qui se sont succédé sur la place Villeneuve Bargemon en 1995, 1996-97 et 2002 ont mis au jour du verre médiéval. Le mobilier le plus riche est celui de la fouille de 1996-97 (MCR96) : il forme deux ensembles homogènes du début du XIV ${ }^{\mathrm{e}} \mathrm{s}$. Trois contextes des fouilles de 2002 (BRG02) ont également fourni des verres; peu nombreux et de très petite taille, ces fragments proviennent de niveaux de rue constitués au cours du XIII ${ }^{\mathrm{e}} \mathrm{s}$. Des quatre fragments de verres médiévaux des fouilles de 1995 (CSR95), l'un est en position résiduelle $\left(\mathrm{n}^{\circ} 14\right.$, US 3011); les trois autres sortent de strates constituées au cours du XII ${ }^{\mathrm{e}}$ s., mais l'un d'eux ( $\left.{ }^{\circ} 15\right)$ est semblable aux types attribués au XIII's.

- Deux niveaux de la fin du XIII et du XIV es. des fouilles de la place Jules-Verne, zone 5 ont livré trois pièces.

On voit donc que ces éléments, peu nombreux (81 pièces), sont très dispersés. Les associations de mobilier ne sont notables que dans le comblement du puits PT2017 de la rue Trinquet, (4 objets); dans deux contextes de la place Villeneuve Bargemon (MCR96), US 2464 ( 6 objets) et US 2439 (7 objets) et dans le niveau 4348 de l'Alcazar (4 verres).

\section{Les séries de verres médiévaux}

Nous avons choisi de présenter le mobilier par types et non par sites ou par contextes. Neuf séries ont été constituées : la première comprend le mobilier du XII et du début du XIII ${ }^{\mathrm{e}} \mathrm{s}$. ; les deux groupes suivants, gobelets et verres bicolores, sont des objets de la seconde moitié ou de la fin du XIII ${ }^{\mathrm{e}} \mathrm{s}$. Viennent ensuite les verres à tige et les gobelets à côtes hélicoïdales qui se situent à la fin du XIII ${ }^{\mathrm{e}}$ et au début du XIV ${ }^{\mathrm{e}}$ s. Les autres pièces (gobelets divers, guttrolfs, bouteilles soufflées dans un moule) peuvent être contemporaines des précédentes, mais sont en usage durant tout le $\mathrm{XIV}^{\mathrm{e}} \mathrm{s}$. Des éléments de vaisselle de la fin du $X^{2}$ s. et quatre verres de la fin du XVI et du début du XVII ${ }^{e}$ s. ferment cet inventaire. Le tableau mis en annexe (voir Annexe 2) permet de reconstituer les assemblages.

\subsection{Le verre potassique $\mathrm{XII}{ }^{\mathrm{e}}-\mathrm{XIII}{ }^{\mathrm{e}} \mathrm{s}$.}

Sous ce titre, nous avons rassemblé des verres friables et d'aspect noirâtre qui sont probablement fabriqués avec des cendres végétales potassiques (fig. 213). Aucune analyse de composition n'a cependant pu être faite sur ce mobilier, mais la mauvaise conservation de ces objets laissent penser qu'ils contiennent des cendres potassiques et qu'ils sont vraisemblablement antérieurs au XIII ${ }^{\mathrm{e}}$ s., ce que confirment parfois les contextes de découverte et/ou la forme de l'objet. L'évolution de la composition des verres en Provence, connue par des recherches antérieures, montre que les verres de tradition antique (fabriqués avec une soude minérale, le natron) sont présents jusqu'au VIII ${ }^{\mathrm{e}} \mathrm{s}$. au moins. Les verres des $\mathrm{X}^{\mathrm{e}}, \mathrm{XI}^{\mathrm{e}}$ et $\mathrm{XII}^{\mathrm{e}}$ s. sont élaborés à partir de cendres potassiques, venant de divers végétaux en particulier de fougères. L'introduction des cendres sodiques se fait à un moment imprécis, mais sans doute vers la fin du XII ${ }^{\mathrm{e}} \mathrm{s}$. ou au début du XIII ${ }^{\mathrm{e}} \mathrm{s}$. L'utilisation de ce nouveau fondant (cendres de plantes halophytes, principalement des salicornes croissant en Camargue) et probablement aussi le choix de la silice, permet d'obtenir un verre clair qui (mais cela les verriers ne pouvaient le savoir) résistera bien mieux que le verre potassique aux outrages du temps.

Extrêmement fragile le mobilier médiéval le plus précoce ne subsiste que sous forme de débris sur trois sites marseillais.

- Deux fragments des fouilles de Puget III (fig. 213, $\mathbf{n}^{\circ}$ 1-2) appartiennent à la partie médiane reliant la coupe et le pied d'un récipient de profil non restituable : il pourrait s'agir de verres bitronconiques (Foy 


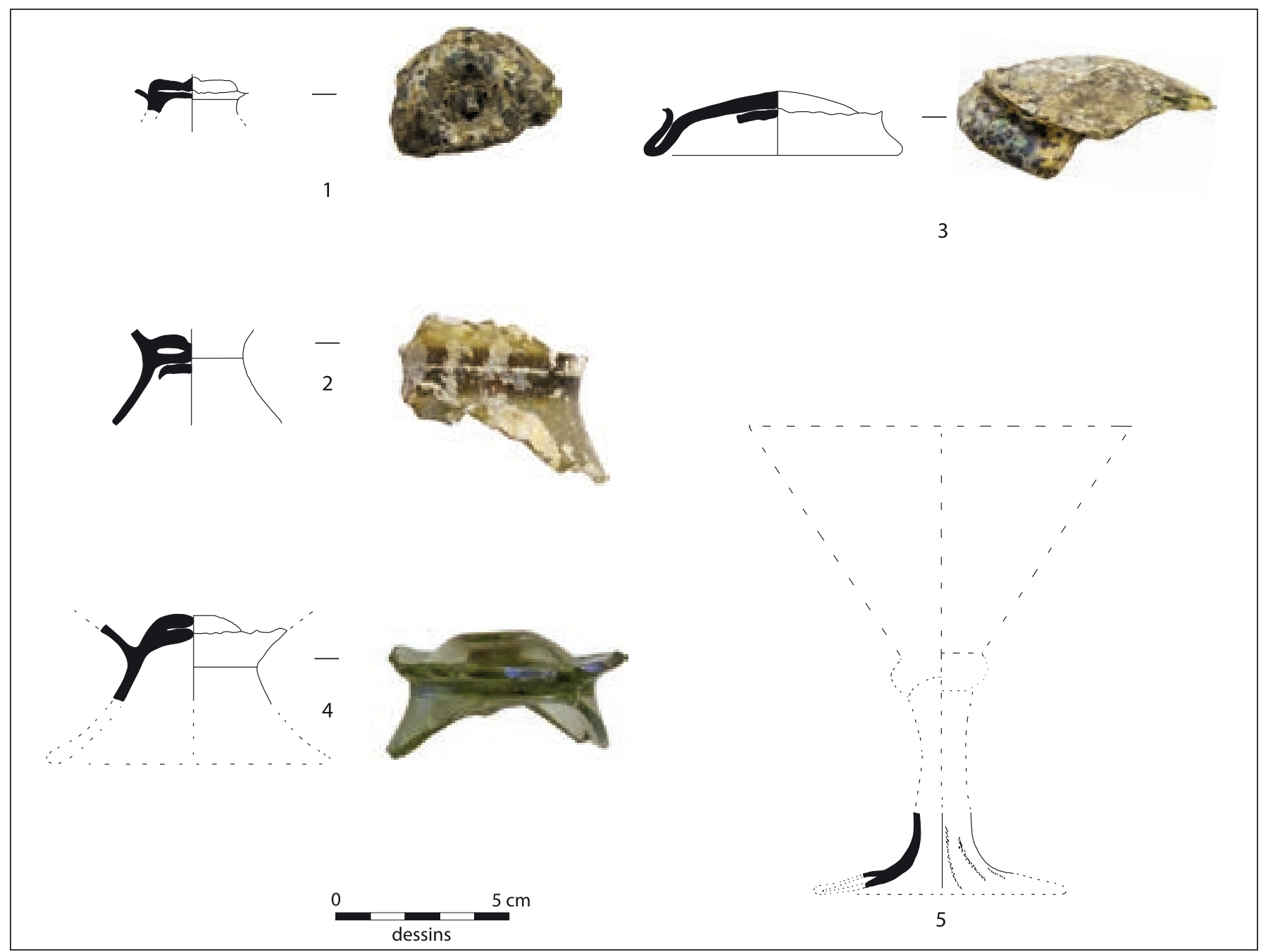

Fig. 213. Verres à cendres potassiques (?) XII $s$. ? Verres bitronconiques ( $n^{\circ} 1-2$ et 4), pied annulaire $\left(n^{\circ} 3\right)$, pied d'un verre à tige $\left(n^{\circ} 5\right)$. 1-3 : Puget III ; $4-5$ : place Villeneuve-Bargemon (D. Foy/CCJ).

1988, p. 196 et 199-200, forme A3) en usage aux XII ${ }^{\mathrm{e}}$ ou au début du XIII ${ }^{\mathrm{e}} \mathrm{s}$. Le troisième témoin (fig. 213, $\mathbf{n}^{\circ} \mathbf{3}$ ), un fond annulaire creux (Foy 1988, p. 195-196, forme A1), pourrait être contemporain des précédents. Les deux pièces de la fouille de la place VilleneuveBargemon, conduite en 1995, sont issues de recharges de rue datables du courant du XII ${ }^{\mathrm{e}}$ s. : l'une (fig. 213, $\left.\mathbf{n}^{\circ} 4\right)$ est identifiable à un verre bitronconique ou bien caliciforme (Foy 1988, p. 197-198, forme A2) ; l'autre (fig. 213, $\mathbf{n}^{\circ} \mathbf{5}$ ) est la base d'une tige creuse torsadée. Ce dernier fragment est comparable à du mobilier retrouvé à l'abbaye de Psalmody (Foy 1988, fig. 49-4,5 et 11 et fig. 50) et dans le comblement de deux puits languedociens sis à Roujan (À travers le verre 1989, notices 105 et 106) et à Montpellier (Foy 1995 ; et Deguara 2007, fig. 131). Ce support pourrait cependant renvoyer à des vaisselles dont la coupe est beaucoup plus large (Penna 2003, fig. 171, n84).

\subsection{Les gobelets à gouttes étirées de la seconde moitié du XIII' $\mathbf{s}$.}

L'ornementation qui consiste à déposer sur les parois d'un verre des nodules de matière vitreuse de forme grossièrement pyramidale n' est pas une invention des verriers médiévaux, mais cette technique décorative jouit d'une grande faveur du XIII ${ }^{\mathrm{e}}$ au $\mathrm{XVI}^{\mathrm{e}} \mathrm{s}$. dans plusieurs pays, avec une chronologie qui diffère d'une région à l'autre.

Ce décor rapporté probablement au bout d'une tige métallique est déposé en vrille ou bien appliqué comme une pastille, puis étiré de façon à former des aspérités pointues; la goutte de verre peut aussi être pincée pour accentuer la pointe sommitale. Cette ornementation, formée de protubérances régulièrement disposées sur 2, 3 ou 4 rangs horizontaux afin de couvrir presque toute la panse du récipient, est le dénominateur commun d'une catégorie de verres nommée dans la littérature 


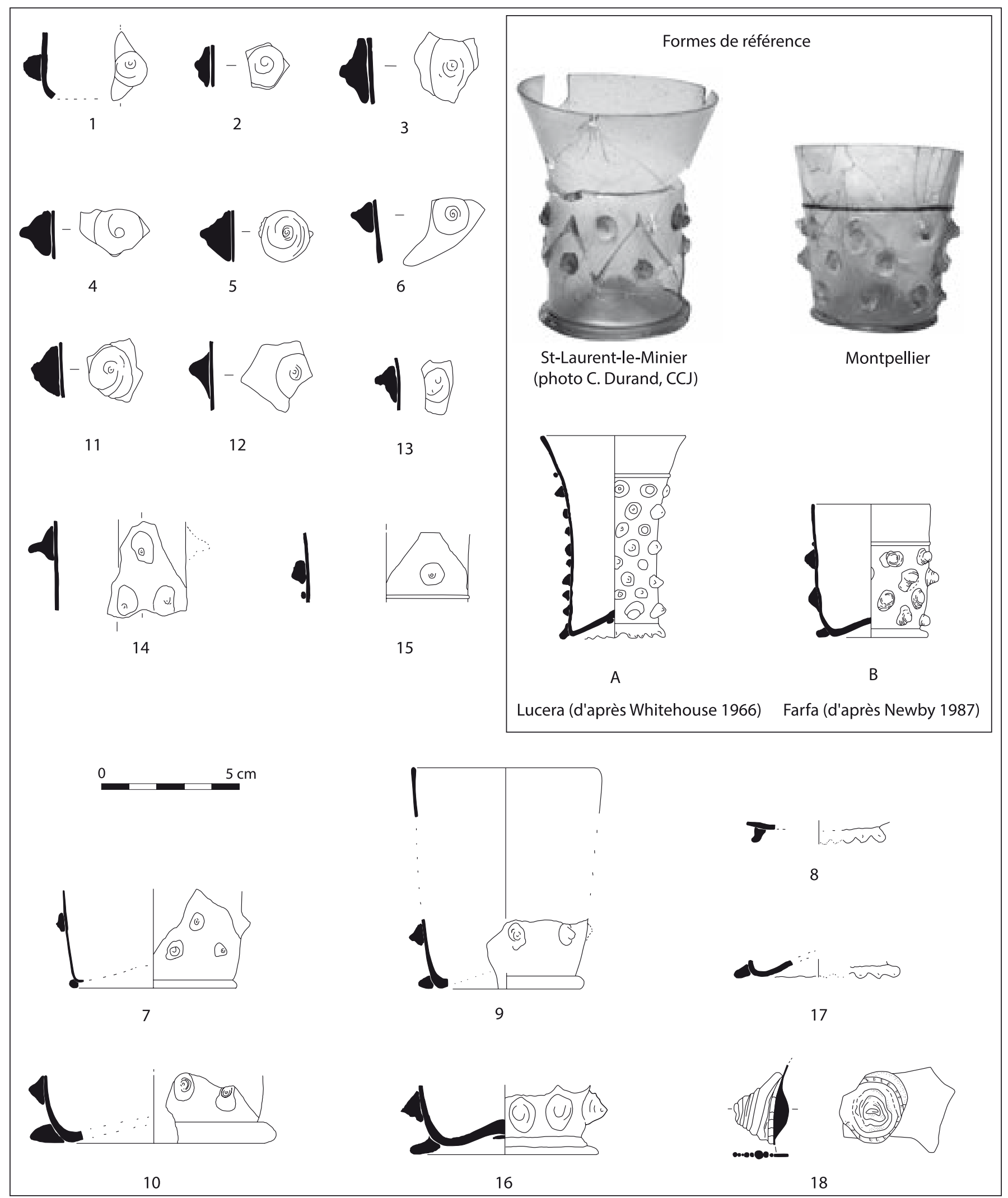

Fig. 214. (ci-dessus) et Fig. 215. (page 264) Gobelets à gouttes appliquées. Parois de gobelets décorées d'une goutte de verre appliquée et étirée ( $\left.n^{\circ} 1-4,16-17\right)$, parois de gobelets décorées d'une goutte de verre appliquée et étirée $\left(n^{\circ} 5-6,11-15\right)$, fonds de gobelet $\left(n^{\circ} 8-10\right)$, gobelets à décor de gouttes appliquées $\left(n^{\circ} 7,18\right)$. 1-4, 8 : Alcazar ; 5-6, 9-10 : place Villeneuve-Bargemon ; $7:$ Tunnel de la Major ; $11-17$ : place Général-de-Gaulle ; 18 : rue Trinquet. (D. Foy/CCJ). 
archéologique Nuppenbecher (Baumgartner, Krueger 1988, p. 192-217).

En Provence et en Languedoc, ce décor semble uniquement - ou principalement présent - sur des gobelets à corps cylindrique et rebord droit ou au contraire au rebord en entonnoir (fig. 214 et 215). Leur fond est cerné d'un cordon de verre rapporté, lisse ou dentelé et un filet de verre de même teinte que l'objet ou coloré en bleu cobalt est habituellement appliqué au-dessus des gouttes en relief; plus rarement les filets de verre peuvent dessiner une résille ou des zigzags entre les globules de verre. Ces formes qui sont communes à plusieurs pays, de la Syrie à l'Allemagne, en passant par la Grèce, les Balkans et l'Italie sont en usage au cours du XIII ${ }^{e}$ s. Plusieurs centres producteurs ont été identifiés notamment à Corinthe (Weinberg 1975 et 1981 ; Whitehouse 1991 et 1993), mais aussi en Provence, à Planier, sur la commune de Signes, dans le département du Var (Foy 1988, p. 148-158 et 209-211). Ce décor est un bon marqueur dans le Midi de la France car il a été utilisé sur une assez courte durée qui n'excède guère la fin du XIII ${ }^{\mathrm{e}} \mathrm{s}$. ou le premier quart du $\mathrm{XIV}^{\mathrm{e}} \mathrm{s}$. Ce n'est pas le cas partout. En effet, un grand nombre de verreries du courant $\mathrm{du} \mathrm{XIV}^{\mathrm{e}} \mathrm{s}$. mises au jour en Italie centrale et méridionale portent encore ces aspérités ${ }^{22}$ et au tout début $\mathrm{du} \mathrm{XV}^{\mathrm{e}} \mathrm{s}$. encore, l'appellation ciatis imperlatis est réservée à ces objets ${ }^{23}$. Cette technique ornementale a également eu la faveur des ateliers septentrionaux comme en témoignent les vestiges de la verrerie de Herbeumont (Luxembourg) qui fonctionnait dans le courant du XIV ${ }^{\mathrm{e}}$ s. (Fontaine-Hodiamont, Hossey 2010, pl. XIV). L'iconographie confirme l'usage de ces verres « perlés » durant cette même période (Whitehouse 2010, fig. 4, 5). En Allemagne, ce décor se transformera en grosses aspérités et persistera jusqu'à l'époque post médiévale sur des verres de formes diverses.

En revanche, en Provence, on constate que les ateliers du $\mathrm{XIV}^{\mathrm{e}} \mathrm{s}$. ont délaissé ce procédé ornemental puisque ni l'officine de Rougiers active dans le second quart du $\mathrm{XIV}^{\mathrm{e}} \mathrm{s}$, ni celle de Cadrix située à Saint-Maximin-laSainte-Baume et datée du troisième quart du $\mathrm{XIV}^{\mathrm{e}} \mathrm{s}$. (Foy 1988) ne produisent ces décorations. Les deux fragments trouvés lors des fouilles des fours de La Seube à Claret, datés du tout début du XIV ${ }^{\mathrm{e}} \mathrm{s}$. (Lambert 1972, pl. VIII, $\mathrm{n}^{\circ} 7$; id. 1982), ne sont pas suffisants pour prouver une production locale, mais il est fort possible que

22 C'est le cas à Tuscania où furent trouvés, dans le comblement de fosses daté de la fin du $\mathrm{XIV}^{\mathrm{e}}$ s., divers gobelets à gouttes appliquées et étirées: Whitehouse 1987.

23 En 1406 à Murano, parmi plusieurs milliers de verre provenant d'une saisie et mis aux enchères apparaissent ces gobelets « imperlatis » : Zecchin 1987, p. 36. la fabrication de ces gobelets "perlés » se soit poursuivie dans les deux premières décennies du $\mathrm{XIV}^{\mathrm{e}} \mathrm{s}$. On ne peut pour autant penser que tous les verres à gouttes rapportées découverts dans le Midi méditerranéen de la France proviennent forcément des officines régionales ; certains peuvent relever d'importations. On remarque en effet des différences dans le mobilier marseillais. Les pièces soufflées dans un verre fin et décorées de cabochons assez peu saillants sont proches des fabrications de l'atelier de Planier. En revanche, les fragments qui sont dotés de protubérances très étirées rappellent nombre de trouvailles italiennes.

Plus d'une vingtaine de découvertes sont signalées en plusieurs points de Marseille. Ces témoignages modestes ne permettent pas d'avoir une idée de la forme générale de ces verres à boire qu'il faut restituer sur le modèle des trouvailles faites en Languedoc, à Saint-Laurent-le Minier dans le Gard (gobelet à bord largement évasé) et dans le comblement d'un puits montpelliérain (gobelet à bord droit ; Plaisirs et manières de table, p. 185 ; Foy 1995). Ces deux types de gobelets sont également produits et utilisés en Grèce et en Italie, par exemple au château de Lucera, dans les Pouilles (Whitehouse 1966, p. 127-129, fig. 31, reproduit ici fig. 214, A) ou dans l'abbaye de Farfa, dans le Latium (Newby 1987, p. 263 265 ; reproduit ici fig. 214, B).

La plupart des attestations marseillaises sont des débris de parois portant une goutte de verre étirée et parfois vrillée. Les fouilles du quartier Sainte-Barbe ont déjà fourni plusieurs pièces dont la plus précoce (Foy 1997, p. 61, fig. $39, \mathrm{n}^{\circ} 10$ ), se rencontre dès le début du XIII ${ }^{\mathrm{e}} \mathrm{s}$. (Foy 1997, p. 61, fig. 39, n 10 ). L'aspect noirâtre de ce fragment le différencie des autres découvertes. En effet, toutes les autres pièces marseillaises ou plus largement provençales et languedociennes sont fabriquées dans un verre incolore légèrement jaunâtre. Bien conservée cette matière a gardé sa brillance; elle a été probablement élaborée en utilisant des cendres végétales sodiques provenant de salicornes ou autres plantes halophytes comme cela a été démontré pour les productions de l'officine de Planier. Ces verres sodiques, décorés de gouttes étirées, sont présents en Provence dans les contextes de la seconde moitié du XIII' ${ }^{\mathrm{s}}$ s. de l'atelier de Planier, dans deux niveaux du castrum de Rougiers et dans divers sites religieux et d'habitats (castrum de Rougiers, Prieuré de Saint-Symphorien-de-Buoux, synagogue de Carpentras et motte de Cadarache : Mouton 1994). En Languedoc, on les signale à Montpellier, sur l'atelier de verrier de La Seube et à Montségur (Tricoire, Matthieu, 1974, p. 24). À Marseille, ils ont été exhumés, outre du quartier Sainte-Barbe (Foy 1997, p. 61, fig. 39, n 11, 17), dans les chantiers de la place Général-de-Gaulle (fig. 214 et 215, $\mathbf{n}^{\circ}$ 11-16) et de l'Alcazar (fig. 214 et 215, $\mathbf{n}^{\circ} \mathbf{1 - 4}$ ). 


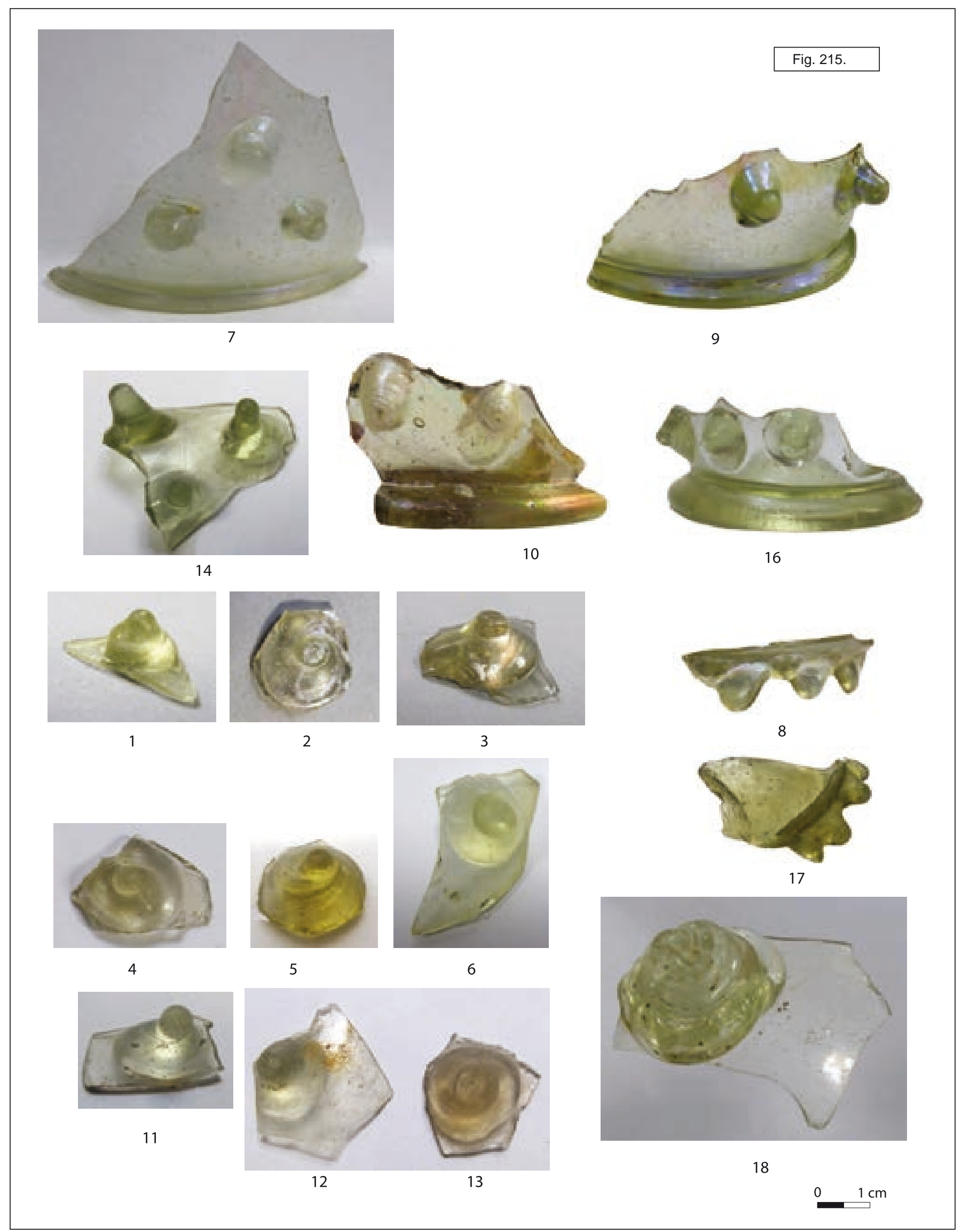


Dans les mêmes contextes se trouvent parfois des éléments de base de gobelet cernées d'un cordon lisse ou dentelé (fig. 214 et 215, $n^{\circ} 8$ et 17). Des cabochons identiques ont été mis au jour lors des excavations de la place Villeneuve-Bargemon réalisées en 2002 (fig. 214 et 215, $\mathbf{n}^{\circ}$ 5-6) et du Tunnel de la Major (fig. 214 et 215, ${ }^{\circ}$ 7). Ce dernier fragment, un des mieux conservés, est la base d'un gobelet dont le pied est constitué d'un filet de verre lisse. Les gouttes étirées, disposées en quinconce, sont préservées sur deux rangs. Les verres extraits des fouilles de 1995 de la place Villeneuve-Bargemon (fig. 214 et 215, $\mathbf{n}^{\circ}$ 9-10) sont également des bases de gobelets à anneau lisse et l'un d'eux (fig. 214 et $\mathbf{2 1 5}, \mathbf{n}^{\circ} \mathbf{1 0}$ ) est dans un niveau contenant des céramiques du $\mathrm{XII}^{\mathrm{e}} \mathrm{s}$. : c'est l'élément le plus précoce qui pourrait laisser penser que ce décor apparaît avant le XIII ${ }^{e}$ s. Cette datation haute n'est pas confirmée par d'autres trouvailles extérieures à Marseille.

Les six exemplaires des fouilles de la place Généralde-Gaulle ont des cabochons peu saillants (fig. 214 et 215, $\left.\mathbf{n}^{\circ} \mathbf{1 1}-12,15\right)$ ou au contraire très étirés. Ces derniers pourraient (?) être des importations italiennes (fig. 214 et $\left.\mathbf{2 1 5}, \mathbf{n}^{\circ} \mathbf{1 3}-14,16\right)$. La qualité du verre verdâtre ou jaunâtre, robuste est remarquable ; la brillance est très bien conservée. À ces fragments, il faut rajouter un pied formé d'un cordon dentelé qui supportait probablement un gobelet à gouttes étirées (fig. 214 et 215, $\mathbf{n}^{\circ} \mathbf{1 7}$ ).

Le chantier de la rue Trinquet a fourni un exemplaire qui présente une pastille inhabituelle par sa taille importante et son façonnement : ce cabochon n'est pas fait par étirement de la matière vitreuse mais par enroulement en colimaçon pyramidal d'un filet de verre (fig. 214 et 215, $\mathbf{n}^{\circ} \mathbf{1 8}$ ). Ce fragment de paroi appartient à une toute autre forme, sans doute plus grande que celle du gobelet.

\subsection{Les verres bicolores de la seconde moitié du XIII' $s$.}

Deux verres colorés dans la masse en bleu cobalt et décorés en surface de filets de verre blanc décrivant des motifs dits « de plume d'oiseau » sont présents dans des niveaux d'occupation clairement datés de la fin du $\mathrm{XIII}^{\mathrm{e}} \mathrm{s}$. ou du début du XIV ${ }^{\mathrm{e}} \mathrm{s}$. des fouilles de l'Alcazar (fig. 216 et 217, $\mathbf{n}^{\circ} \mathbf{1 - 2}$ ). Ces fragments de panse dont un renvoie à une petite bouteille cylindrique, évoquent directement une des productions de l'atelier varois de Planier. Ils sont donc contemporains des gobelets décrits ci-dessus. Ces verres, rarement attestés, sont vraisemblablement des objets semi-luxueux.

Les verriers provençaux utilisaient très peu de colorants. Les données des textes, de l'archéologie et de l'archéométrie nous apprennent pourtant que le cobalt était employé pour obtenir la couleur bleue. Désigné sous le nom de safre, ou de chafarone ${ }^{24}$ dans les sources italiennes, la substance colorante commercialisée était obtenue en mélangeant du minerai de cobalt grillé avec de la silice et parfois un fondant. Ce verre (peut-être à l'état de fritte) contenant une forte proportion de cobalt était vendu sous forme de petites pierres ou de poudre. Onéreux, ce safre, importé d'Allemagne et plus précisément des Monts métallifères, comme le révèlent les analyses chimiques, était utilisé avec parcimonie car son pouvoir colorant était puissant. Les filets de verre bleu qui décorent de nombreuses verreries provençales du courant du $\mathrm{XIV}^{\mathrm{e}} \mathrm{s}$. sont obtenus par un cobalt de même origine (Gratuze et al. 1992).

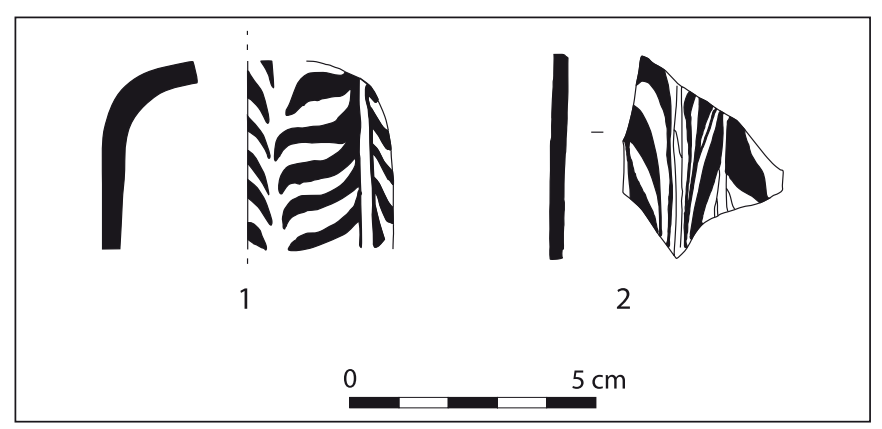

Fig. 216. et Fig. 217. Verres bicolores. Vaisselle bleu cobalt à filets blancs marbrés. Alcazar. (D. Foy/CCJ).

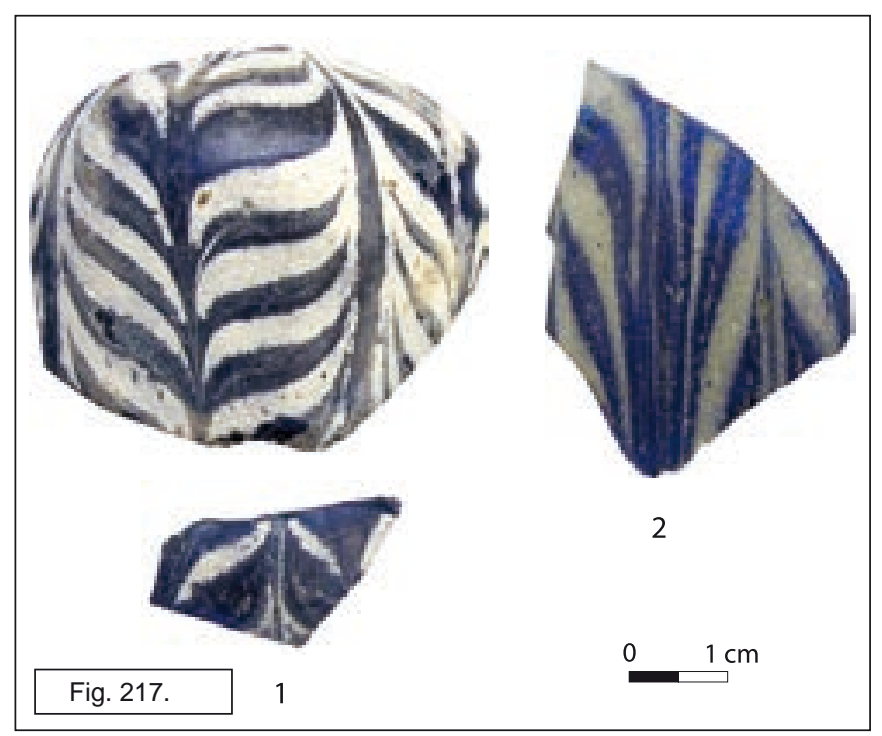

24 Le saffre per colorar veyre est mentionné au début du XIV ${ }^{\mathrm{e}} \mathrm{s}$. à l'entrée d'Avignon, mais son origine n'est pas indiquée : Pansier 1926, À travers le verre, p. 40. Le terme chafarone tantôt assimilé au saffre ou zaffera (Zecchin 1987, vol. 1, p. 108-113) ou bien au saphir (Bienvenu, Lautier, p. 73, note 28) est mentionné dans le traité d'Antoine de Pise, verrier en activité en Italie à la fin du XIV ${ }^{\mathrm{e}} \mathrm{s}$. et au début du siècle suivant; sa provenance allemande est clairement notée : "L'accurro si se fa d'una pietra che se porta de la Magna che à se nome chafarone ». 


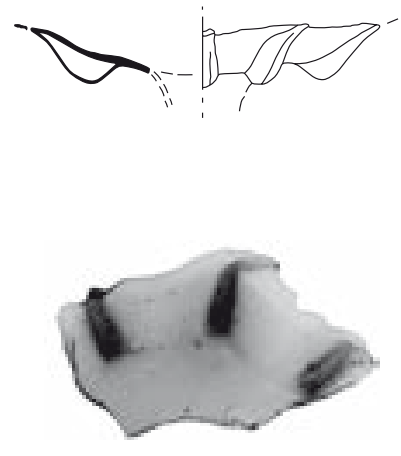

1
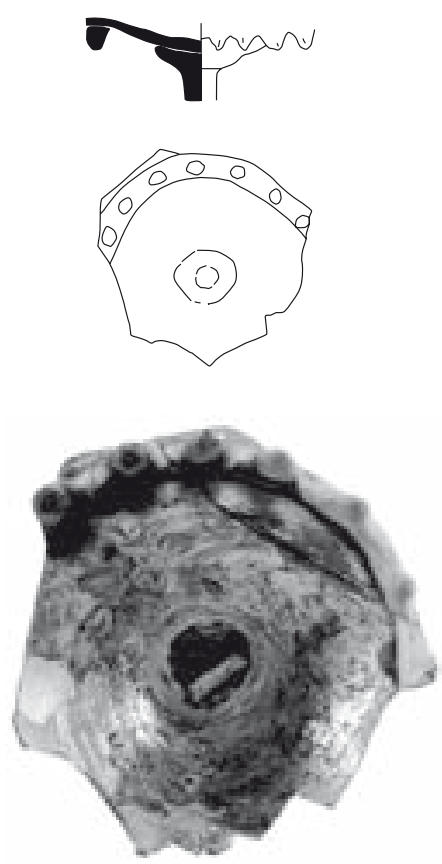

4

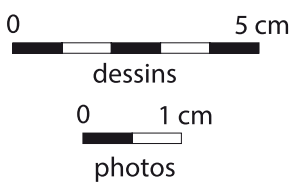

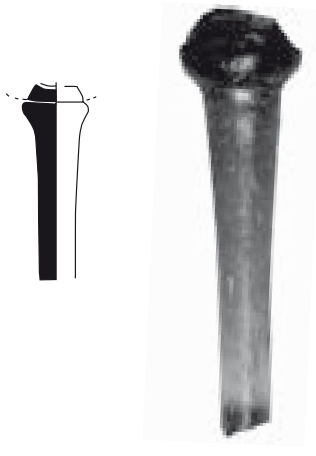

2

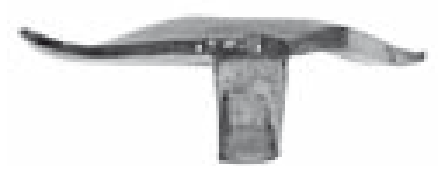

5
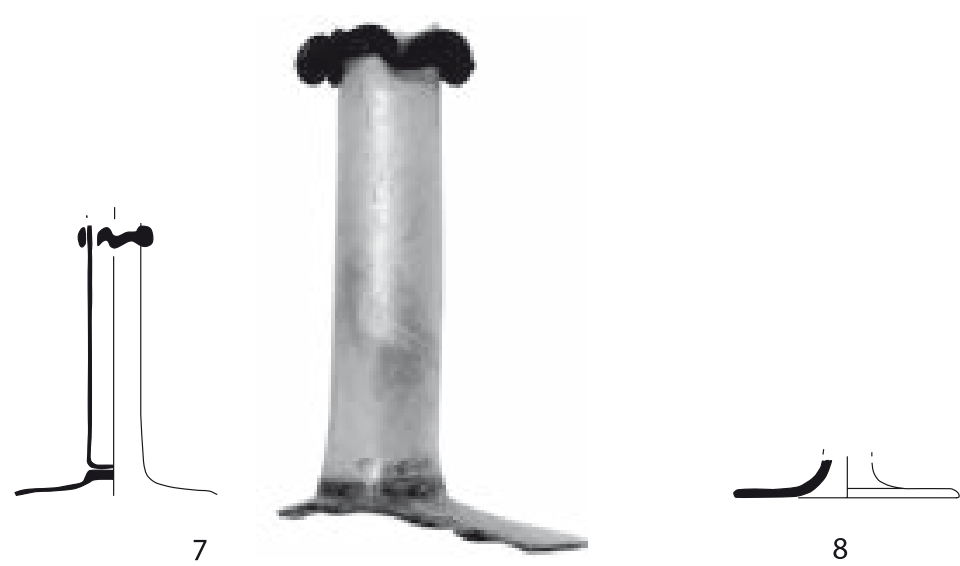

8

Fig. 218. Verres à tige. Fragment d'une coupe côtelée d'un verre à tige, bleu-vert ( $\left.n^{\circ} 1\right)$, tige pleine, bleu-vert ( $\left.n^{\circ} 2\right)$, base de la coupe d'un verre à tige creuse, décor appliqué bleu, verre incolore $\left(n^{\circ} 3\right)$, verre à tige pleine, base de la coupe évasée entourée d'un cordon plissé, verre incolore, très irisé $\left(n^{\circ} 4\right)$, verre à tige pleine, verre verdâtre lumineux $\left(n^{\circ} 5\right)$, verre à tige à coupe très évasée reposant sur un bouton plat, incolore $\left(n^{\circ} 6\right)$, verre à tige creuse entourée d'un cordon plissé bleu $\left(n^{\circ} 7\right)$, fragment d'un pied de verre à tige ? ( $\left.{ }^{\circ} 8\right)$. $1:$ rue Trinquet ; $2-3:$ Alcazar ; 4-6, 8 : place Général-de-Gaulle ; 7 : place Jules-Verne. (D. Foy/CCJ). 


\subsection{Les verres à tige de la fin du $\mathrm{XIII}^{\mathrm{e}}$ et du $\mathrm{XIV}^{\mathrm{e}} \mathrm{s}$.}

Les verres à boire portés par une tige (ou jambe) séparant la coupe du pied, plus élégants que les simples gobelets, sont, à la fin du XIII e s. et au XIV ${ }^{\mathrm{e}}$ s., peu utilisés dans le midi méditerranéen. Quelques éléments de cette forme recueillis dans les fouilles de la place Général-de-Gaulle, de l'Alcazar, de la place Jules-Verne et de la rue Trinquet font apparaître plusieurs modèles incomplètement définis.

- Un verre à tige de teinte bleu-vert (fig. 218, $\left.\mathbf{n}^{\circ} \mathbf{1}\right)$ dont la coupe évasée était ornée de nervures très épaissies à leur base est sans doute à rapprocher de plusieurs pièces à coupe large et basse, découvertes dans diverses régions du territoire français, en particulier à Besançon, en Île de France (À travers le verre 1989, notices 149156), mais aussi en Poitou (Berthon, Zélie 2010, p. 122-125) et en Aquitaine ${ }^{25}$. On ne sait si la tige était creuse ou pleine. Ce verre, qui est peut-être une importation provient du comblement du puits PT2017 de la rue Trinquet, daté de la première moitié ou du milieu $\mathrm{du} \mathrm{XIV}^{\mathrm{e}} \mathrm{s}$. Il était associé à un gobelet et une bouteille, formes habituelles dans le courant du XIV es. La tige rectiligne et massive issue des fouilles de l'Alcazar (fig. 218, $\mathbf{n}^{\circ} \mathbf{2}$ ), également de teinte bleu-vert soutenu, pourrait correspondre au même type de verre, lequel se sépare des nombreux exemplaires avignonnais dotés d'une tige en verre massif, mais fabriqués dans un verre très clair (Foy 1988, p. 205-209).

- Le second verre à tige creuse provient d'un sol du début du $\mathrm{XIV}^{\mathrm{e}} \mathrm{s}$. des fouilles de l'Alcazar; un filet de verre bleu pâle à peine perceptible indique que le verre devait être rehaussé d'une décoration bleue rapportée sur toute la coupe et fondue dans la matière vitreuse incolore (fig. 218, $\mathbf{n}^{\circ} 3$ ).

- Les quatre fragments de la place Général-de-Gaulle révèlent trois autres variantes de verre à tige réalisées dans un verre clair plus ou moins bien conservé. Le cordon festonné à la base d'une coupe supportée par une tige pleine (fig. 218, $\mathbf{n}^{\circ} 4$ ) est une ornementation qui se retrouve sur des types très différents les uns des autres et originaires de diverses régions : l'est de la France et la Rhénanie (À travers le verre 1989, notice 140 ; Cabart 2010, p. 340), la région toulousaine et la Provence. Le fragment marseillais agrémenté de ce feston se différencie du modèle à tige creuse de Toulouse et d'Aix-en-Provence (À travers le verre 1989, notice 167 ; Lagrue 2004, p. 11). Sa matière très irisée contraste avec celle des deux autres pièces incolores et lumineuses. Ces deux derniers exemplaires ne paraissent pas décorés :

25 Fouilles de la place Camille-Jullian à Bordeaux dans des contextes du XIII ${ }^{\mathrm{e}} \mathrm{s}$. ; inédit. l'une est la base tronconique d'une coupe à tige massive (fig. 218, $\mathbf{n}^{\circ} 5$ ) l'autre au profil plus évasé et galbé est séparé de la tige par un anneau plat (fig. 218, $\mathbf{n}^{\circ} \mathbf{6}$ ).

- La tige creuse baguée d'un cordon ondé bleu appartient à un modèle non identifié ; c'est un des rares fragments de verre médiéval des fouilles de la place Jules-Verne (fig. 218, $\mathbf{n}^{\circ}$ 7). Ce décor rappelle celui des goulots des petites fioles côtelées utilisées vers la fin du XIII ${ }^{\mathrm{e}}$ s. (Foy 1988, fig. 96). Un fragment de large pied en forme de disque est le support de ces vaisselles (fig. 218, $\mathbf{n}^{\circ}$ ).

\subsection{Les gobelets}

On ignore quelles étaient les vaisselles de verre les plus communes durant l'époque carolingienne et les $\mathrm{XII}^{\mathrm{e}}$ et $\mathrm{XIII}^{\mathrm{e}} \mathrm{s}$. en Provence. Le simple gobelet cylindrique ou tronconique apparaît dans le courant du $\mathrm{XIII}^{\mathrm{e}} \mathrm{s}$. et sera le verre à boire le plus fréquent durant le $\mathrm{XIV}^{\mathrm{e}} \mathrm{s}$. en Italie comme en France méditerranéenne. Après les fabrications de vases à décor de gouttes rapportées, d'autres verres soufflés à la volée ou, le plus souvent, soufflés dans un moule, sont réalisés dans une matière mince et très claire. D'autres encore reçoivent un décor appliqué de filets de verre bleu couvrant les parois ; ils sont moins fréquents que les pièces moulées qui peuvent recevoir en haut des parois, et en guise de lèvre, un filet bleu appliqué. Nous ignorons tout des moules utilisés par les artisans provençaux. Cependant, l'examen du mobilier assure qu'il s'agit de moule univalve dans lequel le verrier introduisait une ébauche du verre, formée de la paraison (petite masse de verre prélevée du four), régularisée sur le marbre et légèrement soufflée pour avoir une taille convenable. Ce type de moule servait à imprimer les décors gravés sur les parois internes du moule, mais ne conditionnait pas le profil exact ni le gabarit de l'objet. C'était une sorte de pré-moulage : en effet une fois sortis du moule, les verres étaient re soufflés ce qui explique que les motifs décoratifs soient déformés, dilatés ou resserrés, surtout dans la partie haute du verre. Les objets étaient ensuite repris au pontil pour le façonnement final.

Nous distinguerons plusieurs types de gobelets en fonction des décors ; la mauvaise conservation ne permet pas de reconnaître les profils et de séparer les objets en fonction de ce paramètre ; nous savons toutefois que plusieurs gabarits existaient. La hauteur moyenne se situe entre 6 et $10 \mathrm{~cm}$ pour une largeur maximale de 5,5 à $8 \mathrm{~cm}$. Les profils sont cylindriques ou tronconiques, trapus ou plus élancés. Le fond refoulé porte la marque du pontil et le rebord à lèvre arrondi est dans le prolongement des parois. Dans certains cas, un filet bleu rapporté forme la lèvre. 


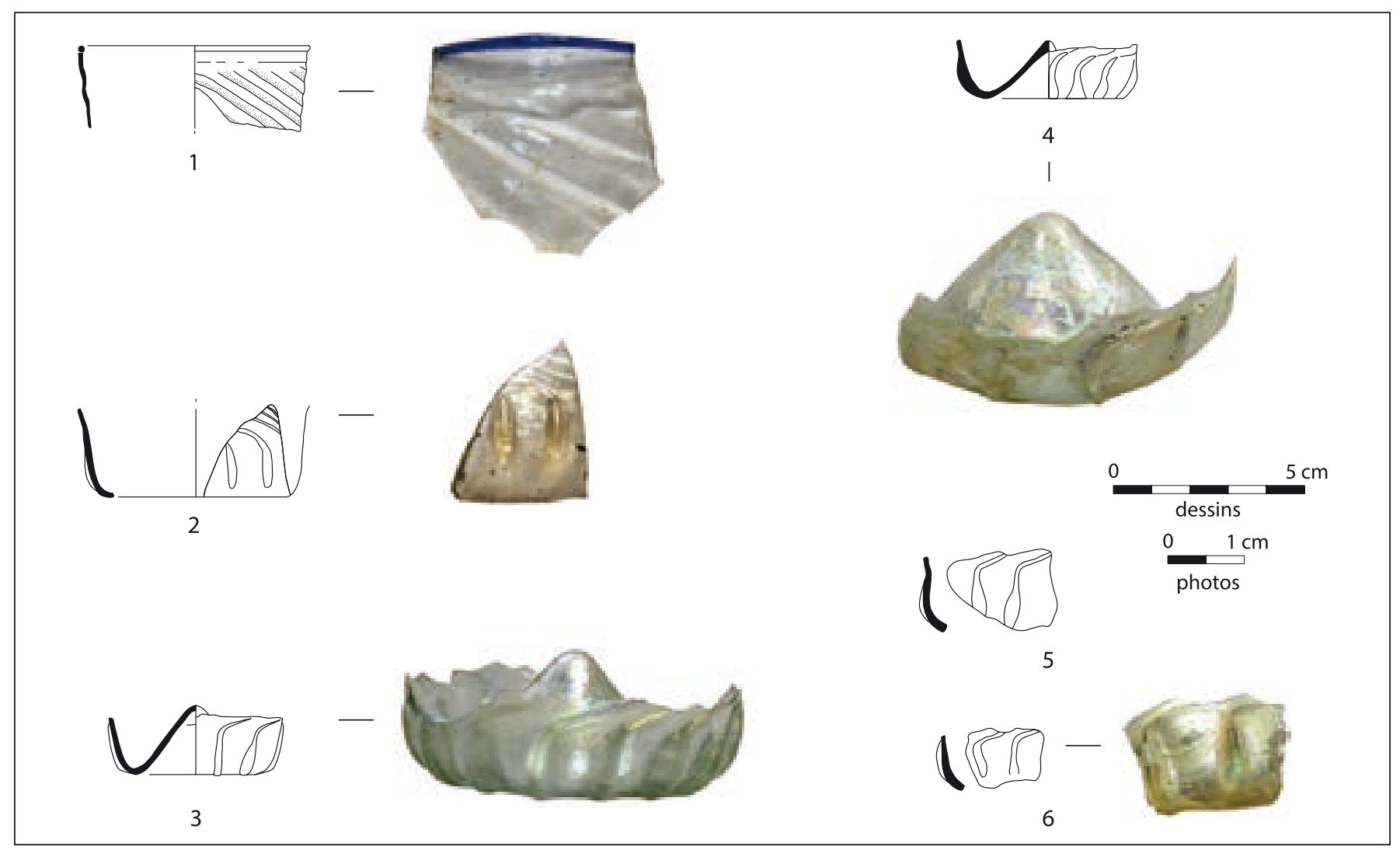

Fig. 219. Gobelet à côtes hélicoïdales. Rebord ( $\left.n^{\circ} 1\right)$, base (n²-6). 1-2 : place Général-de-Gaulle ; 3 : îlot 24N ; 4-6 : Alcazar. (D. Foy/CCJ).

\subsubsection{Gobelets à côtes hélicoïdales épaissies à leur base}

Un petit lot de fonds de gobelets se caractérise par son décor de côtes courtes et en fort relief formant, à leur base, des $\mathrm{S}$ ou des sortes de virgules qui se prolongent par des nervures hélicoïdales très fines qui s'enroulaient sur les parois pour se terminer à quelques millimètres du rebord. Ce type de gobelet, présent sur plusieurs sites provençaux (Foy 1988, fig. 58), est contemporain des verres à gouttes rapportés ou immédiatement postérieur. À Marseille, on le connaît dans les fouilles de Sainte-Barbe (Foy 1997, fig. 39, n²2-23), dans deux contextes de la zone 2 de la place Général-de-Gaulle (fig. 219, $\mathbf{n}^{\circ}$ 1-2), dans l'îlot $24 \mathrm{~N}$ dit îlot des Phocéens (fig. 219, $\mathbf{n}^{\circ} 3$ ) et dans deux contextes de l'Alcazar : les deux fragments de l'unité stratigraphique 4348 (fig. 219, n 5-6) sont dans un niveau de destruction contenant de la céramique et plusieurs verres du premier tiers du $\mathrm{XIV}^{\mathrm{e}} \mathrm{s}$.; l'unité stratigraphique 4520 (fig. 219, $\mathbf{n}^{\circ} \mathbf{4}$ ), où est un troisième fond, contient du mobilier résiduel du début du XIV $\mathrm{X}$. Des gobelets présentant le même aspect sont encore utilisés à la fin du Moyen Âge (À travers le verre 1989, notice 255), mais en Provence ces objets paraissent de bons marqueurs pour la période de transition entre le $\mathrm{XIII}^{\mathrm{e}}$ et le $\mathrm{XIV}^{\mathrm{e}} \mathrm{s}$. Plusieurs découvertes, hors Provence, mais dans le midi méditerranéen, sont signalées (Alessandri 2000, fig. 152, 3).

\subsubsection{Autres gobelets}

$\mathrm{Au}$ cours du $\mathrm{XIV}^{\mathrm{e}} \mathrm{s}$., les motifs imprimés sur les fonds et les parois des gobelets se diversifient. Ce mobilier est fabriqué dans une matière souvent très mince, de teinte légèrement bleutée, verdâtre ou jaunâtre, mais qui paraît assez claire du fait de la minceur du verre. Les nervures verticales fines ou plus épaisses sont visibles à l'Alcazar, sur un fond jaunâtre, relativement épais (fig. 220 et 221, $\mathbf{n}^{\circ} \mathbf{1}$ ) et sur des parois verdâtres (fig. 220 et 221, $\mathbf{n}^{\circ} \mathbf{2}$ ). D'autres décors rayonnants formant des pétales ou un grenetis sous les fonds, se transforment généralement sur les parois en petites pastilles rondes ou en motifs losangés : plusieurs exemplaires ont été collectés dans des contextes de la première moitié du $\mathrm{XIV}^{\mathrm{e}} \mathrm{s}$. à l'Alcazar (fig. 220 et $\mathbf{2 2 1}, \mathbf{n}^{\circ} \mathbf{3 - 5}$ ), mais aussi à sur la place Général-de-Gaulle (fig. 220 et $\mathbf{2 2 1}, \mathbf{n}^{\circ} \mathbf{6}$ 9) et dans le puits PT2017 de la rue Trinquet (fig. 220 et $\mathbf{2 2 1}, \mathbf{n}^{\circ} \mathbf{1 0}$ ). Les gobelets non décorés sont également observés à l'Alcazar (fig. 221, $\mathbf{n}^{\circ} \mathbf{1 2}$ ) et dans un bel assemblage de la première moitié $\mathrm{du}^{\mathrm{XIV}} \mathrm{s}$. à la place 


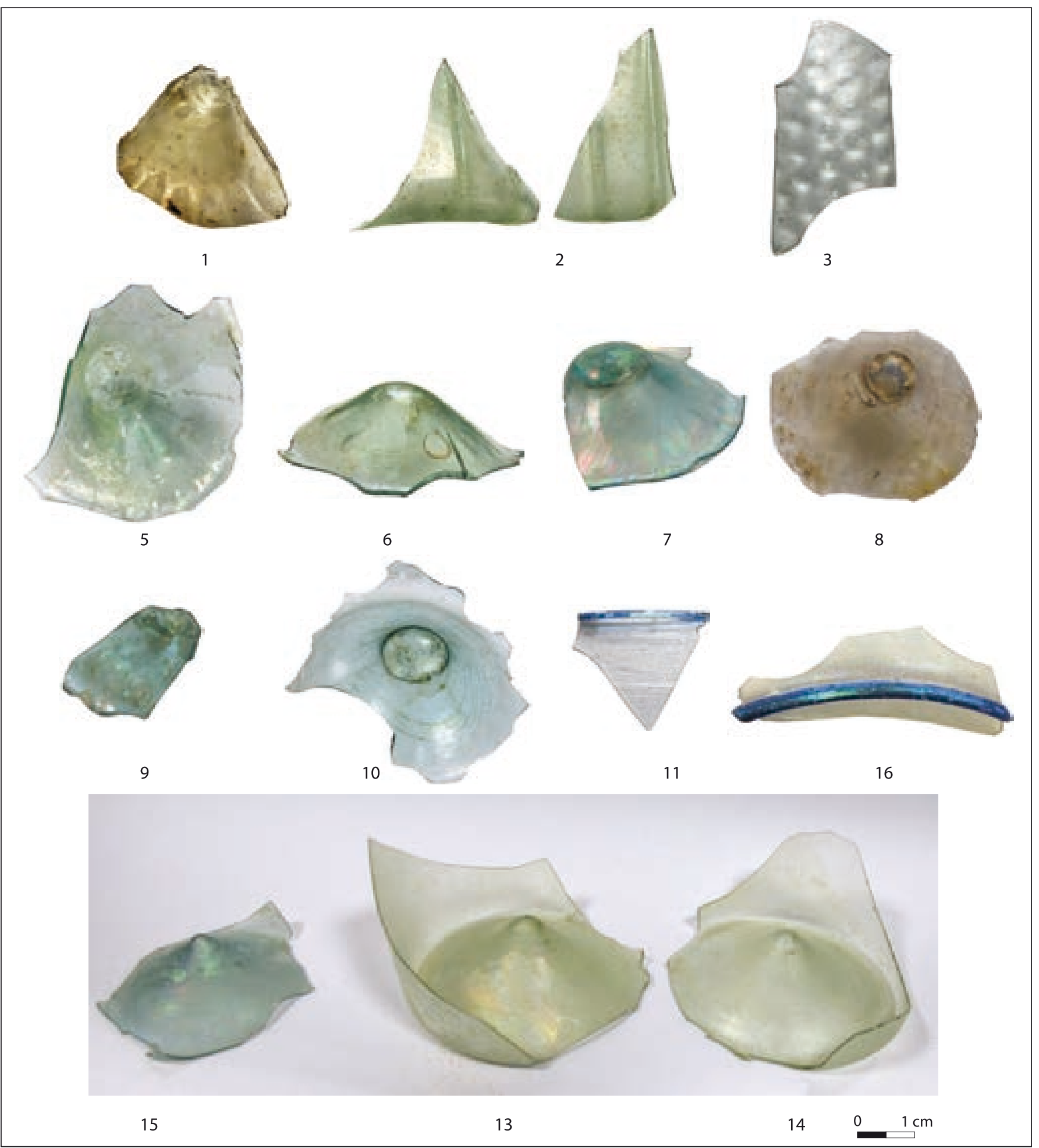

Fig. 220. (ci-dessus) et Fig. 221. (page suivante) Gobelets. Fond de gobelet jaunâtre, soufflé dans un moule, décor de nervures verticales ( $\left.{ }^{\circ} 1\right)$, paroi de gobelet verdâtre, soufflé dans un moule, décor de nervures verticales $\left(n^{\circ} 2\right)$, paroi de gobelet incolore, soufflé dans un moule, décor de pastilles rondes ( $\left.n^{\circ} 3-4\right)$, fond de gobelet verdâtre, soufflé dans un moule, décor rayonnant de pétales puis de grenetis $\left(n^{\circ} 5\right)$, fond de gobelet verdâtre, soufflé dans un moule, décor rayonnant de pétales $\left(n^{\circ} 6\right)$, fond de gobelet bleuté, soufflé dans un moule, décor de grenetis en cercle $\left(n^{\circ} 7\right)$, fond de gobelets respectivement incolore et bleuté, soufflés dans un moule, décor rayonnant de nervures fines et grenetis en cercles concentriques ( $n^{\circ} 8-9$ ), fond de gobelet verdâtre, soufflé dans un moule, décor rayonnant de pétales sous le fond et de petites pastilles rondes sur les parois ( $\left.\mathrm{n}^{\circ} 10\right)$, rebord de gobelet incolore, lèvre formée d'un filet bleu appliqué $\left(n^{\circ} 11\right)$, fond et rebord de gobelets verdâtres, non décoré $\left(n^{\circ} 12-14\right)$, fond bleuté d'un gobelet non décoré $\left(n^{\circ} 15\right)$, base d'un gobelet formé d'un cordon bleu (n¹6). 1-5, 11-12 : Alcazar ; 6-9 : place Général-de-Gaulle ; 10 : rue Trinquet ; 13-15 : place Villeneuve-Bargemon ; 16 : Tunnel de la Major. (D. Foy/CCJ). 


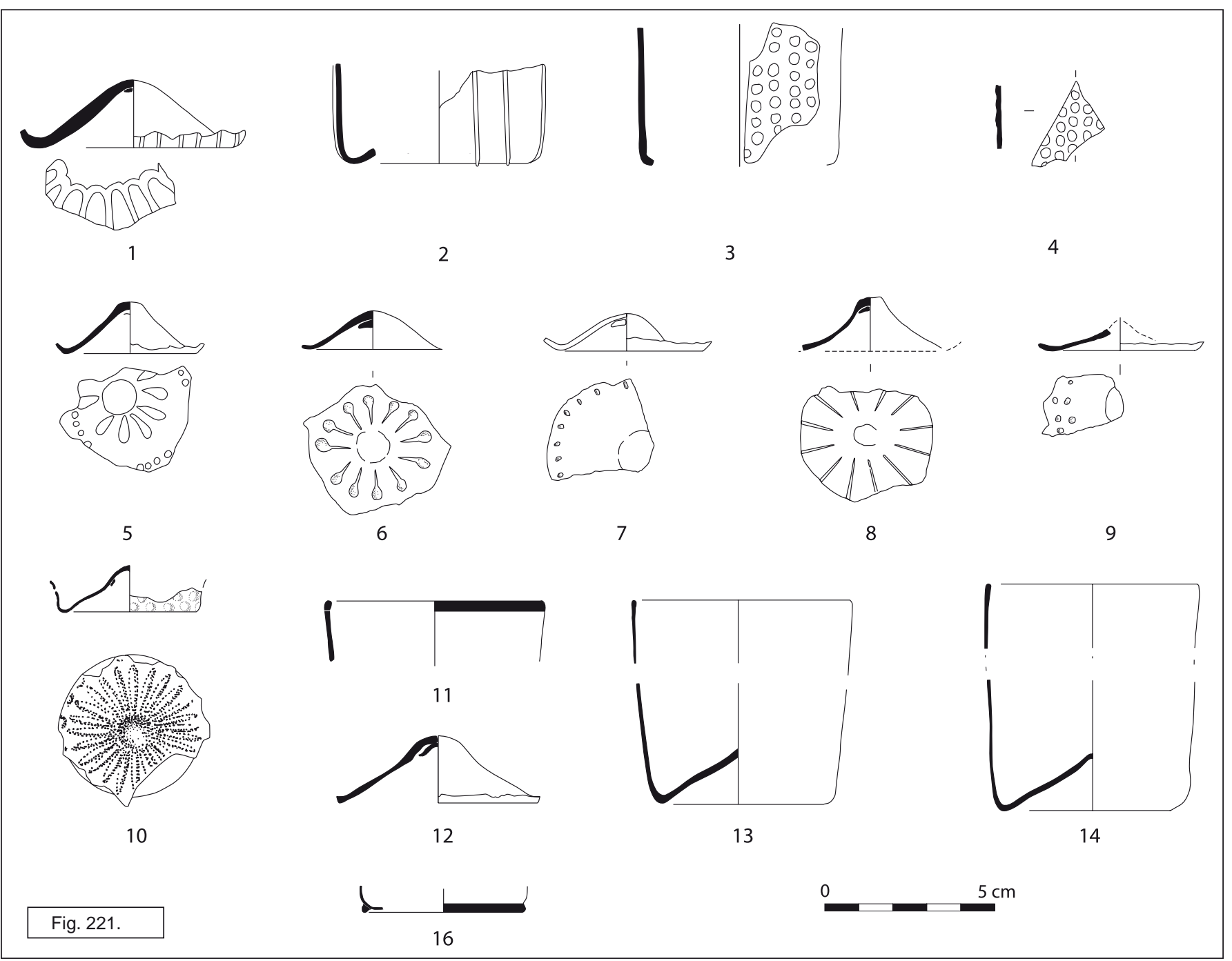

Villeneuve-Bargemon (fig. 220 et 221, $\mathbf{n}^{\circ}$ 13-15). Un fond, provenant du Tunnel de la Major, est entouré d'un filet bleu : il appartient à un gobelet ou à une coupelle (fig. 220 et 221, $\mathbf{n}^{\circ} 16$ ).

\subsection{Les guttrolfs}

On désigne par guttrolf plusieurs récipients : les plus anciens dont le corps comprend deux parties reliées par plusieurs canaux souvent torsadés font partie du répertoire de la verrerie mérovingienne. Les guttrolfs médiévaux sont des flacons pansus, sortes d'ampoules, dotés d'un goulot divisé en plusieurs canaux. La panse n'est pas forcément partagée en deux contenants comme c'est le cas pour les huiliers-vinaigriers modernes. Le goulot des guttrolfs médiévaux est souvent composé de deux ou plusieurs tubes séparés qui se rejoignent dans la partie supérieure pour ne former qu'une seule embouchure. Ces contenants sont connus dans plusieurs régions : dans les pays germaniques, ils sont essentiellement datés de la fin du XIV et $\mathrm{XV}^{\mathrm{e}} \mathrm{s}$. (Baumgartner, Krueger 1988, p. 320-325), dans l'atelier d'Herbeumont au Luxembourg (Fontaine-Hodiamont, Hossey, fig. 23 et pl. IV-12), probablement en activité dans le courant du $\mathrm{XIV}^{\mathrm{e}}$ s., un exemplaire est signalé sans que l'on puisse dire s'il fait partie des fabrications locales; d'autres pièces sont mentionnées en Île-de-France et Périgord. Les découvertes provençales, relativement nombreuses dans les contextes d'habitats et d'ateliers (Foy 1988, p. 240-241) sont considérées comme des produits des officines régionales du $\mathrm{XIV}^{\mathrm{e}} \mathrm{s}$., mais les trouvailles signalées de longue date dans les nécropoles de la région bordelaise laissent penser que ces flacons, simples ampoules sphériques emmanchées d'un goulot simple ou double et torsadé, étaient déjà en usage au cours du $\mathrm{XII}^{\mathrm{e}}$ ou du XIII ${ }^{\mathrm{e}}$ s. (Marysse 1986).

Utilisés pour boire ou pour verser très lentement, voire goutte à goutte (d'où le nom dérivant du latin 


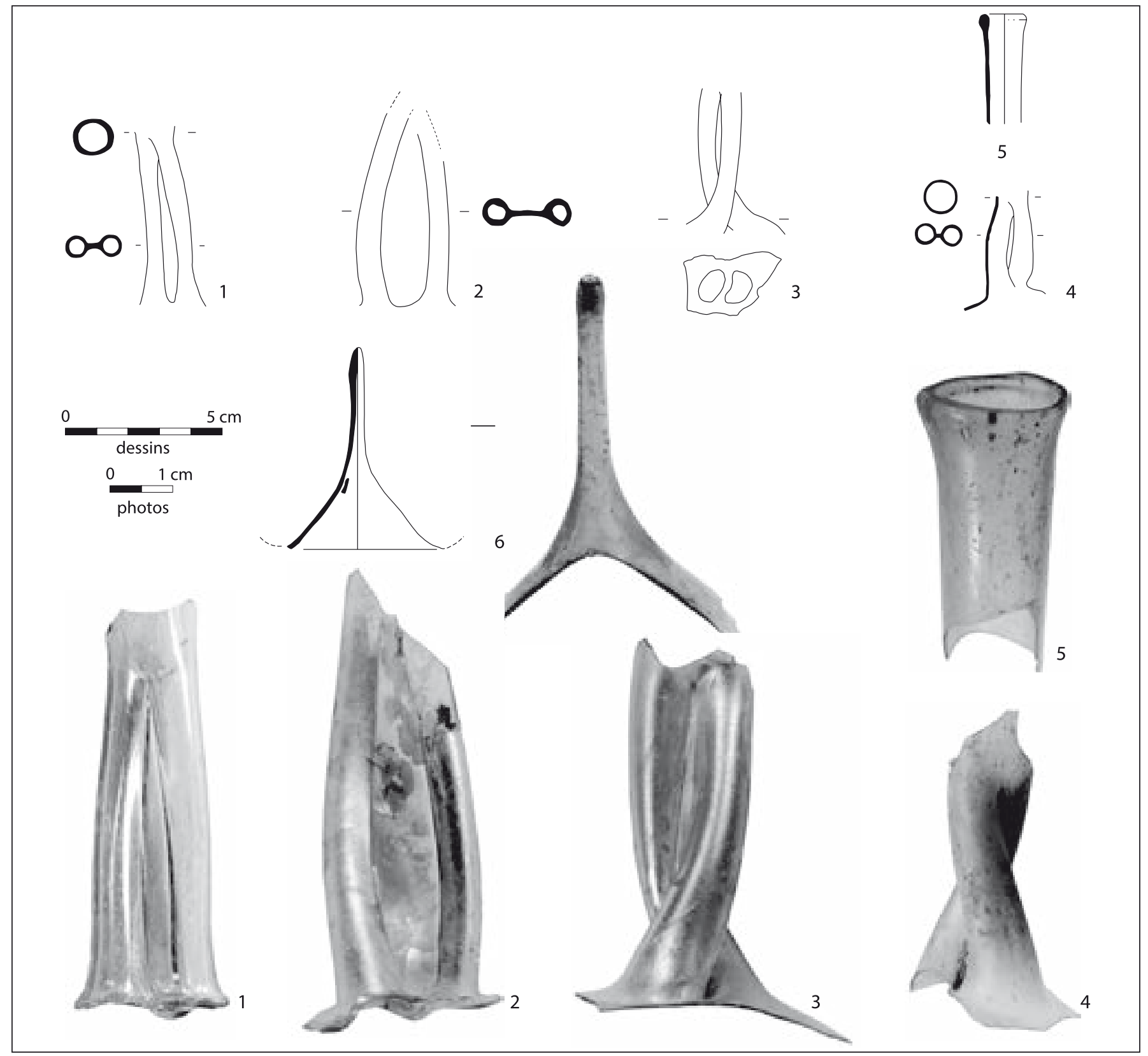

Fig. 222. Guttrolfs. goulot à deux canaux, verre jaunâtre bien conservé $\left(n^{\circ} 1\right)$, goulot à deux canaux, verre incolore légèrement jaunâtre, irisé $\left(n^{\circ} 2\right)$, goulot à deux canaux, verre incolore légèrement verdâtre, irisé $\left(n^{\circ} 3\right)$, goulot à deux canaux, verre incolore, jaunâtre, terne $\left(n^{\circ} 4\right)$, embouchure d'un goulot verdâtre et fond verdâtre $\left(n^{\circ} 5\right)$, base d'un guttrolf ( $\left.n^{\circ} 6\right)$. 1 : Alcazar ; 2-3 : place Général-de-Gaulle ; 4-6 : place Villeneuve-Bargemon. (D. Foy/CCJ).

gutta, goutte ou très petite quantité) ces flacons-guttrolfs sont, comme le suggèrent les trouvailles fréquentes, des objets relativement communs, faisant partie du mobilier du service de table, mais on pourrait aussi imaginer qu'ils servent pour garnir les luminaires d'huile. Ils apparaissent dans les sources écrites provençales sous le nom de cotofle ou cotifle (Foy 1988, p. 240).

À Marseille, quatre éléments de goulot sont apparus dans des contextes datés de la fin du XIII e et du $\mathrm{XIV}^{\mathrm{e}} \mathrm{s}$. Nous en connaissons un à l'Alcazar dans un niveau d'occupation contenant du mobilier de la fin du
XIII ${ }^{\mathrm{e}}$ s. (fig. 222, $\mathbf{n}^{\circ} \mathbf{1}$ ), deux autres dans les fouilles de la place Général-de-Gaulle (fig. 222, $\mathbf{n}^{\circ} \mathbf{2 - 3}$ ) et un dernier à Villeneuve-Bargemon (fig. 222, $\mathbf{n}^{\circ}$ 4), dans un bel assemblage de céramiques et de verres que nous pouvons dater de la première moitié du $\mathrm{XIV}^{\mathrm{e}} \mathrm{s}$. Dans ce contexte se trouvent à la fois un goulot formé de deux canaux entrelacés, un goulot avec embouchure (fig. 222, $\mathbf{n}^{\circ}$ 5) qui pourrait être la partie supérieure d'un guttrolf ainsi qu'un fond à culot rentrant et effilé (fig. 222, $\mathbf{n}^{\circ} \mathbf{6}$ ). Bien que découverts dans un même niveau, ces éléments peuvent appartenir à des pièces différentes. 


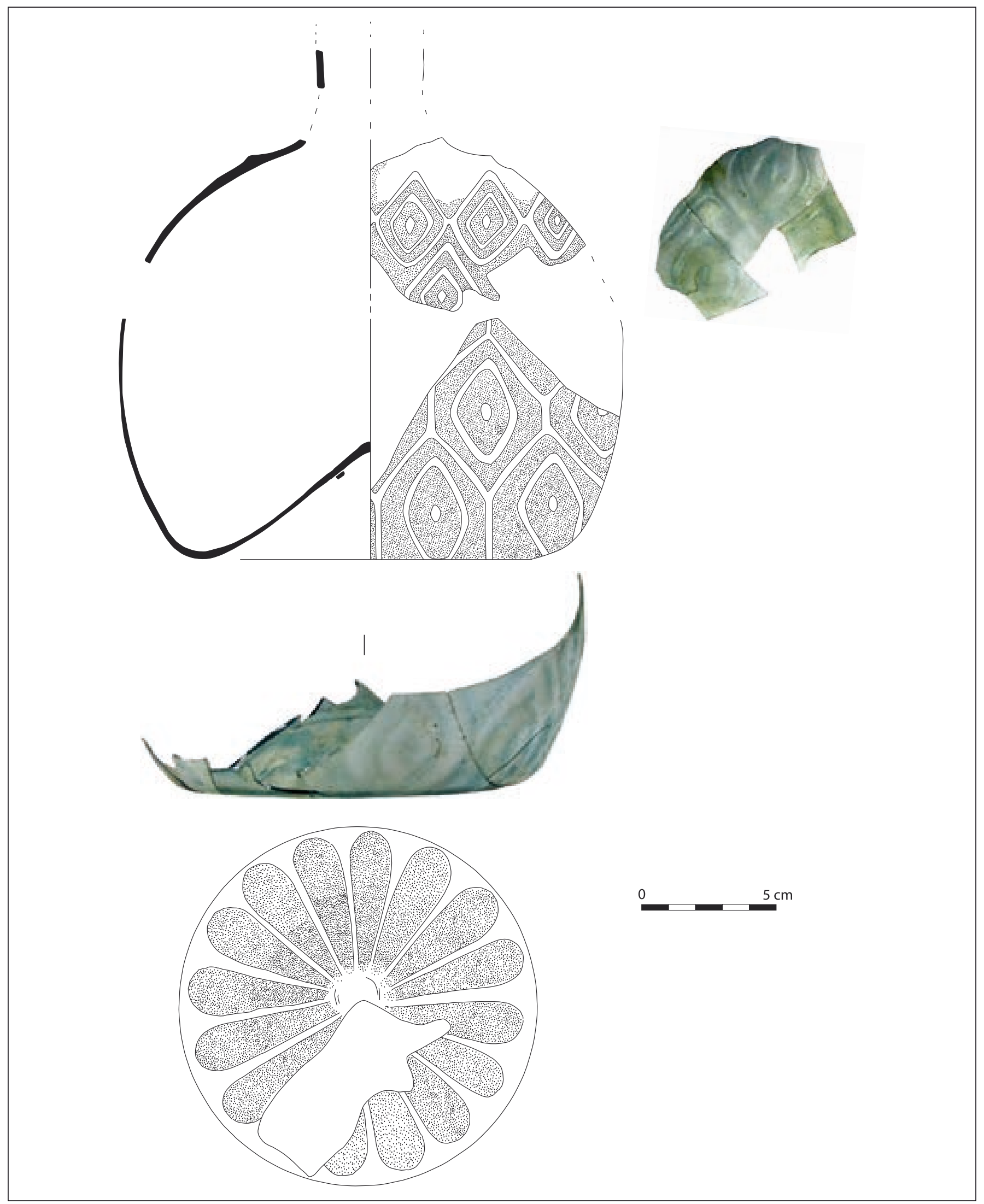

Fig. 223. Bouteille soufflée dans un moule. Fond, panse et épaulement d'une bouteille. Décor moulé en creux : sous le fond rosace à 16 pétales ; sur la panse résille composée de grands motifs hexagonaux renfermant un ovale pointé. Sur l'épaulement, ces motifs se rétrécissent. Tout autour se développe un décor de grands motifs hexagonaux renfermant un ovale pointé qui couvre la panse. Place Villeneuve-Bargemon. (D. Foy/CCJ). 


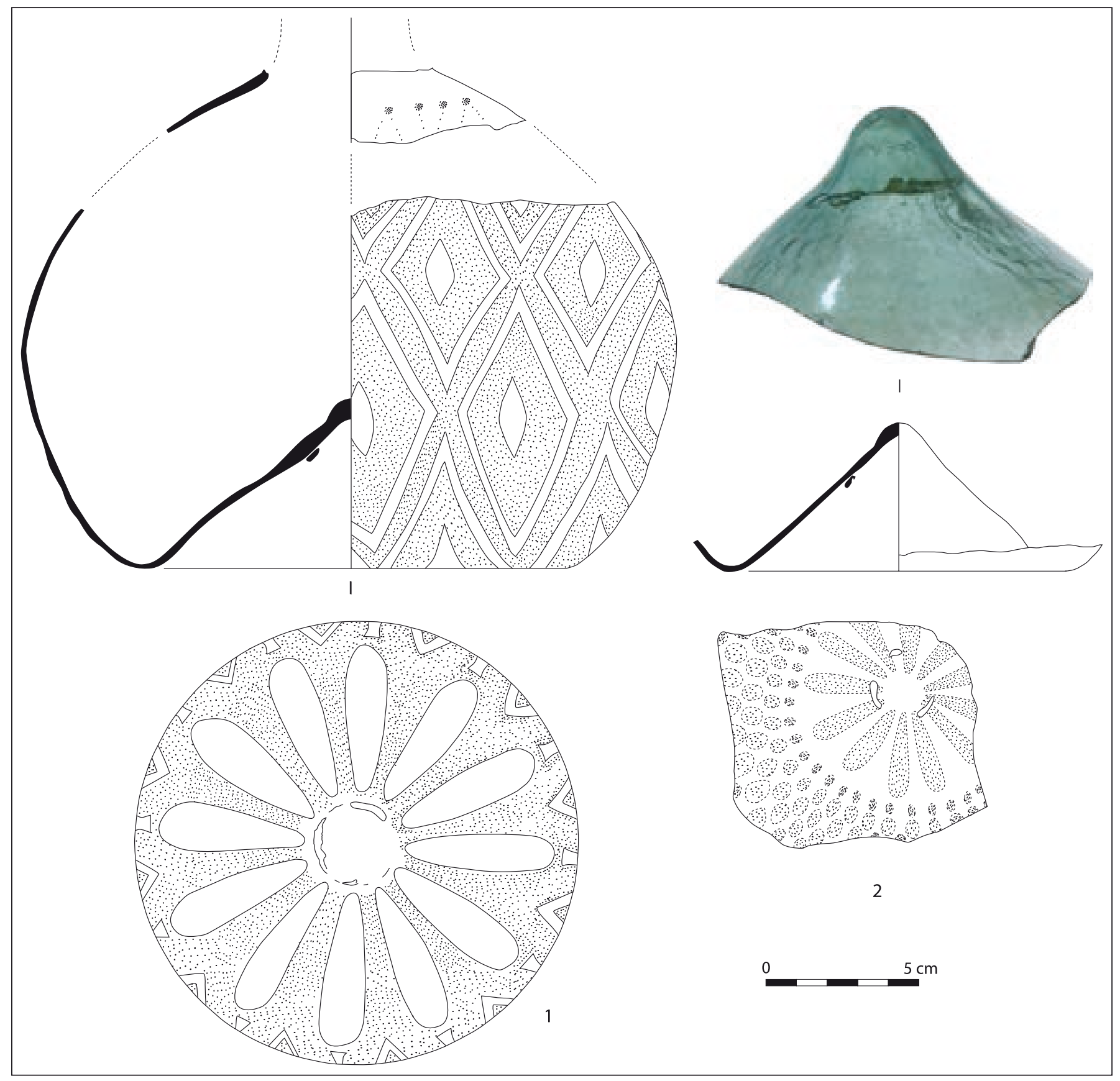

Fig. 224. (ci-dessus) et 225. (page suivante) Bouteilles soufflées dans un moule. Fond, panse et épaulement et fragment de goulot d'une bouteille, décor moulé : sous le fond rosace à 12 pétales en relief ; sur la panse treillis de grands losanges emboîtés ; sur l'épaulement : pointillés. Verre bleu-vert, lumineux $\left(n^{\circ} 1\right)$, fond bleu-vert soufflé dans un moule : décor en creux d'une rosace à 12 pétales entourée de petites pastilles rondes disposées en cercles concentriques. La marque du pontil couvre le décor $\left(n^{\circ} 2\right)$. Place Villeneuve-Bargemon. (D. Foy/CCJ).

\subsection{Les bouteilles soufflées dans un moule}

Le récipient en verre qui semble le plus usité en Provence et Languedoc méditerranéen, durant tout le $\mathrm{XIV}^{\mathrm{e}} \mathrm{s}$, , est une bouteille à panse grossièrement sphérique, sans anse et au goulot cylindrique (fig. 223 à 227). Fabriqués dans un verre bleu-vert non décoloré et relativement robuste, ces vases étaient soufflés dans un moule qui a imprimé un décor du fond jusqu'à l'épaulement de la pièce. Le goulot est très souvent agrémenté d'une bague ou de multiples bagues de verre formées en enroulant un cordon de verre laissé lisse ou bien incisé à l'outil pour apparaître godronné. Ces récipients que l'on connaît également en Ligurie (Fossati, Mannoni 1975) en Catalogne (Mach, à paraître) et à Majorque (Capellà Galmès 2002, p. 38-39 et notice 14) sont fabriqués dans 

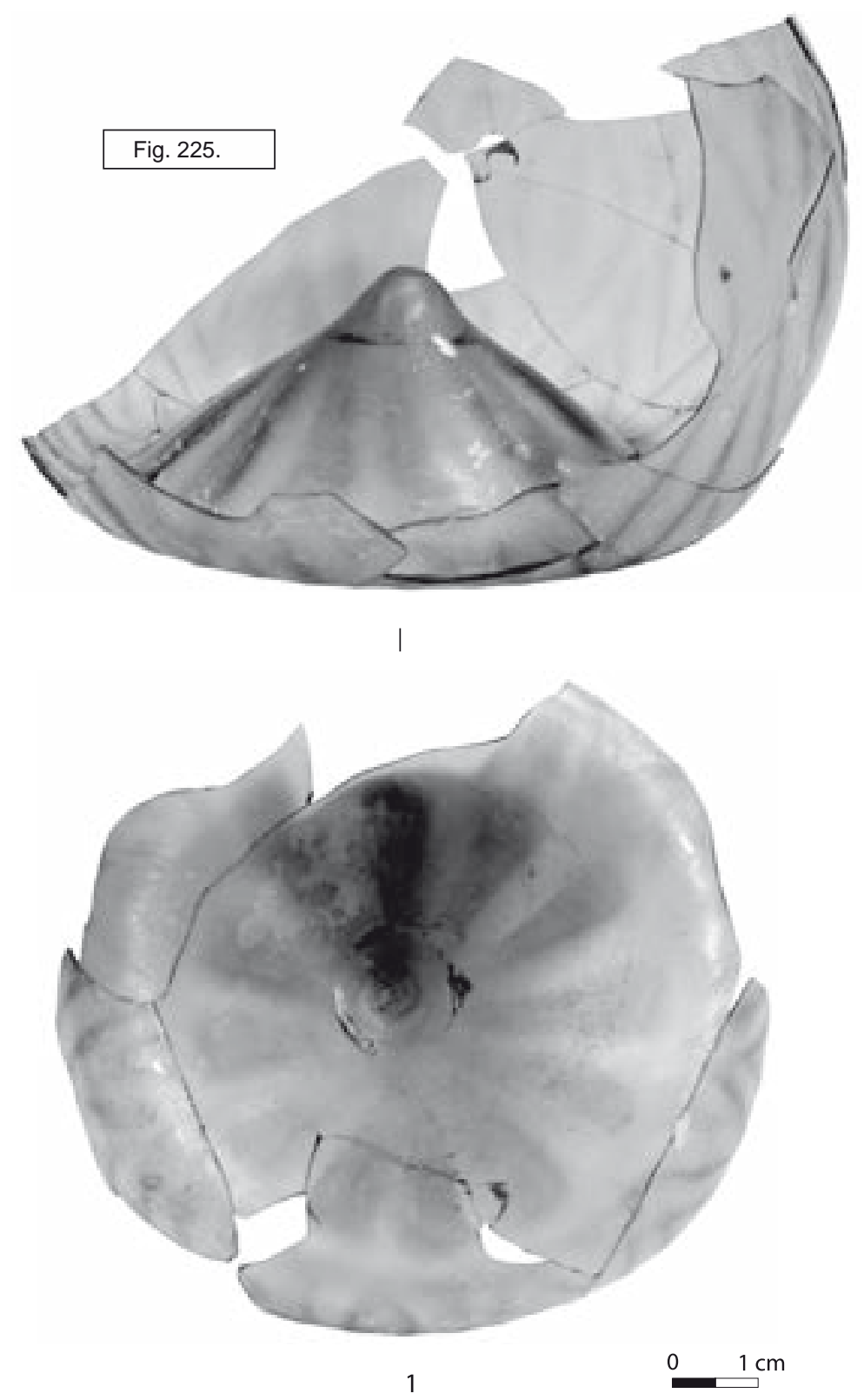

des gabarits divers ; nous proposons de voir en eux les «amphores » à mesurer et servir le vin mentionnées dans les textes provençaux (cf. note 21, p. 259), bien qu'ils ne soient pas dotés d'anse. Les modèles les plus réduits, tels ceux que nous connaissons par plusieurs découvertes nîmoises, n'excèdent pas une quinzaine de centimètres de hauteur ; d'autres atteignaient vraisemblablement 35 à $40 \mathrm{~cm}$. Aucune pièce de grand gabarit ne nous est parvenue complète, mais les goulots retrouvés dans les fouilles urbaines d'Avignon et à Marseille laissent imaginer des contenants de grande capacité (Foy 1988, p. 241-250).

Ces bouteilles qui apparaissent probablement à la fin $\mathrm{du} \mathrm{XIII}^{\mathrm{e}} \mathrm{s}$. semblent toujours utilisées au $\mathrm{XV}^{\mathrm{e}}$ comme en témoignent plusieurs trouvailles italiennes. Les décors sont invariablement des rosaces imprimées sous les fonds, mais sur les panses et jusqu'à l'épaulement, les résilles sont formées de motifs plus variés. Les plus fréquentes sont composées de cellules hexagonales qui se dilatent dans la partie supérieure en ovales ; les treillis de losanges et les cannelures sont plus rares. Les deux bouteilles de grand format provenant de la place Villeneuve-Bargemon (fig. 223 fig. 224, $n^{\circ} 1$ et 225) offrent un décor jusqu'ici non observé de très grands motifs de losanges ou de figures hexagonales emboîtés. Douze pièces au minimum sont comptabilisées dans les fouilles marseillaises, toujours dans des contextes du début du XIV ${ }^{\mathrm{e}} \mathrm{s}$. La moitié a été exhumée des fouilles de la place Villeneuve-Bargemon. Ces vases sont plusieurs fois découverts associés par deux ou trois (fig. 223 à 226 et fig. 227, $\mathbf{n}^{\circ} \mathbf{1}$ ) ; un fond au décor caractéristique fait partie du comblement du puits PT2017 de la rue Trinquet (fig. 227, $\mathbf{n}^{\circ} \mathbf{6}$ ) ; trois pièces au moins sont dénombrées sur le chantier de la place Général-de-Gaulle par un goulot (fig. 227, $\mathbf{n}^{\circ} \mathbf{3}$ ) et deux fonds (fig. 227, $\mathbf{n}^{\circ} \mathbf{4}-\mathbf{5}$ ) venant de contextes différents; un second goulot et un fond non décorés pourraient également appartenir à un gros contenant, mais nous ne pouvons pas assurer qu'il s'agit d'une forme identique (fig. 227, $\mathbf{n}^{\circ} \mathbf{9 - 1 0}$ ). En revanche, un goulot à double bague du chantier de l'Alcazar identifie une bouteille probablement décorée par soufflage dans un moule (fig. 227, $\mathbf{n}^{\circ}$ 2). Deux autres pièces proviennent de la place Jules-Verne : un col à double bague godronnée attenant à un épaulement signale une bouteille probablement de très grand gabarit (fig. 227, $\mathbf{n}^{\circ}$ 7). Des fragments d'un fond orné d'une rosace à 12 pétales en creux, très altérés identifient peut-être un second récipient (fig. 227, ${ }^{\circ} \mathbf{8}$ ).

\subsection{Autres flacons}

Quelques rares éléments signalent des contenants ne formant pas de série. Deux goulots en verre incolore parfaitement transparent sont bagués : l'un provenant de la rue Leca, dans un niveau de surface, est cerclé d'un double filet bleu cobalt; la qualité du verre et le décor renvoient probablement à une vaisselle du $\mathrm{XIV}^{\mathrm{e}} \mathrm{s}$. (fig. 228, $\mathbf{n}^{\circ} \mathbf{1}$ ); le second, place Villeneuve-Bargemon, dans le contexte du début du $\mathrm{XIV}^{\mathrm{e}} \mathrm{s}$. dans lequel sont associés plusieurs verres (fig. $\mathbf{2 2 8}, \mathbf{n}^{\circ} \mathbf{2}$ ) porte un large cordon festonné de teinte sombre, probablement bleu foncé, veiné de rouge, couleur traduisant le cuivre. En verre incolore verdâtre relativement robuste et bien conservé (fig. 228, $\mathbf{n}^{\circ} \mathbf{3}$ ), un goulot à bord légèrement évasé peut être daté du XIV ${ }^{\mathrm{e}} \mathrm{s}$. car il a été trouvé associé au fond moulé de la fig. $227, n^{\circ} 4$. 


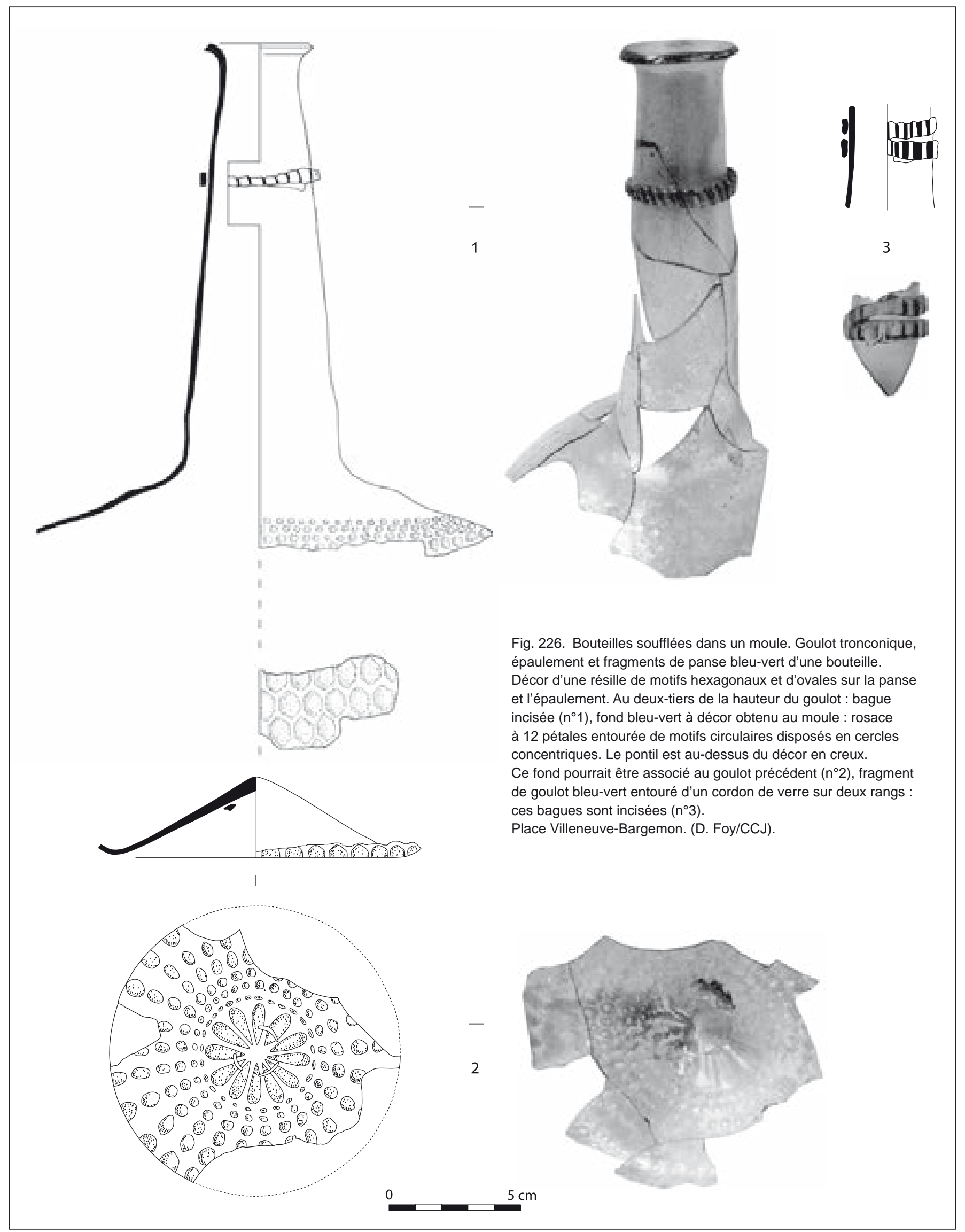




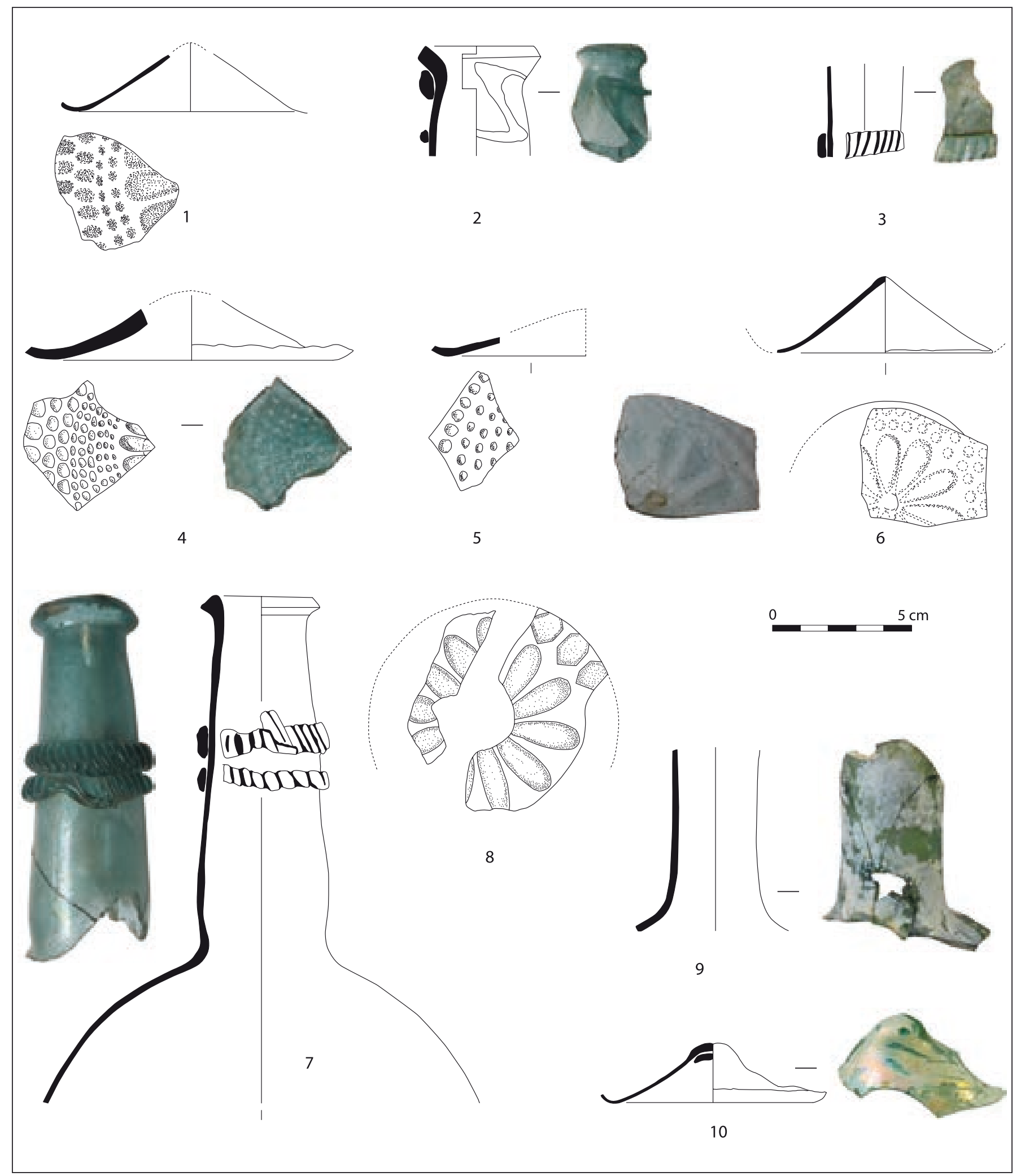

Fig. 227. Bouteilles soufflées dans un moule. Fond bleu-vert soufflé dans un moule, décor en creux d'une rosace entourée de petites pastilles rondes disposées en cercles concentriques ( $\left.n^{\circ} 1\right)$, goulot à décor rapporté, filet de verre rapporté en zig-zag ou bien filet formant une double bague dont on voit ici le raccord d'un rang à l'autre $\left(n^{\circ} 2\right)$, goulot à décor rapporté, bague incisée ( $\left.n^{\circ} 3\right)$, fond à décor moulé, rosace entourée de pastilles en cercles concentriques $\left(n^{\circ} 4,6\right)$, fragment de fond à décor moulé, pastilles en cercles concentriques $\left(n^{\circ} 5\right)$, goulot à double bague rapporté, épaulement d'une bouteille probablement soufflée dans un moule $\left(n^{\circ} 7\right)$, fragments d'un fond à décor moulé, rosace $\left(n^{\circ} 8\right)$, goulot et fond non décorés ( $\left.n^{\circ} 9-10\right)$. 1 : place Villeneuve-Bargemon ; 2 : Alcazar ; 3-5, 9-10 : place Général-de-Gaulle ; 6 : rue Trinquet ; 7-8 : place Jules-Verne. (D. Foy/CCJ). 


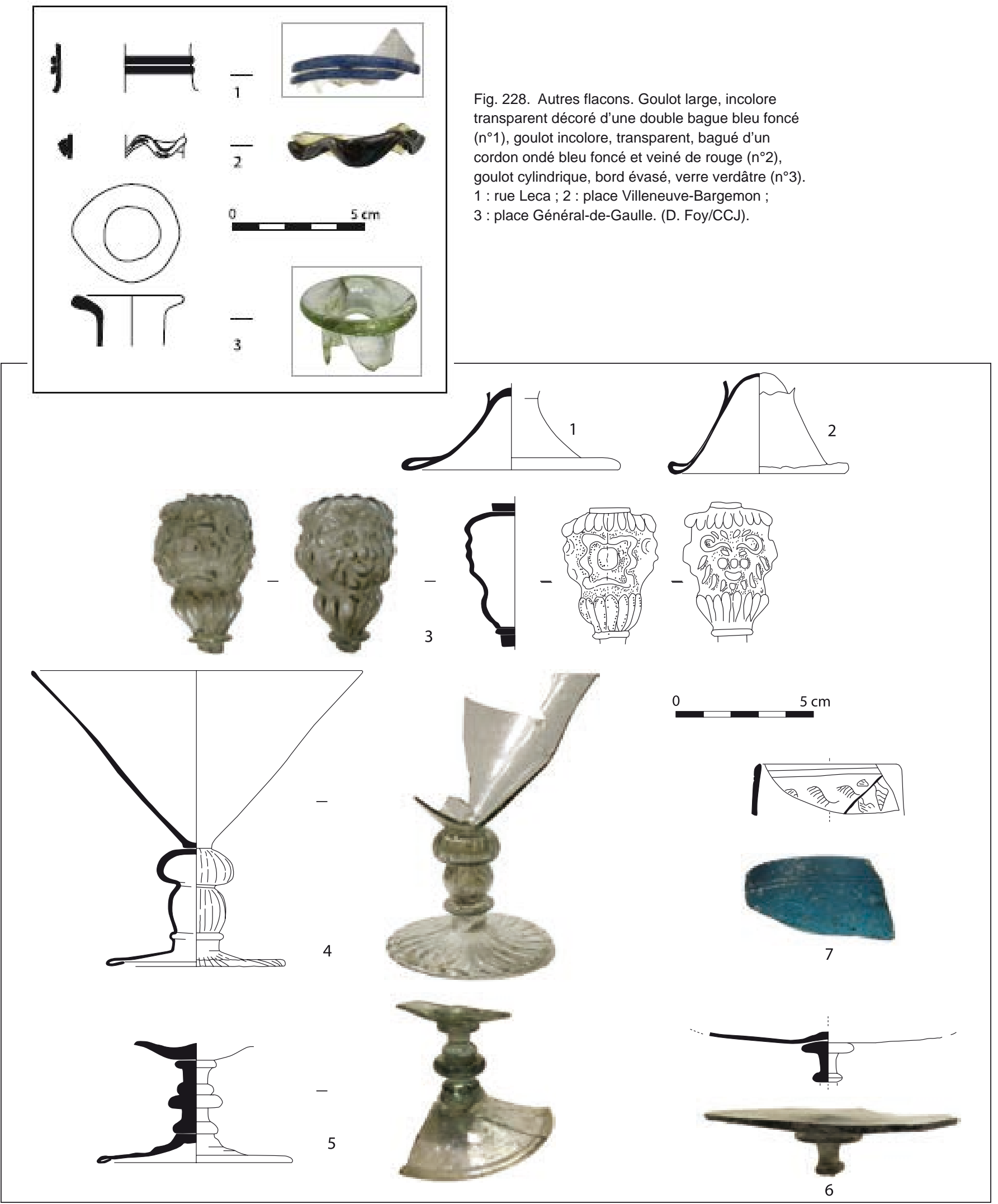

Fig. 229. Verres de la fin du XVe s. et de l'époque Moderne. Pied tronconique refoulé, incolore, irisé $\left(n^{\circ} 1\right)$, pied tronconique refoulé, grisâtre ( $\left.n^{\circ} 2\right)$, jambe incolore soufflée dans un moule portant deux motifs décoratifs alternant avec deux mufles de lion ; la suture du moule passe sur les motifs décoratifs $\left(n^{\circ} 3\right)$, verre conique à jambe soufflée dans un moule $\left(n^{\circ} 4\right)$, jambes pleines et moulées de verres à large coupe $\left(n^{\circ} 5-6\right)$, rebord vert émeraude à décor incisé, probablement XVII ${ }^{\text {S. }}\left(n^{\circ} 7\right)$. 1-2 : place Général-de-Gaulle ; 3 : place Villeneuve-Bargemon ; 4-6 : place Jules-Verne ; 7 : rue Leca. (D. Foy/CCJ). 


\section{Les verres de la fin du Moyen Âge et de l'Époque moderne}

Le mobilier des derniers temps du Moyen Âge est quasiment absent des chantiers de fouilles de Marseille étudiés : seuls quelques fonds tronconiques sont révélateurs de la vaisselle de table de la fin du $\mathrm{XV}^{\mathrm{e}} \mathrm{s}$. ou du $\mathrm{XVI}^{\mathrm{e}} \mathrm{s}$. Deux pièces provenant de deux contextes de la place Général-de-Gaulle ont été sélectionnées (fig. 229, $\mathrm{n}^{\circ}$ 1-2).

Les verres d'Époque moderne, relativement peu nombreux, n'ont pas été étudiés dans leur totalité. Seules, quelques pièces décorées ont retenu notre attention; elles témoignent de l'uniformité de la vaisselle luxueuse dite « façon de Venise » qui se développe à partir du XVI ${ }^{\mathrm{e}} \mathrm{s}$. Quatre pièces appartenant à cette série sont présentées.

- Une jambe soufflée dans un moule est composée d'un bulbe à quatre faces décorées : les motifs décoratifs alternent avec deux mufles de lion (fig. $229, \mathbf{n}^{\circ} 3$ ). La base de la jambe comprend dix godrons allongés et la calotte bulbe 17 perles. Cet élément a été découvert dans un niveau de la place Villeneuve-Bargemon contenant des céramiques du courant du XVI ${ }^{\mathrm{e}} \mathrm{s}$. Les verres à jambe à mufle de lion (stelo a protomi leonine) sont fréquemment retrouvés dans toute l'Europe jusqu'en Angleterre (Willmott 2000) et en France ils sont plus particulièrement attestés dans l'est du territoire (Goetz 1990), dans des niveaux de la fin du XVI ${ }^{\mathrm{e}}$ et du début du XVII ${ }^{\mathrm{e}} \mathrm{s}$. Ils ont été produits dans plusieurs ateliers aux mains de verriers émigrés d'Altare, mais ils ont fait également l'objet d'importations comme en témoigne leur présence dans la cargaison de l'épave de Gnalic en Adriatique (Lazar,
Willmott 2006, p. 35-39). Ces produits n'étaient pas encore signalés en Provence.

Les multiples moules dédiés à l'image du lion permettaient d'obtenir de nombreuses variantes. Celui qui fut utilisé pour la pièce marseillaise offre un beau relief : les joues, la truffe et le menton du fauve accentués sont presque des demi sphères, les arcades sourcilières très marquées se prolongent en volutes qui signifient les oreilles, la barbe bien dessinée est divisée en six lobes. Les motifs décoratifs qui séparent les mufles sont composés d'une olive flanquée de quatre lignes en accolade formant un cartouche. Cette composition est proche de certaines pièces de Montbéliard (Goetz 1990), et du type $\mathrm{V}$ défini dans les collections des musées royaux de Bruxelles (Lefrancq 2010), mais elle s'en sépare par le motif décoratif plus complet (4 lignes sinueuses en accolades contre 2 dans les collections belges) et la base à 12 godrons bien séparés.

- Les trois autres verres à jambe sélectionnées viennent d'un même contexte de la place Jules-Verne regroupant une dizaine de verres du $\mathrm{XVII}^{\mathrm{e}} \mathrm{s}$. Une pièce au profil complet présente une coupe conique portée par une jambe à double bulbe côtelé, soufflée dans un moule $\left(n^{\circ} 84\right)$. Les deux autres pièces, des tazza, ont une jambe massive moulurée. La coupe plus évasée que celle de l'exemplaire précédent devait être tronconique (fig. 229 , $\mathbf{n}^{\circ} \mathbf{5}$ ) ou bien très large et basse (fig. 229, $\mathbf{n}^{\circ} \mathbf{6}$ ).

Un fragment de rebord vertical soufflé dans un verre émeraude est doté d'un décor gravé dont le style (rayures parallèles remplissant les motifs) et l'iconographie (feuillages stylisés) rappellent les productions de la fin du $\mathrm{XVI}^{\mathrm{e}}$ et de la première moitié du XVII ${ }^{\mathrm{e}} \mathrm{s}$. (fig. 229, n 7) émanant de plusieurs ateliers européens. 


\section{Chapitre 2}

\section{Les monnaies médiévales et modernes (Alcazar et Tunnel de la Major)}

\section{(Joëlle Bouvry ${ }^{26}$ )}

$\mathrm{L}$ a présente étude propose d'apporter un premier regard sur les monnaies (peu nombreuses, disons-le tout de suite) découvertes sur deux des chantiers de fouille choisis pour cette étude : l'Alcazar et le Tunnel de la Major. La présentation s'effectuera par chantier et est suivie par une brève étude de la circulation monétaire. (voir tableau en Annexe 3)

\section{Le site de l'Alcazar}

La fouille du site de l'Alcazar a révélé 57 monnaies médiévales et modernes, ainsi qu'un méreau qui n'a pu être identifié et un objet monétiforme qui pourrait être un jeton du XVII ${ }^{e} \mathrm{~s}$. Le mauvais état de conservation de 15 pièces (représentant $25,42 \%$ du lot), réduites souvent à des fragments, n'ont pas permis leur identification.

Près de la moitié de l'ensemble des monnaies exhumées $(49,16 \%)$ appartient à la période moderne et le quart $(25,42 \%)$ à la période médiévale. A l'exception de trois monnaies en argent, ce sont toutes des monnaies en cuivre ou en alliage cuivreux, fractions des systèmes monétaires alors en usage; perdues, égarées dans les terrains où elles ont été trouvées. Elles témoignent de la circulation monétaire à Marseille. Toutefois, près de la moitié des monnaies médiévales est restée indéterminée; les quelques exemplaires identifiés sont représentatifs à la fois des productions et des échanges des XIII et $\mathrm{XIV}^{\mathrm{e}} \mathrm{s}$.

\subsection{Les monnaies médiévales}

La présence de la Maison aragonaise est marquée par l'obole du royal coronat d'Alphonse I ou II d'Aragon (1167-1196-1209) (fig. 230, $\mathbf{n}^{\circ} \mathbf{1}$ ). Cette petite espèce

26 Conservateur du Patrimoine, Chargée du Cabinet des Monnaies et Médailles de Marseille. est frappée à partir de 1186 à Marseille (Rolland 1958, $\mathrm{n}^{\circ} 12$ ) et confirmée sous Alphonse II en 1202.

Raymond-Bérenger V, dernier comte de Provence de la dynastie catalano-aragonaise, frappe à Marseille une petite espèce en alliage cuivreux, le menut (Poey d'Avant 1858-1862, n`3935; Rolland 1958, $\mathrm{n}^{\circ} 18$, p. 111) (fig. $230, \mathbf{n}^{\circ}$ 2) marqué pour la première fois d'un blason, celui de la maison d'Aragon, ici à trois pals. Cette petite monnaie est créée en 1243, deux ans avant la mort du comte. Guère en faveur ${ }^{27}$, elle s'échange peu. À la même époque circule à Marseille le denier raimondin, frappé à Sorgues par le comte de Toulouse Raymond VII (1222-1249) pour son marquisat de Provence. Cette pièce (Poey d'Avant 1858-1862, $\mathrm{n}^{\circ}$ 3723-3725, pl. XXXI) (fig. 230, $\mathbf{n}^{\circ}$ 3) porte au droit, une étoile à 6 rais dans un croissant et au revers, une grande croix évidée, cléchée et pommetée qui coupe la légende D[VX]M[ARCHIOCOMESPALATII]. Selon la chronologie proposée par J.-C. Moesgaard (2004, p. 180), cette émission aurait commencé vers 1250 ce qui correspond à la datation du contexte de découverte.

À la mort de Raymond-Bérenger V en 1245, le comté passe, à la faveur du mariage de l'héritière Béatrice de Provence avec Charles Ir d'Anjou, sous l'autorité de la dynastie angevine. Charles $\mathrm{I}^{\text {er }}$ bat monnaie à Marseille dès 1248-1249. Une obole de Marseille (Rolland 1958, $\mathrm{n}^{\circ} 26$ ou 28, p. 206) (fig. 230, $\mathbf{n}^{\circ}$ 4), frappée à partir de 1257, a été mise au jour en zone 4 , dans une unité stratigraphique de la première moitié $d u \mathrm{XIV}^{\mathrm{e}} \mathrm{s}$., où a été également découverte une obole (Poey d'Avant 18581862, n${ }^{\circ} 4490$, pl. XCVII, n9) (fig. 230, $\mathbf{n}^{\circ} 5$ ) au nom de Raymond IV (III) ${ }^{28}$ (1314-1340), prince d'Orange.

Un autre exemplaire (inv. 24.99.502, Poey d'Avant 1858-1862, n 4490, pl. XCVII, n9) a été trouvé en zone 11 dans une fosse de récupération datée du moment de la destruction du faubourg, vers 1360. Autre monnaie

27 Alors que la guerre albigeoise s'achève, le comte affirme ainsi sa suzeraineté retrouvée à Marseille et scellée par un traité de paix signé à Tarascon le 22 juin 1243.

28 Compte tenu de la complexité de la désignation successorale liée à la situation juridique de la principauté, je suivrai les derniers travaux de Jean-Louis Charlet 2006 [2008], p. 13. 
du XIV ${ }^{\text {e }}$ s., frappée entre 1330 et 1337 à Avignon et révélée dans une terre de jardin rapportée postérieurement en zone 3, l'obole (inv. 24.99.892) de Robert d'Anjou (Rolland 1958, n54).

Une seule monnaie (inv. 24.99.462) atteste de relations extérieures, celle de Gênes (Lunardi 1975, p. 105). En argent, elle a été frappée au nom du doge Tommaso de Campofregoso entre 1436 et 1442.

\subsection{Les monnaies modernes}

Près de la moitié des monnaies trouvées sur le site, datent de la période moderne. Elles sont au nombre de 28 ; un cinquième d'entre elles restent indéterminées et presque la moitié des monnaies identifiées datent du XVII ${ }^{\mathrm{e}} \mathrm{s}$. Ce sont des doubles tournois en cuivre (fig. $\mathbf{2 3 0}, \mathbf{n}^{\circ} \mathbf{8}$ ) frappés à la fin du règne de Louis XIII (1610-1643) : inv. 24.99.578, 24.99.579, 24.99.504 (Duplessy 2001, II, $\mathrm{n}^{\circ} 1378$ ), 24.99.550, 24.99.512, 24.99.510, 24.99.554 (Duplessy 2001, $\mathrm{n}^{\circ} 1372$ ) mais aussi des liards et des doubles tournois émis à Trévoux par les princes de Dombes, Henri (15921608) - inv. 24.99.517 (Poey d'Avant 1858-1862, n5155, pl. CXVI, 13), Marie de Montpensier (1608-1626) (Poey d'Avant 1858-1862, n5172, pl. CXVII, 2) (fig. 230, $\mathbf{n}^{\circ} 9$ ) et Gaston d'Orléans (1627-1650) inv. 24.99.824, 24.99.511 (Poey d'Avant 1858-1862, n' 5200 , pl. CXVII, 17), 24.99.818 et 24.99.553 (Poey d'Avant 1858-1862, $\mathrm{n}^{\circ}$ 5201, pl. CXVII, 17).

Trouvées en remblais ou en situation sur les parcelles fouillées (inv. 24.99.550, parcelle 19; inv. 24.99.553 et 24.99.554 parcelle 28), elles correspondent généralement bien aux datations proposées par l'archéologie. Seule la monnaie (fig. 230, $\mathbf{n}^{\circ} \mathbf{1 0}$ ) datée de 1642, inciterait à proposer une datation postérieure pour le remblai sous la calade de la parcelle 22.

Les 8 pièces retrouvées datant du XVIII ${ }^{\mathrm{e}} \mathrm{s}$. sont des productions locales. Cinq dardennes ${ }^{29}$, monnaies en alliage cuivreux de six deniers frappées dans l'atelier d'Aix entre 1709 et 1712 ont été mises au jour dont une en zone 1 (inv. 24.99.826) et une seconde en zone 3, dans la couche antérieure à la reconstruction de la parcelle 18 datée du début du XVIII ${ }^{\mathrm{e}}$ s. (fig. 230, ${ }^{\circ} 11$ ). La couche immédiatement antérieure au réaménagement de l'auberge du Petit-Saint-Jean (après 1754) a livré deux dardennes (inv. 24.99.513, Duplessy 2001, n ${ }^{\circ} 1593$, et 24.99.514) ainsi qu'un double sol en billon, émis à Dijon en 1739 (Duplessy 2001, n $^{\circ}$ 1690) (fig. 230, $\mathbf{n}^{\circ} \mathbf{1 2}$ ). Le

29 La nouvelle monnaie ordonnée le 16 octobre 1709 ayant été fabriquée grâce à la fonte des canons mis au rebut à l'arsenal de Toulon, il a été considéré comme plus pratique de fondre sur place le métal des canons. Ce qui fut fait au hameau de Dardennes, près de Toulon. remblai dans la parcelle 28, daté de la fin du XVIII ${ }^{\mathrm{e}}$ s., a également livré une dardenne (inv. 24.99.817).

Indépendamment du groupe précédent, deux autres pièces ont été révélées par la fouille ; un plomb de scellement, encore non identifié (inv. 24.99.508), trouvé dans le sol de la parcelle 18 daté de la première moitié du XVIII ${ }^{\mathrm{e}}$ s. et une pièce de 5 centimes datée de 1796 (inv. 24.99.461 : Mazard 1965, I, n²74), découverte dans le comblement du puits ovoïde de la parcelle 21.

\section{Les monnaies du Tunnel de la Major}

Les 12 monnaies médiévales et modernes mises au jour lors de la fouille présentent 6 monnaies indéterminées et donc 6 monnaies identifiées dont 4 médiévales et 2 modernes.

Deux royaux coronats frappés sous Alphonse $\mathrm{I}^{\mathrm{er}}$ ou Alphonse II d'Aragon (1167-1196-1209) ont été découverts dans le sol de la maison 3B datée du XIII ${ }^{\mathrm{e}} \mathrm{s}$. Cette monnaie émise à partir de 1186 a circulé au XIII $\mathrm{s}$. (Rolland 1958, $\mathrm{n}^{\circ}$ 13) (fig. 230, $\mathbf{n}^{\circ}$ 7). Le deuxième exemplaire a pu être reconnu dans le fragment exhumé dans le remblai de préparation du sol du deuxième état moderne de la maison du chapitre. Il partageait le même contexte (US 3129) que deux autres monnaies frappées

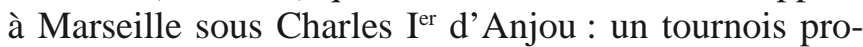
vençal (inv. 50.99.004 : Rolland 1958, $\mathrm{n}^{\circ} 20$ ou 22$)^{30}$ en trois fragments et une obole marseillaise (Rolland 1958, $\mathrm{n}^{\circ}$ 26) (fig. 230, $\mathbf{n}^{\circ}$ ).

Deux monnaies modernes ont été identifiées, un douzain (inv. 50.99.001; Duplessy 2001, $\mathrm{n}^{\circ} 1251$ ) frappé sous Henri IV, en 1593, à Montpellier et mis au jour lors de la démolition de l'îlot devant la cathédrale vers 1855 et un double tournois (inv. 50.99.002), trouvé dans un contexte de sépulture au chevet de la cathédrale et daté fin $\mathrm{XII}^{\mathrm{e}}-\mathrm{XIV}^{\mathrm{e}} \mathrm{s}$. (contexte 7014).

Toutes les monnaies retrouvées et identifiées sont des monnaies divisionnaires locales en cuivre ou en alliage cuivreux. Leur mauvais état de conservation restreint malheureusement l'identification et donc leur exploitation archéologique.

\section{La circulation monétaire}

Aux XIII ${ }^{e}$ et $\mathrm{XIV}^{\mathrm{e}}$ s. comme aux XVII ${ }^{\mathrm{e}}$ et $\mathrm{XVIII}^{\mathrm{e}} \mathrm{s}$., ce sont de petites monnaies divisionnaires en cuivre, sans grand pouvoir d'achat, pour la plupart fabriquées en Provence, qui circulent et sont perdues dans les terrains

30 Première monnaie frappée en Provence par Charles I ${ }^{\text {er }}$ d'Anjou, à partir de 1249 . 


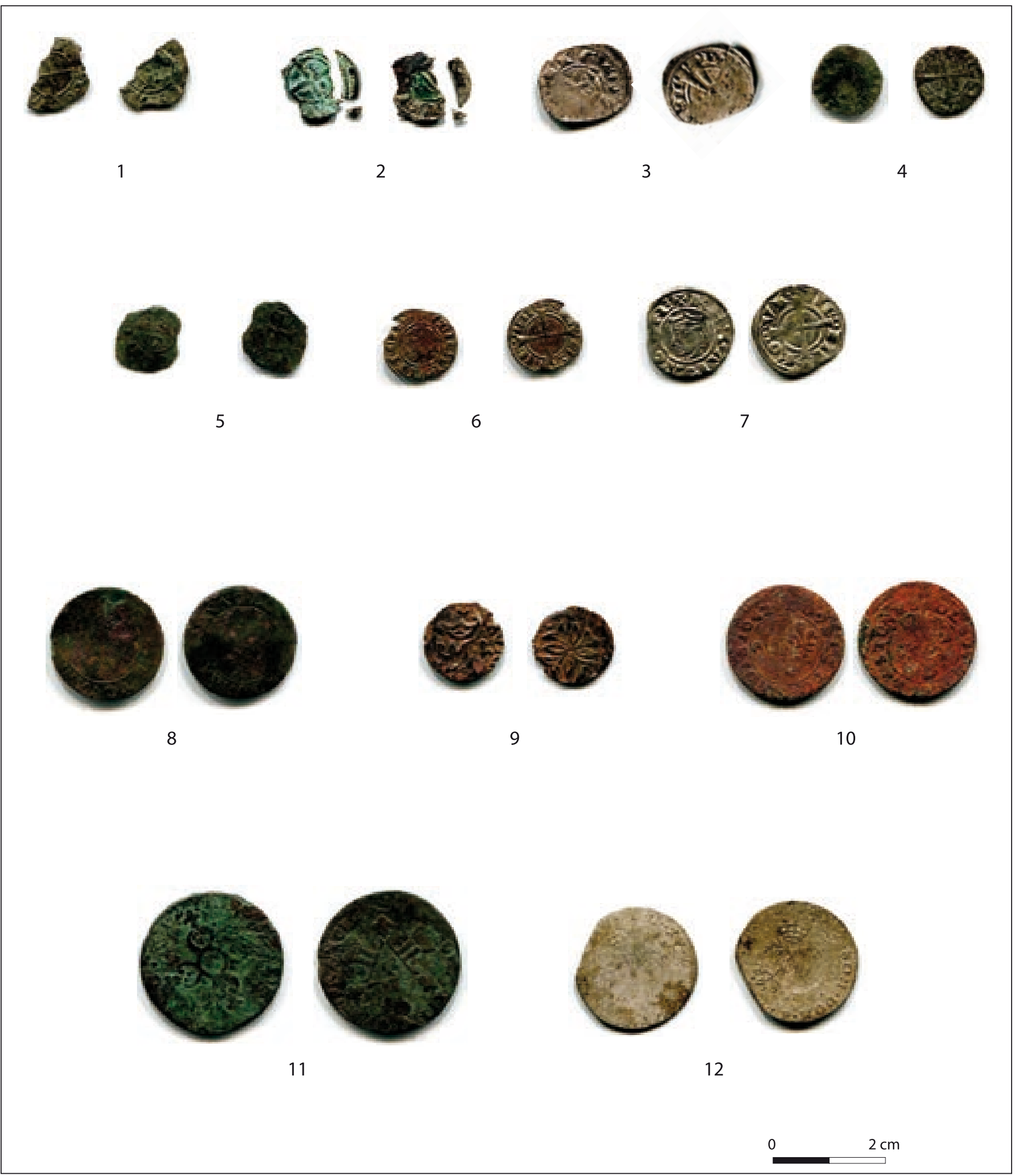

Fig. 230. Monnaies médiévales. 1 : obole coronat d'Alphonse ler ou II d'Aragon, comte de Provence ; 2 : menut marseillais de Raymond-Bérenger $\mathrm{V}$, comte de Provence ; 3 : denier raimondin de Raymond VII, comte de Toulouse ; 4, 6 : obole de Marseille de Charles ler d'Anjou, comte de Provence ;

5 : obole de Raymond IV (III), prince d'Orange ; 7 : royal coronat d'Alphonse ler ou II d'Aragon, comte de Provence. Monnaies modernes.

8 : double tournois de Louis XIII, roi de France ; 9 : liard de Marie de Montpensier, princesse de Dombes ; 10 : double tournois de Gaston d'Orléans, prince de Dombes $; 11$ : six deniers dits dardennes de Louis XV, roi de France ; 12 : double sol tournois de Louis XV, roi de France. 1-5, 8-12 : Alcazar. 6-7 : Tunnel de la Major. 
fouillés. Les trois monnaies contenant une proportion d'argent sont le raimondin de 1250, la monnaie génoise de 1436-1442 et le double sol tournois de 1739.

Il est à noter qu'au $\mathrm{XIII}^{\mathrm{e}}-\mathrm{XIV}^{\mathrm{e}} \mathrm{s}$., les princes d'Orange imitent certaines des monnaies des comtes de Provence. Or, nous constatons, en zone 4 et même contexte (inv. 24.99.581), dans le premier sol de l'espace $2 \mathrm{H} 2$ daté de la première moitié du $\mathrm{XIV}^{\mathrm{e}} \mathrm{s}$., la présence de la monnaie de Raymond IV (III) d'Orange (inv. 24.99.577) et de l'obole de Marseille de Charles Ir d'Anjou (inv. 24.99.576) émise en 1257. Ce type, imité dans la Principauté, était encore familier au XIV ${ }^{\mathrm{e}} \mathrm{s}$.

$\mathrm{Au}$ XVII ${ }^{\mathrm{e}}$ s., les Princes de Dombes imitent des monnaies des rois de France. Leurs doubles tournois circulent ensemble et sont découverts dans la même terre fouillée; ainsi, le double tournois de 1642 au nom de
Gaston d'Orléans (inv. 24.99.511) et celui de Louis XIII (inv. 24.99.512) trouvés en même contexte (261) dans le remblai sous la calade de la parcelle 22 .

$\mathrm{Au} \mathrm{XVIII}{ }^{\mathrm{e}}$ s., les fouilles archéologiques mettent en évidence la forte présence des pièces de six deniers dites dardennes. Trois ateliers furent chargés de cette fabrication La Rochelle, Montpellier et Aix. La proximité de ce dernier atelier et la grande quantité d'exemplaires frappés de 1709 à 1712 (39 millions : Ganne 2008, p. 43) justifient la bonne représentation de cette monnaie sur le site.

Si l'étude numismatique apporte les précisions chronologiques, diplomatiques, historiques à un règne, elle est corroborée par la confrontation aux trouvailles archéologiques, convaincants témoignages de l'usage et de la circulation des monnaies. 


\section{Chapitre 3}

\section{Quelques pipes en terre issues des fouilles de Marseille}

(Peter J. Davey ${ }^{31}$, traduction Véronique Abel)

$\mathrm{C}$ texte présente une collection de quelque 28 fourneaux de pipes en terre issus des fouilles de Marseille. Des tuyaux ont aussi été recueillis mais ils ne sont pas pris en compte dans cette étude. La majorité des pipes provient du site de la Bourse (fig. 231), complétée par les collections plus restreintes de l'Alcazar et de la place Villeneuve-Bargemon, et quelques découvertes de la rue de l'Évêché, de l'Hôtel-Dieu, de la Charité, de la Parette et de la rue Leca. Presque toutes ces pipes ont une forme et une pâte blanche caractéristiques des productions d'Europe du Nord à partir du XVII ${ }^{e} \mathrm{~s}$.

\section{Présentation générale}

La plupart de ces pipes étaient associées à des céramiques de la fin du XVII ${ }^{\mathrm{e}}$ ou du XVIII ${ }^{\mathrm{e}} \mathrm{s}$. Une seule découverte isolée concerne une pipe à tuyau court d'Europe du Sud, de type ottoman.

\subsection{Les pipes hollandaises exportées}

L'identification et la datation des pipes de style hollandais retrouvées en dehors des Pays-Bas sont d'une grande complexité. En premier lieu, il existe dans ce pays de nombreux centres de production, variant les formes, les décorations et les marques (van Oostveen, Stam 2011). Alors que les principaux centres que sont Amsterdam à partir du début du XVII ${ }^{\mathrm{e}}$ s., et Gouda principalement après la fondation de sa corporation, restent les provenances les plus probables des objets retrouvés à l'étranger, c'est la production dans son ensemble qui doit être prise en compte. Les fabricants hollandais ont produit des pipes techniquement et stylistiquement tellement supérieures par rapport aux autres centres d'Europe

31 National Pipe Archive, University of Liverpool. du nord, que leurs formes et leurs marques furent largement copiées de la Scandinavie à l'Allemagne. Bien que de nombreuses copies soient grossières et facilement reconnaissables, certaines sont d'excellente qualité et ne peuvent être identifiées en l'absence de découvertes de référence sur les sites de production.

\subsection{Les marques sur pipe}

L'identification des marques sur les talons pose un problème particulier. À Gouda, la question du nombre distinctif, des marques initiales ou du symbole était étroitement contrôlée par la Guilde. Toutes ces marques ont fait l'objet d'une série d'études sérieuses (par exemple Goedewaagen, Helbers 1942 ; van der Meulen 1988, 2003 ; Duco 2003). Elles furent cependant largement copiées dans d'autres villes hollandaises et au-delà. Les historiens et les archéologues les représentent habituellement de manière graphique stylisée qui ne reflète pas les changements de poinçons qui furent fréquents (cf. infra $\S 2.1 .2$.). L'étude la plus récente sur les ateliers de Gouda (Duco 2003) a tenté, en partie, de tenir compte des variantes de marques les plus évidentes, mais les dessins sont toujours ceux de poinçons-type, plutôt que de poinçons particuliers (par exemple Duco 2003, p. 130, n88). Tant que tous les poinçons hollandais ne seront pas répertoriés de manière extrêmement précise, il restera difficile d'être sûr qu'une marque donnée est de Gouda, des Pays-Bas ou d'origine étrangère.

Une tentative a été faite dans les années 1980 pour représenter les détails des marques et des décors hollandais par photographie. Krommenhoek et Vrij (1986, p. 31-63) présentent 400 photographies agrandies de timbres de talons néerlandais dont de nombreux sont très ressemblants entre eux mais différents dans le détail. Malheureusement, les provenances ne sont pas indiquées et les marques ne sont pas reliées à des formes précises de pipes.

Même si les photos sont bien meilleures que les dessins, car elles montrent les plus petites différences entre les poinçons, une méthode plus précise en trois 


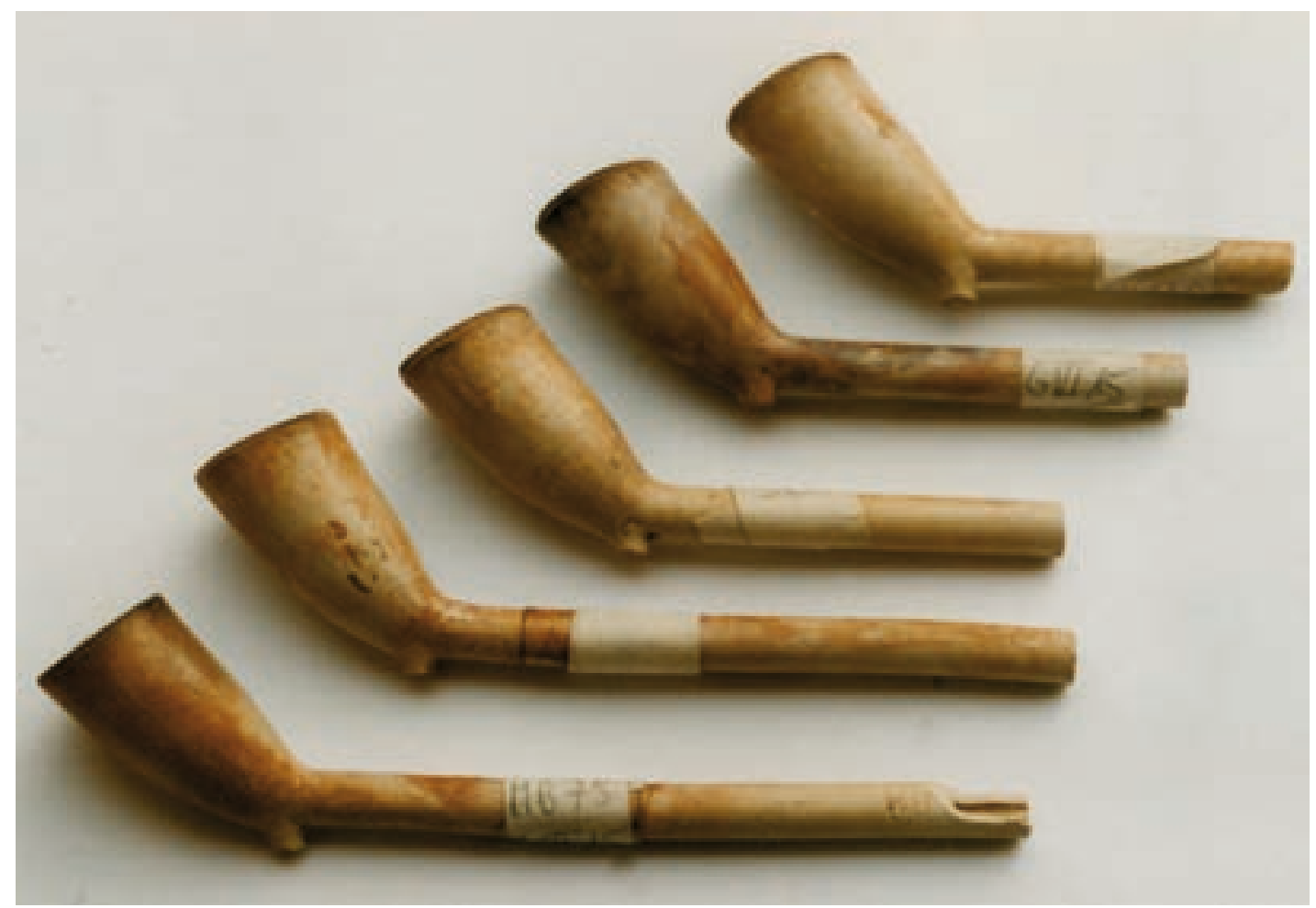

Fig. 231. Pipes trouvées à la Bourse (cl. M. Raphaël).
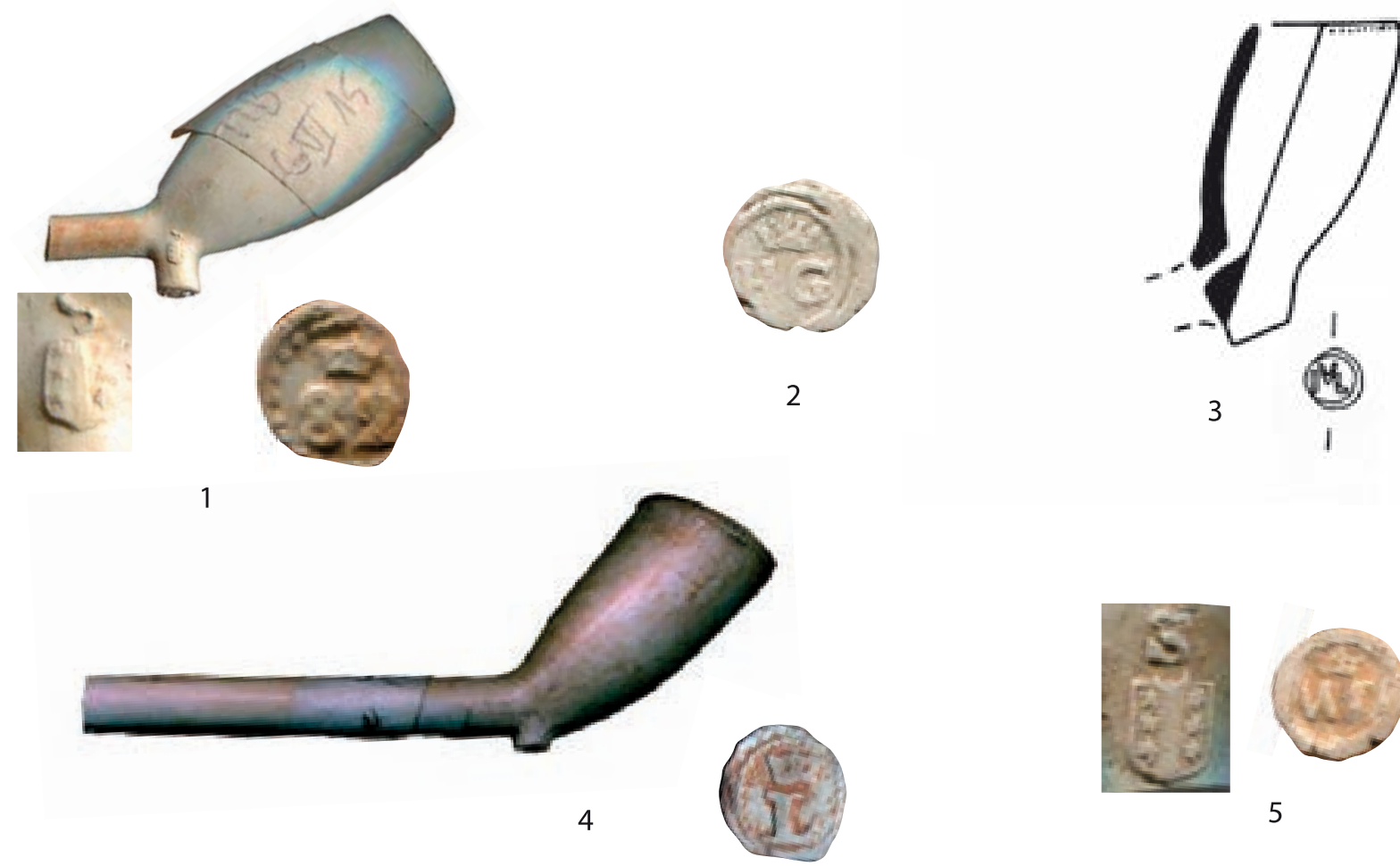

5

Fig. 232. Marques sur talon de pipes : « 82 » couronné $\left(n^{\circ} 1\right)$, « HG » couronné $\left(n^{\circ} 2\right)$, « IVL » $\left(n^{\circ} 3\right)$, « $L$ » couronné $\left(n^{\circ} 4\right)$, « WS » couronné $\left(n^{\circ} 5\right)$ (cl. V. Abel). 1-2, 4-5 : la Bourse ; 3 : la Charité. 


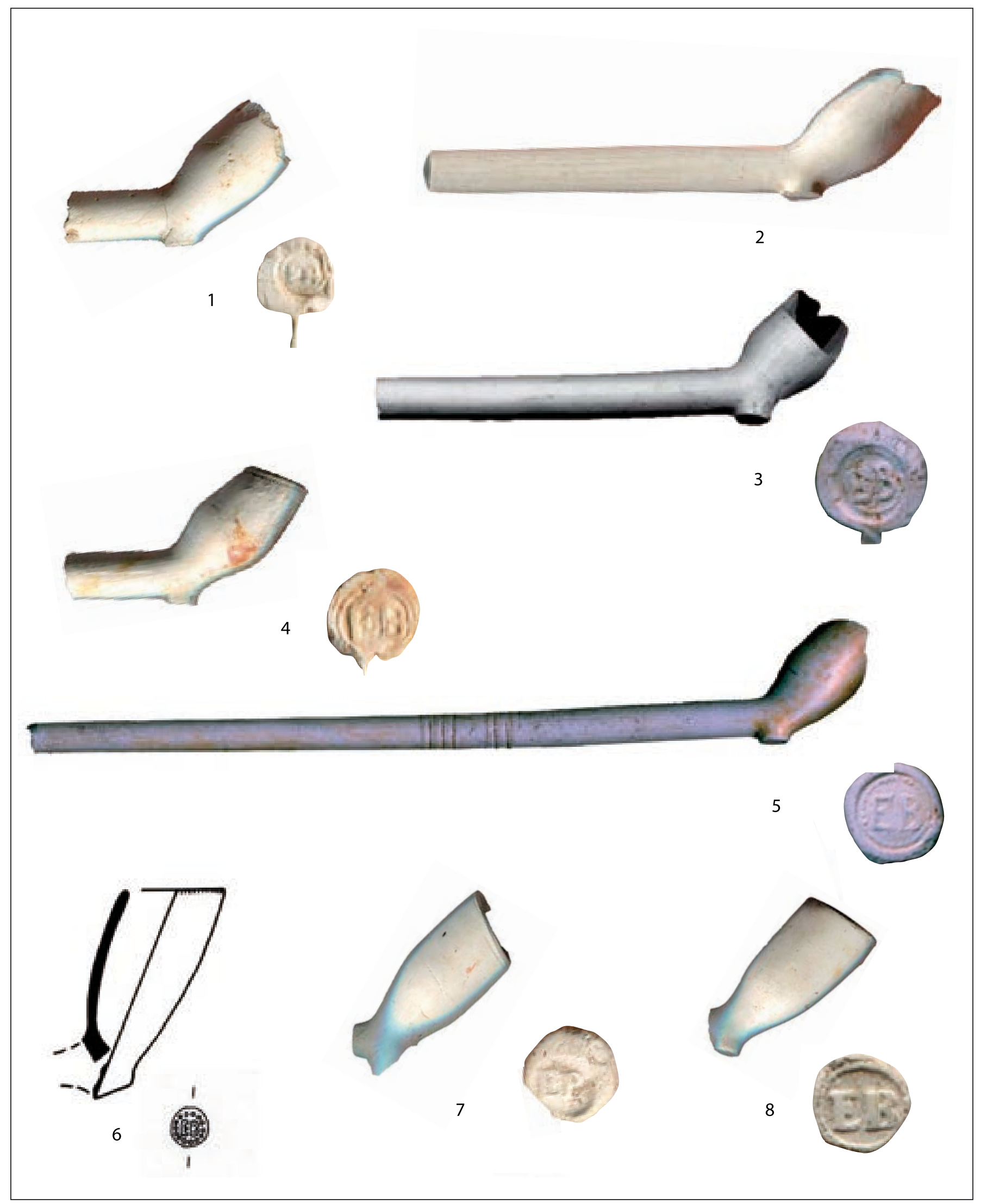

Fig. 233. Marques sur talon de pipes : «EB » (cl. V. Abel). 1, 4-5, 8 : la Bourse ; 2 : rue de l'Evêché ; 3 : rue Leca ; 6 : la Charité ; $7:$ place Villeneuve-Bargemon. 
dimensions, qui n'est pas soumise aux aléas de l'ombre, est encore préférable.

\subsection{La datation}

Un autre problème connexe est la datation des pipes de Gouda en utilisant le nom du fabricant et la date d'enregistrement de la marque dans les archives de la Guilde. S'il est à peu près certain que les marques étaient en usage avant leur approbation, la difficulté la plus persistante est que, une fois autorisées, elles peuvent avoir eu cours pendant deux siècles ou plus. Quand les marques déposées ont été utilisées sur le long terme, les indices donnés par la forme et d'autres éléments décoratifs doivent passer en priorité. La méthode de datation déductive de Don Duco, qui tient pleinement compte de toutes les variables observables, reste la seule méthode satisfaisante de datation (Duco 1987, p. 141-146).

La datation par le diamètre du trou des tuyaux pour les pipes hollandaises a depuis longtemps été reconnu comme insatisfaisant et très trompeur (Duco 1987, p. 135-136). Le système a été modifié de manière spécifique pour les pipes hollandaises par la formule « $\mathrm{ABO}$ » de Friederich. Il a pu conduire à des résultats « impossibles » (Duco 1987, p. 136-138). Ainsi, les dates proposées par M. Raphaël en 1994 pour le lot présenté ici sont en grande partie erronées.

Comme la datation des assemblages de céramiques associées aux pipes est essentielle, il ne faut pas oublier que les pipes, contrairement à la plupart des céramiques, ont une durée de vie très courte. Leur survie se mesure en jours plutôt qu'en semaines ou en années. Compte tenu de l'évolution rapide de leurs formes et de leurs décors, ces pipes sont donc intrinsèquement plus fiables en tant qu'indicateur chronologique que la poterie qui a une plus longue durée de vie et qui est souvent ménagée.

\subsection{Méthodologie}

Sur proposition de V. Abel, l'auteur a pu examiner la quasi-totalité des pipes en octobre 2010. Les objets en argile blanche de style hollandais sont étudiés dans l'ordre suivant : chiffres, initiales et symboles.

Dans chaque cas, une tentative a été faite pour déterminer si le fourneau est néerlandais, la copie d'une pipe néerlandaise ou un produit local. Cette évaluation est basée sur la méthode Duco, tenant compte notamment de la forme (basistype), de la marque, de la fabrication, de la finition et de la qualité générale. Les marques sont analysées en utilisant les références les plus récentes (van der Meulen 2003, Duco 2003) croisées avec l'ensemble des photographies publiées (Krommenhoek, Vrij 1986). Le cas échéant, une certaine considération est donnée à des exemples similaires d'autres sources.

\section{Le catalogue des pipes}

Nous étudierons ici d'abord les pipes présentant des marques avec des lettres ou des chiffres, puis des symboles. Enfin, nous sortirons de l'Europe du Nord pour l'étude d'une pipe provenant du monde ottoman.

\subsection{Les marques avec des lettres ou des chiffres}

Les marques avec des lettres et des chiffres sont bien représentés dans le corpus étudié ; nous en avons repéré six différentes.

\subsection{1. $\ll 82$ » couronné}

Un grand fourneau globulaire, avec un talon prononcé, bien fini et dont le polissage est très poussé, porte une empreinte en relief « $82 »$ couronnée sur le dessous du talon (fig. $232, \mathbf{n}^{\circ} \mathbf{1}$ ). De chaque côté du talon est moulée une représentation des armoiries de Gouda surmontée par la lettre $\ll S »$.

Il s'agit d'une forme Duco Basistype 3 qui se situe entre 1725 et 1800 et même au-delà (Duco 1987, p. 44-45, p. 141). La marque « 82 » couronnée a été enregistré à Gouda par Thomas Soufree en 1734 et détenue par la famille Goedewaagen à partir de 1850 jusqu'en 1945 (Duco 2003, p. 196 ; van der Meulen 2003, p. 96). Duco a deux versions de la marque : l'une a un cercle continu sur le bord et l'autre, comme dans l'exemple de la Bourse, un cadre circulaire défini par des points. La lettre « $\mathrm{S}$ » sur les armes de Gouda est l'abréviation de «slechte», mot hollandais qui signifie « ordinaire » ou « inférieur». Elle fut introduite en 1740 pour désigner des produits de second choix (Van Oostveen, Stam 2011, p. 90).

Dans un contexte européen, la pipe est de bonne qualité et elle est presque à coup sûr un produit de Gouda postérieur à 1740. Compte tenu de la poterie associée, elle semble susceptible d'avoir été produite par Thomas Soufree (1734-1743) ou Willem Schippers (1743-1791) durant la période 1740-1790. Une pipe similaire a été trouvée dans le port de la quarantaine à Pomègues (Gosse 2007, p. 134).

\subsubsection{Les marques «EB »}

Huit des pipes considérées ici portent la marque en relief « EB » sur le dessous du talon (fig. 233). Les 
formes des pipes et leurs marques sont très variées. Les premières formes de cette marque sont associées à un fabricant anglais, Edward Bird, qui s'établit à Amsterdam en 1630 et y mourut en 1665 (Duco 1981, p. 306). La marque a d'abord été enregistrée à Gouda en 1672 et est restée en usage jusqu'en 1725. van der Meulen (2003, p. 66) a publié une version simplifiée et couronnée, tandis que Duco (2003, p. 155) a un type ordinaire et deux couronnes, l'une avec un point entre les lettres. Ces pipes sont décrites ci-dessous dans un ordre chronologique approximatif.

La plus ancienne forme est un fourneau Duco Basistype 1 de la Bourse, qui n'est pas poli et qui a été assez grossièrement taillé. Son rebord semble avoir été ébréché intentionnellement, peut-être pour réduire sa taille (fig. 233, $\mathbf{n}^{\circ} \mathbf{1}$ ). Le lettrage de la marque EB, qui est située dans un cercle de corde moulé, est aussi un peu maladroit. Sur la base de sa forme, cette pipe peut se situer entre 1625 et 1675 environ (Duco 1987, p. 26-27). Compte tenu de la qualité moyenne de la finition, elle semble plus susceptible d'être un produit d'Edward Bird d'Amsterdam, que l'on date entre 1650 et 1665.

Une autre forme ancienne a été récupérée dans la rue de l'Évêché (L.-F. Gantès 1985) (fig. 233, n²). Elle est polie et bien finie avec polissage de bonne qualité. C'est une forme Basistype 1 datant de 1660-1690 environ (Duco 1987, p. 141), donc probablement un produit de Adriaen Van der Cruis qui travailla à Gouda à partir de 1672 et jusqu'en 1719 (Duco 2003, p. 155).

Un dernier fourneau Basistype 2 a été trouvé dans la ville dans un contexte contenant des céramiques du début du XVIII ${ }^{\mathrm{e}}$ s. (fig. 233, $\mathbf{n}^{\circ} \mathbf{4}$ ). La marque EB plutôt rudimentaire est fixée dans un simple cadre de corde moulé, mais la qualité générale est bonne avec un polissage très bien exécuté. Pour ce qui est de la forme, dont le bord est légèrement pincé, elle se situe au début de la série et date probablement des environs de 1675 à 1690.

Un autre fourneau de Basistype 1 de la Bourse est de bonne qualité, poli et abondamment décoré à la roulette autour de la tige (1971 FIII 11) (fig. 233, n5). Celle-ci aussi est presque certainement une pipe d'Adriaen van der Cruis produite dans les dernières années du $\mathrm{XVII}^{\mathrm{e}} \mathrm{s}$., entre 1680 et 1700 environ.

Le dernier fourneau «EB» de Basistype 1 a été trouvé dans la fouille de la rue Leca (fig. $233, \mathbf{n}^{\circ} \mathbf{3}$ ). Il est de bonne facture, tiré à partir d'un moule de bonne qualité et finition. Le bord est endommagé. Le cachet en relief sur le talon a clairement un lettrage « EB » rustique situé dans un cercle de corde moulé. Cette pipe est moins certainement un produit Gouda que les deux précédentes; elle est probablement datée des environs de 1680 à 1700.
Un fourneau de bonne qualité, en forme d'entonnoir (Trechter kopf) avec un talon endommagé et polissage de bonne qualité a été trouvé à la Charité avec des céramiques de la fin du XVII ${ }^{\mathrm{e}}$ s. (fig. 233, $\mathbf{n}^{\circ}$ 6). Le cachet «EB » du talon est situé dans un cercle de petits points espacés. Cette forme Basistype 2 est généralement datée de 1675 à 1740 (Duco 1987, p. 27). La forme fine et assez étroite mais sophistiquée de cet exemple suggère un produit de Gouda et une date dans la première partie de cette série, disons de 1680 à 1710 .

Un autre fourneau Basistype 2 de bonne qualité a été retrouvé lors des fouilles de la place VilleneuveBargemon (fig. $\mathbf{2 3 3}, \mathbf{n}^{\circ}$ 7). Il semble poli et fini avec soin. Le talon «EB » est légèrement endommagé, le timbre est clair et ne dispose pas d'un cadre autour. En termes généraux, il est très proche de la découverte de la Charité et de date similaire, entre 1680 et à 1710 environ.

Un seul fourneau Basistype 3 ovoïde a été récupéré à la Bourse (fig. 233, n⿳8 $\mathbf{8}$ ). Ce fourneau est bien façonné avec un polissage très poussé et le tampon pour la marque est propre et net, avec un lettrage de type serif dans un cercle de corde moulé. La forme du fourneau est assez mince et doit dater de la période ancienne du type, probablement de 1700 à 1720 (Duco 1987, p. 44-47).

Bien que les huit fourneaux marqués «EB » soient probablement d'origine hollandaise, ils sont issus de huit poinçons différents. Leur chronologie va de 1650 jusqu'à une date aussi tardive que 1720. Cette importation plus ou moins continue se reflète dans le matériel du port de la quarantaine à Pomègues où 271 pipes d'Europe du Nord à talon estampillé ont été récupérées (Gosse 2007, p. 120-149). Sur 29 pipes portant la marque EB, onze sont couronnés, avec apparemment un point entre les lettres. Alors que Gosse a mis un dessin stylisé de chaque timbre à côté d'une photo du fourneau, il est clair à partir de l'image agrandie du timbre qu'un certain nombre de matrices différentes sont représentées. En réalité, de nombreux exemplaires couronnés semblent ne pas comporter de point entre les lettres; cependant les dessins en montrent un pour chaque marque (Gosse 2007, p. 127-129). Gosse suggère également que onze des pipes sont des copies probables ou possibles, le plus souvent en se basant sur leur qualité inférieure. Alors que deux ou trois des pipes sont de forme inhabituelle et de mauvaise qualité, il semble plus que probable qu'elles sont d'origine néerlandaise plutôt que française. Bien que la guilde de Gouda ait passé beaucoup de temps à essayer de contrôler l'utilisation de ses marques (Duco 2003, p. 254-255), il est clair que cela ne fut pas du tout un succès complet (par exemple van Oostveen, Stam 2011, p. 124-126). À l'heure actuelle, il n'est pas possible, parmi le grand nombre de pipes de style Gouda, de 


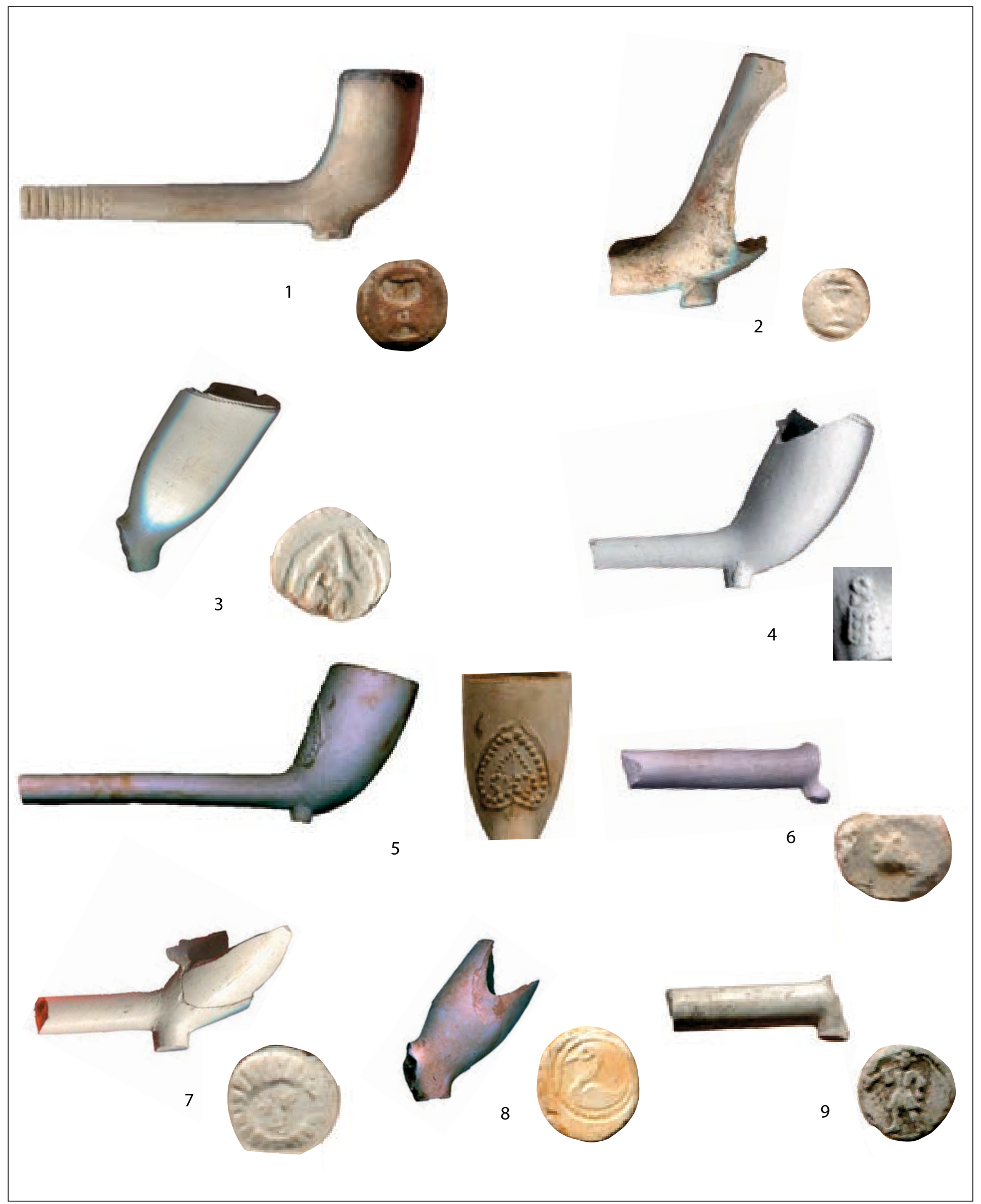

Fig. 234. Marques sur talon de pipes : calice $\left(n^{\circ} 1-2\right)$, renard à l'affut $\left(n^{\circ} 3\right)$, blason $\left(n^{\circ} 4\right)$, coeur renversé $\left(n^{\circ} 5\right)$, étoile $\left(n^{\circ} 6\right)$, soleil $\left(n^{\circ} 7\right)$, cygne $\left(n^{\circ} 9\right)$, trompette $\left(n^{\circ} 10\right)$ (cl. V. Abel). 1, 3, 5, 7-8 : la Bourse ; 2 : la Parette ; 4 : Hôtel-Dieu ; 6 : Alcazar ; 9 : rue Leca. 


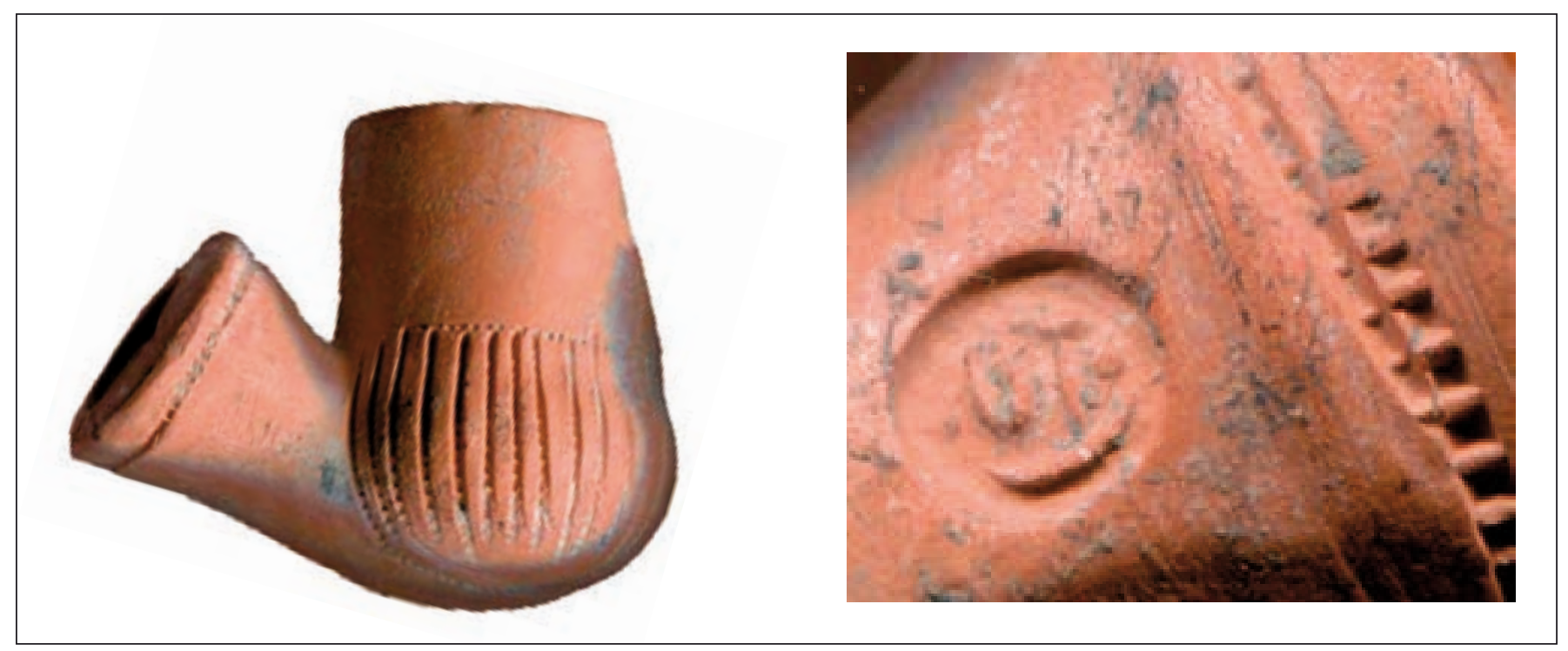

Fig. 235. pipe ottomane (cl. V. Abel). Marseille.

piètre qualité et marquées, de distinguer avec certitude celles qui ont été produites à Gouda de celles d'un autre centre néerlandais.

Les pipes dont le talon est estampillé «EB » sont les plus courantes de style hollandais trouvées à Marseille ; elles sont aussi souvent recueillies aux États-Unis, en particulier dans les colonies néerlandaises telles que la Nouvelle-Amsterdam (New-York). Comme pour Marseille, les tuyaux ont de nombreuses moisissures et utilisent différentes matrices (Mc Cashion 1979, p. 92-102). Cette marque est aussi la plus fréquente parmi celles trouvés aussi loin que le nord-est du Brésil (Mello, Punambucano, 1983).

\subsection{3. «HG » couronné}

Un talon légèrement endommagé provenant de la Bourse a une empreinte en relief sur la face inférieure dans laquelle les lettres HG surmontées d'une couronne sont conformes à une corde circulaire cadre moulé (fig. 233, $\mathbf{n}^{\circ} 2$ ). S'il s'agit d'un produit des ateliers de Gouda, il a été produit par Hendrick Gloudijse Marté qui y travaillait de 1694 à 1715 (Duco 2003, p. 159). Si le tuyau est plus ancien, il peut être le produit de Hendrick Gerdes d'Amsterdam (1668-1684). Trois exemples de ce timbre ont été recueillis sur un site indien Mohawk de l'État de New-York qui est précisément daté de 1667 à 1693 et qui inclut un fourneau sans talon d' «exportation». Pour cette raison et vu leurs formes, ces pipes furent attribuées à Amsterdam (Mc Cashion 1979, p. 128-132). En d'autres termes, cette pipe a probablement été faite à
Amsterdam entre 1670 et 1690 , ou à Gouda entre 1690 et 1715 .

\subsection{4. «IVL»}

Un fourneau Basistype 2 avec polissage soigné présente sur le talon une marque en relief de trois lettres, «IVL », dont la lettre centrale (V) est placée entre et au-dessus des autres (fig. 232, $\mathbf{n}^{\circ} \mathbf{3}$ ). C'est la marque du fabriquant de Gouda, Jacob Dircksz van Leeuwen, qui a travaillé de 1676 à 1700 (Duco 2003, p. 177). D'après la forme du tuyau, elle doit dater de 1680 à 1700 (Duco 1987, p. 44-45). On ne connaît aucun autre exemple à Marseille et dans sa région.

\subsection{5. «L» couronné}

Cinq fourneaux Basistype 2 de style hollandais estampillés d'un « L » couronné en relief sur le talon ont été recueillis dans un même contexte lors des fouilles de la Bourse (Inv. MB75 GVI - 15-25.05.76) (fig. 232, $\left.\mathbf{n}^{\circ} 4\right)$. Ils sont très ressemblants dans leur forme et les détails de leur marque et proviennent certainement d'un même lot. Ils conservent tous une partie de tuyau dont la longueur varie de 52 à 124 mm (Raphaël 1994, p. 17-20). Le plus long des tuyaux (102 mm) est décoré à la roulette. Du même contexte est issu un fourneau d'un caractère différent (cf. infra $\$ 2.2 .4$.) et 24 fragments de tuyaux, dont quatre porte-parole et trois autres exemplaires à décor de roulette. L'estampille est bien exécutée, avec un « $\mathrm{L}$ » élégant à empattements, une couronne soignée et un cercle de corde moulé. La marque 
«L » couronné a été enregistrée à Gouda par Cornelis Luijnenburg en 1726, elle fut utilisée jusqu'en 1925 et, de 1753 jusqu'en 1821, elle appartient aux membres de la famille Verzijl qui étaient de grands exportateurs de pipes (van der Meulen 2003, p. 76 ; Duco 2003, p. 152). D'après la forme élancée qui commence à être ovoïde (Duco a Basistype 3), ce groupe est susceptible de dater de 1720 à 1750 environ.

La marque «L» couronné fait partie d'un petit groupe qui était à l'origine attribué à un fabricant qui eut une telle réussite que ses productions sont devenues des modèles de qualité des pipes en terre et ont été utilisées dans de nombreux autres centres. Par exemple, la marque TD qui semble avoir son origine chez Dormer Thomas à Londres dans les années 1740 a été largement utilisée au XIX ${ }^{\mathrm{e}}$ s. en Écosse (Gallagher, 1987), dans le nord et le sud de la France (Tymstra 1981; Leclaire, Leclaire 2008, p. 73-75), aux États-Unis (Sudbury 1979, p. 206) et au Canada (Walker 1983, p. 84-87; Ritchie 1983, p. 117-120). De même Vandenbosche à Arras produisit des copies de pipes de Verzyl, y compris le décor imprimé à la roulette et la marque du talon (Deloffre et Jacques 2006, p. 56). Le cachet «L» couronné est devenu très apprécié en Irlande, où il a été utilisé par un certain nombre de fabricants sur les très grossières «formes néerlandaises » (Norton 2009, p. 78-79).

Gosse (2007, p. 132-147) comptabilise 26 exemplaires de la marque «L » couronné à Pomègues. Là aussi, il utilise un dessin unique pour représenter le poinçon, mais leur pluralité est mise en évidence par les photographies. Ces différences se traduisent dans les formes, qui sont très variées. En utilisant ces critères, il a classé les pipes comme étant soit « Gouda », soit «possible Gouda », soit «probables produits français ». Ces derniers sont souvent associés à des lettres moulées à l'avant du fourneau et sont très peu susceptibles de venir des Pays-Bas. Les pipes de la Bourse sont similaires aux six premiers exemplaires de Pomègues; elles ont des formes standard de Gouda et sont plus susceptibles d'être d'origine néerlandaise.

\subsection{6. «WS » couronné} Bourse.

Deux pipes portant ce timbre ont été trouvées à la

Un fourneau élancé Basistype 2 au polissage soigné, portant sur le talon une marque endommagée «WS » couronné en relief a été retrouvée à la Bourse (inv. MB DIII 6, 4 Mai 68). Selon Duco (2003, p. 167). La marque a été enregistrée à Gouda en 1652 par Willem Stevensz de Jonge et son utilisation a continué jusqu'en 1925. Van der Meulen (2003, p. 86) fournit une typologie de 1668 jusqu'en 1955. Un seul objet identique a été recueilli à Pomègues et il est daté de 1670 à 1690 (Gosse 2007, p. 121). Compte tenu de la grande qualité de celui découvert à Marseille, une origine à Gouda et une date de 1675 à 1700 est la plus probable.

Le second talon imprimé «WS » est de qualité inférieure. Il porte les armes de Gouda et la lettre $\mathrm{S}$ posée sur le côté du talon (fig. $\mathbf{2 3 2}, \mathbf{n}^{\circ} \mathbf{5}$ ). Il s'agit probablement d'un produit de Gouda qui doit dater de la période de 1740 à 1760, voire plus tard.

\subsection{Les marques avec symboles}

Huit symboles différents ont été retrouvés sur les pipes marseillaises.

\subsubsection{Calice}

Deux exemples de pipes de style hollandais portant un calice en relief sur le talon figurent d'une part dans la collection de la Bourse (fig. 234, $\mathbf{n}^{\circ} \mathbf{1}$ ), d'autre part dans celle de La Parette (fig. $\mathbf{2 3 4}, \mathbf{n}^{\circ}$ 2). Cette dernière est une forme tardive de Basistype 2, datant de 1720-1740 environ. De qualité modeste, elle est très grossièrement finie, sans aucun polissage. Le timbre est en relief et peu net. L'exemplaire de la Bourse est tout à fait différent (inv. MB DIII 4-6 Mai 68). Il est poli, bien fini et agrémenté d'un décor à la molette et d'un «anneau de perles ». Il semble aussi avoir été intensivement utilisé. La forme n'est pas typique des pipes hollandaises, mais remonte probablement aux alentours de 1730-1750.

Gosse (2007, p. 123-139) répertorie 15 marques de calice à Pomègues. Il les identifie comme étant la marque d'un roemer enregistré à Gouda en 1676 par Willem Claesz Boot et utilisée jusqu'en 1914 (Van der Meulen 2003, p. 49 ; Duco 2003, p. 142). Si l'on confronte les marques de Marseille aux registres néerlandais, il est clair qu'il ne s'agit pas de la même estampille. Une comparaison par dessin et photos est très parlante. Le roemer néerlandais - un récipient à boire en verre ou en grès - a une tige convexe et un bassin en forme de coupe. Sur tous les exemplaires de Marseille, l'estampille est tripartite sous forme d'un bossage central au-dessus de la tige, ce qui suggère un calice, plutôt qu'un récipient à boire ordinaire. Se basant sur des critères de forme et de qualité, Gosse a suggéré que 11 de ses 15 exemplaires furent produits soit à Arras par Vandenbosche, soit à Dunkerque par Pierre de la Ruelle (Gosse 2007, p. 137). Bien qu'il n'ait pas pu trouver de correspondance exacte, cela reste envisageable, étant donné que la marque ne figure pas dans les listes néerlandaises et que les formes des pipes ne sont pas typiques de la production néerlandaise. 
Ainsi, les deux pipes au calice provenant de la fouille terrestre de Marseille sont probablement des produits de fabricants du Nord de la France pendant la période 1720-1750.

\subsubsection{Un renard à l'affût}

Un fourneau Basistype 2 très finement réalisé, élégant et poli de la Bourse porte une empreinte en relief indistincte sur le talon (fig. $\mathbf{2 3 4}, \mathbf{n}^{\circ} \mathbf{3}$ ). Il a été poli avec une grande compétence et bien fini. La marque appartient presque certainement au groupe enregistré à Gouda en 1674 par Jacob Hendrikz de Vos et représentant un renard campé dans diverses attitudes.

La marque fut utilisée jusqu'en 1866. Deux versions d'un renard sur ses gardes, dans lesquelles l'animal regarde dans deux directions différentes, sont enregistrées par Duco (2003, p. 130). L'estampille de la Bourse montre le renard tourné vers la gauche avec une grande queue courbe sur la droite. Sa forme et sa qualité suggèrent que la pipe a été faite par De Vos à Gouda entre 1680 et 1700 .

\subsubsection{Blason de Gouda}

Un fourneau Basistype 3 un peu endommagé et finement exécuté a été récupéré sur le chantier de l'Hôtel-Dieu (fig. 234, $\mathbf{n}^{\circ} \mathbf{4}$ ). Il ne porte qu'un blason de Gouda moulé surmonté par la lettre $S$ sur le côté du talon. Cette pipe est presque certainement un produit de Gouda postérieur à 1740 (cf. supra § 2.1.1.), elle est susceptible de se placer dans le créneau 1760-1800.

\subsubsection{Coeur inversé}

Un seul fourneau et une partie de tuyau ont été trouvés dans le même contexte que le groupe « $\mathrm{L}$ » couronné de la Bourse (fig. 234, ${ }^{\circ} 5$ ) (cf. supra § 2.1.5.). Un cœur inversé formé par deux séries de points se remarque sur le fourneau. Son moule est lâche, et les bords du motif ne se rejoignent pas précisément. Le polissage remonte haut vers le bord mais par ailleurs l'objet n'est pas marqué. Cette pipe est presque certainement produite à Saint-Quentin-La-Poterie (Gard) où un certain nombre de fabricants ont utilisé ce type de décor (Leclaire, Leclaire 2008, p. 10-13). Les exemplaires dont les fabricants peuvent être identifiés datent de 1760 environ (Gabriel Deleuze), 1773 (Pierre Abauzit) et 1784 (Jean-Henri Taulon). Il est peu probable que cet objet, auquel manque le monogramme, puisse être antérieur à 1750 . C'est donc lui qui fournira un terminus post quem pour l'ensemble du contexte de la Bourse.

\subsection{5. Étoile}

Le site de l'Alcazar a livré une portion de tuyau poli et talon endommagé portant une grossière estampille en forme d'étoile (fig. 234, $\mathbf{n}^{\circ} \mathbf{6}$ ). Même si un certain nombre de marques d'étoiles a été enregistré à Gouda dès 1628 (Duco 2003, p. 149), cet objet semble trop grossier pour un produit néerlandais. Il est très différent des deux découverts à Pomègues qui portent des étoiles à six branches à la manière de Gouda (Gosse 2007, p. 124). L'épaisseur relative de la tige et la forme du talon suggère une date dans la dernière partie du XVII ${ }^{\mathrm{e}} \mathrm{s}$., c'est à dire autour de 1680-1700.

\subsubsection{Soleil}

Un fourneau fragmentaire Basistype 2 de la Bourse a un talon marqué d'un soleil à 24 rayons et visage humain (inv. MB DI-8 25/09/69) (fig. 234, $\mathbf{n}^{\circ}$ 7). Le tuyau est bien fait et terminé ; il est poli. La marque au soleil, enregistrée à Gouda en 1667 par Pieter Dominikus, est restée en usage jusqu'à 1842 (van der Meulen 2003, p. 56 ; Duco 2003, p. 148). Il en existe au moins quatre modèles différents : Duco en connaît deux avec une série de rayons serrés et un très proche de celui de la Bourse avec une conception beaucoup plus simple. Van der Meulen a aussi publié ce type ainsi qu'une version couronnée. Une photographie de cette conception plus simple figure dans Krommenhoek et Vrij (1986, p. 56-57, n³27).

Dix exemples ont été récupérés à Pomègues (Gosse 2007, p. 124-141). Ceux-ci incluent des versions plus ou moins complexes de la marque, réparties sur une gamme de formes. Comme pour les autres types communs, un grand nombre de matrices est représenté.

La qualité et la forme de la pipe de la Bourse suggère une origine de Gouda et une date dans la période 1680-1720.

\subsubsection{Cygne}

Un fourneau endommagé Basistype 1, poli, provenant de la Bourse porte un poinçon représentant un cygne qui nage, dans un cercle dentelé (inv. MB71 FIII 11, novembre 71) (fig. 234, $\mathbf{n}^{\circ} \mathbf{8}$ ). Cette marque a été enregistrée à Gouda en 1660 par Arijen Davidsz Kuijnenbrouck et elle a été utilisée jusqu'en 1808 (Duco 2003, p. 133). Duco recense trois modèles de marques où se trouve le cygne qui nage. L'un est en creux, les deux autres sont en relief. Van der Meulen (2003, p. 42) en présente également deux versions. L'exemple de la Bourse est d'une conception différente car le cygne a un œil large et son dos se creuse. Il est presque certainement produit à Gouda entre 1670 et 1690. 


\subsubsection{Trompette}

Un tuyau avec fragment de talon poli trouvé à Marseille portent une empreinte en relief complexe qui montre un homme jouant de la trompette (fig. 234, $\mathbf{n}^{\circ} \mathbf{9}$ ). Cette marque a été enregistrée à Gouda en 1674 par Aert Poulwelsz Ands Vaeck et utilisée jusqu'en 1919 (Duco 2003, p. 134) ; van der Meulen (2003, p. 37) la fait se poursuivre jusqu'en 1945. Duco montre trois exemples de trompette sous des angles différents. Des clichés de quatre poinçons différents sont illustrés par Krommenhoek et Vrij (1986, p. 35). Trois fourneaux complets ont été récupérés à Pomègues, dont l'un (3F087) est très proche de celui de Marseille ; le fragment peut être marqué par le même poinçon (Gosse 2007, p. 130). Bien qu'il n'en reste qu'un petit fragment, il appartient à une pipe bien façonnée qui est probablement un produit de Gouda, se situant approximativement entre 1680 et 1750 .

\subsection{La pipe ottomane}

Une pipe en terre rouge (fig. 235) presque complète, à tuyau court, figure dans le mobilier de Marseille ${ }^{32}$. La moitié inférieure du fourneau est décorée de lignes verticales tracées à la roulette limitées par une ligne horizontale et complétées une ligne autour du bord du fourneau. Sur le côté gauche de la douille par rapport au fumeur, se trouve une estampille en relief de style arabe, présumée être la marque du fabricant. La douille n'a pas de collier - une caractéristique normale pour les formes ottomanes anciennes - et elle est assez grossièrement décorée.

Par sa forme et son décor, cette pipe est typique de la production turque de la première moitié du $\mathrm{XIX}^{\mathrm{e}} \mathrm{s}$. Sa mauvaise qualité peut être confrontée avec la trouvaille de Vranje, aujourd'hui en Serbie, au Novi Sad Museum (Gačić 2011, p. 103, n 103) de mêmes forme et techniques décoratives. La pièce serbe est polie, et les motifs gravés sont beaucoup plus soignés. Une marque très proche est répertoriée à Novi Sad (Gačić 2011, p. 60, en bas à gauche).

Gosse (2007, p. 150-314) a comptabilisé un nombre considérable de tuyaux ottomans à Pomègues, y compris un grand nombre semblables par leur forme et leur décor à l'objet recueilli dans la cité marseillaise. Toutes ces pipes ont des colliers. L'absence de comparaison directe avec Pomègues est probablement due à la chronologie des dépôts, qui sont essentiellement de la fin du XVII ${ }^{e}$ et du XVIII ${ }^{\mathrm{e}} \mathrm{s}$. Peu de pipes sont datées du $\mathrm{XIX}^{\mathrm{e}} \mathrm{s}$. dans ce contexte.

\footnotetext{
32 Hôtel-Dieu 2009, us 2001.
}

\section{Discussion}

Les 26 pipes en terre de style hollandais étudiées ici datent de 1650 pour la plus ancienne, et s'échelonnent jusqu'à 1800. L'activité de fumer est davantage représentée pour la période allant de 1680 à 1750 (fig. 236). Malgré la mention d'archive d'un fabricant pipier à Marseille en 1693, la production locale véritable ne commence pas manifestement avant 1775 au plus tôt (Raphaël 2003, p. 14-16).

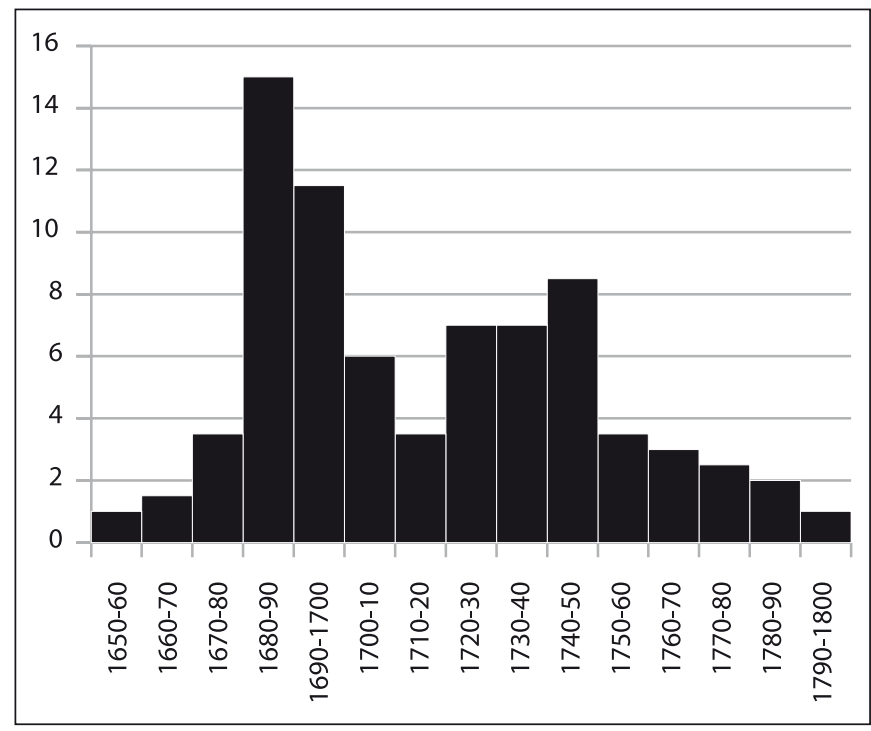

Fig. 236. Nombre de pipes retrouvées dans les chantiers marseillais par décennie (1650-1800).

Pour ce qui est de leur origine, une pipe est un produit d'Amsterdam, une autre provient soit d'Amsterdam soit de Gouda et 19 sont presque certainement issues des ateliers de Gouda. En outre, sont identifiées une pipe française de Saint-Quentin, et trois autres qui semblent être des pipes de formes et marques néerlandaises produites à Arras ou à Dunkerque dans le nord de la France.

La pipe de style ottoman a presque certainement été réalisée en Turquie au début du $\mathrm{XIX}^{\mathrm{e}} \mathrm{s}$.

Cette collection de pipes archéologiques de Marseille offre des comparaisons intéressantes avec celle du port de la Quarantaine à Pomègues. Les trois marques de style hollandais les plus courantes provenant de la ville («EB », « $\mathrm{L} »$ couronné et calice) sont aussi les plus nombreuses à Pomègues, où l'éventail est cependant beaucoup plus large. Certains exemplaires uniques trouvent leur équivalent à Pomègues («82 8 couronné, «WS » couronné, étoile, soleil et trompettiste). Les marques « HG » couronné, «IVL », le renard et le cygne n'ont pas été enregistrées à Pomègues. 
La différence la plus importante entre les deux ensembles est qu'aucun produit italien et une seule et unique pipe de style ottoman a été trouvée dans Marseille même, alors que les pièces de ces deux provenances sont largement plus nombreuses que les produits de style hollandais à Pomègues. Il semblerait que les types italien et ottoman, qui ont été largement commercialisés dans la région méditerranéenne dans les $\mathrm{XVIII}{ }^{\mathrm{e}}$ et $\mathrm{XIX}^{\mathrm{e}} \mathrm{s}$., n'étaient pas appréciés dans la cité marseillaise.

Cela soulève la question du très petit nombre total de pipes recueillies lors des fouilles. Sur trois grands sites dans la ville, un total de 24000 fragments, représentant 3131 objets, ont été recensés. Y figurent seulement 206 fragments de pipe $(0,86 \%$ de l'ensemble), représentant un minimum de 22 pipes ( $0,7 \%$ de la collection). Cela contraste nettement avec les sites d'autres pays, même s'il existe une grande variation de quantités de pipes selon les sites où au moins $5 \%$ des assemblages d'artefacts post-médiévaux se composent de pipes. Le pourcentage est souvent beaucoup plus élevé. Par exemple, les fouilles de la Tour du Connétable à Pontefract Castle dans le Yorkshire (Roberts 2002) ont livré 4910 fragments déterminant au moins 2634 objets. Parmi ceux-ci, se trouvaient 2069 fragments de pipe $(42 \%)$ et au moins 579 pipes (22\%). De même, lors des fouilles à Dunbar en Écosse (Perry 2000) on a retrouvé 1512 fragments d'artefacts de toutes sortes dont 317 fragments de pipes en terre $(21 \%)$; lors des fouilles urbaines à Cork en Irlande (Hurley 1997), sur 322 artefacts récupérés, 76 (24\%) étaient des pipes en terre.

La longue série de fouilles de Port-Royal, en Jamaïque, qui a été détruite par un tremblement de terre en 1692, a produit un total de 21575 pipes (Fox 1999). Bien que leur fréquence varie d'un bâtiment à l'autre ou d'une pièce à l'autre, les pipes forment au moins $10 \%$ de l'ensemble, et dans certaines pièces de boutiques, elles atteignent 75 à $80 \%$ de tous les objets présents.

L'extrême rareté des pipes de Marseille, la date relativement tardive à laquelle elles apparaissent et leur valeur intrinsèque élevée - la majorité provenant de Pays-Bas - suggèrent fortement que fumer la pipe dans la ville jusqu'à la fin du XVIII ${ }^{\mathrm{e}} \mathrm{s}$. était l'apanage d'une petite élite fortunée. 



\section{Chapitre 4}

\section{Étude de mobilier manufacturé non céramique}

\section{(Olivier Thuaudet ${ }^{33}$, Marie-Astrid Chazottes ${ }^{34}$ )}

\section{Introduction \\ (O.Thuaudet, M.-A. Chazottes)}

L'intérêt porté au mobilier manufacturé non céramique du Moyen Âge central à l'Époque contemporaine, et notamment celui métallique et en matière dure d'origine animale, a varié de manière importante au cours du temps. Comprendre cette évolution s'avère nécessaire pour penser l'évolution de disciplines qui se révèlent dans leurs problématiques actuelles assez jeunes. Il n'est pas ici question de proposer une historiographie complète mais d'essayer de brosser les grandes lignes de leur parcours.

Pendant très longtemps, les recherches se sont focalisées sur une part très restreinte des objets mis au jour, la faute notamment à une vision empreinte d'histoire des arts. Ainsi, l'orfèvrerie civile ou religieuse, portée par l'attrait des matériaux précieux, des considérations d'ordre symbolique ou religieux, mais surtout esthétique, a été marquée dès le second quart du $\mathrm{XIX}^{\mathrm{e}} \mathrm{s}$., par une multiplication des études sur le mobilier accompagnées parfois de recherches en archives et plus rarement d'extraits littéraires médiévaux. L'étude des sceaux et plus particulièrement de leurs empreintes a également fait l'objet des plus vives attentions. Des considérations politiques, héraldiques, sur l'histoire des grandes familles, parfois artistiques semblent être à la source de l'apparition précoce puis du développement de la sigillographie à partir du milieu du $\mathrm{XIX}^{\mathrm{e}} \mathrm{s}$.

Le développement industriel au XIX ${ }^{\mathrm{e}}$ s., a nécessité dans le nord de l'Europe, la multiplication des grands travaux de dragage pour adapter les fleuves et les rivières aux besoins de la navigation moderne. Un grand

33 Doctorant Aix-Marseille Université, CNRS, LA3M (UMR 7298), «Les accessoires vestimentaires en Provence du XI ${ }^{\mathrm{e}}$ au $\mathrm{XVI}^{\mathrm{e}}$ s. », sous la direction de A. Hartmann-Virnich (co-dir. M.-C. Bailly-Maître).

34 Doctorante AMU, CNRS, LA3M (UMR 7298), «L'économie des matières dures d'origine animale en Provence du $\mathrm{X}^{\mathrm{e}}$ au XVIII' ${ }^{\mathrm{e}} \mathrm{s}$. » sous la direction de A. Hartmann-Virnich (co-dir. H. Amouric). nombre d'objets de toutes sortes et de toutes époques ont alors été mis au jour, récupérés par des érudits et parfois publiés. La contribution la plus intéressante est certainement celle de L. Forgeais, qui de 1862 à 1866, publie les cinq tomes de sa Collection de plombs historiés trouvés dans la Seine. L'étude reste malgré tout très iconographique. Ses travaux seront décriés par quelques-uns qui lui reprochent d'accorder de l'intérêt à des objets qu'ils jugent sans intérêt pour l'histoire des arts. Le mouvement est toutefois enclenché et dans les années 1870 , Viollet-le-Duc, en publiant son Dictionnaire raisonné $d u$ mobilier français, participe à l'ouverture du champ d'étude ; l'iconographie y tient cependant un rôle très majoritaire, et pour le mobilier, la part belle est faite aux productions de qualité. Camille Enlart au début du siècle suivant, avec le tome 3 de son Manuel d'Archéologie française, donne une bien plus grande place au mobilier «commun ». À cette époque, l'intérêt des chercheurs pour les objets manufacturés, notamment en contexte funéraire, permet l'établissement des premières typologies pour le haut Moyen Âge. Mais, les périodes plus tardives sont grandement délaissées (fig. 248).

La genèse des études sur le mobilier manufacturé non céramique est à rechercher en Angleterre où de très nombreuses publications de fouilles présentent, à partir des années 1960, du matériel archéologique. Ce n'est qu'à partir du début des années 1970 que l'on assiste en France, avec le développement des fouilles de sites du bas Moyen Âge, à une augmentation très importante des publications présentant du mobilier. Le sud du territoire et l'Alsace sont alors, pour des raisons différentes, les précurseurs d'un mouvement qui ne tarde pas à se diffuser. Mais, il faut attendre les travaux fondateurs de G. Démians d'Archimbaud sur Rougiers, publiés en 1980, pour qu'apparaisse en France le premier essai de classement typologique du mobilier métallique et en matière dure d'origine animale pour le bas Moyen Âge. Il ne porte alors que sur les objets découverts sur ce site, mais il s'appuie toutefois sur les rares comparaisons disponibles à cette époque. La publication en 1983 de la thèse de J.-Cl. Béal, bien que s'intéressant à la seule période antique, donne une impulsion à l'analyse des objets en os, en bois de cervidé et en ivoire. Par la suite, 
la multiplication des études de site et des catalogues présentant du mobilier manufacturé non céramique s'accroît de manière considérable. Cette évolution va de pair pour le métal avec une prise en compte de problématiques nouvelles liées à l'archéométrie comme l'origine et le choix des matériaux, les techniques de fabrication, etc. Il faut toutefois reconnaître que les recherches typologiques pour le matériel métallique ou en matière dure d'origine animale sont assez rares, faute de spécialistes en nombre suffisant.

Les fouilles réalisées à Marseille ces trente dernières années ont livré un mobilier en métal et en matière dure d'origine animale assez peu abondant. La collection présentée ici compte un peu plus de 730 objets, découverts sur dix-neuf sites ${ }^{35}$ fouillés entre 1980 et 2008. Deux sites dont le mobilier a été en totalité ou en partie publié ont été rejetés de l'étude ${ }^{36}$. Les objets du corpus sont essentiellement métalliques, en alliage cuivreux pour la très grande majorité. Une demi-douzaine de pièces est en matériau blanc - étain ou plomb ou encore alliage des deux - sans qu'il soit possible de le déterminer visuellement; seules des analyses renseigneraient sur leur composition. Presque soixante-dix objets sont en matière dure d'origine animale dont dix en nacre, trois en corail et le reste en os. Dans les autres matériaux, on compte trois individus en or, un en argent, cinq boutons en corozo, deux ensembles de perles de buis, deux perles en jais et dix autres en verre. Deux objets en alliage cuivreux découverts dans des caveaux du XVIII ${ }^{\mathrm{e}} \mathrm{s}$. de la Vieille Major sont en attente de restauration et seront présentés dans le volume dédié à cet édifice.

Les conditions d'enfouissement au sein des contextes archéologiques ont été, à Marseille, préjudiciables à la conservation des objets en fer : une très grande majorité est perdue sous une épaisse couche de corrosion qui souvent ne renferme plus de cœur métallique. La plupart du mobilier en fer se révèle être, après une observation attentive, des clous, des tiges et des fragments de tôles dont l'origine ne peut être décelée. Pourtant, des recherches récentes, à Marseille par exemple ${ }^{37}$, ont montré qu'un mobilier particulièrement riche pouvait être perceptible après restauration ou passage par la radiographie de nodules ou de masses sélectionnées. Mais un tel proces-

35 Alcazar, avenue Vaudoyer, collège Vieux-Port, église abbatiale Saint-Victor, Espace Bargemon, Esplanade de la Major, Hospice de la Vieille Charité, Ilot 24 N, Ilot 55, Ilot 61-62 N (Les Pistoles), Place de la Providence, Place Villeneuve-Bargemon, Puget III, Ilot $39 \mathrm{~N}$ (R.H.I. Bon-Jésus), Rue Leca, 14 rue Trinquet, Saint-Laurent, Tunnel de la Major, Vieille Major.

36 Il s'agit des fouilles du Parc Sainte-Barbe (Vallauri 1997) et de la place Général-de-Gaulle (Suviéri, De Boisséson 2001).

37 Suviéri 1998 repris dans Suviéri 2001a et Suviéri, De Boisséson 2001. sus, coûteux en temps et financièrement, n'a pu être mené ici. Le rare mobilier en fer clairement identifiable a donc été rejeté de cette étude pour ne pas biaiser la réflexion. De même, tous les éléments considérés comme résiduels - dont la datation chrono-typologique ne laisse aucun doute - ont été également ignorés ${ }^{38}$.

L'étude a été scindée en quinze sections regroupant chacune un type de mobilier particulier. Les six premières sont relatives à l'apparence : objets portés sur le costume ou liés à la toilette; les cinq suivantes sont consacrées à l'instrumentum de l'artisanat ou du quotidien et aux loisirs, la douzième à l'ameublement et à la serrurerie, la treizième aux clous et rivets, les deux dernières aux déchets de fabrication et aux objets indéterminés.

Les objets enregistrés dans la base de données du dépôt archéologique de Marseille sont précédés d'un numéro de site. Les pièces retrouvées lors des fouilles de l'abbaye Saint-Victor possèdent, dans la presque totalité des cas, un numéro d'inventaire donné lors des opérations. Pour les autres sites, les objets sont identifiés par leur numéro d'inventaire municipal, ou à défaut par leur numéro d'unité stratigraphique (voir Annexe 1 et 5)

L'étude technique - et anatomique pour le mobilier en matière dure d'origine animale - est associée, autant que possible, à une approche comparative susceptible de replacer ces objets dans une période chronologique. Pour le matériel métallique, en l'absence de précision sur le matériau, il s'agit d'un alliage cuivreux. Dans ce cas, l'objet est nécessairement le résultat d'une fonte. Le produit obtenu est soit un objet qui n'a plus qu'à recevoir une finition, soit une ébauche qui a besoin d'être travaillée par des phases de déformation plastique et de recuit.

\section{Les anneaux et boucles avec ou sans chape mobile (O. Thuaudet)}

La boucle est d'un usage polyvalent, qu'elle soit de ceinture, de bandoulière, de baudrier, de chaussure, qu'elle fixe des éléments d'armure, de harnachement du cheval, qu' elle serve à sangler un linceul, etc. Son emploi dans la ceinture est de loin majoritaire et la plupart des objets décrits ci-dessous ont probablement joué ce rôle. Même si l'iconographie atteste de l'usage de tel ou tel type pour telle ou telle fonction, cette source ne donne qu'un aperçu fragmentaire de la réalité. Les possibilités d'emploi d'une boucle sont aussi variées que celles des

38 Les agrafes à double crochet, parfois encore employées au $\mathrm{XI}^{\mathrm{e}}$ s., n'ont pas été prises en compte. Leur étude n'a d'intérêt que dans l'optique d'une analyse complète du corpus de cet accessoire du costume quelque soit sa période d'utilisation. 
lanières en cuir ou en tissu. Celles des anneaux circulaires sont encore plus vastes à cause de leur forme simple et donc indémodable, car propre à tout. Les conditions de dépôt, de conservation ou de découverte ne permettent pas toujours la conservation de l'ardillon des boucles, ni même de leur chape. Toute tentative de caractérisation typologique des boucles basée sur ces deux éléments est donc vouée à l'échec. La forme du cadre et ses dimensions, qui influent d'ailleurs certainement sur la destination des boucles et anneaux, apparaissent comme le seul moyen de construire une typo-chronologie.

\subsection{Les anneaux et boucles circulaires à cadre homogène}

Il est possible de répartir les anneaux et les boucles circulaires (voir Annexe 4, $\mathbf{n}^{\circ} \mathbf{1}$ ) en deux grands ensembles distincts, ceux dont le diamètre est supérieur à $2 \mathrm{~cm}$ - anneaux et boucles - et ceux pour lequel il est inférieur ou égal à cette valeur - annelets et bouclettes. Ces derniers sont régulièrement retrouvés en fouille ; à ce jour, plus de deux cents exemplaires ont été recensés en Provence.

Un sous-groupe se distingue au sein même des annelets. Il rassemble les objets dont le diamètre est compris entre 0,8 et $1 \mathrm{~cm}$. À Marseille, sur dix-huit annelets circulaires mis au jour, sept s'y rattachent. Ces objets, en alliage cuivreux, pourvus d'un cadre de section quadrangulaire $(\mathrm{e}=0,09$ à $0,2 \mathrm{~cm})$ pour la plupart ont probablement été obtenus par découpe à l'emporte-pièce (ex : fig. 237, $\mathbf{n}^{\circ} \mathbf{3}$ et 4). Ces caractéristiques sont communes à la plupart des exemplaires connus. Certains annelets ont une section circulaire (fig. $237, \mathbf{n}^{\circ} 2$ ), signe d'une mise en forme différente, à l'aide d'une pince ou par la fonte selon qu'il y ait ou non une interruption du cadre. Il n'est pas possible de situer exactement la date d'apparition des anneaux circulaires : quelque soit leur taille, ils apparaissent dès une haute antiquité. Toutefois, à partir du XII ${ }^{\mathrm{e}}$ s., en Europe de l'Ouest, la proportion des annelets dénombrés dans les fouilles archéologiques augmente progressivement. Elle atteint son acmé entre la deuxième moitié du $\mathrm{XIII}^{\mathrm{e}}$ et le milieu du $\mathrm{XVI}^{\mathrm{e}}$ s. Ces annelets deviennent d'un usage peu courant par la suite. Les premiers temps de leur renouveau sont illustrés, à Marseille, par cinq exemplaires : le premier (fig. 237, $\mathbf{n}^{\circ} \mathbf{1}$ ) dans un épandage du $\mathrm{XII}^{\mathrm{e}} \mathrm{s}$., un second $(\mathrm{d}=0,9 \mathrm{~cm})$ trouvé dans le bourg de Morier dans un sol de la fin du XII ${ }^{\mathrm{e}}$ ou du début du XIII ${ }^{\mathrm{e}}$ s., les deux derniers $(\mathrm{d}=0,8$ et $0,9 \mathrm{~cm})$, datés du XIII ${ }^{\mathrm{e}}$ s., localisés dans un caveau de la cathédrale ${ }^{39}$ et dans une tombe

39 L'un des onze individus du caveau est daté par ${ }^{14} \mathrm{C}$ de $1224-1291$ avec un maximum de probabilité autour de 1278. d'adulte à proximité des remparts (Puget III). Les neuf autres spécimens (ex : fig. $237, \mathbf{n}^{\circ} \mathbf{5}$ et $\mathbf{6}$ ) proviennent de contextes variés, parfois remaniés, de la fin du Moyen Âge ou de l'Époque moderne, de différents sites.

Quelques bouclettes ont pu perdre leur ardillon et être identifiées comme des annelets. Trois bouclettes en alliage cuivreux, parfaitement identifiables, de $1,3 \mathrm{~cm}$ de diamètre $(\mathrm{e}=0,14$ à $0,16 \mathrm{~cm})$ ont été retrouvées à l'Alcazar : l'une a été façonnée à partir d'un fil tréfilé enroulé sur lui-même (fig. 237, $\mathbf{n}^{\circ}$ 7) ; les deux dernières (fig. 237, $\mathbf{n}^{\circ} 8$ ), dont un spécimen non figuré mis au jour dans une tranchée d'épierrement de la fin du XIII ou du début du $\mathrm{XIV}^{\mathrm{e}} \mathrm{s}$., par découpe à l'emporte-pièce. Dans chaque cas, l'ardillon est un simple fil dont la base est enroulée autour du cadre. L'évolution de l'utilisation de ces bouclettes est semblable à celle constatée pour les annelets, à ceci près que la première attestation connue est de la première moitié du XIII $\mathrm{s}$.

L'usage des annelets est multiple. La culture matérielle médiévale et moderne montre qu'ils ont pu entrer dans la composition de protections de maille, de chấnettes de suspension ou de ceinture à agrafe ou d'œillets de vêtement pour le passage de lacets. La dernière interprétation, proposée par D. Andrews dès 1978, a été confirmée par O. Berthon en 2012. Les annelets équipés d'un ardillon ont pu également aider à la fixation d'une lanière. Il est ordinairement reconnu que les mailles treslies sont en fer ; pourtant, des fragments en alliage cuivreux, parfois avec rivetage, ont été découverts sur différents sites archéologiques dont certains en Provence : à l'abbaye de Montmajour à Arles, place de la Principale et impasse de l'Oratoire à Avignon. Il a été retrouvé un groupe de mailles treslie en alliage cuivreux dans un «magma» de fer au Castellu de Baricci (fin $\left.\mathrm{XIV}^{\mathrm{e}}-1505\right)$ et un annelet à rivet $\left(\mathrm{XIV}^{\mathrm{e}}-\mathrm{XV}^{\mathrm{e}} \mathrm{s}\right.$. $)$ au village médiéval de l'Ortolo en Corse (Comiti 1996, p. 20, 24). Le château de Peyrepertuse dans l'Aude a livré trois anneaux liés, dont un avec rivet (Barrère 2000, p. 231). Sur le site de la Crypta Balbi à Rome, un annelet à rivet a été découvert dans un contexte de la deuxième moitié du XIII' s. (Sfligliotti 1990, p. 548). Il n'apparaît pas toujours évident de différencier les annelets des « anneaux de main» ou joncs lorsqu'ils sont de grande taille. D'autres auteurs proposent que les bouclettes aient servi à la fermeture des chaussures (Démians d'Archimbaud 1980, p. 490 ; Viara 1996, p. 384 ; Burille 1996, p. 57 ; Colardelle 1999, t. 6, p. 30). Cette fonction est attestée par des spécimens en fer au diamètre compris entre 1 et $1,6 \mathrm{~cm}$ conservés sur des chaussures à Londres, et datés de la seconde moitié du $\mathrm{XIV}^{\mathrm{e}} \mathrm{s}$. et de la première moitié du XV (Egan, Pritchard 2002, p. 60-63). Les chaussures londoniennes pourvues d'un système d'attache à boucle sont rares avant cette période (Grew, De Neergaard 2001, 


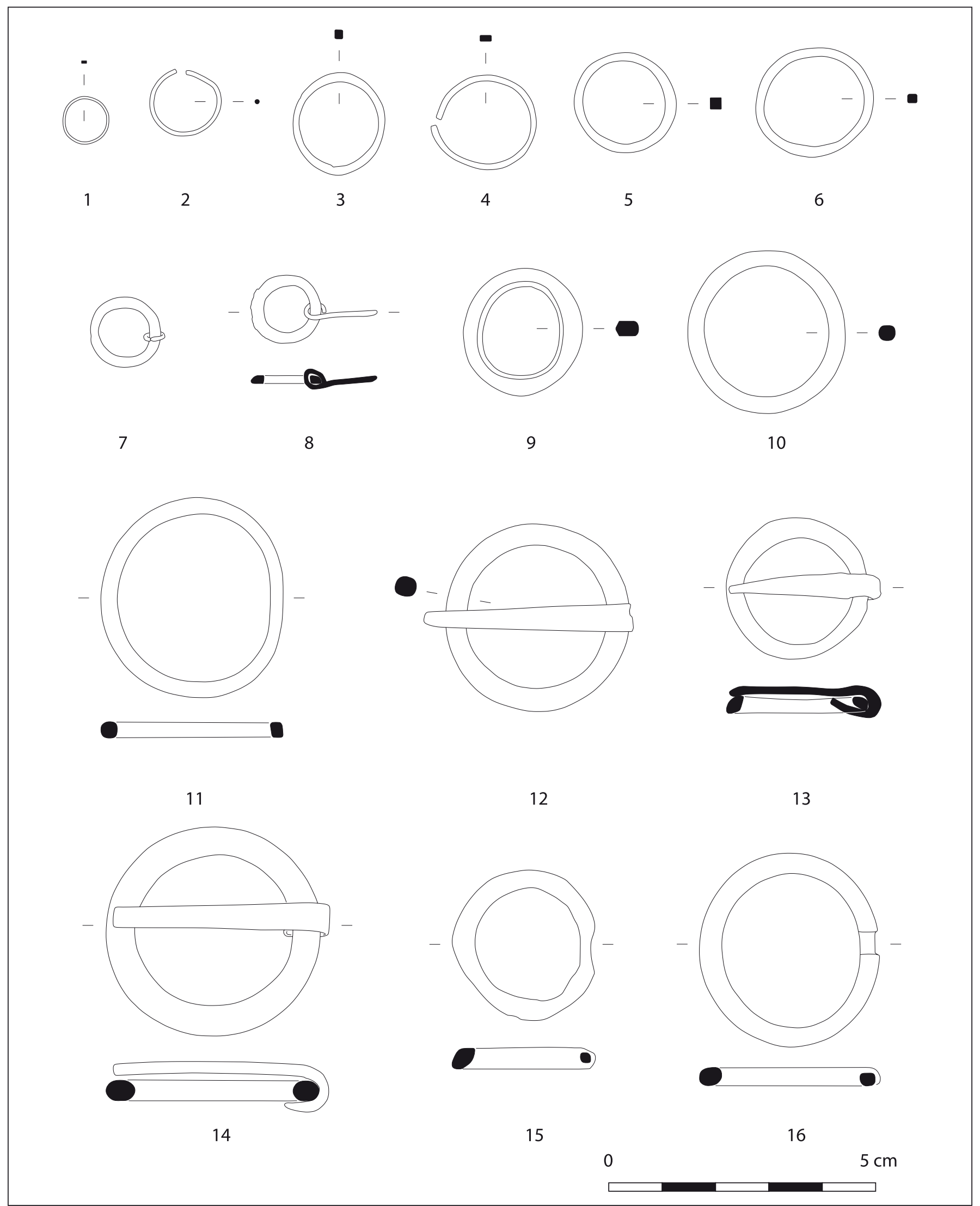

Fig. 237. Anneaux et boucles circulaires à fenêtre unique (O. Thuaudet). 1-5, 8-12, 15 : Alcazar ; 6-7 : Tunnel de la Major ; 13 : la Charité ; 14 : collège Vieux-Port ; 16 : llot 55. 
p. 17, 25, 29 et 38). D'après M.-É. Gardel, les annelets au diamètre de $1,2 \mathrm{~cm}$ peuvent provenir de tuniques de mailles, alors que ceux des chausses ou des gants sont d'un diamètre généralement plus réduit $(0,8 \mathrm{~cm})$. Lors des fouilles du village médiéval de Vilarnau, un annelet de $1,5 \mathrm{~cm}$ de diamètre a été retrouvé au niveau du pubis d'un squelette d'adulte non daté (Passarius et al. 2008, p. 241). Les auteurs envisagent qu'il ait pu servir au maintien d'un vêtement, peut-être au nouage d'une ceinture. Dans ce cas particulier, comme pour celui découvert au niveau des deux pieds superposés d'un squelette (XVIII ${ }^{\mathrm{e}} \mathrm{s}$.) retrouvé dans l'église SaintLaurent-de-Grenoble (Colardelle 1999, t. 6, p. 30), ils ont pu servir au nouage du lien fermant le linceul. En Italie, la fouille d'un cimetière a permis d'en retrouver vingt-sept exemplaires entiers ou fragmentaires répartis sur l'épaule gauche d'un adolescent de douze/quinze ans et sous la partie droite du bassin d'un enfant de neuf ans $^{40}$ (Amici 1986, tableau ${ }^{\circ}{ }^{4}$ ). Peut-être s'agit-il de restes de chaînettes?

Un peu moins d'une trentaine d'anneaux ou de boucles circulaires a été répertoriée, en provenance de divers contextes de la fin du XIII ${ }^{\mathrm{e}}$ jusqu'au $\mathrm{XIX}^{\mathrm{e}} \mathrm{s}$. (ex : fig. 237, $\mathbf{n}^{\circ} \mathbf{9}$ et 10). Découverts sur la quasi-totalité des sites marseillais, ils mesurent jusqu'à 4,3 cm de diamètre. D'épaisseur et de section variable, confectionnés par martelage ou plus probablement par la fonte sans que le mode opératoire soit assuré dans la plupart des cas, ces objets se caractérisent par une très grande diversité. L'un d'eux (fig. 237, $\mathbf{n}^{\circ} \mathbf{1 1}$ ) se caractérise par un aplatissement de la courbure du cadre qui pourrait correspondre à l'emplacement d'un ardillon disparu. Trois boucles, obtenues par fonte, ont conservé un ardillon plat dont l'extrémité est rectangulaire, légèrement arrondie ou épointée (fig. 237, $\mathbf{n}^{\circ} 12$ à 14). La boucle $\mathrm{n}^{\circ} 13$ présente la particularité de disposer d'un cadre à section en amande, caractéristique attestée du XIII ${ }^{e}$ au $X{ }^{e}$ s. Son ardillon conserve des traces de dorure au revers. Son épointement se retrouve sur certains exemplaires interprétés comme fermail par G. Egan et Fr. Pritchard (Egan, Pritchard 1996, p. 64-65, 248-260), mais la distinction entre boucles et fermaux est loin d'être, comme ici, toujours évidente.

Les anneaux et les boucles circulaires présentent à la fois une persistance et une variété de formes si importante qu'il est impossible de mettre en évidence une quelconque typologie ou évolution chronologique, même après comparaison avec la bibliographie française et étrangère. Leur morphologie passe-partout conduit à les utiliser de multiples manières qu'il est illusoire de vouloir lister : élément d'attache ou de suspension scellé

40 Le décompte pour chaque squelette n'est pas fourni. dans un mur, élément d'attelage ou de harnachement, boucle de ceinture, fermail, etc. En fer ou en alliage cuivreux, les anneaux et les boucles sont connus depuis une haute antiquité et sont restés en usage sans interruption jusqu'à nos jours.

\subsection{Les boucles ovales à replat}

Deux boucles obtenues par fonte présentent une morphologie qui ne laisse aucun doute sur la présence d'un ardillon aujourd'hui perdu (voir Annexe 4, $\mathbf{n}^{\circ}$ 2). La première (fig. $237, \mathbf{n}^{\circ} \mathbf{1 5}$ ) se caractérise par un replat et un rétrécissement du cadre destiné à recevoir la base d'un ardillon perdu. Un léger élargissement, à l'opposé, marque la réception de la pointe de l'ardillon. Cet objet se rattache à un ensemble de boucles circulaires ou ovales provençales offrant les mêmes caractéristiques. Assez souvent, l'élargissement destiné à recevoir la pointe de l'ardillon s'accompagne d'une dépression. Ces boucles doivent être distinguées de celles dont le rétrécissement est strictement localisé, comme pour un exemplaire du corpus (fig. $\mathbf{2 3 7}, \mathbf{n}^{\circ} \mathbf{1 6}$ ). Dans les deux cas, le replat est caractéristique des $\mathrm{XIII}^{\mathrm{e}}-\mathrm{XIV}^{\mathrm{e}} \mathrm{s}$. La tournure de la première boucle est cependant moins homogène que celles des sous-types actuellement reconnus.

\subsection{Les boucles non circulaires à fenêtre unique}

La forme semi-ovale est de loin la plus courante dans la deuxième partie du Moyen Âge. De la plus simple, à cadre homogène, à la plus complexe, à talons et à traverse distale moulurée, les variations morphologiques sont extrêmement riches. La collection marseillaise en contient neuf exemples fabriqués par fonte (voir Annexe 4, n³).

Une première boucle (fig. $\mathbf{2 3 8}, \mathbf{n}^{\circ} \mathbf{1}$ ), à traverse proximale de section circulaire et traverse distale en amande et oblique, présente une déformation dont l'intensité ne peut être que le résultat d'un geste volontaire. Cet objet a été découvert dans un remblai contenant de la céramique du second quart ou de la fin du VI ${ }^{\mathrm{e}} \mathrm{s}$. (Tunnel de la Major), mais sa datation typologique ne correspond absolument pas. Les comparaisons disponibles situent la fabrication de cette boucle entre les $\mathrm{X}^{\mathrm{e}}-\mathrm{XI}^{\mathrm{e}} \mathrm{s}$. et le $\mathrm{XV}^{\mathrm{e}} \mathrm{s}$., mais son matériau et surtout l'orientation oblique de la traverse distale réduisent l'intervalle aux $\mathrm{XIII}^{\mathrm{e}}, \mathrm{XIV}^{\mathrm{e}}$ et $\mathrm{XV}^{\mathrm{e}} \mathrm{s}$. En conséquence, soit cet objet doit être considéré comme une intrusion, soit les céramiques contenues dans ce niveau sont entièrement résiduelles.

Une seconde boucle (fig. $\mathbf{2 3 8}, \mathbf{n}^{\circ} \mathbf{2}$ ) présente un cadre cintré de section losangique. Sa traverse proximale est 


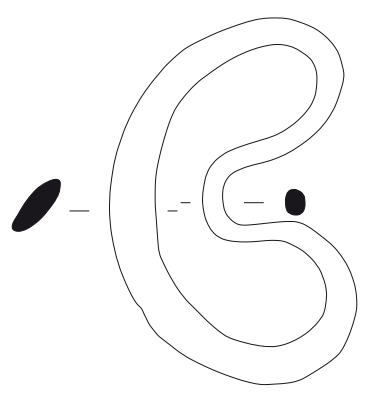

1

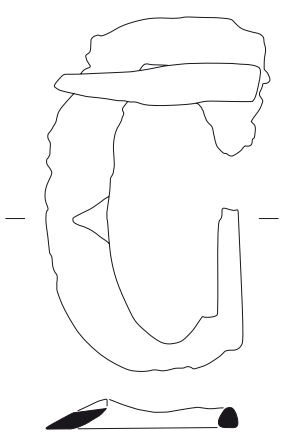

5
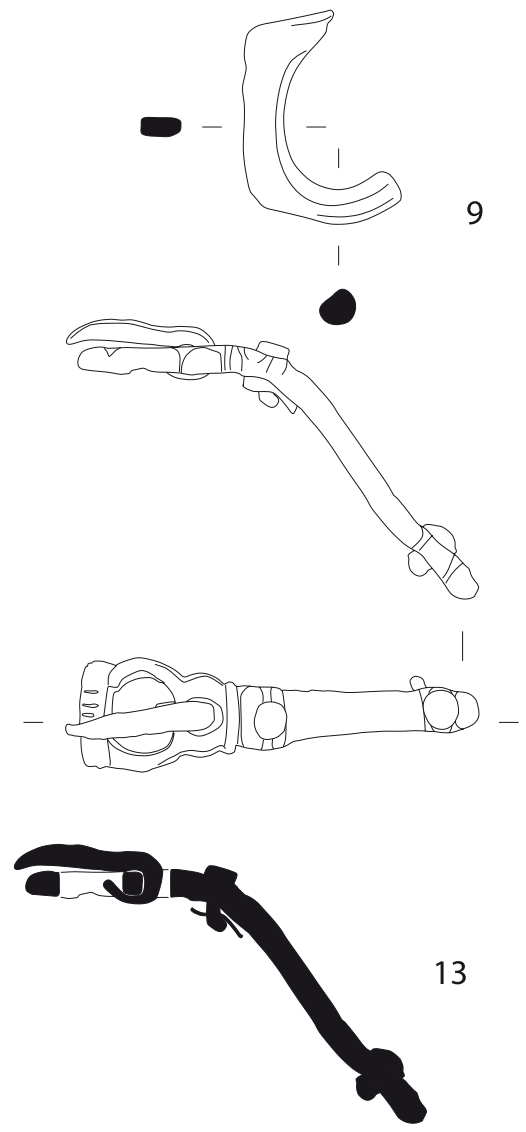

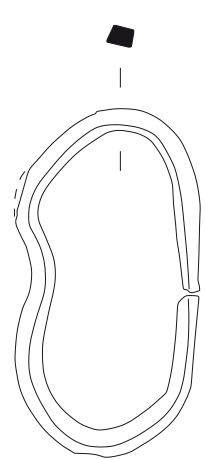

2

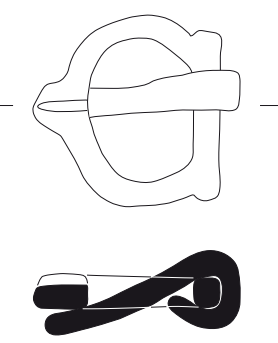

6

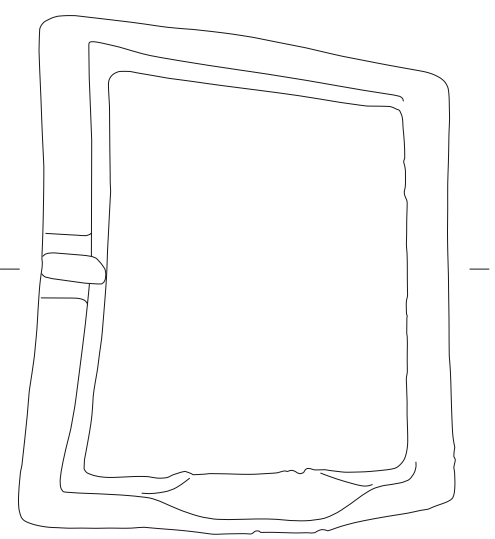

0

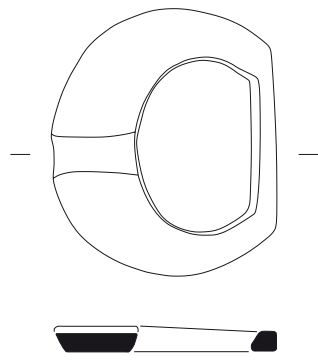

3

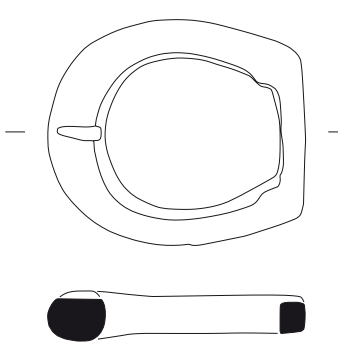

4
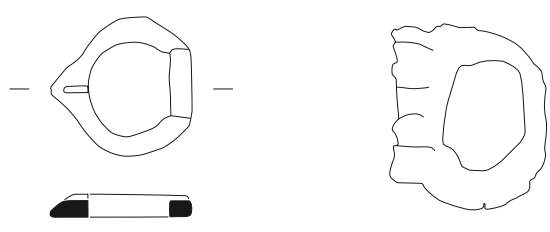

8

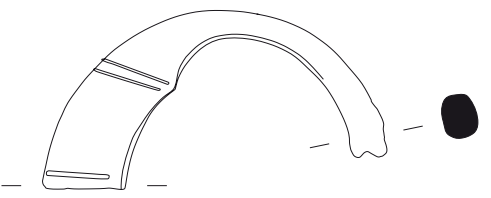

11

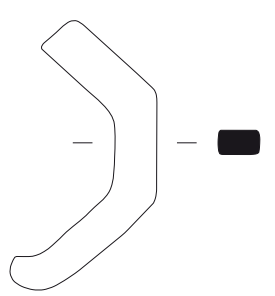

12

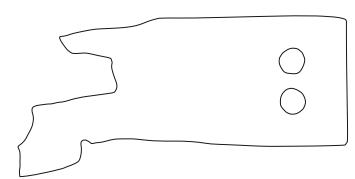

$5 \mathrm{~cm}$

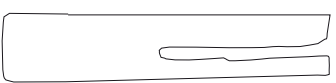

Fig. 238. Boucles non circulaires à fenêtre unique et boucles à chape intégré (1-13: O. Thuaudet ; 14 : M.-A. Chazottes).1, $9:$ Tunnel de la Major ; 2 : Saint-Victor ; 3 : Pistoles ; 4, 12 : llot 24N ; 5 : llot 55 ; 6-7, 10-11, 13 : Alcazar ; 8 : place Villeneuve-Bargemon ; 14 : parvis de l'église Saint-Laurent. 
cassée en son centre et son cadre porte des traces de limage. Ce tracé, connu dès l'époque gallo-romaine, se perpétue jusqu'au $\mathrm{XVI}^{\mathrm{e}} \mathrm{s}$. avec des types très variés. En l'occurrence, l'exemplaire marseillais est fort similaire à une pièce de Rougiers datée de la fin XIII ${ }^{\mathrm{e}}$-début du $\mathrm{XIV}^{\mathrm{e}}$ s. $^{41}$ (Démians d'Archimbaud 1980, p. 491, pl. 465, $\mathrm{n}^{\circ} 38$ ).

La traverse distale du $\mathbf{n}^{\circ} \mathbf{3}$, élargie et plate, conserve des traces de limage au revers, et à l'avers une large dépression longitudinale destinée à recevoir la pointe de l'ardillon. Ce type de boucle, parfaitement connu, dont la diffusion se limite en grande partie au Midi-Pyrénées, au Languedoc et à la Provence est caractéristique du $\mathrm{XIV}^{\mathrm{e}} \mathrm{s}$. et perdure peut-être au début du siècle suivant.

L'une des boucles semi-ovales (fig. 238, $\mathbf{n}^{\circ} \mathbf{4}$ ), plus longue que large, se caractérise par un cadre de section ovale ou, pour la traverse proximale amincie, quadrangulaire, et dispose d'une dépression sur la traverse distale. Les boucles semi-ovales sans talon, plus larges que longues, semblent apparaître au XII ${ }^{e}$ ou XIII ${ }^{e}$ s. et se perpétuer jusqu'au $\mathrm{XVI}^{\mathrm{e}} \mathrm{s}$. Elles se distinguent globalement en fonction de la zone dans laquelle le cadre outrepasse la largeur de la traverse proximale. Cet objet se rattache au groupe dans lequel cette caractéristique se situe au centre ou dans la zone inférieure. Un spécimen du second quart ou du milieu du XIV ${ }^{\mathrm{e}} \mathrm{s}$. du quartier Sainte-Barbe, à cadre homogène, est la seule autre boucle découverte à Marseille qui puisse se rapprocher de celui de notre corpus ${ }^{42}$. L'élargissement et l'épaisseur de la traverse distale de cette boucle en font un exemplaire atypique.

La boucle $\mathbf{n}^{\circ} \mathbf{5}$, plus large que longue, possède une dépression triangulaire sur sa traverse distale élargie, et un ardillon plat soudé à un amas d'oxydes. Des objets découverts entre autres à l'abbaye de l'Escaladieu (non daté) à Bonnemazon, dans les Hautes-Pyrénées (Platt dir., 1971, p. 38), sur le site de L'Esquerda (hors stratigraphie) à Roda de Ter, en Espagne (Ollich 1976, p. 509), à la Maison forte de Naux (dernier tiers du $\mathrm{XIV}^{\mathrm{e}} \mathrm{s}$.) à Colayrac-Saint-Cirq, en Lot-et-Garonne (Ballarin et al. 2007, p. 132) s'en rapprochent tout en s'en distinguant par des détails morphologiques. Certaines spécificités morphologiques des boucles 4 et 5 permettent de les situer entre les $\mathrm{XIII}^{\mathrm{e}}$ et $\mathrm{XV}^{\mathrm{e}} \mathrm{s}$.

Deux boucles semi-ovales de petite taille (fig. 238, $\mathbf{n}^{\circ} \mathbf{6}$ et 7) conservent un ergot triangulaire à dépression destiné à réceptionner la pointe de l'ardillon. La première est à traverse proximale amincie, la deuxième, à talon,

41 La datation stratigraphique est tirée des archives du LA3M.

42 Objet figuré dans Vallauri 1997, p. 64, fig. 40, n6. Les archives $\mathrm{du} \mathrm{LA} 3 \mathrm{M}$ ont fournies la datation stratigraphique. avec des traces d'oxyde de fer indiquant le matériau de l'ardillon. Ces deux petites boucles appartiennent à un type dont l'utilisation est assurée du milieu du XIII' $\mathrm{s}$. à la fin $d u X \mathrm{XIV}^{\mathrm{e}} \mathrm{s}$. : deux exemplaires similaires ont été retrouvés à Marseille dans le quartier Sainte-Barbe (Vallauri 1997, p. 64, fig. 40, $\mathrm{n}^{\circ} 4$ ), dans des niveaux de la fin du XIII ${ }^{\mathrm{e}}$ au milieu du XIV $\mathrm{X}^{\mathrm{e}} \mathrm{s} .{ }^{43}$.

Les boucles $\mathbf{n}^{\circ} \mathbf{8}$ et $\mathbf{9}$ de la fig. $\mathbf{2 3 8}$ présentent une barre au niveau de la partie centrale de la traverse distale, vierge de toute ornementation pour l'une, à décor de bosses pour l'autre. La pauvreté des éléments de comparaison actuellement connus pour la seconde ne permet de proposer qu'un intervalle entre les XIII ${ }^{e}$ et $\mathrm{XIV}^{\mathrm{e}} \mathrm{s}$. Les éléments sont en revanche beaucoup plus nombreux pour la première. Mais ces objets proviennent de contextes mal datés ou de fiabilité incertaine. Là encore, l'intervalle $\mathrm{XIII}{ }^{\mathrm{e}}-\mathrm{XIV}^{\mathrm{e}} \mathrm{s}$. est le seul à pouvoir être considéré.

La boucle trapézoïdale $\mathbf{n}^{\circ} \mathbf{1 0}$ (fig. $\mathbf{2 3 8}$ ), à dépression encadrée de deux moulures sur la traverse distale, présente un aplatissement au centre de la traverse latérale gauche, possible conséquence d'un coup de marteau alors que l'objet venait d'être démoulé. La forme trapézoïdale est déjà connue à Colletière, en Isère, dans la première moitié du $\mathrm{XI}^{\mathrm{e}} \mathrm{s}$. pour un spécimen en fer (Colardelle, Verdel 1993, p. 212), mais elle ne devient courante qu'aux $X^{\prime} V^{\mathrm{e}}$ et $X^{\mathrm{X}} \mathrm{s}$. et passe de mode au cours du XVI ${ }^{\mathrm{e}} \mathrm{s}$. Le modelé et le matériau de la boucle plaident en faveur d'une datation tardive, l'objet ne semble donc pas antérieure au $\mathrm{XIV}^{\mathrm{e}} \mathrm{s}$.

L'objet $\mathbf{n}^{\circ} 11$ (fig. 238) pose un problème d'identification. Sa forme peut en effet correspondre à une boucle, mais le tracé de sa rive interne ainsi que la section quadrangulaire de sa "traverse distale », très épaisse pour une boucle en alliage cuivreux, sont atypiques. En outre, des incisions sont disposées symétriquement sur chacune des deux faces principales, Peut-être est-ce un fermail ?

Une dernière boucle (fig. $\mathbf{2 3 8}, \mathbf{n}^{\circ} \mathbf{1 2}$ ), bien que fragmentaire, se distingue par une angulation du cadre ( $\mathrm{L}$ reconstituée $=2,4 \mathrm{~cm}$ ). Il apparaît possible de restituer une forme hexagonale. Cette conformation rare, s'il s'agit bien d'une boucle, est connue par un objet retrouvé lors de fouilles anciennes dans ou à proximité de la Chapelle des Gicons, à Saint-Didier dans les Hautes-Alpes, par un objet bulgare particulièrement orné du plateau de Choumen (Doncheva 2006). Si on en juge par l'évolution morphologique générale des boucles du costume, cet objet ne peut être antérieur à la seconde moitié du XIII s., ni postérieur au XVI ${ }^{\mathrm{e}} \mathrm{s}$.

43 Contexte stratigraphique issu des archives du LA3M. 


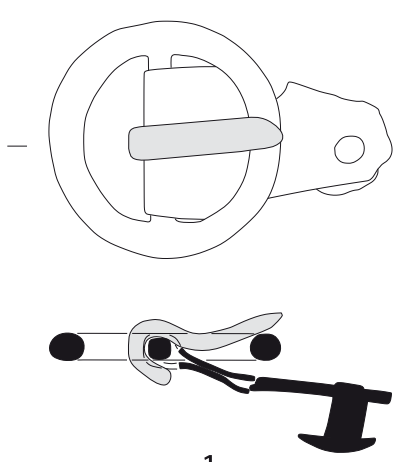

1

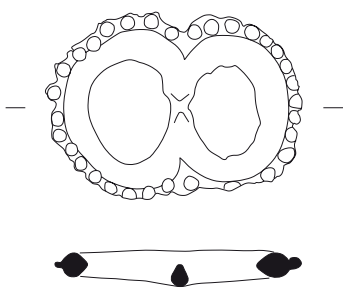

4

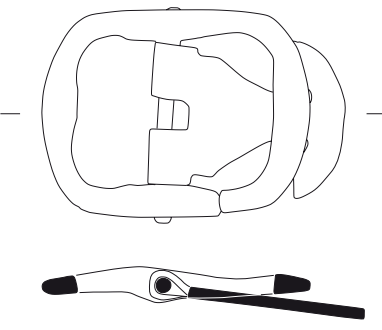

7

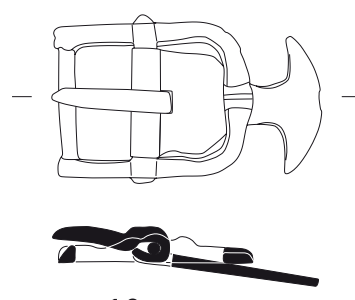

10

0
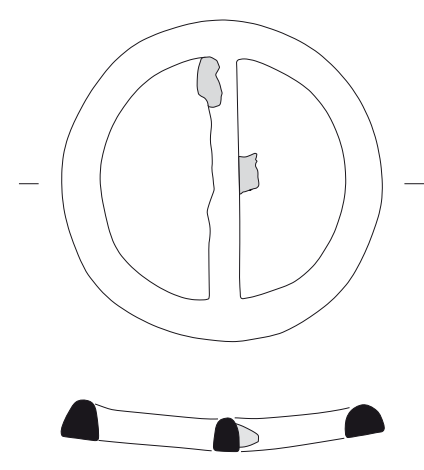

2

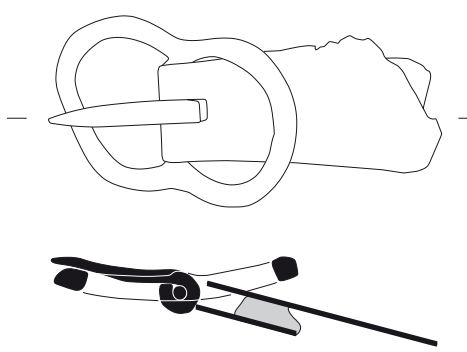

5
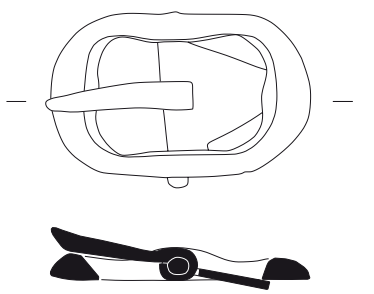

8
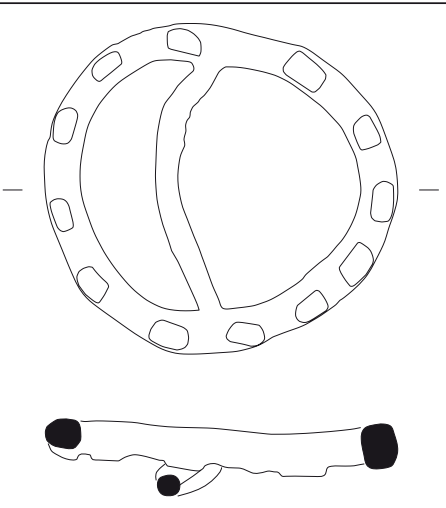

3
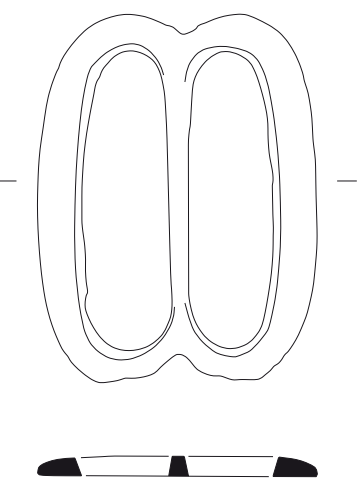

6

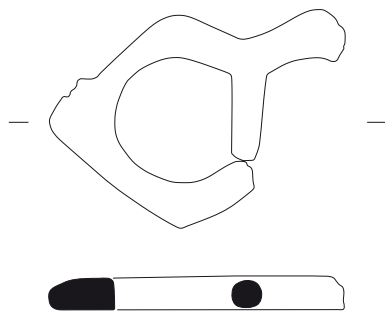

9

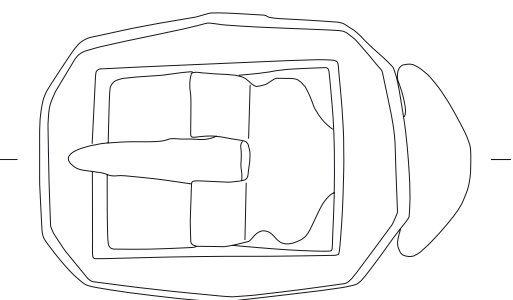

11

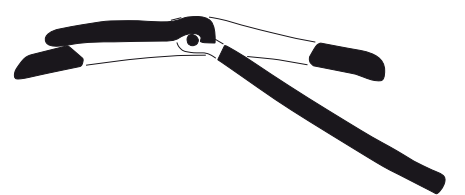

Fig. 239. Boucles à double fenêtre (O. Thuaudet). 1 : Saint-Victor ; 2,5 : Tunnel de la Major ; 3 : llot $55 ; 4,10$ : place Villeneuve-Bargemon ; 6 : rue Leca ; 7, 9 : Alcazar ; 8 : place des Pistoles ; 11 : Esplanade de la Major. 


\subsection{Les boucles à double fenêtre}

Parmi les onze boucles à double fenêtre du corpus (voir Annexe 4, $\mathbf{n}^{\circ} \mathbf{4}$ ), toutes obtenues par fonte, trois d'entre elles sont de forme circulaire et à traverse diamétrale. La plus petite présente un profil plat (fig. 239, $\left.\mathbf{n}^{\circ} \mathbf{1}\right)$. Il est concave pour une boucle de taille médiane (fig. 239, $\mathbf{n}^{\circ}$ 2). Ces deux boucles ont conservé un ardillon en fer ou les traces de sa présence. Une chape est encore rattachée à la traverse diamétrale de l'une d'elles, ce qui est très rare pour ce type de boucle. La tôle s'amenuise vers son extrémité proximale où elle est traversée par un rivet en fer à tête circulaire bombée. Une boucle semblable, à ardillon en fer, trouvée dans une réoccupation de la seconde moitié du $\mathrm{XV}^{\mathrm{e}}$ - première moitié du $\mathrm{XVI}^{\mathrm{e}} \mathrm{s}$. des thermes gallo-romains de Bliesbruck en Moselle (Clemens, Petit 1995, p. 77), a également conservé une chape terminée en partie proximale, dans le sens de la largeur, par deux petits rivets en alliage cuivreux matés au revers de la tôle. Ils retenaient une lanière de cuir insérée dans la chape, a contrario du rivet de la boucle de la collection qui traversait une courroie trop épaisse pour la chape. Les petites boucles circulaires à traverse diamétrale, parfois de profil concave ou convexe sont attestées du XIII ${ }^{e}$ au XVI ${ }^{e}$ s. Elles ont servi à fixer la ceinture, mais également les chaussures et, si l'on en croit E. Blanche, les éperons (cité dans Egan, Pritchard 2002, p. 65). Un usage dans le harnachement est envisageable étant donné le calibre de la lanière auquel est encore accrochée la boucle $\mathbf{n}^{\circ} \mathbf{1}$. La $\mathbf{n}^{\circ} \mathbf{2}$ appartient à un type beaucoup moins bien connu, dont les quelques exemplaires sont répertoriés entre les $\mathrm{XIII}^{\mathrm{e}}$ et $\mathrm{XV}^{\mathrm{e}} \mathrm{s}$. Une troisième boucle circulaire à traverse diamétrale (fig. 239, $\mathbf{n}^{\circ} \mathbf{3}$ ), de plus grande dimension, déformée, est recouverte à l'avers, sur tout son pourtour, de pastilles ovales. Deux boucles à pastilles circulaires mais à digitations en bordure, avec une chape, ont été découvertes en Italie dans un contexte de la seconde moitié du XIII ${ }^{\mathrm{e}}$ s. et deux autres, sans chape, sont mal datées (Piuzzi 1998, p. 281-282, 285 ; Piuzzi et al. 2003, p. 98 ; Piuzzi 2003, p. 175).

La première des trois boucles à double fenêtre ovale symétrique retrouvées à Marseille, est en matériau blanc, vraisemblablement un alliage étain-plomb. Elle est ornée au bas d'un gradin (fig. 239, $\mathbf{n}^{\circ} \mathbf{4}$ ) et, en bordure du cadre, d'une série de bossettes disposées symétriquement sur les deux faces (fig. 239, $\mathbf{n}^{\circ} \mathbf{4}$ ). Elle appartient à un type attesté à Avignon (Impasse de l'Oratoire) par huit exemplaires, dont quatre ornés de manière identique à celle-ci. À l'exception d'un spécimen daté du $\mathrm{XIV}^{\mathrm{e}} \mathrm{s}$. - vraisemblablement de la deuxième moitié -, tous les objets avignonnais ont été retrouvés hors stratigraphie ou dans des couches superficielles. Des boucles similaires, mais sans décor, sont recensées à Londres de la deuxième moitié du $\mathrm{XIV}^{\mathrm{e}} \mathrm{s}$. à la première moitié du siècle suivant (Egan, Pritchard 2002, p. 86-87). L'une d'elles, de la première moitié du $\mathrm{XV}^{\mathrm{e}} \mathrm{s}$., est identique à notre exemplaire et conserve un fragment de lanière de cuir autour de sa traverse médiane. Ces boucles, qui ont parfois gardé leur ardillon en fer, sont interprétées comme des boucles de chaussure (Egan, Pritchard 2002, p. 86). La boucle en alliage cuivreux $\mathbf{n}^{\circ} \mathbf{5}$, légèrement concave et déformée, est encore rattachée à sa chape qui contient des fragments de tissu. Les boucles à double fenêtre ovale sont actuellement attestées de la première moitié du XI' $\mathrm{s}$. au XVIII ${ }^{\mathrm{e}} \mathrm{s}$. Aucune caractéristique ne permet d'avancer pour le moment une datation. La boucle $\mathbf{n}^{\circ} \mathbf{6}$ présente la particularité d'être bien plus large que longue. Les boucles de ce type se rencontrent de temps à autre à la toute fin du Moyen Âge ou à l'Époque moderne, mais rares sont celles qui présentent un tel rapport de proportions. Un spécimen ( $\mathrm{L}$ x $1=3,5 \times 4,5 \mathrm{~cm}$ ) hors stratigraphie, et à profil plus quadrangulaire, du Castello di Montereale Valcellina (Frioul-Vénétie julienne), en Italie (Piuzzi 1987, p. 144), pourrait s'en rapprocher. Peut-être faut-il y voir, comme pour certains exemplaires de plus grande taille, une boucle de courroie de suspension de fourreau d'épée, comme les identifient R. Whitehead (2003, p. 56-57) et G. Bailey (1993, 2001², p. 24-25), et qu'ils datent du XVII ${ }^{\mathrm{e}}$ s. Cette interprétation, de même que la datation typologique proposée - les objets n'ont pas de contexte stratigraphique connu - est à prendre avec prudence. Les publications présentant des boucles du costume moderne en contexte bien documenté sont peu nombreuses. Dans le cas présent, il paraît évident que la boucle $\mathbf{n}^{\circ} \mathbf{5}$ a été déposée en même temps que le corps des pestiférés. Cet objet ne peut de toute manière pas être antérieur au $\mathrm{XVI}^{\mathrm{e}} \mathrm{s}$. d'après les données actuelles sur l'évolution morphologique des boucles.

Un sol du site de l'Alcazar a livré une boucle à double fenêtre semi-ovale (fig. 239, $\mathbf{n}^{\circ}$ 7). Sa chape, dont une petite partie affinée a été enroulée autour de la traverse médiane en fer puis soudée par martelage, se termine en ancre. Une boucle plus étroite (fig. $239, \mathbf{n}^{\circ} \mathbf{8}$ ) a été découverte dans une tranchée de récupération de mur datée des $\mathrm{V}^{\mathrm{e}}-\mathrm{VI}^{\mathrm{e}} \mathrm{s}$. par la céramique (Les Pistoles). Étant donné la morphologie de la boucle, il ne peut s'agir que d'un élément moderne. Cet objet conserve un ardillon et une chape dont l'extrémité cassée devait se terminer en ancre. Cet élément qui vient se fixer dans la lanière, le tissu ou le cuir à refermer, est d'après Fr. Doré utilisé à la fin du XVII et au XVIII ${ }^{\mathrm{e}}$ s. (2008, p. 18). Il constitue avec le cadre et la traverse médiane, une boucle à système, accessoire qui n'est alors plus que rarement utilisé pour la ceinture, mais plutôt employé pour la fermeture 
des cols, des chaussures et des culottes ou encore parfois à la décoration des chapeaux (Doré 2008, p. 20). Ces boucles apparaissent en Angleterre et sont diffusées avec un léger décalage en Europe continentale. La forme du cadre de nos objets est, selon R. Whitehead, celle d'une boucle de chaussure, attribuable aux années 16601720 (Whitehead 2003, p. 100). D'après le catalogue de G. Bailey ce type est datable de fin XVII ${ }^{e}$ - début $\mathrm{XVIII}^{\mathrm{e}}$ s., même si quelques exemplaires peuvent être plus tardifs: milieu-fin du XVIII ${ }^{\mathrm{e}} \mathrm{s}$. (Bailey 2005, p. 4-12). Pour Fr. Doré, cette forme de cadre est largement employée en France de la fin du XVII ${ }^{\mathrm{e}}$ au milieu de XVIII' s. (Doré 2008, p. 14). À l'échelle régionale, un exemplaire de ce modèle est recensé à Avignon (Place de la Principale) et un autre sur la colline du Château à Nice (Thuaudet à paraître).

La boucle $\mathbf{n}^{\circ} \mathbf{9}$ est issue du même contexte que l'objet $\mathrm{n}^{\circ} 7$ (Alcazar). Son tracé angulaire rappelle celui d'une boucle retrouvée dans un silo comblé au $\mathrm{XVII}^{\mathrm{e}} \mathrm{s}$. du vieux village de Jouques, dans les Bouches-du-Rhône (Meyer 2006, p. 79).

Une boucle à double fenêtre asymétrique (fig. 239, $\mathbf{n}^{\circ} \mathbf{1 0}$ ), l'une semi-ovale, l'autre quadrangulaire à traverse distale amincie, appartient à un type qui apparaît vers le milieu du Moyen Âge en adoptant plusieurs variantes. La plupart d'entre elles sont fixées à une chape ou à une lanière par l'intermédiaire d'une traverse droite amincie, opposée à celle arrondie (Barrère 1999, p. 825, fig. 1, $\mathrm{n}^{\circ} 10$ ). L'ardillon, quant à lui, est installé au milieu de la traverse médiane au moyen d'un retrait. Quelques boucles vraisemblablement destinées à des éperons sont retenues par la traverse médiane (Colardelle, Verdel 1993, p. 214, fig. 11 et 12). L'exemplaire marseillais est l'héritier direct de ces deux modes de fixation. Signe évident de sa filiation, il a conservé l'amincissement et un certain arrondi de la section de la traverse droite, dont la fonction originelle était de faciliter le mouvement de rotation. Il a également gardé la traverse médiane sans cantonnement des bouclettes d'éperon. Curieusement, le montage de la chape et de l'ardillon a été réalisé à l'envers, comme le montrent les dépressions dégageant une moulure centrale, moulure destinée à accueillir la pointe de l'ardillon. Cette boucle à système appartient à un type répandu en Angleterre entre 1660 et 1720 (Whitehead 2003, p. 97), et entre la fin du XVII et le milieu du XVIII ${ }^{\mathrm{e}}$ s. en France (Doré 2008, p. 14).

Le cimetière moderne de la cathédrale (Esplanade de la Major) a livré une unique boucle (fig. 239, $\mathbf{n}^{\circ} \mathbf{1 1}$ ), à double fenêtre quadrangulaire à pans coupés et chape mobile terminée en ancre. L'ardillon incomplet, auquel est encore accroché un fragment de cuir à oillet, repose sur un cadre dont la forme serait connue de 1765 à 1820 (Doré 2008, p. 15).

\subsection{Des ardillons isolés}

Quelques ardillons confectionnés par mise en forme d'un fil ou d'une tôle épaisse ont été trouvés isolés (voir Annexe 4, $\mathbf{n}^{\circ} \mathbf{5}$ ) : l'un de type tige (fig. 240, $\mathbf{n}^{\circ} \mathbf{1}$ ), l'autre plutôt plat (fig. $\mathbf{2 4 0}, \mathbf{n}^{\circ} \mathbf{2}$ ), décoré de deux incisions à la jonction du nœud et de la tige. Cette ornementation se rencontre encore aux $\mathrm{XIV}^{\mathrm{e}}$ et $\mathrm{XV}^{\mathrm{e}} \mathrm{s}$.

Un ardillon isolé en alliage cuivreux (fig. 240, $\mathbf{n}^{\circ} \mathbf{3}$ ) rappelle par la présence d'un fragment de tige en fer dans son nœud qu'un certain nombre de boucles en fer n'ont pu être prises en compte.

\subsection{Les mordants et chapes isolés}

Le nombre de chapes et de mordants retrouvés est particulièrement restreint (voir Annexe 4, $\mathbf{n}^{\circ} \mathbf{6}$ ). Pour les chapes, citons tout d'abord un spécimen entier, confectionné par pliage d'une tôle préalablement découpée (fig. 240, $\mathbf{n}^{\circ}$ 4). Bien que les exemplaires de si petite dimension avec rivet isolé soient rares dans la deuxième partie du Moyen Âge, on en retrouve parfois attachées à des boucles servant à la fixation des éperons ou des chaussures (Colardelle, Verdel 1993, p. 214, fig. 11 et 12 ; Lebole di Gangi 1993, p. 468, fig. 4, n 12 ). Les fouilles réalisées au château de Mornas dans le Vaucluse ont livré un objet similaire dans un contexte du XVe-XVII ${ }^{\mathrm{e}}$ s. (Goury 1983, pl. 9). Un possible fragment a été collecté hors stratigraphie lors des fouilles des Pistoles de 1989. Son extrémité proximale est découpée de deux triangles, chose très courante à la fin du Moyen Âge, mais elle ne présente pas de rivets de fixation comme d'ordinaire. Il subsiste donc un doute quant à l'identification de cet objet.

Un premier mordant est constitué de deux tôles brasées à leur extrémité distale et reliées en partie proximale par un fort rivet à tête bombée et par une contre-rivure circulaire plate (fig. $\mathbf{2 4 0}, \mathbf{n}^{\circ} \mathbf{5}$ ). La face supérieure, recouverte de dorure à l'exception du rivet où elle a disparu, est ornée sur trois cotés d'une ligne de zigzag. Ce décor est très répandu du $\mathrm{XIII}^{\mathrm{e}}$ au $\mathrm{XV}^{\mathrm{e}} \mathrm{s}$. mais se rencontre déjà antérieurement. Des fibres de tissu sont encore conservées à l'intérieur du mordant.

Les fouilles de l'abbaye Saint-Victor ont livré deux mordants. L'objet $\mathbf{n}^{\circ} \mathbf{6}$ (fig. 240) est constitué de deux tôles, dont une incomplète, fixées grâce à deux rivets en fer. Une tôle intermédiaire de renforcement est visible en partie distale. Obtenu par pliage d'une tôle, un deuxième mordant (fig. 240, $\mathbf{n}^{\circ}$ ) est traversé par une plaquette en forme de U dont les extrémités sont matées au revers. Deux rivets ont assuré la fixation sur une lanière de tissu dont il reste de nombreux fragments. Un décor incisé 


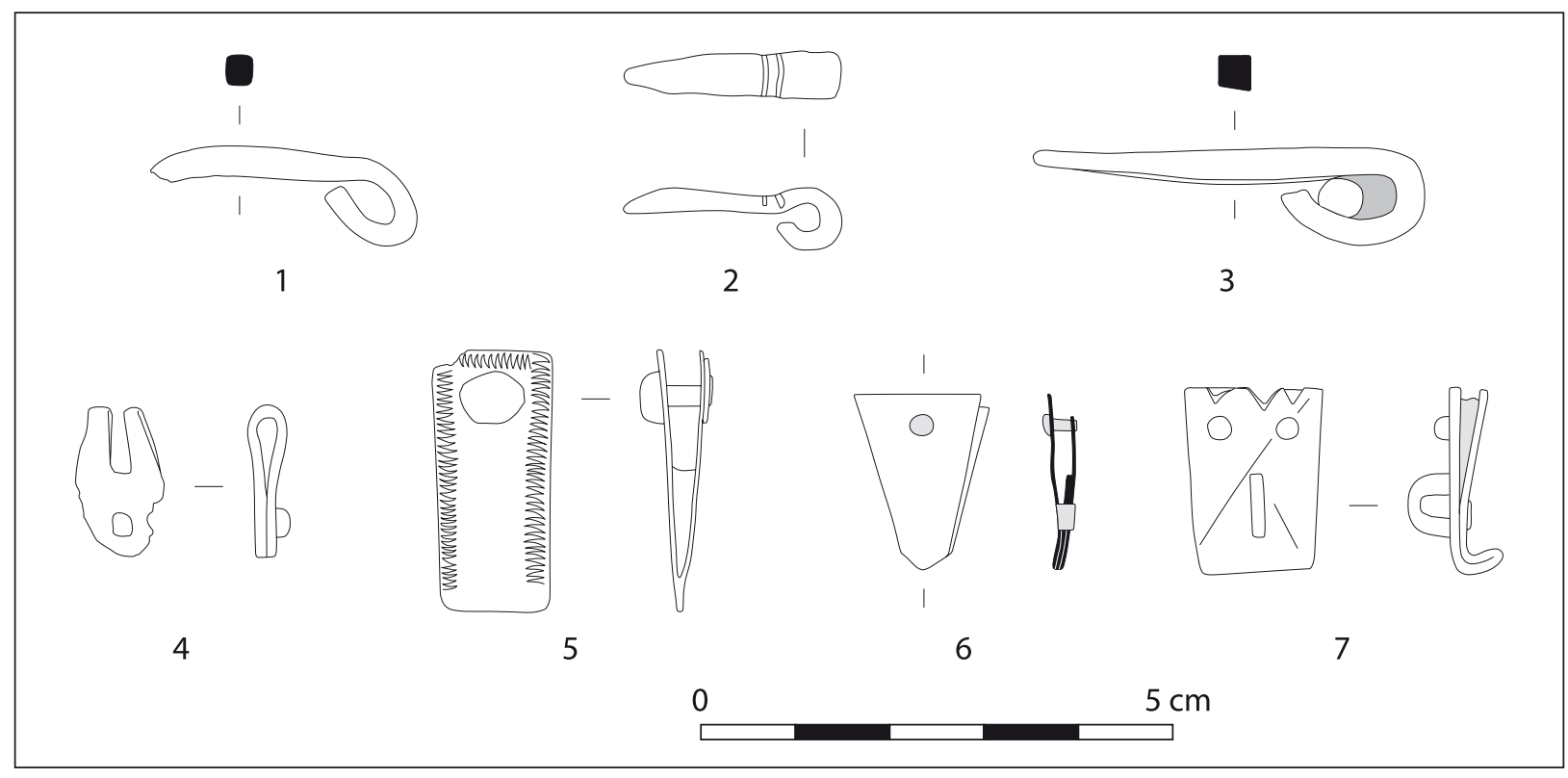

Fig. 240. Ardillons, chape et mordants (O. Thuaudet). 1 : Ilot $55 ; 2$ : Puget III ; 3, 5 : Alcazar ; 4 : place de la Providence ; 6-7 : Saint-Victor.

indéterminé semble avoir couvert l'avers de l'objet selon une disposition en $\mathrm{X}$. Le bord proximal est découpé de trois triangles, opération réalisée après repli de la tôle principale comme le montre l'entaille de la partie revers.

D'après les observations effectuées jusqu'à présent sur l'ensemble des mordants et des chapes retrouvés dans les fouilles provençales, il apparait que ces tôles sont régulièrement retouchées à la lime après pliage afin de faire coïncider les bords entre eux. C'est le cas, notamment, lorsque les découpes sont complexes ou l'empilement de tôle important.

\section{Les boucles à chape intégrée}

Les boucles à chape intégrée constituent un groupe à part, du fait de leur conformation particulière, mais également par une certaine rareté qui rend très difficile l'analyse typologique lorsqu'elles ne présentent pas de caractères propres à des types à chape mobile. L'iconographie, les sources archivistiques et littéraires se révèlent pour le moment muettes. Il n'est pas exclu que ces boucles aient eu quelques usages spécifiques.

\subsection{Une boucle en alliage cuivreux à chape intégrée (O. Thuaudet)}

La boucle $\mathbf{n}^{\circ} 13$ (voir Annexe 4, ${ }^{\circ}$ ) (fig. 238), à cadre semi-ovale et traverse distale à barre décorée de cinq rainures (trois visibles sur le dessin), est rattachée à une chape inamovible traversée à chacune de ses extrémités par un rivet. L'ensemble est le résultat d'une fonte. Une perforation à proximité de la fenêtre de la boucle permet le passage d'un ardillon de bonne taille obtenu peut-être par fonte et rajouté après coup. L'un des rivets conserve encore la rondelle qui assurait une meilleure fixation à la lanière. Cette boucle a été retrouvée dans une fosse comblée au milieu ou dans la seconde moitié du XVII ${ }^{\mathrm{e}}$ s. (Alcazar), mais sa datation typologique est toute autre. En effet, deux objets presque identiques, à ardillon de type fil, ont été découverts, l'un avec des traces de dorure au château de Montaldo di Mondovì (Piémont, Italie), dans un contexte du XIII' $\mathrm{s}$. (Cortelazzo, Lebole di Gangi 1991, p. 225) et l'autre à l'abbaye de Silvacane dans les Bouches-du-Rhône, dans un sol daté de la seconde moitié du XIII ${ }^{\mathrm{e}} \mathrm{s}$. (Fixot, Pelletier 1990, fig. 32). Deux autres objets, à chape peu ou pas moulurée, toujours en alliage cuivreux sont connus sur le site de Brandes en Oisans (XIII ${ }^{\mathrm{e}}-\mathrm{XIV}^{\mathrm{e}} \mathrm{s}$.) à l'Alpe-d'Huez en Isère (Bailly-Maître, Bruno Dupraz 1994, p. 128), et à San Domenico al Priamàr (contexte inconnu) à Savone (Ligurie), en Italie (Viara 1996, p. 384). Ces comparaisons permettent de dater l'objet marseillais du courant du XIII ${ }^{\mathrm{e}} \mathrm{s}$.

\subsection{Une boucle en os à chape intégrée (M.-A. Chazottes)}

La boucle de ceinture en os (fig. $238, \mathbf{n}^{\circ} \mathbf{1 4}$ ) du site du parvis de l'église Saint-Laurent (voir Annexe 4, $\mathbf{n}^{\circ} \mathbf{8}$ ) est à chape intégrée : la chape et la boucle constituent une seule entité. La partie reliée au vêtement est conservée 
dans sa totalité mais seule l'amorce de la fenêtre de la boucle de ceinture et l'encoche de l'ardillon sont encore en place. La chape, de forme et de section quadrangulaires, est fendue dans son épaisseur, dans le sens longitudinal. Elle comporte par ailleurs, deux perforations circulaires perpendiculaires à son axe.

Vierge de tout décor, cet élément de costume du bas Moyen Âge extrait d'une matrice paraxiale façonnée à la scie et au ciseau, connaît plusieurs parallèles de chronologie similaire et de morphologie identique. Des objets particulièrement intéressants et bien conservés proviennent des fouilles du Collège Mignet à Aix-enProvence et sont datés du XIV ${ }^{\mathrm{e}} \mathrm{s}$. Les fouilles du village médiéval de Goltho en Angleterre (Beresford 1975, p. 78, $\mathrm{n}^{\circ} 4-5$ ) et celles du Kiosque à Douai (Chaoui-Derieux 2010, p. 68, fig. 9) livrent également des exemplaires analogues. La seule distinction entre ces boucles et celle de la cité phocéenne concerne l'apposition d'un décor de gorges incisées.

À la même période, il devait également coexister un deuxième type de boucle : celui à chape et boucle articulée. Les chapes rectangulaires de ce type sont plus longues que larges, et les objets du $\mathrm{XV}^{\mathrm{e}} \mathrm{s}$. découverts lors de la fouille du Marais-Vert à Strasbourg en sont des témoins (Maire 1990, pl. 2, ${ }^{\circ} \mathrm{F}$ ). Tout comme le premier type, ces pièces ne comportent que quelques gorges en $\mathrm{V}$ parallèles entre elles et perpendiculaires à l'axe.

Ces éléments de ceinture se révèlent donc généralement d'une grande simplicité, autant dans la forme que dans l'ornement. Cet aspect plus épuré semble caractéristique des boucles du bas Moyen Âge. En effet, celles de l'Antiquité tardive et du haut Moyen Âge comportent une profusion de décor autant sur la boucle que sur la chape. Par ailleurs, au début de la période médiévale, les boucles sont articulées et maintenues par des pièces souvent en fer. Les motifs sont très divers : géométriques sur les boucles mérovingiennes de Berry-Les-BellesFontaines dans l'Yonne (Biton, Gaillard de Sémainville 1988, p. 293, fig. 2) ou de d'Esclavolles-Lurey dans la Marne (Lemoine, Rodet-Belarbi, 2010, p. 43, fig. 15), historiés et sculptés sur celles de Saint-Césaire à Arles (Ibid., 2010, p. 38, fig. 7) ou de Saint-Candau dans le Gard (Guyon, Heijmans 2001, p. 218, n82).

\section{Les appliques de lanière ou de vêtement}

Une quinzaine d'appliques métalliques et deux exemplaires en nacre ont été dénombrés. L'iconographie, les sources archivistiques et certaines découvertes archéologiques montrent qu'elles furent majoritairement employées sur les lanières et notamment les ceintures et courroies de harnachement. Elles attestent également de leur emploi, de manière moins fréquente, sur des livres, des aumônières, des gants, des chaussures ou le vêtement de dessus ${ }^{44}$.

\subsection{Les appliques métalliques (O. Thuaudet)}

Certains des objets étudiés (voir Annexe 4, $\mathbf{n}^{\circ} \mathbf{9}$ ) ont été obtenus par découpe à l'emporte-pièce. Lorsque la matrice de cet outil est en relief, elle emboutit en même temps la tôle et lui donne éventuellement un décor. D'après les recherches menées par N. Thomas, les perforations destinées à la fixation sont réalisées après emboutissage (Thomas 2009, p. 727). Parmi ces objets, les $\mathrm{n}^{\circ} 6$ à $8,10-11,15$ à 17 ont été obtenus directement par fonte. Très diversifiées dans leur morphologie, la plupart de ces appliques peuvent se répartir entre celles de forme naturelle ou stylisée, celles de forme quadrangulaire ou bien encore celles de forme circulaire.

Les appliques circulaires sont de loin les plus courantes. Les exemplaires découverts à l'Alcazar (fig. 241, $\mathbf{n}^{\circ} \mathbf{1}$ et 2) sont bombés ou plats et percés en leur centre. Ce type d'applique se rencontre sur de nombreux sites européens entre la fin $\mathrm{du}^{\mathrm{XIII}}{ }^{\mathrm{e}} \mathrm{s}$. et la première moitié $\mathrm{du} \mathrm{XV}^{\mathrm{e}} \mathrm{s}$. Il semble qu'il ne soit pas possible de les confondre avec des contre-rivures. En effet, dans la deuxième partie du Moyen Âge et au début de l'Époque moderne, les contre-rivures en alliage cuivreux conservées au dos d'une applique ou plus rarement d'un autre objet, ne dépassent jamais les $4 \mathrm{~mm}$ de diamètre. La date d'apparition des appliques circulaires plates est incertaine. Il en a été découvert un exemplaire à Agrigente en Sicile, dans un contexte semble-t-il antérieur au XIII' $\mathrm{s}$. (Cavallaro 2007, p. 276). À Rougiers dans le Var, ces appliques se rencontrent dès le début de l'occupation du site, soit à la fin du XII ${ }^{\mathrm{e}}$ ou dans la première moitié du XIII' s. (Démians d'Archimbaud 1980, p. 510). Un exemplaire plus ancien (dernier quart du $\mathrm{X}^{\mathrm{e}}-1^{\text {er }}$ tiers $\mathrm{du} \mathrm{XI}^{\mathrm{e}} \mathrm{s}$.) a été retrouvé sur la motte de Niozelles dans les Alpes-de-Haute-Provence (Mouton 2003, p. 211). Mais son identification reste incertaine car son diamètre $(2,1 \mathrm{~cm})$ et celui de sa perforation $(0,45 \mathrm{~cm})$ sont assez importants. L'applique $\mathbf{n}^{\circ} \mathbf{2}$ se distingue de la précédente par son bombement, créé par emboutissage. Elle a conservé son rivet et son contre-rivet circulaire, légèrement concave. Cette forme apparaît dans la première moitié du $\mathrm{XIV}^{\mathrm{e}} \mathrm{s}$. et continue d'être employée jusque semble-t-il dans la première moitié du $\mathrm{XVI}^{\mathrm{e}} \mathrm{s}$.

L'applique $n^{\circ} 3$ (fig. 241), d'une forme un peu particulière, ne connaît aucun élément de comparaison

44 Se reporter par exemple à Egan, Pritchard 2002, p. 162. 

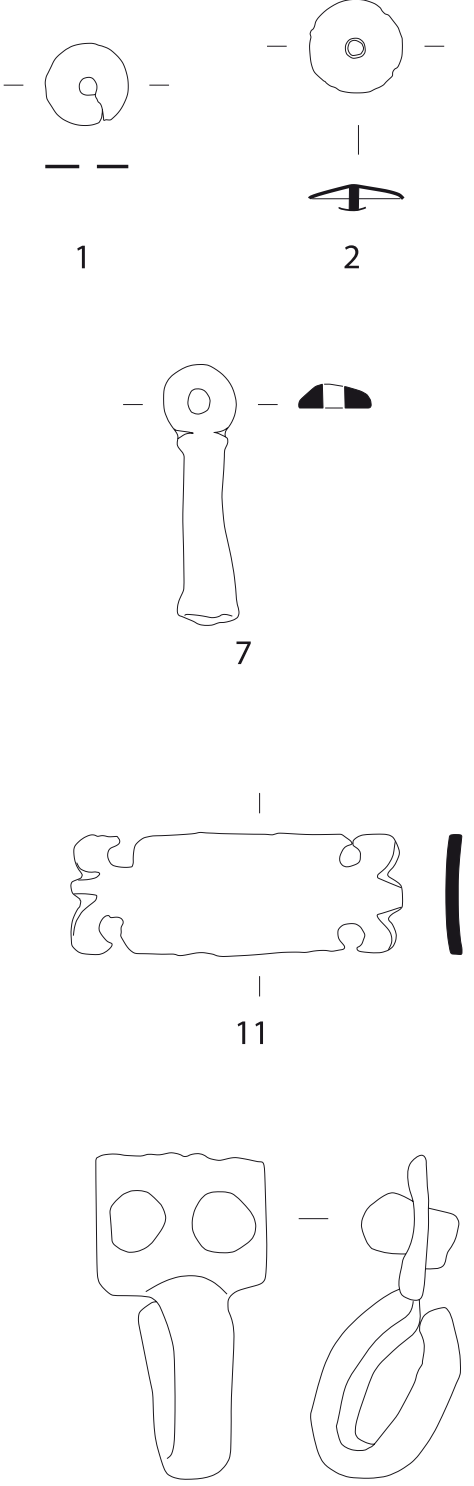

15

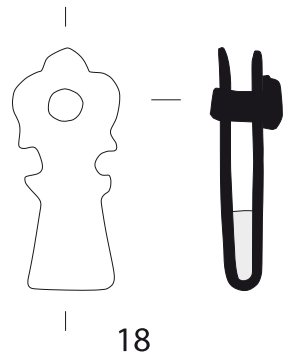

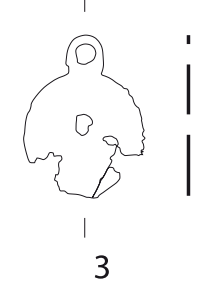

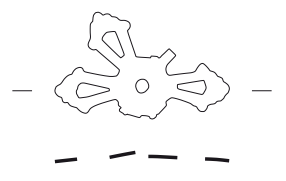

4
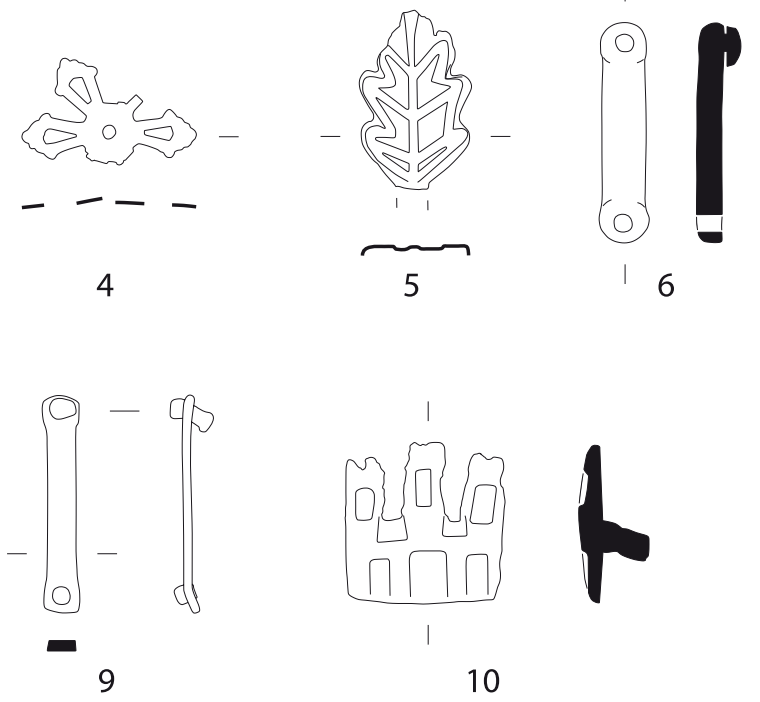

8

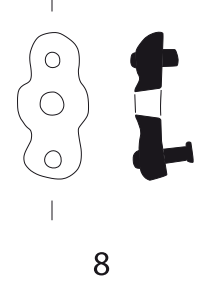

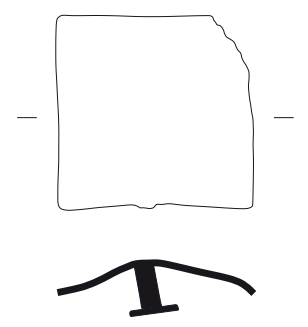

12

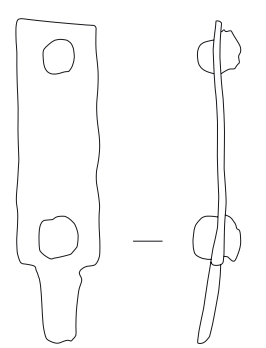

16

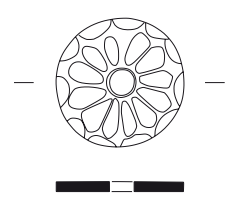

19

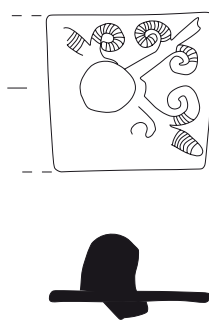

13
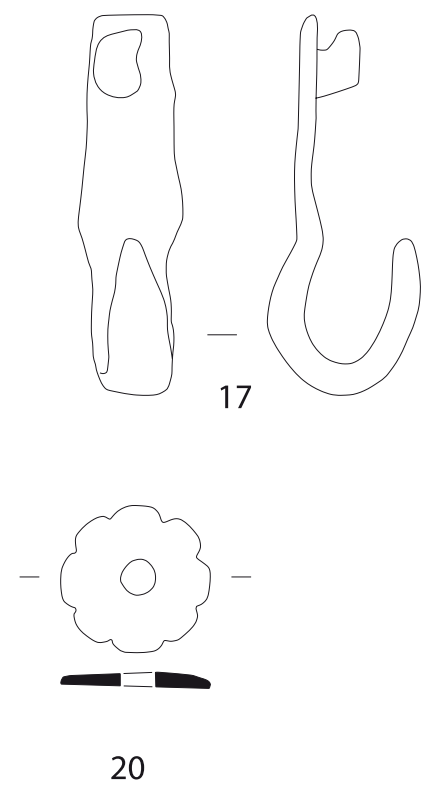

$5 \mathrm{~cm}$

Fig. 241. Appliques de lanière ou de vêtement (O. Thuaudet). 1-2, 6-8, 10-13, 15, 18 : Alcazar ; 3 : place des Pistoles ; 4, 14,20 : Tunnel de la Major ; 5, 9, 17 : Saint-Victor ; 16 : Puget III ; 19 : Vieille-Major. 
dans la bibliographie. Elle est perforée au niveau de son excroissance arrondie (une autre perforation, centrale, a été entraînée par l'oxydation).

L'une des deux appliques à motif végétal (fig. 241, n'4) présente la particularité d'avoir des pétales festonnés ajourés - six à l'origine - de forme globalement pentagonale. Ces pétales rayonnent autour du bombement central, perforé pour le passage d'un rivet. Retrouvé dans un contexte moderne, cet objet, quoique sans comparaison connue, ne peut dater que de la fin du Moyen Âge ou du tout début de l'Époque moderne au vu de sa morphologie.

Un fragment de tôle emboutie (fig. 241, $\mathbf{n}^{\circ} \mathbf{5}$ ) porte un décor en forme de feuille (de chêne ?) dont les nervures sont figurées par un surhaussement. L'applique est cassée au niveau de sa base. Un élément similaire en provenance d'un niveau du $X^{\text {e }}$ ou $X{ }^{e} I^{e}$ s. du site d'Apcher à Prunières, en Lozère, brisé au même endroit, utilise le même procédé de surhaussement mais pour individualiser les différentes parties de la feuille. À Brandes-en-Oisans à l'Alpe d'Huez, en Isère, une feuille nervurée selon le même principe est datée des XIII ${ }^{\mathrm{e}}$ $\mathrm{XIV}^{\mathrm{e}}$ s. (Bailly-Maître, Bruno Dupraz 1994, p. 128). Une perforation pour rivet est placée à chaque extrémité.

Trois appliques quadrangulaires étroites, à perforations pour rivets traversant opposés, ont été découvertes sur le site de l'Alcazar. L'une d'elles (fig. 241, n⿳06), longiligne et épaisse, entièrement dorée, conserve un rivet à rivure circulaire concave pleine. Elle provient d'un contexte daté du XII ${ }^{\mathrm{e}} \mathrm{s}$. (Alcazar), et constitue la plus ancienne applique étroite et homogène dont la datation soit assurée. Une autre a bien été retrouvée sur le site de Saint-Martin à Chabrillan dans la Drôme, attribuée aux $\mathrm{XI}^{\mathrm{e}}-\mathrm{XII}{ }^{\mathrm{e}} \mathrm{s}$., mais elle était hors contexte (Rolland 2006, p. 426, $\left.n^{\circ} 100\right)$. De même, sur le site de Montbaron à Levroux dans l'Indre, une longue applique rectangulaire a été retrouvée dans un contexte de datation incertaine : $\mathrm{XI}^{\mathrm{e}}$-XII ${ }^{\mathrm{e}}$-début du XIII ${ }^{\mathrm{e}}$ s. (Querrien, Blanchard 2004, p. 123). Ce type d'applique semble disparaître un peu avant le milieu du $\mathrm{XIV}^{\mathrm{e}} \mathrm{s}$. et ne doit pas être confondu avec d'autres parfaitement quadrangulaires, parfois avec gradins, dont la datation est postérieure.

La morphologie d'une seconde applique (fig. 241, $\mathbf{n}^{\circ}$ 7) est proche de bon nombre d'appliques étroites et, notamment d'un type à élargissement central perforé servant d'œillet. Ce type apparaît dans la deuxième moitié du XII ${ }^{\mathrm{e}} \mathrm{s}$. et semble perdurer jusque dans la première moitié du XIV ${ }^{\mathrm{e}} \mathrm{s}$.

La troisième applique (fig. $241, \mathbf{n}^{\circ} \mathbf{8}$ ) est plus courte mais les différentes parties qui la composent sont légèrement bombées. Une ouverture centrale sert d'œillet. Sa datation correspond à celle de deux autres exemples similaires, l'un découvert à Rougiers dans une couche mise en place vers 1285-1309/15 (Démians d'Archimbaud 1980, p. 513, pl. 476, n¹1), l'autre sur le site de Swan Lane à Londres, dans un contexte daté vers 12701350 (Egan, Pritchard 2002, p. 213, n 1155 ).

Collectée hors stratigraphie à l'abbaye Saint-Victor, l'applique quadrangulaire étroite $\mathbf{n}^{\circ} \mathbf{9}$ (fig. 241), obtenue à partir d'une tôle plate découpée, est traversée par deux rivets en fer. Ce type n'est attesté archéologiquement que par quelques rares spécimens du XIII ${ }^{e}$ s. mais son utilisation durant une partie du $\mathrm{XIV}^{\mathrm{e}} \mathrm{s}$. est fort probable.

L'applique $\mathbf{n}^{\circ} \mathbf{1 0}$ (fig. 241) prend la forme d'un château à deux tours d'angle et donjon central. Une dépression dans la partie inférieure figure une porte. Sa surface à l'avers porte des traces de dorure. Un rivet intégré assurait la fixation au revers. Des objets plus frustres du second ou du troisième quart du $\mathrm{XIV}^{\mathrm{e}} \mathrm{s}$. ont été découverts sur le site du château de Pymont dans le Jura (Pymont 1993, fig. 70, $\mathrm{n}^{\circ} 1915,1981,1987$ ), un exemplaire datant de la fin du XIII ${ }^{e}$ ou du milieu du $\mathrm{XIV}^{\mathrm{e}} \mathrm{s}$. au village de Dracy à Baubigny en Côte-d'Or (Piponnier 1975, p. 159), et un spécimen du $\mathrm{XIV}^{\mathrm{e}} \mathrm{s}$. à la Grange du Mont à Charny dans le même département (Beck 1989, p. 73).

Un objet avec des traces de dorure (fig. 241, $\mathbf{n}^{\circ} \mathbf{1 1}$ ), légèrement bombé, est composé d'une fleur de lys de part et d'autre d'un corps central rectangulaire. L'attache s'effectuait sans doute grâce à quatre rivets disposés entre les feuilles latérales des fleurs et la partie principale. Le motif de la fleur de lys se rencontre sur quelques appliques de costume médiévales datées du $\mathrm{XIV}^{\mathrm{e}} \mathrm{s}$.

Deux appliques quadrangulaires, l'une entière et bombée (fig. 241, $\mathbf{n}^{\circ} \mathbf{1 2}$ ), à rivet brasé au revers, à contre-rivet circulaire plat (e tôle $=0,07 \mathrm{~cm}$ ), l'autre fragmentaire (fig. 241, $\mathbf{n}^{\circ}$ 13), à rivet traversant et tête à capuchon (e tôle $=0,11 \mathrm{~cm}$ ), ont été découvertes à l'Alcazar. L'objet $\mathbf{n}^{\circ} \mathbf{1 3}$, incomplet, est orné d'un motif de quatre fleurs de lys rayonnantes sur fond doré - la corrosion en a fait disparaître une. De petites rainures conservées par endroit occupent l'intérieur. L'observation des traces montre qu'un poinçon a été nécessaire à la réalisation du décor.

L'œillet $\mathbf{n}^{\circ} \mathbf{1 4}$, une tôle emboutie au moyen d'une emboutisseuse (fig. 241), est constitué d'une unique tôle emboutie, insérée en force dans une perforation, à moins que le support n'ait été en cuir, auquel cas la mise en place s'est effectuée par assouplissement à la vapeur d'eau ou à l'eau bouillante. Cet objet appartient à l'Époque contemporaine.

Trois appliques ont été employées pour la suspension à la ceinture d'une bourse, d'une aumônière, d'un couteau ou de tout autre objet (fig. 241, $\mathbf{n}^{\circ} 15$ à 16). Le $\mathbf{n}^{\circ} 15$ est constitué d'une plaquette quadrangulaire traversée par deux rivets à tête bouletée, et terminée par 
un crochet. La datation de son contexte concorde avec la chronologie de ce type dont la plaque est généralement de plus grande longueur. De différentes tailles, avec deux ou quatre rivets, les exemplaires de ce modèle se caractérisent par un crochet bien plus épais que la plaque support. Le spécimen le plus ancien connu actuellement (fig. 241, $\mathbf{n}^{\circ}$ 16) provient du comblement de la tranchée de fondation du rempart de la fin du XII ${ }^{\mathrm{e}}$ ou du début du $\mathrm{XIII}^{\mathrm{e}} \mathrm{s}$. (Puget III). Sa plaque, assez étroite, est traversée par deux rivets à tête hémisphérique. De son crochet, il n'est conservé que le départ. L'applique $\mathbf{n}^{\circ} 17$ (fig. 241, $\mathbf{n}^{\circ} 17$ ) se distingue par son rivet intégré, mais un deuxième situé au-dessus de la jonction avec le crochet peut avoir disparu. Ce type d'applique de suspension est attesté jusqu'à la fin du XIV ${ }^{\mathrm{e}}$ ou le début du XV $\mathrm{XV}^{\mathrm{e}} \mathrm{s}$.

La dernière applique métallique, le $\mathbf{n}^{\circ} 18$ (fig. 241), constituée d'une unique tôle pliée et découpée, est traversée par un rivet en partie proximale et retient des restes de cuir. Cet objet est d'interprétation incertaine : peut-être s'agit-il d'une applique de suspension.

\subsection{Les appliques en nacre}

\section{(M.-A. Chazottes, O. Thuaudet)}

Deux appliques circulaires en nacre (voir Annexe 4, $\mathbf{n}^{\circ} \mathbf{1 0}$ ) - de costume ?-, perforées en leur centre (fig. 241, $\mathbf{n}^{\circ} 19$ et 20), ont été confectionnées par meulage de pièces de matière première préalablement découpées ${ }^{45}$. L'objet $\mathrm{n}^{\circ} \mathbf{1 9}$ présente de légères dépressions semi-circulaires en bordure, elles sont ovales et disposées en corolle au centre. Obtenues par meulage, elles créent une irisation tout juste perceptible selon l'angle de la lumière et de l'observateur. Après passage à la meule, l'applique $\mathbf{n}^{\circ} \mathbf{2 0}$, aux faces lisses, a été taillée avec un outil tranchant pour lui apporter sa forme octolobée.

\section{Les éléments de fixation du costume}

La boucle est sans doute le moyen de fixation le plus courant au Moyen Âge. Mais selon le type de vêtement ou d'accessoire - par exemple les chaussures et les aumônières - et la mode du moment, d'autres éléments de fixation comme les boutons, les lacets, les épingles, les agrafes et des chaînettes pour la suspension viennent compléter et/ou agrémenter le costume.

45 Processus décrit par E. de Valicourt dans l'édition refondue du t. 1 de son Nouveau manuel complet du tourneur ou traité théorique et pratique de l'art du tour paru en 1846 à Paris à la Librairie encyclopédique de Roret, p. 118-119.

\subsection{Les boutons}

Les boutons de la collection peuvent être rangés en deux grandes catégories basées sur leur moyen d'attache au support : les boutons à trous dont le corps est cousu directement; les boutons à bélière fixés par l'intermédiaire d'une petite tige ou tôle formant un anneau rattachée au corps du bouton.

\subsubsection{Les boutons à trous (M.-A. Chazottes, O. Thuaudet)}

Les boutons à trous sont attestés archéologiquement à partir du XIII ${ }^{\mathrm{e}}$ s., peut-être dans la deuxième moitié de ce siècle. Jusqu'au XVI ${ }^{\mathrm{e}}$ s., ils comptent deux perforations, plus rarement trois ou quatre, mais sont peu fréquents. Ils sont fabriqués dans des matériaux assez variés : alliage blanc, schiste, os, tesson réutilisé, tôles en alliage cuivreux. Leur proportion augmente au XVII $\mathrm{s}$. et le modèle à quatre trous devient majoritaire aux XIX ${ }^{\mathrm{e}}$ et $\mathrm{XX}^{\mathrm{e}} \mathrm{s}$. L'os, la nacre et le corozo sont de loin les plus employés. Ils sont remplacés au cours du siècle dernier par les plastiques et les résines. La morphologie des boutons étudiés ici est très variée et les documents rassemblés jusqu'à présent ne permettent pas d'en proposer une typo-chronologie assurée (voir Annexe 4, $\mathbf{n}^{\circ} \mathbf{1 1}$ ).

Le corpus marseillais comprend neuf boutons en os à quatre trous, découverts dans des comblements de fosse ou de cuve généralement mal datés, situés entre le milieu du $\mathrm{XVII}^{\mathrm{e}} \mathrm{s}$. et le début du $\mathrm{XX}^{\mathrm{e}} \mathrm{s}$. Ces boutons proviennent des sites de l'Alcazar et du Tunnel de la Major. Ils peuvent être scindés en trois ensembles. Le premier contient les spécimens à revers bombé et couronne prononcée, plate ou légèrement arrondie, voire absente (fig. 242, $\mathbf{n}^{\circ} 10,11,13,15$ ). Leur diamètre est compris entre 1,7 et $1,8 \mathrm{~cm}$ pour 0,19 à $0,27 \mathrm{~cm}$ de hauteur. Le deuxième groupe rassemble les boutons à un revers plat formant, au niveau de la jonction avec l'avers, un arrondi ou un angle aigu (fig. 242, ${ }^{\circ} 8,9,14,17,18$ ). Ils mesurent entre 1,5 et $2 \mathrm{~cm}$ de diamètre pour 0,2 à $0,29 \mathrm{~cm}$ de hauteur. Le troisième ensemble est constitué d'un seul bouton, le $\mathbf{n}^{\circ} \mathbf{1 9}$, de $0,28 \mathrm{~cm}$ de haut, à face supérieure bombée et revers légèrement concave. Il a été retrouvé hors stratigraphie (Ilot $24 \mathrm{~N}$ ).

Ces boutons peuvent être taillés dans une matrice paraxiale résultant du débitage de la diaphyse d'un os long, ou d'une rondelle sciée perpendiculairement à l'axe longitudinal. Ces éléments de costume ont également pu être prélevés dans une côte comme l'attestent des déchets de fabrication, notamment sur le site de l'Alcazar (cf. § 14). Des traces de râpe ont été relevées au revers du $\mathbf{n}^{\circ} \mathbf{9}$ et au centre du revers du $\mathbf{n}^{\circ} \mathbf{1 3}$, signe d'une mise à niveau de la matière avant le détourage. 


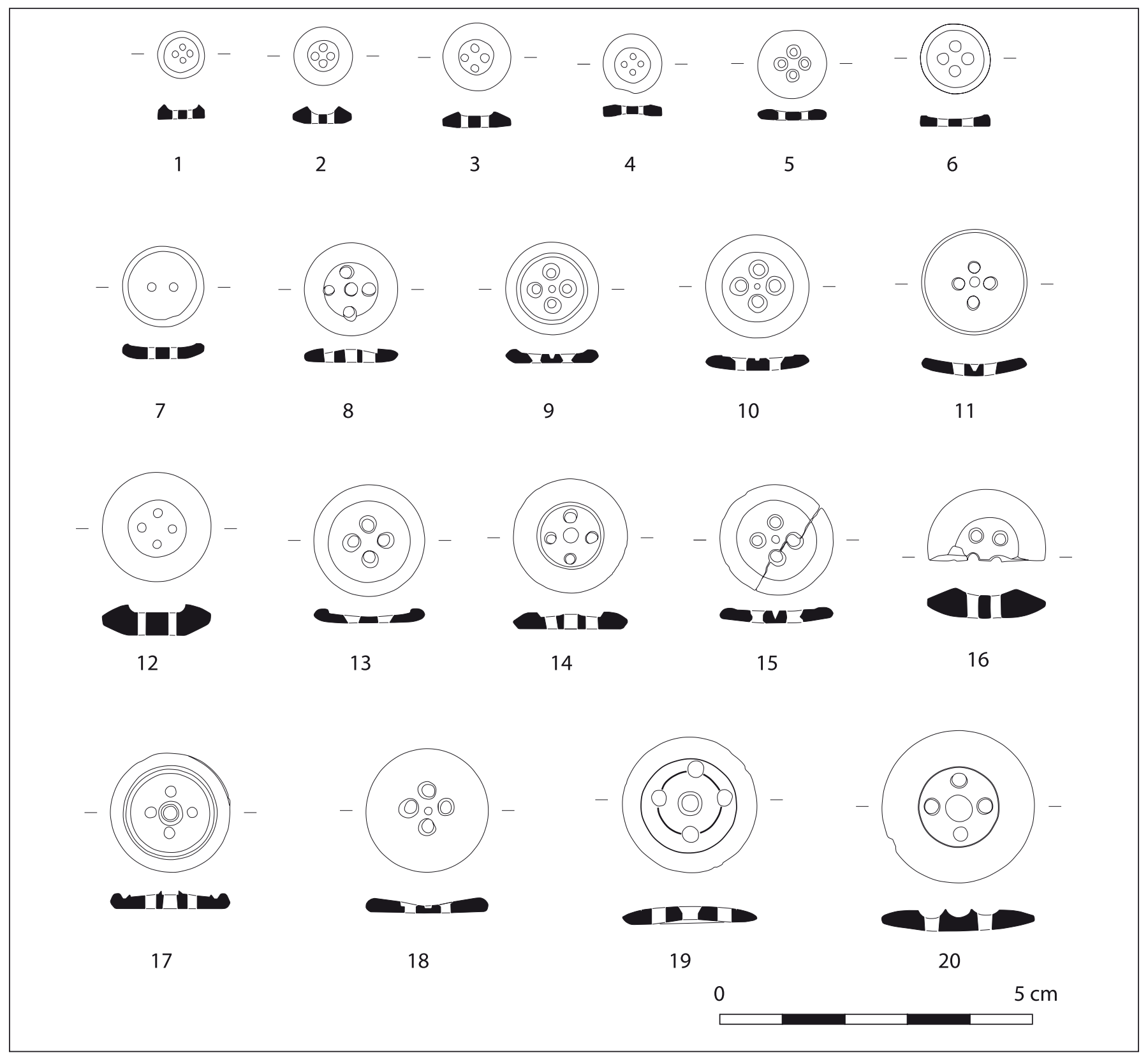

Fig. 242. Boutons à trous (O. Thuaudet). 1, 3-5, 7-10, 13-17, 20 : Tunnel de la Major ; 2 : place Villeneuve-Bargemon ; $6,11,18$ : Alcazar ; 12 : rue Trinquet ; 19 : llot $24 \mathrm{~N}$.

Les spécimens $\mathbf{n}^{\circ} \mathbf{8}$ et $\mathbf{1 4}$ présentent de la matière spongieuse au revers.

L'ensemble des pièces présente des traces de tournage. Quelques-unes conservent encore au centre de la face avers (fig. 242, $\mathbf{n}^{\circ} \mathbf{9}, \mathbf{1 5}, \mathbf{1 8}$ ) ou sur les deux côtés (fig. 242, $\mathbf{n}^{\circ} \mathbf{1 0}$ et 11) la marque laissée par une pointe. Des marques de détourage sont visibles sur les deux faces (fig. 242, $\mathbf{n}^{\circ} 10,17$ ) ou seulement au revers (fig. 242, $\mathbf{n}^{\circ} \mathbf{8}$, 13, 14) de certains exemplaires. Cette étape de fabrication permet le détachage des boutons de leur plaquette d'extraction mais également la création des bombements, de concavités et d'incisions (fig. 242, $\mathbf{n}^{\circ} 19$ ).

Les boutons n ${ }^{\circ} 8,14,17$ et $\mathbf{1 9}$, perforés en leur centre, correspondent peut-être à une deuxième technique. Chr. Vallet mentionne dans son article consacré à l'atelier de fabrication de perles et de boutons de la place de la Motte de Limoges, l'utilisation d'une mèche à trois pointes : deux pointes latérales découpent le contour du bouton selon l'axe donné par une mèche centrale, qui elle-même perfore au fur et à mesure l'os de part en part (Vallet 2002, p. 146-147). Sur les objets $\mathbf{n}^{\circ} \mathbf{1 4}$ et 17, un 
arrachement lamellaire positif est conservé au niveau de la tranche, ce qui signifie que l'artisan n'a pas achevé le détourage et que le bouton a été extrait de la plaquette par pression.

Une fois l'ébauche détachée de sa plaquette, le fabriquant fore l'objet pour réaliser les trous, comme le montre l'empiétement sur la couronne du $\mathbf{n}^{\circ} \mathbf{8}$. Les boutons $\mathrm{n}^{\circ} \mathbf{9}, \mathbf{1 0}$ et $\mathbf{1 5}$ montrent des traces de perforation des trous depuis les deux faces, alors qu'elle s'effectue ordinairement à partir de l'avers. L'observation de ces trois objets révèle que le forage depuis le revers n'est réalisé que pour compléter celui de l'avers.

L'étude de tous ces boutons en os établit que la plupart d'entre eux, si ce n'est la totalité, ont été tournés des deux côtés. Pour les boutons des groupes 2 et 3, le tournage du revers est limitée à la bordure, pour ceux du groupe 1, il participe pleinement à la mise en forme.

Six boutons à trous en nacre ont été collectés dans des niveaux de la fin de l'Époque moderne ou contemporaine (fig. $\mathbf{2 4 2}, \mathrm{n}^{\circ} \mathbf{1}, \mathbf{4}, \mathbf{5}, \mathbf{6}, \mathbf{7}, \mathbf{2 0}$ ). Ils présentent tous une dépression centrale concave accueillant deux ou quatre perforations. Le spécimen $\mathbf{n}^{\circ} \mathbf{2 0}$ se distingue par une légère gorge en avant de la dépression et qui la souligne du même coup, ainsi qu'un bombement à cuvette centrale. La nacre est d'une couleur blanche (fig. 242, $\mathbf{n}^{\circ} \mathbf{1}, 5,6$ ) à violacée soutenue (fig. $242, \mathbf{n}^{\circ} \mathbf{2 0}$ ) en passant par le violet pâle (fig. 242, $\mathbf{n}^{\circ} \mathbf{4}$ ) et par un mordoré tirant vers le violet (fig. 242, $\mathbf{n}^{\circ}$ 7). Les effets d'irisement sont très variés. Quelques boutons ont conservé au revers une portion plus ou moins importante de coquille. Elle est de couleur brune pour le $\mathbf{n}^{\circ} \mathbf{4}$ et grisviolet sur le $\mathbf{n}^{\circ} \mathbf{2 0}$ où elle constitue plus de la moitié de l'épaisseur. Il existe plusieurs types de nacre : les objets peuvent avoir été fabriqués à partir d'une huître perlière blanche ou noire ou de coquillages variés, et plus récemment du troca. Beaucoup moins chère que l'huître perlière, cette deuxième matière n'est employée qu'à partir du début du $\mathrm{XX}^{\mathrm{e}} \mathrm{s}$. (Fournier et al., 2001, p. 64). Il n'a pas été possible pour le moment de proposer des hypothèses quant à l'origine de la matière des objets évoqués ici.

L'élaboration des artéfacts en nacre est d'après la chaîne opératoire décrite par E. de Valicourt dans son Nouveau manuel complet du tourneur (Valicourt 1846, p. 118-119) légèrement différente de ceux en os. Néanmoins, la première étape du travail s'appuie toujours sur le choix de la matière première. L'artisan débite ensuite le coquillage en carrés, au moyen d'une scie fortement trempée en raison de la dureté du matériau. Seule une partie du coquillage originel est utilisable du fait de sa conformation. Pour donner aux pièces leur forme ronde, le fabricant utilise une scie annulaire ou un trépan à couronne. Sur une meule à aiguiser continuellement humidifiée, il finit d'enlever la coquille et aplatit ou arrondit les ébauches. Un linge imbibé d'acide sulfurique est ensuite appliqué pour éliminer le plus possible le calcaire et donner un aspect poli. L'objet est enfin foré et, dans la majorité des cas, la mèche perce le bouton de l'avers vers le revers. Le bouton $\mathbf{n}^{\circ} \mathbf{5}$ présente même un arrachement lamellaire négatif au revers dû au retrait de la mèche du foret. Cependant, la pièce $\mathbf{n}^{\circ} \mathbf{7}$ comporte des barbes au revers ce qui signifie que le forage a été effectué depuis cette face. Cette même face conserve des traces de taille. À l'avers, la couronne montre des marques de râpe ou de lime. Des marques de détourage sont également visibles au revers du $\mathbf{n}^{\circ} \mathbf{2 0}$.

L'emploi du corozo pour les boutons $\mathrm{n}^{\circ} \mathbf{2}, \mathbf{3}, \mathbf{1 2}$ et 16 (fig. 242) et un dernier exemplaire non figuré, est incompatible avec un contexte antérieur à 1860/1865 (Poirot et al. 1992, p. 135). Ces boutons eurent beaucoup de succès parmi les couches modestes de la population en raison de leur faible prix (Ibid., p. 135). Cette matière blanche, dite ivoire végétal, est tirée des noix du palmier Phytelephas rencontré dans les forêts amazoniennes. Utilisée par les populations locales, elle n'est connue des Européens que tardivement. La datation des contextes des objets $\mathbf{n}^{\circ} \mathbf{2}, \mathbf{3}$ et $\mathbf{1 6}$, vers le milieu du $\mathrm{XIX}^{\mathrm{e}}$ s., correspond plus ou moins à celle de l'introduction du corozo dans la fabrication des boutons. Cette datation est peut-être à revoir dans le cas du comblement du silo dans lequel a été retrouvé l'exemplaire $\mathbf{n}^{\circ} \mathbf{1 2}$ (14 rue Trinquet). Le mobilier céramique indique une datation aux alentours des $\mathrm{XI}^{\mathrm{e}}$-XII ${ }^{\mathrm{e}}$ s., mais il est également possible que le bouton soit un élément infiltré. Aucune trace de fabrication n'est visible sur ces boutons en corozo. À l'avers, une couronne légèrement bombée ouvre sur une dépression concave généralement profonde, perforée par quatre trous. L'ensemble, hormis le $\mathbf{n}^{\circ} \mathbf{3}$, présente un profil convexe à l'avers comme au revers, obtenu par une taille manuelle ou par détourage avec un tour. Le forage des perforations n'intervient là encore qu'en dernier ressort. La matière se travaille aisément et se durcit d'elle-même après sa mise en forme.

\subsubsection{Les boutons à bélière (O. Thuaudet)}

Les boutons globulaires (voir Annexe 4, $\mathbf{n}^{\circ} \mathbf{1 2}$ ), tel celui reconstitué sur la fig. $\mathbf{2 4 6}, \mathbf{n}^{\circ} \mathbf{4}$, sont réalisés par brasure de deux cupules embouties. Au préalable, une attache, appelée bélière, est passée au travers d'une perforation dans la cupule supérieure, ses extrémités sont ensuite repliées au revers de celle-ci puis brasées. Le diamètre est généralement compris entre 0,8 et $1 \mathrm{~cm}$, la hauteur bélière comprise entre 1 et $1,5 \mathrm{~cm}$. Ce type de boutons, avec ces dimensions, apparaîtrait dès le $\mathrm{X}^{\mathrm{e}} \mathrm{s}$. d'après des exemplaires découverts au château 
de Montarrenti dans la province de Sienne en Italie (Cantini 2003, p. 174-175, n²3). D’autres spécimens ont été retrouvés dans l'occupation des $\mathrm{XI}^{\mathrm{e}}-\mathrm{XII}^{\mathrm{e}} \mathrm{s}$. de la tour médiévale de la Collina di San Giorgio à Filattiera (Toscane) en Italie (Cabona et al. 1982, p. 352). Cependant, l'espace est resté à l'air libre quelques temps avant d'être recouvert d'une couche de guano, ce qui a pu favoriser les intrusions de mobilier. Ce type de bouton ne devient courant qu'à partir de la fin du XIII ${ }^{\mathrm{e}} \mathrm{s}$. et semble passer de mode dans la première moitié du $\mathrm{XV}^{\mathrm{e}} \mathrm{s}$. Deux exemplaires fragmentaires ont été collectés à l'Alcazar, dans un sol de la fin du XIII ${ }^{\mathrm{e}}$ ou du début du XIV ${ }^{\mathrm{e}}$ s., et dans l'incendie du milieu du $\mathrm{XIV}^{\mathrm{e}} \mathrm{s}$. du bourg de Morier (Alcazar). Trois autres proviennent d'un remblai de la deuxième moitié du $\mathrm{XIII}^{\mathrm{e}} \mathrm{s}$. (place de la Providence), du remplissage d'une fosse du XVII ${ }^{\mathrm{e}}$ s. (Hospice de la Vieille-Charité), d'un remblai du XVIII' s. (abbaye Saint-Victor). L'épaisseur de la tôle est de 0,04 ou $0,05 \mathrm{~cm}$. La fouille d'une nécropole italienne du Bas Moyen Âge à San Vito (Frioul-Vénétie julienne) en Italie, a permis la découverte d'objets du même type sur des inhumations, la plupart du temps au niveau des avant-bras (manches ?) ou du bassin (fermeture des braies ?) des inhumés (Amici 1986, p. 253). Des boutons de même constitution mais de dimensions et de formes légèrement différentes apparaissent après le $\mathrm{XIV}^{\mathrm{e}} \mathrm{s}$. Un spécimen de construction identique au type précédent mais à cupules côtelées a été découvert sur le site du Tunnel de la Major (fig. 243, $\mathbf{n}^{\circ} \mathbf{1}$ ).

Le bouton $\mathbf{n}^{\circ} \mathbf{2}$ de la fig. $\mathbf{2 4 3}$ actuellement déformé mais originellement sphérique, est constitué de deux cupules brasées, en forme de rosace et à décor embouti constitué de points et de cercles ajourés en leur centre. Une ouverture a été pratiquée au sommet de chaque cupule pour permettre leur suspension. Découvert dans un comblement de cuve de la fin du XIX $^{\mathrm{e}}$ ou du début du $\mathrm{XX}^{\mathrm{e}}$ s., cet objet pourrait être plus ancien : il est presque identique à un bouton mis au jour sur le site de la ville disparue de Glarentza à Kastro Kyllene (préfecture d'Eleia) dans le Péloponnèse (Barbaritsa 2005, p. 50-51). Ce dernier, collecté dans un cimetière fonctionnant du XIII ${ }^{e}$ au XVII ${ }^{\mathrm{e}}$ s., est doré et attaché, par l'intermédiaire d'une bélière et d'un anneau, à une agrafe de type "porte de chapelier»(Bertrand 1777, p. 590). Il est interprété comme un bouton, éventuellement celui d'un prélat.

D'autres exemplaires marseillais viennent encore compléter le lot des boutons, dont certains de la toute fin de l'Époque moderne, d'autres contemporains. Deux tôles estampées de motifs floraux (fig. $\mathbf{2 4 3}, \mathbf{n}^{\circ} \mathbf{3}$ et $\mathbf{4}$ ) se fixaient par repli de la bordure de la feuille métallique sur une âme de bois, d'os, de corozo, de métal ou de cuir. Celle-ci était percée de trous au travers desquels passaient les fils textiles. Une de ces tôles figure une fleur dont les six pétales sont tête-bêche avec des chevrons, le tout séparé par des lignes. L'autre représente des fleurs écloses ou à l'état de bouton dans un cadre cordé. Le relief est, dans les deux cas, en grande partie constitué de petites bosses circulaires ou ovales. L'objet en bois $n^{\circ} 5$ (fig. 243) correspond peut-être à une âme de bouton .

Les exemplaires $n^{\circ} \mathbf{6}$ à $\mathbf{8}$ ne présentent aucune trace d'ornementation. Il n'est pas impossible que ces boutons aient été destinés à l'uniforme militaire : en effet, certains corps de l'armée ou régiments ont parfois disposés de boutons unis (Fallou 1915). Le bouton $\mathbf{n}^{\circ} \mathbf{9}$ est orné au revers d'un cercle creux, sans doute obtenu par impression. Quant au $\mathbf{n}^{\circ} \mathbf{1 0}$, il porte le décor suivant : un cercle de gros points encadré par deux cercles de petits traits à peine perceptibles. Les objets $\mathbf{n}^{\circ} \mathbf{1 1}$ et 12 portent au revers des inscriptions en relief dans un cercle de grènetis. Elles sont relatives aux fabricants et peut-être à la référence du bouton. Il est figuré sur le premier : COULORD ${ }^{*} \mathrm{H}^{*} \mathrm{STANDARD}^{46}$ suivi d'une figure illisible. Sur le second, on retrouve : LC et PARIS au milieu d'étoiles et au-dessous d'une couronne. Ces boutons ont certainement été obtenus par découpe à l'emporte-pièce et les inscriptions et décors ont été réalisés par emboutissage.

Les boutons $\mathrm{n}^{\circ} \mathbf{1 3}$ à 15 , tous découverts dans des contextes du XVIII ${ }^{\mathrm{e}} \mathrm{s}$., sont pourvus d'une courte bélière, brasée au revers d'une plaque circulaire bombée. Dans le cas des $n^{\circ} \mathbf{1 3}$ et $\mathbf{1 4}$, la bélière est fixée à une tôle de forte épaisseur. La base de la bélière du $\mathrm{n}^{\circ} 14$ est noyée sous la brasure. L'objet $\mathbf{n}^{\circ} \mathbf{1 5}$ est fabriqué à partir d'une tôle fortement bombée. Une tension dans l'axe de l'objet a engendré une dépression en son centre et fracturé la bélière brasée au revers. Qu'ils aient un corps bombé ou plat, ces deux formes de bouton se diffusent à partir du XVII ${ }^{\mathrm{e}}$, peut-être la fin, jusqu' au XIX ${ }^{\mathrm{e}} \mathrm{s}$.

Coulée dans un moule en deux parties se rejoignant au niveau de l'attache, la pièce $\mathbf{n}^{\circ} \mathbf{1 6}$, en matériau blanc, est de type à culot lanterne (fig. 243). Il porte un décor d'étoile à cinq branches irrégulières, cerclée par l'inscription NOUS PIONNIERS. Créés par ordonnance royale en 1776, supprimé en 1779, reconstitués en 1792 pour être définitivement supprimés en 1814, les «pionniers » sont dans l'Ancien Régime des soldats destinés à « être employés pendant la paix à des travaux publics et à servir en temps de guerre à la suite des états-majors des armées » (Fallou 1915, p. 124). Ils sont, lors de leur seconde création, affectés avec les sapeurs aux travaux militaires soit en campagne, soit dans les places fortes. Ils sont alors constitués de conscrits qui se sont mutilés pour se soustraire au service, «d'hommes noirs »,

46 Il existe un doute quant à la lecture de la première lettre : $\mathrm{C}$ ou $\mathrm{G}$ ? 


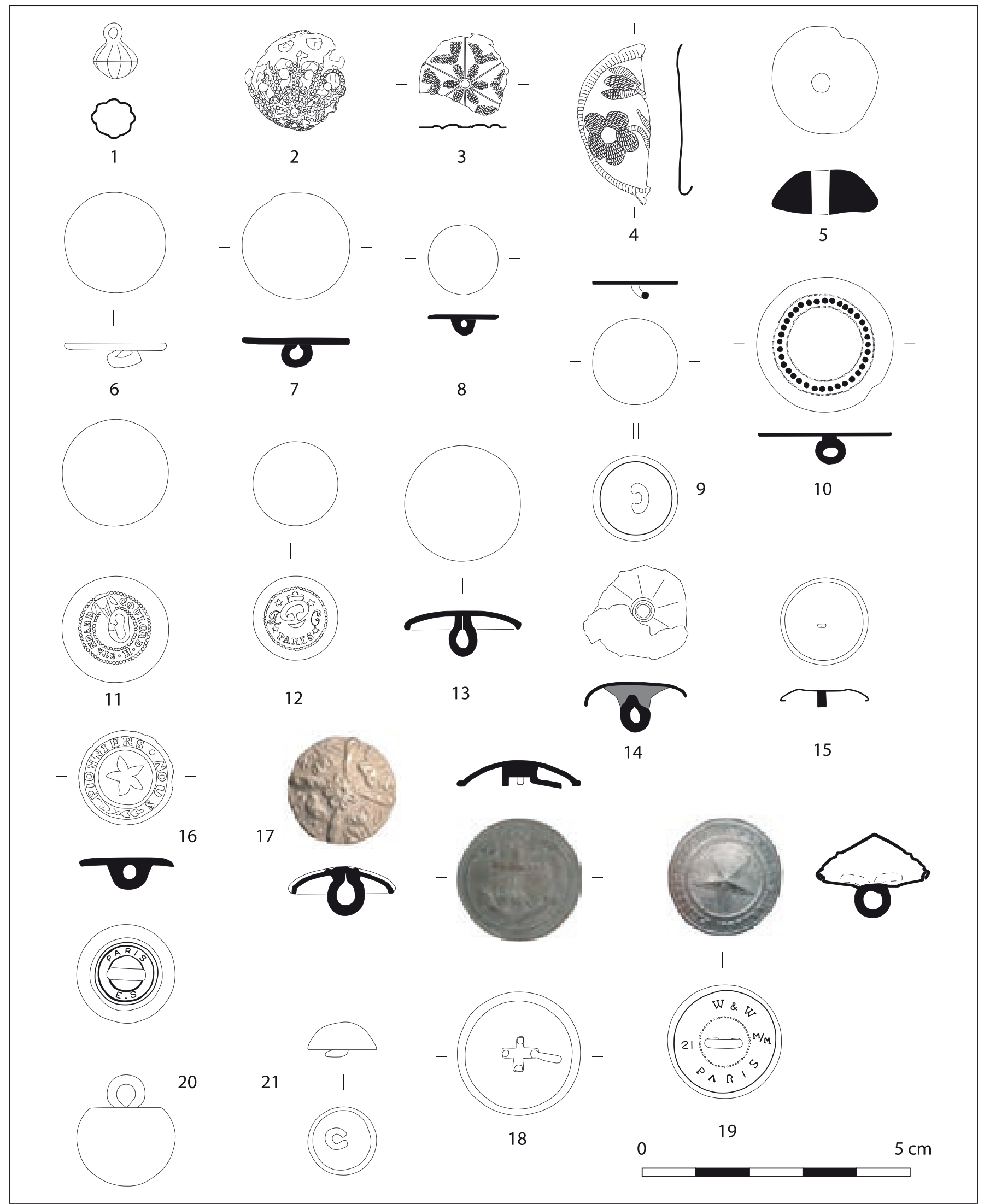

Fig. 243. Boutons à bélière (O. Thuaudet). 1, 7, 13, 20 : Tunnel de la Major ; 2-3, 17, 19 : Alcazar ; 4, 9, 11, 15-16 : Vieille-Major ; 5, 21 : Saint-Victor : 6 : place Villeneuve-Bargemon ; 8,14 : llot $55 ; 10$ : Rocade L2 ; 12, 18 : place des Pistoles. 
de prisonniers de guerre (Fallou 1915, p. 124-125). La collection offre là un rare exemplaire de bouton de pionniers car ils sont fort peu connus. L. Fallou rapporte que le 18 mars 1814, il est institué des boutons « en métal blanc empreint du nom des corps de pionniers » mais ceux-ci auraient été dissous avant qu'il leur soit donné la possibilité de les porter (Fallou 1915, p. 125).

La décoration végétale du bouton $\mathrm{n}^{\circ} 17$ (fig. 243 ; fig. 246), quatre fleurs en bordure séparées par des motifs fusiformes aboutissant à une fleur à huit pétales, est obtenue par fonte. Elle est similaire, par son organisation et le modelé du motif sur fond rayé, à un bouton anglais de contexte inconnu (Bailey 2004, p. 66, fig. 9.188). La pièce du corpus comporte une bélière brasée au revers.

L'objet $\mathbf{n}^{\circ} 18$ (fig. $\mathbf{2 4 3}$ ) possède également un corps obtenu par moulage. L'attache qui est brasée semble avoir été de type à culot lanterne. Il est figuré à l'avers une ancre avec sa corde entre deux bourgeons de feuille liés par la même tige. Ce bouton au métal de couleur cuivrée fut porté par l'infanterie de marine entre 1871 et 1900, puis par l'infanterie coloniale du 7 juillet 1900 jusque peut-être 1914 (Fallou 1915, p. 283).

La chaîne opératoire qui a conduit à la réalisation des objets $\mathbf{n}^{\circ} \mathbf{1 9}, \mathbf{2 0}$ et $\mathbf{2 1}$ (fig. 243) est difficile à restituer. Une première tôle emboutie en reçoit une seconde, préalablement traversée par une bélière. Le bord de la tôle supérieure paraît être rabattu sur un gradin de la deuxième. Mais l'absence de noyau interne, si on en juge par la masse de ces boutons, n'explique pas comment la tôle inférieure tient en place lors de cette opération. Possède-t-elle un rebord qui vient se bloquer au contact de la tôle supérieure?

Le site de l'Alcazar a révélé neuf exemplaires identiques au $\mathbf{n}^{\circ} 19$ (fig. 243 ; fig. 246, $\mathbf{n}^{\circ}$ 2), en matériau blanc indéterminé et siglés à l'avers ADMINISTRATION PENITENTIAIRE avec une étoile à cinq branches sur fond rayé. Le revers est orné d'un cercle de points entourant la bélière et d'une inscription étagée, le tout en creux. Ces boutons $(\mathrm{d} \times \mathrm{h}=2,1 \times 1,5 \mathrm{~cm})$ ont été retrouvés dans le même contexte que 52 exemplaires identiques mais de plus petite taille $(\mathrm{d} \times \mathrm{h}=1,5 \times 1,3 \mathrm{~cm})$. Le libellé au revers mentionne le nom du fabricant (W \& W), sa localisation (PARIS) ainsi que la référence du bouton (21 et M/M). Le nombre 21 correspond au diamètre, en millimètres $(\mathrm{M} / \mathrm{M})$, de l'accessoire : il est indiqué 15 pour ceux de dimension inférieure. Le motif de l'étoile régulière à cinq branches, sur fond vierge ou rayé, entouré d'une inscription, se rencontre sur des boutons militaires du temps de la Monarchie de Juillet jusqu'au moins le début de la première Guerre Mondiale (Fallou 1915, p. 55, 106-108, 189). Il existe également, non rayé, avec le sigle ADMINISTRATION PENITENTIAIRE sur des exemplaires datés de la Troisième République (Fallou 1915, p. 206).
L'objet $\mathbf{n}^{\circ} 14$ (fig. 243) est confectionné à partir de tôles de cuivre ou d'alliage cuivreux. Il porte au revers l'inscription PARIS E.S, marque du fabricant, encadrée par deux cercles, le tout en creux. Sa tôle supérieure déborde largement sur celle inférieure.

\subsection{Les épingles (O. Thuaudet)}

D'un usage courant, l'épingle à tête enroulée (voir Annexe 4, $\mathbf{n}^{\circ} \mathbf{1 3}$ ) est connue à travers toute l'Europe de l'Ouest sur toutes sortes de sites : cimetière, site castral, ville, village, etc. Ce type apparaît au début du $\mathrm{XIII}^{\mathrm{e}} \mathrm{s} .{ }^{47}$. Il connaît une forte diffusion et disparaît certainement à la fin du $\mathrm{XIX}^{\mathrm{e}}$ ou au début du $\mathrm{XX}^{\mathrm{e}} \mathrm{s}$. avec l'apparition des procédés de fabrication actuels. La gente féminine est, à cette époque, grande consommatrice d'épingles métalliques car elles permettent de fixer ou d'ôter avec facilité certaines pièces du costume. On les emploie également pour la couture. Quelques peintures montrent leur utilisation dans la coiffure ou dans le vêtement féminin - par exemple sur un triptyque de Stephan Lochner peint vers 1440 et conservé à la cathédrale de Cologne -, sans que l'on puisse déterminer leur typologie exacte en raison de la petite dimension de leur tête. Retrouvées en contexte funéraire, elles sont interprétées comme moyen de fixation du costume ou du linceul. Sur le site de Brandes-en-Oisans à l'Alpe d'Huez en Isère, M.-Ch. Bailly-Maître a remarqué que la très grande majorité des épingles à tête enroulée provient de l'église, hors de tout contexte funéraire. Elle l'interprète comme un souci de soigner son apparence pour aller à la messe (Bailly-Maître, Bruno-Dupraz 1994, p. 132).

Bien qu'elles constituent un produit de grande consommation et de faible coût, leur fabrication nécessite un grand nombre d'opérations. La chaîne opératoire décrite par Delaire dans l'Encyclopédie de Diderot et d'Alembert, identique à celle des auteurs du chapitre Art de l'épinglier paru en 1777 dans le tome VII des Descriptions des arts et métiers, n'est pas toujours en adéquation avec le mobilier archéologique ${ }^{48}$.

47 La présence d'une épingle à tête enroulée dans un remblai daté vers 900-1050 dans l'église Saint-Laurent-de-Grenoble est certainement à mettre en relation avec la construction de caveaux modernes et de fouilles archéologiques anciennes qui ont pu polluer certaines couches. Se reporter à Colardelle 2008, p. 232, 237-238. Un autre spécimen a été mis au jour dans le comblement d'une inhumation antérieure au XIe s. sur le site de Montaigut à Gissac dans le Tarn, mais l'agrandissement du château, qui succède à cette utilisation sépulcrale, au $\mathrm{XV}^{\mathrm{e}}$ s., a été suivi de remaniements et de vidanges de sépultures. Voir Hibon et al. 2002, p. 144, 146-147).

48 Données en cours de publication. 


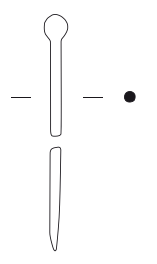

1

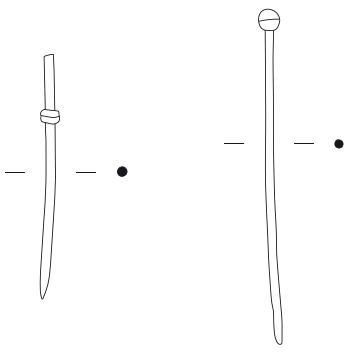

2

3

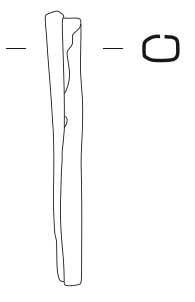

8
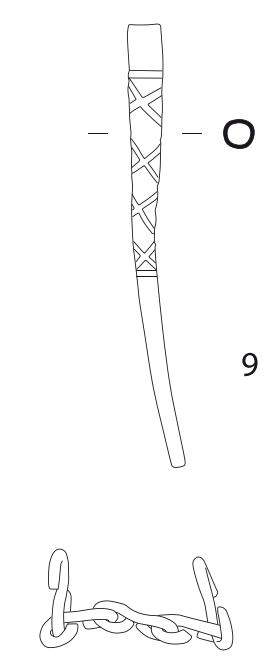

16

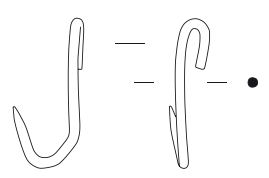

17

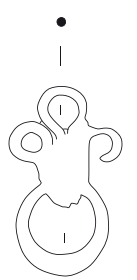

I

I

19

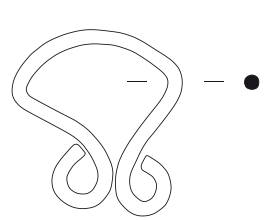

20

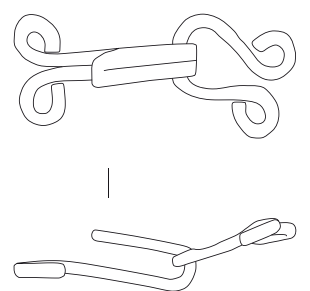

21

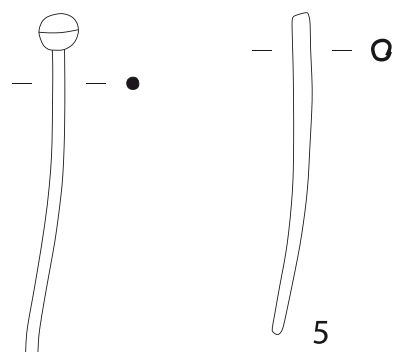

4

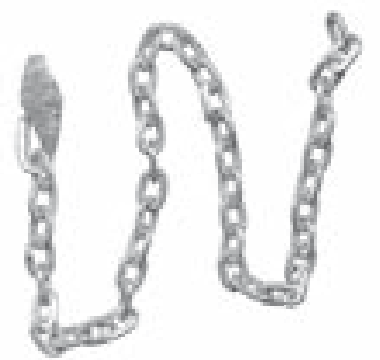

18
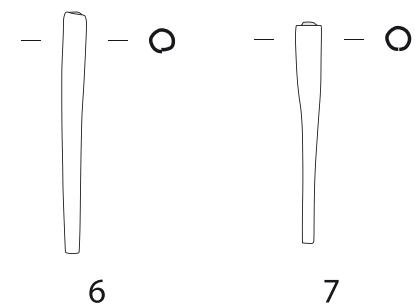

7

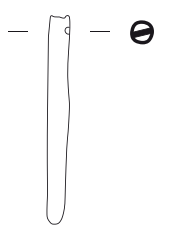

12

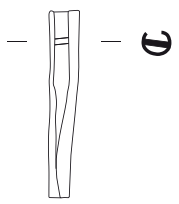

13

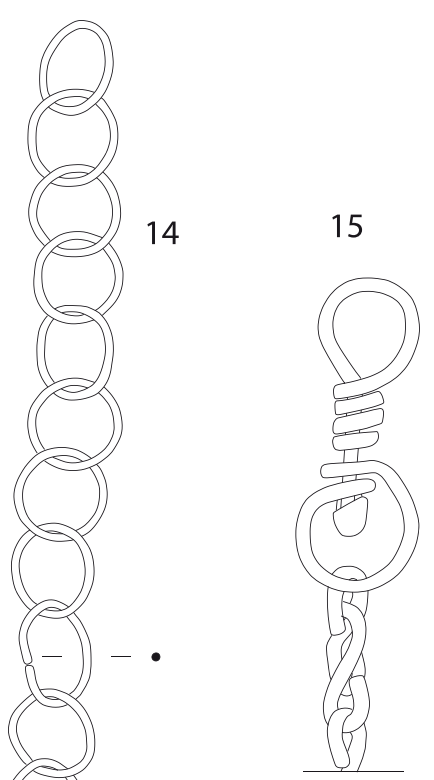

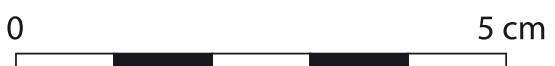

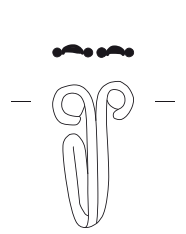

22

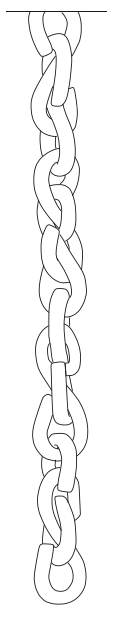

Fig. 244. Épingles, ferrets de lacet, agrafes et chaînettes (O. Thuaudet). 1-2, 6-7, 10-11, 17, 20 : Saint-Victor ; 3 : place de la Providence ; 4, 18 : place des Pistoles ; 5, 12, 19 : Alcazar ; 8 : Tunnel de la Major ; 9, 13, 21-22 : Vieille-Major ; 14 : collège Vieux-Port ; 15 : Bon Jésus ; 16 : la Charité. 
Les fouilles marseillaises ont livré un peu moins de 200 de ces objets dans des niveaux du XIII ${ }^{\mathrm{e}}$ au début du $\mathrm{XX}^{\mathrm{e}} \mathrm{s}$., pour les trois quarts d'entre eux dans des contextes des $\mathrm{XVI}^{\mathrm{e}}$ au XVIII ${ }^{\mathrm{e}}$ s. (fig. 244, $\mathbf{n}^{\circ} 1$ à 4). Ils proviennent en majorité de contextes remaniés, d'ossuaires ou de comblements de caveaux. Les exemplaires les plus anciens (XIII ${ }^{\mathrm{e}} \mathrm{s}$.) ont été retrouvés dans des remblais à l'abbaye Saint-Victor et sur le site de Puget III. Les épingles étudiées mesurent entre 2,1 et $6 \mathrm{~cm}$ avec un pic autour de $2,5 \mathrm{~cm}$ pour un diamètre de la tige compris entre 0,06 et $0,19 \mathrm{~cm}$ avec une plus grande concentration à $0,11 \mathrm{~cm}$. L'extrême diversité des contextes ne prête pas à une analyse statistique de ces épingles et de leurs caractéristiques. Quelques fragments d'épingles en fer ont été extraits d'un ossuaire du XVIII ${ }^{e}$ s. à la Vieille-Major et d'un remblai du XIII's. à l'abbaye Saint-Victor, mais soit la tête manque soit elle est trop oxydée, il n'est donc pas possible de vérifier la présence d'une tête enroulée.

Lors de la fouille des pestiférés ensevelis rue Leca (1720-1722), deux épingles en alliage cuivreux ont été retrouvées plantées au niveau du gros orteil de deux femmes. Elles ont été interprétées comme le résultat d'un geste du « croque-mort » dans le but de vérifier la réalité du décès (Dutour et al. 1994, p. 194-196, 199-200).

\subsection{Les ferrets de lacets (O. Thuaudet)}

Les ferrets métalliques en alliage cuivreux sont souvent les seuls vestiges qui attestent de l'existence de lacets en matière périssable (voir Annexe 4, n⿳1014). Ces ferrets sont fabriqués par l'enroulement bord à bord, parfois avec un léger chevauchement, d'une mince tôle autour de l'extrémité d'un cordon. Cette tôle peut être laissée telle quelle ou retouchée par un léger martelage du bout inférieur, destiné à en rabattre légèrement ou complètement les bords et à former un arrondi. Une même opération peut être exécutée en partie proximale pour mieux fixer le ferret sur le cordon, mais cela est bien plus rare. Pour consolider la fixation, un rivet est souvent rajouté dans la partie supérieure du ferret. Aucune corrélation n'a pu être établie entre la forme du ferret (conique, cylindrique), son degré de retouche ou sa longueur en fonction de la chronologie. La fragmentation de beaucoup de ces objets et l'oxydation par recouvrement ou nivellement de leur surface rendent souvent difficile la perception de la présence ou de l'absence de rivet. Mais un abrasement avec une brosse à fibre de verre lève généralement le doute. Cependant, après sectionnement, quelques ferrets considérés dans un premier temps comme sans rivet se sont révélés en disposer. Avec une étude minutieuse beaucoup de ferrets mentionnés dans la bibliographie pourraient donc révéler un rivet. Il existe un déséquilibre important entre ce qui est observé en matière de ferrets en Provence et ce que rapportent les publications européennes. Ces objets sont généralement découverts dans toutes sortes de contextes et parmi ceux-ci bien évidemment les sépultures. Ils sont alors généralement interprétés comme provenant du vêtement de l'inhumé.

D'après les données actuelles, les ferrets de lacet sans rivet apparaîtraient au début du XII ${ }^{\mathrm{e}}$ s., mais ils ne deviennent courant qu'à partir du début du XIII ${ }^{e}$ s. et perdurent, sans que leur succès se démentisse, jusqu'à nos jours. Les sites de l'Alcazar (fig. 244, $\mathbf{n}^{\circ} \mathbf{5}$ ), de l'abbaye Saint-Victor (fig. 244, $\mathbf{n}^{\circ} \mathbf{6}$ et 7), du Tunnel de la Major (fig. 244, $\mathbf{n}^{\circ}$ 8), de la Vieille-Major (fig. 244, $n^{\circ}$ 9) ont livré dans des remblais modernes ou contemporains dix-huit spécimens. Ils conservent parfois quelques fragments de cuir ou de tissu. Quatre exemplaires sont issus d'un remblai de la $1^{\text {ère }}$ moitié du XIII ${ }^{e} s$. de l'abbaye Saint-Victor. Le $\mathbf{n}^{\circ} \mathbf{9}$ est orné par estampage, de croisillons en relief positif limités par deux lignes parallèles. Un ferret de lacet décoré de croisillons gravés a été retrouvé dans une couche du XIV ${ }^{\mathrm{e}}$ s., voire peut-être du milieu du siècle, à la Maison des Chevaliers à Pont-Saint-Esprit dans le Gard (Leclaire 1992, p. 69). Le $\mathbf{n}^{\circ} \mathbf{1 0}$ est gravé de lignes incisées formant une spirale. Les extrémités des lignes ne sont pas parfaitement jointives au niveau du rebord de la tôle, ce qui montre qu'elles ont été exécutées avant la mise en forme. Un objet mal renseigné mais assez approchant provient d'un contexte du XVI ${ }^{\mathrm{e}} \mathrm{s}$. du château de Montaldo di Mondovì (Piémont) en Italie (Cortelazzo, Lebole di Gangi 1991, p. 226). Un autre, aux lignes horizontales, a été retrouvé dans un niveau $\mathrm{du} \mathrm{XV}^{\mathrm{e}}$ s. dans la Maison des Chevaliers de Pont-SaintEsprit dans le Gard (Leclaire 1992, p. 69).

Les ferrets avec rivet, parfois en fer (fig. 244, ${ }^{\circ} 11$ ), ne sont pas connus avant le $\mathrm{XIV}^{\mathrm{e}} \mathrm{s}$. et sont encore attestés au XVII ${ }^{\mathrm{e}} \mathrm{s}$. Le corpus marseillais en contient six exemplaires (fig. 244, $\mathbf{n}^{\circ} \mathbf{1 2}$ ) dont deux, certainement en position résiduelle, dans le comblement d'une tombe de la première moitié du XVIII ${ }^{\mathrm{e}} \mathrm{s}$. (Vieille-Major, fig. 244, $\mathbf{n}^{\circ} \mathbf{1 3}$ ) et dans un remblai à peine antérieur à la Grande Peste de 1720 (Esplanade Major).

\subsection{Les agrafes et chaînettes ( $O$. Thuaudet)}

Quelques fragments de chaînettes de plusieurs types ont été retrouvés dans des contextes médiévaux et modernes (voir Annexe 4, $\mathbf{n}^{\circ} \mathbf{1 5}$ ). Leur emploi dans le costume, en tant qu'élément de suspension ou d'attache, est possible mais rien ne permet de l'affirmer. Ces chaînettes sont constituées de tronçons de fils de même diamètre, certainement mis en forme avec une pince. 
Une portion de chaînette à maillons en $S$ (fig. 244, ${ }^{\circ}{ }^{15}$ ) est terminée à une extrémité par une partie rotative, formée d'un émerillon et d'un tourillon. Un autre fragment est constitué de maillons en $\mathrm{S}$ simples et en $\mathrm{S}$ désaxés (fig. 244, $\mathbf{n}^{\circ}$ 16). Ces deux types de maillon existent déjà à l'époque romaine. Ils peuvent être terminés par un crochet en $S$ désaxé à pointe effilée (fig. 244, $\mathbf{n}^{\circ} \mathbf{1 7}$ ). Des chaînettes à maillons ovales ou circulaires ont été également retrouvées (fig. 244, $\mathrm{n}^{\circ} 14$ et 18). L'objet $\mathrm{n}^{\circ} 14$ est terminé par une sorte «d'agrafe » à pied circulaire portant des traces de dorure, et obtenue par fonte. Sa fonction reste inconnue. Les maillons du $\mathrm{n}^{\circ} \mathbf{1 8}$ sont de section quadrangulaire arrondie. Cet objet en or (5,9 gr.) comporte une forme losangique décorée sur une face de stries disposées en arêtes de poisson. Au revers, on retrouve une inscription : HONU [...] ONE.

Les éléments d'agrafe en fil $\mathbf{n}^{\circ} \mathbf{1 9}$ et $\mathbf{2 0}$ (fig. 244), constituent dans les deux cas la partie femelle du dispositif de fixation. La partie mâle en forme de crochet est illustrée par des dispositifs complets ( $\mathrm{d}$ fil $=0,11$ à $0,14 \mathrm{~cm}$ ) retrouvés dans un même caveau de la VieilleMajor (fig. 244, $\mathbf{n}^{\circ} \mathbf{2 1}$ et 22), par un individu déformé d'un contexte moderne ou contemporain du site de Puget III $(\mathrm{d}=0,13 \mathrm{~cm})$. La chaîne opératoire de leur fabrication est en partie décrite dans l'édition de 1777 du tome VII des Descriptions des arts et métiers faites ou approuvées par messieurs de l'Académie royale des sciences de Paris (p. 589-590). Les étapes suivantes y sont retracées par Duhamel (fig. 246, $\mathrm{n}^{\circ} \mathbf{6 a}$ ) :

- pliage en deux du fil,

- aplatissement au marteau du bout plié (seulement pour le $\mathbf{n}^{\circ} 19$, fig. 244),

- recourbement des extrémités pour faire les volutes avec une pince dont les mâchoires sont « terminée(s) par deux poinçons arrondis »,

- déformation avec le même outil du bout aplati pour faire l'anse, ou recourbement pour réaliser le crochet.

À ces opérations, il convient de rajouter pour le $\mathbf{n}^{\circ} \mathbf{1 9}$

(fig. 244) les actions ci-après (fig. 246, $\mathbf{n}^{\circ}$ 6b) :

- recourbement de l'extrémité d'un deuxième fil,

- insertion du fil entre les deux extrémités du premier fil,

- enroulement d'un troisième fil autour de l'assemblage ainsi constitué pour le fixer (fil amalgamé par l'oxydation en une sorte de plaquette sur le $\mathbf{n}^{\circ} \mathbf{1 9}$ ).

La fabrication de ces accessoires rentre dans les attributions des épingliers du XVIII ${ }^{\mathrm{e}} \mathrm{s}$. du nord de la France selon Duhamel. Ces éléments d'agrafe apparaissent dans la seconde moitié du XIII ${ }^{\mathrm{e}}$ s. et perdurent encore de nos jours. L'exemplaire $\mathbf{n}^{\circ} \mathbf{1 9}$ est cependant le plus ancien de son sous-type, lequel est lui-même assez rare. Il n'est pas mentionné dans l'ouvrage susnommé et le plus récent connu à ce jour est celui accompagnant une sépulture du
$\mathrm{XVI}^{\mathrm{e}}$ s. à Cadrix (Saint-Maximin-la-Sainte-Baume dans le Var). Son emploi n'a peut-être pas dépassé ce siècle.

\section{La bijouterie}

Les perles, bagues, anneaux et objets de dévotion présentent la caractéristique commune de pouvoir orner le vêtement, ses accessoires ou bien encore le corps, à l'exception des enseignes absentes ici. Le lien avec le religieux est évident pour les objets de dévotion, mais il n'est pas absent des perles et bagues. Les perles entrent dans la confection d'ornements liturgiques et sont constitutives des chapelets. Quant aux anneaux et bagues, ils sont, pour la période qui nous intéresse, le « symbole des liens indéfectibles du mariage » selon la formule aujourd'hui consacrée. Bénis par l'officiant, ils font un peu plus encore entrer les nouveaux mariés, chrétiens, dans la communauté de Dieu. Portés par les hauts dignitaires de l'église, ils sont un des signes de leur investiture.

\subsection{Les perles isolées \\ (M.-A. Chazottes, O. Thuaudet)}

Les perles : objet de parure, ou objet à vocation religieuse ? Déterminer si ces pièces isolées proviennent de chapelets ou de colliers est souvent assez délicat d'autant que le contexte de découverte le renseigne rarement (voir Annexe 4, $n^{\circ} 16$ ).

Le chapelet se porte généralement à la main, il est formé de perles enfilées et groupées par dizaines. À chaque grain que l'on fait glisser entre ses doigts correspond une prière - des Pater et des Ave en fonction de la taille du grain - qui s'accompagne d'indulgences (Berton 2000, p. 48). Par ailleurs, depuis son apparition au cours du XII ${ }^{\mathrm{e}} \mathrm{s}$., la symbolique religieuse de cet objet s'est peu à peu imprégnée de superstition : protection contre les maladies, les maléfices... (Thiriet 1997, p. 22). A contrario des perles de chapelets, les perles de colliers sont exclusivement des éléments de parure et même si ces derniers ont parfois un rôle prophylactique, ces bijoux sont portés par plaisir, ils participent à l'embellissement de la personne mais ne sont pas utilisés dans la récitation de prières.

Dans la plupart des cas, la morphologie des perles référencées n'est pas suffisamment caractéristique pour une datation typo-chronologique.

Une perle sphérique en verre bleu (fig. $245, \mathbf{n}^{\circ} \mathbf{1}$ ) présente un aspect spiralé, signe d'une torsion de la pâte de verre dans le sens de la longueur. Une autre perle, également en verre bleu, est signalée comme provenant d'un 
caveau du XVIII ${ }^{\text {s. }}$ (Villemeur, Henry 2000, p. 15, 48). Ce contexte contenait aussi des perles en cornaline - en ambre ? qui n'ont pu être retrouvées - (Villemeur, Henry 2000, p. 15, 48).

Dans l'abbaye Saint-Victor, des remblais des $\mathrm{XV}^{\mathrm{e}}$ et $\mathrm{XVI}^{\mathrm{e}} \mathrm{s}$. ont livré sept exemplaires annulaires en verre bleu (fig. 245, $\mathbf{n}^{\circ} \mathbf{2}$ à 4), et des remblais des $\mathrm{XVI}^{\mathrm{e}}$ et $\mathrm{XVII}^{\mathrm{e}} \mathrm{s}$. des perles sphériques ou annulaires en verre noir (fig. $\mathbf{2 4 5}, \mathbf{n}^{\circ} \mathbf{5}$ et $\mathbf{6}$ ). Une dernière perle facettée en verre transparent (fig. $\mathbf{2 4 5}, \mathbf{n}^{\circ} \mathbf{1 0}$ ) a probablement été obtenue par moulage. Quatre perforations se rejoignent au centre pour permettre la fixation dans un collier ou tout autre bijou de verroterie.

Six perles en jais, une variété très carbonée de lignite, (fig. 245, $\mathrm{n}^{\circ} \mathbf{7}$ à 9, 11 à 13 ) ont été inventoriées pour des niveaux des $\mathrm{XVII}^{\mathrm{e}}$ et XVIII ${ }^{\mathrm{e}} \mathrm{s}$. Ces perles ovoïdes ou annulaires ont été tournées, puis perforées et polies. Les perles en jais sont produites dès l'Antiquité romaine mais semblent avoir peu de faveur durant une bonne partie du Moyen Âge. C'est à partir du XIV ${ }^{\mathrm{e}} \mathrm{s}$. que les sites archéologiques, mais également les sources d'archives, livrent à nouveau du matériel en jais, surtout dans le sud de la France. L'Ariège et le Dauphiné en ont été les principaux centres d'extraction et de production, aussi bien à l'Époque moderne et contemporaine, et la petite bijouterie de deuil en a été le principal débouché (Encyclopédie Diderot et d'Alembert : article Jais).

Une unique perle en buis (fig. 245, $\mathbf{n}^{\circ} \mathbf{1}$ ) comporte deux perforations disposées perpendiculairement. Un fragment de tige en fer est encore en place dans l'une d'elles. Il s'agit très probablement d'une perle qui, assemblée avec d'autres, formait une croix de chapelet ou alors permettait le départ d'une partie pendante.

Onze perles ovoïdes (fig. 245, $\mathbf{n}^{\circ} \mathbf{1 5}$ ) et une perle annulaire en os (fig. 245, $\mathbf{n}^{\circ} \mathbf{1 6}$ ) ont été découvertes dans un même caveau du Tunnel de la Major. Deux autres perles ovoïdes proviennent de l'abbaye Saint-Victor (fig. 245, $\mathrm{n}^{\circ} \mathbf{1 8}$ ) et une dernière du site des Pistoles (fig. 245, $\mathbf{n}^{\circ}$ 17). A celles-ci s'ajoutent trois perles de même morphologie mais teintées: deux en pourpre (fig. 245, $\mathbf{n}^{\circ}$ 19) et la dernière avec quelques traces rosées. Des perles de la même couleur ont été également découvertes dans l'église Saint-Blaise à Arles, dans des remblais du $\mathrm{XVIII}^{\mathrm{e}} \mathrm{s}$. Une dernière perle ovale en os (fig. 245, $\mathbf{n}^{\circ}$ 22) présente un décor quadrillé oblique. Des exemples similaires modernes sont recensés au cimetière Saint-Jacques de La Ciotat dans les Bouchesdu-Rhône (Richier et al. 2011). Toutes les perles ont été obtenues par tournage, soit du haut vers le bas dans une matrice paraxiale, soit de gauche à droite ou inversement à partir d'une baguette de forme quadrangulaire. Ce tournage a permis de créer des perles jointives ensuite séparées par tournage ou sciage. Les traces de ce dernier procédé sont visibles sur une perle de l'abbaye Saint-Victor $\left(\mathbf{n}^{\circ} \mathbf{1 8}\right)$.

Les deux derniers objets de cette série sont en corail. Le $\mathbf{n}^{\circ} 21$ (fig. 245) est une perle sphérique traversée à une extrémité par un rivet maté en alliage cuivreux, avec perforation pour la suspension à l'opposé. Le second fait probablement partie d'une ébauche de perle entièrement polie (fig. $245, \mathbf{n}^{\circ} \mathbf{2 0}$ ).

\subsection{Les bagues et anneaux (O. Thuaudet)}

Les anneaux et bagues se distinguent suivant que les joncs sont surmontés ou non d'un chaton (voir Annexe 4, $\mathbf{n}^{\circ} \mathbf{1 7}$ ).

Parmi les anneaux à jonc simple, la plupart, comme le $\mathbf{n}^{\circ} \mathbf{1}$ (fig. 245, $\mathbf{n}^{\circ} \mathbf{2 3}$ ), ont un jonc dont la section est plate au revers et bombée à l'avers. Trois autres exemplaires (fig. 245, $\left.\mathbf{n}^{\circ} \mathbf{2 4}\right)$ au jonc plus ou moins épais $(\mathrm{e}=0,09$ à $0,15 \mathrm{~cm}$ ) ont été retrouvés dans des tombes d'adultes du XIII ${ }^{\mathrm{e}}$ s. (Puget III). Un anneau en or (fig. 245, $\mathbf{n}^{\circ} \mathbf{2 5}$ ), provenant d'un caveau de même datation (Tunnel de la Major), se distingue par sa section ovale ( $\mathrm{m}=1,93 \mathrm{gr}$ ). Ces objets ont sans doute été obtenus par fonte, car aucune trace de brasure n'a pu être observée, ce qui aurait été le cas si ces anneaux avaient été réalisés à partir d'un fil dont les extrémités avaient été réunies.

La bague $\mathbf{n}^{\circ} \mathbf{2 6}$ (fig. $245, \mathbf{n}^{\circ} \mathbf{1}$ ), au jonc de section en amande, obtenu par fonte, possède un chaton hexagonal aux faces concaves ${ }^{49}$. Le serti clos de la bague en or $\mathbf{n}^{\circ} 27$ (fig. 245) conserve encore sa pierre verte (fig. 245, $\mathbf{n}^{\circ}$ 7) de nature indéterminée, couleur émeraude. Le serti est constitué d'une bâte posée de chant sur une feuille de fond à laquelle elle est soudée (fig. 245, $\mathbf{n}^{\circ} \mathbf{8}$ ). En revanche, sa jonction avec le jonc semble vierge de toute trace de soudure. La base du chaton et le jonc sont donc le résultat d'une fonte. Quatre dépressions rectilignes et opposées, perpendiculaires à l'axe du jonc, sont visibles au revers de la tôle de fond (fig. 245, $\mathbf{n}^{\circ} \mathbf{9}$ ). Ces traces d'outil (?) n'ont pu être interprétées. Le jonc, porte de part et d'autre du serti, deux lignes évidées limitées par deux élargissements quadrangulaires, eux-mêmes traversés par deux segments creux. Cette ornementation résulte d'un enlèvement de matière. La confection de cette bague $(\mathrm{m}=1,27 \mathrm{gr})$ est de qualité : elle ne porte pas de trace de fissure et la soudure est quasiment invisible.

Une première bague (fig. 245, $\mathbf{n}^{\circ} \mathbf{2 8}$ ) est constituée d'un jonc de section ovale dont les extrémités étaient

49 D'après une photo du rapport de fouille, il était rempli d'une pâte blanche. Celle-ci s'est par la suite désagrégée en une fine poudre retrouvée dans le sachet où l'objet était stocké. 
brasées au revers d'une «applique » obtenue par fonte. Selon le même principe, les extrémités du jonc de l'objet $\mathbf{n}^{\circ} 29$ (fig. 245), de section quadrangulaire, s'aplatissent et sont brasées au revers d'une plaque ovoïde gravée d'un $\mathrm{M}$ dans un cadre. Une autre bague (fig. 245, $\mathbf{n}^{\circ} \mathbf{3 1}$ ) présente un jonc, à section plate au revers et bombée à l'avers, dont les extrémités sont aplaties et brasées au revers d'un chaton circulaire embouti. Il retient un fragment de verre bleu outremer.

Le chaton $\mathbf{n}^{\circ} \mathbf{3 0}$ (fig. 245) est constitué de deux tôles en or $(\mathrm{m}=0,26 \mathrm{gr})$ : la première est enroulée en cylindre et brasée de champ sur la seconde, plate et avec deux perforations réalisées de la face supérieure vers la face inférieure. Ces trous sont destinés à recevoir les extrémités du jonc sur lesquels est directement posée la pierre. Cette pierre est de couleur rose-violacé $(0,05 \mathrm{gr})$, avec des inclusions. Sa forme losangique de même que ses facettes émoussées sont irrégulières. Il semblerait que ce soit un grenat. Des traces de limage sont visibles sur les bords des deux tôles, mais également au revers de la tôle de fond, ce qui montre qu'elles sont antérieures aux perforations. En effet, elles n'ont pas entamé le reflux du métal provoqué par le poinçonnage.

\subsection{Les objets de dévotion (O. Thuaudet)}

Il convient de distinguer au sein des objets de dévotion deux catégories. Les médailles, crucifix et pendentifs d'une part, et les « reliquaires » d'autre part. Tous sont le support d'une piété, peuvent être le souvenir d'un pèlerinage, d'un évènement personnel ou familial, l'affichage d'une foi, ou rappeler le souvenir d'un être cher. Les seconds, toutefois, sont destinés à conserver un témoignage matériel d'une activité de dévotion ou d'une personne. Dans ce dernier cas, il ne s'agit pas à proprement d'un objet de dévotion au sens ordinaire. Mais, la pratique régulière du souvenir d'un proche présente avec l'exercice religieux de fortes parentés.

\subsubsection{Les médailles, crucifix et pendentif}

Cinq médailles et deux crucifix obtenus par frappe témoignent d'une forme de dévotion populaire qui se développe à partir de la fin du XVI s. (voir Annexe 4, $\mathbf{n}^{\circ} \mathbf{1 8}$ ). Les crucifix $\mathbf{n}^{\circ} \mathbf{1}$ et $\mathbf{3}$ de la fig. $\mathbf{2 4 7}$ présentent une morphologie classique pour les périodes postérieures au $\mathrm{XVI}^{\mathrm{e}} \mathrm{s}$. Le Christ - seul élément confectionné par fonte - est riveté sur sa croix au niveau des pieds et de chacune des mains. L'un de ces objets a conservé l'extrémité de sa chaînette de suspension.

La médaille miraculeuse $\mathbf{n}^{\circ} \mathbf{2}$ porte sur l'avers l'image de l'Immaculée Conception: la Vierge se tient debout sur le globe éclairé par les rayons de ses mains, symbole des grâces qu'elle obtient pour les hommes. Elle est entourée par une inscription sur deux rangs, O MARIE CONCUE SANS PECHE PRIEZ POUR NOUS QUI AVONS RECOURS A VOUS. Au revers, figurent les saints cœurs de Jésus et de Marie surmontés d'un $\mathrm{M}$ - pour miraculeux -, sommé d'une croix dans un encadrement d'étoiles à cinq branches. L'imagerie de l'avers retrace les visions de 1830 de la sœur Catherine Labouré, fille de la Charité, rue du Bac à Paris (Laurentin 1990, p. 60-79). Cet objet, produit à plusieurs millions d'exemplaires, à travers différentes versions, a conservé sa chaînette à maillons en $\mathrm{S}$ désaxés ou en $\mathrm{S}$ simples lorsqu'ils reçoivent une perle. Trente-six perles en buis tournées ont été décomptées. Certaines sont ornées de deux couples de rainures, peutêtre pour marquer les paters de ce chapelet dont $49 \mathrm{~cm}$ sont conservés. La perforation de ces perles n'est pas de même diamètre aux deux extrémités. Cet ensemble provient d'un comblement de caveau du XVIII' s. dans la Vieille-Major.

Le monogramme du Christ (IHS), surmonté de la croix, avec au-dessous les trois clous de la passion, est visible sur une face de la médaille ${ }^{\circ} 4$ (fig. 247), dans un cercle de grènetis. En bordure, l'inscription V R S N S M V + S M Q L I V B + est l'abrégé du distique latin Vade retro satan non mihi vena sunt malas quae libas ipse venena bibas, soit: «Retire-toi Satan, ne viens pas me conseiller de tes vanités; le breuvage que tu verses est le mal ; bois toi-même tes poisons ». Sur l'autre face, les lettes CSPB encadrent une croix de Jérusalem. Elles signifient Crux sancti patris Benedicti, «Croix du saint Père Benoît ». On retrouve dans la croix les initiales CSSML verticalement et NDSMD horizontalement, ce qui signifie Crux sacra sit mihi lux et Non draco sit mihi dux. On peut les traduire par: "Que la sainte croix soit ma lumière », "Que le dragon ne soit pas mon chef (ou mon guide) ». Autant d'inscriptions confirmant sa vocation prophylactique : préserver du démon, guérir de toutes sortes de maladies, protéger des accidents, etc. (Villeval 1983). Le fait que la bélière soit sur le même plan que le corps de la médaille la rend moins adaptée à la suspension à un cordon ou à un chapelet. Il est d'ailleurs intéressant de remarquer qu'il s'agit de la seule médaille religieuse trouvée hors de tout contexte funéraire ou para-funéraire. Elle était plutôt destinée à être fixée sur un mur ou une poutre.

Sur une face de la médaille $\mathbf{n}^{\circ} \mathbf{6}$ (fig. 247), un ange tend un objet à l'Enfant, une main levée, debout sur les genoux de sa mère. Dans l'encadrement du coin supérieur gauche, on croit apercevoir un calice surmonté d'une hostie sommée de trois rayons, signe de son sacrifice futur. Sur l'autre face, deux personnages 


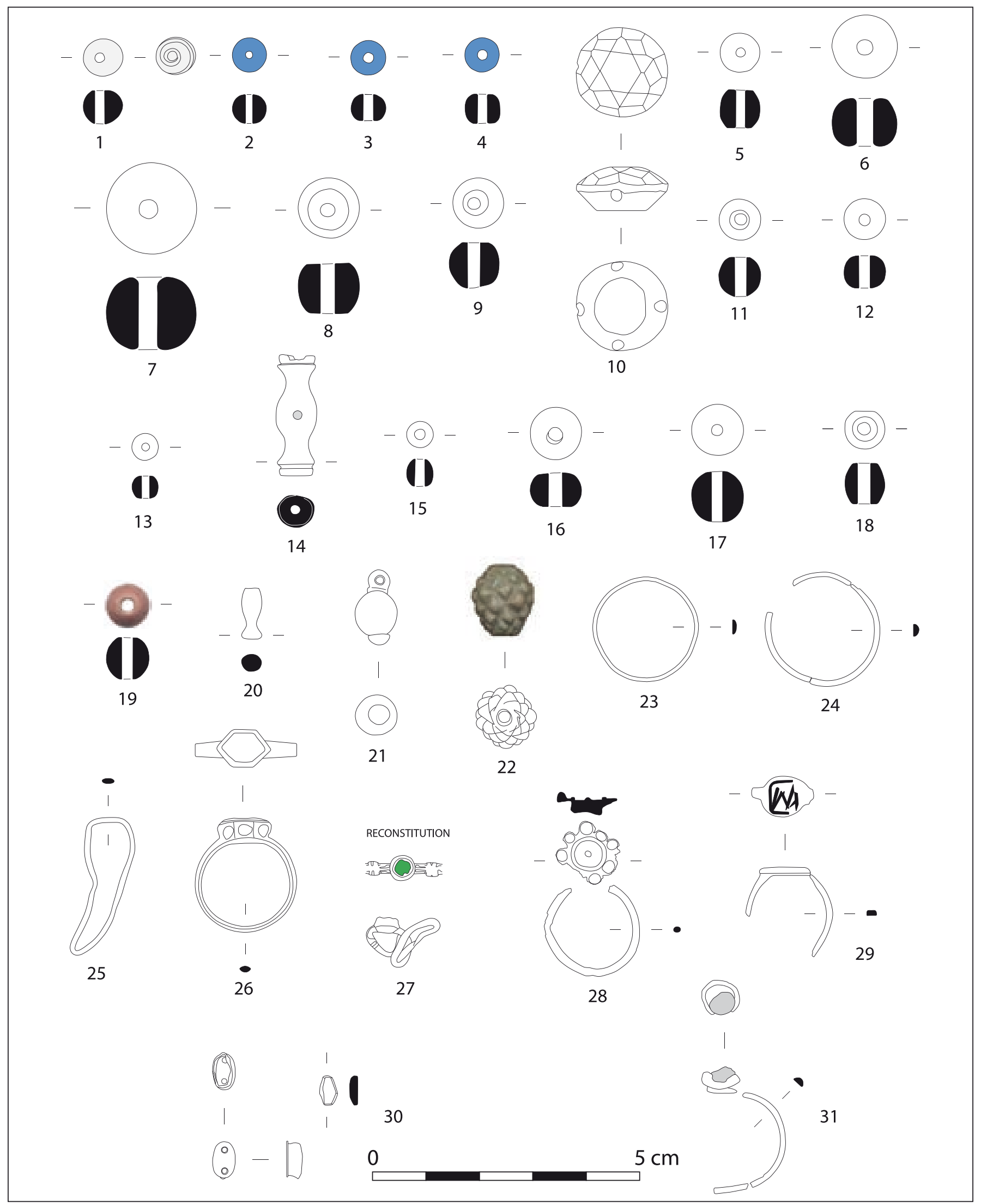

Fig. 245. Perles, bagues et anneaux (O. Thuaudet). 1, 27-28 : place Villeneuve-Bargemon ; 2-6, 12-14, 18, 20, 22, $29-30$ : Saint-Victor ; 7-11, 19, 26 : Vieille-Major ; 15-16, 23, 25 : Tunnel de la Major ; 17 : place des Pistoles ; 21 : parvis de l'église Saint-Laurent ; 24,31 : Puget III. 

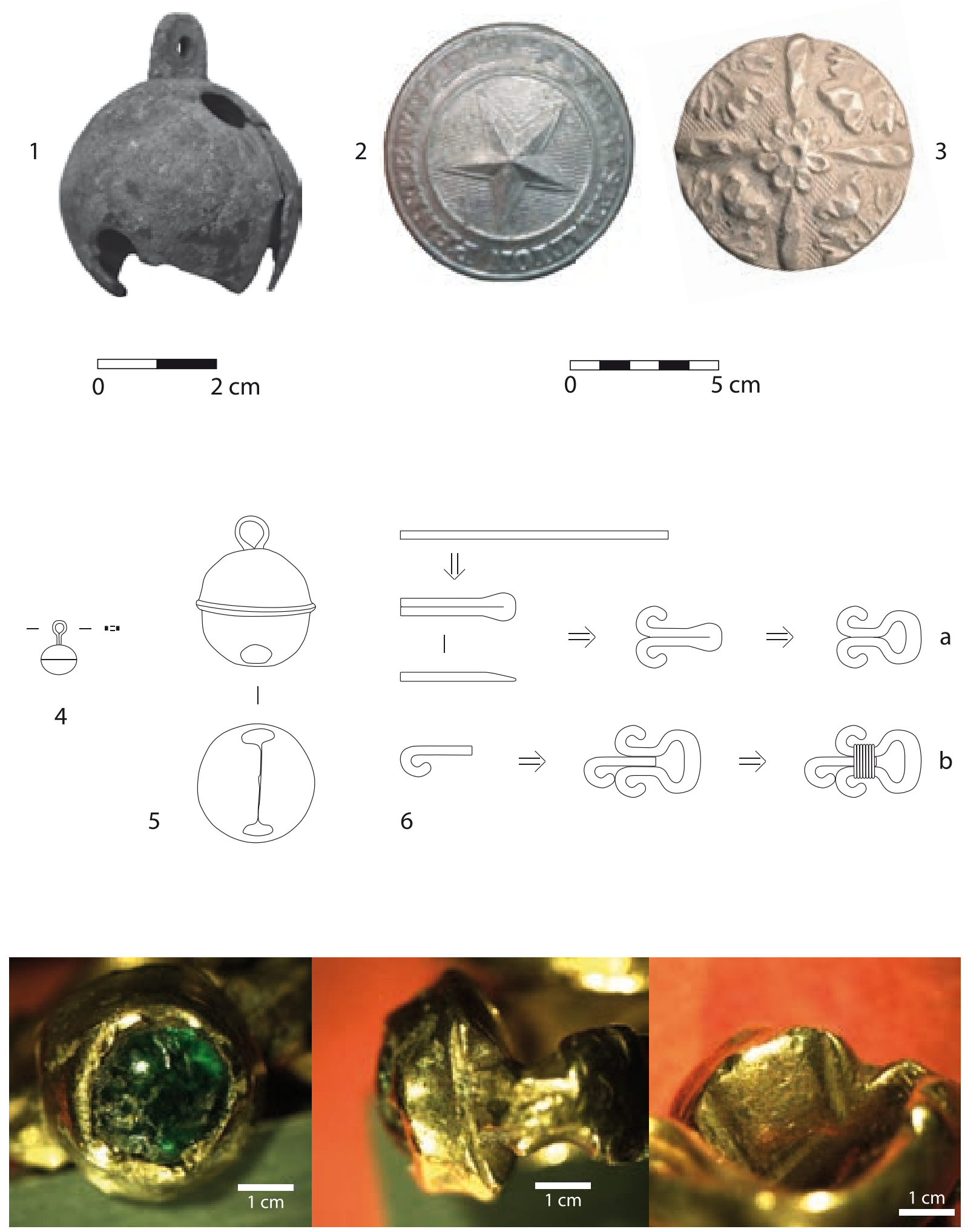

Fig. 246. $n^{\circ} 1:$ grelot ; $n^{\circ} 2:$ bouton de la Fig. $243: 19 ; n^{\circ} 3:$ bouton de la Fig. $243: 17 ; n^{\circ} 4:$ reconstitution d’un bouton globulaire ; $n^{\circ} 5$ : reconstitution d’un grelot caréné ; $n^{\circ} 6$ : illustration de la chaîne opératoire de fabrication d'une agrafe en fil ; $n^{\circ} 7$ à $9:$ vues de détail de la bague de la Fig. $243: 1$ (présence d'un reflet prenant la forme d'une ligne sur l'image n`9 entre les deux dépressions). 1 : Alcazar. 


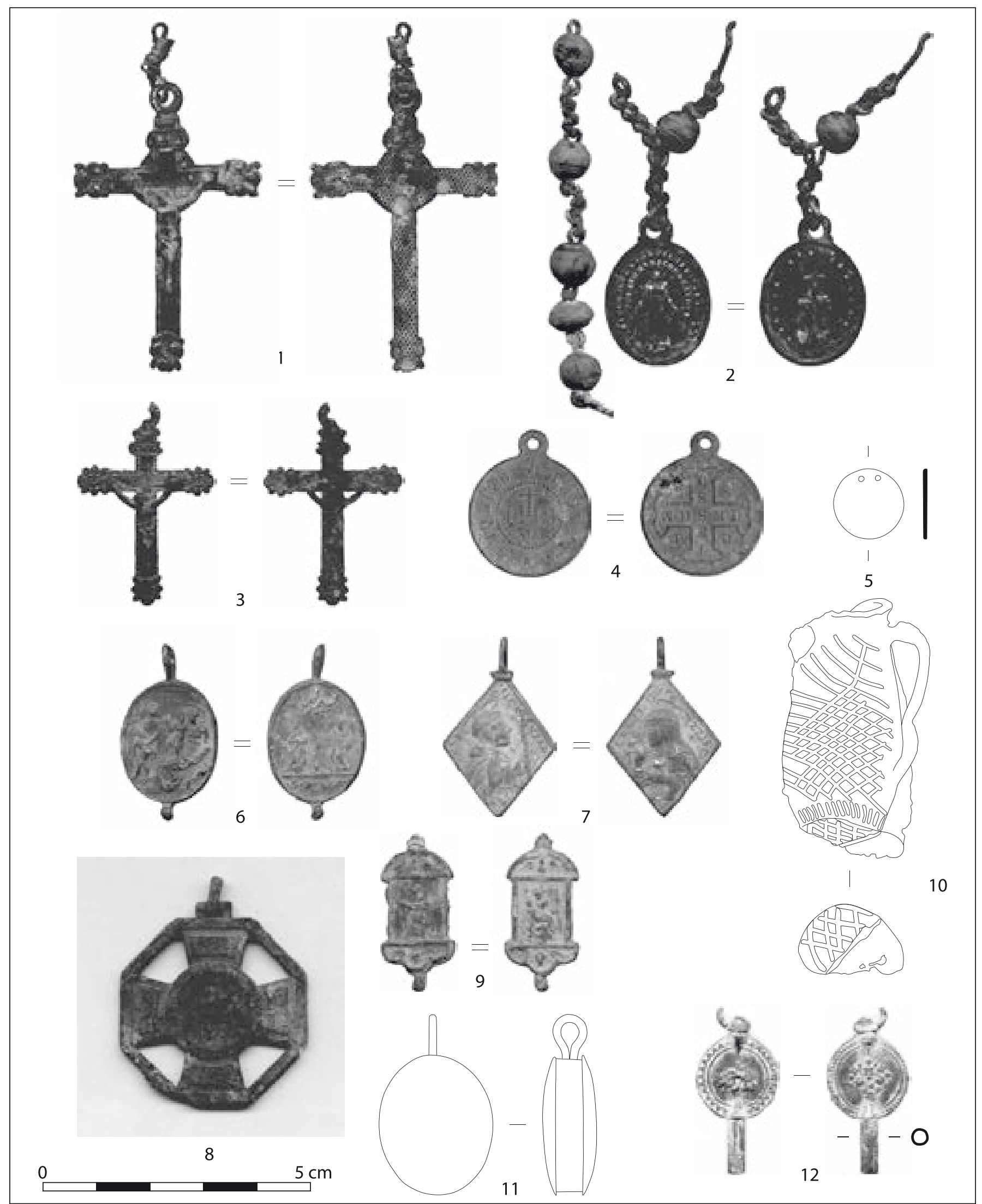

Fig. 247. Médailles, crucifix, pendentifs et « reliquaires » (O. Thuaudet). 1-3, 11 : Vieille-Major ; 4-5, 8 : place des Pistoles ; 6-7, 9 : Saint-Victor ; 10 : place Villeneuve-Bargemon. 


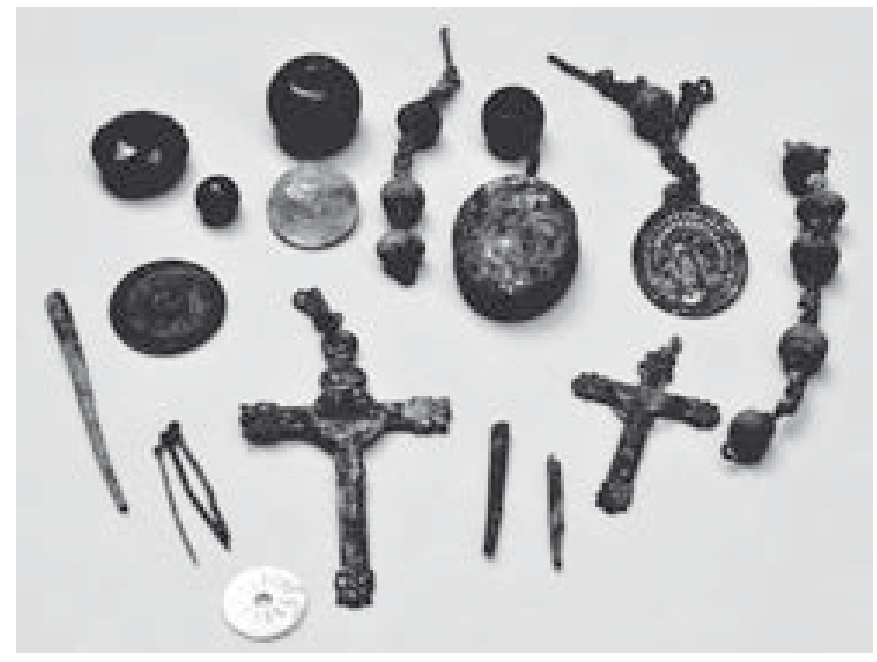

Fig. 248. Mobilier retrouvé lors des fouilles de 1994 dans la Vieille-Major (O. Thuaudet).

identifiés par leurs initiales .S.P.S.P., saint Pierre et saint Paul, tiennent leurs attributs respectifs, la clef et l'épée. Un objet inidentifiable est posé au sol entre les deux apôtres. Dans la partie supérieure, le Christ (?) sort d'une nuée et écarte les bras, il tient un globe (?) dans une main. Les deux apôtres sont chargés par le Christ d'apporter la bonne parole. La finesse du modelé ne permet pas d'envisager une datation antérieure à la fin du XVII ${ }^{\mathrm{e}} \mathrm{s}$.

La première des deux médailles religieuses suivantes (fig. 247, $\mathrm{n}^{\circ}$ 7), losangique, représente un moine de profil, tourné vers la droite, la main droite relevée, la main gauche serrée autour d'un bâton terminé par une croix. En bordure, on retrouve l'inscription S(AINT). PIE(RRE).D.ALCANTAR. Sur la face opposée, une religieuse de profil, est tournée vers la gauche, un voile sur la tête retenu en place par un serre-tête végétal (?). Elle tient de la main gauche son cœur et de la main droite une fleur (un lys blanc ?). Il est inscrit S(AINTE).M(ARIE).MAD(ELAINE).DE.PAZZIS. CA(THERINE). L'espagnol Pierre Garavito né en 1499 à Alcantar et mort en 1462, commença sa carrière ecclésiastique comme prédicateur. Un temps ermite, il crée une nouvelle branche de l'Ordre des Franciscains, plus austère et plus pauvre, celle des Franciscains déchaussés ou « alcantarins ». Sainte Marie-Madeleine de Pazzi, Catherine de son nom de baptême (1466-1507), née dans une noble famille florentine, fut très pieuse dès son plus jeune âge. Carmélite à seize ans, elle vécut dans une grande austérité, et eut de nombreuses extases - la première à douze ans. Ces deux saints ont été tous deux canonisés par le pape Clément IX le 28 avril 1669. Il est probable que cette médaille fut produite pour célébrer cet évènement.
La seconde médaille, la $\mathbf{n}^{\circ} \mathbf{9}$, assez élimée, figure sous un portique un Christ en croix et sur l'autre une Pietà. L'organe de fixation n'a pas été conservé.

La médaille militaire n'8 n'a pu être identifiée, les figures disposées sur les deux faces étant à peine perceptibles.

Le dernier objet, un pendentif en nacre (fig. 247, $\mathbf{n}^{\circ} \mathbf{5}$ ), dispose de deux petits trous l'un à côté de l'autre, probablement pour le passage d'un fil au vu de leur taille. La nacre est rarement utilisée au Moyen Âge et il faut attendre la fin de l'Époque moderne pour qu'elle devienne courante dans les accessoires du costume.

\subsubsection{Les « reliquaires"}

Une ampoule de pèlerinage (voir Annexe 4, $\mathbf{n}^{\circ}$ 19) (fig. 247, $\mathbf{n}^{\circ} 10$ ), en alliage étain-plomb, est ornée sur ses deux faces d'un guillochis, complété à la base par une frise de lignes verticales. Deux anses permettent de la suspendre, autour du cou par exemple, par une cordelette. À l'intérieur de ces fioles, les pèlerins rapportaient de l'eau bénite, de l'huile sainte, de la cire de bougie ou toutes autres reliques (terre, bois, tissus, etc.) recueillies dans un lieu saint. La conservation de leur contenu était assurée par écrasement du goulot après remplissage.

Une petite boîte dorée correspond certainement à un petit pendentif reliquaire (fig. 247, $\mathbf{n}^{\circ} \mathbf{1 1}$ ). Confectionnée à partir d'au moins trois tôles métalliques, elle n'a pas pu être ouverte. On peut imaginer qu'elle contenait un portrait ou une mèche de cheveux. Une bélière permettait sa suspension.

\subsection{Une clef de montre (O. Thuaudet)}

La clef de montre $n^{\circ} 12$ (voir Annexe 4, $n^{\circ} 20$ ) est constituée d'un «médaillon » circulaire, avec sur une face un bouquet de fleur en relief positif dans un cadre composé d'une suite de « $\mathrm{S}$ ». Au revers, une bordure de lignes courbes se rejoint au niveau de « trilobes » encerclant un cavalier sur un sol moutonneux (des nuages ?). En partie sommitale un axe retient un tourillon prolongé par un anneau de suspension. À l'opposé, une tige creuse s’insérait dans le mécanisme de la montre.

\section{La toilette}

L'histoire de l'hygiène est loin d'être une suite continue de progrès. Les régressions ont été monnaies courantes. Si elle se conjugue au collectif, notamment avec les nombreuses réglementations communales 


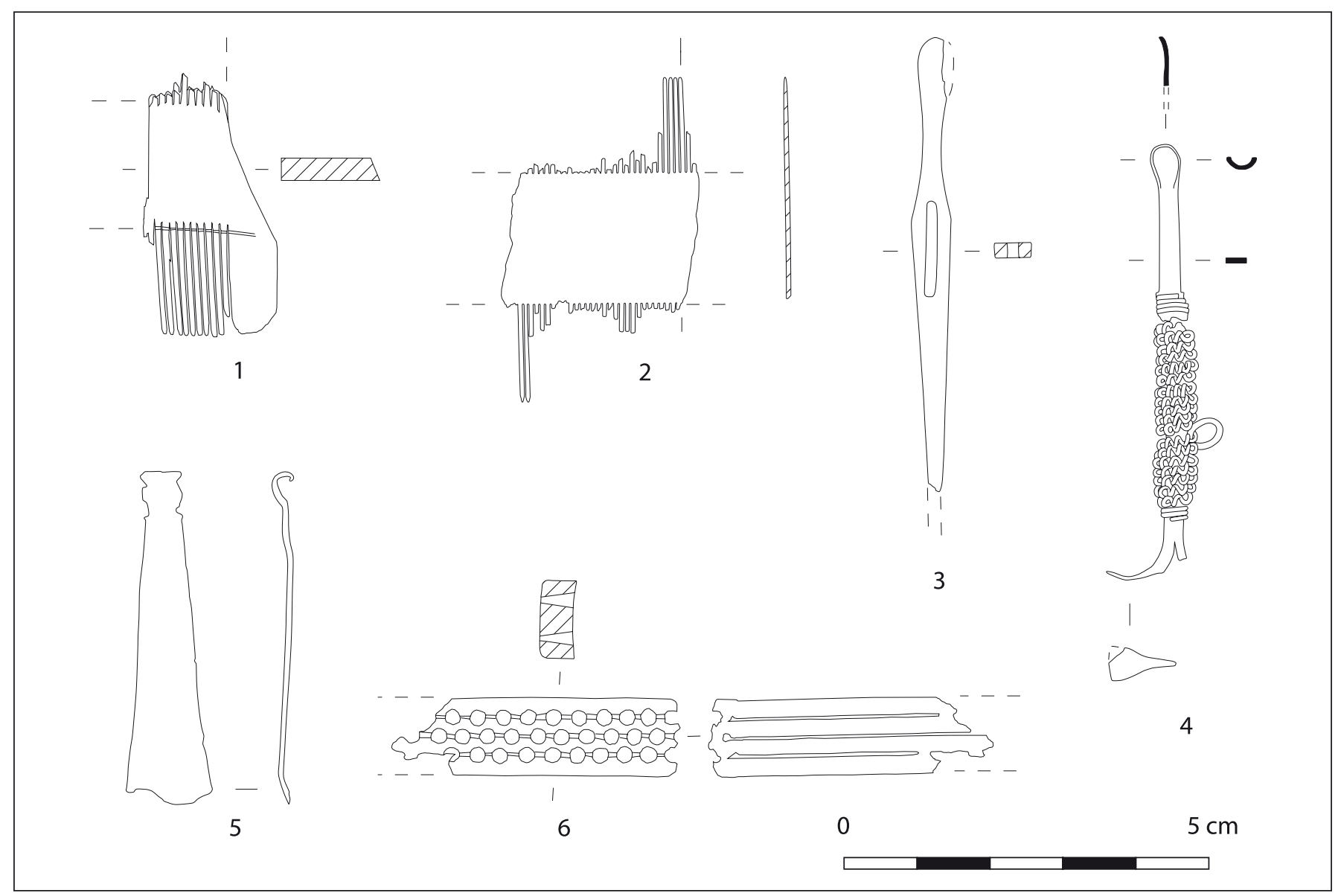

Fig. 249. Objets de toilette (1-3, 6 : M.-A. Chazottes ; 4-5 : O. Thuaudet). 1 : Alcazar ; 2-3 : Tunnel de la Major ; 4-5 : Ilot 55 ; 6 : Vieille-Major.

provençales touchant les parties publiques de la cité (rues, places, fossés, etc.), l'hygiène est aussi un problème personnel qui touche au savoir-vivre et à l'apparence que l'on veut se donner.

\subsection{Les objets liés à la toilette en os et ivoire (M.-A. Chazottes)}

Un fragment d'élément de peigne monobloc provient de la fouille de l'Alcazar (voir Annexe 4, $\mathbf{n}^{\circ} \mathbf{2 1}$ ) (fig. 249, $\mathbf{n}^{\circ} \mathbf{1}$ ). L'extrémité conservée a été peu travaillée et les angles ont juste été arrondis. Cette pièce, qui devait être à double denture, ne conserve ni rivet, ni perforation. Sur la plaquette, on retrouve également deux stries parallèles à l'axe longitudinal, le long desquelles s'alignent les dents du peigne. L'artisan a, de cette manière, matérialisé la limite à ne pas dépasser lors du sciage de la denture. Cette plaquette de peigne, issue d'une matrice paraxiale, a certainement été débitée et façonnée dans un os long et l'on retrouve des traces de sciage aux extrémités. Le fabricant a ensuite procédé à la formation des gorges et de la denture. Chaque dent a ainsi été détachée de la plaquette par sciage.

Un peigne de même type en ivoire, sans aucun décor (fig. 249, $\mathbf{n}^{\circ}$ 2), dispose d'une double denture, l'une épaisse, l'autre plus fine.

Les peignes de type monobloc semblent produits sans interruption entre l'Antiquité et les prémices de l'industrialisation, comme en atteste les peignes antiques conservés au Musée de Nyon en Suisse (Andéres 2006, fig. 37), et de Niort (Bertrand 1996, p. 281) ou encore celui découvert sur le site de Saint-Florent à Orange (Prévot 2004, pl. 3, n 17). Ils ne disparaissent pas durant le haut Moyen Âge et des exemplaires mérovingiens ont notamment été découverts dans un sarcophage lors des fouilles de l'église Saint-Pierre de Montmartre à Paris (Dureuil, Béal 1996, n²72). Pour le XI ${ }^{\mathrm{e}}$ s., des objets analogues proviennent de Charavines (Gaborit-Chopin, Bardoz 2005, p. 94, n ${ }^{\circ} 3$ ). La basilique de Saint-Denis (Toulouse à Tripoli 1989, p. 109, n³0) ainsi que l'église de Martre Tolosane en Haute-Garonne (Ibid., p. 109, $\mathrm{n}^{\circ} 28$ ) livrent des exemples légèrement plus tardifs, des $\mathrm{XI}^{\mathrm{e}}-\mathrm{XII}^{\mathrm{e}} \mathrm{s}$. La production semble ensuite s'intensifier et 
les parallèles se font plus nombreux à partir de la fin du XIII ${ }^{\mathrm{e}}$ s. et au $\mathrm{XIV}^{\mathrm{e}} \mathrm{s}$., notamment à Rougiers dans le Var (Démians d'Archimbaud 1980, fig. 412, n²), à Southampton en Angleterre (Platt, Coleman-Smith 1975 , p. 273, ${ }^{\circ} 1939$ ) mais également sur les sites londoniens de Queen Victoria Street (Egan, Pritchard 1991, p. 375, n¹738) et de Lower Thames Street [149] (Ibid., p. 371, $\left.{ }^{\circ} 1726\right)$. La fabrication ne semble pas faiblir aux $\mathrm{XV}^{\mathrm{e}}-\mathrm{XVI}^{\mathrm{e}} \mathrm{s}$. comme en témoignent le site de l'Île de Martigues (Chausserie-Laprée et al. 1984, $\mathrm{n}^{\circ}$ 202), la fouille du Palais-des-Papes à Avignon (Grasse 1998, p. 80, n ${ }^{\circ}$ ) ou le village de Southampton (Platt, Coleman-Smith 1975, p. 275, $\left.\mathrm{n}^{\circ} 1944\right)$. Leur production se poursuit encore aux XVII ${ }^{\mathrm{e}}$ et $\mathrm{XVIII}{ }^{\mathrm{e}}$ s. et des découvertes dans plusieurs églises à Gênes (Bandini 1999, p. 93, $\mathrm{n}^{\circ} 22-23$ ) et à Pavie en Italie (Ward-Perkins 1978 , p. 136, n॰39-40) l'attestent.

Le $\mathbf{n}^{\circ} \mathbf{3}$ semble pouvoir être identifié comme un cureoreille (fig. 249, $\mathbf{n}^{\circ} \mathbf{3}$ ). Il s'agit d'un objet présentant un fût assez plat de section quadrangulaire et, en partie médiane, une perforation perpendiculaire à l'axe longitudinal. Sur l'extrémité conservée, on retrouve une petite curette, l'autre extrémité est cassée mais peut avoir eu la forme d'un cure-ongle ou un cure-dent, comme cela se rencontre assez régulièrement à la période médiévale (Démians d'Archimbaud et al. 1981, p. 81 ; Boudriot 1995, pl. 1, n³ ; Motteau 1991, p. 43, n²15).

Parmi les objets liés à la toilette, une brosse provient du quartier de la Cathédrale (fig. 249, $\mathbf{n}^{\circ} \mathbf{6}$ ). Cet objet très fragmenté n'est plus pourvu de son manche. De forme quadrangulaire et de profil droit, il présente une face inférieure légèrement concave, scandée de 27 perforations circulaires perpendiculaires à l'axe longitudinal. Ces dernières sont rangées en trois lignes parallèles. A. Mac Gregor indique que les fils étaient rassemblés puis insérés dans les trous de la brosse jusqu'à ce qu'ils remplissent la perforation (Mac Gregor 1985, p. 183). Une fois en place, ils étaient réajustés afin d'être tous de la même longueur. La face supérieure, bombée, est pourvue de gorges très épaisses parallèles à l'axe longitudinal. Ces dernières communiquent avec les perforations en partie inférieure. A. Mac Gregor précise que les fils introduits venaient se loger et s'ancrer dans les rainures supérieures (Mac Gregor 1985, p. 183). Une brosse similaire datée du XVII ${ }^{\mathrm{e}}$ s., a été découverte lors de la fouille de la nécropole de Saint-Laurent à Grenoble (Burille 1996, p. 164).

L'industrie de la brosse se développe en France, et notamment dans le Nord, à partir de 1810. La brosserie regroupe à la fois les brosses de ménage et d'habits, les brosses à dents, les pinceaux... L'industrie atteint son apogée au début du $\mathrm{XX}^{\mathrm{e}}$ s. et crée un grand nombre d'emplois majoritairement féminins. Il est assez difficile d'estimer le nombre de personnes ayant travaillé à la confection de ces brosses, dans la mesure où elles pouvaient exercer à domicile, comme complément d'activité. À titre d'exemple, dans le pays de Thelles et la Vallée du Thérain vers Beauvais, 350 salariés ont été recensés en 1865 dans ce secteur d'activité, 2000 en 1895 et 3600 en 1911. À l'apogée de cette industrie, on estime que plus de 10000 personnes vivaient de cet artisanat rien que dans le département de l'Oise (Brancotte 2001, p. 42-49). La première guerre mondiale marque le déclin de l'activité. En effet, des techniques plus modernes, américaines et japonaises, sont introduites et les premières machines allemandes à monter les brosses, sont importées. À titre comparatif, le montage à la main d'une brosse à dent prenait six minutes en 1905. Grâce à l'utilisation de la machine semi-automatique, ce temps est tombé à une minute, puis 20 secondes grâce à une machine automatique. Aujourd'hui, une seule seconde est suffisante. Les matériaux employés évoluent également et l'os est remplacé par le plastique injecté. Les plus grandes fabriques se maintiennent et se modernisent, mais les petits ateliers ne subsistent pas. L'utilisation de l'os décline donc avec la modernisation des techniques et des matériaux employés (Brancotte 2001, p. 49-50).

Pour en revenir à la brosse découverte dans le quartier de la Cathédrale (fig. 249, $\mathbf{n}^{\circ}$ ) ), les fils insérés devaient être des poils de sanglier ou de porc. Le manche est peutêtre issu de la diaphyse d'un os long de bœuf, tibia ou fémur (Brancotte 2001, p. 47). Au XIX ${ }^{\mathrm{e}}$ s., les fabriques de brosses sont encore artisanales et les brosses sont fabriquées à la main (Brancotte 2001, p. 46-49). Comme pour la fabrication de tout objet en os, les extrémités articulaires doivent préalablement être ôtées. La diaphyse est ensuite sciée parallèlement et perpendiculairement à l'axe dans le but d'obtenir des plaquettes. La plaquette osseuse est, dans un premier temps, laissée aux soins d'une «décoreuse », ce tour moderne qui va permettre d'entailler l'ébauche et de lui donner sa forme galbée. À ce stade, les ouvriers liment les bords, coupent et atténuent les angles des ébauches. L'étape suivante est le blanchiment de l'os qui doit perdre sa couleur jaune pâle. Les manches encore rugueux vont ensuite être polis. La dernière étape de la fabrication consiste à percer et contrepercer la tête de la brosse. Ainsi, dans la partie concave de la tête sont percés des trous circulaires qui ne sont pas traversant. Sur la partie supérieure, galbée, l'artisan fait des entailles parallèles entre elles, à la scie afin que tous les trous d'une même rangée soient reliés.

Plusieurs types de montages existent. Le montage français consiste à faire passer un fil assez long dans l'une des rainures de contreperçage et de le faire ressortir au niveau du trou le plus proche du manche. Les fils repliés sont fixés dans la boucle de ce fil. L'ouvrier 
tire ensuite l'ensemble dans le but d'insérer de force les fils et de les maintenir dans les perforations circulaires. L'opération est répétée pour chaque trou et chaque rainure de contreperçage. Une fois la brosse fabriquée et les fils insérés, l'artisan uniformise la longueur des fils et polit l'objet afin de lui donner un aspect brillant.

\subsection{Les objets liés à la toilette, en métal (O. Thuaudet)}

Les objets de toilette en alliage cuivreux sont illustrés par deux exemples (voir Annexe 4, $\mathbf{n}^{\circ} \mathbf{2 2}$ ). Le premier est une pince à épiler d'un type classique pour le bas Moyen Âge (fig. 249, $\mathbf{n}^{\circ} \mathbf{5}$ ). On retrouve au niveau de la pliure formant ressort des échancrures réalisées au moment de la découpe de la tôle. L'instrument s'élargit en partie distale. Un recourbement terminal permet le pincement du poil pour l'extraction. Le second objet sert à la fois de cure-oreille et de cure-ongle (fig. 249, $\left.\mathbf{n}^{\circ} \mathbf{4}\right)$. Il est constitué d'une tôle épaisse terminée par un cuilleron - obtenu par emboutissage ? - à une extrémité. A l'opposé, la découpe de la tôle dans le sens de la longueur a permis l'obtention de deux tiges, dont une seule est conservée, et qui ont été martelées pour obtenir une partie plane adaptée au curage des ongles. La partie centrale est entourée d'un fil spiralé dont les sections terminales sont enroulées autour de la tôle pour l'immobiliser. Un petit anneau confectionné à partir d'un fil vient s'y fixer, il sert à la suspension. Cet instrument de toilette semble caractéristique des $\mathrm{XIII}{ }^{\mathrm{e}}-\mathrm{XV}^{\mathrm{e}} \mathrm{s}$. d'après les données actuelles.

\section{Les instruments sonores (O. Thuaudet)}

Les instruments sonnant et tintinnabulant participent du paysage sonore des sociétés médiévales, modernes et contemporaines : signal d'appel, de reconnaissance, de localisation - pour les troupeaux notamment -, d'expression des sentiments humains - festivités, enterrements, processions ...- - (voir Annexe 4, $\left.\mathbf{n}^{\circ} \mathbf{2 3}\right)$.

Parmi les instruments sonores, citons tout d'abord trois clochettes obtenues par moulage. L'une d'elle, découverte dans des rejets domestiques datés du XVI ${ }^{\mathrm{e}} \mathrm{s}$. (R.H.I. Bon-Jésus), n'est plus conservée que dans sa partie supérieure. Une seconde, entière mais très oxydée et dont la forme est difficilement identifiable $(\mathrm{d} \times \mathrm{h}=4,3 \mathrm{x}$ $5,8 \mathrm{~cm})$, a été retrouvée dans un remblai du XVIII ${ }^{\mathrm{e}} \mathrm{s}$. (Tunnel de la Major). La troisième (fig. 251, $\mathbf{n}^{\circ} \mathbf{5}$ ) est illustrée par un fragment de robe.

Cinq grelots carénés, la plupart fragmentaires (reconstitution : fig. 246, $\mathbf{n}^{\circ}$ 5), les autres écrasés, ont été retrouvés dans l'abandon de latrines du début du $\mathrm{XIV}^{\mathrm{e}} \mathrm{s}$. (Tunnel de la Major), dans des terres de jardin du XIV ${ }^{\mathrm{e}} \mathrm{s}$. (Alcazar), dans un remblai préparatoire de sol caladé du $\mathrm{XVI}^{\mathrm{e}} \mathrm{s}$. (Ilot 55). Un spécimen découvert dans un remblai du début du XVIII ${ }^{\mathrm{e}} \mathrm{s}$. (Vieille-Major) a conservé une bille de fer. Les dimensions des objets du corpus s'échelonnent entre 1,7 et $2,1 \mathrm{~cm}$ de diamètre pour 1,8 à $2,3 \mathrm{~cm}$ de haut. La tôle a une épaisseur comprise entre 0,04 et $0,08 \mathrm{~cm}$. Deux sonnailles ou gros grelots sphériques (en très mauvais état pour l'un et incomplet pour l'autre) complètent la collection des instruments sonores: le premier (h totale $\mathrm{x} \mathrm{d}=3,7 \mathrm{x}$ env. $2,8 \mathrm{~cm}$ ) provient d'une couche de la deuxième moitié du XIX ${ }^{\mathrm{e}} \mathrm{s}$. (Tunnel de la Major), le second (fig. 246, $\mathbf{n}^{\circ} \mathbf{1}$ ) du comblement d'une cuve constitué vers 1720-1730 (Alcazar).

Les petits grelots ont pu être accrochés à la ceinture, à des chaînes, à des pièces du costume liturgique comme cela se retrouve dans l'iconographie et les sources archivistique ; plus généralement, ils étaient fixés à de petits animaux. Les plus gros ont pu servir à l'attelage des bestiaux ou comme signalement au cou des animaux d'élevage tels que les moutons, chèvres ou brebis. Tous ou presque ont été confectionnés selon le même principe : insertion puis brasure des extrémités d'une bélière au revers d'une des deux cupules hémisphériques, et ensuite brasure de la première cupule sur la deuxième. Une fente traverse la cupule inférieure et relie deux ouvertures circulaires destinées à laisser s'échapper le son. Ce type de grelot se retrouve dès le $\mathrm{XIV}^{\mathrm{e}} \mathrm{s}$. Le $\mathbf{n}^{\circ} \mathbf{1}$ de la fig. $\mathbf{2 4 6}$ constitue la seule exception. Il est le résultat d'une fonte. Une ligne creuse à l'intérieur témoigne de l'assemblage en deux parties du noyau interne du moule, maintenu en place grâce à quatre tenons qui ont laissé quatre ouvertures circulaires, deux pour chaque moitié de l'objet. Comme pour les petits grelots en tôle, on note la présence d'une fente en partie inférieure. Cette fente et les quatre ouvertures circulaires permettaient au son de s'échapper.

\section{L'outillage}

Le mobilier référencé est particulièrement centré sur les activités de travail de textile et des cuirs. La cause en est l'impossibilité actuelle d'étudier de manière sérieuse le mobilier en fer. Une grande partie de l'outillage, notamment celui agricole, mais également celui nécessaire à certaines activités artisanales fait donc défaut.

\subsection{L'outillage des activités textile (O. Thuaudet)}

Les activités textiles, qu'elles soient artisanales ou pratiquées dans la sphère privée, sont illustrées par de 
nombreux dés à coudre et de probables thies de fuseau (voir Annexe 4, $\mathbf{n}^{\circ} \mathbf{2 4}$ ) . Ces dernières sont confectionnées dans une tôle enroulée préalablement estampée et/ ou incisée. Une extrémité du fil à tordre et à enrouler est attachée au recourbement terminal de cet objet destiné à être fixé à une extrémité du fuseau. Il est aussi envisageable d'interpréter ces objets comme des crochets utilisés dans la confection textile du même nom - et donc dite «au crochet ». Deux de ces thies portent un décor gravé similaire (fig. $\mathbf{2 5 0}, \mathbf{n}^{\circ} \mathbf{1}$ et $\mathbf{2}$ ) : des courbes obliques circonscrites par une ou deux lignes horizontales. Les objets $\mathbf{n}^{\circ} \mathbf{3}$ et $\mathbf{4}$ de la fig. 250 ont été tout d'abord estampés, puis certaines zones ainsi délimitées ont été remplies de traits verticaux parallèles ou d'un quadrillage oblique incisé. Le $\mathbf{n}^{\circ} \mathbf{5}$ (fig. 250) est le seul dont le décor paraît être imprimé dans le métal. Pour l'ensemble de ces thies, l'ornementation est continue entre les deux bords de la tôle enroulée ce qui, dans le cas d'un décor gravé, rend nécessaire une réalisation après mise en forme. Les embouts 1 à 4 conservent un crochet ou un début de crochet à leur extrémité. Des objets non datés au décor identique aux $\mathbf{n}^{\circ} \mathbf{1}$ et $\mathbf{2}$ ont été retrouvés sur le site du quartier de l' ̂̂le à Martigues dans les Bouches-du-Rhône (Martigues 1984, p. 47, n²07 et 208) et lors des fouilles du château d'Amphoux dans le Var (Lemoine 2008, p. 686-687, fig. 9, n³).

Les dés à coudre sont employés autant dans les activités textiles que dans le travail du cuir. D'après les données actuelles, les dés à coudre métalliques à indentation circulaire ou triangulaire apparaissent sur le territoire français à la fin du $\mathrm{XII}^{\mathrm{e}} \mathrm{s}$. - à peu près au même moment que les ciseaux. Pourtant, ceux à indentations circulaires sont attestés dès le VIII ${ }^{\mathrm{e}} \mathrm{s}$. dans le monde byzantin (Holmes 1985). Ces dés adoptent très rapidement une grande diversité dans leur forme et dans la disposition de leur indentation. Certains types deviennent caractéristiques d'aires géographiques bien circonscrites

Le corps du spécimen $\mathbf{n}^{\circ} \mathbf{6}$ (fig. 250), de type bague, est le résultat de l'enroulement d'une tôle dont la jointure a été martelée, engendrant ainsi un bourrelet. Son piquetage circulaire, obtenu par poinçonnage de la face extérieure, est aligné verticalement de bas en haut sur neuf à onze rangs. La superposition de certains points met en évidence le sens du poinçonnage. Ce dernier n'a pu être déterminé sur le $\mathbf{n}^{\circ} \mathbf{7}$ (fig. 250), également de type bague, dont l'indentation s'aligne sur 8 rangs. Ce dé embouti comportait originellement une calotte, découpée sommairement dans un second temps, peut-être parce que le dé était trop large pour qu'il se fixe bien sur le doigt.

Les dés à coudre de type bague sont préférentiellement employés - sans exclusivité toutefois - par les tailleurs, fabricants de chaussure ou de harnachement, selliers, tapissiers et autres métiers similaires, sans qu'il existe de raison évidente à ce choix (Holmes 1985, p. 163-166). On les retrouve parmi les plus anciens exemplaires découverts sur le territoire français de même que dans le monde byzantin.

De conception plus récente, le dé $\mathbf{n}^{\circ} \mathbf{8}$ (fig. 250) n'est pas sans évoquer des formes hispano-moresques ayant cours du $\mathrm{X}^{\mathrm{e}}$ au $\mathrm{XIII}^{\mathrm{e}}$ s., dont il peut dériver. Le corps tronconique, incisé à sa base, est parcouru par douze rangs horizontaux de points ronds, alignés de gauche à droite et de bas en haut. Il se poursuit par une calotte à ouverture sommitale, elle-même incisée de deux cercles. Ce type de dé, réalisé par emboutissage, est cantonné au seul $\mathrm{XIV}^{\mathrm{e}} \mathrm{s}$. d'après les informations réunies. Un autre fragment de dé à coudre dont il n'est conservé qu'une faible partie de la calotte percée (e tôle $=0,05 / 0,06 \mathrm{~cm}$ ), a été collecté dans un remblai $\left(\mathrm{XVIII}^{\mathrm{e}}-\mathrm{XIX}^{\mathrm{e}} \mathrm{s}\right.$.) des fouilles de l'avenue Vaudoyer. Le corps du dé est recouvert de points circulaires alignés en rangées verticales de douze. Sa calotte, semble-t-il vierge d'indentation, est de morphologie commune car très ramassée.

Trois autres dés à coudre à calotte bombée, fabriqués par emboutissage d'une tôle, présentent des caractéristiques qui ne peuvent être qu'antérieures aux procédés mécaniques du XVIII' $\mathrm{s}$. L'un d'eux, découvert dans un dépotoir du second quart du XVII ${ }^{\mathrm{e}} \mathrm{s}$. (Les Pistoles), porte une ligne incisée à la base du corps (e tôle $=0,04 \mathrm{~cm}$ ) audessus de laquelle sont ordonnés douze rangs de points ronds alignés de la gauche vers la droite. On retrouve le même agencement pour les six rangs de la calotte. Un autre exemplaire (fig. 250, $\mathbf{n}^{\circ}$ 9) est gravé de deux lignes incisées à la base du corps. L'indentation est organisée sur le corps de l'objet en une spirale de sens gauchedroite, de bas en haut, sur neuf rangs. Elle se poursuit de la même manière sur la calotte, sur quatre rangs. Le troisième dé à coudre (fig. $\mathbf{2 5 0}, \mathbf{n}^{\circ} \mathbf{1 0}$ ) porte également deux incisions à la base, mais son indentation en spirale est triangulaire. Sept à huit rangs sont visibles sur le corps, trois à quatre autres sur la calotte. Comme toujours dans le cas de l'indentation spiralée, le passage du corps à la calotte se fait sans interruption.

Les cinq dés à coudre suivants présentent toutes les caractéristiques des dés de l'Époque moderne et contemporaine. Le premier exemplaire (fig. 250, $\mathbf{n}^{\circ} \mathbf{1 1}$ ) est le résultat d'une fonte. L'apposition des indentations a vraisemblablement nécessité une chauffe afin de ramollir le métal. Le corps de l'objet, en forme de cloche, est recouvert d'un poinçonnage circulaire, aligné horizontalement sur onze rangs, avec une tentative d'organisation en nid d'abeille. Sur la calotte, les points sont quadrangulaires et organisés selon un quadrillage à huit 


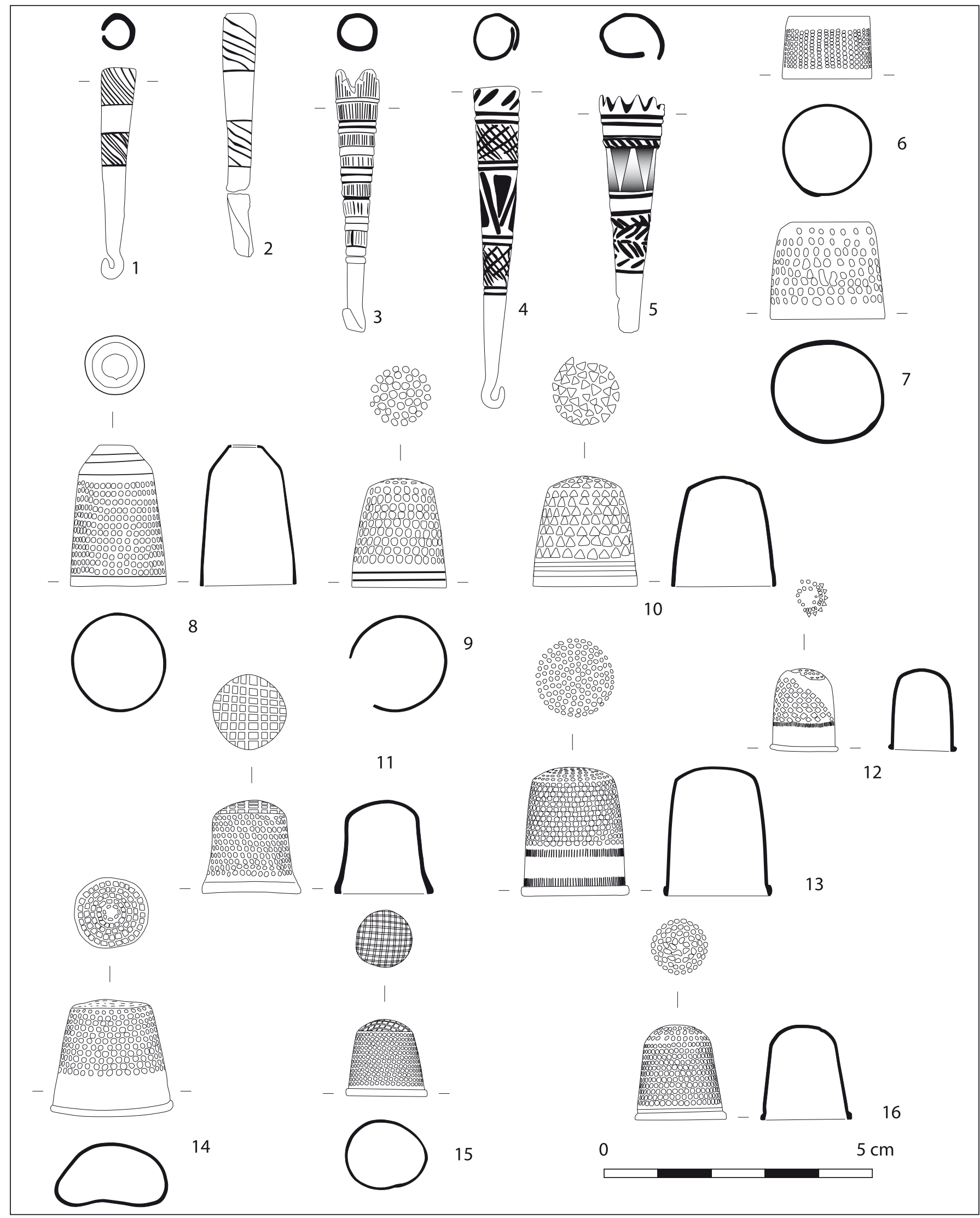

Fig. 250. Outillage des activités textiles (O. Thuaudet). 1-2, 6, 11 : Alcazar ; 3-4 : collège Vieux-Port ; 5, 8, 13-14 : place Villeneuve-Bargemon ; 7, 16 : llot $55 ; 9-10,15$ : place des Pistoles ; 12 : Tunnel de la Major. 
rangs. Ils ont été réalisés à l'aide d'une molette. Cette indentation apparaît tardivement, sans doute au XVII ${ }^{\mathrm{e}} \mathrm{s}$. L'agencement en nid d'abeille, quant à lui, est attesté dès le $\mathrm{XIV}^{\mathrm{e}} \mathrm{s}$., mais sa disposition ne devient régulière qu'avec les procédés de pressage inventés dans la deuxième moitié du XVIII ${ }^{\mathrm{s}} \mathrm{s}$. Les dés à coudre $\mathrm{n}^{\circ} \mathbf{1 2}, \mathbf{1 3}, \mathbf{1 4}$, 15 et 16 (fig. 250), mis en forme par emboutissage, en sont de bons exemples. Leur indentation, d'une extrême régularité, est le résultat de l'application «en force» d'une molette (Holmes 1985, p. 135). Tous possèdent un bourrelet à la base - pour protéger le doigt si l'aiguille ripe - et une indentation en nid d'abeille limitée pour la plupart aux deux tiers supérieurs du corps. Les points du $\mathbf{n}^{\circ} \mathbf{1 2}$ sont losangiques et alignés sur dix rangs, alors qu'ils sont circulaires sur les autres dés et alignés sur onze et douze rangs. Le $\mathbf{n}^{\circ} \mathbf{1 3}$ reçoit sept rangs de points ronds sur sa calotte bombée. Ils sont au nombre de quatre sur celle du $\mathbf{n}^{\circ} \mathbf{1 6}$. Deux lignes incisées sont visibles à la base du dé. La calotte du $\mathbf{n}^{\circ} \mathbf{1 4}$, plate, est imprimée de cinq rangs de points quadrangulaires autour du centre laissé vierge. Celle du $\mathbf{n}^{\circ} \mathbf{1 5}$ est recouverte d'une indentation carrée disposée en un quadrillage serré. Quant au $\mathbf{n}^{\circ} \mathbf{1 2}$, l'oxydation ne permet de découvrir sur sa calotte que deux alignements concentriques de points ronds inscrits à l'intérieur d'un cercle de points triangulaires. Les objets 12 et 13 (fig. 250) sont également ornés d'une à deux rangées de traits verticaux parallèles; la première circonscrit la partie inférieure de l'indentation, la seconde la base du corps.

\subsection{L'outillage de la pêche (O. Thuaudet)}

Deux hameçons en alliage cuivreux de taille similaire (fig. $251, \mathbf{n}^{\circ} \mathbf{1}$ ) constituent les seuls outils en rapport avec l'activité maritime (voir Annexe 4, $\mathbf{n}^{\circ}$ 25) Ils ont été retrouvés dans l'abbaye Saint-Victor. Leur œillet de fixation a disparu, mais la pointe triangulaire est conservée sur l'un d'eux. Le second spécimen ( $\mathrm{L}$ x l $=1,7 \mathrm{x}$ $1,2 \mathrm{~cm}$ ) a été ramassé dans un contexte indéterminé de la nef. Recueilli sur le site de l'Ilot 55, l'objet $\mathbf{n}^{\circ} \mathbf{2}$ de la fig. 251, en matériau blanc, à peu près sphérique, est aplati aux extrémités. Sa perforation de part en part et son poids $(21,99 \mathrm{~g})$ conduisent à l'interpréter comme une fusaïole ou un peson ou bien encore un plomb de pêche.

\subsection{Un poinçon en os (M.-A. Chazottes)}

Le poinçon est-il un outil spécifique au tissage ou un objet polyvalent (voir Annexe 4, $\mathbf{n}^{\circ} \mathbf{2 6}$ ) ? Voici l'une des réflexions développées par Dorothée Chaoui-Derieu et
Jean-François Goret dans un article entièrement consacré à ces objets pour le nord de la France (Chaoui-Derieux, Goret 2008, p. 79-91).

Dans son Dictionnaire de l'ameublement et la décoration depuis le XIII ${ }^{e}$ s., Henry Havard donne une définition du poinçon en indiquant que le « mot désigne un fer pointu qui sert à percer des trous. Le poinçon appliqué aux usages journaliers, a de tout temps fait partie de l'attirail des trousses de toilette ou des fournitures de bureau » (Havard 1887-1890, p. 461-462). Si l'on excepte la matière mentionnée, cette définition pourrait correspondre aux objets découverts par l'archéologie qui ont certainement servi à perforer de multiples pièces. En revanche, cela ne correspond pas toujours aux données textuelles et le mot poinçon, notamment au $\mathrm{XV}^{\mathrm{e}} \mathrm{s}$., semble parfois répondre à des besoins bien différents. Tous les poinçons cités dans les livres de comptes du roi René proviennent de matières coûteuses et parfois importées comme l'ivoire ${ }^{\mathbf{5 0}}$ ou le corail $^{51}$. Leur préciosité paraît contraire à une utilisation pour la perforation d'éléments de cuir ou de tissu par exemple. Par ailleurs, Victor Gay dans son Glossaire archéologique du Moyen Âge et de la Renaissance assimile le poinçon à une broche pour les cheveux, presque toujours surmontée d'un motif sculpté (Gay 1887, p. 221). Achetées en même temps que les peignes ou les miroirs ${ }^{52}$, ces broches en ivoire ne répondent pas à la même destination fonctionnelle que le poinçon découvert à Marseille.

Ce poinçon (fig. 251, $\mathbf{n}^{\circ} \mathbf{3}$ ) conserve en partie haute et médiane les traces d'une ancienne ornementation à caractère esthétique autant que fonctionnel

5020 octobre 1452 : «A Jacques Depoise, mercier, ledit jour, cent quatorze solz deux deniers, à lui deuz tant pour deuz demiz sainctz. de laton, pour ung petit coffret ferré, deux paix une d'ivoire et l'autre de laton, trois poinzcons d'yvoire, une escriptores dorée, une bourse, ung cadran, plusieurs couteaulx et ung peigne d'yvoire, deux petilz marteaulx, deux petites choppines de chapelle, que pour aultres couteaux emmanchez de cyprez, pour tout ce, par certificacion d'icellui sénéchal, CXIIII s. II d. » (Arnaud d'Agnel 1910, p. 323, n²473).

25 Octobre 1452: "A lui, ledit jour, quinze solz, pour aultres poinçons enmanchez d'ivoire, donnez par ledit seigneur à aultres femmes, pour ce XVs. » (Arnaud d'Agnel 1910, p. 324, n²474).

25 Octobre 1452 : «A lui (Jacques Depoix, mercier), ledit jour, quize solz pour aultres poinçons, emmanchez d'ivoire, donnez par ledit seigneur à aultres femmes, pour ce XVs. » (Arnaud d'Agnel 1910, p. $\left.324, n^{\circ} 2475\right)$.

5122 septembre 1479: «le XXII ${ }^{e}$ dudit moys à Gaspart Deliges, courailler, baillé $V f$ pour une branche de coural, une forchectes et deux poinssons, aussi de coural, achapez par monseigneur, pour ce $V f$.» (Arnaud d'Agnel 1910, p. 350, n 1055).

52 «A Richard des Grès, pingnier, pour un pingne un miroir et une broche, tout d'ivoire, Cpte d'hôtel de Charles VI. Monteil, XIVs. épit., 82, note $195 »$ (Gay 1887, p. 221). 
(Chaoui-Derieux, Goret 2008, p. 80). Les gorges horizontales peu profondes et parallèles entre elles ont été partiellement effacées, peut-être à la suite d'une utilisation intensive. Ainsi, l'absence de lignes en partie basse du poinçon ne signifie pas que cette portion n'a jamais été incisée. D'une datation comprise entre le IX ${ }^{\mathrm{e}}$ et le $\mathrm{X}^{\mathrm{e}} \mathrm{s}$., le poinçon du site de Villiers-le-Sec dans le Val d'Oise est pourvu du même décor que celui de Marseille, mais il est mis en œuvre en partie proximale, médiane et distale (Cuisénier, Guadagnin 1988, p. 286, n²88). La découverte d'objets identiques lors de fouilles à Tours (Motteau 1991, p. 112, n515) et dans la motte castrale de Château-Thierry dans l'Aisne (Goret 1997, p. 106, $\mathrm{n}^{\circ} 2$ ), témoigne également de l'existence de ces poinçons aux $\mathrm{X}^{\mathrm{e}}-\mathrm{XI}^{\mathrm{e}} \mathrm{s}$.

\section{Ustensiles et récipients}

Les recherches archéologiques, en archive, et dans une moindre mesure l'iconographie, indiquent que la grande majorité des récipients et des ustensiles sont réalisés en céramique - et donc hors du champ de cette étude -, en matériaux putrescibles comme le bois, ou aisément réutilisables comme l'étain, le plomb et leurs alliages. À cela, il faut rajouter l'intérêt économique qu'il y a à recycler des objets d'un certain poids comme les chaudrons en cuivre ou en alliage cuivreux et, pour des raisons exposées en introduction, l'absence de toute coutellerie, généralement en fer. Tout cela concourt bien évidemment à réduire le spectre du matériel susceptible d'être découvert.

\subsection{Les cuillères ( $O$. Thuaudet)}

Quatre cuillères de table, obtenues par fonte, donnent un aperçu de l'évolution du mobilier en métal depuis le bas Moyen Âge (voir Annexe 4, $\mathbf{n}^{\circ} \mathbf{2 7}$ ). Un cuilleron en alliage blanc (fig. $\mathbf{2 5 1}, \mathbf{n}^{\circ} \mathbf{6}$ ) présente la rare particularité d'être décoré de motifs géométriques en relief positif. Quatre lignes parallèles de chevrons, dont les deux centrales avec bossettes quadrangulaires, sont disposées dans la longueur. Les autres rangées sont constituées de chevrons imbriqués alignés tête-bêche. Deux objets, fabriqués dans le même matériau, à cuilleron plus ovale et décoré d'incisions, ont été retrouvés hors stratigraphie à proximité du château de Grigny dans le Pas-de-Calais (Dilly et al. 1999, p. 113, n³-104 et 3-105). Un autre objet, à cuilleron large et long à motifs animaliers et géométriques en relief positif, daté de la fin du Moyen Âge, a été découvert sur le site de Thames Exchange à Londres (Egan 2010, p. 248).
Le cuilleron $\mathrm{n}^{\circ} \mathbf{4}$ de la fig. 251, ovale et d'un bel arrondi $(\mathrm{e}=0,05 \mathrm{~cm})$, est rattaché à un manche de section losangique, dont l'extrémité gravée sur ses quatre faces d'une croix de Saint-André est précédée par trois dépressions (fig. $\mathbf{2 5 4}, \mathrm{n}^{\circ} \mathbf{1}$ ). Ce cuilleron a été retravaillé par martelage. La marque du fabricant, un $\mathrm{T}$ dans un cercle, est visible au revers dans la partie supérieure gauche du cuilleron (fig. $254, \mathbf{n}^{\circ}$ 2).

L'exemplaire $\mathrm{n}^{\circ} \mathbf{1}$ de la fig. 252, à cuilleron allongé et pointu, possède un manche de section quadrangulaire qui s'élargit à son extrémité. L'objet $\mathbf{n}^{\circ} \mathbf{2}$ de la fig. $\mathbf{2 5 2}$, en alliage blanc, se caractérise par un cuilleron allongé et un manche court s'élargissant à son extrémité. À Marseille, un ustensile similaire et dans le même matériau, a été retrouvé dans un contexte du XVIII ${ }^{\mathrm{e}} \mathrm{s}$. sous l'actuelle place Général-de-Gaulle (Suviéri, De Boisséson 2001, p. $\left.218, \mathrm{n}^{\circ} 107\right)$.

Les cuillères de table en métal sont, depuis l'Antiquité romaine et jusqu'au $\mathrm{XI}^{\mathrm{e}}$ ou $\mathrm{XII}^{\mathrm{e}}$ s., à cuilleron allongé et manche en forme d'une tige. Elles se transforment peu à peu au cours du XIII ${ }^{\mathrm{e}} \mathrm{s}$. : leur cuilleron s'élargit ou devient circulaire. Cet ustensile reste toutefois rare encore à cette époque, signe de la prédominance d'objets en matériaux périssables tels que le bois. Quelques spécimens en bois ont été découverts lors de la fouille d'un puits du XIII' ${ }^{\mathrm{e}}$ s., rue de la Barellerie à Montpellier (Hérault). Ceux-ci présentent un bouton terminal (Leenhardt et al. 1999, p. 167-168). Cette particularité est attestée pour le premier tiers du XIV ${ }^{\mathrm{e}} \mathrm{s}$. sur une cuillère en argent d'un trésor ariégeois portant un poinçon avec les armes de Jean XXII (Savès 1971, p. 41). Les cuillères en métal à manche à extrémité décorée comme celles de la fig. $\mathbf{2 5 1}, \mathbf{n}^{\circ} \mathbf{4}$ deviennent très courantes à partir de la deuxième moitié du $X^{\mathrm{e}} \mathrm{s}$. et jusque dans le courant du XVII ${ }^{\mathrm{e}} \mathrm{s}$. Elles sont alors remplacées par des ustensiles à manche à extrémité élargie comme le $\mathrm{n}^{\circ} \mathbf{2}$ de la fig. 252. Parfois le cuilleron s'allonge, mais cette caractéristique ne devient la norme qu'au siècle suivant. C'est vraisemblablement au $\mathrm{XX}^{\mathrm{e}} \mathrm{s}$. que certains cuillerons se terminent en pointe comme celui de la fig. $252, \mathbf{n}^{\circ} 1$.

\subsection{Les manches (M.-A. Chazottes)}

Le manche $\mathbf{n}^{\circ} \mathbf{1}$ (fig. 253) est un canif en os (voir Annexe 4, $\mathbf{n}^{\circ} \mathbf{2 8}$ ). La partie conservée de l'ustensile de table ou de voyage montre une forme plus ou moins triangulaire avec une section ovale. L'extrémité $\mathrm{du}$ manche se termine par une excroissance de forme circulaire dont le diamètre s'avère plus important que la largueur de l'artéfact. Même s'ils ne présentent aucun ornement géométrique ou figuré, les différents pans de 


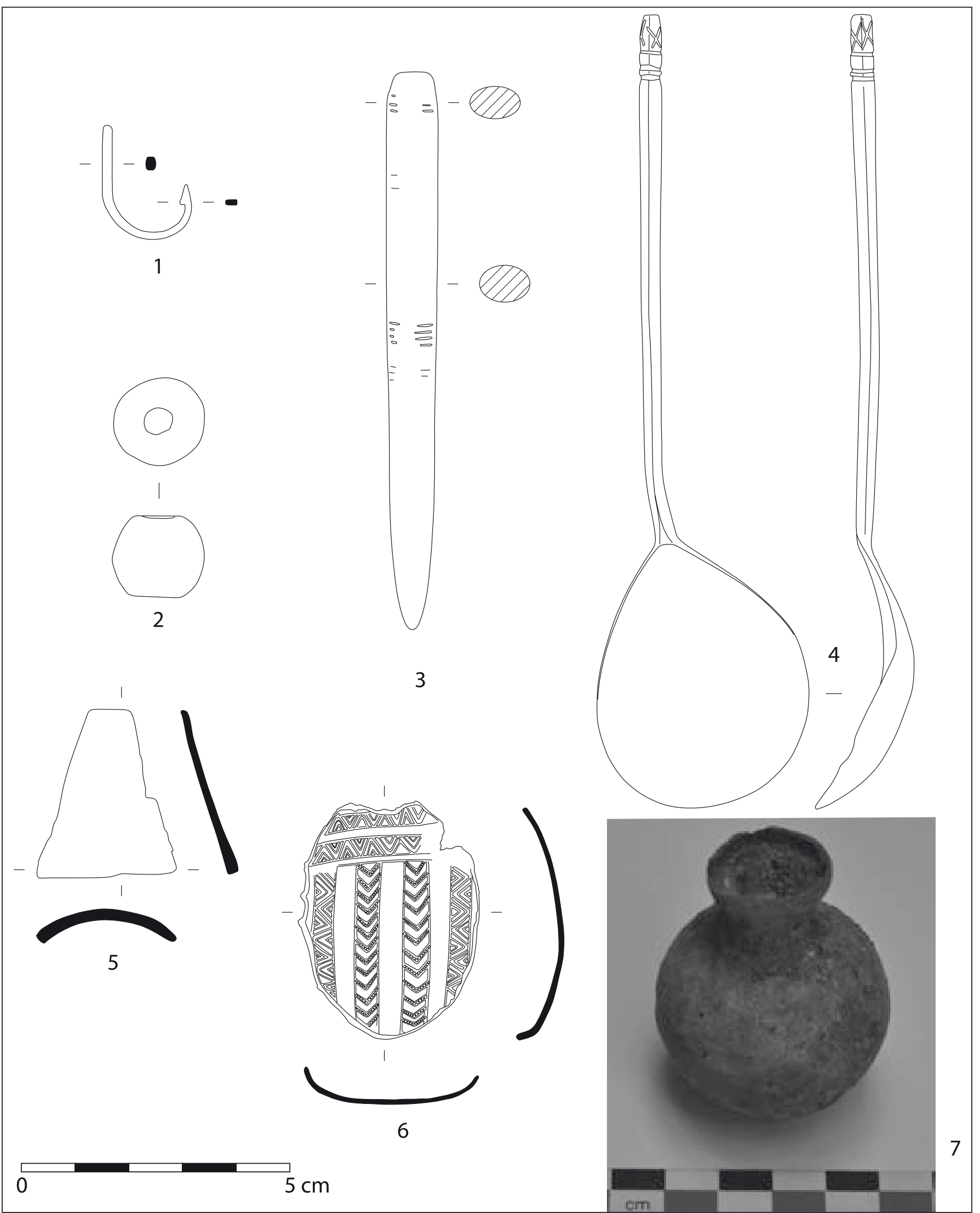

Fig. 251. Outils, ustensiles et petit mobilier utilitaire (O. Thuaudet sauf $3:$ M.-A. Chazottes). 1,3 : Saint-Victor ; 2 : llot 55 ; 4 -5 : Alcazar ; 6 : place Villeneuve-Bargemon ; 7 : Puget III. 


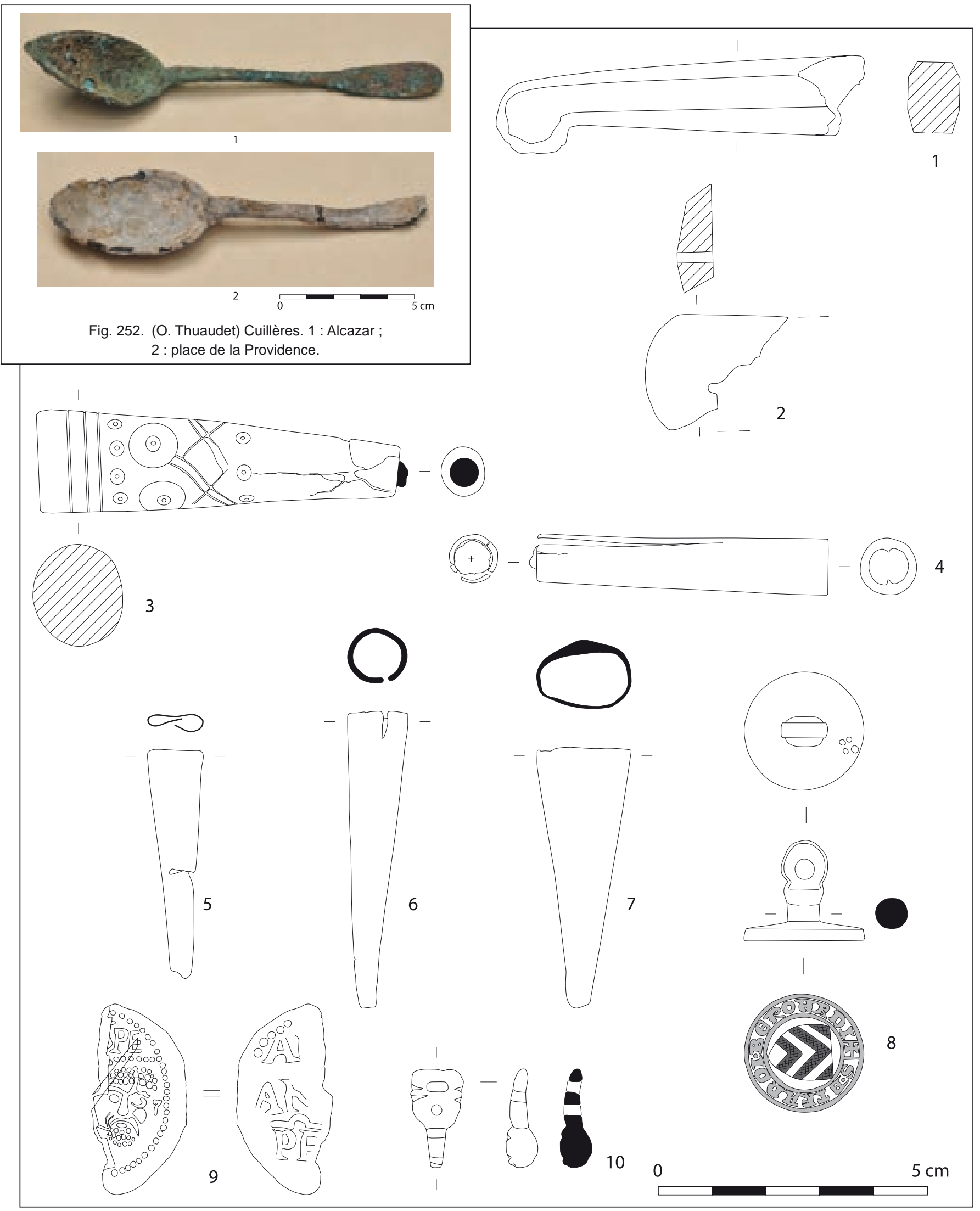

Fig. 253. 1-4 : M.-A. Chazottes, 5-10 : O. Thuaudet) Outils, ustensiles et petit mobilier utilitaire. 1, 3, 7, 9 : Saint-Victor ; 2, $10:$ Alcazar ; 4 : Tunnel de la Major ; 5 : place des Pistoles ; 6 : rue Leca ; 8 : place Villeneuve-Bargemon. 
râpage, stigmates de la fabrication, peuvent avoir été laissés volontairement afin de constituer un décor.

Dans les publications, les photographies ne présentent souvent que la face supérieure des objets et les descriptions sont parfois succinctes, ce qui empêche de distinguer les manches pourvus ou non d'une fente. Des canifs en os sont attestés pour la période médiévale notamment sur le site de Montségur dans l'Ariège pour les XII ${ }^{\mathrm{e}}$-XIII ${ }^{\mathrm{e}} \mathrm{s}$. (Archéologie et vie quotidienne 1990, n³23, p. 193), ou à Mignet à Aix-en-Provence au XIV e s. ((Richarté, Vallauri, Foy, travail inédit, fig. 38c). Néanmoins, la forme n'apparaît pas durant le Moyen Âge et des pièces similaires des $\mathrm{II}^{\mathrm{e}}-\mathrm{III}^{\mathrm{e}} \mathrm{s}$. sont connues, par exemple, à Avenches en Suisse (Schenk 2008, p. 268, n 403). Notre manche n'est pas orné mais de multiples parallèles antiques le sont. Ainsi, des chiens (Mikler 1997, pl. 45, n6 ; Béal 1980, pl. 11, $\mathrm{n}^{\circ} 13338$ ), des dauphins (Dureuil, Béal 1996, nº7) et même des animaux fantastiques (Ibid., n ${ }^{\circ}$ 96) décorent ces manches à lame repliée.

Un deuxième exemplaire, le $\mathbf{n}^{\circ} \mathbf{3}$ (fig. 253), est extrait d'un andouiller de cerf de l'abbaye Saint-Victor. Cet objet de section circulaire, dont le diamètre se réduit entre la partie proximale et distale, a été évidé légèrement à l'endroit où le diamètre est le plus réduit. Toute la surface - qui ne comporte aucune trace de perlures - est scandée de motifs décoratifs avec trois incisions perpendiculaires à l'axe en partie proximale et une ornementation composite sur le reste du manche. Quatre doubles ocelles pointés se tiennent donc en partie médiane avec, audessus et en-dessous de ce registre, une rangée de petits ocelles simples répartis régulièrement sur l'ensemble de la pièce. Tous ces ocelles sont reliés entre eux par des incisions obliques, réalisées avec moins de soin puisque l'on retrouve des traces de raccord entre les incisions.

Un troisième manche est assez fragmenté ${ }^{53}$ (fig. 253, $\mathbf{n}^{\circ}$ 2). Il s'agit d'une plaquette de forme plus ou moins quadrangulaire avec une face inférieure lisse et une face supérieure bombée. La partie conservée montre l'amorce d'un rivet en fer. L'objet, issu d'une matrice paraxiale, présente des traces obliques de sciage, en partie inférieure. En face supérieure, des traces de râpe parallèles à l'axe longitudinal ainsi que des traces plus inclinées sont conservées. Le manche a ensuite été foré et les différentes parties de l'objet ont sans doute été rivetées.

Un dernier manche provient des fouilles du Tunnel de la Major (fig. 253, $\mathbf{n}^{\circ} \mathbf{4}$ ). Le départ de la lame, ainsi que la soie en fer, sont encore conservés à l'intérieur. Extrait d'un métatarse d'ovin/caprin, cet objet de section circulaire, autant en partie proximale, médiane que distale, a été entièrement évidé.

53 Identification I. Rodet-Belarbi (INRAP).

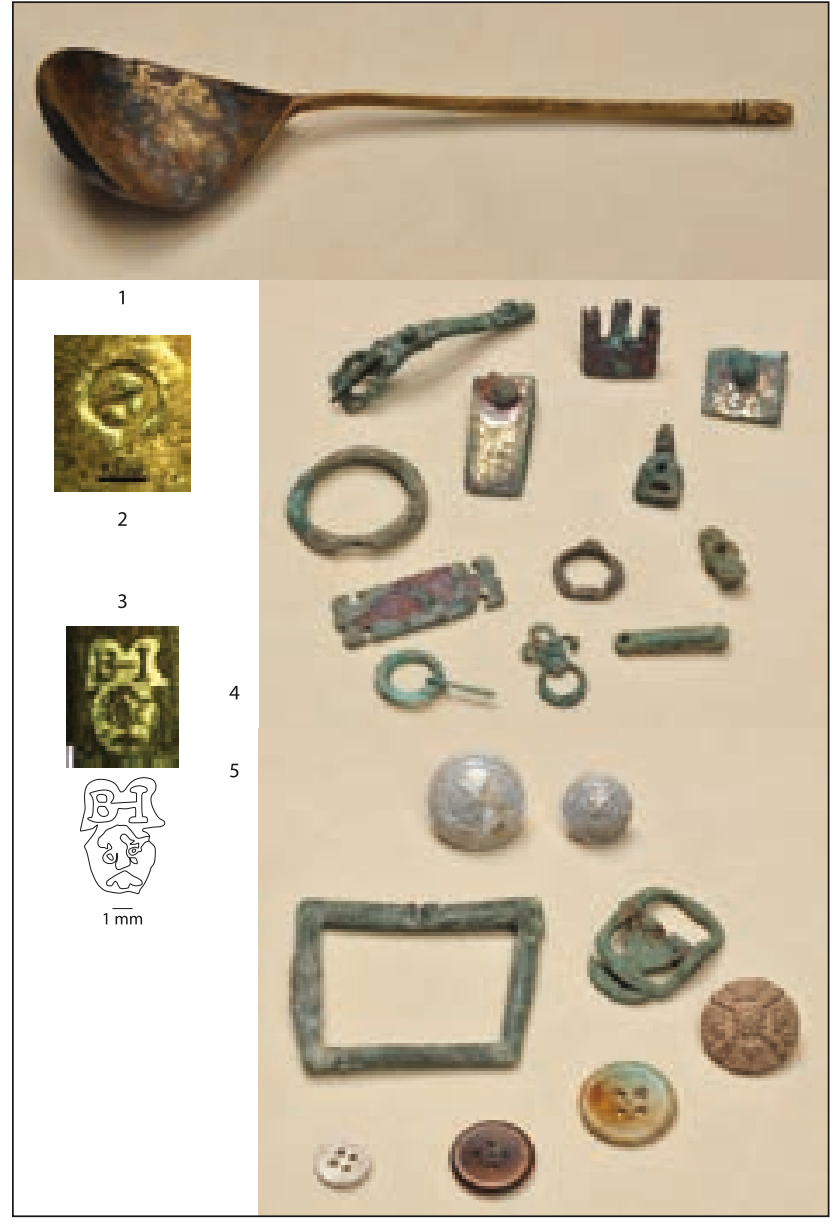

Fig. 254. Cuillère et marque au dos du cuilleron de la Fig. 251, 4 ( $n^{\circ} 1-$ 2), marque sur l'objet de la Fig. 261, 1 ( ${ }^{\circ} 3$ ), accessoires du costume du Moyen Âge $\left(n^{\circ} 4\right)$, et d'époque moderne et contemporaine $\left(n^{\circ} 5\right)$ (O. Thuaudet).

\subsection{Les bouterolles (O. Thuaudet)}

Trois tôles enroulées, sans ornement, peuvent être interprétées comme des bouterolles (voir Annexe 4, $\mathbf{n}^{\circ} 29$ ), c'est-à-dire des extrémités de fourreau d'épée ou plus probablement de couteau (fig. $253, \mathbf{n}^{\circ} \mathbf{5}, \mathbf{6}$ et $\mathbf{7}$ ). Un bourrelet de matière est visible à la jointure des deux bords martelés de la tôle du $\mathbf{n}^{\circ} \mathbf{7}$.

\subsection{Un récipient indéterminé (O. Thuaudet)}

Recueilli lors du décapage préliminaire du site de Puget III (voir Annexe 4, $\mathbf{n}^{\circ}$ 30), un petit récipient de fonction indéterminée est composé d'une première tôle battue pour prendre la forme d'une sphère, sur laquelle vient s'emboîter un goulot obtenu par enroulement d'une seconde tôle chaudronnée (fig. 251, $\mathbf{n}^{\circ}$ 7). 


\section{Le domaine de l'écrit (O. Thuaudet)}

Le domaine de l'écrit est illustré par deux ensembles d'objets différents : un mordant d'agrafe de livre d'une part, une matrice et une empreinte de sceau d'autre part.

\subsection{Les sceaux}

Une matrice de sceau (voir Annexe 4, ${ }^{\circ} \mathbf{3 1}$ ) (fig. 253, $\mathbf{n}^{\circ} \mathbf{8}$ ), très bien conservée, à anneau de suspension, porte le motif d'un écu chevronné dont les chevrons creux sont garnis d'un quadrillage. Le tout est encadré par l'inscription en négatif + S.BIRARDI-BEROARDI, disposée entre deux cercles. Sur le dessus de l'objet, quatre points creux agencés en losange constituent peut-être la marque de l'artisan.

Un remblai déposé dans la chapelle Saint-Mauront (abbaye Saint-Victor), du début du XIII s., a fourni un fragment de bulle papale (fig. 253, $\mathbf{n}^{\circ}$ ) ) en matériau blanc du type classique $(\mathrm{e}=0,48 / 0,56 \mathrm{~cm})$. On retrouve sur une face le visage d'un personnage barbu au-dessus de l'inscription SPE renvoyant à saint Pierre, ainsi qu'un encadrement de grènetis. Au revers, une inscription s'étalait sur trois niveaux : A...... AN.... PP.... (un tilde en forme d'oméga coiffe les lettres PP). Les trois premières lettres conservées, par leur disposition, ne peuvent s'appliquer qu'au nom d'Alexandre parmi la liste des papes. Depuis le début du $\mathrm{XI}^{\mathrm{e}} \mathrm{s}$. jusqu'au milieu du XIII ${ }^{\mathrm{e}} \mathrm{s}$., trois papes ont portés ce prénom : Alexandre II (1061), Alexandre III (1159) et Alexandre IV (1254-1261). Si le dernier doit être repoussé étant donné la datation du contexte, le premier peut également être exclu pour différentes raisons. D'une part, il n'est pas certain qu'Alexandre II ait utilisé ce type de sceau car, rare avant Pascal II (1099), il ne deviendrait la norme qu'avec ce dernier (Cambin 1996, p. 202). En outre, le dessin et le modelé de ces objets tendent à s'affiner avec le temps et celui du corpus est sur ce point plus évolué par exemple qu'une bulle papale d'Innocent II (1130-1143) découverte sur le site de la Collina di San Pietro à Castel San Pietro (canton du Tessin) en Suisse (Cambin 1996). Il semble donc qu' on puisse voir dans cette empreinte, une bulle pontificale d'Alexandre III.

\subsection{Un mordant d'agrafe de livre}

Le mordant en question (voir Annexe 4, $\mathbf{n}^{\circ}$ 32) (fig. 253, $\mathbf{n}^{\circ} \mathbf{1 0}$ ) appartient soit à une lanière d'agrafe de livre, soit à une ceinture. Ces objets sont avérés archéologiquement, en Europe de l'ouest continentale et au
Royaume-Uni, du XIV e au XVI ${ }^{\mathrm{e}}$ s. Différents auteurs ont mis en évidence leur présence sur des manuscrits français, anglais et allemands dès le XII ${ }^{\mathrm{e}} \mathrm{s}$. (Egan 2010, p. 277-280 ; Fingerlin 1971, p. 136). Une recherche iconographique a permis de rassembler un ensemble d'œuvres illustrant cet emploi de la fin du XII ${ }^{\mathrm{e}} \mathrm{s}$. au début du XVI ${ }^{\mathrm{e}}$ s. en Europe occidentale (Italie, sud-est et nord de la France). En Provence, on en retrouve sur :

- les statues de saint Pierre et de saint Jean l'Évangéliste du portail de Saint-Trophime (vers 1180-1190) (fig. 255, $\mathbf{n}^{\circ} 3$ et 4 ),

- sur un livre porté par saint André, sculpture appartenant au tombeau de Philippe de Cabassole (mort en 1372) conservé au musée du Petit Palais d'Avignon mais provenant du Palais des Papes (fig. 255, $\mathbf{n}^{\circ} \mathbf{2}$ ),

- dans une sculpture de saint Pierre (fin du XIV ${ }^{\mathrm{e}} \mathrm{s}$.), aujourd'hui au musée du Petit Palais d'Avignon (fig. 255, $\mathbf{n}^{\circ} \mathbf{1}$ ) et originaire de la Chartreuse de Bonpas (Vaucluse),

- sur un ouvrage tenu par la Vierge de l'Annonciation peinte au revers du Buisson Ardent de Nicolas Froment (vers 1475), à la cathédrale Saint-Sauveur d'Aix-en-Provence.

Quelque soit leur origine géographique, toutes les agrafes de ce type sont figurées ou retrouvées avec une perforation centrale, ouverture servant à passer une tige traversant la couverture et éventuellement fixée par une applique. Généralement, un court mordant de tôle, traversé d'un ou deux rivets et parfois décoré d'incisions en bordure, assure la liaison avec la lanière. L'agrafe, obtenue par fonte, est quelquefois agrémentée de moulures. Sur quelques exemplaires, l'extrémité prend la forme d'une tête animale. Lorsqu'il existe une excroissance en partie distale comme pour l'exemplaire du corpus, l'iconographie n'est pas assez précise pour révéler l'ouverture transversale que l'on constate régulièrement sur le mobilier archéologique. Dans le cas des sculptures de saint Pierre et saint André conservées au Petit Palais d'Avignon, un anneau circulaire traverse l'extrémité de l'agrafe. S'agit-il par ce moyen de favoriser la préhension ? Il est plus probable que cet anneau, remplaçant le rivet et fixé à la couverture, possède une ouverture dans son cadre pour passer au travers de l'agrafe. Cette caractéristique est absente sur les deux sculptures, ce qui n'est pas étonnant vu l'importance minime de ce détail par rapport à l'apparence générale de ces statues. Aucun trou n'est visible au travers de notre objet mais, chose surprenante, un coup de poinçon a été donné à l'endroit où il aurait pu exister. Les agrafes de ce type et leurs ouvertures sont le résultat d'une fonte; une personne aurait-t-elle essayé de modifier l'objet pour l'adapter à un autre mode de fixation? 


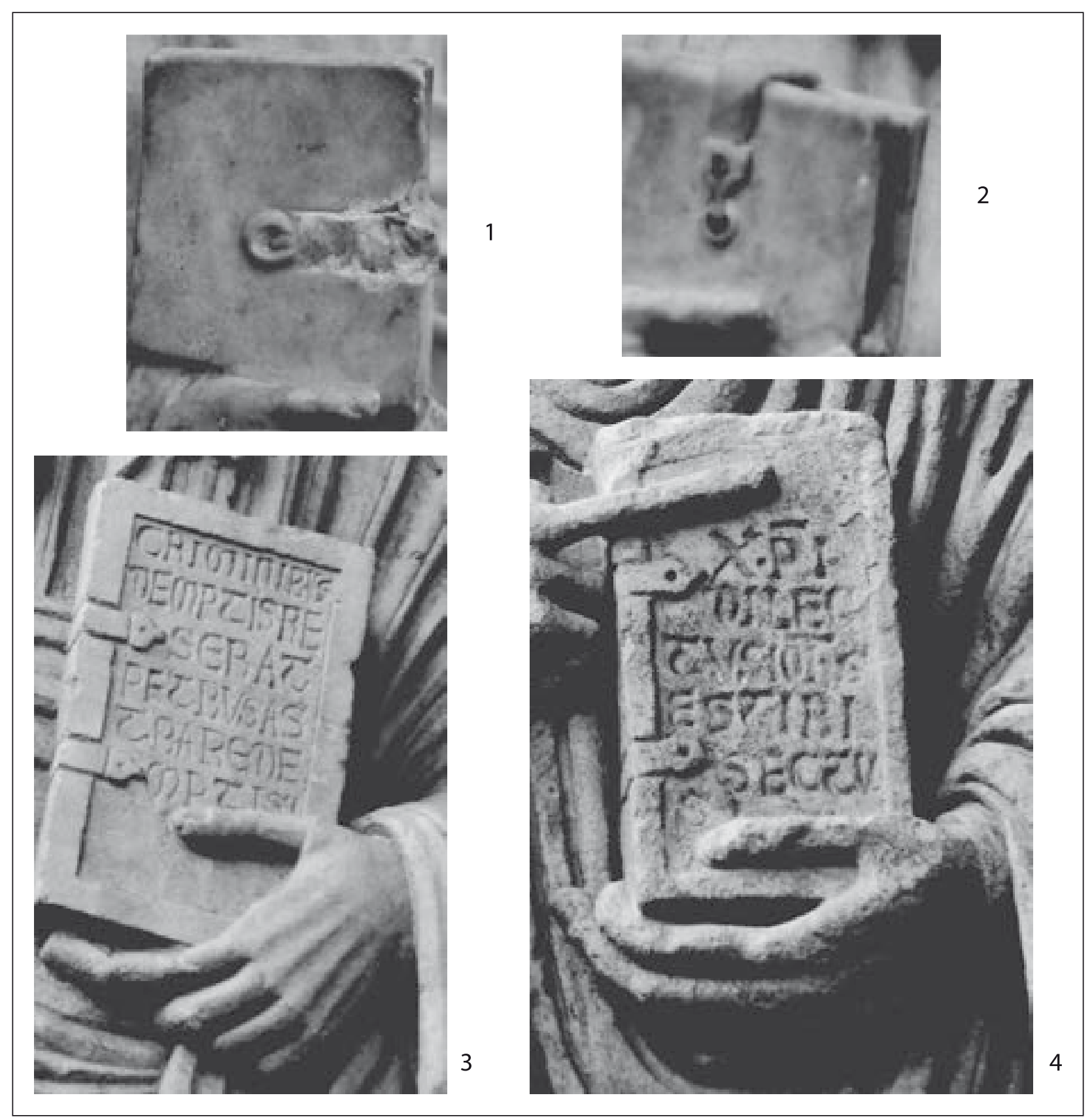

Fig. 255. Mordants d'agrafes de livre dans l'iconographie provençale (O. Thuaudet). Fig. 1 et 2 : statues de saint André et saint Pierre conservées au musée du Petit Palais à Avignon ; 3 et 4 : Portail de Sainte-Trophime d'Arles.

Il existe des similitudes morphologiques entre ce type d'agrafe de livre et celui de quelques agrafes de ceinture ou d'attache de fourreau. À partir de cette constatation et en s'appuyant sur un dessin de E. Viollet-le-Duc (Viollet-le-Duc 1874, p. 11), I. Fingerlin a formulé l'hypothèse que certains de ces objets ont pu être employés dans le costume et fonctionner avec une chaînette à crochet - mais pourquoi pas également avec un anneau ouvert - qui en relierait les deux extrémités (Fingerlin, p. 136, 140, fig. 241,

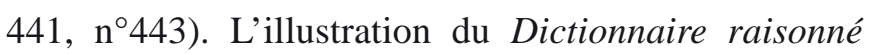
figure un objet de grande taille décoré de coups de poinçons, retrouvé lors de fouilles menées au château de Pierrefonds et que l'auteur date du XIV ${ }^{\mathrm{e}} \mathrm{s}$. (Violletle-Duc 1874, p. 11). I. Fingerlin reste circonspect quant à l'exactitude du dessin. Nous sommes beaucoup moins méfiants car un exemplaire presque en tout point identique a été retrouvé à Digne dans le comblement d'une fosse daté de la fin du XIII ${ }^{\mathrm{e}}-\mathrm{XV}^{\mathrm{e}} \mathrm{s}$. Il est nécessaire pour répondre aux multiples questions que posent ces objets 
de procéder à une étude approfondie et à grande échelle des agrafes conservées sur les manuscrits, et de faire des recherches plus pointilleuses dans l'iconographie. La présence presque systématique des deux ouvertures précédemment décrites, quelque soit l'origine géographique de la découverte archéologique, de l'iconographie et des livres conservés est particulièrement intéressante. Elle signifie que ces objets sont produits selon un modèle générique, donc susceptible de convenir à de nombreuses utilisations est à divers modes de fixation. Ce constat est d'ailleurs commun à beaucoup d'autres objets de fixation ou d'attache.

\section{Le jeu}

Les activités ludiques sont relativement bien illustrées dans le corpus, notamment par des dés et pièces de jeu en matière dure d'origine animale. L'archéologue est toutefois réduit sur ce point à ne travailler que sur une petite part d'entre elles, la plupart ne laissant pas de traces matérielles ou susceptibles d'être aisément conservées - les cartes à jouer par exemple. Bon nombre de règlements municipaux puis royaux ont cherché à encadrer la pratique de certains jeux, notamment ceux de hasard, susceptibles de donner lieu à des débordements.

\subsection{Les dés et autres pièces de jeu (M.-A. Chazottes)}

Trente-deux dés à jouer, un pion de jeu et un jeton de dame ainsi que deux dominos ont été retrouvés (voir Annexe 4, $\mathbf{n}^{\circ} 33$ ). Vingt-neuf dés à jouer proviennent d'un même contexte des $X V^{\mathrm{e}}-\mathrm{XV}^{\mathrm{e}}$ s. (fig. 256, n 2-10). Parmi eux, cinq sont certainement pipés et comportent des chiffres répétés plusieurs fois (fig. 256, $\mathbf{n}^{\circ} \mathbf{2}, \mathbf{4 - 6}$ ). Sur un unique spécimen, le chiffre quatre se retrouve sur l'ensemble de ces six faces (fig. 256, $\mathbf{n}^{\circ} \mathbf{3}$ ). Parmi les lots de dé à jouer truqués déjà connus, celui découvert dans des latrines, datées du XIV ${ }^{\mathrm{e}} \mathrm{s}$, lors de la fouille de la place Camille-Jullian à Bordeaux (Maurin 1989-1990, p. 42, fig. 28), est particulièrement intéressant du fait du nombre exceptionnel d'objets : plus de 200.

Les autres dés à jouer étudiés semblent de « bon aloi ». Ils sont tous de forme et de section quadrangulaires avec la somme des faces opposées égales à 7 (fig. 256, $\mathbf{n}^{\circ} \mathbf{1}$, 2, 8). Dix-neuf présentent de simples ponctuations, six exemplaires sont munis d'ocelles simples pointés et sur un spécimen, les chiffres sont inscrits à l'aide d'ocelles doubles pointés (fig. 256, $\mathbf{n}^{\circ}$ ). Des traces d'une substance noire décorative ou utilitaire sont par ailleurs conservées sur 20 individus.
Tous ces dés sont certainement issus d'une matrice paraxiale débitée dans la diaphyse d'un os long. Peu de traces de fabrication sont conservées sur les objets mais on peut émettre l'hypothèse, au vu des déchets trouvés sur d'autres sites qu'une fois la matrice débitée, elle était façonnée afin d'obtenir des baguettes de forme et de section quadrangulaires dans lesquelles des petits cubes étaient découpés. La dernière étape consistait à inscrire les chiffres sur chaque dé à jouer et l'artisan a certainement tourné chaque face afin d'apposer des ocelles simples ou doubles. Le petit trou au centre de chaque ocelle est la marque de la pointe du tour ou du compas.

À ces objets en os s'ajoute un dé à jouer (fig. 256, $\mathbf{n}^{\circ} \mathbf{9}$ ), unique par son matériau, en corail d'un rose saumon prononcé.

Ces dés à simples ou doubles ocelles pointés, connus depuis l'époque romaine, se retrouvent régulièrement en contextes médiévaux et modernes. Des exemples identiques sont donc connus tant pour l'An Mil que pour le $\mathrm{XVI}^{\mathrm{e}}$ s. et cela autant au sud qu'au nord de la France. Ainsi, des dés similaires ont notamment été retrouvés à Avignon au Petit Palais (Chazottes 2012, pl. 6-8) à Peyrepertuse (Bayrou 2000, fig. 130, $\mathrm{n}^{\circ} 16$ ) ou à Andone pour l'An Mil (Bourgeois, Rodet-Belarbi 2009, p. 264, $n^{\circ} 1985$ ) ; à Essertines (Piponnier 1993, p. 151, n²) ou à Toulouse pour le XIV e s. (Molet 1988, p. 134) ou encore au château de Butenheim à Petit-Landau en Alsace pour le XVI' ${ }^{\mathrm{e}}$ s. (Schnitzler 1990, p. 446, n³.103).

Un pion de jeu en os (place Villeneuve-Bargemon), de forme ogivale, à base circulaire, présente encore des traces de matière spongieuse (fig. 256, $\mathbf{n}^{\circ} \mathbf{1 0}$ ). Il n'est pourvu d'aucun décor mais, au sommet de la tête, un trou de tournage assez profond est conservé. Cet objet a dû être fabriqué à partir d'une matrice paraxiale débitée dans la diaphyse d'un os long. La portion débitée devait encore contenir de la spongiosa, ce qui explique sa légère présence sur l'objet. D'un point de vue technique, ce pion a été tourné et des traces de tournage sont conservées à la base mais également sur le corps et la tête de l'élément de jeu. Ces traces ont certainement été atténuées par le polissage de la pièce.

Fig. 256. Le jeu (M.-A. Chazottes, sauf 14 : O. Thuaudet).

1, 13 : Alcazar

2-8, 10 : place Villeneuve-Bargemon ;

9 : Saint-Victor ; 11 : Vieille-Major ;

12 : Tunnel de la Major;

14 : place des Pistoles. 


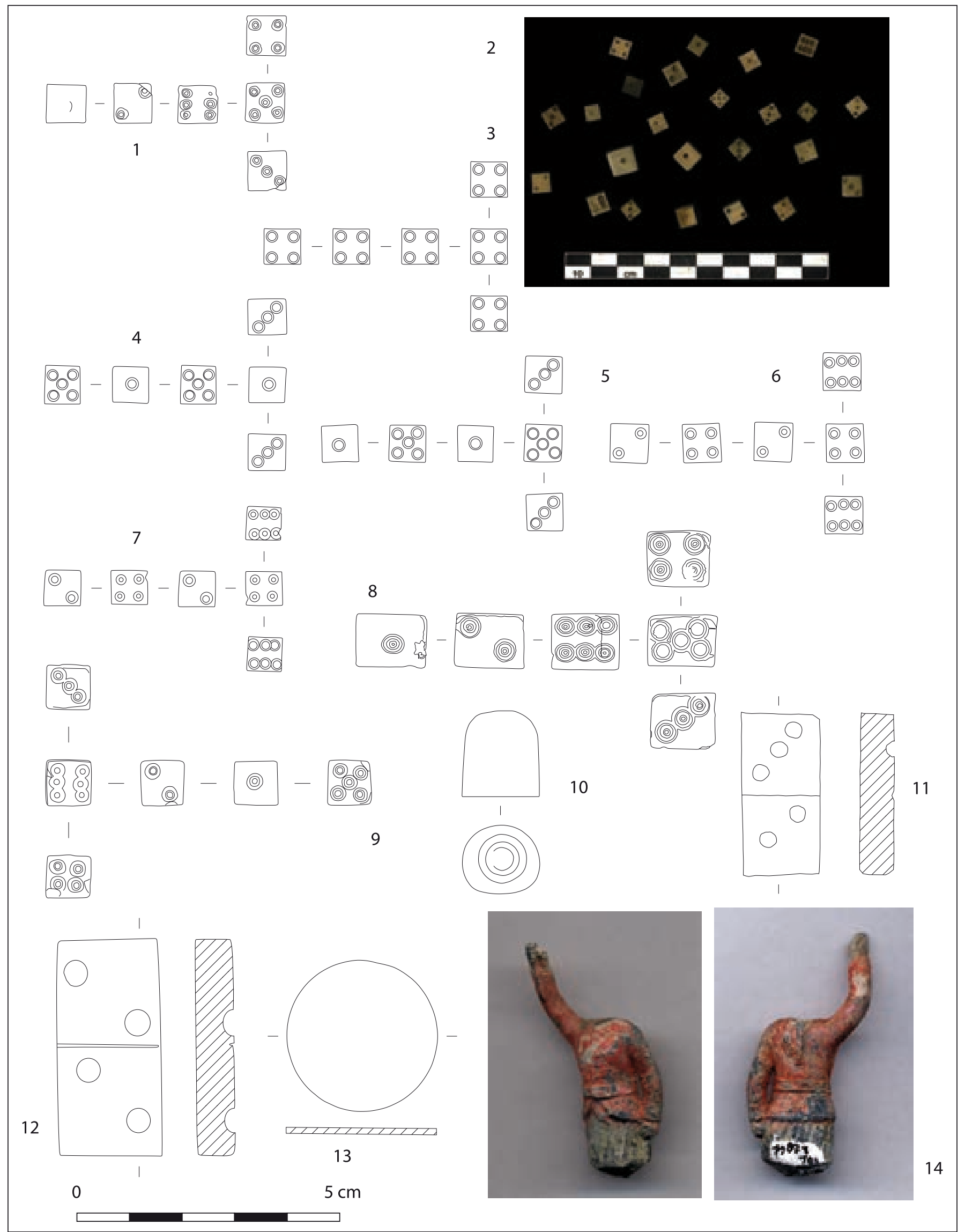


Ce type de pion est bien connu pour la période médiévale. Ainsi, une pièce identique mais en ivoire a été mise au jour au château des Baux-de-Provence dans les Bouches-du-Rhône (Chazottes 2012, n 4, pl. 10) et un autre spécimen est issu du château de Crèvecœuren-Auge (Calvados). Ce dernier, daté des $\mathrm{XI}^{\mathrm{e}}-\mathrm{XII}^{\mathrm{e}} \mathrm{s}$., présente un décor contrairement à l'exemplaire marseillais (Goret, Poplin 2008, p. 66, fig. 5). Deux pions similaires datés des $\mathrm{XII}^{\mathrm{e}}-\mathrm{XIII}{ }^{\mathrm{e}} \mathrm{s}$. - l'un en ivoire, l'autre en buis - ont été retrouvés à Tours (Motteau 1991, p. 48, n²70-271). D'autres encore sont connus pour le $\mathrm{IX}^{\mathrm{e}} \mathrm{s}$. avec "l'échiquier de Charlemagne » (Pastoureau 1990, p. 27) et pour le bas Moyen Âge ou le début de l'Époque moderne au château de Grigny dans le Pas-de-Calais (Dilly, Piton et al. 1987, p. 87, $\mathrm{n}^{\circ} 2.72$ ).

Le quatrième objet lié au jeu est un jeton de dame (Alcazar) de forme circulaire, de profil droit et d'épaisseur assez faible (fig. 256, $\mathbf{n}^{\circ} \mathbf{1 3}$ ). Ses deux faces sont lisses et ne comportent aucun ornement.

Les deux dernières pièces sont des dominos issus du quartier de la cathédrale, de forme et de section quadrangulaires, avec une face inférieure lisse et une face supérieure partagée en deux espaces séparés par une gorge en $\mathrm{V}$ de part et d'autre de laquelle on retrouve les ponctuations (fig. 256, $\mathbf{n}^{\circ} \mathbf{1 1}$ et 12). Ces dominos sont certainement le résultat de la taille d'une matrice paraxiale prélevée dans la diaphyse d'un os long. Après le débitage des plaquettes, les objets ont été façonnés et sciés afin d'obtenir la taille désirée, puis l'artisan a dû ménager au ciseau les rainures centrales et enfin forer chaque espace du nombre de ponctuation voulu.

\subsection{Un soldat de plomb (O. Thuaudet)}

Un soldat de plomb (voir Annexe 4, $\mathbf{n}^{\circ} \mathbf{3 4}$ ) conserve des traces de peinture rouge sur sa veste et de bleu (?) sur son pantalon (?) bouffant (djellaba ?). Cette figurine représente peut-être un tirailleur algérien donnant l'assaut (fig. 256, $\mathbf{n}^{\circ} \mathbf{1 4}$ ).

\section{L'ameublement et la serrurerie}

L'ameublement et la serrurerie sont illustrés par quelques éléments métalliques et en os, vestiges d'un mobilier généralement en bois disparu. Mais, un parcours de la bibliographie montre fort bien que la plupart des éléments relatifs à ce domaine sont en fer. Si l'on excepte la serrurerie, l'archéologue est particulièrement démuni quant à la reconstitution du mobilier originel à partir des vestiges conservés.

\subsection{Les éléments métalliques d'ameublement et de serrurerie ( $O$. Thuaudet)}

Le mobilier métallique en rapport avec l'ameublement rassemble cinq objets, pour la plupart obtenus par fonte (voir Annexe 4, $\mathbf{n}^{\circ} 35$ ). Le premier $(\mathrm{L}=3,1 \mathrm{~cm}$, non figuré) est un anneau circulaire à vis de fixation, retrouvé dans un comblement de caniveau du milieu du $\mathrm{XIX}^{\mathrm{e}}$ s. (Espace Bargemon). Un autre anneau, quadrangulaire $(\mathrm{d}$ cadre $=0,37 \mathrm{~cm})$, composé d'une tige de section circulaire coudée (fig. $\mathbf{2 5 7}, \mathbf{n}^{\circ} \mathbf{1}$ ), a probablement servi à l'attache ou à la suspension. Une unique charnière de meuble est d'un type à charnons (fig. 257, $\mathbf{n}^{\circ} \mathbf{2}$ ). L'élément femelle, en tôle martelée, est la seule partie conservée. Une possible paumelle ou cavalier (fig. 257, $\mathbf{n}^{\circ} \mathbf{5}$ ), et un fragment d'ornement à pampres végétaux de plus forte épaisseur à la base (fig. $257, \mathbf{n}^{\circ} \mathbf{4}$ ), ont été mis au jour dans des contextes médiévaux. L'applique $\mathbf{n}^{\circ} \mathbf{6}$ (fig. 257), recouverte de grènetis, dispose de trois points de fixation. Cet objet, probablement embouti, est parsemé de formes ovales la plupart du temps ajourées. Il s'agit sans doute d'une applique de meuble étant donné sa morphologie.

La pièce $\mathbf{n}^{\circ} \mathbf{3}$ de la fig. 257 est composée d'une plaque principale, décorée en bordure de chaque côté de trois incisions, et de deux incisions larges et profondes disposées perpendiculairement sur une zone surélevée. Une terminaison à feuillage stylisé montre au revers un surhaussement rectangulaire, traversé par deux perforations retenant des fragments de tige. À l'opposé, deux charnons sont enroulés autour d'une tige aux extrémités bouletées. Cet objet est un moraillon dont l'auberon a disparu. Il devait s'adapter à un coffre étant donné sa taille. Bien que hors contexte, une datation typologique de la fin du Moyen Âge ou du début de l'Époque moderne est envisageable.

Une unique clef (fig. 257, $\mathbf{n}^{\circ}$ 9) complète ce lot de mobilier. C'est une clef de coffret ou de petit meuble à anneau circulaire à excroissance arrondie. Sa tige pleine débute par deux moulures. Le panneton est de forme quadrangulaire, sans découpe. Un objet presque identique, à tige forée, a été mis au jour dans une tranchée de drainage du XIV ${ }^{\mathrm{e}}$ s. au Château de Portchester (Royaume-Uni). Une autre clef à tige de type indéterminé est conservée au Musée Calvet, à Avignon. Un troisième spécimen à tige forée est entreposé au musée Le Secq des Tournelles à Rouen (Vaudour s.d., p. 51, n¹60).

\subsection{Un possible pied de meuble (M.-A. Chazottes)}

L'objet $\mathrm{n}^{\circ} 7$ (fig. 257) dont la destination fonctionnelle est encore imprécise peut correspondre à un 


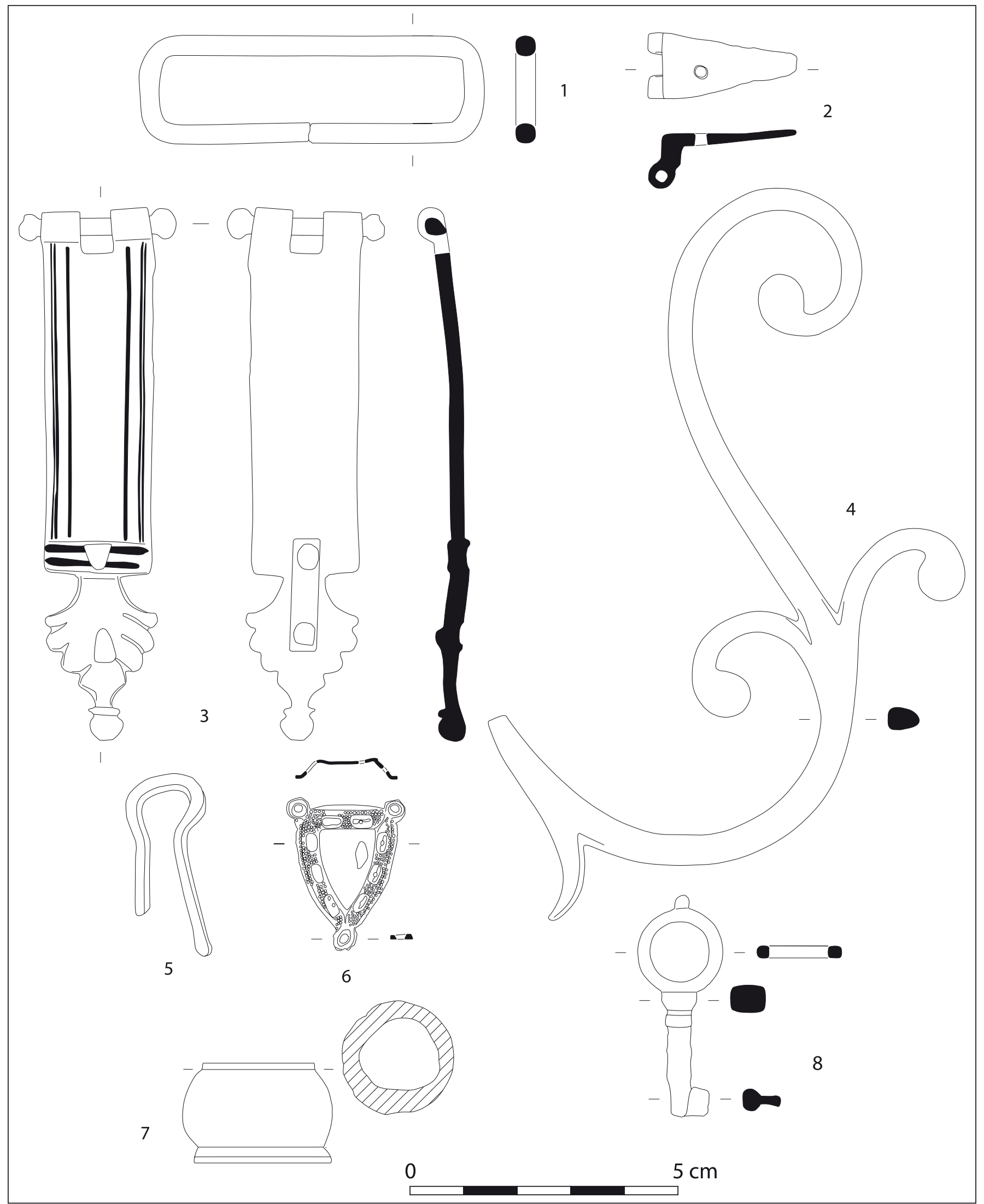

Fig. 257. Ameublement et serrurerie (O. Thuaudet sauf 7 : M.-A. Chazottes). 1, 7, 9 : Alcazar ; 2-6 : place Villeneuve-Bargemon ; 8 : Tunnel de la Major. 


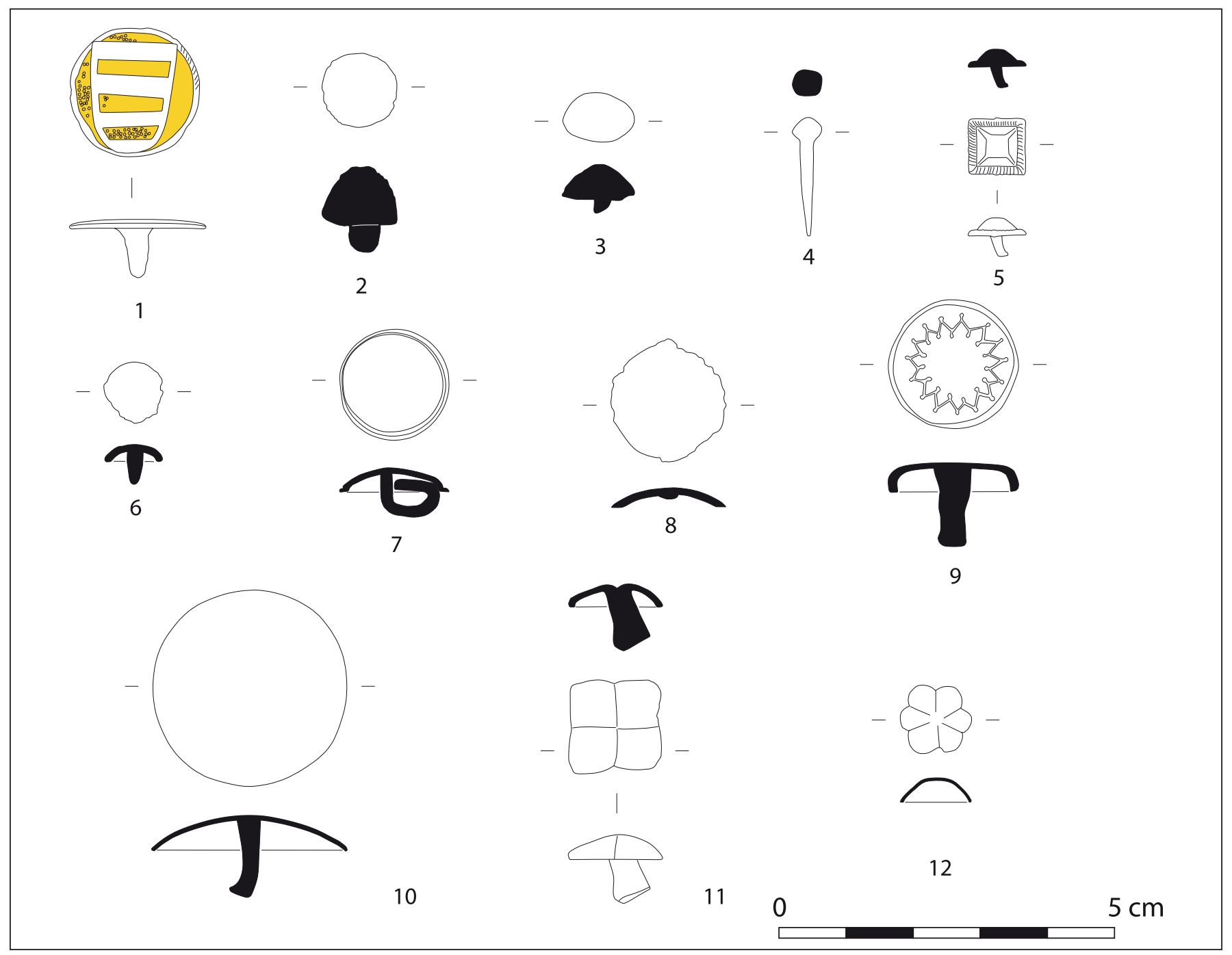

Fig. 258. Clous et rivets (O. Thuaudet). 1-4, 6-12 : Alcazar ; 5 : place Villeneuve-Bargemon.

élément terminal de meuble (voir Annexe 4, n³6). Il est extrait d'un métatarse de bœuf et se présente sous la forme d'une moulure de section circulaire avec deux ressauts, l'un en partie proximale, le second à l'autre extrémité formant deux gorges en V. Des objets approchants proviennent de Portchester Castle en Angleterre pour les XII ${ }^{e}-X I I{ }^{e}$ s. (Hinton 1977, p. 208, n ${ }^{\circ}$ 4) et du Château de Montmorin dans le Puy-de-Dôme pour les $\mathrm{XIII}^{\mathrm{e}}-\mathrm{XIV}^{\mathrm{e}} \mathrm{s}$. (Boudriot 1995, pl. 1, no6). Cependant, une fouille narbonnaise en cours d'étude (Rodet-Belarbi à paraître) a livré des objets antiques similaires.

\section{Les clous et rivets $(O$. Thuaudet $)$}

Un important lot, en alliage cuivreux, est constitué de rivets et de clous (voir Annexe 4, $\mathbf{n}^{\circ} \mathbf{3 7}$ ). Dans la plupart des cas, leur typologie ne permet pas de les dater, il n'est donc pas exclu que des objets antiques se soient glissés dans la collection.

Un premier clou (fig. $\mathbf{2 5 8}, \mathbf{n}^{\circ} \mathbf{1}$ ) se distingue par une tige de section circulaire et surtout par une tête plate ornée d'un écu à trois fasces (selon la terminologie héraldique) qui, tout comme la partie entre la bordure et l'écu, est couverte de dorure. Sur la surface la mieux conservée, on peut apercevoir des cercles réalisés à l'aide d'un poinçon circulaire concave.

Trois clous (Tunnel de la Major), non figurés, présentent également une tête circulaire plate, mais leur tige est de section quadrangulaire. Le premier a été collecté dans un remblai du XIX ${ }^{\mathrm{e}}$ s., les suivants dans une rue du XII ${ }^{\mathrm{e}} \mathrm{s}$. Le site des Pistoles a livré un fragment de clou semblable dans un sol de la première moitié du $\mathrm{XIII}^{\mathrm{e}}$ ou du début du $\mathrm{XIV}^{\mathrm{e}} \mathrm{s}$. Un autre spécimen de la même fouille, à tige de section circulaire provient d'un dépotoir du second quart du XVII ${ }^{\mathrm{e}} \mathrm{s}$. Le diamètre de la 


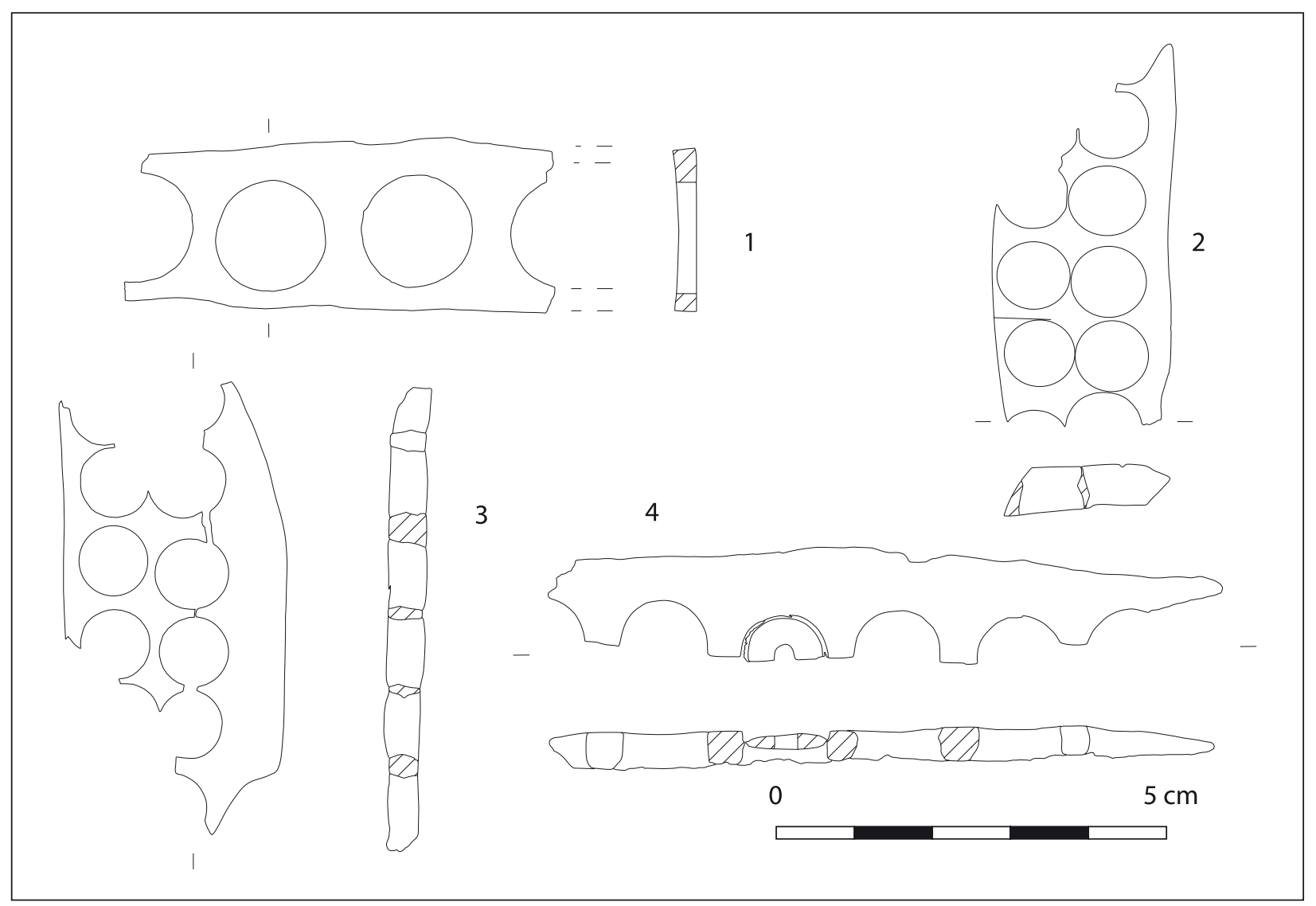

Fig. 259. Déchets de fabrication en matière dure animale (M.-A. Chazottes). 1-3 : Tunnel de la Major ; 4 : Vieille-Major.

tête de ces clous est compris entre 0,6 et $1,6 \mathrm{~cm}$ et leur tige atteint lorsqu' elle est complète $1,5 \mathrm{~cm}$ de long. Leur confection a nécessité l'usage d'une cloutière.

De nombreux spécimens de clous ont été collectés sur le site de l'Alcazar : deux d'entre eux, fragmentaires, se terminent par une tête circulaire pleine et bombée (fig. 258, $\mathbf{n}^{\circ} \mathbf{2}$ et 3 ), un troisième possède un profil de la tête et une section de la tige losangiques (fig. 258, $\mathbf{n}^{\circ} \mathbf{4}$ ), d'autres ont une tête convexe creuse. C'est le cas d'une sorte de punaise (fig. $\mathbf{2 5 8}, \mathbf{n}^{\circ} \mathbf{6}$ ) mais également des exemplaires $\mathbf{n}^{\circ} \mathbf{7}$ et $\mathbf{n}^{\circ} \mathbf{8}$, dont la tige est recourbée jusque sous la tête à gradin en périphérie.

Un ensemble est constitué de cinq clous : à tête carrée bombée ( 1 tête $=0,88 \mathrm{~cm}$ ), à bosse centrale encadrée d'un motif cordé (fig. $\mathbf{2 5 8}, \mathbf{n}^{\circ} \mathbf{5}$ ). Ils sont, avec un sixième légèrement plus petit $(1$ tête $=0,79 \mathrm{~cm})$, issus du même contexte.

Le clou $\mathbf{n}^{\circ} \mathbf{9}$ (fig. 258) se distingue par sa tête, étamée ou argentée, ornée d'un cercle de zigzags aux angles bouletés en relief positif. Il partage avec l'objet $\mathbf{n}^{\circ} \mathbf{1 0}$ (fig. 258) un même élargissement à l'extrémité de sa tige, résultat d'un matage.

Le site de l'Alcazar a également fourni deux rivets d'un genre un peu particulier: l'un en forme de fleur à quatre pétales bombés, à rivet de forte épaisseur (fig. 258, $\mathbf{n}^{\circ} 11$ ); le second, à tête à six pétales bombés (fig. 258, $\mathbf{n}^{\circ} 12$ ).

Les pièces $\mathrm{n}^{\circ} \mathbf{1}, \mathbf{2}, \mathbf{3}$ et $\mathbf{5}$ ont été confectionnées par fonte, et les $n^{\circ} \mathbf{4}$ et $\mathbf{6}$ à partir d'une tige passée à la cloutière. Le procédé de fabrication des autres clous paraît être plus complexe : à la tête, probablement le résultat d'un emboutissage - notamment les $\mathbf{n}^{\circ} \mathbf{1 1}$ et $\mathbf{1 2}$ - ou d'une fonte - le $\mathbf{n}^{\circ} \mathbf{9}$-, est vraisemblablement rajouté une tige réalisée à part. L'absence de tige pour le $\mathbf{n}^{\circ} \mathbf{1 2}$, la présence d'un monticule de métal - reste de brasure ? - au revers du $\mathbf{n}^{\circ} \boldsymbol{8}$, et l'aspect « gracile» des tetes par rapport aux tiges semblent confirmer cette hypothèse.

Une rondelle de rivetage $(\mathrm{d} \times \mathrm{e}=0,8 \times 0,07 \mathrm{~cm}$, non figurée) découverte dans une cuve comblée à la fin du $\mathrm{XIX}^{\mathrm{e}}$ ou au début du $\mathrm{XX}^{\mathrm{e}} \mathrm{s}$. (Alcazar) clôt cet inventaire.

\section{Les déchets de fabrication en os (M.-A. Chazottes)}

Quelques déchets permettent d'illustrer une activité de fabrication de nature inconnue - artisanale ou domestique - à Marseille (voir Annexe 4, n³8). 
Quatre plaquettes d'extraction de jetons ou de boutons ont été découvertes dans des contextes des XVII ${ }^{\mathrm{e}}$ et XVIII' s. à l'Alcazar, au Tunnel de la Major et à la Vieille-Major (fig. 259, $\mathbf{n}^{\circ} 1$ à 4). Il s'agit de fragments de plaquettes en os de faible épaisseur $(0,3 \mathrm{~cm})$ pour l'une et d'épaisseur plus importante pour les deux autres. De forme et de section quadrangulaires, elles sont scandées de multiples perforations parfaitement circulaires et conservent l'amorce de plusieurs autres.

Les plaquettes $n^{\circ} \mathbf{1}$ et $\mathbf{4}$ (fig. 259) présentent une face supérieure lisse et incurvée et une face inférieure pourvue de matière spongieuse, ce qui indique que ces objets ont été débités dans une côte. À l'inverse, les deux autres (fig. 259, $\mathbf{n}^{\circ} \mathbf{2}$ et $\mathbf{3}$ ) ont certainement été débitées dans la diaphyse d'un os long étant donné la forte proportion d'os compact et l'absence de matière spongieuse.

L'artisan a donc dans un premier temps, soit séparé la côte en deux dans le sens longitudinal sans racler la matière spongieuse, soit scié des plaquettes rectangulaires dans une diaphyse d'os long. Les boutons ont ensuite été extraits de la plaquette à l'aide d'un tour ou d'une mèche à trois pointes. L'intérieur des perforations présente des traces de détourage mais pas d'arrachement lamellaire. Le fabricant a donc détouré entièrement ces ébauches sans finir son détachage par pression. Cependant, pour les plaquettes issues du Tunnel de la Major, les perforations circulaires présentent à l'intérieur des profils en $\mathrm{V}$, ce qui indique que l'artisan a travaillé la plaquette en face inférieure puis a terminé le détachage en détourant la face supérieure (ou inversement). Ce type de déchet se rencontre très régulièrement pour la période moderne et des plaquettes similaires ont été mises au jour à Savone notamment, dans des niveaux datés entre les XVIII ${ }^{\mathrm{e}}$ et $\mathrm{XIX}^{\mathrm{e}}$ s. (Varaldo 2001, p. 458).

\section{Les objets indéterminés}

La publication des objets qui n'ont pu être identifiés n'est pas aussi courante qu'on pourrait l'espérer. Pourtant, l'évolution des connaissances mais aussi l'expérience d'autres spécialistes peut conduire à leur interprétation. Parmi les nombreux objets indéterminés, nous avons sélectionné ceux dont l'état de conservation et l'intégrité étaient suffisants.

\subsection{Les objets indéterminés en os ou en nacre (M.-A. Chazottes)}

Parmi les pièces indéterminées (voir Annexe 4, $\mathbf{n}^{\circ} 39$ ), une plaquette est de forme et de section quadrangulaires, à profil droit (fig. 260, $\left.\mathbf{n}^{\circ} \mathbf{1}\right)$. Elle présente une face inférieure plane, scandée de stries de sciage et une face supérieure polie, munie d'un décor peint. Bien que la couleur rouge soit altérée, on devine deux cercles concentriques délimitant un motif de félin passant, dont la tête est tournée vers la queue. On ne retrouve sur cette plaquette ni trou de rivet, ni trace de fer qui pourrait permettre d'affirmer qu'il s'agit d'une plaquette d'ameublement. Ce type de décor est connu sur un peigne liturgique du XII ${ }^{\mathrm{e}}$ s., découvert à MartresTolosane en Haute-Garonne (De Toulouse à Tripoli 1989, p. $109, \mathrm{n}^{\circ} 28$ ).

Une deuxième plaquette, certainement issu d'une matrice paraxiale, est peut-être également liée à l'ameublement (fig. 260, $\mathbf{n}^{\circ} \mathbf{2}$ ). Elle possède une face inférieure lisse et une face supérieure bombée à motif de feuille avec des nervures. Les seules traces de fabrication conservées sont les enlèvements exécutés au ciseau pour la création du décor.

L'objet $\mathbf{n}^{\circ} \mathbf{3}$ (fig. 260) se compose de trois parties : un fût, un socle et une tête. Le fût de section circulaire, dont le diamètre semble se réduire régulièrement de la tête vers l'extrémité conservée, est orné d'un décor tressé qui ouvre sur un socle de section ovale aplatie, scandé de deux stries formant des gorges en V. Ce socle soutient par ailleurs l'amorce d'une tête qui a pu être moulurée. D'un point de vue technique, on peut uniquement affirmer que le décor tressé de la pièce n'a pas été réalisé au tour, car celui-ci est trop irrégulier. Aucune comparaison n'est à ce jour connue et la fonction de cet objet n'est pas clairement identifiée. Il peut s'agir d'une épingle ou de tout autre objet au corps long et fin (fuseau, cure-oreille...).

Trois objets qui pourraient être des boutons à une seule perforation comme le propose $\mathrm{P}$. Courtaud dans son article sur le site d'Anse Sainte-Marguerite en Guadeloupe (Courtaud, Romon 2004, p. 58-67), sont des rondelles perforées. Le premier exemplaire provient de l'Alcazar, les deux autres du Tunnel de la Major (fig. 260, $\mathbf{n}^{\circ} \mathbf{4}$ à 6). De forme circulaire, ils ont deux faces lisses et une perforation circulaire au centre. Deux d'entre eux sont en os et révèlent encore des traces de tournage mais ces dernières - très irrégulières pour le $\mathbf{n}^{\circ} \mathbf{4}$ - indiquent que l'opération a été effectuée en plusieurs fois. Les objets ont ensuite été forés et on peut imaginer que le négatif de la pointe du tour a disparu lors du forage. La dernière rondelle a été taillée dans de la nacre.

Le septième objet indéterminé est de section circulaire en partie proximale, ovale en partie médiane et très aplatie en partie distale (fig. $\mathbf{2 6 0}, \mathbf{n}^{\circ} \mathbf{8}$ ). Le diamètre de la pièce se réduit ainsi de la tête vers l'autre extrémité de l'objet, qui est de forme arrondie. En partie proximale, la tête est en forme de cône peu saillant. Les traces de 

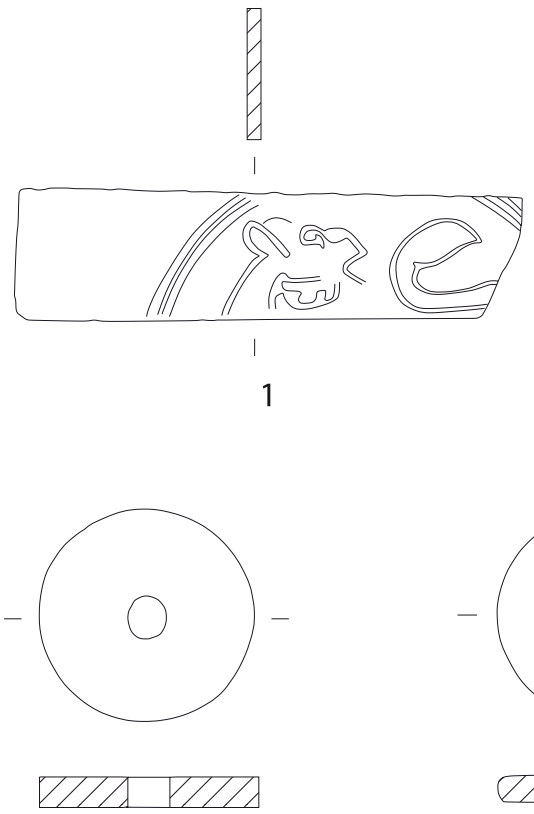

4

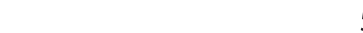
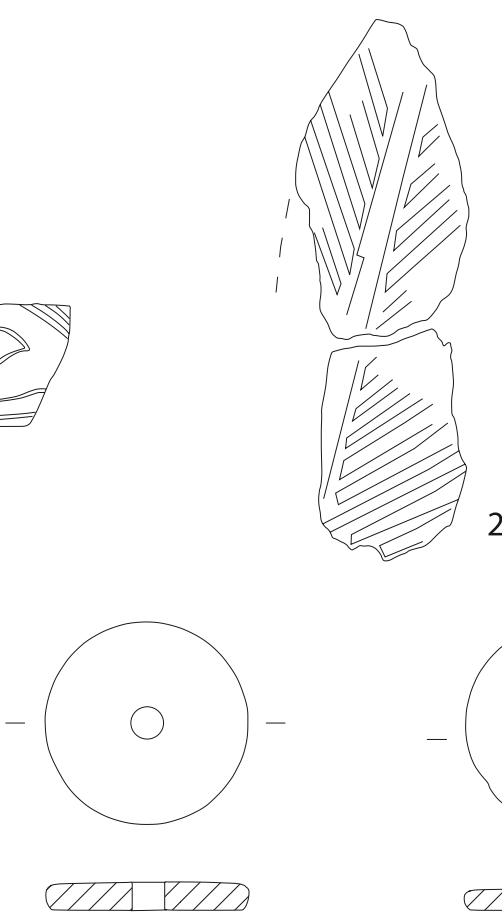

5
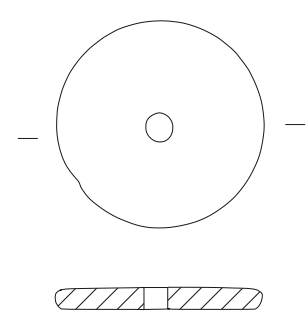

6
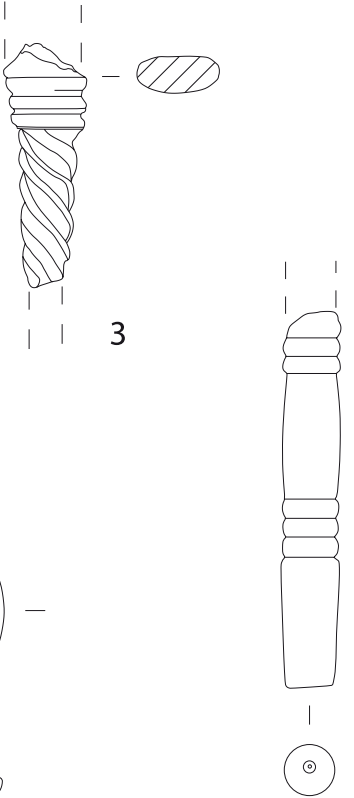

7

9

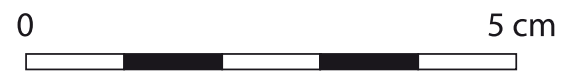

Fig. 260. Objets en os indéterminés (M.-A. Chazottes). 1, 3-4, 8 : Alcazar ; 2 : Vieille-Major ; 5-7 : Tunnel de la Major ; 9 : place Villeneuve-Bargemon.

fabrication ne sont pas conservées mais il est probable que cet artéfact est issu d'une matrice paraxiale qui a ensuite été façonné à la râpe ou au ciseau puis poli.

La huitième pièce, de section circulaire, est décorée, en partie supérieure et médiane, d'une alternance de gorges et de bombements réalisés au tour (fig. 260, $\mathbf{n}^{\circ}$ 7). L'objet, très fragmentaire, pourrait être interprété comme un stylet, un fragment de cure-oreille ou tout objet au corps long et fin.

Un dernier objet (fig. 260, $\mathbf{n}^{\circ}$ ) ) pourrait être un manche de couteau qui comprend une face inférieure lisse et plate, deux bords droits de largeur inégale et une face supérieure bombée. Une des extrémités est cassée mais l'autre présente une perforation circulaire parallèle à l'axe longitudinal de l'objet.

\subsection{Les objets indéterminés en métal (O. Thuaudet)}

L'objet $\mathrm{n}^{\circ} 1$ (fig. 261) est constitué de deux tôles (voir Annexe 4, $\mathbf{n}^{\circ} \mathbf{4 0}$ ). La première, à bordure à pans coupés sur une petite partie de sa longueur, est décorée de deux ensembles de trois lignes incisées au-dessous de l'empreinte d'un poinçon. Cette dernière (fig. 261, $\mathbf{n}^{\circ} 3$ ) figure un visage humain et les lettres BI, certainement la marque d'un fabriquant. Deux rivets retiennent la seconde plaque. L'un d'eux traverse également un fragment de cuir enserré entre les deux tôles et est maintenu par un contre-rivet à bordure ondulée. Des traces de limage sont visibles sur les rives et au niveau des pans coupés. 


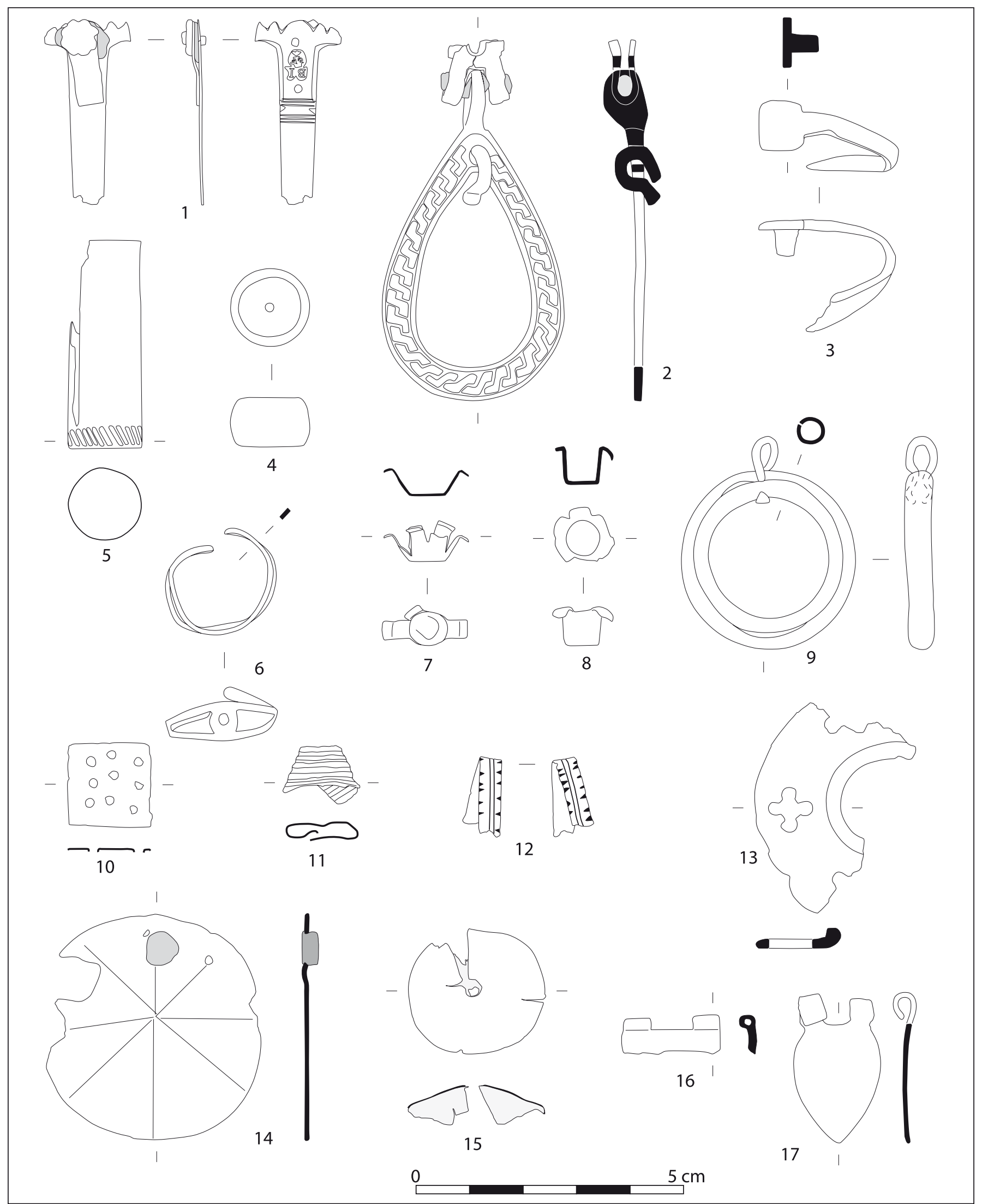

Fig. 261. Objets en métal indéterminés (O. Thuaudet). 1-2, 10-12, 15 : Saint-Victor ; 3, 7, 14, 17 : Alcazar ; 4-6, 13 : place des Pistoles ; 8 : Tunnel de la Major ; 9, 16 : place Villeneuve-Bargemon. 


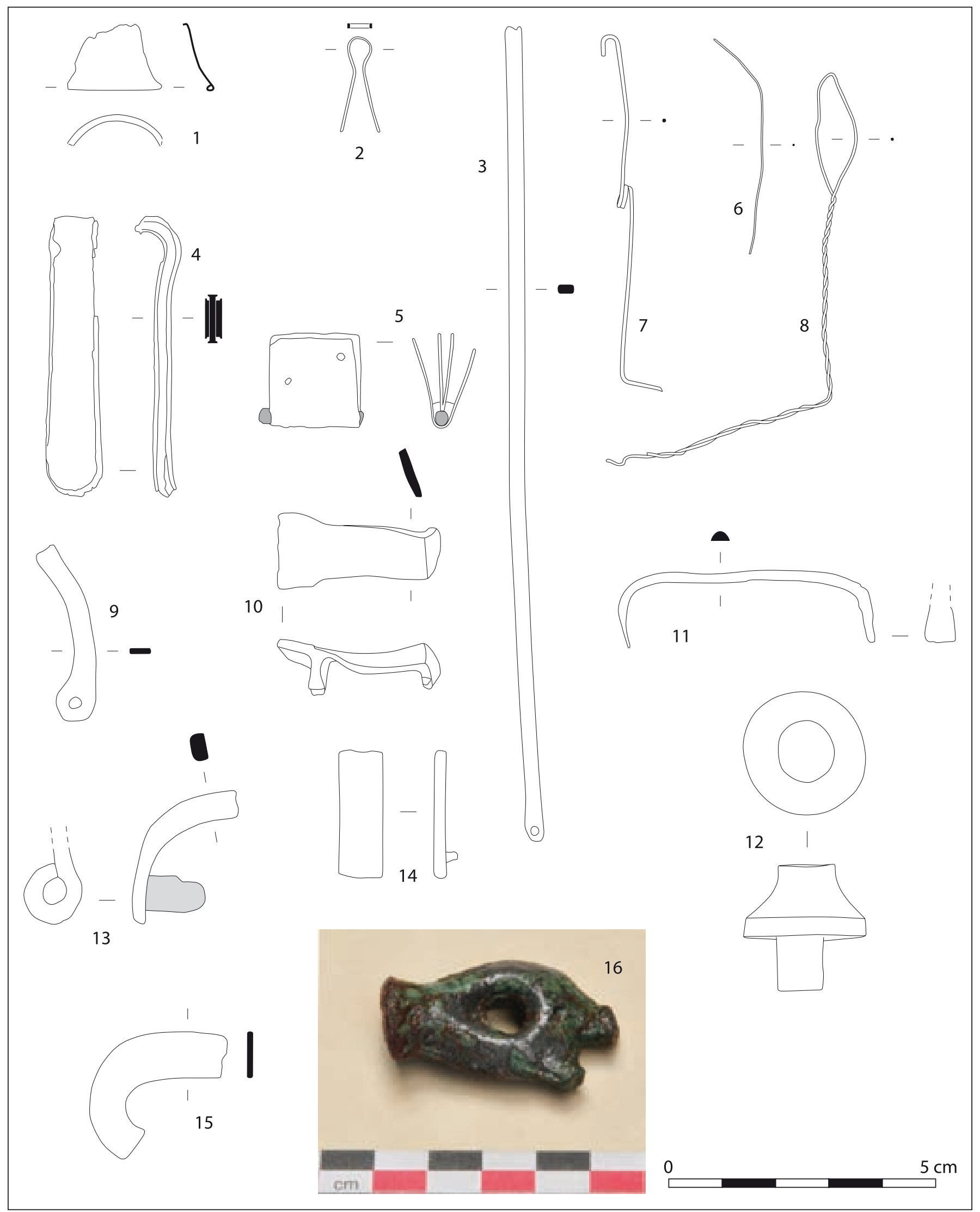

Fig. 262. Objets en métal indéterminés (O. Thuaudet). 1-2 : place Villeneuve-Bargemon ; 3 : Vieille-Major ; 4-5, 10 : Alcazar ; 6-8 : Saint-Victor ; 9 : Puget III ; 11 : Tunnel de la Major ; 12, 14, 16 : place des Pistoles ; 13 : llot $55 ; 15$ : llot $24 \mathrm{~N}$. 
Le $\mathbf{n}^{\circ} \mathbf{2}$ (fig. 261, $\mathbf{n}^{\circ} \mathbf{2}$ ) est d'une morphologie assez particulière. Un anneau obtenu par fonte, en forme de goutte d'eau, au cadre orné de S imbriqués, en relief, est rattaché par le moyen d'une bélière traversée par une tige en fer à un élément de charnière. Un fil en alliage cuivreux traverse la partie supérieure du cadre et semble avoir servi d'ardillon.

L'objet $\mathbf{n}^{\circ} \mathbf{3}$ (fig. 261) peut-il avoir eu une fonction de suspension? Il est constitué d'une plaquette $(\mathrm{e}=0,19 \mathrm{~cm})$ à rivet intégré poursuivie par une languette recourbée et cassée dont l'extrémité était peut-être traversée par ce rivet. Cette configuration se retrouve parfois sur des appliques de petite taille.

Un possible poids circulaire $(13,05 \mathrm{~g})$ en matériau blanc (fig. 261, $\mathbf{n}^{\circ} \mathbf{4}$ ) possède en son centre un trou dans lequel a pu s'insérer une tige de métal.

Deux douilles cylindriques fermées à une extrémité ont été découvertes, l'une à l'Alcazar (remblai, fin XIII'début $X V^{\mathrm{e}} \mathrm{s}$.), l'autre aux Pistoles (fig. 261, n⿳5 5). Ce dernier objet est décoré d'incisions obliques à la base. Son emploi en tant que boîte, peut-être pour des épingles, est envisageable.

L'objet $\mathbf{n}^{\circ} \mathbf{6}$ (fig. 261) pourrait correspondre à une bague, mais certains points rendent cette interprétation peu probable: l'ouverture du «jonc» tout d'abord, dont les extrémités sont arrondies, la conformation du « chaton» qui ne connait aucun équivalent, et enfin la présence d'une forte masse de fer (non représentée) sur ce chaton.

Les $\mathrm{n}^{\circ} \mathbf{7}$ et $\mathbf{8}$ de la fig. $\mathbf{2 6 1}$ sont fabriqués à partir d'une tôle emboutie découpée en languettes, et le $\mathbf{n}^{\circ} \mathbf{9}$ est réalisé à partir d'une tôle circulaire enroulée sur sa largeur, et traversée par un fil servant de bélière. Quelques tôles isolées sont traversées par une ou plusieurs perforations. Elles sont alignées trois par trois pour l'une d'elles (fig. 261, $\mathbf{n}^{\circ} 10$ ). Un décor se retrouve également sur d'autres objets comme celui de lignes estampées pour la tôle $\mathbf{n}^{\circ} \mathbf{1 1}$ en alliage d'argent (fig. 261), de deux lignes incisées au centre et de dents de loup en bordure pour le $\mathbf{n}^{\circ} \mathbf{1 2}$, sous la forme de croix ajourées pour la pièce $\mathbf{n}^{\circ} \mathbf{1 3}$, de lignes rayonnantes gravées sur une tôle circulaire traversée par le reste d'un rivet en fer (fig. 261, $\mathbf{n}^{\circ} \mathbf{1 4}$ ). Le $\mathbf{n}^{\circ} 15$ est une tôle circulaire conique perforée en son centre et entièrement remplie de brasure au revers.

Dans le reste du mobilier figure des tôles qui ont fonctionné avec une charnière obtenue par enroulement de languettes (fig. 261, $\mathbf{n}^{\circ} \mathbf{1 6}$ et 17), une tôle au profil proche d'une clochette (fig. 262, $\mathbf{n}^{\circ} \mathbf{1}$ ), une tige de section aplatie recourbée (fig. 262, $\mathbf{n}^{\circ} \mathbf{2}$ ), une autre perforée à chaque extrémité (fig. 262, $\mathbf{n}^{\circ} \mathbf{3}$ ) et une dizaine de fragments de fils. Retrouvés dans des contextes du bas Moyen Âge, modernes ou contemporains, ils sont de différents diamètres. La plupart sont globalement rectilignes (fig. 262, $\mathbf{n}^{\circ} \mathbf{6}$ ), mais quelques-uns présentent parfois un ou plusieurs enroulements (fig. 262, $\mathbf{n}^{\circ}$ 7). Un spécimen aux extrémités entrelacées forme un anneau en son centre (fig. 262, $\mathbf{n}^{\circ}$ 8). Tous ces éléments pourraient aussi bien n'être que des déchets (résidus ou ratés) résultant du travail du métal à moins qu'ils ne soient d'un usage plus spécifique, difficile à établir: attache, suspension d'éléments?

D'autres sont obtenus par assemblage de tôles en alliage cuivreux (fig. 262, $\mathbf{n}^{\circ}$ 4) auxquels peut être ajoutée une tige en fer prise dans une masse de brasure (fig. 262, $\mathrm{n}^{\circ} \mathbf{5}$ ). L'exemplaire $\mathrm{n}^{\circ} \mathbf{1 0}$ de la fig. 262, obtenu par fonte, conserve des traces de dorure sur toutes les faces. Un autre est constitué d'une tige bombée à l'avers s'élargissant et s'aplatissant aux extrémités (fig. 262, $\mathbf{n}^{\circ} 11$ ). Terminons avec deux fragments de tige à œillet (fig. 262, ${ }^{\circ} 9$ ) dont l'un retenant une tige en fer (fig. 262, $\mathrm{n}^{\circ} \mathbf{1 3}$ ), une tôle quadrangulaire avec un rivet intégré (fig. 262, $\mathbf{n}^{\circ} 14$; e = 0,22 cm), une tôle courbe assez épaisse (fig. 262, $\mathbf{n}^{\circ} \mathbf{1 5}$ ), et deux objets issus de fonte (fig. $262, n^{\circ} 12$ et 16).

\section{Conclusion (O. Thuaudet, avec la coll. de M.-A. Chazottes)}

Les fouilles marseillaises, malgré l'ampleur des surfaces traitées et les profondeurs atteintes, livrent un répertoire d'objets non céramique assez pauvre et qui, en comparaison avec d'autres sites régionaux, n'est pas représentatif des objets en usage aux périodes médiévales et modernes. Il est donc difficile de proposer une vision d'ensemble de la culture matérielle à Marseille pour la période étudiée.

Concernant le mobilier métallique, l'analyse des objets en fer, ignorés en raison de leur dégradation et de l'absence de budget pour réaliser des radiographies ou des nettoyages en laboratoire, aurait sans conteste, enrichi le catalogue des formes et, par ce fait, des usages qui leur sont affectés. Les opérations conduites sur le site castral de Fos-sur-Mer (Bouches-du-Rhône) ${ }^{54}$ et de Rougiers (Var) ${ }^{55}$, sur des étendues plus restreintes, ont livré un mobilier, fer non compris, plus riche et plus diversifié. Il en est de même à Avignon pour les fouilles

\section{Données inédites.}

55 Des recherches ayant pour objectif d'actualiser les données concernant les accessoires du costume de ce site à la lumière des connaissances actuelles sont en cours d'achèvement. Il est important de noter que le nombre de ces objets est bien plus important que ce que laisse paraître la version publiée en 1980 de la thèse de G. Démians d'Archimbaud. 
des jardins du Petit Palais ${ }^{56}$, de l'Impasse de l'Oratoire ${ }^{57}$ ou de la Rue de la Banasterie ${ }^{58}$ mais elles ont porté sur des époques où la présence papale enrichissait considérablement la ville. À l'inverse, les opérations aixoises sont relativement indigentes pour la période médiévale, parfois à cause des remaniements modernes, souvent du fait de leur emprise en dehors du périmètre de la cité médiévale. À Marseille, les remontées salines du terrain ont pu désagréger certains objets en métal, mais l'étude a montré que les objets cuivreux, qui constituent la majeure partie du corpus, ont relativement peu souffert de l'oxydation au contraire de ceux en fer. La nature des sites fouillés est-elle en cause ? Retrouve-t-on plus de mobilier dans les inhumations que dans l'habitat? Il n'y a pas lieu de le croire, les publications et les sites provençaux en cours d'étude ne révèlent rien à ce sujet si ce n'est que les contextes funéraires fournissent un mobilier plutôt récurrent et essentiellement en rapport avec le costume. La récupération des métaux peut-elle entrer en ligne de compte? Le bon sens le voudrait mais les arguments manquent du fait de l'absence de preuve archéologique et du peu de données que fournissent les archives. L'absence de mobilier cuivreux ne sous-entend pas pour autant qu'il ait été recyclé. Des facteurs sociaux et économiques voire culturels peuvent selon le contexte géographique et chronologique entrer en ligne de compte pour expliquer la moindre utilisation d'objets manufacturés en métal. Une dizaine a été retrouvée dans des sols et ce, presque exclusivement, sur le site de l'Alcazar. Doit-on envisager que les occupants successifs d'un lieu accordaient une importance particulière à son entretien ? Cette hypothèse est d'autant plus plausible qu'aucun dépotoir médiéval ou moderne de grande importance n'a été mis au jour. La population a pu déposer, effectivement, la majorité de ses ordures dans des espaces délimités, prévus ou non à cet effet par les édiles communales, et ces lieux n'ont pas, actuellement, été atteints par les fouilles. Il n'est donc pas étonnant de constater une prédominance de remblais et comblements de toute sorte dans les contextes du corpus. Ces apports de terres ont pu mêler intimement leurs propres déchets avec ceux présents lors de leur épandage. En outre, les remaniements modernes ont en de nombreux endroits achevé de mélanger le mobilier. Ainsi qu'il peut être constaté à travers les datations

56 Fouille d'un dépotoir et de quelques maisons médiévales. En cours d'étude (responsable d'opération : J. Thiriot, LA3M, UMR 7298, CNRS).

57 Habitats médiévaux (responsable d'opération: R. Boiron et Fr. Paone, INRAP).

58 Habitats médiévaux (responsable d'opération : D. Carru, Service départemental archéologique du Vaucluse). typo-chronologiques fournies dans cette étude, les objets médiévaux ne sont, que pour moitié, retrouvés dans une strate correspondant avec cette datation et qui n'est pas nécessairement le contexte primaire de dépôt. Les unités stratigraphiques ayant livré le plus grand nombre de ce mobilier se révèlent être des remblais ou comblements de caniveau ou de fosses de la toute fin de l'Époque moderne ou contemporaine. Une exception existe sur le site de la place Villeneuve-Bargemon où le comblement des $\mathrm{XIV}^{\mathrm{e}}-\mathrm{XV}^{\mathrm{e}} \mathrm{s}$. d'un puits propose un bel éventail d'objets abandonnés ou perdus, aussi bien en céramique qu'en métal et en os : deux anneaux circulaires (fig. 237, $\mathbf{n}^{\circ}$ 9), deux boucles (fig. $\mathbf{2 3 8}, \mathbf{n}^{\circ} \mathbf{8}$ et fig. 239, $\mathbf{n}^{\circ} \mathbf{4}$ ), deux bagues (fig. 245, $\mathbf{n}^{\circ} \mathbf{2 7}$ et $\mathbf{2 8}$ ), une applique (fig. 257, $\mathbf{n}^{\circ} \mathbf{6}$ ), une ampoule de pèlerinage (fig. $\mathbf{2 4 7}, \mathbf{n}^{\circ} 10$ ), un dé à coudre (fig. 250, $\mathbf{n}^{\circ} \mathbf{8}$ ), un sceau (fig. $253, \mathbf{n}^{\circ} 8$ ), une cuillère (fig. $251, \mathbf{n}^{\circ} \mathbf{6}$ ), un pion de jeu (fig. 256, $\mathbf{n}^{\circ} \mathbf{3}$ ), six clous décoratifs (fig. $\mathbf{2 5 8}, \mathbf{n}^{\circ} \mathbf{5}$ ), un fil en alliage cuivreux, un possible manche de couteau (fig. $253, \mathbf{n}^{\circ} \mathbf{9}$ ) et vingt-neuf dés à jouer en os (fig. 256, $\left.\mathbf{n}^{\circ} \mathbf{2}-10\right)$. Malgré cela, l'interprétation d'ensembles mobiliers est très limitée par la distribution des objets au sein de contextes très variés, souvent en dépôt secondaire, sur un intervalle chronologique large.

Le corpus est néanmoins d'un intérêt certain du point de vue chrono-typologique et des techniques de fabrication. L'étude d'un objet ne peut se restreindre à une analyse morphologique, elle doit autant que possible s'attarder et réfléchir sur l'aspect technique - et anatomique pour les objets en matière dure d'origine animale - de sa confection, isoler les points saillants qui font la spécificité de certaines opérations. Par exemple, une large bibliographie illustre des processus comme la fonte et les différentes manières de la réaliser mais il n'en demeure pas moins nécessaire de signaler qu'un objet est le résultat d'un moulage quand bien même cela peut paraître évident. L'expérience montre qu'il existe des cas peu ordinaires. Le questionnement crée la réflexion et de simples constatations permettent, audelà d'une simple description morphologique, de faire ressortir les caractéristiques de chaînes opératoires. La présente recherche s'est donc essayée à l'observation technique et à son interprétation ; les propositions en résultant doivent être complétées, corroborées ou infirmées par d'autres études. Il apparaît que des processus différents peuvent présider à la confection d'un même objet. Par exemple, la mise en forme des dés à coudre évolue au cours du temps. Ils sont fabriqués tout d'abord par fonte ou martelage d'une tôle sur une forme. L'examen d'objets provençaux montre que la déformation plastique inhérente à l'emploi du marteau disparaît dans la première moitié du XVIII ${ }^{\mathrm{e}} \mathrm{s}$. et est remplacée par celle résultant d'un emboutissage mécanique. Si l'auteur 
de l'étude ne mentionne pas le procédé employé pour la mise en œuvre d'un dé à coudre, il n'apparaît pas évident de le caractériser à partir d'un dessin et, dans la mesure où il est possible de raisonner jusqu'à un certain degré sur l'épaisseur des tôles, le raisonnement est rendu encore plus ardu par l'absence de prise de dimensions ou leur manque de précision.

L'avancement des recherches concernant la typologie du mobilier non céramique et son évolution morphologique au cours du temps, notamment pour celui en métal, conduit peu à peu à mieux caractériser la culture matérielle de la seconde partie du Moyen Âge et de l'Époque moderne. Des évolutions majeures se révèlent progressivement, notamment dans le costume, et elles sont de mieux en mieux sériées chronologiquement. Le corpus marseillais en illustre certaines. Les fouilles de Marseille n'ont livré qu'une pièce pour les $\mathrm{IX}^{\mathrm{e}}-\mathrm{XI}^{\mathrm{e}} \mathrm{s}$., en grande partie à cause du peu de contextes datés de cette période. Toutefois, la bibliographie de référence ne fournit elle-même que de rares exemples. Il semble par conséquent difficile d'objecter que cela résulte d'un déficit de fouilles : la parution entre autres des études sur le Castrum d'Andone (Bourgeois dir. 2009), le château de Blois (Aubourg, Josset 2003), plus anciennement de Charavines (Colardelle, Verdel 1980), les travaux du LA3M sur le sud-est de la France (notamment ceux de Daniel Mouton: Mouton 2003) sont particulièrement significatifs. Le XII ${ }^{e}$ s. se caractérise par une proportion un peu plus importante d'objets en alliage cuivreux, cependant il faut attendre le milieu du XIII's. pour assister à une augmentation massive dans l'emploi de ce matériau, et ce jusqu' au $\mathrm{XIV}^{\mathrm{e}} \mathrm{s}$. Les contextes marseillais l'illustrent, bien que leur datation ne soit pas toujours très précise. A peine $2,5 \%$ du mobilier métallique est issu de niveaux du XII ${ }^{\mathrm{e}}$ s., contre $16 \%$ pour le $\mathrm{XIII}^{\mathrm{e}} \mathrm{s}$. Il faut toutefois tempérer ce chiffre, la nature des couches entrant en jeu. Les contextes funéraires redeviennent en effet à partir du XIII ${ }^{\mathrm{e}} \mathrm{s}$. une source de mobilier. La faible proportion d'unités stratigraphiques de ce type pour les $\mathrm{XIV}^{\mathrm{e}}, \mathrm{XV}^{\mathrm{e}}$ et $\mathrm{XVI}^{\mathrm{e}}$ s. explique ainsi la baisse du ratio à $7-8 \%$. Il est de $59 \%$ pour la période $\mathrm{XVII}^{\mathrm{e}}-\mathrm{XIX}^{\mathrm{e}}$ s., à cause des fouilles réalisées à la cathédrale de la VieilleMajor et à l'abbaye Saint-Victor. Cependant, du fait des remaniements modernes, une partie du matériel est de datation plus ancienne.

Les accessoires du costume sont révélateurs des aspects sociaux et économiques d'une période, ce qui se traduit par des modes et des ports différents selon les catégories sociales, la richesse, le sexe, la fonction, l'aspect que l'on veut se donner ou celui qui est imposé. La collection marseillaise propose une vision fragmentaire de cette réalité caractérisée par une extraordinaire diversité des formes et des ornementations, dont les spécificités sont communes à une grande partie de l'Europe de l'ouest et se diffusent au-delà. D'importantes capacités de production ${ }^{59}$, des courants commerciaux intenses ont engendré une « internationalisation » du costume en favorisant les échanges intellectuels et de biens, agissant ainsi sur la manière de soigner son apparence. Des objets marseillais trouvent donc leur semblable en des points fort éloignés. La trajectoire suivie par les accessoires du costume est identique à celle de l'ensemble du mobilier cuivreux dont il constitue une part conséquente. Son développement est donc intimement lié à celui de ce matériau, mais bien entendu aussi à l'évolution de la mode. Le milieu du XIII ${ }^{\mathrm{e}} \mathrm{s}$. marque véritablement le début de cet espace européen dont les prémices se perçoivent antérieurement. La collection marseillaise est, pour la fin de l'époque Moderne et le début de l'Époque contemporaine, assez riche en boutons, perles, boucles et petits objets religieux. Les caveaux de la VieilleMajor utilisés lors des trois premiers quarts du XVIII ${ }^{\mathrm{e}}$ s., le comblement d'une fosse du milieu XVIII ${ }^{\mathrm{e}}$-milieu $\mathrm{XIX}^{\mathrm{e}} \mathrm{s}$. du site du Tunnel de la Major, et les remblais de l'abbaye Saint-Victor ont fourni la plus grande part de ces objets. Une augmentation de la proportion des accessoires du costume en contexte funéraire se perçoit très distinctement dès le début de la période moderne dans la documentation archéologique. Il faut sans doute y voir l'émergence de nouveaux gestes mais également d'autres évolutions comme celle du costume avec notamment un emploi de plus en plus fréquent du bouton. Une manifestation plus importante du sentiment religieux est attestée, conséquence probable, tout au moins au début, des guerres de Religion et des réformes qu'elles provoquent. Durant la période $\mathrm{XVI}^{\mathrm{e}}-\mathrm{XVII}{ }^{\mathrm{e}} \mathrm{s}$., la morphologie, l'ornementation et parfois la fonction de la quasi-totalité des accessoires du costume se modifient à des moments et à des degrés divers. La fin de l'Époque moderne et le début de l'Époque contemporaine se distinguent par une amplification et une diversification du mobilier, non plus seulement à l'échelle continentale mais aussi à l'échelle internationale. En France, le commerce de la mercerie parisienne commence peu à peu à créer la mode et conduit progressivement à une disparition des costumes régionaux, laquelle est actuellement imperceptible archéologiquement.

Le travail des matières premières est faiblement illustré par le corpus : des thies de fuseau, des dés à

59 N. Thomas propose une reconstitution du procédé de fabrication d'appliques métalliques qui le conduit à évaluer la production mensuelle de quatre ouvriers à plus de 10000 exemplaires par mois (2009, p. 757). Plusieurs dizaines de milliers d'épingles à tête enroulée peuvent être confectionnées quotidiennement au XVIII $\mathrm{e}$ s. par un seul atelier d'après les auteurs de l'article «Art de l'épinglier » de la Description des Arts et métiers. 
coudre, des hameçons, un poinçon, des déchets de travail en matière dure d'origine animale. Aucun élément ne permet de juger de la nature et de l'ampleur exacte de ces activités : artisanat ou travaux domestiques ? Il est quelque peu surprenant de noter qu' aucun ensemble de déchets de travail des alliages cuivreux n'a pu être clairement identifié.

Le mobilier métallique, marqué par une grande polyvalence d'usage, doit être considéré de plus en plus comme un élément aidant à la datation et les imprécisions rencontrées sont amenées à diminuer avec les études futures. Il en est de même pour les objets en matière dure d'origine animale. L'analyse morphologique et technique, l'élaboration de typo-chronologies, les analyses de composition et la métallographie - ou les études anatomiques -, l'étude de l'iconographie, des actes notariés, des règlements communaux et ordonnances royales, de la littérature s'imposent comme une énumération non exhaustive des multiples axes de recherche possibles pour extraire le maximum d'informations sur le mobilier et son contexte d'utilisation. La présente contribution ne se prête pas à ce genre de recherche, à cause de la diversité des objets, au contraire d'une étude typologique sur un domaine particulier. Une connaissance plus pointue du mobilier manufacturé non céramique s'avère par conséquent indispensable et seules la multiplication et l'interconnexion des études permettront d'y parvenir. 



\section{Conclusion générale}

\section{L'exception marseillaise : absences surprenantes et luxe étonnant}

\section{(Véronique Abel, Florence Parent)}

$\mathrm{P}$ our appréhender, ou plus exactement essayer d'appréhender, la vie quotidienne aux époques médiévales et modernes, les chercheurs actuels disposent de plusieurs sources: littérature d'époque, documentation juridique (actes notariés et comptables notamment), iconographie et archéologie. Toutes sont complémentaires, toutes ont leurs limites; mais, de toutes, l'archéologie est sans doute la moins artificielle car, pour reprendre les termes de la chercheuse Irène Fabry, elle est «fondée sur des éléments très concrets, indices de vie et d'organisation des sociétés passées, [elle] est [donc] la discipline la plus immédiatement tournée vers l'étude de la vie quotidienne et de ses activités » (Fabry 2008, p. 7).

Vaisselles en céramique ou en verre, monnaies, articles en métal ou en os, autant d'objets retrouvés en fouille et ayant accompagné les Marseillais dans leur quotidien de jadis. Quand nous les retrouvons, ils ont perdu leur utilité : égarés, mis au rebut ou abandonnés pour des raisons qui nous échappent. Dans de rares cas, ils accompagnent les défunts dans leur dernière demeure. Les découvertes d'un chantier nous permettent donc d'approcher une réalité disparue, mais cette réalité sera toujours altérée, tronquée. Il est en effet extrêmement rare de retrouver les ustensiles à l'endroit même où ils ont servi. Il est nécessaire, quelle que soit la catégorie d'objets considérée, de pouvoir étudier de grandes séries pour pouvoir aller au-delà du particulier et en dégager les « grandes tendances».

\section{Les objets à travers les siècles : bilan par catégories}

À l'exception des récipients en terre cuite, tous les ustensiles peuvent être recyclés une fois perdue leur utilité. Ils sont donc rarement mis tout simplement au rebut. Les objets en matériaux périssables tels l'osier ou le bois peuvent attiser le feu dans l'âtre, ou parfois se décomposer tranquillement pour amender le sol. Ceux en verre ou en métal (y compris les monnaies) sont refondus pour en réaliser des nouveaux comme neufs. En témoigne la réglementation municipale obligeant de revendre le verre cassé à la ville ou au four de verrier (cf. supra $2^{\mathrm{e}}$ partie, ch. $1, \S 1.1$.). Dans certains cas, les articles en os, en corail ou autres matériaux d'origine animale, les gemmes aussi, se retaillent pour être remis au goût du jour. Autant d'objets que nous ne retrouvons donc pas en fouille.

\subsection{La vaisselle en céramique}

Tout au long de ces périodes, il n'est question que de céramiques en contexte de consommation, renseignant sur les approvisionnements d'une ville portuaire et sur les usages quotidiens de ceux qui y vivaient. Les indices de production ne sont que de rarissimes exceptions. La terre cuite permet cependant d'étudier les matériaux et leur mise en œuvre, compensant tant bien que mal le manque d'accès aux vestiges d'ateliers. Ainsi un objet céramique porte témoignage de sa naissance, de ses origines géographiques et des techniques employées, des courants commerciaux qui l'ont amené jusqu'à Marseille, et de ses utilisateurs qui s'en sont servis puis débarrassés.

Notre vision du premier Moyen Âge dans la cité phocéenne reste encore confuse. Pour connaître la culture matérielle des Marseillais à cette époque, nous ne disposons pas d'autre objet que la céramique. Les données, fournies par un unique chantier (celui de l'Esplanade de la Major), sont très récentes et extrêmement restreintes. Nous avons cependant la chance que ce chantier ait livré une stratigraphie très claire assortie de céramiques quasi complètes qu'on est tenté de situer dans le courant du VIII ${ }^{\mathrm{e}} \mathrm{s}$. Mais seules sont identifiées pour l'instant quelques produits «locaux-régionaux » en pâte grise. Par ailleurs, ils ont été découverts dans la destruction de la résidence épiscopale de la ville et ne peuvent à eux seuls refléter les habitudes de vie de la population marseillaise. Reste à savoir dans quelles mesures ces vases rendent compte du statut social de leurs propriétaires.

Les $\mathrm{X}^{\mathrm{e}}$ et $\mathrm{XI}^{\mathrm{e}}$ s. commencent à être mieux perçus même si le mobilier archéologique, exclusivement céramique, 
reste parcimonieux. Pour nos yeux contemporains, se dégage de cette période une certaine "monotonie», aussi bien dans les techniques que dans le répertoire des produits locaux et/ou régionaux, où seul semble compter le rôle fonctionnel de ces objets éminemment utilitaires : exclusivement des pots, tous munis d'un fond lenticulaire, adoptant toujours des tonalités grises à brunes et jamais de décor. Les importations sont infimes et se comptent sur les doigts d'une main. Comme ailleurs en Provence, elles font plutôt figures de curiosités que de témoignages d'échanges commerciaux : présent d'un bateau déchargeant sa cargaison au port, échange contre service rendu, souvenir ?...

En 1995, les découvertes sous la place VilleneuveBargemon ont grandement contribué à la connaissance de la vaisselle en usage à Marseille au XII ${ }^{\mathrm{e}}$ s., que plusieurs fouilles limitrophes sont venues renforcer depuis. Aucun quartier marseillais n'a, pour l'instant, offert une documentation céramique aussi abondante pour cette période mais tous confirment, à leur mesure, les données recueillies. Les vernis semblent toujours inconnus des potiers provençaux et le gris reste la couleur dominante des vases dont les formes varient assez peu. Les pots et nouvellement les pégaus (de taille plus réduite que les pots et dotés d'une anse) sont prépondérants ; c'est le cas dans toute la Provence à la même période. Dans le quartier de la rive nord du Port, des formes inédites apparaissent, inconnues dans le reste de la ville et, à une échelle plus large, en Provence. Ces quelques tasses (ou chopes), jattes et probables pichets pourraient être l'expression de nouveaux usages culinaires, ou seraient plutôt en liaison avec une ou des activités spécifiques (mais non déterminées) se déroulant ici, à l'image des fragments de godets qui sont les rares vestiges suggérant la présence d'une noria. Les décors sont encore extrêmement rares et rudimentaires (bâtonnets à la molette, ondes incisées), l'aspect fonctionnel prévaut toujours sur l'esthétique, contrastant en cela avec les produits importés de plus en plus présents, en provenance du monde islamique pour la majorité (Maghreb, Sicile, al Andaluz...) ou du monde byzantin pour un plus faible nombre (Grèce et Mer Égée). Ces importations offrent des couleurs et une diversité de formes inconnues des poteries provençales. La plupart est également vernissée, voire émaillée. Sur bon nombre de critères, les apports étrangers complètent et compensent le panel restreint des produits régionaux. Leur introduction dans les foyers marseillais est nettement plus sensible qu'aux siècles précédents : d'une poignée auparavant, ils passent autour des 10 à $20 \%$ suivant les sites dans les niveaux du XII $\mathrm{s}$. La plupart allie le fonctionnel à l'esthétique, les qualités culinaires à celles du service de table : avec elles, le récipient devient à la fois utile et agréable. Leurs formes plus variées accompagnent ou insufflent vraisemblablement de nouvelles pratiques alimentaires, culinaires, domestiques...

Cette évolution, amorcée dans le courant du XII ${ }^{\mathrm{e}}$ s., s'ancre et s'amplifie dans les siècles suivants. Dès la fin du siècle, apparaissent les premières marmites régionales qui supplanteront peu à peu les pots à cuire. Les accompagnent rapidement, jattes, bassins, plats, coupes, pichets et cruches : ustensiles autrefois importés que les potiers commencent à fabriquer dès le début du XIII ${ }^{\mathrm{e}} \mathrm{s}$. À Marseille, ainsi que dans l'ouest varois et dans la basse vallée du Rhône. Au même moment et aux mêmes endroits, l'emploi de la cuisson/post-cuisson oxydante se répand, comme celui de la glaçure et de l'émail. Cependant quelques produits à pâte nue continuent à être fabriqués et employés pour certains usages domestiques ou artisanaux. Les rares fouilles d'officines locales ou régionales montrent la diversité de produits et de techniques utilisées au sein de mêmes ateliers (Sainte-Barbe à Marseille).

Les officines locales et régionales semblent maintenant suffisamment achalandées en ustensiles culinaires et utilitaires pour satisfaire la communauté marseillaise, qui en importent très peu passées les premières décennies du XIII ${ }^{\mathrm{e}} \mathrm{s}$. : tout au plus quelques bassins (encore sont-ils colorés) et peut-être quelques plats de cuisson. En revanche, Marseille continue volontiers d'accueillir du reste du bassin méditerranéen de la vaisselle décorée, qu'elle soit émaillée à décor polychrome, engobée à décor incisé, glaçurée à décor estampé... Ses sources d'approvisionnement se rapprochent cependant au fil du XIII ${ }^{\mathrm{e}} \mathrm{s}$. : les rapports avec le Maghreb et la Mer Égée s'amenuisent doucement, tandis que les produits italiens et espagnols s'imposent peu à peu jusqu'à constituer au $\mathrm{XIV}^{\mathrm{e}} \mathrm{s}$. l'essentiel des apports extérieurs. Au moins jusqu'au milieu du XIII ${ }^{\mathrm{e}}$ s., Marseille est plus «perméable » que l'intérieur de la Provence aux importations de céramiques : c'est un grand port, le négoce y est important. À partir de la fin du XIII ${ }^{\mathrm{e}} \mathrm{s}$. et durant tout le $\mathrm{XIV}^{\mathrm{e}}$, les trois sources d'approvisionnement quasi exclusives de la ville sont la basse vallée du Rhône - principalement des ustensiles utilitaires et quelques faïences -, l'Espagne - régions de Valence et de Catalogne - et l'Italie, plus exactement la Toscane. La répartition des apports est alors semblable à celle du reste de la Provence. Toutefois, à Marseille, apparaissent encore ça et là quelques articles plus lointains et plus exotiques.

Le $\mathrm{XV}^{\mathrm{e}} \mathrm{s}$. marseillais se dérobe encore totalement à nos yeux. Pour le $\mathrm{XVI}^{\mathrm{e}}$ s., les données étaient et restent plutôt rares, bien que le mystérieux hiatus du $\mathrm{XV}^{\mathrm{e}} \mathrm{s}$. les mette en valeur. Récemment, un chantier a permis de préciser la chronologie en révélant des marqueurs 
qui faisaient largement défaut jusque-là. Les typologies restent cependant à construire presque entièrement. De même, le premier tiers du XVII ${ }^{\mathrm{e}} \mathrm{s}$. n'est pas formellement documenté dans notre corpus. Ce n'est qu'à l'apparition des productions de l'arrière-pays marseillais, peu avant le milieu du siècle, que la situation se clarifie vraiment et que se forment des séries, des cortèges et des typologies, sans doute sous les effets croisés d'un accroissement des équipements et des repères fiables que deviennent, à partir de là, les productions locales. Le XVIII ${ }^{\mathrm{e}} \mathrm{s}$. bénéficie des bases posées précédemment et de volumes importants. Depuis peu, l'extrême fin en est mieux cernée, permettant de voir comment les prémices d'industrialisation se remarquent dans la céramique.

Marseille se montre ainsi plus ouverte aux marchandises en provenance d'Italie et de Provence orientale, ceci sur toute la période Moderne. La céramique la révèle toutefois encore sensible aux apports espagnols $\mathrm{au} \mathrm{XVI}^{\mathrm{e}} \mathrm{s}$. Les produits septentrionaux ou orientaux sont anecdotiques sur toute la durée ; une exception cependant, celles des pipes. Alors que les pipes ottomanes et italiennes sont largement majoritaires dans le port de quarantaine de Pomègues, au large de Marseille, sur terre, dans la ville même, ce sont celles de Hollande que l'on retrouve de préférence.

Les vases d'usage quotidien à l'Époque moderne sont pour la plupart dans la lignée de ceux du bas Moyen Âge, tant dans les formes que dans les provenances. Archaïsme ou dynamisme? Le maintien, ou mieux encore le regain, de la technique de la post-cuisson réductrice pour des vases aux formes nouvelles (marmites sans col par exemple) jusqu'au milieu du XVII ${ }^{\mathrm{e}} \mathrm{s}$. à Marseille peut faire naître nombre d'hypothèses mais point de réponse convaincante (coût moindre, tentative d'imiter le métal, etc.).

Fréjus est, au XVI ${ }^{\mathrm{e}} \mathrm{s}$., l'un des rares centres provençaux de potiers produisant exclusivement de la vaisselle vernissée. Très proche d'aspect des productions ligures, ce centre adopte pourtant et produit en très grandes séries des écuelles dont la forme semble née telle que nous la connaissons dans les ateliers de faïence à Valence. Les spécialisations des ateliers régionaux de terres vernissées vont croissantes au fil de la période moderne. Les ateliers puisant dans des terres réfractaires se spécialisent dans les vases à cuire même si demeure une production de vaisselle à diffusion locale. La zone de l'Uzège, qui fournit par exemple Nîmes pour presque tous ses besoins en céramiques au début du XVI ${ }^{\mathrm{e}}$ s., n'écoule pas de volumes significatifs à Marseille. Les ateliers de Vallauris s'imposent comme fournisseurs des cuisines marseillaises à partir du milieu du XVII ${ }^{\mathrm{e}} \mathrm{s}$. Ils sont concurrencés brièvement vers la fin du XVII ${ }^{\mathrm{e}} \mathrm{s}$. par des jattes et marmites de Ligurie. Dans le courant du XVII s., l'exploitation des argiles non réfractaires s'intensifie. Le terroir et l'arrière-pays marseillais (vallée de l'Huveaune) deviennent les fournisseurs de vaisselle d'usage commun de la cité marseillaise et de la basse Provence, jusqu'à la fin de la période Moderne et au-delà (exportant même jusqu'en Amérique et dans les îles à partir du XVIII ${ }^{\mathrm{e}} \mathrm{s}$.).

La vaisselle de table de la période Moderne est caractérisée par quelques «formes » de terre vernissée assez semblables d'un bout à l'autre de la zone méditerranéenne de la France. L'écuelle en est l'une des pièces maîtresses. Son diamètre (autour de $13 \mathrm{~cm}$ ) et sa morphologie la rapprochent de nos bols contemporains ; elle est toutefois moins profonde, donc de capacité plus réduite, et pourvue presque systématiquement de deux oreilles. L'assiette est le second vase à usage individuel, son diamètre reste toujours inférieur à $21 \mathrm{~cm}$, la taille de notre actuelle assiette à dessert. Les gobelets en céramique semblent inexistants ; la tasse signant la consommation des produits exotiques (thé, café, chocolat) est rare en terre vernissée et ne se trouve guère qu'à Marseille, dans la seconde moitié du XVII ${ }^{\mathrm{e}} \mathrm{s}$. Les plats de service sont variés selon les centres producteurs, alors que leur taille est semblable, environ $24 \mathrm{~cm}$ de diamètre. C'est avec la faïence au XVIII' ${ }^{\mathrm{e}}$ s. que les échelles changent. L'assiette individuelle en faïence, véritable ancêtre des assiettes d'aujourd'hui, adopte le diamètre du plat collectif en terre vernissée. Les vases à liquides sont parfois très diversifiés mais toujours dominés par deux objets bien typés : le pichet à anse latérale unique et bec pincé, servant plutôt à verser les liquides, et la cruche à petit bec tubulaire et anse « de panier » supérieure, ayant favorisé le transport de ces mêmes liquides. Le pot de chambre se remarque en ville à partir du XVI ${ }^{\mathrm{e}} \mathrm{s}$., il est parmi les objets très répandus dès le milieu du XVII ${ }^{\mathrm{e}} \mathrm{s}$.

La mode des décors d'engobes atteint les ateliers dans le courant du XVII ${ }^{\mathrm{e}}$ s. et se voit interprétée de manière variable. Les décors les plus courants de la céramique utilisée à Carcassonne au XVII ${ }^{\mathrm{e}} \mathrm{s}$. sont des ondes peignées presque dissimulées sous l'engobe alors que dans les régions de Nîmes, de Marseille ou d'Avignon ce sont, pour une période comparable, des filets d'engobe contrastant qui sont appliqués. Dans l'arrièrepays marseillais leur succède une explosion de créativité atteignant les décors, qu'ils soient jaspés ou incisés et rehaussés de vert et de rouge, et les formes dont l'éventail s'élargit spectaculairement.

S'il n'y a bien sûr aucun effet de succession de la terre vernissée à la faïence, on constate cependant une sorte de transmission de relais de l'une à l'autre. L'apparition de la faïence régionale dans les niveaux archéologiques se fait à Marseille vers la fin du XVII ${ }^{\mathrm{e}}$ s., ne contredisant pas en cela les dates de naissance traditionnellement admises pour cette production particulière. C'est le moment où 
la créativité des potiers de l'arrière-pays marseillais est à son maximum. Celle-ci décline ensuite, alors que la faïence locale trouve sa place, discrète dans la céramique d'usage quotidien, mais refuge du décor qui est quant lui à peu près abandonné par les potiers. Le XVIII $s$. méridional voit plutôt des équilibres se rétablir entre les approvisionnements extérieurs et les productions locales, jusqu'à la fin du siècle où les ateliers de terre vernissée tentent de récupérer les techniques de production de la faïence avant d'amorcer leur inexorable déclin.

De la céramique utilisée au début du XVIII ${ }^{\mathrm{e}} \mathrm{s}$. découverte par l'archéologie marseillaise, ne subsiste guère qu'un quotidien fait de poteries vernissées locales arrivant de la proche vallée de l'Huveaune, de vases à cuire de Provence orientale sans doute déchargées sur les quais par caboteurs ou de plus imposants navires, et de quelques faïences colorées d'origine à peine plus lointaine auxquelles se mêlent des assiettes plus communes.

Privée de la dimension visuelle si importante en archéologie et contrainte à un changement d'échelle important, cette analyse n'est pas sans enseignement: l'équipement domestique apparaît alors semblable à celui du $\mathrm{XIV}^{\mathrm{e}} \mathrm{s}$. Pendant quatre cents ans, les proportions entre les catégories de céramiques oscillent et nous passionnent. Des provenances apparaissent, s'installent, disparaissent, sans changement radical.

En constante, les approvisionnements de la cité sont issus de l'arrière-pays et des côtes proches pour un usage quotidien, et plus lointain mais de la Méditerranée européenne pour se démarquer de celui-ci. Les ustensiles de base varient dans leur apparence, mais assez peu sur l'essentiel. La marmite, l'écuelle ou l'assiette ont une sorte de statut universel, de même que le pichet à anse latérale pour verser les liquides et la cruche à petit bec tubulaire et anse « de panier ». Les techniques sont fermement établies : le potier tourne des vases, qu'il enduit de vernis se vitrifiant dans son four en même temps que l'argile se fige, pour les rendre imperméables et support ou protection d'un décor.

À la fin du XVIII ${ }^{\mathrm{e}}$ s., cette scène de genre appartient au passé. Entre-temps, les faïenciers régionaux ont assimilé la révolution technologique du façonnage mécanisé. Quant aux poteries vernissées, elles ne sortiront plus du rudimentaire et de l'utilitaire, mis à part quelques ateliers qui se saisissent des techniques de pointe de la faïence en cultivant leur identité et leur différence par des vernis transparents. Peu résisteront à la porcelaine, dont une branche devient commune par l'industrialisation, et à la «faïence fine» qui acquiert au $\mathrm{XIX}^{\mathrm{e}} \mathrm{s}$. un statut de vaisselle de luxe pour les décors raffinés et les services aux pièces innombrables et de milieu de gamme par son aspect protéiforme.

\subsection{La vaisselle en verre}

De l'usage d'objets en verre dans la Marseille médiévale, nous n'avons quasiment pas de témoignages tangibles avant le XIII ${ }^{\mathrm{e}} \mathrm{s}$. L'essentiel date de la seconde moitié du XIII et du XIV ${ }^{\mathrm{e}} \mathrm{s}$. Les simples gobelets à boire (cylindriques ou tronconiques), accompagnés des flacons-guttrolfs à partir de la fin du XIII ${ }^{\mathrm{e}}$ s., font partie des ustensiles communément employés jusqu'à la fin du $\mathrm{XIV}^{\mathrm{e}} \mathrm{s}$.

Des gobelets à boire, ceux à décor de gouttes étirées (qui ont cours au XIII ${ }^{\mathrm{e}} \mathrm{s}$.), sont bien plus fréquents à Marseille que dans le reste du Midi méditerranéen. Bien que quelques fragments apparaissent dans des niveaux riches en céramiques du XII ${ }^{e}$ s., il ne semble pas, au vu des nombreuses trouvailles faites en France et surtout en Italie, que l'on puisse faire remonter cette production, commune à plusieurs pays, au-delà du $\mathrm{XIII}^{\mathrm{e}} \mathrm{s}$. En revanche, les flacons-guttrolfs sont certainement en usage dès la fin du XIII ${ }^{\mathrm{e}}$ s., conformément à ce qui est observé ailleurs. Les bouteilles soufflées dans un moule découvertes dans cinq secteurs de la ville confirment la popularité de ces contenants de divers gabarits, servant vraisemblablement à mesurer le vin. Comme pour la vaisselle en terre cuite, apparaissent ici et là des récipients en verre plus élégants comme les verres à tige ou quelques-uns décorés de manière plus singulière.

\subsection{Les monnaies}

Ici, les données n'ont été étudiées pour l'instant que sur deux sites : le quartier autour de la Cathédrale (Tunnel de la Major) et le faubourg de Morier (Alcazar). Les informations les plus nombreuses concernent les $\mathrm{XIII}^{\mathrm{e}}$ et $\mathrm{XIV}^{\mathrm{e}} \mathrm{s}$., ainsi que les $\mathrm{XVII}^{\mathrm{e}}$ et $\mathrm{XVIII}{ }^{\mathrm{e}} \mathrm{s}$. Ce sont alors presque exclusivement des monnaies divisionnaires en cuivre, sans grand pouvoir d'achat, qui sont égarées et nous parviennent. Toutes périodes confondues, seules trois monnaies contenant une proportion d'argent ont été retrouvées, datant de 1250, 1436-1442 et 1739. Soit qu'elles aient été l'objet d'une vigilance particulière liée à leur valeur, soit qu'elles aient peu circulé à Marseille.

De manière logique, les frappes locales et régionales sont les mieux représentées : tournois provençal, obole marseillaise, deniers dardennes. Une unique monnaie atteste des relations avec l'Italie, monnaie qui aurait été frappée à Gênes dans la première moitié du $\mathrm{XV}^{\mathrm{e}} \mathrm{s}$. : cette période est pourtant curieusement non représentée dans les fouilles marseillaises. Mais la période de frappe d'une monnaie n'a rien à voir avec la longévité de sa circulation, l'archéologie est là pour en attester. Et celle-là est en argent... 


\subsection{Les objets en métal, os, corne, ivoire...}

Dans ces catégories, le mobilier est moins abondant et moins varié à Marseille qu'alentours et seule la ville d'Aix présente une situation analogue. Il s'agit pour l'essentiel d'articles en alliage cuivreux (rappelons que les objets en fer n'ont pas été pris en compte dans cette étude), que suivent les objets en os ; très peu sont en nacre ou en verre (une dizaine d'objets de chaque), encore moins en corail, corozo, jais, buis, argent ou or. La plus grande partie provient de contextes d'inhumation et a donc été abandonnée, volontairement et avec soin, aux côtés des défunts. En plus de dévoiler les évolutions des rites funéraires, l'examen de ces sépultures révèle des modifications majeures dans les habitudes vestimentaires et leurs accessoires.

Dans ces circonstances bien particulières, les objets de la période médiévale ne sont que pour moitié retrouvés dans leur contexte d'origine : leur éparpillement au sein de contextes remaniés ou d'une chronologie large empêche quasiment toute vision synthétique. Les premiers siècles du Moyen Âge n'ont livré qu'une pièce (IX ${ }^{\mathrm{e}}-\mathrm{XI}^{\mathrm{e}} \mathrm{s}$.). Au XII ${ }^{\mathrm{e}}$ s., les objets en alliage cuivreux se font un peu plus nombreux. Il faut cependant attendre le milieu du XIII' s. pour que l'emploi de ce matériau s'intensifie, et ce jusqu' au XIV es. Ầ partir du XVII e s., la quantité de ces objets redevient significative.

À toutes les époques, les boucles sont les articles en métal les plus répandus. Au Moyen Âge, elles sont le moyen de fixation le plus courant et peuvent être complétées par d'autres accessoires, tels des appliques parfois en os ou des chaînettes. La proportion d'accessoires de costume augmente nettement dès le début de la période Moderne dans les contextes funéraires : apparaissent alors les boutons, accompagnés de perles, boucles et petits objets religieux qui deviennent très fréquents. Durant cette période, la morphologie, l'ornementation et parfois la fonction de la quasi-totalité des accessoires du costume se modifient à des moments et à des degrés divers. La fin de l'Époque moderne et le début de l'Époque contemporaine se distinguent par une amplification et une diversification du mobilier, non plus seulement à l'échelle nationale (le commerce de la mercerie parisienne commence peu à peu à créer la mode) mais aussi à l'échelle continentale et internationale. Le début de l'espace européen transparaît véritablement dans les habitudes vestimentaires dès le milieu du $\mathrm{XIII}^{\mathrm{e}} \mathrm{s}$. mais les prémices se perçoivent antérieurement.

Le travail des matières premières est faiblement illustré par le corpus : des thies de fuseau, des dés à coudre, des hameçons, un poinçon, des déchets de travail en matière dure animale. Aucun élément ne permet de juger de la nature et de l'ampleur exacte des activités artisanales ou domestiques, les deux étant souvent intimement liées.

\section{Les objets au jour le jour}

Un bilan par fonction permet d'analyser comment les objets renseignent le cadre de vie des Marseillais et leurs activités quotidiennes. De prime abord, un certain nombre de lacunes apparaissent au travers des collections médiévales et modernes amassées en fouilles dans les différents quartiers de la ville et étudiées ici. Certaines de ces carences soustraient tout un pan de vie des habitants : l'étude des ustensiles en alliage ferreux aurait probablement comblé nombre d'elles. D'autres, paradoxalement, sont très signifiantes : mises en perspective avec les données archéologiques et/ou d'autres sources, elles parviennent à révéler un certain mode de vie des habitants. Mais en aucun cas de pouvoir cerner tous les aspects de la vie quotidienne et de ses activités. D'ailleurs passer en revue toutes les fonctions des objets nécessiterait un volume entier. Sont donc présentés ici leurs principaux apports concernant le cadre de vie et les activités quotidiennes des Marseillais, sans prétendre aucunement à l'exhaustivité. L'iconographie choisie pour illustrer certains aspects de la vie quotidienne permet de mettre en relation l'objet et l'homme et de remettre au premier plan l'être humain qui n'est jamais présent qu'en filigrane au travers de l'archéologie.

Pour les périodes médiévales et modernes, les maisons et rues marseillaises sont, au mieux, préservées au niveau du rez-de chaussée. La plupart du temps, les creusements de caves modernes à l'intérieur des bâtisses ont fait disparaître les sols. Des aménagements modernes ne subsistent bien souvent que les éléments en soussol, c'est-à-dire les caves, si bien qu'il ne reste guère que les quelques menus objets énumérés au cours de cette ouvrage pour traduire le mode de vie des hommes et des femmes qui ont résidé et travaillé là. Mis bout à bout, ces menus objets finissent ou finiront toutefois par construire des séries.

Un bémol cependant, riche d'enseignement pourtant : les sols conservés, que ce soit ceux des rues, ceux des caves, ou les rares préservés en rez-de-chaussée des demeures, sont tous régulièrement balayés et entretenus, si bien qu'ils recèlent peu d'objets. Quelques fragments auront pourtant échappé à la vigilance du balayeur et nous sont parvenus. Cette situation dénote le soin apporté aux espaces de vie, qu'ils soient privés ou publics ${ }^{60}$. Qu'il en soit ainsi ou qu'ils aient été égarés,

60 Ces espaces sont-ils entretenus dans une perspective de confort ou de propreté ? La réponse dépasse le cadre de notre ouvrage. 
tous ces ustensiles se retrouvent à un autre endroit que celui même où ils ont pu servir - sans compter les remaniements des époques postérieures inhérents à toute ville en constante évolution.

De nombreuses études démontrent que, pendant la période médiévale, vie domestique et vie laborieuse sont intimement liées au sein de la maison. Certes, ces notions ont évolué peu à peu durant la période Moderne. Ce mélange des fonctions, leur interaction dans la vie quotidienne et dans les espaces de vie se transposent à une grande partie des objets.

\subsection{Se chauffer, s'éclairer, cuisiner, manger et boire}

Les ustensiles liés à la nourriture sont parmi les mieux représentés dans les fouilles marseillaises, comme souvent en archéologie : la vaisselle en terre est omniprésente à toutes les époques. Au fil des siècles, la distinction entre celle à usage culinaire et celle réservée au service est de plus en plus flagrante. Cette distinction s'accompagne inévitablement d'une plus grande diversité des formes, des contenances et des décors; c'est ce que nous avons notamment tenté de présenter dans la première partie de cet ouvrage. Sur la table, plats, coupes, écuelles, cruches et pichets en céramique côtoient gobelets et bouteilles en verre. Il n'existe pas de vase à boire en céramique à Marseille, au contraire d'autres villes comme Aix et Avignon. Il faut attendre la période Moderne pour que les assiettes en faïence fassent leur apparition sur les tables. Nous pouvons noter l'absence ou la quasi-absence dans les collections étudiées de certains accessoires comme les louches, les cuillères... Quatre cuillères en métal seulement sont dénombrées, dont une seule pour la fin du Moyen Âge. La plupart devait être en matériau putrescible (bois) ou en fer. De rares couteaux sont perceptibles au travers de leurs manches en os ou de leurs bouterolles en métal, jamais leur lame (sans doute en fer). Il faut également noter l'absence totale de découvertes de vaisselle en métal ou en bois, pour tous les sites et pour toutes les époques considérées dans ce volume, alors que ces éléments sont bien présents dans les inventaires notariés (Herbeth 1983) ${ }^{61}$.

Liés également à la préparation culinaire, les mortiers sont très présents dans les inventaires marseillais du Moyen Âge, qui en recensent dans une maison sur deux (Herbeth 1983, p. 90): de préférence en pierre, parfois en marbre ou en bois. Aucun élément de ce type

61 Des récipients en bois sont signalés enfouis au fond d'un puits de la récente fouille rue Trinquet : leur étude modifierait sans doute le propos. n'apparaît dans les fouilles archéologiques pour cette période. Ceux découverts pour l'Antiquité sont généralement en céramique. Ceux aperçus dans les remblais d'Époque moderne ou contemporaine sont en marbre ou en pierre, mais ne sont que rarement pris en compte dans les études sur le mobilier.

Où et comment se déroulent la cuisson des aliments ? Quelques foyers à même le sol ont pu être reconnus au rez-de-chaussée de certaines maisons médiévales. Leur fonction est sans doute multiple : cuisiner, chauffer, travailler, voire éclairer. Les cheminées sont extrêmement rares, la seule attestée date du $\mathrm{XIV}^{\mathrm{e}}$ s. et se trouve dans la maison canoniale (Bouiron et al. 2011, p. 150-151). Pour l'Époque moderne, aucune trace de cheminée ni de pièce vouée à la cuisine mais les sources écrites situent généralement la cuisine à l'étage ou en entresol (Bouiron et al. 2011, p. 154-162). Cela a pu également être le cas à l'époque médiévale ${ }^{62}$. Ainsi, si les pots à cuire et les marmites nous sont bien connus, leur mode d'utilisation est plus problématique. Ont-ils été posés à même les braises, sur un trépied en métal ou accrochés à une crémaillère ? C'est ce que suggèrent nombre d'illustrations, aussi bien médiévales que modernes (fig. 263). Les inventaires de notaire laissent supposer que, dès le $\mathrm{XIII}^{\mathrm{e}}$ s., le support privilégié des chaudrons et marmites est le trépied en fer (Herbeth 1983, p. 90).

Le foyer, quelles que soient les époques, est un élément crucial des habitations : non seulement il permet de cuisiner mais il sert également à réchauffer les locaux et leurs occupants (Alexandra-Bidon 2006). Les auteurs du précédent volume suggèrent l'emploi de braseros en appoint (Bouiron et al. 2011, p. 151). Nous n'avons pas trace de ces chauffages mobiles qui pouvaient être en métal. Mais des ustensiles spécifiques ne sont pas forcément requis pour cet usage et les pots en terre cuite peuvent aussi bien convenir, ils sont de toute façon destinés à être portatif et à supporter la forte température produite par les braises.

Les maisons marseillaises livrent peu d'éléments d'éclairage. L'utilisation des lampes à huile (toutes en céramique sauf une en verre) est attestée par quelques fragments au XII ${ }^{\mathrm{e}} \mathrm{s}$. et au début du siècle suivant, lampes que l'on remplissait probablement goutte à goutte à l'aide de petits flacons en verre, les flacons-guttrolfs. Ces lampes et leurs accessoires de remplissage disparaissent totalement par la suite. Cette situation va sans doute de pair avec l'emploi généralisé des chandelles en cire (fig. 264). Pourtant, chandeliers et bougeoirs sont rares : un seul exemplaire pour la fin du Moyen Âge

$62 \mathrm{Au}$ mieux, l'archéologie marseillaise arrive à percevoir le rez-de-chaussée des maisons ou des immeubles. Rien ne permet d'affirmer l'absence de cheminées dans les étages supérieurs. 

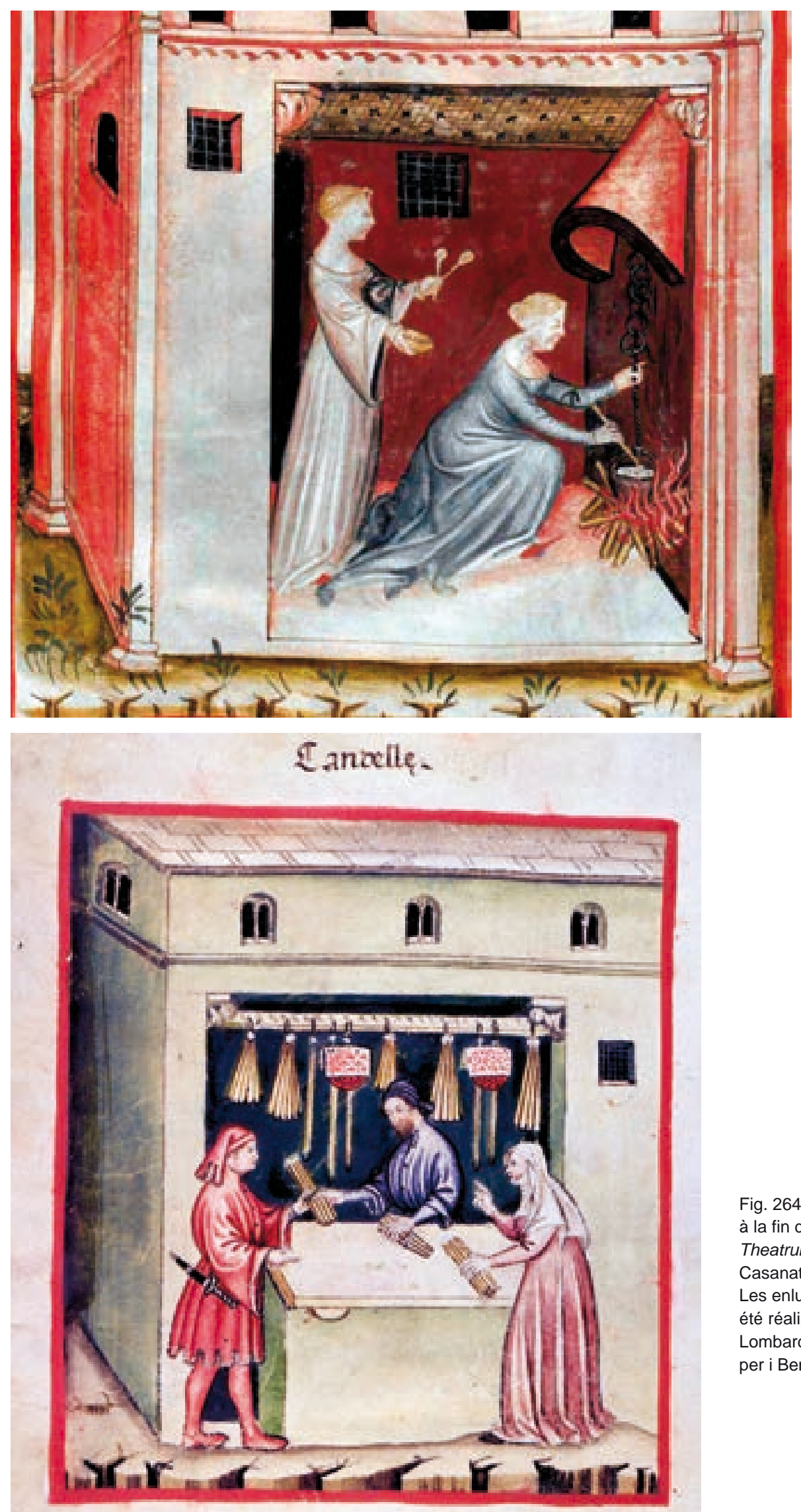

Fig. 263. Deux femmes s'affairant autour du foyer. Tandis que l'une mélange une préparation bouillante dans le chaudron suspendu à la crémaillère, la seconde lui tend deux cuillères et un bol en bois. Image extraite du Tacuinum sanitatis Codex Vindobonensis Series Nova 2644 fol. 90 , conservé à l'Österreichische Nationalbibliothek de Vienne (Autriche), DR. Le manuscrit proviendrait d'Italie du Nord et aurait été enluminé à la fin du XIV ${ }^{\mathrm{E}}$ ou au début du $X V^{\mathrm{e}} \mathrm{s}$.
Fig. 264. Un vendeur de chandelles représenté à la fin du XIV ${ }^{e}$ ou au début du XV $\mathrm{X}$ s. dans le Theatrum Sanitatis conservé à la Biblioteca Casanatense de Rome (Ms. 4182 fol. 186). Les enluminures du manuscrit auraient été réalisées par Giovannino De Grassi en Lombardie (Italie). "Su concessione del Ministero per i Beni e le Attività Culturali", DR. 
dans le bourg de Morier, quelques fragments de bougeoirs de la fin du XVII ${ }^{e}$ s. dans le dépotoir du Pharo, un unique dans le quartier du Port dans les dernières décennies du XVIII ${ }^{e} s$. Tous sont en céramique. S'il y en eut en métal, ils ont probablement disparu lors d'une refonte. La rareté des luminaires a été signalée dans d'autres villes de France et d'Italie, au moins pour la période médiévale (Alexandre-Bidon 2006, p. 136). Mais estil vraiment nécessaire de posséder un bougeoir ou un candélabre pour poser une chandelle ou la tenir sans se brûler la main?

\subsection{Aménager, meubler, ranger}

Les terre cuites architecturales n'ont pas été prises en compte dans cet ouvrage. Mentionnons néanmoins que, pour le Moyen Âge, les sols découverts in situ sont en terre battue. Ils apparaissent au rez-de-chaussée des maisons, étage voué le plus souvent aux activités professionnelles, à une boutique ou aux animaux. Ces sols de terre pouvaient être recouverts de nattes comme en témoignent les résidus carbonisés dans une maison du bourg de Morier (Bouiron et al. 2011, fig. 93). La fabrication de carreaux vernissés et décorés par les potiers médiévaux de Sainte-Barbe est pourtant établie. Cette production était vraisemblablement destinée à des édifices de prestige. Cependant, trois spécimens ont été découverts dans la cité, en dehors de leurs ateliers de fabrication : un carreau émaillé décoré en vert et brun d'un aigle héraldique échoué au fond d'un puits de la place Jules-Verne (Smail 2009, p. 254, fig. 107b), à proximité un zellige - carreau en forme d'étoiles à 8 branches - uniformément recouvert d'émail vert-bleuté (place Villeneuve-Bargemon) et un dernier zellige décoré d'une étoile brune sur fond émaillé blanc dans le faubourg Sainte-Catherine (Smail 2009, p. 254, fig. 107c). Il est possible que les sols des étages aient été habillés de carreaux en terre cuite, que les nombreux remaniements auront évacués.

Les vestiges de pavements décorés de la période Moderne ne concernent, intra muros, que des édifices religieux (chapelle de l'Hôtel-Dieu, des Carmes) ou des pièces erratiques des fouilles de la place JulesVerne. Les sols de caves exhumés sont parfois pavés de galets, presque toujours de terre cuite sans revêtement (navettes, mallons). Il devait en être de même dans les étages supérieurs.

D'après les sources documentaires, caisses et coffres en bois semblent les meubles les plus communément employés dans les maisons médiévales. Dans les habitations modestes, ils sont même le meuble principal après le lit (Esquieu 2008). Cette situation perdure encore pendant une bonne partie de la période Moderne. Le bois supportant mal les outrages du temps, ce sont les charnières qui suggèrent ici la présence de ces coffres, une petite clef celle de coffrets. Certaines appliques en métal et un objet en os (pied ?) ont pu servir à leur construction et à leur décoration. Caisses et coffres avaient des usages multiples : on y entreposait les denrées, le linge ou la vaisselle, peut-être les quelques tirelires découvertes ici ou là. Polyvalents, ils pouvaient aussi bien servir de banc (Esquieu 2008, p. 243).

Des niches aménagées dans les murs ou des armoires murales en bois ont également pu contribuer au rangement des maisons et des boutiques. Ainsi pouvait-on entreposer ou exposer la vaisselle en céramique, en métal ou en verre, et d'autres produits encore.

\subsection{Transporter, stocker, conserver}

Transport et stockage des denrées sont des questions essentielles de survie, elles le sont encore de nos jours. Pendant toute l'Antiquité, les amphores ont joué un rôle primordial en ces domaines, elles sont d'ailleurs très bien représentées dans les fouilles archéologiques marseillaises ${ }^{63}$. Au Moyen Âge, il semble que le terme d'amphore désigne plutôt des récipients en verre de différentes contenances (cf. supra $2^{\mathrm{e}}$ partie, ch. 1, § 1.1.) tandis que les poteries de gros volumes sont généralement identifiées comme des jarres aussi bien aux périodes médiévales que modernes. De ces dernières, quelques spécimens ont été repérés sur chacun des sites marseillais : au Moyen Âge, de rares jarres proviennent $\mathrm{du}$ monde islamique, quelques gros pots de l'arrièrepays marseillais ; Les dépôts de calcite sur les parois de plusieurs exemplaires médiévaux montrent que, pour l'essentiel, jarres et gros pots servaient au stockage de l'eau. Quelques-uns ont pu également contenir de l'huile. À partir du milieu du XVII s., les jarres de stockage de denrées semblent devenir un peu plus nombreuses, la plupart provient de la région de Biot.

Certains pots ou marmites ont probablement servi non seulement à la cuisson mais aussi au stockage de denrées élémentaires. En effet, comme le fait remarquer à juste titre A. Bazzana dans l'un de ses articles, « un récipient culinaire a, dans sa fonction de cuisson, une durée de vie limitée car les parois s'imprègnent peu à peu d'odeurs qui tendent à devenir désagréables ; si l'on souhaite conserver la poterie, il convient d'en changer l'emploi » qui peut alors «être converti en vase pour

63 Ceci sera l'objet du prochain volume dans cette collection (Bien, Lang, Bouiron à paraître). 
réserves sèches »(Bazzana 2010,p. 45). Dans ce cas, leur deuxième vie est insoupçonnable à nos yeux puisqu'elle ne touche pas l'intégrité du vase. Cependant, à part les quelques jarres, tous les pots retrouvés peuvent contenir des quantités de l'ordre de quelques litres ou quelques kilogrammes, qu'on imagine faciles à entreposer dans une cuisine, sur un étal de boutique. Nous l'avons vu plus haut, les caisses et coffres en bois servaient aussi au rangement et au stockage des réserves. Ces multiples contenants permettaient de stocker les denrées domestiques avec un minimum d'encombrement et donc de les répartir en plusieurs endroits d'un même local.

Mais dans quels conteneurs et où est entreposé le gros des marchandises ? Sacs en textile ou en peau, outres, corbeilles en osier peuvent convenir à cet usage. Une autre réponse qui vient immédiatement à l'esprit est celle des tonneaux en bois. Pour le Moyen Âge, l'exemple de certaines cargaisons de verre nous montre que certains récipients ne servent qu'au transport des marchandises, leur contenu étant simplement transvasés dans d'autres récipients (de moindre contenance ?) au moment de la livraison, pour être ensuite immédiatement remplis par un autre produit à livrer. À l'Époque moderne, les sous-sols des boutiques hébergent volontiers des cuves maçonnées servant au stockage de vin ou d'huile. Dans ce cas, les récipients, quelle que soit leur nature (jarres, tonneaux...) ne servaient vraisemblablement qu'au transport de marchandises.

Un autre embryon de réponse à la question du stockage «de masse » des denrées sèches peut se trouver dans les aires d'ensilage de céréales qui s'échelonnent $\mathrm{du} \mathrm{IX}^{\mathrm{e}}$ au $\mathrm{XII}^{\mathrm{e}} \mathrm{s}$. en différents points à la frange de la ville, puis dans les annoneries (halles aux grains) qui, d'après la documentation archivistique, leur succèdent. La principale réserve de grain se situerait près du Port (Bouiron et al. 2011, p. 185).

\subsection{Prendre soin de soi et de son cadre de vie}

L'entretien des lieux privés ou publics semble une préoccupation majeure, aussi bien à l'époque médiévale que moderne. Cette préoccupation transparaît au travers de l'archéologie : tous les sols de maison et de rue sont régulièrement balayés et sans doute lessivés pour certains pavements, on y trouve généralement très peu de résidus et d'objets. Les intérieurs sont également bien rangés, on l'a vu précédemment.

Les pots de fleurs sont présents à toutes les époques. Cultiver des plantes sur le rebord de la fenêtre ou dans la cour permet de faire entrer un peu de nature dans la ville. Utiles en cuisine, de nombreuses plantes cultivées sont parées de vertus prophylactiques comme le basilic, la marjolaine, le lys. Elles se retrouvent en général dans les préparations des apothicaires.

Avec l'entretien des espaces, se pose la question de la gestion des déchets. À Aix-en-Provence, Arles, Fos-sur-Mer, Avignon, Toulouse et bien d'autres villes encore, pas une fouille de quartiers anciens sans qu'on ne découvre une fosse à déchets. Marseille se démarque des villes de la région sur cette question. L'absence de dépotoir soulignée tout au long de l'ouvrage nous prive de la plus grande partie des objets accompagnant les Marseillais au quotidien. Très peu de dépotoirs domestiques, aucun d'usage collectif, n'ont été repérés en fouille, même sur les chantiers archéologiques de grande superficie. Que faisaient donc les habitants de cette ville de leurs déchets ? Certes, quelques puits ont manifestement servi de vidoir après leur mise hors service mais toujours de manière ponctuelle. La plupart du temps, ces ouvrages ont régulièrement été curés pour rester en fonction presque jusqu'à nos jours. Place VilleneuveBargemon, près d'une trentaine de puits ont été dégagés, certains construits dès le XII ${ }^{\mathrm{e}} \mathrm{s}$., et un seul pourrait avoir ponctuellement servi de dépotoir (cf. infra). Même la noria n'a pas rempli cette fonction après son abandon, pourtant l'excavation à combler devait être d'un volume important. À proximité immédiate, place Jules-Verne, les puits sont un peu plus nombreux à recevoir des « ordures » au moment de leur abandon. Dans le quartier épiscopal, un lot de vaisselle a été rejeté au fond de l'un d'entre eux au cours du XIII' ${ }^{\mathrm{e}}$ s. (Moliner 1990). Seuls les puits du quartier de la Bourse semblent faire exception et avoir servi de dépotoir au $\mathrm{XVI}^{\mathrm{e}} \mathrm{s}$., bien qu'il ne s'agisse pas ici non plus d'un dépotoir collectif.

C'est bien peu par rapport au nombre de bâtisses, de rues, de jardins et de monuments fouillés ces vingt dernières années dans le centre-ville marseillais et la question de la gestion des déchets est donc légitime. Les rejets retrouvés dans quelques structures paraissent anecdotiques par rapport au volume de déchets qu'a pu générer la population marseillaise au cours du millier d'années abordées ici. Si ces rejets ne sont pas entreposés à proximité immédiate de leur lieu d'utilisation, contrairement à ce qui semble être le cas dans la plupart des villes (Cataldo 2002), où sont-ils acheminés et enterrés? Les chantiers archéologiques se situent tous intra muros ou à proximité de la ville. Les données manquantes ont donc de grandes chances de se trouver dans ces parties inexplorées que sont les zones non ou peu urbanisées aux époques médiévales et modernes, les fossés des remparts, mais aussi le Port, déversoir naturel qui, en dépit de toutes les interdictions, sert de gigantesque poubelle depuis l'Antiquité.

L'entretien de la personne n'est pas non plus laissé de côté. Pour preuve, l'établissement dès le XII's s. de 


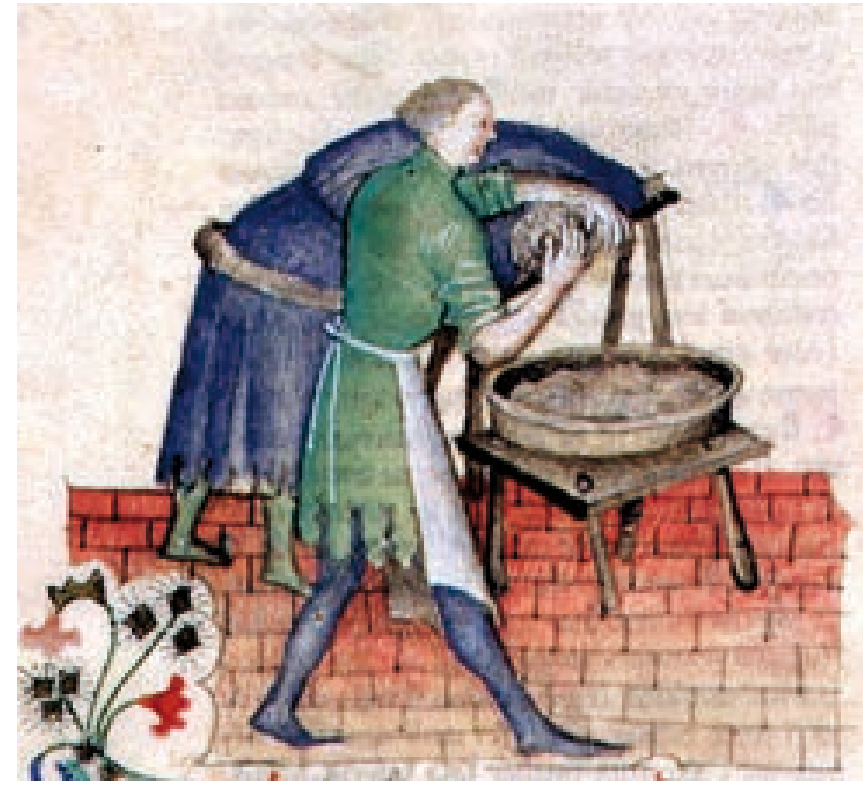

Fig. 265. Représentation d'un homme se faisant aider à se laver les cheveux dans un bassin/tian (en bois ? en céramique ?), issue de l'Historia plantarum probablement illustrée par Giovannino De Grassi en Lombardie (Italie) vers 1400. (Biblioteca Casanatense de Rome - Ms 459, fol. 142v)

"Su concessione del Ministero per i Beni e le Attività Culturali", DR.

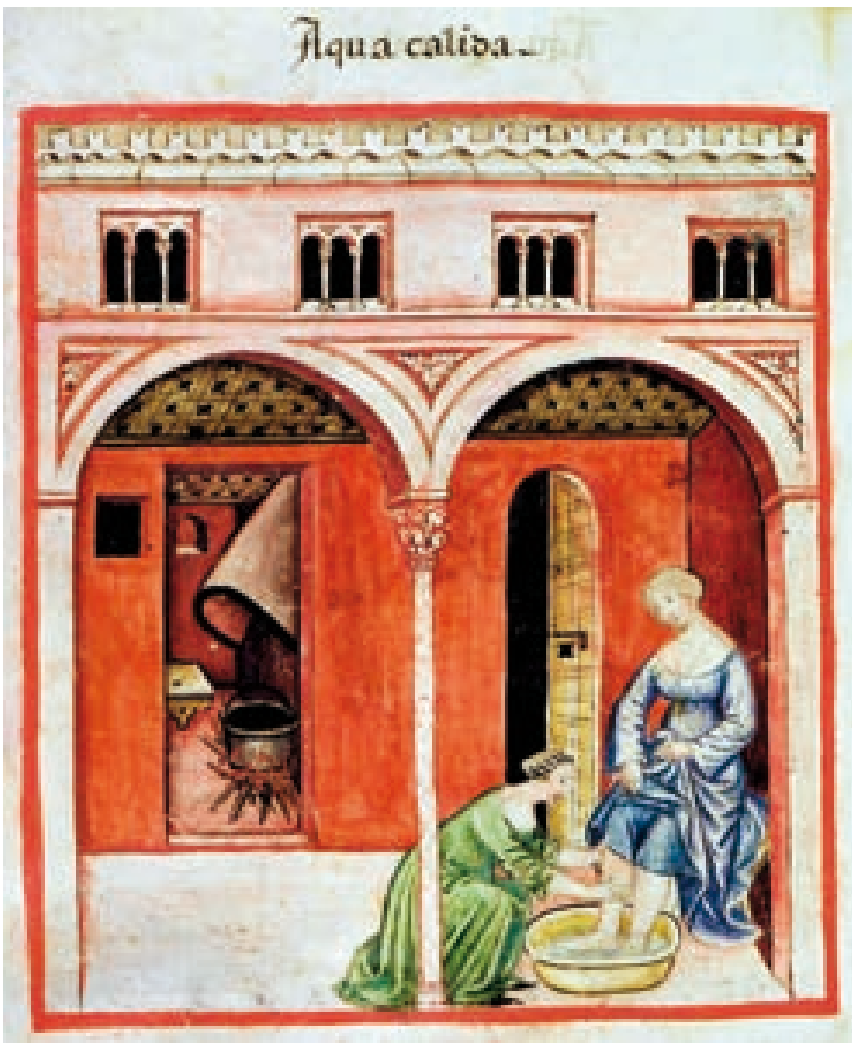

Fig. 266. Bains et lavage des pieds dans un bassin rempli d'eau chaude. (Theatrum Sanitatis. Biblioteca Casanatense de Rome - Ms. 4182 fol. 172. Autour de 1400). "Su concessione del Ministero per i Beni e le Attività Culturali", DR.

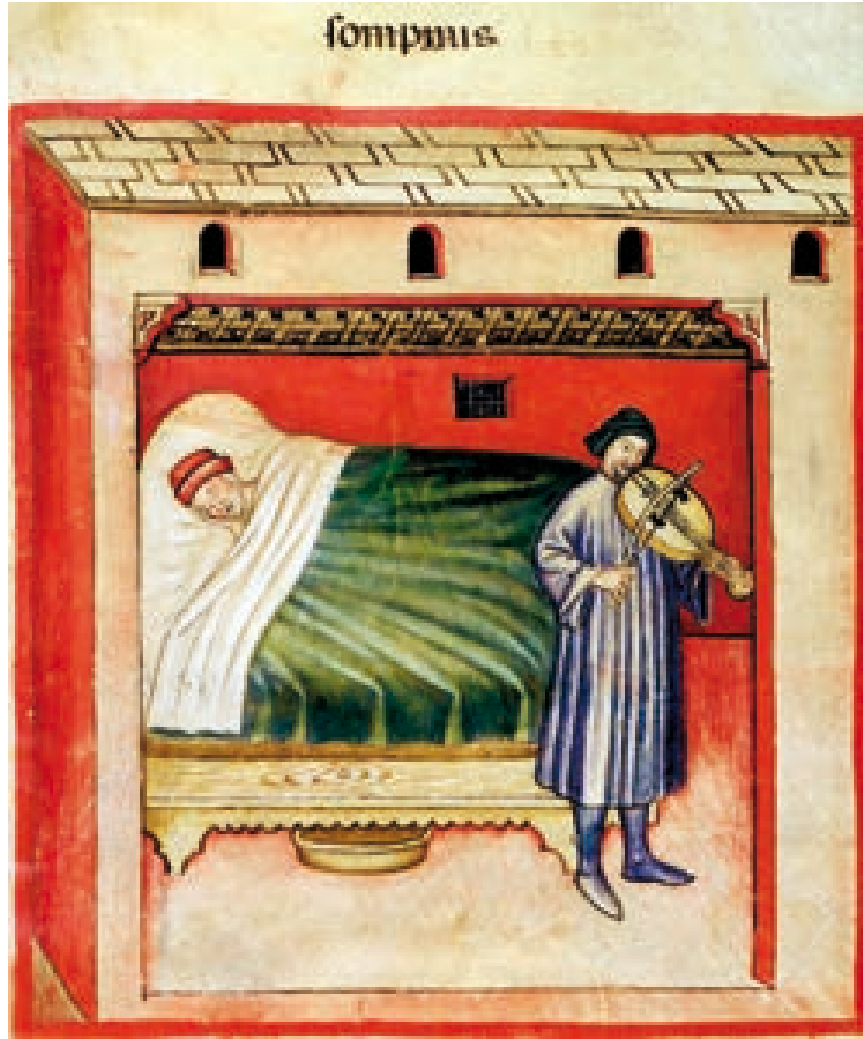

Fig. 267. Enluminure illustrant le sommeil dans le Theatrum sanitatis. Sous le lit de l'homme endormi se remarque un bassin destiné aux besoins naturels (Biblioteca Casanatense de Rome - Ms. 4182 fol. 194.

Autour de 1400). "Su concessione del Ministero per i Beni e le Attività Culturali”, DR.

bains publics, d'étuves plus exactement, dans le quartier du Mazeau (Bouiron et al. 2011, p. 185). L'hygiène corporelle n'est donc pas délaissée, d'ailleurs de nombreux textes la mentionnent. Les nombreux bassins/tians en céramique présents en fouille tout au long de ces périodes servent aussi bien aux préparations culinaires, d'abreuvoirs pour les animaux, qu'à la lessive et aux ablutions quotidiennes (fig. 265 et 266). Ils sont remplis d'eau à l'aide des nombreuses cruches et gargoulettes découvertes. Le nécessaire de toilette est complété par des cure-oreilles et ongles en ivoire ou métal, une pince à épiler en métal, quelques fragments de peignes et une brosse en os.

Quant aux besoins naturels, les pots de chambre (en céramique) apparaissent visiblement dans la première moitié du XVI ${ }^{\mathrm{e}} \mathrm{s}$. Aux siècles précédents, nous n'avons pas trace de récipients spécifiquement destinés à cet usage. Sans doute qu'ils existent dans d'autres matériaux ou que les bassins/tians, récipients polyvalents par excellence, jouent ce rôle également, comme le suggèrent quelques illustrations de la fin du Moyen Âge (fig. 267). 
Des éléments de parure viennent compléter le tableau des soins apportés au corps et à la personne. Boucles, anneaux et annelets en alliage cuivreux sont sans doute les éléments les plus nombreux à évoquer le vêtement et ses accessoires de fixation, tout du moins pour l'époque médiévale car ils tendent à se raréfier par la suite. Un autre élément, le bouton, semble apparaître au cours du Moyen Âge : les premiers visibles à Marseille sont à bélière et en métal (à l'Alcazar dès la fin du XIII ${ }^{\mathrm{e}} \mathrm{s}$.). Les boutons à trous, généralement en os, semblent introduits plus tardivement, sans doute vers le milieu du XVII ${ }^{\mathrm{e}} \mathrm{s}$. Agrafes et chaînettes ont également pu contribuer à l'habillement.

Joncs simples ou à chaton, les bagues sont les seuls bijoux découverts. L'une d'entre elles a été perdue au fond d'un puits mais l'essentiel provient de sépultures médiévales ou modernes. Toutes les sépultures ne contiennent pas de bagues, loin s'en faut, mais comment interpréter ce fait: ces objets sont-ils si précieux (au moins affectivement) pour que les êtres chers ne puissent s'en séparer? Au contraire, sont-ils le signe d'un statut particulier du défunt ou d'une dévotion spéciale?

Enfin cette ébauche d'inventaire des soins apportés à la personne ne serait pas complète sans la mention de quelques éléments anecdotiques, sans doute en lien avec la cosmétique. En effet, même si ce n'est pas mentionné dans le chapitre les concernant, quelques fragments de pipe en terre blanche portent des traces de pigments rouges encore graisseux. Ces pigments imprègnent également les ébréchures, signe qu'ils ont été appliqués après brisure de l'objet, réduit alors à un simple bâtonnet cylindrique. Bien sûr, seules des analyses permettraient d'identifier la composition de cet « enduit» dans lequel nous sommes pourtant tentées de percevoir un colorant pour les lèvres, le tuyau de pipe brisé ayant alors servi d'applicateur, tel nos sticks actuels.

\subsection{Exprimer sa piété}

La place de la religion dans les gestes de la vie quotidienne est difficile à estimer pour ces époques. À l'époque médiévale, elle semble peu ostentatoire. Plutôt discrète, peut-être s'exprime-t-elle d'avantage par les actions que par l' «étalage » d'objets significatifs, à moins que ces derniers ne soient réservés à une certaine catégorie de population. L'unique signe de dévotion retrouvé pour cette période est une ampoule de pèlerinage de l'extrême fin du Moyen Âge, échouée au fond d'un puits du quartier du Mazeau. Comme nombre d'objets manquants dans les sources archéologiques, ils peuvent exister en matériau périssable et ainsi nous échappent totalement.

Les marques de dévotion deviennent plus évidentes à l'Époque moderne et s'expriment essentiellement dans les lieux d'inhumation. Les perles (en verre, en jais...) découvertes dans les sépultures à partir des $\mathrm{XV}^{\mathrm{e}}-\mathrm{XVI}^{\mathrm{e}} \mathrm{s}$., pourraient appartenir à des colliers, mais des chapelets semblent plus probants vu le contexte. Les médailles pieuses et crucifix en pendentifs commencent à faire partie de la panoplie funéraire après le $\mathrm{XVI}^{\mathrm{e}} \mathrm{s}$. La piété ne se manifeste pas exclusivement face à la mort et les fragments de bénitiers de chevet en terre vernissée et faïence de la fin du XVII ${ }^{e}$ siècle et du siècle suivant témoignent qu'il existe bien des objets de piété à « usage domestique ».

\section{6. Écrire}

Cette activité, largement documentée par la littérature et l'iconographie, l'est beaucoup moins par l'archéologie. Parchemins, papiers, plumes et encres ont bien peu de chances de traverser les siècles. Ceux qui y sont parvenus sont aujourd'hui précieusement conservés dans les bibliothèques ou dans quelques collections privées.

L'écrit, les écrits, sont les principales sources documentaires des historiens et des archéologues, s'agissant de manuscrits, de littérature, d'actes juridiques, de documents administratifs et, plus prosaïques encore, d'actes notariés. Comment savoir à laquelle de ces catégories appartenait le livre dont une agrafe a été découverte dans le bourg médiéval de Morier? Peut-être s'agit-il

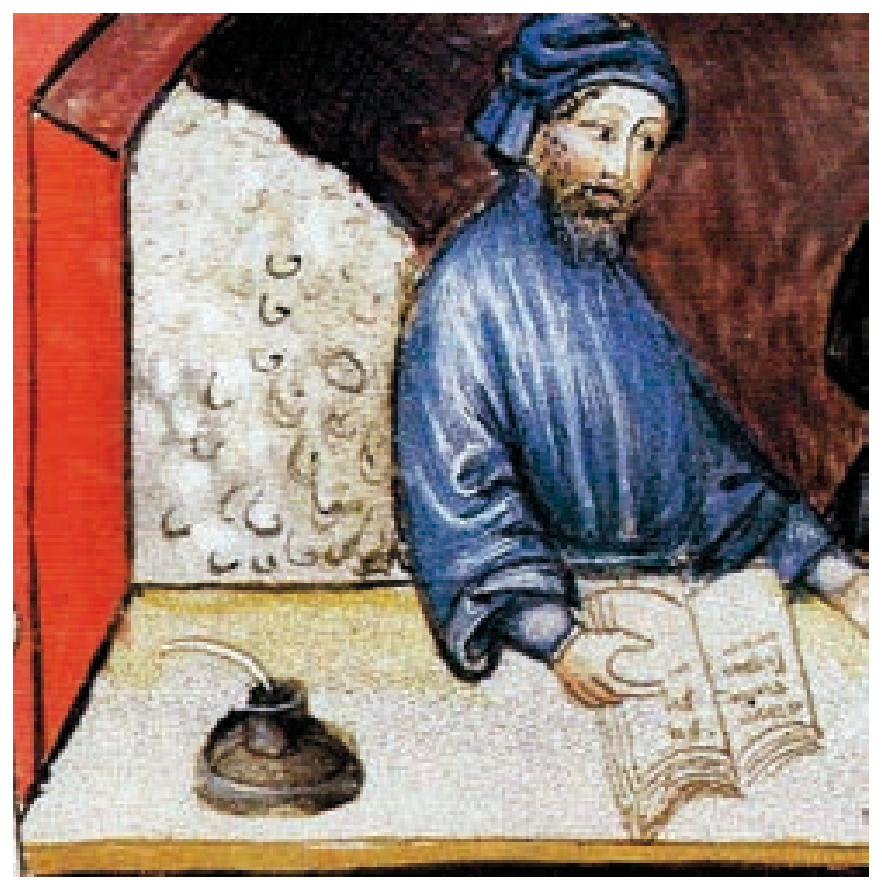

Fig. 268. Encrier, plume et livre sur un étal de marchand de sel.

(Tacuinum sanitatis. Codex Vindobonensis Series Nova 2644, fol. 128, Österreichische Nationalbibliothek de Vienne - Autriche, DR). 


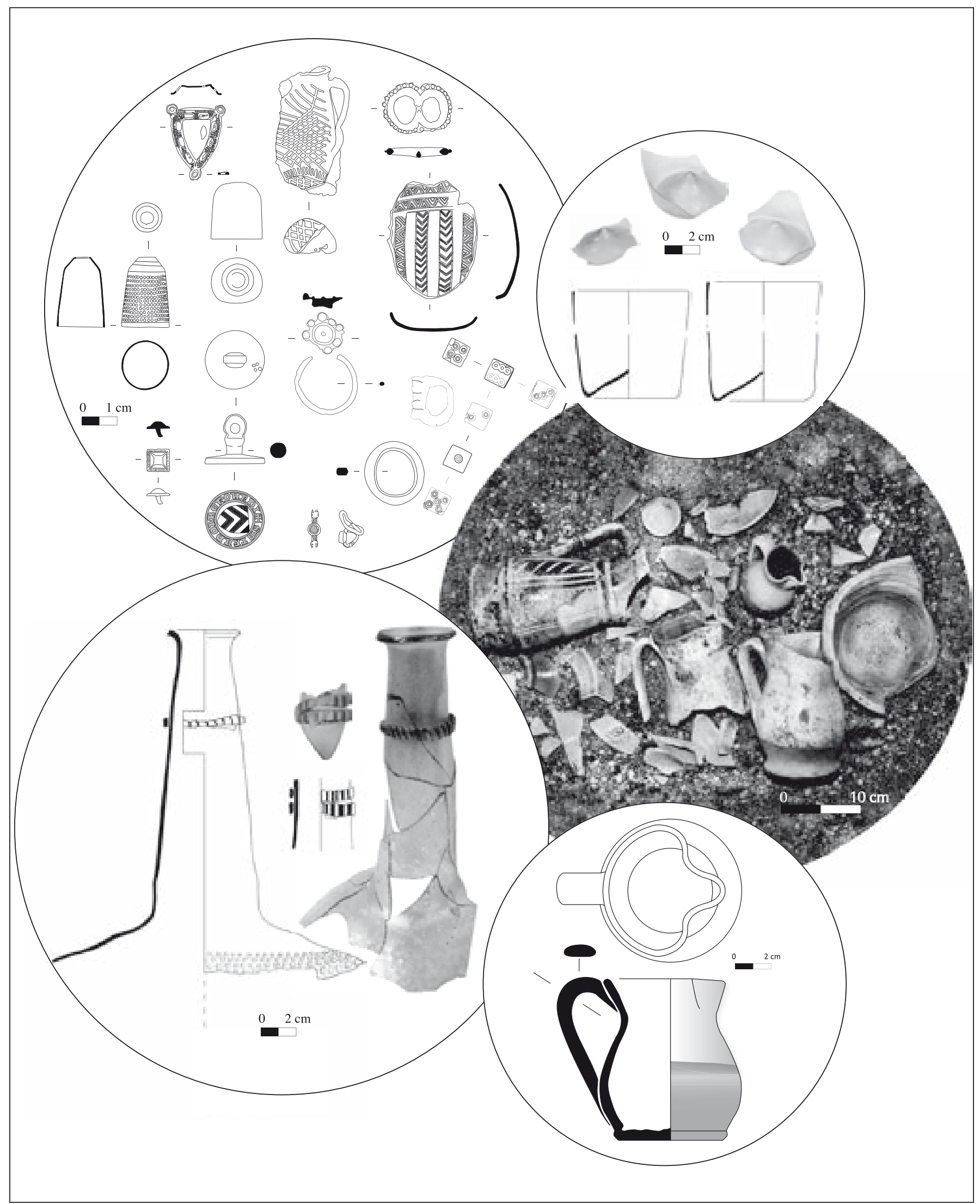

Fig. 269. Assemblage d'objets enfouis dans un puits du quartier du Mazeau (place Villeneuve-Bargemon). DAO : V. Abel/Inrap, M.-A. Chazottes/LA3M, D. Foy/CCJ, O. Thuaudet/LA3M, FI. Parent/Inrap. Photo : T. Maziers/Inrap. 
tout simplement du journal (de comptabilité ?) d'un artisan, d'un commerçant, d'un habitant du quartier. Pour y inscrire ses notes ou sa comptabilité, le «scribe»a sans doute utilisé le même genre d'ustensile que les deux encriers pique-plume retrouvés du côté du Port (place Villeneuve-Bargemon et Hôtel-Dieu), certes plus récents de deux siècles au moins : plume, encrier et livre semblent difficilement indissociables (fig. 268).

\subsection{Se divertir, se détendre}

La détente n'est pas absente de la vie des Marseillais. Taraïettes (vaisselle miniature) à toutes les époques, sifflets en céramique pour la période Moderne ainsi qu'un petit soldat en plomb d'Époque contemporaine nous font entrer dans le domaine de l'enfance et de ses jouets. Certains des grelots référencés peuvent aussi avoir égayé les bambins. À côté de ces jouets manufacturés, dont une partie doit être également en matériaux périssables, les jouets de fortune ne peuvent être décelés par l'archéologue : objets domestiques détournés, cailloux ramassés dans une ruelle, osselets et toute une panoplie d'objets insignifiants qu'un enfant, encore aujourd'hui, a tôt fait de s'approprier pour un amusement souvent éphémère.

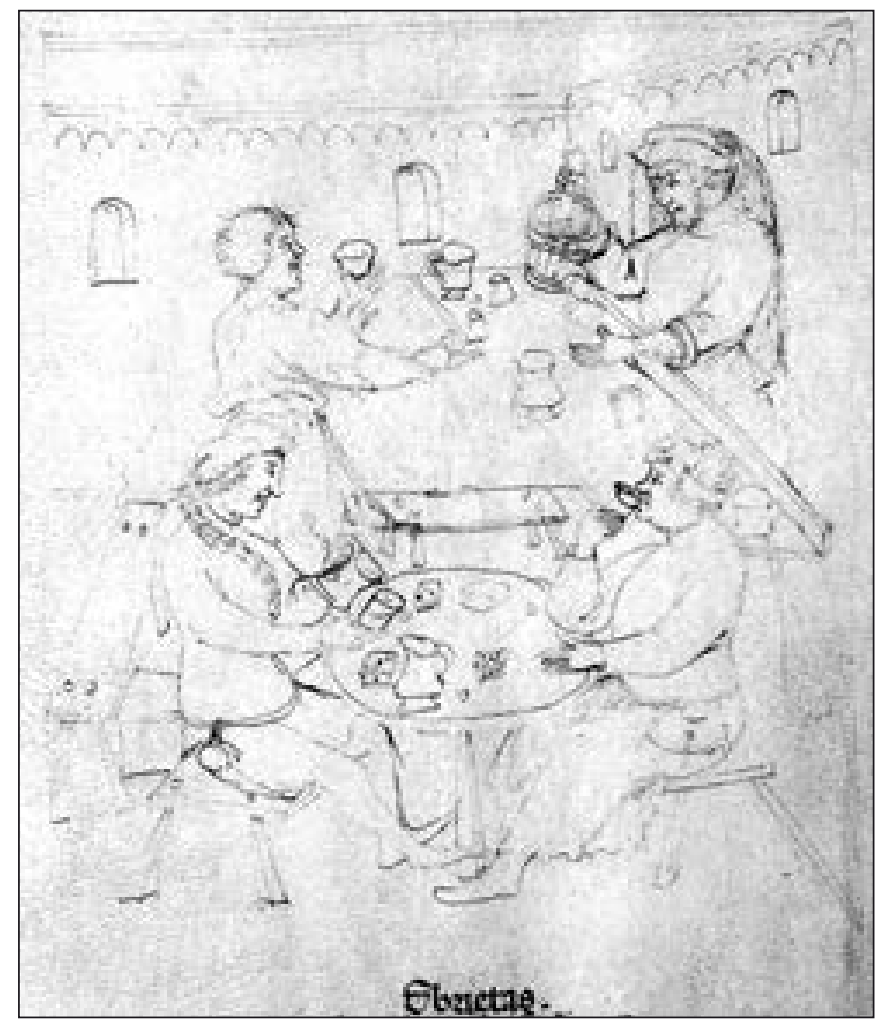

Fig. 270. Ambiance à l'intérieur d'une auberge/taverne. Dessin illustrant l'état d'ébriété dans un des manuscrits du Tacuinum Sanitatis conservé à la Bibliothèque Générale de Philosophie et Lettres de l'Université de Liège (ms 1041, fol. 66),DR.
Les adultes, de leurs côtés, s'adonnent aux jeux de société : dés à jouer (dont certains pipés) et pion en os d'un jeu indéterminé dès l'époque médiévale, puis jeu de dames et dominos. Les plaisirs du tabac participent sans doute à la détente d'une petite élite fortunée à partir du milieu du XVII ${ }^{\mathrm{e}}$ s.

L'intense activité commerciale de Marseille favorise l'implantation d'auberges dès l'époque médiévale. Lieux de promiscuité et de convivialité par excellence (on y dort, on y mange, on y boit), elles sont parfois aussi synonymes d'excès : on s'y enivre et on y joue beaucoup. Documentées par les textes au moins dès le XIII ${ }^{\mathrm{e}}$ s., elles ne sont guère mises en évidence par l'archéologie car peu différenciables des immeubles ordinaires (Bouiron et al. 2011, p. 198). Leurs équipements ne diffèrent guère non plus des ustensiles domestiques. Cependant, un puits du quartier du Mazeau a retenu notre attention : abandonnés là vers la fin du $\mathrm{XIV}^{\mathrm{e}}$ ou au début du $\mathrm{XV}^{\mathrm{e}} \mathrm{s}$., les ustensiles dédiés essentiellement à la boisson (cruches, pichets, bouteille, gobelets) côtoient un pion de jeu et une trentaine de dés dont certains sont truqués. Une quinzaine d'objets exceptionnels sont mêlés à cet assemblage: deux anneaux circulaires, deux boucles, deux bagues, une applique, une ampoule de pèlerinage, un dé à coudre, un sceau, une cuillère ornée, six clous décoratifs, et un manche probable de couteau (fig. 269). Autant d'objets évoquant l'univers de la boisson, du jeu, des tricheries et des vols à la sauvette encouragés par la promiscuité et l'ébriété et qu'on assimile facilement à l'ambiance d'une auberge (fig. 270).

\subsection{Travailler}

Du monde du travail proviennent de rares signes dans les objets archéologiques : les outils aussi bien que les produits liés au petit artisanat et au commerce sont peu illustrés par les fouilles et se confondent souvent avec ceux des activités domestiques, surtout pour la période médiévale.

La vaisselle en terre cuite évidemment est présente presque à profusion comparée au reste des objets. Avec celle en verre, elle a autant d'utilité dans les maisons que dans les boutiques et auberges où elles permettent de stocker, présenter et servir toutes sortes de produits (fig. 271).

Quelques dés à coudre en métal, dont certains d'époque médiévale et des embouts de fuseau (thies) renseignent fugacement les activités textiles. Un poinçon en os pourrait s'y rattacher, ainsi que de nombreuses épingles en métal. Les travaux textiles relèvent aussi bien de l'artisanat que de la sphère privée. Curieusement aucun peson ou fusaïole en céramique ou en pierre n'est 


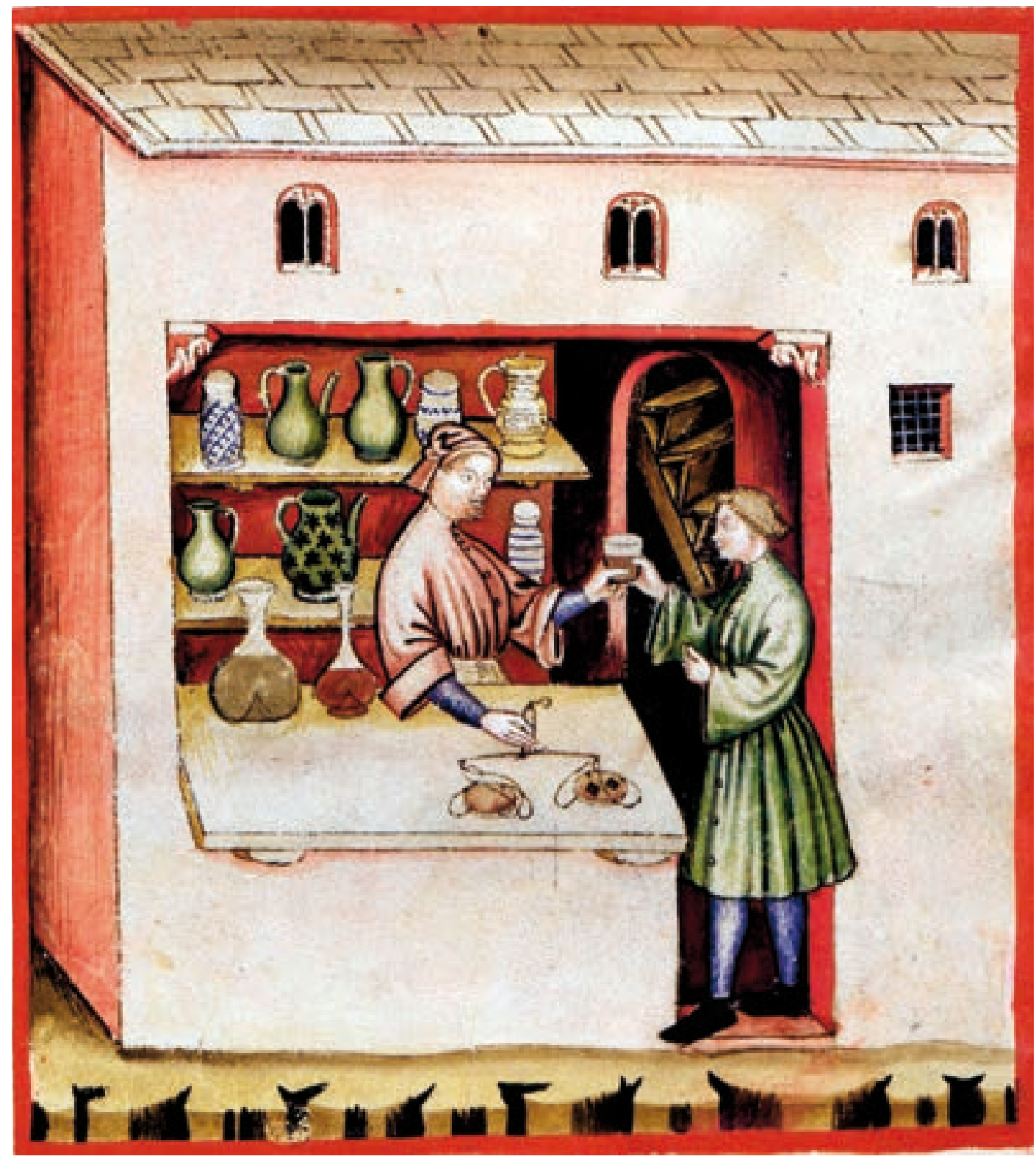

Fig. 271. Dans l'échoppe de ce marchand de vinaigre, les étagères sont remplies de poteries contenant ses produits. On peut d'ailleurs remarquer sur l'étagère du haut à droite, une cruche en majolique probablement toscane (Theatrum Sanitatis. Biblioteca Casanatense de Rome - Ms. 4182 fol. 183. Vers 1400). "Su concessione del Ministero per i Beni e le Attività Culturali".

signalé, alors qu'ils sont fréquents au Moyen Âge dans d'autres sites provençaux.

Deux hameçons sont signalés, ce qui est très peu pour une ville qui tire nombre de ses ressources de la mer et où la pêche était certainement un des principaux moyens de subsistance. Ces objets ont certainement eu une utilité essentiellement domestique, des filets convenant mieux à une pêche plus abondante. Mais ici encore, l'absence de pesons étonne. Une visite plus «perspicace » des collections entreposées au dépôt archéologique de Marseille permettrait peut-être de relativiser cette observation.

Le petit artisanat du corail est attesté archéologiquement en plusieurs points de la ville exclusivement par ses résidus (Bouiron et al. 2011, p. 189-192), mais les objets fabriqués et commercialisés par les corailleurs ou les orfèvres (bijoux et autres pièces d'ornement) nous sont quasiment inconnus : 2 perles et un dé à jouer. Il est probable (comme le signalent les auteurs du précédent volume de cette série consacrée aux fouilles récentes à Marseille) que ces articles étaient exclusivement destinés au commerce extérieur, en raison de leur forte valeur marchande.

De la même manière, peu d'articles en métal nous sont parvenus en comparaison du nombre de petits ateliers de métallurgie identifiés en divers lieux, intra muros ou dans les faubourgs limitrophes. Leur perception provient essentiellement de l'identification des déchets qu'elle génère (épandages de cendres, scories), très exceptionnellement par un objet, fini ou non, oublié parmi ces déchets et, tout aussi exceptionnellement, par 
des creusets ou des boîtes à cémenter nécessaires à leur fabrication (Richarté 2001, p. 163-165; Bouiron et al. 2011, p. 190-192). La faible découverte de produits finis en métal s'explique en grande partie par la nature du matériau, qui permet de multiples refontes et donc un recyclage infini des objets. À part ceux disposés au côté du défunt au moment de son inhumation ou appartenant à ses derniers atours, tous les autres objets métalliques retrouvés semblent avoir été tout simplement égarés plutôt qu'abandonnés après usage.

Grands complexes artisanaux, proto-industries et industries font la renommée et la prospérité de Marseille. Les complexes artisanaux médiévaux sont renseignés archéologiquement moins par leurs produits que par leurs installations (Bouiron et al. 2011, p. 188-197). Pour cause, tanneries et teintureries ne fabriquent que des produits périssables. Seule la fouille des ateliers potiers du quartier Sainte-Barbe a révélé simultanément les infrastructures de productions et les produits finis (certes défectueux). Aux époques suivantes, installations et objets manufacturés sont rarement découverts de concert. Certaines proto-industries ou industries ne se dévoilent qu'à travers les objets qu'ils ont fournis et ne permettent donc pas de préjuger de la taille des installations de production. Un atelier de faïence est reconnu au Pharo à la fin du XVII ${ }^{\mathrm{e}}$ s. grâce aux articles et aux cendres et charbons recalés dans une fosse. La fabrication de faïence fine à l'extrême fin du XVIII ${ }^{\mathrm{e}}$ s. est perceptible par d'originaux objets découverts en fouilles; c'est seulement mis en parallèle avec ceux en vitrine au Musée de la Faïence de la ville, qu'ils ont permis de comprendre qu'ils avaient été fabriqués dans les ateliers d'un certain Joseph Henri Martin à proximité de la Porte d'Aix. Aucune trace archéologique non plus s'apparentant à des raffineries de sucre, activité pourtant florissante à Marseille aux XVIII ${ }^{e}$ et $\mathrm{XIX}^{\mathrm{e}} \mathrm{s}$. Elles transparaissent néanmoins au travers des formes à sucre et pots à mélasse rejetés pour combler l'anse de l'Ourse au moment des grands réaménagements du milieu du XIX ${ }^{\mathrm{e}} \mathrm{s}$.

L'image de Marseille reste encore à l'heure actuelle celle d'une grande ville portuaire essentiellement tournée vers la Méditerranée, où le commerce maritime tient une place de première importance. Une grande part, voire la majeure partie de l'économie de la cité découle de cet intense trafic maritime. Les céramiques sont là pour témoigner de ces échanges, aussi bien à l'époque médiévale que moderne. Nous nous sommes pourtant contentées d'évoquer les poteries entrant à Marseille. Les autres produits et matériaux importés (draps, épices, matières premières...) n'ont pas été abordés dans cet ouvrage, ni même les nombreux produits manufacturés exportés par les négociants marseillais à travers tout le bassin méditerranéen. Ils font partie de la vie et de l'économie de la ville mais ont quitté le sol marseillais et ne peuvent donc pas se retrouver en fouilles dans la cité.

\section{En attendant de nouvelles découvertes...}

Pour la première fois depuis longtemps à Marseille, différentes catégories de mobilier sont confrontées et mises en relation les unes avec les autres. Les apports de chacune et de l'ensemble sont indéniables dans l'appréhension de la culture matérielle à Marseille tant pour le Moyen Âge que pour les Temps modernes. L'archéologie préventive et sa méthodologie étant en constante évolution, nous espérons que les catégories de mobilier souvent délaissées au profit de la céramique seront désormais mieux intégrées dans le processus d'études des sites. Ce premier bilan est loin d'être exhaustif et de nombreuses pistes restent encore à explorer.

On ne perçoit pas de différence dans les niveaux de vie des utilisateurs quelle que soit la période concernée, Moyen Âge ou Époque moderne, et quel que soit le quartier considéré. Les objets du quotidien qui nous parviennent sont relativement modestes. Ils sont essentiellement utilitaires, nombreux à avoir plusieurs usages et sans doute plusieurs vies. Les objets «précieux» ne figurent quasiment jamais dans les fouilles marseillaises, tout au plus ceux malencontreusement égarés. On imagine facilement qu'ils ont fait l'objet d'une attention particulière de la part de leurs propriétaires.

Mises en parallèle avec les collections de mobiliers récoltées sur d'autres sites provençaux, les collections marseillaises semblent montrer que le «train de vie» des Marseillais est un peu plus luxueux que celui de leurs congénères provençaux. Â l'échelle de la ville pourtant, la possession de ces objets ne semblent pas être une originalité ni l'apanage d'une élite : ils équipent la plupart des intérieurs marseillais. Bien sûr, la place singulière de Marseille permet à ses habitants de profiter d'avantage que ceux de l'arrière-pays de produits exotiques.

Ce volume n'est qu'une étape dans notre approfondissement de la connaissance des sociétés médiévales et modernes. Il bénéficie de l'apport de l'archéologie dans une des grandes villes du bassin Méditerranéen et sera, nous l'espérons, utile à tous ceux qui travaillent sur le cadre matériel. En attendant que de nouvelles découvertes viennent renforcer ou bouleverser ce qui a été énoncé ici. 



\section{Annexe 1}

\section{Liste des opérations archéologiques}

Chacun des chantiers effectués dans la ville de Marseille (fouilles, sondages, surveillance de travaux) porte un numéro d'inventaire attribué par l'Atelier du Patrimoine de la Ville de Marseille, composé du numéro du site (numérotation continue au fur et à mesure de l'exécution des travaux et correspondant à la localisation du site) suivi de l'année de réalisation du chantier (un même site pouvant porter plusieurs dates suivant les différentes tranches de travaux). Voici la liste des chantiers et du code attribué par l'Atelier du Patrimoine.

Par ordre alphabétique

\begin{tabular}{|c|c|c|}
\hline Nom du site & Responsable & $\begin{array}{l}\text { Code chantier (Atelier } \\
\text { du Patrimoine) }\end{array}$ \\
\hline Alcazar (BMVR) & M. Bouiron & 24.99 \\
\hline (La) Bourse (1967-1984) & divers & $86.67-84$ \\
\hline (La) Bourse (sondages 2006) & N. Scherrer & $86.06 \mathrm{R}$ \\
\hline (Les) Carmes & G. Bertucchi & 90.85 \\
\hline (Les) Catalans & L. Long & Sans $\mathrm{n}^{\circ}$ \\
\hline César 1 & V. Abel/R. Thernot & 52.95 \\
\hline César 2 & A. Hesnard & 52.96 \\
\hline (La) Charité 1983 & L.-F. Gantès & 02.83 \\
\hline Collège Vieux-Port & P. Mellinand & 131.05 \\
\hline Église abbatiale Saint-Victor & $\begin{array}{l}\text { G. Démians d'Archimbaud/ } \\
\text { M. Fixot/J.-P. Pelletier }\end{array}$ & $175.69-76$ \\
\hline Espace Bargemon & P. Mellinand & 52.02 \\
\hline Esplanade de la Major & F. Paone & 158.08 \\
\hline Fort Saint-Jean 1984 & L.-F. Gantès, G. Hadji-Minaglou & 26.84 \\
\hline Fort Saint-Jean 1990 & J. Collinet & 26.90 \\
\hline Fort Saint-Jean 1993-1994 & P. Mellinand & 45.93 \\
\hline Fort Saint-Jean 2005 & P. Mellinand & 134.05 \\
\hline (La) Fouragère (Métro) & B. Sillano & 115.03 \\
\hline Hôtel-Dieu & P. Mellinand & 155.09 \\
\hline Ilot 24N & L.-F. Gantès & $01.85 \mathrm{R}$ et 01.86 \\
\hline Ilot 55 & M. Moliner & $06.86 \mathrm{R}$ et 06.87 \\
\hline (La) Parette (Rocade L2) & B. Sillano & 105.01 \\
\hline Parvis de l'église Saint-Laurent & L.-F. Gantès/M. Bouiron & 08.86 \\
\hline Pavillon Bargemon & F. Raynaud & 48.94 \\
\hline Pharo (jardin du palais du) & M. Moliner & 43.94 \\
\hline (Les) Pistoles (llot 61-62N) $1^{\mathrm{e}}$ phase & L.-F. Gantès & 11.87R et 11.89 \\
\hline (Les) Pistoles $2^{\mathrm{e}}$ phase & M. Moliner & 11.95 \\
\hline Place de la Providence (sondages) & M. Bouiron & $56.98 \mathrm{R}$ \\
\hline Place Général-de-Gaulle & M. Bouiron & 31.92 \\
\hline Place Jules-Verne & A. Hesnard & 30.92 \\
\hline Puget III & L.-F. Gantès/M. Moliner & 19.89R et 19.90 \\
\hline Républiquel Surverse Vieux-Port & B. Sillano & 143.06 \\
\hline RHI Bon Jésus & P. Reynaud & 25.91 \\
\hline Rue de la République (sondages) & B. Sillano & 126.04R \\
\hline Rue Leca & F. Conche & 46.94 \\
\hline Rue de l'Evêché & M. Moliner & 03.85 \\
\hline
\end{tabular}




\begin{tabular}{|l|l|l|}
\hline Nom du site & Responsable & $\begin{array}{l}\text { Code chantier (Atelier } \\
\text { du Patrimoine) }\end{array}$ \\
\hline Rue Trinquet & F. Paone & 142.07 \\
\hline Saint-Jean-du Désert (faïencerie) & V. Abel & 53.94 \\
\hline Tunnel de la Major (sondages) & M. Bouiron & $50.94 \mathrm{R}$ \\
\hline Tunnel de la Major & F. Conche/O. Maufras & 50.99 \\
\hline Vieille-Major & F. Paone/l. Villemeur & 49.94 et 49.00 \\
\hline
\end{tabular}

Par code chantier

\begin{tabular}{|c|c|}
\hline Code chantier (Atelier du Patrimoine) & Nom du site \\
\hline 01.85R et 01.86 & Ilot $24 \mathrm{~N}$ \\
\hline 02.83 & Charité 1983 \\
\hline 03.85 & Rue de l'Evêché \\
\hline $06.86 \mathrm{R}$ et 06.87 & Ilot 55 \\
\hline 08.86 & Parvis de l'église Saint-Laurent \\
\hline 11.87R et 11.89 & Les Pistoles (llot $61-62 N) 1^{\mathrm{e}}$ phase \\
\hline 11.95 & Les Pistoles $2^{\mathrm{e}}$ phase \\
\hline 19.89R et 19.90 & Puget III \\
\hline 24.99 & Alcazar (BMVR) \\
\hline 25.91 & RHI Bon Jésus \\
\hline 26.84 & Fort Saint-Jean 1984 \\
\hline 26.90 & Fort Saint-Jean 1990 \\
\hline 30.92 & Place Jules-Verne \\
\hline 31.92 & Place Général-de-Gaulle \\
\hline 43.94 & Pharo (jardin du palais du) \\
\hline 45.93 & Fort Saint-Jean 1993-1994 \\
\hline 46.94 & Rue Leca \\
\hline 48.94 & Pavillon Bargemon \\
\hline 49.94 et 49.00 & Vieille-Major \\
\hline $50.94 \mathrm{R}$ & Tunnel de la Major (sondages) \\
\hline 50.99 et 50.00 & Tunnel de la Major \\
\hline 52.95 & César 1 \\
\hline 52.96 et 52.97 & César 2 \\
\hline 52.02 & Espace Bargemon \\
\hline 53.94 & Saint-Jean-du Désert (faïencerie) \\
\hline $56.98 \mathrm{R}$ & Place de la Providence (sondages) \\
\hline $86.67-84$ & La Bourse (1967-1981) \\
\hline $86.06 \mathrm{R}$ & La Bourse (sondages 2006) \\
\hline 90.85 & Les Carmes \\
\hline 105.01 & La Parette (Rocade L2) \\
\hline 115.03 & La Fourragère (Métro) \\
\hline $126.04 \mathrm{R}$ & Rue de la République (sondages) \\
\hline 131.05 & Collège Vieux-Port \\
\hline 134.05 & Fort Saint-Jean 2005 \\
\hline 142.07 & Rue Trinquet \\
\hline 143.06 & République/Surverse Vieux-Port \\
\hline 155.09 & Hôtel-Dieu \\
\hline 158.08 & Esplanade de la Major \\
\hline $175.69-76$ & Église abbatiale Saint-Victor \\
\hline Sans $n^{\circ}$ & Les Catalans \\
\hline
\end{tabular}


Annexe 2

\section{Détail de l'inventaire du verre}

\begin{tabular}{|c|c|c|c|}
\hline Sites & $\begin{array}{l}\text { Unité } \\
\text { stratigraphique }\end{array}$ & Identification & Figure $n^{\circ}$ \\
\hline \multirow{3}{*}{ Puget III } & 117 & Partie médiane d'un verre bitronconique (?) & fig. $213, n^{\circ} 1$ \\
\hline & 478 & Partie médiane d'un verre bitronconique (?) & fig. $213, n^{\circ} 2$ \\
\hline & 207 & Pied annulaire creux & fig. $213, n^{\circ} 3$ \\
\hline \multirow{4}{*}{$\begin{array}{l}\text { Villeneuve-Bargemon } \\
\text { (1995) CSR95 }\end{array}$} & $3136-3152$ & Partie médiane d'un verre caliciforme & fig. $213, n^{\circ} 4$ \\
\hline & 3027 & Verre à tige creuse & fig. $213, n^{\circ} 5$ \\
\hline & 3011 & Base d'un gobelet à goutte étirée et rebord. & fig. 214 et $215, n^{\circ} 9$ \\
\hline & 3092 & Base d'un gobelet à goutte étirée & fig. 214 et $215, n^{\circ} 10$ \\
\hline \multirow{14}{*}{$\begin{array}{l}\text { Villeneuve-Bargemon } \\
\text { (1996) MCR96 }\end{array}$} & 2464 & Base d'un gobelet non décoré & fig. 220 et $221, n^{\circ} 13$ \\
\hline & 2464 & Base d'un gobelet non décoré & fig. 220 et $221, n^{\circ} 14$ \\
\hline & 2464 & Base d'un gobelet non décoré & fig. 220 et $221, n^{\circ} 15$ \\
\hline & 2464 & Bouteille soufflée dans un moule & fig. $226, n^{\circ} 1$ \\
\hline & 2464 & Fond d'une bouteille soufflée dans un moule & fig. $226, n^{\circ} 2$ \\
\hline & 2464 & Goulot d'une bouteille soufflée dans un moule & fig. $226, n^{\circ} 3$ \\
\hline & 2439 & Goulot d'une ampoule-gutroff & fig. $222, n^{\circ} 4$ \\
\hline & 2439 & Goulot d'une ampoule-gutroff (?) & fig. $222, n^{\circ} 5$ \\
\hline & 2439 & Fond d'une ampoule-gutroff (?) & fig. $222, n^{\circ} 6$ \\
\hline & 2439 & Bouteille soufflée dans un moule & fig. $223, n^{\circ} 1$ \\
\hline & 2439 & Bouteille soufflée dans un moule & fig. 224 et $225, n^{\circ} 1$ \\
\hline & 2439 & Fond d'une bouteille soufflée dans un moule & fig. 224 et $225, n^{\circ} 2$ \\
\hline & 2439 & Goulot & fig. $228, n^{\circ} 2$ \\
\hline & 2427 & Verre à jambe à décor de mufle de lion & fig. $229, n^{\circ} 3$ \\
\hline \multirow{3}{*}{$\begin{array}{l}\text { Villeneuve-Bargemon } \\
\text { (2002) BRG02 }\end{array}$} & 5126 & Paroi de gobelet décorée d'une goutte étirée & fig. 214 et $215, n^{\circ} 5$ \\
\hline & 5129 & Paroi de gobelet décorée d'une goutte étirée & fig. 214 et $215, n^{\circ} 6$ \\
\hline & 5343 & Fond d'une bouteille soufflée dans un moule & fig. $222, n^{\circ} 1$ \\
\hline \multirow[t]{13}{*}{ Alcazar } & 1299 & $\begin{array}{l}\text { Base de paroi de gobelet à goutte étirée } \\
\text { (+ fond à anneau appliqué) }\end{array}$ & fig. 214 et $215, n^{\circ} 1$ \\
\hline & 4338 & Paroi de gobelet décorée d'une goutte étirée & fig. 214 et $215, n^{\circ} 2$ \\
\hline & 4338 & Fond de gobelet à décor de gouttes rapportées (?) & fig. 214 et $215, n^{\circ} 8$ \\
\hline & 11039 & Paroi de gobelet décorée d'une goutte étirée & fig. 214 et $215, n^{\circ} 3$ \\
\hline & 11114 & Paroi de gobelet décorée d'une goutte étirée & fig. 214 et $215, n^{\circ} 4$ \\
\hline & 7398 & Bouteille bicolore & fig. 216 et $217, n^{\circ} 1$ \\
\hline & 8015 & Fragments bicolores & fig. 216 et $217, n^{\circ} 2$ \\
\hline & 4276 & Verre à tige & fig. $218, n^{\circ} 2$ \\
\hline & 4437 & Verre à tige & fig. $218, n^{\circ} 3$ \\
\hline & 8015 & Paroi d'un gobelet moulé (pastilles & fig. 220 et $221, n^{\circ} 4$ \\
\hline & 4520 & Base d'un gobelet moulé (côtes hélicoïdales) & fig. $219, n^{\circ} 4$ \\
\hline & 4348 & Base d'un gobelet moulé (côtes hélicoïdales) & fig. $219, n^{\circ} 5$ \\
\hline & 4348 & Base d'un gobelet moulé (côtes hélicoïdales) & fig. $219, n^{\circ} 6$ \\
\hline
\end{tabular}




\begin{tabular}{|c|c|c|c|}
\hline \multirow{8}{*}{ Alcazar } & 4348 & Base d'un gobelet moulé (décor rayonnant) & fig. 220 et $221, n^{\circ} 5$ \\
\hline & 4348 & Rebord de gobelet formé d'un filet bleu & fig. 220 et $221, n^{\circ} 11$ \\
\hline & 11001 & Base d'un gobelet moulé (côtes) & fig. 220 et $221, n^{\circ} 1$ \\
\hline & 11116 & Base d'un gobelet moulé (côtes) & fig. 220 et $221, n^{\circ} 2$ \\
\hline & 11116 & Base d'un gobelet non décoré & fig. 220 et $221, n^{\circ} 12$ \\
\hline & 11007 & Paroi d'un gobelet moulé (pastilles) & fig. 220 et $221, n^{\circ} 3$ \\
\hline & 7208 & Goulot d'une ampoule-gutroff & fig. $222, n^{\circ} 1$ \\
\hline & 7202 & Goulot d'une bouteille soufflée dans un moule & fig. $227, n^{\circ} 2$ \\
\hline \multirow{4}{*}{ Rue Trinquet } & 2017 & Paroi décorée d'une goutte formée d'un fil enroulé & fig. 214 et $215, n^{\circ} 18$ \\
\hline & 2017 & Verre à tige côtelé & fig. $218, n^{\circ} 1$ \\
\hline & 2017 & Gobelet moulé (fond à décor rayonnant) & fig. 220 et $221, n^{\circ} 10$ \\
\hline & 2017 & Fond d'une bouteille soufflée dans un moule & fig. $227, n^{\circ} 6$ \\
\hline \multirow{2}{*}{ Tunnel de la Major } & 2426 & Base d'un gobelet à décor de gouttes étirées & fig. 214 et $215, n^{\circ} 7$ \\
\hline & 3128 & Base d'un gobelet à pied annulaire bleu & fig. 220 et $221, n^{\circ} 16$ \\
\hline \multirow{15}{*}{$\begin{array}{l}\text { Place Général-de-Gaulle } \\
\text { Zone } 1\end{array}$} & $1-695$ & Paroi de gobelet décorée d'une goutte étirée & fig. 214 et $215, n^{\circ} 13$ \\
\hline & $1-411$ & $\begin{array}{l}\text { Paroi d'un gobelet à décor de } \\
\text { gouttes étirées sur } 2 \text { rangs }\end{array}$ & fig. 214 et $215, n^{\circ} 14$ \\
\hline & $1-447$ & $\begin{array}{l}\text { Paroi de gobelet décorée d'une goutte } \\
\text { étirée et d'un filet appliqué }\end{array}$ & fig. 214 et $215, n^{\circ} 15$ \\
\hline & $1-212$ & Verre à tige & fig. $218, n^{\circ} 4$ \\
\hline & 3-476 & Verre à tige & fig. $218, n^{\circ} 5$ \\
\hline & $1-201$ & Base d'un gobelet moulé à décor rayonnant & fig. 220 et $221, n^{\circ} 7$ \\
\hline & $1-204$ & Verre à tige & fig. $218, n^{\circ} 6$ \\
\hline & $1-100$ & Goulot d'une ampoule-gutroff & fig. $222, n^{\circ} 2$ \\
\hline & $1-259$ & Goulot d'une ampoule-gutroff & fig. $222, n^{\circ} 3$ \\
\hline & $1-283$ & Goulot d'une bouteille soufflée dans un moule & fig. $227, n^{\circ} 3$ \\
\hline & $1-145$ & Fond d'une bouteille soufflée dans un moule & fig. $227, n^{\circ} 4$ \\
\hline & $1-145$ & Goulot & fig. $228, n^{\circ} 3$ \\
\hline & $1-120$ & Fond d'une bouteille soufflée dans un moule & fig. $227, n^{\circ} 5$ \\
\hline & $1-340$ & Goulot d'une bouteille & fig. $227, n^{\circ} 9$ \\
\hline & $1-340$ & Fond d'une bouteille non décorée & fig. $227, n^{\circ} 10$ \\
\hline \multirow{4}{*}{ Zone 2} & $2-362$ & Base d'un gobelet moulé à décor rayonnant & fig. 220 et $221, n^{\circ} 6$ \\
\hline & $2-809$ & Base d'un gobelet moulé à décor rayonnant & fig. 220 et $221, n^{\circ} 8$ \\
\hline & $2-809$ & Base d'un gobelet moulé à décor rayonnant & fig. 220 et $221, n^{\circ} 9$ \\
\hline & $2-249$ & Pied d'un verre $X V^{e}-X V l^{e}$ siècle & fig. $229, n^{\circ} 1$ \\
\hline \multirow{7}{*}{ Zone 3} & $3-541$ & Paroi de gobelet décorée d'une goutte étirée & fig. 214 et $215, n^{\circ} 11$ \\
\hline & $3-459$ & Base d'un gobelet à décor de gouttes étirées & fig. 214 et $215, n^{\circ} 16$ \\
\hline & $3-408$ & Base d'un gobelet à décor de gouttes étirées (?) & fig. 214 et $215, n^{\circ} 17$ \\
\hline & 3-362 & Pied d'un verre à tige (?) & fig. $218, n^{\circ} 8$ \\
\hline & $3-374$ & Rebord d'un gobelet moulé (côtes hélicoïdales) & fig. $211, n^{\circ} 1$ \\
\hline & $3-262$ & Base d'un gobelet moulé (côtes hélicoïdales) & fig. $211, n^{\circ} 2$ \\
\hline & $3-238$ & Pied d'un verre $X V^{e}-X V l^{e}$ siècle & fig. $229, n^{\circ} 2$ \\
\hline Zone 4 & $4-271$ & Paroi de gobelet décorée d'une goutte étirée & fig. 214 et $215, n^{\circ} 12$ \\
\hline \multirow[t]{2}{*}{ Rue Leca } & 2001 & Goulot & fig. $228, n^{\circ} 1$ \\
\hline & 2001 & Rebord gravé moderne & fig. $229, n^{\circ} 7$ \\
\hline \multirow{2}{*}{$\begin{array}{l}\text { Place Jules-Verne } \\
\text { Zone } 5\end{array}$} & JV5-296 & Verre à tige & fig. $218, n^{\circ} 7$ \\
\hline & JV5-181 & Goulot d'une bouteille soufflée dans un moule & fig. $227, n^{\circ} 7$ \\
\hline
\end{tabular}


ANNEXES

\begin{tabular}{|l|l|l|l|}
\hline \multirow{3}{*}{$\begin{array}{l}\text { Zlace Jules-Verne } \\
\text { Zone 5 }\end{array}$} & JV5-181 & Fond d'une bouteille soufflée dans un moule & fig. 227, $\mathrm{n}^{\circ} 8$ \\
\cline { 2 - 4 } & JV5-302 & Verre conique à jambe soufflée dans un moule & fig. 229, $\mathrm{n}^{\circ} 4$ \\
\cline { 2 - 4 } & JV5-302 & Jambe moulurée & fig. 229, $\mathrm{n}^{\circ} 5$ \\
\cline { 2 - 4 } & JV5-302 & Jambe moulurée d'une tazza & fig. 229, $\mathrm{n}^{\circ} 6$ \\
\hline \multirow{2}{*}{ Ilot 24 N } & $2-103$ & Base d'un gobelet à côtes hélicoïdales & fig. $219, \mathrm{n}^{\circ} 3$ \\
\hline
\end{tabular}


Annexe 3

\section{Les monnaies}

\begin{tabular}{|c|c|c|c|c|c|c|c|c|}
\hline Fouille & $n^{\circ}$ inv & Zone & Contexte & Autorité & dénomination & légende droit & description droit & légende revers \\
\hline Alcazar & 859 & $\mathrm{Z1}$ & 1006 & Moderne & ind. & ind. & dans le champ N[ ]L & ind. \\
\hline Alcazar & 826 & $\mathrm{Z1}$ & 1161 & Louis XIV (1643-1715) & $\begin{array}{c}\text { six deniers (dardenne) } \\
\text { en } 2 \text { fragments }\end{array}$ & ind. & ind. & traces \\
\hline Alcazar & 887 & $\mathrm{Z1}$ & 1161 & ind. & Objet monétiforme & $\begin{array}{l}\text { sur une face, } \\
\text { quadrillage au centre }\end{array}$ & & \\
\hline Alcazar & 885 & $\mathrm{Z1}$ & 1176 & ind. & ind.(4 fragments) & ind. & ind. & ind. \\
\hline Alcazar & 886 & $\mathrm{Z1}$ & 1176 & ind. & ind.(fragment) & ind. & ind. & ind. \\
\hline Alcazar & 506 & $\mathrm{Z1}$ & 1192 & ind. & ind. & ind. & ind. & ind. \\
\hline Alcazar & 520 & $\mathrm{Z1}$ & 1265 & & petit denier & AVINIO & clef & NE-NS-IS \\
\hline Alcazar & 521 & $\mathrm{Z1}$ & 1265 & \begin{tabular}{|c|} 
Raymond VII de \\
Toulouse (1222-1249)
\end{tabular} & denier raimondin & [R.CO]MES & $\begin{array}{l}\text { étoile à } 6 \text { rais } \\
\text { et croissant }\end{array}$ & $\mathrm{D}[-\mathrm{V}-\mathrm{X}]-\mathrm{M}$ \\
\hline Alcazar & 517 & Z2 & 2125 & $\begin{array}{l}\text { Henri de Dombes } \\
\quad(1592-1608)\end{array}$ & liard & $\begin{array}{l}\text { [H.P.DOMBAR.D.] } \\
\text { MONTISP[.M. }\end{array}$ & $\begin{array}{l}\text { H couronnée } \\
\text { entre } 3 \text { lis }\end{array}$ & $\begin{array}{l}\text { [DNS.ADIVTOR. } \\
\text { MEVS.millésime] }\end{array}$ \\
\hline Alcazar & 860 & $\mathrm{Z2}$ & 2125 & $X V I I^{e} s$. & Jeton (?) & & $\begin{array}{l}\text { personnage assis } \\
\text { à g.sur un siège } \\
\text { sans dossier.ll } \\
\text { tient une hampe } \\
\text { des deux mains }\end{array}$ & \\
\hline Alcazar & 861 & $\mathrm{Z3}$ & 3034 & ind. & ind. Concrétions & ind. & ind. & ind. \\
\hline Alcazar & 892 & Z3 & 3049 & $\begin{array}{l}\text { Robert d'Anjou } \\
(1309-1343)\end{array}$ & Obole & IERL:ET:SICIL:REX & $\begin{array}{c}\text { couronne surmontant } \\
\text { les lettres } R O B / T\end{array}$ & COMES PVINCIE \\
\hline Alcazar & 513 & Z3 & 3139 & $\begin{array}{l}\text { Louis XIIIII } \\
(1643-1715)\end{array}$ & $\begin{array}{l}\text { Six deniers } \\
\text { (dardennes) }\end{array}$ & $\begin{array}{l}\text { [LOUISXIII.ROY. } \\
\text { DE.FRANCE. } \\
\text { ET.DE.NAV] }\end{array}$ & $\begin{array}{c}\text { Trois groupes de } \\
\text { deux L adossées, } \\
\text { chacun sous une } \\
\text { couronne, posés en } \\
\text { triangle. Cantonnés } \\
\text { de trois lis divergeant. } \\
\text { Au centre marque } \\
\text { de l'atelier d'Aix }\end{array}$ & $\begin{array}{l}\text { SIX.DENIERS. } \\
\text { DE.FRANCE.17.. }\end{array}$ \\
\hline Alcazar & 514 & $\mathrm{Z3}$ & 3139 & ind. & $\begin{array}{l}\text { Six deniers } \\
\text { (dardennes) }\end{array}$ & ind. & $\begin{array}{l}\text { traces de trois } \\
\text { groupes de deux } \\
\mathrm{L} \text { adossées. }\end{array}$ & ind. \\
\hline Alcazar & 515 & Z3 & 3139 & Louis XV (1715-1774) & double sol & $\begin{array}{l}\text { LVD.XV.D.G.[FR. } \\
\text { ET.NAV.REX] }\end{array}$ & $\begin{array}{l}\text { L couronné entre } \\
3 \text { lis posés } 2 \text { et } 1\end{array}$ & $\begin{array}{c}\text { SIT.NOM. } \\
\text { DOM.P[BENEDICTVM]1739 }\end{array}$ \\
\hline Alcazar & 508 & $\mathrm{Z3}$ & 3159 & & plomb de scellement & PONNV sur une face & & \\
\hline
\end{tabular}




\begin{tabular}{|c|c|c|c|c|c|c|c|}
\hline description revers & atelier & date & métal & $\begin{array}{l}\text { poids } \\
\text { en } \mathrm{g} \text {. }\end{array}$ & module & réf. Biblio & Référence Bouiron et al. 2011 \\
\hline Croix florencée & & $\begin{array}{l}\text { première moitié } \\
\text { XVIIII } \mathrm{s} \text {. }\end{array}$ & alliage $\mathrm{cu}$ & 1,16 & 21 & & $\begin{array}{l}\text { parcelle } 41 \text {, remblai de nivellement } \\
(\text { p.413, col. d.) XVIII-XVIII } s \text {. }\end{array}$ \\
\hline \multirow[t]{2}{*}{ ind. } & & début XVIII $\mathrm{e}$. & alliage $\mathrm{cu}$ & 2,7 & 25 & & $?$ \\
\hline & & ind. & alliage $\mathrm{cu}$ & 2,25 & 21 & & $?$ \\
\hline ind. & & XIII $\mathrm{s}$ & alliage $\mathrm{cu}$ & & & & $\begin{array}{l}\text { fondation du mur de la parcelle } 40 \\
\text { sur la rue (p. } 413 \text { col. g.) mi XVII e ? }\end{array}$ \\
\hline ind. & & $X I I I^{e}-X V^{e} s .(?)$ & alliage $\mathrm{cu}$ & & & & $\begin{array}{l}\text { fondation du mur de la parcelle } 40 \\
\text { sur la rue (p. } 413 \text { col. g.) mi XVII } ?\end{array}$ \\
\hline ind. & ind. & v.XII s. (?) & & 0,52 & & & $\begin{array}{l}\text { comblement d'aire de gachage liée } \\
\text { à la construction des murs dans les } \\
\text { aprcelles } 41 \text { et } 42 \text { (p. } 407 \text { col. g.) }\end{array}$ \\
\hline $\begin{array}{l}\text { Croix coupant } \\
\text { la légende }\end{array}$ & & XIII s. & $\mathrm{Ag}$ & 0,39 & 16 & $\begin{array}{c}\text { Poey d'Avant, } n^{\circ} 4131 \text {, } \\
\text { pl.XCIII, } n^{\circ} 16\end{array}$ & $\begin{array}{l}\text { Niveau de cailloutis, première } \\
\text { recharge de la voie orientale } \\
\text { (p. } 380 \text { col. d.) } 2^{\mathrm{e}} \text { moitié } X I I^{\mathrm{e}} \mathrm{s} \text {. }\end{array}$ \\
\hline $\begin{array}{l}\text { Croix de Toulouse } \\
\text { longue }\end{array}$ & & v. 1250 & alliage $\mathrm{cu}$ & 0,52 & 16 & \begin{tabular}{|c|} 
Poey d'Avant, ${ }^{\circ} 3723-3725$ \\
pl.LXXXI, 17Moesgaard, \\
BSFN, 1989, 8, p.645- \\
$649 ; 1996,5$, p.91 \\
\end{tabular} & $\begin{array}{l}\text { Niveau de cailloutis, première } \\
\text { recharge de la voie orientale } \\
\text { (p. } 380 \text { col. d.) } 2^{2} \text { moitié XIIIle } s \text {. }\end{array}$ \\
\hline $\begin{array}{l}\text { Croix pattée, evidée } \\
\text { et anglée de feuilles }\end{array}$ & & & alliage $\mathrm{cu}$ & 0,92 & 15 & $\begin{array}{l}\text { Poey d'Avant, } n^{\circ} 5155 \text {, } \\
\text { pl.CXVI, } n^{\circ} 13\end{array}$ & $\begin{array}{l}\text { Comblement de fosse à chaux } \\
\text { (p. } 415 \text { col. g.) v. } 1720-1730\end{array}$ \\
\hline $\begin{array}{l}\text { en trois lignes [ ] ]/.. } \\
\text { RI/.E à l'exergue } 167 .\end{array}$ & & dernier tiers $\mathrm{XVIII}{ }^{\mathrm{e}} \mathrm{s}$. & alliage $\mathrm{cu}$ & 2,35 & 18 & & $\begin{array}{l}\text { Comblement de fosse à chaux } \\
\text { (p. } 415 \text { col. g.) v. } 1720-1730\end{array}$ \\
\hline ind. & & ind. & alliage $\mathrm{cu}$ & 5,89 & 31 & & \\
\hline $\begin{array}{c}\text { Croix pattée } \\
\text { cantonnée au } \\
\text { deuxième canton } \\
\text { d'un lis } \\
\end{array}$ & Avignon & $1330-1337$ & alliage $\mathrm{cu}$ & 0,31 & 15 & H.Rolland, $n^{\circ} 54$ & $\begin{array}{l}\text { Terres de jardin (p. } 403 \text { col. g.) } \\
\quad X V l^{\mathrm{e}}-1^{\mathrm{e}} \text { moitié } \mathrm{XVII} \text { s. ? }\end{array}$ \\
\hline $\begin{array}{l}\text { Crois anillée } \\
\text { fleurdelisée }\end{array}$ & Aix & $\begin{array}{l}\text { (ordonnance } 16 \\
\text { octobre 1709) }\end{array}$ & alliage $\mathrm{cu}$ & 4,19 & 26 & J.Duplessy, n¹593² & $\begin{array}{l}\text { Couche immédiatement antérieure au } \\
\text { réaménagement de l'auberge du Petit } \\
\text { Saint-Jean (p. 417-419) post. } 1754\end{array}$ \\
\hline ind. & ind. & & alliage cu & 4,82 & & & $\begin{array}{l}\text { Couche immédiatement antérieure au } \\
\text { réaménagement de l'auberge du Petit } \\
\text { Saint-Jean (p. 417-419) post. } 1754\end{array}$ \\
\hline \multirow[t]{2}{*}{$\begin{array}{l}\mathrm{L} \text { cursive et rameau } \\
\text { entrecroiséssous } \\
\text { une couronne }\end{array}$} & Dijon (P) & 1739 & billon & 1,62 & 21 & J.Duplessy, $n^{\circ} 1690$ & $\begin{array}{l}\text { Couche immédiatement antérieure au } \\
\text { réaménagement de l'auberge du Petit } \\
\text { Saint-Jean (p. 417-419) post. } 1754\end{array}$ \\
\hline & & & & 5,98 & & & $\begin{array}{l}\text { Sol de la parcelle } 18 \text { (p. } 417 \text { col. } \\
\text { d. + fig. 266) 1e moitié XVIIII s. }\end{array}$ \\
\hline
\end{tabular}




\begin{tabular}{|c|c|c|c|c|c|c|c|c|}
\hline Fouille & noinv $^{\circ}$ & Zone & Contexte & Autorité & dénomination & légende droit & description droit & légende revers \\
\hline Alcazar & 855 & Z3 & 3202 & & ind. & ind. & ind. & ind. \\
\hline Alcazar & 578 & & 3212 & Louis XIII (1610-1643) & double tournois & $\begin{array}{l}\text { [LOUIS XIII.R.DE. } \\
\text { FR]AN.ET.NAV }\end{array}$ & & DOUBLETOURNOIS16.. \\
\hline Alcazar & 579 & Z3 & 3212 & Louis XIII (1610-1643) & double tournois & ind. & ind. & DOUBLE TOURNOIS \\
\hline Alcazar & 465 & Z3 & 3215 & $\begin{array}{l}\text { Louis XIIII } \\
(1643-1715)\end{array}$ & $\begin{array}{l}\text { Six deniers } \\
\text { (dardennes) }\end{array}$ & $\begin{array}{l}\text { LOUISXIIII.ROY. } \\
\text { DE.FRANCE. } \\
\text { ET.DE.NAV }\end{array}$ & \begin{tabular}{|c|} 
Trois groupes de deux \\
lettres adosséschacun \\
sous une couronne \\
posée en triangle. \\
Au centre marque \\
de l'atelier d'Aix \\
\end{tabular} & $\begin{array}{c}\text { SIX.DENIERS. } \\
\text { DE.FRANCE.1712 }\end{array}$ \\
\hline Alcazar & 851 & Z3 & 3225 & Moderne & $\begin{array}{l}\text { ind. Flan lisse } \\
\text { bien circulaire }\end{array}$ & ind. & ind. & ind. \\
\hline Alcazar & 893 & Z3 & 3231 & République française & 10 centimes & & $\begin{array}{l}\mathrm{R} F \text { de part et } \\
\text { d'autre d'un trou }\end{array}$ & \\
\hline Alcazar & 504 & Z3 & 3257 & Louis XIII (1610-1643) & double tournois & $\begin{array}{c}\text { LOVISXIII.R.D.FRAN. } \\
\text { ET.NAV.A }\end{array}$ & tête laurée du roi à g. & DOUBLETOURNOIS1642.. \\
\hline Alcazar & 518 & Z3 & 3264 & $\begin{array}{c}\text { Marie de Montpensier, } \\
\text { princesse de Dombes } \\
(1608-1626)\end{array}$ & liard & $\begin{array}{c}\text { [M.P.DOMBARD. } \\
\text { MONTISP] }\end{array}$ & $\begin{array}{c}\text { M couronnée } \\
\text { entre } 3 \text { lis }\end{array}$ & $\begin{array}{l}\text { [DNS.ADIVTOR. } \\
\text { MEVS.millésime] }\end{array}$ \\
\hline Alcazar & 519 & Z3 & 3284 & ind. & ind. & ind. & ind. & ind. \\
\hline Alcazar & 464 & Z3 & 3303 & ind. & ind. & ind. & ind. & ind. \\
\hline Alcazar & 824 & Z4 & 4015 & & $\begin{array}{l}6 \text { fragments } \\
\text { très fragiles }\end{array}$ & [ ...]ASTO[ & ind. & ind. \\
\hline Alcazar & 550 & Z4 & 4257 & Louis XIII (1610-1643) & double tournois & [LOVIS...]NAV & buste à dr. & [DOUBLE TOURNOIS date] \\
\hline Alcazar & 1156 & Z4 & 4260 & ind. & 4 fragments & ind. & ind. & ind. \\
\hline Alcazar & 511 & Z4 & 4261 & $\begin{array}{c}\text { Gaston d'Orléans, } \\
\text { prince des Dombes } \\
(1627-1650)\end{array}$ & double tournois & $\begin{array}{c}\text { GASTON.VSVE } \\
\text { DE.L[A.SOV.DOM] }\end{array}$ & Buste & DOVBLE TOVRNOIS 1642 \\
\hline Alcazar & 512 & Z4 & 4261 & Louis XIII (1610-1643) & double tournois & $\begin{array}{l}\text { LOIVISXIII.R.DE. } \\
\text { FRAN.ET.DE.NAV] }\end{array}$ & Buste du Roi à dr. & DOUBLE TOURNOIS $16 .$. \\
\hline Alcazar & 847 & Z4 & 4277 & ind. & ind. (fragment) & ind. & ind. & ind. \\
\hline Alcazar & 462 & Z4 & 4338 & \begin{tabular}{|c|} 
République de Gênes \\
doge Tommaso \\
de Campofregoso \\
$(1436-1442)$
\end{tabular} & & [ ]IAII:XX[ ] & porte dans un grènetis & $+C O[N R A] D$ (fleur)REX:RO \\
\hline Alcazar & 461 & Z4 & 4354 & |ère République & 5 centimes & $\begin{array}{l}\text { REPUBLIQUE } \\
\text { FRANCAISE }\end{array}$ & $\begin{array}{c}\text { Buste de la } \\
\text { République à g. au } \\
\text { dessous, DUPRE } \\
\text { en cursive }\end{array}$ & \\
\hline Alcazar & 884 & Z4 & 4354 & ind. & ind.(fragment) & ind. & ind. & ind. \\
\hline Alcazar & 460 & Z4 & 4425 & $\begin{array}{l}\text { Alphonse I et } \\
\text { II d'Aragon } \\
\text { (1167-1196-1209) }\end{array}$ & $\begin{array}{l}\text { obole du royal } \\
\text { coronat (fragment) }\end{array}$ & REX A[RAGONE] & $\begin{array}{c}\text { tête couronnée à g. } \\
\text { couronne à } 3 \text { points } \\
\text { pleins sur le bandeau, } \\
\text { point plein au sommet. }\end{array}$ & PO-V[I-NC-I]A \\
\hline Alcazar & 1145 & Z4 & 4441 & ind. & ind. & ind. & ind. & ind. \\
\hline
\end{tabular}




\begin{tabular}{|c|c|c|c|c|c|c|c|}
\hline description revers & atelier & date & métal & $\begin{array}{l}\text { poids } \\
\text { en g. }\end{array}$ & module & réf. Biblio & Référence Bouiron et al. 2011 \\
\hline ind. & & ind. & alliage $\mathrm{cu}$ & 1,42 & 16 & & $\begin{array}{l}\text { Terres de jardin (p. } 403 \text { col. g.) } \\
\quad X V l^{\mathrm{e}}-1^{\mathrm{e}} \text { moitié } \mathrm{XVII} \text { s. ? }\end{array}$ \\
\hline & & Entre 162 et 1643 & & 2,61 & & & ? \\
\hline ind. & & $\begin{array}{l}\text { deuxième moitié } \\
\text { XVIII } s .\end{array}$ & alliage cu & 1,22 & 19 & & $?$ \\
\hline $\begin{array}{l}\text { croix anilée } \\
\text { fleurdelisée }\end{array}$ & $\begin{array}{l}\text { Aix-en- } \\
\text { Provence }\end{array}$ & $\begin{array}{l}1712 \text { (à partir du } \\
16 \text { octobre } 1709 \text { ) }\end{array}$ & $\mathrm{cu}$ & 4,94 & 25 & & $\begin{array}{l}\text { Couche antérieure à la } \\
\text { reconstruction de la parcelle } 18 \\
\text { (p. } 417 \text { col. d.) début XVIII s. ? }\end{array}$ \\
\hline ind. & & $X V I^{\prime} I^{e} s$. & alliage cu & 3,3 & 22 & & $\begin{array}{l}\text { Sol de la pièce } 17 \mathrm{C} \text { (p. } 419 \\
\text { col. g.) } 2^{\mathrm{e}} \text { moitié XVIII } \mathrm{s} \text {. }\end{array}$ \\
\hline $10 \mathrm{C}$ & & $X X^{e} s$ & alliage & 1,93 & 20 & & $?$ \\
\hline $\begin{array}{l}\text { Trois lis } 2 \text { et } 1 \text { dans } \\
\text { un cercle intérieur }\end{array}$ & Paris (A) & 1642 & alliage cu & 2,26 & 21 & J.Duplessy, II, n¹378 & $?$ \\
\hline $\begin{array}{l}\text { Croix pattée évidée } \\
\text { et anglée de feuilles }\end{array}$ & & & alliage $\mathrm{cu}$ & 0,52 & 15 & $\begin{array}{l}\text { Poey d'Avant, } n^{\circ} 5172 \text {, } \\
\text { pl.CXVII, } n^{\circ} 2\end{array}$ & $\begin{array}{l}\text { Terres de jardin (p. } 403 \text { col. g.) } \\
\quad X V l^{\mathrm{e}}-1^{\mathrm{e}} \text { moitié } \mathrm{XVII} \text { s. ? }\end{array}$ \\
\hline ind. & & $X V I I I{ }^{e} s$ & alliage $\mathrm{cu}$ & 1,66 & & & \\
\hline ind. & ind. & Moyen-Age & alliage cu & 2,44 & 20 & & \\
\hline ind. & & médiéval ou moderne & alliage $\mathrm{cu}$ & & & & $\begin{array}{l}\text { Remblai de nivellement de la parcelle } 20 \\
\text { sur la calade (p. } 412 \text { col. d.) fin XVIII s.? }\end{array}$ \\
\hline trois lis disposés 2 et 1 & & & $\mathrm{cu}$ & 1,56 & 20 & & $\begin{array}{l}\text { Mur de la parcelle } 19 \text { (p. 405- } \\
\text { 406) milieu XVII' s. ? }\end{array}$ \\
\hline ind. & & & alliage cu & 0,47 & & & $\begin{array}{l}\text { Comblement de la tranchée du mur de } \\
\text { la parcelle } 22 \text { (p. 405) milieu XVIII s. ? }\end{array}$ \\
\hline Trois lis posés 2 et 1 & & 1642 & alliage cu & 2,3 & 21 & $\begin{array}{l}\text { Poey d'Avant, II, n5201, } \\
\text { pl.CXVII, n } 17\end{array}$ & $\begin{array}{l}\text { Remblai sous la calade de la parcelle } \\
22 \text { (p. 405) } 1^{\mathrm{e}} \text { moitié } X \mathrm{~V} \|^{\mathrm{e}} \mathrm{s} \text {. ? }\end{array}$ \\
\hline Trois lis posés 2 et 1 & ind. & & alliage cu & 2,09 & 21 & & $\begin{array}{l}\text { Remblai sous la calade de la parcelle } \\
22\left(\text { p. 405) } 1^{\mathrm{e}} \text { moitié } X \mathrm{~V} I I^{\mathrm{e}} \mathrm{s} \text {. ? }\right.\end{array}$ \\
\hline ind. & & ind. & alliage cu & 0,28 & 12 & & \\
\hline $\begin{array}{l}\text { croix pattée dans } \\
\text { un grènetis }\end{array}$ & Gênes & $X V^{e} s$ & $\mathrm{Ag}$ & 0,45 & 16 & G.Lunardi, p.105 & $?$ \\
\hline $\begin{array}{l}\text { CINQ/CENTIMES/ } \\
\text { L'AN } 5 \text { (tranche } \\
\text { en chevrons) }\end{array}$ & Paris & 1796 & alliage cu & 10,02 & & $\begin{array}{c}\text { J.Mazard, Histoire } \\
\text { monétaire et numismatique } \\
\text { contemporaine, } 1790- \\
1963, \text { t.1, n²274 }\end{array}$ & $\begin{array}{l}\text { Comblement du puits ovoïde de } \\
\text { la parcelle } 21 \text { (p. 411-412) }\end{array}$ \\
\hline ind. & & ind. & alliage cu & & & & $\begin{array}{l}\text { Comblement du puits ovoïde de } \\
\text { la parcelle } 21 \text { (p. 411-412) }\end{array}$ \\
\hline $\begin{array}{l}\text { croix pattée coupant } \\
\text { la légende, chaque } \\
\text { branche ponctuépar } \\
3 \text { points pleins. }\end{array}$ & Marseille & à partir de 1186 & alliage $\mathrm{cu}$ & 0,15 & & H.Rolland, n¹2 & $\begin{array}{l}\text { Niveau de récupération du faubourg } \\
\text { médiéval (p. 402) v. } 1360\end{array}$ \\
\hline ind. & & & $\begin{array}{l}\text { alliage cu } \\
\text { percé calciné }\end{array}$ & 1,66 & & & \\
\hline
\end{tabular}




\begin{tabular}{|c|c|c|c|c|c|c|c|c|}
\hline Fouille & $n^{\circ}$ inv & Zone & Contexte & Autorité & dénomination & légende droit & description droit & légende revers \\
\hline Alcazar & 551 & Z4 & 4565 & & & ind. & ind. & ind. \\
\hline Alcazar & 577 & 4 & 4581 & $\begin{array}{l}\text { Raymond IV (III) } \\
(1314-1340)\end{array}$ & & +DEI[GRACIA] & $\begin{array}{l}\text { ds le champ RA } \\
\text { sous un cornet }\end{array}$ & [PRI:AVRASI]CE \\
\hline Alcazar & 576 & & 4581 & $\begin{array}{c}\text { Charles ler d'Anjou } \\
\quad(1245-1285)\end{array}$ & obole de Marseille & COMES PVINCIE & Tête du comte à g. & MAS SIL IEN SIS \\
\hline Alcazar & & $\mathrm{Z5}$ & 5220 & Louis XIII (1610-1643) & double tournois & $\begin{array}{c}\text { [LOVISX] } \\
\text { III R.D.[FRAN. } \\
\text { ET.DE.NAV.] }\end{array}$ & ind. & $\begin{array}{c}\text { [DOVBLE] } \\
\text { TOVRNOI[S(date)] }\end{array}$ \\
\hline Alcazar & 817 & Z5 & 5222 & Louis XIV (1643-1715) & six deniers (dardenne) & ind. & ind. & ind. \\
\hline Alcazar & 818 & $\mathrm{Z5}$ & 5222 & $\begin{array}{l}\text { Gaston d'Orléans, } \\
\text { prince des Dombes } \\
(1627-1650)\end{array}$ & double tournois & $\begin{array}{l}\text { +GASTON.VSVS } \\
\text { DE.LA.SOV.DOM }\end{array}$ & & $\begin{array}{l}\text { [DOVBLE TOVRNOIS } \\
\text { millésime] }\end{array}$ \\
\hline Alcazar & 782 & Z5 & 5229 & Moderne & ind. (fragment) & ind. & ind. & ind. \\
\hline Alcazar & 505 & Z5 & 5310 & & & + +R. ... REX & ind. & SIT:N ... VIN \\
\hline Alcazar & 554 & Z5 & 5421 & Louis XIII (1610-1643) & double tournois & $\begin{array}{c}\text { LOUIS XIII R.D.FRAN. } \\
\text { ET.NAVA.D. }\end{array}$ & $\begin{array}{l}\text { dans un cercle, } \\
\text { buste du roi à dr. }\end{array}$ & DOUBLE TOURNOIS 1637 \\
\hline Alcazar & 553 & Z5 & 5429 & $\begin{array}{c}\text { Gaston d'Orléans, } \\
\text { prince des Dombes } \\
(1627-1650)\end{array}$ & & $\begin{array}{l}\text { [GASTON.VSV.D] } \\
\text { E.LA.SO[V.DOM] }\end{array}$ & buste à dr. & DO[UBLE TOURNOI]S 1639 \\
\hline Alcazar & 763 & $\mathrm{Z} 5$ & 5587 & ind. & ind. (fragile) & ind. & ind. & ind. \\
\hline Alcazar & 784 & Z5 & 5587 & ind. & ind. (fragment) & ind. & ind. & ind. \\
\hline Alcazar & 467 & Z8 & 8001 & & $\begin{array}{l}\text { méreau percé } \\
\text { en son centre }\end{array}$ & $\begin{array}{l}\text { texte en lettres } \\
\text { gothiques illisibles }\end{array}$ & $\begin{array}{c}\text { dans un trilobe } \\
\text { double aux angles } \\
\text { saillants ponctués } \\
\text { de deux annelets, } \\
\text { un globe divisé } \\
\text { en trois parties et } \\
\text { surmonté d'une croix } \\
\end{array}$ & $\begin{array}{l}\text { texte en lettres } \\
\text { gothiques illisibles. }\end{array}$ \\
\hline Alcazar & 472 & Z9 & 9033 & & monnaie & ind. & buste à dr. & ind. \\
\hline Alcazar & 889 & Z11 & 11018 & ind. & $\begin{array}{l}\text { monnaie ind.3 } \\
\text { fragments }\end{array}$ & ind. & ind. & ind. \\
\hline Alcazar & 502 & Z11 & 11048 & $\begin{array}{l}\text { Raymond IV (III) } \\
(1314-1340)\end{array}$ & monnaie & +DEI.GRACIA & RA sous un cornet & [PRI:AV]RASICE \\
\hline Alcazar & 888 & Z11 & 11092 & ind. & en poudre & & & \\
\hline Alcazar & 503 & Z11 & 11142 & $\begin{array}{l}\text { Raymond-Berenger } \\
\quad \vee(1209-1245)\end{array}$ & $\begin{array}{l}\text { menut marseillais } \\
\text { (fragment) }\end{array}$ & [R:BE.CO.MES] & écu à 3 pals & {$[P \ldots] \mathrm{VI}[. . \mathrm{N} . . \mathrm{Cl} . . \mathrm{E}]$} \\
\hline Alcazar & 852 & Z3 & $3215 b$ & ind. & ind. & ind. & ind. & ind. \\
\hline Alcazar & 849 & Z4 & $4272 a$ & Médiévale & ind. Percée & +REX:[ ...] VS & motif dans un grènetis & E. . \\
\hline
\end{tabular}




\begin{tabular}{|c|c|c|c|c|c|c|c|}
\hline description revers & atelier & date & métal & $\begin{array}{l}\text { poids } \\
\text { en g. }\end{array}$ & module & réf. Biblio & Référence Bouiron et al. 2011 \\
\hline ind. & & $X I I I^{e}-X I V^{e} s$ & alliage $\mathrm{cu}$ & 0,3 & 15 & & $\begin{array}{l}\text { Recharge du sol de l'espace } 2 \mathrm{H} 2 \\
\text { (p. } 387 \text { col. d.) 1e moitié XIVe s. }\end{array}$ \\
\hline $\begin{array}{l}\text { Croix pattée } \\
\text { dans un cercle }\end{array}$ & & XIVe s. & & 0,17 & & $\begin{array}{l}\text { Poey d'Avant p.391, } \\
\text { n}^{\circ} 4490 \text { pl.XCVII, n9 }\end{array}$ & $\begin{array}{l}\text { 1er sol de l'espace } 2 \mathrm{H} 2 \text { ( } \mathrm{p} \text {. } \\
\text { 387) 1e moitié XIV's. }\end{array}$ \\
\hline \begin{tabular}{|c|} 
croix pattée coupant le \\
grènetis et la légende \\
trois points à chaque \\
extrémité de la croix \\
\end{tabular} & & 1257 & alliage $\mathrm{cu}$ & 0,38 & & $\begin{array}{l}\text { H.Rolland, p. } 206 \text {, } \\
\text { n²6 ou } 28\end{array}$ & $\begin{array}{l}\text { 1er sol de l'espace } 2 \mathrm{H} 2 \text { ( } \mathrm{p} . \\
387) \text { 1e moitié XIVe s. }\end{array}$ \\
\hline Trois lis posés 2 et 1 & ind. & & alliage cu & 1,7 & & & $\begin{array}{l}\text { Remblai dans l'espace occidental } \\
\text { de la parcelle } 28 \text { antérieur à } \\
\text { l'agrandissement de Louis XIV }\end{array}$ \\
\hline ind. & & début XVIIII s. & alliage $\mathrm{cu}$ & 4,56 & 25 & & Remblai dans la parcelle 28 fin $X V I I I{ }^{e} \mathrm{~s}$. \\
\hline $\begin{array}{l}3 \text { lis posés } 2 \text { et } 1 \\
\text { sous un lambel }\end{array}$ & & $\begin{array}{l}\text { deuxième quart } \\
\text { du XVIII } \mathrm{S} \text {. }\end{array}$ & alliage $\mathrm{cu}$ & 2,53 & 21 & & Remblai dans la parcelle 28 fin $X V I I I^{e} s$. \\
\hline ind. & & $\mathrm{XVII}$ s. & alliage cu & 0,68 & 17 & & $?$ \\
\hline Croix pleine & ind. & $X V I I I^{e}-X V I I I I^{e}$ s. (?) & & 0,63 & & & $\begin{array}{l}\text { Comblement de l'angle sud-ouest } \\
\text { de la parcelle } 30 \text { (plan p. } 424 \text { ) }\end{array}$ \\
\hline $\begin{array}{l}\text { dans un cercle } 3 \text { lis } \\
\text { disposée } 2 \text { et } 1\end{array}$ & Lyon & 1637 & alliage cu & 2,09 & & J.Duplessy, $n^{\circ} 1372$ & $\begin{array}{c}\text { Parcelle 28, postérieure à } \\
\text { la calade au moment de } \\
\text { l'agrandissement (p. 408-409) }\end{array}$ \\
\hline trois lis sous un lambel & & 1639 & $\mathrm{cu}$ & 1,73 & & $\begin{array}{l}\text { Poey d'Avant,III, p.105, } \\
\text { n5201, pl.CXVII, n²8 }^{\circ}\end{array}$ & $\begin{array}{l}\text { Parcelle } 28,1^{\mathrm{e}} \text { phase avant } \\
\text { l'agrandissement (p. 403-404) }\end{array}$ \\
\hline ind. & & ind. & alliage $\mathrm{cu}$ & 3,38 & 25 & & Collecteur contemporain \\
\hline ind. & & ind. & alliage cu & 0,75 & 16 env. & & Collecteur contemporain \\
\hline \begin{tabular}{|c|} 
Trois fleurs de lis \\
disposées en triangle \\
et alternant avec \\
trois couronnelles \\
surmontées d'annelets
\end{tabular} & & & & 1,23 & & & $\begin{array}{l}\text { Mur sud de l'espace 4B1 } \\
\quad \text { (p. 391) v. } 1300 ?\end{array}$ \\
\hline $\begin{array}{l}\text { Personnage debout } \\
\text { de face, tête à g., } \\
\text { corne d'abondance } \\
\text { sur le bras à dr. } \\
\end{array}$ & & romaine & alliage $\mathrm{cu}$ & 1,3 & & & ? \\
\hline ind. & & $X I I I^{e}-X I V{ }^{e} s$ & alliage $\mathrm{cu}$ & 0,04 & & & $\begin{array}{l}\text { Comblement de fosse de récupération } \\
\text { de l'espace } 4 \mathrm{D} \text { v. } 1360\end{array}$ \\
\hline Croix & & $1182-1235$ & alliage $\mathrm{cu}$ & 0,2 & 13 & $\begin{array}{c}\text { Poey d'Avant, II, } \\
\text { n }^{\circ} 4490, \text { pl.XCVII, n } 9\end{array}$ & $\begin{array}{l}\text { Comblement de fosse de récupération } \\
\text { de l'espace } 4 \mathrm{D} \text { v. } 1360\end{array}$ \\
\hline & & & & & & & $\begin{array}{l}\text { Remplissage de fosse dans } \\
\text { l'espace } 4 C 4 \text { (p. } 393 \text { col. d.) }\end{array}$ \\
\hline \begin{tabular}{|c|} 
Croix pattée coupant \\
la légende et un \\
cercle intérieur, un \\
globule au 1er canton, \\
trois globules aux \\
extrémités de la croix.
\end{tabular} & Marseille & 1243 & alliage cu & 0,24 & & H.Rolland ${ }^{\circ} 18$ & $\begin{array}{c}\text { Comblement d'une fosse contre le } \\
\text { fossé, contemporaine de la tannerie ??? } \\
\text { (non décrite dans la publi mais apparaît } \\
\text { sur le plan de la fig. 232, p. 369) }\end{array}$ \\
\hline $\begin{array}{l}\text { trace d'une } \\
\text { couronne? }\end{array}$ & & ind. & alliage cu & 3,75 & 24 & & $\begin{array}{l}\text { Couche antérieure à la } \\
\text { reconstruction de la parcelle } 18 \\
\text { (p. } 417 \text { col. d.) début XVIIII } \mathrm{s} \text {. ? }\end{array}$ \\
\hline $\begin{array}{l}\text { Croix dans un } \\
\text { double cercle }\end{array}$ & & XIII $\mathrm{s}$. & alliage cu & 0,86 & 18 & & $\begin{array}{l}\text { Remblai préalable à la construction } \\
\text { de la parcelle } 19 \text { (p. 412) }\end{array}$ \\
\hline
\end{tabular}




\begin{tabular}{|c|c|c|c|c|c|c|c|c|}
\hline Fouille & $n^{\circ}$ inv & Zone & Contexte & Autorité & dénomination & légende droit & description droit & légende revers \\
\hline Alcazar & 848 & Z4 & $4272 b$ & ind. & (fragment) & ]SOVIC[ & ind. & ind. \\
\hline Alcazar & 846 & Z4 & $4333 a$ & ind. & ind. & ind. & ind. & ind. \\
\hline Alcazar & 845 & Z4 & $4333 b$ & ind. & ind. & ind. & ind. & ind. \\
\hline Alcazar & 853 & Z2 & \begin{tabular}{|} 
Décapage \\
2101-2102- \\
$2103-2104$
\end{tabular} & USA & 1 cent & IN GOD WE TRVST & $\begin{array}{l}\text { le buste de Lincoln, } \\
\text { de part et d'autre } \\
\text { LIBERTY et } 1909\end{array}$ & \\
\hline Alcazar & 844 & Z8 & $8064 b$ & ind. & ind. & ind. & ind. & ind. \\
\hline $\begin{array}{c}\text { Tunnel de } \\
\text { la Major }\end{array}$ & 1 & Z3 & 3002 & Henri IV & douzain (6e type) & $\begin{array}{l}\text { HENRICVS. } \\
\text { IIII.D.G.FRA[ET]. } \\
\text { NAVAREX. }\end{array}$ & $\begin{array}{c}\text { écu de France } \\
\text { couronné, accosté } \\
\text { de deux H; à la } \\
\text { pointe de l'écu N }\end{array}$ & $\begin{array}{c}\text { [SIT] NOMEN.DNI. } \\
\text { BENEDICT.1593 }\end{array}$ \\
\hline $\begin{array}{c}\text { Tunnel de } \\
\text { la Major }\end{array}$ & 2 & $\mathrm{Z7}$ & 7014 & ind. & double tournois & ind. & ind. & [DOUBLE TOUR]NOIS \\
\hline $\begin{array}{c}\text { Tunnel de } \\
\text { la Major }\end{array}$ & 3 & Z3 & $3129-1$ & $\begin{array}{l}\text { Charles ler d'Anjou } \\
\quad(1246-1285)\end{array}$ & obole marseillaise & $\begin{array}{l}\text { +.COMES. } \\
\text { PROVINCIE }\end{array}$ & tête à g. & MAS-SIL-IEN-SIS \\
\hline $\begin{array}{c}\text { Tunnel de } \\
\text { la Major }\end{array}$ & 4 & Z3 & $3129-2$ & $\begin{array}{l}\text { Charles ler d'Anjou } \\
\quad(1246-1285)\end{array}$ & $\begin{array}{l}\text { tournois provençal } \\
\text { en } 3 \text { fragments } \\
\text { associables }\end{array}$ & ind. & ind. & PROV[ ] \\
\hline $\begin{array}{c}\text { Tunnel de } \\
\text { la Major }\end{array}$ & 5 & Z3 & $3129-3$ & $\begin{array}{l}\text { Alphonse ler et } \\
\text { Alphonse II d'Aragon } \\
\text { (1167-1196-1209) }\end{array}$ & royal coronat fragment & [RE]X:A[RAGONE] & tête à g. & ind. \\
\hline $\begin{array}{c}\text { Tunnel de } \\
\text { la Major }\end{array}$ & 6 & Z3 & 3314 & ind. & ind. & ind. & ind. & ind. \\
\hline $\begin{array}{c}\text { Tunnel de } \\
\text { la Major }\end{array}$ & 7 & Z6 & 6091 & $\begin{array}{l}\text { Alphonse ler et } \\
\text { Alphonse II d'Aragon } \\
\text { (1167-1196-1209) }\end{array}$ & royal coronat & REX.ARA.GONE & $\begin{array}{l}\text { tête couronnée du roi } \\
\text { à g. dans un grènetis }\end{array}$ & $\mathrm{PO} / \mathrm{VI} / \mathrm{NC} / \mathrm{IA}$ \\
\hline
\end{tabular}


ANNEXES

\begin{tabular}{|c|c|c|c|c|c|c|c|}
\hline description revers & atelier & date & métal & $\begin{array}{l}\text { poids } \\
\text { en } \mathrm{g} \text {. }\end{array}$ & module & réf. Biblio & Référence Bouiron et al. 2011 \\
\hline $\begin{array}{l}\text { Croix pattée, deux } \\
\text { fleurs de lis (?) }\end{array}$ & & ind. & alliage cu & 0,46 & 17 & & $\begin{array}{l}\text { Remblai préalable à la construction } \\
\text { de la parcelle } 19 \text { (p. 412) }\end{array}$ \\
\hline ind. & & ind. & alliage $\mathrm{cu}$ & 1,29 & 14 & & $\begin{array}{l}\text { Parcelle } 24 \text { avant l'agrandissement } \\
\text { (p. } 405 \text { col. g.) }\end{array}$ \\
\hline ind. & & ind. & alliage cu & 2,24 & 20 & & $\begin{array}{l}\text { Parcelle } 24 \text { avant l'agrandissement } \\
\text { (p. } 405 \text { col. g.) }\end{array}$ \\
\hline $\begin{array}{l}\text { entre deux épis de } \\
\text { blé ONE/CENT/ } \\
\text { UNITED STATES/ } \\
\text { OF AMERICA }\end{array}$ & & 1909 & $\mathrm{cu}$ & 2,34 & 19 & & Début de la fouille, contemporain \\
\hline ind. & & ind. & alliage $\mathrm{cu}$ & 1,82 & 20 & & $\begin{array}{l}\text { A l'intérieur de l'îlot de l'Alcazar, } \\
\text { avant la construction des } \\
\text { parcelles } 12-15 \text { (p. 414-415) }\end{array}$ \\
\hline $\begin{array}{l}\text { Croix échancrée, } \\
\text { cantonnée de deux } \\
\text { lis et de deux H } \\
\text { couronnées }\end{array}$ & Montpellier (N) & 1593 & billon & 1,66 & 24 & J.Duplessy, n¹251 & $\begin{array}{l}\text { Démolition de l'îlot devant } \\
\text { la cathédrale v. } 1855\end{array}$ \\
\hline $\begin{array}{l}\text { Très corrodée avec } \\
\text { perte de l'épiderme }\end{array}$ & & $\mathrm{XVII}{ }^{\mathrm{e}} \mathrm{s}$ & alliage $\mathrm{cu}$ & 1,58 & 20 & J.Duplessy,II,p.215-225 & $\begin{array}{l}\text { Sépulture au chevet de la } \\
\text { cathédrale (volume cathédrale } \\
\text { à paraître) fin XII'-XIV } \mathrm{s} \text {. }\end{array}$ \\
\hline $\begin{array}{l}\text { Croix qui coupe la } \\
\text { légende, chaque } \\
\text { hampe s'achève } \\
\text { par trois points. }\end{array}$ & Marseille & v.1257 & alliage $\mathrm{cu}$ & 0,29 & 14 & H.Rolland, $\mathrm{n}^{\circ} 26$ & $\begin{array}{l}\text { Remblai de préparation du sol } \\
\text { du 2e état moderne de la maison } \\
\text { du chapitre (volume cathédrale } \\
\text { à paraître) milieu XVIIII } s \text {. ? }\end{array}$ \\
\hline ind. & & v.1249 & alliage $\mathrm{cu}$ & 0,06 & & H.Rolland, $\mathrm{n}^{\circ} 20$ ou 22 & $\begin{array}{l}\text { Remblai de préparation du sol } \\
\text { du 2e état moderne de la maison } \\
\text { du chapitre (volume cathédrale } \\
\text { à paraître) milieu XVIII } s . ?\end{array}$ \\
\hline ind. & & $\begin{array}{l}\text { deuxième moitié } \\
\text { du XII } s .\end{array}$ & alliage $\mathrm{cu}$ & 0,08 & 15 & & $\begin{array}{l}\text { Remblai de préparation du sol } \\
\text { du 2e état moderne de la maison } \\
\text { du chapitre (volume cathédrale } \\
\text { à paraître) milieu XVIIII } \mathrm{s} \text { ? }\end{array}$ \\
\hline ind. & & ind. & alliage $\mathrm{cu}$ & 1,09 & 16 & & $\begin{array}{l}\text { Construction d'un puits au nord de } \\
\text { la rue Four-du-Chapitre (volume } \\
\text { cathédrale à paraître, visible sur la } \\
\text { fig. } 127 \text { p. 225) peut-être fin XII } s \text {. }\end{array}$ \\
\hline $\begin{array}{l}\text { Croix pattée } \\
\text { coupant la légende, } \\
\text { ponctuée de trois } \\
\text { globules pleins. }\end{array}$ & Marseille & $X I I I^{e} s$. & billon & 0,68 & 16 & H.Rolland, $n^{\circ} 13$ & $\begin{array}{c}\text { Sol de la maison 3B, deuxième } \\
\text { état (p. } 226 \text { col.g.) XIII s. ? }\end{array}$ \\
\hline
\end{tabular}




\section{Détail du mobilier métallique et en matières dures d'origine animale, par catégories fonctionnelles}

\begin{tabular}{|c|c|c|}
\hline $\mathrm{N}^{\circ}$ figure & Nature du contexte & Dimensions \\
\hline \multicolumn{3}{|c|}{1 - Anneaux et boucles circulaires } \\
\hline $237, n^{\circ} 1$ & Épandage, vraisemblable curage de four, XII siècle & Cadre : ép. = 0,05 cm \\
\hline $237, n^{\circ} 2$ & Remblai, chapelle Saint-Mauront, XVII siècle & Cadre : diam. fil $=0,09 \mathrm{~cm}$ \\
\hline $237, n^{\circ} 3$ & Comblement de fosse à chaux, vers $1720-1730$ & Cadre : ép. = 0,16 cm \\
\hline $237, n^{\circ} 4$ & Comblement de fosse, fin XIIIe - début XIVe siècle & Cadre : ép. $=0,13 \mathrm{~cm}$ \\
\hline $237, n^{\circ} 5$ & Remblai préparatoire de sol, chapelle Saint-Mauront, $X V I I^{e}$ siècle & Cadre : ép. $=0,2 \mathrm{~cm}$ \\
\hline $237, n^{\circ} 6$ & Remblai, porche Isarn, XVIII' siècle & Cadre : ép. = 0,19 cm \\
\hline $237, n^{\circ} 7$ & Décapage initial, moderne & Cadre : ép. $=0,15 \mathrm{~cm} ;$ Ardillon : diam. $=0,1 \mathrm{~cm}$ \\
\hline $237, n^{\circ} 8$ & Couche de démolition, $1^{\mathrm{e}}$ moitié $\mathrm{XIV}{ }^{\mathrm{e}}$ siècle & Cadre : ép. $=0,16 \mathrm{~cm} ;$ Ardillon : diam. $=0,1 \mathrm{~cm}$ \\
\hline $237, n^{\circ} 9$ & Comblement de puits, $\mathrm{XIVe}-\mathrm{XV}$ e siècles & Cadre : ép. = 0,28 cm \\
\hline $237, n^{\circ} 10$ & Comblement de caveau, cour sud, XIXe siècle & Cadre : ép. = 0,27 cm \\
\hline $237, n^{\circ} 11$ & Remblai, début XIVe siècle & Cadre : ép. = 0,33 cm \\
\hline $237, \mathrm{n}^{\circ} 12$ & Couche d'incendie, faubourg de Morier, milieu XIVe siècle & Cadre : ép. $=0,37 \mathrm{~cm}$; Ardillon : ép. $\max =0,2 \mathrm{~cm}$ \\
\hline $237, \mathrm{n}^{\circ} 13$ & Remblai, XIV $-X^{e}$ siècles & $\begin{array}{l}\text { Cadre : ép. } \max =0,34 \mathrm{~cm} ; \\
\text { Ardillon : ép. } \max =0,18 \mathrm{~cm}\end{array}$ \\
\hline $237, \mathrm{n}^{\circ} 14$ & Couche de destruction, moderne & Cadre : ép. $=0,39 \mathrm{~cm}$; Ardillon : ép. max $=0,2 \mathrm{~cm}$ \\
\hline \multicolumn{3}{|c|}{2 - Les boucles ovales à replat } \\
\hline $237, \mathrm{n}^{\circ} 15$ & Terres de jardin, fin XIVe - XVIIe siècle & Cadre : ép. $\max =0,37 \mathrm{~cm}$ \\
\hline $237, n^{\circ} 16$ & H.S. & Cadre : ép. $\max =0,34 \mathrm{~cm}$ \\
\hline \multicolumn{3}{|c|}{3 - Les boucles non circulaires à fenêtre unique } \\
\hline $238, n^{\circ} 1$ & Remblai, $2^{\mathrm{e}}$ quart vie - fin $\mathrm{Vl}^{\mathrm{e}}$ siècle & Cadre : ép. $\max =0,22 \mathrm{~cm}$ \\
\hline $238, n^{\circ} 2$ & Contexte inconnu & Cadre : ép. $\max =0,32 \mathrm{~cm}$ \\
\hline $238, n^{\circ} 3$ & Sol d'habitat, $1^{\mathrm{e}}$ moitié XIII - début XIVe siècle & Cadre : ép. max $=0,28 \mathrm{~cm}$ \\
\hline $238, n^{\circ} 4$ & Couche de ruissellement, non datée & Cadre : ép. $\max =0,53 \mathrm{~cm}$ \\
\hline $238, n^{\circ} 5$ & H.S. & Cadre : ép. $\max =0,24 \mathrm{~cm}$ \\
\hline $238, n^{\circ} 6$ & Calade de rue, fin XIII - début XIVe siècle & $\begin{array}{l}\text { Cadre : ép. } \max =0,23 \mathrm{~cm} ; \\
\text { Ardillon : diam. }=0,26 \mathrm{~cm}\end{array}$ \\
\hline $238, n^{\circ} 7$ & Couche d'incendie, faubourg du Morier, milieu XIVe siècle & Cadre : ép. max =0,29 cm \\
\hline $238, n^{\circ} 8$ & Comblement de puits, XIVe - XVe siècles & Cadre : ép. $\max =0,34 \mathrm{~cm}$ \\
\hline $238, n^{\circ} 9$ & Remblai, moderne ou contemporain & Cadre : ép. max = 0,37 cm \\
\hline $238, n^{\circ} 10$ & Comblement de fosse à chaux, vers 1720 - 1730 & Cadre : ép. $\max =0,38 \mathrm{~cm}$ \\
\hline $238, n^{\circ} 11$ & Remblai, vers 1750 & Cadre : ép. max = 0,42 cm \\
\hline $238, n^{\circ} 12$ & Couche de ruissellement, non datée & Cadre : ép. $=0,26 \mathrm{~cm}$ \\
\hline \multicolumn{3}{|c|}{4 - Les boucles à double fenêtre } \\
\hline $239, n^{\circ} 1$ & Remblai, XVIII siècle & $\begin{array}{l}\text { Cadre : ép. }=0,29 \mathrm{~cm} ; \\
\text { Chape : ép. tôle =0,08 cm }\end{array}$ \\
\hline $239, n^{\circ} 2$ & $\begin{array}{l}\text { Comblement de tranchée de fondation contemporaine } \\
\text { des travaux d'agrandissement de la chapelle des } \\
\text { Pénitents blancs de Saint-Lazare en } 1606\end{array}$ & Cadre : ép. max $=0,4 \mathrm{~cm}$ \\
\hline $239, n^{\circ} 3$ & H.S. & Cadre : ép. $\max =0,39 \mathrm{~cm}$ \\
\hline
\end{tabular}




\begin{tabular}{|c|c|c|}
\hline $239, n^{\circ} 4$ & Comblement de puits, $\mathrm{XIV}$ - $\mathrm{XV}^{\mathrm{e}}$ siècles & Cadre : ép. $\max =0,38 \mathrm{~cm}$ \\
\hline $239, n^{\circ} 5$ & Contexte inconnu & $\begin{array}{l}\text { Cadre : ép. } \max =0,24 \mathrm{~cm} ; \\
\text { Chape : ép. tôle }=0,05 \mathrm{~cm}\end{array}$ \\
\hline $239, n^{\circ} 6$ & Fosse de pestiférés, 1720 - 1722 & Cadre : ép. max = 0,25 cm \\
\hline $239, n^{\circ} 7$ & Remblai, vers 1750 & $\begin{array}{l}\text { Cadre : ép. } \max =0,35 \mathrm{~cm} ; \\
\text { Chape : ép. }=0,12 \mathrm{~cm}\end{array}$ \\
\hline $239, n^{\circ} 8$ & Remblai, $V^{e}-V^{e}$ siècles & $\begin{array}{l}\text { Cadre : ép. } \max =0,31 \mathrm{~cm} ; \\
\text { Chape : ép. }=0,1 / 0,12 \mathrm{~cm} ; \\
\text { Ardillon : ép. } \max =0,14 \mathrm{~cm}\end{array}$ \\
\hline $239, n^{\circ} 9$ & Remblai, vers 1750 & Cadre : ép. $\max =0,33 \mathrm{~cm}$ \\
\hline $239, n^{\circ} 10$ & Dépôt de latrine, fin $X V I^{\mathrm{e}}$ siècle & Cadre : ép. $\max =0,33 \mathrm{~cm}$ \\
\hline $239, n^{\circ} 11$ & Remblai d'installation de sépultures, 1720 & $\begin{array}{l}\text { Cadre : ép. } \max =0,43 \mathrm{~cm} ; \\
\text { Chape : ép. tôle }=0,25 \mathrm{~cm} ; \\
\text { Ardillon : ép. }=0,26 \mathrm{~cm}\end{array}$ \\
\hline \multicolumn{3}{|c|}{5 - Les ardillons isolés } \\
\hline $240, n^{\circ} 1$ & H.S. & ép. tôle = 0,27 cm \\
\hline $240, n^{\circ} 2$ & Comblement de tranchée de fondation, $\mathrm{XII}$ - début XIII siècle & ép. tôle $=0,17 / 0,25 \mathrm{~cm}$ \\
\hline $240, n^{\circ} 3$ & Sol d'habitat, faubourg Morier, fin XIIII - début XIVe siècle & ép. tôle = 0,33 cm \\
\hline \multicolumn{3}{|c|}{6 - Les mordants et chapes isolés } \\
\hline $240, n^{\circ} 4$ & 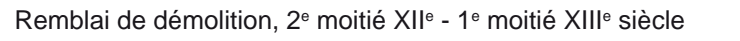 & ép. tôle = 0,12 cm \\
\hline $240, n^{\circ} 5$ & Terres de jardin, fin XIV ${ }^{e}$ XVII e siècle & ép. tôle = 0,07 cm \\
\hline $240, n^{\circ} 6$ & Ossuaire, porche Isarn, $2^{\mathrm{e}}$ moitié $\mathrm{XIV}{ }^{\mathrm{e}}$ siècle & ép. tôle = 0,05 cm \\
\hline $240, n^{\circ} 7$ & Contexte inconnu & ép. tôle $=0,07 / 0,1 \mathrm{~cm}$ \\
\hline \multicolumn{3}{|c|}{7 - Boucle en alliage cuivreux à chape intégrée } \\
\hline $238, n^{\circ} 13$ & Comblement de fosse, milieu - $2^{\mathrm{e}}$ moitié $\mathrm{XVII}$ siècle & ép. $\max =0,27 \mathrm{~cm}$ \\
\hline \multicolumn{3}{|c|}{8 - Boucle en os à chape intégrée } \\
\hline $238, n^{\circ} 14$ & Contexte des XIII' $-\mathrm{XIV}^{\mathrm{e}}$ siècles & ép. $=0,07 \mathrm{~cm}$ \\
\hline \multicolumn{3}{|c|}{9 - Les appliques métalliques } \\
\hline $241, n^{\circ} 1$ & Comblement de cuve, fin XIXe - début $X X^{e}$ siècle & ép. tôle = 0,04 cm \\
\hline $241, n^{\circ} 2$ & Comblement de cuve, fin $X I X^{e}$ - début $X X^{e}$ siècle & ép. tôle = 0,04 cm \\
\hline $241, n^{\circ} 3$ & Comblement, non datée & ép. tôle = 0,04 cm \\
\hline $241, n^{\circ} 4$ & Comblement de fosse, milieu XVIII - milieu XIX ${ }^{\mathrm{e}}$ siècle & ép. tôle = 0,04 cm \\
\hline $241, n^{\circ} 5$ & Remblai, ancienne sacristie, moderne & ép. tôle = 0,05 cm \\
\hline $241, n^{\circ} 6$ & Fosse, XII siècle & ép. $=0,25 \mathrm{~cm}$ \\
\hline $241, n^{\circ} 7$ & Remblai, moderne & ép. =0,31 cm \\
\hline $241, n^{\circ} 8$ & Foyer, fin XIII - début XIVe siècle & ép. $=0,25 \mathrm{~cm}$ \\
\hline $241, n^{\circ} 9$ & Contexte inconnu & ép. tôle = 0,12 cm \\
\hline $241, n^{\circ} 10$ & Comblement de fosse, fin XIII - début XIVe siècle & ép. $=0,25 \mathrm{~cm}$ \\
\hline $241, \mathrm{n}^{\circ} 11$ & Remblai, milieu XVIII siècle & ép. $=0,17 \mathrm{~cm}$ \\
\hline $241, n^{\circ} 12$ & Comblement de cuve, vers $1720-1730$ & ép. tôle $=0,07 \mathrm{~cm}$ \\
\hline $241, n^{\circ} 13$ & Comblement de fosse, fin XIII ${ }^{\mathrm{e}}$ - début $\mathrm{XIV}^{\mathrm{e}}$ siècle & ép. tôle = 0,11 cm \\
\hline $241, \mathrm{n}^{\circ} 14$ & Comblement de fosse, milieu XVIII - milieu XIXe siècle & ép. tôle $=0,05 \mathrm{~cm}$ \\
\hline $241, n^{\circ} 15$ & Comblement de tranchée, fin XIII - début XIVe siècle & ép. plaque $=0,16 / 0,26 \mathrm{~cm}$ \\
\hline $241, n^{\circ} 16$ & Comblement de tranchée de fondation, $\mathrm{XII}$ - début XIII siècle & ép. plaque $=0,09 \mathrm{~cm}$ \\
\hline 241, $\mathrm{n}^{\circ} 17$ & Remblai, XVIII' siècle & ép. plaque $=0,4 / 0,6 \mathrm{~cm}$ \\
\hline $241, \mathrm{n}^{\circ} 18$ & Remblai de destruction, milieu XIV ${ }^{e}$ siècle & ép. tôle = 0,11/0,12 cm \\
\hline \multicolumn{3}{|c|}{10 - Les appliques en nacre } \\
\hline $241, n^{\circ} 19$ & Ossuaire de caveau, $1694-\mathrm{XVIII}$ e siècle & ép. = 0,13 cm \\
\hline $241, n^{\circ} 20$ & Remblai, moderne ou contemporain & ép. $=0,17 \mathrm{~cm}$ \\
\hline
\end{tabular}




\begin{tabular}{|c|c|c|}
\hline \multicolumn{3}{|c|}{11 - Les boutons à trous } \\
\hline $242, n^{\circ} 1$ & Remblai, chapelle, 1731 & $\mathrm{~d} \times \mathrm{h}=2,2 \times 0,85 \mathrm{~cm}$ \\
\hline $242, n^{\circ} 2$ & Comblement de caniveau, milieu XIXe siècle & $\mathrm{d} \times \mathrm{h}=0,95 \times 0,27 \mathrm{~cm}$ \\
\hline $242, n^{\circ} 3$ & Remblai préparatoire de calade, $\mathrm{XIX}^{\mathrm{e}}$ siècle & $\mathrm{d} \times \mathrm{h}=1,6 \times 0,7 \mathrm{~cm}$ \\
\hline $242, n^{\circ} 4$ & Comblement de fosse, milieu XVIII - milieu XIX ${ }^{\mathrm{e}}$ siècle & $\mathrm{d} \times \mathrm{h}=1 \times 0,19 \mathrm{~cm}$ \\
\hline $242, n^{\circ} 5$ & Comblement de fosse, milieu XVIII - milieu XIX ${ }^{\mathrm{e}}$ siècle & $\mathrm{d} \times \mathrm{h}=1,1 \times 0,18 \mathrm{~cm}$ \\
\hline $242, n^{\circ} 6$ & Couche d'aménagement du théâtre de l'Alcazar, milieu XIXe siècle & $\mathrm{d} \times \mathrm{h}=1,1 \times 0,18 \mathrm{~cm}$ \\
\hline $242, n^{\circ} 7$ & Comblement de fosse, fin $\mathrm{XIX}^{\mathrm{e}}$ siècle & $\mathrm{d} \times \mathrm{h}=1,3 \times 0,19 \mathrm{~cm}$ \\
\hline $242, n^{\circ} 8$ & Comblement de fosse, milieu XVIII - milieu XIXe siècle & $\mathrm{d} \times \mathrm{h}=1,5 \times 0,22 \mathrm{~cm}$ \\
\hline $242, n^{\circ} 9$ & Comblement de fosse, milieu XVII - milieu XIX siècle & $\mathrm{d} \times \mathrm{h}=1,5 \times 0,2 \mathrm{~cm}$ \\
\hline $242, n^{\circ} 10$ & Comblement de fosse, milieu XVII - fin XIX siècle & $\mathrm{d} \times \mathrm{h}=1,7 \times 0,27 \mathrm{~cm}$ \\
\hline $242, n^{\circ} 11$ & Remblai, $2^{\mathrm{e}}$ moitié $\mathrm{XIX}{ }^{\mathrm{e}}$ siècle & $\mathrm{d} \times \mathrm{h}=1,7 \times 0,19 \mathrm{~cm}$ \\
\hline $242, n^{\circ} 12$ & Comblement de silo, $\mathrm{XI}^{\mathrm{e}}$ - XII siècles ? & $\mathrm{d} \times \mathrm{h}=1,7 \times 0,48 \mathrm{~cm}$ \\
\hline $242, n^{\circ} 13$ & Comblement de fosse, milieu XVII - fin XIXe siècle & $\mathrm{d} \times \mathrm{h}=1,8 \times 0,23 \mathrm{~cm}$ \\
\hline 242, $\mathrm{n}^{\circ} 14$ & Comblement de fosse, milieu XVII - milieu XIX ${ }^{e}$ siècle & $\mathrm{d} \times \mathrm{h}=1,85 \times 0,29 \mathrm{~cm}$ \\
\hline $242, n^{\circ} 15$ & Comblement de fosse, milieu XVIII ${ }^{\mathrm{e}}$ - milieu XIXe siècle & $\mathrm{d} \times \mathrm{h}=1,8 \times 0,19 \mathrm{~cm}$ \\
\hline $242, n^{\circ} 16$ & Comblement de fosse, milieu XVIII - milieu XIXe siècle & $\mathrm{d} \times \mathrm{h}=1,9 \times 0,45 \mathrm{~cm}$ \\
\hline 242, $\mathrm{n}^{\circ} 17$ & Comblement de fosse, milieu XVIIe - fin XIXe siècle & $\mathrm{d} \times \mathrm{h}=0,19 \times 0,24 \mathrm{~cm}$ \\
\hline $242, n^{\circ} 18$ & Comblement de cuve, fin $X I X^{e}$ - début $X X^{e}$ siècle & $\mathrm{d} \times \mathrm{h}=2 \times 0,22 \mathrm{~cm}$ \\
\hline 242, $\mathrm{n}^{\circ} 19$ & H.S. & $\mathrm{d} \times \mathrm{h}=2,1 \times 0,28 \mathrm{~cm}$ \\
\hline $242, n^{\circ} 20$ & Comblement de fosse, milieu XVIII ${ }^{\mathrm{e}}$ - milieu XIX ${ }^{\mathrm{e}}$ siècle & $\mathrm{d} \times \mathrm{h}=2,5 \times 0,32 \mathrm{~cm}$ \\
\hline \multicolumn{3}{|c|}{12 - Les boutons à bélière } \\
\hline $243, n^{\circ} 1$ & Remblai de démolition, $2^{\mathrm{e}}$ moitié $\mathrm{XIII}{ }^{\mathrm{e}}$ siècle & \\
\hline $243, n^{\circ} 2$ & Comblement de cuve, fin $\mathrm{XIXe}$ - début $20^{\mathrm{e}}$ siècle & ép. tôle = 0,05 cm \\
\hline $243, n^{\circ} 3$ & Remblai, $2^{\mathrm{e}}$ moitié XVIII' siècle & ép. tôle = 0,04 cm \\
\hline $243, n^{\circ} 4$ & Remblai, $1^{\mathrm{e}}$ moitié XVIII siècle & ép. tôle $=0,04 \mathrm{~cm}$ \\
\hline $243, n^{\circ} 5$ & Remblai, XVIIII siècle & \\
\hline $243, n^{\circ} 6$ & Remblai, $3^{e}$ quart $\mathrm{XVIII}{ }^{\mathrm{e}}$ siècle & ép. tôle = 0,15 cm \\
\hline $243, n^{\circ} 7$ & Remblai d'abandon, $2^{\mathrm{e}}$ moitié $\mathrm{XVIII}{ }^{\mathrm{e}}$ siècle & ép. tôle = 0,14 cm \\
\hline $243, n^{\circ} 8$ & H.S. & ép. tôle = 0,06 cm \\
\hline $243, n^{\circ} 9$ & Ossuaire de caveau, 1694 - XVIIII siècle & ép. tôle = 0,09 cm \\
\hline $243, n^{\circ} 10$ & Remblai ?, fin XVIIle - ? & ép. tôle = 0,07 cm \\
\hline $243, n^{\circ} 11$ & Remblai, début XVIII siècle & ép. tôle = 0,11 cm \\
\hline $243, n^{\circ} 12$ & Comblement de cave, moderne ou contemporain & ép. tôle = 0,05 cm \\
\hline $243, n^{\circ} 13$ & Remblai, chapelle, 1731 & ép. tôle $=0,12 \mathrm{~cm}$ \\
\hline $243, n^{\circ} 14$ & Mur, XVIe - XVIII siècles & ép. tôle = 0,12 cm \\
\hline $243, n^{\circ} 15$ & Remblai, début XVIII siècle & ép. tôle = 0,04 cm \\
\hline $243, n^{\circ} 16$ & Remblai d'abandon, XVIIII - XIXe siècles & ép. $=0,15 \mathrm{~cm}$ \\
\hline $243, n^{\circ} 17$ & Comblement de cuve, fin $X I X^{e}$ - début $X X^{e}$ siècle & ép. $\max =0,19 \mathrm{~cm}$ \\
\hline $243, n^{\circ} 18$ & Comblement de cave, postérieur au milieu du XVIII siècle & ép. $=0,08 / 0,09 \mathrm{~cm}$ \\
\hline $243, n^{\circ} 19$ & Remblai, milieu XIXe - XXe siècle & \\
\hline $243, n^{\circ} 20$ & Comblement de tranchée, $1^{\mathrm{e}}$ moitié $\mathrm{XIX}$ siècle & \\
\hline $243, n^{\circ} 21$ & Contexte inconnu & \\
\hline \multicolumn{3}{|c|}{13 - Les épingles } \\
\hline $244, n^{\circ} 1$ & Couche de sable, nef ? - $1^{\mathrm{e}}$ moitié XIIII siècle & diam. tige $=0,08 \mathrm{~cm}$; tête $: \mathrm{h} \times \mathrm{I}=0,13 \times 0,19 \mathrm{~cm}$ \\
\hline $244, n^{\circ} 2$ & Couche de sable, nef ? - $1^{\mathrm{e}}$ moitié XIIII siècle & diam. tige $=0,1 \mathrm{~cm} ;$ tête $: \mathrm{h} \times \mathrm{I}=0,18 \times 0,2 \mathrm{~cm}$ \\
\hline $244, n^{\circ} 3$ & Couche de limon argileux, milieu XVII ${ }^{e}$ siècle & diam. tige $=0,11 \mathrm{~cm}$; tête : $\mathrm{h} \times \mathrm{I}=0,24 \times 0,23 \mathrm{~cm}$ \\
\hline
\end{tabular}




\begin{tabular}{|c|c|c|}
\hline $244, n^{\circ} 4$ & Comblement de fosse, $\mathrm{XIII}$ - XIV siècles & diam. tige $=0,13 \mathrm{~cm}$; tête $: \mathrm{h} \times \mathrm{I}=0,36 \times 0,39 \mathrm{~cm}$ \\
\hline \multicolumn{3}{|c|}{14 - Les ferrets de lacets } \\
\hline $244, n^{\circ} 5$ & Remblai, XIII - XVIII siècles? & ép. tôle = 0,04 cm \\
\hline $244, n^{\circ} 6$ & Couche de sable, nef ? - $1^{\mathrm{e}}$ moitié XIII' siècle & ép. tôle = 0,04 cm \\
\hline $244, n^{\circ} 7$ & Couche de sable, nef ? - $1^{\mathrm{e}}$ moitié XIII ${ }^{\mathrm{e}}$ siècle & ép. tôle = 0,04 cm \\
\hline $244, n^{\circ} 8$ & Remblai préparatoire de calade, $\mathrm{XIX}^{\mathrm{e}}$ siècle & ép. tôle = 0,04 cm \\
\hline $244, n^{\circ} 9$ & Remblai, $1^{\mathrm{e}}$ moitié XVIII siècle & ép. tôle = 0,04 cm \\
\hline $244, n^{\circ} 10$ & Couche de sable, nef ? - $1^{\mathrm{e}}$ moitié XIII ${ }^{\mathrm{e}}$ siècle & ép. tôle = 0,04 cm \\
\hline $244, n^{\circ} 11$ & Remblai préparatoire de sol, chapelle Saint-Mauront, XVIIle siècle & ép. tôle = 0,04 cm \\
\hline $244, n^{\circ} 12$ & Remblai, $X V I^{e}$ siècle & ép. tôle = 0,04 cm \\
\hline $244, n^{\circ} 13$ & Comblement de sépulture, $1^{\mathrm{e}}$ moitié $\mathrm{XVIII}{ }^{\mathrm{e}}$ siècle & ép. tôle = 0,04 cm \\
\hline \multicolumn{3}{|c|}{15 - Les agrafes et chaînettes } \\
\hline $244, n^{\circ} 14$ & Comblement de fosse, moderne & diam. fil = 0,15 cm \\
\hline $244, n^{\circ} 15$ & Remblai, $\mathrm{XVI}$ siècle & diam. fil = 0,15 cm \\
\hline $244, n^{\circ} 16$ & Comblement de caniveau, $\mathrm{XII}$ siècle ? & diam. fil $=0,1 \mathrm{~cm}$ \\
\hline $244, n^{\circ} 17$ & Couche de sable, nef ? - $1^{\mathrm{e}}$ moitié XIII' siècle & diam. fil $=0,11 \mathrm{~cm}$ \\
\hline $244, n^{\circ} 18$ & Décapage, contemporain & fil : I x ép. = 0,1 × 0,07 cm \\
\hline $244, n^{\circ} 19$ & Comblement de tranchée d'épierrement, fin XIII - début XIVe siècle & diam. fil $=0,1 \mathrm{~cm}$ \\
\hline $244, n^{\circ} 20$ & Comblement de caveau, porche Isarn, XVII - XVIII siècles & diam. fil = 0,18 cm \\
\hline $244, n^{\circ} 21$ & Ossuaire de caveau, ? - $1^{\mathrm{e}}$ moitié XVIII siècle & diam. fil $=0,16 \mathrm{~cm}$ \\
\hline $244, n^{\circ} 22$ & Ossuaire de caveau, ? - $1^{\mathrm{e}}$ moitié XVIII siècle & diam. fil = 0,11 cm \\
\hline \multicolumn{3}{|c|}{16 - Les perles isolées } \\
\hline $245, n^{\circ} 1$ & Comblement de caniveau, milieu XIXe siècle & \\
\hline $245, n^{\circ} 2$ & $\begin{array}{l}\text { Remblai préparatoire de sol, chapelle Saint- } \\
\text { Mauront, } 2^{\mathrm{e}} \text { moitié } \mathrm{XV} I^{\mathrm{e}} \text { siècle }\end{array}$ & \\
\hline $245, n^{\circ} 3$ & Remblai, moderne & \\
\hline $245, n^{\circ} 4$ & Remblai, moderne & \\
\hline $245, n^{\circ} 5$ & Remblai, porche Isarn, XVIII siècle & \\
\hline $245, n^{\circ} 6$ & Remblai préparatoire de sol, chapelle Saint-Mauront, XVIIe siècle & \\
\hline $245, n^{\circ} 7$ & Comblement de sépulture, $1^{\mathrm{e}}$ moitié $\mathrm{XVIII}$ e siècle & \\
\hline $245, n^{\circ} 8$ & Comblement de sépulture, $1^{\text {e }}$ moitié $\mathrm{XVIII}{ }^{\mathrm{e}}$ siècle & \\
\hline $245, n^{\circ} 9$ & Abandon de caveau, $\mathrm{XVIII}{ }^{e}$ siècle & \\
\hline $245, n^{\circ} 10$ & Ossuaire de caveau, $1694-\mathrm{XVIII}$ e siècle & \\
\hline $245, n^{\circ} 11$ & Ossuaire de caveau, 1694 - XVIII siècle & \\
\hline $245, n^{\circ} 12$ & Remblai préparatoire de sol, chapelle Saint-Mauront, XVIIe siècle & \\
\hline $245, n^{\circ} 13$ & Remblai préparatoire de sol, chapelle Saint-Mauront, $X V I I$ e siècle & \\
\hline $245, n^{\circ} 14$ & $\begin{array}{l}\text { Remblai préparatoire de sol, chapelle Saint- } \\
\text { Mauront, } 2^{\mathrm{e}} \text { moitié } \mathrm{XVI} \mathrm{l}^{\mathrm{e}} \text { siècle }\end{array}$ & \\
\hline $245, n^{\circ} 15$ & Sépulture, XIIII siècle & \\
\hline $245, n^{\circ} 16$ & Sépulture, XIII siècle & \\
\hline $245, n^{\circ} 17$ & Couche moderne & \\
\hline $245, n^{\circ} 18$ & Remblai, porche Isarn, XVIII siècle & \\
\hline $245, n^{\circ} 19$ & Ossuaire de caveau, 1694 -1776 & \\
\hline $245, n^{\circ} 20$ & Remblai préparatoire de sol, chapelle Saint-Mauront, XVII siècle & \\
\hline $245, n^{\circ} 21$ & Empierrement, bas Moyen Âge & \\
\hline $245, n^{\circ} 22$ & Remblai préparatoire de sol, chapelle Saint-Mauront, $X V I I{ }^{e}$ siècle & \\
\hline \multicolumn{3}{|c|}{17 - Les bagues et anneaux } \\
\hline $245, n^{\circ} 23$ & Sépulture, XIIII siècle & ép. jonc $=0,09 \mathrm{~cm}$ \\
\hline
\end{tabular}




\begin{tabular}{|c|c|c|}
\hline $245, n^{\circ} 24$ & Sépulture, main droite, $\mathrm{XIII}$ - début XIVe (?) siècle & ép. jonc = 0,09 cm \\
\hline $245, n^{\circ} 25$ & Sépulture, XIII siècle & ép. jonc $=0,08 / 0,11 \mathrm{~cm}$ \\
\hline $245, n^{\circ} 26$ & Ossuaire de caveau, 1694 - 1776 & ép. jonc $=0,12 / 0,18 \mathrm{~cm}$ \\
\hline $245, n^{\circ} 27$ & Comblement de puits, $\mathrm{XIV}$ - XVe siècles & ép. jonc $=0,2 \mathrm{~cm}$ \\
\hline $245, n^{\circ} 28$ & Comblement de puits, $\mathrm{XIVe}-\mathrm{XV}^{\mathrm{e}}$ siècles & $\begin{array}{l}\text { diam. jonc }=0,12 / 0,17 \\
\text { ép. applique }=0,35 \mathrm{~cm}\end{array}$ \\
\hline $245, n^{\circ} 29$ & Remblai d'installation de sépulture, cour sud, $\mathrm{Xl}$ e siècle & $\begin{array}{l}\text { ép. jonc }=0,06 / 0,11 \mathrm{~cm} \\
\text { Pierre : } L \times I \times e=0,54 \times 0,32 \times 0,15 \mathrm{~cm}\end{array}$ \\
\hline $245, n^{\circ} 30$ & Couche de sable, nef, ? - $1^{\mathrm{e}}$ moitié XIII ${ }^{\mathrm{e}}$ siècle & ép. tôle = 0,04 cm \\
\hline $245, n^{\circ} 31$ & Sépulture d'adulte, $\mathrm{XIII}$ siècle & ép. jonc $=0,1 \mathrm{~cm}$ \\
\hline \multicolumn{3}{|c|}{18 - Médailles, crucifix et pendentif } \\
\hline $247, n^{\circ} 1$ & Ossuaire de caveau, 1694 - XVIII siècle & ép. $\max =0,1 \mathrm{~cm}$ \\
\hline $247, n^{\circ} 2$ & Ossuaire de caveau, 1694 - XVIIII siècle & ép. max médaille $=0,13 \mathrm{~cm}$; diam. fil $=0,12 \mathrm{~cm}$ \\
\hline $247, n^{\circ} 3$ & Ossuaire de caveau, $1694-\mathrm{XVIII}$ e siècle & ép. $\max =0,14 \mathrm{~cm}$ \\
\hline $247, n^{\circ} 4$ & Comblement de cave, moderne ou contemporain & ép. max $=0,08 \mathrm{~cm}$ \\
\hline $247, n^{\circ} 5$ & Comblement de cave, postérieur au XV siècle & ép. $=0,08 \mathrm{~cm}$ \\
\hline $247, n^{\circ} 6$ & Remblai, porche extérieur, moderne & ép. max $0,33 \mathrm{~cm}$ \\
\hline $247, n^{\circ} 7$ & Remblai, porche Isarn, XVIII' siècle & ép. $\max =0,25 \mathrm{~cm}$ \\
\hline $247, n^{\circ} 8$ & Contexte inconnu & ép. max $=0,24 \mathrm{~cm}$ \\
\hline $247, n^{\circ} 9$ & Comblement de caveau, porche Isarn, $\mathrm{XVII}$ - XVIII e siècles & ép. $\max =0,23 \mathrm{~cm}$ \\
\hline \multicolumn{3}{|c|}{19 - Les « reliquaires » } \\
\hline $247, n^{\circ} 10$ & Comblement de puits, $\mathrm{XIV}^{\mathrm{e}}-\mathrm{XV}^{\mathrm{e}}$ siècles & \\
\hline $247, n^{\circ} 11$ & Ossuaire de caveau, 1694 - ? & \\
\hline \multicolumn{3}{|c|}{20 - Clef de montre } \\
\hline $247, \mathrm{n}^{\circ} 12$ & Remblai préparatoire de calade, $\mathrm{XIX}^{\mathrm{e}}$ siècle & \\
\hline \multicolumn{3}{|c|}{21 - Les objets liés à la toilette en os et ivoire } \\
\hline $249, n^{\circ} 1$ & Remblai préparatoire de sol, vers 1750 & ép. $=0,3 \mathrm{~cm}$ \\
\hline $249, n^{\circ} 2$ & Comblement de fosse, milieu XVIII - milieu XIX ${ }^{e}$ siècle & diam. tête $=0,5 \mathrm{~cm}$ \\
\hline $249, n^{\circ} 3$ & Comblement de fosse, milieu XVIII - milieu XIXe siècle & ép. corps $=0,2 \mathrm{~cm}$ \\
\hline $249, n^{\circ} 6$ & Contexte du XIXe siècle & ép. $=0,5 \mathrm{~cm}$ \\
\hline \multicolumn{3}{|c|}{22 - Les objets liés à la toilette en métal } \\
\hline $249, n^{\circ} 4$ & H.S. & ép. manche $=0,08 \mathrm{~cm}$ \\
\hline $249, n^{\circ} 5$ & H.S. & ép. $=0,08 \mathrm{~cm}$ \\
\hline \multicolumn{3}{|c|}{23 - Les instruments sonores } \\
\hline $246, n^{\circ} 1$ & Comblement de cuve, vers 1720 - 1730 & ép. $=0,12 \mathrm{~cm}$ \\
\hline $251, n^{\circ} 5$ & Comblement de fosse à chaux, milieu XVII siècle & ép. $=0,23 \mathrm{~cm}$ \\
\hline \multicolumn{3}{|c|}{24 - L'outillage des activités textile } \\
\hline $250, n^{\circ} 1$ & Remblai, milieu XIXe - $20^{e}$ siècle & ép. tôle = 0,07/0,13 cm \\
\hline $250, n^{\circ} 2$ & Décapage initial, moderne & ép. tôle $=0,06 \mathrm{~cm}$ \\
\hline $250, n^{\circ} 3$ & Démontage des murs d'une cave, non daté & ép. tôle = 0,11/0,12 cm \\
\hline $250, n^{\circ} 4$ & H.S. & ép. tôle = 0,1 cm \\
\hline $250, n^{\circ} 5$ & Contexte inconnu & ép. tôle $=0,1 \mathrm{~cm}$ \\
\hline $250, n^{\circ} 6$ & Sol d'habitat, fin XIIIe - début XIVe siècle & ép. tôle $=0,06 / 0,07 \mathrm{~cm}$ \\
\hline $250, n^{\circ} 7$ & H.S. & ép. tôle = 0,03/0,09 cm \\
\hline $250, n^{\circ} 8$ & Comblement de puits, $\mathrm{XIV}^{\mathrm{e}}-\mathrm{XV}^{\mathrm{e}}$ siècles & ép. tôle $=0,05 \mathrm{~cm}$ \\
\hline $250, n^{\circ} 9$ & Nettoyage de coupe de tranchée, moderne ou contemporain? & ép. tôle $=0,06 \mathrm{~cm}$ \\
\hline $250, n^{\circ} 10$ & Comblement de fosse, moderne & ép. tôle $=0,07 / 0,08 \mathrm{~cm}$ \\
\hline
\end{tabular}




\begin{tabular}{|c|c|c|}
\hline $250, n^{\circ} 11$ & Chape de carrelage, $1720-1750$ & ép. tôle = 0,07/0,13 cm \\
\hline $250, n^{\circ} 12$ & Comblement de fosse, milieu XVIII - milieu XIXe siècle & ép. tôle $=0,06 / 0,07 \mathrm{~cm}$ \\
\hline $250, n^{\circ} 13$ & Comblement de caniveau, milieu XIX ${ }^{e}$ siècle & ép. tôle $=0,07 / 0,11 \mathrm{~cm}$ \\
\hline $250, n^{\circ} 14$ & Comblement de caniveau, milieu XIX ${ }^{e}$ siècle & ép. tôle $=0,08 / 0,12 \mathrm{~cm}$ \\
\hline $250, n^{\circ} 15$ & Comblement de fosse ? moderne ou contemporain? & ép. tôle = 0,07 cm \\
\hline $250, n^{\circ} 16$ & H.S. & ép. tôle $=0,05 / 0,08 \mathrm{~cm}$ \\
\hline \multicolumn{2}{|c|}{25 - L'outillage de la pêche } & \\
\hline $251, n^{\circ} 1$ & Remblai de la fosse de construction d'un regard, XVIII siècle & \\
\hline $251, n^{\circ} 2$ & H.S. & \\
\hline \multicolumn{2}{|c|}{26 - Poinçon en os } & \\
\hline $251, n^{\circ} 3$ & Sépulture, $X I^{\mathrm{e}}-1^{\mathrm{e}}$ moitié $\mathrm{XIII}$ siècle & \\
\hline \multicolumn{3}{|c|}{27 - Les cuillères } \\
\hline $251, n^{\circ} 4$ & Comblement de citerne, $\mathrm{XVI} \mathrm{e}^{\mathrm{e}}-\mathrm{XVII}$ siècles & Cuilleron : $p \times$ ép. $=0,5 \times 0,05 \mathrm{~cm}$ \\
\hline $251, n^{\circ} 6$ & Comblement de puits, $\mathrm{XIV}^{\mathrm{e}}-\mathrm{XV}^{\mathrm{e}}$ siècles & Cuilleron : $p \times$ ép. $=0,7 \times 0,12 \mathrm{~cm}$ \\
\hline $252, n^{\circ} 1$ & Comblement de caniveau, contemporain & Cuilleron : $p=0,9 \mathrm{~cm}$ \\
\hline $252, n^{\circ} 2$ & Comblement de cave, moderne & Cuilleron : $p=0,9 \mathrm{~cm}$ \\
\hline \multicolumn{3}{|c|}{28 - Les manches } \\
\hline $253, n^{\circ} 1$ & Contexte des XIII - XIV siècles (monnaie) & ép. $=0,6 / 1,05 \mathrm{~cm}$ \\
\hline $253, n^{\circ} 2$ & Remblaiement, $\mathrm{XVII}$ siècle & ép. $\max =0,7 \mathrm{~cm}$ \\
\hline $253, n^{\circ} 3$ & Sépulture, $X I^{\mathrm{e}}-1^{\mathrm{e}}$ moitié $\mathrm{XII}{ }^{\mathrm{e}}$ siècle & diam. $=0,1 / 0,29 \mathrm{~cm}$ \\
\hline $253, n^{\circ} 4$ & Contexte du XVIIIe siècle & $\mathrm{d}=0,09 / 0,11 \mathrm{~cm}$ \\
\hline \multicolumn{3}{|c|}{29 - Les bouterolles } \\
\hline $253, n^{\circ} 5$ & Couche de la $2^{e}$ moitié du XVIe siècle & ép. tôle $=0,2 \mathrm{~cm}$ \\
\hline $253, n^{\circ} 6$ & Fosse de pestiférés, 1720-1722 & ép. tôle = 0,11 cm \\
\hline $253, n^{\circ} 7$ & Contexte inconnu & ép. tôle $=0,07 \mathrm{~cm}$ \\
\hline \multicolumn{3}{|c|}{30 - Récipient indéterminé } \\
\hline $251, n^{\circ} 7$ & H.S. & \\
\hline \multicolumn{3}{|c|}{31 - Les sceaux } \\
\hline $253, n^{\circ} 8$ & Comblement de puits, $\mathrm{XIV}$ - $\mathrm{XV}^{\mathrm{e}}$ siècles & \\
\hline $253, n^{\circ} 9$ & Remblai, chapelle Saint-Mauront, début XIII siècle & \\
\hline \multicolumn{3}{|c|}{32 - Mordant d'agrafe de livre } \\
\hline $253, n^{\circ} 10$ & Remblai, $\mathrm{XVI}$ e siècle & \\
\hline \multicolumn{3}{|c|}{33 - Dés et autres pièces de jeu } \\
\hline $256, n^{\circ} 1$ & Terres de jardin, XIVe siècle & $\mathrm{I}=0,8 \mathrm{~cm}$ \\
\hline $256, n^{\circ} 2$ & Comblement de puits, $\mathrm{XIV}^{\mathrm{e}}-\mathrm{XV}^{\mathrm{e}}$ siècles & $I \max =1,5 \mathrm{~cm} ; I \min =0,6 \mathrm{~cm}$ \\
\hline $256, n^{\circ} 3$ & Comblement de puits, $\mathrm{XIV}^{\mathrm{e}}-\mathrm{XV}^{\mathrm{e}}$ siècles & $\mathrm{I}=0,72 \mathrm{~cm}$ \\
\hline $256, n^{\circ} 4$ & Comblement de puits, $\mathrm{XIV}^{\mathrm{e}}-\mathrm{XV}^{\mathrm{e}}$ siècles & $\mathrm{I}=0,72 \mathrm{~cm}$ \\
\hline $256, n^{\circ} 5$ & Comblement de puits, $\mathrm{XIV}^{\mathrm{e}}-\mathrm{XV}$ e siècles & $\mathrm{I}=0,8 \mathrm{~cm}$ \\
\hline $256, n^{\circ} 6$ & Comblement de puits, $\mathrm{XIV}^{\mathrm{e}}-\mathrm{XV}$ siècles & $\mathrm{I}=0,8 \mathrm{~cm}$ \\
\hline $256, n^{\circ} 7$ & Comblement de puits, $\mathrm{XIV}^{\mathrm{e}}-\mathrm{XV}^{\mathrm{e}}$ siècles & $\mathrm{I}=0,7 \mathrm{~cm}$ \\
\hline $256, n^{\circ} 8$ & Remblai, XIVe $-\mathrm{XVIII}{ }^{\mathrm{e}}$ siècles & $\mathrm{I}=1,1 \mathrm{~cm}$ \\
\hline $256, n^{\circ} 9$ & Remblai, chapelle Saint-Mauront, XVIIe siècle & $\mathrm{I}=0,85 \mathrm{~cm}$ \\
\hline $256, n^{\circ} 10$ & Comblement de puits, $X I V^{e}-X V^{e}$ siècles & diam. $\max \times \mathrm{h}=0,15 \times 0,16 \mathrm{~cm}$ \\
\hline $256, n^{\circ} 11$ & Ossuaire de caveau, $\mathrm{XVIII}{ }^{\mathrm{e}}$ siècle & ép. $=0,7 \mathrm{~cm}$ \\
\hline $256, \mathrm{n}^{\circ} 12$ & H.S. & ép. $=0,8 \mathrm{~cm}$ \\
\hline $256, n^{\circ} 13$ & Collecteur, vers 1920 - 1930 & diam. $x$ ép. $=2,9 \times 0,15 \mathrm{~cm}$ \\
\hline
\end{tabular}




\begin{tabular}{|c|c|c|}
\hline \multicolumn{2}{|c|}{34 - Soldat de plomb } & \\
\hline $256, n^{\circ} 14$ & Comblement de cave, postérieur au milieu du XVIII siècle & \\
\hline \multicolumn{3}{|c|}{35 - Éléments métalliques d'ameublement et de serrurerie } \\
\hline $257, n^{\circ} 1$ & Comblement de collecteur, vers 1920-1930 & diam. tige $=0,37 \mathrm{~cm}$ \\
\hline $257, n^{\circ} 2$ & Comblement de caniveau, milieu XIX ${ }^{\mathrm{e}}$ siècle & ép. plaque = 0,16 cm \\
\hline $257, n^{\circ} 3$ & Us technique, non datée & ép. plaque $=0,3 \mathrm{~cm}$ \\
\hline $257, n^{\circ} 4$ & Comblement de banquette, moderne & ép. = 0,39/0,52 cm \\
\hline $257, n^{\circ} 5$ & Remblai, fin XIIe - début XIII siècle & ép. max = 0,45 cm \\
\hline $257, n^{\circ} 6$ & Comblement de puits, $\mathrm{XIV}^{\mathrm{e}}-\mathrm{XV}^{\mathrm{e}}$ siècles & ép. $=0,07 \mathrm{~cm}$ \\
\hline $257, n^{\circ} 8$ & Remblai préparatoire de calade, $1^{\mathrm{e}}$ moitié $\mathrm{XVII}$ siècle & ép. part. circ. $=0,14 \mathrm{~cm}$ \\
\hline \multicolumn{3}{|c|}{36 - Pied de meuble? } \\
\hline $257, n^{\circ} 7$ & Contexte du XIII siècle & diam. $=0,21 / 0,3 \mathrm{~cm}$ \\
\hline \multicolumn{3}{|c|}{37 - Clous et rivets } \\
\hline $258, n^{\circ} 1$ & Remblai de démolition, faubourg du Morier, $1^{\mathrm{e}}$ moitié XIVe siècle & ép. tête = 0,17 cm \\
\hline $258, n^{\circ} 2$ & Remblai préparatoire de sol, vers $1680-1710$ & h tête $=0,8 \mathrm{~cm}$ \\
\hline $258, n^{\circ} 3$ & Sol, $\mathrm{XVI}{ }^{\mathrm{e}}$ siècle & $\mathrm{h}$ tête $=0,55 \mathrm{~cm}$ \\
\hline $258, n^{\circ} 4$ & Comblement de collecteur, vers 1920-1930 & $\mathrm{h}$ tête $=0,35 \mathrm{~cm}$ \\
\hline $258, n^{\circ} 5$ & Comblement de puits, $\mathrm{XIV}$ - $\mathrm{XV}^{\mathrm{e}}$ siècles & $\mathrm{h}$ tête $=0,25 \mathrm{~cm}$ \\
\hline $258, n^{\circ} 6$ & Comblement de tranchée de fondation de puits, vers 1730 - 1780 & ép. tête = 0,12 cm \\
\hline $258, n^{\circ} 7$ & Comblement de fosse, vers 1720 & ép. tête $=0,11 \mathrm{~cm}$ \\
\hline $258, n^{\circ} 8$ & Comblement de fosse, vers 1720 & ép. tête = 0,09 cm \\
\hline $258, n^{\circ} 9$ & Comblement de fosse, fin XIII - début XIVe siècle & ép. tête $=0,1 / 0,18 \mathrm{~cm}$ \\
\hline $258, \mathrm{n}^{\circ} 10$ & Remblai de démolition, milieu XIVe siècle & ép. tête $=0,09 \mathrm{~cm}$ \\
\hline $258, n^{\circ} 11$ & Comblement de fosse, fin XIII ${ }^{\mathrm{e}}$ - début $\mathrm{XIV}^{\mathrm{e}}$ siècle & ép. tête = 0,14 cm \\
\hline $258, n^{\circ} 12$ & Terres de jardin, XIV e siècle & ép. tête $=0,04 / 0,08 \mathrm{~cm}$ \\
\hline \multicolumn{3}{|c|}{38 - Déchets de fabrication en os } \\
\hline $259, n^{\circ} 1$ & Contexte du milieu du XVIII siècle & ép. $\max =0,3 \mathrm{~cm}$ \\
\hline $259, n^{\circ} 2$ & Comblement de fosse à chaux, vers 1720 - 1730 & ép. $\max =0,6 \mathrm{~cm}$ \\
\hline $259, n^{\circ} 3$ & Contexte inconnu & diam. tête $=0,6 \mathrm{~cm}$ \\
\hline $259, n^{\circ} 4$ & Abandon de caveau, $\mathrm{XVIII}{ }^{\mathrm{e}}-\mathrm{XI} \mathrm{X}^{\mathrm{e}}$ siècles & ép. max = 0,45 cm \\
\hline \multicolumn{3}{|c|}{39 - Objets indéterminés en os ou en nacre } \\
\hline $260, n^{\circ} 1$ & Terres de jardin, fin XIVe $-\mathrm{XVII}$ siècle & ép. $=0,2 \mathrm{~cm}$ \\
\hline $260, n^{\circ} 2$ & Ossuaire de caveau, $\mathrm{XVIII}$ e siècle & ép. max $=0,6 \mathrm{~cm}$ \\
\hline $260, n^{\circ} 3$ & Terres de jardin, XIVe siècle & \\
\hline $260, n^{\circ} 4$ & Contexte moderne & ép. $=0,3 \mathrm{~cm}$ \\
\hline $260, n^{\circ} 5$ & Comblement de fosse, milieu XVIII - milieu XIXe siècle & ép. $=0,3 \mathrm{~cm}$ \\
\hline $260, n^{\circ} 6$ & $\begin{array}{l}\text { Remblai de nivellement après la destruction } \\
\text { du rempart, } 1^{\mathrm{e}} \text { moitié } \mathrm{XVIII} \text { siècle }\end{array}$ & ép. $=0,2 \mathrm{~cm}$ \\
\hline $260, n^{\circ} 7$ & Comblement de fosse, milieu XVIII - milieu XIXe siècle & diam. $=0,55 / 0,6 \mathrm{~cm}$ \\
\hline $260, n^{\circ} 8$ & Contexte du XIXe siècle (datation du verre) & diam. $\max =0,12 \mathrm{~cm}$ \\
\hline $260, n^{\circ} 9$ & Comblement de puits, $\mathrm{XIV}^{\mathrm{e}}-\mathrm{XV}^{\mathrm{e}}$ siècles & I $x \mid \times$ ép. $=7,9 \times 1,2 \times 0,7 \mathrm{~cm}$ \\
\hline \multicolumn{3}{|c|}{40 - Objets indéterminés en métal } \\
\hline $261, n^{\circ} 1$ & $\begin{array}{l}\text { Remblai préparatoire de sol, chapelle Saint- } \\
\text { Mauront, } 2^{2 \mathrm{e}} \text { moitié } \mathrm{XV} I^{\mathrm{e}} \text { siècle }\end{array}$ & ép. $=0,08 \mathrm{~cm}$ \\
\hline $261, n^{\circ} 2$ & Remblai, chapelle Saint-Mauront, début XIII siècle & ép. cadre. $=0,34 \mathrm{~cm}$ \\
\hline $261, n^{\circ} 3$ & Terres de jardin, fin XIV ${ }^{e}$ XVII e siècle & ép. = 0,19 cm \\
\hline $261, n^{\circ} 4$ & Contexte moderne & \\
\hline $261, n^{\circ} 5$ & Comblement de structure, contemporain & ép. $=0,05 \mathrm{~cm}$ \\
\hline
\end{tabular}




\begin{tabular}{|c|c|c|}
\hline $261, n^{\circ} 6$ & Comblement de cave, moderne & ép. $=0,08 \mathrm{~cm}$ \\
\hline $261, n^{\circ} 7$ & Comblement de cuve, fin $X I X^{e}$ - début $X X^{e}$ siècle & ép. $=0,06 \mathrm{~cm}$ \\
\hline $261, n^{\circ} 8$ & Comblement de fosse, milieu XVIII - milieu XIXe siècle & ép. $=0,08 \mathrm{~cm}$ \\
\hline $261, n^{\circ} 9$ & Comblement de caniveau, milieu XIXe siècle & ép. $=0,07 \mathrm{~cm}$ \\
\hline $261, n^{\circ} 10$ & Remblai préparatoire de sol, chapelle Saint-Mauront, $X \mathrm{VII}{ }^{\mathrm{e}}$ siècle & ép. $=0,04 \mathrm{~cm}$ \\
\hline $261, n^{\circ} 11$ & Contexte inconnu & ép. $=0,04 / 0,05 \mathrm{~cm}$ \\
\hline $261, \mathrm{n}^{\circ} 12$ & Contexte inconnu & ép. $=0,06 \mathrm{~cm}$ \\
\hline $261, n^{\circ} 13$ & Nettoyage, postérieur milieu XVIII siècle & ép. $=0,19 \mathrm{~cm}$ \\
\hline $261, n^{\circ} 14$ & Sol, début XIVe siècle & ép. $=0,09 \mathrm{~cm}$ \\
\hline $261, n^{\circ} 15$ & Contexte inconnu & ép. $=0,04 \mathrm{~cm}$ \\
\hline $261, n^{\circ} 16$ & Comblement de caniveau, milieu XIXe siècle & ép. $=0,16 \mathrm{~cm}$ \\
\hline $261, n^{\circ} 17$ & Décapage initial, XVIII siècle - ? & ép. $=0,1 \mathrm{~cm}$ \\
\hline $262, n^{\circ} 1$ & Contexte inconnu & ép. $=0,04 \mathrm{~cm}$ \\
\hline $262, n^{\circ} 2$ & Comblement de caniveau, milieu XIXe siècle & ép. $=0,05 \mathrm{~cm}$ \\
\hline $262, n^{\circ} 3$ & Remblai, $1^{\mathrm{e}}$ moitié $\mathrm{XVIII}$ e siècle & ép. $=0,19 \mathrm{~cm}$ \\
\hline $262, n^{\circ} 4$ & Remblai, milieu XVII siècle & ép. totale $=0,41 \mathrm{~cm}$ \\
\hline $262, n^{\circ} 5$ & Terres de jardin, fin XIV - XVIIe siècle & ép. tôle $=0,05 / 0,07 \mathrm{~cm}$ \\
\hline $262, n^{\circ} 6$ & Couche de sable, nef ? - $1^{\mathrm{e}}$ moitié XIIII siècle & diam. $=0,04 \mathrm{~cm}$ \\
\hline $262, n^{\circ} 7$ & H.S. & diam. fil $=0,07 \mathrm{~cm}$ \\
\hline $262, n^{\circ} 8$ & Remblai, chapelle Saint-Mauront, $2^{\mathrm{e}}$ moitié $\mathrm{XV} l^{\mathrm{e}}$ siècle & diam. fil $=0,05 \mathrm{~cm}$ \\
\hline $262, n^{\circ} 9$ & Remblai d'installation de sépultures, XIII siècle & ép. = 0,05/0,11 cm \\
\hline $262, n^{\circ} 10$ & Terres de jardin, fin XIVe - XVIII siècle & \\
\hline $262, n^{\circ} 11$ & Remblai, moderne ou contemporain & ép. $=0,17 \mathrm{~cm}$ \\
\hline $262, n^{\circ} 12$ & Comblement de fosse, XIII - XIVe siècles & \\
\hline $262, n^{\circ} 13$ & Aménagement de sol, $\mathrm{XVI} \mathrm{I}^{\mathrm{e}}-\mathrm{XVII}$ siècles & \\
\hline $262, n^{\circ} 14$ & Contexte moderne & ép. $=0,22 \mathrm{~cm}$ \\
\hline $262, n^{\circ} 15$ & Remplissage de tranchée de fondation, contemporain & ép. $=0,12 \mathrm{~cm}$ \\
\hline $262, n^{\circ} 16$ & Sol de cuisine, première moitié XIII - début XIVe siècle & \\
\hline
\end{tabular}




\section{Numéro d'inventaire des différents objets figurés dans le volume}

La liste qui suit renvoie, pour chaque fragment figuré dans ce volume, au numéro d'inventaire attribué à chaque objet dans la base de donnée de l'Atelier du Patrimoine et permettant donc de les retrouver dans les collections amassées au Dépôt Archéologique Municipal de Marseille. En général, ce numéro d'inventaire se compose de l'identification du site suivi d'un chiffre dit d' « isolation » de 1 à l'infini pour chaque site et attribué au moment de l'étude des objets. Pour exemple, 158.08.244 correspond à l'isolation n²44 du chantier de l'Esplanade de la Major (158.08).

Quand aucun numéro d'isolation n'a été attribué au moment de l'étude, la référence du chantier est suivie du numéro de l'unité stratigraphique d'où provient l'objet précédé de la mention « us ». Par exemple 142.07 us 1042 : l'objet provient de l'us 1042 du site de la rue Trinquet (142.07).

Liste des $\mathrm{n}^{\circ}$ d'inventaire par figure

\begin{tabular}{|c|c|c|c|c|c|c|c|c|c|}
\hline \multirow{2}{*}{\multicolumn{2}{|c|}{$\begin{array}{l}\text { Figure } 2 \\
\quad 158.08 .244\end{array}$}} & \multirow[t]{2}{*}{4} & \multirow[t]{2}{*}{52.02 .573} & 2 & 52.02 .508 & 6 & 52.02 .598 & \multicolumn{2}{|c|}{ Figure 27} \\
\hline & & & & 3 & 52.02 .555 & 7 & 24.99 us 8127 & & 52.02 .564 \\
\hline & & \multicolumn{2}{|c|}{ Figure 11} & 4 & 52.02 .520 & & & & \\
\hline \multicolumn{2}{|c|}{ Figure 3} & 1 & 52.95 .98 & 5 & 52.95 .116 & \multicolumn{2}{|c|}{ Figure 23} & \multicolumn{2}{|c|}{ Figure 28} \\
\hline & 158.08 .245 & 2 & 142.07 us 1009 & 6 & 52.02 .527 & 1 & 52.95 .120 & & 52.02 .672 \\
\hline & & 3 & 52.95 .27 & 7 & 24.99.1374 & 2 & 52.95 .11 & & \\
\hline \multicolumn{2}{|c|}{ Figure 4} & 4 & 52.95 .7 & 8 & 52.02 .674 & 3 & 52.95 .32 & \multicolumn{2}{|c|}{ Figure 29} \\
\hline & 158.08 .246 & 5 & 142.07 .67 & 9 & 52.02 .553 & 4 & 52.95 .49 & & 142.07 .64 \\
\hline & & 6 & 52.95 .28 & 10 & 52.02 .522 & 5 & 52.95 .50 & 2 & 52.95 .39 \\
\hline \multicolumn{2}{|c|}{ Figure 5} & 7 & 52.95 .96 & & & 6 & 52.95 .10 & 3 & 52.95 .139 \\
\hline 1 & $50.99 .666 / 2$ & 8 & 52.95 .100 & \multicolumn{2}{|c|}{ Figure 17} & 7 & 52.95 .126 & 4 & 52.95 .40 \\
\hline 2 & 50.99 .645 & 9 & 52.95 .97 & 1 & 52.02 .566 & 8 & 52.95 .35 & 5 & 52.02 .536 \\
\hline 3 & 142.07 us 1042 & 10 & 142.07 us 1009 & $\begin{array}{l}1 \\
2\end{array}$ & 52.95 .123 & 9 & 52.95 .112 & 6 & 52.02 .597 \\
\hline 4 & $50.99 .666 / 1$ & \multirow{2}{*}{\multicolumn{2}{|c|}{1152.95 .95}} & 3 & 52.95 .2 & 10 & 52.95 .4 & 7 & 52.95 .43 \\
\hline 5 & $50.99 .666 / 1$ & & & 4 & 52.95 .1 & 11 & 52.95 .3 & 8 & 52.95 .41 \\
\hline 6 & 50.99 us $3575 / 4$ & \multicolumn{2}{|c|}{ Figure 12} & 5 & 52.95 .2 & 12 & 52.02 .539 & 9 & 52.95 .42 \\
\hline 7 & 50.99 .441 & 1 & 52.02 .568 & 6 & 52.95 .29 & 13 & 52.02 .516 & 10 & 52.95 .75 \\
\hline 8 & 50.99 .555 & $\begin{array}{l}1 \\
2\end{array}$ & 52.02 .514 & & & $\begin{array}{l}10 \\
14\end{array}$ & 52.95 .33 & 11 & 52.95 .87 \\
\hline 9 & 142.07 .63 & 3 & 52.02 .560 & Fig & ure 18 & $\begin{array}{l}14 \\
15\end{array}$ & 52.95 .81 & 12 & 52.95 .87 \\
\hline 10 & 143.06 .121 & 4 & 52.02 .558 & 1 & 52.02 .526 & & & & \\
\hline 11 & 50.99 us $3575 / 11$ & 5 & 52.02 .680 & 2 & 52.95 .5 & & ure 24 & Fig & ure 30 \\
\hline 12 & 50.99 us $2226 / 2$ & 6 & 52.95 .106 & & & 1 & 52.95 .38 & 1 & 52.95 .13 \\
\hline 13 & 50.99 us $2226 / 1$ & 7 & 52.95 .105 & Fig & ure 19 & $\begin{array}{l}1 \\
2\end{array}$ & 52.95 .37 & 2 & 52.02 .515 \\
\hline 14 & 50.99 us $3575 / 9$ & 8 & 142.07 .70 & 1 & 52.02 .524 & & & 3 & 52.95 .47 \\
\hline \multirow[t]{2}{*}{15} & 142.07 .65 & $\begin{array}{l}0 \\
9\end{array}$ & 52.02 .519 & $\begin{array}{l}1 \\
2\end{array}$ & 52.95 .113 & \multicolumn{2}{|c|}{ Figure 25} & 4 & 52.95 us 7013 \\
\hline & & & 52.02 .510 & 3 & 52.95 .117 & 1 & 52.02 .602 & 5 & 52.95 .46 \\
\hline & ure 6 & 11 & 52.02 .556 & & & 2 & 52.02 .530 & 6 & 52.95 .8 \\
\hline 1 & 131.05 .87 & 12 & $\begin{array}{l}52.02 .556 \\
52.02 .521\end{array}$ & Fig & ure 20 & 3 & 52.95 .111 & & \\
\hline 2 & 24.99 us $1186-1857$ & 13 & $\begin{array}{l}52.02 .521 \\
52.02 .571\end{array}$ & & 52.02 .507 & 4 & 52.95 .121 & Fig & are 31 \\
\hline & & 14 & 24.99 .1450 & & & 5 & 52.95 .110 & 1 & 52.95 .44 \\
\hline Fig & ure 8 & 15 & $\begin{array}{l}24.99 .1450 \\
142.07 \text { us } 2065\end{array}$ & Fig & ure 21 & 6 & 52.02 .505 & 2 & 52.95 .48 \\
\hline 1 & 52.95 us 3091 & 15 & $\begin{array}{l}142.07 \text { us } 2005 \\
52.02 .559\end{array}$ & 1 & 52.95 .52 & 7 & 52.02 .677 & 3 & 52.95 .45 \\
\hline 2 & 52.95 .102 & 17 & 142.07 us 1004 & 2 & 142.07 .62 & 8 & 52.02 .567 & 4 & 52.95 .78 \\
\hline 3 & 52.95 .99 & $\begin{array}{l}1 \\
18 \\
18\end{array}$ & $\begin{array}{l}142.07 \text { us } 1004 \\
52.02 .554\end{array}$ & 3 & 52.95 .34 & $\begin{array}{l}8 \\
9\end{array}$ & $\begin{array}{l}52.02 .561 \\
52.95 .19\end{array}$ & & \\
\hline 4 & 52.95 .101 & & & 4 & 52.95 .107 & 10 & $\begin{array}{l}52.95 .19 \\
52.95 .18\end{array}$ & Fig & ure 32 \\
\hline 5 & 52.02 .511 & & ure 13 & 5 & 52.95 .53 & $\begin{array}{l}10 \\
11\end{array}$ & $\begin{array}{l}52.95 .18 \\
52.83 .15\end{array}$ & 1 & 52.95 .137 \\
\hline 6 & 52.02 .513 & 1 & 52.95 .108 & 6 & 52.95 .31 & $\begin{array}{l}11 \\
12\end{array}$ & $\begin{array}{l}52.03 .15 \\
52.02 .574\end{array}$ & 2 & 52.95 .51 \\
\hline 7 & 52.02 .518 & $\begin{array}{l}1 \\
2\end{array}$ & 52.95 .104 & 7 & 52.95 .80 & 12 & $\begin{array}{l}52.02 .5 / 4 \\
52.95 .24\end{array}$ & 3 & 52.95 .136 \\
\hline 8 & 52.02 .512 & $\begin{array}{l}2 \\
3\end{array}$ & $\begin{array}{l}32.95 .104 \\
24.99 .1375\end{array}$ & 8 & 52.95 .30 & 13 & 52.95 .24 & 4 & 52.95 .86 \\
\hline 9 & 52.02 .561 & $\begin{array}{l}3 \\
4\end{array}$ & $\begin{array}{l}24.99 .13 / 5 \\
52.02 .538\end{array}$ & 9 & 52.95 .56 & & ure 26 & 5 & 52.02 .523 \\
\hline 10 & 52.95 .103 & $\begin{array}{l}4 \\
5\end{array}$ & 142.07 us 2065 & 10 & 52.02 .671 & 1 & 52.95 .26 & 6 & 52.02 .545 \\
\hline 11 & 142.07 us 1009 & 6 & 52.02 .599 & 11 & 52.02 .669 & $\begin{array}{l}1 \\
2\end{array}$ & 52.95 .109 & 7 & 52.02 .600 \\
\hline $\begin{array}{l}11 \\
12\end{array}$ & 52.02 .565 & 6 & 52.02 .599 & $\begin{array}{l}11 \\
12\end{array}$ & 52.02 .562 & $\begin{array}{l}2 \\
3\end{array}$ & $\begin{array}{l}52.95 .109 \\
52.95 .14\end{array}$ & & \\
\hline & & & ure 14 & 13 & 52.95 .79 & 4 & $\begin{array}{l}52.95 .14 \\
52.95 .17\end{array}$ & & ure 33 \\
\hline Fig & ure 9 & 1 & 52.02 .630 & 14 & 52.02 .665 & $\begin{array}{l}4 \\
5\end{array}$ & 52.95 .122 & 1 & 52.95 .134 \\
\hline 1 & 52.95 .119 & $\begin{array}{l}\perp \\
2\end{array}$ & 52.02 .529 & 15 & 52.95 .54 & 6 & 52.02 .601 & 2 & 52.02 .506 \\
\hline 2 & 52.95.118 & 3 & 52.02 .679 & 16 & 52.95 .9 & 7 & 52.95 .20 & 3 & 52.95 .135 \\
\hline 3 & 52.02 .528 & 4 & 52.02 .678 & 17 & 52.95 .55 & 8 & 52.95 .22 & & \\
\hline 4 & 52.02 .675 & $\begin{array}{l}4 \\
5\end{array}$ & 155.09 .109 & & & 9 & 52.02 .664 & Fig & ure 34 \\
\hline 5 & 142.07 us 1094 & & & Fig & ure 22 & 10 & $\begin{array}{l}52.02 .064 \\
52.95 .58\end{array}$ & 1 & 52.02 .525 \\
\hline & & & ure 15 & 1 & 52.95 .36 & $\begin{array}{l}10 \\
11\end{array}$ & $\begin{array}{l}52.95 .58 \\
52.95 .57\end{array}$ & 2 & 52.95 .138 \\
\hline & ure 10 & & $86.06 \mathrm{R}$ us 1020 & 2 & 52.95 .92 & $\begin{array}{l}11 \\
12\end{array}$ & $\begin{array}{l}52.95 .51 \\
52.02 .534\end{array}$ & & \\
\hline 1 & 52.02 .563 & & & 3 & $52.95 .73-74$ & 13 & $\begin{array}{l}52.02 .034 \\
52.95 .25\end{array}$ & Fig & ure 35 \\
\hline 2 & 52.02 .572 & & ure 16 & 4 & 52.95 .93 & 14 & $\begin{array}{l}52.95 .25 \\
52.95 .21\end{array}$ & 1 & 52.95 .131 \\
\hline 3 & 52.95 .6 & 1 & 52.02 .557 & 5 & 52.02 .673 & $\begin{array}{l}14 \\
15\end{array}$ & 52.95 .23 & 2 & 52.95 .125 \\
\hline
\end{tabular}




\begin{tabular}{|c|c|c|c|c|c|c|c|c|c|}
\hline \multirow[t]{2}{*}{3} & 52.95 .124 & 7 & 24.99.711 & \multicolumn{2}{|c|}{ Figure 59} & 5 & 50.00 .865 & 2 & 143.06 .123 \\
\hline & & 8 & 24.99 .696 & 1 & 131.05 .90 & 6 & 50.00 .892 & 3 & 08.86 .174 \\
\hline \multicolumn{2}{|c|}{ Figure 36} & 9 & 24.99 .701 & 2 & 24.99 .1373 & 7 & 50.00 .642 & 4 & 08.86 .107 \\
\hline 1 & 52.95 .71 & 10 & 52.02 .676 & 3 & 24.99.1373bis & & & 5 & 08.86 .175 \\
\hline 2 & 52.95 .133 & 11 & 24.99.1264 & & & & are 72 & & \\
\hline 3 & 52.95 .84 & 12 & 24.99 .697 & & dre 60 & & 50.00 .637 & & are 85 \\
\hline 4 & 52.95 .63 & 13 & 52.02 .605 & 1 & 131.05.96 & & & & 24.99.1451 \\
\hline 5 & 52.95 .67 & & & 2 & 56.98R.49 & & are 73 & & \\
\hline 6 & 52.95 .70 & & ure 47 & 3 & 24.99.1291 & 1 & 50.00 .905 & & ure 86 \\
\hline 7 & 52.95 .72 & 1 & & & & 2 & 50.00 .663 & 1 & 24.99 .730 \\
\hline 8 & 52.95 .68 & & $9.1427-1430-1434-1437$ & & ure 61 & 3 & 50.00 .659 & 2 & 24.99.1295 \\
\hline 9 & 52.95 .69 & 2 & 24.99 .1444 & 1 & 24.99 .705 & 4 & 50.00 .890 & 3 & 24.99 .1257 \\
\hline 10 & 52.95 .61 & & & 2 & 08.86 .80 & 5 & 50.00 .906 & 4 & 24.99.1294 \\
\hline 11 & 52.95 .62 & & ure 48 & & & 6 & 50.00 .871 & & \\
\hline 12 & 52.95 .85 & 1 & 24.99.1419 & & ure 62 & 7 & 50.00 .644 & & ure 87 \\
\hline 13 & 52.95 .59 & 2 & $126.04 R .6$ & 1 & 24.99 .731 & & & 1 & 24.99 .1428 \\
\hline 14 & 52.95 .65 & 3 & 131.05 .193 & 2 & 131.05 .98 & & are 74 & 2 & 24.99 .25 et 24.99 .26 \\
\hline 15 & 52.95 .83 & 4 & 143.06 .6 & 3 & 52.02 .569 & 1 & 50.00 .860 & & \\
\hline 16 & 52.95 .66 & 5 & 143.06 .5 & 4 & 52.02 .540 & 2 & 50.00 .903 & & ure 88 \\
\hline 17 & 52.02 .547 & 6 & 24.99 .1368 & 5 & 52.02 .548 & 3 & 50.00 .875 & 1 & 52.96 .8064 \\
\hline 18 & 52.95 .60 & 7 & 52.02 .541 & 6 & 24.99.1404 & 4 & 50.00 .903 & 2 & 52.96 .8065 \\
\hline 19 & 52.95 .82 & 8 & 143.06 .2 & 7 & 24.99 .1416 & 5 & 50.00 .863 & 3 & 52.96 .8067 \\
\hline 20 & 52.02 .533 & 9 & 24.99.1419 & 8 & 24.99 .733 & 6 & 50.00 .864 & & \\
\hline 21 & 52.95 .132 & 10 & 52.02 .607 & 9 & 24.99 .1403 & 7 & 50.00 .904 & & ure 89 \\
\hline 22 & 52.95 .64 & 11 & 08.86 .84 & & & 8 & 50.00 .661 & 1 & 52.96 .8061 \\
\hline 23 & 52.95 .12 & 12 & 08.86 .161 & & ure 63 & & & 2 & 52.96 .8052 \\
\hline & & 13 & 08.86 .162 & 1 & 50.00 us $3170-3$ & & are 75 & 3 & 52.96 .8056 \\
\hline & ure 37 & & & 2 & 50.00 us $3170-2$ & 1 & 50.00 .652 & 4 & 52.96 .8059 \\
\hline 1 & 52.95 .94 & & ure 49 & 3 & 50.00 .640 & 2 & 50.00 .648 & & \\
\hline 2 & 52.95 .91 & & 24.99 .745 & 4 & 50.00 us $3170-1$ & 3 & 50.00 .869 & & ure 90 \\
\hline 3 & 52.95 .127 & & & 5 & 50.00 .888 & 4 & 50.00 .658 & 1 & 52.96 .8057 \\
\hline 4 & 52.95 .76 & & are 50 & 6 & 50.00 .667 & & & 2 & 52.96 .8050 \\
\hline & & 1 & 08.86 .76 & & & & are 76 & & \\
\hline & ire 39 & 2 & 126.04R.5 & & ure 64 & & 50.00 .868 & & are 91 \\
\hline & 52.02 .544 & & & 1 & 50.00 us 2218 & & & 1 & 52.96 .8063 \\
\hline & & & ure 51 & 2 & $50.00 .638 b$ & & are 77 & & \\
\hline & are 40 & 1 & 24.99 .1370 & 3 & $50.00 .666 a$ & 1 & 50.00 .897 & & ure 93 \\
\hline 1 & 24.99 .1420 & 2 & 24.99 .1217 & 4 & 50.00 us $2150-4$ & 2 & 50.00 .885 & 1 & 52.96 .8058 \\
\hline 2 & 56.98 .48 & 3 & 52.02 .546 & 5 & $50.00 .638 a$ & 3 & 50.00 .862 & 2 & 52.96 .8060 \\
\hline 3 & 24.99 .1400 & 5 & 08.86 .82 & 6 & 50.00 .664 & 4 & 50.00 .878 & 3 & 52.96 .8062 \\
\hline 4 & 24.99 .723 & & & 7 & 50.00 .661 & 5 & 50.00 .905 & 4 & 52.96 .8055 \\
\hline 5 & 24.99 .695 & & ure 52 & 8 & 50.00 .861 & 6 & 50.00 .877 & 5 & 52.96 .8066 \\
\hline 6 & 143.06 .122 & 1 & 24.99.1432 & & & 7 & 50.00 .859 & & \\
\hline 7 & 24.99.1408 & 2 & 52.02 .683 & & ure 65 & 8 & 50.00 .891 & & ure 94 \\
\hline 8 & 24.99 .720 & & & 1 & 50.00 us $3491-3$ & & & 1 & 155.09 .2832 \\
\hline 9 & 24.99.1401 & & ure 53 & 2 & 50.00 .656 & & ure 78 & 2 & 45.93.1394, 1395 \\
\hline & & 1 & 56.98R.43 & 3 & 50.00 us $3491-4$ & 1 & 50.00 .653 & & $45.93 .1373,1393$ \\
\hline & are 41 & 2 & 24.99 .727 & 4 & 50.00 .649 & 2 & 50.00 .636 & 3 & 45.93 .8525 \\
\hline & 24.99 .722 & & & 5 & 50.00 .646 & 3 & 50.00 .665 & 4 & 45.93 .8514 \\
\hline & & & ure 54 & 6 & 50.00 .655 & & & 5 & 45.93 .8523 \\
\hline & ure 42 & 1 & 52.02 .670 & & & & are 79 & 6 & 45.93 .8516 \\
\hline 1 & 24.99.1598 & 2 & 24.99 .1452 & & ure 66 & 1 & 142.07 .1 & 7 & $86.67-84.1056$ \\
\hline 2 & 56.98 .46 & 3 & 24.99.1595 & 1 & 50.00 .643 & 2 & 142.07 .27 & & \\
\hline 3 & 52.02 .568 & & & 2 & 50.00 .654 & 3 & 126.04 .1 & & ure 95 \\
\hline 4 & 24.99 .1379 & & ure 55 & & & 4 & 08.86 .126 & 1 & 45.93 .8506 \\
\hline 5 & 24.99 .707 & 1 & 24.99 .1425 & & ure 67 & 5 & 08.86 .172 & 2 & 45.93 .8504 \\
\hline 6 & 24.99.1210 & 2 & 24.99 .1205 & 1 & 50.00 .881 & 6 & 08.86 .168 & 3 & 45.93 .8505 \\
\hline & & 3 & $126.04 R .2$ & 2 & 50.00 .882 & & & 4 & 45.93 .8503 \\
\hline & are 43 & 4 & 24.99.1597 & 3 & 50.00 .893 & & are 80 & & \\
\hline 1 & 52.02 .543 & & & & & 1 & 08.86 .81 & & are 96 \\
\hline 2 & 24.99 .1393 et 1398 & & גre 56 & & ure 68 & 2 & 08.86 .156 & & 45.93 .8500 \\
\hline 3 & 52.02 .552 & 1 & 143.06 .9 & 1 & 50.00 .635 & 3 & 08.86 .74 & & \\
\hline 4 & 24.99 .752 & 2 & 08.86 .90 & 2 & 50.00 .908 & 4 & 08.86 .170 & & ure 97 \\
\hline & & 3 & 56.98R.50 & 3 & 50.00 .870 & 5 & 08.86 .169 & 1 & 155.09 .2828 \\
\hline & ure 44 & 4 & 08.86 .17 & 4 & 50.00 .647 & & & 2 & 155.09 .2826 \\
\hline 1 & 24.99 .1439 & 5 & 08.86 .178 & & & & Ire 81 & 3 & 45.93 .8502 \\
\hline 2 & 24.99 .1440 & & & & ure 69 & 1 & 08.86 .83 & 4 & 134.05 .1410 \\
\hline & & & ure 57 & & 50.00 .662 & 2 & 131.05 .94 & 5 & 134.05 .1338 \\
\hline & ure 45 & 1 & 52.02 .549 & & & 3 & 24.99 .1286 & & \\
\hline 1 & 24.99 .1449 & 2 & 24.99 .708 & & ure 70 & 4 & 08.86 .142 & & ure 98 \\
\hline 2 & 24.99.1402 & 3 & 52.02 .542 & 1 & 50.00 .650 & 5 & 143.06 .130 & 1 & 134.05 .1406 \\
\hline 3 & 24.99 .706 & 4 & 08.86 .77 & 2 & 50.00 .651 & 6 & 08.86 .173 & 2 & 45.93 .1396 \\
\hline 4 & 24.99 .1596 & 5 & 56.98R.42 & 3 & 31.92 & & & 3 & 155.09 .2846 \\
\hline 5 & 24.99.1279 & 6 & 24.99.1376 & 4 & 31.92 & & ure 82 & 4 & 134.05.1396 \\
\hline 6 & 24.99 .1411 & 7 & 56.98R.41 & 5 & 50.00 .879 & 1 & 08.86 .176 & 5 & $86.67-84.1051$ \\
\hline & & & & 6 & $50.00 .638 a$ & 2 & 08.86 .85 & 6 & 45.93 .8501 \\
\hline & ure 46 & & ure 58 & 7 & 50.00 .639 & 3 & 08.86 .177 & & \\
\hline 1 & 52.02 .550 & 1 & 24.99 .1 & & & 4 & 08.86 .108 & & ure 99 \\
\hline $\begin{array}{l}+ \\
2\end{array}$ & 24.99.1372 & 2 & 08.86 .133 & & ure 71 & $\begin{array}{l}4 \\
5\end{array}$ & 08.86 .176 & 1 & $86.67-84.1062$ \\
\hline 3 & 24.99.1285 & 3 & 131.05 .5 & 1 & 26.90.sans $n^{\circ}$ & 6 & 143.06 .134 & 2 & $86.67-84.1061$ \\
\hline 4 & 52.02 .606 & 4 & 126.04R.4 & 2 & 26.90 sans $n^{\circ}$ & & & & \\
\hline 5 & 24.99 .702 & 5 & 131.05 .4 & 3 & 26.90 sans $n^{\circ}$ & & ure 83 & & are 100 \\
\hline 6 & 24.99 .698 & & & 4 & 50.00 .876 & 1 & 143.06 .133 & 1 & $86.67-84.1029$ \\
\hline
\end{tabular}




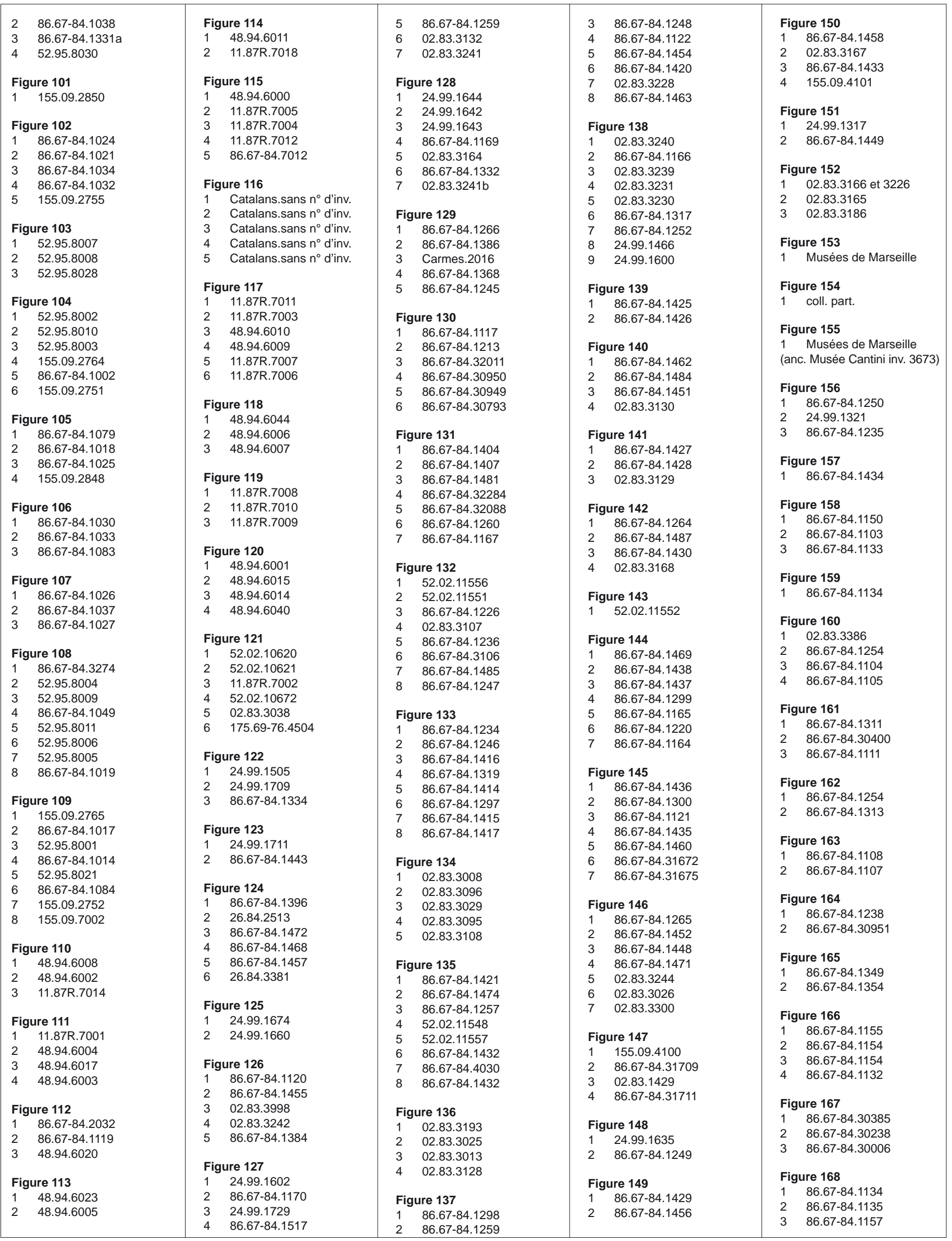




\begin{tabular}{|c|c|c|c|c|c|c|c|c|c|}
\hline \multicolumn{2}{|c|}{ Figure 169} & \multirow{2}{*}{$\begin{array}{l}4 \\
5\end{array}$} & \multirow{2}{*}{$\begin{array}{l}86.67-84.1336 \\
86.67-84.1446\end{array}$} & & ure 192 & & ure 205 & & ure 218 \\
\hline 1 & 86.67-84.1159 & & & 1 & 46.94 .2483 & 1 & 52.02.10181b & 1 & 142.07 us 2017 \\
\hline 2 & $86.67-84.1163$ & 6 & $86.67-84.1355$ & 2 & 46.94 .2484 & 2 & 52.02 .10362 & 2 & 24.99 us 4276 \\
\hline 3 & $86.67-84.1160$ & & & 3 & 46.94 .2485 & 3 & 52.02 .10360 & 3 & 24.99 us 4437 \\
\hline 4 & $86.67-84.1158$ & & ure 181 & & & 4 & 52.02 .10361 & 4 & 31.92 us $1-212$ \\
\hline & & 1 & 02.83 .3518 & & ure 193 & 5 & 52.02 .10205 & 5 & 31.92 us $3-476$ \\
\hline & ure 170 & 2 & $86.67-84.31187$ & 1 & 158.08.1970 & 6 & Marseille & 6 & 31.92 us $1-204$ \\
\hline 1 & $86.67-84.30411$ & 3 & $86.67-84.1263$ & 2 & 158.08.2256 & & & 7 & 50.00 us $5-296$ \\
\hline 2 & $86.67-84.30408$ & 4 & $86.67-84.1233$ & 3 & 158.08.1974 & & ure 206 & 8 & 31.92 us $3-362$ \\
\hline 3 & $86.67-84.32127$ & 5 & $86.67-84.1406$ & 4 & 158.08.2218 & 1 & 155.09.2609 & & \\
\hline 4 & $86.67-84.32126$ & 6 & $86.67-84.1475$ & 5 & 46.94 .2471 & 2 & 155.09.2601 & & ure 219 \\
\hline 5 & $86.67-84.30418$ & 7 & 86.67-84.1402 & 6 & 46.94 .2451 & 3 & 155.09 .2615 & 1 & 31.92 us $3-374$ \\
\hline 6 & $86.67-84.30421$ & & & 7 & 46.94.2469 & 4 & $86.67-84.1518$ & 2 & 31.92 us $3-262$ \\
\hline 7 & $86.67-84.30374$ & & ure 182 & 8 & $86.67-84.1318$ & & & 3 & 01.86 us $2-103$ \\
\hline 8 & $86.67-84.1325$ & 1 & 52.96 .8086 & & & & ure 207 & 4 & 24.99 us 4520 \\
\hline 9 & $86.67-84.1102$ & & (MHM M0918-99-3-47) & & ure 194 & 1 & 155.09.2611 & 5 & 24.99 us 4348 \\
\hline & & 2 & Musée de Genève (Suisse) & 1 & 46.94 .2476 & 2 & 155.09 .2613 & 6 & 24.99 us 4348 \\
\hline Fig & ure 171 & & & 2 & $86.67-84.1237$ & & & & \\
\hline 1 & $86.67-84.1101$ & & ure 183 & 3 & 158.08 .2180 & & ure 208 & Fig & ure 220 et 221 \\
\hline & & 1 & MHD.4027 & 4 & 158.08.2219 & 1 & 155.09.2617 & 1 & 24.99 us 11001 \\
\hline & ure 172 & 2 & 02.83 .3385 & 5 & 158.08 .2187 & 2 & 155.09 .2621 & 2 & 24.99 us 11116 \\
\hline 1 & $86.67-84.30986$ & 3 & 02.83 .3383 & 6 & $86.67-84.1378$ & 3 & 155.09 .2619 & 3 & 24.99 us 11007 \\
\hline 2 & $86.67-84.30060$ & 4 & MHD.4050 & & & 4 & 155.09 .2620 & 4 & 24.99 us 8015 \\
\hline 3 & $86.67-84.1324$ & 5 & 02.83 .3382 & & ure 195 & 5 & 155.09 .2624 & 5 & 24.99 us 4348 \\
\hline 4 & $86.67-84.30952$ & 6 & MHD.4030 & 1 & 46.94 .2472 & & & 6 & 31.92 us 2-362 \\
\hline & & 7 & Mucem 1938.12.63 & 2 & 158.08.1973 & & ure 209 & 7 & 31.92 us $1-201$ \\
\hline & ure 173 & & & 3 & 46.94 .2504 & 1 & 155.09 .2623 & 8 & 31.92 us $2-809$ \\
\hline 1 & $86.67-84.1152$ & & ure 184 & 4 & 90.85 .2010 & 2 & 155.09 .2625 & 9 & 31.92 us $2-809$ \\
\hline 2 & $86.67-84.1324$ & 1 & 43.94 sans $n^{\circ}$ d'inv. & & & 3 & $86.67-84.1356$ & 10 & 142.07 us 2017 \\
\hline & & 2 & 43.94 sans $n^{\circ}$ d'inv. & & ure 196 & 4 & 155.09 .2622 & 11 & 24.99 us 4348 \\
\hline & ure 174 & 3 & $86.67-84.31557$ & 1 & 56.02 .10192 & 5 & 155.09 .2725 & 12 & 24.99 us 11116 \\
\hline 1 & 02.83 .3479 & 4 & 24.99 .1842 & & & & & 13 & 52.96 us 2464 \\
\hline 2 & $86.67-84.1439$ & & & & ure 197 & & ure 210 & 14 & 52.96 us 2464 \\
\hline 3 & $86.67-84.1479$ & & ure 185 & 1 & $86.67-84.1206$ & 1 & 155.09 .2711 & 15 & 52.96 us 2464 \\
\hline & & 1 & $86.67-84.1290$ & 2 & $86.67-84.1338$ & 2 & 155.09 .2712 & 16 & 50.00 us 3128 \\
\hline & ure 175 & 2 & $86.67-84.1288$ & 3 & $86.67-84.1372$ & 3 & 155.09 .2710 & & \\
\hline 1 & 02.83 .3362 & 3 & $86.67-84.1289$ & & & & & & ure 222 \\
\hline 2 & $86.67-84.1394$ & 4 & $86.67-84.1292$ & & ure 198 & & ure 211 & 1 & 24.99 us 7208 \\
\hline 3 & 86.67-84.1401 & 5 & $86.67-84.1287$ & 1 & $86.67-84.1204$ & 1 & 155.09.2696 & 2 & 31.92 us $1-100$ \\
\hline & & 6 & $86.67-84.1291$ & & & 2 & 155.09 .2687 & 3 & 31.92 us $1-259$ \\
\hline & ure 176 & & & & ure 199 & 3 & 155.09 .2690 & 4 & 52.96 us 2439 \\
\hline 1 & $86.67-84.1390$ & & ure 186 & 1 & $86.67-84.1363$ & 4 & 155.09 .2685 & 5 & 52.96 us 2439 \\
\hline 2 & $86.67-84.31769$ & 1 & 43.94 sans $n^{\circ}$ d'inv. & 2 & $86.67-84.1630$ & 5 & 155.09 .2699 & 6 & 52.96 us 2439 \\
\hline 3 & $86.67-84.31760$ & 2 & 43.94 sans $n^{\circ}$ d'inv. & 3 & $86.67-84.1361$ & 6 & 155.09 .2695 & & 02.00 us 2400 \\
\hline 4 & 02.83 .3026 & 3 & 43.94 sans $n^{\circ} d^{\prime} i n v$. & & & & & & ure 223 \\
\hline & & 4 & $86.67-84.1293$ & & ure 200 & & ure 212 & & 52.96 us 2439 \\
\hline & ure 177 & 5 & 26.84 .5 & 1 & $86.67-84.1374$ & 1 & 155.09 .2681 & & \\
\hline 1 & 86.67-84.1244 & & & 2 & $86.67-84.1375$ & 2 & 155.09 .2682 & & ure 224 et 225 \\
\hline 2 & $86.67-84.1391$ & & ure 187 & 3 & $86.67-84.1316$ & 3 & 52.02 .10170 & 1 & 52.96 us 2439 \\
\hline 3 & $86.67-84.31767$ & 1 & 43.94 sans $n^{\circ}$ d'inv. & 4 & $86.67-84.1356$ & 4 & 155.09 .2602 & 2 & 52.96 us 2439 \\
\hline 4 & $86.67-84.1477$ & 2 & 43.94 sans $n^{\circ}$ d'inv. & 5 & $86.67-84.1201$ & 5 & 155.09 .2626 & & \\
\hline 5 & 86.67-84.1392 & 3 & 43.94 sans $n^{\circ}$ d'inv. & 6 & $86.67-84.1202$ & & & & ure 226 \\
\hline & & 4 & 43.94 sans $n^{\circ}$ d'inv. $^{2}$ & & & & ure 213 & 1 & 52.96 us 2464 \\
\hline Fig & ure 178 & & & & ure 201 & 1 & 19.90 us 117 & 2 & 52.96 us 2464 \\
\hline 1 & 02.83 .3041 & & ure 188 & 1 & 52.02 .10405 et & 2 & 19.90 us 478 & 3 & 52.96 us 2464 \\
\hline 2 & 02.83 .3042 & 1 & 158.08 .1972 & & 52.02 .10363 & 3 & 19.90 us 207 & & \\
\hline 3 & 02.83 .3043 & 2 & 46.94 .2482 & 2 & 31.92 .907 & 4 & 52.95 us $3136-3152$ & & ure 227 \\
\hline & & 3 & 46.94 .2481 & 3 & 115.03 .3002 & 5 & 52.95 us 3027 & 1 & 52.02 us 5543 \\
\hline Fig & ure 179 & 4 & 46.94 .2535 & 4 & 56.98 .59 & & & 2 & 24.99 us 7202 \\
\hline 1 & $86.67-84.1450$ & 5 & 158.08.1971 & & & & ure 214 et 215 & 3 & 31.92 us $1-283$ \\
\hline 2 & $86.67-84.1321$ & 6 & 46.94 .2480 & & ure 202 & 1 & 24.99 us 1299 & 4 & 31.92 us $1-145$ \\
\hline 3 & $86.67-84.1303$ & 7 & 158.08.2097 & 1 & 155.09 .2672 & 2 & 24.99 us 4338 & 5 & 31.92 us $1-120$ \\
\hline 4 & $86.67-84.1302$ & & & 2 & 155.09 .2673 & 3 & 24.99 us 11039 & 6 & 142.07 us 2017 \\
\hline 5 & $86.67-84.1322$ & & ure 189 & 3 & 155.09 .2727 & 4 & 24.99 us 11114 & 7 & 30.92 us $5-181$ \\
\hline 6 & $86.67-84.1337$ & 1 & 90.85 .2001 & 4 & 155.09 .2603 & 5 & 52.02 us 5126 & 8 & 30.92 us $5-181$ \\
\hline 7 & $86.67-84.1301$ & 2 & 90.85 .2006 & 5 & 155.09 .2674 & 6 & 52.02 us 5129 & 9 & 31.92 us $1-340$ \\
\hline 8 & $86.67-84.30157$ & 3 & 90.85 .2002 & 6 & 155.09 .2708 & 7 & 50.00 us 3426 & 10 & 31.92 us $1-340$ \\
\hline 9 & $86.67-84.1229$ & 4 & 90.85 .2020 & & & 8 & 24.99 us 4338 & & \\
\hline 10 & $86.67-84.1219$ & 5 & 90.85 .2008 & & are 203 & 9 & 52.95 us 3011 & & ure 228 \\
\hline 11 & 86.67-84.1168 & 6 & 90.85 .2007 & 1 & 155.09 .2678 & 10 & 52.95 us 3092 & 1 & 46.94 us 2001 \\
\hline 12 & $86.67-84.1127$ & 7 & 90.85 .2019 & 2 & 155.09 .2679 & 11 & 31.92 us $3-541$ & 2 & 52.96 us 2439 \\
\hline 13 & $86.67-84.1125$ & & & 3 & 155.09 .2677 & 12 & 31.92 us $4-271$ & 3 & 31.92 us $1-145$ \\
\hline 14 & $86.67-84.1120$ & & ure 190 & 4 & 155.09 .2676 & 13 & 31.92 us $1-695$ & & \\
\hline 15 & $86.67-84.1121$ & 1 & 158.08 .2280 & 5 & 155.09 .2674 & 14 & 31.92 us $1-411$ & & ure 229 \\
\hline 16 & $86.67-84.1222$ & 2 & 158.08.2277 & 6 & 155.09 .2680 & 15 & 31.92 us $1-447$ & 1 & 31.92 us $2-249$ \\
\hline 17 & $86.67-84.32008$ & 3 & 158.08 .2290 & 7 & 155.09 .2709 & 16 & 31.92 us $3-459$ & 2 & 31.92 us $3-238$ \\
\hline 18 & $86.67-84.31649$ & 4 & 46.94 .2478 & 8 & 155.09 .2628 & 17 & 31.92 us $3-408$ & 3 & 52.96 us 2427 \\
\hline 19 & $86.67-84.1219$ & & & 9 & 155.09 .2633 & 18 & 142.07 us 2017 & 4 & 30.92 us $5-302$ \\
\hline & & & ure 191 & & & & & 5 & 30.92 us $5-302$ \\
\hline & ure 180 & 1 & 46.94 .2475 & & ure 204 & & ure 216 et 217 & 6 & 30.92 us $5-302$ \\
\hline 1 & $86.67-84.1471$ & 2 & 158.08 .2263 & 1 & 155.09 .2604 & 1 & 24.99 us 7398 & 7 & 46.94 us 2001 \\
\hline 2 & $86.67-84.1447$ & 3 & 46.94 .2474 & 2 & 155.09 .2607 & 2 & 24.99 us 8015 & & \\
\hline 3 & $86.67-84.30330$ & 4 & $86.67-84.1800$ & & & & & & \\
\hline
\end{tabular}




\begin{tabular}{|c|c|c|c|c|c|c|c|c|c|}
\hline \multicolumn{2}{|c|}{ Figure 230} & \multicolumn{2}{|c|}{ Figure 239} & \multicolumn{2}{|c|}{$16 \quad 49.00 .6$} & Fig & ure 249 & 4 & 24.99 us 5587 \\
\hline 1 & 24.99 .460 & 1 & $175.69-76.125$ & 17 & 24.99 us 2149 & 1 & 24.99 .1905 & 5 & 52.97 .15 \\
\hline 2 & 24.99 .503 & 2 & 50.00 us 4127 & 18 & 11.87 .2 & 2 & 50.00 .65 & 6 & 24.99 us 4054 \\
\hline 3 & 24.99 .521 & 3 & 06.87 .752 & 19 & 24.99 us 2041 & 3 & 50.00 .63 & 7 & 24.99 us 3185 \\
\hline 4 & 24.99 .576 & 4 & 52.97 .17 & 20 & 50.00 us 3356 & 4 & 6.87 us HS & 8 & 24.99 us 3185 \\
\hline 5 & 24.99 .577 & 5 & 50.00 us 3317 & 21 & $175.69-76.495$ & 5 & 6.87 .222 & 9 & 24.99 us 11013 \\
\hline 6 & 50.00 .7 & 6 & 46.94 us 95 & & & 6 & 49.94 us HS & 10 & 24.99 us 7025 \\
\hline 7 & 50.94 .3 & 7 & 24.99 us 4252 & Figu & ure 244 & & & 11 & 24.99 us 11011 \\
\hline 8 & 24.99 .554 & 8 & 11.95 us $9-175$ & 1 & $175.69-76.431$ & Fig & ure 250 & 12 & 24.99 us 11015 \\
\hline 9 & 24.99 .518 & 9 & 24.99 us 4252 & 2 & $175.69-76.499$ & 1 & 24.99 us 1001 & & \\
\hline 10 & 24.99 .511 & 10 & 52.02 us 5381 & 3 & 56.98 us 213 & 2 & 24.99 us 3238 & Fig & ure 259 \\
\hline 11 & 24.99 .465 & 11 & 158.08 us 2010 & 4 & 11.89 .218 & 3 & 131.05 us HS & 1 & 50.00 .1865 \\
\hline 12 & 24.99.1690 & & & 5 & 24.99 .1787 & 4 & 131.05 us HS & 2 & 50.00 .76 \\
\hline & & Fig & ure 240 & 6 & $175.69-76.431$ & 5 & 52.97 us 2075 & 3 & 50.00 .51 \\
\hline Fig & ure 231 & 1 & 06.87 .107 & 7 & $175.69-76.431$ & 6 & 24.99 us 4581 & 4 & 49.00 .9 \\
\hline 1 & $86.67-84.32207$ & 2 & 19.90 .28 & 8 & 50.00 us 3102 & 7 & 06.87 .110 & & \\
\hline & & 3 & 24.99 us 4437 & 9 & 49.94 .20 & 8 & 52.97 .3 & Fig & ure 260 \\
\hline Fig & ure 232 & 4 & 56.98 us 144 & 10 & $175.69-76.431$ & 9 & 11.89 .361 & 1 & 24.99 .1866 \\
\hline 1 & $86.67-84.32204$ & 5 & 24.99 .1809 & 11 & $175.69-76$ us n 2 & 10 & 11.95 us $8-162$ & 2 & 49.00 .59 \\
\hline 2 & $86.67-84.30922$ & 6 & $175.69-76.144$ & $\begin{array}{l}11 \\
12\end{array}$ & 24.99 us 3217 & 11 & 24.99 .1808 & 3 & 24.99 .1869 \\
\hline 3 & 02.83 .3375 & 7 & $175.69-76.361$ & $\begin{array}{l}12 \\
13\end{array}$ & 49.94.120 & 12 & 50.00 us 3016 & 4 & 24.99.1904 \\
\hline 4 & $86.67-84.32202$ & & & $\begin{array}{l}13 \\
14\end{array}$ & 131.05 us 3191 & 13 & 52.02 us 5003 & 5 & 50.00 .61 \\
\hline 5 & $86.67-84.30584$ & Fig & ure 241 & 15 & 25.91 us 163 & 14 & 52.02 us 5003 & 6 & 50.00 .59 \\
\hline & & & 24.99 us 2149 & 16 & 02.83 us 34 & 15 & 11.89 .282 & 7 & 50.00 .80 \\
\hline Fig & ure 233 & 2 & 24.99 us 2149 & 17 & $175.69-76.498$ & 16 & 06.87 .818 & 8 & 24.99 .1901 \\
\hline 1 & $86.67-84.32218$ & 3 & 11.95 .1618 & $\begin{array}{l}11 \\
18\end{array}$ & 11.89 .280 & & & 9 & 52.97 .11 \\
\hline 2 & 03.85. sans $n^{\circ}$ & 4 & 50.00 us 306 & $\begin{array}{l}10 \\
19\end{array}$ & 24.99 us 11039 & Fig & ure 251 & & \\
\hline 3 & 46.94 .2452 & 5 & $175.69-76.133$ & 20 & $175.69-76.212$ & 1 & $175.69-76.388$ & Fig & ure 261 \\
\hline 4 & $86.67-84.30985$ & 6 & 24.99 .1813 & 21 & 49.94 .35 & 2 & 06.87 .282 & 1 & $175.69-76$ us sm Z 1, 1 \\
\hline 5 & $86.67-84.32206$ & 7 & 24.99 us 1206 & $\begin{array}{l}\angle 1 \\
22\end{array}$ & $\begin{array}{l}49.94 .35 \\
49.94 .35\end{array}$ & 3 & $175.69-76.1460$ & 2 & $175.69-76.738$ \\
\hline 6 & 02.83 .3374 & 8 & 24.99 us 4552 & 22 & 49.94 .35 & 4 & 24.99 .1806 & 3 & 24.99 us 11001 \\
\hline 7 & 52.02 .11616 & 9 & $175.69-76.879$ & Figu & ure 245 & 5 & 24.99 us 3284 & 4 & 11.89 us $4-280$ \\
\hline 8 & $86.67-84.30670$ & 10 & 24.99 us 11130 & 1 & 52.02 us 3003 & 6 & 52.97.19 & 5 & 11.87 us $1-129$ \\
\hline & & 11 & 24.99 .1834 & 2 & $175.69-76.700$ & 7 & 19.90 .23 & 6 & 11.89 .281 \\
\hline & ure 234 & 12 & 24.99 us 2119 & 3 & $175.69-76$ us pe, $Z 1$, brm & & & 7 & 24.99 us 2149 \\
\hline 1 & $86.67-84.32211$ & 13 & 24.99 us 11130 & 4 & $175.69-76$ us pe, $Z 1$, brm & Fig & ure 252 & 8 & 50.00 us 3016 \\
\hline 2 & 105.01 .1203 & 14 & 50.00 us 3016 & $\begin{array}{l}4 \\
5\end{array}$ & $175.69-76.368$ & 1 & 24.99 us 5274 & 9 & 52.02 us 5003 \\
\hline 3 & $86.67-84.31416$ & 15 & 24.99 us 11022 & 6 & $175.69-76.674$ & 2 & 56.98 us 141 & 10 & $175.69-76.653$ \\
\hline 4 & 115.09 .2627 & 16 & 19.89 us $1-160$ & 7 & 49.94 .121 & & & 11 & $175.69-76.1146$ \\
\hline 5 & $86.67-84.32198$ & 17 & $175.69-76.134$ & 8 & 49.94 .164 & Fig & ure 253 & 12 & 175.69-76.487B \\
\hline 6 & 24.99.us 2128 & 18 & 24.99 us 11007 & 9 & 49.00 .2 & 1 & $175.69-76.649$ & 13 & 11.87 us 100 \\
\hline 7 & $86.67-84.32220$ & 19 & 49.94 .60 & 10 & 49.94 .111 & 2 & 24.99 .1900 & 14 & 24.99 us 7459 \\
\hline 8 & $86.67-84.32207$ & 20 & 50.94 .1 & 11 & 49.94 .112 & 3 & $175.69-76.1575$ & 15 & $175.69-76.894$ \\
\hline 9 & 46.94 .2539 & & & $\begin{array}{l}11 \\
12\end{array}$ & $175.69-76.699$ & 4 & 50.00 .58 & 16 & 52.02 us 5003 \\
\hline & & & ure 242 & 13 & $175.69-76.656$ & 5 & 11.89 .682 & 17 & 24.99 us 3139 \\
\hline Fig & ure 235 & 1 & 50.94 .3 & 14 & $175.69-76.707$ & 6 & 46.94 us 1151 & & \\
\hline 1 & 155.09 us 2001 & 2 & 52.02 .821 & $\begin{array}{l}14 \\
15\end{array}$ & 50.00 us 5085 & 7 & $175.69-76.119$ & Fig & ure 262 \\
\hline & & 3 & 50.94 .2 & 16 & 50.00 us 505 & 8 & 52.97 .2 & 1 & 52.02 us 5302 \\
\hline Fig & ure 237 & 4 & 50.00 .47 & 17 & 11.89 .104 & 9 & $175.69-76.725$ & 2 & 52.02 us 5003 \\
\hline 1 & 52.02 us 5178 & 5 & 50.00 .48 & $\begin{array}{l}11 \\
18\end{array}$ & $\begin{array}{l}11.09 .104 \\
175.69-76.368\end{array}$ & 10 & 24.99 .1817 & 3 & 49.94 .178 \\
\hline 2 & $175.69-76.688$ & 6 & 24.99 .1864 & $\begin{array}{l}10 \\
19\end{array}$ & 49.00 .5 & & & 4 & 24.99 us 3215 \\
\hline 3 & 24.99 us 5126 & 7 & 50.00 .54 & 20 & $175.69-76.671$ & Fig & ure 256 & 5 & 24.99 us 11001 \\
\hline 4 & 24.99 us 7603 & 8 & 50.00 .50 & 21 & $\begin{array}{l}170.09-10.011 \\
8.86 .3\end{array}$ & 1 & 24.99 .1868 & 6 & $175.69-76.431$ \\
\hline 5 & $175.69-76.682$ & 9 & 50.00 .51 & $\begin{array}{l}21 \\
22\end{array}$ & $175.69-76.660$ & 2 & 52.97 .5 & 7 & $175.69-76.382$ \\
\hline 6 & $175.69-76.88$ & 10 & 50.00 .55 & $\begin{array}{l}22 \\
23\end{array}$ & 50.00 us 5085 & 3 & 52.97 .6 & 8 & $175.69-76.698$ \\
\hline 7 & 24.99 .88 & $\begin{array}{l}10 \\
11\end{array}$ & 24.99 .1862 & $\begin{array}{l}23 \\
24\end{array}$ & 19.90 .92 & 4 & 52.97 .7 & 9 & 19.90 .123 \\
\hline 8 & 24.99 us 7004 & $\begin{array}{l}11 \\
12\end{array}$ & $\begin{array}{l}24.99 .1002 \\
142.07 .227\end{array}$ & $\begin{array}{l}24 \\
25\end{array}$ & 50.00 us 5085 & 5 & 52.97 .8 & 10 & 24.99 .1815 \\
\hline 9 & 52.97 .6 & 13 & 50.00 .56 & 26 & 49.00 .1 & 6 & 52.97 .9 & 11 & 50.00 us 2967 \\
\hline 10 & $175.69-76$ us cs, Z V, cv & $\begin{array}{l}13 \\
14\end{array}$ & 50.00 .52 & $\begin{array}{l}26 \\
27\end{array}$ & $\begin{array}{l}49.00 .1 \\
52.97 .5\end{array}$ & 7 & 52.97 .10 & 12 & 11.89 .219 \\
\hline 11 & 21.89 .45 & 15 & 50.00 .53 & 28 & 52.97 .4 & 8 & 52.02 .822 & 13 & 06.87 .820 \\
\hline 12 & 24.99 us 7397 & 16 & 50.00 .46 & $\begin{array}{l}20 \\
29\end{array}$ & $175.69-76.796$ & 9 & $175.69-76.648$ & 14 & 11.89 us $2-102$ \\
\hline 13 & 02.83 us S E12, c 31 & 17 & 50.00 .57 & $\begin{array}{l}29 \\
30\end{array}$ & $175.69-76.556$ & 10 & 52.97 .4 & 15 & 01.86 .258 \\
\hline 14 & 131.05 us 1151 & 18 & 24.99 .1861 & 31 & $\begin{array}{l}1 / 5.09-76.556 \\
19.90 .148\end{array}$ & 11 & 49.00 .58 & 16 & 11.89 .407 \\
\hline 15 & 24.99 us 11001 & 19 & 1.86 .1342 & & & 12 & 50.00 .64 & & \\
\hline 16 & 06.86 .804 & 20 & 50.00 .49 & Figu & ure 246 & 13 & 24.99.1907 & & \\
\hline & & & & 1 & 24.99 us 2119 & 14 & 11.87 .822 & & \\
\hline Fig & ure 238 & Fig & ure 243 & $\begin{array}{l}1 \\
2\end{array}$ & 24.99 us 2041 & & & & \\
\hline 1 & 50.00 us 2695 & 1 & 50.00 us 2128 & 3 & 24.99 us 2149 & Fig & ure 257 & & \\
\hline 2 & $175.69-76.625$ & 2 & 24.99 us 2149 & $7-9$ & 52.02 .5 & 1 & 24.99 .1818 & & \\
\hline 3 & 11.89 .419 & 3 & 24.99 .1828 & & & 2 & 52.02 us 5003 & & \\
\hline 4 & 01.86 .35 & 4 & 49.94 .175 & Figu & are 247 & 3 & 52.02 us 15048 & & \\
\hline 5 & 06.87 .122 & $\begin{array}{l}4 \\
5\end{array}$ & $175.69-76.257$ & 1 & 49.94 .37 & 4 & 52.97 us 2086 & & \\
\hline 6 & 24.99 us 7160 & 6 & 52.02 us 5053 & $\begin{array}{l}1 \\
2\end{array}$ & 49.94 .37 & 5 & 52.02 us 4107 & & \\
\hline 7 & 24.99 us 7123 & 7 & 50.00 us 7304 & $\begin{array}{l}2 \\
3\end{array}$ & $\begin{array}{l}49.94 .31 \\
49.94 .33\end{array}$ & 6 & 52.97.11 & & \\
\hline 8 & 52.97.14 & 8 & 06.87 .124 & 4 & $\begin{array}{l}49.94 .33 \\
11.87 .1\end{array}$ & 7 & 24.99 .1918 & & \\
\hline 9 & 50.00 us 2184 & $\begin{array}{l}0 \\
9\end{array}$ & 49.94 .168 & $\begin{array}{l}4 \\
5\end{array}$ & $\begin{array}{l}11.81 .1 \\
11.89 .243\end{array}$ & 8 & 50.00 us 3102 & & \\
\hline 10 & 24.99 us 2126 & 10 & 12.03 us 105 & $\begin{array}{l}5 \\
6\end{array}$ & $175.69-76$ us pe, $Z 1$, brm & 9 & 24.99 us 4261 & & \\
\hline 11 & 24.99 us 4252 & $\begin{array}{l}10 \\
11\end{array}$ & 49.94 .162 & $\begin{array}{l}6 \\
7\end{array}$ & $\begin{array}{l}1 / 5.69-16 \text { us pe, } \angle 1, \mathrm{Dm} \\
175.69-76.253\end{array}$ & & & & \\
\hline 12 & 01.86 .535 & $\begin{array}{l}1+ \\
12\end{array}$ & 11.89 .255 & 8 & $\begin{array}{l}1 / 5.69-/ 6.253 \\
11.87 .3\end{array}$ & & ure 258 & & \\
\hline 13 & 24.99 us 2110 & $\begin{array}{l}12 \\
13\end{array}$ & 50.00 us 4197 & $\begin{array}{l}8 \\
9\end{array}$ & $\begin{array}{l}11.87 .3 \\
175.69-76.213\end{array}$ & 1 & 24.99 us 4276 & & \\
\hline 14 & 8.86 .182 & $\begin{array}{l}10 \\
14\end{array}$ & 06.87 .118 & 10 & $\begin{array}{l}1 / 5.69-16.213 \\
52.97 .8\end{array}$ & 2 & 24.99 us 4087 & & \\
\hline & & $\begin{array}{l}14 \\
15\end{array}$ & 49.94 .161 & 10 & $\begin{array}{l}52.91 .8 \\
49.94 .56\end{array}$ & 3 & 24.99 us 4271 & & \\
\hline
\end{tabular}




\section{Index des numéros d'objet par chantier}

Nous donnons ci-dessous le détail par chantier de l'inventaire des objets reproduits dans les figures ou mentionnés dans le texte. Les objets sont notés avec le $\mathrm{n}^{\circ}$ d'inventaire global par chantier, ou par leur unité stratigraphique.

\begin{tabular}{|c|c|c|c|c|}
\hline Ilot $24 \mathrm{~N}$ & Rue de l’Evêché & 11.87R.2 : fig. $243, n^{\circ} 18$ & 24.99 .25 : fig. $87, n^{\circ} 2$ & 24.99 .1404 : fig. $62, n^{\circ} 6$ \\
\hline fouille & 03.85.sans $n^{\circ}$ : fig. $233, n^{\circ} 2$ & 11.87R.3 : fig. $247, \mathrm{n}^{\circ} 8$ & 24.99 .26 : fig. $87, n^{\circ} 2$ & 24.99 .1408 : fig. $40, n^{\circ} 7$ \\
\hline 01.86 .35 : fig. $238, n^{\circ} 4$ & & 11.87R.822 : fig. $256, n^{\circ} 14$ & 24.99 .88 : fig. $237, \mathrm{n}^{\circ} 7$ & 24.99 .1411 : fig. $45, n^{\circ} 6$ \\
\hline 01.86 .258 : fig. $262, n^{\circ} 15$ & Ilot 55 & 11.87R.7001 : fig. $111, n^{\circ} 1$ & 24.99 .460 : fig. $230, n^{\circ} 1$ & 24.99 .1416 : fig. $62, n^{\circ} 7$ \\
\hline 01.86 .535 : fig. $238, n^{\circ} 12$ & diagnostic & 11.87R.7002 : fig. $121, n^{\circ} 3$ & 24.99 .465 : fig. $230, n^{\circ} 11$ & 24.99 .1419 : fig. $48, n^{\circ} 1$ \\
\hline 01.86 .1342 : fig. $242, n^{\circ} 19$ & 06.86 .804 : fig. $237, n^{\circ} 16$ & 11.87R.7003 : fig. $117, n^{\circ} 2$ & 24.99 .503 : fig. $230, n^{\circ} 2$ & 24.99 .1419 : fig. $48, n^{\circ} 9$ \\
\hline 01.86 us $2-103$ : fig. $219, n^{\circ} 3$ & & 11.87R.7004 : fig. $115, n^{\circ} 3$ & 24.99 .511 : fig. $230, n^{\circ} 10$ & 24.99 .1420 : fig. $40, n^{\circ} 1$ \\
\hline & fouille & 11.87R.7005 : fig. $115, n^{\circ} 2$ & 24.99 .518 : fig. $230, n^{\circ} 9$ & 24.99 .1425 : fig. $55, n^{\circ} 1$ \\
\hline La Charité & 06.87 .107 : fig. $240, n^{\circ} 1$ & 11.87R.7006 : fig. $117, n^{\circ} 6$ & 24.99 .521 : fig. $230, n^{\circ} 3$ & $24.99 .1427-1430-1434-1437$ \\
\hline 02.83 .1429 : fig. $147, \mathrm{n}^{\circ} 3$ & 06.87 .110 : fig. $250, n^{\circ} 7$ & 11.87R. 7007 : fig. $117, n^{\circ} 5$ & 24.99 .554 : fig. $230, n^{\circ} 8$ & fig. $47, n^{\circ} 1$ \\
\hline 02.83 .3008 : fig. $134, n^{\circ} 1$ & 06.87 .118 : fig. $243, n^{\circ} 14$ & 11.87R.7008 : fig. $119, n^{\circ} 1$ & 24.99 .576 : fig. $230, n^{\circ} 4$ & 24.99 .1428 : fig. $87, \mathrm{n}^{\circ} 1$ \\
\hline 02.83 .3013 : fig. $136, \mathrm{n}^{\circ} 3$ & 06.87 .122 : fig. $238, n^{\circ} 5$ & 11.87R.7009 : fig. $119, n^{\circ} 3$ & 24.99 .577 : fig. $230, n^{\circ} 5$ & 24.99 .1432 : fig. $52, n^{\circ} 1$ \\
\hline 02.83 .3025 : fig. $136, \mathrm{n}^{\circ} 2$ & 06.87 .124 : fig. $243, n^{\circ} 8$ & $11.87 R .7010$ : fig. $119, n^{\circ} 2$ & 24.99 .695 : fig. $40, n^{\circ} 5$ & 24.99 .1439 : fig. $44, n^{\circ} 1$ \\
\hline 02.83 .3026 : fig. $176, \mathrm{n}^{\circ} 4$ & 06.87 .222 : fig. $249, \mathrm{n}^{\circ} 5$ & $11.87 R .7011$ : fig. $117, n^{\circ} 1$ & 24.99 .696 : fig. $46, n^{\circ} 8$ & 24.99 .1440 : fig. $44, n^{\circ} 2$ \\
\hline 02.83 .3026 : fig. $146, n^{\circ} 6$ & 06.87 .282 : fig. $251, \mathrm{n}^{\circ} 2$ & $11.87 R .7012$ : fig. $115, n^{\circ} 4$ & 24.99 .697 : fig. $46, \mathrm{n}^{\circ} 12$ & 24.99.1444 : fig. $47, \mathrm{n}^{\circ} 2$ \\
\hline 02.83 .3029 : fig. $134, n^{\circ} 3$ & 06.87 .752 : fig. $239, n^{\circ} 3$ & 11.87R.7014 : fig. $110, n^{\circ} 3$ & 24.99 .698 : fig. $46, n^{\circ} 6$ & 24.99 .1449 : fig. $45, n^{\circ} 1$ \\
\hline 02.83 .3038 : fig. $121, n^{\circ} 5$ & 06.87 .818 : fig. $250, n^{\circ} 16$ & 11.87R.7018 : fig. $114, n^{\circ} 2$ & 24.99 .701 : fig. $46, n^{\circ} 9$ & 24.99 .1450 : fig. $12, n^{\circ} 14$ \\
\hline 02.83 .3041 : fig. $178, n^{\circ} 1$ & 06.87 .820 : fig. $262, n^{\circ} 13$ & & 24.99 .702 : fig. $46, n^{\circ} 5$ & 24.99 .1451 : fig. 85 \\
\hline 02.83 .3042 : fig. $178, n^{\circ} 2$ & 06.87 us HS : fig. $249, n^{\circ} 4$ & fouille 1989 & 24.99 .705 : fig. $61, n^{\circ} 1$ & 24.99 .1452 : fig. $54, n^{\circ} 2$ \\
\hline 02.83 .3043 : fig. $178, \mathrm{n}^{\circ} 3$ & & 11.89 .104 : fig. $245, n^{\circ} 17$ & 24.99 .706 : fig. $45, n^{\circ} 3$ & 24.99 .1456 :p. 176, col. \\
\hline 02.83.3095 : fig. $134, n^{\circ} 4$ & Parvis de l'église & 11.89 .218 : fig. $244, n^{\circ} 4$ & 24.99 .707 : fig. $42, n^{\circ} 5$ & gauche \\
\hline 02.83 .3096 : fig. $134, n^{\circ} 2$ & Saint-Laurent & 11.89 .219 : fig. $262, n^{\circ} 12$ & 24.99 .708 : fig. $57, n^{\circ} 2$ & 24.99.1464 :p. 219, col. \\
\hline 02.83 .3107 : fig. $132, n^{\circ} 4$ & 08.86 .3 : fig. $245, n^{\circ} 21$ & 11.89 .243 : fig. $247, n^{\circ} 5$ & 24.99 .711 : fig. $46, n^{\circ} 7$ & gauche \\
\hline 02.83 .3108 : fig. $134, n^{\circ} 5$ & 08.86 .17 : fig. $56, n^{\circ} 4$ & 11.89 .255 : fig. $243, n^{\circ} 12$ & 24.99 .720 : fig. $40, n^{\circ} 8$ & 24.99 .1466 : fig. $138, n^{\circ} 8$ \\
\hline 02.83 .3128 : fig. $136, n^{\circ} 4$ & 08.86 .74 : fig. $80, n^{\circ} 3$ & 11.89 .280 : fig. $244, n^{\circ} 18$ & 24.99 .722 : fig. 41 & 24.99 .1492 :p. 161, col. \\
\hline 02.83 .3129 : fig. $141, \mathrm{n}^{\circ} 3$ & 08.86 .76 : fig. $50, n^{\circ} 1$ & 11.89 .281 : fig. $261, n^{\circ} 6$ & 24.99 .723 : fig. $40, n^{\circ} 4$ & gauche \\
\hline 02.83 .3130 : fig. $140, n^{\circ} 4$ & 08.86 .77 : fig. $57, n^{\circ} 4$ & 11.89 .282 : fig. $250, n^{\circ} 15$ & 24.99 .727 : fig. $53, n^{\circ} 2$ & 24.99 .1503 :p. 161, col. \\
\hline 02.83 .3132 : fig. $127, n^{\circ} 6$ & 08.86 .80 : fig. $61, n^{\circ} 2$ & 11.89 .361 : fig. $250, n^{\circ} 9$ & 24.99 .730 : fig. $86, n^{\circ} 1$ & gauche \\
\hline 02.83 .3164 : fig. $128, n^{\circ} 5$ & 08.86 .81 : fig. $80, n^{\circ} 1$ & 11.89.407 : fig. $262, n^{\circ} 16$ & 24.99 .731 : fig. $62, n^{\circ} 1$ & 24.99 .1505 : fig. $122, n^{\circ} 1$ \\
\hline 02.83 .3165 : fig. $152, n^{\circ} 2$ & 08.86 .82 : fig. $51, n^{\circ} 5$ & 11.89 .419 : fig. $238, n^{\circ} 3$ & 24.99 .733 : fig. $62, n^{\circ} 8$ & 24.99 .1595 : fig. $54, n^{\circ} 3$ \\
\hline 02.83 .3166 et 3226 : fig. 152 & 08.86 .83 : fig. $81, n^{\circ} 1$ & 11.89 .682 : fig. $253, n^{\circ} 5$ & 24.99 .745 : fig. 49 & 24.99 .1596 : fig. $45, n^{\circ} 4$ \\
\hline & 08.86 .84 : fig. $48, n^{\circ} 11$ & 11.89 us $2-102$ : fig. $262, n^{\circ} 14$ & 24.99 .752 : fig. $43, n^{\circ} 4$ & 24.99 .1597 : fig. $55, n^{\circ} 4$ \\
\hline 02.83 .3167 : fig. $150, \mathrm{n}^{\circ} 2$ & 08.86 .85 : fig. $82, n^{\circ} 2$ & 11.89 us $4-280$ : fig. $261, n^{\circ} 4$ & 24.99 .1205 : fig. $55, n^{\circ} 2$ & 24.99 .1598 : fig. $42, n^{\circ} 1$ \\
\hline 02.83 .3168 : fig. $142, n^{\circ} 4$ & 08.86 .90 : fig. $56, n^{\circ} 2$ & & 24.99 .1210 : fig. $42, n^{\circ} 6$ & 24.99 .1600 : fig. $138, n^{\circ} 9$ \\
\hline 02.83 .3186 : fig. $152, \mathrm{n}^{\circ} 3$ & 08.86 .107 : fig. $83, n^{\circ} 4$ & fouille 1995 & 24.99 .1217 : fig. $51, n^{\circ} 2$ & 24.99 .1602 : fig. $127, n^{\circ} 1$ \\
\hline 02.83 .3193 : fig. $136, n^{\circ} 1$ & 08.86 .108 : fig. $82, n^{\circ} 4$ & 11.95 .1618 : fig. $241, n^{\circ} 3$ & 24.99 .1257 : fig. $86, \mathrm{n}^{\circ} 3$ & 24.99 .1635 : fig. $148, n^{\circ} 1$ \\
\hline 02.83 .3228 : fig. $137, \mathrm{n}^{\circ} 7$ & 08.86 .126 : fig. $79, n^{\circ} 4$ & 11.95 us $8-162$ : fig. $250, n^{\circ} 10$ & 24.99 .1264 : fig. $46, n^{\circ} 11$ & 24.99 .1642 : fig. $128, n^{\circ} 2$ \\
\hline 02.83 .3230 : fig. $138, n^{\circ} 5$ & 08.86 .133 : fig. $58, n^{\circ} 2$ & 11.95 us $9-175$ : fig. $239, n^{\circ} 8$ & 24.99 .1279 : fig. $45, n^{\circ} 5$ & 24.99 .1643 : fig. $128, n^{\circ} 3$ \\
\hline 02.83 .3231 : fig. $138, n^{\circ} 4$ & 08.86 .142 : fig. $81, n^{\circ} 4$ & & 24.99 .1285 : fig. $46, n^{\circ} 3$ & 24.99 .1644 : fig. $128, n^{\circ} 1$ \\
\hline 02.83 .3239 : fig. $138, n^{\circ} 3$ & 08.86 .156 : fig. $80, n^{\circ} 2$ & Puget III & 24.99 .1286 : fig. $81, n^{\circ} 3$ & 24.99 .1660 : fig. $125, n^{\circ} 2$ \\
\hline 02.83 .3240 : fig. $138, n^{\circ} 1$ & 08.86 .161 : fig. $48, n^{\circ} 12$ & diagnostic & 24.99 .1291 : fig. $60, n^{\circ} 3$ & 24.99 .1674 : fig. $125, n^{\circ} 1$ \\
\hline 02.83 .3241 : fig. $127, n^{\circ} 7$ & 08.86 .162 : fig. $48, n^{\circ} 13$ & 19.89 us $1-160$ : fig. $241, n^{\circ} 16$ & 24.99 .1294 : fig. $86, n^{\circ} 4$ & 24.99 .1690 : fig. $230, n^{\circ} 12$ \\
\hline 02.83 .3241 : fig. $128, n^{\circ} 7$ & 08.86 .168 : fig. $79, n^{\circ} 6$ & & 24.99 .1295 : fig. $86, n^{\circ} 2$ & 24.99 .1709 : fig. $122, n^{\circ} 2$ \\
\hline 02.83 .3242 : fig. $126, n^{\circ} 4$ & 08.86 .169 : fig. $80, n^{\circ} 5$ & fouille & 24.99 .1317 : fig. $151, n^{\circ} 1$ & 24.99 .1710 :p. 157, col. droite \\
\hline 02.83 .3244 : fig. $146, n^{\circ} 5$ & 08.86 .170 : fig. $80, n^{\circ} 4$ & 19.90 .123 : fig. $262, n^{\circ} 9$ & 24.99 .1321 : fig. $156, n^{\circ} 2$ & 24.99 .1711 : fig. $123, n^{\circ} 1$ \\
\hline 02.83 .3300 : fig. $146, \mathrm{n}^{\circ} 7$ & 08.86 .172 : fig. $79, n^{\circ} 5$ & 19.90.148 : fig. $245, n^{\circ} 31$ & 24.99 .1368 : fig. $48, n^{\circ} 6$ & 24.99 .1729 : fig. $127, n^{\circ} 3$ \\
\hline 02.83 .3362 : fig. $175, n^{\circ} 1$ & 08.86 .173 : fig. $81, n^{\circ} 6$ & 19.90 .23 : fig. $251, n^{\circ} 7$ & 24.99 .1370 : fig. $51, n^{\circ} 1$ & 24.99 .1787 : fig. $244, n^{\circ} 5$ \\
\hline 02.83 .3374 : fig. $233, n^{\circ} 6$ & 08.86 .174 : fig. $83, n^{\circ} 3$ & 19.90 .28 : fig. $240, n^{\circ} 2$ & 24.99 .1372 : fig. $46, n^{\circ} 2$ & 24.99 .1806 : fig. $251, n^{\circ} 4$ \\
\hline 02.83 .3375 : fig. $232, \mathrm{n}^{\circ} 3$ & 08.86 .175 : fig. $83, n^{\circ} 5$ & 19.90 .92 : fig. $245, n^{\circ} 24$ & 24.99 .1373 : fig. $59, n^{\circ} 2$ & 24.99 .1808 : fig. $250, n^{\circ} 11$ \\
\hline 02.83 .3382 : fig. $183, n^{\circ} 5$ & 08.86 .176 : fig. $82, n^{\circ} 1$ & 19.90 us 117 : fig. $213, n^{\circ} 1$ & 24.99 .1373 bis : fig. $59, n^{\circ} 3$ & 24.99 .1813 : fig. $241, n^{\circ} 6$ \\
\hline 02.83 .3383 : fig. $183, \mathrm{n}^{\circ} 3$ & 08.86 .176 : fig. $82, n^{\circ} 5$ & 19.90 us 207 : fig. $213, n^{\circ} 3$ & 24.99 .1374 : fig. $16, n^{\circ} 7$ & 24.99 .1815 : fig. $262, n^{\circ} 10$ \\
\hline 02.83 .3385 : fig. $183, n^{\circ} 2$ & 08.86 .177 : fig. $82, n^{\circ} 3$ & 19.90 us 478 : fig. $213, \mathrm{n}^{\circ} 2$ & 24.99 .1375 : fig. $13, n^{\circ} 3$ & 24.99 .1817 : fig. $253, n^{\circ} 10$ \\
\hline 02.83 .3386 : fig. $160, n^{\circ} 1$ & 08.86 .178 : fig. $56, n^{\circ} 5$ & & 24.99 .1376 : fig. $57, n^{\circ} 6$ & 24.99 .1818 : fig. $257, n^{\circ} 1$ \\
\hline 02.83 .3479 : fig. $174, \mathrm{n}^{\circ} 1$ & 08.86 .182 : fig. $238, n^{\circ} 14$ & Avenue Vaudoyer & 24.99 .1379 : fig. $42, n^{\circ} 4$ & 24.99.1828 : fig. $243, n^{\circ} 3$ \\
\hline 02.83.3518 : fig. $181, \mathrm{n}^{\circ} 1$ & & fouille 1989 & 24.99.1393 et 1398 : fig. 43 , & 24.99 .1834 : fig. $241, n^{\circ} 11$ \\
\hline 02.83 .3998 : fig. $126, n^{\circ} 3$ & Les Pistoles & 21.89 .45 : fig. $237, n^{\circ} 11$ & $\mathrm{n}^{\circ} 2$ & 24.99 .1842 : fig. $184, n^{\circ} 4$ \\
\hline 02.83 us $34:$ fig. $244, n^{\circ} 16$ & diagnostic & & 24.99 .1400 : fig. $40, n^{\circ} 3$ & 24.99 .1861 : fig. $242, n^{\circ} 18$ \\
\hline 02.83 us S E12 c. 31 : fig. 237 , & $11.87 \mathrm{R}$ us $100:$ fig. $261, \mathrm{n}^{\circ} 13$ & Alcazar & 24.99 .1401 : fig. $40, n^{\circ} 9$ & 24.99.1862 : fig. $242, n^{\circ} 11$ \\
\hline$n^{\circ} 13$ & $11.87 R$ us $1-129:$ fig. $261, n^{\circ} 5$ & fouille & 24.99 .1402 : fig. $45, n^{\circ} 2$ & 24.99 .1864 : fig. $242, n^{\circ} 6$ \\
\hline & $11.87 R .1$ : fig. $247, n^{\circ} 4$ & 24.99 .1 : fig. $58, n^{\circ} 1$ & 24.99 .1403 : fig. $62, n^{\circ} 9$ & 24.99 .1866 : fig. $260, n^{\circ} 1$ \\
\hline
\end{tabular}


24.99.1868 : fig. $256, n^{\circ} 1$ 24.99.1869 : fig. $260, n^{\circ} 3$ 24.99 .1900 : fig. $253, n^{\circ} 2$ 24.99.1901 : fig. $260, n^{\circ} 8$ 24.99.1904 : fig. $260, n^{\circ} 4$ 24.99.1905: fig. $249, \mathrm{n}^{\circ} 1$ 24.99 .1907 : fig. $256, n^{\circ} 13$ 24.99.1918 : fig. $257, \mathrm{n}^{\circ} 7$ 24.99 us 1001 : fig. $250, n^{\circ} 1$ 24.99 us $1186-1857$ : fig. 6 , $\mathrm{n}^{\circ} 2$

24.99 us 1206 : fig. $241, \mathrm{n}^{\circ} 7$ 24.99 us 1299 : fig. $214-215$, $\mathrm{n}^{\circ} 1$

24.99 us 1809 : fig. $240, n^{\circ} 5$ 24.99 us 2041 : fig. $246, n^{\circ} 2$ 24.99 us 2041 : fig. $243, n^{\circ} 19$ 24.99 us 2110 : fig. $238, n^{\circ} 13$ 24.99 us 2119 : fig. $246, n^{\circ} 1$ 24.99 us 2119 : fig. $241, n^{\circ} 12$ 24.99 us 2126 : fig. $237, n^{\circ} 3$ 24.99 us 2126 : fig. $238, n^{\circ} 10$ 24.99 us 2128 : fig. $234, n^{\circ} 6$ 24.99 us 2149 : fig. $241, n^{\circ} 1$ 24.99 us 2149 : fig. $241, n^{\circ} 2$ 24.99 us 2149 : fig. $243, n^{\circ} 2$ 24.99 us 2149 : fig. $246, n^{\circ} 3$ 24.99 us 2149 : fig. $261, n^{\circ} 7$ 24.99 us 2149 : fig. $243, n^{\circ} 17$ 24.99 us 3139 : fig. $261, n^{\circ} 17$ 24.99 us 3185 : fig. $258, n^{\circ} 7$ 24.99 us 3185 : fig. $258, n^{\circ} 8$ 24.99 us 3215 : fig. $262, n^{\circ} 4$ 24.99 us 3217 : fig. $244, n^{\circ} 12$ 24.99 us $3238:$ fig. $250, \mathrm{n}^{\circ} 2$ 24.99 us 3284 : fig. $251, n^{\circ} 5$ 24.99 us 4054 : fig. $258, n^{\circ} 6$ 24.99 us 4087 : fig. $258, n^{\circ} 2$ 24.99 us 4252 : fig. $239, n^{\circ} 7$ 24.99 us 4252 : fig. $239, n^{\circ} 9$ 24.99 us 4252 : fig. $238, n^{\circ} 11$ 24.99 us 4261 : fig. $257, n^{\circ} 9$ 24.99 us 4271 : fig. $258, n^{\circ} 3$ 24.99 us 4276 : fig. $258, n^{\circ} 1$ 24.99 us 4276 : fig. $218, n^{\circ} 2$ 24.99 us 4338 : fig. $214-215$, $\mathrm{n}^{\circ} 2$

24.99 us 4338 : fig. 214-215, $\mathrm{n}^{\circ} 8$

24.99 us 4348 : fig. $219, n^{\circ} 5$ 24.99 us 4348 : fig. $220-221$, $\mathrm{n}^{\circ} 5$

24.99 us 4348 : fig. $219, n^{\circ} 6$ 24.99 us 4348 : fig. $220-221$, $\mathrm{n}^{\circ} 11$

24.99 us 4437 : fig. $218, n^{\circ} 3$ 24.99 us 4437 : fig. $240, n^{\circ} 3$ 24.99 us 4520 : fig. $219, n^{\circ} 4$ 24.99 us 4552 : fig. $241, n^{\circ} 8$ 24.99 us 4581 : fig. $250, n^{\circ} 6$ 24.99 us 5274 : fig. $252, n^{\circ} 1$ 24.99 us 5587 : fig. $258, n^{\circ} 4$ 24.99 us 7004 : fig. $237, n^{\circ} 8$ 24.99 us 7025 : fig. $258, n^{\circ} 10$ 24.99 us $7123:$ fig. $238, n^{\circ} 7$ 24.99 us 7160 : fig. $238, n^{\circ} 6$ 24.99 us 7202 : fig. $227, n^{\circ} 2$ 24.99 us 7208 : fig. $222, n^{\circ} 1$ 24.99 us 7397 : fig. $237, n^{\circ} 12$ 24.99 us 7398 : fig. $216-217$, $\mathrm{n}^{\circ} 1$

24.99 us 7459 : fig. $261, n^{\circ} 14$ 24.99 us 7603 : fig. $237, \mathrm{n}^{\circ} 4$ 24.99 us 8015 : fig. 216-217, $\mathrm{n}^{\circ} 2$

24.99 us 8015 : fig. 220-221, $\mathrm{n}^{\circ} 4$

24.99 us 8127 : fig. $22, n^{\circ} 7$ 24.99 us 11001 : fig. 220-221 $\mathrm{n}^{\circ} 1$

24.99 us 11001 : fig. $261, n^{\circ} 3$ 24.99 us 11001 : fig. $262, n^{\circ} 5$
24.99 us 11001 : fig. $237, \mathrm{n}^{\circ} 15$ 24.99 us 11007 : fig. 220-221, n 3

24.99 us 11011 : fig. $258, n^{\circ} 11$ 24.99 us 11013 : fig. $258, n^{\circ} 9$ 24.99 us 11015 : fig. $258, n^{\circ} 12$ 24.99 us 11022 : fig. $241, n^{\circ} 15$ 24.99 us 11039 : fig. 214-215, $\mathrm{n} \times 3$

24.99 us 11039 : fig. $244, n^{\circ} 19$ 24.99 us 1107 : fig. $241, n^{\circ} 18$ 24.99 us 11114 : fig. 214-215, $\mathrm{n}^{\circ} 4$

24.99 us 11116 : fig. 220-221, $\mathrm{n} \times 2$

24.99 us 11116 : fig. 220-221, $\mathrm{n}^{\circ} 12$

24.99 us 11130 : fig. $241, n^{\circ} 10$ 24.99 us 11130 : fig. $241, n^{\circ} 13$

RHI Bon Jésus

fouille

25.91 us 163 : fig. $244, n^{\circ} 15$

Fort Saint-Jean

fouille 1984

26.84 .5 : fig. $186, n^{\circ} 5$

26.84 .2513 : fig. $124, n^{\circ} 2$

26.84 .3381 : fig. $124, n^{\circ} 6$

fouille 1990

26.90 sans $n^{\circ}:$ fig. $71, n^{\circ} 1$

26.90.sans $n^{\circ}$ : fig. $71, n^{\circ} 2$

26.90.sans $n^{\circ}$ : fig. $71, n^{\circ} 3$

Place Jules-Verne

fouille

30.92 us 5-181 : fig. $227, n^{\circ} 7$ 30.92 us $5-181$ : fig. $227, n^{\circ} 8$ 30.92 us $5-296$ : fig. $218, n^{\circ} 7$ 30.92 us 5-302: fig. $229, n^{\circ} 4$ 30.92 us 5-302: fig. $229, n^{\circ} 5$ 30.92 us $5-302$ : fig. $229, n^{\circ} 6$

Place Général-de-Gaulle fouille

31.92 : fig. $70, n^{\circ} 3$

31.92 : fig. $70, n^{\circ} 4$

31.92.907 : fig. $201, n^{\circ} 2$

31.92 us $1-100$ : fig. $222, n^{\circ} 2$

31.92 us $1-120$ : fig. $227, n^{\circ} 5$

31.92 us $1-145:$ fig. $228, n^{\circ} 3$

31.92 us $1-145:$ fig. $227, n^{\circ} 4$ 31.92 us $1-201$ : fig. 220-221, $\mathrm{n}^{\circ} 7$

31.92 us $1-204:$ fig. $218, n^{\circ} 6$ 31.92 us $1-212$ : fig. $218, n^{\circ} 4$ 31.92 us $1-259$ : fig. $222, n^{\circ} 3$ 31.92 us $1-283$ : fig. $227, n^{\circ} 3$ 31.92 us $1-340:$ fig. $227, n^{\circ} 9$ 31.92 us $1-340$ : fig. $227, n^{\circ} 10$ 31.92 us $1-411$ : fig. 214-215, $\mathrm{n}^{\circ} 14$

31.92 us 1-447 : fig. 214-215, $\mathrm{n}^{\circ} 15$

31.92 us 1-695 : fig. 214-215, $\mathrm{n}^{\circ} 13$

31.92 us $2-249$ : fig. $229, n^{\circ} 1$ 31.92 us $2-362$ : fig. $220-221, n^{\circ} 6$ 31.92 us 2-809 : fig. 220-221 $\mathrm{n}^{\circ} 8$

31.92 us 2-809 : fig. 220-221, $\mathrm{n}^{\circ} 9$

31.92 us $3-238$ : fig. $229, n^{\circ} 2$ 31.92 us $3-262$ : fig. $219, n^{\circ} 2$ 31.92 us $3-362$ : fig. $218, n^{\circ} 8$ 31.92 us $3-374$ : fig. $219, n^{\circ} 1$ 31.92 us 3-408 : fig. 214-215, $\mathrm{n}^{\circ} 17$

31.92 us 3-459 : fig. 214-215, $\mathrm{n}^{\circ} 16$

31.92 us $3-476$ : fig. $218, n^{\circ} 5$
31.92 us $3-541$ : fig. 214-215 $\mathrm{n}^{\circ} 11$ 31.92 us 4-271 : fig. 214-215, $n^{\circ} 12$

Pharo

43.94.sans $n^{\circ}$ : fig. $184, n^{\circ} 1$ 43.94.sans $n^{\circ}$ : fig. $186, n^{\circ} 1$ 43.94. sans $n^{\circ}$ : fig. $187, n^{\circ} 1$ 43.94.sans $n^{\circ}$ : fig. $184, n^{\circ} 2$ 43.94.sans $n^{\circ}$ : fig. 186, $n^{\circ} 2$ 43.94.sans $n^{\circ}$ : fig. $187, n^{\circ} 2$ 43.94.sans $n^{\circ}$ : fig. $186, n^{\circ} 3$ 43.94.sans $n^{\circ}$ : fig. 187, $n^{\circ} 3$ 43.94.sans $n^{\circ}$ : fig. $187, n^{\circ} 4$

Fort Saint-Jean (chapelle) 45.93.1373 : fig. $94, n^{\circ} 2$ 45.93.1393 : fig. $94, n^{\circ} 2$ 45.93.1394 : fig. $94, n^{\circ} 2$ 45.93.1395 : fig. $94, n^{\circ} 2$ 45.93.1396 : fig. $98, n^{\circ} 2$ 45.93 .8500 : fig. 96

45.93 .8501 : fig. $98, n^{\circ} 6$ 45.93.8502 : fig. $97, n^{\circ} 3$ 45.93.8503 : fig. $95, n^{\circ} 4$ 45.93.8504 : fig. $95, n^{\circ} 2$ 45.93 .8505 : fig. $95, n^{\circ} 3$ 45.93.8506 : fig. $95, n^{\circ} 1$ 45.93 .8507 :p. 119 , col. droite 45.93 .8509 :p. 121, col. droite 45.93 .8510 :p. 121, col. droite 45.93 .8514 : fig. $94, n^{\circ} 4$ 45.93 .8515 :p. 121 , col. droite 45.93.8516 : fig. $94, n^{\circ} 6$ 45.93 .8523 : fig. $94, n^{\circ} 5$ 45.93 .8525 : fig. $94, n^{\circ} 3$

\section{Rue Leca}

fouille

46.94.2451 : fig. $193, n^{\circ} 6$ 46.94.2452 : fig. $233, n^{\circ} 3$ 46.94 .2469 : fig. $193, n^{\circ} 7$ 46.94.2471 : fig. $193, n^{\circ} 5$ 46.94.2472 : fig. $195, n^{\circ} 1$ 46.94.2474 : fig. $191, n^{\circ} 3$ 46.94.2475 : fig. $191, n^{\circ} 1$ 46.94.2476 : fig. $194, n^{\circ} 1$ 46.94.2478 : fig. $190, n^{\circ} 4$ 46.94 .2480 : fig. $188, n^{\circ} 6$ 46.94 .2481 : fig. $188, n^{\circ} 3$ 46.94 .2482 : fig. $188, n^{\circ} 2$ 46.94 .2483 : fig. $192, n^{\circ} 1$ 46.94.2484 : fig. 192, n² 46.94 .2485 : fig. $192, n^{\circ} 3$ 46.94.2504 : fig. $195, n^{\circ} 3$ 46.94 .2535 : fig. $188, n^{\circ} 4$ 46.94.2539: fig. $234, n^{\circ} 9$ 46.94 us 1151 : fig. $253, n^{\circ} 6$ 46.94 us 2001 : fig. $228, n^{\circ} 1$ 46.94 us 2001 : fig. $229, n^{\circ} 7$ 46.94 us 95 : fig. $239, n^{\circ} 6$

\section{Pavillon Bargemon}

48.94.6000 : fig. $115, n^{\circ} 1$ 48.94 .6001 : fig. $120, n^{\circ} 1$ 48.94 .6002 : fig. $110, n^{\circ} 2$ 48.94 .6003 : fig. $111, n^{\circ} 4$ 48.94 .6004 : fig. $111, \mathrm{n}^{\circ} 2$ 48.94 .6005 : fig. $113, n^{\circ} 2$ 48.94.6006 : fig. $118, \mathrm{n}^{\circ} 2$ 48.94 .6007 : fig. $118, n^{\circ} 3$ 48.94.6008 : fig. $110, n^{\circ} 1$ 48.94.6009 : fig. $117, n^{\circ} 4$ 48.94.6010 : fig. $117, n^{\circ} 3$ 48.94 .6011 : fig. $114, n^{\circ} 1$ 48.94.6014 : fig. $120, \mathrm{n}^{\circ} 3$ 48.94.6015 : fig. $120, n^{\circ} 2$ 48.94.6017 : fig. $111, n^{\circ} 3$ 48.94 .6020 : fig. $112, n^{\circ} 3$ 48.94.6023 : fig. $113, n^{\circ} 1$ 48.94 .6040 : fig. $120, n^{\circ} 4$

48.94.6044 : fig. $118, n^{\circ} 1$

\section{Vieille-Major}

fouille 1994

49.94.20 : fig. $244, n^{\circ} 9$

49.94 .33 : fig. $247, n^{\circ} 3$

49.94.35 : fig. $244, n^{\circ} 21$

49.94 .35 : fig. $244, n^{\circ} 22$

49.94.37 : fig. $247, n^{\circ} 1$

49.94 .37 : fig. $247, n^{\circ} 2$

49.94 .56 : fig. $247, n^{\circ} 11$

49.94 .60 : fig. $241, n^{\circ} 19$

49.94 .111 : fig. $245, n^{\circ} 10$

49.94.112 : fig. $245, n^{\circ} 11$

49.94 .120 : fig. $244, n^{\circ} 13$

49.94 .121 : fig. $245, n^{\circ} 7$

49.94.161 : fig. $243, n^{\circ} 15$

49.94.162 : fig. $243, n^{\circ} 11$

49.94.164 : fig. $245, n^{\circ} 8$

49.94.168 : fig. $243, n^{\circ} 9$

49.94 .175 : fig. $243, n^{\circ} 4$

49.94.178 : fig. $262, n^{\circ} 3$

49.94 us HS : fig. $249, n^{\circ} 6$

fouille 2000

49.00 .1 : fig. $245, n^{\circ} 26$

49.00 .2 : fig. $245, n^{\circ} 9$

49.00 .5 : fig. $245, n^{\circ} 19$

49.00 .6 : fig. $243, n^{\circ} 16$ 49.00 .9 : fig. $259, n^{\circ} 4$ 49.00 .58 : fig. $256, \mathrm{n}^{\circ} 11$ 49.00 .59 : fig. $260, n^{\circ} 2$

\section{Tunnel de la Major}

50.94 .1 : fig. $241, n^{\circ} 20$

50.94 .2 : fig. $242, n^{\circ} 3$

50.94 .3 : fig. $242, n^{\circ} 1$

50.94.3b : fig. $230, n^{\circ} 7$

fouille 1999

50.99 .441 : fig. $5, n^{\circ} 7$

50.99 .555 : fig. $5, n^{\circ} 8$

50.99 .645 : fig. $5, n^{\circ} 2$

$50.99 .666 / 1$ : fig. $5, n^{\circ} 4$ et 5

$50.99 .666 / 2$ : fig. $5, n^{\circ} 1$

50.99 us $2226 / 1$ : fig $5, n^{\circ} 13$

50.99 us $2226 / 2$ : fig. $5, n^{\circ} 12$

50.99 us $3575 / 11$ : fig. $5, n^{\circ} 11$

50.99 us $3575 / 4$ : fig. $5, n^{\circ} 6$

50.99 us $3575 / 9$ : fig. $5, n^{\circ} 14$

fouille 2000

50.00 .7 : fig. $230, n^{\circ} 6$ 
50.00 us 4197 : fig. $243, n^{\circ} 13$ 50.00 us 505 : fig. $245, n^{\circ} 16$ 50.00 us 5085 : fig. $245, n^{\circ} 15$ 50.00 us 5085 : fig. $245, n^{\circ} 23$ 50.00 us 5085 : fig. $245, n^{\circ} 25$ 50.00 us 7304 : fig. $243, n^{\circ} 7$

Place Villeneuve-Bargemon fouille César 1

52.95.1 : fig. $17, n^{\circ} 4$ 52.95.2 : fig. $17, n^{\circ} 3$ et 5 52.95.3 : fig. $23, n^{\circ} 11$ 52.95 .4 : fig. $23, n^{\circ} 10$ 52.95 .5 : fig. $18, n^{\circ} 2$ 52.95 .6 : fig. $10, n^{\circ} 3$ 52.95 .7 : fig. $11, n^{\circ} 4$ 52.95 .8 : fig. $30, n^{\circ} 6$ 52.95 .9 : fig. $21, n^{\circ} 16$ 52.95.10 : fig. $23, n^{\circ} 6$ 52.95 .11 : fig. $23, n^{\circ} 2$ 52.95.13 : fig. $30, n^{\circ} 1$ 52.95 .12 : fig. $36, n^{\circ} 23$ 52.95.14 : fig. $26, \mathrm{n}^{\circ} 3$ 52.95.15 : fig. $25, n^{\circ} 11$ 52.95 .17 : fig. $26, n^{\circ} 4$ 52.95 .18 : fig. $25, n^{\circ} 10$ 52.95 .19 : fig. $25, n^{\circ} 9$ 52.95 .20 : fig. $26, n^{\circ} 7$ 52.95.21 : fig. $26, \mathrm{n}^{\circ} 14$ 52.95.22 : fig. $26, n^{\circ} 8$ 52.95 .23 : fig. $26, n^{\circ} 15$ 52.95 .24 : fig. $25, n^{\circ} 13$ 52.95 .25 : fig. $26, \mathrm{n}^{\circ} 13$ 52.95.26 : fig. $26, n^{\circ} 1$ 52.95.27 : fig. $11, n^{\circ} 3$ 52.95.28 : fig. $11, n^{\circ} 6$ 52.95 .29 : fig. $17, \mathrm{n}^{\circ} 6$ 52.95 .30 : fig. $21, n^{\circ} 8$ 52.95 .31 : fig. $21, n^{\circ} 6$ 52.95.32 : fig. $23, n^{\circ} 3$ 52.95.33 : fig. $23, n^{\circ} 14$ 52.95 .34 : fig. $21, n^{\circ} 3$ 52.95 .35 : fig. $23, n^{\circ} 8$ 52.95.36 : fig. $22, n^{\circ} 1$ 52.95 .37 : fig. $24, n^{\circ} 2$ 52.95.38 : fig. $24, n^{\circ} 1$ 52.95 .39 : fig. $29, n^{\circ} 2$ 52.95 .40 : fig. $29, n^{\circ} 4$ 52.95 .41 : fig. $29, n^{\circ} 8$ 52.95 .42 : fig. $29, n^{\circ} 9$ 52.95 .43 : fig. $29, n^{\circ} 7$ 52.95.44 : fig. $31, n^{\circ} 1$ 52.95.45 : fig. $31, n^{\circ} 3$ 52.95 .46 : fig. $30, n^{\circ} 5$ 52.95 .47 : fig. $30, n^{\circ} 3$ 52.95 .48 : fig. $31, n^{\circ} 2$ 52.95 .49 : fig. $23, n^{\circ} 4$ 52.95 .50 : fig. $23, n^{\circ} 5$ 52.95.51 : fig. $32, n^{\circ} 2$ 52.95 .52 : fig. $21, n^{\circ} 1$ 52.95 .53 : fig. $21, n^{\circ} 5$ 52.95 .54 : fig. $21, n^{\circ} 15$ 52.95 .55 : fig. $21, n^{\circ} 17$ 52.95 .56 : fig. $21, n^{\circ} 9$ 52.95 .57 : fig. $26, n^{\circ} 11$ 52.95 .58 : fig. $26, n^{\circ} 10$ 52.95 .59 : fig. $36, \mathrm{n}^{\circ} 13$ 52.95 .60 : fig. $36, n^{\circ} 18$ 52.95 .61 : fig. $36, n^{\circ} 10$ 52.95.62 : fig. $36, n^{\circ} 11$ 52.95 .63 : fig. $36, n^{\circ} 4$ 52.95 .64 : fig. $36, n^{\circ} 22$ 52.95 .65 : fig. $36, \mathrm{n}^{\circ} 14$ 52.95 .66 : fig. $36, n^{\circ} 16$ 52.95 .67 : fig. $36, n^{\circ} 5$ 52.95 .68 : fig. $36, n^{\circ} 8$ 52.95 .69 : fig. $36, n^{\circ} 9$ 52.95 .70 : fig. $36, n^{\circ} 6$ 52.95.71 : fig. $36, n^{\circ} 1$ 52.95.72 : fig. $36, n^{\circ} 7$ 52.95.73-74: fig. $22, n^{\circ} 3$ 52.95 .75 : fig. $29, n^{\circ} 10$
52.95.78 : fig. $31, n^{\circ} 4$ 52.95 .79 : fig. $21, n^{\circ} 13$ 52.95 .80 : fig. $21, n^{\circ} 7$ 52.95 .81 : fig. $23, n^{\circ} 15$ 52.95 .82 : fig. $36, n^{\circ} 19$ 52.95 .83 : fig. $36, n^{\circ} 15$ 52.95 .84 : fig. $36, n^{\circ} 3$ 52.95 .85 : fig. $36, n^{\circ} 12$ 52.95 .86 : fig. $32, n^{\circ} 4$ 52.95 .87 : fig. $29, n^{\circ} 11$ 52.95 .87 : fig. $29, \mathrm{n}^{\circ} 12$ 52.95 .91 : fig. $37, \mathrm{n}^{\circ} 2$ 52.95 .92 : fig. $22, n^{\circ} 2$ 52.95 .93 : fig. $22, n^{\circ} 4$ 52.95.94 : fig. $37, n^{\circ} 1$ 52.95 .95 : fig. $11, n^{\circ} 11$ 52.95 .96 : fig. $11, n^{\circ} 7$ 52.95.97 : fig. $11, n^{\circ} 9$ 52.95 .98 : fig. $11, n^{\circ} 1$ 52.95 .99 : fig $8, n^{\circ} 3$ 52.95 .100 : fig. $11, n^{\circ} 8$ 52.95 .101 : fig. $8, n^{\circ} 4$ 52.95 .102 : fig. $8, n^{\circ} 2$ 52.95.103 : fig. $8, n^{\circ} 10$ 52.95 .104 : fig. $13, n^{\circ} 2$ 52.95 .105 : fig. $12, n^{\circ} 7$ 52.95.106 : fig. $12, n^{\circ} 6$ 52.95.107 : fig. $21, n^{\circ} 4$ 52.95 .108 : fig. $13, n^{\circ} 1$ 52.95.109 : fig. $26, n^{\circ} 2$ 52.95 .110 : fig. $25, n^{\circ} 5$ 52.95 .111 : fig. $25, n^{\circ} 3$ 52.95 .112 : fig. $23, n^{\circ} 9$ 52.95 .113 : fig. $19, n^{\circ} 2$ 52.95 .116 : fig. $16, n^{\circ} 5$ 52.95.117 : fig. $19, \mathrm{n}^{\circ} 3$ 52.95.118 : fig. $9, n^{\circ} 2$ 52.95.119 : fig. $9, \mathrm{n}^{\circ} 1$ 52.95.120 : fig. $23, \mathrm{n}^{\circ} 1$ 52.95.121 : fig. $25, n^{\circ} 4$ 52.95 .122 : fig. $26, n^{\circ} 5$ 52.95 .123 : fig. $17, \mathrm{n}^{\circ} 2$ 52.95 .124 : fig. $35, n^{\circ} 3$ 52.95 .125 : fig. $35, n^{\circ} 2$ 52.95 .126 : fig. $23, n^{\circ} 7$ 52.95.127 : fig. $37, n^{\circ} 3$ 52.95.131 : fig. $35, n^{\circ} 1$ 52.95 .132 : fig. $36, n^{\circ} 21$ 52.95.133 : fig. $36, \mathrm{n}^{\circ} 2$ 52.95.134 : fig. $33, n^{\circ} 1$ 52.95 .135 : fig. $33, n^{\circ} 3$ 52.95 .136 : fig. $32, n^{\circ} 3$ 52.95.137 : fig. $32, n^{\circ} 1$ 52.95 .138 : fig. $34, n^{\circ} 2$ 52.95 .139 : fig. $29, n^{\circ} 3$ 52.95 .176 : fig. $37, n^{\circ} 4$ 52.95.8001 : fig. $109, \mathrm{n}^{\circ} 3$ 52.95 .8002 : fig. $104, n^{\circ} 1$ 52.95 .8003 : fig. $104, n^{\circ} 3$ 52.95 .8004 : fig. $108, n^{\circ} 2$ 52.95 .8005 : fig. $108, \mathrm{n}^{\circ} 7$ 52.95 .8006 : fig. $108, n^{\circ} 6$ 52.95 .8007 : fig. $103, n^{\circ} 1$ 52.95 .8008 : fig. $103, \mathrm{n}^{\circ} 2$ 52.95 .8009 : fig. $108, n^{\circ} 3$ 52.95 .8010 : fig. $104, \mathrm{n}^{\circ} 2$ 52.95 .8011 : fig. $108, n^{\circ} 5$ 52.95.8021 : fig. $109, n^{\circ} 5$ 52.95 .8028 : fig. $103, n^{\circ} 3$ 52.95 .8030 : fig. $100, n^{\circ} 4$ 52.95 us 3011 : fig. 214-215, $\mathrm{n}^{\circ} 9$

52.95 us 3027 : fig. $213, n^{\circ} 5$ 52.95 us 3091 : fig. $8, n^{\circ} 1$ 52.95 us 3092 : fig. 214-215 $\mathrm{n}^{\circ} 10$

52.95 us $3136-3152$ : fig. 213 , $\mathrm{n}^{\circ} 4$

52.95 us 7013 : fig. $30, n^{\circ} 4$

réseaux César 2 52.96.8050 : fig. $90, \mathrm{n}^{\circ} 2$
52.96 .8052 : fig $89, n^{\circ} 2$ 52.96 .8055 : fig. $93, n^{\circ} 4$ 52.96 .8056 : fig. $89, n^{\circ} 3$ 52.96 .8057 : fig. $90, n^{\circ} 1$ 52.96 .8058 : fig. $93, n^{\circ} 1$ 52.96 .8059 : fig. $89, n^{\circ} 4$ 52.96 .8060 : fig. $93, n^{\circ} 2$ 52.96 .8061 : fig. $89, n^{\circ} 1$ 52.96 .8062 : fig. $93, n^{\circ} 3$ 52.96 .8063 : fig. $91, n^{\circ} 1$ 52.96 .8064 : fig. $88, n^{\circ} 1$ 52.96 .8065 : fig. $88, n^{\circ} 2$ 52.96 .8066 : fig. $93, n^{\circ} 5$ 52.96 .8067 : fig. $88, n^{\circ} 3$ 52.96 .8076 :p. 211 , col. droite 52.96 .8086 : fig. $182, n^{\circ} 1$

52.96 .8087 :p. 211 , col. droite 52.96 .8088 :p. 211 , col. droite 52.96 .8089 :p. 211 , col. droite 52.96 .8090 :p. 211 , col. droite 52.96 .8093 :p. 211, col. droite 52.96 us $2427:$ fig. $229, n^{\circ} 3$ 52.96 us 2439 : fig. 224-225, n 52.96 us 2439 : fig. 224-225 $\mathrm{n}^{\circ} 2$

52.96 us 2439 : fig. $228, n^{\circ} 2$ 52.96 us 2439 : fig. $222, n^{\circ} 4$ 52.96 us 2439 : fig. $222, n^{\circ} 5$ 52.96 us 2439 : fig. $222, n^{\circ} 6$ 52.96 us 2439 : fig. 223

52.96 us 2464 : fig. $226, \mathrm{n}^{\circ} 1$ 52.96 us 2464 : fig. $226, n^{\circ} 2$ 52.96 us 2464 : fig. $226, n^{\circ} 3$ 52.96 us 2464 : fig. 220-221, $\mathrm{n}^{\circ} 13$

52.96 us 2464 : fig. 220-221, $\mathrm{n}^{\circ} 14$

52.96 us 2464 : fig. 220-221, $\mathrm{n}^{\circ} 15$

fouille César 2

52.97 .2 : fig. $253, n^{\circ} 8$

52.97 .3 : fig. $250, n^{\circ} 8$

52.97 .4 : fig. $256, n^{\circ} 10$

52.97 .4 : fig. $245, n^{\circ} 28$

52.97 .5 : fig. $256, n^{\circ} 2$

52.97 .5 : fig. $245, n^{\circ} 27$

52.97 .6 : fig. $256, n^{\circ} 3$

52.97.7 : fig. $256, n^{\circ} 4$

52.97 .8 : fig. $256, n^{\circ} 5$

52.97 .8 : fig. $247, n^{\circ} 10$

52.97 .9 : fig. $256, n^{\circ} 6$

52.97.10 : fig. $256, \mathrm{n}^{\circ} 7$

52.97 .11 : fig. $257, n^{\circ} 6$

52.97.11 : fig. $260, n^{\circ} 9$ 52.97 .14 : fig. $238, n^{\circ} 8$ 52.97 .15 : fig. $258, n^{\circ} 5$ 52.97 .17 : fig. $239, \mathrm{n}^{\circ} 4$ 52.97 .19 : fig. $251, n^{\circ} 6$ 52.97 us 2075 : fig. $250, n^{\circ} 5$ 52.97 us 2086 : fig. $257, n^{\circ} 4$ 52.97 us 2464 : fig. $237, n^{\circ} 9$

fouille Espace Bargemon 52.02 .5 : fig. $246, n^{\circ} 7-9$ 52.02 .505 : fig. $25, n^{\circ} 6$ 52.02 .506 : fig. $33, \mathrm{n}^{\circ} 2$ 52.02 .507 : fig. 20

52.02 .508 : fig. $16, \mathrm{n}^{\circ} 2$ 52.02 .510 : fig. $12, n^{\circ} 10$ 52.02 .511 : fig. $8, n^{\circ} 5$ 52.02 .512 : fig. $8, n^{\circ} 8$ 52.02 .513 : fig. $8, \mathrm{n}^{\circ} 6$ 52.02 .514 : fig. $12, \mathrm{n}^{\circ} 2$ 52.02 .515 : fig. $30, n^{\circ} 2$ 52.02 .516 : fig. $23, n^{\circ} 13$ 52.02 .518 : fig. $8, n^{\circ} 7$ 52.02 .519 : fig. $12, n^{\circ} 9$ 52.02 .520 : fig. $16, n^{\circ} 4$ 52.02 .521 : fig. $12, n^{\circ} 12$ 52.02 .522 : fig $16, n^{\circ} 10$ 52.02 .523 : fig. $32, n^{\circ} 5$

52.02524 : fig $19, n^{\circ} 1$ 52.02 .525 : fig. $34, \mathrm{n}^{\circ} 1$ 52.02 .526 : fig. $18, n^{\circ} 1$ 52.02 .527 : fig. $16, \mathrm{n}^{\circ} 6$ 52.02 .528 : fig. $9, n^{\circ} 3$ 52.02 .529 : fig. $14, \mathrm{n}^{\circ} 2$ 52.02 .530 : fig. $25, n^{\circ} 2$ 52.02 .533 : fig. $36, n^{\circ} 20$ 52.02 .534 : fig. $26, \mathrm{n}^{\circ} 12$ 52.02 .536 : fig. $29, n^{\circ} 5$ 52.02 .538 : fig. $13, n^{\circ} 4$ 52.02 .539 : fig. $23, n^{\circ} 12$ 52.02 .540 : fig. $62, \mathrm{n}^{\circ} 4$ 52.02 .541 : fig. $48, n^{\circ} 7$ 52.02 .542 : fig. $57, n^{\circ} 3$ 52.02 .543 : fig. $43, n^{\circ} 1$ 52.02 .544 : fig. 39 52.02 .545 : fig. $32, n^{\circ} 6$ 52.02 .546 : fig. $51, n^{\circ} 3$ 52.02 .547 : fig. $36, n^{\circ} 17$ 52.02 .548 : fig. $62, n^{\circ} 5$ 52.02 .549 : fig. $57, n^{\circ} 1$ 52.02 .550 : fig. $46, \mathrm{n}^{\circ} 1$ 52.02 .552 : fig. $43, n^{\circ} 3$ 52.02 .553 : fig. $16, n^{\circ} 9$ 52.02 .554 : fig. $12, n^{\circ} 18$ 52.02 .555 : fig. $16, n^{\circ} 3$ 52.02 .556 : fig. $12, \mathrm{n}^{\circ} 11$ 52.02 .557 : fig. $16, n^{\circ} 1$ 52.02 .558 : fig. $12, n^{\circ} 4$ 52.02 .559 : fig. $12, \mathrm{n}^{\circ} 16$ 52.02 .560 : fig. $12, n^{\circ} 3$ 52.02 .561 : fig. $8, n^{\circ} 9$ 52.02 .562 : fig. $21, n^{\circ} 12$ 52.02 .563 : fig. $10, n^{\circ} 1$ 52.02 .564 : fig. 27 52.02.565 : fig. $8, \mathrm{n}^{\circ} 12$ 52.02 .566 : fig. $17, n^{\circ} 1$ 52.02 .567 : fig. $25, n^{\circ} 8$ 52.02 .568 : fig. $12, n^{\circ} 1$ 52.02 .568 : fig. $42, n^{\circ} 3$ 52.02 .569 : fig. $62, n^{\circ} 3$ 52.02571 : fig. $12, \mathrm{n}^{\circ} 13$ 52.02 .572 : fig. $10, n^{\circ} 2$ 52.02 .573 : fig. $10, \mathrm{n}^{\circ} 4$ 52.02 .574 : fig. $25, \mathrm{n}^{\circ} 12$ 52.02 .597 : fig. $29, \mathrm{n}^{\circ} 6$ 52.02.598 : fig. $22, n^{\circ} 6$ 
52.02.10568 :p. 234 , col. gauche 52.02.10620 : fig. $121, n^{\circ} 1$ 52.02.10621 : fig. $121, \mathrm{n}^{\circ} 2$ 52.02.10664 :p. 151, col. droite

52.02 .10665 :p. 151, col. gauche

52.02.10666 :p. 151, col. gauche

52.02 .10667 :p. 151 , col. gauche

52.02.10672 : fig. $121, n^{\circ} 4$ 52.02.10674 :p. 151 , col. droite 52.02 .10675 :p. 151, col. droite 52.02 .10676 :p. 151, col. droite 52.02 .10679 :p. 151 , col gauche

52.02.10680 :p. 151, col. gauche

52.02.10681 :p. 151, col. gauche

52.02 .10682 :p. 151, col. gauche

52.02.10683 :p. 151, col. gauche

52.02.10687 :p. 151, col. gauche

52.02.10688 :p. 151, col. gauche

52.02 .10738 :p. 241 , col. droite 52.02 .10739 :p. 241 , col. droite 52.02 .10740 :p. 241, col. gauche

52.02.10741 :p. 241, col. gauche

52.02 .10745 :p. 248 , col. droite 52.02 .11506 :p. $159, \mathrm{col}$.

gauche

52.02.11507 :p. 159, col. gauche

52.02.11508 :p. 159, col. gauche

52.02.11515 :p. 161, col. droite 52.02 .11516 :p. 166 , col. gauche

52.02 .11520 :p. 161 , col. gauche

52.02.11521 :p. 161 , col. gauche

52.02 .11522 :p. 161, col gauche

52.02.11527 :p. 161, col gauche

52.02 .11532 :p. 166, col. droite 52.02 .11533 :p. 166 , col. droite 52.02 .11534 :p. 166, col. droite 52.02 .11535 :p. 166, col. droite 52.02 .11536 :p. 166 , col. droite 52.02 .11537 :p. 166 , col. droite 52.02.11548 : fig. $135, n^{\circ} 4$ 52.02.11551 : fig. $132, n^{\circ} 2$ 52.02.11552 : fig. 143 52.02.11556 : fig. $132, n^{\circ} 1$ 52.02.11557 : fig. $135, n^{\circ} 5$ 52.02.11616 : fig. $233, n^{\circ} 7$ 52.02 .11616 :p. 156 , col. droite 52.02 us 15048 : fig. $257, n^{\circ} 3$ 52.02 us 3003 : fig. $245, n^{\circ} 1$ 52.02 us 4107 : fig. $257, n^{\circ} 5$ 52.02 us 5003 : fig. $257, n^{\circ} 2$ 52.02 us 5003 : fig. $262, n^{\circ} 2$ 52.02 us $5003:$ fig. $261, n^{\circ} 9$ 52.02 us 5003 : fig. $250, n^{\circ} 13$ 52.02 us 5003 : fig. $250, n^{\circ} 14$ 52.02 us 5003 : fig. $261, n^{\circ} 16$ 52.02 us 5053 : fig. $243, n^{\circ} 6$ 52.02 us 5126 : fig. 214-215, $\mathrm{n}^{\circ} 5$

52.02 us 5129 : fig. 214-215, $\mathrm{n}^{\circ} 6$

52.02 us 5178 : fig. $237, n^{\circ} 1$
52.02 us 5302 : fig. $262, n^{\circ} 1$ 52.02 us 5343 : fig. $227, n^{\circ} 1$ 52.02 us 5381 : fig. $239, n^{\circ} 10$

Saint-Jean-du-Désert 53.94 .201 :p. 241 , col. droite

Place de la Providence 56.98R 41 : fig. $57, \mathrm{n}^{\circ} 7$ 56.98R. 42 : fig. $57, n^{\circ} 5$ 56.98R. 43 : fig. $53, n^{\circ} 1$ $56.98 R .46$ : fig. $42, n^{\circ} 2$ 56.98R. 48 : fig. $40, n^{\circ} 2$ 56.98R. 49 : fig. $60, n^{\circ} 2$ $56.98 R .50$ : fig. $56, n^{\circ} 3$ 56.98R.59 : fig. $201, \mathrm{n}^{\circ} 3$ $56.98 \mathrm{R}$ us 141 : fig. $252, \mathrm{n}^{\circ} 2$ 56.98R us $144:$ fig. $240, n^{\circ} 4$ 56.98R us 213 : fig. $244, n^{\circ} 3$

\section{La Bourse}

fouille Centre Bourse 86.67-84.1002 : fig. $104, n^{\circ} 5$ 86.67-84.1014 : fig. $109, n^{\circ} 4$ 86.67-84.1017 : fig. $109, n^{\circ} 2$ 86.67-84.1018 : fig. $105, n^{\circ} 2$ 86.67-84.1019 : fig. $108, n^{\circ} 8$ 86.67-84.1021 : fig. 102, $\mathrm{n}^{\circ} 2$ 86.67-84.1024 : fig. 102, $n^{\circ} 1$ $86.67-84.1025$ : fig. $105, n^{\circ} 3$ 86.67-84.1026 : fig. 107, $\mathrm{n}^{\circ} 1$ 86.67-84.1027 : fig. $107, \mathrm{n}^{\circ} 3$ 86.67-84.1029 : fig. $100, n^{\circ} 1$ 86.67-84.1030 : fig. $106, n^{\circ} 1$ 86.67-84.1032 : fig. $102, n^{\circ} 4$ 86.67-84.1033 : fig. 106, $n^{\circ} 2$ 86.67-84.1034 : fig. 102, $\mathrm{n}^{\circ} 3$ 86.67-84.1037 : fig. $107, n^{\circ} 2$ 86.67-84.1038 : fig. $100, n^{\circ} 2$ 86.67-84.1049 : fig. $108, n^{\circ} 4$ 86.67-84.1051 : fig. $98, n^{\circ} 5$ $86.67-84.1053$ :p. 125 , col. droite

86.67-84.1054 :p. 125, col. droite

$86.67-84.1055$ :p. 125 , col. droite

86.67-84.1056 : fig. $94, \mathrm{n}^{\circ} 7$ 86.67-84.1057 :p. 124, col. gauche

$86.67-84.1058$ :p. 125 , col. droite

86.67-84.1061 : fig. 99, $n^{\circ} 2$ 86.67-84.1062 : fig. $99, n^{\circ} 1$ 86.67-84.1079 : fig. $105, n^{\circ} 1$ 86.67-84.1083 : fig. 106, $n^{\circ} 3$ 86.67-84.1084 : fig. $109, n^{\circ} 6$ $86.67-84.1101$ : fig. $171, n^{\circ} 1$ 86.67-84.1102 : fig. $170, n^{\circ} 9$ 86.67-84.1103 : fig. $158, n^{\circ} 2$ 86.67-84.1104 : fig. $160, n^{\circ} 3$ 86.67-84.1105 : fig. $160, n^{\circ} 4$ 86.67-84.1107 : fig. $163, n^{\circ} 2$ 86.67-84.1108 : fig. $163, n^{\circ} 1$ 86.67-84.1111 : fig. $161, n^{\circ} 3$ 86.67-84.1117 : fig. $130, n^{\circ} 1$ 86.67-84.1119 : fig. $112, n^{\circ} 2$ $86.67-84.1120$ : fig. $126, n^{\circ} 1$ $86.67-84.1120$ : fig. $179, n^{\circ} 14$ 86.67-84.1121 : fig. $145, \mathrm{n}^{\circ} 3$ 86.67-84.1121 : fig. $179, n^{\circ} 15$ 86.67-84.1122 : fig. $137, n^{\circ} 4$ 86.67-84.1125 : fig. $179, \mathrm{n}^{\circ} 13$ 86.67-84.1127 : fig. $179, n^{\circ} 12$ 86.67-84.1132 : fig. $166, n^{\circ} 4$ 86.67-84.1133 : fig. $158, n^{\circ} 3$ 86.67-84.1134 : fig. $168, \mathrm{n}^{\circ} 1$ 86.67-84.1134: fig. 159 $86.67-84.1135$ : fig. $168, n^{\circ} 2$ $86.67-84.1150$ : fig. $158, n^{\circ} 1$ 86.67-84.1152 : fig. $173, n^{\circ} 1$ 86.67-84.1154 : fig. $166, n^{\circ} 2$
86.67-84.1154 : fig. $166, n^{\circ} 3$ 86.67-84.1155 : fig. $166, \mathrm{n}^{\circ}$ $86.67-84.1157$ : fig. $168, n^{\circ} 3$ 86.67-84.1158 : fig. $169, \mathrm{n}^{\circ} 4$ 86.67-84.1159 : fig. $169, n^{\circ} 1$ 86.67-84.1160 : fig. $169, n^{\circ} 3$ 86.67-84.1163 : fig. $169, n^{\circ} 2$ 86.67-84.1164: fig. $144, n^{\circ} 7$ 86.67-84.1165 : fig. $144, n^{\circ} 5$ 86.67-84.1166 : fig. $138, \mathrm{n}^{\circ} 2$ 86.67-84.1167 : fig. $131, n^{\circ} 7$ 86.67-84.1168 : fig. $179, \mathrm{n}^{\circ} 11$ 86.67-84.1169 : fig. $128, n^{\circ} 4$ 86.67-84.1170 : fig. $127, n^{\circ} 2$ 86.67-84.1201 : fig. $200, n^{\circ} 5$ 86.67-84.1202: fig. $200, n^{\circ} 6$ 86.67-84.1204 : fig. $198, n^{\circ} 1$ 86.67-84.1206 : fig. $197, n^{\circ} 1$ 86.67-84.1213 : fig. $130, n^{\circ} 2$ 86.67-84.1219 : fig. $179, n^{\circ} 10$ 86.67-84.1219 : fig. $179, n^{\circ} 19$ $86.67-84.1220$ : fig. $144, n^{\circ} 6$ 86.67-84.1222 : fig. $179, \mathrm{n}^{\circ} 16$ 86.67-84.1226 : fig. $132, n^{\circ} 3$ 86.67-84.1229 : fig. $179, n^{\circ} 9$ 86.67-84.1233 : fig. $181, n^{\circ} 4$ 86.67-84.1234 : fig. $133, n^{\circ} 1$ 86.67-84.1235 : fig. $156, n^{\circ} 3$ $86.67-84.1236$ : fig. $132, n^{\circ} 5$ 86.67-84.1237 : fig. $194, \mathrm{n}^{\circ} 2$ 86.67-84.1238 : fig. $164, n^{\circ} 1$ 86.67-84.1244 : fig. $177, \mathrm{n}^{\circ} 1$ $86.67-84.1245$ : fig. $129, n^{\circ} 5$ 86.67-84.1246 : fig. $133, \mathrm{n}^{\circ} 2$ 86.67-84.1247 : fig. $132, n^{\circ} 8$ 86.67-84.1248 : fig. $137, n^{\circ} 3$ 86.67-84.1249 : fig. $148, n^{\circ} 2$ 86.67-84.1250 : fig. $156, n^{\circ} 1$ 86.67-84.1252: fig. $138, n^{\circ} 7$ 86.67-84.1254 : fig. $162, n^{\circ} 1$ 86.67-84.1254 : fig. $160, \mathrm{n}^{\circ} 2$ 86.67-84.1257 : fig. $135, n^{\circ} 3$ 86.67-84.1259 : fig. $137, n^{\circ} 2$ 86.67-84.1259 : fig. $127, n^{\circ} 5$ 86.67-84.1260 : fig. $131, n^{\circ} 6$ 86.67-84.1263 : fig. $181, \mathrm{n}^{\circ} 3$ 86.67-84.1264 : fig. $142, n^{\circ} 1$ $86.67-84.1265$ : fig. $146, n^{\circ} 1$ 86.67-84.1266 : fig. $129, n^{\circ} 1$ 86.67-84.1287 : fig. $185, n^{\circ} 5$ 86.67-84.1288 : fig. $185, \mathrm{n}^{\circ} 2$ 86.67-84.1289 : fig. $185, n^{\circ} 3$ 86.67-84.1290 : fig. $185, n^{\circ} 1$ 86.67-84.1291 : fig. $185, n^{\circ} 6$ 86.67-84.1292 : fig. $185, n^{\circ} 4$ 86.67-84.1293: fig. $186, n^{\circ} 4$ 86.67-84.1297 : fig. $133, n^{\circ} 6$ 86.67-84.1298 : fig. $137, n^{\circ} 1$ 86.67-84.1299 : fig. $144, n^{\circ} 4$ $86.67-84.1300$ : fig. $145, n^{\circ} 2$ 86.67-84.1301 : fig. $179, n^{\circ} 7$ 86.67-84.1302: fig. $179, n^{\circ} 4$ 86.67-84.1303 : fig. $179, n^{\circ} 3$ 86.67-84.1311 : fig. $161, n^{\circ} 1$ 86.67-84.1313 : fig. $162, n^{\circ} 2$ 86.67-84.1316 : fig. $200, n^{\circ} 3$ $86.67-84.1317$ : fig. $138, n^{\circ} 6$ 86.67-84.1318 : fig. $193, n^{\circ} 8$ 86.67-84.1319: fig. $133, n^{\circ} 4$ 86.67-84.1321 : fig. $179, \mathrm{n}^{\circ} 2$ 86.67-84.1322 : fig. $179, n^{\circ} 5$ 86.67-84.1324 : fig. $173, \mathrm{n}^{\circ} 2$ 86.67-84.1324: fig. $172, n^{\circ} 3$ $86.67-84.1325$ : fig. $170, n^{\circ} 8$ 86.67-84.1331a : fig. $100, n^{\circ} 3$ 86.67-84.1332: fig. $128, n^{\circ} 6$ 86.67-84.1334: fig. $122, n^{\circ} 3$ 86.67-84.1336 : fig. $180, n^{\circ} 4$ 86.67-84.1337 : fig. $179, n^{\circ} 6$ 86.67-84.1338 : fig. $197, \mathrm{n}^{\circ} 2$ $86.67-84.1349$ : fig. $165, n^{\circ} 1$ 86.67-84.1354 : fig. $165, n^{\circ} 2$

86.67-84.1355 : fig. $180, n^{\circ} 6$ 86.67-84.1356 : fig. $209, n^{\circ} 3$ 86.67-84.1356 : fig. $200, n^{\circ} 4$ $86.67-84.1360$ : fig. $199, n^{\circ} 2$ $86.67-84.1361$ : fig. $199, n^{\circ} 3$ 86.67-84.1363 : fig. $199, n^{\circ} 1$ 86.67-84.1368 : fig. $129, n^{\circ} 4$ 86.67-84.1372: fig. $197, n^{\circ} 3$ 86.67-84.1374 : fig. $200, n^{\circ} 1$ 86.67-84.1375 : fig. $200, \mathrm{n}^{\circ} 2$ 86.67-84.1378 : fig. $194, n^{\circ} 6$ $86.67-84.1384$ : fig. $126, n^{\circ} 5$ 86.67-84.1386 : fig. $129, n^{\circ} 2$ $86.67-84.1390$ : fig. $176, n^{\circ} 1$ 86.67-84.1391 : fig. $177, \mathrm{n}^{\circ} 2$ 86.67-84.1392 : fig. $177, \mathrm{n}^{\circ} 5$ 86.67-84.1394 : fig. $175, n^{\circ} 2$ 86.67-84.1396 : fig. $124, n^{\circ} 1$ 86.67-84.1401 : fig. $175, n^{\circ} 3$ 86.67-84.1402: fig. 181, n०7 86.67-84.1404 : fig. $131, n^{\circ} 1$ 86.67-84.1406 : fig. $181, n^{\circ} 5$ 86.67-84.1407 : fig. $131, \mathrm{n}^{\circ} 2$ 86.67-84.1414: fig. $133, n^{\circ} 5$ 86.67-84.1415 : fig. $133, n^{\circ} 7$ 86.67-84.1416 : fig. $133, n^{\circ} 3$ 86.67-84.1417 : fig. $133, n^{\circ} 8$ 86.67-84.1420 : fig. $137, n^{\circ} 6$ $86.67-84.1421$ : fig. $135, n^{\circ} 1$ 86.67-84.1425 : fig. $139, n^{\circ} 1$ 86.67-84.1426 : fig. $139, n^{\circ} 2$ 86.67-84.1427 : fig. $141, \mathrm{n}^{\circ} 1$ $86.67-84.1428$ : fig. $141, n^{\circ} 2$ 86.67-84.1429 : fig. $149, \mathrm{n}^{\circ} 1$ $86.67-84.1430$ : fig. $142, n^{\circ} 3$ 86.67-84.1432 : fig. $135, n^{\circ} 6$ 86.67-84.1432 : fig. $135, n^{\circ} 8$ 86.67-84.1433 : fig. $150, \mathrm{n}^{\circ} 3$ 86.67-84.1434 : fig. 157 $86.67-84.1435$ : fig. $145, n^{\circ} 4$ 86.67-84.1436 : fig. $145, n^{\circ} 1$ $86.67-84.1437:$ fig. $144, n^{\circ} 3$ 86.67-84.1438: fig. $144, n^{\circ} 2$ 86.67-84.1439 : fig. $174, n^{\circ} 2$ 86.67-84.1443 : fig. $123, n^{\circ} 2$ 86.67-84.1446 : fig. $180, n^{\circ} 5$ 86.67-84.1447 : fig. $180, n^{\circ} 2$ 


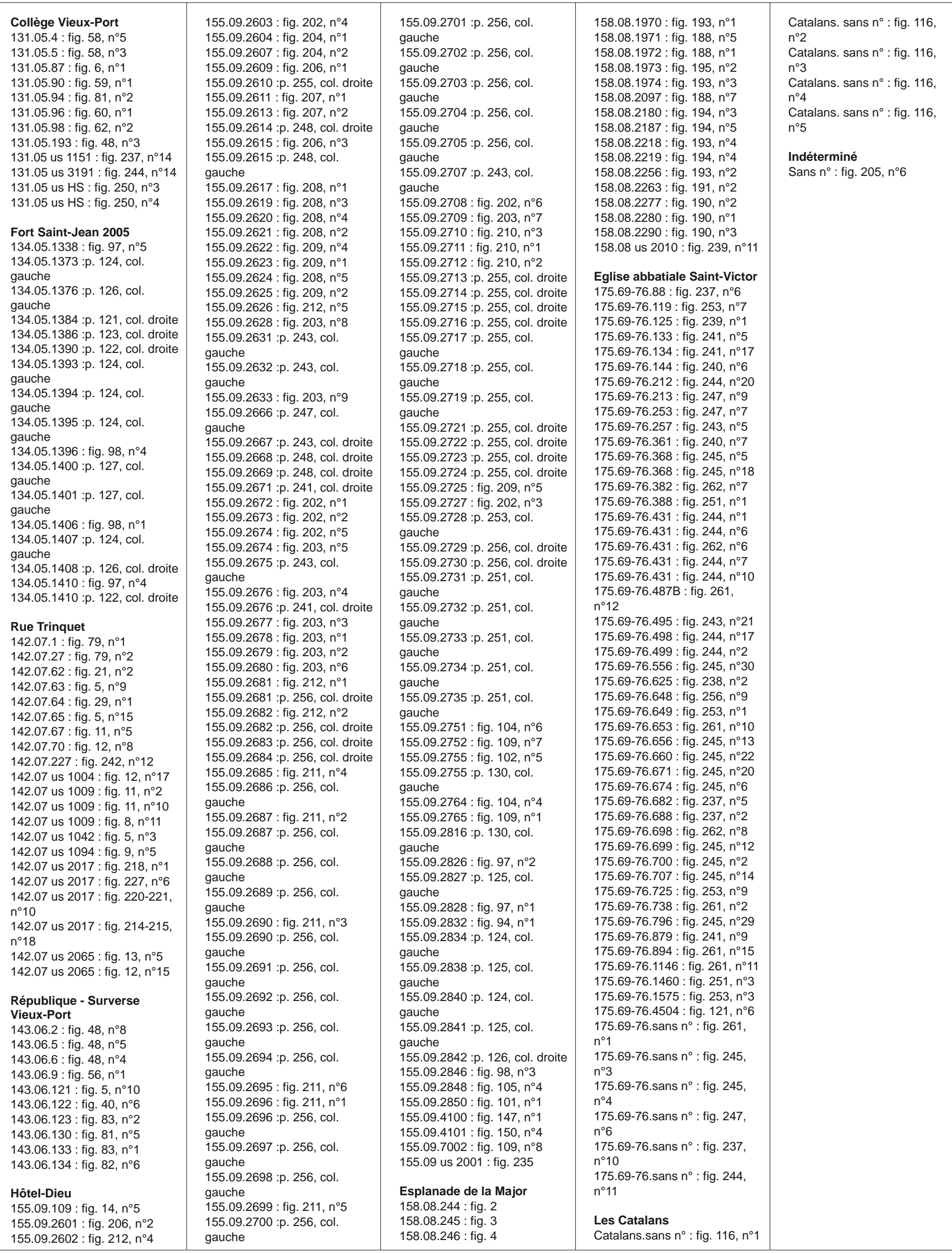





\section{Bibliographie}

Abel 1987 : ABEL (V.) - La céramique commune à Marseille au XVII ${ }^{e}$ siècle : l'exemple de deux dépotoirs domestiques du site de la Charité, Archéologie du Midi Médiéval, 5, 1987, p. 153-165.

Abel 1988: ABEL (V.) - La céramique du XVI e siècle sur le site de la Bourse : premiers éléments pour une typologie à Marseille, Archéologie $d u$ Midi Médiéval, 6, 1988, p. 161-172.

Abel 1993 : ABEL (V.) - Faïence et archéologie : l'exemple marseillais ? In : Faïence et archéologie. Mémoires de l'Académie de Moustiers, 1991. Moustiers, 1993, p. 7-16.

Abel 1997 : ABEL (V.) - Productions de l'aire marseillaise au XVIII' siècle : carreaux découverts à Saint-Jean-du-Désert. In : La céramique médiévale en Méditerranée : Actes du $6^{e}$ congrès de l'AIECM2, Aix-en-Provence, 13-19 nov. 1995. Aix-en-Provence, 1997, p. 681-684.

Abel 2001 : ABEL (V.) - La céramique moderne. In : Bouiron (M.) dir. - Marseille, du Lacydon au faubourg Sainte-Catherine (Ve s. av. J.-C. XVIII ${ }^{e}$ s.) : les fouilles de la place Général-de-Gaulle. Paris, 2001, p. 167-201 (Documents d'archéologie française, 87).

Abel 2011a : ABEL (V.) - Céramiques de l'arc méditerranéen. In : Bellan (G.), Journot (F.) dir. - Archéologie de la France moderne et contemporaine. Paris : La Découverte, 2011, p. 110-113.

Abel 2011b : ABEL (V.) - La production sucrière à Marseille : Apports archéologiques à la question. In : Sucré, salé, Archéopages, 31, 2011, p. 52-59. Abel 2011c : ABEL (V.) - Résistances : céramiques grises et vases modelés. In : Bellan (G.), Journot (F.) dir. - Archéologie de la France moderne et contemporaine. Paris : La Découverte, 2011, p. 111.

Abel, Démians d'Archimbaud 1993: ABEL (V.), DÉMIANS D'ARCHIMBAUD - L'humilité selon Saint-Victor. In : Un goût d'Italie : céramiques et céramistes italiens en Provence du Moyen-Âge au XXe siècle: exposition LAMM-CNRS/Ville d'Aubagne. Aix-en-Provence : Éditions Narration, 1993, p. 74-75.

Abel et al. 2010 : ABEL (V.), AMOURIC (H.), BIENFAIT (D.), CARRU (D.), CAULIEZ (J.), CONVERTINI (F.), CROZE (D.), GUYONNET (F.), ISAAC (A.-M.), RIPERT (I.), SAUZADE (G.), WAKSMAN (Y.) - Potiers à Bédoin, 2000 ans de tradition. Activités et industries autour du Mont Ventoux des origines à nos jours. Ville de Bédoin/INRAP, 2010, $120 \mathrm{p}$. (catalogue d'exposition).

Aguado 1986 ; AGUADO VILlALBA (J.) - Cerámica hispanomusulmana de Toledo. In : Actes du II ${ }^{\mathrm{eme}}$ Colloque international de céramologie médiévale méditerranéenne, Tolède 1981. Madrid 1987, p. 127-134.

Alessandri 2000 : ALESSANDRI (P.) - La verrerie. In: Bayrou (L.) Peyrepertuse forteresse royale. Carcassonne : Centre d'Archéologie Médiévale du Languedoc, 2010, p. 234-236 (Archéologie du Midi Médiéval, suppl. 3 ).

Alexandre-Bidon 2005 : ALEXANDRE-BIDON (D.) - Une Archéologie du goût. Céramique et consommation (Moyen Age, Temps modernes). Paris : Picard, 2005, 301 p. (coll. Espaces médiévaux).

Alexandra-Bidon 2006 : ALEXANDRA-BIDON (D.) - Le confort dans la maison médiévale. Une synthèse des données. In : Alexandra-Bidon (D.), Piponnier (F.), Poisson (J.-M.) dir. - Cadres de vie et manière d'habiter (XII ${ }^{-}$$X V I^{e}$ siècle). Actes du VIII e congrès international d'archéologie médiévale (Paris 11-13 octobre 2001). Caen, 2006. p. 129-144.

Allan 1971 : ALLAN (J.). - Medieval Middle Eastern Pottery. Oxford, 1971. 44 p. : ill.

Amici 1986: AMICI (S.) - Il corredo delle sepoltore basso-medieval, Archeologia Medievale, XIII, 1986, p. 252-255.
Amigues, Mesquida Garcia 1993 : AMIGUES (F.), MESQUIDA GARCIA (M.) - Les ateliers et la céramique de Paterna (XIII ${ }^{-}-X V^{e}$ s. ). [Béziers], [1993] (catalogue d'exposition, Musée Saint-Jacques).

Amouric et al. 1999 : AMOURIC (H.), RICHEZ(F.), VALLAURI(L.). - Vingt mille pots sous les mers. Le commerce de la céramique en Provence et Languedoc du Xe au XIX's. Aix-en-Provence : Édisud, 1999 (catalogue d'exposition, Musée d'Istres).

Amouric et al. 2006 : AMOURIC (H.), VALLAURI (L.), VAYSSETTES (J.-L.) - Ligurie, Provence, Languedoc : partenaires privilégiés des échanges céramiques du Moyen Âge à l'époque contemporaine. Atti XXXVII convegno internazionale della ceramica, Centro ligure per la storia della ceramica, Albisola, 2005. Borgo S. Lorenzo : All'insegno del Giglio, 2006, p. 129-142. Amouric et al. 2009 : AMOURIC (H.), VALLAURI (L.), VAYSSETTES (J.-L.) - Terres de feu de lumière et de songes, dans le Midi français, $X$-XXe siècles. Nîmes : Lucie Editions, 408 p.

Amouric, Vallauri 2005 : AMOURIC (H.), VALLAURI (L.) - Voyages et métamorphoses de la jarre, catalogue d'exposition. Aubagne, 2005, $192 \mathrm{p}$.

Andrews 1978 : ANDREWS (D.) - Vetri, metalli e reperti minori dell'area sud del convento di San Silvestro a Genova, Archeologia Medievale, V, 1978, p. 162-207.

Apt et Castellet 1982 : Apt et Castellet. Marseille, 1982 (catalogue d'exposition, Musée des Beaux-Arts).

Arcelin, Truffeau-Libre 1998 : ARCELIN (P.) dir., TRUFFEAU-LIBRE(M.) - La Quantification des céramiques. Table-ronde des 7-9 avril 1998. Bibracte, 1998.

Archéologie et vie quotidienne 1990 : Archéologie et vie quotidienne aux $13^{e}$ et $14^{e}$ siècles en Midi Pyrénées, Musée des Augustins : 7 mars-31 mai 1990. Toulouse: Association pour la promotion de l'archéologie et des musées archéologiques en Midi-Pyrénées, 1990, 347 p.

Ardizzone et al. 2004 : ARDIZZONE (F.), MOLINARI (A.), NEFF (A.) - Qualche considerazione sulle "matrici culturale" d'alcune produzion ceramiche della sicilia occidentale islamica. In : La Sicile à l'époque islamique. Questions de méthodes et renouvellement récent des problématiques, Mélanges de l'École Française de Rome. Moyen Age, 116-1. Rome, 2004, p. 191-205.

Argueyrolles 2000 : ARGUEYROLLES (L.). - Nouvelles données sur les ateliers d'Ollières (Var) : le dépotoir de la Petite-Bastide, Archéologie du Midi Médiéval, XVIII, 2000, p. 121-142.

Arnaud d'Agnel 1908 : ARNAUD D'AGNEL (G.) - Les Comptes du roi René, vol. 1, Paris : A. Picard, 1908, 409 p.

Arnaud d'Agnel 1910a : ARNAUD D'AGNEL (G.) - Les Comptes du roi René, vol. 2, Paris : A. Picard, 1910, 513 p.

Arnaud d'Agnel 1910b : ARNAUD D'AGNEL (G.). - La Faïence et la porcelaine de Marseille. Paris/Marseille, 1910.

A travers le verre 1989 : FOY (D.), SENNEQUIER (G.) - À travers le verre du Moyen Âge à la Renaissance. Rouen, 1989 (catalogue d'exposition, Musée départemental des Antiquités de Seine-Maritime).

Aubourg, Josset 2003 : AUBOURG (V.) dir., JOSSET (D.) dir. - Le site du promontoire du château de Blois du VIII ${ }^{\mathrm{e}}$ au XI $\mathrm{e}$ s. (Loir-et-Cher) - Seconde partie: le mobilier non céramique, Revue archéologique du Centre de la France, 42, 2003, p. 169-216.

Avissar, Stern 2005 : AVISSAR (M.), STERN (E. J.) - Pottery of the crusader, ayyubid, and mamelouk periods in Israel, IAA Reports, 26. Jérusalem, 2005. 
Bailly-Maître, Bruno Dupraz 1994 : BAILLY-MAÎTRE (M.-C.), BRUNO DUPRAZ (J.) - Brandes en Oisans, la mine d'argent des Dauphins (XII$X I V^{e}$ s.). Lyon, SRA Rhône-Alpes, 1994, 169 p. (Documents d'archéologie en Rhône-Alpes, 9)

Bailey 2004: BAILEY (G.) - Buttons and fasteners (500 BC-AD 1840). Witham : Greenlight Publishing, 2004, 113 p.

Bailey 2005: BAILEY (G.) - Detector finds 1. Witham: Greenlight Publishing, 2005, 97 p.

Baratier, Reynaud 1951 : BARATIER (E.), REYNAUD (F.) - Histoire $d u$ commerce de Marseille. II : de 1291 à 1480. Marseille, 1951.

Barbaritsa 2005 : BARBARITSA (E.) - Metal objects. In : Glarentza (Clarence). Athènes : Hellenic Ministry of Culture, 6th Ephorate of Byzantine Antiquities, 2005, $50 \mathrm{p}$.

Barbieux, Gabriel 2006a : BARBIEUX (J.), GABRIEL (M.) - Les fabricants de pipes en terre du Nord de la France. In : Barbieux (J.), Gabriel (M.) éd. - Nom d'une pipe! La pipe et le tabac dans le Nord, Flandres Hainaut. Tourcoing: Éditions Musée d'Histoire de Tourcoing, 2006, p. 85-110.

Barbieux, Gabriel 2006b : BARBIEUX (J.), GABRIEL (M.) - Les productions catalogues. In : Barbieux (J.), Gabriel (M.) éd. - Nom d'une pipe! La pipe et le tabac dans le Nord, Flandres Hainaut. Tourcoing : Éditions Musée d'Histoire de Tourcoing, p. 125-268.

Barone 1966 : BARONE (R.) - Anatomie comparée des mammifères domestiques. Tome 1, Ostéologie, Lyon : École nationale vétérinaire, laboratoire anatomie, 1966, $811 \mathrm{p}$.

Barra et al. 2004 : BARRA (C.), GUILlAUME (M.), MAUFRAS (O.), VASSELIN (B.), VOYEZ (C.) - Les fouilles archéologiques du Tunnel de la Major à Marseille (Bouches-du-Rhône). Aix-en-Provence/Nîmes : SRA PACA/Inrap, 2004, 3 vol., 394 p., 351 fig., 219 p.

Barrère 1999 : BARRÈRE (M.) - Les objets en métal. In : GARDEL (M.-É.) dir. - Cabaret, histoire et archéologie d'un castrum. Les fouilles du site de Cabaret à Lastours (Aude). Carcassonne : C.V.P.M., 1999, p. 819-853.

Barrère 2000 : BARRÈRE (M.) - Métal (Alliage cuivreux). In : Bayrou (L.) dir. - Peyrepertuse, forteresse royale. Carcassonne : Éditions du Centre d'Archéologie Médiévale du Languedoc, 2000, p. 213-235 (Archéologie du Midi Médiéval, suppl. 3).

Baumgartner, Krueger 1988 : BAUMGARTNER (E.), KRUEGER (I.) Phönix aus Sand und Asche. Glas des Mittelalters. Munich, 1988 (catalogue d'exposition, Rheinisches landesmuseum Bonn et Historisches Museum Basel).

Bayrou 2000: BAYROU (L.) dir. - Peyrepertuse, Forteresse royale. Carcassonne : Edition du centre d'archéologie médiévale du Languedoc, 2000, 287 p. (Archéologie du Midi Médiéval, suppl. 3)

Bazzana 1990 : BAZZANA (A.) - La cerámica d'uso comun. In : Lerma (J.), Guichard (P.), Bazzana (A.), Paz Soler (M.), Navarro (J.-V.), Barceló (C.). - La cerámica islámica en la ciutad de Valencia, II, Estudios. Ayuntamiento de Valencia, 1990, p. 61-67.

Bazzana 2010 : BAZZANA (A.) - Signale et signum..., l'objet porteur d'indices et d'informations : quelques exemples dans l'Occident musulman médiéval, Mélanges de la Casa Velasquez, 40-1, 2010, p. 33-55.

Bazzana et al. 1983 : BAZZANA (A.), LERMA (J. V.) coll., NAVARRO (J.) coll., PAZ SOLER (M.) coll., LAMBLIN (M.-P.) coll., MONTMESSIN (Y.) coll. - La cerámica islámica en la ciutad de Valencia. Catálogo. Ayuntamento de Valencia : Delegación municipal de cultura, 1983.

Beck 1989 : BECK (P.) dir. - Une ferme seigneuriale au XIVe siècle, la grange du Mont (Charny, Côte-d'Or). Paris : Éditions de la maison des Sciences de l'Homme, 1989, 149 p. (Documents d'archéologie française, 20).

Bellan, Journot 2011 : BELLAN (G.) dir., JOURNOT (F.) dir. - Archéologie de la France moderne et contemporaine. Paris : La Découverte, 2011.

Beltran 2011 : BELTRAN (J.) - Pisa arcaica decorada en verde y/o manganeso y ceramica vidriada : Un contexto de la primera midad del siglo XIII en Barcelona. In : VIII Congreso Internacional de Ceramica Medieval en el Mediterraneo, Ciudad Real - Almagro, 2006. Madrid : Associatión Española de Arquelogía Medieval, 2011.

Bérard et al. 1990 : BERARD (G.), BOUGOBBA (A.), LUCA (B. de), LANDURE (C.), REHALA (N.) - Aix-en-Provence, Rue des Magnans 18.
Habitat urbain gallo-romain et médiéval. In: Notes d'information et de liaison, 7, 1990. Aix-en-Provence : SRA PACA, p. 72-73.

Beresford 1975 : BERESFORD (G.) - The medieval clay-land village: Excavations at Goltho and Barton Blount. London: Society for Medieval Archaeology, 1975, $106 \mathrm{p}$.

Bernal Casasola et al. 2003 : BERNAL CASASOLA (D.), FERNANDEZ GALLEGO (C.), JIMÉNEZ-CAMINO ALVAREZ (R.). - Algeciras Andalusi (siglos VIII-XIV). Algeciras : Fundacion Municipal de Cultura «José Luis Cano », 2003.

Berti 1998 : BERTI (F.-B.) - Storia della ceramica di Montelupo, uomini e fornaci in un centro di produzione dal XIV al XVIII secolo : Volume secondo, le ceramiche da mensa dal 1480 alla fine del XVIII secolo. Montelupo Fiorentino : Aedo, 1998.

Berti, Giorgio 2011 : BERTI (G.), GIORGO (M.) a cura di - Ceramiche con coperture vetrificate usate come "bacini". Importazioni a Pisa e in altri centri della Toscana tra fine X e XIII secolo. In: Ricerche di Archeologia Altomedievale e Medievale. Firenze : All'Insegna del Giglio ed., 2011, 64 p.

Berti, Tongiorgi 1977 : BERTI (G.), TONGIORGI (L.) - Ceramica pisana. Secoli XIII-XV. Pise, 1977, 159 p.

Berti, Tongiorgi 1981 : BERTI (G.), TONGORGI (L.) - I bacini ceramici medievali delle chiese di Pisa, Quaderni di cultura materiale, 3. Roma, 1981. Berti, Tongiorgi 1982 : BERTI (G.), TONGIORGI (L.) - Aspetti della produzione pisana de ceramica ingobbiata, Archeologia Medievale, IX, 1982, p. 141-174.

Berton 2000 : BERTON (O.) - Les objets de piété dans les inventaires après décès de l'arrière-pays varois : 1693-1789. Aix-en-Provence: Université d'Aix-Marseille I, 66 p. (Mémoire de maîtrise d'histoire moderne sous la direction de Gabriel Audisio).

Berthon 2012 : BERTHON (A.) - Oeillets, barbacanes, agrafes et annelets. Fermer discrètement son vêtement à la fin du Moyen Âge et à l'Époque moderne, Bulletin Instrumentum, 36, 2012, p. 43-45.

Berthon, Zélie 2010 : Berthon (A.A.), Zélie (B.) - La vaisselle en verre dans un contexte monastique : un important corpus des XIII ${ }^{\mathrm{e}}$-XVIe siècles découvert à l'abbaye St-Cyprien (Poitiers, 86) L'abbaye Saint Cyprien et la fouille préventive de l'hôpital Pasteur, Bulletin de l'Association française pour l'Archéologie du Verre, 2010, p. 120-133.

Bertrand 1777 : BERTRAND (J.-É.) (édit.) - Descriptions des arts et métiers faites ou approuvées par messieurs de l'Académie royale des sciences de Paris, nouvelle édition, $t$. VII, contenant l'art de la draperie, l'art de friser ou ratiner les étoffes de laine, l'art de faire les tapis, façon de Turquie, l'art du chapelier, l'art du tonnelier, l'art de convertir le cuivre en laiton \& l'art de l'épinglier. Neuchâtel: Imprimerie de la Société Typographique,1777, 606 p., 22 pl.

Betton et al. 1991 : BETTON (F.), BURAVAND (V.), VALLAURI (L.) - Un lot de vaisselle moderne déposé dans l'église Sainte-Anne de Boulbon (Bouches-du-Rhône), Archéologie du Midi médiéval, 8-9, 1990-1991, p. $155-168$.

Biccone 2006 : BICCONE (L.). - Invetriate monochrome decorate a stampo dallo scavo del Palazzo Giudicale di Ardara (SS). In : Atti XXXVII convegno internazionale della ceramica, Centro ligure per la storia della ceramica, Albisola, 2005. Borgo S. Lorenzo : All'insegno del Giglio, 2006, p. 251-264. Bien, Lang, Bouiron à paraître : BIEN (S.) dir, LANG (S) dir, BOUIRON (M.) dir. - Fouilles à Marseille : les mobiliers de l'Antiquité et de l'Antiquité tardive. Aix-en-Provence : éditions errance/Centre Camille Jullian, à paraître (Bibliothèque d'Archéologie Méditerranéenne et Africaine. Études Massaliètes). Bienvenu, Lautier 2008 : BIENVENU (K.), LAUTIER (C.) - Traité d'Antoine de Pise. Assise, Bibliothèque du sacro Convento, MS.692. Traduit de l'Italien. In : Lautier (C.), Sandron (D.) dir. - Antoine de Pise : l'Art du vitrail vers 1400. Paris : CTHS, 2008.

Biton, Gaillard de Sémainville 1988: BITON (R.), GAILLARD DE SÉMAINVILLE (H.) - Une plaque-boucle mérovingienne en os à Berry-LesBelles-Fontaines (Yonne), Revue Archéologique de l'Est et du Centre-Est, 39, 1988, p. 291-296.

Blaison et al. 1995 : BLAISON (J.-L.), BONHOURE (I.), MARCHESI (H.), THIRIOT (J.) - Les ateliers de la region d'Apt. In : 1500 ans de céramique en Vaucluse : Ateliers et productions de poteries du Ve siècle au début $d u$ 
XX $X^{e}$ siècle. Aix-en-Provence : Ed. Narrations, 1995, p. 45-52 (catalogue d'exposition, Musée des faïences de la Tour d'Aigues).

Boato et al. 1990 : BOATO (A.), CABONA (D.), FOSSATI (S.), GOMBARO (L.), GIANNICHEDDA (E.), GIOVINAZZO (R.), PIZZOLO (O.) - Scavo dell'area est del villaggio abbandonato di Monte Zignago: Zignago 4, Archeologia Medievale, XVII, 1990, p. 355-410.

Bonifay 1983 : BONIFAY (M.) - Éléments d'évolution des céramiques de l'Antiquité tardive à Marseille d'après les fouilles de La Bourse, Revue Archéologique de Narbonnaise, XVI, 1983, p. 285-346.

Bonifay 2004 : BONIFAY (M.) - Études sur la céramique romaine tardive d'Afrique, VIII. Oxford, 2004. 525 p. (BAR. International series).

Boudriot 1995 : BOUDRIOT (G.) - Le dépotoir du Château de Montmorin, Pages d'archéologie régionale en Rhône-Alpes, 1995, p. 29-38.

Bouiron 2001a : BOUIRON (M.) dir. - Marseille, du Lacydon au faubourg Sainte-Catherine ( $V^{e}$ s. av. J.-C.-XVIII ${ }^{e}$ s.) : Les fouilles de la place Généralde-Gaulle. Paris : Éditions de la Maison des sciences de 1'Homme, 2001. 340 p. : ill. (Documents d'archéologie française, 87).

Bouiron 2001b : BOUIRON (M.) dir. - L'Alcazar, 26 siècles d'occupation suburbaine à Marseille. Marseille/Nîmes : AFAN, 2001 (rapport de fouilles). Bouiron et al. 1994 : BOUIRON (M.), DE LUCA (B.), GANTÈS (L.-F.) - Les fouilles de l'Avenue Vaudoyer, étude d'impact du souterrain Major. Marseille, 1994, 32 p., 1 pl. (rapport de fouille de sauvetage).

Bouiron et al. 1995 : BOUIRON (M.), COLLINET (J.) coll., GANTÈS (L.-F.) coll., PARENT (F.) coll., POURNOT (J.) coll., RICHIER (A.) coll., SILLANO (B.) coll., VOYEZ (C.) coll. - Sondages Archéologiques. Tunnel de la Major (Marseille). Marseille/ Aix-en-Provence, 1995, 123 p. (rapport de sondages). Bouiron et al. 1999 : BOUIRON (M.) dir., ABEL (V.) coll., BERTOMEU (E.) coll., COGNARD (F.) coll., DUCOUT (G.) coll., MAURIN (M.) coll., MOROLDO (F.) coll., PARENT (F.) coll., PASQUINI (R.) coll., SCHERRER (N.) coll. - Place de la Providence (Marseille -13). Marseille, 1999, 106 p. (rapport de sondages).

Bouiron et al. 2011 : BOUIRON (M.) dir, PAONE (F.) dir, SILLANO (B.) dir, CASTRUCCI (C.) dir, SCHERRER (N.) dir - Fouilles à Marseille. La ville médiévale et moderne. Aix-en-Provence: éditions errance/Centre Camille Jullian, 2011, 463 p. (Bibliothèque d'archéologie méditerranéenne et africaine, 7 ; Études massaliètes, 10).

Bourgeois 2009 : BOURGEOIS L. dir. - Une résidence des comtes d'Angoulême autour de l'An Mil : le castrum d'Andone (Villejoubert, Charente) : publication des fouilles d'André Debord (1971-1995). Caen : CRAHM, 2009, $560 \mathrm{p}$.

Bourgeois, Rodet-Belarbi 2009 : BOURGEOIS (L.), RODET-BELARBI (I.) - Le mobilier en os et en bois de cervidé : témoins de fabrication et produits finis. In : Bourgeois (L.) dir. - Une résidence des comtes d'Angoulême autour de l'An Mil : le castrum d'Andone (Villejoubert, Charente) : publication des fouilles d'André Debord (1971-1995). Caen : CRAHM, 2009, p. 256-275.

Brancotte 2001 : BRANCOTTE (D.) - La brosserie dans le Pays de Thelle et la vallée du Thérain. In : Fournier (B.), Frichet-Colzy (H.), Plouvier (M.) dir. - Le bois, l'os, la corne, l'ivoire, la nacre, aspect de la tabletterie en France. Amiens : AGIR-PIC, p. 41-50.

Breichner 2000 : BREICHNER (H.) - Le four I de l'atelier de potiers médiéval à Mas-Viel (Argelliers-Hérault) : étude du matériel céramique. Aixen-Provence, 2000, 141 p. (Mémoire de maîtrise sous la direction de Nolwenn Lecuyer).

Breichner et al. 2002 : BREICHNER (H.), CHABAL (L.), LECUYER (N.), SCHNEIDER (L.) - Artisan potier et exploitation du bois dans les chênaies du nord de Montpellier au XIII ${ }^{\mathrm{e}}$ siècle (Hérault, Argelliers, Mas-Viel), Archéologie du Midi Médiéval, 20, 2002, p. 57-106.

Bruno et al. 2006 : BRUNO (G. A.), CAPELLI (C.), CABELLA (R.) - Dati archeologici e archeometrici su ceramiche invetriate dall'area dello stretto di Messina. In: Atti XXXVII convegno internazionale della ceramica, Centro ligure per la storia della ceramica, Albisola, 2005. Borgo S. Lorenzo : All'insegno del Giglio, 2006, p. 367-380.

Burille 1996 : BURILLE (C.) - Étude du mobilier de la nécropole de Saint-Laurent de Grenoble (IVe - XVIII ${ }^{e}$ s.). Aix-en-Provence : Université d'Aix-Marseille I, 1996, 2 vol., 106 p., 172 p. (mémoire de Maîtrise d'Archéologie médiévale sous la direction de M. Fixot et N. Lécuyer).
Cabart 2010 : CABART (H.) - Verres du XIVe siècle décorés de pointillés, pétales, lunules et losanges. In : Fontaine-Hodiamont (C.) dir. - D'Ennion au Val Saint-Lambert. Le verre soufflé-moulé, actes du colloque international de l'Association française pour l'Archéologie du Verre, Bruxelles-Namur, 17-19 octobre 2008. Bruxelles, 2010, p. 339-344. (Scientia Artis, 3).

Cabona et al. 1982 : CABONA (D.), MANNONI (T.), PIZZOLO (O.) - Gli scavi nel complesso medievale di filattiera in Lungiana, $1:$ La collina di San Giorgio, Archeologia Medievale, IX, 1982, p. 331-357.

Cabona et al. 1986 : CABONA (D.), GARDINI (A.), PIZZOLO (O.) - Nuovi dati sulla circulazione delle ceramiche mediterranee dallo scavo di Palazzo Ducale di Genova (secc. XII-XIV). In : La Ceramica Medievale nel Mediterraneo occidentale, Sienna-Faenza, 1984. Florence, 1986, p. 453-482. Cameirana 1970 : CAMEIRANA (A.) - La "terraglia" nera ad Albisola all'inizio dell'800. In : Atti del III Convegno internazionale della ceramica, 1970, p. 61-115.

Cameirana 1990 : CAMEIRANA (A.) dir. - Antica maiolica savonese. Collezione Principe Arimberto Boncompagni Ludovisi. Savona, 1990 (catalogue d'exposition, Savona Complesso Monumentale del Priamar).

Capellà Galmés 2010 : CAPELLÀ GALMÉS (M.A.) - Assaig de tipologia del vidre d'època medieval a Mallorca (segles XIV-XV), Quaderns de Ca Gran Cristiana, 14. Palma de Mallorca, 2002.

Capelli et al. 2004 : CAPELLI (C.), RICHARTE (C.), VALLAURI (L.), WAKSMANN (Y.) - Ceramiche del gruppo Port Saint Symeon ware rinvenute a Genova, Marsiglia e Beirut. Dati archeologici e archeometrici. In : Atti del XXXVII Convegno Internazionale Della Ceramica, Albisola. Savona, 2004. p. 81-87.

Capelli et al. 2006: CAPELLI (C.), PARENT (F.), RICHARTÉ (C.), VALLAURI (L.), CABELLA (R.) - Ceramiche invetriate di importazione in provenza in epoca bassomedievale : dati archeologici e archeomagnetrici. In : Atti XXXVII convegno internazionale della ceramica, Centro ligure per la storia della ceramica, Albisola, 2005. Borgo S. Lorenzo : All'insegno del Giglio, 2006, p. 189-200.

Capelli et al. 2009: CAPELLI (C.), PARENT (F.), RICHARTÉ (C.), VALLAURI (L.), CABELLA (R.) - Essai de caractérisation des céramiques importées en Provence aux $\mathrm{XII}^{\mathrm{e}}$ et XIII' ${ }^{\mathrm{e}} \mathrm{s}$. In : VIII Congreso Internacional de Ceramica Medieval en el Mediterraneo, Ciudad Real - Almagro, 2006. Madrid : Associatión Española de Arquelogía Medieval, 2009, p. 937-946

Carme, Demangeot 2012 : CARME (R.), DEMANGEOT (C.), BARRERE (M.) coll., CHEVALIER (C.) coll., CLOAREC (A.) coll., COMELONGUE (M.) coll., DIEULAFAIT (F.) coll., GUIONOVA (G.) coll., PEDOUSSAUT (L.) coll., PY (M.) coll., VALLAURI (L.) coll., VASCHALDE (C.) coll. Collège Eugène Vigne, Avenue de Farciennes. Beaucaire, Gard. Balma, 2012 (Rapport Final d'Opération Archéologique).

Carru 1989 : CARRU (D.) - Céramiques d'un dépotoir du XVI ${ }^{e}$ siècle à Avignon, Archéologie du Midi Médiéval, VII, 1989, p. 187-210.

Carsana 2002 : CARSANA (V.) - Ceramica di importazione da contesti di XII e XIII secolo a Napoli, Archeologia Medievale, XXIX, 2002, p. 499-509. Cataldo 2002 : CATALDO (J.) - La gestion des déchets domestiques dans la maison médiévale urbaine : réflexions à partir de données archéologiques du sud-ouest de la France. In : La maison au Moyen Âge dans le Midi de la France. Actes des journées d'études de Toulouse. 19-20 mai 2001. Toulouse, 2002, p. 229-238 (Mémoires de la Société Archéologique du Midi de la France, Hors série).

Cathma 1986 : CATHMA - La céramique du haut Moyen Âge en France méridionale. Éléments comparatifs et essai d'interprétation. In : La Ceramica Medievale nel Mediterraneo occidentale, Sienna-Faenza, 1984. Florence, 1986, p. 45-47.

Cathma 1993 : CATHMA - Céramiques languedociennes du haut Moyen Âge $\left(\mathrm{VII}^{\mathrm{e}}-\mathrm{XI}^{\mathrm{e}} \mathrm{s}\right.$.). Études micro-régionales et essai de synthèse, Archéologie du Midi Médiéval, XI, 1993, p. 111-228.

Cavallaro 2007 : CAVALLARO (N.) - Gli oggetti metallici. In : Bonacasa Carra (R.M.), Ardizzone (F.) dir. - Agrigento dal Tardo Antico al Medioevo : Campagne di scavo nell'area della necropoli paleocristiana. Todi : Tau Editrice, 2009, p. 273-278 (Ricerche di Archeologia e Antichità Cristiane, 2). Chaoui-Derieux, Goret 2008 : CHAOUI-DERIEUX (D.), GORET (J.-F.) - Les outils en os du haut Moyen-Âge : état de la question et présentation 
d'une expérience en cours. In : L'habitat rural du haut Moyen-Âge en Île-deFrance. Paris, 2002, p. 79-91 (supplément au BAVF, 2).

Chaoui-Derieux 2010 : CHAOUI-DERIEUX (D.) - Socio-economic and Cultural Implications in Medieval Society: the Unpublisched Collection of the Region of Douai (France). In : Legrand-Pineau (A.), Sidéra (I.) dir-- Ancient and moderne bone artefacts from America to Russia, Oxford, Archaeopress, 2010, p. 65-70.

Charlet 2008 : CHARLET (J.-L.) - Le monnayage de la principauté d'Orange au nom de Raymond des Baux (I) : Raymond IV (1314-1340), Annales du Groupe Numismatique de Provence, 2006 [2008].

Chazottes 2011 : CHAZOTTES (M.-A) - Le mobilier en matière dure animale conservé au dépôt archéologique de Marseille : inventaire raisonné, approche typologique, anatomique et technique. Aix-en-Provence : Université d'AixMarseille I, 2011, 2 vol., 265 p. ; 92 fig., LXXIV pl., 519 fiches (mémoire de Master 1 d'Archéologie médiévale sous la direction de N. Lécuyer).

Chazottes 2012 : CHAZOTTES (M.-A.) - Le mobilier en matière dure d'origine animale en Provence et en Languedoc entre le Ve et XVIII siècle : étude de cas. Aix-en-Provence : Aix-Marseille Université, 2012, 279 p., 140 p. (mémoire de master 2 d'Archéologie médiévale sous la direction de Nolwenn Lecuyer).

Colardelle, Verdel 1993 : COLARDELLE (M.), VERDEL( É.) - Le mobilier métallique : typologie. In : Colardelle (M.), Verdel (É.) dir. - Les habitats $d u$ lac de Paladru (Isère) dans leur environnement. La formation d'un terroir au 11e siècle, 1993, p. 204-219 (Documents d'archéologie française, 40).

Colardelle 1999a : COLARDELLE (R.) - L'église Saint-Laurent, de la nécropole gallo-romaine au monument historique, Genoble (Isère). Aix-enProvence, Université d'Aix-Marseille I, 1999, X vol. (Thèse d'Archéologie médiévale sous la direction de G. Démians d'Archimbaud).

Colardelle 1999b : COLARDELLE (R.) - La ville et la mort : Saint-Laurent de Grenoble, 2000 ans de tradition funéraire. Turnhout : Brepols, 2008, $383 \mathrm{p}$. (Bibliothèque de l'Antiquité tardive, 11).

Comiti 1996 : COMITI (P.-J.). - Les métaux en Corse, du XIIIe au XVIe siècle. Aix-en-Provence, Université d'Aix-Marseille I, 1996, 2 vol., 93 p., 15 pl., 52 ill. (mémoire de Maîtrise d'Archéologie médiévale sous la direction de M. Fixot et G. Comet).

Conche 1998 : Conche (F.) dir. - Fouille archéologique rue Jean-François Leca (Marseille, Bouches-du-Rhône). Nîmes : Afan, 1998, 2 vol., 253 p., $280 \mathrm{p}$. (Document final de synthèse).

Cortelazzo, Lebole di Gangi 1991: CORTELAZZO (M.), LEBOLE DI GANGO (C.M.) - I manufatti metallici. In: Michelete (E.), Venturino Gambari (M.) dir. - Montaldo di Mondovì, un insediamento protostorico, un castello. Rome : Leonardo, 1991, p. 203-234.

Coulon et al. 2007 : COULON (D.), PICARD (C.), VALERIAN (D.) dir. Espaces et réseaux en Méditerranée. $V I^{e}-X V I^{e}$ siècle, vol. I, La configuration des réseaux. Paris : Bouchène, 2007, éd. p. 16-17.

Cuiségnier, Guadagnin 1988 : CUISÉNIER (J.), GUADAGNIN (R.) - Un village au temps de Charlemagne : moines et paysans de l'abbaye de SaintDenis du VII à l'an mil. Paris : Errance, 1988, 357 p.

D'Angelo 2004 : D'ANGELO (F.) - La ceramica islamica in Sicilia. In : d'Angelo (F.) dir., Molinari (A.) dir., Nef (A.) dir. - La Sicile à l'époque islamique. Questions de méthode et renouvellement récent des problématiques, Mélanges de l'École Française de Rome. Moyen Age, 116-1, 2004, p. $130-143$.

D'Anna et al. 2003 : D'ANNA (A.), DESBAT (A.), GARCIA (D.), SCHMITT (A.), VERHAEGHE (F.) - La Céramique : La poterie du Néolithique aux Temps Modernes. Paris : Errance, 2003 (Archéologiques).

D’Onofrio, d'Agostino 1987 : D'ONOFRIO (A.-M.), D'AGOSTINO (B.) - Ricerche Archeologiche a Napoli : lo scavo in largo S. Anielo (1982-1983). Naples, 1987, $221 \mathrm{p}$.

Dectot 2008 : DECTOT (X.), MAKARIOU (S.) dir. - Reflets d'or. D'orient en occident, la céramique lustrée, IXe-XVe siècle. Paris : Réunion des Musées Nationaux, 2008. $127 \mathrm{p}$

Deferrari 2001 : DEFERRARI (G.) - Invetriata da fuoco. In : Varaldo (C.) - Archeologia urbana a Savona: scavi e ricerche nel complesso monumentale del Priamàr. II.2. : Palazzo della Loggia. Bordighera-Savona, 2001, p. $310-340$.
Deguara 2007 : DEGUARA (L.) - Le verre et l'éternité. Du verre antique au verre contemporain. Montpellier, 2007 (catalogue d'exposition, Musée languedocien de Montpellier)

Déléry 2003 : DELERY (C.) - Perspectives méthodologiques concernant l'étude de la céramique de Cuerda Seca en Al-Andalus (IX'-XIVe s.) : d'un objet archéologique à un objet historique ? Arqueologia Medieval, 8, 2003, p. 193-236.

Déléry 2004 : DELERY (C.) - Un reflejo de la Lorca Islámica a través del estudio de la cerámica de Cuerda Seca encontrada en su entorno, AlbercA, 2, 2004, p. 167-176.

Déléry 2006 : DÉLÉRY (C.) - Dynamiques économiques, sociales et culturelles d'al-Andalus à partir d'une étude de la céramique de cuerda seca seconde moitié du $X^{e}$ siècle-première moitié du XIII ${ }^{e}$ siècle. Toulouse, Université de Toulouse II, 2006 (Thèse de doctorat d'Histoire).

Déléry 2008 : DÉLÉRY (C.) - Le Maghreb et al-Andalus. In : DECTOT (X.), MAKARIOU (S.) dir. - Reflets d'or. D'orient en occident, la céramique lustrée, IX ${ }^{e}-X V^{e}$ siècle. Paris : Réunion des Musées Nationaux, 2008, 127 p.

Déléry, Gomez-Martinez 2006 : Déléry (C.), Gómez Martínez (S.) Algunas piezas orientales y el problema del origen de la técnica de cuerda seca. In : Al-Ândalus, espaço de mudança. Mértola : Ed. Campo Arqueológico de Mértola, 2006, p. 148-160.

Deloffre, Jacques 2006 : DELOFFRE (V.), JACQUES (A.) - La piperies Vandenbosche et la fabrication des pipes en terre á Arras'. In : J. Barbieux and M. Gabriel (eds). Nom d'une pipe! La pipe et le tabac dans le Nord, Flandres Hainaut. Tourcoing : Éditions Musée d'Histoire de Tourcoing, p. 46-58.

Démians d'Archimbaud 1980 : DÉMIANS D'ARCHIMBAUD (G.) - les fouilles de Rougiers. Contribution à l'archéologie de l'habitat rural médiéval en pays méditerranéen. Paris, 1980, $724 \mathrm{p}$.

Démians d'Archimbaud et al. 1980 : DÉMIANS D'ARCHIMAUD (G.), VALLAURI (L.), THIRIOT (J.) - Céramiques d'Avignon, les fouilles de l'hôtel de Brion et leur matériel. Avignon, 1980.

Démians d'Archimbaud et al. 1981 : DÉMIANS D'ARCHIMBAUD (G.), ESQIEU (Y.), FOY (D.), VALLAURI (L.) - Aujourd'hui le Moyen-Âge : archéologie et vie quotidienne en France Méridionale. Aix-En-Provence : Société Provençale de reprographie, 1981, 125 p. (Catalogue d'exposition). Démians D'archimbaud et al. 1986 : DÉMIANS D'ARCHIMBAUD (G.), LEMOINE (C.), VALLAURI (L.), PICON (M.) - Recherches de laboratoire sur les ateliers médiévaux espagnols. In : A cerâmica medieval no mediterrâneo occidental, Tolède, 1981. Madrid, 1986, p. 43-45.

Démians D'archimbaud et al. 2003 : DÉMIANS D'ARCHIMBAUD (G.) VALLAURI (L.), PARENT (F.), RICHARTÉ (C.)- La circulation de céramiques byzantines, chypriotes et du levant chrétien en Provence, Languedoc et Corse du $\mathrm{X}^{\mathrm{e}}$ au XIV ${ }^{\mathrm{e}}$ siècle. In : Actes du VII ${ }^{\mathrm{e}}$ congrès international sur la céramique médiévale en Méditerranée, Thessalonique, 1999. Athènes, 2003, p. $137-152$.

Démians d'Archimbaud, Picon 1980 : DEMIANS D'ARCHIMBAUD (G.), PICON (M.) - Les céramiques médiévales en France méditerranéenne; recherches archéologiques et de laboratoire. In: Demians d'Archimbaud (G.), Picon (M.) dir. - La céramique médiévale en Méditerranée occidentale, $X^{e}-X V^{e}$ siècles, Valbonne 1978. Paris : éd. du C.N.R.S 1980.

Démians d'Archimbaud, Vallauri 1998a : DEMIANS d'ARCHIMBAUD (G.), VALLAURI (L.) - De Kairouan à Avignon : les voies de la faïence dans l'Occident médiéval, L'Archéologue, avril-mai 1998.

Démians d'Archimbaud, Vallauri 1998b : DÉMIANS D'ARCHIMBAUD (G.), VALLAURI (L.) - Productions et importations de céramiques médiévales dans le Midi méditerranéen français. In: Monografies d'Arqueologia medieval $i$ postmedieval $n^{\circ} 4$. Cerámica medieval i postmedieval, Circuits productius $i$ sequeüències culturals. Barcelone: Universitat de Barcelona, 1998, p. 73-110 (Monografies d'archeologia medieval i postmedieval, 4).

Démians d'Archimbaud, Pelletier 1995 : DÉMIANS D'ARCHIMBAUD (G.), PELLETIER (J.-P.) - Le temps des gris (VIII ${ }^{\mathrm{e}}-\mathrm{XIII}{ }^{\mathrm{e}}$ siècles). In : Terres de Durance : Céramiques de l'Antiquité aux Temps Modernes. Aix-enProvence : Éd. Narration, 1995, p. $42-43$ (catalogue d'exposition, Musées de Digne et de Gap).

De Toulouse à Tripoli 1989: De Toulouse à Tripoli, la puissance toulousaine au XII siècle (1080 - 1208), exposition, Musée des Augustins, Toulouse, 
6 janvier-20 mars 1989. Toulouse : Musée des Augustins, 1989, 305 p. (catalogue d'exposition).

Di Gangi, Lebole 1997 : DI GANGI (G.), LEBOLE (C.-M.) - Anfore, ceramica d'uso comune e ceramica rivestita tra VI e XIV secolo in Calabria : prima classificazione e osservazioni sulla distribuzione e la circulazione dei manufatti. In : La céramique médiévale en Méditerranée, Actes du VI ${ }^{e}$ congrès de l'AIECM2 , Aix-en-Provence, 13-18 novembre 1995. Aix-enProvence, 1997, p. 153-166.

Dilly et al. 1999 : DILLY (G.), PITON (D.), TRÉPAGNE (Cl.), BRUNA (D.), DUSSERE (Fl.), LABROT (J.), STOCK (B.) - Du château de Grigny au siège d'Hesdin, exposition : Hôtel-de-Ville, Hesdin, 25 juin au 17 octobre 1999, Nord-Ouest Archéologie, 10. Berck-sur-Mer : Centre de recherches archéologiques et de diffusion culturelle, 1999, $157 \mathrm{p}$.

Donations Jourdan-Barry 1999: Donations Jourdan-Barry : MarseilleMoustiers, faïence-porcelaine. Marseille, 1999, 151 p. (Catalogue d'exposition, Musée de la Faïence, Château Pastré).

Doré 2008: DORÉ (F.) - Marques et signatures. Poinçons de maîtres. Les boucles de costumes en France 1650-1830. Paris : Massin Éditeur, 2008, 165 p. Dubus, Pannequin 1999: DUBUS (M.), PANNEQUIN (B.) éd. - La Céramique française sous l'Empire à travers l'enquête des préfets. Paris : RMN, 1999.

Duco 1981: DUCO (D.H.) - De kleipijp in de zeventiende eeuwse Nederlanden. In : The Archaeology of the Clay Tobacco Pipe V. Oxford, 1981, p. 111-468 (British Archaeological Reports, International Series 106).

Duco 1987 : DUCO (D.H.) - De Nederlandse Kleipijp : handbook voor dateren en determineren. Leyde : Stichting Pijpenkabinet, 1987.

Duco 2003 : DUCO (D.H.) - Merken en merkenrecht van de pijpenmakers in Gouda. Amsterdam : Pijpenkabinet, 2003.

Duco 2004 : DUCO (D.H.) - Century of change : the European clay pipe, its final flourish and ultimate fall. Amsterdam : Pijpenkabinet, 2004.

Dureuil, Béal 1996 : DUREUIL (J.-F.), BÉAL (J.-C.) - La tabletterie galloromaine et médiévale, une histoire d'os. Paris : Paris Musée, 1996, 123 p.

Egan 2010: EGAN (G.) - The medieval household, daily living c.1150c.1450. Medieval finds from excavations in London, $\mathrm{n}^{\circ} 6$. Woodbridge : The Boydell Press, XIII, 2010, 342 p.

Egan, Pritchard 2002: EGAN (G.), PRITCHARD (F.) dir. - Dress accessories, 1150-1450. Medieval finds from excavations in London, $\mathrm{n}^{\circ} 3$, Woodbridge : The Boydell Press, XVI, 2002, 410 p.

Esquieu 2008 : ESQUIEU (Y.) - Armarium : mobilier et espaces de rangements dans les maisons médiévales du sud-est de la France. In : La maison au Moyen Âge dans le Midi de la France. Actes des journées d'études de Cahors. 6-7-8 juillet 2006. Toulouse, 2008, p. 241-254 (Mémoires de la Société Archéologique du Midi de la France, Hors série).

Fabry 2008 : FABRY (I.) - Introduction. In : Les activités quotidiennes au Moyen Âge. Questes. Bulletin des jeunes chercheurs médiévistes, 15, septembre 2008, p. 7-18.

Faïence 1990 : FAÏENCE - La Fä̈ence de Marseille au XVIII e siècle. La manufacture de la Veuve Perrin. Marseille : Centre de la vieille Charité, 1990. Fallou 1915 : FALLOU (L.) - Le bouton d'uniforme français (De l'AncienRégime à fin juillet 1914). Saint-Germain-les-Arpajon : Le Fouilleur, 1915, 327 p., XV pl.

Fingerlin 1971 : FINGERLIN (I.) - Gürtel des hohen und späten Mittelalters. Regensburg : Deutscher Kunstverlag, 1971, 496 p.

Fiorilla 2006 : FIORILLA (S.) - Primi dati sulle ceramiche invetriate su ingobbio siciliane. In: Atti XXXVII convegno internazionale della ceramica, Centro ligure per la storia della ceramica, Albisola, 2005. Borgo S. Lorenzo : All'insegno del Giglio, 2006, p. 381-388.

Fixot 1982 : FIXOT (M.) - A la recherche des formes les plus anciennes de la fortification privée : l'enceinte de Cadrix (commune de Saint-Maximin, Var). In : Actes des IX et $X^{\mathrm{e}}$ Colloques de Château-Gaillard, Durham 1980. Caen : C.R.A.M. 1982, p. 386-406.

Fixot, Pelletier 1990 : FIXOT (M.), PELLETIER (J.-P.) - Porteries, bâtiments d'accueil et métallurgie aux abbayes de Silvacane et du Thoronet, Archéologie Médiévale, XX, 1990, p. 181-252.

Fixot, Pelletier 1995 : FIXOT (M.), PELLETIER (J.-P.) - Ganagobie : huit siècles de céramiques communes grises. In :Terres de Durance : Céramiques de l'Antiquité aux Temps Modernes. Aix-en-Provence : Éd. Narration, 1995 p. 44-48 (Catalogue d'exposition, Musées de Digne et de Gap).

Fixot, Pelletier 2004 : FIXOT (M.), PELLETIER (J.-P.) - Saint Victor de Marseille de la basilique paléochrétienne à l'abbatiale médiévale. Marseille, 2004, $115 \mathrm{p}$.

Flores Escobosa et al. 1999 : FLORES ESCOBOSA (I.), MUÑOZ MARTÍN (M.-D.-M.), LIROLA DELGADO (J.) - Las producciones de un alfar islámico en Almería, Arqueología y Territorio Medieval, 6. Jaén, 1999, p. 207-239.

Fontaine-Hodiamont, Hossey, 2010 : FONTAINE-HODIAMONT (C.), HOSSEY (G.) - L'atelier de verrier d'Herbeumont et la production de verres soufflés-moulés, XIVe-début XVe siècle. In : Fontaine-Hodiamont (C.) dir. - D'Ennion au Val Saint-Lambert. Le verre soufflé-moulé, actes du colloque international de l'Association française pour l'Archéologie du Verre, Bruxelles-Namur, 17-19 octobre 2008. Bruxelles, 2010, p. 345-374 (Scientia Artis, 3).

Fossati, Mannoni 1975 : FOSSATI (S.), MANNONI (T.) - Lo scavo della vetreria medievale di Monte Lecco, Archeologia Medievale, 2, 1975, p. 31-98. Fox 1999 : FOX (G.L.) - The kaolin clay tobacco pipe collection from Port Royal, Jamaica, Oxford, 1999 (British Archaeological Reports, International Series 809).

Foy 1988 : FOY (D.) - Le Verre médiéval et son artisanat en France méditerranéenne. Paris, 1988.

Foy 1995 : FOY (D.) - Verreries de Montpellier. In : Leenhardt (M.) dir. Poteries d'Oc. Céramiques languedociennes VII ${ }^{e}$-XVIII ${ }^{e}$ siècles, catalogue d'exposition, Musée archéologique de Nîmes oct. 1995-février 1996. [Nîmes], 1995, p. $48-49$ et p. 71 , fig. 37.

Foy 1997 : FOY (D.) - Le verre médieval. In : Marchesi (H.), ThirioT (J.), VALLAURI (L.) dir. - Marseille, les ateliers de potier du XIII' s. et le quartier Sainte-Barbe (Ve-XVII ${ }^{e}$ s.). Paris, 1997, p. 60-62 (Documents d'Archéologie française, 65).

François et al. 2003 : FRANÇOIS (V.), NICOLAÏDES (A.), VALLAURI (L.), WAKSMAN (Y.) - Premiers éléments pour une caractérisation des productions de céramiques de Beyrouth entre domination franque et mamelouke. In : actes $d u V_{V I}{ }^{e}$ congrès international sur la céramique médiévale en Méditerranée, Thessalonique, 1999. Athènes, 2003, p. 325-340.

Fulford, Peacock 1984: FULFORD (M.-G.), PEACOCK (D.-P.-S.) - Excavations at Cathage : the bristish mission. In : The avenue du president Habib Bourguiba, Salambo : the pottery and others ceramic objects from the site, vol.1, 2. Scheffield, 1984, $284 \mathrm{p}$.

Gačić 2011 : Gačić (D.) - The pipes from museum collections of Serbia. Novi Sad : City Museum of Novi Sad, 2011.

Ganne, Pournot-Bouvry 2008 : GANNE (P.), POURNOT-BOUVRY (J.) - Monnaies d'Aix-en-Provence-milieu XV'-fin XVIII siècle : la collection Philippe Ganne. Marseille : Cabinet des monnaies et médailles, 2008.

Gantès 1989 : GANTĖS (L.-F.) dir. - Rapport préliminaire sur l'opération de diagnostic archéologique effectuée au quartier Sainte Barbe à Marseille sur l'emplacement de l'îlot Puget III. Marseille, 1989, 24 p., 13 pl. (rapport de sondages archéologiques).

Gantès 1994 : GANTÈS (L.-F.) dir. - Marseille. Les fouilles archéologiques des Pistoles - îlots 61N-62N. Marseille, 1994, 174 p., 9 pl. (rapport de fouilles). Gantès, Bouiron 1987 : GANTÈS (L.-F.), BOUIRON (M.) - Marseille, Parvis Saint-Laurent, fouilles archéologiques. Marseille, 1987, 7 p., 10 pl. (rapport de fouilles).

Gantès, Moliner 1988 : GANTÈS (L.-F.), MOLINER (M.) - Marseille, Le Panier, îlot 61 N. Marseille, 1998, 28 p., 29 pl. (rapport de fouilles).

Gantès, Moliner 1990 : [GANTÈS (L.-F.), MOLINER (M.)] - Marseille, itinéraire d'une mémoire. Cinq années d'archéologie municipale. Marseille, 1990.

Gantès, Moliner 1994 : GANTÈS (L.-F.), MOLINER (M.) - Marseille, les fouilles archéologiques du Parc des Phocéens - îlot 24N. Marseille, 1994, 94 p. 83 fig. (rapport de fouilles).

Gantès, Putzola 1983 : GANTÈS (L.-F.), PUTZOLA (J.-C.) - Rapport de fouilles, 1983, Hospice de la Vieille Charité. Marseille, Bouches-du-Rhône, Marseille, 1983, 51 p. (rapport de fouilles).

Gardini 2000 : GARDINI (A.) - Ceramiche d'importazione dall'area mediterranea e produzioni locali a Genova nei secoli XII-XIII. In : Peduto (P.), 
Widemann (F.) - L'ambiante culturale a Ravello nel medioevo : il caso della famiglia Rufolo. Bari : Edipuglia, 2000, p. 271-281. (Centro universitario europeo per i beni culturali. Ravello. Archeologia, storia, cultura : 1).

Gay 1887 : GAY (V.) - Glossaire archéologique du Moyen-Âge et de la Renaissance, t. 1. Paris : Librairie de la Société bibliographique, 1887, $806 \mathrm{p}$.

Gayraud 1997 : GAYRAUD (R.-P.) - Les céramiques égyptiennes à glaçure, $\mathrm{IX}^{\mathrm{e}}-\mathrm{XIII}{ }^{\mathrm{e}}$ siècles. In : La céramique médiévale en Méditerranée : Actes du $\mathrm{VI}^{e}$ Congrès de l'AIECM2, 1995. Aix-en-Provence, 1997, p. 261-270.

Gelichi 1977 : GELICHI (S.) - La Badia al Fango : considerazioni sui materiali di superficie, Archeologia medievale, IV, 1977, p. 306-313.

Gelichi 1993 : GELICHI (S.) - Alla fine della Graffita : ceramiche e centri di produzione nell'Italia settentrionale tra XVI e XVII secolo : exposition Argenta, Convento dei Cappuccini, 1992. Firenze : All'insegna del giglio, 1993.

Giorgio 2010 : GIORGIO (M.) - L'ultima maiolica pisana : novità e aggiornamenti sulla produzionz di maiolica arcaica a Pisa nel XV secolo. In : Atti del XLIII convegno internazionale della ceramica. Albisola, 2010 : 215-228. Goedewaagen, Helbers 1942 : GOEDEWAAGEN (D.A.), HELBERS (G. C.) - Goudsche pijpen, geschiedenis van de pijpmakerij te Gouda. Amsterdam : NV Uitgeversmaatschappij Atlantic, 1942.

Goetz 1990 : GOETZ (B.) - Montbéliard-Cabaret de l'Hôtel de ville : verrerie du premier quart du XVII ${ }^{\mathrm{e}}$ siècle. In : Verrerie de l'Est de la France XIIIe-XVIIIe siècles. Fabrication-Consommation. Dijon, 1990, p. 187-219 (Supplément à la revue archéologique de l'Est et du Centre-Est, 9).

Gomez et al. à paraître : GOMEZ (S.), LOPES (V.), SANTOS (A.-R.) - Ceramicàs des arrabal de Mertola (Portugal). Contexto y uso de los objetos en un espacio portuario andalusi. In : IX Congreso Internazionale sulla ceramica medievale nel Mediterraneo. Venise, 23-29 novembre 2009, à paraître. Gomez Martinez 1997 : GOMEZ MARTINEZ (S.) - Ceràmica decorada islàmica de Mértola - Portugal (ss. IX-XIII). In : La céramique médiévale en Méditerranée, Actes du VI congrès de l'AIECM2 (Aix-en-Provence 13-18 novembre 1995). Aix-en-Provence, 1997, p. 311-326.

Goret 1997 : GORET (J.-F.) - Le mobilier osseux travaillé découvert sur le site du Vieux Château-Thierry (Aisne), 9 $9^{\mathrm{e}}-10^{\mathrm{e}}$ siècles, Revue Archéologique de Picardie, 3/4, 1997, p. 101-137.

Goret, Poplin 2008 : GORET (J.-F.), POPLIN (F.) - Trois pièces d'échec en ivoire de morse découvertes au château de CrèveCoeur-en-Auge (Calvados), Archéologie médiévale, 38, 2008 : 61-69.

Gosse 2007 : GOSSE (P.) - Les pipes de la quarantaine: fouilles du port antique de Pomègues. Oxford, 2007 (British Archaeological Reports, International Series 1590).

Goury 1983 : GOURY (J.) - La Forteresse : four de boulanger du moyen Âge, Mornas (Vaucluse). Aix-en-Provence, 1993, 5 p., 2 pl., 17 pl. (rapport de fouilles).

Gragueb Chatti 2006 : GRAGUEB CHATTI (S.) - Recherches sur la céramique islamique de deux cités princières en Tunisie (Raqquada et Sabra Mansouriyya). Aix-en-Provence : LAMM-CNRS, 2006, 2072 p. (Thèse de $3^{\text {e }}$ cycle, sous la direction de M. Michel Fixot).

Grassi 1999 : GRASSI (F.) - Le ceramiche invetriate da cucina dal XIII alla fine del XIV secolo nella Toscana Meridionale, Archeologia medievale, XVI, 1999, p. 429-435.

Gratuze et al. 1992: GRATUZE (B.), SOULIER (I.), BARRANDON (J.-N.), FOY (D.) - De l'origine du cobalt dans les verres, Revue d'archéométrie, 6, 1992, p. 97-108.

Grew, De Neergaard 2001 : GREW (F.), DE NEERGAARD (M.) - Shoes and pattens. Medieval finds from excavations in London, $\mathrm{n}^{\circ} 2$. Woodbridge : The Boydell Press, 2001, 145 p.

Grube 1976 : GRUBE (E.-J.) - Islamic pottery of the eighth to the fifteenth century in the Keir collection. Londres, 1976. 378 p. : ill.

Gurrea, Martin 2009 : GURREA (R.), MARTIN (A.) - La ceramica islamica de Ibiza (ss. X-XIII). In : VIII Congreso Internacional de Ceramica Medieval en el Mediterraneo, Ciudad Real - Almagro, 2006. Madrid : Associatión Española de Arquelogía Medieval, 2009, p. 313-326.

Guillemé-Brulon 1997: GUILLEMÉ-BRULON (D.) - Moustiers \& Marseille : sources et rayonnement. Paris : Massin, 1997, $160 \mathrm{p}$.
Guyon, Heijmans 2001 : GUYON (J.), HEIJMANS (M.) - D'un monde à l'autre: Naissance d'une chrétienté en Provence, $I V^{e}-V^{e}$ siècles, Catalogue d'exposition, 15 septembre 2001- 6 janvier 2002, Musée de l'Arles Antique. Arles : Éditions du Musée d'Arles Antique, 2001, 243 p.

Havard 1887-1890 : HAVARD (H.) - Dictionnaire de l'ameublement et de la décoration depuis le $13^{e}$ siècle jusqu'à nos jours. Paris : Ancienne maison Quantin, Librairies-imprimeries réunies, May et Motteroz, 1887-1890, 4 vol. Herbeth 1983 : HERBETH (P.) - Les ustensiles de cuisine en Provence médiévale (XIII ${ }^{\mathrm{e}}-\mathrm{XV} \mathrm{V}^{\mathrm{e}}$ siècles), Médiévales, 5, 1983, p. 89-93.

Hibon et al. 2002 : HIBON (L.), POUJOL (J.), GRUAT (P.), MARTY (G.), COSTERLINCK (É.), SIMONIN (M.) - La nécropole du château de Montaigut - nouvelles fouilles : la salle des gardes, Gissac, Cahiers d'archéologie aveyronnaise, 16, 2002, p. 133-155.

Higgins 1987 : HIGGINS (D. A.) - The interpretation and regional study of clay tobacco pipes : a case study of the Broseley district. Liverpool, 1987 (Unpublished Ph.D thesis).

Holmes 1985 : HOLMES (E. F.) - A history of thimbles, Cornwall books. Londres, 1985, $253 \mathrm{p}$.

Homsy-Gottwalles 2009 : HOMSY-GOTTWALLES (G.) - Recherches sur la céramique glaçurée de Beyrouth à la période médiévale : I $X^{e}-X V^{e}$ siècle. Poitiers, 2009, 439 p. (Thèse sous la direction de $\mathrm{M}^{\text {lle }}$ le professeur Pascale Ballet).

Horry 2012 : HORRY (A.) - Poteries de Lyon : 1500-1850 Morceaux choisis. Lyon : Editions Lyonnaises d'Art et d'Histoire / INRAP, 2012.

Hurley 1997 : HURLEY (M.) - Excavations at North gate, Cork, 1994. Cork : Cork Corporation, 1997.

Istria 1996 : ISTRIA (D.) - Les céramiques médiévales importées en Corse : $\mathrm{XIII}^{\mathrm{e}}$ - première moitié du XIV ${ }^{\mathrm{e}}$ siècle, Bulletin de la Société des sciences historiques et naturelles de la Corse, 674-675, 1996, p. 9-29.

Jimenez Castillo et al. 1997 : JIMENEZ CASTILLO (P.), NAVARRO PALAZZON (J.), COLL CONESA (J.) contrib., BARRACHINA (J.) contrib. - Sobre cuatro casas andalusíes y su evolución (siglo X-XIII). Murcie: Consejalia de Cultura, Festejos y Turismo, 1997 (Platéria, Excavaciones Arqueológicas en la ciutad de Murcia, 14).

Julien 1996-1997 : JULIEN (T.) - La céramique à Fréjus (Var) de l'antiquité aux temps modernes d'après les fouilles de la place Formigé (1988). Aix-enProvence : Université de Provence, 1997 (Mémoire de maîtrise).

Kauffmann et al. 1992 : KAUFFMANN (A.), OGGIANO-BITAR (H.), SAUZE (É.) coll., LAAGE (A.) coll., CARNOY (D.) coll., CUZON (J.) coll. - Les Faïences de la Tour-d'Aigues : catalogue des collections du musée des Faïences et de l'Euvre, Château de la Tour-d'Aigues. Avignon, 1992.

Krommenhoek, Vrij 1986: KROMMENHOEK (W.), VRIJ (A.) Kleipijpen: drie eeuwen Nederlandse kleipijpen in foto's. Amstelveen: Drukkerij WEVO, 1986.

Lagrue 2004 : LAGRUE (J.-P.) dir. - Le verre un art du feu au Moyen Âge. Catalogue d'exposition, juillet-octobre 2004, Église Saint-Sauveur de l'Hauture. Fos-sur-Mer. Fos-sur-mer, 2004, 44 p.

Lambert 1972 : LAMBERT (N.) - La Seube : témoin de l'art du verre en France méridionale du Bas-Empire à la fin du Moyen Âge, Journal of Glass Studies, 14, 1972, p. 77-116.

Lambert 1982-1983 : LAMBERT (N.) - La verrerie médiévale forestière de la Seube, Archéologie du Languedoc, 5, p. 177-244.

Laurentin 1990 : LAURENTIN (R.) - Vie de Catherine Labouré, voyante de la rue du Bac : 1806-1876. Bourges: DDB, 1990, 2 vol., 402 p., 666 p.

Lavagna-Varaldo 1989 : LAVAGNA (R.), VARALDO (C.) - La graffita arcaica tirrenica di produzione savonese alla luce degli scarti di fornace dei secoli XII e XIII. In : Atti XIX Convegno internazionale della ceramica. La ceramica graffita. Albisola, 1989, p. 119-130.

Lazar, Willmott 2006 : LAZAR (I.), WILLMOTT (H.) - The Glass from the Gnalic Wreck. Koper, 2006.

Lebole di Gangi 1993 : LEBOLE di GANGI (C. M.) - Manufatti metallici e reperti votivi. In: Scavi medievali in Calabria: Gerace 3, Archeologia medievale, XX, 1993, p. 468-475.

Leclaire, Leclaire 2008 : LECLAIRE (A.), LECLAIRE (M.) - Les pipiers Saint-Quentinois XVIII ${ }^{e}$ - XIX ${ }^{\mathrm{e}}$ siècles, Journal de l'Académie Internationale de la Pipe, 1. Liverpool : L’Académie Internationale de la Pipe, 2008. 
Leenhardt 1995a : LEENHARDT (M.) - Naissance et développement des glaçures de l'Uzège. In : LEENHARDT (M.) dir. - Poteries d'Oc, céramiques languedociennes $\mathrm{VII}^{e}$-XVII ${ }^{e}$ siècles. Aix-en-Provence : éd. Narration, 1995, p. 55-57 (Catalogue d'exposition, Musée archéologique de Nîmes).

LeenhardT 1995b : LEENHARDT (M.) - Vie quotidienne à Montpellier. In : LEENHARDT (M.) dir. - Poteries d'Oc, céramiques languedociennes VII ${ }^{e}$ - XVII ${ }^{e}$ siècles. Aix-en-Provence : Éd. Narration, 1995, p. $45-47$ (Catalogue d'exposition, Musée archéologique de Nîmes).

Leenhardt 1999 : LEENHARDT (M.) - Un puits : reflet de la vie quotidienne à Montpellier au XIII" s. Archéologie du Midi médiéval, XVII, 1999, p. 109-186.

Leenhardt et al. 1993 : LEENHARDT (M.) dir., RAYNAUD (C.) dir., SCHNEIDER (L.) dir. - Céramiques languedociennes du Haut Moyen Âge (VII-XI ${ }^{\mathrm{e}}$ s.) : Études micro-régionales et essai de synthèse, Archéologie du Midi médiéval, XI, 1993, p. 111-228.

Leenhardt et al. 1995 : LEENHARDT (M.), RAMONAT (R.), RAYNAUD (C.), SCHNEIDER (L.) - Poteries rouges des garrigues montpelliéraines. In: Poteries d'Oc : céramiques languedociennes VII ${ }^{e}$ XVII ${ }^{e}$ siècles. Aixen-Provence : éd. Narration, 1995, p. 34-35 (Catalogue d'exposition, Musée archéologique de Nîmes).

Leenhardt et al. 1996 : LEENHARDT (M.), PITON (J.), VALLAURI (L.), FOY (D.) - L'évolution des vaisselles médiévales à Arles : l'exemple du dépotoir des Prêcheurs, Archéologie du Midi médiéval, XIV, 1996, p. 99-141.

Leenhardt et al. à paraître: LEENHARDT (M.), VALLAURI (L.), VAYSSETTES (J.-L.) - Les productions de céramique et les échanges dans l'aire montpelliéraine au Moyen Age. In: Actes du colloque international «De la céramique à l'Histoire », Université de Perpignan, 23-25 novembre 2000, à paraître.

Leenhardt, Thiriot 1989 : LEENHARDT (M.), THIRIOT (J.) - Poteries grises médiévales produites à Saint-Gilles-du-Gard. Archéologie du Midi médiéval, VII, 1989, p. 73-106.

Leenhardt, Vallauri 1997-1998 : LEENHARDT (M.), VALLAURI (L.) - De la cuisine à la table : vaisselles de terre en Languedoc au XIII ${ }^{\mathrm{e}}$ et XIV ${ }^{\mathrm{e}}$ siècles, Archéologie du Midi médiéval, XV-XVI, 1997-1998, p. 215-233.

Lefrancq 2010 : LEFRANCQ (J.) - Pour un corpus des éléments moulés et estampés dans le verre façon de Venise : l'exemple des Musées royaux d'Art et d'Histoire de Bruxelles. In : Fontaine-Hodiamont (C.) dir. - D'Ennion au Val Saint-Lambert. Le verre soufflé-moulé, actes du colloque international de l'Association française pour l'Archéologie du Verre, Bruxelles-Namur, 17-19 octobre 2008. Bruxelles, 2010, p. 375-390 (Scientia Artis 3).

Lemoine 2008 : LEMOINE (Y.). - Petits objets antiques et médiévaux récemment découverts dans le centre-ouest du Var. In : Archéologies de Provence et d'ailleurs : mélanges offerts à Gaëtan Congès et Gérard Sauzade. p. 675696, (Supplément du Bulletin Archéologique de Provence, 5).

Lemoine et al. 2010 : LEMOINE (Y.), RODET-BELARBI (I.), POIGNANT (S.), MARCHAISSEAU (V.), GORET (J.-F.) - Sept nouveaux exemplaires de plaques-boucles mérovingiennes en matière dure animale, Archéologie médiévale, 40, 2010, p. 33-49.

Lunardi 1975 : LUNARDI (G.) - Le Monete della Repubblica di Genova. Gênes, 1975, 466 p.

Mc Cashion 1979 : MC CASHION (J.H.) - A preliminary chronology and discussion of seventeenth and early eighteenth century clay tobacco pipes from New York State sites. In: The Archaeology of the Clay Tobacco Pipe II, Oxford, 1979, p. 63-149 (British Archaeological Reports, International Series 60).

Mac Gregor 1985 : MAC GREGOR (A.) - Bone Antler Ivory and Horn, The technology of skeletal materials since the roman period. Londres, Croom Helm, 1985, 245 p.

Mach à paraître : MACH (J.) - Sur la table ou dans l'église, le verre dans les villes roussillonnaises de la fin du XIII ${ }^{\mathrm{e}}$ au $\mathrm{XVII}{ }^{\mathrm{e}}$ siècle. In : Un palais dans la ville. Le Palais des Rois de Majorque à Perpignan, colloque international, 20- 22 mai 2011, à paraître.

Magnani, Munarini 1998 : MAGNANI (R.), MUNARINI (M.) - La Ceramica graffita del Rinascimento tra Po, Adige e Oglio : exposition Revere, Palazzo Ducale. Montorio : Belriguardo, 1998.
Maire 1990 : MAIRE (J.) - Les objets et leur fabrication à Strasbourg. In : Schnitzler (B.) dir. - Vivre au Moyen Âge: 30 ans d'archéologie en Alsace. Strasbourg : Musée de la ville de Strasbourg, 1990, p. 81-87 (catalogue d'exposition).

Mannoni 1975 : MANNONI (T.) - La ceramica medievale a Genova e nella Liguria. Gênes, 1975, 206 p.

Marchesi et al. 1997 : MARCHESI (H.), THIRIOT (J.), VALLAURI (L.) dir., LEENHARDT (M.) coll. - Marseille, les ateliers de potiers $d u X^{X I I I^{e}} s$. et le quartier Sainte-Barbe ( $V^{e}-X V I I^{e}$ s.). Paris, Maison des sciences de l'Homme, 1997, 390 p. (Documents d'archéologie française, 65).

Mari 1996: MARI (E.) - Jarres-en-Provence : l'histoire des anciennes jarres provençales. s.l., 1996.

Martigues 1984 : Le quartier de l'Ile à Martigues, six années de recherches archéologiques. Martigues : Musée d'Art et d'Archéologie, 1996, 64 p.

Martinez Lillo, Matesanz Vera 1991: MARTINEZ LILLO (S.), MATESANZ VERA (P.) - Cerâmicas cristinas y musulmanas de la Marca Central : siglos X, XI, y XII. In : A cerâmica medieval no Mediterrâneo occidental, Lisbonne, 16-22 novembre 1987. Mertola, 1991, p. 273-284.

Marysse 1986: Marysse (I.) - L’orcel, mobilier funéraire médiéval. Découvertes anciennes et récentes en Aquitaine, Société archéologique de Bordeaux, LXXVII, 1986, p. 21-26.

Maternati-Baldouy 1997 : MATERNATI-BALDOUY (D.) - Faïence et porcelaine de Marseille, XVII ${ }^{e}$-XVIII ${ }^{e}$ siècles. Marseille : Musées de Marseille, $1997,303 \mathrm{p}$.

Mazard 1965 : MAZARD (J.) - Histoire monétaire et numismatique contemporaine, 1790-1963, vol. 1. Paris-Bâle : Bourgey ed. et Monnaies et médailles s.a., 1965,294 p.

Mellinand 2005 : MELLINAND (P.) dir. - Espace Bargemon à Marseille (Bouches-du-Rhône). Nîmes : INRAP Méditerranée, 2005. 919 p. (rapport de fouilles).

Mellinand, Gantès 2006 : MELLINAND (P.) dir., GANTÈS (L.-F.) dir. - Collège Vieux-Port, 2 rue des Martégales à Marseille (Bouches-du-Rhône). Nîmes : INRAP Méditerranée, 2006, 279 p., 239 p. (rapport de fouilles).

Mehler 2010 : MEHLER (N.) - Tonpfeifen in Bayern (ca. 1600-1745), Bonn: Dr Rudolf Habelt GMBH.

Mello, Pernambucano 1983 : MELLO, PERNAMBUCANO (U. de) - Clay pipes from north-east Brazil. In: The Archaeology of the Clay Tobacco Pipe VIII. Oxford, 1983, p. 259-286 (British Archaeological Reports, International Series 175).

Mesquida Garcia 2006 : MESQUIDA GARCIA (M.) - Paterna centro productor de cerámica dorada en la Edad Media. Paterna, lustre pottery center in Middle Ages. In: Avances en arqueometría. VI congreso ibérico de arqueometría. Universitat de Girona, 16-19 novembre 2005. Gérone, 2006 : Lulu. com, p. 7-20.

Meulen 2003 : MEULEN (J. van der) - Goudse pijpenmakers en hun merken, Den Haag: Pijpelogische Kring Nederland, Leiden en de Stedelijke musea Gouda, 2003.

Meyer 2006 : MEYER (Y.) - Les silos médiévaux. In : Un village, son histoire, Jouques. Jouques : Association des amis de Jouques, 2006, p. 74-80.

Mikler 1997: MIKLER (H.) - Die römischen Funde aus Bein im Landesmuseum Mainz. Montagnac: Monique Mergoil, 1997, 173 p. (Monographie Instrumentum, 1).

Milanese et al. 2006: MILANESE (M.), BICCONE (L.), ROVINA (D.), MAMELI (P.) - Forum Ware da recenti ritrovamenti nella Sardegna nord- occidentale. In : Atti XXXVII convegno internazionale della ceramica, Centro ligure per la storia della ceramica, Albisola, 2005. Borgo S. Lorenzo : All'insegno del Giglio, 2006, p. 201-218.

Minovez 2004 : MINOVEZ (J.-C.) éd. - Faïence fine et porcelaine : les hommes, les objets, les lieux, les techniques, actes du colloque MartresTolosane, septembre 2001. Cnrs-Université de Toulouse-Le Mirail. Toulouse, 2004.

Miroudot 2008: MIROUDOT (D .) - La production abbasside. In : Dectot (X.) ; Makariou (S.) dir. - Reflets d'or. D'orient en occident, la céramique lustrée, $I X^{e}-X V^{e}$ siècle. Paris : Réunion des Musées Nationaux (RMN), 2008. $127 \mathrm{p}$ 
Moesgaard 2004 : MOESGAARD (J.-C.) - Le titre, la valeur et la chronologie des raimondins du marquisat de Provence (XII ${ }^{e}-\mathrm{XIII}{ }^{\mathrm{e}}$ siècles), Bulletin de la Société française de numismatique, 59, 2004 p. 180-189.

Molet 1988 : MOLET (H.) - Autres type d'objets, l'ancienne église SaintPierre-des-cuisines à Toulouse, Mémoires de la Société archéologique du Midi de la France, 48, 1988, p. 133-137.

Molinari 1997 : MOLINARI (A.) - Momenti di cambiamento nelle produzioni ceramiche siciliane. In : La céramique médiévale en Méditerranée, Actes du VI congrès de l'AIECM2, 13-18 novembre 1995. Aix-en-Provence, 1997, p. 375-382.

Molinari, Cassai 2006 : MOLINARI (A.), CASSAI (D.) - La Sicilia ed il Mediterraneo nel XIII secolo. Importazioni ed esportazione di ceramiche fini e da trasporto. In : Atti XXXVII convegno internazionale della ceramica, Centro ligure per la storia della ceramica, Albisola, 2005. Borgo S. Lorenzo : All'insegno del Giglio, 2006, p. 89-112.

Moliner 1990 : MOLINER (M.) - Protomajolique et majolique archaïque du XIII $\mathrm{e}$ s. à Marseille. In : Atti XXIII convegno internazionale della ceramica. Albisola : Centro ligure per la storia della ceramica, 1990, p. 203-217.

Moliner 1993 : MOLINER (M.) - Un puits du Panier. In : Amouric (H.), Abel (V.) dir. - Un goût d'Italie : céramiques et céramistes italiens en Provence du Moyen Âge au XXe s. Aix-en-Provence : éd. Narration, 1993, p. 15-17 (catalogue d'exposition, Aubagne).

Moliner 1994 : MOLINER( M.) dir. - Marseille. Les fouilles archéologiques de l'îlot 55 - rue de la Cathédrale. Marseille/Aix-en-Provence, SRA PACA, 1994, 267 p., 124 fig. (rapport de fouilles).

Moliner 1996 : MOLINER( M.) dir. - Marseille. Les fouilles archéologiques de la place des Pistoles, campagne 1995. Aix-en-Provence, SRA PACA, 286 p. (rapport de fouilles).

Moliner, Gantès 1986 : MOLINER (M.), GANTÈS (L.-F.) - Marseille Le Panier, îlot 55. Marseille/Aix-en-Provence, SRA PACA, 18 p. 26 pl. (rapport de diagnostic archéologique)

Moliner, Moerman, Martin 1993 : MOLINER (M.), MOERMAN (M.), MARTIN (L.) - Marseille. Puget III. Aix-en-Provence, SRA PACA, 1986, 91 p. (rapport de fouilles)

Motteau 1991: MOTTEAU (J.) - Catalogue des objets des fouilles 1973-1977. In : Recherches sur Tours, $n^{\circ} 5$. Tours : Association pour le développement des études d'archéologie urbaine à Tours, 1991, 138 p. (Supplément à la revue archéologique du Centre de la France, 2).

Mouton 1994 : MOUTON (D.) - Deux mottes dans un terroir provençal en transformation: Saint-Paul-lès-Durance, $\mathrm{XI}^{\mathrm{e}}$-XIII ${ }^{\mathrm{e}}$ siècles, Archéologie médiévale, XXIV, 1994, p. 201-249.

Mouton 1995 : MOUTON (D.) - Niozelles : Céramiques autour de l'An Mil. In: Terres de Durance : Céramiques de l'Antiquité aux Temps Modernes. Aix-en-Provence : Ed. Narration, 1995, p. $49-50$ (catalogue d'exposition, Musée de Digne et de Gap).

Mouton 2003 : MOUTON (D.). - La Roca de Niozelles et les mottes castrales du bassin de la Durance moyenne et ses abords. Aix-en-Provence, Université d'Aix-Marseille I, 2003, 3 vol., 307+292+95 p. (thèse d'Archéologie médiévale sous la direction de Gabrielle Démians d'Archimbaud).

Navarro-Palazón 1991 : NAVARRO PALAZÓN (J.) - Una casa islámica en Murcia: estudio de su ajuar (siglo XIII). Murcie : Centro de Estudios Árabes y Arqueológicos Ibn Arabi. Ayuntamiento de Murcia, 1991, 276 p. (Islam y arqueología, 1).

Navarro-Palazón 1993 : NAVARRO PALAZÓN (J.) - La cultura del Islam. In : Alonso (S.) dir. - El Reino de Murcia hoy. Murcie : Cámara Oficial de Comercio, Industria y Navegación, v. II, 1993, p. 115-126.

Newby 1987 : NEWBY (M.) - Medieval Glass from Farfa. In : Annales $d u$ 10e Congrès international de l'Association internationale pour l'Histoire du Verre (Madrid-Ségovie 1985). Amsterdam, 1987, p. 255-270.

Nin et al. 1996 : NIN (N.), BOUTTEVIN (C.), BRIEN (F.), CLAUDE (S.), DUFRAIGNE (J.-J.), LÉAL (E.), LEGUILLOUX (M.), LUTTI (M.), NALIN (A.-C.), THERNOT (R.) - Palais Monclar. Campagne de fouille préventive : La Maison d'arrêt. Aix-en-Provence : SRA PACA-AFAN, 1996. 6 vol. (rapport de fouilles).

Norton 2009 : NORTON (J.) - Ireland, Journal of the Académie Internationale de la Pipe, 2. Liverpool : L'Académie Internationale de la Pipe, 2009, p. 75-80.
Oikonomou Laniado 1997 : OIKONOMOU LANIADO (A.) - Céramique commune byzantine d'Argos. In : La céramique médiévale en Méditerranée, Actes du VIe congrès de l'AIECM2 (Aix-en-Provence 13-18 novembre 1995). Aix-en-Provence, 1997, p. 237-238.

Ollich I Castanyer et al. 1995 : OLLICH I CASTANYER (I.), OCAÑA I SUBIRANA (M.), RAMISA I VERDAGUER (M.), DE ROCAFIGUERA I ESPONA (M.) - A banda i banda del Ter. Història de Roda. Vic : Eumo Editorial, 1995, $271 \mathrm{p}$.

Oostveen, Stam 2011 : OOSTVEEN (J. van), STAM (R.) - Productiecentra van Nederlandse kleipijpen. Leiden : Pijpelogische Kring Nederland, 2011.

Palazzi et al. 2003: PALAZZI (P.), PARODI (L.), FALCETTI (C.), FRONDONI (A.), MURIALDO (G.). - Archeologia urbana a Finalborgo (1997-2001) : Gli scavi nella piazza e nel complesso conventuale di Santa Caterina, Archeologia medievale, XXX, 2003, p. 183-242.

Pales 1971 : PALES (L.) - Atlas ostéologique pour servir à l'identification des mammifères du quaternaire. Tome III, Les membres herbivores. Paris : Edition du centre national de la recherche scientifique, 1971, $84 \mathrm{pl}$.

Pansier 1926: PANSIER (P.) - Les gabelles d'Avignon de 1310 à 1397, annales d'Avignon et du Comtat Venaissin, 12, 1926, p. 37-63.

Paone et al. 1999a : PAONE (F.), PARENT (F.), THERNOT (R.) - La création d'un quartier à Marseille à la fin du XII ${ }^{\mathrm{e}}$ siècle. In : Hesnard (A.), Moliner (M.), Conche (F.), Bouiron (M.) - Parcours de ville : Marseille: 10 ans d'archéologie, 2600 ans d'histoire. Aix-en-Provence : Édisud, 1999, p. 75-76 (catalogue d'exposition, Musée d'Histoire de Marseille).

Paone et al. 1999b: PAONE (F.), VILLEMEUR (I.), BERTOMEU (É.), RICHIER (A.), BOUIRON (M.), VALETTE (F.) - La cathédrale de la Vieille Major, Marseille (Bouches-du-Rhône). Aix-en-Provence : SRA-PACA, 1995, 105 p., 43 fig. (rapport de fouille).

Paone 2008 : PAONE (F.) dir. - 14, Rue Trinquet à Marseille (Bouches-duRhône). Nîmes : Inrap, 2008, 2 vol., 329 p. (rapport de fouille).

Paone et al. 2012 : PAONE Fr., MELLINAND (P.), PARENT (F.) dir. Bouches-du-Rhône, Marseille, Esplanade de La Major, Évolution du site de l'époque grecque à nos jours, Nîmes: Inrap, 2012, 3 vol., 551 p. (rapport de fouille).

Papanikola-Bakirtzi 1999 : PAPANIKOLA-BAKIRTZI (D.) - Byzantine Glazed Ceramics. The Art of Sgraffito. Athènes: Papanikola-Bakirtzi D., 1999, $270 \mathrm{p}$.

Parent 1992 : PARENT (F.) - Les céramiques du Bas Moyen Age. In : Brien (F.), Lagrue (J.P.), Laurier (F.), Pasqualini (M.), Vecchione (M.). - Hyères (Var). Fouilles de l'église Saint-Pierre et de ses abords, Archéologie du Midi médiéval, X, 1992, p. 135-156.

Parent 1997 : PARENT (F.) - Première approche des céramiques médiévales du chantier "Musée César I". In : Thernot (R.) dir. - César médiéval et moderne : Étude du mobilier céramique. Aix-en-Provence/Nimes, 1997, p. 1-8 (rapport de fouille).

Parent 2005 : PARENT (F.) - Aperçu des céramiques en usage à Marseille au $X I I^{e}$ siècle et au début du XIII e siècle au travers des découvertes du chantier Villeneuve-Bargemon, In : Mellinand (P.) dir. - Espace Bargemon à Marseille (Bouches-du-Rhône). Nîmes-Aix-en-Provence : Inrap, 2005, p. 845-868 (rapport de fouille).

Parent, Vallauri 2001 : PARENT (F.), VALLAURI (L.) coll. - Le mobilier céramique de la période médiévale. In : Bouiron (M.) dir. - L'Alcazar (BMVR), 26 siècles d'occupation suburbaine à Marseille (Bouches-duRhône), vol.2-3. Aix-en-Provence, 2001, p. 393-450 (rapport de fouille).

Pastoureau 1990 : PASTOUREAU (M.) - L'échiquier de Charlemagne, un jeu pour ne pas jouer. Paris : Adam. Riro, 1990, 63 p.

Passarius et al. 2008: PASSARIUS (O.), DONAT (R.), CRUBÉZY (É.), KEYSER (C.), LUDES (B.), DABERNAT (H.), DEDOUIT (F.), ABOUDHARAM (G.), DRANCOURT (M.), CATAFAU (A.) - Le cimetière de Villarnau. In : Passarius (O.), Donat (R.), Catafau (A.) dir. - Vilarnau, un village du Moyen Âge en Roussillon. Canet-en-Roussillon : Éditions Trabucaire, Conseil Général des Pyrénées-Orientales, 2008, p. 220-241.

Patterson 1995 : PATTERSON (H.) - Analisi mineralogiche sulle ceramiche medievali di alcuni siti della Sicilia occidentale. In: Actes $d u V^{e}$ colloque international sur la céramique médiévale en Méditerranée occidentale, 1991. Rabat, 1995, p. 219-220. 
Peduto 2000 : PEDUTO (P.) - La ceramica invetriata dalla villa Rufolo di Ravello. In: PAtitucci Uggeri (S.) - La ceramica invetriata tardomedievale dell'Italia centro-meridionale, Quaderni di Archeologia medievale, III, Florence : A l'Insegna del Giglio, 2000. p. 16-41.

Pelletier 1996 : PELLETIER (J.-P.) - Le règne des pots du haut Moyen Age (IX ${ }^{\mathrm{e}}-\mathrm{XI}^{\mathrm{e}}$ siècles). In : 1500 ans de céramique en Vaucluse : ateliers et productions de poteries du V ${ }^{\mathrm{e}}$ siècle au début du XX ${ }^{\mathrm{e}}$ siècle. La Tour d'Aigues, 1996, p. 26-37 (catalogue d'exposition, Musée des Faïences).

Pelletier 1997a : PELLETIER (J.) - Les céramiques communes grises en Provence de l'Antiquité tardive au XIII ${ }^{\mathrm{e}}$ siècle. In : La céramique médiévale en Méditerranée : Actes du VI Congrès de l'AIECM2, 13-18 novembre 1995. Aix-en-Provence : Narration éditions, 1997, p. 111-124.

Pelletier 1997b : PELLETIER (J.-P.) - Les céramiques communes régionales en pâtes brune et grise. In : Marchesi (H.), Thiriot (J.), Vallauri (L.), Leenhardt (M.) dir. -Marseille, les ateliers de potiers du XIII siècle et le quartier Sainte-Barbe (Ve-XVII ${ }^{e}$ s.). Paris, 1997, p. 66-76 (Documents d'archéologie française, 65).

Pelletier et al. 2000 : PELLETIER (J.-P.), POGUET (M.), RIGOIR (Y.) coll., LEGUILLOUX (M.) contrib., COLUMEAU (P.) contrib. L'occupation du site Saint-Pierre 1, de l'Age du Fer au $X^{\mathrm{e}}$ siècle et premières études des céramiques. In : Leveau (P.) dir., Saquet (J. P.) dir. - Milieu et Sociétés dans la vallée des Baux, études présentées au colloque de Mouriès. Montpellier, 2000, p. 275-338 (Supplément à la Revue archéologique de Narbonnaise, 31).

Pelletier et al. 2005 : PELLETIER (J.-P.), RICHARTÉ (C.), WAKSMAN (Y.) - Première découverte d'une production de céramiques grises médiévales à Bédoin, Archéologie du Midi médiéval, XXIII-XXIV, 2005, p. 483-497.

Pelletier, Bérard 1997 : PELLETIER (J.-P.), BÉRARD (G.) - Restes d'un four du $\mathrm{XI}^{\mathrm{e}}$ siècle à Cabasse (Var). In : La céramique médiévale en Méditerranée: Actes du VI congrès de l'AIECM2, 13-18 novembre 1995. Aix-en-Provence, 1997, p. 125-128.

Pelletier, Fixot 1995 : PELLETIER (J.-P.), FIXOT (M.) - Ganagobie : huit siècles de céramiques communes grises. In : Terre de Durance, céramiques de l'Antiquité aux temps modernes, catalogue d'exposition, Musées de Digne et de Gap, 1995, éd. Narration, p. 56-62, 68-70, 82-83.

Pelletier, Poguet 2008 : PELLETIER (J.-P.), POGUET (M.) - Le haut Moyen Âge dans la villa Saint-Pierre 1 à Eyguières (Bouches-du-Rhône), Archéologie du Midi médiéval, XXVI, 2008, p. 3-16.

Pelletier, Vallauri 1992 : PELLETIER (J.-P.), VALLAURI (L.) - Mimet ; à la recherche d'un atelier perdu, Archéologie du Midi médiéval, XI, 1992, p. 229-239.

Penna 2003 : Penna (M.-T.) - Deux ensembles de verrerie médiévale. In : GUYARD (L.), Le Collège de France (Paris). Du quartier gallo-romain au Quartier latin. Paris : éd. Maison des sciences de l'Homme, 2003, p. 220-225 (Documents d'archéologie française, 95).

Picon 1973 : PICON (M.) - Introduction à l'étude technique des céramiques sigillées de Lezoux. Université de Dijon, 1973, 135 p.

Pignates et poêlons 1996 : Pignates et poêlons : poterie culinaire de Vallauris. Vallauris, 1996, 95 p. (catalogue d'exposition, musée Magnelli).

Piponnier 1975 : PIPONNIER (F.) - Une maison villageoise au XIV ${ }^{e}$ siècle : le mobilier. In : Rotterdam papers II : a contribution to medieval archaeology : teksten van lezingen gehouden tijdens het Symposium 'Woning en huisraad in de Middeleeuwen', te Rotterdam van 20 t/m 22 maart 1973. Utrecht : Stichting het Nederlandse gebruiksvoorwerp, 1975 (Rotterdam papers 2, p. 151-170).

Piponnier et al. 1993 : PIPONNIER (F.) dir., ALEXANDRE-BIDON (D.) coll., BECK-BOSSARD (C.) coll., CARCEL (A.) coll. - Le château d'Essertine, Loire. Lyon : Service régional de l'archéologie, 1993, 1 vol., 175 p. (Documents d'archéologie en Rhône-Alpes, 8).

Piuzzi et al. 2003: PIUZZI (F.), DI MEO (S.), COSSIO (S.), MARCHESE (G.), PUTANO (F.), BRANCATI (C.), MAZZEI (M.), VIGNOLA (M.) - La sequenza periodizzata delle fasi identificate (Anni 1997-'99 - 2001-'02). In : Piuzzi (F.) dir. - Progetto castello della motta di Savorgnano. Ricerche di archeologia medievale nel nord-est italiano : 1. Indagini 1997-'99, 2001-'02. Florence : All'Insegna del Giglio, 2003, p. $37-123$.
Plaisirs et manières de table 1992 : Plaisirs et manières de table aux XIV et $X V^{e}$ siècles. Catalogue d'exposition. Musée des Augustins, Toulouse, avriljuin 1992. Toulouse, 1992, $345 \mathrm{p}$.

Poey d'Avant 1860 : POUEY D'AVANT (F.) - Monnaies féodales de France : deuxième volume. Paris : Camille Rollin Ed., 1860, 418 p.

Poirot et al. 1992 : POIROT (A.), ALEXANDRE-BIDON (D.), COULON (G.), GAILLARD (N.) - Les objets de parure et de piété et les accessoires du vêtement. In : Zadora-Rio (É.), Galiné (H.) et al. - Fouilles et prospections à Rigny-Ussé (Indre-et-Loire), rapport préliminaire 1986-1991, Revue archéologique du Centre de la France, 31, 1992, p. 143-166.

Popović 1989: POPOVIC (M.) - Importation et production locale de céramique à Ras. In : Deroche (V.), Spieser (J. M.) éd. - Recherches sur la céramique byzantine. Actes du colloque organisé par l'École Française d'Athènes. Athènes, 1989, p. 119-130.

Pymont 1993 : Pymont, La forteresse oubliée : XIII ${ }^{e}-X V^{e}$ siècle - entre les Vienne et les Chalon. Catalogue d'exposition, Musée archéologique de Lons-le-Saunier, 30 avril 1993-10 janvier 1994. Lons-le-Saunier : Section d'archéologie de la société d'émulation du Jura, Centre jurassien du Patrimoine, 1993, $140 \mathrm{p}$.

Querrien et Blanchard 2004: QUERRIEN (A.), BLANCHARD (J.) - La résidence aristocratique rurale de Montbaron: structures et mobilier, Archéologie médiévale, 34, p. 67-130.

Raffaelli 2002 : RAFFAELLI (L.) - Le matériel céramique médiéval des fouilles de la Cour de l'Archevêché d'Aix-en-Provence. Aix-en-Provence : Université de Provence Aix-marseille I, 2002, 2 vol., 87 p. (Mémoire de mâ̂trise d'archéologie).

Ragona 1995 : RAGONA (A.) - La ceramica in Sicilia : dalle origini all'ottocento. Palermo : Sellerio, 1975, $356 \mathrm{p}$.

Raphaël 1991 : RAPHAEL (M.) - La pipe en terre et son périple à travers la France. Vitrolles : Editions Aztec, 1991.

Raphaël 2003 : RAPHAEL (M.) - La pipe en terre à Marseille: deux cent soixante trois ans d'industrie pipière 1693-1956. Nice : Imprimerie Toscane, 2003.

Raphaël 2004 : RAPHAEL (M.) - Rapport d'étude des pipes trouveés lors des travaux du Centre Bourse à Marseille, chantier de la Bourse. Marseille : INRAP, 2004 (doc. dact.).

Ricci 2010: RICCI (M.) - Le majoliche laziali. Ceramiche medievali e del primo rinascimento (1000-1530) Museo nazionale de la crypta balbi. Ceramiche medievali e moderne. Verona : Electa, 2010. 317 p.

Richarté 2001 : RICHARTÉ (C.) - La consommation de vaisselle de la fin du XII ${ }^{e}$ s. à la fin du XIVe s. dans le faubourg Sainte-Catherine. Essai de typochronologie. In : Bouiron (M.) dir. - Marseille, du Lacydon au faubourg Sainte-Catherine ( $V^{e}$ s. av. J.-C. - XVIII ${ }^{\text {s. }}$ ) : les fouilles de la place Généralde-Gaulle. Paris : édition de la Maison des Sciences de l'Homme, 2001, p. 136-167 (Documents d'archéologie française, 87).

Richarté 2004 : RICHARTÉ (C.) - Première étude céramologique des contextes des $\mathrm{X}^{\mathrm{e}}-\mathrm{XI}^{\mathrm{e}} \mathrm{s}$. à la première moitié du XIV ${ }^{\mathrm{e}} \mathrm{s}$. In : Bien (S.), Gaita (C.), Lang (S.), Mezzoud (A.), Michel (D.), Pellé (R.), Richarté (C.) - Les fouilles archéologiques du Tunnel de la Major à Marseille (Bouches-duRhône) : Volume 2 : Les mobiliers et les matériaux de construction. Document Final de Synthèse. Nîmes, 2004, 219 p.

Richarté 2009 : RICHARTÉ (C.) - Nouvelles données sur le vaisselier du couvent des Dominicaines à Aix-en-Provence au début du XIV ${ }^{\mathrm{e}} \mathrm{s}$. In : Actes du VIII ${ }^{e}$ congrès de l'AIECM2, Almagro-Ciudad Real, 27 février-3 mars 2006. Madrid : Associatión Española de Arquelogía Medieval, 2009, vol. 1. p. 109-133.

Richarté et al. 2005 : RICHARTÉ (C.), VALLAURI (L.), FOY (D.) - Un noble vaisselier aixois au début du $14^{\mathrm{e}}$ siècle. In: Mélanges Gagnières. Avignon, 2005, p. 1-62 (Documents d'archéologie vauclusienne, 7).

Ritchie 1983: RITCHIE (C.F.) - Tobacco-pipes from Fort Walsh, Saskatchewan, a north-west mounted police post. In : The Archaeology of the Clay Tobacco Pipe VIII. Oxford, 1983, p. 89-183 (British Archaeological Reports, International Series, 175).

Richier et al. 2011 : RICHIER (A.), AUBOURG (C.), BARBIER (S.), BERTOMEU (E.), THUAUDET (O.), WICHA (S.) - L'îlot Saint-Jacques : du vignoble champêtre au cimetière paroissial : Bouches-du-Rhône, La Ciotat, Carré Saint-Jacques. Rapport de fouilles. Nîmes, 2011. 
Roberts 2002 : ROBERTS (I.) - Pontefract Castle archaeological excavations 1982-86. Leeds : West Yorkshire Archaeology Service, 2002.

Rolland 1956 : ROLLAND (H.). Monnaies des comtes de Provence (XII ${ }^{e_{-}}$ $X V^{e}$ siècle). Histoire monétaire, économique et corporative, description raisonnée. Paris : A.-J. Picard, E. Bourgey, 1956, 272 p.

Rolland 2006 : ROLLAND (M.) - Catalogue des objets. In : Maufras (O.) dir. - Habitats, nécropoles et paysages dans la moyenne et la basse vallée du Rhône (VII $-X V^{e}$ s.). Contribution des travaux du TGV-Méditerranée à l'étude des sociétés rurales médiévales. Paris, Éditions de la maison des Sciences de l'Homme, 2006, p. 409-426 (Documents d'archéologie française, 98).

Rosselo Bordoy 1978 : ROSSELO BORDOY (G.) - Ensayo de sistematizacion de la ceramica arabe en Mallorca. Palma de Mallorca: Instituto de Estudios Baleáricos, 1978. 338 p.

Rosselo Bordoy 1995 : ROSSELO BORDOY (G.). - La céramique verte et brune en al-Andalus du X ${ }^{\mathrm{e}}$ au XIII ${ }^{\mathrm{e}}$ siècle. In : Le Vert et le Brun, de Kairouan à Avignon, céramiques du $X^{e}-X V^{e} s$. : exposition Marseille, La Vieille Charité, novembre 1995 - janvier 1996. Marseille : Musées de Marseille, 1995, p. $105-118$.

Rotili 2006 : ROTILI (M.) - Ceramica invetriata da Montella e rocca San Felice in Irpinia. In : Atti XXXVII convegno internazionale della ceramica, Centro ligure per la storia della ceramica, Albisola, 2005. Borgo S. Lorenzo : All'insegno del Giglio, 2006, p. 281-298.

Salinas Pleguezuelo à paraître : SALINAS PLEGUEZUELO (E.). - Las producciones cerámicas de un alfar del siglo XII en CórdobaI. In : X Congreso Internazionale sulla ceramica medievale nel Mediterraneo, Venise, 23-29 novembre 2009, à paraitre.

Savès 1971 : SAVÈS (G.) - Trésor d'orfèvrerie méridionale du XIV ${ }^{\mathrm{e}}$ siècle, Mémoires de la Société archéologique du Midi de la France, XXXVI, 1971, p. 21-54.

Schenk 2008: SCHENK (A.) - Regards sur la tabletterie antique, les objets en os, bois de cerf et ivoire du Musée Romain d'Avenches. Avenches : Association pro Aventico, 2008, 336 p.

Scherrer 2011: SCHERRER (N.) - Autour du Jardin des Vestiges à Marseille (Bouches-du-Rhône) : fragments d'histoire médiévale et moderne, Archéologie du Midi médiéval, 29, 2011, p. 43-56.

Schneider 1995 : SCHNEIDER (L.) - Le château de Beaucaire : nouvelles données chonologiques. In : Leenhardt (M.) dir. - Poteries d'Oc, céramiques languedociennes VII ${ }^{e}$-XVII e siècles. Aix-en-Provence : ed. Narration, 1995, p. 52 (catalogue d'exposition, Musée archéologique de Nîmes).

Schnitzler 1990 : SCHNITZLER (B.) - Vivre au Moyen Âge, 30 ans d'archéologie en Alsace. Strasbourg : Musée de la ville de Strasbourg, 1990, $523 \mathrm{p}$.

Sfligiotti 1990 : SFLIGIOTTI (P.) - Manufatti in metallo, osso, terracotta, pietra. In : Saguí (L.) dir. -Archeologia urbana a Roma: il progetto della Cripta Balbi, 5: L'esedra della Crypta Balbi nel medioevo (XI-XV secolo), part 2. Florence : 1l'Insegna del Giglio, 1990 , p. 513-552.

Shishkina, Pavchinskaya 1992 : SHISHKINA (C.C.), PAVCHINSKAYA (L.V.) - La production céramique de Samarcande du VIII ${ }^{\mathrm{e}}$ au XIII ${ }^{\mathrm{e}}$ siècle. In : Terres secrètes de Samarcande : céramiques du VIII ${ }^{e}$ au XIII ${ }^{e}$ siècle. Paris, 1992, p. 47-73 (catalogue d'exposition, Institut du Monde Arabe).

Smail 2009 : SMAIL (D.L.) - Le peuple de la ville : Marseille et ses habitants au XIVe siècle. In : Pecout (T.) coord. - Marseille au Moyen Age, entre Provence et Méditerranée. Les horizons d'une ville portuaire. Méolans : éd. Désiris, 2009, p. 247-259.

Soustiel 1985: SOUSTIEL (J.) - La céramique islamique : le guide du connaisseur. Paris : Ed. Vilo, 1985. 427 p.

Stern, Waksman 2003 : STERN (E.), WaKSMAN (Y.) - Pottery from crusader Acre : A typological and analytical study. In : actes du VII congrès international sur la céramique médiévale en Méditerranée, Thessalonique, 1999. Athènes, 2003, p. 167-180.

Sudbury 1979 : SUDBURY (B.) - Historic clay tobacco pipemakers in the United States of America. In: The Archaeology of the Clay Tobacco Pipe II. Oxford, 1979, p. 151-341 (British Archaeological Reports, International Series, 60).

Suviéri 1998 : SUVIÉRI (V.) - Étude du mobilier de la fouille de la place du Général-de-Gaulle (Marseille). Époques médiévales et modernes.
Aix-en-Provence : Université d'Aix-Marseille I, 1998, 69 p., 34 pl. (mémoire de DEA d'Archéologie médiévale sous la direction de M. Fixot).

Suviéri 2001 : SUVIÉRI (V.) - Le reste du mobilier. In : Bouiron (M.) dir. - Marseille, du Lacydon au faubourg Sainte-Catherine. Les fouilles de la place du Général-de-Gaulle. Paris : Éditions de la maison des Sciences de l'Homme, 2001, p. 207 (Documents d'archéologie française, 87).

Suviéri, de Boisséson 2001 : SUVIÉRI (V.), DE BOISSÉSON (L.) - Les époques médiévale et moderne. In : Bouiron (M.) dir. - Marseille, du Lacydon au faubourg Sainte-Catherine. Les fouilles de la place du Général-de-Gaulle. Paris : Éditions de la maison des Sciences de l'Homme, 2001, p. 207-226 (Documents d'archéologie française, 87).

Thernot 1996 : THERNOT (R.) dir. - Marseille (Bouches-du-Rhône). Le site de l'Hôtel de Ville. César médiéval et moderne. Aix-en-Provence : SRAPACA, 1996 (rapport de fouilles).

Thiriet 1997 : THIRIET (C.) - Les reflets de la foi dans les inventaires après décès. Marseille 1556-1575. Aix-en-Provence : Université Aix-Marseille 1, 1997, 2 vol., 111 p. (Mémoire de maîtrise d'Histoire moderne, sous la direction de Gabriel Audisio).

Thiriot 1991 : THIRIOT (J.) - Céramiques fines islamiques du Midi de la France au bas Moyen Age. In : A cerâmica medieval no Mediterrâneo occidental, Lisbonne, 16-22 novembre 1987. Mértola, 1991, p. 27-48.

Thiriot 1995 : THIRIOT (J.) - Céramiques fines et orientales. In : Carru (D.) dir. - De l'Orient à la table du Pape. L'importation des céramiques méditerranéennes dans la région d'Avignon aux XIVe-XVIe siècles. Avignon : Service d'Archéologie de Vaucluse, 1995, p. 24-48 (Documents d'Archéologie Vauclusienne, 5).

Thomas 2009 : THOMAS (N.) - Les ateliers urbains de travail du cuivre et de ses alliages au bas Moyen Âge : Archéologie et histoire d'un site parisien du XIV e siècle dans la Villeneuve du Temple (1325-1350). Paris : Université de Paris I Panthéon-Sorbonne, 2009, 974 p., 285 p. (thèse d'Archéologie médiévale sous la direction de Paul Benoit).

Thuaudet 2013 : THUAUDET (O.) - Étude du mobilier archéologique issu des fouilles anciennes. Le mobilier métallique. In : Bouiron (M.) dir. - Nice. La colline du Château. Histoire millénaire d'une place forte. Nice : Mémoires millénaires, 2013, p. 267-277.

Torre, Ciarrochi 2006: TORRE (P.), CIARROCHI (B.) - Ceramica invetriata dall'altomedioevo all'età post-medievale negli scavi di Monte d'Argento (Minturno, LT). In : Genova e Savona: la Liguria crocevia della ceramica, Atti XXXVII convegno internazionale della ceramica, Centro ligure per la storia della ceramica, Albisola, 2005. Borgo S. Lorenzo : All'insegno del Giglio, 2006, p. 265-280.

Torremocha Silva, Oliva Cozar 2002 : TORREMOCHA SILVA(A.), OLIVA COZAR (Y.) - La Ceràmica Musulmana de Algeciras. Algeciras : Museo Municipal, 2002, 262 p. (Coleccion Historia : Caetaria monografias, 1).

Treglia, Richarté à paraître : TREGLIA (J.-C.), RICHARTÉ (C.) - Premiers éléments pour une caractérisation des contextes haut Moyen age de l'abbaye de Montmajour, à paraitre.

Treglia et al. 2012 : TREGLIA (J.-C.), RICHARTE (C.), CAPELLI (C.), WAKSMAN (Y.), Importations d'amphores médiévales dans le Sud-est de la France $\left(X^{e}-X I I^{e}\right.$ s.). Premières données archéologiques et archéométriques In : Gelichi (S.) dir., Actes du IX ${ }^{\mathrm{e}}$ Congrès International de l'AIECM2 (Venise, 23-29 novembre 2009). 2012, p. 205-207.

Tymstra 1981 : TYMSTRA (F.) - De pijpenstad St Omer, Pijpelogische Kring Nederland, 14, 1981, p. 43-47.

Tymstra, Van der Meulen 1988 : TYMSTRA (F.), VAN DER MEULEN (J.) - De kleipijp als bodemvondst. Leyde : Pijpelogische Kring Nederland, 1988.

Valicourt 1846 : VALICOURT (E.) - Nouveau manuel complet du tourneur ou traité théorique et pratique de l'art du tour, t. 1, (refondu). Paris : Librairie encyclopédique de Roret, 1846, XII-336 p.

Valicourt 1848 : VALICOURT (E.) - Nouveau manuel complet du tourneur [Texte imprimé] : ou traité théorique et pratique de l'art du tour contenant la description des appareils et des procédés les plus usités pour tourner les bois, les métaux, les pierres, l'ivoire, la corne, l'écaille, la nacre, etc., ainsi que les notions de forge, d'ajustage et d'ébénisterie indispensables au tourneur. Paris : Roret, 1848, 376 p. 
Vallauri 1995 : VALLAURI (L.) - La circulation des céramiques méditerranéennes au Moyen Age : exemples en Provence et en Corse. In : Recherches récentes d'archéologie médiévale en Corse : actes du séminaire d'archéologie, Ajaccio, avr. 1994, patrimoine d'une île, Patrimoniu insulanu. Ajaccio, 1995, p. 65-69.

Vallauri 1997a : VALLAURI (L.) - Les céramiques importées. In : Marchesi (H.), Thiriot (J.), Vallauri (L.), LeenhardT (M.) dir. - Marseille, les ateliers de potiers du XIII ${ }^{e}$ siècle et le quartier Sainte-Barbe (Ve-XVII ${ }^{e}$ s.). Paris, 1997, p. 79-92 (Documents d'archéologie française, 65).

Vallauri 1997b : VALLAURI (L.) - Les objets du quotidien. In : Marchesi (H.), Thiriot (J.), Vallauri (L.), Leenhardt (M.) dir. - Marseille, les ateliers de potiers du XIII e siècle et le quartier Sainte-Barbe (Ve-XVII ${ }^{e}$ s.). Paris, 1997, p. 63-65 (Documents d'archéologie française, 65).

Vallauri et al. 1997 : VALLAURI (L.), LEENHARDT (M.), PICON (M.) coll., PORTER (Y.) coll. - Les productions céramiques. In : Marchesi (H.), Thiriot (J.), Vallauri (L.), Leenhardt (M.) dir. -Marseille, les ateliers de potiers du XIII e siècle et le quartier Sainte-Barbe (Ve-XVII ${ }^{e}$ s.). Paris, 1997, p. 165-332 (Documents d'archéologie française, 65).

Vallauri et al. 2003 : VALLAURI (L.), DEMIANS D'ARCHIMBAUD (G.), PARENT (F.) coll., RICHARTÉ (C.) coll. - La circulation des céramiques byzantines, chypriotes et du Levant chrétien en Provence, Languedoc et Corse $\mathrm{du} \mathrm{X}^{\mathrm{e}}$ au $\mathrm{XIV}^{\mathrm{e}} \mathrm{s}$. In : actes du VII ${ }^{e}$ congrès international sur la céramique médiévale en Méditerranée, Thessalonique, 1999. Athènes, 2003, p. 137-152. Vallauri, Leenhardt 1997 : VALLAURI (L.), LEENHARDT (M.). - Les productions céramiques. In : Marchesi (H.), Thiriot (J.), Vallauri (L.), Leenhardt (M.) dir. - Marseille, les ateliers de potiers du XIII e siècle et le quartier Sainte-Barbe (Ve-XVII ${ }^{e}$ s.). Paris, 1997, p. 166-332 (Documents d'archéologie française, 65).

Vallejo-Triano, Escudero-Aranda 1998: VALLEJO TRIANO (A.), ESCUDERO ARANDA (J. ) - Aportaciones para una tipología de la cerámica común califal de Madinat al-Zahra, Arqueología y Territorio Medieval, 6, 1998, p. 133-176.

Vallet 2002 : VALLET (C.) - Un atelier de fabrication de perles et de boutons en os du XVIII e siècle, place de la Motte à Limoges, Travaux d'archéologie limousine, 22, 2002, p. 145-150.

Varaldo 2001 : VARALDO (C.) - Archeologiaurbana a Savona : scavi e ricerche nel complesso monumentale del Priamàr. II, Palazzo della Loggia (scanvi 1969-1989), I matériali, t. 2. Bordighera: Instituto internazionale di studi ligure, 2001, $611 \mathrm{p}$.

Varella Gomes 2011 : VARELLA GOMES (R.) - Sives (Xelb), uma cidade do Gharb Al-Andalus: a zona da Arrochella, espaços e quotidiano, Trabalhos de arqueologia, 53. Lisbonne, 2011, $411 \mathrm{p}$.

Vaudour s.d. : VAUDOUR (C.). - Clefs et serrures des origines au commencement de la Renaissance. Catalogue du musée, fascicule II. Le Secq des Tournelles, s.d., 77 p.

Vayssettes 1998 : VAYSSETTES (J.-L.) - Céramique à Uzès, de la faïence fine aux terres mêlées. Montpellier : Petits carnets de la terre cuite, 1998, $24 \mathrm{p}$. Le Vert et le Brun 1995 : Le Vert et le Brun, de Kairouan à Avignon, céramiques $d u X^{e}-X V^{e}$ s. Catalogue d'exposition, Marseille. La Vieille Charité, novembre 1995 - janvier 1996. Marseille : Musées de Marseille, 1995, $246 \mathrm{p}$ : ill.
Viara 1996 : VIARA (G. G.) - Manufatti in metallo, osso e terracotta. In : Lo savo della contrada di S. Domenico, al priamàr (Savona). Relazioni preliminari sulle campagne di scavo 1989-1995, Archeologia medievale, XXIII, 1996, p. 383-385.

Villemeur, Henry 2000 : VILLEMEUR (I.), HENRY (É.). - La cathédrale de La Vieille Major, Marseille (Bouches-du-Rhône). Aix-en-Provence : SRAPACA, 2000, 52 p. (rapport de fouille).

Viollet-le-Duc 1874 : VIOLLET-LE-DUC (E.) - Dictionnaire raisonné du mobilier français de l'époque carlovingienne à la Renaissance. t. 3, Vêtement, bijoux de corps, objets de toilette. Paris : Librairie Gründ et Maguet, 1874, 479 p., 13 pl.

Walker 1983 : WALKER (I.C.) - Nineteenth-century clay tobacco-pipes in Canada. In: The Archaeology of the Clay Tobacco Pipe VIII. Oxford, 1983, p. 1-87 (British Archaeological Reports, International Series, 175).

Weinberg 1975 : WEINBERG (G.D.) - A Medieval Mystery : Byzantine Glass Production, Journal of Glass Studies, 17, 1975, p. 127-141.

Weinberg 1981 : WEINBERG (G.D.) - The importance of Greece in Byzantine Glass Manufacture. Actes du XV Congrès international d'Etudes byzantines (Athènes, 1976), II Art et Archéologie. Athènes, 1981, p. 915-918.

Whitehead 2003 : WHITEHEAD (R.) - Buckles (1250-1800), Witham, Greenlight Publishing, 2003, 126 p.

Whitehouse 1966: Whitehouse (D.) - Ceramiche e vetri medioevali provenienti dal Castello di Lucera, Bolletino d'Arte, LI, serie VI, 1966, p. 171-178.

Whitehouse 1987 : Whitehouse (D.) -Medieval Glass from Tarquinia. In : Annales du 10 Congrès international de l'Association internationale pour l'Histoire du Verre (Madrid-Ségovie 1985). Amsterdam, 1987, p. 317-330.

Whitehouse 1991: Whitehouse (D.) - Glassmaking at Corinth :A Reassessment. In : Foy (D.), SENNEQUIER (G.) dir. - Ateliers de verriers de l'Antiquité à la période pré-industrielle. Rouen : Association française pour l'archéologie du verre, 1991, p. 73-82.

Whitehouse 1993 : Whitehouse (D.) - The Date of the «Agora South Centre» Workshop at Corinth, Archeologia medievale, 20, 1993, p. 659-662.

Whitehouse 2010 : Whitehouse (D.) - Medieval glass for popes, princes and peasants. Catalogue d'exposition, Corning Museum, mai 2010-janvier 2011. Corning, 2010.

Willmott 2000 : WILLMOTT (H.) - The classification and mould-grouping of lion mask stems from London. In : Annales du 14e Congrès international de l'Association internationale pour l'Histoire du Verre (Venezia-Milano 1998). Lochem, 2000, p. 389-395.

Zecchin 1987 : ZECCHIN (L.) - Vetro e vetrai di Murano. Studi sulla storia del vetro, vol. I. Venise, 1987.

Zerubia 1995 : ZERUBIA (R.) - Saint-Michel de Cousson et sa nécropole. In : Terres de Durance : Céramiques de l'Antiquité aux temps modernes. Aixen-Provence : Ed. Narration, 1995, p. 71 (catalogue d'exposition, Musée de Digne. Musée Départemental de Gap).

Zozaya 1981 : ZOZAYA (J.) - Aperçu général sur la céramique espagnole. In : Demians d'Archimbaud (G.), Picon (M.) dir. - La céramique médiévale en Méditerranée occidentale, $X^{e}-X V^{e}$ siècles, Valbonne 1978. Paris : éd. du C.N.R.S., 1980, p. 265-320. 



\section{PUBLICATIONS DU CENTRE CAMILLE JULLIAN}

http://sites.univ-provence.fr/ccj/spip.php?rubrique79

\section{Disponibles gratuitement en ligne :}

Revue Antiquités africaines, ${ }^{\circ} 1$ (1967) à 29 (1993), sur le portail Persée :

(http://www.persee.fr/web/revues/home/prescript/revue/antaf)

Collection Archaeonautica, ${ }^{\circ} 1$ (1977) à 14 (1998), sur le portail Persée :

(http://www.persee.fr/web/revues/home/prescript/revue/nauti)

Barrière mobile 3 ans.

Collection Etudes massaliètes, $n^{\circ} 1$ (1986) à 9 (2007), sur le site du CCJ :

(http://ccj.univ-provence.fr/spip.php?rubrique83)

ou sur celui du Centre de Conservation du Livre à Arles :

(http://www.e-corpus.org/search/search.php?search=search\&page=1\&q=études+massaliètes\&search=Rechercher)

Bibliothèque d'Archéologie Méditerranéenne et Africaine (BiAMA) :

A partir de 2013 (barrière mobile 3 ans) sur le site Revues.org 


\section{BIBLIOTHÈQUE D’ARCHÉOLOGIE MÉDITERRANÉENNE ET AFRICAINE (BiAMA)}

Éditions Errance, éditeur du groupe Actes Sud, BP 9003813633 Arles Cédex http://www.librairie-epona.fr/ La BiAMA prend la suite des Travaux du Centre Camille Jullian11

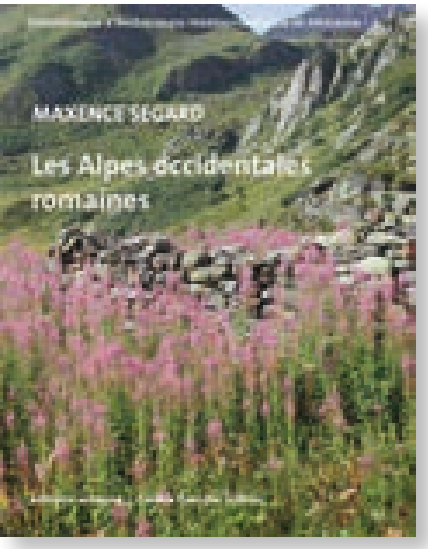

1

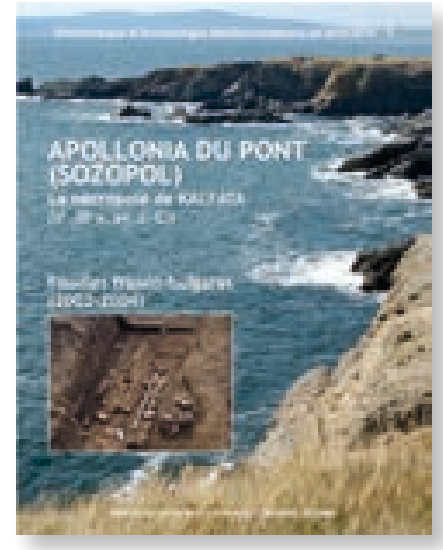

5

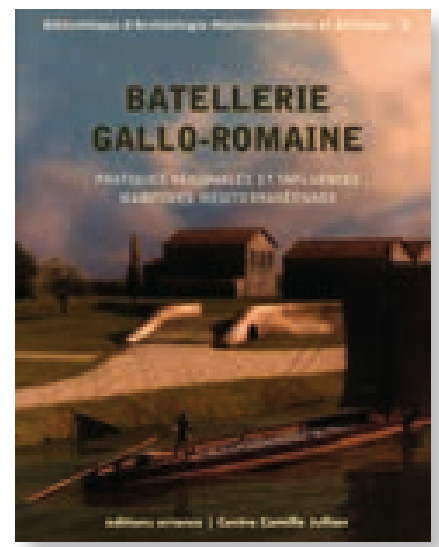

9
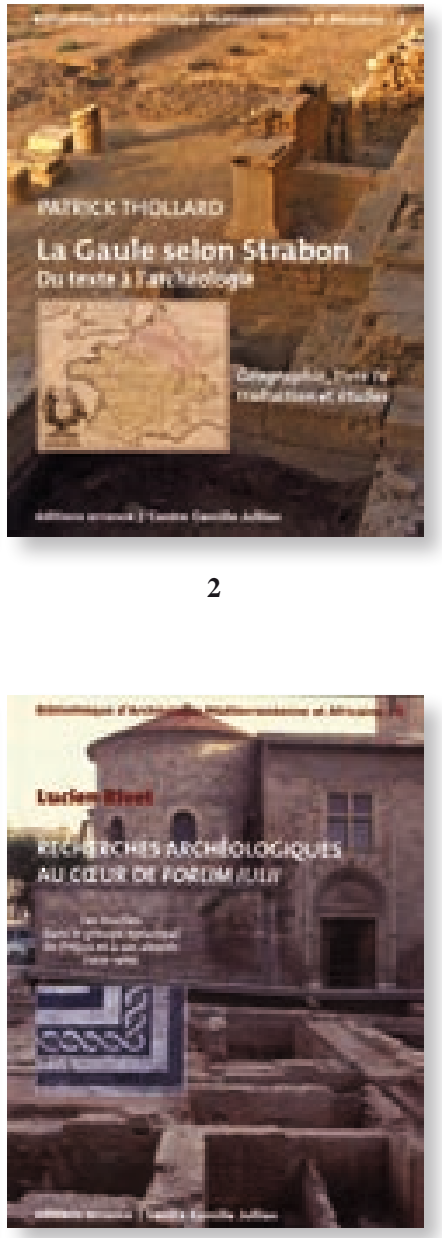

6

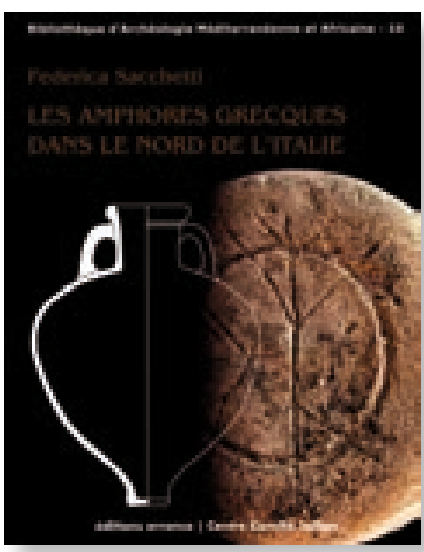

10
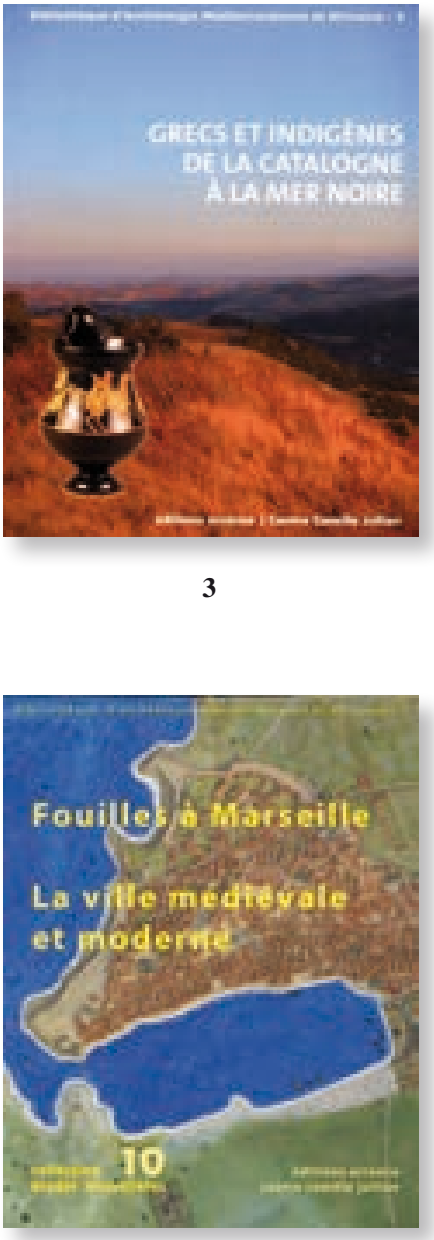

7

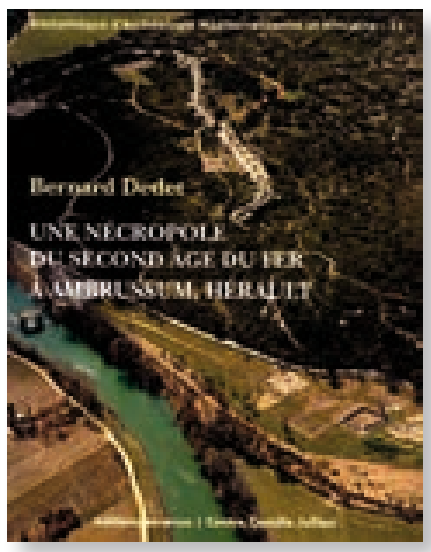

11

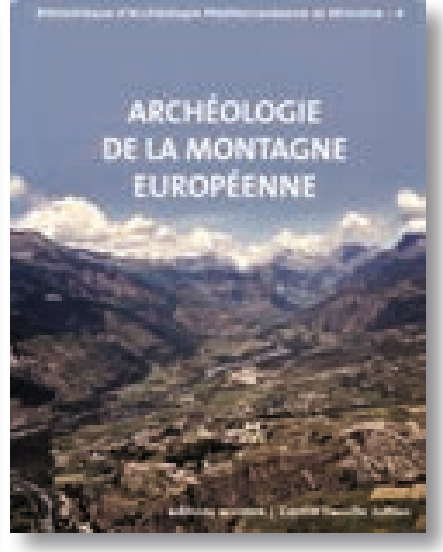

4

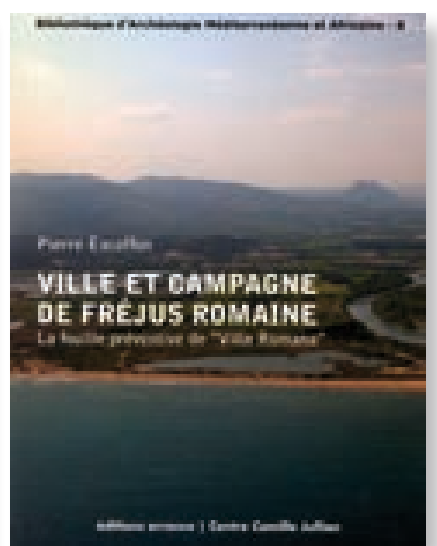

8

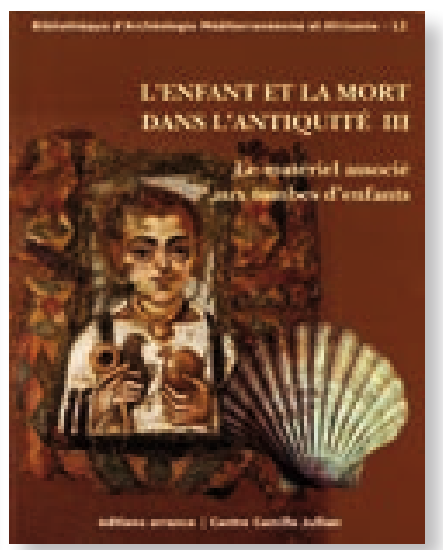

12 


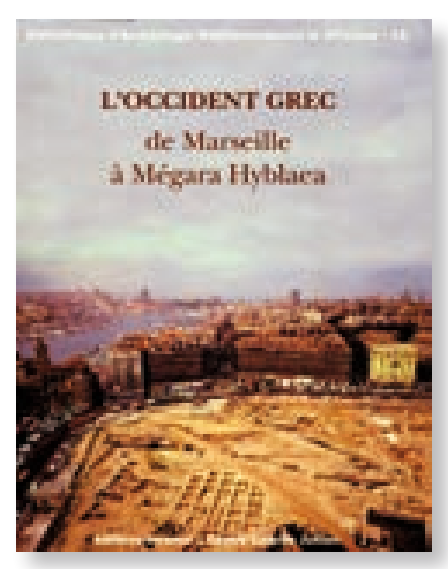

13
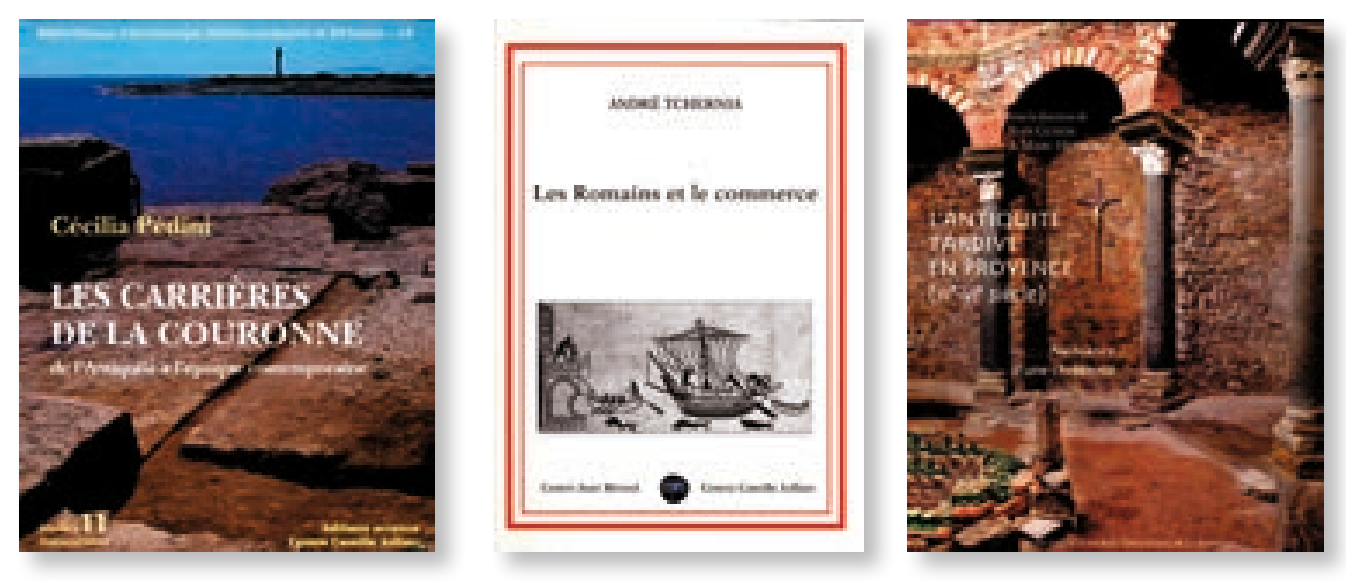

1. M. Segard, Les Alpes Occidentales à l'époque romaine, Développement urbain et exploitation des ressources des régions de montagne (Gaule Narbonnaise, Italie, provinces alpines), Paris 2009, 288 p.

2. Patrick Thollard, La Gaule selon Strabon : du texte à l'archéologie (Géographie livre IV). Traduction et études, Paris, 2009, 265 p.

3. Grecs et indigènes de la Catalogne à la mer Noire, actes des rencontres du programme européen Ramses (20062008), édités par H. Tréziny, Paris 2010, 716 p.

4. Archéologie de la montagne européenne. Actes de la table ronde internationale de Gap (29 septembre-1 ${ }^{\text {er }}$ octobre 2008), textes réunis par Stéfan Tzortzis et Xavier Delestre, avec la collaboration de Jennifer Greck, Paris 2010, 333 p. 5. A. Hermary (éd.), Apollonia du Pont (Sozopol) La nécropole de Kalfata (Ve - III ${ }^{e}$ s. av J.-C.) - Fouilles francobulgares (2002-2004), 2010, $432 \mathrm{p}$.

6. L. Rivet, Recherches archéologiques au coeur de Forum Iulii - Les fouilles dans et autour du groupe cathédral de Fréjus (1979-1989), 2010, 420 p.

7. Sous la direction de Marc Bouiron, Françoise Paone, Bernard Sillano, Colette Castrucci et Nadine Scherrer, Fouille à Marseille, la ville médiévale et moderne, (ÉtMassa 10), 2011, 463 p.

8. P. Excoffon, Ville et campagne de Fréjus romaine. La fouille préventive de «Villa Romana 2011, 306 p.

9. Sous la direction de Giulia Boetto, Patrice Pomey, André Tchernia, Batellerie gallo-romaine : pratiques régionales et influences maritimes méditerranéennes, 2011, $191 \mathrm{p}$.

10. F. Sacchetti, Les amphores grecques dans le Nord de l'Italie. Echanges commerciaux entre les Apennins et les Alpes aux époques archaïque et classique, 2013, 287 p.

11. B. Dedet, Une nécropole du second Âge du Fer à Ambrussum, Hérault, 2012, 288 p.

12. L'enfant et la mort dans l'Antiquité. III. Le matériel associé aux tombes d'enfants, Actes du colloque international organisé à la Maison Méditerranéenne des Sciences de l'Homme (MMSH) d'Aix-en-Provence, 20-22 janvier 2011, édités par A. Hermary et C. Dubois, 2012. 460 p.

13. L'Occident grec de Marseille à Mégara Hyblaea. Hommage à Henri Tréziny. Textes réunis et édités par Sophie Bouffier et Antoine Hermary. Paris, 2013, 296 p.

14. C. Pédini, Les carrières de la couronne, de l'Antiquité à l'époque contemporaine, (ÉtMassa 11), Paris 2013, 288 p.

Hors collection 2011 A. Tchernia, Les Romains et le commerce, 2011, 439 p.

Hors collection 2013 J. Guyon et M. Heijmans (dir.), L'Antiquité tardive en Provence (IVe-VIe siècle) : naissance d'une chrétienté, 2013, 223 p. 


\section{COLLECTION ÉTUDES MASSALIÈTES (EtMassa)}

1. Le territoire de Marseille grecque, actes de la table ronde d'Aix-en-Provence, 1985, édités par M. Bats et $\mathrm{H}$. Tréziny, Université de Provence, Aix-en-Provence, 1986.

2. Les amphores de Marseille grecque, actes de la table ronde de Lattes, 1988, édités par M. Bats, Université de Provence/ADAM éditions, Aix-en-Provence/Lattes, 1990.

3. Marseille grecque et la Gaule, actes des colloques de Marseille et Aix-en-Provence, 1990, édités par M. Bats, G. Bertucchi, G. Congès, H. Tréziny, Université de Provence / ADAM éditions, Aix-en-Provence / Lattes, 1992.

4. Sur les pas des Grecs en Occident. Hommages à André Nickels, édités par P. Arcelin, M. Bats, G. Marchand, M. Schwaller, éditions Errance / ADAM éditions, Paris-Lattes 1995.

5. Fouilles à Marseille. Les mobiliers (I ${ }^{e r}-V I I^{e}$ s. ap. J.-C.), vol. collectif sous la direction de M. Bonifay, M.-Br. Carre et Y. Rigoir, éditions Errance / ADAM éditions, Paris-Lattes 1998.

6. Les cultes des cités phocéennes, actes du coll. d'Aix-en-Provence/ Marseille, juin 1999, édités par A. Hermary et H. Tréziny, Édisud/Centre C. Jullian, Aix-en-Provence, 2000.

7. Marseille. Trames et paysages urbains de Gyptis au Roi René, Actes du colloque international d'archéologie, Marseille, 3-5 novembre 1999, textes réunis et édités par M. Bouiron et H. Tréziny, B. Bizot, A. Guilcher, J. Guyon et M. Pagni, Édisud/Centre C. Jullian, Aix-en-Provence, 2001.

8. La nécropole de Sainte-Barbe à Marseille (IVe s. av. J.-C. - II e s. ap. J.-C.), vol. collectif sous la direction de M. Moliner, Édisud/Centre C. Jullian, Aix-en-Provence, 2003.

9. Olbia de Provence à l'époque romaine, vol. collectif sous la direction de Michel Bats, Édisud/Centre C. Jullian, Aix-en-Provence, 2007.

10. M. Bouiron et al. (éd.), Fouilles à Marseille. Approche de la ville médiévale et moderne, 2011, 464 p. (= BiAMA 7).

11. C. Pédini, Les carrières de la couronne, de l'Antiquité à l'époque contemporaine,2013, 288 p. (= BiAMA 14).

Les volumes sont disponibles en format pdf sur : http://sites.univ-provence.fr/ccj/spip.php?rubrique83, grâce au soutien du Centre de conservation du livre à Arles (e-corpus).

\section{COLLECTION ÉTUDES D'ANTIQUITÉS AFRICAINES}

CNRS Editions, 15 rue Malebranche, 75005 Paris - http://www.cnrseditions.fr

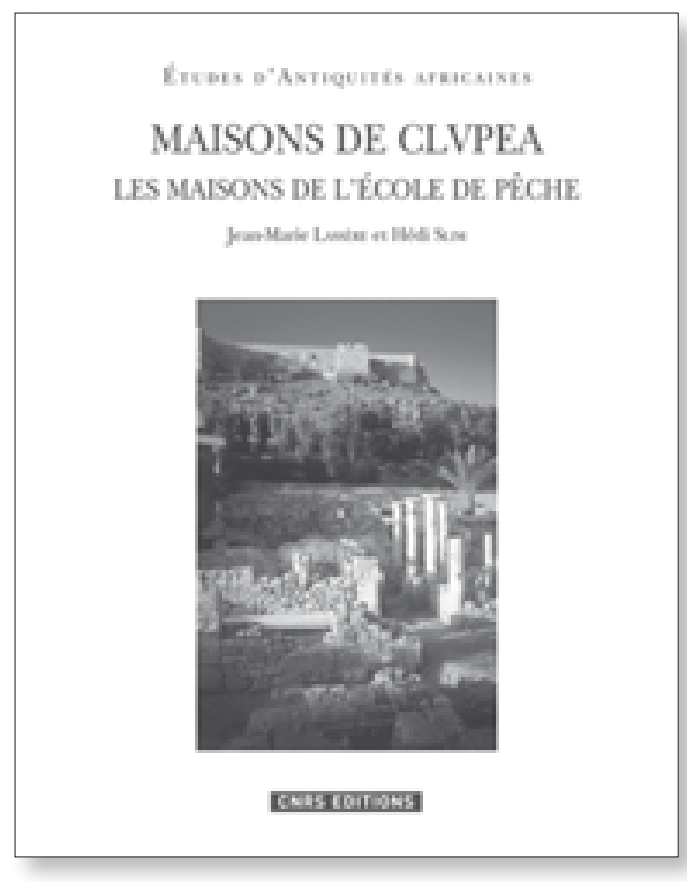

Derniers volumes parus :

- Liliane Ennabli, La basilique de Carthagenna et le locus des sept moines de Gafsa. Nouveaux édifices chrétiens de Carthage, 2000.

- François Baratte, Janet Lang, Catherine Metzger et Susan La Niece, Le trésor de Carthage: contribution à l'étude de l'orfèvrerie de l'Antiquité tardive, 2002.

- Nadine Labory, Inscriptions antiques du Maroc, 2. Inscriptions latines - Supplément, 2003.

- Hédi Slim, Pol Trousset, Roland Paskoff et Ameur Oueslati, avec la collaboration de Michel Bonifay et Jean Lenne, Le littoral de la Tunisie. Étude géoarchéologique et historique, 2004.

- Sabah Ferdi, Corpus des mosaïques de Cherchel, 2005.

- Lieux de cultes : aires votives, temples, églises, mosquées. IX Colloque international sur l'histoire et l'archéologie de l'Afrique du Nord antique et médiévale (Tripoli, 19-25 février 2005), 2008.

- Jean-Marie Lassère, Maisons de Clupea. Exemples de l'architecture domestique dans un port de l'Afrique proconsulaire. Les maisons de l'Ecole de pêche, avec une étude de la céramique par Jean Piton, 2010. 


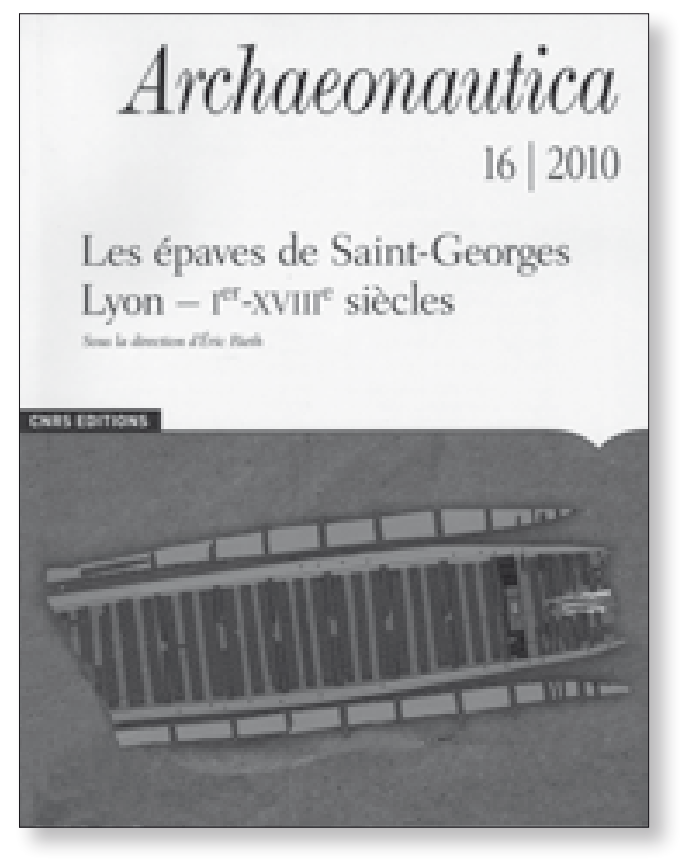

\author{
COLLECTION ARCHAEONAUTICA \\ CNRS Editions, 15 rue Malebranche, 75005 Paris \\ http://www.cnrseditions.fr
}

Derniers volumes parus :

14. P. Pomey, E. Rieth (dir.), Construction navale, maritime et fluviale. Approches archéologiques, historique et ethnologique Actes du Septième Colloque International d'Archéologie Navale Proceedings of the Seventh International Symposium on Boat and ship Archaeology, Ile Tatihou 1994 (Saint-Vaast-la-Hougue). Paris $1998,335 \mathrm{p}$.

15. 2008, L'archéologie maritime et navale de la Préhistoire à l'époque contemporaine, Paris 2009.

16. E. Rieth (dir.) Les épaves de Saint-Georges - Lyon (I ${ }^{e r}$-XVIII ${ }^{e}$ s.) : analyse architecturale et études complémentaires, Paris $2010.335 \mathrm{p}$. 17. Recueil d'articles, 2012. Paris 2012. 197 p.

\title{
REVUE ANTIQUITÉS AFRICAINES
}

CNRS Editions, 15 rue Malebranche, 75005 Paris - http://www.cnrseditions.fr

Les volumes 1 (1967) à 29 (1993) de la revue sont accessibles sur le portail Persée à l'adresse :

http://www.persee.fr/web/revues/home/prescript/revue/antaf

Dernier volume paru, t. 46-48, 2010-2012

\section{TRAVAUX DU CENTRE CAMILLE JULLIAN}

Derniers volumes parus :

21. Techniques et économie antiques et médiévales. Le temps de l'innovation, actes du colloque d'Aix-en-Provence (mai 1996), réunis par D. Garcia et D. Meeks, éd. Errance, Paris, 1997, 1 vol., 240 p.

22. Fouilles à Marseille. Les mobiliers ( $I^{e r}-V I I^{e}$ s. ap. J.-C.), ouvrage collectif sous la direction de M. Bonifay, M.-Br. Carre et Y. Rigoir (Ét. massa. 5), éd. ADAM-Errance, Lattes/Paris, 1998, 1 vol., 443 p.

23. J. Guyon, N. Nin, L.Rivet, S. Saulnier, Atlas topographique des villes de Gaule méridionale. 1, Aix-en-Provence, Montpellier, 1998 (Supplément 30 à la R.A.N.)

24. B. Sabattini, dir. La céramique attique du IVe siècle en Méditerranée occidentale, Actes du Colloque International d'Arles (7-9 décembre 1995), Naples, Centre Jean Bérard, 2000 (= Collection du Centre Jean Bérard, 19).

25. J.-P Morel, C. Rondi-Costanzo et D. Ugolini, éd., Corallo di ieri, corallo di oggi, Actes du Colloque International du Centre Universitaire Européen pour les Biens Culturels, Ravello, Italie (13-15 décembre 1996), Bari, Edipuglia, 2000 (= CUEBC, Scienze e materiali del patrimonio culturale, 5).

26. P. Leveau et J.-P. Saquet, éd., Milieu et sociétés dans la Vallée des Baux. Études présentées au colloque de Mouriès. Montpellier, 2000 (= Suppl. 31 à la R.A.N.).

27. L. Rivet, D. Brentchaloff, S. Roucole, S. Saulnier, Atlas topographique des villes de Gaule méridionale 2. Fréjus, Montpellier, 2000 (= Suppl. 32 à la R.A.N.).

28. P. Lévêque et J.-P. Morel, dir., Céramiques hellénistiques et romaines. III, Paris, 2001.

29. Ph. Columeau, Alimentation carnée en Gaule du Sud : VII e s. av. J.-C.-XIVe s., éditions Université de Provence, Aix-en-Provence 2002.30. J.-P. Brun et Ph. Jockey, éd., TECHNAI. Techniques et sociétés en Méditerranée, Hommage à M.-Cl. Amouretti, Paris, Maisonneuve et Larose, 2001 (MMSH, coll. L'atelier méditerranéen), Aix-en-Provence 2001.

30. J.-P. Brun et Ph. Jockey, éd., TECHNAI. Techniques et sociétés en Méditerranée, Hommage à M.-Cl. Amouretti, Paris, Maisonneuve et Larose, 2001 (MMSH, coll. L'atelier méditerranéen), Aix-en-Provence 2001. 
Achevé d'imprimer en Janvier 2014 par l'imprimerie Sepec à Peronnas

Dépôt légal : Janvier 2014

$\mathrm{N}^{\circ} \mathrm{d}$ 'imprimeur :

Imprimé en France 